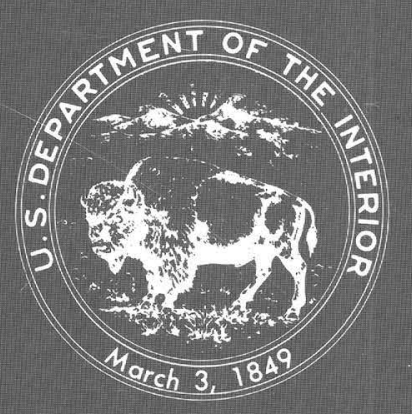

\title{
STUDIES IN DIAGENESIS
}

\section{U.S. GEOLOGICAL SURVEY BULLETIN 1578}

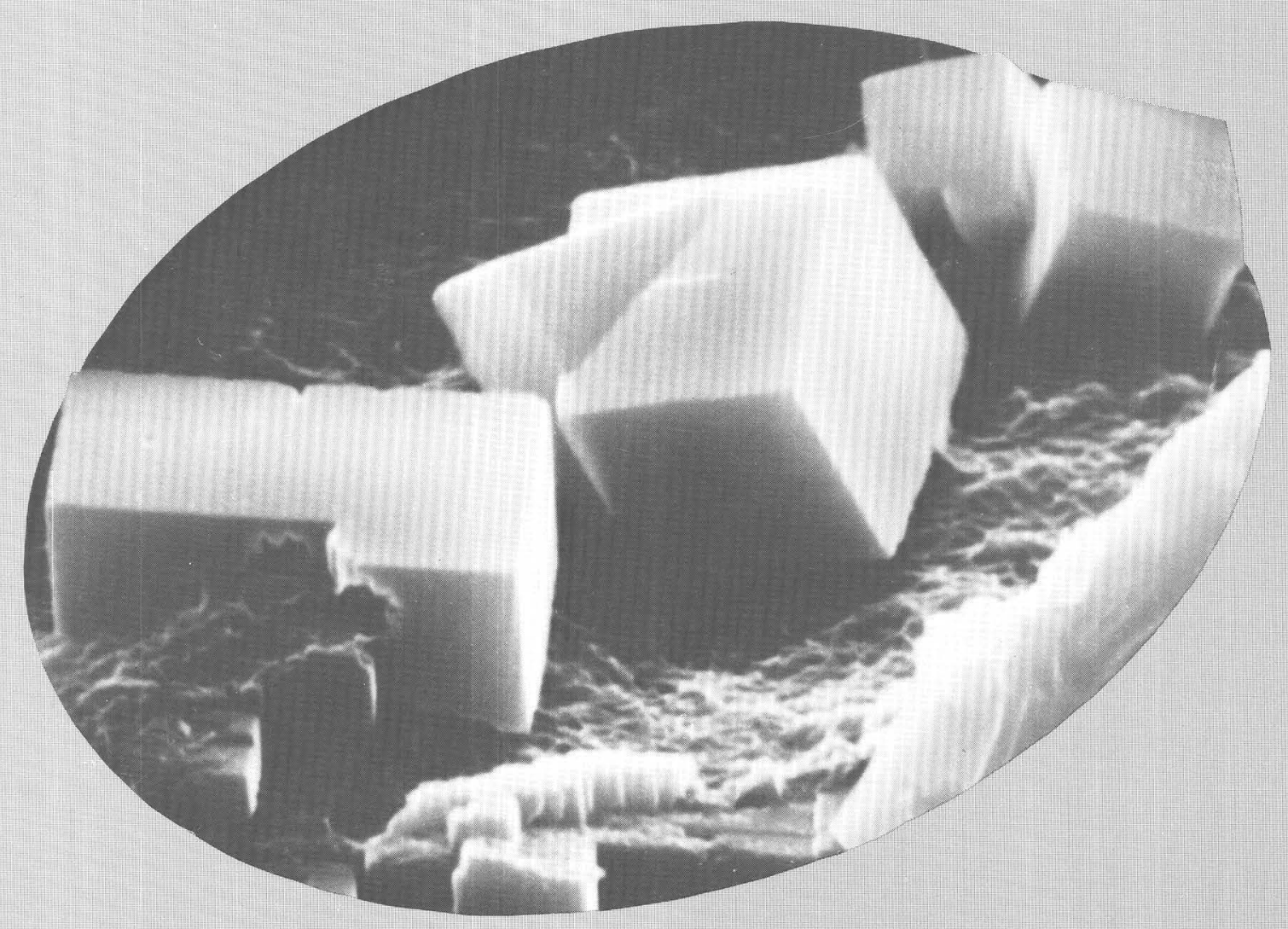


Cover shows scanning electron micrograph of late-stage smectite (lower left) coating earlier chabazite crystals formed on early-stage smectite, in altered Pliocene vitric tuff, Durkee, Oregon. See article by A.J. Gude 3rd, and R.A. Sheppard, (this volume, p. 301-333). 


\section{Studies in Diagenesis}

FREDERICK A. MUMPTON, Editor

\section{MARC W. BODINE, JR.,}

Workshop Convenor and Organizing Committee Chairman

Papers presented at a U.S. Geological Survey workshop on

diagenesis in sedimentary rocks, Golden, Colorado, March 1982 


\section{DEPARTMENT OF THE INTERIOR \\ DONALD PAUL HODEL, Secretary}

U.S. GEOLOGICAL SURVEY

Dallas L. Peck, Director

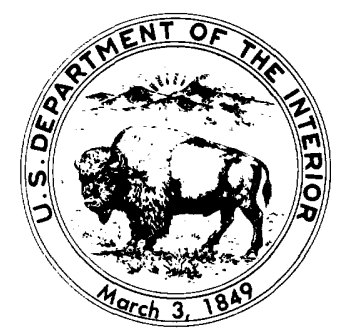

For sale by the

Books and Open-File Reports Section

U.S. Geological Survey

Federal Center

Box 25425

Denver, CO 80225

Library of Congress Cataloging in Publication Data

Studies in diagenesis.

(U.S. Geological Survey bulletin ; 1578)

Bibliography: $p$.

Supt. of Docs. no.: I 19.3:1578

1. Diagenesis-Congresses. I. Mumpton, Frederick Albert, 1932- . II. Bodine, Marc W. III. Series.

QE75.B9 no. 1578

$557.3 \mathrm{~s}$

[QE571]

[551.3]

$87-600128$ 


\section{PREFACE}

The collection of research papers in this volume evolved from a workshop on diagenesis in sedimentary rocks sponsored by the U.S. Geological Survey. The workshop was held March 16-18, 1982, in Golden, Colorado, and was attended by 248 participants from the Survey's Geologic and Water Resources Divisions.

The idea for the workshop came to four of us-Walt Dean, Phoebe Hauff, Harry Tourtelot, and me-during a series of informal discussions in late 1980. The complexity and interdisciplinary nature of the broad range of diagenetic processes were clearly recognized, as was their importance in the genesis, transport, emplacement, and mode of occurrence of a wide variety of organic fuels and mineral resources. The advantages of bringing together scientists who were actively engaged in diagenesis studies from several branches in two divisions of the Survey were readily apparent, and so a proposal for such a multidisciplinary and interdivisional workshop was formulated. The proposal was accepted and approved by the Survey in early 1981 .

The workshop comprised two days of technical sessions consisting of oral papers and concurrent poster displays. A third day was set aside so that participants could schedule one-on-one conferences with any of the invited guest speakers or arrange small group discussions on topics of mutual interest. Each of the four half-day technical sessions represented a different aspect of diagenesis-chemical, carbonate, fine clastic, and coarse clastic-and began with an invited review paper on the theme of that session. The program opened with an overview "keynote" paper by Robert M. Garrels on the role of diagenesis in the geochemical cycle. In the first session, Robert A. Berner reviewed advances in several aspects of sediment-fluid interaction accompanying early diagenesis, and Lynton Land surveyed diagenesis in carbonate rocks to lead off the second session. In the third session John Hower reviewed the advancements in clay mineral diagensis, and in the final session Raymond Siever discussed thermal and burial relationships during the history of sedimentary basins.

During these sessions 50 Survey authors presented 22 talks and 9 poster displays on topics ranging from diagenesis in limestones to uranium deposits to zeolitic tuffs. The authors reported findings of field, laboratory, and theoretical investigations dealing with such disparate approaches as organic geochemistry of hydrocarbon maturation, stable isotope fractionation, petrographic analysis, mineral equilibria and dissolution kinetics, mapping and field relations, and trace element geochemistry. The concurrent poster sessions presented results of more intensely focused studies.

The workshop's flavor and organization have been retained in this volume. In addition to overview papers by four of the participants, the volume contains most of the Survey research papers that were presented at the workshop. They range in length from expanded versions of extended abstracts to condensations of lengthier treatises. The remaining papers have either been published elsewhere or incorporated into works of broader scope. Only a minimum effort has been made to formalize the stimulating presentation style of the authors in order to preserve and emphasize their unique approaches to this complex and difficult subject. 
The organizing committee is grateful to the distinguished scientists whose informative review papers lead off each of the sections of this volume. The untimely death of John Hower precludes inclusion of his review paper in this volume. All who participated in the workshop keenly feel his passing. The success of the workshop was in large part due to the contributions of time and talent of the other members of the organizing committee: Bruce Bohor, Lorna M. Carter, Walter E. Dean, Jr., Donald L. Gautier, Martin B. Goldhaber, Phoebe L. Hauff, Zell E. Peterman, Omer B. Raup, Betty A. Skipp, and Harry A. Tourtelot. My appreciation is also extended to Frederick A. Mumpton, who accepted the task of editing this volume, and to Diane C. Schnabel, who guided it through its publication hurdles. My thanks also go to Artis M. Schack, Jane A. Edwards, and their coworkers for timely and accurate manuscript preparation. Arthur L. Isom designed the attractive cover.

Marc W. Bodine, Jr., Workshop Convenor and Organizing Committee Chairman 


\section{CONTENTS}

PREFACE, by Marc W. Bodine, Jr. III

PART I. INTRODUCTION

Sediment cycling and diagenesis, by Robert M. Garrels 1

PART II. CHEMICAL DIAGENESIS

A kinetic approach to chemical diagenesis, by Robert A. Berner 13

Seasonal diagenetic changes in salts of Owens Lake, California, 1970-77, by George I. Smith and Irving Friedman 21

Influence of iron and manganese on the chemical partitioning of copper, zinc, and chromium during early diagenesis in outer continental-shelf sediments from the Gulf of Mexico, by Lorraine H. Filipek $\mathbf{3 1}$

Mobility and distribution of heavy metals during the formation of first-cycle red beds, by Robert A. Zielinski, Salman Bloch, and Theodore R. Walker $\mathbf{5 1}$

Stoichiometry of organic decomposition in sediments of the Potomac River estuary, by David L. Parkhurst and Steven D. Goodwin 61

Relation of hydrocarbon type to maturity of organic matter in Upper Cretaceous chalks, eastern Denver basin, by Dudley D. Rice 75

Relationship between vitrinite reflectance, metamorphic grade, and temperature in the Cerro Prieto, Salton Sea, and East Mesa geothermal systems, Salton Trough, United States and Mexico, by Charles E. Barker, Bonnie L. Crysdale, and Mark J. Pawlewicz 83

Origin and diagenesis of Cretaceous organic-carbon-rich lithofacies in the Atlantic Ocean, by Walter E. Dean and Michael A. Arthur 97

PART III. CARBONATE DIAGENESIS

Limestone diagenesis-Some geochemical considerations, by Lynton S. Land 129

A comparative study of the dissolution and crystal growth kinetics of calcite and aragonite, by Eurybiades Busenberg and L. Niel Plummer 139

Effect of magnesium ions on calcium carbonate nucleation and crystal growth in dilute aqueous solutions at $25^{\circ} \mathrm{C}$, by Michael M. Reddy 169

Authigenic potassium feldspar in ribbon rocks of the Cambrian Conococheague Limestone, western Maryland, by Paul P. Hearn, Jr., Roy C. Lindholm, and John F. Sutter 183

Diagenesis of the Todilto Limestone Member of the Wanakah Formation, Chama basin, New Mexico, by Jennie Ridgely 197

Mineralogy and stable isotope geochemistry of carbonate and sulfate minerals in diagenetically altered Tertiary and Cretaceous sandstones, Uinta basin, Utah, by Janet K. Pitman, Martin B. Goldhaber, and Thomas D. Fouch 207

Diagenetic relationships in a hydrocarbon-productive chalk-The Cretaceous Niobrara Formation, by Richard M. Pollastro and Peter A. Scholle 219 


\section{PART IV. DIAGENESIS IN CLASTIC ROCKS}

Burial diagenesis of sandstones, by Raymond Siever 237

Diagenesis of the Morrison Formation, Smith Lake uranium district, McKinley County, New Mexico, by Neil S. Fishman and Richard L. Reynolds 249

Diagenesis and uranium mineralization in the Westwater Canyon Member of the Morrison Formation, Grants uranium region, northwestern New Mexico, by Paula L. Hansley 265

Diagenesis and the sources of the ore-forming fluids, Tony $M$. vanadium-uranium deposit, Henry structural basin, Utah, by H. Roy Northrop, Martin B. Goldhaber, C. Gene Whitney, Fred Peterson, Richard L. Reynolds, and John A. Campbell 281

Clay mineral diagenesis in lacustrine sediments, by Blair F. Jones 291

Zeolitic diagenesis of tuffs in an Upper Miocene lacustrine deposit near Durkee, Baker County, Oregon, by Arthur J. Gude 3rd, and Richard A. Sheppard 301

Magadi-type chert-A distinctive diagenetic variety from lacustrine deposits, by Richard A. Sheppard and Arthur J. Gude 3rd 335

Salt-induced diagenesis of argillaceous sediments, by Charles W. Holmes 347

Sodium-potassium ion exchange during smectite diagenesis-A theoretical discussion, by Dennis D. Eberl 363 


\title{
Sediment Cycling and Diagenesis
}

By ROBERT M. GARRELS, Department of Marine Science, University of South Florida, St. Petersburg, Florida 33701

\section{CONTENTS}

\author{
Abstract 2 \\ Introduction $\mathbf{2}$ \\ Acknowledgments 3 \\ Diagenetic changes in shales 3 \\ Isotopes as guide to diagenesis 6 \\ $\delta^{18} \mathrm{O}$ problems 6 \\ Carbon and sulfur isotopes 6
}

Carbonate problems 8

Paleozoic carbonates 10

Selective loss or preservation 10

Mercury in Early Proterozoic shales 10

The calcium problem 10

Other similar problems 10

Summary 10

References cited $\mathbf{1 0}$

\section{FIGURES}

1. Schematic diagram showing that original minerals of a shale could react to yield a simple three-phase system-quartz, illite, chlorite 4

2. Compositions of fine-grained rocks of various ages plotted as a function of $\mathrm{Na}_{2} \mathrm{O} / \mathrm{Al}_{2} \mathrm{O}_{3}$ ratio versus $\mathrm{K}_{2} \mathrm{O} / \mathrm{Al}_{2} \mathrm{O}_{3}$ ratio 5

3. Variation in $\delta^{18} \mathrm{O}$ in carbonates and cherts as function of geologic age 7

4. Plot of calcium and magnesium in carbonate rocks as function of their age 9

\section{TABLE}

1. Comparison of the major elements of Archean, Early Proterozoic, and Phanerozoic shales 6 


\section{Abstract}

Global compositional and mineralogic differences in rocks as a function of their ages can seldom be unequivocally interpreted as primary or diagenetic. Most mineralogic differences between Mesozoic-Cenozoic and older rocks are diagenetic and represent a tendency for the original aggregates of many phases to change to equilibrium assemblages. For shales, this assemblage is generally chlorite-quartz-illite-feldspar; for carbonate rocks, it is calcite-dolomite. Average differences in bulk chemical compositions of shales with age are small; carbonate rocks show an irregular continuous increase in the $\mathrm{Mg} / \mathrm{Ca}$ ratio with age.

The $\delta^{34} \mathrm{~S}$ isotope composition of calcium sulfate deposits and the $\delta^{13} \mathrm{C}$ isotope values for carbonate rocks, if carefully chosen, reveal the isotopic sulfur and carbon values of the oceans from which they came, and are currently the most trustworthy and useful tools of the geologist studying sedimentary cycling. Global oxidative transfer of organic carbon to carbonate is counterbalanced by reductive transfer of sulfate to sulfide.

\section{INTRODUCTION}

Any reasonable estimate of the rates of erosion of the land areas of the world through geologic time yields a total mass of eroded sediments several to many times the mass of sediments in existence today. Also, 80 percent or more of the material currently being transported to the oceans by streams is derived from sedimentary rocks. The inevitable conclusion is that sedimentary rocks do not exist forever; instead, they are removed from the Earth's surface environment by subduction of oceanic plates, they are metamorphosed by classical processes involving folding and intrusion, or they are uplifted, eroded, and reborn as new sediments.

Although data on the masses of sedimentary rocks remaining today, as a function of their ages, are not nearly as complete as one could wish, there is no doubt that, to a first approximation, the mass of rock remaining of a given age diminishes exponentially with increasing age. This relation is consistent with an erosion-depositiondestruction system, in which the amount of sediment deposited per year is nearly constant (averaged over tens of millions of years), and the amount of sediment destroyed, by whatever processes, has been proportional to the amount in existence at the time of destruction.

The simplest system that can be imagined to explain the present-day distribution of the mass of sedimentary rocks as a function of their ages is an entirely cannibalistic system in which a sedimentary mass was created early in the Earth's history, about 4 billion years ago, by interaction of volatiles exuded by a differentiating Earth with the primitive crystalline crust. This sedimentary mass would then have been eroded from the land areas into the seas and eventually returned to the land areas for reerosion. A model of such an unrealistic system, in which depositional rates were constant and in which the amount of eroded material required to achieve the constant depositional rate was derived from the remnants of older sediments in proportion to their remaining masses, produces a first-order replica of what exists now in terms of sediment mass distribution as a function of sediment age. The model, although it reproduces sediment mass-age relations qualitatively, is inherently incomplete because sedimentary rocks are derived today not only from preexisting sedimentary rocks, but from the 20 percent or so of the land area that is underlain by crystalline rocks, mostly of igneous rather than sedimentary composition. The production of new sedimentary rocks from these crystalline rocks requires reaction with acid volatiles, such as $\mathrm{CO}_{2}, \mathrm{HCl}, \mathrm{HF}$, and $\mathrm{H}_{2} \mathrm{~S}$. Thus, the answer to this question must be that the acidic volatile compounds necessary to convert igneous rocks into sedimentary rocks (for example, $\mathrm{CaSiO}_{3}$ to $\mathrm{CaCO}_{3}$ ) are continously resupplied to the surface environment by the removal of such volatiles from sedimentary rocks that have been heated and squeezed during subduction or classical metamorphism. This process recreates the original igneous minerals and returns the volatiles to the surface environment via volcanoes, hot springs, and similar venting systems.

The gross aspects of the Earth-sediment system can be outlined with some confidence. If the deposits of a given period, such as the Cambrian, are considered from their time of deposition to the present and compared to the properties of the Cambrian rocks surviving today, the following relations must hold: (1) the sample of originally deposited Cambrian rocks available for inspection today is only a fraction, and probably a small fraction, of the rocks originally deposited; (2) the proportions of sedimentary rock types in the remaining Cambrian may or may not be a fair sample of the original proportions; and (3) the remaining Cambrian rocks have existed for 500 million years or more and have been subjected to various degrees of metamorphism, ground-water circulation, and other processes that may have changed their bulk chemical and isotopic compositions, as well as their mineralogies.

A dilemma exists in trying to discuss long-term diagenetic or secondary changes in sedimentary rocks. If differences are found between Cambrian shales and Jurassic shales, what parts of those differences are between the Cambrian shales as originally deposited and the Jurassic shales as originally deposited? Furthermore, what part can be attributed to chemical and mineralogic changes that have taken place in these shales since they were deposited, and what part can be attributed to selective preservation of various types of shales because of the vagaries of selective erosion or other destruction?

When faced with problems like this, there is a tendency for scientists to become polarized and to embrace one view or the other without much compromise, as was true a few generations ago when the problem of continental drift or permanence became an issue. In the United States in the 1930's and 1940's, anyone who proposed 
continental drift was forced to disprove continental permanence. To some extent, the same situation exists today with respect to the chemical compositions and mineralogies of ancient sediments. One extreme view is that the remaining sediments of a given age are a fair sample of the total mass of sediments of that age that once were deposited, and that any secular trends of sediment composition deduced from this conclusion are valid if one wants to compare what was deposited in the Cambrian Period with that in the Jurassic Period. The other school, of course, can be termed the Uniformitarianism School and claims that all sediments are identical when deposited; differences now observed between Cambrian and Jurassic sediments are the products of selective preservation of those sediments plus selective chemical changes engendered by greater exposure to post-depositional agents (for example, ground water) that could leach some components, increase others, and in general tend to produce a false impression of the relations of the original deposits.

Garrels and Mackenzie (1971), in their book “Evolution of Sedimentary Rocks," emphasized postdepositional change as the reason for apparent secular changes in sedimentary rocks. They suggested that chemical analyses of sedimentary rocks had been used uncritically as a means of revealing true primary changes in chemical compositions of sediments through time. They therefore emphasized the data on diagenetic changes and may have produced a document that, read by itself, advocates a viewpoint overly strong in favor of diagenetic change.

Garrels and MacKenzie (1971) tried to make clear that current data are not adequate to permit discrediting the hypothesis of the constant original sediment composition and mineralogy. They were able to show that the differences between Mesozoic and Paleozoic shales could be attributed to post-depositional changes, or perhaps that post-depositional changes tend to obliterate real initial compositional and, especially, mineralogic differences. They posed a challenge-what are the true secular changes in sedimentary compositions (and they must exist), and what are the changes superimposed by aging processes and selective erosion?

In the interpretation of the history of the Earth, it is of critical importance that the nature of the original sedimentary deposits of a given age be known. One comes to the question of which elements, which isotopes, which data of any kind can be trusted to record and preserve their original values to a given time later in Earth history.

The readers of any scientific paper cannot ever be really up to date on such currently controversial issues. This problem of the interpretation of the Earth's history is one of the most basic in geology and has been and is now being worked on by many able researchers. The origin of dolomite is just one aspect of the problem, and it is rumored that the mass of scientific literature on dolomite exceeds the existing mass of dolomite. In the present paper, the number of references has been kept small, but those selected are representative sources that will give the interested reader extensive bibliographies. True secular changes in sedimentary rocks, versus changes resulting from post-depositional processes, are actively being sorted out, and important progress is anticipated. This paper focuses on some of these continuing problems, wherein sediment cycling is related to diagenetic change.

\section{Acknowledgments}

Ideas presented in this paper have a long history. Through the years they have evolved from discussions with many persons, especially R. A. Berner, J. I. Drever, B. Gregor, W. Hoefs, W. Holser, H. D. Holland, the late John Hower, C. Junge, I. R. Kaplan, J. Lawrence, A. Lerman, F. T. Mackenzie, J. McKenzie, the late E. A. Perry, Jr., E. C. Perry, Jr., A. B. Ronov, the late T. J. Schopf, M. Schidlowski, and J. Veizer. Support for the preparation of this material came from National Science Foundation Grant \#EAR-8107736.

\section{DIAGENETIC CHANGES IN SHALES}

The record of post-depositional changes in rocks is well documented in shaly rocks (see Perry and Hower, 1970; Hower and others, 1976). As initially deposited, they contain a wealth of mineral phases, most of which are clearly out of equilibrium with most of the others in any final equilibrium sense. The original muddy or shaly sediment that is deposited contains a variety of minerals, plus a most important set of organic materials. The chemistry of the changes that take place shortly after deposition, especially as it is related to the complexities of the decomposition of organic materials, has been documented in detail elsewhere (see Berner, 1981).

Muds that eventually become shales are mixtures of many mineral phases. These phases are brought to the depositional environment physically, as solid phases in the suspended load of streams. They then coagulate as a result of encountering the high salinity of sea water, and deposit as a remarkable conglomeration of tiny quartz grains; a variety of clay minerals, including montmorillonites, mixed-layer minerals, vermiculites, degraded micas, and chlorites; detrital feldspars; and odds and ends of other mineral species. The most important aspect of a freshly deposited shale is that a variety of mineral compounds is involved. All these phases cannot simultaneously be in equilibrium with the aqueous phase. The pore waters respond to the most reactive and, in general, the most soluble.

What happens in detail in the pore waters of shales is not known (it is almost impossible to sample such 
waters), but chemical analyses of the waters are consistent with the achievement of equilibrium between the pore waters and the more reactive (and perhaps metastable) constituents of the shale. For example, fresh shales (or muds) have dissolved silica values much higher than those in equilibrium with quartz.

Fresh muds or shales violate the phase rule-many more phases are present than components, and these phases cannot all be in equilibrium. One can think of diagenesischemical and mineralogical changes prior to severe metamorphism-as progress toward true equilibrium among mineral phases at low temperature and pressure. The equilibrium assemblage for the multimineralic original shales is a chlorite-illite-quartz rock with either feldspar or, more rarely, kaolinite. It takes time to produce this simple assemblage, but the assemblage does indeed describe the clay mineralogy of Paleozoic and many Proterozoic shales. The clay mineralogy of these old shales must be secondary. Montmorillonite is a common weathering product in modern soils. It changes to illite after burial by substitution of $\mathrm{K}^{+}$in the interlayer positions, coupled with an addition of $\mathrm{Al}^{3+}$ and a loss of $\mathrm{Si}^{4+}$ from the tetrahedral positions. All these changes are well documented as being postdepositional-the mixed-layer illite/montmorillonite minerals of Paleozoic shales must once have been montmorillonites, like those found in Mesozoic shales.

The above relations show that the illite-chloritequartz monotonous mineral assemblage in Paleozoic shales is expected as an equilibrium end product for the multitude of minerals originally deposited in shales. Figure 1 is a schematic diagram adapted from Garrels and Mackenzie (1974) to show how the variety of phases present in a newly deposited mud could react through time to produce an equilibrium assemblage of illite, chlorite, and quartz. The bulk compositions of Paleozoic, Mesozoic-Cenozoic, and Proterozoic shaly rocks are plotted to show that the final product falls into the illite-chlorite-quartz triangle.

Figure 2 has been adapted from a figure by Garrels and Mackenzie (1971) chiefly by adding Cameron and Garrels' (1980) data for Early Proterozoic and Archean shales.

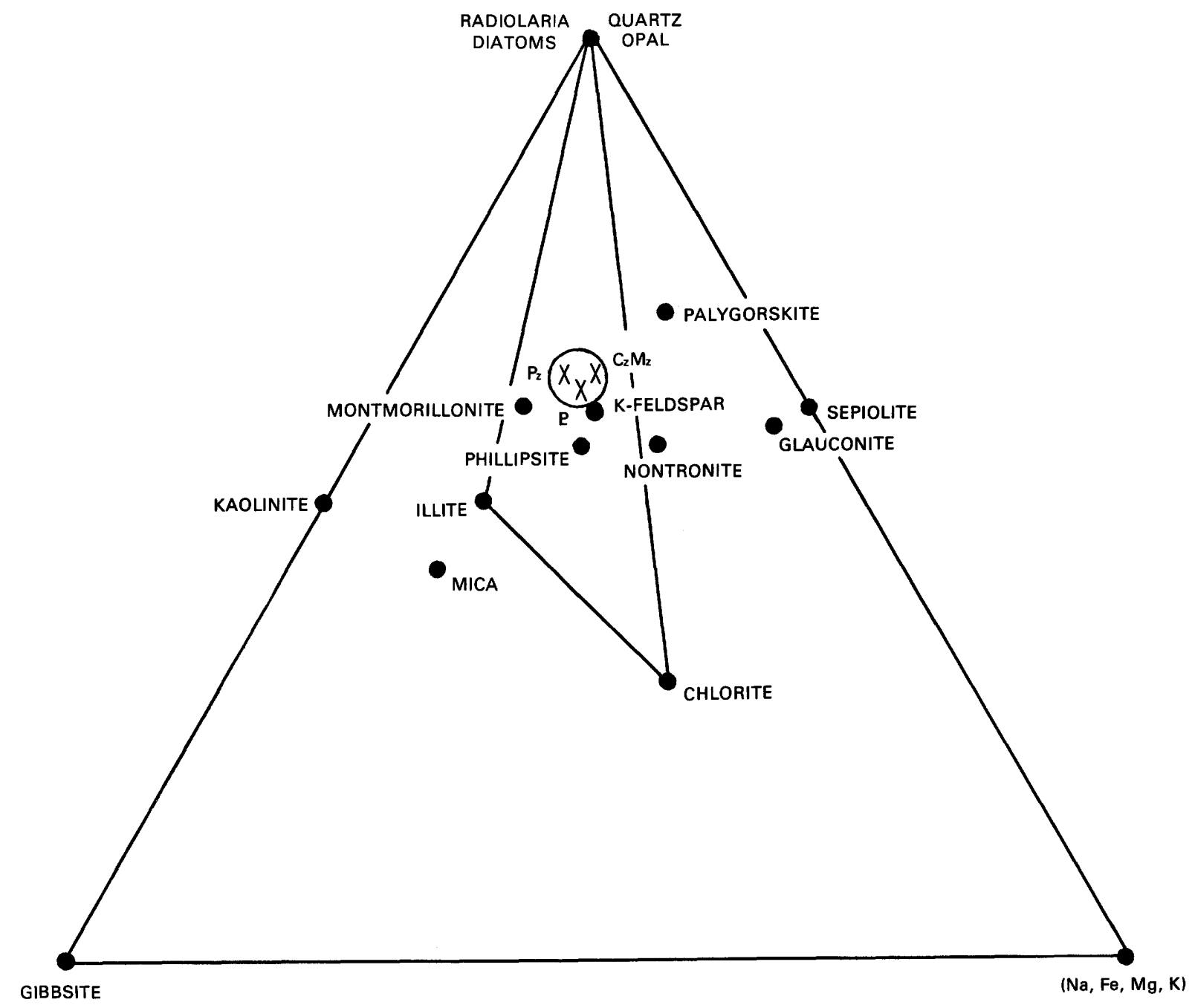

Figure 1. Schematic diagram showing that a mixture of original minerals in a shale with bulk compositions lying in the circle could react to yield a simple three-phase assemblage-quartz + illite + chlorite. P, Proterozoic; Pz, Paleozoic; CzMz, Cenozoic-Mesozoic. Modified from Garrels and Mackenzie (1974). 


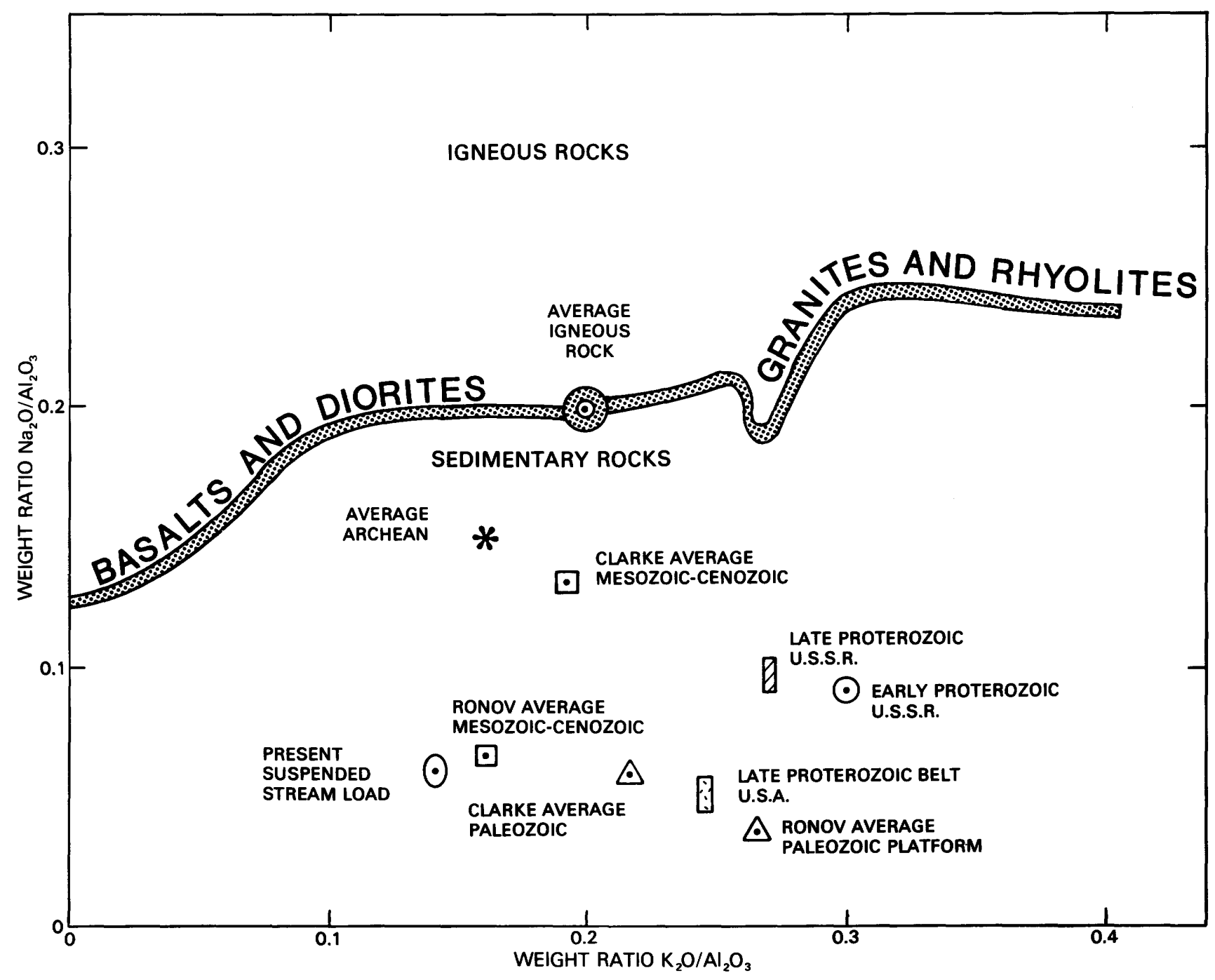

Figure 2. Compositions of fine-grained igneous and sedimentary rocks of various ages plotted as function of $\mathrm{Na}_{2} \mathrm{O} / \mathrm{Al}_{2} \mathrm{O}_{3}$ ratio versus $\mathrm{K}_{2} \mathrm{O} / \mathrm{Al}_{2} \mathrm{O}_{3}$ ratio. Modified from Garrels and Mackenzie (1971, fig. 9.2, p. 229). Clarke average from Clarke (1924); Ronov average from Ronov and Migdisov (1971).

The similarity of composition of Paleozoic shales to those of both the Early and Late Proterozoic suggests similar source areas and the attainment of similar stable assemblages. On the other hand, Archean shales reveal their kinship to the basaltic crust from which many of them were derived. Interestingly, they are high in $\mathrm{Na}_{2} \mathrm{O}$, but nearly as low in $\mathrm{CaO}$ as Proterozoic shales, perhaps pointing to a breakdown during weathering of highcalcium plagioclase, with recrystallization of albitic material (see Land and Milliken, 1981). One common interpretation is that the Mesozoic-Cenozoic shales (Ronov values) still show their compositional inheritance from the same types of materials being carried by rivers today. Paleozoic and Proterozoic shales exhibit postdepositional gain in $\mathrm{K}_{2} \mathrm{O}$, related perhaps in part to slow addition of $\mathrm{K}^{+}$to highly charged clay minerals. The reduction of $\mathrm{Fe}^{3+}$ in the octahedral sites of phyllosilicates may increase their negative charge and cause them to fix $\mathrm{K}^{+}$and to lose interlayer water.

Alternatively, a shift in provenance has taken place with Archean and Mesozoic-Cenozoic shales representing times of more mafic crystalline sources. Veizer and Jansen (1979), in an important paper on basement and sedimentary recycling, and Engel and others (1974) presented in detail the case for more mafic sources for Archean and Mesozoic sediments, as compared to Paleozoic and Proterozoic ones. At the other extreme are Garrels and Mackenzie (1972), who constructed a cycling model (not including Archean sediments) that produced all sedimentary rocks by deposition of sediments like those of today. Diagenetic changes were held accountable for differences in composition as a function of age. 
The general chemical characteristics of shales as a function of age are shown in table 1 (Cameron and Garrels, 1980). The basic similarities are obvious; indeed, if one compares the three sets of analyses, oxide by oxide, no overall trends are apparent. For some oxides the Archean shales are more like Phanerozoic than Early Proterozoic shales; for other oxides the reverse is true. The differences among the analyses easily could be the result of sampling procedures and selection of shale types. Perhaps the two most interesting features are the lack of an age trend in the iron content or in the organic carbon content.

\section{ISOTOPES AS GUIDE TO DIAGENESIS}

\section{$\delta^{18} \mathrm{O}$ problems}

As shown in figure $3, \delta^{18} \mathrm{O}$ values of carbonates diminish irregularly with increasing age. The curve for silicates is roughly parallel to the $\delta^{18} \mathrm{O}$ carbonate curve, averaging about 5 per mil higher. The modern value for carbonates in equilibrium with sea water is about +30 per mil $\delta^{18} \mathrm{O}$, that for siliceous organisms about +35 per mil. The mean value for all carbonates is probably about

Table 1. Comparison of Archean, Early Proterozoic (Aphebian), and Phanerozoic shales

[Modified from Cameron and Garrels (1980), table III]

\begin{tabular}{|c|c|c|c|}
\hline & Archean & Aphebian & $\begin{array}{c}\text { Phanerozoic } \\
\text { (carbonate } \\
\text { free) }\end{array}$ \\
\hline $\mathrm{SiO}_{2}$ & 60.52 & 65.00 & 63.11 \\
\hline $\mathrm{TiO}_{2}$ & 0.76 & 0.76 & 0.89 \\
\hline $\mathrm{Al}_{2} \mathrm{O}_{3}$ & 17.63 & 16.22 & 18.80 \\
\hline $\mathrm{Fe}_{2} \mathrm{O}_{3}$ & 7.91 & 6.37 & 7.79 \\
\hline Mg0 & 3.47 & 2.51 & 3.11 \\
\hline $\mathrm{CaO}$ & 2.16 & 0.52 & 0.07 \\
\hline $\mathrm{Na}_{2} \mathrm{O}$ & 2.62 & 1.44 & 1.27 \\
\hline $\mathrm{K}_{2} \mathrm{O}$ & 2.84 & 4.83 & 3.69 \\
\hline c & 0.77 & 1.68 & 0.87 \\
\hline$S$ & 0.66 & 0.65 & 0.38 \\
\hline Totals & 99.98 & 99.98 & 99.98 \\
\hline $\begin{array}{r}\delta^{34} S(\%) \\
(\text { per mil) }\end{array}$ & $\begin{array}{l}+1.31 \\
\pm 0.32\end{array}$ & $\begin{array}{r}+11.79 \\
\pm 4.37\end{array}$ & -12 \\
\hline
\end{tabular}

+20 per mil, that for silicate minerals, about +17 per mil.

At least four explanations for these isotope-time trends exist. One is exchange with ground waters, which are typically much lighter isotopically than sea water; a second is metamorphism and consequent isotope exchange among minerals; a third is formation in an ocean that had a $\delta^{18} \mathrm{O}$ value smaller than today's; and a fourth is precipitation of the minerals from a much warmer ocean.

$\mathrm{Li}$ (1972) performed a clever isotope balance that suggests that the ocean has been about the same isotopically, or heavier, through time. He showed that reaction of an original ocean, with an expected $\delta^{18} \mathrm{O}$ value of +6 to +9 per mil (values representative of water emitted from the crystallization of igneous rocks), to give an ocean with the zero $\delta^{18} \mathrm{O}$ value of today would indeed produce a mass of sediment about equal to that existing today with the mean $\delta^{18} \mathrm{O}$ value of that sedimentary mass. An important implication of Li's calculation is that no major net loss of silicate-containing sediments has taken place from the exogenic cycle by subduction or related processes.

It is surprising that there has been so little followup on the work of Knauth and Epstein (1976), who used deuterium-oxygen isotope plots of $\mathrm{SiO}_{2}$ minerals of various ages to reconstruct a generalized temperature history of the ocean. If their methods and results are valid, the temperature history of the earth must have been a major control of the course of organic evolution. If values of $60^{\circ} \mathrm{C}$ or higher during the Archean and Early Proterozoic are correct, they provide a simple explanation for the approximately 2 billion years that seem to have elapsed between the invention of photosynthesis by procaryotes and the appearance of eucaryotic organisms. Despite the warnings of many of his biologically oriented colleagues, this author is still impressed with the possibility that the only kinds of organisms that could have survived above about $65^{\circ} \mathrm{C}$ would be classified as procaryotes, and that physicochemical temperature barriers to the development of eucaryotic cells exist that defy even the flexibility of evolutionary change.

\section{Carbon and sulfur isotopes}

Values for carbon and sulfur isotope ratios for carbonates, organic carbon, sulfates, and sulfides that are indeed representative of the conditions of their formation are becoming available in increasing numbers. They are the most important and trustworthy information about ancient environments (except for fossils) available to us today. Holser and Kaplan's (1966) work on ancient evaporites demonstrated firmly that the $\delta^{34} \mathrm{~S}$ values for calcium sulfates were indeed close to the $\delta^{34} \mathrm{~S}$ values of 


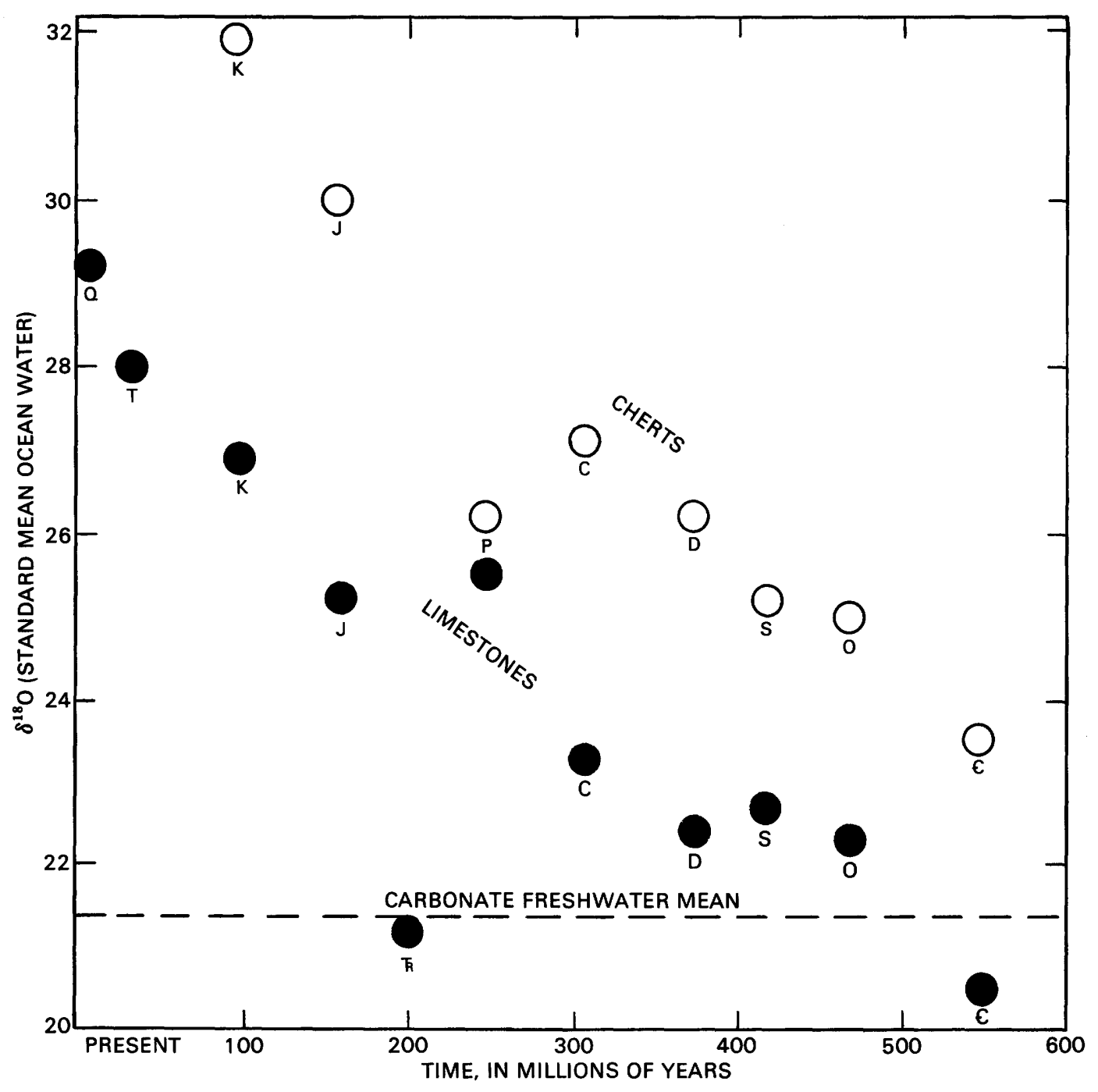

Figure 3. Variations in $\delta^{18} \mathrm{O}$ values of carbonates and cherts as a function of geologic age. Data from Degens and Epstein (1962). Q, Quaternary; T, Tertiary; K, Cretaceous; J, Jurassic; Tr, Triassic; P, Permian; C, Carboniferous; D, Devonian; S, Silurian; O, Ordovician, $E$, Cambrian.

contemporary oceanic sulfate. Their paper must therefore be regarded as one of the most important geological publications of the 20th century. It is apparently the only current unequivocal source of information concerning ancient ocean compositions. A recent update of that paper (Claypool and others, 1980) adds valuable information but does not change the basic patterns established in 1966.

It has slowly become apparent also that the $\delta^{13} \mathrm{C}$ values of ancient carbonate minerals and organic materials are trustworthy in the sense that they have generally not changed significantly from the time they were buried a meter or so in sediment.

Variations in $\delta^{34} \mathrm{~S}$ values with time are much greater than those of $\delta^{13} \mathrm{C}$, chiefly because percentage variations in carbon fluxes are much smaller than those for sulfur fluxes. Recently, Veizer and others (1980) accumulated all available $\delta^{13} \mathrm{C}$ values for carbonate minerals and showed that variations definitely exist within Phanerozoic time. They also showed that these variations are consistent with the predictions of Garrels and Perry (1974), who suggested that the carbon and sulfur cycles must be so closely linked that changes in sulfur isotopes of sea water (and thus in evaporites) should be reflected in changes of carbon isotopes. It is remarkable that the $\delta^{13} \mathrm{C}$ values of marine carbonate minerals have fluctuated a few per mil around zero, and that the mean $\delta^{13} \mathrm{C}$ values of organic materials, although much more variable than those of carbonates, have averaged about 25 per mil lower than those of contemporaneous carbonates for more than 3 billion years (Schidlowski and others, 1984 , p. 158). The conclusion from these data is that the ratio of carbonate carbon deposited to organic carbon deposited has not changed much from about 4:1 
through all of recorded Earth history, and that the effective isotope fractionation between inorganic and organic carbon has averaged about 25 per mil. Because the percentage of organic carbon in sedimentary rocks also has been nearly constant with time (Cameron and Garrels, 1980), there is a further, but less certain, implication that the rates of deposition of inorganic and organic carbon have also changed little during more than 3 billion years.

Several articles have appeared in the last 10 years that use the age relations of $\delta^{13} \mathrm{C}$ and $\delta^{34} \mathrm{~S}$ to interpret the global oxygen budget (see Schidlowski and others, 1977). Garrels and Lerman (1981) came to the following conclusions: (1) The total oxygen produced, as measured by the total amount of buried organic carbon in sedimentary rocks, is greater than that stored in sulfate in sediments and in the ocean plus that represented by ferric iron in various minerals. Several estimates of the oxygen budget find this excess of oxygen produced over oxygen stored to be perhaps as much as $400 \times 10^{18}$ moles (roughly equivalent to the total oxygen in calcium sulfate deposits of all ages). (2) Oxygen stored in iron minerals may have been produced chiefly at about the time of formation of the banded iron formations, some 2 billion years ago. One kind of evidence is the disappearance at that time of thick strata of ferrous carbonates and silicates. (3) Since the beginning of the Phanerozoic Era, the Earth's surface has been dominated by the carbonate carbon-organic carbon-sulfate sulfur-sulfide reciprocal oxidation-reduction system (organic carbon + sulfate $=$ sulfide + carbonate). (4) The amount of oxygen stored in sulfate has fluctuated by amounts several times larger than the amount now in the atmosphere, but there seems to be no consistent trend over the last billion years. Oxygen storage was minimal at the beginning of Cambrian time, irregularly rose to a maximum in the Permian, and has since declined somewhat.

A current major mystery is the nature of the sulfur cycle during the Archean and Early Proterozoic. Apparently, the sulfate-reducing bacteria did not evolve importantly until about 2.3 billion years ago (Cameron, 1983). This conclusion is based on consistent mean $\delta^{34} \mathrm{~S}$ values of sulfides of about zero for all Archean sedimentary sulfides. Many deposits have a range of values, but the mean values are always close to that of the primordial meteorite sulfur standard. No values have been published for the $\delta^{34} \mathrm{~S}$ of bedded sedimentary anhydrite or gypsum deposits older than about 2.3 billion years (Cameron, 1983).

Cameron and Garrels (1980) found an amazing average value of +12 per mil for the $\delta^{34} \mathrm{~S}$ of the sulfide of 400 Early Proterozoic shales. Early Proterozoic shales have consistently positive values for the $\delta^{34} \mathrm{~S}$ of their pyrite sulfur. Where has the light sulfur necessary to produce these high positive values gone? Is it possible that bacterial oxidation of sulfides during the Early
Proterozoic yielded sulfates with $\delta^{34} S$ values lower than their parent sulfides, and that the isotopically light sulfate was removed by reduction at high temperature by circulation through seafloor basalts? Some sulfide oxidation pathways, although apparently not important today, selectively utilize light sulfur (Schidlowski and others, 1984 , p. 167).

\section{CARBONATE PROBLEMS}

A major secular trend of sedimentary rocks that indeed may be primary is the change over the past several billion years from the Early Proterozoic deposition of iron carbonates and silicates, to early Phanerozoic deposition of dolomites and magnesium-rich clays, to the Mesozoic-Cenozoic calcite limestones and clays. If these changes are considered as a chemical problem of the relations of three sets of carbonates and silicates, clearly no given value of atmospheric carbon dioxide can have more than one of the three pairs in equilibrium. The thermodynamic values required to decide exactly in terms of parts per million the $\mathrm{CO}_{2}$ pressure in equilibrium with the three systems are not well enough known, but these systems certainly are in the order, from highest $\mathrm{CO}_{2}$ required to lowest, iron carbonate-silicate, dolomitesilicate, calcite-silicate (see Holland, 1968). The problem is complicated by the oxidation state of the iron in the iron carbonates and silicates. The loss of ferrous carbonate from sedimentary systems was probably caused by an increase of atmospheric oxygen, rather than a decrease in atmospheric $\mathrm{CO}_{2}$. Nevertheless, the basins of deposition of the iron carbonates and silicates of the banded iron formations required a higher $\mathrm{CO}_{2}$ pressure for codeposition of both phases than the Early Phanerozoic basins producing dolomites and Mg clays; the $\mathrm{CO}_{2}$ pressure for modern basins producing calcite and clays is still lower.

This author's interpretation considers that Early Proterozoic time had low oxygen pressures and relatively high $\mathrm{CO}_{2}$ pressures (perhaps $10^{-2}$ atmospheres). Iron behaved like calcium and magnesium and produced extensive deposits of ferrous carbonates and aluminumfree silicates. As the sulfide reservoir diminished as an oxygen sink, because of the irreversible oxidation to sulfate, more oxygen became available for oxidation of ferrous compounds. The oxidation of ferrous carbonate produced $\mathrm{CO}_{2}$, and the global balance of oxygen and $\mathrm{CO}_{2}$ changed significantly. The change to an oxygenated atmospheric system during the Proterozoic must have had far-reaching consequences, strangely enough not well documented by studies of sediments of the 2-billion- to 1-billion-year range. We are far from understanding these secular changes, but it is not inconceivable that the lowering of $\mathrm{CO}_{2}$ in the atmosphere, because of a smaller contribution from depth as the thermal gradient diminished, 
was important in shifting from an anaerobic world in the Archean to an aerobic one in the Late Proterozoic. Whatever the reasons, iron changed from a dominantly $2+$ valent element to a $3+$ valent element at about 2 billion years ago.

In figure 4 , the $\mathrm{Ca} / \mathrm{Mg}$ ratio of carbonate rocks is plotted as a function of time. If the data relate to primary deposition, the percentage of dolomite in carbonate rocks has been declining for 600 million years or more. As pointed out by Holland (1968), the occurrence of dolomite, whatever its origin, is promoted by high $\mathrm{CO}_{2}$ pressure in the atmosphere; low $\mathrm{CO}_{2}$ pressure favors clay minerals rather than dolomite. Little dolomite has formed over the last 100 million years. All these relations make it important to wonder if the $\mathrm{CO}_{2}$ content of the atmosphere has not been declining slowly but steadily over vast time intervals. If the $\mathrm{CO}_{2}$ content of the atmosphere is conceived as a steady state balance between use of $\mathrm{CO}_{2}$ by weathering and production by deep processes, such as volcanism, metamorphism, and subduction, it is reasonable that the aging Earth, despite its obviously important tectonic activity, is in fact senescent and not performing today in terms of its transfer of energy and materials from depth to surface as well as it did billions of years ago. If so, the carbonate changes suggested may be real long-term trends.

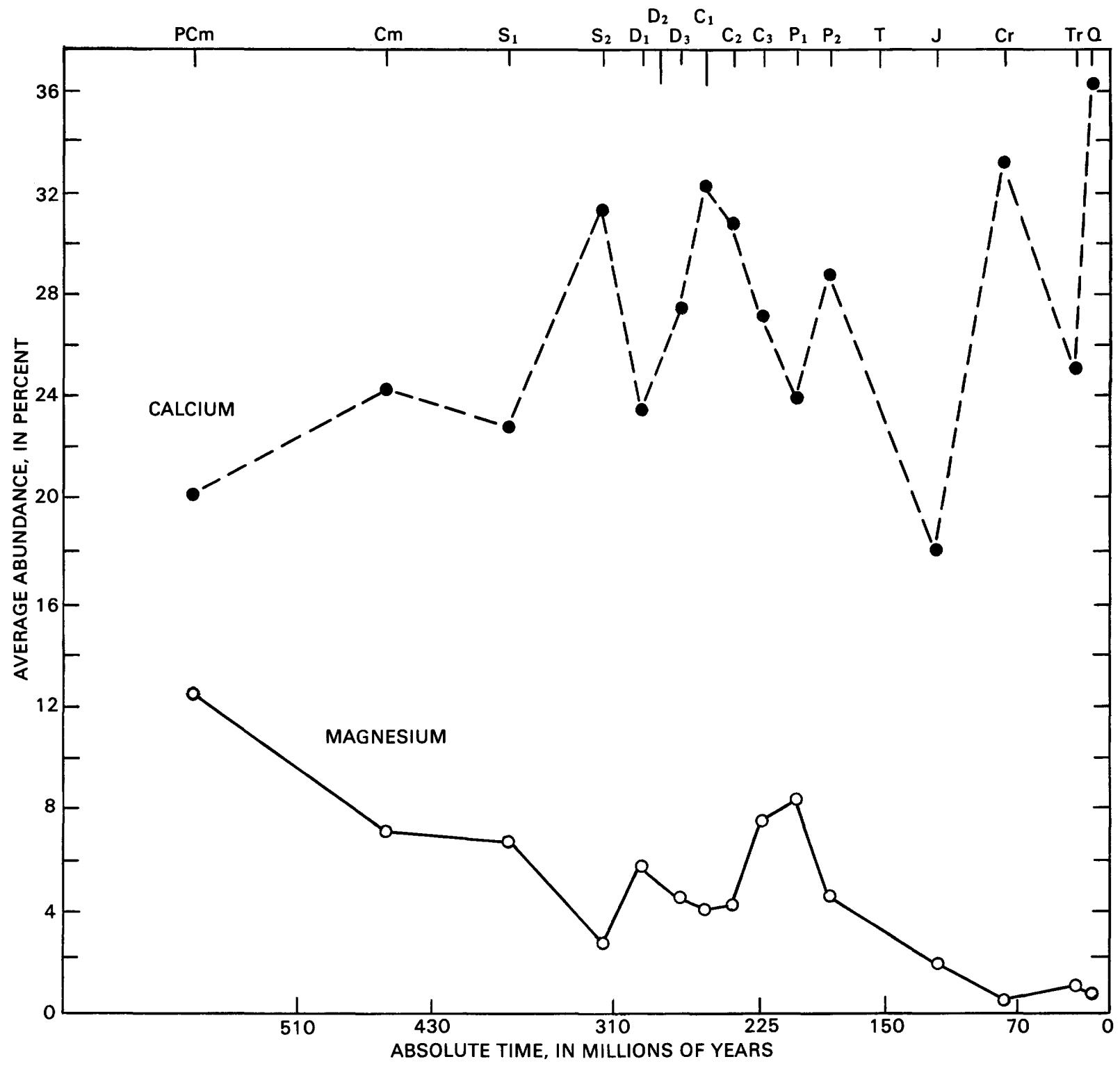

Figure 4. Calcium and magnesium in carbonate rocks as a function of their age; from Vinogradov and others (1957). PCm, Precambrian; $\mathrm{Cm}$, Cambrian; $\mathrm{S}_{1}$, Silurian $1 ; \mathrm{S}_{2}$, Silurian 2; $\mathrm{D}_{1}$, Devonian 1; $\mathrm{D}_{2}$, Devonian 2; $\mathrm{D}_{3}$, Devonian 3; $\mathrm{C}_{1}$, Carboniferous 1; $\mathrm{C}_{2}$, Carboniferous 2; $\mathrm{C}_{3}$, Carboniferous 3; $\mathrm{P}_{1}$, Permian 1; $\mathrm{P}_{2}$, Permian 2; $\mathrm{T}$, Triassic; J, Jurassic; $\mathrm{Cr}$, Cretaceous; Tr, Tertiary; Q, Quaternary. 


\section{Paleozoic carbonates}

An important facet of the general relations among carbonate minerals in terms of what they once were and what they are now is the possibility that many species of organisms that today secrete aragonite or high-magnesium calcite may have secreted nearly pure calcite during Paleozoic time (see Sandberg, 1975). This possibility is particularly important to the general theme of diagenetic change. If, as generally assumed, present-day aragonitesecreting organisms produced aragonite 400 million years ago, the fact that the remains of these organisms today are calcite means that diagenetic changes have managed to cause recrystallization. This problem was discussed above, but it is worth reinforcing the point here. Until the kinetics of precipitation of the organisms are understood, the interpretation of the fossil record cannot be unequivocal. Chave (1960) was among the first to state clearly the importance of secondary changes of fossil remains in the interpretation of the organism relations of the original assemblage, especially the selective loss of more soluble varieties of skeletons.

\section{SELECTIVE LOSS OR PRESERVATION}

In the interpretation of differences in the compositions of sedimentary rocks as a function of their ages, the effects of diagenetic changes have been stressed as causing changes in mineralogy as well as in composition. Another factor that is potentially just as important can be called selective loss or preservation. Geologists are just beginning to come to grips with this problem as information emerges on subduction of sediments and on removal of constituents from sea water at ocean ridges. Most of the sediment models that have been made assume either a closed cycling system or one in which the chemistry of new sediments, created by acid volatiles recirculated into the exogenic cycle, is the same as that of the lost materials. A few of the relations that are puzzling in light of current knowledge are discussed below.

\section{Mercury in Early Proterozoic shales}

Cameron and Jonasson (1972) showed that mercury in Early Proterozoic shales is enriched by a factor of about 10 over younger shales, and that enrichment is quite general. The age range of the Early Proterozoic shales sampled is several hundred million years, so that at the end of Early Proterozoic time a mass of mercury-enriched shales presumably existed comparable to the current Mesozoic-Cenozoic shale mass. Of course, most of the original Early Proterozoic shales have disappeared, but in a cannibalistic sediment system their constituent elements should still be cycling. Somehow a large mass of mercury has been removed from the exogenic system.
(One might guess subduction of the shales or removal by seawater circulation at ridges.)

\section{The calcium problem}

Sedimentary rocks have a much lower percentage of $\mathrm{Na}_{2} \mathrm{O}$ than the igneous rocks from which they came; but the missing sodium seems to be balanced by sodium in the ocean and in evaporites. On the other hand, sedimentary rocks, by most measures, have about twice as much calcium as their igneous forebears. Calcium from basalts is being exchanged for magnesium during the circulation of sea water through ridges-one way to account for the calcium excess-but there seems to be no corresponding magnesium depletion in sedimentary rocks as compared to the average igneous rock. Sibley and Vogel (1976) suggested that the calcium excess may be the result of subduction of pre-Mesozoic, calcium-free deep-sea sediments. If their sole deficiency was carbonates, calcium would indeed be concentrated in the surviving shallowwater sediments.

\section{Other similar problems}

Selective loss into the mantle of sulfate sulfur and oxygen would affect the mean isotopic composition of the sulfur remaining in the exogenic cycle, as well as cause imbalances in the exogenic oxygen and carbon reservoirs. Li's (1972) mass and isotope balance for sediments and sea water described above has implications that no large fractional loss of sediments to the mantle has taken place. Many more relations of this kind must exist that could be investigated to examine the degree to which the exogenic cycle is a closed system with respect to the mass of the circulating elements.

\section{SUMMARY}

To read the environments of the geologic past and to reconstruct the flows of energy and materials, we must be able to deduce the original compositions, structures, textures, and mineralogies of sedimentary rocks. Diagenetic changes have played a major role in changing mineralogies and bulk compositions as well, and an attempt has been made here to show that we are in the midst of sorting out primary and secondary features. Also, our reading of the record can be warped by selective losses or gains of materials from the exogenic cycle.

\section{REFERENCES CITED}

Berner, R. A., 1981, Authigenic mineral formation resulting from organic matter decomposition in modern sediments: Fortschritte der Mineralogie, v. 59, p. 117-135. 
Cameron, E. M., 1983, Evidence from early Proterozoic anhydrite for sulfur isotopic partitioning in Precambrian oceans: Nature, v. 304, p. 54-56.

Cameron, E. M., and Garrels, R. M., 1980, Geochemical compositions of some Precambrian shales from the Canadian Shield: Chemical Geology, v. 28, p. 181-197.

Cameron, E. M., and Jonasson, I. R., 1972, Mercury in Precambrian shales of the Canadian Shield: Geochimica et Cosmochimica Acta, v. 36, p. 985-1005.

Chave, K. E., 1960, Carbonate skeletons to limestonesProblems: Transactions of the New York Academy of Sciences, Series II, v. 23, p. 14-24.

Clarke, F. W., 1924, Data of geochemistry: U.S. Geological Survey Bulletin 770, 841 p.

Claypool, G. E., Holser, W. T., Kaplan, I. R., Sakai, H., and Zak, I., 1980, The age curves of sulfur and oxygen isotopes in marine sulfate and their mutual interpretation: Chemical Geology, v. 28, p. 199-260.

Degens, E. T., and Epstein, S., 1962, Relationship between $\mathrm{O}^{18} / \mathrm{O}^{16}$ ratios in coexisting carbonates, cherts, and diatomites: American Association of Petroleum Geologists Bulletin, v. 46, p. 534-542.

Engel, A. E. J., Itson, S. P., Engel, C. G., and Stickney, D. M., 1974, Crustal evolution and global tectonics; A petrogenic view: Geological Society of America Bulletin, v. 85, p. 843-858.

Garrels, R. M., and Lerman, A., 1981, Phanerozoic cycles of sedimentary carbon and sulfur: Proceedings of the National Academy of Sciences, U.S.A., v. 78, p. 4652-4656.

Garrels, R. M., and Mackenzie, F. T., 1971, Evolution of sedimentary rocks: New York, W. W. Norton, p. 229.

1972, A quantitative model for the sedimentary rock cycle: Marine Chemistry, v. 1, p. 27-41.

1974, Chemical history of the oceans deduced from postdepositional changes in sedimentary rocks, in Hay, W. W., ed., Studies in paleooceanography: Society of Economic Paleontologists and Mineralogists Special Publication 20, p. 193-204.

Garrels, R. M., and Perry, E. A., Jr., 1974, Cycling of carbon, sulfur, and oxygen through geologic time, in Goldberg, $\mathrm{E}$. D., ed., The sea, v. 5: New York, John Wiley \& Sons, p. 303-336.

Holland, H. D., 1968, The abundance of $\mathrm{CO}_{2}$ in the Earth's atmosphere through geologic time, in Ahrens, L. H., ed., Origin and distribution of the elements: Oxford and New York, Pergamon Press, p. 949-954.

Holser, W. T., and Kaplan, I. R., 1966, Isotope geochemistry of sedimentary sulfates: Chemical Geology, v. 1, p. 93-135.
Hower, J., Eslinger, E. V., Hower, M. E., and Perry, E. A., 1976, Mechanism of burial metamorphism of argillaceous sediment; 1. Mineralogical and chemical evidence: Geological Society of America Bulletin, v. 87, p. 725-737.

Knauth, L. P., and Epstein, S., 1976, Hydrogen and oxygen isotope ratios in nodular and bedded cherts: Geochimica et Cosmochimica Acta, v. 40, p. 1095-1108.

Land, L. S., and Milliken, K. L., 1981, Feldspar diagenesis in the Frio Formation, Brazoria County, Texas Gulf Coast: Geology, v. 9, p. 314-318.

Li, Y. H., 1972, Geochemical mass balance among lithosphere, hydrosphere, and atmosphere: American Journal of Science, v. 272, p. 119-137.

Perry, E., and Hower, J., 1970, Burial diagenesis in Gulf Coast pelitic sediments: Clays and Clay Minerals, v. 18, p. 165-177.

Ronov, A. B., and Migdisov, A. A., 1971, Geochemical history of the crystalline basement and the sedimentary cover of the Russian and North American platform: Sedimentology, v. 16, p. $137-185$.

Sandberg, P. A., 1975, New interpretations of Great Salt Lake ooids and of ancient nonskeletal carbonate mineralogy: Sedimentology, v. 22, p. 497-537.

Schidlowski, M., Junge, C. E., and Pietrek, H., 1977, Sulfur isotope variations in marine sulfate evaporites and the Phanerozoic oxygen budget: Journal of Geophysical Research, v. 82, p. 2557-2565.

Schidlowski, M., Hays, J. M., and Kaplan, I. R., 1984, Isotopic inferences of ancient biochemistries-Carbon, sulfur, hydrogen, and nitrogen, in Schopf, J. W., ed., Earth's earliest biosphere: Princeton, New Jersey, Princeton University Press, p. 149-183.

Sibley, D. G., and Vogel, T. A., 1976, Chemical mass balance of the Earth's crust-The calcium dilemma(?) and the role of pelagic sediment: Science, v. 192, p. 551-553.

Veizer, J., Holser, W. T., and Wilgus, C. K., 1980, Correlation of ${ }^{13} \mathrm{C} /{ }^{12} \mathrm{C}$ and ${ }^{34} \mathrm{~S} /{ }^{32} \mathrm{~S}$ secular variations: Geochimica et Cosmochimica Acta, v. 44, p. 579-587.

Veizer, J., and Jansen, S. L., 1979, Basement and sedimentary recycling and continental evolution: Journal of Geology, v. 87, p. 341-370.

Vinogradov, A. P., Ronov, A. B., and Ratynskii, V. M., 1957, Variations in the chemical composition of carbonate rocks of the Russian platform: Geochimica et Cosmochimica Acta, v. 12, p. 273-276. 



\title{
A Kinetic Approach to Chemical Diagenesis
}

\section{By Robert A. Berner, Department of Geology and Geophysics, Yale University, New Haven, Connecticut 06511}

\section{CONTENTS}

\author{
Abstract 14 \\ Introduction 14 \\ Diaigenetic equations and steady state 14 \\ Kiretics of diagenetic organic matter decomposition 15 \\ Conclusion 20 \\ Acknowledgment 20 \\ Rejerences cited 20
}

\section{FICiURES}

1. Diagramatic representation of steady state diagenesis $\mathbf{1 5}$

2. Distribution of dissolved nitrate, manganese, and iron versus depth in a pelagic sediment from the equatorial Atlantic Ocean 16

3. Distribution of dissolved sulfate and methane vs. depth for anoxic sediments from the FOAM site of Long Island Sound 18

4. Plot of rate of organic matter decomposition $R_{\mathrm{i}}$ versus concentration of added organic carbon $\Delta G$ for anoxic sediments from Long Island Sound 19

5. Log-log plot of the rate constant $k$ for organic matter decomposition via bacterial sulfate reduction versus sedimentation rate $\omega$ for a variety of marine sediments 20

TABLE

1. Sequence of organic matter decomposition reactions and corresponding standard state free energy changes 16 


\section{Abstract}

The study of chemical diagenesis can be approached from three viewpoints: observational, thermodynamic, and kinetic. In this paper the kinetic approach is briefly presented in terms of one-dimensional concentration-vs-depth diagenetic equations, which include expressions for diffusion, particle bioturbation, sediment burial, pore water flow, and chemical reaction. A simplifying concept for deducing rates of diagenetic chemical reactions is that of steady state diagenesis. Application of steady state diagenetic equations to the problem of microbiological organic matter decomposition reveals that organic matter can be divided into a number of fractions, each of which undergoes decomposition via first order kinetics and is characterized by a reactivity rate constant, $k$, whose value can range worldwide over a factor of $10^{7}$.

\section{INTRODUCTION}

The study of chemical diagenesis (diagenesis is defined here as all chemical changes taking place in a subaqueous sediment both during and after deposition) can be approached in several different ways. First, and foremost, one must discern what changes actually take place during burial over time and this requires detailed mineralogical, petrographic, and chemical observations. One might call this the observational approach; it forms the foundation for all other approaches. Diagenetic changes are studied by examination of ancient rocks which have undergone replacement, cementation, compaction, etc. or by tracing changes occurring with depth (time) in modern, unlithified sediments.

Once sufficient data have been gathered, one normally encounters difficulties in discriminating between diagenetic changes and historical changes, in other words, those occurring at the time of deposition. At this point, chemical thermodynamics becomes a very useful tool. Through calculations of free energy changes and equilibrium constants, one can determine where true equilibrium lies, and this points to the direction in which diagenesis must proceed. For example, if a stratigraphic succession shows younger calcitic fossils overlying older aragonitic fossils, then the difference cannot be due to progressive diagenesis because thermodynamic calculations indicate that calcite is more stable than aragonite under diagenetic conditions and therefore cannot convert to aragonite with time. This kind of approach can be called the thermodyamic approach to diagenesis, and it directly complements the observational approach. In fact, observed changes over long periods sometimes can be used to check thermodynamic predictions.

Once sedimentologic observations and thermodynamic calculations have been made, the question still remains as to how fast and by what chemical mechanisms diagenesis take place. This leads to a theoretical or quantitative kinetic approach to diagenesis, a topic which will be pursued in the present paper. I will present some rather simple models which illustrate how the fundamental principles of chemical kinetics can be applied to diagenetic problems. Equations are derived which are then applied to a common problem, the bacterial decomposition of organic matter, to illustrate the power of the kinetic approach. For further discussion of diagenetic modeling, the reader should consult books on early diagenesis such as Berner (1980) and Lerman (1979) which apply kinetics to a number of low-temperature geologic processes.

\section{DIAGENETIC EQUATIONS AND STEADY STATE}

Although there are numerous exceptions, one can safely say that, in general, diagenetic changes are mainly vertical in nature; that is, diagenesis takes place during burial and affects wide areas at the same time. This is especially true of fine-grained marine sediments (muds) during early diagenesis. Here, vertical changes occur on a scale of a few centimeters to a few tens of meters as opposed to lateral changes on the scale of many kilometers.

If diagenetic changes are predominantly vertical in nature, one can describe them simply in terms of depth and time and this leads to the concept of the diagenetic equation (Berner, 1980). All processes affecting a given layer of sediment during burial can be described in terms of three processes: diffusion, advection, and chemical (including radiochemical) reaction. If changes occur only with depth and time, this can be expressed as follows: For solid components within the layer:

$$
\left(\frac{\partial c_{s}}{\partial t}\right)_{L}=D_{B} \frac{\partial^{2} c_{s}}{\partial x^{2}}+\Sigma R_{s} .
$$

For dissolved components within the layer:

$$
\left(\frac{\partial c}{\partial t}\right)_{L}=D_{s} \frac{\partial^{2} c}{\partial x^{2}}-v_{g} \frac{\partial c}{\partial x}+\Sigma R,
$$

where: $\quad c_{s}=$ concentration of a solid component (in terms of mass per unit mass of total solids)

$c=$ concentration of a dissolved component (in terms of mass per unit volume of pore water)

$t=$ time

$x=$ depth (measured positively downward)

$v_{g}=$ rate of vertical velocity of the pore water relative to the layer

$R_{s}, R=$ rate of each chemical reaction affecting $c_{s}$ and $c$, respectively

$D_{s}=$ molecular diffusion coefficient for the whole sediment (pore water and particles)

$D_{B}=$ biodiffusion coefficient used to describe bioturbational mixing of particles on the assumption that it can be treated as a random walk process. 
Here, the derivatives $\left(\partial c_{s} / \partial t\right)_{L}$ and $(\partial c / \partial t)_{L}$ refer to all diagenetic changes occurring in the sediment layer $(L)$ as it is buried. Also, to simplify matters it is assumed that compaction, and diffusion or flow of pore water due to biological activity (irrigation), are all negligible.

The above equations imply a reference frame for depth $x$ fixed to a given sediment layer. When studying early diagenesis, a more useful reference is the sedimentwater interface and this is what will be adopted here. Diagenesis, by definition, begins at the sediment-water interface and continues as sediment layers are buried below it. In this case the layer can be considered as being buried at a velocity which relates depth to time:

$$
\omega=\mathrm{dx} / \mathrm{dt} .
$$

With this definition equations 1 and 2 can be transformed to:

$$
\begin{gathered}
\left(\frac{\partial c_{s}}{\partial t}\right)_{x}=D_{B} \frac{\partial^{2} c_{s}}{\partial x^{2}}-\omega \frac{\partial c_{s}}{\partial x}+\Sigma R_{s} \text { and } \\
\left(\frac{\partial c}{\partial t}\right)_{x}=D_{s} \frac{\partial^{2} c}{\partial x^{2}}-\left(\omega+v_{g}\right) \frac{\partial c}{\partial x}+\Sigma R .
\end{gathered}
$$

Here the derivatives $\left(\partial c_{s} / \partial t\right)_{x}$ and $(\partial c / \partial t)_{x}$ record all changes, both diagenetic and historical, occurring at a fixed depth below the sediment-water interface in contrast to equations 1 and 2 which describe only diagenetic changes that occur within a fixed layer.

Adoption of the sediment-water interface as reference frame (equations 4 and 5) leads to a most useful generalization, that of steady state diagenesis. In steady state diagenesis all diagenetic changes are so adjusted that no net change in concentration occurs at a fixed depth $x$. This means that for all depths:

$$
\left(\frac{\partial c}{\partial t}\right)_{x}=0
$$

Under this situation all changes are diagenetic in origin and none are historical. (Strictly speaking constant properties can also be due to the maintenance of chemical equilibrium, but this will not concern us here since we are interested in the diagenetic approach to equilibrium.) This can be seen most clearly for $x=0$, the sedimentwater interface. If for all values of $t, \mathrm{~d} c_{s} / \mathrm{d} t=0$ at $x$ $=0$, there can be no changes in $c_{s}$, after burial, due to historical fluctuations at the time of deposition. This means that a layer presently at a depth $x$, at the time of deposition, originally exhibited the properties displayed by the layer presently undergoing deposition. This is illustrated in figure 1 . The usefulness of the steady-state assumption is that diagenetic changes, which occur over time, can be witnessed as changes with depth and related to time via the parameter $\omega$ (equation 3). By doing this

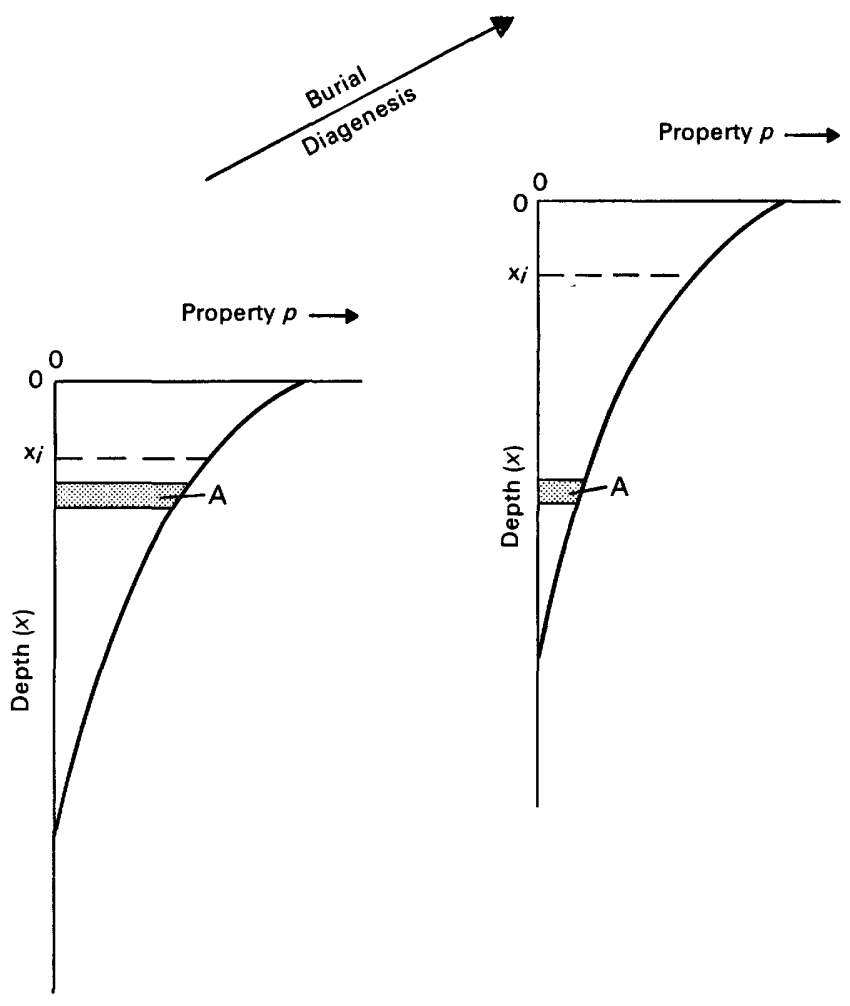

Figure 1. Diagrammatic representation of steady state diagenesis. Note that sediment property $p$ within a layer $(A)$ changes as the layer is buried, but that the value of $p$ at a fixed depth $x_{i}$, remains constant with time (modified from Berner, 1980).

we can study chemical kinetics "in the field" and thereby extract data on the rates and mechanisms of reactions from the sediments themselves.

\section{KINETICS OF DIAGENETIC ORGANIC MATTER DECOMPOSITION}

As a way of illustrating the use of the diagenetic equation, a subject is chosen here which is of great interest to those studying early diagenesis in modern sediments. This is the microbiological decomposition of organic matter. The discussion will focus on the complete transformation of complex, polymeric sedimentary organic matter to simple dissolved molecules and ions and not be concerned with the various intermediate steps along the way which may involve many different compounds and many different microorganisms. In other words, only the overall process of organic matter decomposition will be considered without involving subjects which more properly fall under the disciplines of organic geochemistry and geomicrobiology.

Organic matter undergoes decomposition via biologically mediated reactions with a variety of oxidizing agents, the actual decomposition process depending on the chemistry of the pore water. Under oxic conditions, the reaction can be simply described as: 


$$
\mathrm{CH}_{2} \mathrm{O}+\mathrm{O}_{2} \rightarrow \mathrm{CO}_{2}+\mathrm{H}_{2} \mathrm{O},
$$

where $\mathrm{CH}_{2} \mathrm{O}$ represents complex, polymeric (solid) sedimentary organic matter. This reaction produces abundant energy for metabolic processes and is the preferred one, providing $\mathrm{O}_{2}$ is present. However, in most marine sediments $\mathrm{O}_{2}$ becomes completely consumed in the uppermost few $\mathrm{cm}$ to few tens of $\mathrm{cm}$, and, continued organic matter decomposition proceeds under anoxic conditions (e.g. Berner, 1980).

Anoxic decomposition processes succeed $\mathrm{O}_{2}$ reduction and one another in the order of free energy release (e.g. Claypool and Kaplan, 1974; Froelich and others, 1979). In other words, of a number of available oxidizing agents present, the one yielding the most energy is used first until it is depleted. This is followed by utilization of the next most energy-producing agent until it is depleted and so on. The processes in order of decreasing energy yield are: nitrate reduction (denitrification), manganese and iron oxide reduction, sulfate reduction, and fermentation. These processes result in the liberation to solution of $\mathrm{N}_{2}, \mathrm{Mn}^{2+}, \mathrm{Fe}^{2+}, \mathrm{H}_{2} \mathrm{~S}$, and $\mathrm{CH}_{4}$, as well as $\mathrm{CO}_{2}$ and $\mathrm{HCO}_{3}^{-}$. Characteristic reactions along with the standard state free energy yields are shown in table 1 .

In most marine sediments nitrate reduction is unimportant because of the low concentration of dissolved nitrate which is rapidly consumed upon burial. Also, iron and manganese oxide reduction is very slow, because solid compounds are involved. This results in continual liberation of $\mathrm{Mn}^{2+}$ and $\mathrm{Fe}^{2+}$ during the ensuing processes of sulfate reduction and fermentative methane formation because of the persistence of the iron and manganese oxides. Nitrate reduction and iron and manganese oxide reduction are most notable in sediments deposited slowly in the deep sea where organic matter decomposition is slow and the processes of sulfate reduction and methane formation occur only at great depth. Some examples, taken from the work of Froelich and others (1979), are shown in figure 2 .

Table 1. Sequence of organic matter decomposition reactions and corresponding standard state free energy changes

[Organic matter represented by $\mathrm{CH}_{2} \mathrm{O}$ (sucrose)]. [Modified from Berner, 1980]

\begin{tabular}{lc}
\hline \multicolumn{1}{c}{ Reaction } & $\begin{array}{c}\Delta \mathrm{C}^{\circ} \text {, in kilojoules } \\
\text { per mole of } \mathrm{CH}_{2} \mathrm{O}\end{array}$ \\
\hline $\mathrm{CH}_{2} \mathrm{O}+\mathrm{O}_{2} \rightarrow \mathrm{CO}_{2}+\mathrm{H}_{2} \mathrm{O}$ & -475 \\
$5 \mathrm{CH}_{2} \mathrm{O}+4 \mathrm{NO}_{3}^{-} \rightarrow 2 \mathrm{~N}_{2}+4 \mathrm{HCO}_{3}^{-}+\mathrm{CO}_{2}+3 \mathrm{H}_{2} \mathrm{O}$ & -448 \\
$\mathrm{CH}_{2} \mathrm{O}+3 \mathrm{CO}_{2}+\mathrm{H}_{2} \mathrm{O}+2 \mathrm{MnO}_{2} \rightarrow 2 \mathrm{Mn}^{+2}+4 \mathrm{HCO}_{3}^{-}$ & -349 \\
$\mathrm{CH}_{2} \mathrm{O}+7 \mathrm{CO}_{2}+4 \mathrm{Fe}(\mathrm{OH})_{3} \rightarrow 4 \mathrm{Fe}^{++}+8 \mathrm{HCO}_{3}^{-}+3 \mathrm{H}_{2} \mathrm{O}$ & -114 \\
$2 \mathrm{CH}_{2} \mathrm{O}+\mathrm{SO}_{4}^{2-} \rightarrow \mathrm{H}_{2} \mathrm{~S}+2 \mathrm{HCO}_{3}^{-}$ & -77 \\
$2 \mathrm{CH}_{2} \mathrm{O} \rightarrow \mathrm{CH}_{4}+\mathrm{CO}_{2}$ & -58 \\
\hline
\end{tabular}

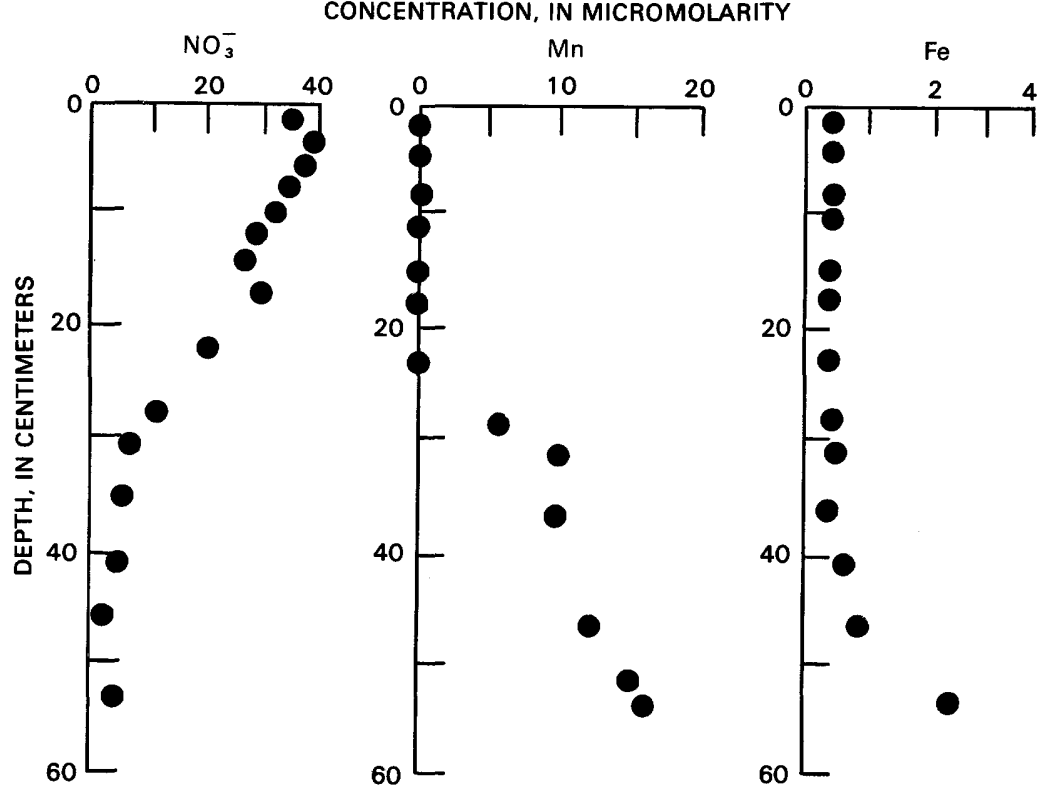

Figure 2. Distribution of dissolved nitrate, manganese, and iron versus depth in a pelagic sediment from the equatorial Atlantic Ocean (modified from Froelich and others, 1979). 
The characteristic process of anoxic organic matter decomposition in marine sediments, especially those deposited near the continents, is bacterial sulfate reduction (see, for example, Goldhaber and Kaplan, 1974; Goldhaber and others, 1977). Most shallowly buried marine muds deposited on the continental shelves exhibit evidence for sulfate reduction in terms of decreases with depth in dissolved sulfate and the presence of $\mathrm{H}_{2} \mathrm{~S}$ and (or) iron sulfides. The overall reaction for bacterial sulfate reduction results in $\mathrm{H}_{2} \mathrm{~S}$ formation:

$$
2 \mathrm{CH}_{2} \mathrm{O}+\mathrm{SO}_{4}{ }^{2-} \rightarrow \mathrm{H}_{2} \mathrm{~S}+2 \mathrm{HCO}_{3}^{-}
$$

and this $\mathrm{H}_{2} \mathrm{~S}$ reacts with detrital iron minerals to form various iron sulfides, with the end product being pyrite, $\mathrm{FeS}_{2}$.

In marine sediments where unusually high concentrations of readily metabolized organic matter are deposited or in fresh water sediments where initial concentrations of sulfate are normally low, sulfate can be completely removed, and high concentrations of dissolved methane, formed by fermentation, may then appear. An example of sulfate reduction and methane formation, as evidenced by interstitial water chemistry, is shown in figure 3 .

The microbiological decomposition of organic matter, regardless of process, can be treated quantitatively. One approach (see, for example, Jorgensen, 1978; Berner, 1974, 1980; Westrich and Berner, 1984) is to assume that a given group of compounds of similar reactivity are destroyed at a rate directly proportional to the amount present, in other words, decomposition is assumed to follow first order kinetics. Mathematically this can be expressed as:

$$
R_{i}=k_{i} G_{i}
$$

where: $G_{i}=$ concentration, expressed in terms of mass of carbon per unit volume of pore water, of a group of compounds $i$ of similar reactivity which can undergo bacterial decomposition.

$k_{i}=$ first order rate constant for the group

$R_{i}=$ rate of decomposition of group $i$.

Here, $G_{i}$ can be thought of as representing the amount of organic matter and $k_{i}$ its reactivity. The total organic matter in the sediment can be divided into a number of different groups of different reactivities $\left(k_{i}\right)$ such that:

and

$$
G_{T}=\Sigma G_{i}
$$

$$
R_{T}=\Sigma k_{i} G_{i},
$$

where $G_{T}=$ total organic carbon

$R_{T}=$ rate of total organic carbon destruction.
Assuming that the organic matter is present only as a solid (that is, it is non-diffusable), which is reasonable for the complex polymeric material represented as $\mathrm{CH}_{2} \mathrm{O}$ in table 1, one obtains from the diagenetic equation for solids (equation 4) and equation 9:

$$
\left(\frac{\partial G_{i}}{\partial t}\right)_{x}=D_{B} \frac{\partial^{2} G_{i}}{\partial x^{2}}-\omega \frac{\partial G_{i}}{\partial x}-k_{i} G_{i} .
$$

Assuming steady state $\left(\left(\partial G_{i} / \partial t\right)_{x}=0\right)$ and using the boundary conditions, $x=0, G_{i}=G_{o_{i}}, x \rightarrow \infty, G_{i} \rightarrow 0$, solution of equation 12 yields:

$$
G_{i}=G_{o_{i}} \exp \left(\frac{\omega-\left(\omega^{2}+4 k_{i} D_{B}\right)^{1 / 2}}{2 D_{B}}\right) \mathrm{x} .
$$

Below the top few tens of centimeters, or for sediments overlain by anoxic waters, bioturbation can be ignored. Under these conditions, $D_{B}=0$, and (equation 13) reduces to:

$$
G_{i}=G_{o_{i}} \exp -\left(\frac{k_{i}}{\omega}\right) x .
$$

In terms of rate of decomposition, $R_{i}$, equations 13 and 14 can be recast, using equation 9 , as:

$$
R_{i}=R_{o_{i}} \exp \left(\frac{\omega-\left(\omega^{2}+4 k_{i} D_{B}\right)^{1 / 2}}{2 D_{B}}\right) x
$$

and:

$$
R_{i}=R_{o_{i}} \exp -\left(\frac{k_{i}}{\omega}\right) x .
$$

By applying equations 13-16 to data for organic matter content or decomposition rate in sediments undergoing steady state diagenesis, and knowing the values of $\omega$ and $D_{B}$, one can obtain values for $k_{i}$, the intrinsic reactivity of the organic matter.

In most studies sediments at a given locality have been treated as though they contained only one group of organic compounds of one reactivity $k$. This has led to the use of so-called "one- $G$ " models (Berner, 1974; Lasaga and Holland, 1976; Toth and Lerman, 1977; Murray and others, 1978; Müller and Mangini, 1980). The normal procedure has not been to fit diagenetic equations such as 13 and 14 to organic carbon data, but to work with pore water data for the concentration of an oxidizing agent, mainly sulfate. For example, the value of $k$ can be obtained, if bioturbation is ignored, by substituting equation 14 into a diagenetic equation for dissolved sulfate. This can be done because the rate of sulfate 


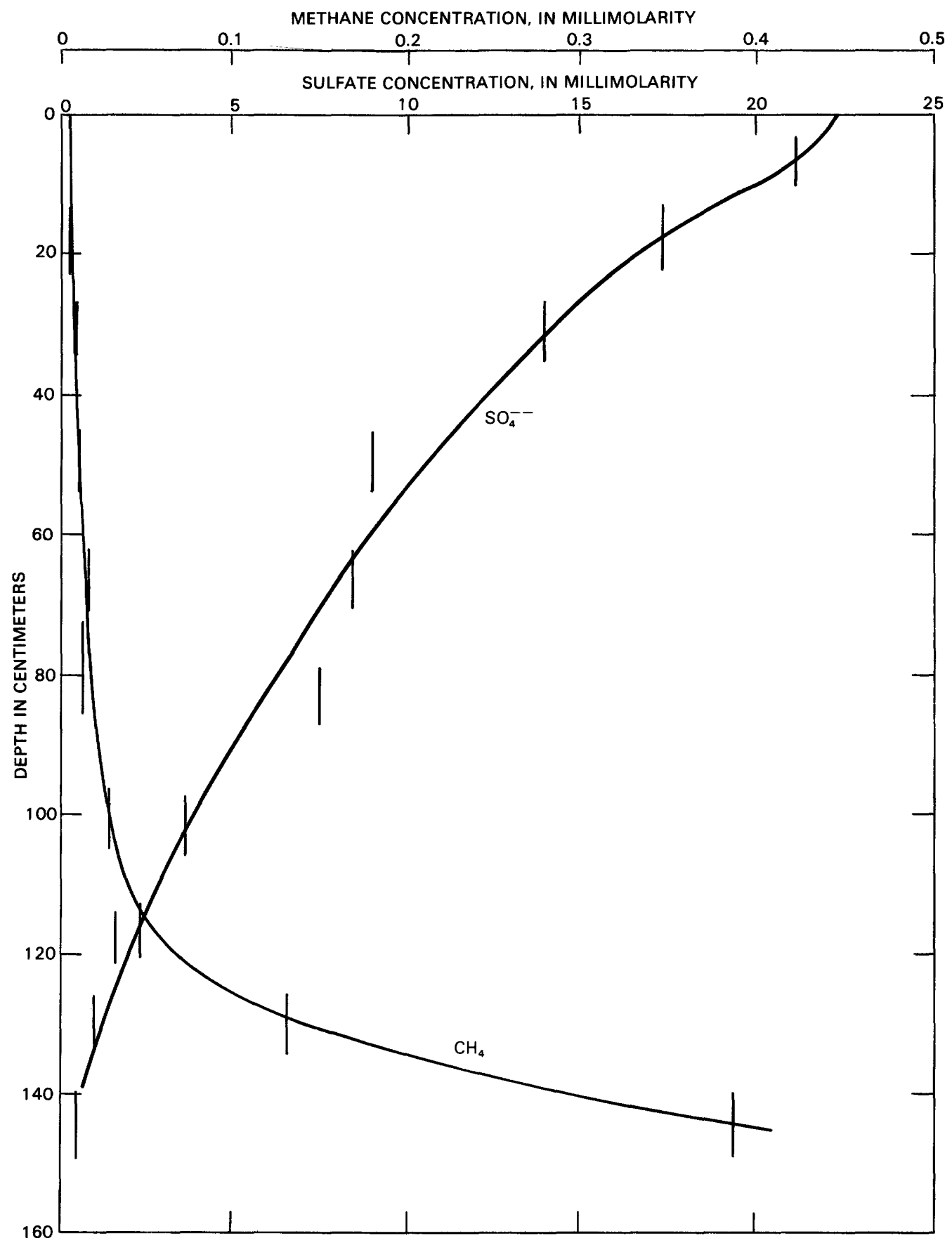

Figure 3. Distribution of dissolved sulfate and methane vs. depth for anoxic sediments from the FOAM site of Long Island Sound. Vertical bars represent sampled depth ranges (data from Goldhaber and others, 1977; Martens and Berner, 1977).

reduction is directly proportional to the rate of organic matter decomposition by this process. From reaction 8 :

$$
R_{s}=1 / 2 R_{i}
$$

Where $R_{s}=$ rate of sulfate reduction, so that, from equations 9,14 , and 17 :

$$
R_{s}=1 / 2 k_{i} G_{o_{i}} \exp -\left(k_{i} / \omega\right) x .
$$

Inserting equation 18 into a diagenetic equation for sulfate:

$$
\left(\frac{\partial c}{\partial t}\right)_{x}=D_{s} \frac{\partial^{2} c}{\partial x^{2}}-\omega \frac{\partial c}{\partial x}-1 / 2 k_{i} G_{o_{i}} \exp -\left(k_{i} / \omega\right) x,
$$


where $c$ refers to the concentration of dissolved sulfate in interstitial waters. This equation can be solved for steady state, and the resulting expression fitted to dissolved sulfate-vs-depth data to obtained values of $k_{i}$.

Detailed sampling at some sediment locations has revealed that the entire profiles of rate of organic matter decomposition-vs-depth cannot be fitted to a simple exponential as represented by equations 15 and 16, (e.g. see Jørgensen, 1978; Berner, 1980; Westrich, 1983). In this case the general or multi- $G$ situation, as represented by equations 10 and 11 , provides a better description of organic matter decomposition and a better fit to the data. In other words, there is a successive disappearance with depth of progressively less reactive (lower $k$ ) compounds. Although organic matter reactivity normally varies from sediment site to sediment site, it can also vary with depth (time) at a single site.

The necessity for utilizing multi- $G$ models has been brought out most forcefully by the work of Westrich (1983) (see also Westrich and Berner, 1984). Like most previous workers, Westrich also studied organic matter decomposition by examining depth changes in the concentration of oxidizing agent, in this case sulfate, rather than changes in organic matter itself. Unlike most previous workers Westrich actually measured rates of sulfate reduction using a radiotracer technique. In this way he could obtain directly, via the stoichiometric relation 8 , the rate of organic matter decomposition $R_{i}$. Westrich then showed that over successive depth portions of a sediment from Long Island Sound (the FOAM site) the values of $R_{i}$ followed exponential relations predicted by equations 15 and 16 , but with a different $k$ value for each depth portion. The $k$ values obtained by him by curve fitting to equations 15 and 16 also agreed with independent rate experiments performed in the laboratory using the same muds.

Westrich and Berner (1984) reported the results of additional laboratory experiments which test the validity of equation 9. By subjecting marine plankton to oxic degradation in seawater for various periods of time it was possible to prepare freeze-dried samples of marine organic matter of varying reactivity. Addition of successively greater amounts of each dried sample to anoxic Long Island Sound mud resulted in corresponding increases in rates of organic matter decomposition via bacterial sulfate reduction. A linear correlation was found for each of the dried samples which verifies the assumption of first order kinetics embodied in equation 9. An example is shown in figure 4. Not only was a linear correlation found, but the more (oxically) degraded plankton was found to decompose more slowly and, hence, have a lower $k$ value as predicted by the multi- $G$ model.

By piecing together rate constants based on laboratory experiments, measured in situ rates of $\mathrm{O}_{2}$ and sulfate reduction, and the use of diagenetic equations for a wide variety of sediments, Westrich (1983) was able

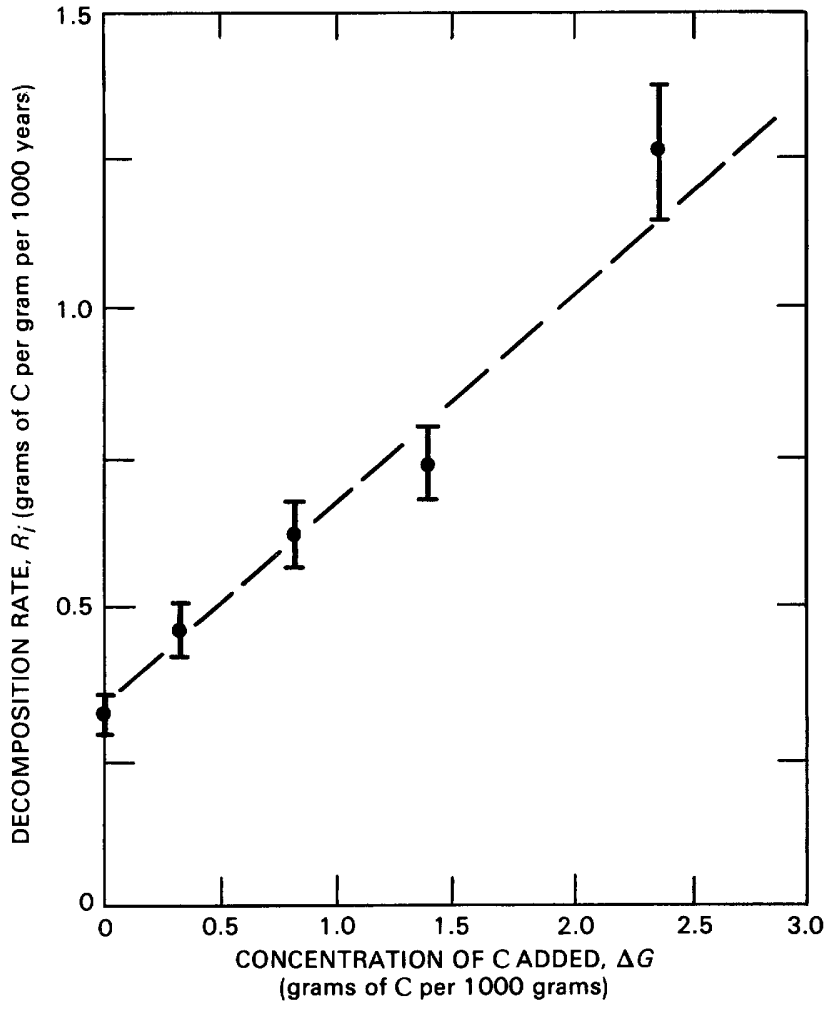

Figure 4. Plot of rate of organic matter decomposition $R_{i}$ (equal to twice the rate of sulfate reduction) versus the concentration of added organic carbon $\Delta C$ for anoxic sediments from Long Island Sound. Temperature $=22^{\circ} \mathrm{C}$. Added organic carbon represents dried Long Island Sound plankton which had previously undergone oxic bacterial degradation in the laboratory for 72 days. Note the linear correlation which verifies equation 9. Vertical bars represent total range of measurement reproducibility (data from Westrich and Berner, 1984).

to deduce that sedimentary organic matter, on a worldwide basis, can be divided into approximately eight groups whose reactivity ranges over seven orders of magnitude in $k_{i}$. However, further measurements may show that these are only minimum numbers. The major point is that reactivity can vary greatly from place to place.

Regardless of the actual number of groups, it can be shown that the rate constant for organic matter decomposition, for marine sediments where only one group dominates, is closely correlated with sedimentation rate. This is shown in figure 5. The basic reason for this is that as depositional burial slows, there is more time for the oxic destruction of reactive compounds at the sedimentwater interface so that only the less reactive, or more refractory, compounds become buried to undergo further decomposition via anoxic processes within the sediment. By contrast, with fast sedimentation highly reactive substances are buried and react quickly with interstitial dissolved sulfate. It is in these rapidly deposited sediments 
where sulfate can become quickly exhausted and methane can consequently appear at shallow depths in the sediment.

\section{CONCLUSION}

From the application of diagenetic equations to the problem of microbiological organic matter decomposition in sediments, rate constants have been obtained which characterize the reactivity of various organic fractions towards decomposition. These constants are not only useful in themselves for classifying sedimentary organic matter, but they can be related to other factors such as rates of deposition. This approach should be applicable to other diagenetic problems such as authigenic mineral formation, dissolution, and replacement. From such modeling combined with laboratory rate studies, it should be possible to derive much more information on the rates and mechanisms of sedimentary chemical reactions. In this way we may ultimately gain a better idea of the time frame over which diagenesis occurs.

\section{ACKNOWLEDGMENT}

This research was supported by National Science Foundation Grant OCE 81-09454. I am indebted to Joseph T. Westrich for helpful discussions and for making available to me some of his unpublished data on bacterial sulfate reduction.

\section{REFERENCES CITED}

Berner, R. A., 1974, Kinetic models for the early diagenesis of nitrogen, sulfur, phosphorus and silicon in anoxic marine sediments, in Goldberg, E. D., ed., The sea, v. 5: New York, Wiley, p. 425-450.

Berner, R. A., 1978, Sulfate reduction and the rate of deposition of marine sediments: Earth and Planetary Science Letters, v. 37, p. $492-498$.

Berner, R. A., 1980, Early diagenesis; A theoretical approach: Princeton, New Jersey, Princeton University Press, 241 p.

Claypool, G., and Kaplan, I. R., 1974, The origin and distribution of methane in marine sediments, in Kaplan, I. R., ed., Natural gases in marine sediments: New York, Plenum, p. 99-139.

Froelich, P. N., Klinkhammer, G. P., Bender, M. L., Luedtke, N. A., Hartman, B., and Maynard, V., 1979, Early oxidation of organic matter in pelagic sediments of the eastern equatorial Atlantic; Suboxic diagenesis: Geochimica et Cosmochimica Acta, v. 43, p. 1075-1090.

Goldhaber, M. B., Aller, R. C., Cochran, J. K., Rosenfeld, J. K., Martens, C. S., and Berner, R. A., 1977, Sulfate reduction, diffusion, and bioturbation in Long Island Sound sediments; Report of the FOAM group: American Journal of Science, v. 277, p. 193-237.

Goldhaber, M. B., and Kaplan, I. R., 1974, The sulfur cycle, in Goldberg, E. D. ed., The sea, v. 5: New York, Wiley, p. 569-655.

Jørgensen, B. B., 1978, Comparison of methods for the quantification of bacterial sulfate reduction in coastal marine

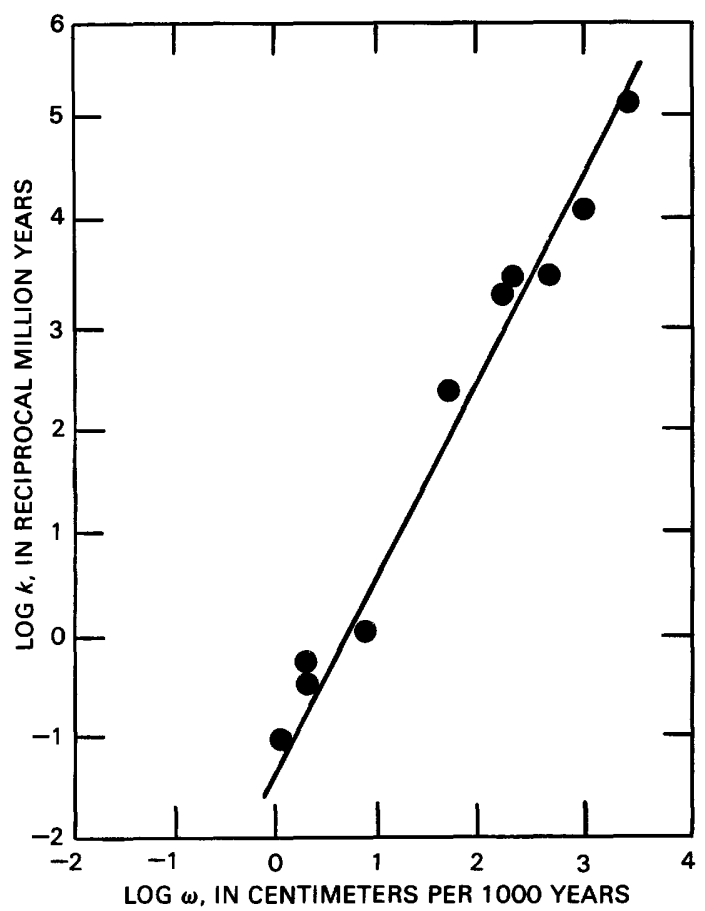

Figure 5. Log-log plot of the rate constant $k$ for organic matter decomposition via bacterial sulfate reduction versus sedimentation rate $\omega$ for a variety of marine sediments ranging from harbor muds to deep sea clays. (Modified from Toth and Lerman, 1977; Berner, 1978; Berner, 1980.)

sediments II. Calculation from mathematical models: Geomicrobiology Journal, v. 1, p. 20-47.

Lasaga, A. C., and Holland, H. D., 1976, Mathematical aspects of nonsteady state diagenesis: Geochimica et Cosmochimica Acta, v. 40 , p. $257-266$.

Lerman, A., 1979, Geochemical processes: Water and sediment environments: New York, Wiley, 481 p.

Martens, C. S., and Berner, R. A., 1977, Interstitial water chemistry of anoxic Long Island Sound sediments. 1. Dissolved gases: Limnology and Oceanography, v. 22, p. 10-25.

Müller, P. J., and Mangini, A., 1980, Organic carbon decomposition rates in sediments of the Pacific manganese nodule belt dated by ${ }^{230} \mathrm{Th} /{ }^{231} \mathrm{~Pa}$ : Earth and Planetary Science Letters, v. 51, p. 94-114.

Murray, J. W., Grundmanis, V., and Smethie, W. M., 1978, Interstitial water chemistry in the sediments of Saanich inlet: Geochimica et Cosmochimica Acta, v. 42, p. 1011- 1026.

Toth, D. J., and Lerman, A., 1977, Organic matter reactivity and sedimentation rates in the ocean: American Journal of Science, v. 277 , p. 265-285.

Westrich, J. T., 1983, The consequences and controls of bacterial sulfate reduction in near shore marine sediments: unpublished Ph.D. dissertation, New Haven, Connecticut, Yale University, $530 \mathrm{p}$.

Westrich, J. T., and Berner, R. A., 1984, The role of sedimentary organic matter in bacterial sulfate reduction; the $G$ model tested: Limnology and Oceanography, v. 29, p. 236-249. 


\section{Seasonal Diagenetic Changes in Salts of Owens Lake, California, 1970-77}

By GEORGE I. SMITH, U.S. Geological Survey, 345 Middlefield Road, MS 902, Menlo Park, California 94025, and

IRVING FRIEDMAN, U.S. Geological Survey, Box 25046, Denver Federal Center, MS 963, Denver, Colorado 80225

\section{CONTENTS}

\section{Abstract 22}

Introduction 22

Study methods 22

Salt crystallization 22

Mineralogic and isotopic evidence of diagenesis 24

Conclusions 28

References cited 28

FIGURES

1. Map showing location of Owens Lake and positions of lake shorelines February 1913, August 1969, and April 197123

2. Plot of changes observed at Owens Lake between September 1970 and August 197126

3. Plot showing ranges of $\delta \mathrm{D}$ values of salts and interstitial brines, 1970-77 28

TABLE

1. Data for Owens Lake brines and salts, 1970-77 24 


\begin{abstract}
After the 1968-69 flooding and partial solution of salts on the floor of normally dry Owens Lake, salts were redeposited over a 12-month period starting September 1970. Over the next several years, seasonal changes in the mineralogy and deuterium/hydrogen $(\mathrm{D} / \mathrm{H})$ ratios of the new hydrated salts and their interstitial brines indicated continuing postdepositional reactions, or diagenesis. Winter cooling promoted crystallization of natron and mirabilite; summer warming promoted recrystallization of these minerals to trona and burkeite. Natron and mirabilite crystallized late each autumn, incorporating $\mathrm{Na}$, $\mathrm{CO}_{3}$, and $\mathrm{SO}_{4}$ from trona and burkeite, and 10 moles of $\mathrm{H}_{2} \mathrm{O}$ each from the isotopically heavy lake brine produced by summer-long evaporation. Trona and burkeite crystallized each spring, with trona deriving $\mathrm{Na}$ and $\mathrm{CO}_{3}$ from natron, and $\mathrm{H}_{2} \mathrm{O}$ mostly from the decomposing natron and mirabilite rather than from the overlying lake, which was isotopically lighter at the end of the wet season. During diagenesis, the initial wide range in the $\mathrm{D} / \mathrm{H}$ ratios in trona narrowed, and the ratios in both trona and interstitial brines approached those of the underlying undissolved salts that crystallized-and presumably followed the same diagenetic path-earlier this century.
\end{abstract}

\section{INTRODUCTION}

Owens Lake, in southeast California (fig. 1), desiccated in 1921 after its water supply was diverted to Los Angeles, and a 1.5- to 2.0-m-thick layer of salts was deposited. At the end of the abnormally wet 1968-69 winter, Owens River flood waters partially dissolved that surface salt layer, and those saline components recrystallized during 1970 and 1971 as the lake redesiccated. Samples of the lake brines and crystallizing salts were collected during 1970-71 (Friedman and others, 1976; Smith and others, in press), and samples and cores of the older undissolved salts and the recrystallizing new salts were taken periodically between 1970 and 1977 . Mineral compositions of the salts were monitored, as were the deuterium concentrations in the hydrogen-bearing saline minerals and interstitial brines. Seasonal and longer-term changes in both mineral compositions and isotope ratios were observed. The deuterium concentrations in the 1970-71 salts and brines initially differed greatly from those of the older undissolved salt layers, but over several years, their values slowly converged as a result of diagenesis. The diagenetic process was driven by seasonal temperature changes in the saline layers, and our observations suggest that it was approaching completion only after 7 years of repeated cycles. What follows is a description of those observations.

This process may characterize the early histories of most saline deposits that contain sodium sulfate and sodium carbonate mineral suites which include phases whose solubilities are markedly temperature dependent. Care must be exercised in extracting paleoclimate information from the mineralogic and isotopic character of deposits of these types, because minerals containing these components are unlikely to be the crystals that originally precipitated from lake waters. Evidence for diagenesis of this type, however, documents minimum limits on seasonal temperature changes at the time of original deposition, and the suite that is eventually buried to a depth at which annual temperature variations cease should reflect mean annual temperatures.

\section{STUDY METHODS}

Saline minerals settling from the lake surface were collected by underwater traps, and sediments accumulating on the lake floor during and after desiccation were sampled as cores. All samples were collected at a station near the lowest part of the lake floor (fig. 1). Coring, done with several types of portable equipment, was difficult because of the varied physical properties of these salts. Layers dominated by halite and burkeite were hard, tended to plug the core barrel, and prevented the recovery of salts from deeper layers. Mud and layers composed of trona, nahcolite, natron, or mirabilite tended to be soft and were commonly pushed aside by the core barrel or fell out as the core barrel was raised.

The interstitial brines were extracted from freshly cored salts for isotope analysis by squeezing them in a reinforced syringe through a screen-supported layer of filter paper into abottle which was promptly capped. The dewatered salts were left in the sealed syringe until they reached the laboratory. Although those samples proved to be a little more stable than samples collected and transported wet, most samples composed of natron or mirabilite were partially or totally altered to other minerals by the time they reached the laboratory. For deuterium analysis, this alteration posed no problem because all water of hydration that was expelled or recrystallized during spontaneous phase changes remained in the syringe and was reflected in the isotope analysis of the bulk sample. Determination of the original lakefloor mineralogy was more difficult. Fortunately, most samples were also studied in the field immediately after collection using a petrographic microscope, so the lakefloor mineralogy could be reconstructed from field descriptions of the salt-crystal habits and the physical properties of the original samples, plus laboratory determinations of the percentage of crystallization water and the $\mathrm{X}$-ray diffraction mineralogy of the secondary suites.

\section{SALT CRYSTALLIZATION}

Calculations based on data of Gale $(1914$, p. 258 , fig. 58),Friedman and others (1976, table 1), and Smith and others (in press) show that about 20 percent of the $1.5-\mathrm{m}$ - to $2.0-\mathrm{m}$-thick bed of salts that crystallized from 


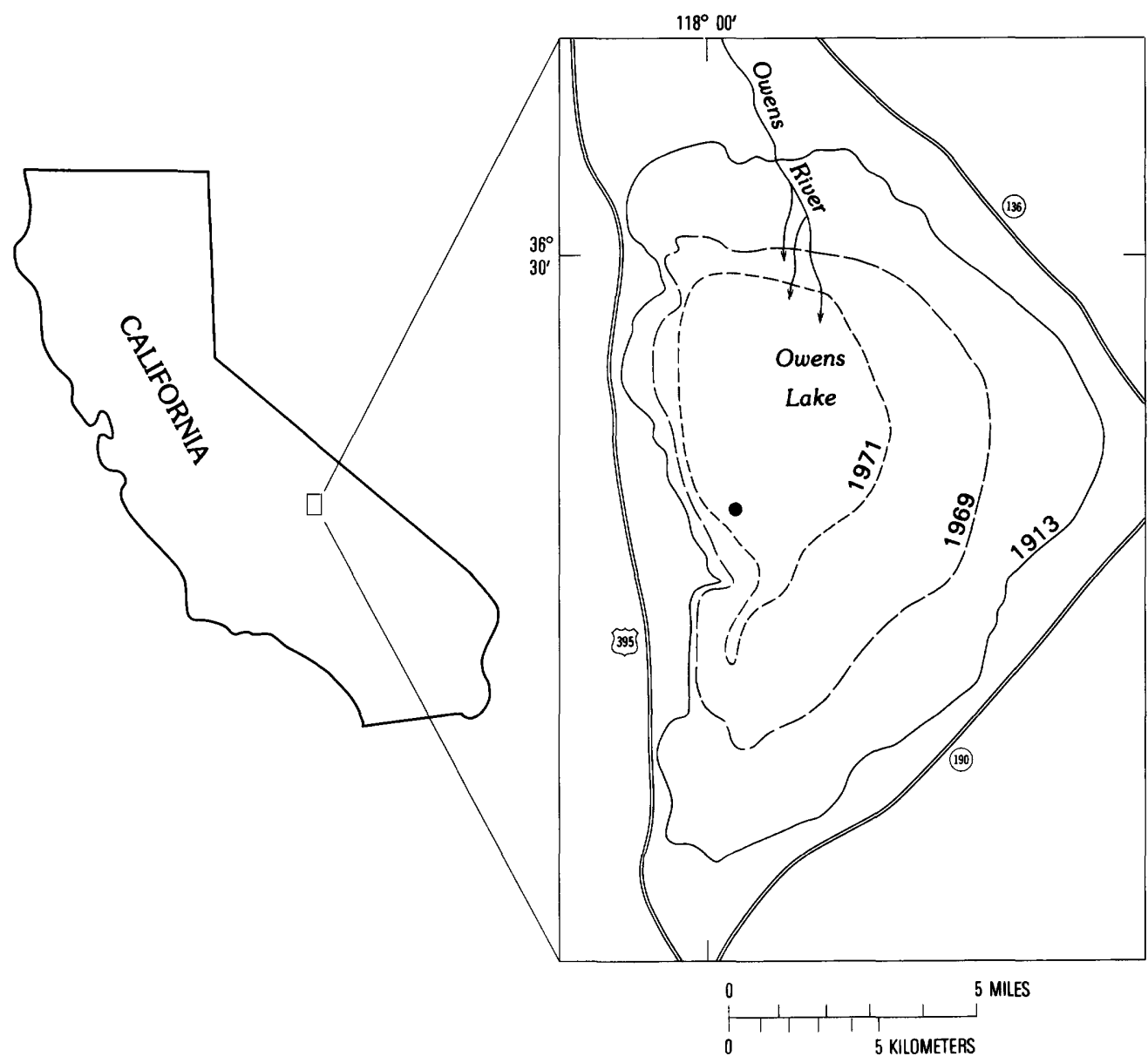

Figure 1. Location of Owens Lake and positions of lake shorelines February 1913 (prior to its first desiccation), August 1969 (maximum area during period discussed here), and April 1971 (4 months prior to reaching near-dryness). Sample site (black circle) is near lowest point in lake floor.

the lake earlier this century was dissolved in 1969-70. The first new salts precipitated from the lake in mid-September 1970 when brine concentrations (table 1) reached about $300 \mathrm{~g} / \mathrm{L}$ (grams per liter). In most places, the new salts were deposited on an older layer of hard or muddy salts that apparently inhibited deeper solution and later served as a stratigraphic marker in the cores.

The species of crystallizing salts and the deuterium concentrations of the hydrated species are also listed in table 1, and the sequential changes in the compositions of solids and brines during this crystallization period are shown diagrammatically in figure 2 . In general, $\mathrm{Na}-$ carbonates crystallized first, $\mathrm{Na}$-sulfates second, and $\mathrm{NaCl}$ last, the classical crystallization sequence for systems having these compositions. The species of crystallizing salts, however, and the time of day that crystallization was most rapid, depended on the season. During winter, radiative overnight cooling of the lake surface water accelerated the predawn crystallization of two 10-hydrate minerals on the surface, natron $\left(\mathrm{Na}_{2} \mathrm{CO}_{3} \cdot 10 \mathrm{H}_{2} \mathrm{O}\right)$ and mirabilite $\left(\mathrm{Na}_{2} \mathrm{SO}_{4} \cdot 10 \mathrm{H}_{2} \mathrm{O}\right)$. Their crystals coalesced into large floating rafts, some of which dissolved as the surface warmed the next morning although others foundered earlier and sank. Crystals were not forming on the lake surface at the time of the early morning January 1971 collection, but several centimeters of rain had fallen on the lake in late November and December, and an abnormally warm day preceded the collection date. Hence, the lake surface water did not cool sufficiently overnight to reach its new saturation temperature of about $5^{\circ} \mathrm{C}$. By April 1971, however, the lake brine and the accumulating salt layer had warmed, and all the mirabilite on the lake floor had returned to solution and most of the natron had dissolved or reacted diagenetically to form nahcolite $\left(\mathrm{NaHCO}_{3}\right)$ or trona $\left(\mathrm{Na}_{2} \mathrm{CO}_{3} \cdot \mathrm{NaHCO}_{3} \cdot 2 \mathrm{H}_{2} \mathrm{O}\right)$, thus reducing the thickness of the new salt layer and increasing both the total amount of salt in solution and the brine concentrations (fig. 2B). By July, most of the dissolved sulfate had crystallized from the brine as burkeite $\left(\mathrm{Na}_{2} \mathrm{CO}_{3} \cdot \mathrm{Na}_{2} \mathrm{SO}_{4}\right)$ which is stable only above $14^{\circ} \mathrm{C}$; all other Na-carbonates had crystallized to trona, and evaporation that reached its daily maximum in midafternoon was producing large rafts of crystals dominated by halite ( $\mathrm{NaCl})$. By August, the lake was nearly dry. 
Table 1. Data for Owens Lake brines and salts, 1970-77

[g/L, grams per liter; $\mathrm{g} / \mathrm{mL}$, grams per milliliter; ${ }^{\circ} \mathrm{C}$, degrees Celsius; leaders (---) indicate no measurements]

\begin{tabular}{|c|c|c|c|c|c|c|c|c|c|}
\hline \multirow{3}{*}{ Collection date } & \multicolumn{5}{|c|}{ Brine 1} & \multicolumn{4}{|c|}{ Salts } \\
\hline & \multicolumn{2}{|c|}{ Total dissolved solids } & \multirow[t]{2}{*}{$\begin{array}{l}\text { Density } \\
(\mathrm{g} / \mathrm{mL})\end{array}$} & \multirow[t]{2}{*}{$\begin{array}{l}\text { Temperature } \\
\left({ }^{\circ} \mathrm{C}\right)\end{array}$} & \multirow[t]{2}{*}{$\delta D^{2}$} & \multicolumn{2}{|c|}{$\begin{array}{c}\text { Initial salts } \\
(1970-71)\end{array}$} & \multicolumn{2}{|c|}{$\begin{array}{l}\text { Examples of diagenetic } \\
\text { salts observed later } \\
\text { in same horizon }(1970-71)\end{array}$} \\
\hline & $(g / L)$ & $\left(\right.$ tonnes $\left.\times 10^{6}\right)$ & & & & Mineral(s) & $\begin{array}{c}\delta D^{2} \\
\text { (per mil) }\end{array}$ & Minerals & $\begin{array}{c}\delta D^{2} \\
(p e r \text { mil) }\end{array}$ \\
\hline Sept. 16,1970 & 296.6 & 26.7 & 1.20 & $15-16$ & -21 & $\begin{array}{l}\text { Nahcolite, } \\
\text { trona. }\end{array}$ & -106 & Trona------ & -89 to -126 \\
\hline Nov. 18,1970 & --- & --- & --- & $6-11$ & -18 & $\begin{array}{l}\text { Natron. } \\
\text { Mirabilite. }\end{array}$ & $\begin{array}{r}+5 \\
-20\end{array}$ & $\begin{array}{l}\text { Trona, } \\
\text { burkeite. }\end{array}$ & -85 to -95 \\
\hline Jan. 19, 1971 & 239.8 & 14.6 & 1.17 & $5-8$ & -44 & $\begin{array}{l}\text { Natron, } \\
\text { mirabilite. }\end{array}$ & -2 to -15 & $\begin{array}{l}\text { Trona, } \\
\text { burkeite. }\end{array}$ & -85 to -95 \\
\hline March 10, 1971 & --- & --- & --- & $11-12$ & -36 & $\begin{array}{l}\text { Trona, } \\
\text { nahcolite } \\
\text { natron. }\end{array}$ & $-26 \pm$ & Trona------ & -85 to -95 \\
\hline April 13, 1971 & 387.5 & 17.7 & 1.26 & $13-20$ & -18 & $\begin{array}{l}\text { Nahcolite, } \\
\text { trona. }\end{array}$ & $-56 \pm$ & Trona------- & -85 to -95 \\
\hline July 7, 1971 & 450.0 & 12.5 & 1.30 & $27-28$ & -2 & $\begin{array}{l}\text { Halite, } \\
\text { burkeite, } \\
\text { trona. }\end{array}$ & --- & $\begin{array}{l}\text { Halite, } \\
\text { burkeite, } \\
\text { trona. }\end{array}$ & ${ }^{3}-55 ?$ \\
\hline Aug. 20, 1971 & 470.3 & 8.4 & 1.31 & --- & +3 & $\begin{array}{l}\text { Halite, } \\
\text { burkeite, } \\
\text { trona. }\end{array}$ & --- & $\begin{array}{l}\text { Halite, } \\
\text { burkeite, } \\
\text { trona. }\end{array}$ & $3-55 ?$ \\
\hline
\end{tabular}

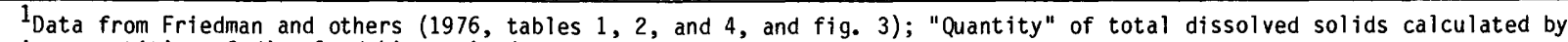
assuming quantities of dissolved $L i$ remained constant.

${ }^{2}$ Values of $\delta D$ are per mil SMOW; values listed for salts are on mixtures of hydrated minerals except for November "Initial salts" samples which were determined on separated samples of listed species.

3 Percentage of trona is about 15 percent; $\delta D$ values probably also reflect brine inclusions and film adhering to crystals of slightly moist samples.
}

\section{MINERALOGIC AND ISOTOPIC EVIDENCE OF DIAGENESIS}

Isotopic characterization of the deuterium/ hydrogen $(\mathrm{D} / \mathrm{H})$ ratios in the hydrated salts and brines collected during the desiccation and diagenetic stages of Owens Lake is expressed as $\delta \mathrm{D}$ per mil, relative to Standard Mean Ocean Water (SMOW), where

$$
\delta \mathrm{D}=\frac{\mathrm{D} / \mathrm{H}(\text { sample })-\mathrm{D} / \mathrm{H} \text { (standard) }}{\mathrm{D} / \mathrm{H} \text { (standard) }} \times 1000 .
$$

Laboratory studies of the $\mathrm{D} / \mathrm{H}$ fractionation factors for the minerals trona, nahcolite (Matsuo and others, 1971), and mirabilite (Stewart, 1974) show that relative to the crystallizing solution, nahcolite and trona are depleted in deuterium and mirabilite is enriched; these data allow us to make this preliminary isotopic evaluation of the processes operating during crystallization and diagenesis of those minerals. Isotope fractionation factors for natron, a mineral discovered to be important in this process, have not yet been determined satisfactorily in the laboratory, but the following field evidence suggests that at the nighttime temperatures frequently reached by
Owens Lake surface water during the autumn and winter seasons, natron was enriched in deuterium by $20-25$ per mil relative to the brine. The lake surface brines during October and November had $\delta \mathrm{D}$ values between -16 and -20 per mil, and natron, recovered in a core obtained in mid-November that represented crystallization after midSeptember, had a $\delta \mathrm{D}$ value of +5 per mil. Between late November 1970 and January 1971 , about $8 \mathrm{~cm}$ of rain fell, altering the $\delta \mathrm{D}$ composition of the lake to -45 per mil, reducing the concentration of solids in its brines, and slowing or suspending salt crystallization (fig. 2). By midJanuary, mixtures of natron and mirabilite, crystallized at unknown times during the brine's isotopic transition, had $\delta \mathrm{D}$ values ranging from -2 to -17 per mil, further suggesting that both minerals concentrate deuterium.

Salts crystallizing at the surface and collected in underwater sediment traps in September 1970 were composed mostly of nahcolite (fig. 2), which had a deuterium concentration $(\delta \mathrm{D})$ value of -106 per mil. In November, a layer representing the same salts collected in the September trap was recovered in a core. By then, in the new environment produced by burial in an accumulating salt layer, nahcolite had reacted diagenetically to form trona, which also had a $\delta \mathrm{D}$ value of -106 per mil SMOW. 
The reaction of nacolite requires the addition of new hydrogen from water:

$$
\begin{aligned}
3 \mathrm{NaHCO}_{3} & +\mathrm{H}_{2} \mathrm{O} \\
& =\mathrm{Na}_{2} \mathrm{CO}_{3} \cdot \mathrm{NaHCO}_{3} \cdot 2 \mathrm{H}_{2} \mathrm{O}+\mathrm{CO}_{2} .
\end{aligned}
$$

Calculations based on the known isotope fractionation factor of trona (Matsuo and others, 1971) show that recrystallization took place under equilibrium conditions at lake-floor temperatures averaging $12^{\circ} \mathrm{C}$ (observed range, $8^{\circ}-16^{\circ} \mathrm{C}$ ), and that the required hydrogen was derived almost entirely from lake-bottom water which served as an open-system reservoir of nearly constant composition $(\delta \mathrm{D}=-16$ to -20 per mil) during this period. In a closed system, with hydrogen derived solely from the saline layer itself (a mix of approximately three moles of nahcolite and one mole of interstitial brine having $\delta \mathrm{D}=-21$ per mil), calculations based on equation 1 show that the secondary trona would have had a $\delta \mathrm{D}$ value near -78 per mil.

By April 1971, as the lake water and floor warmed, more than half the mirabilite had dissolved; about 10 percent of the natron had also dissolved, some was preserved, and the rest reacted in place to become trona and nahcolite. The mixtures of Na-carbonate minerals had $\delta \mathrm{D}$ values ranging from -26 to -101 per mil. Those reactions release hydrogen in the form of water and proceed as follows:

$$
\begin{aligned}
3 \mathrm{Na}_{2} \mathrm{CO}_{3} \cdot 10 \mathrm{H}_{2} \mathrm{O}+\mathrm{CO}_{2} & =2 \mathrm{Na}_{2} \mathrm{CO}_{3} \cdot \mathrm{NaHCO}_{3} \cdot 2 \mathrm{H}_{2} \mathrm{O}+25 \mathrm{H}_{2} \mathrm{O}
\end{aligned}
$$

and

$$
\mathrm{Na}_{2} \mathrm{CO}_{3} \cdot 10 \mathrm{H}_{2} \mathrm{O}+\mathrm{CO}_{2}=2 \mathrm{NaHCO}_{3}+9 \mathrm{H}_{2} \mathrm{O} .
$$

The large amounts of water expelled by reactions 2 and 3 , plus that liberated by the solution of mirabilite, were isotopically heavier ( $\delta \mathrm{D}=+5$ to -17 per mil) than the lake brine ( $\delta \mathrm{D}=-44$ to -18 per mil) during the period in which the trona and nahcolite crystallized. The isotope composition of those crystals, while growing diagenetically in the accumulating salt bed, had to be influenced by the brines released by reactions 2 and 3 , and we conclude that they were in fact almost unaffected by the isotope chemistry of the overlying lake water. At $5^{\circ}-15^{\circ} \mathrm{C}$, the estimated temperature range in the upper part of the salt bed during this season, trona crystallizing under equilibrium conditions would have $\delta \mathrm{D}$ values that were depleted 95-85 per mil relative to the brine from which they crystallized (Matsuo and others, 1971). Diagenetic trona collected from these zones in July 1971 had $\delta \mathrm{D}$ values ranging from -95 to -85 per mil, implying equilibrium crystallization from brines having $\delta \mathrm{D}$ values ranging from +10 to -10 per mil. These values are close to those of the mixtures of 10-hydrate minerals that crystallized the previous winter, but they do not resemble those of the overlying lake brine during the period of trona crystallization.

Mineralogic documentation of seasonal diagenetic processes taking place between 1971 and 1977 was more difficult. The existence in cores of 10-hydrate phases during winter was never confirmed by X-ray diffraction because of their instability after collection. Repeated seasonal change in the salt mineralogy and brine composition of Owens Lake has been reported previously (Dub, 1947, p. 2), and for the following three additional reasons we conclude that both 10 -hydrate phases formed during most winters of the 1971-77 period. The first reason is that in the $\mathrm{Na}_{2} \mathrm{CO}_{3}-\mathrm{NaHCO}_{3}-\mathrm{NaCl}$ and $\mathrm{Na}_{2} \mathrm{CO}_{3}-\mathrm{Na}_{2} \mathrm{SO}_{4}-\mathrm{NaCl}$ systems, the interstitial brine (regardless of whether it resembled its September 1970 composition when crystallization started or its August 1971 composition when it ceased) was in the natron stability field, or on the boundary between it and the mirabilite field, at all temperatures lower than about $20^{\circ} \mathrm{C}$ (Freeth, 1923; Teeple, 1929); temperatures of the salt layer at depths of about $1 \mathrm{~m}$ in January of both 1971 and 1972 were about $13^{\circ} \mathrm{C}$.

The second reason is that in cores collected in January 1972 (samples and data we have not yet interpreted or otherwise introduced here), a layer composed entirely of trona in April 1971 was composed of salts that were observed dehydrating in the air shortly after being brought to the surface. Natron and mirabilite are the only $\mathrm{Na}$-carbonate and $\mathrm{Na}$-sulfate minerals having this property. By the time the wet cores reached the X-ray diffraction laboratory, trona and burkeite were the only minerals in these suite that were detected. For isotope analysis, however, interstitial brines were also extracted in the field from a duplicate set of samples, leaving a nearly dry and less reactive mix in the sealed syringe. The percentages of hydrogen in the dewatered salts, determined during isotope analysis and expressed as $\mathrm{H}_{2} \mathrm{O}$, ranged from 2 to 18 percent in all but one sample which had a value of 27 percent. In pure samples, these percentages are nahcolite 11 , trona 20 , mirabilite 56 , and natron 60 . It appears therefore, that a small amount of natron or mirabilite was still preserved in that one sample, and that larger amounts were probably present in the original core. No cores were collected during the midwinter season in later years.

The third reason for concluding that repeated annual cycles involving phase changes were responsible for these observations is our lack of an alternative explanation for some of them. In late 1970, a range of more than 100 per mil in $\delta \mathrm{D}$ values existed in various mixtures of hydrated minerals on the lake floor (fig. 3). By 1974 , this wide variation in $\delta \mathrm{D}$ values had decreased markedly, and between 1974 and 1977, the variation continued to decrease and approached the $\delta \mathrm{D}$ values observed throughout the study in the undissolved pre-1970 salt bed (fig. 3). The $\delta \mathrm{D}$ values of the $1970-77$ interstitial brines also approached those in the older deposits. Thus, some 


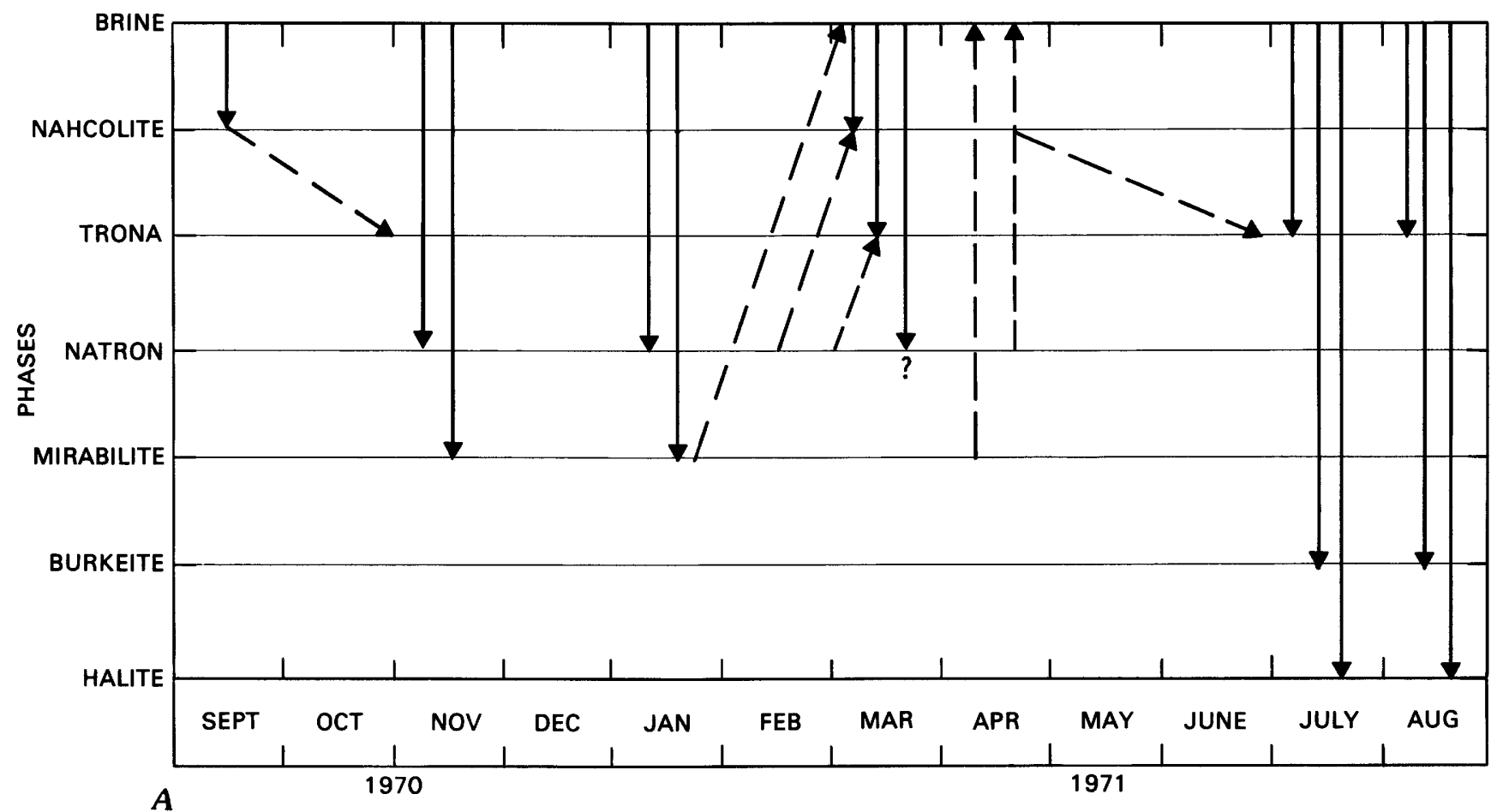

Figure 2 (above and facing page). Changes observed in Owens Lake between September 1970 (when salts first crystallized) and August 1971 (when lake had nearly dried). A, Phase changes: crystallization of listed mineral phases from brine phase (solid lines) and their diagenesis or resolution (dashed lines). B, Brine changes: variations in concentrations and quantities of solids remaining in solution, in $\delta \mathrm{D}$ values, and in lake-floor temperatures. SMOW, Standard Mean Ocean Water.

form of seasonal evolution that included the destruction and recrystallization of hydrated salt species had to be responsible for the continuing shifts in $\delta \mathrm{D}$ values toward the older ones.

Together, these observations suggest a scenario by which the original range of observed $\delta \mathrm{D}$ values would converge on the theoretical values that should result from equilibrium crystallization at the observed temperatures, and the smaller shifts in the $\delta \mathrm{D}$ values of the interstitial brines can be reasonably explained. The seasonal evolution of mirabilite and burkeite is not reconstructed because they account for only about 15 percent of the total assemblage and the warm-season sulfate contains no water of hydration; this scenario traces only the evolution of the natron and trona:

1. Early winter diagenetic recrystallization of trona to natron is represented by equation 2 reacting toward the left. In addition to 2 moles of trona, it requires 25 moles (67 volume percent) of water which probably exhausted the interstitial brines and extracted water from the overlying lake. In midsummer to late autumn, prior to significant rainfall on the lake, the $\delta \mathrm{D}$ values of lake and interstitial brines collected in 1973, 1974, and 1977 averaged $-33,-34$, and -41 per mil (range, -30 to -50 per mil). Lake waters became isotopically lighter after the rains began. Assuming a fractionation factor of -25 per mil, crystallization of natron from a -35 to -50 per mil brine would produce crystals with $\delta \mathrm{D}$ values of -10 to -25 per mil.

2. Regeneration of trona the following spring, at $5^{\circ}-15^{\circ} \mathrm{C}$, in a bed with its interstitial brines dominated by the expelled water of crystallization from natron would have produced trona with $\delta \mathrm{D}$ values between -85 and -95 per mil lighter-values at the isotopically light end of all ranges observed during the study and very close to the final range of values observed in September 1977 (fig. 3). The shift toward isotopically lighter interstitial brines after July 1971 (fig. 3) suggests that by the end of the 6-year period, about half the 25 moles of water required for each mole of natron had come from the overlying lake after it had received some rain (average $\delta \mathrm{D}$ values about -75 per mil; Friedman and others, 1976, p. 509) or a smaller amount of inflowing surface water (which is isotopically even lighter). The heavy end of the range of isotopic values in the salts also shifted greatly toward the light end in response to the introduction of this water. The isotopic compositions of the salts and interstitial brines in November 1974 represent an intermediate point in such change.

3. We finally hypothesize that prior to each cool season, the deuterium content of lake water again increased as a result of summer and autumn evaporation, bringing the lake and shallow interstitial brines back to $\delta \mathrm{D}$ values of about -35 per mil and allowing the same mineralogic and isotopic cycle to be repeated. 

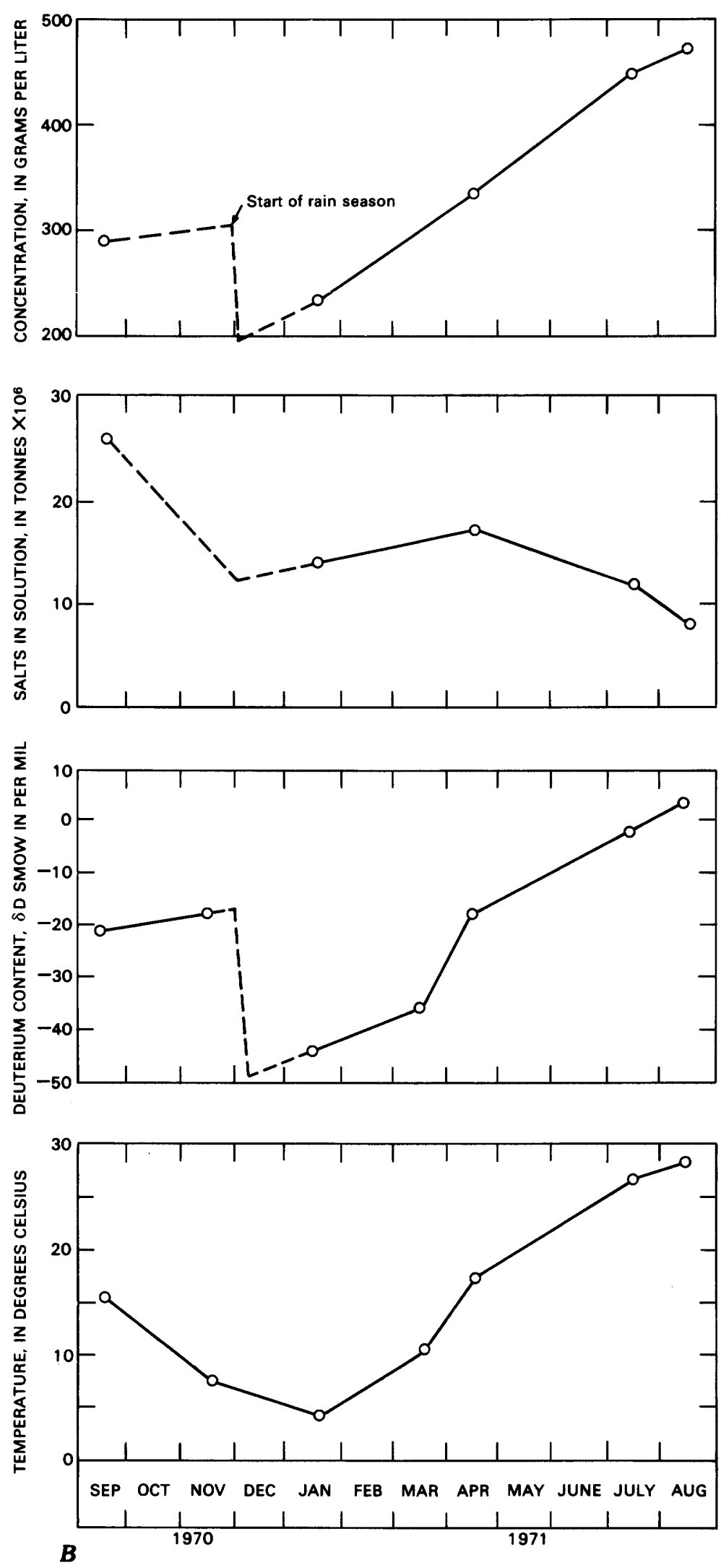


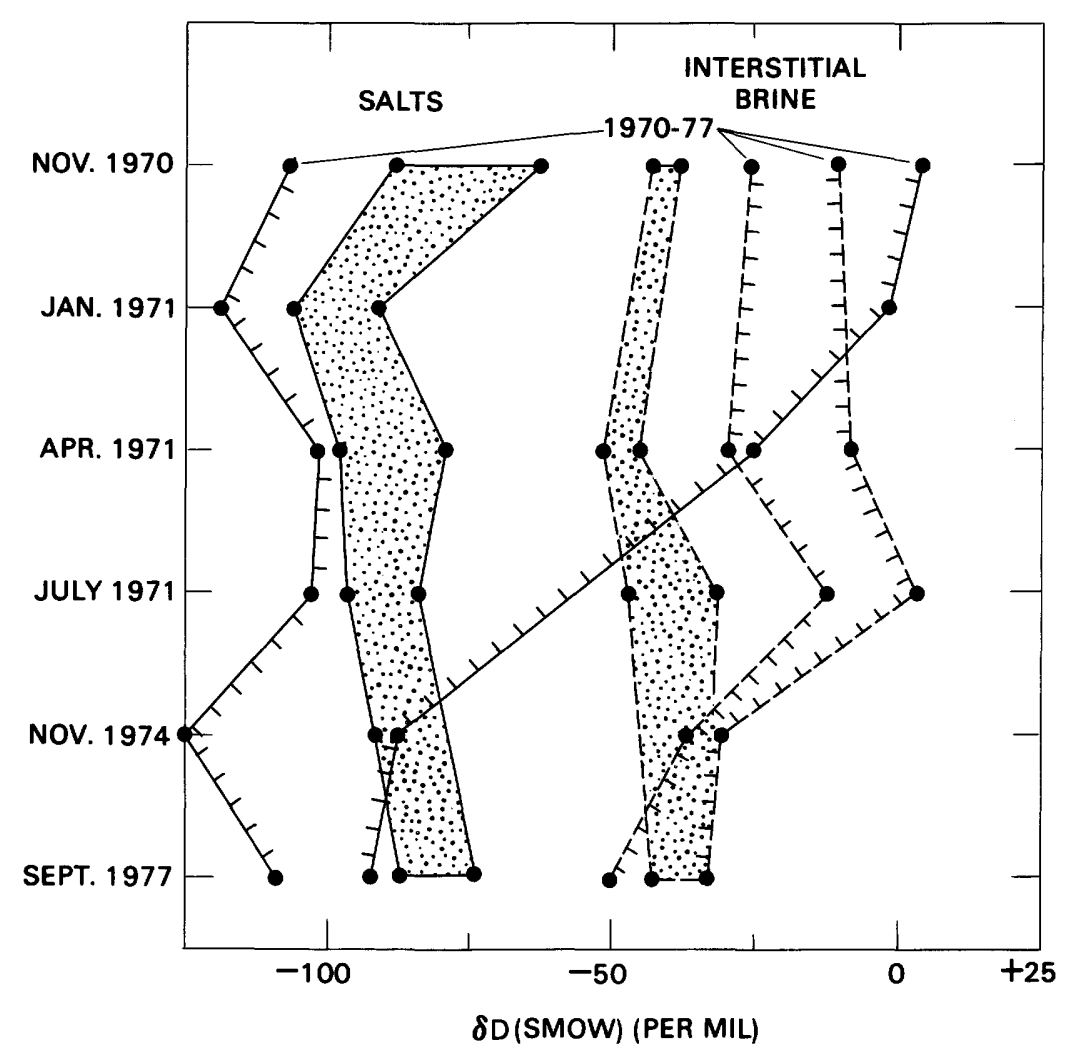

Figure 3. Ranges of $\delta \mathrm{D}$ values measured in samples of salts (solid lines) and interstitial brines (dashed lines, 1970-77). Values measured from salts and brines representing undissolved (pre-1970) salt beds, collected on indicated dates, fall within ranges indicated by stippled areas; those measured from samples representing post-1970 salt beds, collected on the same dates, fall within ranges bounded by hachured lines.

With time, the variable distribution of isotopes created during original crystallization from the lake was replaced by the less variable distribution created at the times of diagenesis. The original hydrogen-bearing phases represented crystallization produced by short-term, mostly diurnal, extremes in atmospheric temperature that needed to affect only the surface millimeter of lake water, whereas the diagenetic phases represented crystallization in response to seasonal temperature changes that lasted long enough to warm or cool the entire brine body and salt bed. With further burial, seasonal temperature variations will be reduced, and the "last" diagenetic changes will occur under conditions that approximate mean annual values.

\section{CONCLUSIONS}

The mineral species observed crystallizing from the brines of Owens Lake in 1970-71, and the subsequent mineralogic and isotopic changes in the recrystallizing layer of salts, were results of seasonal variations in the temperatures of the lake brines and near-surface deposits. Winter cooling produced the 10-hydrate minerals, natron and mirabilite, and summer warming caused these minerals to dissolve and their componenets to recrystallize as trona and burkeite. Once crystallized, very little halite dissolved seasonally. With time, all original carbonate and sulfate minerals underwent one or more cycles of diagenetic reactions, and the isotopic compositions of the brines and Na-carbonate salts became more homogeneous; $\delta \mathrm{D}$ values for trona evolved toward -100 per mil, for natron toward -10 per mil, and for late summer lake and interstitial brine toward -35 per mil. They also evolved toward the isotopic composition of the brines and undissolved salts in the pre-1970 saline layers, which probably attained their isotopic makeup by the same seasonal diagenetic process after they crystallized earlier this century. Clearly, however, the seasonal mineralogic changes and the accompanying partitioning of deuterium and hydrogen between brines and salts is a complex process, and additional data are needed to refine these conclusions further.

\section{REFERENCES CITED}

Dub, G. D., 1947, Owens Lake-Source of sodium minerals: American Institute of Mining and Metallurgical Engineers Technical Publication 2235, 13 p. 
Freeth, F. A., 1923, II. The system $\mathrm{Na}_{2} \mathrm{O}-\mathrm{CO}_{2}-\mathrm{NaCl}-\mathrm{H}_{2} \mathrm{O}$ considered as two four-component systems: Philosophical Transactions of the Royal Society of London, Series A, v. 223, p. 35-87.

Friedman, Irving, Smith, G. I., and Hardcastle, K. G., 1976, Studies of Quaternary saline lakes-II. Isotopic and compositional changes during desiccation of the brines in Owens Lake, California, 1969-1971: Geochimica et Cosmochimica Acta, v. 40, p. 501-511.

Gale, H. S., 1914, Salines in the Owens, Searles, and Panamint basins, southeastern California: U.S. Geological Survey Bulletin 580-L, p. 251-323.

Matsuo, Sadao, Friedman, Irving, and Smith, G. I., 1971, Studies of Quaternary saline lakes-I. Hydrogen isotope fractionation in saline minerals: Geochimica et Cosmochimica Acta, v. 36, p. 427-435.

Smith, G. I., Friedman, Irving, and McLaughlin, R. J., 1987, Studies of Quaternary saline lakes-III. Mineral, chemical, and isotopic evidence of salt solution and crystallization processes in Owens Lake, California, 1969-1971: Geochimica et Cosmochimica Acta v. 51, no. 4.

Stewart, M. K., 1974, Hydrogen and oxygen isotope fractionation during crystallization of mirabilite and ice: Geochimica et Cosmochimica Acta, v. 38, p. 167-172.

Teeple, J. E., 1929, The industrial development of Searles Lake brines with equilibrium data: American Chemical Society Monographic Series 49, 182 p. 



\title{
Influence of Iron and Manganese on the Chemical Partitioning of Copper, Zinc, and Chromium during Early Diagenesis in Outer Continental Shelf Sediments from the Gulf of Mexico
}

\author{
By LORRAINE H. FILIPEK, U.S. Geological Survey, 913 National Center, \\ Reston, Virginia 22092
}

\section{CONTENTS}

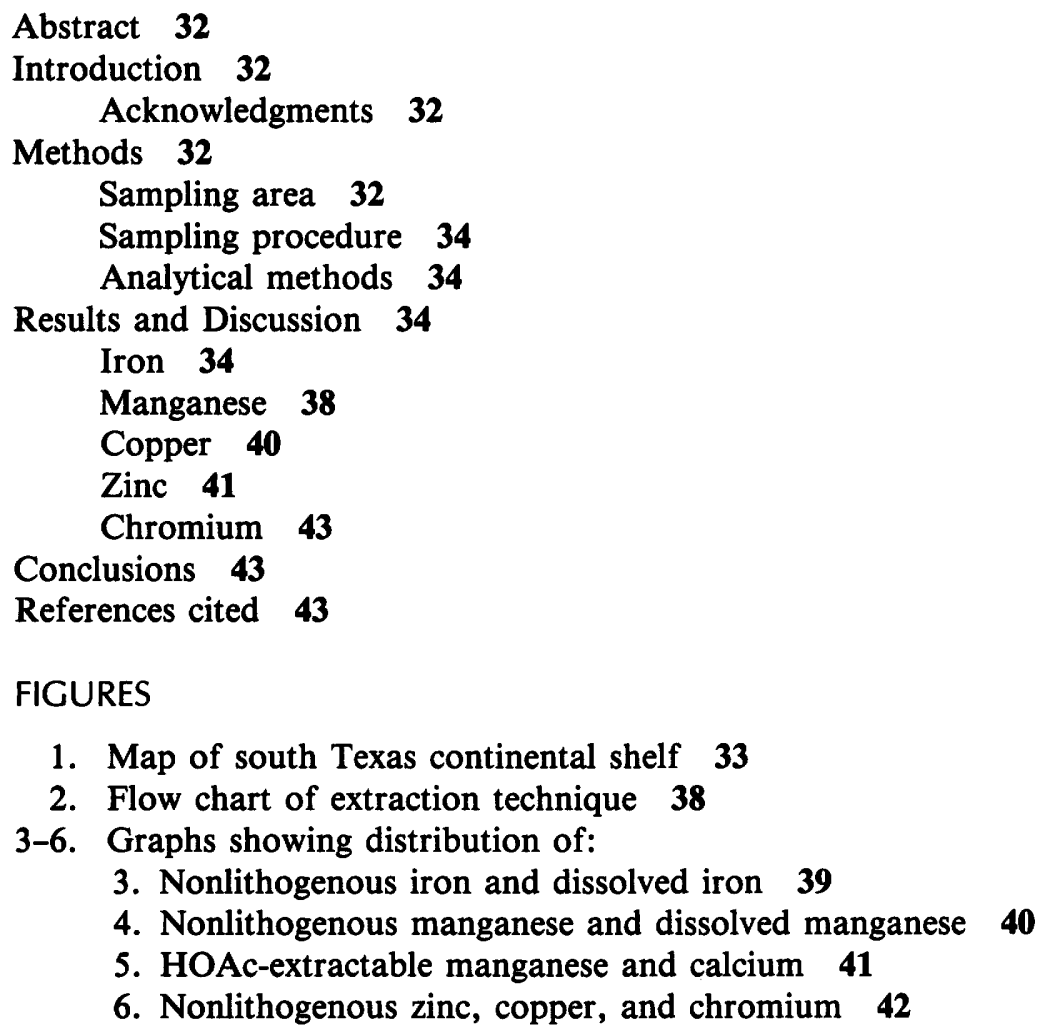

FIGURES

1. Map of south Texas continental shelf 33

2. Flow chart of extraction technique $\mathbf{3 8}$

3-6. Graphs showing distribution of:

3. Nonlithogenous iron and dissolved iron 39

4. Nonlithogenous manganese and dissolved manganese $\mathbf{4 0}$

5. HOAc-extractable manganese and calcium 41

6. Nonlithogenous zinc, copper, and chromium 42

TABLE

1. Correlation coefficients of nonlithogenous metals in cores 35

\section{APPENDIXES}

1. Concentrations of sulfur, carbon, calcium, sulfate, iron, and manganese in cores 45

2. Concentration of iron in extracts from cores 46

3. Concentration of manganese in extracts from cores 47

4. Concentration of copper in extracts from cores 48

5. Concentration of zinc in extracts from cores 49

6. Concentration of chromium in extracts from cores 


\section{Abstract}

To study how iron and manganese influence the chemistry of copper, zinc, and chromium in continental-shelf sediments during early diagenesis, a sequence of six extractions was used to isolate various forms of these five metals from the uppermost 1.5-2 $\mathrm{m}$ of sediment from the outer continental shelf off the coast of Texas. Three cores were collected from lowcarbonate sediments in which sulfate reduction was minor. Concentrations in the extracts suggest that the geochemistry of all five metals changed during diagenesis; however, only manganese showed signs of vertical remobilization and only at the shallowest site (water depth $=32 \mathrm{~m}$ ), which possessed the strongest redox (oxidation-reduction) gradient. In all cores the redox conditions appeared to be too low for the formation of extensive manganese oxides; hence, most of the nonlithogenous manganese was present as a carbonate or in an exchangeable form soluble in 1 molar acetic acid (HOAC).

Hydrous iron oxides and organically bound iron were the major nonlithogenous iron components in the more oxidized parts of the cores. Iron in pyrite increased with depth throughout the core lengths. Coprecipitation and dissolution of trace metals with hydrous iron oxides was in the order $\mathrm{Zn}>\mathrm{Cu}>\mathrm{Cr}$. In reducing parts of the core, copper sulfides were also a dominant form of nonlithogenous copper, especially at the shallowest site. Both organic materials and sulfides appeared to be important in the diagenesis of zinc, whereas organic materials appeared to be the most important sink for chromium. Exchangeable (HOAc-soluble) $\mathrm{Zn}$ and $\mathrm{Cr}$ correlated strongly with $\mathrm{HOAc}$-soluble $\mathrm{Fe}$, which appeared to be a reduced form of iron; however, $\mathrm{HOAc}$-soluble $\mathrm{Cu}$, where measurable, was independent of other metals. Of the total chromium content, 10-20 percent was in nonlithogenous components; of iron, 40-50 percent; of zinc, 50-60 percent; of copper, 30-65 percent; and of manganese, 75-90 percent. Only copper, however, showed a significant trend with grain size of the sediment and distance from shore; the percentage of the total copper content present in nonlithogenous components increased from the nearest-shore sandy silts to the shelf-edge muds.

Outer continental-shelf sediments provide a geographically large environmental transition between organic-poor, suboxic pelagic sediments and organic-rich, anoxic nearshore sediments. Based on the present results, the chemistry of this shelf environment appears to be controlled mainly by the precipitation and dissolution of hydrous iron oxides, accompanied by minor sulfate reduction. Even though reduced iron is in excess over sulfide, copper and zinc appear to compete successfully for the sulfide so that the shelf sediments provide a sink for these trace metals and act as an important control in their geochemical cycling.

\section{INTRODUCTION}

Many surficial enrichments of metals in sediments have been attributed to pollution (Nriagu and others, 1979; Hamilton-Taylor, 1979); however, natural diagenetic processes may also redistribute metals to the surface of, or within, a sediment column. For example, the diagenetic remobilization of manganese is a well- documented phenomenon (Robbins and Callender, 1975; Holdren and others, 1975). Similarly, iron can also undergo extensive chemical redistribution during diagenesis due to its sensitivity to changes in redox (oxidation-reduction) potential. Because the oxides of both iron and manganese are highly effective scavangers of trace metals, the reduction of these oxides would probably result in the mobilization of associated trace metals.

The purpose of this study was to investigate the influence of iron and manganese diagenesis on copper, zinc, and chromium in low-carbonate, outer continentalshelf sediments in which sulfate reduction is minor. The outer continental-shelf environment was chosen for study because it is the transition zone between nearshore sediments, which become anoxic within a few centimeters of the sediment surface (see, for example, Goldhaber and others, 1977), and pelagic muds, which remain oxic to suboxic over depths of several meters (see, for example, Froelich and others, 1979). This transition zone may be an important sink for metals released from the continents, either naturally or through pollution.

Cores of the uppermost 1.5-2 m of sediments were collected from the outer Texas continental shelf of the Gulf of Mexico. A sequential extraction scheme was used that removes successively more tightly bound forms of the metals. Statistical correlations were then performed to determine relationships between metals and anionic species and among metals in the various chemically extracted fractions.

\section{Acknowledgments}

I thank R. M. Owen for his guidance and advice and the U.S. Geological Survey in Corpus Christi, Texas, and the crew of the R. V. Decca Profiler for assistance in collecting cores and grab samples used for this study. Special thanks go to C. W. Holmes for his guidance during the cruise and to Cyndi Rice for her able assistance in the field laboratory.

This work was based on part of the author's Ph. D. dissertation and was completed while she was a National Research Council Postdoctoral Research Associate with the U.S. Geological Survey.

\section{METHODS}

\section{Sampling area}

The sampling area has been described previously (Filipek and Owen, 1980; Holmes and Martin, 1978), so only a brief review is given here. Two-meter gravity cores and surface grab samples were collected at each of the three sites shown in figure 1 . Core 19 (lat $28^{\circ} 0^{\prime}$ N., long $96^{\circ} 24^{\prime} \mathrm{W}$.), from a water depth of $32 \mathrm{~m}$, consists of 


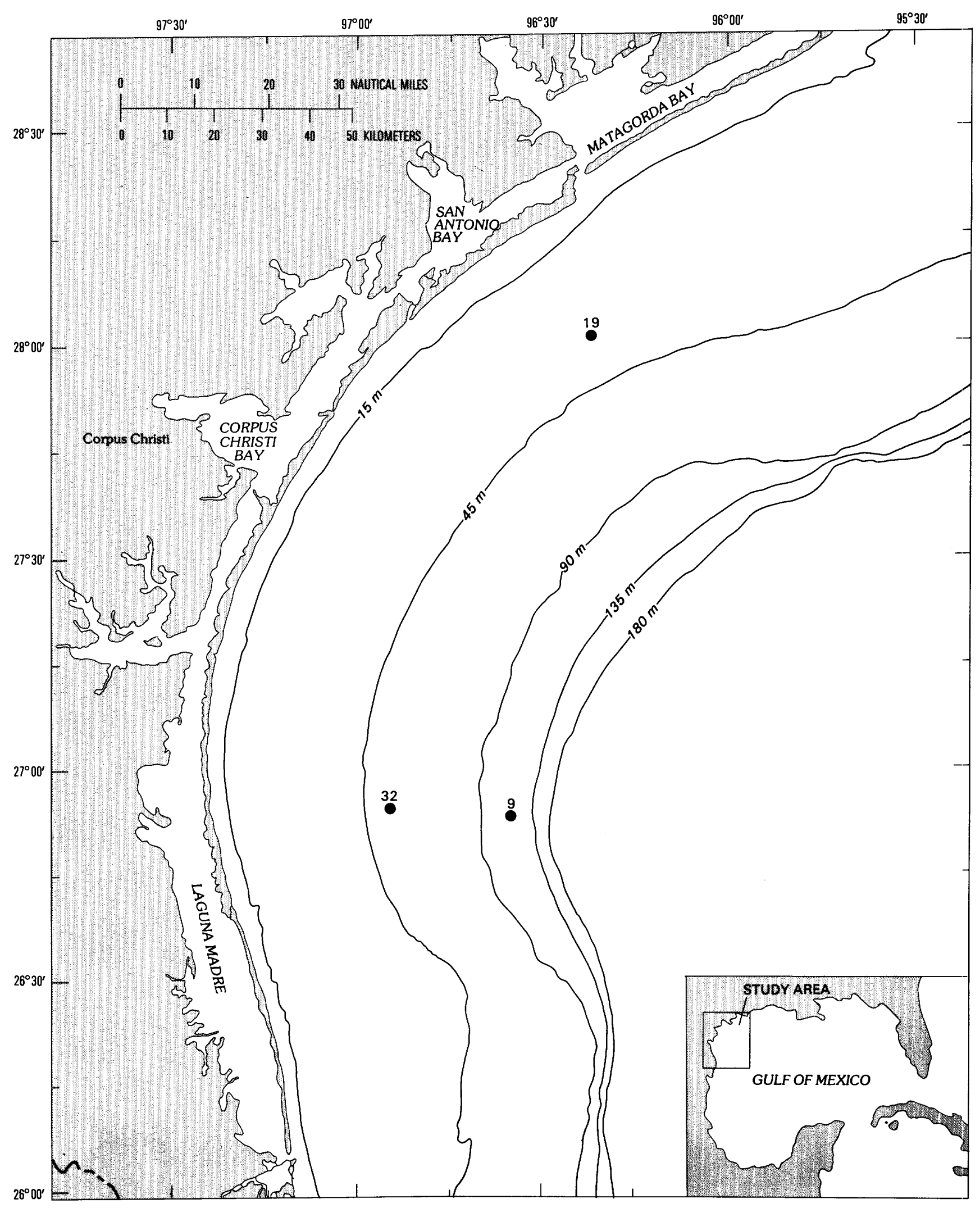

Figure 1. Map of south Texas continental shelf of Gulf of Mexico showing numbered sampling localities (solid dots). Contours are water depths in meters. 
sandy silt with sand lenses. The sedimentation rate in the vicinity of this station is estimated to be $1.44-4 \mathrm{~mm} / \mathrm{yr}$ (Berryhill, 1976). Core 32 (lat $26^{\circ} 54^{\prime}$ N., long $96^{\circ} 52^{\prime}$ W.), from a depth of $61 \mathrm{~m}$, is a silty mud. A core from this location showed no excess ${ }^{210} \mathrm{~Pb}$, suggesting no sedimentation during the last 150 years, but estimates based on organic decomposition rates suggest an average sedimentation rate of $0.3-1 \mathrm{~mm} / \mathrm{yr}$ throughout the present core (Filipek and Owen, 1980). Core 9 (lat 26 ${ }^{\circ} 53^{\prime}$ $\mathrm{N}$., long $96^{\circ} 33^{\prime} \mathrm{W}$.) is a muddy sediment from a water depth of $112 \mathrm{~m}$. The sedimentation rate at this location is $0.54 \mathrm{~mm} / \mathrm{yr}$ (Berryhill, 1976; Holmes and Martin, 1978).

\section{Sampling procedure}

The cores were sectioned on board ship. Interstitial water was expressed using $\mathrm{N}_{2}$, and the water samples were immediately acidified and frozen. The sectioned sediment was placed in plastic bags and refrigerated.

In all three cores, a thin, oxidized surface layer and a subsurface oxidation maximum at about $10 \mathrm{~cm}$ were recognized on the basis of interstitial sulfate concentrations, porosity, and other sediment parameters. This maximum is believed to be due to some activity related to benthic organisms, such as irrigation or the existence of a preferred feeding depth (Filipek and Owen, 1980). Living worms were found concentrated at a depth of $35 \mathrm{~cm}$ in core 19, which is the core having the highest pyrite concentrations and the highest rate of sulfate reduction (Filipek and Owen, 1980).

\section{Analytical methods}

The sequential extraction scheme used here has been published previously (Filipek and Owen, 1978, 1981) and is outlined in figure 2 . The extracts, together with the labels used to simplify discussion, are as follows: (1) dissolved (Diss); (2) acetic acid (HOAc)-dissolves exchangeable metals, acid-soluble sulfides, carbonates; (3) cold hydroxylamine- $\mathrm{HCl}(\mathrm{CHxl})$-dissolves easily reducible species (mainly hydrous manganese oxides; from Chao, 1972); (4) hydrogen peroxide $\left(\mathrm{H}_{2} \mathrm{O}_{2}\right)-$ dissolves metals associated with organic matter and pyrite; (5) hot hydroxylamine- $\mathrm{HCl}(\mathrm{HHxl})$-dissolves moderately reducible species (mainly hydrous iron oxides; see Chester and Hughes, 1967); and (6) hydrofluoric, perchloric, and nitric acids (Lith)-dissolves metals in residual minerals or incorporated in the structure of detrital silicate minerals (lithogeneous metals).

Each of the extracts was analyzed for $\mathrm{Fe}, \mathrm{Mn}, \mathrm{Zn}$, $\mathrm{Cu}$, and $\mathrm{Cr}$, and the HOAc-extract for $\mathrm{Ca}$, by flame atomic absorption spectrophotometry (AA), using appropriate blanks and standards. Associated ligands
(phosphate-P, sulfate-S, total sediment-S (or solid-S), organic- $\mathrm{C}$, and carbonate-C) were measured using standard techniques discussed by Filipek and Owen (1981). Solid-S was labeled "pyrite-S" because analyses of distilled water-rinsed sediment and HOAc-treated sediment resulted in values that generally agreed to within 10 percent, except for the upper $15 \mathrm{~cm}$ of core 9, in which about 40 percent of the sulfur was acid-soluble. Based on the solid-S determinations, the $\mathrm{H}_{2} \mathrm{O}_{2}$-soluble Fe component was further subdivided into pyrite-Fe and Org$\mathrm{Fe}$ (organic $\mathrm{Fe}$ ); that is, pyrite-Fe was estimated as onehalf of the molar value of solid-S, and Org-Fe was estimated by subtracting the amount of $\mathrm{Fe}$ in pyrite from $\mathrm{H}_{2} \mathrm{O}_{2}$-soluble Fe. Errors in Org-Fe due to inclusion of monosulfides are probably quite small because acidsoluble Fe-sulfides were only present to an appreciable extent in near-surface sediments where total sulfur was much less than $\mathrm{H}_{2} \mathrm{O}_{2}$-soluble $\mathrm{Fe}$.

\section{RESULTS AND DISCUSSION}

\section{Iron}

Between 50 and 60 percent of the total iron at all locations was found to be in the lithogenous fraction; that is, in crystal structures of, or in mineral inclusions in, detrital mineral grains (appendix 2). As shown in figure 3 , the most dominant nonlithogenous form was $\mathrm{HHxl}$-soluble $\mathrm{Fe}$ (hydrous iron oxides). In all three cores, the dominant diagenetic processes appear to have been the formation of hydrous iron oxides at the surface and subsurface oxidation maxima (at about $10 \mathrm{~cm}$ ) and the reduction of the oxides below these zones (appendix 2). Concentrations of dissolved iron increased just below zones of maximum $\mathrm{HHxl}$-soluble $\mathrm{Fe}$ concentration, indicating a release of $\mathrm{Fe}^{2+}$ during reduction of the oxides. In core 9 (fig. 3, table 1), reduction of $\mathrm{HHxl}$ soluble $\mathrm{Fe}$ apparently resulted in the formation of the HOAc-soluble $\mathrm{Fe}$, based on the inverse relationship between the two profiles. Concentrations of HOAc-soluble $\mathrm{S}$ were too low for acid-soluble iron sulfides to be a significant fraction of the HOAc-soluble $\mathrm{Fe}$. In addition, solubility estimates suggest that the interstitial waters were generally undersaturated with respect to siderite and vivianite, the most common nonsulfide ferrous iron phases. On the other hand, the association of HOAcsoluble $\mathrm{Fe}$ with $\mathrm{HOAc}$-soluble $\mathrm{Mg}, \mathrm{K}$, and $\mathrm{P}$-in a $\mathrm{Mg}: \mathrm{K}: \mathrm{Fe}: \mathrm{P}$ atomic ratio of about $16: 6: 6: 1$ in all three cores-suggests that these elements were present in highly reactive phases adsorbed on clay minerals similar to the 6:1 iron hydroxide-phosphorus complex reported in certain reducing lacustrine sediments (Williams and others, 1971) and discussed in detail elsewhere (Filipek and Owen, 1981). The reduced or mixed $\left(\mathrm{Fe}^{2+}, \mathrm{Fe}^{3+}\right)$ component is presumed to have formed because sulfate reduction was 
Table 1. Correlation coeffictents for nonl1thogenous metals and other selected sediment variables for cores 9, 32, and 19

\begin{tabular}{|c|c|c|c|c|c|c|c|c|c|c|c|c|c|c|c|c|c|c|c|c|c|c|c|c|}
\hline Depth & 1.00 & & & & & & & & & & & & & & & & & & & & & & & \\
\hline org-c & -.26 & 1.00 & & & & & & & & & & & & & & & & & & & & & & \\
\hline Carb-c & -.58 & -.28 & 1.00 & & & & & & & & & & & & & & & & & & & & & \\
\hline Sol1d-s & .92 & -.28 & -.60 & 1.00 & & & & & & & & & & & & & & & & & & & & \\
\hline Diss-Fe & -.30 & -.41 & .48 & -.33 & 1.00 & & & & & & & & & & & & & & & & & & & \\
\hline Diss-Mn & -.16 & .12 & -.38 & -.07 & -.14 & 1.00 & & & & & & & & & & & & & & & & & & \\
\hline HOAc-soluble Pe & .48 & .06 & -.64 & .55 & -.08 & .30 & 1.00 & & & & & & & & & & & & & & & & & \\
\hline CHx1-soluble Fe & -.45 & .04 & .50 & -.60 & .18 & -.03 & -.81 & 1.00 & & & & & & & & & & & & & & & & \\
\hline $\mathrm{H}_{2} \mathrm{O}_{2}$-soluble Fe & -.39 & -.01 & .36 & -.48 & .41 & -.15 & -.25 & .34 & 1.00 & & & & & & & & & & & & & & & \\
\hline Org-Fe & -.79 & .17 & .57 & -.88 & .42 & -.04 & -.48 & .56 & .83 & 1.00 & & & & & & & & & & & & & & \\
\hline HHx1-soluble Fe & -.04 & -.40 & .63 & -.18 & .21 & -.32 & -.66 & .57 & -.01 & .11 & 1.00 & & & & & & & & & & & & & \\
\hline HOAc-soluble Mn & .62 & -.06 & -.46 & .70 & -.41 & .20 & .49 & -.40 & -.45 & -.68 & -.19 & 1.00 & & & & & & & & & & & & \\
\hline CHx1-soluble Mn & .53 & -.23 & -.15 & .53 & -.11 & .13 & .11 & .14 & -.20 & -.44 & .39 & .59 & 1.00 & & & & & & & & & & & \\
\hline $\mathrm{H}_{2} \mathrm{O}_{2}$-soluble Mn & -.19 & -.18 & .25 & -.30 & .68 & .12 & -.06 & .42 & .67 & .54 & .18 & -.22 & .29 & 1.00 & & & & & & & & & & \\
\hline HHx1-soluble Mn & -.09 & -.24 & .61 & -.24 & .10 & -.34 & -.74 & .60 & .17 & .24 & .94 & -.27 & .29 & .15 & 1.00 & & & & & & & & & \\
\hline HOAc-soluble $\mathrm{Zn}$ & .70 & -.01 & -.67 & .62 & -.14 & .13 & .80 & -.59 & -.37 & -.59 & -.37 & .46 & .28 & -.01 & -.50 & 1.00 & & & & & & & & \\
\hline CHxl-soluble $2 n$ & .35 & -.25 & .28 & .17 & .23 & -.26 & -.09 & .21 & -.08 & -.15 & .43 & -.05 & .25 & .14 & .36 & .09 & 1.00 & & & & & & & \\
\hline $\mathrm{H}_{2} \mathrm{O}_{2}$-soluble $\mathrm{Zn}$ & .17 & -.37 & .12 & .02 & .35 & .32 & .16 & .26 & .28 & .13 & .30 & .17 & .55 & .69 & .22 & .22 & .45 & 1.00 & & & & & & \\
\hline HHx1-soluble $\mathrm{Zn}$ & .12 & -.43 & .56 & -.04 & .20 & -.34 & -.57 & .51 & .20 & .13 & .93 & -.12 & .50 & .33 & .93 & -.29 & .49 & .44 & 1.00 & & & & & \\
\hline $\mathrm{H}_{2} \mathrm{O}_{2}-$ soluble $\mathrm{Cu}$ & .55 & -.30 & -.03 & .33 & .12 & -.04 & .23 & -.08 & -.24 & -.33 & .44 & .27 & .43 & .11 & .37 & .47 & .59 & .61 & .49 & 1.00 & & & & \\
\hline HHxl-soluble Cu & .47 & -.41 & .22 & .37 & .26 & -.27 & .02 & .02 & .02 & -.22 & .50 & .36 & .56 & .29 & .47 & .23 & .45 & .49 & .64 & .72 & 1.00 & & & \\
\hline HOAc-soluble $\mathrm{Cr}$ & -.18 & .09 & .24 & -.26 & .25 & -.08 & .39 & -.19 & .39 & .37 & -.10 & -.23 & -.14 & .32 & -.09 & .22 & .13 & .40 & -.03 & .23 & .03 & 1.00 & & \\
\hline $\mathrm{H}_{2} \mathrm{O}_{2}$-soluble $\mathrm{Cr}$ & -.05 & -.06 & .09 & -.22 & .54 & -.28 & .12 & .08 & .57 & .44 & -.22 & -.33 & -.31 & .52 & -.19 & .24 & .07 & .17 & -.11 & .07 & .20 & .36 & 1.00 & \\
\hline HHX1-soluble $\mathrm{Cr}$ & -.06 & -.48 & .60 & -.18 & .22 & -.56 & -.66 & .43 & .20 & .22 & .85 & -.40 & .13 & .09 & .84 & .42 & 22 & .05 & .81 & .21 & .29 & -.02 & -.03 & 1.00 \\
\hline
\end{tabular}

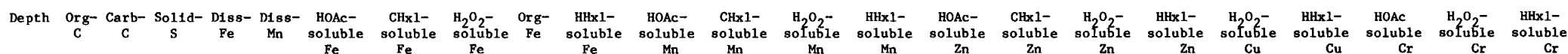


Table 1 . Correlation coefficients for nonlithogenous metals and other selected sediment variables for cores 9,32 , and 19 (c)--Continued
$[P=0.01, R \geq .64 ; \mathrm{P}=0.05, \mathrm{R} \geq .51]$

\begin{tabular}{|c|c|c|c|c|c|c|c|c|c|c|c|c|c|c|c|c|c|c|c|c|c|c|c|}
\hline Depth & 1.00 & & & & & & & & & & & & & & & & & & & & & & \\
\hline org-c & .18 & 1.00 & & & & & & & & & & & & & & & & & & & & & \\
\hline Carb-c & -.46 & -.10 & 1.00 & & & & & & & & & & & & & & & & & & & & \\
\hline Solid-s & .91 & .28 & -.61 & 1.00 & & & & & & & & & & & & & & & & & & & \\
\hline D1ss-Fe & -.32 & -.44 & .41 & -.42 & 1.00 & & & & & & & & & & & & & & & & & & \\
\hline $\mathrm{D} 1 \mathrm{s8}-\mathrm{Mn}$ & -.32 & -.62 & .58 & -.42 & .85 & 1.00 & & & & & & & & & & & & & & & & & \\
\hline HOAC-soluble Fe & .21 & .37 & -.75 & .47 & -.43 & -.49 & 1.00 & & & & & & & & & & & & & & & & \\
\hline CHx1-soluble $\mathrm{Fe}$ & -.69 & .11 & .34 & -.67 & .16 & .21 & .06 & 1.00 & & & & & & & & & & & & & & & \\
\hline $\mathrm{H}_{2} \mathrm{O}_{2}$-soluble $\mathrm{Fe}$ & .62 & .04 & -.49 & .54 & -.07 & -.26 & .22 & -.51 & 1.00 & & & & & & & & & & & & & & \\
\hline Org-Fe & -.57 & -.29 & .32 & -.73 & .43 & .28 & -.37 & .37 & .18 & 1.00 & & & & & & & & & & & & & \\
\hline HHx1-soluble $\mathrm{Fe}$ & .02 & .14 & .35 & -.10 & -.04 & .04 & -.41 & -.17 & -.20 & -.05 & 1.00 & & & & & & & & & & & & \\
\hline HOAc-soluble Mn & .75 & .40 & -.49 & .77 & -.29 & -.49 & .27 & -.48 & .31 & -.66 & -.09 & 1.00 & & & & & & & & & & & \\
\hline CHx1-soluble Mn & .83 & .47 & -.58 & .87 & -.43 & -.55 & .40 & -.44 & .44 & -.65 & -.11 & .89 & 1.00 & & & & & & & & & & \\
\hline $\mathrm{H}_{2} \mathrm{O}_{2}$-soluble $\mathrm{Mn}$ & .76 & .47 & -.31 & .62 & -.29 & -.51 & .02 & -.47 & .49 & -.34 & .02 & .80 & .84 & 1.00 & & & & & & & & & \\
\hline HHxl-soluble Mn & -.29 & .10 & .26 & -.28 & .10 & .08 & -.14 & -.05 & -.08 & .27 & .75 & -.36 & -.36 & -.32 & 1.00 & & & & & & & & \\
\hline HOAc-soluble $\mathrm{Zn}$ & -.15 & -.03 & -.43 & .04 & .48 & .18 & .44 & .13 & .14 & .07 & -.40 & .01 & -.02 & -.20 & -.09 & 1.00 & & & & & & & \\
\hline CHx1-soluble $\mathrm{Zn}$ & -.34 & .06 & -.17 & -.13 & .27 & .18 & .36 & .27 & -.29 & -.8 & .07 & -.26 & -.22 & -.44 & .25 & .73 & 1.00 & & & & & & \\
\hline $\mathrm{H}_{2} \mathrm{O}_{2}$-soluble $\mathrm{Zn}$ & .83 & .39 & -.18 & .66 & -.08 & -.17 & .06 & -.36 & .53 & -.34 & .06 & .67 & .73 & .80 & -.28 & -.09 & -.28 & 1.00 & & & & & \\
\hline HHx1-8oluble $2 n$ & -.32 & -.50 & .19 & -.28 & -.08 & .18 & -.20 & -.07 & -.31 & .08 & .43 & -.50 & -.47 & -.55 & .51 & -.27 & .14 & -.65 & 1.00 & & & & \\
\hline $\mathrm{H}_{2} \mathrm{O}_{2}$-soluble Cu & .74 & .43 & -.44 & .73 & -.40 & -.47 & .38 & -.40 & .34 & -.58 & -.13 & .70 & .80 & .77 & -.43 & -.01 & -.10 & .73 & -.47 & 1.00 & & & \\
\hline HHxi-soluble Cu & .35 & .52 & .02 & .39 & -.31 & -.29 & .16 & -.32 & -.15 & -.57 & .42 & .37 & .46 & .42 & .28 & -.26 & .02 & .26 & .08 & .48 & 1.00 & & \\
\hline $\mathrm{H}_{2} \mathrm{O}_{2}$-soluble $\mathrm{Cr}$ & .11 & .33 & -.66 & .26 & -.44 & -.64 & .60 & -.08 & .38 & .00 & -.30 & .19 & .32 & .28 & -.19 & .24 & .02 & .04 & -.27 & .46 & -.00 & 1.00 & \\
\hline HHx1-soluble $\mathrm{Cr}$ & -.21 & .17 & .34 & -.29 & .11 & .23 & -.08 & .27 & -.32 & .08 & .47 & -.39 & -.21 & -.21 & .52 & -.13 & .31 & -.08 & .24 & -.27 & .43 & -.45 & 1.00 \\
\hline
\end{tabular}

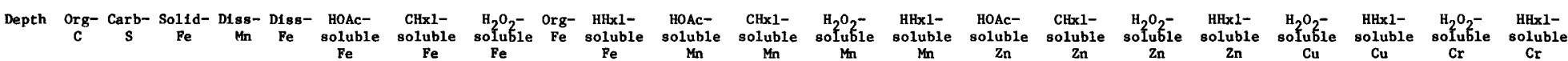


Table 1. Correlation coefficients for nonlithogenous metals and other selected sediment variables for cores 9, 32, and 19--Continued $0.01, R \geq .66$; and $P=0.05, R \geq .53]$

\begin{tabular}{|c|c|c|c|c|c|c|c|c|c|c|c|c|c|c|c|c|c|c|c|c|c|c|c|c|}
\hline Depth & 1.00 & & & & & & & & & & & & & & & & & & & & & & & \\
\hline Org-C & -.15 & 1.00 & & & & & & & & & & & & & & & & & & & & & & \\
\hline Carb-c & -.39 & -.22 & 1.00 & & & & & & & & & & & & & & & & & & & & & \\
\hline Solid-s & .61 & -.04 & -.47 & 1.00 & & & & & & & & & & & & & & & & & & & & \\
\hline D1ss-Fe & .31 & .25 & -.35 & .32 & 1.00 & & & & & & & & & & & & & & & & & & & \\
\hline Diss-Mn & .33 & -.17 & .44 & .35 & .07 & 1.00 & & & & & & & & & & & & & & & & & & \\
\hline BOAc-soluble Fe & -.04 & -.24 & -.14 & .65 & -.14 & .13 & 1.00 & & & & & & & & & & & & & & & & & \\
\hline CHx1-soluble Fe & -.19 & .81 & -.07 & -.22 & -.09 & -.07 & -.41 & 1.00 & & & & & & & & & & & & & & & & \\
\hline $\mathrm{H}_{2} \mathrm{O}_{2}$-soluble Fe & .48 & -.14 & -.18 & .14 & .14 & -.25 & -.16 & -.26 & 1.00 & & & & & & & & & & & & & & & \\
\hline org-Fe & -.17 & -.05 & .21 & -.67 & -.12 & -.49 & -.61 & -.01 & .63 & 1.00 & & & & & & & & & & & & & & \\
\hline HHx1-soluble Fe & -.19 & .74 & -.30 & .00 & .24 & -.43 & .01 & .56 & -.06 & -.03 & 1.00 & & & & & & & & & & & & & \\
\hline HOAc-soluble Mn & -.18 & .66 & -.13 & -.28 & .07 & -.24 & -.45 & .86 & -.19 & .07 & .74 & 1.00 & & & & & & & & & & & & \\
\hline CHx1-soluble Mn & -.03 & .70 & -.26 & -.10 & .11 & -.17 & -.38 & .88 & -.16 & -.04 & .73 & .97 & 1.00 & & & & & & & & & & & \\
\hline $\mathrm{H}_{2} \mathrm{O}_{2}-$-8olubie Mn & .04 & .62 & -.17 & -.36 & .12 & -.32 & -.67 & .73 & .28 & .47 & .61 & .84 & .82 & 1.00 & & & & & & & & & & \\
\hline HHxl-soluble Mn & -.34 & .54 & -.21 & -.20 & .38 & -.58 & -.14 & .32 & .04 & .24 & .80 & .58 & .52 & .51 & 1.00 & & & & & & & & & \\
\hline HOAc-soluble $\mathrm{Zn}$ & -.55 & .14 & -.10 & .19 & -.23 & -.31 & .73 & -.07 & -.20 & -.24 & .32 & -.12 & -.13 & -.34 & .29 & 1.00 & & & & & & & & \\
\hline CHx1-soluble $2 \mathrm{n}$ & .18 & .60 & -.45 & .56 & -.06 & .14 & .33 & .53 & -.17 & -.57 & .36 & .27 & .42 & .13 & -.00 & .36 & 1.00 & & & & & & & \\
\hline $\mathrm{H}_{2} \mathrm{O}_{2}$-soluble $\mathrm{Zn}$ & .45 & .09 & -.26 & .09 & .32 & -.10 & -.20 & -.10 & .72 & .43 & .04 & -.09 & -.05 & .38 & -.04 & -.31 & -.07 & 1.00 & & & & & & \\
\hline HHx1-soluble $\mathrm{Zn}$ & -.16 & .66 & -.37 & .06 & .25 & -.48 & -.03 & .53 & .18 & .12 & .91 & .71 & .72 & .65 & .81 & .34 & .36 & .09 & 1.00 & & & & & \\
\hline $\mathrm{H}_{2} \mathrm{O}_{2}$-soluble $\mathrm{Cu}$ & .45 & -.03 & -.40 & .81 & .40 & .27 & .61 & -.33 & .29 & -.40 & -.06 & -.44 & -.28 & -.33 & -.20 & .22 & .37 & .48 & -.01 & 1.00 & & & & \\
\hline HHx1-soluble Cu & .05 & .69 & -.41 & .25 & .26 & -.16 & -.01 & .71 & -.03 & -.21 & .85 & .81 & .88 & .65 & .56 & .13 & .55 & .05 & .87 & .10 & 1.00 & & & \\
\hline HOAc-soluble $\mathrm{Cr}$ & -.21 & -.09 & .26 & .09 & -.19 & -.01 & .59 & -.37 & -.14 & -.17 & .22 & -.29 & -.32 & -.39 & .14 & .47 & -.12 & -.17 & .04 & .14 & -.10 & 1.00 & & \\
\hline $\mathrm{H}_{2} \mathrm{O}_{2}$-soluble $\mathrm{Cr}$ & .67 & .05 & -.16 & .23 & .18 & .11 & -.19 & -.06 & .76 & .31 & .00 & -.05 & .01 & .39 & -.15 & -.37 & .11 & .84 & .07 & .37 & .08 & -.21 & 1.00 & \\
\hline HHx1-soluble $\mathrm{Cr}$ & -.83 & .31 & .24 & -.35 & -.03 & -.41 & .19 & .06 & -.17 & .20 & .42 & -.10 & -.03 & -.00 & .59 & .71 & -.05 & -.19 & .42 & -.14 & .07 & .41 & -.38 & 1.00 \\
\hline
\end{tabular}

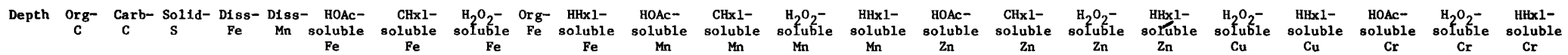




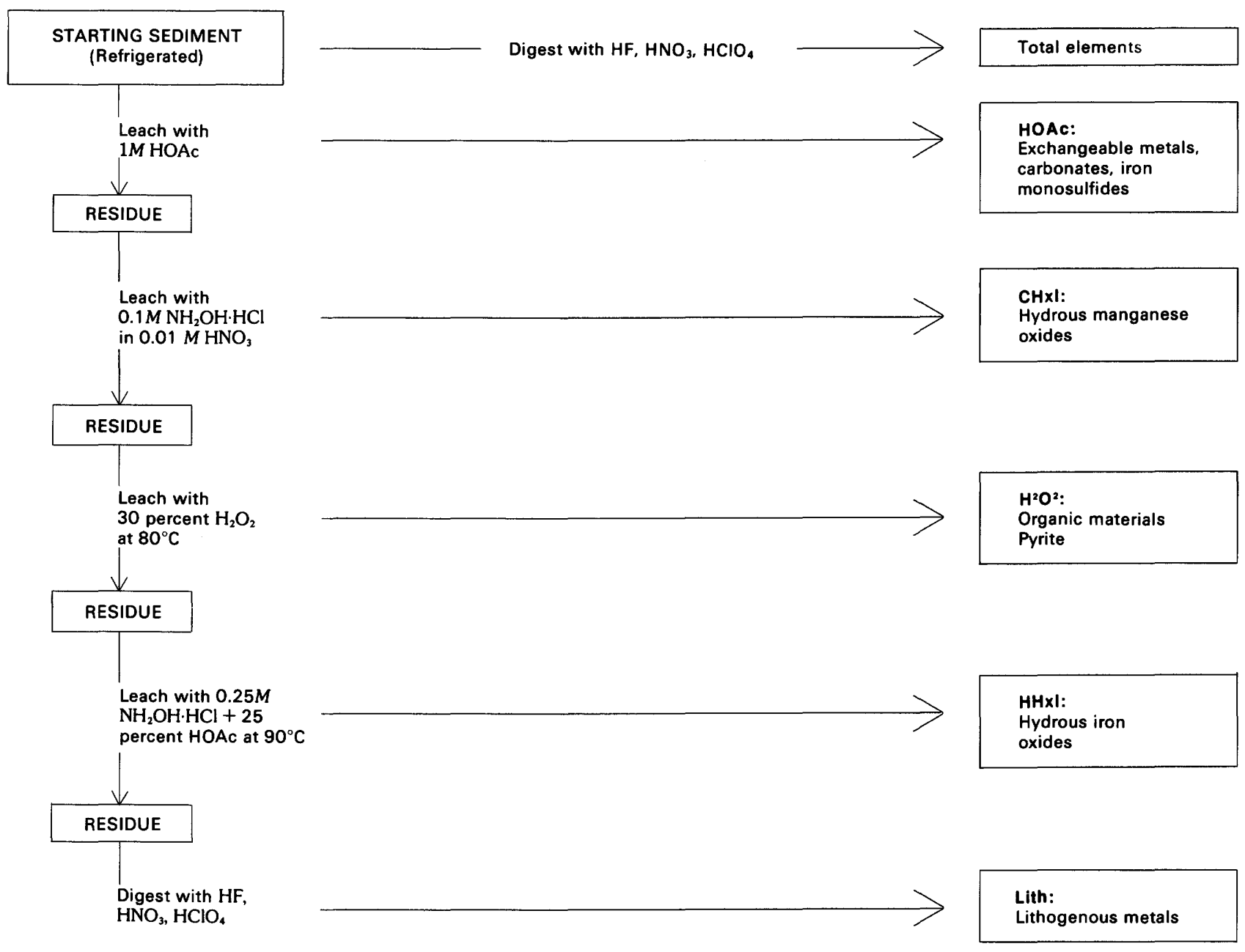

Figure 2. Flow chart of extraction treatments. See Filipek and Owen $(1978,1981)$ for details. HOAc, extractable in acetic acid; $\mathrm{CHxl}$, extractable in $0.1 \mathrm{M} \mathrm{NH}_{2} \mathrm{OH} \cdot \mathrm{HCl} ; \mathrm{H}_{2} \mathrm{O}_{2}$, extractable in 30 percent $\mathrm{H}_{2} \mathrm{O}_{2} ; \mathrm{HHxl}$, extractable in $0.25 \mathrm{M} \mathrm{NH} \mathrm{OH}_{2} \cdot \mathrm{HCl}+25$ percent acetic acid; Lith, extractable after digestion in $\mathrm{HF}, \mathrm{HNO}_{3}, \mathrm{HClO}_{4}$.

not intense enough to supply the sulfide necessary to react with all the reduced iron in these sediments. The HOAcsoluble $\mathrm{Fe}$ and $\mathrm{HHxl}$-soluble $\mathrm{Fe}$ do not show the inverse relationship in core 19 that they show in core 9 (table 1), probably because of the more intense sulfate reduction and concomitant pyrite formation in core 19.

In all three cores, pyrite-Fe increased with depth because of organic decomposition (Filipek and Owen, 1980); however, pyrite-Fe accounted for less than 30 percent of the nonlithogenous iron in all cores, even in core 19 , which had the highest concentrations of solid-S. Concentrations of Org-Fe were erratic but generally decreased with depth in the sediment column.

\section{Manganese}

In terms of relative amounts in each extract, manganese behaved quite differently from iron. The absolute amount of manganese was much less than iron, and most (75-90 percent) of the manganese was in nonlithogenous components. In all three cores, HOAcsoluble Mn was by far the dominant fraction of the element and generally accounted for more than 60 percent of the total metal (fig. 4, appendix 3). All the nonlithogenous manganese components showed slight maxima at the surface and subsurface oxidation maxima, at about the same depths as the minima in dissolved manganese concentrations (fig. 4, appendixes 1 and 3). At the shallowest site (site 19), nonlithogenous manganese was more than twice as concentrated in the uppermost centimeter of sediment than in the remainder of the core, indicating significant diagenetic remobilization of manganese here (appendix 3).

The pore-water profiles of all three cores (appendix 1) and the nonlithogenous manganese profiles of core 

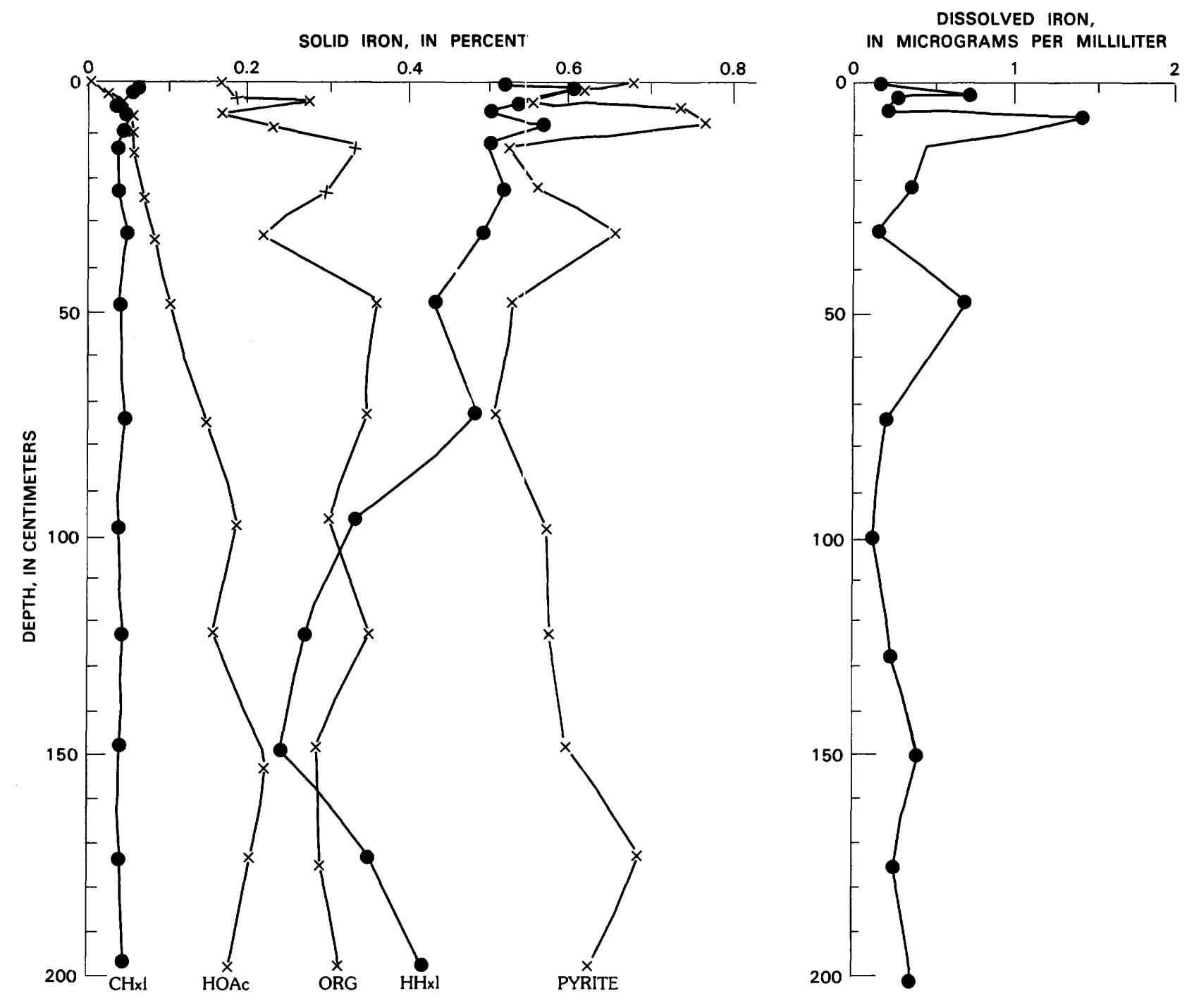

Figure 3. Distribution of nonlithogenous iron and dissolved iron from core 9. $\mathrm{CHxl}, \mathrm{CHxl}$-extractable iron; ORG, iron in organic materials; $\mathrm{HHxl}, \mathrm{HHxl}$-extractable iron; Pyrite, iron in pyrite. (See fig. 2 for extraction treatments.)

19 (appendix 3) suggest that manganese oxides should have been significant in the more oxidizing portions of the cores. The $\mathrm{CHxl}$ (manganese oxide) extract, however, contained only a small percentage of manganese, whereas the HOAc extract was the richest in this element, even at the surface. Based on solubility considerations, manganese soluble in cold weak acid (such as HOAc) is more likely to be manganese carbonate (rhodochriosite) or a mixed ( $\mathrm{Ca}, \mathrm{Mn})$-carbonate than manganese oxide. At equilibrium, the carbonate phases are usually the most stable forms of manganese in reducing sediments (Stumm and Morgan, 1970; Holdren and others, 1975). (Ca,Mn)carbonates of varying $\mathrm{Mn}: \mathrm{Ca}$ ratio have been reported in anoxic marine sediment by Suess (1979) and Pedersen and Price (1982). Therefore, the presence of a carbonate phase could explain the dominance of HOAc-soluble Mn in reducing portions of the present cores, but not in the oxidizing zones.
Two explanations for high concentrations of HOAc-soluble $\mathrm{Mn}$ in oxidizing sediments are possible: First, the formation of rhodochrosite or a mixed (Ca,Mn)-carbonate from $\mathrm{Mn}^{2+}$ may have been kinetically favored in the presence of carbonates, even in oxidizing sediments. Binstock (1978) reported X-ray diffraction evidence for such materials in oxygenated, carbonate-rich clay suspensions. Indirect evidence in the form of strong correlations between manganese and carbonate was reported by Luoma and Bryan (1981) for oxidizing estuarine sediments low in either organic materials or total iron. These authors suggested that manganese carbonate was common wherever other substrates that bind manganese were in low concentration. Filipek and Owen (1979) found that HOAc-soluble Mn was the dominant manganese form in highly oxidized, carbonaterich, surficial lacustrine sediments not containing visible manganese nodules; in contrast, in sediments from 


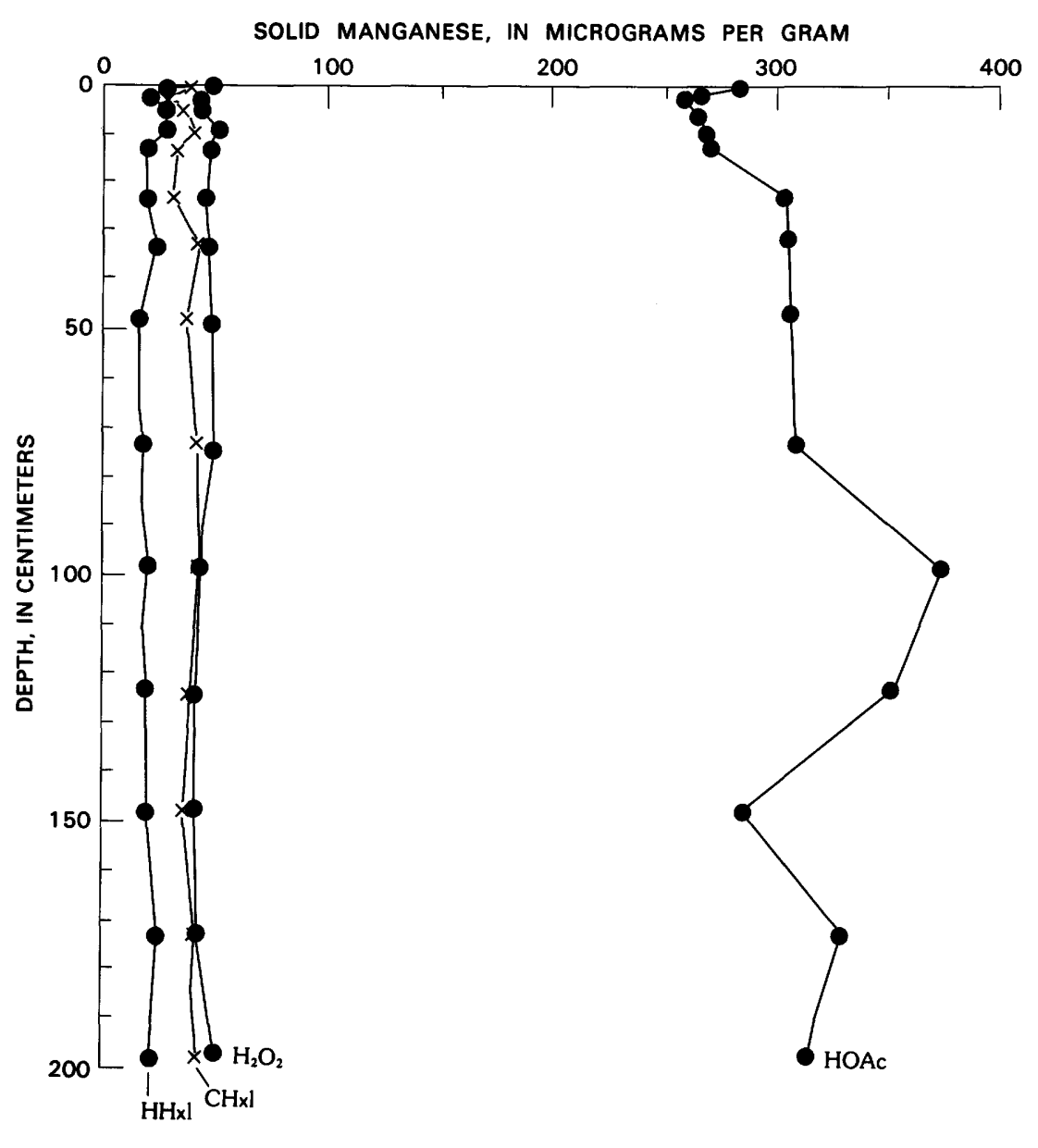

DISSOLVED MANGANESE, IN MICROGRAMS PER MILLILITER

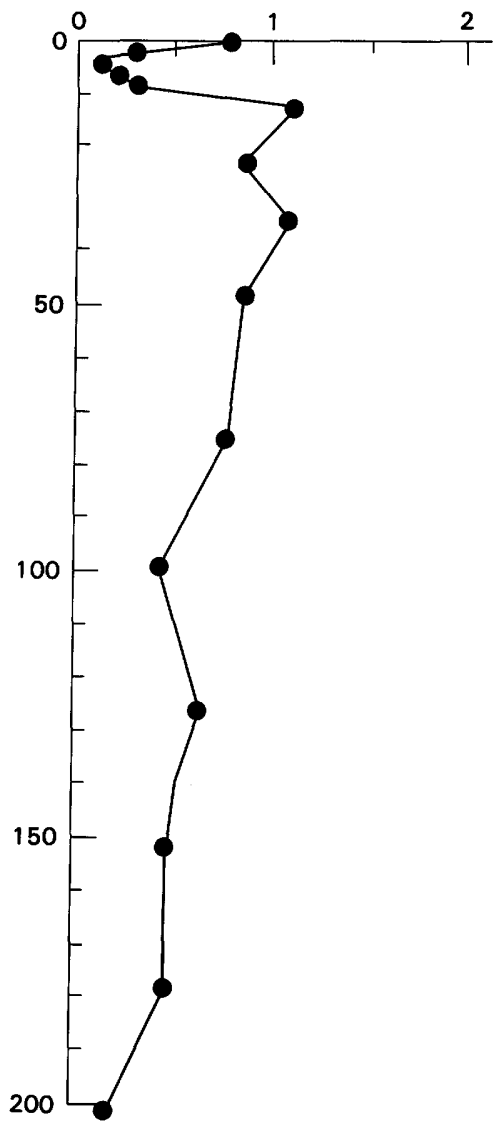

Figure 4. Distribution of nonlithogenous manganese and dissolved manganese in core 9. $\mathrm{CHxl}, \mathrm{CHxl}$-extractable manganese; $\mathrm{HHxl}, \mathrm{HHxl}$-extractable manganese; $\mathrm{H}_{2} \mathrm{O}_{2}, \mathrm{H}_{2} \mathrm{O}_{2}$-extractable manganese; HOAc, HOAc-extractable manganese. (See fig. 2 for extraction treatments.)

neighboring sites containing visible (about $1 \mathrm{~mm}$ ) nodules, the HOAc extraction dissolved very little, and the $\mathrm{CHxl}$ extraction removed most of the manganese.

A second possible explanation has been suggested by G. R. Holdren (University of Rochester, Rochester, New York, oral commun., 1980). Holdren found that finely ground manganese nodules were normally insoluble in dilute acids; however, the nodules became soluble if an aliquot of oxic marine sediment was added to the dilute acid suspension with the nodules. Holdren inferred from these results that the lowered $\mathrm{pH}$ of the extraction aided in the reduction of manganese oxides by organic materials present in the sediment.

In the present sediments, two distinct manganese phases may have been dissolved by HOAc. In the surficial oxidizing sediments, the HOAc-soluble Mn could have originated mainly from noncrystalline hydrous manganese oxides, whereas in the lower reducing portions, the HOAc-soluble $\mathrm{Mn}$ was probably from a (Ca,Mn)-carbonate. The inclusion of manganese oxides in the HOAc extract from oxidizing layers, but not from reducing layers, explains the variable relationship with depth between HOAc-soluble $\mathrm{Ca}$ and HOAc-soluble $\mathrm{Mn}$ in the cores (fig. 5). Based on high correlations with carbonate-C and an approximately $1: 1$ organic-C:HOAcsoluble $\mathrm{Ca}$ molar ratio, HOAc-soluble $\mathrm{Ca}$ represents mainly calcium carbonate in the sediments. Below about $35 \mathrm{~cm}$ in all three cores, both HOAc-soluble $\mathrm{Ca}$ and HOAc-soluble $\mathrm{Mn}$ had similar patterns, suggesting response to $\mathrm{pH}$ changes, or, more likely, the formation of a (Ca,Mn)-carbonate with a Ca:Mn molar ratio of about 80:1 (fig. 5, appendix 1).

\section{Copper}

Copper was the only element studied that varied in chemical partitioning from one core to the next. The percentage of the total copper content in the nonlithogenous components (appendix 4) varied from a 

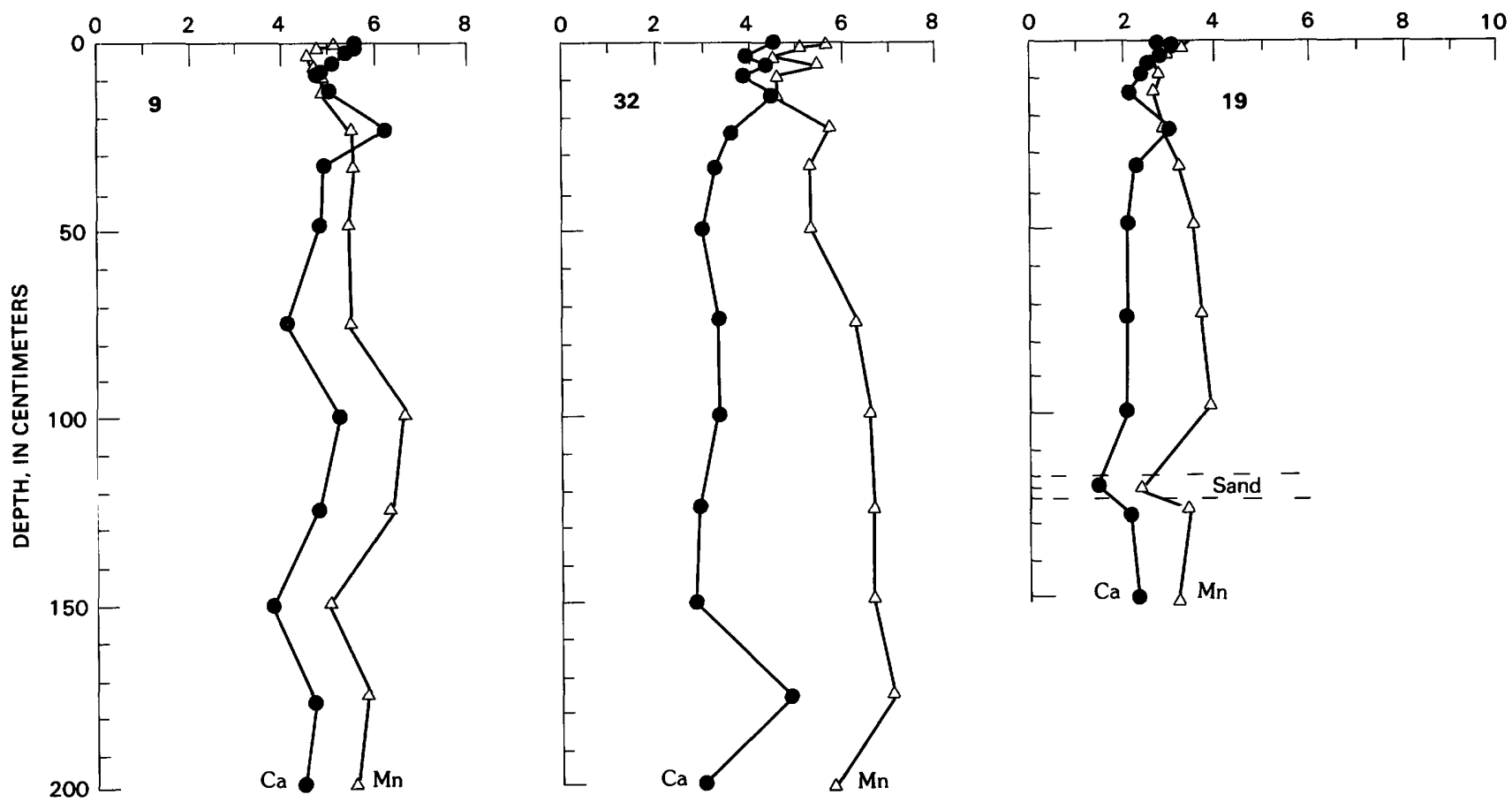

Figure 5. Distribution of HOAc-extractable manganese and calcium in cores 9, 32, and 19 (in micromoles and 100 micromoles per gram of dry sediment, respectively). (See fig. 2 for extraction treatment.) In core 19, sand lens is indicated by horizontal dashed lines.

low of about 30 percent of the total copper throughout the core taken from the shallowest, sandy-silt site icore 19 , water depth $=32 \mathrm{~m}$ ) to about 50 percent at the intermediate site (core 32, water depth $=61 \mathrm{~m}$ ) to about 65 percent at the deepest, muddy site (core 9, water depth $=112 \mathrm{~m}$ ). In all three cores, most of the nonlithogenous copper was in the $\mathrm{H}_{2} \mathrm{O}_{2}^{-}$and $\mathrm{HHxl}-$ soluble forms. In the subsurface, reduced portions of the shallowest site (site 19), $\mathrm{H}_{2} \mathrm{O}_{2}$-soluble $\mathrm{Cu}$ was clearly the dominant nonlithogenous form; at site 32, the amount of $\mathrm{H}_{2} \mathrm{O}_{2}$-soluble $\mathrm{Cu}$ was equal to or slightly greater than the amount of $\mathrm{HHxl}$-soluble $\mathrm{Cu}$; whereas at the deepest site (site 9), the amount of $\mathrm{HHxl}$-soluble $\mathrm{Cu}$ was slightly greater than that of $\mathrm{H}_{2} \mathrm{O}_{2}$-soluble $\mathrm{Cu}$ (appendix 4, fig. 6). In cores 19 and $32, \mathrm{H}_{2} \mathrm{O}_{2}$-soluble $\mathrm{Cu}$ correlated significantly with solid-S $(r=.81$ and .73 , respectively; table 1 ). These correlations strongly suggest the incorporation of copper in pyrite or the formation of ccpper sulfides (covellite or chalcocite?), which are geochemically plausible based on the similar redox stability fields of copper sulfides and pyrite (Sato and Mooney, 1960; Bolviken, 1977).

In cores 9 and 19, HOAc-soluble $\mathrm{Cu}$ and $\mathrm{C} \cdot \mathrm{Hxl}-$ soluble $\mathrm{Cu}$ were below the flame AA detection limit (about $0.01 \mu \mathrm{mol} \mathrm{Cu} / \mathrm{g}$ dry sediment). In the top $10 \mathrm{~cm}$ of core 32 , HOAc-soluble $\mathrm{Cu}$ was a significant portion of the nonlithogenous copper but decreased below this depth (appendix 5) and showed no relation to other sediment components. This trend suggests that: the
HOAc-soluble $\mathrm{Cu}$ in core 32 was in an easily exchangeable form not related to the HOAC-soluble Fe phase discussed previously.

Statistical analyses (table 1) indicate generally high positive correlations between $\mathrm{HHxl}$-soluble $\mathrm{Cu}$ and $\mathrm{HHxl}-$ soluble $\mathrm{Fe}, \mathrm{HHxl}$-soluble $\mathrm{Mn}$, and $\mathrm{CHxl}$-soluble $\mathrm{Mn}$; however, the overall correlation between copper and iron was not as strong as between zinc and iron, suggesting that iron is less influential in copper diagenesis. Moreover, the relatively large number of high correlations between copper and manganese in various extracts suggests a rather strong relation between sediment manganese and copper, even though manganese oxide was not an important phase in these sediments.

\section{Zinc}

In all three cores, the dominant nonlithogenous zinc components were $\mathrm{H}_{2} \mathrm{O}_{2}$-soluble $\mathrm{Zn}$ and $\mathrm{HHxl}$-soluble $\mathrm{Zn}$ (fig. 6, appendix 5). Statistical analyses of the $\mathrm{Zn}$ components and other sediment variables (table 1) indicate that $\mathrm{HHxl}$-soluble $\mathrm{Zn}$ is highly correlated with both $\mathrm{HHxl}$-soluble $\mathrm{Fe}$ and $\mathrm{HHxl}$-soluble $\mathrm{Mn}$ in all three cores, although less significantly so in core 32 , where $\mathrm{HHxl}-$ soluble $\mathrm{Zn}$ and $\mathrm{H}_{2} \mathrm{O}_{2}$-soluble $\mathrm{Zn}$ show a strong inverse relation. Also, HOAc-soluble $\mathrm{Zn}$ has a high positive correlation with HOAc-soluble $\mathrm{Fe}$, especially in low-sulfide cores 9 and 32, suggesting that HOAc-soluble $\mathrm{Zn}$ was 

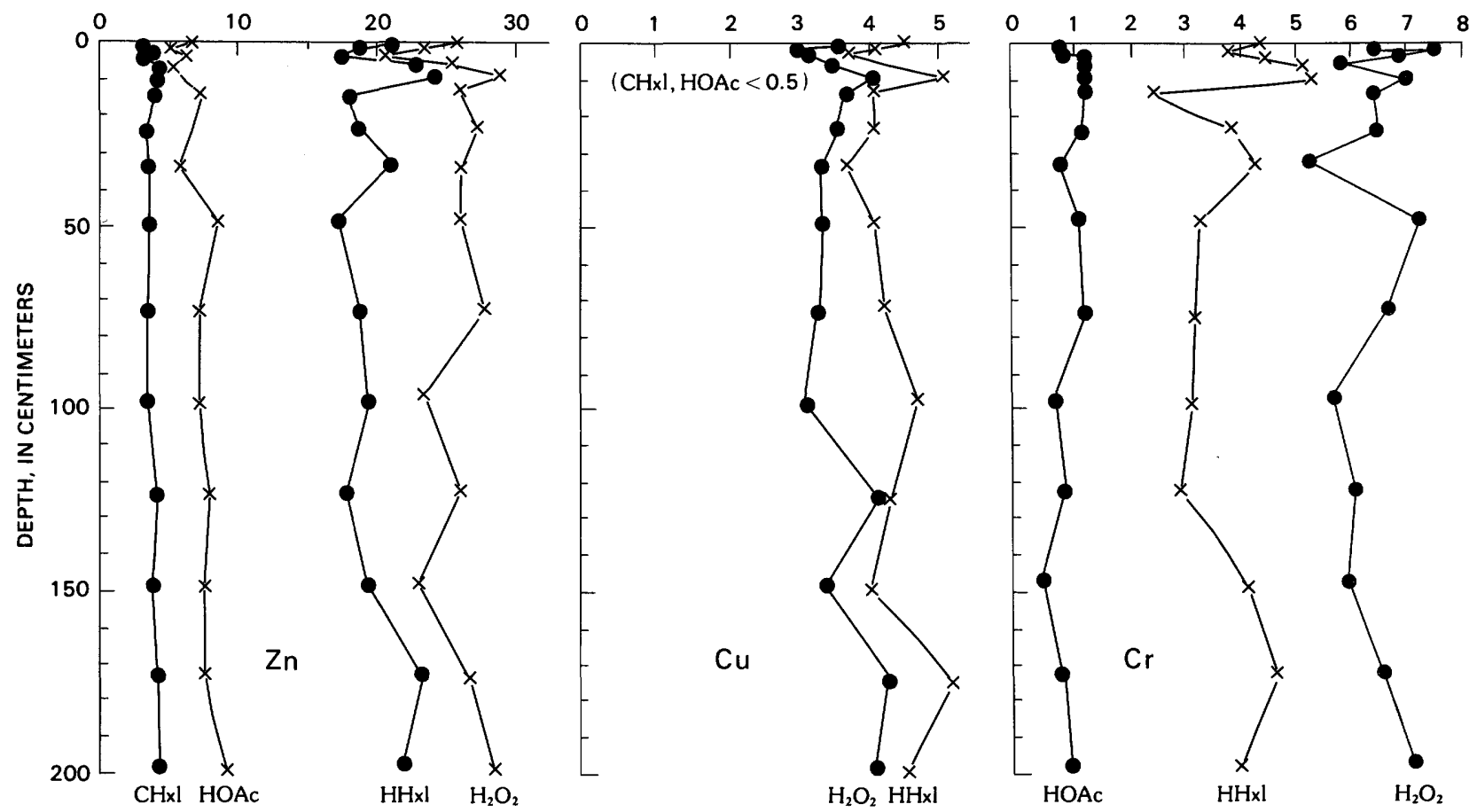

Figure 6. Distribution of nonlithogenous $\mathrm{Zn}, \mathrm{Cu}$, and $\mathrm{Cr}$ in core 9 (in micrograms per gram of dry sediment). $\mathrm{CHxl}, \mathrm{CHxl}$ extractable; $\mathrm{HHxl}$, $\mathrm{HHxl}$-extractable; $\mathrm{H}_{2} \mathrm{O}_{2}$-extractable; $\mathrm{HOAc}$, $\mathrm{HOAc}$-extractable; $\mathrm{H}_{2} \mathrm{O}_{2}, \mathrm{H}_{2} \mathrm{O}_{2}$-extractable. (See fig. 2 for extraction treatments.)

associated with the reduced iron component discussed previously rather than existing as a zinc carbonate. Here also, the relation between zinc and iron indicates the large control that iron had on zinc diagenesis, due to coprecipitation and(or) adsorption processes. The strong relationship between zinc and iron has been reported previously for pelagic sediments by Forstner and Stoffers (1981).

Iron was not the only controlling factor in zinc partitioning, however, because a large part (about $30-50$ percent) of the nonlithogenous zinc was in the $\mathrm{H}_{2} \mathrm{O}_{2}$-soluble extract of all three cores. The zinc in this extract could have come from either an organic complex or a zinc sulfide. Significant correlations between $\mathrm{H}_{2} \mathrm{O}_{2}$-soluble $\mathrm{Zn}$ and solid-S in core 32 (table 1) suggest the presence of zinc sulfide (or $\mathrm{Zn}$ substitution in pyrite) in this core. Sphalerite was probably not in equilibrium in these sediments because its redox stability field is much lower than that expected for these sediments (Bolviken, 1977). On the other hand, wurtzite has been reported in marine sediments (R. Koski, U.S. Geological Survey, Menlo Park, California, oral commun., 1982), and extrapolation of the work of Scott and Barnes (1972) to low temperatures suggests a stability field for wurtzite at higher redox potentials than for sphalerite. For cores 9 and $19, \mathrm{H}_{2} \mathrm{O}_{2}$-soluble $\mathrm{Zn}$ shows no correlation with
solid-S (table 1), nor is it significantly correlated with organic-C. Presley and others (1972) also found no correlation between zinc and organic-C in sediments where they expected that zinc should be the metal most closely associated with organic matter, due to the high concentration of zinc in plankton.

In the present study, no element in any one extract was found to correlate consistently with organic-C content. This lack of correlation could be due to the fact that none of the extractions used effectively removed all metals complexed with organic matter, because the type and strength of the metal-organic bond varied both with the metal and the organic compound. Another possible explanation is that the method used for measuring organic-C, in which sediments were left overnight in 1 $M \mathrm{HCl}$ to dissolve carbonates, gave inaccurate results for organic-C (Froelich, 1980). Alternatively, the lack of correlation between organic- $\mathrm{C}$ and metals in the $\mathrm{H}_{2} \mathrm{O}_{2}$ extract (or any extract) could have been due to differential breakdown of the various types of bonds during diagenesis. In this connection, Price (1976) reported that the metal/organic- $\mathrm{C}$ ratios for $\mathrm{Zn}, \mathrm{Cu}$, and $\mathrm{Pb}$ decreased sharply with depth in rapidly accumulating marine sediments of uniform lithology from Loch Fyne, Scotland. Because the Loch Fyne sediments were oxic, yet contained little manganese or iron hydroxides, Price 
suggested that this decrease was due to breakdown and release of metal-organic substances from the sediment during burial, with rates of release decreasing in the order $\mathrm{Zn}>\mathrm{Cu}>\mathrm{Pb}$. If such differential breakdown is indeed common during diagenesis, organic- $\mathrm{C}$ and organically bound metals should not be linearly correlated throughout the sediment column.

\section{Chromium}

Nonlithogenous chromium accounted for only 1020 percent of the total metal content, making chromium the least chemically available of the metals studied. In all three cores, $\mathrm{H}_{2} \mathrm{O}_{2}$-soluble $\mathrm{Cr}$ was the dominant nonlithogenous chromium component, followed by $\mathrm{HHxl}-$ soluble $\mathrm{Cr}$ (fig. 6, appendix 6). The amount of chromium extracted by HOAc was small in cores 19 and 9 and below the flame AA detection limit (about $0.01 \mu \mathrm{mol} \mathrm{Cr} / \mathrm{g}$ dry sediment) in core 32 , as was the $\mathrm{CHxl}$-soluble $\mathrm{Cr}$ in all three cores. The $\mathrm{H}_{2} \mathrm{O}_{2}$-soluble $\mathrm{Cr}$ showed generally high correlations with organic-Fe, suggesting that much of the chromiurn was associated with organic material. In certain parts of all three cores, there was an indication of opposing behavior of $\mathrm{H}_{2} \mathrm{O}_{2}$-soluble $\mathrm{Cr}$ and $\mathrm{HHxl}$-soluble $\mathrm{Cr}$ (fig. 6, appendix 6), although there was no significant negative correlation throughout the cores.

Chromium is sensitive to redox conditions and can exist in natural environments in both the $\mathrm{Cr}^{3+}$ and $\mathrm{Cr}^{6+}$ states. The higher oxidation state exists mainly as the chromate $\left(\mathrm{CrO}_{4}{ }^{2-}\right)$ or dichromate $\left(\mathrm{Cr}_{2} \mathrm{O}_{7}{ }^{2-}\right)$ species in oxidizing aqueous environments (Canter and Gloyna, 1968); however, upon contact with sediments, these species may be reduced to the much more reactive $\mathrm{Cr}^{3+}$ state, which complexes readily with organics and sorbs in hydrous form to other sediment particles (Cotton and Wilkinson, 1972). The transfer of chromium between the $\mathrm{H}_{2} \mathrm{O}_{2}$-soluble and $\mathrm{HHxl}$-soluble components with changes in redox environment in the present cores could have been due to competition between organic materials and hydrous iron oxides for the reactive $\mathrm{Cr}^{3+}$.

\section{CONCLUSIONS}

The outer continental-shelf sediments of the Gulf of Mexico represent an environment transitional between (1) organic-poor pelagic sediments, in which organic matter decomposition involved reduction of oxygen, hydrous manganese oxides, and hydrous iron oxides over a large depth range in the sediment column, and (2) organic-rich nearshore sediments, in which sulfate is the major oxidant and pyrite production is essentially complete within the uppermost few centimeters. In these outer-shelf sediments, hydrous iron oxides were the major oxidant of organic matter throughout the uppermost two meters, and sulfate reduction was relatively minor. Reduction of manganese oxides appears to have been confined to the sediment surface; thus most manganese in the sediment was HOAc-soluble and probably represents a $(\mathrm{Ca}, \mathrm{Mn})-$ carbonate phase. Therefore, in the outershelf sediments, iron diagenesis was able to exert a significant control over the chemical partitioning of copper, zinc, and chromium due to coprecipitation, dissolution, and adsorption processes, whereas the role of manganese was minor, except possibly at the sediment surface. The extent of control by iron, however, varied with both the metal and, to a lesser extent, location on the shelf.

The major control on the mobility of copper and zinc in the subsurface anoxic sediments appears to have been the formation of sulfide phases. These trace metals either were incorporated into pyrite or formed separate sulfide minerals, and they did so even though sulfate reduction was minor and reduced $\mathrm{Fe}$ was in excess over sulfide. Such an affinity of sulfide for copper and zinc suggests that anoxic sediments could provide an efficient sink for these metals in other relatively low-sulfur environments, such as estuaries or swamps.

\section{REFERENCES CITED}

Berryhill, H. L., Jr., ed., 1976, Environmental studies, South Texas Outer Continental Shelf, 1975, Geology: National Technical Information Service Report PB251-341, 269 p.

Binstock, J. H., 1978, Experimental investigation of silica and manganese sorption onto clay, carbonate, and amorphous silica: 1978 Annual Meeting, Geological Society of America, Abstracts with Programs 10, p. 367.

Bolviken, Bjorn, 1977, The redox potential field of the earth, in Ahrens, L. H., ed., Origin and distribution of the elements, Proceedings of 2d Symposium, Paris, May 1977: New York, Pergamon Press, p. 649-665.

Canter, L. W., and Gloyna, E. F., 1968, Transport of chromium-51 in an organically polluted environment: Engineering Bulletin, Purdue University, Engineering Extension Service, no. 132, pt. 1, p. 374-387.

Chao, T. T., 1972, Selective dissolution of manganese oxides from soils and sediments with acidified hydroxylamine hydrochloride: Soil Science Society of America Proceedings, v. 36, p. 764-768.

Chester, R., and Hughes, M. J., 1967, A chemical technique for the separation of ferromanganese minerals, carbonate minerals, and adsorbed trace elements for pelagic sediments: Chemical Geology, v. 2, p. 249-262.

Cotton, F. A., and Wilksinson, G., 1972, Advanced inorganic chemistry (3d ed.): New York, Wiley-Interscience, 1145 p.

Filipek, L. H., and Owen, R. M., 1978, Analysis of heavy-metal distributions among different mineralogical states in sediments: Canadian Journal of Spectroscopy, v. 23, p. 31-34.

1979 , Geochemical associations and grain-size partitioning of heavy metals in lacustrine sediments: Chemical Geology, v. 26, p. 105-117. 
1980, Early diagenesis of organic carbon and sulfur in outer-shelf sediments from the Gulf of Mexico: American Journal of Science, v. 280, p. 1097-1112.

1981, Diagenetic controls of phosphorus in outer continental-shelf sediments from the Gulf of Mexico: Chemical Geology, v. 33, p. 181-204.

Forstner, Ulrich, and Stoffers, Peter, 1981, Chemical fractionation of transition elements in Pacific pelagic sediments: Geochimica et Cosmochimica Acta, v. 45, p. 1141-1146.

Froelich, P. N., 1980, Analysis of organic carbon in marine sediments: Limnology and Oceanography. v. 25, p. 564-572.

Froelich, P. N., Klinkhammer, G. P., Bender, M. L., Luedtke, N. A., Heath, G. R., Cullen, D., Dauphin, P., Hammond, D., Hartman, B., and Maynard, V., 1979, Early oxidation of organic matter in pelagic sediments of the eastern equatorial Atlantic-Suboxic diagenesis: Geochimica et Cosmochimica Acta, v. 43, p. 1075-1090.

Goldhaber, M. B., Aller, R. C., Cochran, J. K., Rosenfeld, J. K., Martens, C. S., and Berner, R. A., 1977, Sulfate reduction, diffusion, and bioturbation in Long Island Sound sediments-Report of the FOAM group: American Journal of Science, v. 277, p. 193-237.

Hamilton-Taylor, John, 1979, Enrichments of zinc, lead, and copper in recent sediments of Windermere, England: Environmental Science and Technology, v. 13, p. 693-697.

Holdren, G. R., Jr., Bricker, O. P., 3d, and Matisoff, G., 1975, A model for the control of dissolved $\mathrm{Mn}$ in the interstitial waters of Chesapeake Bay, Washington, D. C., in Church, T., ed., Marine chemistry in the coastal environment: Washington, D.C., American Chemical Society, p. 364-381.

Holmes, C. W., and Martin, E. A., 1978, Migration of anthropogenically induced trace metals (barium and lead) in a continental shelf environment, in Proceedings of the 4th joint conference on sensing environmental pollutants, New Orleans, November 1977: Washington, D.C., American Chemical Society, p. 672-676.
Luoma, S. N., and Bryan, G. W., 1981, A statistical assessment of the form of trace metals in oxidized estuarine sediments employing chemical extractants: Science of Total Environment, v. 17, p. 165-196.

Nriagu, J. O., Kemp, A. L. W., Wong, H. K. T., and Harper, N., 1979, Sedimentary record of heavy-metal pollution in Lake Erie: Geochimica et Cosmochimica Acta, v. 43, p. 247-258.

Pedersen, T. F., and Price, N. B., 1982, The geochemistry of manganese carbonate in Panama Basin sediments: Geochimica et Cosmochimica Acta, v. 46, p. 59-68.

Presley, B. J., Kolodny, Y., Nissenbaum, A., and Kaplan, I. R., 1972, Early diagenesis in a reducing fjord, Saanich Inlet, British Columbia-II. Trace element distribution in interstitial water and sediment: Geochimica et Cosmochimica Acta, v. 36, p. 1073-1090.

Price, N. B., 1976, Chemical diagenesis in sediments, in Riley, J. P., and Chester, R., eds., Chemical oceanography, v. 6: New York, Academic Press, p. 158.

Robbins, J. A., and Callender, E., 1975, Diagenesis of manganese in Lake Michigan sediment: American Journal of Science, v. 275, p. 512-522.

Sato, Motoaki, and Mooney, H. M., 1960, The electrochemical mechanism of sulfide self-potential: Geophysics, v. 25, p. 226-249.

Scott, S. D., and Barnes, H. L., 1972, Sphalerite-wurtzite equilibria and stoichiometry: Geochimica et Cosmochimica Acta, v. 36, p. 1275-1295.

Stumm, W., and Morgan, J. J., 1970, Aquatic chemistry: New York, Wiley Interscience, 583 p.

Suess, Erwin, 1979, Mineral phases formed in anoxic sediments by microbial decomposition of organic matter: Geochimica et Cosmochimica Acta, v. 43, p. 339-352.

Williams, J. D. H., Syers, J. K., Shukla, S. S., Harris, R. F., and Armstrong, D. E., 1971, Levels of inorganic and total phosphorus in lake sediments as related to other sediment parameters: Environmental Science and Technology, p. 1113-1120. 
Appendix 1. Concentrations of organic-C, carbonate-C, HOAC-soluble Ca, and solid-S; and dissolved sulfate, $\mathrm{Fe}$, and $\mathrm{Mn}$

[mM, millimolar; $\mu M$, micromolar]

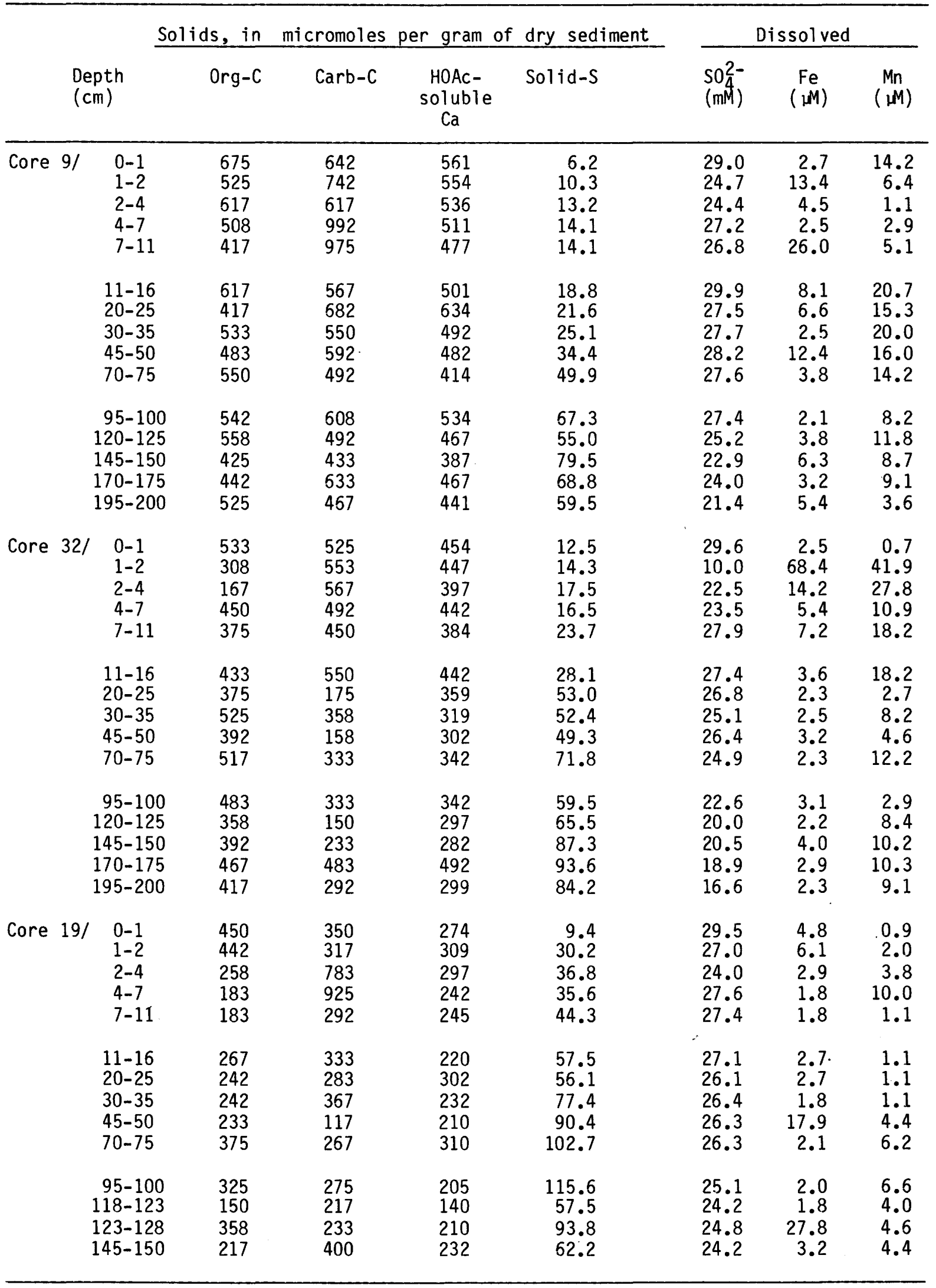


Appendix 2. Concentrations of iron in extracts from cores 9, 32, and 19 [in micromoles Fe per gram dry sediment; n.a., not analyzed]

\begin{tabular}{|c|c|c|c|c|c|c|c|c|c|}
\hline \multicolumn{2}{|c|}{ Depth $(\mathrm{cm})$} & \multirow{2}{*}{$\begin{array}{l}\text { HOAC } \\
28.7 \\
31.3 \\
48.9 \\
28.2 \\
39.3\end{array}$} & \multirow{2}{*}{$\begin{array}{c}\mathrm{CH} \times 1 \\
9.2 \\
8.5 \\
5.6 \\
8.3 \\
7.9\end{array}$} & \multirow{2}{*}{$\begin{array}{c}\mathrm{H}_{2} \mathrm{O}_{2} \\
9.3 .8 \\
114 . \\
101 . \\
94.7 \\
108 .\end{array}$} & \multirow{2}{*}{$\begin{array}{c}\text { Org } \\
90.7 \\
109 \\
94.8 \\
87.6 \\
101 .\end{array}$} & \multirow{2}{*}{$\begin{array}{c}H H \times 1 \\
122 \\
95.9 \\
94.4 \\
132 . \\
138 .\end{array}$} & \multirow{2}{*}{$\begin{array}{l}\text { Lith } \\
406 \\
378 \\
326 \\
407 \\
399\end{array}$} & \multirow{2}{*}{$\begin{array}{l}\text { Sum }^{1} \\
660 \\
627 \\
576 \\
669 \\
692\end{array}$} & \multirow{2}{*}{$\begin{array}{c}\text { Total } \\
574 \\
541 \\
530 \\
577 \\
557\end{array}$} \\
\hline Core 9/ & $\begin{array}{l}0-1 \\
1-2 \\
2-4 \\
4-7 \\
7-11\end{array}$ & & & & & & & & \\
\hline & $\begin{array}{l}11-16 \\
20-25 \\
30-35 \\
45-50 \\
70-75\end{array}$ & $\begin{array}{l}59.0 \\
51.7 \\
37.9 \\
63.5 \\
60.8\end{array}$ & $\begin{array}{l}6.0 \\
6.1 \\
8.0 \\
6.2 \\
6.8\end{array}$ & $\begin{array}{c}96.7 \\
102 . \\
97.3 \\
93.3 \\
111 .\end{array}$ & $\begin{array}{l}87.4 \\
91.3 \\
84.8 \\
76.1 \\
86.1\end{array}$ & $\begin{array}{r}90.7 \\
98.7 \\
117 . \\
92.7 \\
88.3\end{array}$ & $\begin{array}{l}368 \\
321 \\
401 \\
363 \\
403\end{array}$ & $\begin{array}{l}621 \\
580 \\
661 \\
619 \\
670\end{array}$ & $\begin{array}{l}548 \\
577 \\
578 \\
585 \\
593\end{array}$ \\
\hline & $\begin{array}{r}95-100 \\
120-125 \\
145-150 \\
170-175 \\
195-200\end{array}$ & $\begin{array}{l}52.3 \\
60.2 \\
50.1 \\
50.1 \\
54.1\end{array}$ & $\begin{array}{l}5.5 \\
6.5 \\
5.7 \\
6.1 \\
6.9\end{array}$ & $\begin{array}{r}90.9 \\
74.3 \\
81.1 \\
95.5 \\
103 .\end{array}$ & $\begin{array}{l}57.3 \\
46.8 \\
41.4 \\
61.1 \\
73.0\end{array}$ & $\begin{array}{l}99.4 \\
100.5 \\
104.4 \\
121 . \\
110 .\end{array}$ & $\begin{array}{l}449 \\
382 \\
369 \\
342 \\
417\end{array}$ & $\begin{array}{l}697 \\
624 \\
610 \\
616 \\
690\end{array}$ & $\begin{array}{l}598 \\
582 \\
529 \\
549 \\
592\end{array}$ \\
\hline \multirow[t]{3}{*}{ Core $32 /$} & $\begin{array}{l}0-1 \\
1-2 \\
2-4 \\
4-7 \\
7-11\end{array}$ & $\begin{array}{l}16.1 \\
19.9 \\
17.0 \\
34.6 \\
30.9\end{array}$ & $\begin{array}{r}8.7 \\
8.3 \\
8.2 \\
10.3 \\
8.1\end{array}$ & $\begin{array}{l}87.1 \\
91.6 \\
83.5 \\
84.6 \\
73.1\end{array}$ & $\begin{array}{l}80.8 \\
84.4 \\
74.7 \\
76.3 \\
61.2\end{array}$ & $\begin{array}{l}93.5 \\
93.3 \\
82.7 \\
118 . \\
121 .\end{array}$ & $\begin{array}{l}299 \\
288 \\
\text { n.a. } \\
\text { n.a. } \\
316\end{array}$ & $\begin{array}{l}504 \\
501 \\
\text { n.a. } \\
\text { n.a. } \\
549\end{array}$ & $\begin{array}{l}533 \\
386 \\
n . a . \\
529 \\
432\end{array}$ \\
\hline & $\begin{array}{l}11-16 \\
20-25 \\
30-35 \\
45-50 \\
70-75\end{array}$ & $\begin{array}{l}39.7 \\
51.6 \\
59.4 \\
66.5 \\
66.7\end{array}$ & $\begin{array}{l}8.1 \\
6.0 \\
8.4 \\
7.7 \\
9.9\end{array}$ & $\begin{array}{r}89.7 \\
95.5 \\
89.3 \\
101 . \\
84.0\end{array}$ & $\begin{array}{l}75.7 \\
69.0 \\
63.1 \\
76.5 \\
47.8\end{array}$ & $\begin{array}{l}97.1 \\
90.6 \\
93.8 \\
88.7 \\
75.6\end{array}$ & $\begin{array}{l}\text { n.a. } \\
290 \\
\text { n.a. } \\
\text { n.a. } \\
318\end{array}$ & $\begin{array}{l}\text { n.a. } \\
534 \\
\text { n.a. } \\
\text { n.a. } \\
554\end{array}$ & $\begin{array}{l}509 \\
511 \\
541 \\
466 \\
554\end{array}$ \\
\hline & $\begin{array}{r}95-100 \\
120-125 \\
145-150 \\
170-175 \\
195-200\end{array}$ & $\begin{array}{l}49.1 \\
55.2 \\
35.6 \\
29.0 \\
40.4\end{array}$ & $\begin{array}{l}7.3 \\
7.2 \\
6.0 \\
4.2 \\
6.0\end{array}$ & $\begin{array}{r}93.6 \\
89.1 \\
101 . \\
90.1 \\
116.9\end{array}$ & $\begin{array}{l}63.8 \\
55.8 \\
56.6 \\
43.3 \\
74.5\end{array}$ & $\begin{array}{r}88.5 \\
81.9 \\
98.2 \\
117 . \\
97.7\end{array}$ & $\begin{array}{l}576 \\
345 \\
388 \\
394 \\
316\end{array}$ & $\begin{array}{l}815 \\
579 \\
628 \\
634 \\
577\end{array}$ & $\begin{array}{l}588 \\
538 \\
515 \\
588 \\
530\end{array}$ \\
\hline \multirow[t]{3}{*}{ Core 19/ } & $\begin{array}{l}0-1 \\
1-2 \\
2-4 \\
4-7 \\
7-11\end{array}$ & $\begin{array}{l}10.4 \\
17.7 \\
22.5 \\
27.5 \\
32.1\end{array}$ & $\begin{array}{r}13.5 \\
9.0 \\
6.2 \\
5.0 \\
4.8\end{array}$ & $\begin{array}{c}84.0 \\
102 . \\
89.8 \\
79.5 \\
105 .\end{array}$ & $\begin{array}{l}79.2 \\
87.4 \\
71.4 \\
61.7 \\
83.1\end{array}$ & $\begin{array}{r}122 . \\
75.3 \\
61.5 \\
49.5 \\
67.5\end{array}$ & $\begin{array}{l}218 \\
246 \\
193 \\
162 \\
201\end{array}$ & $\begin{array}{l}448 \\
451 \\
373 \\
324 \\
410\end{array}$ & $\begin{array}{l}413 \\
381 \\
323 \\
315 \\
331\end{array}$ \\
\hline & $\begin{array}{l}11-16 \\
20-25 \\
30-35 \\
45-50 \\
70-75\end{array}$ & $\begin{array}{l}35.6 \\
34.1 \\
34.7 \\
30.0 \\
40.2\end{array}$ & $\begin{array}{l}4.8 \\
3.9 \\
5.4 \\
5.0 \\
8.5\end{array}$ & $\begin{array}{c}88.3 \\
89.2 \\
119 . \\
84.3 \\
71.7\end{array}$ & $\begin{array}{l}59.6 \\
61.2 \\
80.6 \\
39.0 \\
20.4\end{array}$ & $\begin{array}{l}80.4 \\
83.8 \\
90.4 \\
70.9 \\
95.9\end{array}$ & $\begin{array}{l}194 \\
223 \\
227 \\
213 \\
287\end{array}$ & $\begin{array}{l}403 \\
434 \\
477 \\
403 \\
503\end{array}$ & $\begin{array}{l}383 \\
408 \\
397 \\
400 \\
419\end{array}$ \\
\hline & $\begin{array}{r}95-100 \\
118-123 \\
123-128 \\
145-150\end{array}$ & $\begin{array}{l}35.0 \\
17.8 \\
24.3 \\
20.4\end{array}$ & $\begin{array}{l}9.0 \\
5.2 \\
5.4 \\
4.7\end{array}$ & $\begin{array}{c}102 . \\
95.5 \\
113 . \\
129 .\end{array}$ & $\begin{array}{l}44.9 \\
66.8 \\
66.3 \\
85.7\end{array}$ & $\begin{array}{l}69.3 \\
34.7 \\
94.2 \\
67.9\end{array}$ & $\begin{array}{l}308 \\
156 \\
272 \\
183\end{array}$ & $\begin{array}{l}524 \\
310 \\
509 \\
406\end{array}$ & $\begin{array}{l}417 \\
293 \\
476 \\
417\end{array}$ \\
\hline
\end{tabular}

${ }^{1}$ Sum $=$ sum of values of all extractions; Total = value of a separate total extraction. 
Appendix 3. Concentrations of manganese in extracts from cores 9, 32, and 19 [in micromoles Mn per gram dry sediment; n.a., not analyzed]

\begin{tabular}{|c|c|c|c|c|c|c|c|c|}
\hline \multicolumn{2}{|c|}{ Depth $(\mathrm{cm})$} & \multirow{2}{*}{$\begin{array}{c}\text { HOAC } \\
5.11 \\
4.75 \\
4.62 \\
4.73 \\
4.80\end{array}$} & \multirow{2}{*}{$\begin{array}{r}\text { CHxl } \\
0.71 \\
.53 \\
.47 \\
.67 \\
.74\end{array}$} & \multirow{2}{*}{$\begin{array}{r}\mathrm{H}_{2} \mathrm{O}_{2} \\
0.85 \\
.87 \\
.75 \\
.78 \\
.96\end{array}$} & \multirow{2}{*}{$\begin{array}{r}H H x\rceil \\
0.48 \\
.38 \\
.38 \\
.50 \\
.52\end{array}$} & \multirow{2}{*}{$\begin{array}{l}\text { Lith } \\
1.41 \\
1.27 \\
1.19 \\
1.36 \\
1.34\end{array}$} & \multirow{2}{*}{$\begin{array}{l}\text { Sum } \\
\end{array}$} & \multirow{2}{*}{$\begin{array}{c}\text { Total }^{1} \\
7.54 \\
7.18 \\
6.76 \\
7.41 \\
7.40\end{array}$} \\
\hline Core 9/ & $\begin{array}{l}0-1 \\
1-2 \\
2-4 \\
4-7 \\
7-11\end{array}$ & & & & & & & \\
\hline & $\begin{array}{l}11-15 \\
20-25 \\
30-35 \\
45-50 \\
70-75\end{array}$ & $\begin{array}{l}4.86 \\
5.50 \\
5.50 \\
5.50 \\
5.55\end{array}$ & $\begin{array}{l}.58 \\
.56 \\
.76 \\
.69 \\
.77\end{array}$ & $\begin{array}{l}.84 \\
.82 \\
.84 \\
.87 \\
.89\end{array}$ & $\begin{array}{l}.35 \\
.36 \\
.45 \\
.28 \\
.35\end{array}$ & $\begin{array}{l}1.23 \\
.97 \\
1.29 \\
1.15 \\
1.26\end{array}$ & $\begin{array}{l}7.85 \\
8.21 \\
8.83 \\
8.49 \\
8.83\end{array}$ & $\begin{array}{l}7.49 \\
8.25 \\
8.54 \\
8.17 \\
8.04\end{array}$ \\
\hline & $\begin{array}{r}95-100 \\
120-125 \\
145-150 \\
170-175 \\
195-200\end{array}$ & $\begin{array}{l}6.72 \\
6.32 \\
5.13 \\
5.90 \\
5.64\end{array}$ & $\begin{array}{l}.77 \\
.71 \\
.67 \\
.74 \\
.77\end{array}$ & $\begin{array}{l}.80 \\
.75 \\
.76 \\
.78 \\
.90\end{array}$ & $\begin{array}{l}.36 \\
.35 \\
.37 \\
.49 \\
.41\end{array}$ & $\begin{array}{l}1.34 \\
1.24 \\
1.21 \\
1.14 \\
1.23\end{array}$ & $\begin{array}{l}9.98 \\
9.36 \\
8.14 \\
9.05 \\
8.95\end{array}$ & $\begin{array}{l}9.37 \\
8.25 \\
7.43 \\
7.56 \\
8.31\end{array}$ \\
\hline Core $32 /$ & $\begin{array}{l}0-1 \\
1-2 \\
2-4 \\
4-7 \\
7-11\end{array}$ & $\begin{array}{l}5.73 \\
5.13 \\
4.53 \\
5.51 \\
4.54\end{array}$ & $\begin{array}{l}0.78 \\
.60 \\
.54 \\
.73 \\
.63\end{array}$ & $\begin{array}{l}0.93 \\
.73 \\
.64 \\
.75 \\
.71\end{array}$ & $\begin{array}{r}0.43 \\
.49 \\
.40 \\
.56 \\
.51\end{array}$ & $\begin{array}{l}1.38 \\
1.69 \\
n . a . \\
n . a . \\
1.54\end{array}$ & $\begin{array}{l}9.26 \\
8.65 \\
\text { n.a. } \\
\text { n.a. } \\
8.03\end{array}$ & $\begin{array}{l}8.70 \\
4.55 \\
\text { n.a. } \\
7.60 \\
5.22\end{array}$ \\
\hline & $\begin{array}{l}11-16 \\
20-25 \\
30-35 \\
45-50 \\
70-75\end{array}$ & $\begin{array}{l}4.55 \\
5.75 \\
5.26 \\
5.33 \\
6.28\end{array}$ & $\begin{array}{l}.64 \\
.72 \\
.85 \\
.83 \\
.97\end{array}$ & $\begin{array}{l}.71 \\
.71 \\
.75 \\
.76 \\
.78\end{array}$ & $\begin{array}{l}.52 \\
.49 \\
.52 \\
.50 \\
.34\end{array}$ & $\begin{array}{l}n . a_{1} \\
1.26 \\
n . a_{0} \\
n . a_{0} \\
1.27\end{array}$ & $\begin{array}{l}\text { n.a. } \\
8.93 \\
n . a . \\
n . a . \\
9.65\end{array}$ & $\begin{array}{l}5.83 \\
6.36 \\
7.63 \\
7.39 \\
8.17\end{array}$ \\
\hline & $\begin{array}{r}95-100 \\
120-125 \\
145-150 \\
170-175 \\
195-200\end{array}$ & $\begin{array}{l}6.57 \\
6.72 \\
6.64 \\
7.03 \\
5.84\end{array}$ & $\begin{array}{l}1.02 \\
1.01 \\
1.20 \\
1.03 \\
.96\end{array}$ & $\begin{array}{l}1.00 \\
.87 \\
.98 \\
.93 \\
.95\end{array}$ & $\begin{array}{l}.42 \\
.39 \\
.43 \\
.52 \\
.44\end{array}$ & $\begin{array}{l}1.90 \\
1.47 \\
1.49 \\
1.42 \\
1.11\end{array}$ & $\begin{array}{c}10.9 \\
10.5 \\
10.8 \\
10.9 \\
9.30\end{array}$ & $\begin{array}{l}9.18 \\
8.31 \\
7.18 \\
7.77 \\
8.07\end{array}$ \\
\hline Core 19/ & $\begin{array}{l}0-1 \\
1-2 \\
2-4 \\
4-7 \\
7-11\end{array}$ & $\begin{array}{l}8.61 \\
3.24 \\
2.97 \\
2.51 \\
2.71\end{array}$ & $\begin{array}{l}1.59 \\
.59 \\
.44 \\
.40 \\
.47\end{array}$ & $\begin{array}{l}1.38 \\
.99 \\
.76 \\
.69 \\
.84\end{array}$ & $\begin{array}{l}0.40 \\
.26 \\
.22 \\
.17 \\
.21\end{array}$ & $\begin{array}{l}1.12 \\
1.18 \\
1.00 \\
.97 \\
1.29\end{array}$ & $\begin{array}{c}13.1 \\
6.26 \\
5.39 \\
4.75 \\
5.54\end{array}$ & $\begin{array}{c}11.5 \\
5.28 \\
4.58 \\
4.24 \\
4.32\end{array}$ \\
\hline & $\begin{array}{l}11-16 \\
20-25 \\
30-35 \\
45-50 \\
70-75\end{array}$ & $\begin{array}{l}2.69 \\
2.89 \\
3.24 \\
3.51 \\
3.73\end{array}$ & $\begin{array}{l}.46 \\
.49 \\
.61 \\
.64 \\
.80\end{array}$ & $\begin{array}{l}.71 \\
.76 \\
.84 \\
.75 \\
.76\end{array}$ & $\begin{array}{l}.30 \\
.33 \\
.30 \\
.24 \\
.17\end{array}$ & $\begin{array}{l}1.20 \\
1.09 \\
1.20 \\
1.06 \\
1.35\end{array}$ & $\begin{array}{l}5.36 \\
5.56 \\
6.20 \\
6.21 \\
6.82\end{array}$ & $\begin{array}{l}4.22 \\
4.85 \\
5.09 \\
5.41 \\
5.52\end{array}$ \\
\hline & $\begin{array}{r}95-100 \\
118-123 \\
123-128 \\
145-150\end{array}$ & $\begin{array}{l}3.84 \\
2.31 \\
3.42 \\
3.15\end{array}$ & $\begin{array}{l}.86 \\
.50 \\
.72 \\
.55\end{array}$ & $\begin{array}{r}.88 \\
.76 \\
.95 \\
1.04\end{array}$ & $\begin{array}{l}.22 \\
.12 \\
.35 \\
.18\end{array}$ & $\begin{array}{r}1.36 \\
1.04 \\
1.23 \\
.88\end{array}$ & $\begin{array}{l}7.16 \\
4.73 \\
6.67 \\
5.81\end{array}$ & $\begin{array}{l}5.11 \\
4.21 \\
5.96 \\
5.43\end{array}$ \\
\hline
\end{tabular}

${ }^{1}$ Sum $=$ sum of values of all extractions; Total = value of a separate total extraction. 
Appendix 4. Concentrations of $\mathrm{Cu}$ in in extracts from cores 9, 32, and 19 [in micromoles $\mathrm{Cu}$ per gram dry sediment; HOAC-soluble and CHxi-soluble $\mathrm{Cu}$ generally below detection limit; n.a., not analyzed]

\begin{tabular}{|c|c|c|c|c|c|c|c|}
\hline Depth & $(\mathrm{cm})$ & $\mathrm{HOAC}$ & $\mathrm{H}_{2} \mathrm{O}_{2}$ & $H H x l$ & Lith & Sum 1 & Total $^{1}$ \\
\hline \multirow[t]{3}{*}{ Core 9/ } & $\begin{array}{l}0-1 \\
1-2 \\
2-4 \\
4-7 \\
7-11\end{array}$ & $<.01^{2}$ & $\begin{array}{r}0.055 \\
.045 \\
.050 \\
.055 \\
.065\end{array}$ & $\begin{array}{r}0.070 \\
.065 \\
.055 \\
.065 \\
.080\end{array}$ & $\begin{array}{r}0.070 \\
.050 \\
.050 \\
.065 \\
.055\end{array}$ & $\begin{array}{r}0.190 \\
.160 \\
.165 \\
.180 \\
.200\end{array}$ & $\begin{array}{r}0.205 \\
.190 \\
.200 \\
.200 \\
.190\end{array}$ \\
\hline & $\begin{array}{l}11-16 \\
20-25 \\
30-35 \\
45-50 \\
70-75\end{array}$ & & $\begin{array}{l}.055 \\
.055 \\
.050 \\
.050 \\
.050\end{array}$ & $\begin{array}{l}.065 \\
.065 \\
.055 \\
.065 \\
.065\end{array}$ & $\begin{array}{l}.045 \\
.040 \\
.060 \\
.050 \\
.060\end{array}$ & $\begin{array}{l}.165 \\
.160 \\
.170 \\
.165 \\
.180\end{array}$ & $\begin{array}{l}.200 \\
.185 \\
.185 \\
.180 \\
.205\end{array}$ \\
\hline & $\begin{array}{r}95-100 \\
120-125 \\
145-150 \\
170-175 \\
195-200\end{array}$ & & $\begin{array}{l}.050 \\
.065 \\
.055 \\
.070 \\
.065\end{array}$ & $\begin{array}{l}.070 \\
.070 \\
.065 \\
.080 \\
.070\end{array}$ & $\begin{array}{l}.055 \\
.055 \\
.045 \\
.055 \\
.065\end{array}$ & $\begin{array}{l}.180 \\
.185 \\
.160 \\
.205 \\
.195\end{array}$ & $\begin{array}{l}.205 \\
.195 \\
.180 \\
.185 \\
.205\end{array}$ \\
\hline \multirow[t]{3}{*}{ Core $32 /$} & $\begin{array}{l}0-1 \\
1-2 \\
2-4 \\
4-7 \\
7-11\end{array}$ & $\begin{array}{r}0.025 \\
.030 \\
.030 \\
.035 \\
.040\end{array}$ & $\begin{array}{r}0.055 \\
.045 \\
.045 \\
.045 \\
.060\end{array}$ & $\begin{array}{r}0.040 \\
.030 \\
.020 \\
.040 \\
.060\end{array}$ & $\begin{array}{r}0.095 \\
.090 \\
n . a . \\
.155 \\
.090\end{array}$ & $\begin{array}{r}0.190 \\
.160 \\
\text { n.a. } \\
.240 \\
.210\end{array}$ & $\begin{array}{r}0.220 \\
.215 \\
\text { n.a. } \\
.240 \\
.235\end{array}$ \\
\hline & $\begin{array}{l}11-16 \\
20-25 \\
30-35 \\
45-50 \\
70-75\end{array}$ & $\begin{array}{l}.020 \\
.010 \\
.010 \\
<.01 \\
<.01\end{array}$ & $\begin{array}{l}.050 \\
.055 \\
.065 \\
.050 \\
.075\end{array}$ & $\begin{array}{l}.050 \\
.020 \\
.065 \\
.050 \\
.040\end{array}$ & $\begin{array}{l}\text { n.a. } \\
.110 \\
\text { n.a. } \\
\text { n.a. } \\
.095\end{array}$ & $\begin{array}{l}\text { n.a. } \\
.185 \\
\text { n.a. } \\
\text { n.a. } \\
.210\end{array}$ & $\begin{array}{l}.245 \\
.240 \\
.230 \\
.200 \\
.285\end{array}$ \\
\hline & $\begin{array}{r}95-100 \\
120-125 \\
145-150 \\
170-175 \\
195-200\end{array}$ & $\begin{array}{c}<.01 \\
<.01 \\
.010 \\
.015 \\
.015\end{array}$ & $\begin{array}{l}.100 \\
.070 \\
.075 \\
.070 \\
.080\end{array}$ & $\begin{array}{l}.070 \\
.045 \\
.050 \\
.085 \\
.030\end{array}$ & $\begin{array}{l}.115 \\
.085 \\
.105 \\
.115 \\
.095\end{array}$ & $\begin{array}{l}.285 \\
.200 \\
.235 \\
.270 \\
.210\end{array}$ & $\begin{array}{l}.300 \\
.225 \\
.240 \\
.240 \\
.220\end{array}$ \\
\hline \multirow[t]{3}{*}{ Core 19/ } & $\begin{array}{l}0-1 \\
1-2 \\
2-4 \\
4-7 \\
7-11\end{array}$ & $<0.01^{2}$ & $\begin{array}{r}0.015 \\
.040 \\
.030 \\
.035 \\
.050\end{array}$ & $\begin{array}{r}0.050 \\
.015 \\
.010 \\
.010 \\
.015\end{array}$ & $\begin{array}{r}0.085 \\
.100 \\
.085 \\
.085 \\
.100\end{array}$ & $\begin{array}{r}0.150 \\
.155 \\
.120 \\
.120 \\
.160\end{array}$ & $\begin{array}{r}0.140 \\
.185 \\
.155 \\
.155 \\
.140\end{array}$ \\
\hline & $\begin{array}{l}11-16 \\
20-25 \\
30-35 \\
45-50 \\
70-75\end{array}$ & & $\begin{array}{l}.035 \\
.040 \\
.040 \\
.045 \\
.050\end{array}$ & $\begin{array}{l}.010 \\
.015 \\
.030 \\
.025 \\
.035\end{array}$ & $\begin{array}{l}.090 \\
.055 \\
.085 \\
.070 \\
.090\end{array}$ & $\begin{array}{l}.135 \\
.105 \\
.155 \\
.140 \\
.170\end{array}$ & $\begin{array}{l}.150 \\
.150 \\
.165 \\
.185 \\
.215\end{array}$ \\
\hline & $\begin{array}{r}95-100 \\
118-123 \\
123-128 \\
145-150\end{array}$ & & $\begin{array}{l}.055 \\
.030 \\
.055 \\
.040\end{array}$ & $\begin{array}{c}.030 \\
<.01 \\
.030 \\
.015\end{array}$ & $\begin{array}{l}.090 \\
.075 \\
.095 \\
.085\end{array}$ & $\begin{array}{l}.175 \\
.105 \\
.180 \\
.140\end{array}$ & $\begin{array}{l}.220 \\
.090 \\
.130 \\
.145\end{array}$ \\
\hline
\end{tabular}

${ }^{1}$ Sum $=$ sum of values of all extractions; Total = value of a separate total extraction.

${ }^{2} \mathrm{HOAC}$-soluble $\mathrm{Cu}$ is less than 0.01 micromoles per gram for all samples in cores 9 and 19. 
Appendix 5. Concentrations of $\mathrm{Zn}$ in extraction cores 9, 32, and 19 [in micromoles Zn per gram dry sediment; n.a., not analyzed]

\begin{tabular}{|c|c|c|c|c|c|c|c|c|}
\hline Depth & $(\mathrm{cm})$ & HOAC & $\mathrm{CHX} 1$ & $\mathrm{H}_{2} \mathrm{O}_{2}$ & $H H x I$ & Lith & Sum ${ }^{1}$ & Total $^{1}$ \\
\hline \multirow[t]{3}{*}{ Core 9/ } & $\begin{array}{l}0-1 \\
1-2 \\
2-4 \\
4-7 \\
7-11\end{array}$ & $\begin{array}{l}0.095 \\
.075 \\
.100 \\
.080 \\
.090\end{array}$ & $\begin{array}{r}0.050 \\
.055 \\
.045 \\
.065 \\
.060\end{array}$ & $\begin{array}{r}0.375 \\
.360 \\
.305 \\
.375 \\
.435\end{array}$ & $\begin{array}{r}0.320 \\
.280 \\
.250 \\
.345 \\
.365\end{array}$ & $\begin{array}{l}0.675 \\
.650 \\
.570 \\
.690 \\
.670\end{array}$ & $\begin{array}{l}1.52 \\
1.42 \\
1.28 \\
1.55 \\
1.61\end{array}$ & $\begin{array}{l}1.22 \\
1.35 \\
1.23 \\
1.36 \\
1.30\end{array}$ \\
\hline & $\begin{array}{l}11-16 \\
20-25 \\
30-35 \\
45-50 \\
70-75\end{array}$ & $\begin{array}{l}.110 \\
.100 \\
.085 \\
.125 \\
.105\end{array}$ & $\begin{array}{l}.060 \\
.050 \\
.050 \\
.050 \\
.050\end{array}$ & $\begin{array}{l}.390 \\
.405 \\
.390 \\
.390 \\
.415\end{array}$ & $\begin{array}{l}.265 \\
.280 \\
.315 \\
.260 \\
.280\end{array}$ & $\begin{array}{l}.545 \\
.580 \\
.765 \\
.650 \\
.735\end{array}$ & $\begin{array}{l}1.47 \\
1.41 \\
1.51 \\
1.47 \\
1.58\end{array}$ & $\begin{array}{l}1.26 \\
1.29 \\
1.39 \\
1.29 \\
1.40\end{array}$ \\
\hline & $\begin{array}{r}95-100 \\
120-125 \\
145-150 \\
170-175 \\
195-200\end{array}$ & $\begin{array}{l}.100 \\
.115 \\
.110 \\
.110 \\
.135\end{array}$ & $\begin{array}{l}.050 \\
.060 \\
.055 \\
.060 \\
.060\end{array}$ & $\begin{array}{l}.350 \\
.385 \\
.340 \\
.395 \\
.420\end{array}$ & $\begin{array}{l}.270 \\
.265 \\
.290 \\
.345 \\
.325\end{array}$ & $\begin{array}{l}.725 \\
.685 \\
.600 \\
.620 \\
.605\end{array}$ & $\begin{array}{l}1.51 \\
1.51 \\
1.39 \\
1.53 \\
1.51\end{array}$ & $\begin{array}{l}1.29 \\
1.27 \\
1.14 \\
1.26 \\
1.24\end{array}$ \\
\hline \multirow[t]{3}{*}{ Core $32 /$} & $\begin{array}{l}0-1 \\
1-2 \\
2-4 \\
4-7 \\
7-11\end{array}$ & $\begin{array}{l}0.100 \\
.180 \\
.095 \\
.105 \\
.120\end{array}$ & $\begin{array}{r}0.045 \\
.070 \\
.050 \\
.060 \\
.080\end{array}$ & $\begin{array}{r}0.235 \\
.255 \\
.145 \\
.240 \\
.195\end{array}$ & $\begin{array}{l}0.250 \\
.270 \\
.415 \\
.350 \\
.385\end{array}$ & $\begin{array}{c}0.640 \\
.610 \\
\text { n.a. } \\
\text { n.a. } \\
.615\end{array}$ & $\begin{array}{l}1.27 \\
1.39 \\
\text { n.a. } \\
0.75 \\
1.40\end{array}$ & $\begin{array}{l}1.35 \\
1.35 \\
\text { n.a. } \\
1.35 \\
1.14\end{array}$ \\
\hline & $\begin{array}{l}11-16 \\
20-25 \\
30-35 \\
45-50 \\
70-75\end{array}$ & $\begin{array}{l}.090 \\
.160 \\
.155 \\
.145 \\
.150\end{array}$ & $\begin{array}{l}.045 \\
.070 \\
.085 \\
.060 \\
.065\end{array}$ & $\begin{array}{l}.225 \\
.170 \\
.235 \\
.170 \\
.280\end{array}$ & $\begin{array}{l}.305 \\
.330 \\
.325 \\
.370 \\
.235\end{array}$ & $\begin{array}{l}\text { n.a. } \\
.550 \\
\text { n.a. } \\
\text { n.a. } \\
.665\end{array}$ & $\begin{array}{l}\text { n.a. } \\
1.28 \\
\text { n.a. } \\
\text { n.a. } \\
1.40\end{array}$ & $\begin{array}{l}1.13 \\
1.22 \\
1.49 \\
1.42 \\
1.33\end{array}$ \\
\hline & $\begin{array}{r}95-100 \\
120-125 \\
145-150 \\
170-175 \\
195-200\end{array}$ & $\begin{array}{l}.125 \\
.130 \\
.125 \\
.090 \\
.115\end{array}$ & $\begin{array}{l}.055 \\
.055 \\
.050 \\
.050 \\
.050\end{array}$ & $\begin{array}{l}.315 \\
.295 \\
.315 \\
.310 \\
.400\end{array}$ & $\begin{array}{l}.270 \\
.260 \\
.300 \\
.350 \\
.265\end{array}$ & $\begin{array}{l}.835 \\
.715 \\
.770 \\
.740 \\
.765\end{array}$ & $\begin{array}{l}1.60 \\
1.45 \\
1.56 \\
1.54 \\
1.60\end{array}$ & $\begin{array}{l}1.35 \\
1.32 \\
1.35 \\
1.38 \\
1.34\end{array}$ \\
\hline \multirow[t]{3}{*}{ Core 19/ } & $\begin{array}{l}0-1 \\
1-2 \\
2-4 \\
4-7 \\
7-11\end{array}$ & $\begin{array}{r}0.080 \\
.095 \\
.085 \\
.085 \\
.095\end{array}$ & $\begin{array}{l}0.050 \\
.055 \\
.040 \\
.040 \\
.040\end{array}$ & $\begin{array}{r}0.235 \\
.295 \\
.225 \\
.220 \\
.325\end{array}$ & $\begin{array}{r}0.280 \\
.180 \\
.120 \\
.100 \\
.150\end{array}$ & $\begin{array}{r}0.545 \\
.715 \\
.615 \\
.610 \\
.450\end{array}$ & $\begin{array}{l}1.19 \\
1.34 \\
1.08 \\
1.05 \\
1.06\end{array}$ & $\begin{array}{l}1.07 \\
1.08 \\
0.90 \\
0.88 \\
0.91\end{array}$ \\
\hline & $\begin{array}{l}11-16 \\
20-25 \\
30-35 \\
45-50 \\
70-75\end{array}$ & $\begin{array}{l}.115 \\
.100 \\
.110 \\
.090 \\
.100\end{array}$ & $\begin{array}{l}.050 \\
.045 \\
.050 \\
.050 \\
.065\end{array}$ & $\begin{array}{l}.230 \\
.230 \\
.235 \\
.235 \\
.240\end{array}$ & $\begin{array}{l}.160 \\
.180 \\
.250 \\
.175 \\
.175\end{array}$ & $\begin{array}{l}.450 \\
.435 \\
.550 \\
.500 \\
.665\end{array}$ & $\begin{array}{l}1.01 \\
0.99 \\
1.19 \\
1.06 \\
1.24\end{array}$ & $\begin{array}{l}0.95 \\
1.10 \\
1.13 \\
1.10 \\
1.25\end{array}$ \\
\hline & $\begin{array}{r}95-100 \\
118-123 \\
123-128 \\
145-150\end{array}$ & $\begin{array}{l}.095 \\
.060 \\
.075 \\
.070\end{array}$ & $\begin{array}{l}.065 \\
.045 \\
.045 \\
.045\end{array}$ & $\begin{array}{l}.260 \\
.230 \\
.325 \\
.350\end{array}$ & $\begin{array}{l}.180 \\
.075 \\
.210 \\
.155\end{array}$ & $\begin{array}{l}.730 \\
.355 \\
.650 \\
.470\end{array}$ & $\begin{array}{l}1.34 \\
0.77 \\
1.30 \\
1.09\end{array}$ & $\begin{array}{l}1.35 \\
0.81 \\
1.22 \\
1.07\end{array}$ \\
\hline
\end{tabular}

${ }^{1}$ Sum $=$ sum of values of all extractions; Total = value of separate total extractions. 
Appendix 6. Concentrations of $\mathrm{Cr}$ in extracts from cores 9, 32, and 19 [in micromoles $\mathrm{Cr}$ per gram dry sediment; $\mathrm{CHx}$-soluble $\mathrm{Cr}$ below detection limit; n.a., not analyzed]

\begin{tabular}{|c|c|c|c|c|c|c|c|}
\hline \multicolumn{2}{|c|}{ Depth $(\mathrm{cm})$} & \multirow{2}{*}{$\begin{array}{c}\text { HOAC } \\
0.015 \\
.015 \\
.025 \\
.025 \\
.025\end{array}$} & \multirow{2}{*}{$\begin{array}{r}\mathrm{H}_{2} \mathrm{O}_{2} \\
0.125 \\
.140 \\
.130 \\
.110 \\
.130\end{array}$} & \multirow{2}{*}{$\begin{array}{r}H H \times 1 \\
0.080 \\
.070 \\
.085 \\
.100 \\
.100\end{array}$} & \multirow{2}{*}{$\begin{array}{l}\text { Lith } \\
0.975 \\
0.960 \\
0.905 \\
0.970 \\
1.05\end{array}$} & \multirow{2}{*}{$\begin{array}{l}\text { Sum }^{1} \\
1.20 \\
1.19 \\
1.14 \\
1.22 \\
1.30\end{array}$} & \multirow{2}{*}{$\begin{array}{l}\text { Total }^{1} \\
1.09 \\
1.16 \\
1.12 \\
1.14 \\
1.12\end{array}$} \\
\hline Core 9/ & $\begin{array}{l}0-1 \\
1-2 \\
2-4 \\
4-7 \\
7-11\end{array}$ & & & & & & \\
\hline & $\begin{array}{l}11-16 \\
20-25 \\
30-35 \\
45-50 \\
70-75\end{array}$ & $\begin{array}{l}.025 \\
.025 \\
.015 \\
.025 \\
.025\end{array}$ & $\begin{array}{l}.120 \\
.125 \\
.100 \\
.135 \\
.125\end{array}$ & $\begin{array}{l}.050 \\
.070 \\
.085 \\
.065 \\
.065\end{array}$ & $\begin{array}{l}0.910 \\
0.850 \\
1.02 \\
0.935 \\
0.975\end{array}$ & $\begin{array}{l}1.10 \\
1.07 \\
1.22 \\
1.16 \\
1.19\end{array}$ & $\begin{array}{l}1.10 \\
1.13 \\
1.22 \\
1.15 \\
1.22\end{array}$ \\
\hline & $\begin{array}{r}95-100 \\
120-125 \\
145-150 \\
170-175 \\
195-200\end{array}$ & $\begin{array}{l}.015 \\
.020 \\
.015 \\
.020 \\
.025\end{array}$ & $\begin{array}{l}.110 \\
.115 \\
.113 \\
.125 \\
.135\end{array}$ & $\begin{array}{l}.060 \\
.060 \\
.080 \\
.090 \\
.080\end{array}$ & $\begin{array}{l}0.935 \\
0.980 \\
0.890 \\
0.940 \\
1.02\end{array}$ & $\begin{array}{l}1.12 \\
1.17 \\
1.10 \\
1.18 \\
1.26\end{array}$ & $\begin{array}{l}1.18 \\
1.19 \\
1.05 \\
1.14 \\
1.17\end{array}$ \\
\hline Core $32 /$ & $\begin{array}{l}0-1 \\
1-2 \\
2-4 \\
4-7 \\
7-11\end{array}$ & ${ }^{2}<0.01$ & $\begin{array}{l}0.085 \\
.065 \\
.050 \\
.075 \\
.080\end{array}$ & $\begin{array}{r}0.035 \\
.035 \\
.025 \\
.035 \\
.045\end{array}$ & $\begin{array}{l}0.94 \\
0.82 \\
\text { n.a. } \\
\text { n.a. } \\
0.81\end{array}$ & $\begin{array}{l}1.05 \\
0.92 \\
\text { n.a. } \\
\text { n.a. } \\
0.94\end{array}$ & $\begin{array}{l}1.17 \\
1.59 \\
\text { n.a. } \\
1.45 \\
1.37\end{array}$ \\
\hline & $\begin{array}{l}11-16 \\
20-25 \\
30-35 \\
45-50 \\
70-75\end{array}$ & & $\begin{array}{l}.085 \\
.105 \\
.075 \\
.100 \\
.090\end{array}$ & $\begin{array}{l}.040 \\
.015 \\
.050 \\
.035 \\
.025\end{array}$ & $\begin{array}{l}\text { n.a. } \\
0.88 \\
1.54 \\
\text { n.a. } \\
1.15\end{array}$ & $\begin{array}{l}\text { n.a. } \\
1.00 \\
1.66 \\
\text { n.a. } \\
1.26\end{array}$ & $\begin{array}{l}1.39 \\
1.55 \\
1.63 \\
1.29 \\
1.44\end{array}$ \\
\hline & $\begin{array}{r}95-100 \\
120-125 \\
145-150 \\
170-175 \\
195-200\end{array}$ & & $\begin{array}{l}.110 \\
.080 \\
.090 \\
.060 \\
.090\end{array}$ & $\begin{array}{l}.025 \\
.035 \\
.030 \\
.035 \\
.030\end{array}$ & $\begin{array}{l}1.32 \\
1.09 \\
1.19 \\
1.18 \\
1.08\end{array}$ & $\begin{array}{l}1.45 \\
1.20 \\
1.31 \\
1.27 \\
1.20\end{array}$ & $\begin{array}{l}1.50 \\
1.35 \\
1.55 \\
1.54 \\
1.32\end{array}$ \\
\hline Core 19/ & $\begin{array}{l}0-1 \\
1-2 \\
2-4 \\
4-7 \\
7-11\end{array}$ & $\begin{array}{r}0.010 \\
.010 \\
.010 \\
.010 \\
.010\end{array}$ & $\begin{array}{r}0.110 \\
.125 \\
.105 \\
.110 \\
.120\end{array}$ & $\begin{array}{l}0.030 \\
.040 \\
.035 \\
.030 \\
.030\end{array}$ & $\begin{array}{l}1.05 \\
1.07 \\
0.770 \\
0.700 \\
0.860\end{array}$ & $\begin{array}{l}1.20 \\
1.24 \\
0.92 \\
0.85 \\
1.02\end{array}$ & $\begin{array}{l}0.79 \\
1.21 \\
1.00 \\
0.94 \\
0.92\end{array}$ \\
\hline & $\begin{array}{l}11-16 \\
20-25 \\
30-35 \\
45-50 \\
70-75\end{array}$ & $\begin{array}{l}.010 \\
.015 \\
.010 \\
.010 \\
.015\end{array}$ & $\begin{array}{l}.115 \\
.100 \\
.115 \\
.110 \\
.115\end{array}$ & $\begin{array}{l}.035 \\
.040 \\
.035 \\
.030 \\
.025\end{array}$ & $\begin{array}{l}1.02 \\
0.96 \\
1.06 \\
0.99 \\
1.20\end{array}$ & $\begin{array}{l}1.19 \\
1.12 \\
1.22 \\
1.14 \\
1.34\end{array}$ & $\begin{array}{l}1.08 \\
1.16 \\
1.20 \\
1.27 \\
1.44\end{array}$ \\
\hline & $\begin{array}{r}95-100 \\
118-123 \\
123-128 \\
145-150\end{array}$ & $\begin{array}{l}.010 \\
.010 \\
.010 \\
.010\end{array}$ & $\begin{array}{l}.130 \\
.110 \\
.135 \\
.170\end{array}$ & $\begin{array}{l}.020 \\
.010 \\
.025 \\
.015\end{array}$ & $\begin{array}{l}1.27 \\
0.74 \\
1.36 \\
1.02\end{array}$ & $\begin{array}{l}1.43 \\
0.87 \\
1.53 \\
1.21\end{array}$ & $\begin{array}{l}1.46 \\
0.59 \\
0.90 \\
0.79\end{array}$ \\
\hline
\end{tabular}

${ }^{1}$ Sum $=$ sum of values of all extractions; Total = value of separate total extraction.

${ }^{2}$ HOAC-soluble is less than 0.01 micromoles per gram for all samples in core 32 . 


\title{
Mobility and Distribution of Heavy Metals During the Formation of First Cycle Red Beds $^{1}$
}

By ROBERT A. ZIELINSKI, U.S. Geological Survey, MS 424, Denver Federal Center Denver, Colorado 80225, SALMAN BLOCH, Oklahoma Geological Survey, 830 VanVleet Oval, Norman, Oklahoma 73019, and THEODORE R. WALKER, University of Colorado, Department of Geology, Boulder, Colorado 80307

\section{CONTENTS}

\author{
Abstract $\mathbf{5 2}$ \\ Introduction $\mathbf{5 2}$ \\ Experimental $\mathbf{5 2}$ \\ Results and discussion $\mathbf{5 4}$ \\ Conclusions $\mathbf{5 8}$ \\ References Cited $\mathbf{5 9}$
}

\section{FIGURES}

1. Generalized geographic map showing sampled outcrop locations $\mathbf{5 3}$

2. Plot showing average composition of the three types of samples studied $\mathbf{5 5}$

3. Graph showing whole-rock percentage of heavy metals dissolved by each of the six leach solutions (see table 1) 56

4. Plot showing total leached whole-rock percentage of heavy metals of the three types of samples studied $\mathbf{5 7}$

5. Plot showing comparison of percentage of whole-rock iron in leachates 5,6 , and 7 versus type of sample studied $\mathbf{5 8}$

\section{TABLE}

1. Summary of leaching conditions

${ }^{1}$ Summarized from Zielinski, R. A., Bloch, Salman, and Walker, T. R., 1983, The mobility and distribution of heavy metals during the formation of first cycle red beds: Economic Geology, v. 78, p. 1574-1589. 


\section{Abstract}

A geologically young (Holocene-Pliocene) red-bed sequence displaying successive stages of development of the red pigmentation was sampled in northern Baja California for the purpose of studying the mobility and distribution of heavy metals during aging of iron oxyhydroxides from the noncrystalline to the crystalline state. Twenty-seven whole-rock samples and a series of successive leachates chosen to dissolve specific forms of iron oxides (noncrystalline, poorly crystalline, crystalline) were analyzed by inductively coupled plasmaoptical emission spectrometry for $\mathrm{V}, \mathrm{Al}, \mathrm{Cr}, \mathrm{Mn}, \mathrm{Fe}, \mathrm{Co}, \mathrm{Ni}$, $\mathrm{Cu}$, and $\mathrm{Zn}$, and by a delayed neutron technique for $\mathrm{U}$. These geochemical data were supported by petrographic, $\mathrm{X}$-ray diffraction, and scanning electron microscopic observations of mineralogical transformations, and by fission-track radiography, and uranium decay-series measurements. The results indicate that the metal content of the studied samples was inherited predominantly from detrital minerals and that reddening of the rock did not promote major open-system migration of heavy metals. Rather, contained metals redistributed on an intergranular scale, moving from detrital mineral hosts to secondary iron oxides. The amount of secondary iron oxides and the fraction of whole-rock metals associated with the oxides increased during the reddening of these beds. Thirteen fine-grained red beds of Pliocene age sampled in this study contain 10-63 percent of their whole-rock metal abundance in leachable sites, that is, secondary iron oxides, minor manganese oxides, and minor exchangeable sites on clays. The average leachable fractions (in percent) increase in the order $\mathrm{Cr}(10), \mathrm{V}(15), \mathrm{Pb}(\geq 20), \mathrm{Zn}$ (22), $\cup(27), \mathrm{Fe}(30), \mathrm{Ni}(41), \mathrm{Cu}(44), \mathrm{Co}(47), \mathrm{Mn}$ (63). These results suggest that red beds that are well flushed by suitable pore fluids (oxidizing or reducing) may be sources of significant quantities of heavy metals.

\section{INTRODUCTION}

Research conducted within the last two decades has shown that the pigmentation of red beds is produced by diagenetic alteration of constituent iron-bearing minerals (Walker, 1967, 1974; Walker and others, 1978; Larsen and Walker, 1975). In-place precipitation and aging of secondary iron oxides (noncrystalline iron oxides, goethite, hematite) during diagenesis of the host sediments has important implications for the geochemical mobility of contained heavy metals. Secondary iron oxides, particularly hydrous forms, are well-documented scavengers of heavy metals in soils and sediments; however, some changes in solution chemistry, such as lowered $\mathrm{pH}$ or the introduction of complexing agents, can promote the release of previously adsorbed metals. In addition, solutions of low Eh may cause the release of metals by the dissolution of secondary iron oxides (bleaching). The concept of mobilization of metals previously adsorbed by red beds suggests that red beds may be a source as well as a concentrator of economically important metals. Observations in support of this hypothesis are the close association of red beds with sediment-hosted stratiform deposits of copper and, to a lesser extent, similar deposits of lead and zinc (Gustafson and Williams, 1981). Other heavy metals such as Co, $\mathrm{Ag}, \mathrm{U}$, and $\mathrm{V}$ are common as minor or major components of metal deposits in and near red beds.

The geochemical mobility of economically important metals during early diagenetic reddening of host sediments is addressed in this study. Whole-rock and leachate analyses for $\mathrm{Fe}, \mathrm{Mn}, \mathrm{Al}, \mathrm{Cu}, \mathrm{Pb}, \mathrm{Zn}, \mathrm{Co}, \mathrm{Ni}$, $\mathrm{Cr}, \mathrm{V}, \mathrm{Pb}$, and $\mathrm{U}$ are combined with petrographic, radiographic, and isotopic data to determine the distribution and mobility of these metals as a function of sedimentary facies, sample age, and degree of reddening. In addition, the leachate results are used to speculate on the relative effectiveness of subsequent leaching of red beds for liberating metals.

\section{EXPERIMENTAL}

The 27 samples chosen for study are increasingly reddened (with age) alluvial fan and tidal-flat sediments of Holocene to Pliocene age from northeastern Baja California (fig. 1). The area is the site of previous red bed studies (Walker, 1967; Walker and others, 1978; Larsen and Walker, 1975) and represents a depositional environment that is analogous to that of many ancient red beds, such as those of Permian and Triassic age in Europe and North Africa and those of Pennsylvanian to Triassic age in the western interior of North America. Whole-rock powders (less than 100 mesh), leach solutions, and residues were analyzed by inductively coupled plasma-optical emission spectrometry and by a delayed neutron procedure for uranium.

To complement the whole-rock data, each sample was crushed, sieved, and subjected to a series of six successive leaching procedures, each chosen to be moderately specific for a particular metal site (table 1). Most leach solutions were acidic and (or) contained complexing agents to stabilize dissolved species. Eh ranged from strongly oxidizing (leach solution 3 ) to strongly reducing (leach solution 6). In general, leach solutions 1-3 removed loosely bound metals and metals associated with minor organic matter and manganese oxides, whereas leach solutions 4-6 were stronger and promoted iron oxide dissolution and attendant bleaching of samples. Additional details of the experimental procedure were described by Zielinski and others (1983).

The use of site-specific leaching for determining the distribution of metals is admittedly imprecise, and the yield of metals from a given leaching may not be complete. Nevertheless, such results are useful for comparing the relative leachability of metals from similarly treated samples, under a variety of conditions. 


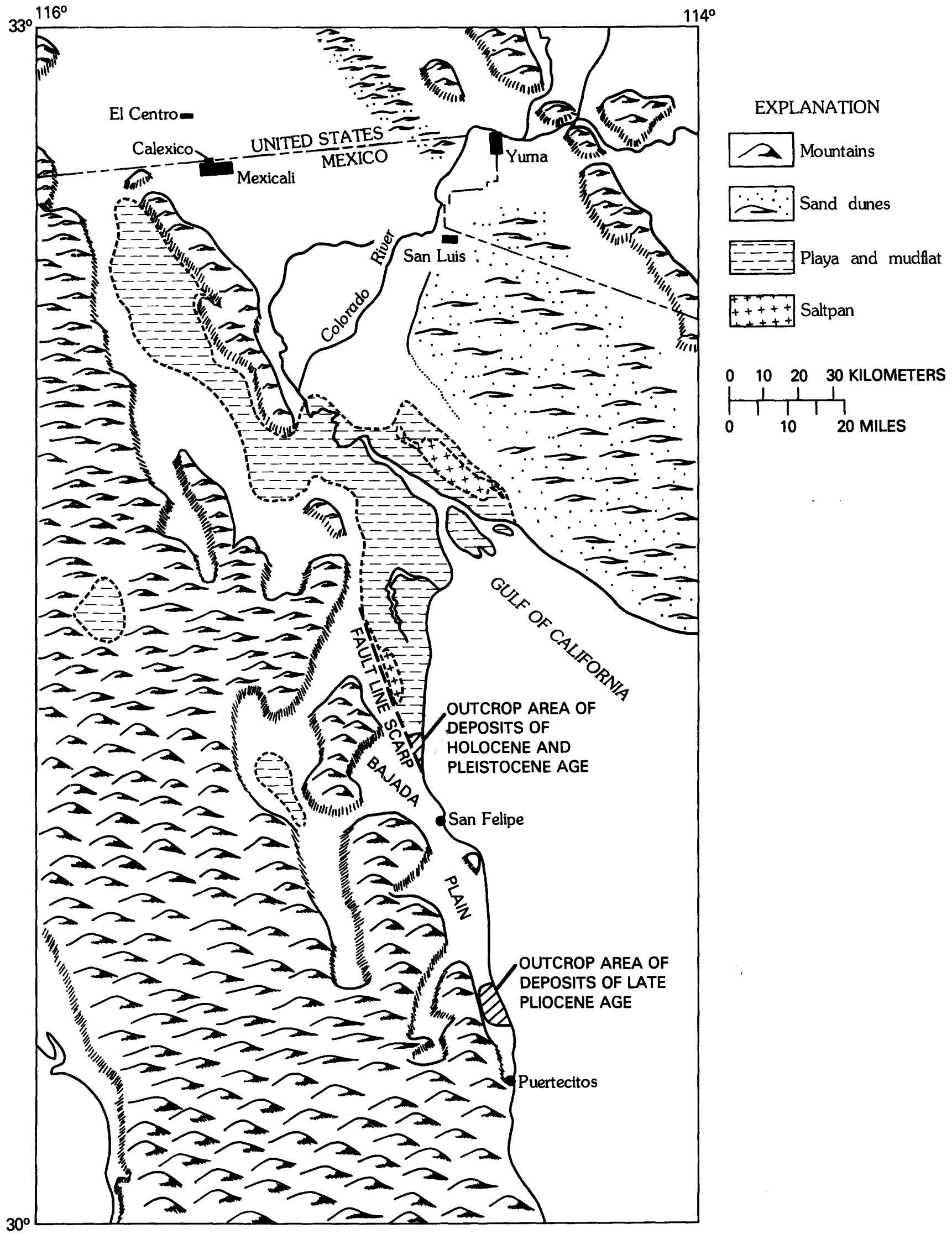

Figure 1. Generalized geographic map showing sampled outcrop locations. Modified from Larsen and Walker (1975). 
Table 1. Summary of leaching conditions

[h, hours; $M$, molar; , approximate value]

\begin{tabular}{|c|c|c|c|c|c|}
\hline $\begin{array}{l}\text { Leach } \\
\text { solution } \\
\text { No. }\end{array}$ & $\begin{array}{l}\text { Solution } \\
\text { composition }\end{array}$ & $\mathrm{pH}$ & $\begin{array}{l}\text { Contact } \\
\text { time }(h)\end{array}$ & Site or phase attacked & Comments \\
\hline 1 & $1 \underline{\mathrm{MgCl}} 2$ & 5 & 2 & $\begin{array}{l}\text { Exchangeable sites on clay; } \\
\text { carbonates. }\end{array}$ & \\
\hline 2 & $0.1 \underline{\mathrm{M}} \mathrm{NH}_{2} \mathrm{OH} \cdot \mathrm{HCl}$ & 4 & 2 & Manganese oxides- & $\begin{array}{l}\text { Dissolves some } \\
\text { noncrystalline } \\
\text { oxides. }\end{array}$ \\
\hline 3 & $\sim 15 \% \quad \mathrm{H}_{2} \mathrm{O}_{2}$ & $\sim 4$ & 5 & Organic matter-a & $\begin{array}{l}\text { At } 50^{\circ} \mathrm{C} \text {; highly } \\
\text { oxidizing. }\end{array}$ \\
\hline 4 & $\begin{array}{c}0.2 \mathrm{M} \text { ammonium oxalate, } \\
0.2 \text { M oxalic acid. }\end{array}$ & 3 & 5 & Noncrystalline iron oxides--- & $\begin{array}{l}\text { Treat in darkened } \\
\text { room; dissolves } \\
\text { some magnetite. }\end{array}$ \\
\hline 5 & $\begin{array}{l}1 \frac{\mathrm{M}}{\mathrm{NH}_{2} \mathrm{OH} \cdot \mathrm{HCl}, 25 \%} \\
(\mathrm{~V} / \mathrm{V}) \text { acetic acid. }\end{array}$ & $\sim 2$ & 5 & $\begin{array}{l}\text { Poorly crystallized } \\
\text { secondary iron oxides. }\end{array}$ & \\
\hline 6 & $\begin{array}{l}\mathrm{Na} \text {-dithionite (solid), } \\
\sim 0.3 \mathrm{M} \mathrm{NaHCO}_{3}, \\
\sim 0.4 \mathrm{M} \mathrm{Na-citrate.}\end{array}$ & 8.3 & 0.5 & $\begin{array}{l}\text { Well-crystallized } \\
\text { secondary iron oxides. }\end{array}$ & $\begin{array}{l}\text { May attack iron- } \\
\text { bearing clays; } \\
75^{\circ} \mathrm{C} \text {; highly } \\
\text { reducing. }\end{array}$ \\
\hline
\end{tabular}

\section{RESULTS AND DISCUSSION}

For the purpose of this study it was most informative to divide the samples into three groups-alluvial fan sediments (7) of Holocene and Pleistocene age, tidalflat sediments (7) of the same age range, and tidal-flat sediments (13) of Pliocene age (fig. 2). Alluvial fan sediments of Holocene to Pleistocene age (column 1, fig. 2) were consistently found to contain more aluminum but less iron and heavy trace metals than contemporaneous tidal-flat sediments (column 2). The large difference in abundance of aluminum, a major element that is relatively insoluble, indicates that the difference in bulk composition of the sediments was probably due to differences in source composition or to mineral fractionation during transport. For example, the alluvium is rich in locally derived granitic detritus, whereas the tidal-flat sediments are rich in detritus transported by the Colorado River from more distant and compositionally varied sources. Alternatively, mineral fractionation during transport increased the content of slow-settling phases, such as clay minerals and biotite, in fine-grained sediments.

In contrast to these results, the average composition of tidal-flat sediments of Holocene-Pleistocene age (column 2) was similar to that of Pliocene equivalents (column 3). This similarity in composition supports the assumption of constant depositional setting for these sediments and suggests that chronologically progressive reddening was not accompanied by major fluxes of heavy metals, at least on a hand-specimen scale.
The amount of each element dissolved by each leach solution is expressed as a percentage of its original wholerock abundance. Results for all 27 samples are summarized in figure 3 . The total percentages of lead and uranium leached from whole-rock samples are minimum values because of the relatively high detection limits for these elements $(\mathrm{Pb}=5-17$ percent and $\mathrm{U}=2-5$ percent of their whole-rock abundances). Leached percentages of aluminum provide an upper-limit estimate of the extent of aluminosilicate dissolution. Elements detected in leachate 1 included $\mathrm{Mn}, \mathrm{Co}, \mathrm{V}, \mathrm{Ni}$, and $\mathrm{Cu}$. These elements, plus $\mathrm{Zn}$, were also detected in the leachates chosen to attack manganese oxides and organic material. Although these latter two materials have high adsorptive capacity, they are apparently too sparse to exert major influence on the heavy-metal budget of the studied samples. In contrast to the first three leach solutions, the leach solutions chosen to attack secondary iron oxides dissolved major percentages of whole-rock metals. In addition to iron, the metals with the greatest relative affinities for the secondary iron oxides appear to be $\mathrm{Mn}$, $\mathrm{Cu}, \mathrm{Ni}, \mathrm{Co}$, and, to a lesser extent, $\mathrm{U}, \mathrm{Zn}$, and $\mathrm{Pb} ; \mathrm{Al}$, $\mathrm{Cr}$, and $\mathrm{V}$ consistently showed the smallest percentages of whole-rock abundance in secondary iron oxides.

Additional information was derived by subdividing total leached whole-rock percentages into the three sample groups of figure 2, as shown in figure 4. In spite of lower metal abundances in alluvium (fig. 2) and a coarser average grain size in leached powders of alluvium, most of the measured heavy metals were more effectively leached from the alluvium. This difference in leachability was 


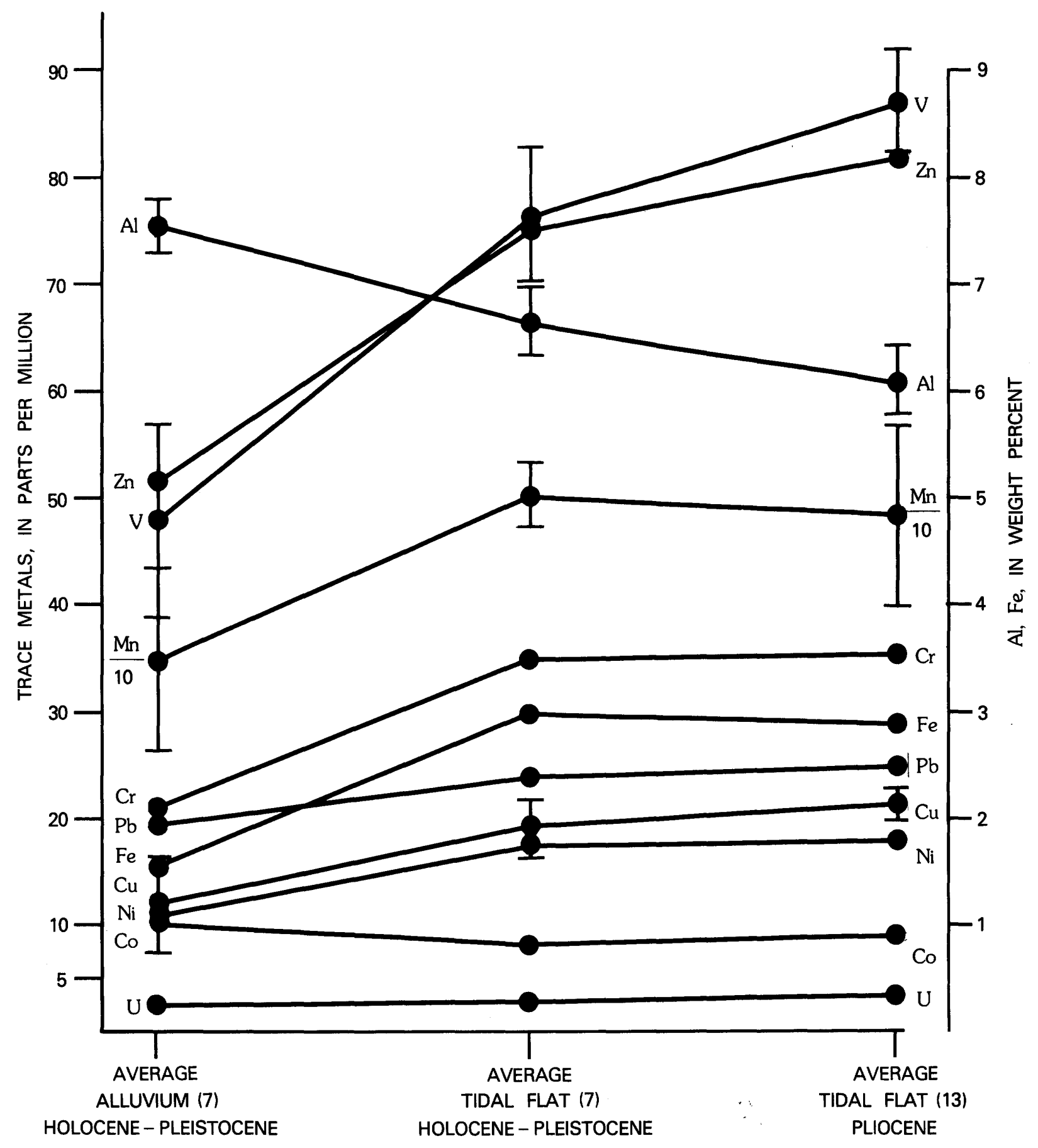

Figure 2. Average composition of samples, plotted as a function of their depositional setting and age. The number of samples in each subgroup is shown in parentheses. Representative error bars encompass \pm 1 standard error of the mean.

observed in most leach steps and probably indicates fundamental differences in the distribution of metals and the accessibility of leach solutions to metal sites. In the finer grained tidal-flat materials, more of the metals were in unleachable structural sites of the relatively abundant clay minerals and biotite, and access of leach solutions to surfaces of iron-bearing grains was hindered by clay coatings that were not removed during grinding. This effect was partly an experimental problem, but is probably also operative in nature.

The leachability of $\mathrm{Pb}, \mathrm{U}$, and, particularly, $\mathrm{Mn}$ was not as sensitive to these proposed differences in intergranular permeability, perhaps because more of these elements were dispersed in minerals that are coarser grained or more insoluble. Possible minerals include feldspar for lead; zircon, sphene, and apatite for uranium; 


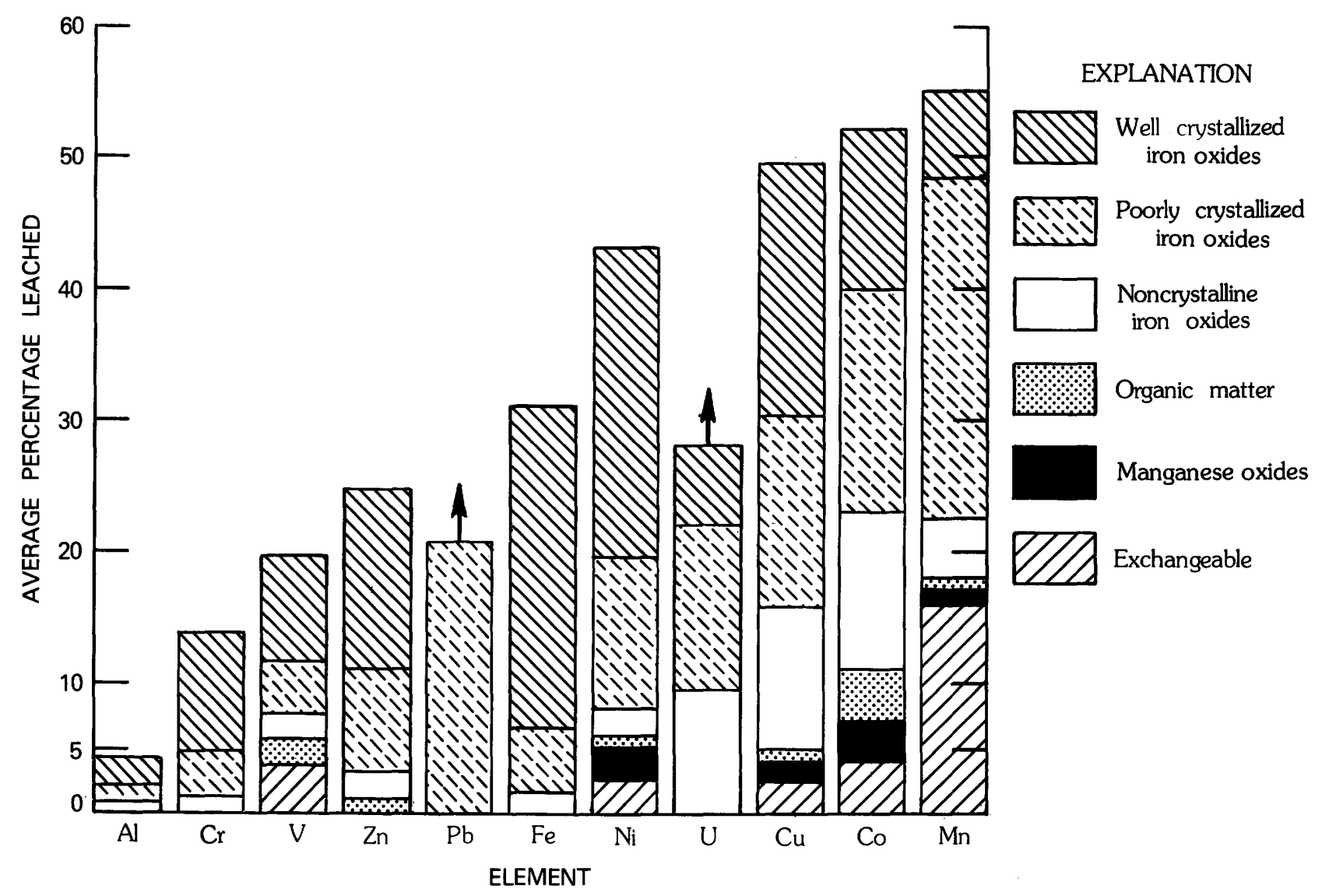

Figure 3. The average whole-rock percentage of heavy metal dissolved by each of six leach solutions. Leach solutions are coded according to the particular metal site under attack. Vertical arrows identify elements with relative high detection limits and therefore underestimated leachability.

and feldspars and titanium phases for manganese. The exceptional leachability of manganese from finer grained samples suggests an additional association with clay surfaces. This hypothesis is supported by the results of leaching that show a relatively high percentage of readily exchangable manganese in the tidal-flat sediments. These results and the results shown in figures 2 and 4 indicate that studies of subtle compositional changes related to progressive diagenesis must be restricted to sediments that are not only products of similar depositional settings but that are also of similar grain size.

With the possible exception of lead, all measured metals were leached in greater percentage from the Pliocene tidal-flat sediments than from the younger equivalents (fig. 4). Increases in leachability with age averaged about 6 percent of whole-rock abundances; iron showed the greatest increase (about 10 whole-rock percentage units). This increased leachability is attributed to timedependent, intergranular-scale redistribution of metals from detrital mineral hosts to leachable sites, primarily secondary iron oxides. As noted, this redistribution of metals did not produce major compositional changes on a hand-specimen scale (fig. 2).
The amount of iron dissolved by leach solutions 4-6 indicates a marked increase in the abundance of wellcrystallized secondary iron oxides (for example, hematite), in the older samples (fig. 5). In another recasting of the data, heavy-metal/iron ratios calculated for each of the final three leachates indicate generally lower ratios in the more abundant, well-crystallized secondary iron oxides. Thus, the apparent closed system behavior of the heavy metals during the diagenetic reddening of the tidalflat sediments was in part the result of distribution of metals between a coexisting population of metal-rich noncrystalline iron oxides and relatively metal-poor, but more abundant, crystalline iron oxides, such as goethite and hematite.

Fission-track radiographs (not presented here) confirmed the association of uranium with uraniferous accessory minerals (zircon, sphene), as well as with secondary iron oxides. Uranium decay-series measurements indicated a dominantly closed-system behavior for uranium in the sedimentary environment; however, samples with a relatively large abundance of uranium in noncrystalline iron oxides (leach solution 4) retained an isotopic signature indicative of minor adsorptive uptake of uranium. 


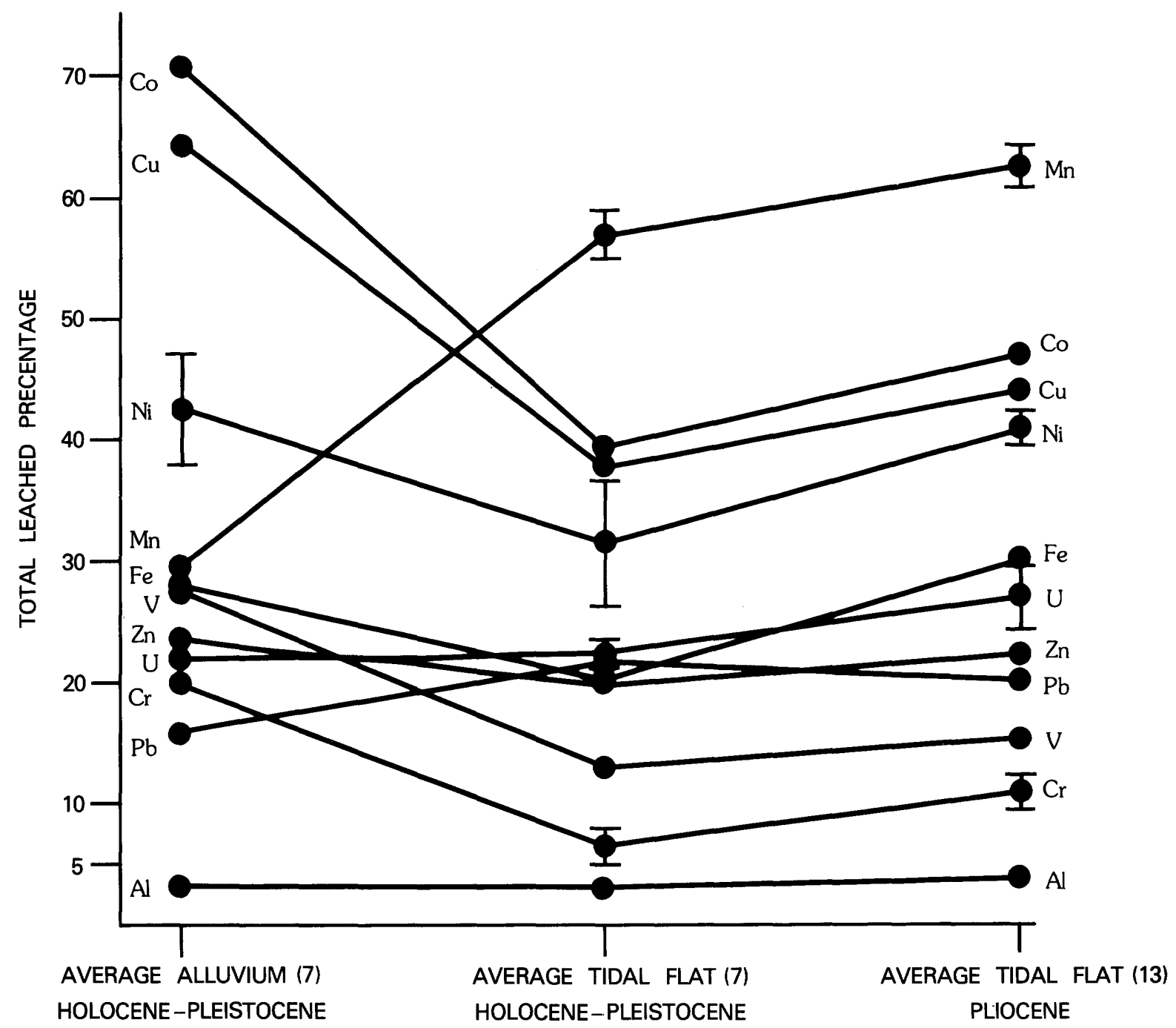

Figure 4. Total leached whole-rock percentage of heavy metals, plotted as a function of depositional setting and age of samples. The number of samples in each subgroup is shown in parentheses. Representative error bars encompass \pm 1 standard error of the mean.

The results of this study indicate a dominant closedsystem behavior of iron and associated metals during the early diagenetic reddening of the tidal-flat sediments. Short-range, perhaps intergranular-scale, movement of metals was favored because of the intimate association of metal-bearing detrital grains and adsorptive grain coatings of secondary iron oxides, the favorable chemical environment (basic-oxidizing) for metal adsorption, and the limited permeability of host sediments. The leachate data, however, also suggest that subsequent changes in the $\mathrm{Eh}, \mathrm{pH}$, or accessibility of pore fluids during more prolonged burial and diagenesis might promote renewed movement of previously fixed metals. Given such changes, young, coarsegrained red beds should react more rapidly than old, fine-grained red beds because of their high intergranular permeability and their greater content of more reactive, noncrystalline and poorly crystalline secondary iron oxides. Old red beds, however, are potentially a greater source of metals than young red beds because secondary iron oxides are more abundant and contain higher percentages of whole-rock heavy metals. Reducing solutions that promoted dissolution of secondary iron oxides (bleaching) were the most effective for liberating heavy metals, but, in general, the geochemical mobility of released metals may be hindered by the formation of insoluble oxides, carbonates, or sulfides. Moderate amounts (1-20 percent) of heavy metals were released during leach stages 1 through 4 , prior to obvious bleaching of samples. As in most of the leaching steps, Mn, $\mathrm{Co}$, and $\mathrm{Cu}$ were liberated in the greatest percentages. Anomalously low concentrations of these elements in some red beds compared with regional or worldwideaveraged values for red beds may be an indication of incipient open-system leaching (Zielinski and others, 1983). 


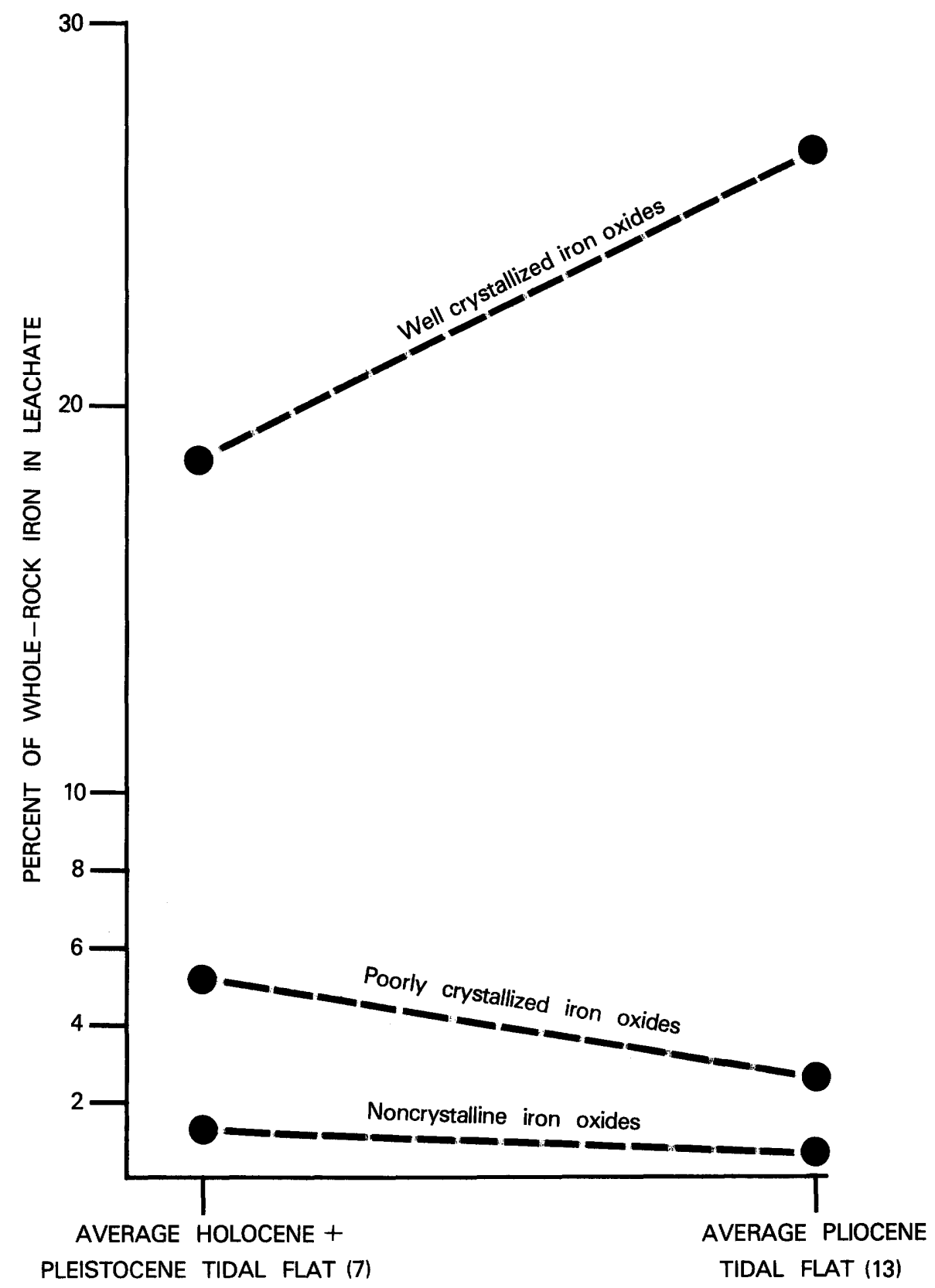

Figure 5. Comparison of percentage of whole-rock iron in leachates 5, 6, and 7 with type of sample studied.

\section{CONCLUSIONS}

1. Large and systematic chemical differences between alluvial fan and tidal-flat sediments of similar age and depositional setting were primarily controlled by differences in provenance and (or) mineral fractionation during deposition. The two sediment types also displayed large differences in their laboratory leaching characteristics that were related to fundamental differences in metal-site distribution and intergranular permeability. These findings emphasize the need to consider a single sediment type when evaluating compositional differences related to progressive diagenesis.

2. The tidal-flat sediments of Holocene-Pliocene age chosen for further study showed little analytically detectable change in heavy-metal content as a function of age, indicating that they had not experienced major open-system fluxes of heavy metals during progressive diagenetic reddening. Laboratory leaching of the same samples, however, indicated major within-sample redistribution of heavy metals that could be related to reddening. For example, as the abundance of secondary iron 
oxides increased, so did the fraction of whole-rock metals associated with them. Well-crystallized forms of secondary iron oxides increased relative to noncrystalline and poorly crystalline forms in the older, redder samples. Heavy-metal/ iron ratios in secondary iron oxides decreased as a function of crystallinity, but the possible loss of heavy metals related to the crystallization of iron oxides was apparently compensated by the consistently greater abundance of wellcrystallized secondary iron oxides in samples of all ages.

3. Hydrous manganese oxides or organic matter were not sufficiently abundant in the studied samples to have a significant effect on the distribution and mobility of metals.

4. Laboratory leaching of all the red-bed sediments (alluvium and tidal-flat) by low-temperature reducing solutions was particularly effective for liberating heavy metals from secondary iron oxides, but the long-range geochemical mobility of heavy metals released in nature is probably hindered by their precipitation as relatively insoluble oxides, sulfides, or carbonates. In contrast, the experimental lowtemperature leaching of red beds by oxidizing solutions was less effective for liberating metals, but less effective leach solutions may be compensated for in nature by increased duration of leaching and by the availability of large volumes of solutions.

\section{REFERENCES CITED}

Gustafson, L. B., and Williams, Neil, 1981, Sediment-hosted stratiform deposits of copper, lead, and zinc, in Skinner, B. J., ed., Economic geology, Seventy-fifth anniversary volume, 1905-1980: Economic Geology Publishing Co., p. 139-178.

Larsen, E. E., and Walker, T. R., 1975, Development of chemical remanent magnetization during early stages of red-bed formation in late Cenozoic sediments, Baja California: Geological Society of America Bulletin, v. 86, p. 639-650.

Walker, T. R., 1967, Formation of red beds in modern and ancient deserts: Geological Society of America Bulletin, v. 78 , p. $353-368$.

1974, Formation of red beds in moist tropical climates; a hypothesis: Geological Society of America Bulletin, v. 85 , p. 633-638.

Walker, T. R., Waugh, B., and Crone, A. J., 1978, Diagenesis in first-cycle desert alluvium of Cenozoic age, southwestern United States and northwestern Mexico: Geological Society of America Bulletin, v. 89, p. 19-32.

Zielinski, R. A., Bloch, S., and Walker, T. R., 1983, The mobility and distribution of heavy metals during the formation of first-cycle red beds: Economic Geology, v. 78, p. 15741589. 



\title{
Stoichiometry of Organic Decomposition in Sediments of the Potomac River Estuary
}

\author{
By DAVID L. PARKHURST, U.S. Geological Survey, Room 621, 215 Dean A. \\ McGee St., Oklahoma City, Oklahoma 73102, and \\ STEVEN D. GOODWIN, U.S. Geological Survey, MS 432, National Center, \\ Reston, Virginia 22092
}

\section{CONTENTS}

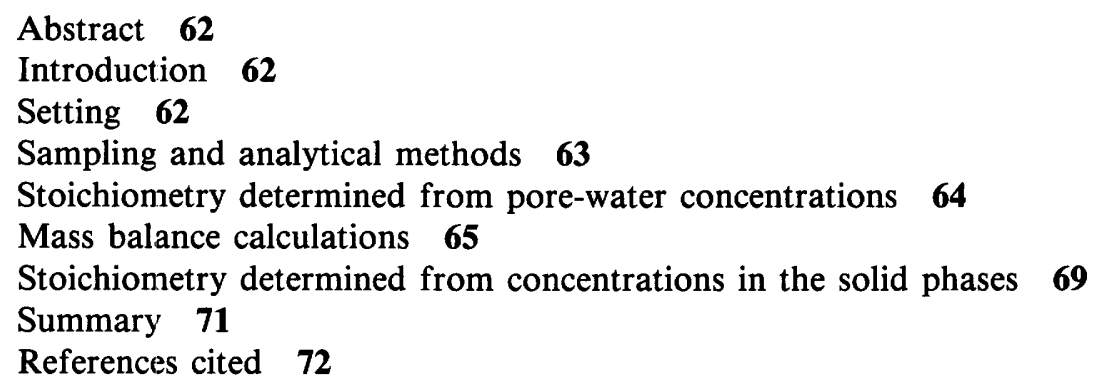

\section{FIGURES}

1. Map showing location of sampling stations V3 and V6 in the Potomac River estuary 63

2. Pore-water data used to determine the $\mathrm{C}: \mathrm{N}$ ratio of organic decomposition $\mathbf{6 6}$

3. Pore-water data used to determine the $\mathrm{C}: \mathrm{S}$ ratio of organic decomposition 67

4. Concentration profiles of sulfate, alkalinity, and ammonium in bottom sediments at station V3 for May 1978 and September 197868

5. Concentration profiles of carbon and nitrogen in the solid phases from stations V3 and V6 70

6. Concentration of carbon versus nitrogen in the solid phases from stations V3 and V6 71

\section{TABLES}

1. Mass accounting for the period May to September 1978 for station V3 69

2. Rates of processes calculated for the period May to September 1978 for station V3 69

3. Flux rates calculated from analyses of pore water and solid phases $\mathbf{7 0}$ 


\section{Abstract}

The decomposition of organic matter in sediment was investigated at two stations near the mouth of the Potomac River estuary. Using the assumption of steady state, equations were derived to determine the $\mathrm{C}: \mathrm{N}$ ratio (carbon to nitrogen ratio) of the reactive organic matter from (1) the pore-water concentrations of alkalinity and ammonium, and (2) the concentration of carbon and nitrogen in the solid phases of the sediment. From the pore-water data, the $\mathrm{C}: \mathrm{N}$ ratio was $7.7: 1$ for decomposition of organic matter by the pathway of sulfate reduction and 7.2:1 by the pathway of methanogenesis. From the solidphase data, the $C: N$ ratio was $5.9: 1$; no distinction could be made betweem the pathways of sulfate reduction and methanogenesis from the solid-phase data. These estimates of the $\mathrm{C}: \mathrm{N}$ ratio of the reactive part of the organic matter are lower than the average $\mathrm{C}: \mathrm{N}$ ratio, 9.6:1, of the organic matter at these sites, suggesting that organic matter with a low $\mathrm{C}: \mathrm{N}$ ratio is decomposed preferentially to organic matter with a high $\mathrm{C}: \mathrm{N}$ ratio.

Pore-water concentrations of alkalinity and sulfate were used to determine the $C: S$ ratio (ratio of carbon released to sulfate consumed) in the decomposition of organic matter by sulfate reduction. The estimated $\mathrm{C}: \mathrm{S}$ ratio, $-2.1: 1$, was close to the theoretical value of $-2.0: 1$.

A mass balance accounting was made for carbon, ammonium, and sulfate at one station for May 1978 to September 1978. Between 10 and 20 percent of the carbon and ammonium, produced by the decomposition of organic matter, was retained in the sediment pore water. More than 80 percent of the carbon and ammonium, produced by decomposition, was released from the sediment pore water to the overlying water. The decrease in sulfate concentration in the pore water during this period accounted for 19 percent of the sulfate consumed in organic decomposition reactions. About 80 percent of the sulfate consumed in organic decomposition reactions was supplied by the overlying water.

The accumulation of carbon, ammonium, and sulfate in the pore water of the sediment due to burial by the accumulating sediment particles was insignificant. Burial accounted for less than 1 percent of the carbon, ammonium, and sulfate involved in decomposition reactions. Only a small fraction of the total ammonium released by the decomposition of organic matter was adsorbed or exchanged onto the solid phases of the sediment. The mass balance calculations demonstrated that nonsteady-state effects accounted for less than 20 percent of the total rate of organic decomposition at one site. These calculations support the steady-state assumption made in the derivation of the equations used to determine the stoichiometry of the reactive part of the organic matter.

\section{INTRODUCTION}

One of the most important chemical reactions in estuarine sedimentary environments is the decomposition of organic matter. The decomposition process controls the rate of release of nutrients from the sediment to the overlying water of the estuary and determines the distribution of chemical species within the solid phases and pore water of the sediment. The goal of this study was to characterize the decomposition of organic matter in the sediment of the Potomac River estuary by determining the stoichiometry of the decomposition reactions, that is, the ratios in which carbon, ammonium, and sulfate are produced or consumed in the decomposition process.

The Potomac River estuary sediment contains organic matter which is derived from both marine and terrigenous sources. The compositions of these materials differ. Redfield (1958) determined an average C:N ratio (carbon to nitrogen ratio) in a sample of marine plankton to be 106:16 (6.6:1). Pockington (1976) found that terrigenous organic matter had significantly higher $C: N$ ratios. The overall $\mathrm{C}: \mathrm{N}$ ratio of the depositing organic matter will affect the stoichiometry of the decomposition reaction, but workers have found that the $C: N$ ratio of the reactive part of the organic matter may not be the same as the overall C:N ratio. Several studies (HolmHansen and others, 1966; Kamatani, 1969; Gordon, 1971) have suggested that nitrogen may be preferentially released in the decomposition of organic matter near the sediment-water interface. Thus, the stoichiometry of the carbon, ammonium, and sulfate in the decomposition reaction depends on the stoichiometry of the reactive part of the organic matter.

The concentrations of carbon, ammonium, and sulfate in the pore water and the concentrations of carbon and nitrogen in the solid phases contain a record of the decomposition reactions in the sediment. The present investigation used both pore-water and solid-phase data to determine the stoichiometry of decomposition reactions. First, the reaction stoichiometry was determined by a steady-state analysis of pore-water concentrations. Two reaction pathways, sulfate reduction and methanogenesis, were considered. Next, a mass balance was calculated for carbon, ammonium, and sulfate at one station. The calculations estimated the importance of nonsteady-state conditions. The importance of ammonium adsorption also was estimated. Finally, the reaction stoichiometry of organic decomposition was determined by a second method which used the concentrations of carbon and nitrogen in the solid phases of the sediment.

\section{SETTING}

The data were obtained from stations V3 and V6 in the lower part of the Potomac River estuary (fig. 1). Samples were collected at both of the stations in May 1978 and September 1978 and from station V3 in March and August 1979. Detailed data for these collections are available in Goodwin and others (1984).

Station V3 is $9 \mathrm{~km}$ from the mouth of the estuary and is situated in $10 \mathrm{~m}$ of water. The salinity of the overlying water ranges from 10 to 15 parts per thousand 


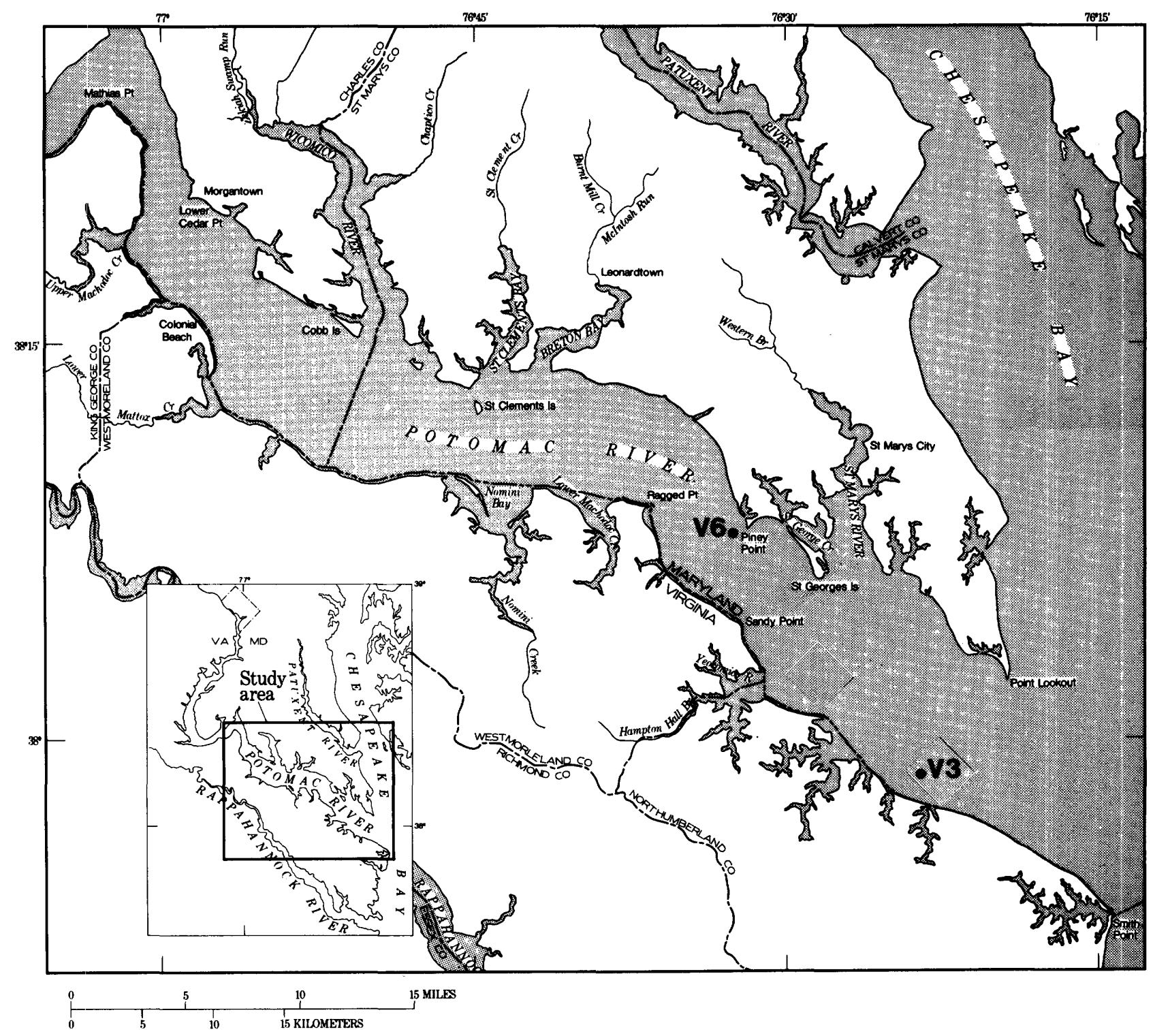

Figure 1. Location of sampling stations $V 3$ and V6 in the Potomac River estuary.

(Blanchard and Hahl, 1981), and the overlying water was oxygenated during all the samplings, even in mid-summer. A brown flocculent layer was present on the surface of the sediment at each sampling. Station V6 is $29 \mathrm{~km}$ from the mouth and is in $25 \mathrm{~m}$ of water. The salinity of the overlying water is slightly higher than at station V3 but has nearly the same range. During the summer samplings, $\mathrm{H}_{2} \mathrm{~S}$ was present in the overlying water and no brown layer was observed on the surface of the sediment.

Organic decomposition is the dominant reaction in the sediment at these stations. Sulfate concentrations decrease with depth in the sediment, and alkalinity and ammonium increase with depth, indicating decomposition of organic matter by the pathway of sulfate reduction. After complete depletion of sulfate, bubble formation and high ammonium ion concentrations suggest that decomposition continues at depth at station V 6 by the pathway of methanogenesis.
The concentration profiles at stations V3 and V6 vary seasonally. Steep gradients, indicating rapid reaction, occur in the summer, and less steep gradients occur in the winter and early spring. At station V3, during summer sampling (but not in spring), a minimum in sulfate and a maximum in alkalinity and ammonium occur within 10 $\mathrm{cm}$ of the sediment-water interface. These concentration changes with time are obvious nonsteady-state characteristics, and must be considered in an analysis of the stoichiometry of the reactions.

\section{SAMPLING AND ANALYTICAL METHODS}

Sediment cores for this study were obtained with a Benthos ${ }^{1}$ gravity coring device. The sediment samples

\footnotetext{
${ }^{1}$ Use of brand names is for descriptive purposes only and does not constitute endorsement by the U.S. Geological Survey.
} 
were extruded from the core liner under a nitrogen atmosphere in a glove box. All further processing took place under a nitrogen atmosphere. Either $2-$ or $2.5-\mathrm{cm}$ sections of sediment were placed into nylon squeezers (Reeburgh, 1967), and the pore water was expressed by the pressure of nitrogen gas against a sheet of dental dam rubber. The pore water was collected in $30-\mathrm{mL}$ syringes. The remaining sediment was freeze-dried for later analysis. The dissolved constituents in the pore water were analyzed within $12 \mathrm{~h}$ after collecting the samples.

Ammonium was determined colorimetrically using the phenolhypochlorite method of Berthelot as described by Solorzano (1969). The ion-exchange-titrimetric method of Dollman (1968) was used to determine sulfate. The alkalinity was determined by a single addition of acid and $\mathrm{pH}$ measurement, followed by a correction to account for the excess acid added (Almgreen and Fonselius, 1976).

The carbon of the solid phases was analyzed using a Model DC-12 Leco Carbon Determinator. Preliminary acidification of the samples to remove inorganic carbon indicated that inorganic carbon was not a significant fraction of the total carbon present in the samples. Therefore, the total carbon determination was taken as a measure of the organic carbon of the samples. Nitrogen concentrations in the solid phases were determined by Kjeldahl digestions (Bremner, 1965). The dissolved and adsorbed ammonia concentrations were found to be small, and the total value was used as an estimate of the organic nitrogen concentration.

\section{STOICHIOMETRY DETERMINED FROM PORE-WATER CONCENTRATIONS}

Berner (1975) gave the following diagenetic equation for sediments:

$$
\frac{\partial C_{i}}{\partial t}=\frac{D_{i}^{s}}{1+K_{i}} \cdot \frac{\partial^{2} C_{i}}{\partial x^{2}}-\omega \frac{\partial C_{i}}{\partial x}+\frac{1}{1+K_{i}} R_{i},
$$

where $C_{i}$ is the concentration in moles per cubic centimeter of pore water for species $i\left(\mathrm{~mol} / \mathrm{cm}^{3}\right) ; D_{i}^{s}$ is the sediment diffusion coefficient in sediment pore water for species $i$, which includes the effects of tortuosity but not of adsorption, in centimeters squared per second $\left(\mathrm{cm}^{2} / \mathrm{s}\right) ; R_{i}$ is the net rate of production (or consumption) of species $i$, in moles per cubic centimeters per second $\left(\mathrm{mol} \cdot \mathrm{cm}^{-3} \mathrm{~s}^{-1}\right) ; x$ is depth from the sedimentwater interface, measured positively downward, in centimeters (cm); $t$ is time, in seconds (s); $\omega$ is the velocity of burial of particles relative to the sediment-water interface, in centimeters per second $(\mathrm{cm} / \mathrm{s})$; and $K$ is a dimensionless coefficient accounting for adsorption. This equation ignores the effects of compaction and assumes constant diffusion coefficients. Further, Berner (1975) stated that if the pore-water concentrations are at steady state and the sedimentation term is small, equation 1 reduces to

$$
D_{i}^{s} \frac{\partial^{2} C_{i}}{\partial x^{2}}=R_{i}
$$

Note that the factor accounting for adsorption, $1 /(1+K)$, cancels out under these assumptions. For the reaction terms $R_{\mathrm{C}}$ (carbon species) and $R_{\mathrm{N}}$ (nitrogen species), there is no evidence of any appreciable chemical reaction other than organic decomposition (the adsorption of ammonium ion is discussed below). Thus, $R_{\mathrm{C}}$ and $R_{\mathrm{N}}$ are assumed to depend only on the rate of decomposition, and the rate of carbon release is related to the rate of nitrogen release by the stoichiometric ratio, $L_{\mathrm{C}: \mathrm{N}}$, as follows:

$$
L_{\mathrm{C}: \mathrm{N}} R_{\mathrm{N}}=R_{\mathrm{C}}
$$

During sulfate reduction the predominant carbon species released to the pore water are $\mathrm{H}_{2} \mathrm{CO}_{3}$ and $\mathrm{HCO}_{3}^{-}$, and the predominant nitrogen species is $\mathrm{NH}_{4}^{+}$. For the $\mathrm{pH}$ range of these pore waters, $\mathrm{CO}_{3}^{2-}$ and $\mathrm{NH}_{3}$ concentrations are negligibly small. Assuming a simple carbohydrate as the source of carbon with nitrogen present in a $\mathrm{C}: \mathrm{N}$ ratio of $6: 1$, the reaction can be written as follows:

$$
\begin{aligned}
\left(\mathrm{CH}_{2} \mathrm{O}\right)_{6} \mathrm{NH}_{3}+3 \mathrm{SO}_{4}^{2-} \rightarrow \mathrm{H}_{2} \mathrm{CO}_{3} \\
+5 \mathrm{HCO}_{3}^{-}+2 \mathrm{HS}^{-}+\mathrm{H}_{2} \mathrm{~S}+\mathrm{NH}_{4}^{+} .
\end{aligned}
$$

For sulfate reduction, equation 3 can be represented as

$$
L_{\mathrm{C}: \mathrm{N}} R_{\mathrm{NH}_{4}^{+}}=R_{\mathrm{H}_{2} \mathrm{CO}_{3}}+R_{\mathrm{HCO}_{3}^{-}}
$$

The chemical equation for methanogenesis can be written as follows:

$$
\begin{aligned}
\left(\mathrm{CH}_{2} \mathrm{O}\right)_{6} \mathrm{NH}_{3}+ & 3 \mathrm{H}_{2} \mathrm{O} \rightarrow 3 \mathrm{CH}_{4} \\
& +2 \mathrm{H}_{2} \mathrm{CO}_{3}+\mathrm{HCO}_{3}^{-}+\mathrm{NH}_{4}^{+} .
\end{aligned}
$$

The molar amount of $\mathrm{CH}_{4}$ produced equals the sum of $\mathrm{H}_{2} \mathrm{CO}_{3}$ and $\mathrm{HCO}_{3}^{-}$. Thus, for methanogenesis,

$$
\begin{aligned}
L_{\mathrm{C}: \mathrm{N}} R_{\mathrm{NH}_{4}^{+}} & =\mathrm{R}_{\mathrm{H}_{2} \mathrm{CO}_{3}}+R_{\mathrm{HCO}_{3}^{-}}+R_{\mathrm{CH}_{4}} \\
& =2\left(\mathrm{R}_{\mathrm{H}_{2} \mathrm{CO}_{3}}+R_{\mathrm{HCO}_{3}^{-}}\right) .
\end{aligned}
$$

Combining equation 5 with equation 2 gives:

$$
\begin{aligned}
D_{\mathrm{H}_{2} \mathrm{CO}_{3}}^{s} \frac{\partial^{2} C_{\mathrm{H}_{2} \mathrm{CO}_{3}}}{\partial x^{2}}+D_{\mathrm{HCO}_{3}^{-}}^{s} & \frac{\partial^{2} C_{\mathrm{HCO}_{3}}{ }^{-}}{\partial x^{2}} \\
= & L_{\mathrm{C}^{N}{ }^{2}} D_{\mathrm{NH}_{4}^{+}}^{s} \frac{\partial^{2} C_{\mathrm{NH}_{4}^{+}}}{\partial x^{2}} .
\end{aligned}
$$


For methanogenesis, the left-hand side of the equation has the additional factor of 2 from equation 7 . The diffusion coefficients of aqueous species in the pore water of sediment generally are assumed to be related to the tracer diffusion coefficients by a common factor, which accounts for tortuosity and viscosity ( $\mathrm{Li}$ and Gregory, 1974):

$$
k D_{i}^{0}=D_{i}^{s}
$$

Substituting for the sediment diffusion coefficients, $D_{i}^{s}$, in equation 8, the factor $k$ cancels throughout leaving the tracer diffusion coefficients in place of the sediment diffusion coefficient. Equation 8 is a function only of depth, and the partial derivatives can be replaced with ordinary derivatives. Assuming the diffusion coefficients are constant, equation 8 can be integrated giving:

$$
\begin{aligned}
D_{\mathrm{H}_{2} \mathrm{CO}_{3}}^{0} \frac{\mathrm{d} C_{\mathrm{H}_{2} \mathrm{CO}_{3}}}{\mathrm{~d} x}+D_{\mathrm{HCO}_{3}^{-}}^{0} \frac{\mathrm{d} C_{\mathrm{HCO}_{3}^{-}}}{\mathrm{d} x} \\
=L_{\mathrm{C}: \mathrm{N}} D_{\mathrm{NH}_{4}^{+}}^{0} \frac{d C_{\mathrm{NH}_{4}^{+}}}{\mathrm{d} x}+A,
\end{aligned}
$$

where $A$ is a constant of integration. The value of $A$ must be zero because the gradients approach zero at infinite depth. Integrating a second time gives the following relationship for concentrations:

$$
\begin{aligned}
\left(D_{\mathrm{H}_{2} \mathrm{CO}_{3}}^{0}\right)\left(C_{\mathrm{H}_{2} \mathrm{CO}_{3}}\right)+\left(D_{\mathrm{HCO}_{3}^{-}}^{0}\right)\left(C_{\mathrm{HCO}_{3}^{-}}\right) & \\
= & L_{\mathrm{C}: \mathrm{N}}\left(D_{\mathrm{NH}_{4}^{+}}^{0}\right)+B,
\end{aligned}
$$

where $B$ is also a constant.

Berner (1977) presented a method for determining the stoichiometry of sulfate-reduction organic decomposition. His method assumed steady-state concentration profiles and included the effects of sedimentation; however, it required that the data fit an exponential curve. Equation 11 is derived assuming steady state, ignoring the effects of sedimentation, but does not assume any particular mathematical form for the concentration profiles.

Equation 11 implies that, given the preceding assumptions, the C:N ratio $\left(L_{\mathrm{C}: \mathrm{N}}\right)$ can be determined from the pore-water concentrations. A plot of the quantity $D_{\mathrm{H}_{2} \mathrm{CO}_{3}}^{0} C_{\mathrm{H}_{2} \mathrm{CO}_{3}}+\left(D_{\mathrm{HCO}_{3}^{-}}^{0}\right)\left(C_{\mathrm{HCO}_{3}^{-}}\right)$versus $\left(D_{\mathrm{NH}_{4}^{+}}^{0}\right)\left(C_{\mathrm{NH}_{4}^{+}}\right)$ should produce a linear relationship with a slope of $L_{\mathrm{C}: \mathrm{N}}$. By the same reasoning, a plot of $D_{\mathrm{H}_{2} \mathrm{CO}_{3}}^{0} C_{\mathrm{H}_{2} \mathrm{CO}_{3}}$ $+\left(D_{\mathrm{HCO}_{3}^{-}}^{0}\right)\left(C_{\mathrm{HCO}_{3}^{-}}\right)$versus $\left(D_{\mathrm{SO}_{4}^{2-}}^{0}\right)\left(C_{\mathrm{SO}_{4}^{2-}}\right)$ can be used to determine the carbon to sulfate ratio, $L_{\mathrm{C}: \mathrm{s}}$.

Figure 2 shows the carbon-nitrogen plot for cores from stations V3 and V6. The distinct change in slope corresponds to the depletion of sulfate in these cores. All points on the greater sloping line have measureable amounts of sulfate ion. All points on the lesser sloping line are at or below the limit of detection for sulfate. The sulfate ion is assumed to be the electron acceptor (sulfate reduction) along the former line, and organic carbon is assumed to be the electron acceptor (methanogenesis) on the latter line.

For sulfate reduction the slope of the line is the $\mathrm{C}: \mathrm{N}$ ratio of the reacting organic matter. For methanogenesis, equation 7 indicates that the slope of the plot must be multiplied by 2 to obtain the C:N ratio. The resultant C:N ratio calculated for sulfate reduction is $7.7: 1$; that calculated for methanogenesis is 7.2:1. These values are close to one another and indicate that the net stoichiometry of the organic matter used during decomposition via both sulfate reduction and methanogenesis is similar. These values for the reactive part of the organic matter are lower than the average $\mathrm{C}: \mathrm{N}$ ratio of $9.4: 1$ for the organic matter at these sites, suggesting a selective utilization of low-C: $\mathrm{N}$ organic matter.

Figure 3 is a plot of the data from stations V3 and V6 for sulfate ion and carbon. The sloping linear relation indicates a $C: S$ ratio of $-2.1: 1$, a value that is consistent with the theoretical value of $-2.0: 1$ for the stoichiometry of sulfate reduction. Note that carbon continues to enter solution at low values of sulfate due to continued methanogenic decomposition following the depletion of sulfate from the pore water.

\section{MASS BALANCE CALCULATIONS}

The preceding analysis was based on the assumption of steady-state profiles for the dissolved constituents. For nonsteady-state profiles, the alkalinity and amount of ammonium ion produced during organic decomposition can (1) be transported out of the sediments (flux, $F)$, (2) be buried below the zone of organic decomposition (burial, $B$ ), or (3) remain in the pore water resulting in a change in concentration (storage, $S$ ). The importance of the steady-state assumption can be investigated by comparing the masses involved in each of these three processes. For a given time period, mass balance stipulates:

$$
R=-F+S+B
$$

where $R$ is the mass of a species released to solution during the period; $F$ is the mass movement into or out of the sediment due to diffusion during the period (a negative value for the quantity $F$ represents diffusion out of the sediment); $S$ is the mass of a species accumulating in the pore water due to concentration changes during the period (this term excludes the effects of sedimentation); and $B$ is the mass of a species accumulating in the pore water due to sedimentation during the period. All 


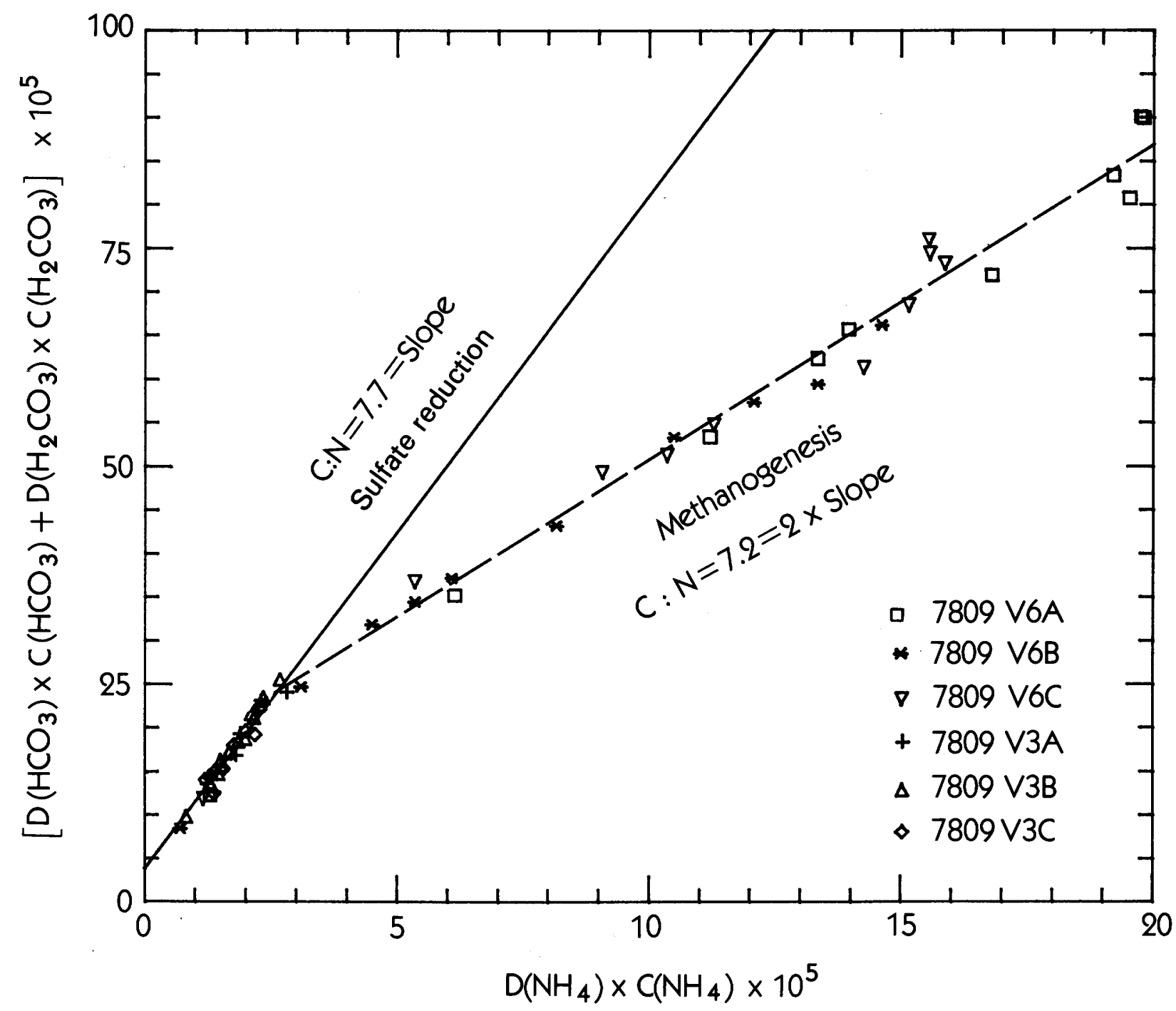

Figure 2. Pore-water data used to determine $\mathrm{C}: \mathrm{N}$ ratio of organic decomposition. For sulfate reduction, $\mathrm{C}: \mathrm{N}$ ratio is equal to slope of line. For methanogenesis, slope must be multiplied by 2 to account for production of reduced carbon (methane) in addition to oxidized carbon. Symbols refer to numbered core samples from stations V 3 and V6 in the Potomac River estuary (fig. 1).

terms are in moles per square centimeter $\left(\mathrm{mol} / \mathrm{cm}^{2}\right)$. Equation 12 can also be applied to the reduction of sulfate ion during decomposition; a negative value for $R$ represents the amount of sulfate ion reduced. The concentration gradients presented in figure 4 indicate that ammonium ions and alkalinity should be diffusing out of the sediment and that sulfate ions should be diffusing into the sediments.

Remember that alkalinity does not represent a single species. At these two stations, bisulfide, as estimated from total sulfide measurements, accounts for less than $1 \mathrm{meq} / \mathrm{L}$ of the alkalinity. Other species contributing to the alkalinity, $\mathrm{CO}_{3}^{2-}, \mathrm{HPO}_{4}^{2-}, \mathrm{H}_{2} \mathrm{PO}_{4}^{-}$, also are present only in low concentrations. Bicarbonate ion is by far the principal species contributing to the alkalinity; its concentration was assumed to be equal to the alkalinity.
Of the terms (equation 12) flux, storage, and burial, storage is the most difficult to estimate. Its estimation requires concentration profiles at different times of year in the same location taken from cores that have identical reaction histories except for the period from one sampling to the next. We have assumed that only the top 20$30 \mathrm{~cm}$ are affected by seasonal variation in reaction rates and that the concentrations at depth are an indicator of past reactions. Thus, the same sequence of reaction was assumed in cores with equal concentrations at depths of 40-60 cm. Cores from station V3 have concentrations at depth which are nearly equal, whereas concentrations at depth at station V6 vary widely. The differences at station V6 have not been attributed to any substantial difference in processes, only to spatial variation in sedimentation, microbial abundance, and extent of reaction. The storage term, and consequently the importance of 


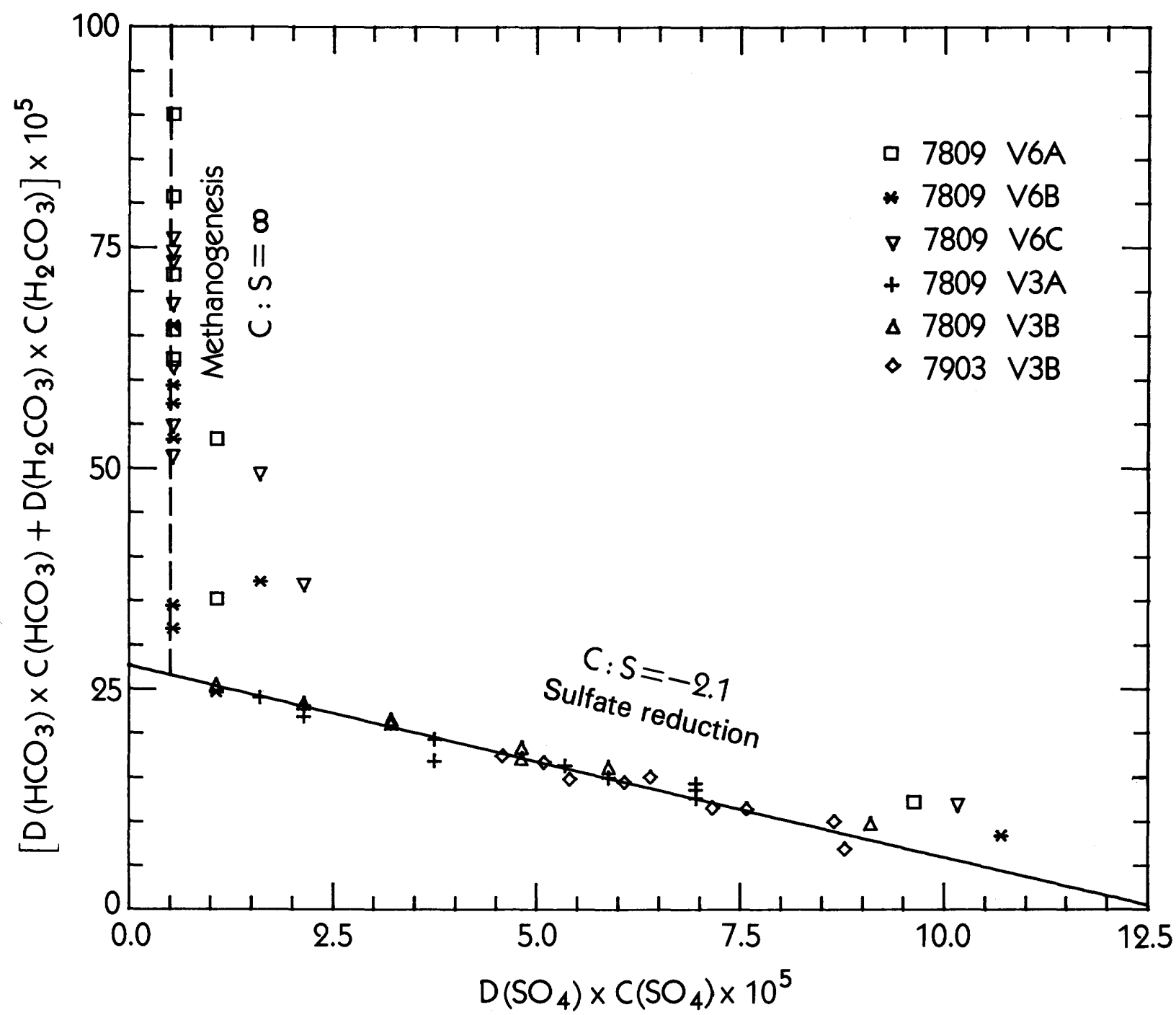

Figure 3. Pore-water data used to determine $\mathrm{C}: \mathrm{S}$ ratio of organic decomposition via sulfate reduction and methanogenesis. Symbols refer to numbered core samples from stations V3 and V6 in the Potomac River estuary (fig. 1).

nonsteady state, could be calculated at station V3 and not at station V6.

The reaction, flux, storage, and burial terms were estimated for station V3 for the period May to September 1978. The steepest gradients occurred during this period of the year indicating that organic decomposition was most rapid at this time. This reasoning is consistent with the observation of Nedwell and Floodgate (1972a, 1972b) that sulfate reduction is temperature dependent.

The flux terms were estimated to be the average of fluxes calculated from the May and September pore-water data. The following equation (Berner, 1980, p. 38) was used to estimate the flux of a constituent, $J_{i}$, at the sediment water interface:

$$
J_{i}=\phi D_{i}^{s}\left(\frac{\partial C_{i}}{\partial x}\right),
$$

where $\phi$ is the porosity, $C_{\mathrm{i}}$ is the concentration of species $i$, and $D_{i}^{s}$ the diffusion coefficient of species $i$ in sediment pore water.

The following relation (Andrews and Bennett, 1981) was used to estimate $D_{i}^{\text {s: }}$

$$
D_{i}^{s}=\frac{D_{i}^{0}}{\phi f},
$$

where $D_{i}^{0}$ is the tracer diffusion coefficient and $f$ is the form factor. Andrews and Bennett (1981) found that $f=\phi^{-3}$ was a good approximation of the form factor in fine-grained muds. The porosity in the upper $2 \mathrm{~cm}$ of cores from station V3 was determined to be 0.91 . The values of $D_{i}^{o}$ were obtained from Li and Gregory (1974) at $25^{\circ} \mathrm{C}$, and the gradient was calculated linearly, using the first two intervals from core $7805 \mathrm{~V} 3$ and core 7809 V3B (fig. 4). The linear approximation probably underestimates the gradient at the sediment-water interface. The flux term, $F$, was calculated by multiplying the flux rate, $J$, by the time interval betweem samplings. 

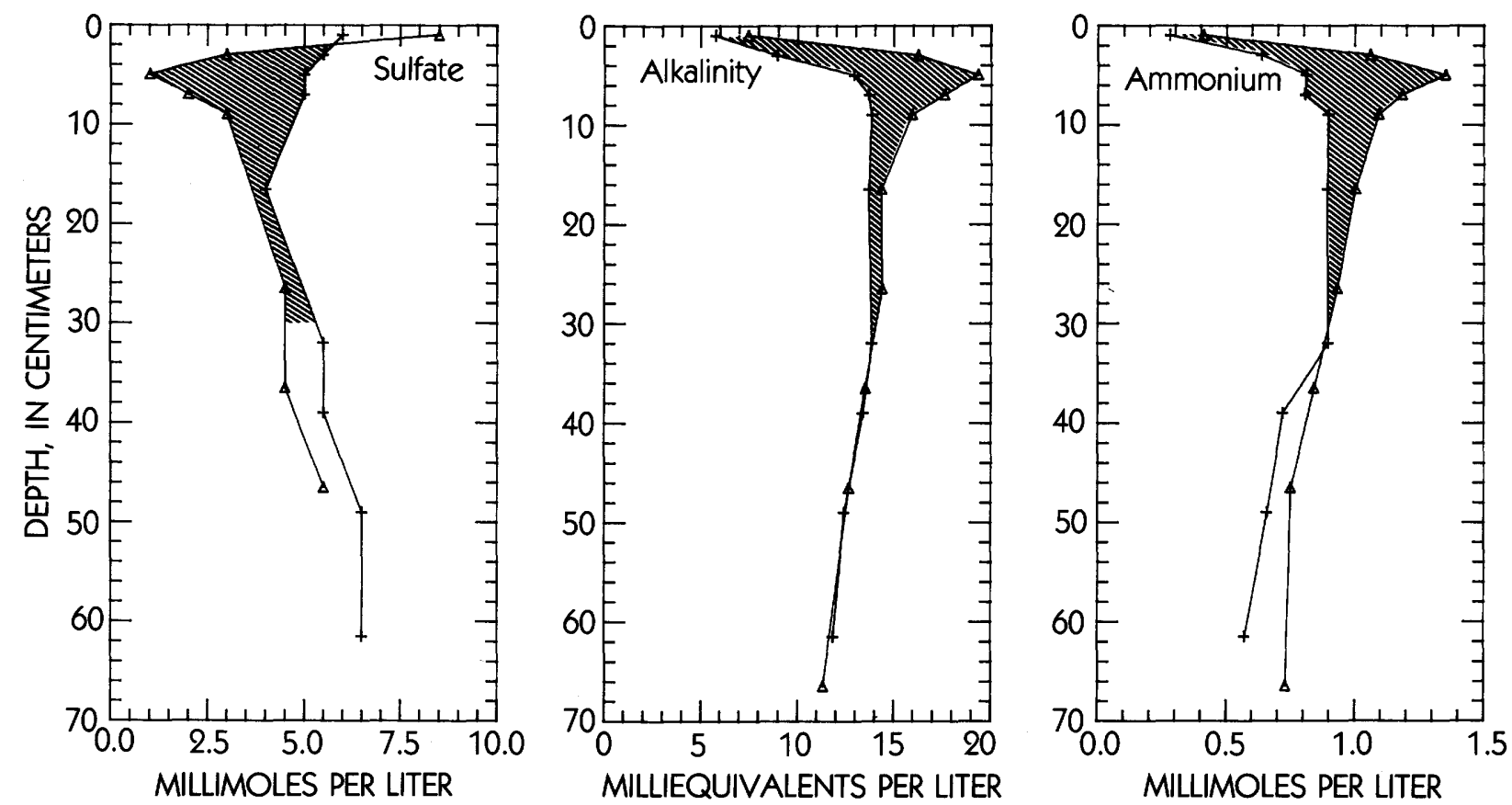

Figure 4. Concentration profiles of sulfate, alkalinity, and ammonium in bottom sediments at station V3 for May 1978 (plus sign) and September 1978 (open triangle). Shaded areas represent storage terms.

Few benthic organisms were observed at station V3 during the present study. The scarcity of benthic macrofauna and the steep concentrations gradients near the surface of the sediment suggest that bioturbation is not an important process here. This conclusion is supported by the work of Callender and Hammond (1982) who showed that the diffusive flux calculations for $\mathrm{NH}_{4}^{+}$at station V3 are, at most, a factor of two lower than in-place measurements. These results indicate that if the estimate of the flux term is in error, it is probably an underestimate. The actual flux is likely to be even more important relative to storage and burial (see tables 1 and 2).

Storage was estimated from the differences in the concentration profiles from May and September over the top $30 \mathrm{~cm}$. The differences were calculated by assuming that concentration changes betweem measured points were linear. On figure 4 , the shaded areas represent the storage terms.

Burial for the same period was estimated as the difference betweem the mass of a species in the pore water that is associated with the sediment accumulating at the surface of the sediment column and the mass of the species that is in the pore water that is buried below $\mathbf{3 0}$ $\mathrm{cm}$, as follows:

$$
B=\left(\omega \phi_{\text {surf }} C_{\text {surf }}-\omega \phi_{30 \mathrm{~cm}} C_{30 \mathrm{~cm}}\right) \Delta t,
$$

where $C_{\text {surf }}$ and $C_{30 \mathrm{~cm}}$ are the concentrations of a species in the overlying water at the surface of the sediments and in the pore water at $30 \mathrm{~cm}$, in millimoles per cubic centimeter $\left(\mathrm{mmol} / \mathrm{cm}^{3}\right) ; \omega$ is the sedimentation rate, in centimeters per year $(\mathrm{cm} / \mathrm{yr}) ; \phi_{\text {surf }}$ and $\phi_{30 \mathrm{~cm}}$ are the porosities at the surface of the sediment and at $30 \mathrm{~cm}$; and $\Delta t$ is the time interval, in years (yr). The sedimentation rate in the vicinity of this station is $0.16 \mathrm{~cm} / \mathrm{yr}$ (Knebel and others, 1981).

The reaction terms (net consumption or production of a species) were obtained as the sum of the other terms as given by equation 12 . Table 1 presents the reaction term as the total mass reacting in the $30-\mathrm{cm}$ sediment column over the entire period. The rate of reaction per day is presented in table 2 . The ratio of alkalinity produced to sulfate reduced is $-2.1: 1$, very close to the $-2: 1$ ratio commonly assumed for sulfate reduction (Berner, 1979). The ratio of alkalinity produced to ammonium produced is 7.5:1.

Burial constitutes an insignificant fraction of the total reaction. The total storage terms range between 10 and 19 percent of the total reaction terms. More than 80 percent of the alkalinity and ammonium released to the pore water during organic decomposition is then released to the overlying water column by diffusion. Similarly, more than 80 percent of the sulfate reduced is supplied by the overlying water.

The possibility of adsorption of ammonium ion onto the solid phases has been excluded from these calculations. Measurements of adsorbed ammonium (Nancy Simon, U.S. Geological Survey, National Center, MS 432, Reston, VA 22092, written commun., 1982) show a maximum concentration of $6 \mu \mathrm{mol} / \mathrm{g}$ (micromoles per gram) in sediment from station V3. At a sediment 
Table 1. Mass accounting for the period May to September 1978 for station V3

[Units: microequivalents per square centimeter $\left(\mu \mathrm{eq} / \mathrm{cm}^{2}\right)$ and micromoles per square centimeter $\left(\mu \mathrm{mol} / \mathrm{cm}^{2}\right)$ ]

\begin{tabular}{lccccc}
\hline Constituent & $\begin{array}{c}\text { Flux } \\
(-\underline{G})\end{array}$ & $\begin{array}{c}\text { Storage } \\
(\underline{S})\end{array}$ & $\begin{array}{c}\text { Burial } \\
(\underline{B})\end{array}$ & $\begin{array}{c}\text { Reaction } \\
(\mathrm{R})\end{array}$ \\
\hline Alkalinity, in $\mu \mathrm{eq} / \mathrm{cm}^{2} \ldots \ldots \ldots \ldots \ldots \ldots$ & 320 & 53 & 0.21 & 373 \\
Ammonium, in $\mu \mathrm{mol} / \mathrm{cm}^{2} \ldots \ldots \ldots \ldots \ldots \ldots$ & 44 & 5 & 0.004 & 49 \\
Sulfate, in $\mu \mathrm{mol} / \mathrm{cm}^{2} \ldots \ldots \ldots \ldots \ldots \ldots$ & -146 & -33 & 0.15 & -179 \\
\hline
\end{tabular}

Table 2. Rates of processes calculated from the period May to September 1978 for station V3 [Units: microequivalents per square centimenter per day ( $\mu \mathrm{eq} / \mathrm{cm}^{2}$-day) and micromoles per square centimenter per day $\left(\mu \mathrm{mol} / \mathrm{cm}^{2}\right.$-day $\left.)\right]$

\begin{tabular}{lccccc}
\hline Constituent & $\begin{array}{c}\text { Flux } \\
(-\underline{F})\end{array}$ & $\begin{array}{c}\text { Storage } \\
(\underline{S})\end{array}$ & $\begin{array}{c}\text { Burial } \\
(\underline{B})\end{array}$ & $\begin{array}{c}\text { Reaction } \\
(\underline{R})\end{array}$ \\
\hline Alkalinity, in $\mu \mathrm{eq} / \mathrm{cm}^{2}$-day $\ldots \ldots \ldots \ldots \ldots$ & 2.41 & 0.40 & 0.002 & 2.81 \\
Ammonium, in $\mu \mathrm{mol} / \mathrm{cm}^{2}$-day $\ldots \ldots \ldots \ldots \ldots$ & 0.33 & 0.04 & $3 \times 10^{-5}$ & 0.37 \\
Sulfate, in $\mu \mathrm{mol} / \mathrm{cm}^{2}$-day $\ldots \ldots \ldots \ldots \ldots \ldots$ & -1.10 & -0.25 & 0.001 & -1.35 \\
\hline
\end{tabular}

accumulation rate of $0.15 \mathrm{~g} / \mathrm{cm}^{2}$-year (grams per square centimeter per year) (Ann Martin, U.S. Geological Survey, Box 25046, DFC, Denver, CO 80225, written commun., $1981)$, the rate of adsorption is $6(0.15) / 365=2.5 \times 10^{-3}$ $\mu \mathrm{mol} / \mathrm{cm}^{2}$-day. Comparison with table 2 shows that ammonium adsorption accounts for less than 1 percent of the total amount of ammonium released by decomposition.

These calculations provide some insight into the importance of several sedimentary processes. The concentration profiles are obviously not at a steady state; however, they imply that storage could be an important process. The preceding calculations demonstrate that storage accounts for 20 percent or less of the organic decomposition reaction. In these sediments the rates of burial and adsorption are insignificant relative to the rate of organic decomposition. An adequate accounting of the rates of reaction can be obtained if the fluxes across the sediment-water interface are known through a yearly cycle. These calculations also imply that the assumptions made in deriving the equation to calculate the stoichiometry of organic decomposition (that is, the assumptions leading to equation 2) are reasonable approximations even with these nonsteadystate conditions.

\section{STOICHIOMETRY DETERMINED FROM CONCENTRATIONS IN THE SOLID PHASES}

The concentrations of organic carbon and nitrogen in the solid phases at stations V3 and V6 systematically decrease with depth (fig. 5). If the sedimentation rate and the sediment composition have been constant, these decreases reflect the amount of organic decomposition. Profiles of ${ }^{210} \mathrm{~Pb}$ (Ann Martin, U.S. Geological Survey, Box 25046, DFC, Denver, CO 80225, written commun., 1981) can be used to corroborate the assumption of steadystate sediment deposition. For the area near station V3, the ${ }^{210} \mathrm{~Pb}$ profiles have a smooth exponential decrease as expected from steady-state sedimentation, and a consistent sedimentation rate of $0.16 \mathrm{~cm} / \mathrm{yr}$ was found. In the area of station V6, the sedimentation rate determined from ${ }^{210} \mathrm{~Pb}$ was less well defined, but a trend indicating a rate of $2 \mathrm{~cm} / \mathrm{yr}$ was found (Knebel and others, 1981). Carbon and nitrogen in the solid phases of cores collected at station V6 are more erratic than at station V3, but a general decrease in concentration with depth was observed. The ${ }^{210} \mathrm{~Pb}$ data suggest that the approximation of steady-state sedimentation can be used at stations V3 and V6.

The flux of carbon and nitrogen out of the sediment can be calculated from the concentrations in the solid phases. The change in concentration of carbon (or nitrogen) multiplied by the sediment accumulation rate $\left(\mathrm{g} / \mathrm{cm}^{2}-\mathrm{yr}\right)$ is an estimate of the flux rate. The fluxes calculated from the solids in this manner are compared in table 3 with fluxes calculated from pore-water concentration gradients.

The fluxes calculated from the solid-phase data are lower than those from the pore-water data. The calculations with the solids are expected to represent long-term 

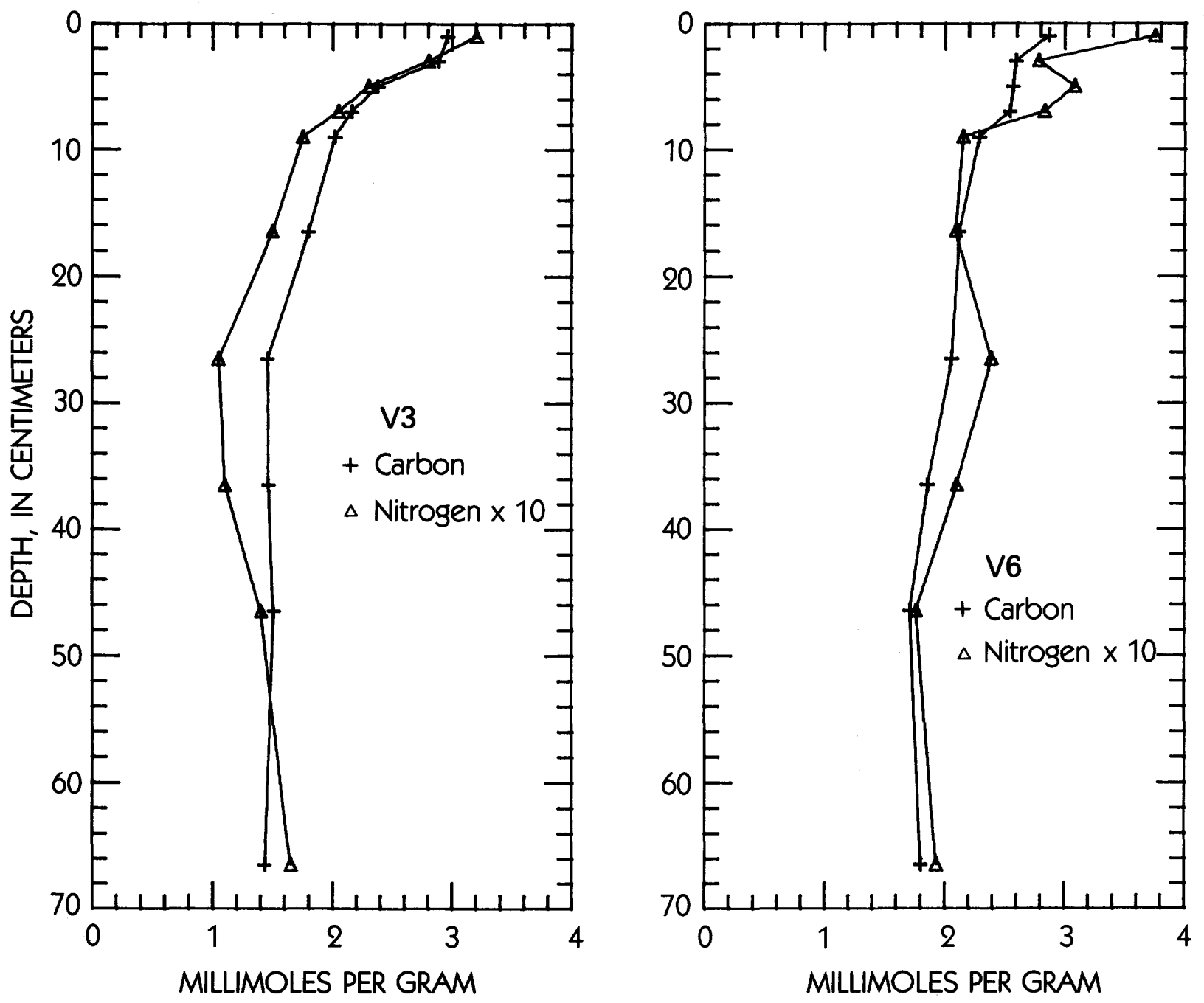

Figure 5. Concentration profiles of carbon and nitrogen in the solid phase for stations V3 (May 1978) and V6 (May 1978).

Table 3. Flux rates calculated from analyses of pore water and solid phases

[Units: micromoles per square centimeter per day $\left(\mu \mathrm{mol} / \mathrm{cm}^{2}\right.$-day)]

\begin{tabular}{|c|c|c|c|c|}
\hline \multirow[t]{2}{*}{ Station } & \multirow[t]{2}{*}{ Element } & \multicolumn{2}{|c|}{$\begin{array}{c}\text { Flux calculated from } \\
\text { pore-water data } \\
\left(\text { umol } / \mathrm{cm}^{2} \text {-day }\right)\end{array}$} & \multirow[t]{2}{*}{$\begin{array}{l}\text { Flux calculated } \\
\text { from solid phase } \\
\text { (umol/ } \mathrm{cm}^{2} \text {-day) }\end{array}$} \\
\hline & & May & August & \\
\hline \multirow[t]{2}{*}{ V3 } & Carbon.......... & 1.31 & 3.38 & 0.63 \\
\hline & Nitrogen......... & 0.25 & 0.42 & 0.09 \\
\hline \multirow[t]{2}{*}{ v6 } & Carbon........... & 4.52 & 6.38 & 1.37 \\
\hline & Nitrogen......... & 0.55 & 1.37 & 0.23 \\
\hline
\end{tabular}

(tens of years) average fluxes. These fluxes should be lower than those calculated from the pore water, which reflect reactions during the late spring and summer, the period with the most rapid rates of decomposition. The large fluxes calculated from the pore-water data indicate that the rate of decomposition is fast enough to produce the observed concentration changes in the solids.
An alternative hypothesis is that the high carbon and nitrogen concentrations near the sediment-water interface are due to a historical increase in the organic fraction of the sediment. If this were true, station V6 should to have high carbon and nitrogen concentrations to a greater depth than station V3 because the sedimentation rate is nearly 10 times greater at station V6 than at station 
V3. In fact, the carbon and nitrogen at station V6 decrease over a depth range similar to that at station V3 as shown on figure 5. These data suggest that organic decomposition is responsible for the concentration decreases in the solid phases with depth, not historical changes in the composition of the sediment.

A plot of organic carbon versus nitrogen in the solid phases should demonstrate the loss of carbon and nitrogen from the sediment solids, if the steady-state assumptions apply. The slope of the plot should be the ratio in which carbon is lost relative to nitrogen, that is, the $\mathrm{C}: \mathrm{N}$ ratio of the reaction. Figure 6 is a plot of such data from stations V3 and V6. There is some scatter in the points, but the data points for each individual core follow a trend from the upper right of the diagram (for samples near the sediment-water interface) to the lower left on the diagram (for samples at depth). The best-fit line for all the data points has a slope of 5.9 .

The C:N ratio of 5.9:1 is in reasonable agreement with the values derived from the pore water concentrations, 7.2:1 and 7.7:1. The intercept of the line on the plot of solid carbon and nitrogen concentrations (fig. 6) is not zero, demonstrating that the stoichiometry of the organic decomposition reactions is not the same as the composition of the bulk organic matter. The average $\mathrm{C}: \mathrm{N}$ ratio of the solids,
9.6:1, is higher than the estimates of the $\mathrm{C}: \mathrm{N}$ ratios of the reactive part of the organic matter. The data presented indicate that part of the organic matter, with a C:N ratio in the range of 5.5:1 to 8:1, is the reactive fraction of the organic matter in the Potomac River estuary. The more refractory organic matter must have a greater $\mathrm{C}: \mathrm{N}$ ratio.

Spiker (1981) and Hunt (1968) concluded on the basis of $\delta^{13} \mathrm{C}$ measurements that marine plankton dominate the organic matter in the lower portion of the Potomac River estuary, although Spiker noted a winter input of terrigenous material. Lyons and Gaudette (1979) suggested that marine organic matter in the estuarine sediments of Great Bay, New Hampshire, is more readily metabolized than the terrigenous organic matter. The data presented in the present study are consistent with the hypothesis that low-C:N marine plankton are the reactive fraction of the organic matter in the sediment near the mouth of the Potomac River estuary. Further work is necessary to determine the nature of the compounds actually decomposed.

\section{SUMMARY}

The decomposition of organic matter in sediment was investigated at two stations near the mouth of the Potomac River estuary. Concentration data for pore water

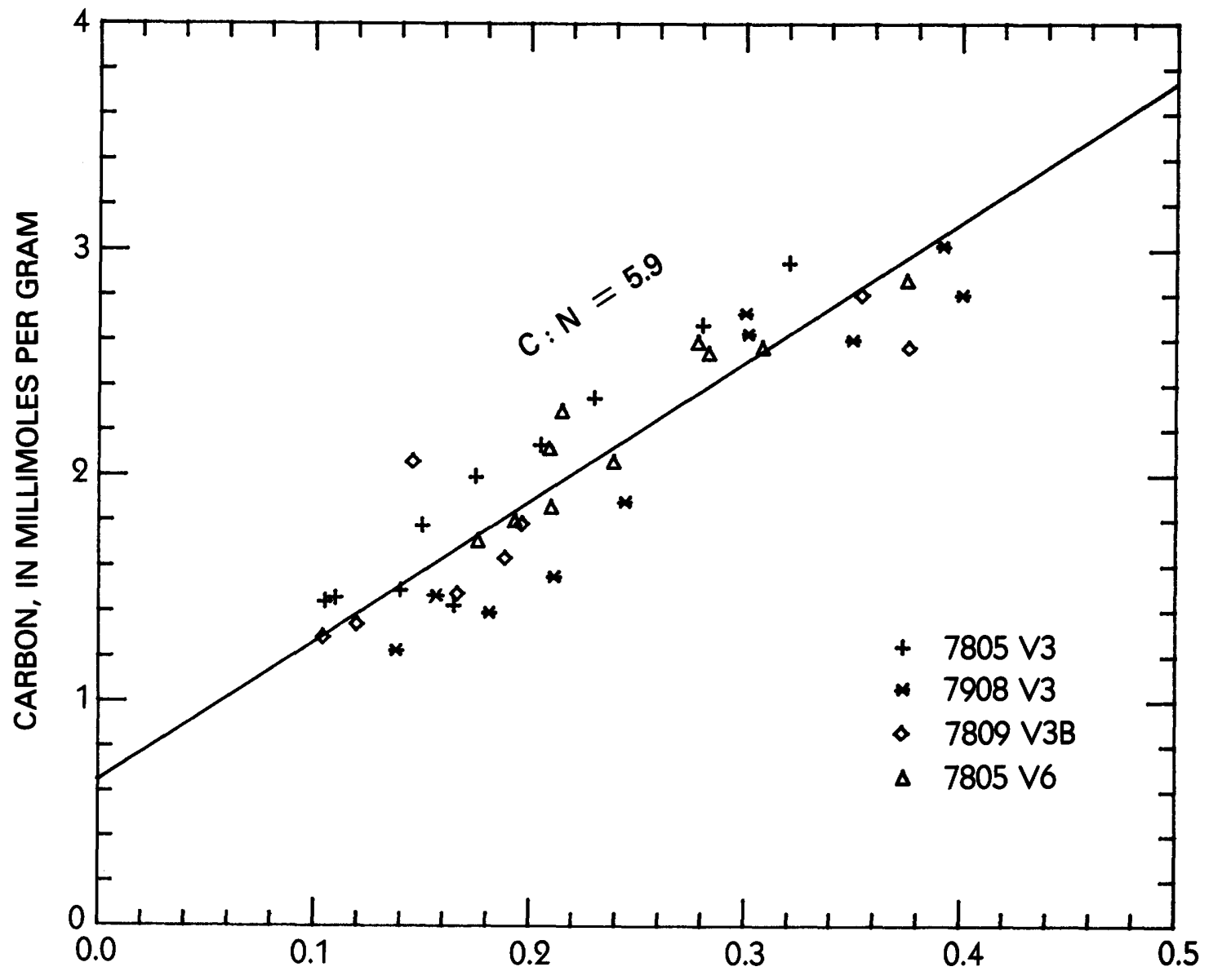

NITROGEN, IN MILLIMOLES PER GRAM

Figure 6. Concentration of carbon versus concentration of nitrogen in solid phases for four cores from stations V3 and V6 in the Potomac River estuary (fig. 1). Slope of line through points is an estimate of C:N ratio of the reacting organic matter. Symbols refer to numbered core samples. 
and solid phases of the sediment were used to determine the stoichiometry of decomposition reactions, and mass balance calculations were made to estimate the importance of storage, burial, and ammonium adsorption.

The pore-water concentrations of alkalinity and ammonium were used to determine the stoichiometry of decomposition reactions. Assuming steady-state conditions, equations were derived to determine the $\mathrm{C}: \mathrm{N}$ ratio of the reactive part of the organic matter. The $\mathrm{C}: \mathrm{N}$ ratio was 7.7:1 for decomposition of organic matter by sulfate reduction and 7.2:1 for decomposition by methanogenesis. By a similar analysis, the C:S ratio was $-2.1: 1$ for sulfate reduction. This ratio is close to the theoretical value of $-2.0: 1$.

A mass-balance accounting was made for carbon, ammonium, and sulfate at one station for May 1978 to September 1978. Between 10 and 20 percent of the carbon and ammonium produced by decomposition of organic matter was retained in the sediment pore water. More than 80 percent of the carbon and ammonium produced by decomposition was released from the sediment pore water to the overlying water. The decrease in sulfate concentration in the pore water during this period accounted for 19 percent of the sulfate consumed in organic-decomposition reactions. About 80 percent of the sulfate consumed in organic-decomposition reactions was supplied by the overlying water.

The rate that carbon, ammonium, and sulfate accumulated in the pore water due to burial was insignificant compared with the rate of decomposition of organic matter. The rate that ammonium was adsorbed onto solid phases of the sediment was less than 1 percent of the rate that ammonium was released by the decomposition of organic matter.

Calculations indicated that storage, a nonsteadystate effect, burial, and ammonium adsorption accounted for less than 20 percent of the total rate of organic decomposition. The calculations support the assumptions made in the derivation of the equations used to determine the stoichiometry of decomposition from pore-water data.

The stoichiometry of organic decomposition reactions was estimated using the concentrations of carbon and nitrogen in the solid phases of the sediment. The estimate of the $\mathrm{C}: \mathrm{N}$ ratio of the reactive organic matter was 5.9:1. The organic-decomposition pathways of sulfate reduction and methanogenesis were not distinguishable using these data. The data presented indicate that part of the organic matter, having a $\mathrm{C}: \mathrm{N}$ ratio in the range 5.5:1 to $8: 1$, is the reactive fraction of the organic matter in the Potomac River estuary. The total C:N ratio of the organic matter is 9.6:1. The more refractory organic matter must have a greater $\mathrm{C}: \mathrm{N}$ ratio.

\section{REFERENCES CITED}

Almgreen, T., and Fonselius S. H., 1976, Determination of alkalinity and total carbonate, in Grasshoff, Klaus, ed.,
Methods of seawater analysis: New York, Verlag Chemie, p. 97-115.

Andrews, D., and Bennett, A., 1981, Measurements of diffusivity near the sediment water interface with a fine scale resistivity probe: Geochimica et Cosmochimica Acta, v. 45, p. 2169-2175.

Berner, R. A., 1975, Diagenetic models of dissolved species in the interstitial waters of compacting sediments: American Journal of Science, v. 275, p. 88-96.

1977, Stoichiometric models for nutrient regeneration in anoxic sediments: Limnology and Oceanography, v. 22, p. 781-786.

1979, A new look at biogenous material in deep sea sediments: Ambio Special Report, v. 6, p. 5-10.

1980, Early diagenesis-A theoretical approach: Princeton, N. J., Princeton University Press, 241 p.

Blanchard, S. F., and Hahl, D. C., 1981, Water quality of the tidal Potomac River and estuary hydrologic data report, 1979 water year: U.S. Geological Survey Open-File Report 81-1074, 149 p.

Bremner, J. M., 1965, Methods of soil analysis-Part 2: Madison, Wisconsin, American Society of Agronomy, p. 1149-1176.

Callender, Edward, and Hammond, D. E., 1982, Nutrient exchange across the sediment-water interface in the Potomac River estuary: Estuarine, Coastal and Shelf Science, v. 15, p. 395-413.

Dollman, G. W., 1968, Determination of sulfate and phosphate in water by ion exchange-titrimetric method: Environmental Science and Technology, v. 2, p. 1027-1029.

Goodwin, S. D., Schultz, B. I., Parkhurst, D. L., Simon, N. S., and Callender, Edward, 1984, Methods for the collection of geochemical data from the sediments of the tidal Potomac River and estuary, and data for 1978-1980: U.S. Geological Survey Open-File Report 84-074, 129 p.

Gordon, D. C., 1971, Distribution of particulate organic carbon and nitrogen at an ocean station in the Central Pacific: Deep-Sea Research, v.18, p. 1127-1134.

Holm-Hansen, O., Strickland, J. D., and Williams, P. M., 1966, A detailed analysis of biologically important substances in a profile off Southern California: Limnology and Oceanography, v: 11, p. 548-561.

Hunt, J. M., 1968, The significance of carbon isotope variations in marine sediments, in Hobson, G. D., ed., Carbon in biochemistry: London, Pergamon Press, p. 27-35.

Kamatani, A., 1969, Regeneration of inorganic nutrients from diatom decomposition: Journal of the Oceanographic Society of Japan, v. 25, p. 63-74.

Knebel, H. J., Martin, E. A., Glen, J. L., and Needel, S. W., 1981, Sedimentary framework of the Potomac River estuary, Maryland: Geological Society of America Bulletin, pt. I, v. 92 , p. $578-589$.

Li, Y.-H., and Gregory, S., 1974, Diffusion of ions in sea water and in deep-sea sediments: Geochimica et Cosmochimica Acta, v. 38, p. 703-714.

Lyons, W. B., and Gaudette, H. E., 1979, Sulfate reduction and the nature of organic matter in estuarine sediments: Organic Geochemistry, v. 1, p. 151-155.

Nedwell, D. B., and Floodgate, G. D., 1972a, Temperatureinduced changes in formation of sulphide in a marine sediment: Marine Biology, v. 14, p. 18-24. 
$1972 b$, The effects of microbial activity upon the sedimentary sulphur cycle: Marine Biology, v. 16, p. 192-200.

Pockington, R., 1976, Terrigenous organic matter in surface sediments from the Gulf of St. Lawrence: Journal of Fisheries Research Board of Canada, v. 33, p. 93-97.

Redfield, A. C., 1958, The biological control of chemical factors in the environment: American Scientist, p. 205-221.

Reeburgh, W. S., 1967, An improved interstitial water sampler: Limnology and Oceanography, v. 12, p. 163-165.
Solorzano, L., 1969, Determination of ammonia in -natural waters by phenol-hypochlorite method: Limnology and Oceanography, v. 14, p. 799-801.

Spiker, E. C., 1981, Carbon isotopes as indicators of the source and fate of carbon in rivers and estuaries, in Carbon dioxide effects research and assessment program, CONF-8009140, Report of a workshop, Woods Hole, Massachusetts, September 21-25, 1980, Flux of organic carbon by rivers to oceans: Washington, D.C., U.S. Department of Energy, p. 73-108. 


\title{
Relation of Hydrocarbon Type to Maturity of Organic Matter in Upper Cretaceous Chalks, Eastern Denver Basin
}

\author{
By DUDLEY D. RICE, U.S. Geological Survey, Box 25046, Denver Federal Center, \\ MS 934, Denver, Colorado 80225
}

\section{CONTENTS}

\author{
Abstract 76 \\ Introduction 76 \\ Hydrocarbon reservoirs 76 \\ Gas geochemistry and origin 76 \\ Source-rock geochemistry 77 \\ Thermal maturity $\mathbf{8 0}$ \\ Summary and conclusions 81 \\ References cited $\mathbf{8 1}$
}

\section{FIGURES}

1. Index map of Denver basin showing contours on Precambrian 77

2. Graph showing changes of $\delta^{13} C_{1}$ with depth of natural gases from Niobrara Formation in Colorado and Kansas 79

3. Modified van Krevelen diagram showing type and maturity of kerogen from three wells $\mathbf{8 0}$

\section{TABLES}

1. Chemical and isotope composition of natural gas from selected wells $\mathbf{7 8}$

2. Details of wells from which core samples were analyzed $\mathbf{7 9}$ 


\section{Abstract}

Oil and wet gas-condensate production has been established from chalk beds of the Upper Cretaceous Niobrara Formation and underlying Codell Sandstone Member of the Carlile Shale in the deeper part of the Denver basin. Dry gas has been produced from chalk reservoirs in the Niobrara on the shallow east flank of the basin. The shallow east-flank gases are chemically dry, isotopically light with respect to $\delta^{13} C_{1}$ values, and are probably of local biogenic origin. The Niobrara contains organic-rich laminations characterized by type II kerogen. This type of organic matter is capable of generating oil and wet gascondensate when subjected to thermal degradation and cracking processes. The thermal maturity pattern present in the Niobrara Formation appears to explain the occurrence of thermogenic hydrocarbons in the deeper part of the basin and biogenic gases on the shallow east flank.

\section{INTRODUCTION}

Oil and wet gas-condensate are produced from chalk beds of the Upper Cretaceous Niobrara Formation and underlying Codell Sandstone Member of the Carlile Shale in the deep Wattenberg area of the Denver basin in north-central Colorado (fig. 1). Dry natural gas has also been produced from chalk reservoirs of the Niobrara Formation in several shallow fields on the eastern flank of the basin in northeastern Colorado and northwestern Kansas. The east-flank gas fields trend northwest-southeast; present-day depths of burial increase from about 250 to $850 \mathrm{~m}$ toward the northwest. The following data and discussion are summarized from a more complete report (Rice, 1984) and concern primarily the nature and origin of gas in this trend with respect to source rocks, kerogen types, and maturity patterns present in the Niobrara. The results of this work, when combined with existing data on hydrocarbon type and thermal maturity from the deeper Wattenberg area of the basin (Clayton and Swetland, 1980; Tainter, 1982; Rice and others, 1984) are of value in predicting regional patterns of thermal maturity and of hydrocarbon distribution related to both thermogenic and biogenic processes of generation.

\section{HYDROCARBON RESERVOIRS}

The gas-bearing reservoirs producing in shallow fields on the east flank of the Denver basin are finegrained chalks consisting predominantly of calcareous nanofossils and microfossils. The chalks are characterized by high porosity (30-45 percent) and low permeability (average 1 millidarcy) at these shallow depths (Lockridge and Scholle, 1978). Core samples of wells from the productive east-flank area (fig. 1) average 30 percent insoluble residue which is concentrated with organic matter in alternating laminations.

Gas-bearing Niobrara chalk reservoirs on the shallow east flank of the basin have apparently lost most of their original high matrix porosity because of depthrelated diagenetic processes (Lockridge and Scholle, 1978). As a result, most productive oil and wet gascondensate reservoirs found in the deeper part of the basin are characterized by fracture-type porosity and permeability (Mallory, 1977; Pollastro and Scholle, 1984). The deep Wattenberg area of the basin in Colorado has areally extensive production from the Codell Sandstone Member of the Carlile Shale, a unit which immediately underlies the Niobrara. Productive Codell reservoirs generally consist of fine-grained shaley and calcareous sandstone and are characterized by low matrix porosity and permeability. Poor matrix reservoir characteristics have been enhanced locally by the formation of natural fracture systems (Petroleum Information, 1983).

\section{GAS GEOCHEMISTRY AND ORIGIN}

Gas samples were collected from seven wells along a southeast-northwest belt that parallels the productive trend of shallow gas fields as shown in figure 1. Presentday depths of burial to the top of the Niobrara chalk reservoirs increase to the northwest from 328 to $842 \mathrm{~m}$. All the gases are uniformly dry; methane generally accounts for more than 98 percent of the hydrocarbon fraction (table 1). In addition, the methane component of the gases is enriched in the light isotope ${ }^{12} \mathrm{C}$, and $\delta^{13} \mathrm{C}_{1}$ values are lighter than -55 per mil. As shown in figure 2, the most significant change in the gases from the Niobrara is that they become isotopically heavier with increasing depth of burial; $\delta^{13} \mathrm{C}_{1}$ values range from -65 per mil at $328 \mathrm{~m}$ to -55 per mil at $842 \mathrm{~m}$.

The chemical and isotope composition of these shallow natural gases suggest that they are dominantly of microbiological or biogenic origin (Rice and Claypool, 1981). Biogenic gas was generated during the immature stage of hydrocarbon generation prior to onset of major oil and gas generation by thermal cracking. The biogenic gas was generated by the breakdown of organic matter at low temperatures by microorganisms in an anaerobic, presumably sulfate-free, environment at low temperatures.

In-place generation of shallow biogenic gas is suggested by the facts that the chalks (1) have low permeability that inhibits long-range migration, (2) are overlain by a thick section of shale (Pierre Shale) containing many bentonites that served as a seal for the gas, and (3) contain organic-rich laminae that provided ample source for gas.

The isotopically light, dry gases characteristic of the shallow east-flank fields are in marked contrast to those encountered in oil and condensate production from reservoirs of Niobrara Formation and underlying Codell Sandstone Member in the Wattenberg area of the Denver basin in Colorado (Rice and others, 1984) (fig. 1). Gases from the Codell in this part of the basin become isotopically heavier $\left(\delta^{13} C_{1}\right.$ values range from -47.8 to -43.5 per mil) as they become chemically drier $\left(C_{1} / C_{1-5}\right.$ range from 0.76 


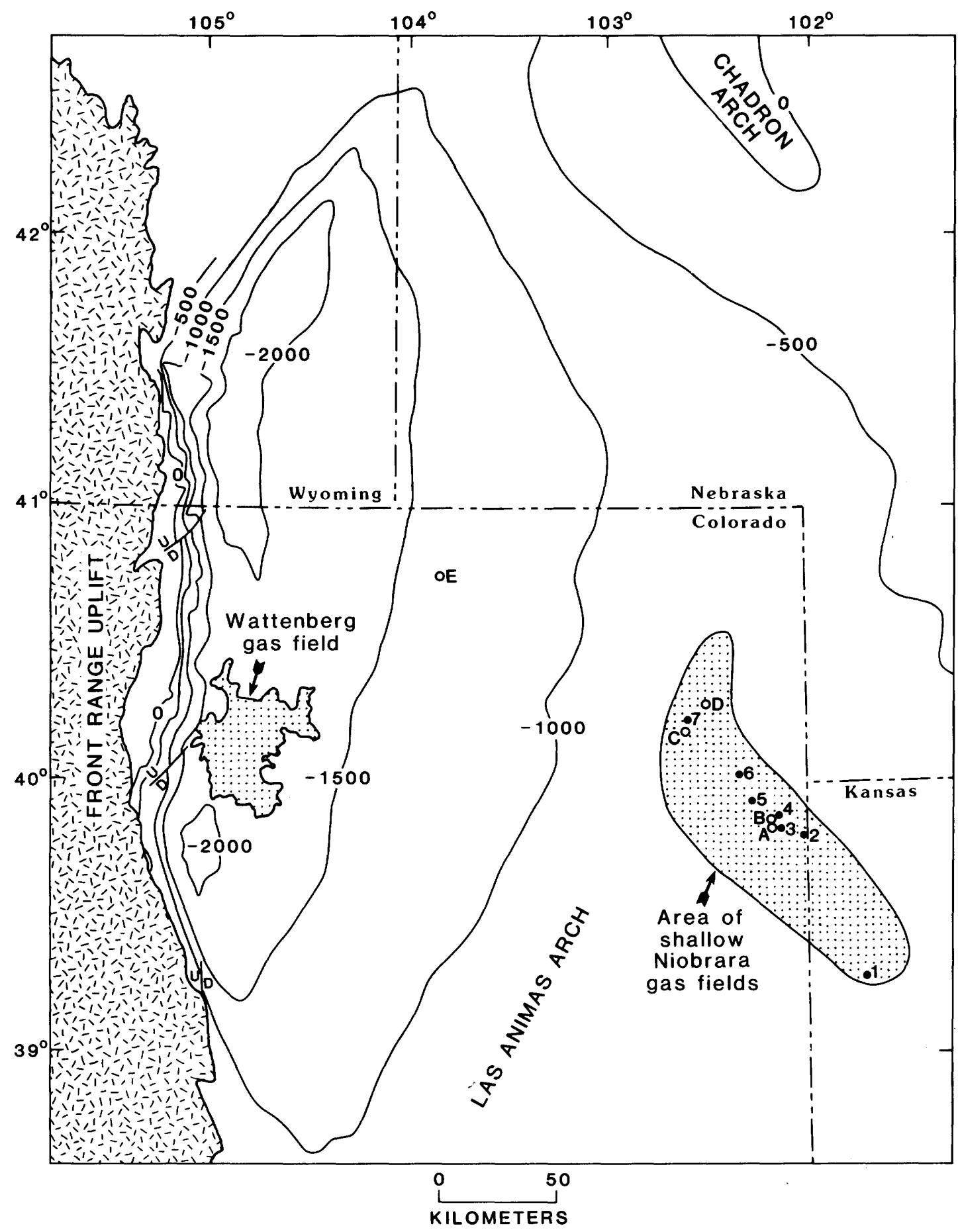

Figure 1. Index map of Denver basin showing structure contours on Precambrian. Contour interval is 500 $\mathrm{m}$. Stipple patterns indicate areas of hydrocarbon production from Niobrara chalks. Location of wells from which gas samples were analyzed are labeled by numbers (table 1) and from which core samples were analyzed are labeled by letters (table 2).

to 0.8 ) at depths ranging from 2,082 to $2,265 \mathrm{~m}$. These gases are probably of thermogenic origin and were formed during the mature stage of hydrocarbon generation.

\section{SOURCE-ROCK GEOCHEMISTRY}

The amount, type, and level of maturation of organic matter within the Niobrara chalks of the eastern Denver basin were evaluated by analyses of core samples from five wells in northeastern Colorado. Location of the wells is shown on figure 1; details of the wells and cored intervals are given in table 2 . Organic carbon values in chalk beds of the Niobrara Formation range from 0.43 to 5.8 percent and average 3.2 percent. The organic 
Table 1. Chemical and isotopic composition of natural gas from selected wells shown in figure 1 [tr., trace; isotope composition in per mil]

\begin{tabular}{|c|c|c|c|c|c|c|c|c|c|c|c|c|c|c|}
\hline $\begin{array}{l}\text { Map } \\
\text { No. }\end{array}$ & Well name & Location & $\begin{array}{l}\text { Pay zone } \\
\text { (meters) }\end{array}$ & $\begin{array}{l}\mathrm{N}_{2} \text { and } \\
(\mathrm{or}) \text { air }\end{array}$ & $\mathrm{CH}_{4}$ & $\mathrm{CO}_{2}$ & $\mathrm{C}_{2} \mathrm{H}_{6}$ & $\mathrm{C}_{3} \mathrm{H}_{8}$ & $1-C_{4} \mathrm{H}_{10}$ & $\mathrm{n}-\mathrm{C}_{4} \mathrm{H}_{10}$ & $1-\mathrm{C}_{5} \mathrm{H}_{12}$ & $\mathrm{n}-\mathrm{C}_{5} \mathrm{H}_{12}$ & $c_{1} / c_{1-5}$ & $8^{13} c_{1}$ \\
\hline \multicolumn{15}{|c|}{ Kansas : } \\
\hline 1. & $\begin{array}{l}\text { Mountain Petroleum } \\
\text { Topl1ff No. 1-10- }\end{array}$ & NW $1 / 4$ SE $1 / 4$ sec. 10, T. 9 S., R. 40 W. & $322-328$ & 5.18 & 93.91 & 0.25 & 0.67 & tr. & tr. & tr. & tr. & tr. & 0.993 & -65.4 \\
\hline \multicolumn{15}{|c|}{ Colorado: } \\
\hline 2. & $\begin{array}{l}\text { Kansas-Ne braska } \\
\text { Natural Gas } \\
\text { Engel No. 1-10- }\end{array}$ & SW $1 / 4$ SW $1 / 4$ sec. 10, T. 3 s., R. 42 W. & $478-482$ & 6.83 & 91.18 & .13 & 1.24 & 0.39 & 0.06 & 0.06 & 0.02 & 0.01 & .981 & -62.5 \\
\hline 3. & $\begin{array}{l}\text { Mountain Petroleum } \\
\text { Ekberg No. 2-34- }\end{array}$ & NW $1 / 4$ NW $1 / 4$ sec. 34, T. 2 S., R. 43 w. & $481-491$ & 5.08 & 92.9 & .29 & 1.16 & .41 & .07 & .06 & tr. & tr. & .982 & -60.8 \\
\hline 4. & $\begin{array}{l}\text { Mountaln Petroleum } \\
\text { State No. 1-16- }\end{array}$ & NE $1 / 4 \mathrm{SW} 1 / 4 \mathrm{sec} .16$, T. 2 S., R. 43 w. & $513-518$ & 5.46 & 92.53 & .23 & 1.06 & .48 & .09 & .08 & .03 & .02 & .981 & -60.1 \\
\hline 5. & $\begin{array}{l}\text { Kansas-Nebraska } \\
\text { Natural Gas } \\
\text { Allison No. 1-29_-- }\end{array}$ & SE $1 / 4$ SE $1 / 4$ sec. 29, T. 1 S., R. 44 W. & $642-647$ & 5.72 & 92.1 & .24 & 1.07 & .55 & .13 & .11 & .04 & .03 & .979 & -58.8 \\
\hline 6. & $\begin{array}{l}\text { Kansas-Nebraska } \\
\text { Natura1 Gas } \\
\text { Ponte No. 1-27- }\end{array}$ & SW $1 / 4$ NE $1 / 4 \mathrm{sec} .27$, T. 1 N., R. 45 W. & $688-695$ & 6.6 & 91.4 & .2 & .91 & .54 & .12 & .12 & .05 & .04 & .981 & -59.7 \\
\hline 7. & $\begin{array}{l}\text { Kansas-Nebraska } \\
\text { Natural Gas } \\
\text { State No. 1-- }\end{array}$ & $\mathrm{NE} 1 / 4 \mathrm{NE} 1 / 4 \mathrm{sec} .16$, T. $3 \mathrm{~N} .$, R. 47 W. & $838-842$ & 5.12 & 92.85 & .43 & 1.05 & .34 & .09 & .07 & .03 & .02 & .976 & -54.7 \\
\hline
\end{tabular}




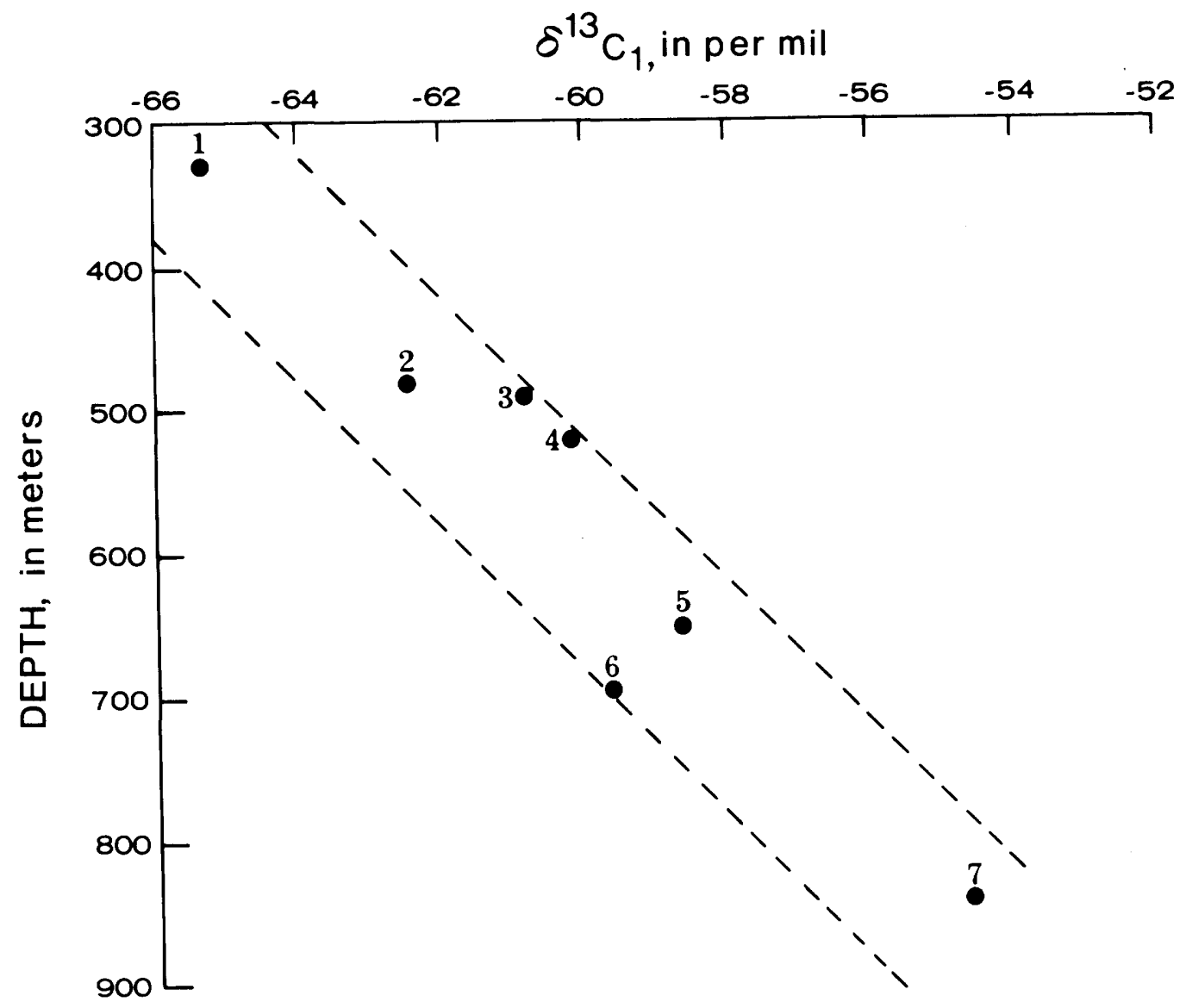

Figure 2. Changes of $\delta^{13} \mathrm{C}_{1}$ with depth of natural gases from Niobrara Formation in Colorado and Kansas. Dots and numbers correspond to wells shown in figure 1 and described in table 1.

Table 2. Details of wells from which core samples were analyzed

\begin{tabular}{|c|c|c|c|c|c|c|c|}
\hline $\begin{array}{l}\text { Map } \\
\text { letter }\end{array}$ & We11 name & Location & $\begin{array}{l}\text { Status } \\
\text { of well }\end{array}$ & $\begin{array}{c}\text { Top } \\
\text { of } \\
\text { Niobrara } \\
\text { (meters) }\end{array}$ & $\begin{array}{l}\text { Pay } \\
\text { interval } \\
\text { (meters) }\end{array}$ & $\begin{array}{l}\text { Cored } \\
\text { interval } \\
\text { (meters) }\end{array}$ & $\begin{array}{c}\text { Maximum } \\
\text { recorded } \\
\text { bottomhole } \\
\text { temperature } \\
\text { (degrees Celsius) }\end{array}$ \\
\hline A. 1 & $\begin{array}{l}\text { Kansas-Nebraska } \\
\text { Natural Gas } \\
\text { Whomble No. 1-32. }\end{array}$ & $\begin{array}{l}\mathrm{NE} 1 / 4 \mathrm{NE} 1 / 4 \mathrm{sec} .32, \\
\text { T. } 2 \text { S., R. } 43 \text { W. }\end{array}$ & Gas we11--- & 454 & $457-466$ & $447-463$ & 36 \\
\hline B. 1 & $\begin{array}{l}\text { Mountain Petroleum } \\
\text { State No. } 1-29 \text {. }\end{array}$ & $\begin{array}{l}\text { SW } 1 / 4 \mathrm{NE} 1 / 4 \text { sec. } 29, \\
\text { T. } 2 \text { S., R. } 43 \text { W. }\end{array}$ & Gas we11--- & 443 & $451-454$ & $445-452$ & 32 \\
\hline c. & $\begin{array}{l}\text { Kansas-Nebraska } \\
\text { Natural Gas } \\
\text { Powell No. 1-33. }\end{array}$ & $\begin{array}{l}\text { NE } 1 / 4 \mathrm{SW} 1 / 4 \mathrm{sec} .33, \\
\text { T. } 3 \mathrm{~N} ., \text { R. } 47 \text { W. }\end{array}$ & $\begin{array}{l}\text { Dry and } \\
\text { abandoned. }\end{array}$ & 853 & & $853-871$ & 47 \\
\hline D. & $\begin{array}{l}\text { J-W Operating } \\
\text { Brophy No. i. }\end{array}$ & $\begin{array}{l}\mathrm{SE} 1 / 4 \mathrm{SE} 1 / 4 \mathrm{sec} .29, \\
\text { T. } 4 \mathrm{~N} ., \mathrm{R} .46 \mathrm{~W} .\end{array}$ & Gas we11--- & 836 & $839-842$ & $842-863$ & 46 \\
\hline E. & $\begin{array}{l}\text { Excelsior 0il } \\
\text { Alice G. Nay No. } 1 .\end{array}$ & $\begin{array}{l}\text { NW } 1 / 4 \mathrm{SE} 1 / 4 \mathrm{sec} .14, \\
\text { T. } 9 \text { N., R. } 58 \text { W. }\end{array}$ & 011 well & 1,646 & $1,681-1,687$ & $1,655-1,667$ & 74 \\
\hline
\end{tabular}

matter is concentrated with larger amounts of insoluble residue in the darker colored laminae.

The hydrocarbon generation potential of organic carbon found in the Niobrara can be evaluated by pyrolysis using a "Rock-Eval" instrument (Espatalie and others, 1977). Both the type and level of maturation of the organic matter can be determined by use of a modified van Krevelen diagram. Samples from three wells (A, C, and $\mathrm{E}$, fig. 1) are plotted on a modified van Krevelen diagram shown in figure 3 . These samples are typical of those from all five wells. All samples shown in figure 3 cluster along the type II path. Type II kerogen is 


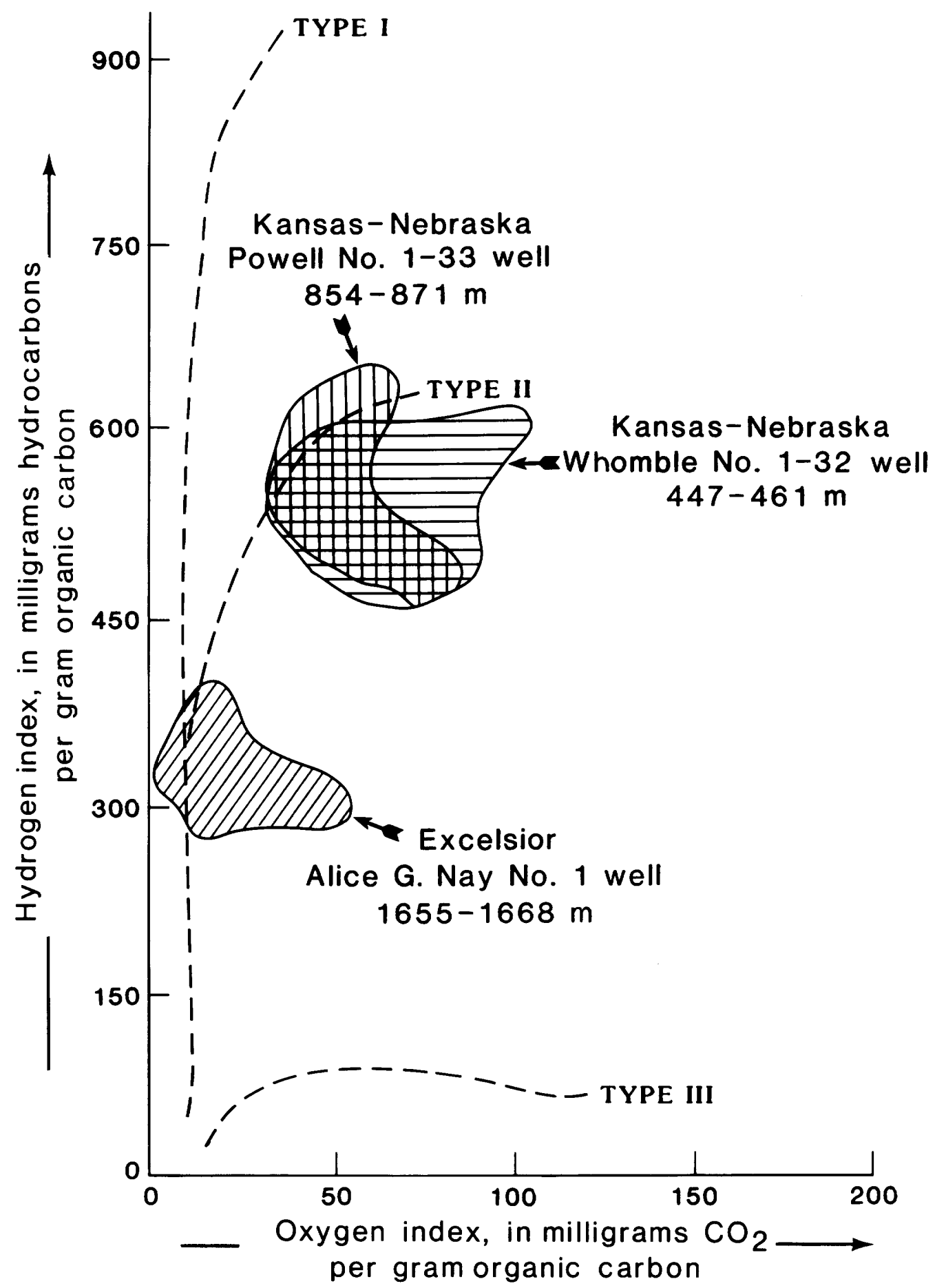

Figure 3. Modified van Krevelen diagram showing type and maturity of kerogen from three selected wells. Pyrolysis data for all five wells are presented in Rice (1984).

hydrogen-rich and is made up predominantly of sapropelic material that is typical of an open-marine environment. Data from visual kerogen analyses and elemental analyses confirm this interpretation of the type of kerogen (Rice, 1984). Type II kerogens are generally considered to generate oil and associated gas during the intermediate stages of thermal history. As temperatures increase, lighter hydrocarbons (wet gas-condensate and finally dry gas) are formed more rapidly because of thermal cracking processes affecting residual kerogen and previously formed heavier hydrocarbons.

\section{THERMAL MATURITY}

In general, the level of maturation in the Niobrara on the shallow east flank of the basin increases to the 
northwest. This increase is consistent with the following changes: (1) present-day depth of burial increases to the northwest, (2) porosity and permeability of the chalks decrease to the northwest (Lockridge and Scholle, 1978), (3) carbon isotope compositions of biogenic gases become heavier within the producing trend to the northwest (fig. 2), and (4) oil has been produced from Niobrara Formation in well E (fig. 1) northwest of the gas-productive area.

Pyrolysis data were used to determine thermal maturity by the position of samples on the evolutionary path of a particular type of kerogen using a modified van Krevelen diagram (fig. 3). As discussed earlier, the kerogen from all five wells examined was classified as type II. Samples from wells $A$ and $C$, which are considered typical for wells $B$ and D also, plot on the immature part of the evolutionary path. Kerogen from samples of well E, 100 $\mathrm{km}$ northwest of the gas-productive area, has a substantially lower "hydrocarbon index" and is probably in the mature stage. The same levels of maturity were indicated by clay-mineral transformations (Pollastro and Scholle, in press) and thermal alteration index, vitrinite reflectance, elemental analysis, and solvent extraction and elution chromatographic data (Rice, 1984). Present-day bottomhole temperatures from wells penetrating the Niobrara Formation suggest that the geothermal gradient was higher and (or) that more overburden was present to account for the generation of liquid hydrocarbons in the vicinity of well $\mathrm{E}$. The pattern of maturity indicated by these data is consistent with that presented for the Niobrara by Tainter (1982) and for the slightly deeper Carlile-Graneros-Mowry interval by Clayton and Swetland (1980). The pattern provides evidence that oil and wet gas-condensate produced from Niobrara and adjacent Codell reservoirs in the deep Wattenberg area of the basin were probably formed by thermal degradation and cracking that affected type II kerogen concentrated in the Niobrara. In contrast, the dry gases found on the shallow eastern flank have been derived from low-temperature microbiological processes.

\section{SUMMARY AND CONCLUSIONS}

Data and interpretations presented in this paper suggest the following conclusions:

1. Organic-rich laminations containing an average of 3.2 percent organic carbon representing type II kerogen are present in the Niobrara Formation.

2. The Niobrara Formation and underlying Codell Sandstone Member of the Carlile Shale produce oil and wet gas-condensate in the deeper part of the Denver basin and dry gas on the shallow eastern flank.

3. The shallow eastern-flank gases are chemically dry and isotopically light $\left(\delta^{13} \mathrm{C}_{1}\right.$ values range from -65 to -55 per mil) and are probably of biogenic origin. Oil and wet gas-condensate produced from deeper in the basin were probably formed by thermal cracking and degradation processes that affected kerogen concentrated in the Niobrara. This interpretation is consistent with the occurrence of isotopically heavier methane gases $\left(\delta^{13} C_{1}\right.$ values range from -47.8 to -43.5 per mil) found in this area.

4. The pattern of source-rock maturity in parts of the Niobrara Formation containing shallow east-flank gas fields, when combined with available data from the deeper part of the basin, is consistent with the geochemistry and types of hydrocarbons present throughout the basin.

\section{REFERENCES CITED}

Clayton, J. L., and Swetland, P. J., 1980, Petroleum generation and migration in Denver basin: American Association of Petroleum Geologists Bulletin, v. 64, p. 1613-1633.

Espitalie, J., Madec, M., Tissot, B., Mennig, J. J., and Leplat, P., 1977, Source rock characterization method for petroleum exploration: Ninth Annual Offshore Technology Conference, Proceedings, v. 3, p. 439-444.

Lockridge, J. P., and Scholle, P. A., 1978, Niobrara gas in eastern Colorado and northwestern Kansas, in Pruitt, J. D., and Coffin, P. E., eds., Energy resources of the Denver basin: Denver, Colorado, Rocky Mountain Association of Geologists, p. 35-49.

Mallory, W. W., 1977, Oil and gas from fractured shale reservoirs in Colorado and northwest New Mexico: Rocky Mountain Association of Geologists Special Publication 1, $38 \mathrm{p}$.

Petroleum Information, 1983, Special report-Codell production; practices and problems: August 25, 1983, p. 7-12.

Pollastro, R. M., and Scholle, P. A., 1984, Hydrocarbons exploration, development from low-permeability chalks-Upper Cretaceous Niobrara Formation, Rocky Mountains region: Oil and Gas Journal, April 12, p. 140-145.

Pollastro, R. M., and Scholle, P. A., in press, Diagenetic relationships in a hydrocarbon-productive chalk; The Cretaceous Niobrara Formation, in Spencer, C. W., and Mast, R. F., eds., Geology of tight gas reservoirs: American Association of Petroleum Geologists Memoir.

Rice, D. D., 1984, Occurrence of indigenous biogenic gas in organic-rich, immature chalks of Late Cretaceous age, eastern Denver basin, in J. G. Palacas, ed., Geochemistry and source-rock potential of carbonate rocks: American Association of Petroleum Geologists Studies in Geology 18 , p. 135-150.

Rice, D. D., and Claypool, G. E., 1981, Generation, accumulation, and resource potential of biogenic gas: American Association of Petroleum Geologists Bulletin, v. 65, p. 5-15.

Rice, D. D., Threlkeld, C. N., and Vuletich, A., 1984, Nature and origin of "vent gases" in the La Salle area, northeastern Colorado: U.S. Geological Survey Open-File Report 85-220, 9 p.

Tainter, P. A., 1982, Investigation of stratigraphic and paleostructural controls on hydrocarbon migration and entrapment in Cretaceous D and J sandstones of the Denver basin: Boulder, Colorado, University of Colorado M.S. thesis, $235 \mathrm{p}$. 



\title{
The Relationship Between Vitrinite Reflectance, Metamorphic Grade, and Temperature in the Cerro Prieto, Salton Sea, and East Mesa Geothermal Systems, Salton Trough, United States and Mexico
}

\author{
BY CHARLES E. BARKER, BONNIE L. CRYSDALE, and MARK J. PAWLEWICZ, \\ U.S. Geological Survey, Box 25046, MS 921, \\ Denver, Colorado 80225
}

\section{CONTENTS}

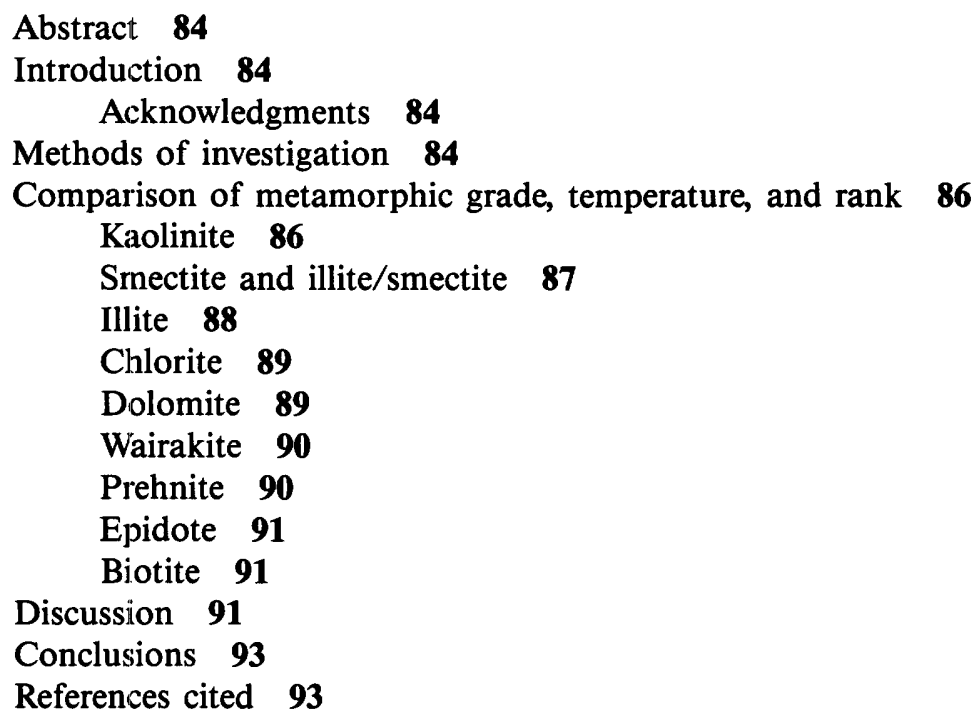

FIGURES

1. Map showing geothermal systems, Salton trough, Mexico and United States 85

2-5. Graphs showing:

2. Borehole temperature and temperature computed from vitrinite reflectance measured at changes in metamorphic grade within the Cerro Prieto geothermal system 87

3. Borehole temperature and temperature computed from vitrinite reflectance measured at changes in metamorphic grade within the Salton Sea and East Mesa geothermal systems $\mathbf{8 8}$

4. Borehole temperature range of each metamorphic grade given in figure 2, Cerro Prieto geothermal system 89

5. Temperature range of selected metamorphic grades in geothermal systems except for the Cerro Prieto system 90

6. Plot comparing of borehole temperature data and other geothermometers in borehole M-94, Cerro Prieto system 92 


\section{Abstract}

The vitrinite reflectance of sedimentary organic matter in the Cerro Prieto, Salton Sea, and East Mesa geothermal systems was found to be strongly related to measured borehole temperature. Vitrinite reflectance was used to estimate the maximum temperature $\left(T_{\max }\right)$ to which rocks in these systems had been exposed because other methods of estimating $T_{\max }$ and thermal history reconstruction showed that these systems are now at maximum temperature. Vitrinite reflectance has an advantage over some inorganic-based geothermometers because the temperature of the borehole can usually be estimated at any depth, giving a continuous thermal record throughout the system. By comparison, an estimation of $T_{\max }$ from changes in mineral assemblages (metamorphic grade) was found to be relatively insensitive. Metamorphic grade is defined as the existence of a particular assemblage of index minerals; however, these assemblages have been found to react or persist over wide temperature ranges; thus, metamorphic grade is only a crude geothermometer.

The degree of inaccuracy possible in estimating $T_{\max }$ using metamorphic grade is illustrated by a short-term thermal event at a depth of 1,300 $\mathrm{m}$ in a borehole in the Cerro Prieto field, Mexico. This thermal event induced a reequilibration of oxygen isotopes and formed high-temperature fluid inclusions in veins and host rock. Vitrinite reflectance increased in the rock, and fission tracks in detrital apatite were completely annealed, indicating a $\mathrm{T}_{\max }$ of $250^{\circ}-300^{\circ} \mathrm{C}$. Metamorphic grade, as estimated by an assemblage change of smectite + kaolinite to illite + chlorite, suggests a $\mathrm{T}_{\max }$ of only $150^{\circ}-180^{\circ} \mathrm{C}$.

The wide temperature range over which certain mineral assemblages can form and (or) persist indicates that metamorphic grade is less accurate than vitrinite reflectance in estimating $T_{\text {max }}$.

\section{INTRODUCTION}

Thermal history of a rock can be inferred by comparing geothermometers that are set by different events in a geothermal system's history. The present study compares the accuracy of geothermometers based on vitrinite reflectance and metamorphic grade with measured temperatures in three Salton Trough geothermal systems: Cerro Prieto (Mexico) and Salton Sea and East Mesa (United States). Geothermal systems are model environments for comparing various geothermometers because of their strong thermal imprint on the rocks and their relatively short, well-known thermal histories.

Temperature in geothermal systems apparently can be estimated by changes in both organic matter (Barker, 1983) and mineral phases (see, for example, Elders and others, 1980; Schiffman and others, 1984). The ability of such geothermometers to estimate the maximum temperature to which a system has been exposed $\left(T_{\max }\right)$ is important because a comparison of past temperatures, as estimated by changes in the rock, and contemporary temperatures indicates whether or not the system has cooled. This is a crucial observation in thermal history reconstruction.

Temperature appears to be the dominant factor in the metamorphism of sedimentary organic matter (OM) (Tissot and Welte, 1984; Durand, 1980). Barker (1983) found that the rank of OM thermal metamorphism in six geothermal systems (including those in the Salton Trough) was solely dependent on $T_{\max }$ after a heating duration of 10,000 years. The stability of minerals in geothermal systems is also dominantly temperature dependent; pressure seems to have only a minor effect on the degree of organic or inorganic metamorphism in these systems (Browne, 1978; Tissot and Welte, 1984). Several other factors, however, such as rock and fluid composition (that is, cation supply) and permeability, affect the metamorphism of minerals, but apparently do not affect organic metamorphism (Stach and others, 1982). The general dependence of metamorphic grade on temperature is illustrated by the consistent occurrence of certain mineral assemblages at similar temperatures in different geothermal systems that have been heated for widely different lengths of time.

Numerous studies indicate that mineral assemblages in geothermal systems result from equilibrium reactions at particular temperatures (Zen and Thompson, 1974; Browne, 1978). Changes in metamorphic grade are therefore indicated by the appearance or disappearance of certain index minerals (as used by Hoffmann and Hower, 1979) and can be correlated with $T_{\max }$ in geothermal systems (see, for example, Elders and others, 1980; Schiffman, 1984). This relationship has therefore been used to infer maximum temperatures in systems where direct temperature measurements have not been made. Metamorphic grade, however, is a discontinuous geothermometer, at best, because temperatures can be estimated only at specific depths in the borehole where changes of mineral assemblages are identified.

\section{Acknowledgments}

Borehole samples and temperature logs were provided by Comision Federal de Electricidad (Cerro Prieto, Mexico) through W. A. Elders (University of California, Riverside) and Marcello Lippman (Lawrence Berkeley Laboratory, Livermore, California).

\section{METHODS OF INVESTIGATION}

Comparison of organic and inorganic metamorphism was limited to three geothermal systems in the Salton Trough-Salton Sea, East Mesa, and Cerro Prieto (fig. 1), because these were the only systems for which adequate $R_{m}, T_{\text {max }}$, and mineral-assemblage data were available. Mineralogy and temperature data for the Salton 


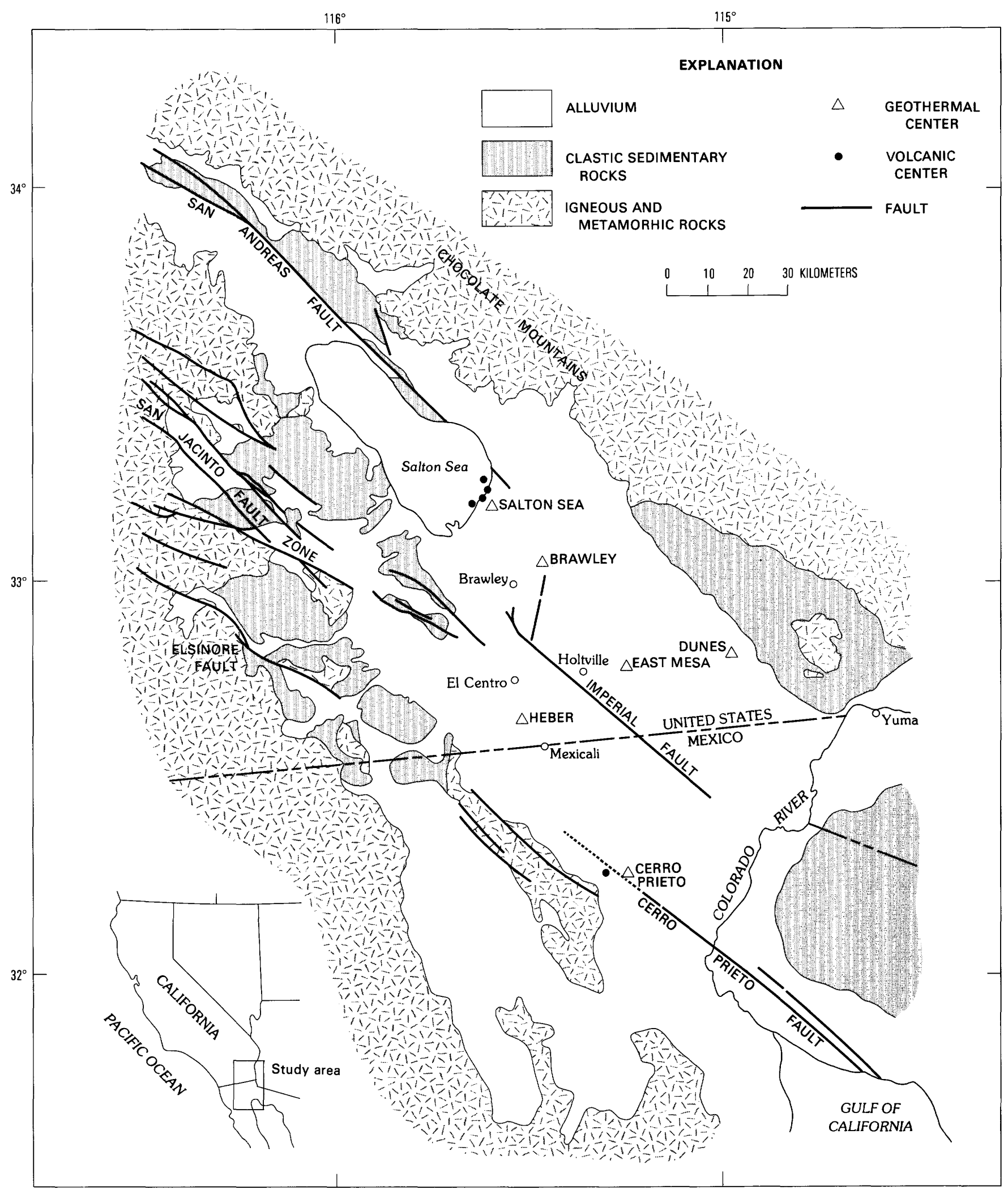

Figure 1. Geothermal systems, Salton Trough, Mexico and United States. The Cerro Prieto, Salton Sea, and East Mesa systems were selected for study. 
Sea system were reported by Muffler and White (1969), Helgeson (1968), Clayton and others (1968), and McDowell and Elders $(1979,1980)$. Hoagland (1976) and Miller (1980) reported similar data for the East Mesa system. Vitrinite reflectance data for the Salton Sea and East Mesa systems were taken from Barker $(1979,1983)$. For the Cerro Prieto system, mineralogical data are from Elders and others $(1977,1978,1979)$, temperature data are from unpublished borehole measurements by the Comision Federal de Electricidad (Mexico), and vitrinite reflectance data are from Barker (1979), Barker and Elders (1981), Barker and others (1981), and unpublished data. Mineral assemblage data in the Cerro Prieto system were compiled from sandstone samples only, except as otherwise noted.

Borehole temperatures $\left(T_{b}\right)$ were measured using recording thermometers after the well had recovered from cooling effects of the drilling fluid. Thermal history reconstruction (Barker, 1983) indicates that present-day borehole temperatures represent the maximum temperatures reached in these systems, and they are used here as measured $T_{\max }$ values. The $T_{b}$ at the depth where a change in metamorphic grade occurred was interpolated from thermometer-recorded temperature logs having the longest borehole re-equilibration time. This depth was used as a reference point to compare the borehole temperature and geothermometer estimates. $R_{m}$ values of $O M$ collected near this same depth were estimated from a manually smoothed $R_{m}$-depth curve. The $R_{m}$ data were converted to a temperature estimate $\left(T_{v r}\right)$ using the temperature- $R_{m}$ curve for western North America geothermal systems (Barker, 1983). The $T_{b}$ and $T_{v r}$ estimates were used as $x-y$ coordinates to plot the change in metamorphic grade in the Cerro Prieto field (fig. 2) and the other Salton Trough fields (fig. 3). A linear equation $T_{v r}=T_{b}$ was plotted on these figures to compare perfect correlation with the data.

Published data on authigenic minerals from geothermal fields were variable in quality. In particular, little information was given on the procedure used to identify the clay minerals, which was highly dependent on the method of sample preparation. Most of the clay mineral identifications in geothermal systems outside the Salton Trough were made by comparing the X-ray diffraction (XRD) patterns of glycolated and unglycolated samples. Diagnostic tests for distinguishing montmorillonite from the rest of the smectite group were apparently not performed, and the general term smectite was used for all these minerals. Illite was variously called K-mica or sericite, and discrete illite and smectite were commonly grouped with mixed-layer illite/smectite (I/S). Likewise, kaolinite was used in many of the papers to indicate only members of the kaolin group and not a specific mineral. Some metamorphic-grade index minerals also occur as detrital grains in the Cerro Prieto sediments, making it difficult to determine the depth of the first authigenic occurrence of a particular mineral. These problems caused us some difficulty in determining the temperature range over which certain index minerals persist.

A change in metamorphic grade is defined as the appearance or disappearance of an index mineral or assemblage of index minerals with increasing depth (temperature) in a borehole. The appearance of an authigenic index mineral was recognized by the first significant increase in abundance above background level, as indicated by XRD, or by its identification based on textural criteria in thin-section studies. The disappearence of an index mineral was recognized by its decrease in abundance to below XRD detection limits. These methods were described in detail by Elders and others (1978).

\section{COMPARISON OF METAMORPHIC GRADE, TEMPERATURE, AND RANK}

A relationship between metamorphic grade, $T_{\mathrm{vr}}$, and $T_{b}$ is indicated by the data cluster about the $T_{v r}$ $=\mathrm{T}_{\mathrm{b}}$ line in all three geothermal systems (figs. 2 and 3 ). Linear regression of these data suggests that correlation between $T_{v r}$ and $T_{b}$ is moderate $\left(r^{2}=0.5\right.$ at Cerro Prieto) to strong ( $r^{2}=0.8$ at Salton Sea/East Mesa). The difference in correlation between $T_{v r}$ and $T_{b}$ in the Cerro Prieto and the other Salton Trough fields is attributed to (1) the greater variability in $T_{b}$ data from Cerro Prieto, which is probably due to widely different borehole recovery times before measurement (Barker and others, 1981), and (2) the fact that some Cerro Prieto data were taken from the margins of the system where short-term heating and (or) cooling events have taken place (Barker and Elders, 1981; Sanford, 1981).

The temperature ranges of metamorphic grades in the Cerro Prieto system (fig. 4) versus those found in other geothermal systems (fig. 5) are discussed in the following sections. This discussion involves comparing the maximum and minimum temperature for the same metamorphic grade in all the boreholes from each geothermal system and the maximum and minimum values of $T_{b}$ and $T_{v r}$. The $T_{b}$ range is listed first, followed by the $T_{v r}$ range (in parentheses) for each metamorphic grade. The temperature ranges for changes in metamorphic grade during burial diagenesis from Hoffman and Hower (1979) are also listed, if available. Metamorphic grades in the Salton Sea and East Mesa systems are not discussed in detail here because these metamorphic grades are not well defined by the sparse data.

\section{Kaolinite}

The Cerro Prieto geothermal reservoir consists of sediments deposited in the Colorado River Delta (Lyons and Van de Kamp, 1979). Kaolinite is a common detrital 


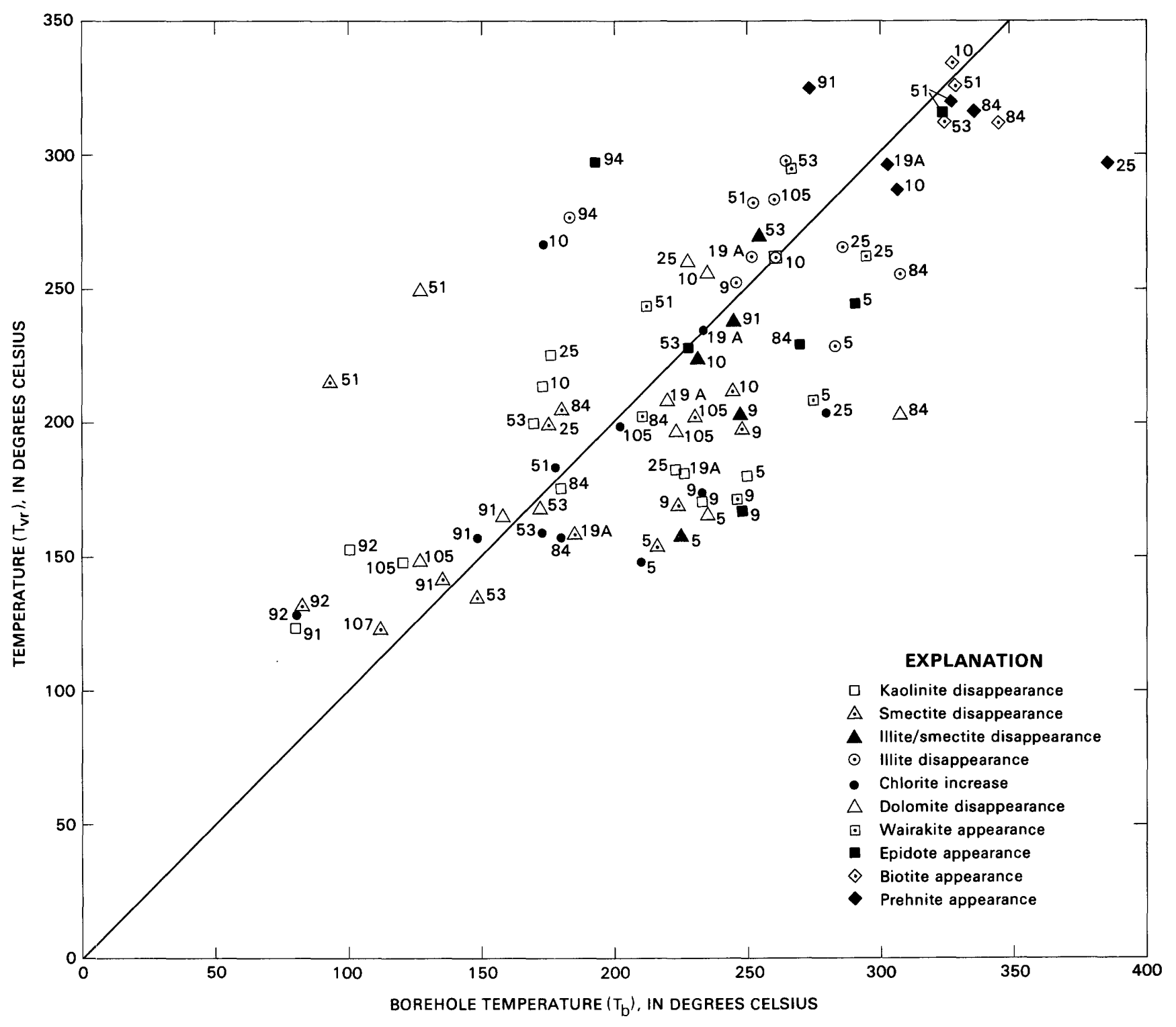

Figure 2. Borehole temperature $\left(T_{b}\right)$ and temperature computed from vitrinite reflectance $\left(T_{v r}\right)$ measured at changes in metamorphic grade within the Cerro Prieto geothermal system. Mineral data from Elders and others (1978). Numbers indicate the borehole in which the metamorphic grades were measured. The line corresponds to $T_{v r}=T_{b}$.

component of unmetamorphosed sediments in the Cerro Prieto system (Muffler and Doe, 1968; Elders and others, 1978). The depth at which kaolinite disappears in the borehole (fig. 4) was used as a reference point to compute $T_{b}$ and to compare with $T_{v r}$ (fig. 2). Kaolinite disappearance persists over a $\mathrm{T}_{\mathrm{b}}$ range of $80^{\circ}-250^{\circ} \mathrm{C}$ (compared with a $\mathrm{T}_{\mathrm{vr}}$ range of $125^{\circ}-260^{\circ} \mathrm{C}$ ) in the Cerro Prieto system, a slightly wider range than the $55^{\circ}-200^{\circ} \mathrm{C}$ $\mathrm{T}_{\mathrm{b}}$ range found for other geothermal systems (fig. 5). Weaver (1979) concluded that kaolinite persists to $375^{\circ} \mathrm{C}$ in low-grade metamorphic environments, and that its disappearance is in part dependent on the available reaction time, the chemistry of associated clay minerals, and the organic content of the rock. These considerations and the wide temperature range over which the mineral apparently disappears in geothermal systems suggest that the presence or absence of kaolinite is a poor geothermometer.

\section{Smectite and illite/smectite}

Smectite is also a common detrital constituent in the Cerro Prieto system (Elders and others, 1978). Smectite (fig. 4) disappears over a $\mathrm{T}_{b}$ range of $80^{\circ}-240^{\circ} \mathrm{C}$ $\left(125^{\circ}-215^{\circ} \mathrm{C} \mathrm{T}_{\mathrm{vr}}\right)$ in the Cerro Prieto system. This $\mathrm{T}_{\mathrm{b}}$ range is not significantly different from the $90^{\circ}-265^{\circ} \mathrm{C}$ (fig. 5) range for smectite disappearence found in other systems, but the $\mathrm{T}_{\mathrm{vr}}$ range $\left(125^{\circ}-215^{\circ} \mathrm{C}\right)$ over which smectite disappears is narrower. Weaver (1979) noted that 


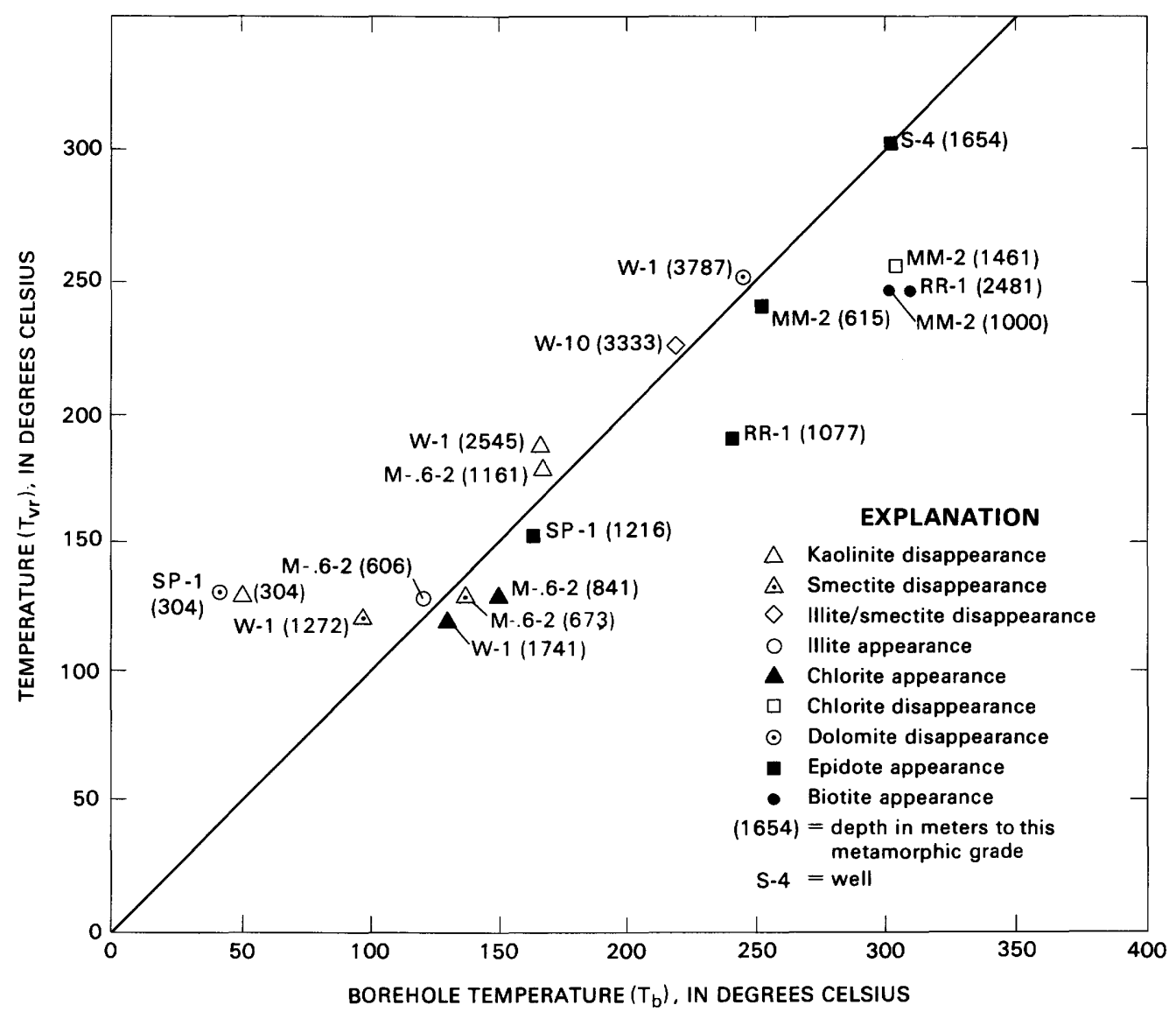

Figure 3. Borehole temperature $\left(T_{b}\right)$ and temperature computed from vitrinite reflectance $\left(T_{v r}\right)$ measured at changes in metamorphic grade within the Salton Sea and East Mesa geothermal systems. The line corresponds to $T_{v r}=T_{b}$. Sportsman- 1 (annotated SP-1) and Wilson-1 (W-1) mineral data from Muffler and White (1969). River Ranch-1 (RR-1), Magmamax-2 (MM-2), and Sinclair-4 (S-4) mineral data from McDowell and Elders (1979, 1980). East Mesa 6-2 (M6-2) mineral data from Hoagland (1976) and Miller (1980).

some ambiguity exists in the method of determining whether smectite is present or absent in a sample, which may explain the difference in the apparent wide temperature range of smectite disappearence. He suggested that the absence of the $17-\AA$ peak in the XRD pattern after glycolation is generally accepted as evidence for the absence of smectite; however, mixed-layer clays may contain as much as 60 percent 10 - $\AA$ layers (40 percent 17 - $\AA$ layers) and still produce a $17-\AA$ peak. Thus, discrete smectite could have disappeared at a lower temperature and at a much shallower depth than that found in these geothermal systems, a contention that is supported by the upper limit of $\mathrm{T}_{\mathrm{vr}}$ being about $35^{\circ}-50^{\circ} \mathrm{C}$ lower than the upper limit of the $T_{b}$ range. Published data on geothermal systems are vague, but the broad temperature range over which smectite seems to disappear is probably due in part to this identification problem. The wide temperature range for smectite disappearance and the ambiguity in its identification make this mineral a poor geothermometer.

In some studies I/S has been lumped with smectite, obscuring the distribution of both minerals; the inability to recognize I/S hinders the determination of smectite disappearance. The disappearance of $\mathrm{I} / \mathrm{S}$ is defined in some papers to be equivalent to the loss of expandable layers upon glycolation. Because of ambiguity in the identification of I/S, no attempt was made here to determine the first appearance of I/S, which should be at about $50^{\circ}-60^{\circ} \mathrm{C}$ (Weaver, 1979; Hoffman and Hower 1979). In the Cerro Prieto system, I/S disappearance was taken to be the absence of I/S having more than 10 percent expandable layers (Elders and others, 1978). Accordingly, I/S disappeared over a $\mathrm{T}_{\mathrm{b}}$ range of $130^{\circ}-255^{\circ} \mathrm{C}\left(\mathrm{T}_{\mathrm{vr}}=\right.$ $160^{\circ}-270^{\circ} \mathrm{C}$ ) in this field, a range comparable to the $120^{\circ}-265^{\circ} \mathrm{C}$ found in other geothermal systems. I/S disappearance is a poor geothermometer in geothermal systems because I/S disappears over a wide temperature range and can apparently persist far above the lowest temperature at which it disappears in other systems $\left(130^{\circ} \mathrm{C}\right)$.

\section{Illite}

Illite is also a common detrital component of the Colorado River delta (Muffler and Doe, 1968) and of the unmetamorphosed sediments in the Cerro Prieto system 

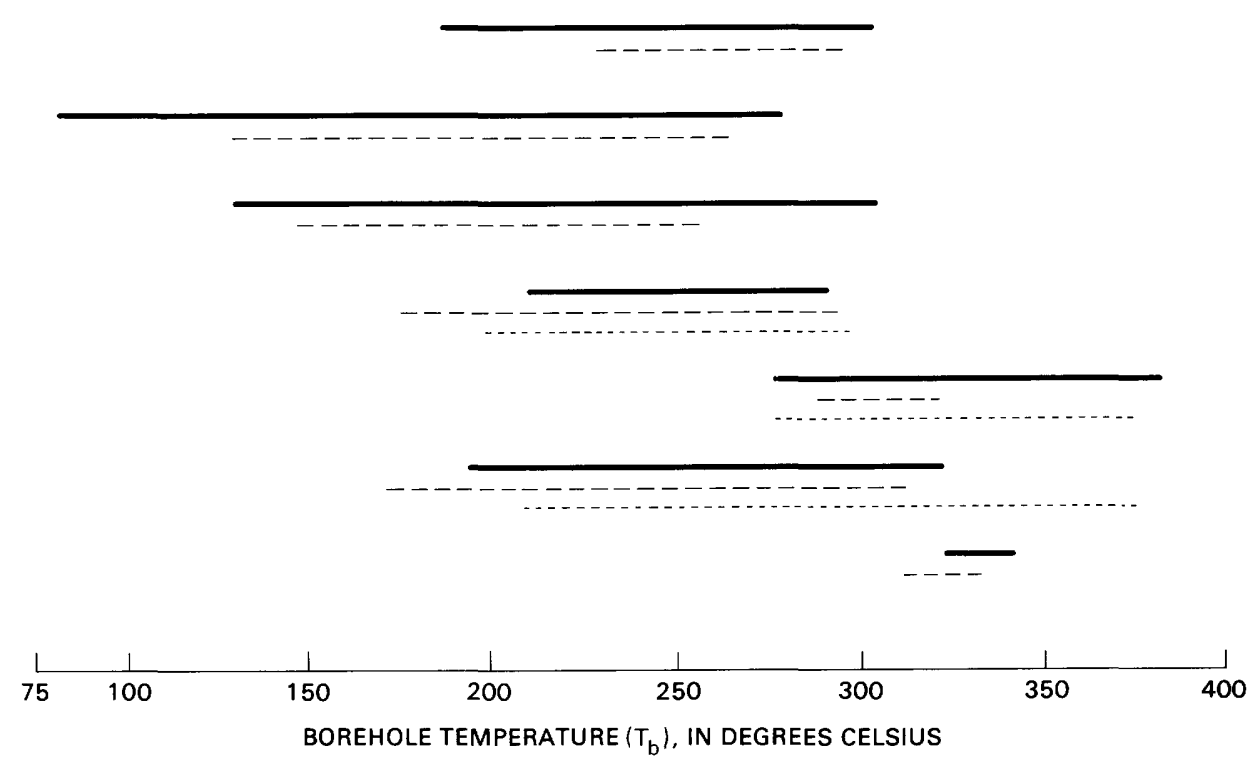

Figure 4. Borehole temperature range of each metamorphic grade, Cerro Prieto geothermal system. Long dashes, range of each metamorphic grade using temperature from vitrinite reflectance $\left(T_{v r}\right)$ given in figure 2 . Short dashes, temperature range of each metamorphic grade measured using temperature estimated from oxygen isotpe analyses $\left(T_{\text {iso }}\right)$ of calcite in sandstone (Schiffman and others, 1984).

(Elders and others, 1978). Consequently, only the last occurrence (disappearance) of illite is important in determining metamorphic grade. Illite disappears over $a T_{b}$ range of $180^{\circ}-310^{\circ} \mathrm{C}\left(\mathrm{T}_{\mathrm{vr}}=230^{\circ}-300^{\circ} \mathrm{C}\right)$ at Cerro Prieto (fig. 4). This range is narrower than the $90^{\circ}-290^{\circ} \mathrm{C}$ $\mathrm{T}_{\mathrm{b}}$ range observed in other geothermal systems (fig. 5). Hoffman and Hower (1979) indicated that illite disappears at about $300^{\circ} \mathrm{C}$ in lower Tertiary and Upper Mesozoic shales. Illite disappearance is a poor geothermometer in geothermal systems because the mineral seems to disappear over a wide temperature range and can apparently persist in some systems far above the lowest temperature $\left(100^{\circ} \mathrm{C}\right)$ at which it disappears in others. These data indicate, however, a consistent upper limit of $300^{\circ} \pm 10^{\circ} \mathrm{C}$ for illite disappearance; thus, illite disappearance may accurately indicate a minimum temperature that the system reached.

\section{Chlorite}

Detrital chlorite is also a common constituent in Cerro Prieto rocks. Consequently, chlorite grade is defined as the shallowest depth at which a significant increase in chlorite content occurs relative to background levels. Chlorite appears over a $\mathrm{T}_{\mathrm{b}}$ range of $80^{\circ}-280^{\circ} \mathrm{C}\left(\mathrm{T}_{\mathrm{vr}}=\right.$ $130^{\circ}-270^{\circ} \mathrm{C}$ ) in the Cerro Prieto system and over a $T_{b}$ range of $70^{\circ}-300^{\circ} \mathrm{C}$ in other systems (figs. 4 and 5). Outside of geothermal systems, the appearance of chlorite has been observed at depths corresponding to temperatures as low as $80^{\circ} \mathrm{C}$ and as high as temperatures equivalent to greenschist metamorphism (greater than $300^{\circ} \mathrm{C}$ ) (Weaver, 1979; Hoffman and Hower, 1979). The appearance of chlorite is a poor geothermometer in geothermal systems because it appears over a wide temperature range, and can apparently persist in some systems far above the lowest temperature $\left(80^{\circ} \mathrm{C}\right)$ at which it disappears in others.

\section{Dolomite}

Dolomite is a detrital component of Salton Trough geothermal systems sediment. Dolomite disappearance, defined here as the last occurrence of detrital dolomite, takes place over $a T_{b}$ range of $130^{\circ}-310^{\circ} \mathrm{C}\left(\mathrm{T}_{\mathrm{vr}}=150^{\circ}-\right.$ $260^{\circ} \mathrm{C}$ ) in the Cerro Prieto system (fig. 4) and a $T_{b}$ range of $50^{\circ}-280^{\circ} \mathrm{C}$ in other Salton Trough systems (fig. 5). In the Salton Sea system, dolomite reacts with kaolinite, ankerite, and ferrous iron to produce chlorite, calcite, and $\mathrm{CO}_{2}$ at temperatures as low as $180^{\circ} \mathrm{C}$ and possibly as low as $125^{\circ} \mathrm{C}$ (Muffler and White, 1969). This mineral has not been found in other geothermal areas (Browne, 1978), so no comparison of this metamorphic 
Kaolinite disappearance

Smectite disappearance

Illite/smectite disappearance

Illite disappearance

Chlorite increase

Dolomite disappearance

Wairakite appearance

Epidote appearance

Prehnite appearance

Biotite appearance

\begin{tabular}{cccccc}
\hline & 1 & 1 & 1 & 1 & 1 \\
50 & 100 & 150 & 200 & 250 & 300
\end{tabular}

Figure 5. Temperature range of selected metamorphic grades in geothermal systems, except for the Cerro Prieto system (given in figure 4). Data from Bird and Elders (1975); Browne (1978); Cavarretta and others (1980); Funicello and others (1979) Hayashi (1973); Kristmannsdottir (1975); McDowell and Elders (1980); Muffler and White (1969); Naboko and Piip (1961); Sheridan and Maisano (1975); Shimazu and Yajima (1973); Sigvaldason (1962); Steiner (1977); Sumi (1968); White and Sigvaldson (1962).

grade with other systems is possible. Dolomite disappearance is a poor geothermometer in geothermal systems because the mineral disappears over a wide temperature range, and can apparently persist in some systems far above the lowest reaction temperature (about $125^{\circ} \mathrm{C}$ ) at which it disappears in others.

\section{Wairakite}

Detrital wairakite has not been found in the Cerro Prieto system (Muffler and Doe, 1968). Authigenic wairakite in other geothermal systems forms at temperatures as low as $140^{\circ} \mathrm{C}$ (and perhaps as low as $75^{\circ} \mathrm{C}$ (Browne, 1978)), or as high as $260^{\circ} \mathrm{C}$ (fig. 5). At Cerro Prieto (fig. 4), wairakite appears over a $T_{b}$ range of $210^{\circ}-290^{\circ} \mathrm{C}\left(\mathrm{T}_{\mathrm{vr}}=170^{\circ}-295^{\circ} \mathrm{C}\right)$. Schiffman and others (1984) reported a wairakite stability range, based on temperatures computed from oxygen isotope $\left(\mathrm{T}_{\text {iso }}\right)$ analyses of calcite cement, of about $200^{\circ}-300^{\circ} \mathrm{C}$ in the Cerro Prieto system. Browne (1978) suggested that wairakite usually appears at a temperature of about $220^{\circ} \mathrm{C}$, but cites examples from the Katayama, Japan, geothermal system in which wairakite apparently formed as low as $75^{\circ}-175^{\circ} \mathrm{C}$. He suggested that these lower temperatures resulted from formation at relatively low pressure. In any case, the apparent wide temperature range for wairakite appearance is $75^{\circ}-300^{\circ} \mathrm{C}$, suggesting it is a poor geothermometer in geothermal systems. A better indicator of the minimum temperature a system has reached is the disappearance of wairakite, which occurs at about $300^{\circ} \mathrm{C}$ in geothermal systems.

\section{Prehnite}

Prehnite is not a detrital phase in the Colorado River delta sediments (Muffler and Doe, 1968) and has not been reported in unmetamorphosed sediments at Cerro Prieto. The first appearence of prehnite at Cerro Prieto (fig. 4) is over a $\mathrm{T}_{\mathrm{b}}$ range of $290^{\circ}-370^{\circ} \mathrm{C}\left(\mathrm{T}_{\mathrm{vr}}=\right.$ $290^{\circ}-325^{\circ} \mathrm{C}$ ). Schiffman and others (1984) found that prehnite, based on temperatures computed from the oxygen isotope calcite-water geothermometer $\left(\mathrm{T}_{\text {iso }}\right)$, appears at a temperature of $275^{\circ} \mathrm{C}$ and persists to at least $370^{\circ} \mathrm{C}$, the maximum $\mathrm{T}_{b}$ in the Cerro Prieto system. Prehnite appears at about $250^{\circ} \mathrm{C}$ in other geothermal systems (fig. 5). The wide temperature range for the appearence of prehnite indicates that it is a poor geothermometer in geothermal systems. 


\section{Epidote}

Epidote-group minerals occur as rare detrital grains in the Cerro Prieto system. Authigenic epidote can be distinguished petrographically by its occurrence as euhedral, pore-filling crystals, distinct from rounded detrital grains. Epidote appearance is defined as the first occurrence with depth of authigenic epidote in the borehole. Epidote appears over a $\mathrm{T}_{\mathrm{b}}$ range of $185^{\circ}-325^{\circ} \mathrm{C}$ $\left(\mathrm{T}_{\mathrm{vr}}=170^{\circ}-315^{\circ} \mathrm{C}\right.$ ) in the Cerro Prieto system (fig. 4) and over a $T_{b}$ range of $135^{\circ}-305^{\circ} \mathrm{C}$ in other geothermal systems (fig. 5). Schiffman and others (1984) reported that epidote appears at a $\mathrm{T}_{\text {iso }}$ of $230^{\circ} \mathrm{C}$ and persists to at least $370^{\circ} \mathrm{C}$, the maximum observed temperature in the Cerro Prieto system. The lower temperature estimates for the other systems appears to be the result of epidote forming at higher temperature in systems that have now cooled (Browne, 1978). The first appearence of epidote in low-presssure geothermal systems is at about $230^{\circ} \mathrm{C}$ (Seki, 1972). Assuming this temperature to be the lower limit of epidote appearance, this reaction apparently occurs over a temperature range of $230^{\circ}-325^{\circ} \mathrm{C}$. The wide temperature range for epidote appearance indicates that this mineral is a poor geothermometer in geothermal systems.

\section{Biotite}

Biotite is a common detrital component in the Cerro Prieto geothermal reservoir rock. The $T_{b}$ range of the first appearance of authigenic biotite (as determined petrographically) is $320^{\circ}-340^{\circ} \mathrm{C}\left(315^{\circ}-335^{\circ} \mathrm{C} \mathrm{T}_{\mathrm{vr}}\right)$ at Cerro Prieto (fig. 4) and $305^{\circ}-340^{\circ} \mathrm{C}$ in other geothermal systems (fig. 5). This narrow temperature range for the first appearance of biotite suggests that it is a good geothermometer; however, it usefulness is limited because authigenic biotite is a relatively rare mineral in geothermal systems (Browne, 1978) and occurs near the bottom of only the hottest boreholes.

\section{DISCUSSION}

The wide temperature range for the occurrence of each metamorphic grade noted here could be due to cooling in the system. Evidence for this cooling is the lower $T_{b}$ compared with $T_{v r}$ because, with cooling, $T_{v r}$ retains the maximum temperature the system has reached, whereas $T_{b}$ decreases. The depths at which these metamorphic grades change, however, are typically marked by similar $T_{b}$ and $T_{v r}$ ranges. Thus, the wide temperature range for each metamorphic grade change appears not to be caused by problems in temperature measurements, such as cooling in the system. Changes of metamorphic grade appear to take place over a considerable temperature range. Consequently, metamorphic grade is a less accurate geothermometer than temperature computed from $R_{m}$ because the OM rank appears to be a direct function of temperature.

The general lack of response of metamorphic grade to increasing temperature may be due to other factors that significantly affect mineral stability, including (1) pressure, (2) bulk-rock composition, (3) fluid composition, (4) permeability, and (5) reaction duration (Zen, 1974; Browne, 1978; Hower, 1981). The role of pressure is minor because geothermal systems generally conform to a hydrostatic gradient and pressure seldom exceeds 200 bars (Browne, 1978). Furthermore, Zen (1974) showed that pressure exerts little direct effect on mineral alteration in geothermal systems.

Bulk-rock composition significantly controls metamorphic mineral formation in geothermal systems. It directly affects the resultant metamorphic mineral asemblages and the apparent degree of diagenesis, even in rocks that have been subjected to similar temperatures (Rettke, 1976; Hower, 1981). At Cerro Prieto, most of the reservoir rock was derived from a single source (Muffler and Doe, 1968), but the depositional environment has sorted this material into sand-rich and mud-rich rock (Lyons and van de Kamp, 1979). These two rock types show moderate differences in metamorphic response, mainly in that with increasing temperature, the index minerals in the permeable sandstone react faster than those in the low permeability mudstone (Elders and others, 1978).

Fluid composition and permeability also significantly affect mineral formation in geothermal systems because these reactions are rarely isochemical and mass transfer is necessary for hydration-dehydration and (or) cation diffusion into and out of a mineral (Browne, 1978; Weaver, 1979). Mass transfer is accomplished through meteoric waters that react with the country rock and hydrothermally altered reservoir rock (Ellis, 1979). Movement of these fluids and their access to the reservoir rock are controlled by permeability. Consequently, in relatively impermeable rocks, equilibrium between the solid and fluid phase is seldom achieved, and authigenic or detrital minerals in the reservoir rock can persist to temperatures past their normal equilibrium stability range. Elders and others (1980) demonstrated that permeability, fluid flow patterns, and temperature are controlling factors in the metamorphism at Cerro Prieto.

The effect of reaction duration on inorganic metamorphism in geothermal systems is important. Weaver (1979) indicated that the formation of illite-rich shales requires temperatures of $200^{\circ}-300^{\circ} \mathrm{C}$ for millions of years. Hoffman and Hower (1979) indicated that reaction duration is significant for increasing metamorphic grade at low temperatures and that these reactions do not approach completion in $10^{7}$ years. Laboratory experiments on smectite, one of the most reactive clay minerals 
APPARENT AGE, IN MILLIONS OF YEARS

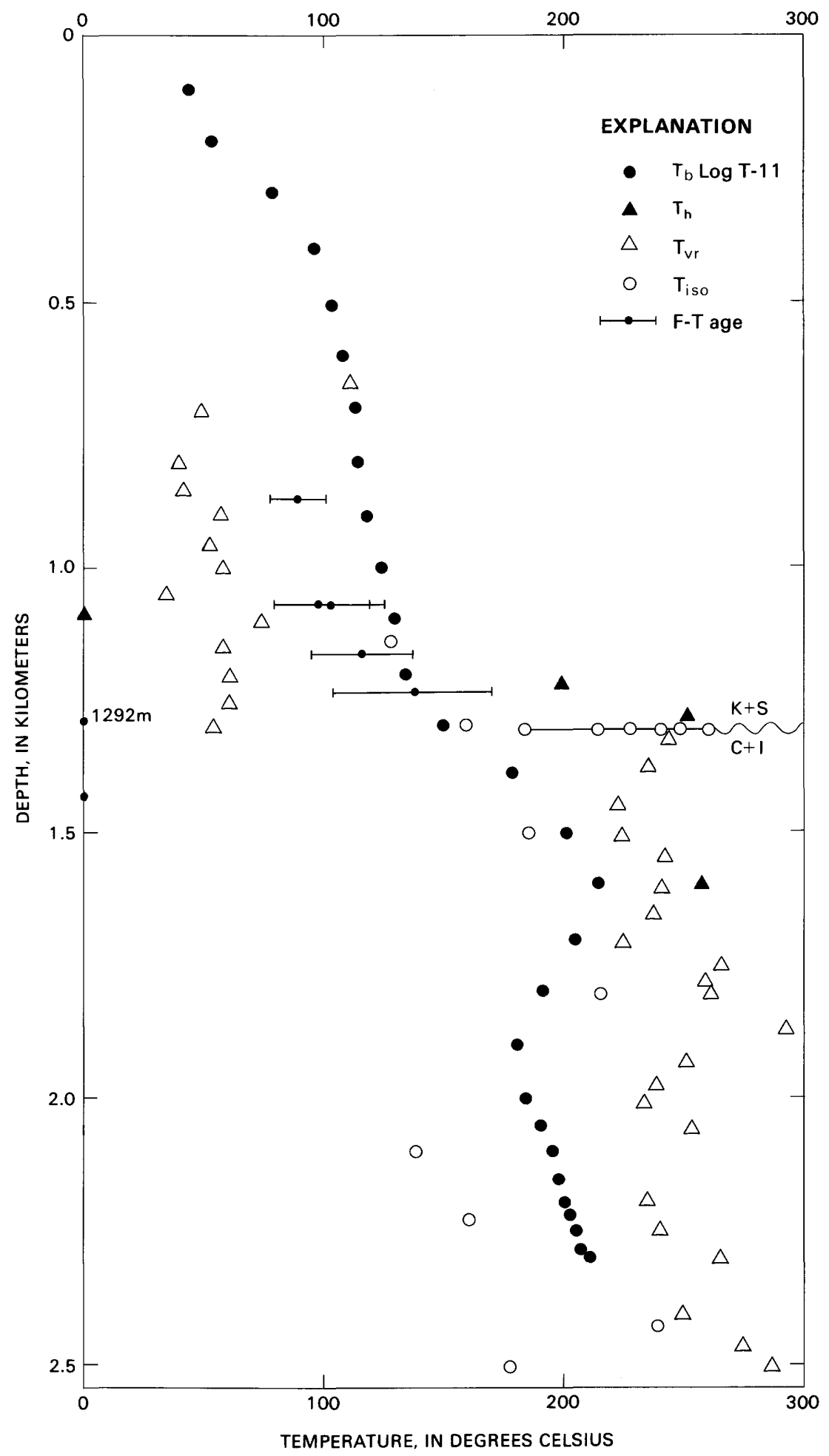

Figure 6. Comparison of borehole temperature $\left(T_{b}\right)$ data and other geothermometers in borehole M-94, Cerro Prieto system. Fission track apatite age (F-T), fluid inclusion $\left(T_{h}\right)$, and oxygen isotope $\left(T_{i}\right)$ data are from Sanford (1981). Mineral data are from Elders and others (1978). Vitrinite reflectance data are from Barker and Elders (1981). F-T dates are plotted with \pm one standard deviation error bars. 
(Weaver, 1979), show that it can probably persist for at least $10^{8}$ years at earth-surface conditions (Eberl and Hower, 1976). Geothermal systems exist for as long as $10^{6}$ years (Barker, 1983), and short-term heating events along the margins of a system may last for less than 100 years (Sanford, 1981). The life span of geothermal systems is at least an order of magnitude smaller than that required for some mineral reactions to equilibrate. Thus, mineral reactions in geothermal systems where temperature can change rapidly should be significantly time dependent. This time dependency is illustrated by a short-term heating event in borehole M-94 at 1,300 m (Cerro Prieto) that produced temperatures of $250^{\circ}$ $300^{\circ} \mathrm{C}$, based on mineral fluid inclusions, mineral oxygen isotopes, and vitrinite reflectance (fig. 6). A study of fission-track annealing in apatite indicated that this heating event lasted only about $10-100$ years (Sanford, 1981). Metamorphic grade changes in borehole M-94, indicated by the disappearence of smectite + kaolinite and the appearence of illite + chlorite, suggested a temperature of only $150^{\circ}-180^{\circ} \mathrm{C}$ (Elders and others, 1980 , their fig. 6).

The time dependency of these mineral reactions suggests that any situation that increases reaction duration in a geothermal system will change the relationship of metamorphic grade to temperature. Thus, reactions should have come closer to completion in the deeper parts of a geothermal system than in the shallower parts, because the deeper parts have been heated longer and to a higher temperature (which promotes reaction). Increasing time also changes the apparent metamorphic grade. Hoffman and Hower (1979) observed that deeply buried Pliocene-Pleistocene shale has a much lower grade mineral assemblage than shale buried since the early Tertiary, although these Pliocene-Pleistocene rocks have attained the same temperature.

The strong correlation between $R_{m}$ and $T_{b}$ indicates that temperature is the most important variable in organic metamorphism (Barker, 1983), a conclusion that is also suggested by the fair to good agreement between $T_{v r}$ and $T_{b}$ at the endpoints of the range for each metamorphic grade. Vitrinite reflectance geothermometry, however, is also flawed because of subjective selection of vitrinite for analysis (Barker and Pawlewicz, 1986), suppression of $\mathrm{R}_{\mathrm{m}}$ in OM-rich rocks (Price and Barker, 1984), and increasing bireflectance with rank that makes the determination of $R_{m}$ progressively less precise (Stach and others, 1982). Further, vitrinite is only found in sedimentary systems, which rigidly restricts its application.

\section{CONCLUSIONS}

Generally, metamorphic grade is a less accurate geothermometer than temperature computed from $R_{m}$.
Exceptions are the appearance of biotite and the disappearance of wairakite and prehnite. Low-temperature phase changes primarily in the clay minerals occur over wide temperature ranges and are unsuitable for accurate geothermometry. At best, metamorphic grades in geothermal systems are discontinuous geothermometers. They can be interpreted precisely only at points where reactions are changing the mineral assemblage.

\section{REFERENCES CITED}

Barker, C. E., 1979, Vitrinite reflectance geothermometry in the Cerro Prieto geothermal field, Baja California, Mexico: University of California, Riverside, Institute of Geophysics and Planetary Physics, UCR/IGPP Report 79/10, $127 \mathrm{p}$.

Barker, C. E., 1983, Influence of time on metamorphism of sedimentary organic matter in liquid-dominated geothermal systems, western North America: Geology, v. 11, p. 384-388.

Barker, C. E., in press, Temperature and time in the thermal maturation of sedimentary organic matter, in Naeser, $\mathrm{N}$. D., and McCulloh, T. H., eds., Assessment of the thermal history of basins: Society of Economic Paleontologists and Mineralogists Special Publication.

Barker, C. E., and Elders, W. A., 1981, Vitrinite reflectance geothermometry and apparent heating duration in the Cerro Prieto geothermal field: Geothermics, v. 10, p. 207-223.

Barker, C. E., Pawlewicz, M. J., Bostick, N. H., and Elders, W. A., 1981, Evolution of the Cerro Prieto geothermal system as interpreted from vitrinite reflectance under isothermal conditions, in Lippman, M., ed., Third symposium on the Cerro Prieto geothermal field, Baja California, Mexico: Comision Federal de Electricidad (Cerro Prieto, Mexico) and University of California, Lawrence Berkeley Laboratory Report LBL-11967, p. 88-101.

Barker, C. E., and Pawlewicz, M. J., 1986, The correlation of vitrinite reflectance with maximum temperature in humic organic matter, in Buntebarth, G., and Stegena, L., eds., Paleogeothermics: New York, Springer-Verlag, p. 80-93.

Bird, D. K., and Elders W. A., 1975, Investigations of the Dunes geothermal anomaly, Imperial Valley: University of California, Riverside, Institute of Geophysics and Planetary Physics, UCR/IGPP Report 75/14, 20 p.

Browne, P. R. L., 1978, Hydrothermal alteration in active geothermal fields: Annual Reviews in Earth and Planetary Science, v. 6, p. 229-250.

Cavaretta, G., Gianelli, G., and Puxeddu, M., 1980, Hydrothermal metamorphism in the Larderello geothermal field, Italy: Geothermics, v. 9, p. 297-314.

Clayton, R. N., Muffler, L. J. P., and White, D. F., 1968, Oxygen isotopic study of calcite and silicates of River Ranch No. 1 Well, Salton Sea geothermal field, California: American Journal of Science, v. 266 p. 968-979.

Durand, B., ed., 1980, Kerogen: Paris, Editions Technip, 519 p. 
Eberl, D. D., and Hower, J., 1976, The kinetics of illite formation: Geological Society of America Bulletin, v. 87, p. 1326-1330.

Elders, W. A., Olson, E. R., Hoagland, J. R., Barker, C. E., Johnson, P. D., and Collier, P., 1977, A comprehensive study of samples from geothermal reservoirs-Petrology and light stable isotope geochemistry of wells M48, M84, M90, M92, and Prian No. 1, in the Cerro Prieto geothermal field, Baja California, Mexico: University of California, Riverside, Institute of Geophysics and Planetary Physics, UCR/IGPP Report 77/37, 274 p.

Elders, W. A., Hoagland, J. R., Olson, E. R., McDowell, S. D., and Collier, P., 1978, A comprehensive study of samples from geothermal reservoirs-Petrology and light stable isotope geochemistry of 23 wells in the Cerro Prieto geothermal field, Baja California, Mexico: University of California, Riverside, Institute of Geophysics and Planetary Physics, UCR/IGPP Report 78/26, 274 p.

Elders, W. A., Hoagland, J. R., Valette-Silver, J. N., Williams, A. E., Barker, C. E., and Collier, P., 1979, A comprehensive study of samples from geothermal reservoirs-Petrology and geochemistry of surface and subsurface samples from the Cerro Prieto geothermal field, Baja California, Mexico: University of California, Riverside, Institute of Geophysics and Planetary Physics, UCR/IGPP Report 79/27, $203 \mathrm{p}$.

Elders, W. A., Hoagland, J. R., and Williams, A. E., 1980, Hydrothermal alteration as an indicator of temperature and flow regime in the Cerro Prieto geothermal field of Baja California: Geothermal Resources Council, Transactions, v. 4, p. 121-125.

Ellis, A. J., 1979, Explored geothermal systems, in Barnes, H. L., ed., Geochemistry of hydrothermal ore deposits, $2 \mathrm{~d}$ ed.: New York, Wiley and Sons, p. 632-678.

Funiciello, R., Mariotti, G., Parotto, M., Preite-Martinez, M., Tecce, F., Toneatti, R., and Turi, B., 1979, Geology, mineralogy, and stable isotope geochemistry of the Cesano geothermal field: Geothermics, v. 8, p. 55-73.

Hayashi, M., 1973, Hydrothermal alteration in the Otake geothermal area, Kyushu, Japan: Japan Geothermal Energy Association, v. 10, p. 9-46.

Helgeson, H. C., 1968, Geologic and thermodynamic characteristics of the Salton Sea geothermal system: American Journal of Science, v. 266, p. 129-166.

Hoagland, J. R., 1976, Petrology and geochemistry of hydrothermal alteration in borehole Mesa 6-2, East Mesa geothermal area, Imperial Valley, California: University of California, Riverside, Institute of Geophysics and Planetary Physics, UCR/IGPP Report 76/12, 90 p.

Hoffman, J., and Hower, J., 1979, Clay mineral assemblages as low grade metamorphic geothermometers-Application to the thrust faulted disturbed belt of Montana, U.S.A, in Scholle, P. A., and Schluger, P. R., eds., Aspects of diagenesis: Society of Economic Paleontologists and Mineralogists Special Publication 26, p. 55-80.

Hower, J., 1981, Shale diagenesis, in Longstaffe, F. J., ed., Short course in clays and the resource geologist: Mineralogical Association of Canada, p. 60-80.

Kristmannsdottir, H., 1975, Hydrothermal alteration of basaltic rocks in Icelandic geothermal areas: Proceedings, second United Nations symposium on development and use of geothermal resources, v. 1, p. 444-446.
Lyons, D. J., and van de Kamp, P. C., 1979, Subsurface geological and geophysical study of the Cerro Prieto geothermal field: Proceedings, second symposium on the Cerro Prieto geothermal field, Baj? California, Mexico, Sponsored by Comision Federal de Electricidad, Mexicalli, Mexico, October, 1979, v. 1, p. 197-186.

McDowell S. D., and Elders, W. A., 1979, Geothermal metamorphism of sandstone in the Salton Sea Geothermal system, in Elders, W. A., ed., Geology and geothermics of the Salton Trough: Geological Society of America, Guidebook 7, San Diego, California, p. 70-76.

McDowell, S. D., and Elders, W. A., 1980, Authigenic layer silicate minerals in borehole Elmore 1, Salton Sea geother" mal field, California, USA: Contributions to Mineralogy and Petrology, v. 74, p. 293-310.

Miller, K. R., 1980, Petrology, hydrothermal mineralogy, stable isotope geochemistry and fluid inclusion geothermometry of borehole Mesa 31-1, East Mesa geothermal field, Imperial Valley, California: University of California, Riverside, Institute of Geophysics and Planetary Physics, UCR/IGPP Report 80/1, 113 p.

Muffler, L. J. P., and Doe, B. R., 1968, Composition and mean age of detritus of the Colorado River delta in the Salton Trough, southeastern California: Journal of Sedimentary Petrology, v. 38, p. 384-399.

Muffler, L. J. P., and White, D. E., 1969, Active metamorphism of Upper Cenozoic sediments in the Salton Sea geothermal field and the Salton Trough, southern California: Geological Society of America Bulletin, v. 80, p. 157-82.

Nakobo, S. I., and Piip, B. I., 1961, Recent metamorphism of volcanic rocks in the region of the Pauzhetsk Hot Springs (Kamchatka): Akademiya Nauk S.S.S.R. Trudy Lab Vulkanologiya, v. 19, p. 99-114. [In Russian].

Price, L. C., and Barker, C. E., 1984, Suppression of vitrinite reflectance in amorphous-rich kerogen-A major unrecognized problem: Journal of Petroleum Geology, v. 8, p. 59-84.

Rettke, R. C., 1976, Clay mineralogy and clay mineral distribution patterns in Dakota Group sediments, northern Denver basin, eastern Colorado and western Nebraska: Cleveland, Ohio, Case Western Reserve University, Ph. D. dissertation, $147 \mathrm{p}$.

Sanford, S. J., 1981, Dating thermal events by fission track annealing, Cerro Prieto geothermal field, Baja California, Mexico: University of California, Riverside, Institute of Geophysics and Planetary Physics, UCR/IGPP Report $81 / 4,105 \mathrm{p}$.

Schiffman, P., Elders, W. A., Williams, A. E., McDowell, S. D., and Bird, D. K., 1984, Active metasomatism in the Cerro Prieto geothermal system, Baja California, Mexico-A telescoped low pressure, low temperature metamorphic facies series: Geology, v. 12, p. 12-15, and p. 255 .

Seki, Y., 1972, Lower grade stability limit of epidote in the light of natural occurrences: Journal of the Geological Society of Japan, v. 78 p. 405-413.

Sheridan, M., and Maisano, M., 1975, Zeolite and sheet silicate zonation in a late Tertiary geothermal basin, near Hassayampa, central Arizona: Proceedings, second United Nations symposium on development and use of geothermal resources, v. 1, p. 597-609. 
Shimazu, M., and Yajima, J., 1973, Epidote and wairakite in drill cores at the Hachimanti geothermal area, northeastern Japan: Journal of Japan Association of Mineralogy, Petrology, and Economic Geology, v. 68, p. 363-371.

Sigvaldason, G. E., 1962, Epidote and related minerals in two deep geothermal drill holes, Reyjavik and Hveragerdi, Iceland: U.S. Geological Survey Professional Paper 450E, p. 77-79.

Stach, E., Mackowsky, M.-Th., Teichmuller, M., Taylor, G. H., Chandra, D., and Teichmuller, R., 1982, Stach's textbook of coal petrology, 3d ed.: Berlin, Gebruder Borntraeger, $535 \mathrm{p}$.

Steiner, A., 1977, The Wairakei geothermal field, North Island, New Zealand: New Zealand Geological Survey Bulletin 90, $36 \mathrm{p}$.

Sumi, K., 1968, Hydrothermal rock alteration of the Matsakawa geothermal area, northeast Japan: Geological Survey of Japan Report 225, 42 p.
Tissot, B. P., and Welte, D. H., 1984, Petroleum formation and occurrence, 2d ed.: New York, Springer-Verlag, 699 p.

Weaver, C. E., 1979, Geothermal alteration of clay minerals and shales; diagenesis; technical report: Office of Nuclear Waste Isolation Technical Report 21, 176 p. [Available from National Technical Information Service, Springfield, VA 22161.]

White, D. E., and Sigvaldason, G. E., 1962, Epidote in hot springs systems and depth of formation of propylitic epidote in epithermal ore deposits: U.S. Geological Survey Professional Paper 450E, p. 80-84.

Zen, E-an, 1974, Burial metamorphism: Canadian Mineralogist, v. 12 , p. $445-455$.

Zen, E-an, and Thompson, A. B., 1974, Low grade regional metamorphism-Mineral equilibrium relations: Annual Review of Earth and Planetary Science, v. 2, p. 179-212. 



\section{Origin and Diagenesis of Cretaceous Deep-Sea, Organic-Carbon-Rich Lithofacies in the Atlantic Ocean}

By WALTER E. DEAN, U.S. Geological Survey, Box 25046, Denver Federal Center, MS 940, Denver, Colorado 80225, and MICHAEL A. ARTHUR, Graduate School of Oceanography, University of Rhode Island, Narragansett, Rhode Island 02882

\section{CONTENTS}

\section{Abstract 99}

Introduction 99

Acknowledgments 100

Oxidation-reduction cycles in the Cretaceous Atlantic Ocean 100

Description of the cycles 100

Cycle periods 103

Diagenetic processes and products 103

Sulfur diagenesis 103

Carbonate diagenesis 104

Phosphate diagenesis 108

Trace elements in organic-carbon-rich strata 108

Models of deposition 118

Bottom-water oxygenation 118

Supply of organic carbon to sediments 118

Conclusions 122

References cited 123

\section{FIGURES}

1. Plots of relative concentrations of ions and gases in pore water versus depth within anoxic sediment 100

2. Continental reconstruction map showing locations of Deep Sea Drilling Project sites where Cretaceous organic-rich strata have been recovered 101

3. Summary stratigraphic column for strata recovered from Deep Sea Drilling Project sites in North Atlantic Ocean 102

4. Plot of concentrations of organic carbon and total sulfur in Cretaceous strata rich in organic carbon from Atlantic Deep Sea Drilling Project sites 105

5. Plots showing relationship between $\delta^{13} \mathrm{C}$ and total dissolved $\mathrm{CO}_{2}$ in pore waters of anoxic sediments during sulfate reduction and methane generation 106

6. Diagram showing ranges and means of oxides and trace element concentrations in claystone and black shale from Deep Sea Drilling Project site 530110

7. Diagram showing ranges and means of oxides and trace element concentrations of interbedded black shale and green claystone from Deep Sea Drilling Project site 367 112, 113

8. Plots of concentrations versus depth for $\mathrm{V}, \mathrm{Cu}, \mathrm{Ni}$, and $\mathrm{Ba}$ in black shale from cores, Deep Sea Drilling Project site 530114

9. Illustrations showing how influx of terrigenous organic matter, surface-water organic productivity, upwelling, and turbidity currents can contribute to accumulation and redeposition of sediments containing varying amounts of organic carbon 120,121 


\section{TABLES}

1. Generalized reactions involving organic matter in pore water and their products 99

2. Average or representative chemical analyses for modern organic-carbon-rich sediments, oxic deep-sea sediments, and Cretaceous black shales and interbedded strata 109

3. Mass accumulation rates of selected components in red, green, and black beds at Deep Sea Drilling Project site 530 116, 117

4. Concentrations of major-element oxides and trace elements and mass accumulation rates for modern and ancient Black Sea sediments 119 


\section{Abstract}

Deep-water sedimentary sequences of Cretaceous age, rich in organic carbon $(O C)$, have been recovered at many Deep Sea Drilling Project (DSDP) sites in the Atlantic Ocean. The OCrich strata occur within cyclic interbeds of shale, marlstone, and (or) limestone which have cycle periods that range from about 20,000 to 100,000 years and average 40,000 to 50,000 years. These cycles may be due to the effects of climate change on the influx of terrigenous organic matter. The variations in supply and (or) preservation of organic matter had pronounced effects on the potential of the sediment for subsequent diagenetic changes and geochemical partitioning in adjacent beds.

Many beds rich in OC contain authigenic iron sulfides, barite, gypsum, dolomite, siderite, rhodochrosite, and (or) other $\mathrm{Mg}$-, $\mathrm{Fe}-$, and $\mathrm{Mn}$-rich carbonate minerals. Authigenic gypsum and barite, precipitated near the lower boundaries of some OCrich layers, may indicate later oxidation of dissolved sulfide. The geochemistry and stable isotope composition of the authigenic carbonate minerals suggest that they were formed under anoxic conditions during and after sulfate reduction, and that some formed from dissolved $\mathrm{CO}_{2}$ in equilibrium with methane. Dolomite is the most common carbonate mineral in OC-rich strata. Siderite is common in sequences that have relatively low concentrations of $\mathrm{OC}$ or high sedimentation rates. Manganese carbonates are rare, probably because manganese is highly mobile under reducing conditions and diffuses out of the anoxic sediment. Although phosphate minerals have not been reported from Cretaceous OC-rich strata, some strata contain as much as 2 percent $\mathrm{P}_{2} \mathrm{O}_{5}$, probably in the form of phosphatic fish debris.

Many trace elements, such as $\mathrm{Cr}, \mathrm{Ni}, \mathrm{V}, \mathrm{Cu}, \mathrm{Zn}$, and Mo, are concentrated in $\mathrm{OC}$-rich lithologies relative to interbedded OC-poor lithologies. The association of high trace-element concentrations with organic matter may be the result of a concentration of these elements by organisms and (or) by chemical sorption and precipitation processes. Detailed trace-element profiles in a thick sequence of OC-rich strata from the South Atlantic Ocean suggest that the source of the organic matter may have been the main controlling factor on the concentration of trace elements; strata containing predominantly marine organic matter tend to have higher trace-element concentrations than those containing predominantly terrestrial organic matter.

Most depositional models that have been used to explain the accumulation of the OC-rich strata imply that reducing conditions in the sediments (and therefore an increased degree of preservation of organic matter) were the result of anoxic or nearanoxic conditions in oceanic bottom waters or in a midwater oxygen-minimum zone. Evidence from several DSDP sites in the Atlantic, however, indicates that anoxia or near-anoxia probably occurred within midwater oxygen-minimum zones and possibly, under extreme conditions, throughout much of the bottom-water mass. Although bottom-water anoxia may have been reached during periods of accumulation of OC-rich strata, it was not necessarily a cause for accumulation of these strata. The main reason for the accumulation of OC-rich strata was an increase in the relative amount of organic debris being deposited. This organic debris was derived from continental margins and transported to slope and basinal sites by turbidity currents.

\section{INTRODUCTION}

Deep-water sedimentary sequences of Cretaceous age that contain beds rich in organic carbon (OC) (more than 1 percent) have been recovered at many Deep Sea Drilling Project (DSDP) sites, particularly in the Atlantic Ocean (Tissot and others, 1980; Summerhayes, 1981; Arthur, Dean, and Stow, 1984; Authur and Dean, 1986). Deposition of OC-rich strata in the Atlantic began in the Early Cretaceous and continued intermittently to the present. Most of these sequences display a marked cyclicity in amount of $\mathrm{OC}$ that is manifested as interbedded lighter and darker shale, marlstone, and (or) limestone. Lower Cretaceous (Neocomian) OC-rich strata occur within carbonate sequences, but most of the other Cretaceous strata in the Atlantic are carbonate poor and clay rich, resulting in cyclic interbedding of red, green, and black claystone or shale.

Organic matter is preserved in relatively high concentrations in deep-sea, OC-rich strata because of a high rate of supply of organic matter, an enhanced preservation under anoxic conditions, an enhanced preservation due to high sedimentation rate, or some combination of these factors. Once the organic matter reaches the sediment, some part of it usually is decomposed. Various oxidizing agents are reduced in a series of oxidationreduction reactions that are largely mediated by bacteria. Some of the possible oxidation-reduction reactions, highly simplified, are shown in table 1 , and their general sequence and distribution with depth below the sediment-water interface is illustrated in figure 1 . The byproducts of these reactions and of the decomposition of organic matter are

Table 1. Selected important generalized reactions involving organic matter in pore water and their products

[Generalized equations from Berner (1980) and Curtis (1980) listed in order of occurrence in anoxic pore waters. $\mathrm{CH}_{2} \mathrm{O}$ is a generalized formula for organic matter]

$$
\begin{aligned}
& \mathrm{CH}_{2} \mathrm{O}+\mathrm{O}_{2} \rightarrow \mathrm{CO}_{2}+\mathrm{H}_{2} \mathrm{O}\left(\mathrm{or}^{+}+\mathrm{HCO}_{3}^{-}\right) \\
& 5 \mathrm{CH}_{2} \mathrm{O}+4 \mathrm{NO}_{3}^{-} \rightarrow 2 \mathrm{~N}_{2}+4 \mathrm{HCO}_{3}^{-} \mathrm{CO}_{2}+3 \mathrm{H}_{2} \mathrm{O} \\
& \mathrm{CH}_{2} \mathrm{O}+3 \mathrm{CO}_{2}+2 \mathrm{MnO}_{2} \rightarrow 2 \mathrm{Mn}^{2+}+4 \mathrm{HCO}_{3}^{-} \\
& \mathrm{CH}_{2} \mathrm{O}+7 \mathrm{CO}_{2}+4 \mathrm{Fe}(\mathrm{OH})_{3} \rightarrow 4 \mathrm{Fe}^{2+}+8 \mathrm{HCO}_{3}^{-}+3 \mathrm{H}_{2} \mathrm{O} \\
& 2 \mathrm{CH}_{2} \mathrm{O}+\mathrm{SO}_{4}^{2-} \rightarrow \mathrm{H}_{2} \mathrm{~S}+2 \mathrm{HCO}_{3}^{-} \\
& 2 \mathrm{CH}_{2} \mathrm{O} \rightarrow \mathrm{CH}_{4}+\mathrm{CO}_{2} \text { (or } \mathrm{CH}_{4}+\mathrm{HCO}_{3}^{-}+\mathrm{H}^{+} \text {) }
\end{aligned}
$$




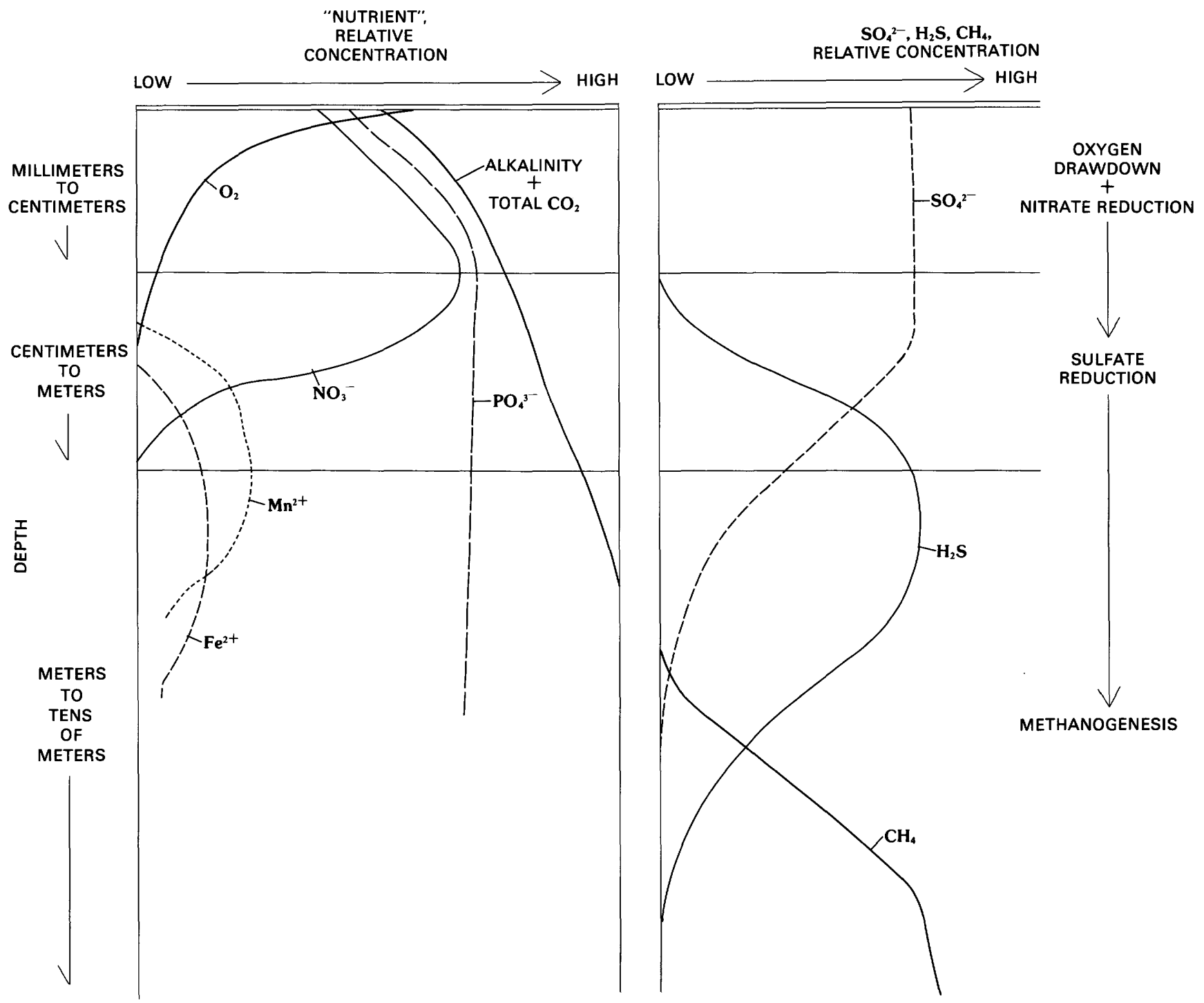

Figure 1. Profiles of relative concentrations in pore water versus depth within anoxic sediment for $\mathrm{O}_{2}, \mathrm{NO}_{3}^{-}, \mathrm{Mn}^{2+}, \mathrm{Fe}^{2+}, \mathrm{PO}_{4}^{3-}$, alkalinity + total $\mathrm{CO}_{2}\left(\mathrm{TCO}_{2}\right), \mathrm{SO}_{4}^{2-}, \mathrm{H}_{2} \mathrm{~S}$, and $\mathrm{CH}_{4}$. Zones of oxygen drawdown and nitrate reduction, sulfate reduction, and methanogenesis are indicated.

various reduced metal species, ammonia, phosphate, sulfide, and large amounts of carbon dioxide and bicarbonate that contribute to increases in the alkalinity of the interstitial waters (Berner, 1980).

Based upon published data collected by many workers, the present paper attempts to: (1) outline the typical chemical and mineralogical compositions of $\mathrm{OC}$ rich facies of Cretaceous age recovered at DSDP sites in the North and South Atlantic Oceans and explain how diagenesis has affected these compositions; (2) discuss the extent to which environment of deposition determines the supply of OC to deep-water sediments and therefore predetermines the extent to which diagenetic reactions and enrichment of certain trace elements can occur; and (3) contrast the chemistry of OC-rich facies from different depositional settings and outline briefly the potential effects of organic carbon accumulation on paleocean chemistry.

\section{Acknowledgments}

We thank Joseph Hatch, Douglas Kirkland, Philip Meyers, Seymour Schlanger, Harry Tourtelot, and Douglas Waples for helpful reviews of the manuscript.

\section{OXIDATION-REDUCTION CYCLES IN THE CRETACEOUS ATLANTIC OCEAN}

\section{Descriptions of cycles}

The oldest OC-rich strata in the North Atlantic Ocean, recovered at more than one site, are interbeds of laminated dark-olive to black marlstone within bioturbated white to light-gray limestone of Tithonian to Neocomian age recovered from DSDP sites 101, 105, 367, 387, 391, 417, 418, 534, and 603 (figs. 2 and 3; Jansa and 


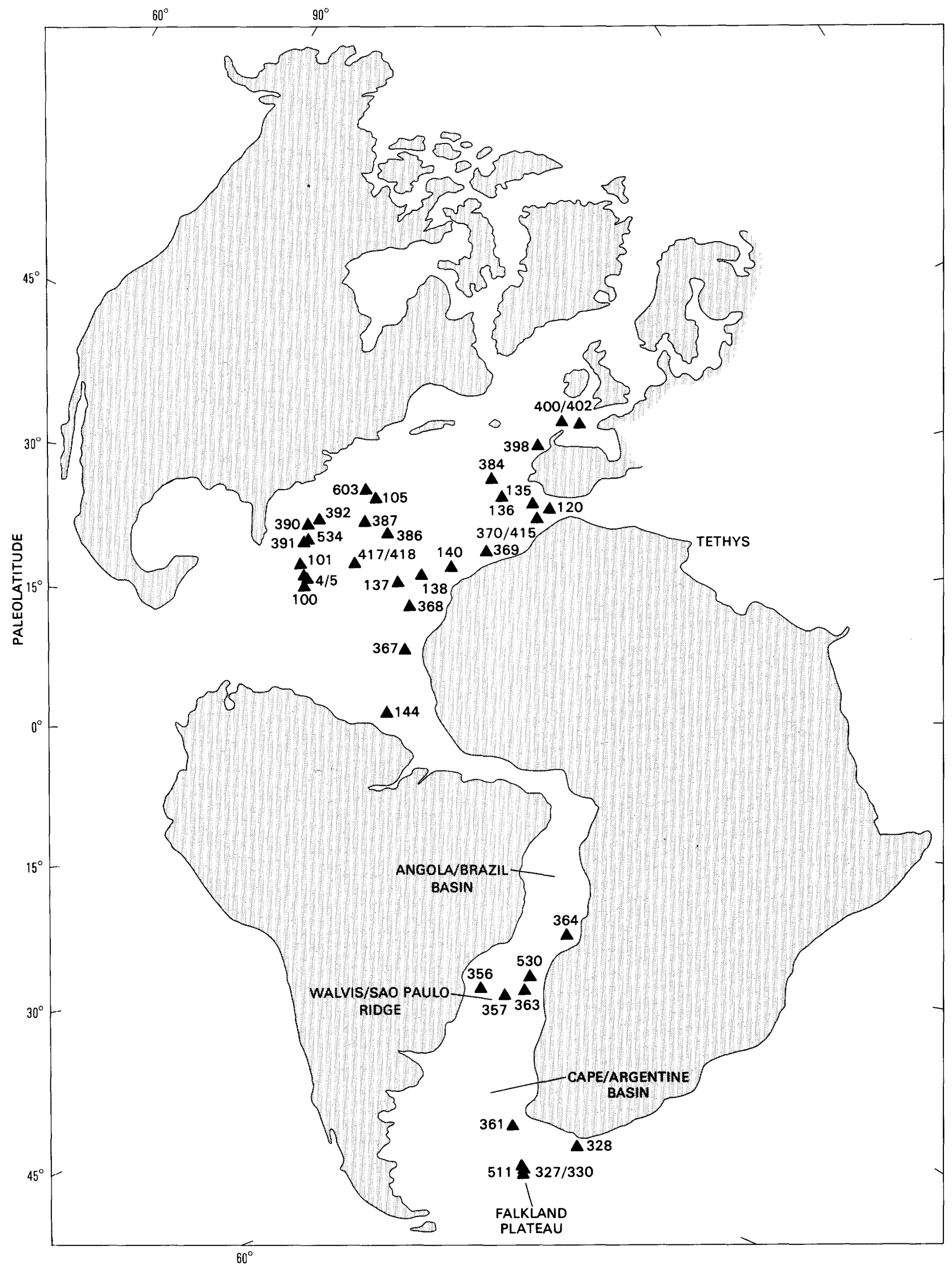

Figure 2. Locations of Deep Sea Drilling Project sites (solid triangles) where Cretaceous organic-carbon-rich strata have been recovered plotted on a continental reconstruction at $100 \pm 10$ million years before present (modified from Sclater and others, 1977). 


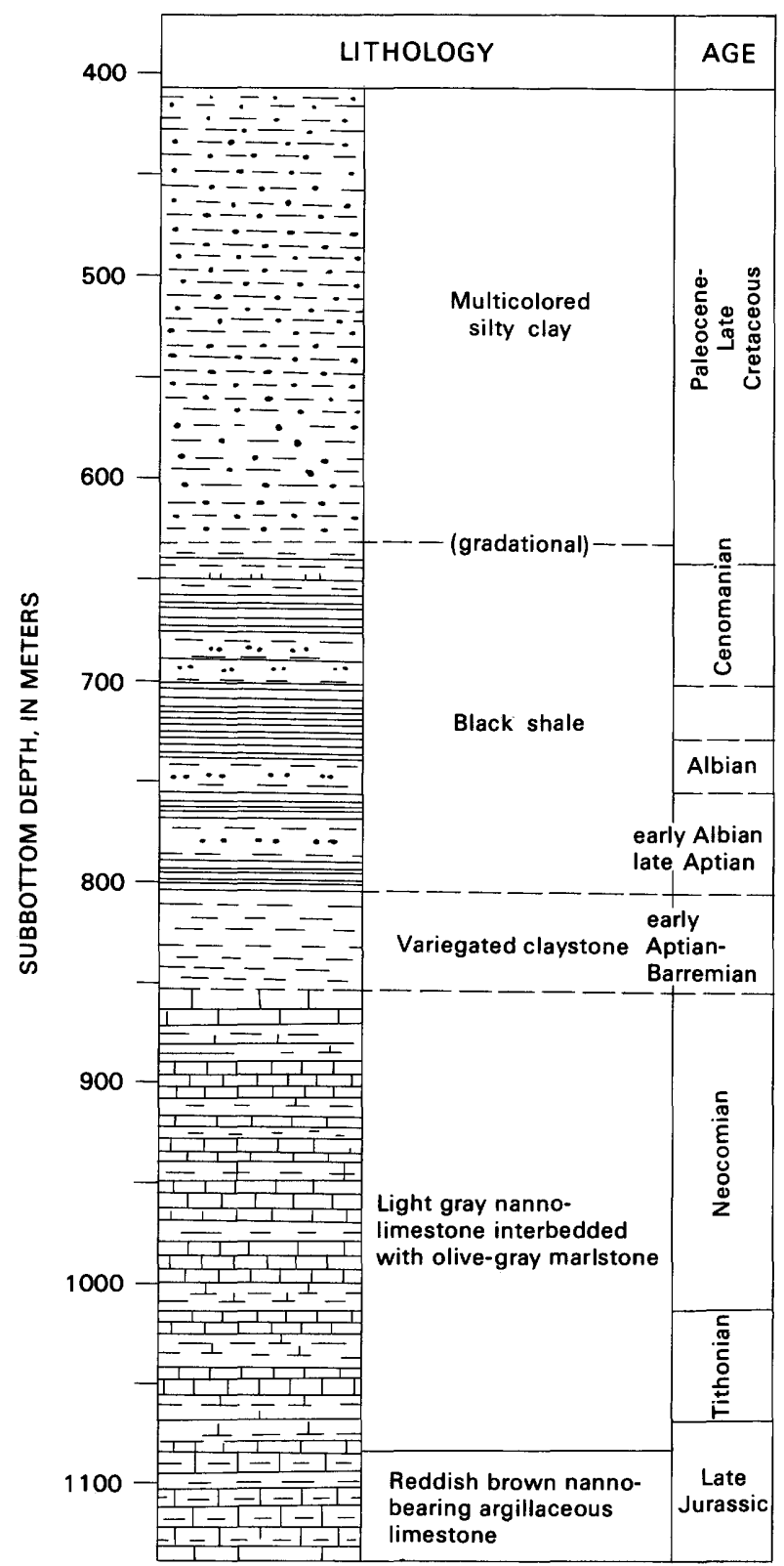

Figure 3. Summary stratigraphic column for strata recovered from Deep Sea Drilling Project sites in North Atlantic Ocean (modified from Jansa and others, 1979).

others, 1978, 1979; Dean and Gardner, 1982; Arthur and Dean, 1986). Upper Jurassic (Callovian-Oxfordian) strata containing as much as 3 percent $O C$ were recently recovered at DSDP site 534 in the Blake-Bahama basin (Sheridan and others, 1982). The Neocomian laminated dark marlstone beds generally contain more than 5 percent $\mathrm{OC}$, and one bed at site 367 in the Cape Verde basin off northwest Africa contains 33 percent OC (Dean and others, 1978; Dean and Gardner, 1982).

The end of deposition of the Neocomian carbonates apparently was caused by a sudden rise in the carbonate compensation depth (CCD) (Thierstein, 1979; Arthur and
Dean, 1986), and the remainder of the section in the North Atlantic through the Eocene is dominated by multicolored clay-rich lithologies. At most DSDP sites in the North Atlantic, the Neocomian carbonates are overlain by the so-called middle Cretaceous (Aptian-Albian to Turonian) black shale facies, but at some sites the two are separated by a thin (less than $10 \mathrm{~m}$ ) unit of interbedded red and green claystones of late Aptian to early Albian age (fig. 3; Jansa and others, 1978; Dean and Gardner, 1982).

The middle Cretaceous so-called "black shale" facies represents the main period of accumulation of organic matter in the Atlantic, and at most DSDP sites it consists of interbedded, green and black clay-rich lithologies (see reviews by Arthur, 1979a; Tucholke and Vogt, 1979; Thierstein, 1979; Arthur and Natland, 1979; Tissot and others, 1979, 1980; Dean and Gardner, 1982; Weissert, 1981; Arthur, Dean, and Stow, 1984; Arthur and Dean, 1986). This facies has been recovered at DSDP sites $4,5,101,105,135,137,138,144,367,368,369$, $370,386,387,391,398,400,402,415,416,417,418,534$, and 603 in the North Atlantic Ocean, and at sites 327, $328,330,356,357,361,363,364,511$, and 530 in the South Atlantic Ocean (fig. 2). The green and black claystone sequences are overlain by Upper Cretaceous green and red claystone. Concentrations of $\mathrm{OC}$ in the black lithologies in the North Atlantic range from less than 1 percent to 37 percent and usually are more than s percent (Lancelot and others, 1978; Tissot and others, 1979, 1980; Summerhayes, 1981; Dean and Gardner, 1982; Arthur, Dean, and Stow, 1984a; Arthur and Dean, 1986). Concentrations of OC generally are lower in black lithologies from western North Atlantic sites than in those from eastern North Atlantic sites. True black shale usually amounts to less than half of the so-called "black shale" facies.

The organic detritus in OC-rich layers may be from autochthonous marine planktonic production or from terrestrial organic debris. According to Tissot and others $(1979,1980)$, and Summerhayes (1981), autochthonous marine organic matter (that is, organic matter containing type II kerogen of Tissot and others, 1974) in continuous sections of Lower Cretaceous rocks in the North Atlantic is found only in the Cape Verde basin (site 367), on the Cape Verde rise (site 368), and on the Demerara rise (site 144). Everywhere else in the North Atlantic, terrestrial organic matter with admixtures of highly degraded, residual, marine organic matter dominates the Lower Cretaceous OC-rich strata (Tissot and others, 1979, 1980; Summerhayes, 1981). The Cretaceous OCrich strata in the southeastern North Atlantic, therefore, appear to have more in common with similar strata in the South Atlantic, where most of the organic matter is derived from marine sources, than with equivalent strata in the rest of the North Atlantic (Tissot and others, 1979, 1980; Summerhayes, 1981; Gilbert, 1984). 
In the South Atlantic sequences, OC concentrations average about 3-4 percent (values as high as 21 percent have been reported for the Aptian-lower Albian) at site 361 in the Cape basin (Arthur and Natland, 1979; Gilbert, 1984). They average about 4-5 percent (values as high as 24 percent have been reported for the lower Albian) at site 364 in the eastern Angola basin. Organic carbon concentrations average about 4 percent in the Hauterivian-lower Aptian strata at site 511 in the Argentine basin, and are less than one percent in the AptianAlbian (Dick and others, 1983; Gilbert, 1984). Black shale beds of Albian to Coniacian-Santonian age at site 530 contain as much as 19 percent OC and contain overall an average of 5.4 percent $\mathrm{OC}$, as compared with less than 0.5 percent $O C$ in intercalated beds of red and green claystone (Deroo and others, 1984; Meyers and others, 1984). Most of the organic matter in black shales at site 530 is of marine origin (Deroo and others, 1984; Gilbert, 1984). Much of the organic matter at site 361 in the Cape basin apparently is redeposited terrestrial organic matter, whereas the organic matter in black shales at sites 364 and 511 is mostly autochthonous marine organic matter (Gilbert, 1984). In spite of these differences in sources of organic matter, the OC-rich strata in all Atlantic basins are interbedded with bioturbated, OC-poor strata.

\section{Cycle periods}

Calculations of periodicities of diagenetic oxidation-reduction cycles, ranging in age from Early Cretaceous to Tertiary, are subject to several assumptions, particularly regarding sedimentation rate. These calculations, however, show that the oxidation-reduction cycles generally have periods ranging from 20,000 to 100,000 years and averaging about $40,000-50,000$ years (Dean and others, 1978; Arthur and Fischer, 1977; Arthur, 1979a; McCave, 1979; Arthur, Dean, Bottjer, and Scholle, 1984). The cyclicity of black shale deposition at site 530 in the southern Angola basin (see discussion in section on Models of Deposition) is much more variable, ranging from 9,600 to 393,000 years, with most values between 40,000 and 220,000 years. The more-regular periodicities at other sites are similar to periodicities of carbonate dissolution, dilution, seasurface temperature fluctuations, and other parameters that are correlated with climatic changes in the Neogene and Quaternary (Broecker and Van Donk, 1970; Ruddiman, 1971; Matthews, 1974; Gardner, 1975; Hays and others, 1976; Dean and others, 1981; Gardner, 1982; Gardner and others, 1984). The cyclic patterns of sedimentation that are so distinctive of the entire stratigraphic sequence in the North and South Atlantic Oceans also may be a response to climatic forcing similar to Quaternary analogues that are largely driven by climate-induced changes in ice volume and bottom-water production and flow. Cycles of climate-induced carbonate dissolution in the North Atlantic apparently extend through the Neogene and possibly the entire Tertiary (Dean and others, 1978, 1981). Matthews and Poore (1980) presented isotope evidence suggesting that changes in sea level related to ice volumes were important throughout the Tertiary.

Regardless of the exact mechanism involved in the formation of the sedimentary cycles, the pronounced cyclicity of the sedimentary section in the Atlantic, particularly in the middle Cretaceous, suggests that there probably were cyclic variations in the influx of terrigenous organic matter and detrital material, the sea-surface production of organic matter and $\mathrm{CaCO}_{3}$, the concentration of dissolved oxygen in deeper water masses, and (or) the preservation of $\mathrm{CaCO}_{3}$.

\section{DIAGENETIC PROCESSES AND PRODUCTS}

\section{Sulfur diagenesis}

Sulfur is incorporated into anoxic, OC-rich sediments mainly through bacterial sulfate reduction. This process is relatively well known (see for example, Berner, 1971, 1974, 1978, 1980, 1982, 1984; Goldhaber and Kaplan, 1974, 1975, 1981; Goldhaber and others, 1977; Jørgensen, 1977; Oremland and Taylor, 1978) and involves the utilization of pore-water sulfate as an electron donor for the oxidation of sedimentary organic matter by bacteria in the absence of dissolved molecular oxygen. Sulfate reduction usually proceeds after all other oxidants have been consumed. For example, Froelich and others (1979) found that oxidants in pelagic sediments in the eastern equatorial Atlantic were consumed in the following order of decreasing energy produced per mole of organic carbon oxidized: $\mathrm{O}_{2}>\mathrm{Mn}$-oxides $>\mathrm{NO}_{2}$ $>$ Fe-oxides $>\mathrm{SO}_{4}^{2-}$. Most $\mathrm{OC}$ (at least 90 percent) in the pelagic rain is oxidized by $\mathrm{O}_{2}$ before reaching the sediment-water interface, but the secondary oxidants are of great importance in regulating the burial and preservation of $\mathrm{OC}$ within the sediments (Bender and Heggie, 1984). In most anoxic sediments, sulfate accounts for most of the oxygen consumption and decomposition of organic matter (Berner, 1984). Jørgensen (1977) found that sulfate reduction accounted for 53 percent of the mineralization of organic matter in anoxic sediments of a fjord in Denmark. He also found that only 10 percent of the sulfide produced by sulfate reduction was precipitated as metal sulfides and that the rest diffused to the surface where it was reoxidized. Berner (1978) suggested than an average of 0.2-0.4 weight percent of the $\mathrm{OC}$ is lost from sediments during sulfate reduction, but this amount may vary depending upon the rate of sedimentation and the amount of sulfate that is available 
by diffusion into the sediment, as well as upon the type and reactivity of organic matter present (Toth and Lerman, 1977; Berner, 1980; Goldhaber and Kaplan, 1980). The reduced sulfur is free to diffuse upward to the sediment-water interface, where it can be oxidized by bacteria, or to diffuse to sites of sulfide precipitation, a major sink for sulfur in anoxic sediments. Modern anoxic sediments contain as much as several weight percent total sulfur. The weight ratio of sulfur to $O C$ in anoxic sediments averages 0.4 , but varies significantly from this value (Berner, 1982; Leventhal, 1983; Berner and Raiswell, 1983). Based on data for sulfur:carbon (S:C) ratios from the Black Sea and Devonian black shales of eastern North America, Levanthal (1983) suggested that $\mathrm{S}: \mathrm{C}$ ratios greater than 0.4 in black shales, with a slope intersect at a positive value of sulfur at zero carbon, signify deposition under an anoxic water column, rather than having only anoxic sediment pore waters.

A plot of OC versus $\mathrm{S}$ for those samples of Cretaceous strata for which both $\mathrm{OC}$ and $\mathrm{S}$ analyses are available (fig. 4) suggests that a S:C ratio of about 0.4 is a reasonable average, similar to the $\mathrm{S}: \mathrm{C}$ ratio in most modern anoxic sediments (Berner and Raiswell, 1983). Kendrick (1979) measured concentrations of total sulfur as much as 4.3 weight percent in OC-rich strata from DSDP sites 386 and 387 . As much as 40 percent of this sulfur apparently is in the organic fraction; the rest is in pyrite. Kendrick interpreted this sulfur enrichment as evidence for the deposition and preservation of $O C$ under an anoxic water column. Low concentrations of $S$ and $\mathrm{OC}$ were interpreted as an indication of oxic bottomwater conditions.

Metal sulfides of varying morphologies are present in nearly all the Cretaceous OC-rich strata recovered from DSDP sites in the Atlantic. Pyrite is the most commonly reported sulfide mineral and occurs as framboids, testfillings of foraminifera, micronodules, replacements or molds of radiolarian tests, and large discrete nodules and lenses. Localized concentrations of pyrite and (or) marcasite are common at contacts between black shale and underlying green claystone beds (Dean and Schreiber, 1978; Arthur, Dean, Bottjer, and Scholle, 1984a; Dean and others, 1984). In fact, sulfide sulfur appears to be highly mobile in sequences of interbedded OC-rich and OC-poor strata (Berner, 1969, 1970), and green claystone beds commonly contain as much total sulfur as adjacent beds of black shale.

Authigenic sulfate minerals such as gypsum and barite also occur within or near the boundaries of some black shale layers. Small (usually less than $10 \mathrm{~mm}$ ) euhedral crystals of barite are common in modern oxic deep-sea sediments, particularly in the equatorial Pacific Ocean (Cronan, 1974; Dean and Schreiber, 1978; Church, 1979), but larger concentrations of barite as nodules, lenses, rosettes, and laminae are not common in modern deep-sea sediments. Such larger aggregates have been described from Cretaceous OC-rich strata from several DSDP sites along the continental margin of northwest Africa (Dean and Schreiber, 1978) and on the Vigo Seamount off Portugal (Arthur, 1979a). Dean and Schreiber (1978) observed that the barite was always associated with organic matter, usually just below an OC-rich layer. They also noted that the barite occurred just below major unconformities and in sections in which the salinity of the interstitial water increased downward, probably related to suspected underlying Jurassic evaporites. Dean and Schreiber (1978) concluded that the main source of barium probably was organic matter, but that the sulfate may have come from the diffusion of seawater-sulfate into the sediments, the oxidation of preexisting pyrite, or the upward diffusion of sulfate from the dissolution of evaporites at depth.

Gypsum has been reported from DSDP cores in a variety of lithologies (Nesteroff, 1973; Briskin and Schreiber, 1978), particularly from anoxic sediments. Gypsum also is intimately associated with OC-rich continental slope sediments from off the coast of Southwest Africa (Seisser and Rogers, 1976).

\section{Carbonate diagenesis}

Many Cretaceous deep-sea black shale sequences contain dolomite, siderite, rhodochrosite, and other $\mathrm{Mg}$-, $\mathrm{Fe}-$, and Mn-rich carbonates. These carbonate minerals also are found in Holocene marine sediments where they are thought to be the products of anaerobic decomposition of organic matter and even to be associated with methane generation (Suess, 1979; Hein and others, 1979; Pedersen and Price, 1982). In fact, the abundance of siderite in some mid-Cretaceous black shales can be taken as evidence for complete reduction of sulfate and mineralization of sulfide (Berner, 1971). Methane generation is common in anaerobic, OC-rich sediments after sulfate reduction has ceased. Methanogenesis, like sulfate reduction, is a bacteria-mediated process that reduces $\mathrm{OC}$, acetate, and $\mathrm{CO}_{2}$ in pore waters and converts them to methane (see, for example, Claypool and Kaplan, 1974; Martens and Berner, 1974; Oremland and Taylor, 1978). During the production of methane, a substantial fractionation of carbon isotopes $\left(50-90\right.$ per mil, $\left.\delta^{13} \mathrm{C}\right)$ takes place between methane and $\mathrm{CO}_{2}$, leaving the residual $\mathrm{CO}_{2}$ enriched in ${ }^{13} \mathrm{C}$ (Presley and others, 1972; Rice and Claypool, 1981; Fuchs and others, 1979). During methane production, values of $\delta^{13} \mathrm{C}$ in total $\mathrm{CO}_{2}$ in pore waters may progressively shift from highly negative to highly positive (fig. 5). Carbonate minerals precipitated from pore waters during methanogenesis therefore may have 


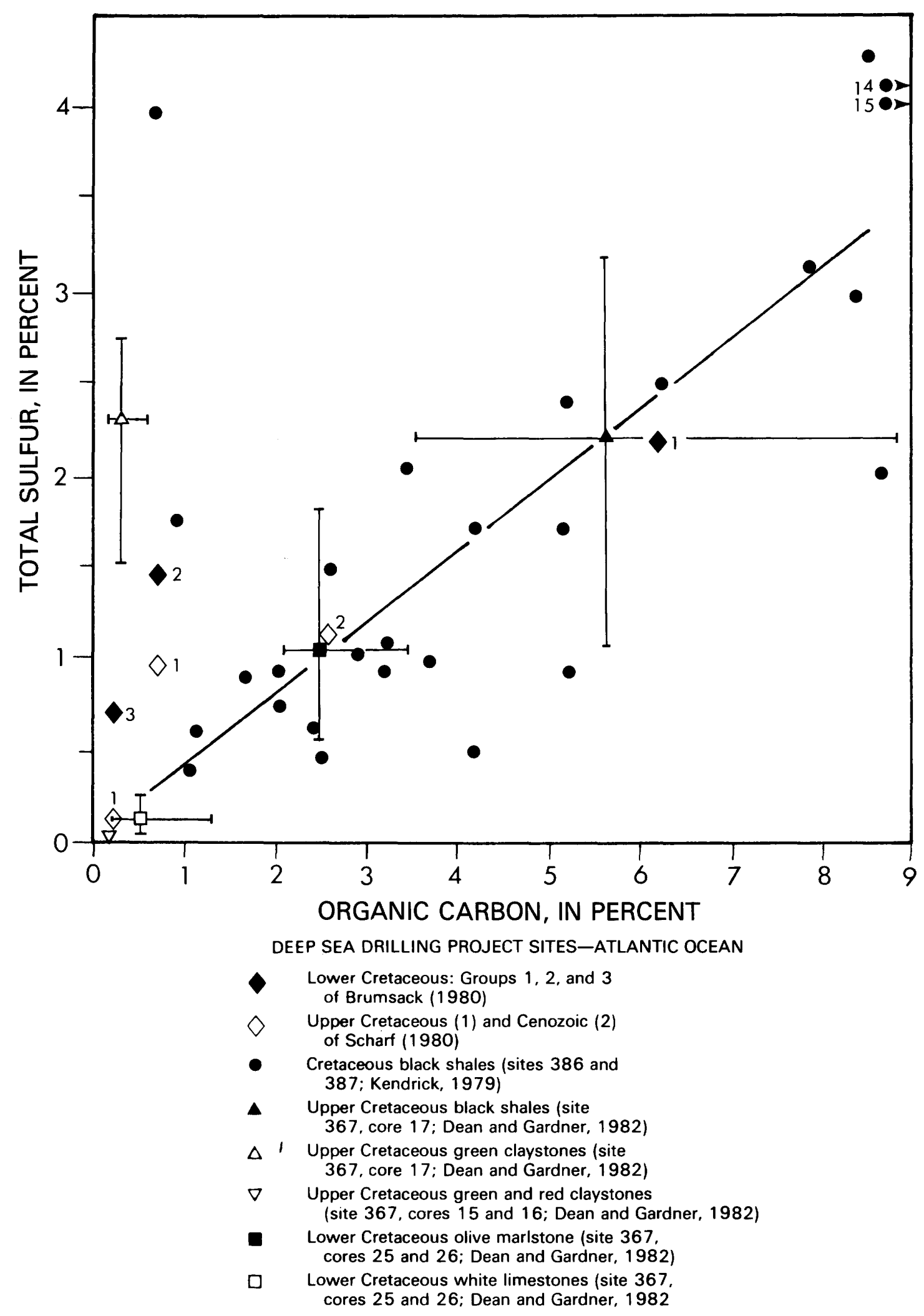

Figure 4. Concentrations of organic carbon and total sulfur in Cretaceous strata rich in organic carbon from Atlantic Deep Sea Drilling Project sites. 
TOTAL DISSOLVED CARBON (TDC), IN MILLMOLES PER LITER
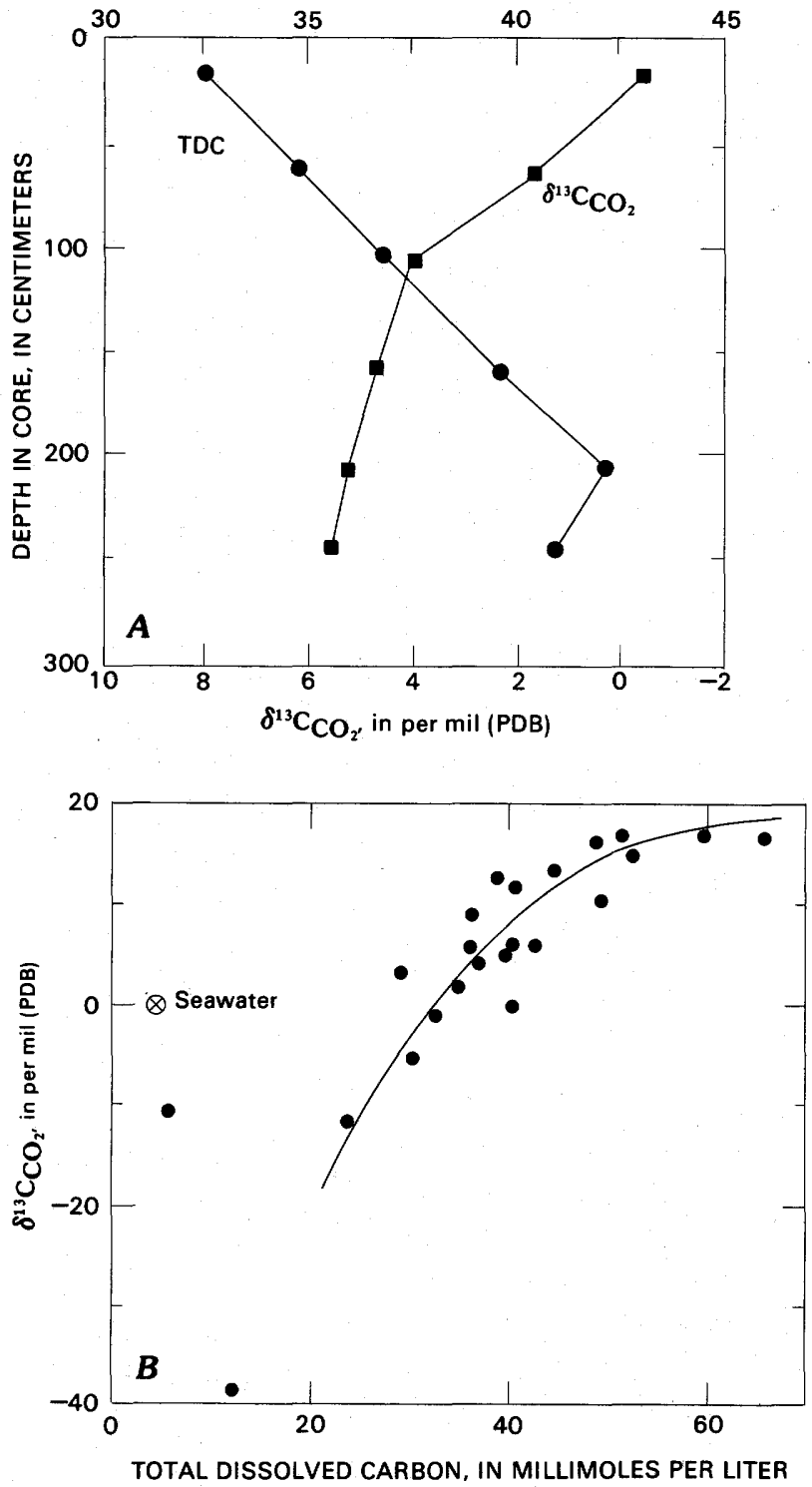

Figure 5. Relationships between $\delta^{13} \mathrm{C}$ and total dissolved $\mathrm{CO}_{2}$ (TDC) in pore waters of anoxic sediments during sulfate reduction and methane generation. A, Core 4 from anoxic Saanich inlet (data of Nissenbaum and others, 1972) showing rapid change to heavier values of $\delta^{13} \mathrm{C}$ in TDC in pore waters with increasing TDC during methane generation. $B$, Plot of $\delta^{13} C$ in TDC in pore water versus concentration of TDC for all data from Saanich inlet reported by Nissenbaum and others (1972) showing isotopically light values of $\delta^{13} \mathrm{C}$ at low concentrations of TDC due to decomposition of organic matter during sulfate reduction and a gradual increase in $\delta^{13} \mathrm{C}$ as methane generation proceeds. C, Example of deeper methane generation at Deep Sea Drilling Project site 147 in the Cariaco trench (Presley and others, 1973) where values of $\delta^{13} \mathrm{C}$ in pore-water TDC increases over tens of meters rather than over several meters, as in $A$ or $B$.

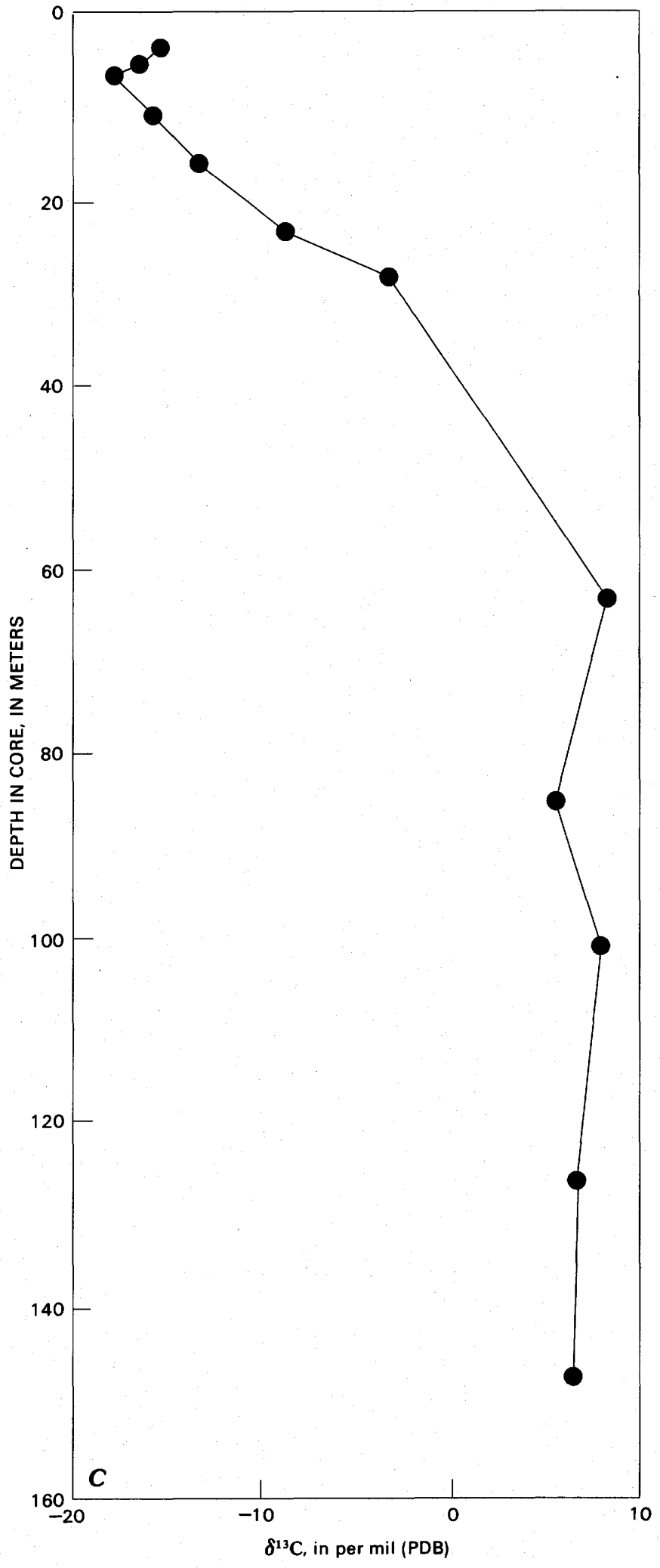


a large range of $\delta^{13} \mathrm{C}$ values. Diffusion and oxidation of methane within more oxic sediments may complicate carbon isotope values and may lead to very light (highly negative) values of $\delta^{13} \mathrm{C}$ in total $\mathrm{CO}_{2}$.

During periods when $\mathrm{OC}$ is being fixed in the sediment at unusually high rates (for example, during the middle Cretaceous), the oceanic surface-water and total-dissolved-carbon reservoirs may become isotopically heavier because of the net transfer of isotopically light $\mathrm{OC}$ to the sediment. Consequently, any biogenic carbonate formed in surface waters during these times would be isotopically heavy (more positive $\delta^{13} \mathrm{C}$ ) (Scholle and Arthur, 1980). For most of the Cretaceous, the $\delta^{13} \mathrm{C}$ of carbonate carbon apparently was between +1.0 and +4.5 per mil (relative to the PDB standard). In anoxic sediments that are relatively depleted in carbonate, diagenetic reactions control the carbon isotope composition of carbonate.

As the decomposition of organic matter proceeds from aerobic degradation through sulfate reduction, the total alkalinity of the pore waters increases (Berner, 1980). Ammonia and phosphate liberated from organic matter and sulfide species resulting from sulfate reduction contribute to the increase in alkalinity. Concentrations of total dissolved carbon (TDC) increase in proportion to the amount of oxidation of OC. The dissolved carbon added to interstitial water has a carbon isotopic composition close to that of the organic matter $\left(\delta^{13} \mathrm{C}\right.$ of about -23 per mil, on average). The initial TDC content in bottom waters in the open ocean today ranges from 2.2 to $2.5 \mathrm{mmol} / \mathrm{L}$, and ranges from about -0.5 to +1.5 per mil in $\delta^{13} \mathrm{C}$ (PDB). The addition of dissolved isotopically light carbon during sulfate reduction causes pore waters to have more negative values of $\delta^{13} \mathrm{C}$, which can approach -20 per mil as the pore-water TDC values increase to as much as 35 to $40 \mathrm{mmol} / \mathrm{L}$.

Concentrations of dissolved $\mathrm{Fe}, \mathrm{Mg}$, and $\mathrm{Mn}$ also increase in anoxic pore waters (see, for example, Manheim, 1976) which, with increased alkalinities, can lead to saturation with respect to a variety of carbonate minerals (Presley and others, 1972). For example, carbon in diagenetic carbonate minerals in highly anoxic sediment from the Baltic Sea has highly negative values of $\delta^{13} \mathrm{C}$ (about -13 per mil; Suess, 1979). Hein and others (1979) measured values of $\delta^{13} \mathrm{C}$ ranging from about -7 to about -21 per mil (average of about -17 per mil) in diagenetic carbonates (high-Mg calcite, nrotodolomite, siderite, rhodochrosite, low-Mg calcite, and manganosiderite) in diatom-rich sediment in DSDP cores from the Bering Sea. Because of the highly negative values of $\delta^{13} \mathrm{C}$, Hein and others (1979) concluded that the carbon in the diagenetic carbonates was derived from the oxidation of organic matter under anaerobic conditions with the production of methane.

Dolomite is the most common carbonate mineral in OC-rich sediments in general; it typically occurs as isolated rhombs less than $62 \mu \mathrm{m}$ in diameter, but also may occur as discrete laminae, beds, and nodules. Sources of magnesium for dolomite formation may be from magnesium dissolved in interstitial waters, magnesium desorbed from clay minerals or biogenic silica (see, for example, Donnally and Merrill, 1977), and (or) upward diffusion from underlying evaporite beds. The latter may have been a source of magnesium for the dolomite found associated with barite in OC-rich strata at DSDP sites 364, 369, and 370 (Dean and Schreiber, 1978; Bolli and others, 1978). The chlorinity of interstitial waters at these three sites increases downward in response to underlying evaporites.

Friedman and Murata (1969) demonstrated that carbon in authigenic dolomite in the OC-rich Monterey Formation (Miocene) of California has a range of $\delta^{13} \mathrm{C}$ values reflecting formation in anoxic waters. Pisciotto and Mahoney (1981) and Kelts and McKenzie (1982) analyzed dolomite samples from Holocene OC-rich sediments from DSDP cores from the California borderland and Gulf of California, respectively. Both workers found large ranges in $\delta^{13} \mathrm{C}$ values of carbonate carbon, apparently reflecting dolomite precipitation both during and after sulfate reduction in pore waters. Pisciotto and Mahoney (1981) found a strong correlation between sedimentation rate and $\delta^{13} \mathrm{C}$ values of dolomite; sediment deposited rapidly apparently began methane generation earlier, had heavier $\delta^{13} \mathrm{C}$ values of dissolved carbon in pore waters, and, therefore, had heavier $\delta^{13} \mathrm{C}$ values in precipitated dolomite.

The exact mechanism of dolomite precipitation in anoxic sediments is unknown, but Baker and Kastner (1980) suggested that dolomite precipitation is favored by a lack of dissolved sulfate in pore waters. Presumably, most of the dolomite precipitates after reduction of sulfate in pore waters is complete.

Siderite is common in many Cretaceous OC-rich sequences at Atlantic DSDP sites, particularly sites 105, 386, 387, and 398. Siderite at sites 105, 386, and 387 occurs mainly as hard, yellow laminae or lenses. The siderite at site 398 occurs in a variety of morphologies including laminae, lenses, and replacements of biogenic calcite (Arthur, 1979a). Stable-isotope values of the siderite reflect an early diagenetic formation $\left(\delta^{13} \mathrm{C}\right.$ values as negative as -5.0 per mil) and (or) replacement of biogenic calcite.

The type of diagenetic carbonate formed in Cretaceous OC-rich sequences probably depends on the chemistry of the initial detrital sediment, the sedimentation rate, and the extent of OC enrichment and sulfate reduction. Siderite appears to be the most common diagenetic carbonate mineral in sequences that have relatively low concentrations of $\mathrm{OC}$ (for example, the western North Atlantic basin) or high sedimentation rates (for example, sites 370 and 398). This distribution may be due to the fact that sulfate is reduced quickly without much incorporation of sulfur into metal sulfides leaving 
a large supply of unmineralized reduced iron. Rhodochrosite and other Mn-rich carbonates are not common in Cretaceous OC-rich strata, although manganese substitution in authigenic carbonates is common. Manganese is highly mobile in anoxic pore waters, and, in sediments deposited more slowly, it probably diffuses out of the sediment too rapidly to be precipitated in the form of carbonate minerals. Impure Mn-rich carbonate phases, usually containing varying amounts of $\mathrm{Ca}, \mathrm{Mn}$, and (or) $\mathrm{Fe}$, occur in reduced marine sediments from many different localities (see, for example, Zen, 1959; Manheim, 1961; Lynn and Bonatti, 1965; Calvert and Price, 1970; Froelich and others, 1979; Hein and others, 1979; Suess, 1979; Pederson and Price, 1982). Most of the manganese in these carbonates may be derived from the dissolution of manganese oxides after burial. The carbonate may be derived from oxidation of organic matter under reducing conditions as long as this reduction is not accompanied by a major decrease in $\mathrm{pH}$. Given a sufficient supply of manganese and dissolved carbonate and a sufficiently high $\mathrm{pH}$, a Mn-rich carbonate layer may form under reducing conditions.

The Cretaceous OC-rich strata in the Atlantic vary considerably in amounts and types of diagenetic carbonate minerals. These minerals deserve more systematic study than has been devoted to them so far; in particular, the chemistry and mineralogy of diagenetic carbonates related to initial sediment properties deserves further study.

\section{Phosphate diagenesis}

We know of no reported carbonate-fluorapatite pellets, nodules, or other phosphate aggregates from Atlantic Cretaceous OC-rich strata, although these strata usually have a large range of phosphorous concentrations $(0.005-$ 1.8 percent $\mathrm{P}_{2} \mathrm{O}_{5}$ ). Most phosphorous is supplied to sediments in productive areas of the oceans in the form of organic matter and fish debris (Froelich and others, 1982). Phosphate is released from organic matter by decomposition both in the water column during settling of organic matter and fecal pellets to the bottom and in pore waters by aerobic and anaerobic decomposition. The carbon:phosphorus $(\mathrm{C}: \mathrm{P})$ ratio in the organic matter increases systematically as the organic matter settles through the water column and during early diagenesis (Müller and Suess, 1980; Krom and Berner, 1981; Froelich and others, 1982). Phosphate produced by decomposing organic matter in the sediment can diffuse out of the sediment into overlying seawater, precipitate in the sediment as a phosphatic mineral, or become adsorbed on ironoxyhydroxides at an oxic-anoxic interface (Berner, 1974).

In general, dissolved phosphate in pore waters of OCrich sediment increases with depth to a maximum that is likely controlled by the precipitation of carbonatefluorapatite. This increase is due to the decomposition of organic matter and possibly the dissolution of fish debris
(Baturin and others, 1970; Berner, 1980; Suess, 1981). Fish debris usually is well preserved in OC-rich strata, suggesting that its dissolution is buffered by the increase in phosphate concentration due to the decomposition of organic matter. Baturin and others (1970) found a maximum phosphate concentration of $9.7 \mu \mathrm{mol} / \mathrm{L}$ in the pore waters of Walvis Bay muds, more than three times the highest concentration in open oceanic deep waters. Phosphate concentrations several orders of magnitude greater than those in overlying seawater have been reported from sediments in nearshore environments (Baturin, 1972, Nissenbaum and others, 1972; Sholkovitz, 1973; Berner, 1974; Suess, 1976; Goldhaber and others, 1977; Krom and Berner, 1981). A limit to the amount of phosphate that can be buried in sediment is the initial $\mathrm{C}: \mathrm{P}$ ratio in the sedimenting organic matter. Deep-water OC-rich sediments may not be a major sink for phosphorous because, although much organic matter may be preserved in anoxic strata, much of the organic phosphorous may have been released by decay of organic matter that settles to the bottom. Thus, the C:P ratio of sedimented organic matter may already be elevated, and the total phosphorous content of deeper-water OC-rich sediment will be low (Glenn and Arthur, 1982) relative to that of OC-rich sediment in shallow water. The average $\mathrm{P}_{2} \mathrm{O}_{5}$ content of modern OC-rich sediment from the Black Sea is 0.17 percent, which is similar to or lower than $\mathrm{P}_{2} \mathrm{O}_{5}$ concentrations in oxic sediments where phosphate is adsorbed onto ferric oxyhydroxides (Berner, 1974).

The average concentration of $\mathrm{P}_{2} \mathrm{O}_{5}$ in black shale from site 530 in the southern Angola basin is 0.19 percent (data of Dean and Parduhn, 1984). The average concentration of OC in all samples of black shale reported by Meyers and others (1984) is 5.4 percent. These two values yield an average C:P atomic ratio of 168 which is high relative to the average C:P ratio of 106 found by Redfield (1958) for freshly fixed planktonic organic matter, and confirmed by more recent studies on plankton and particulate organic matter (for example, Krom and Berner, 1981; Froelich and others, 1982). The C:P ratio of 168 for organic matter in site 530 black shales, however, is lower than the values reported for modern OC-rich sediments (see, for example Sholkovitz, 1973; Krom and Berner, 1981; Froelich and others, 1982). Phosphorus accumulated at rates between 0.013 and $0.58 \mathrm{~g} / \mathrm{cm}^{2} / \mathrm{m}$.y. (average of about 0.2 ) in the black shales at site 530-not exceptionally high values. Phosphate probably occurs mainly in the form of preserved phosphatic fish debris in most deep-sea OC-rich strata.

\section{TRACE ELEMENTS IN ORGANIC-CARBON-RICH STRATA}

The Cretaceous OC-rich strata in the Atlantic provide insight into the general problem of the incorporation of trace metals in OC-rich sediments. Such marine sediments and rocks are known to be significantly enriched in a 
variety of oxidation-reduction-sensitive trace elements (see, for example, Vine and Tourtelot, 1970) relative to average marine sediment and shale, but the degree of enrichment varies greatly. Few systematic studies have been made of major and trace element concentrations in Cretaceous deep-sea OC-rich lithologies, but such studies are important because these extensive lithologic units are potential sinks for OC, sulfur, and certain trace elements. During the deposition of OC-rich sediments, trace elements, OC, and sulfur may be extracted from the oceans at greater than steady-state rates, thereby perturbing the chemical and isotope balances of the ocean. The possible effects of Cretaceous $\mathrm{OC}$ accumulation on the global carbon cycle was discussed by Scholle and Arthur (1980), Arthur (1982), and Arthur and others (1985) who found that average $\delta^{13} \mathrm{C}$ values of oceanic TDC increased during mid-Cretaceous black shale deposition, as did the rates of accumulation of $\mathrm{OC}$ in the deep sea. Average deep-sea accumulation rates of OC were as much as seven times those of today during the peak of Aptian-Albian black shale deposition. Anderson and others (1982) suggested that increased rates of burial of sulfur as metal sulfides in Cretaceous black shales caused significant changes in the oceanic sulfur cycle. Brumsack (1980) also considered the possible effects of Cretaceous black shale deposition on trace metal and carbon cycling, but his estimates of the fluxes of those components to the black shales, probably were too high because he considered the entire thickness of a so-called "black shale" unit to have the composition of his "average" black shale (see table 2). As pointed out earlier, black-shalebearing units recovered from Atlantic DSDP sites commonly contain less than 10 to 20 percent of beds with an OC concentration of more than one percent, but some intervals have more. The geochemistry of interbedded

Table 2. Average or representative chemical analyses for modern organic-carbon-rich sediment, oxic deep-sea sediments, and Cretaceous black shales and interbedded strata

[Values in parentheses are recalculated on a carbonate-free basis. Leaders (---) indicate not analyzed or not reported]

\begin{tabular}{|c|c|c|c|c|c|c|c|c|c|c|c|}
\hline $\begin{array}{l}\text { Element } \\
\text { or oxide }\end{array}$ & Black & k Sea ${ }^{1}$ & $\begin{array}{r}\text { Bunn } \\
\text { No }\end{array}$ & $\begin{array}{l}\text { nefjord, } \\
\text { orway }^{2}\end{array}$ & $\begin{array}{r}\text { South } \\
\text { Af rica } \\
\text { diatom }\end{array}$ & $\begin{array}{l}\text { h West } \\
\text { a shelf } \\
\text { m clay }\end{array}$ & Balti & $=\operatorname{sea}^{4}$ & $\begin{array}{l}\text { Deep-sea } \\
\text { pelagic } \\
\text { clay }\end{array}$ & $\begin{array}{c}\text { Cretaceous } \\
\text { At lantic } \\
\text { black shales }\end{array}$ & $\begin{array}{l}\text { Cretaceous } \\
\text { black shales } \\
\text { DSDP site } 530^{7}\end{array}$ \\
\hline \multicolumn{12}{|c|}{ Percent } \\
\hline $\mathrm{SiO}_{2}$ & 32.5 & $(51.8)$ & 34.9 & $(40.4)$ & 51.2 & $(57.6)$ & 39.0 & $(42.0)$ & 60.4 & --- & 56.7 \\
\hline $\mathrm{Al}_{2} \mathrm{O}_{3}$ & 8.97 & $(14.3)$ & 8.77 & $(10.1)$ & 2.92 & $(3.28)$ & 14.2 & $(15.3)$ & 19.1 & --- & 11.8 \\
\hline $\mathrm{TiO}_{2}$ & .29 & $(.46)$ & .43 & $(.50)$ & .23 & $(.26)$ & .72 & $(.77)$ & .92 & -- & 1.11 \\
\hline $\mathrm{Fe}_{3} \mathrm{O}_{3}$ & 4.82 & $(7.69)$ & 10.4 & $(12.1)$ & 1.62 & $(1.82)$ & 7.7 & $(8.3)$ & 8.93 & 5.06 & 8.5 \\
\hline $\mathrm{CaO}$ & 20.9 & & 7.3 & & 7.26 & & 2.2 & & 1.01 & -- & -- \\
\hline $\mathrm{MgO}$ & 2.21 & $(3.53)$ & 1.83 & $(2.10)$ & 1.33 & $(1.49)$ & 2.7 & & 3.73 & -- & 2.8 \\
\hline $\mathrm{Na}_{2} \mathrm{O}$ & 1.61 & $(2.57)$ & .93 & $(1.08)$ & & --- & .3 & $(.3)$ & 1.67 & --- & 1.39 \\
\hline $\mathrm{K}_{2} \mathrm{O}$ & 1.72 & $(2.75)$ & 2.27 & $(2.63)$ & .71 & $(.80)$ & 4.3 & $(4.6)$ & 3.56 & -- & 3.17 \\
\hline Mno & .066 & ; $(.11)$ & 4.78 & $(5.54)$ & .014 & & 5.2 & $(5.6)$ & .52 & .12 & .07 \\
\hline $\mathrm{P}_{2} \mathrm{O}_{5}$ & .27 & $(.43)$ & .61 & $(.71)$ & 1.59 & $(1.79)$ & .23 & $(.25)$ & .16 & --- & .18 \\
\hline $\mathrm{s}^{2}$ & 2.90 & $(4.61)$ & 4.26 & $(4.94)$ & 1.59 & $(1.79)$ & 2.8 & $(3.0)$ & --- & 2.19 & 2.36 \\
\hline Org-C & 2.25 & (3. 58) & 5.44 & $(6.30)$ & 9.35 & $(10.5)$ & 4.6 & $(5.0)$ & --- & 6.18 & 4.77 \\
\hline \multicolumn{12}{|c|}{ Parts per million } \\
\hline As & \multicolumn{2}{|c|}{--} & 71 & $(82)$ & 16 & & \multicolumn{2}{|c|}{--} & 13 & --- & 32 \\
\hline $\mathrm{Ba}$ & 265 & (423) & 552 & $(640)$ & 198 & (222) & 750 & $(806)$ & 2,300 & 530 & 660 \\
\hline $\mathrm{Cd}$ & \multicolumn{2}{|c|}{--} & & -- & 35 & & - & -- & 0.21 & 0.92 & 8 \\
\hline Co & \multicolumn{2}{|c|}{---} & 60 & (70) & \multicolumn{2}{|l|}{4.6} & 20 & (24) & 74 & 27 & 59 \\
\hline $\mathrm{Cr}$ & 107 & (171) & 107 & (124) & \multicolumn{2}{|l|}{91} & 90 & (97) & 90 & 202 & 180 \\
\hline $\mathrm{Cu}$ & 45 & (72) & 135 & $(157)$ & 68 & (76) & 78 & (84) & 250 & 156 & 150 \\
\hline Mo & 26 & (42) & 26 & (30) & 53 & $(60)$ & 35 & (38) & 27 & 59 & 26 \\
\hline $\mathrm{Ni}$ & 108 & $(172)$ & 45 & (52) & 108 & (121) & 43 & (46) & 225 & 186 & 130 \\
\hline $\mathrm{Pb}$ & 10 & (16) & 167 & (194) & 12 & (13) & 25 & (27) & 80 & 16 & 27 \\
\hline $\mathrm{v}$ & - & -- & 276 & $(320)$ & & & 130 & (140) & 120 & 822 & 460 \\
\hline $2 n$ & 76 & (121) & 944 & $(1,090)$ & 68 & (76) & 110 & (118) & 165 & 828 & 320 \\
\hline
\end{tabular}

${ }^{1}$ Average of modern Black Sea deep-water sediments; data of Hirst (1974).

${ }^{2}$ Average of anoxic sediments from Bunnefjord, Norway (Calvert, 1976).

${ }^{3}$ Average of diatomaceous clays, South West Africa shelf (Calvert, 1976). Values for $\mathrm{MnO}, \mathrm{As}, \mathrm{Cd}, \mathrm{Co}$, and $\mathrm{Cr}$ are averages of samples from the tops of 10 cores of green diatomaceous muds from South West Africa shelf; data of Brongersma-Sanders and others, 1980.

${ }^{4}$ Average of analyses of sediment from Gotland basin, Baltic Sea; data of Manheim (1961).

${ }^{5}$ Average oxidized, deep-sea pelagic clay on a carbonate-, water-, and organic-free basis (Chester and Aston, 1976).

${ }^{6}$ Average of 38 samples of Atlantic Cretaceous black shales; data of Brumsack, 1980.

${ }^{7}$ Average of 28 samples of black shale from Deep Sea Drilling Project (DSDP) site 530, southern Angola basin; data of Dean and Parduhn (1984) recalculated on a carbonate-free basis. 


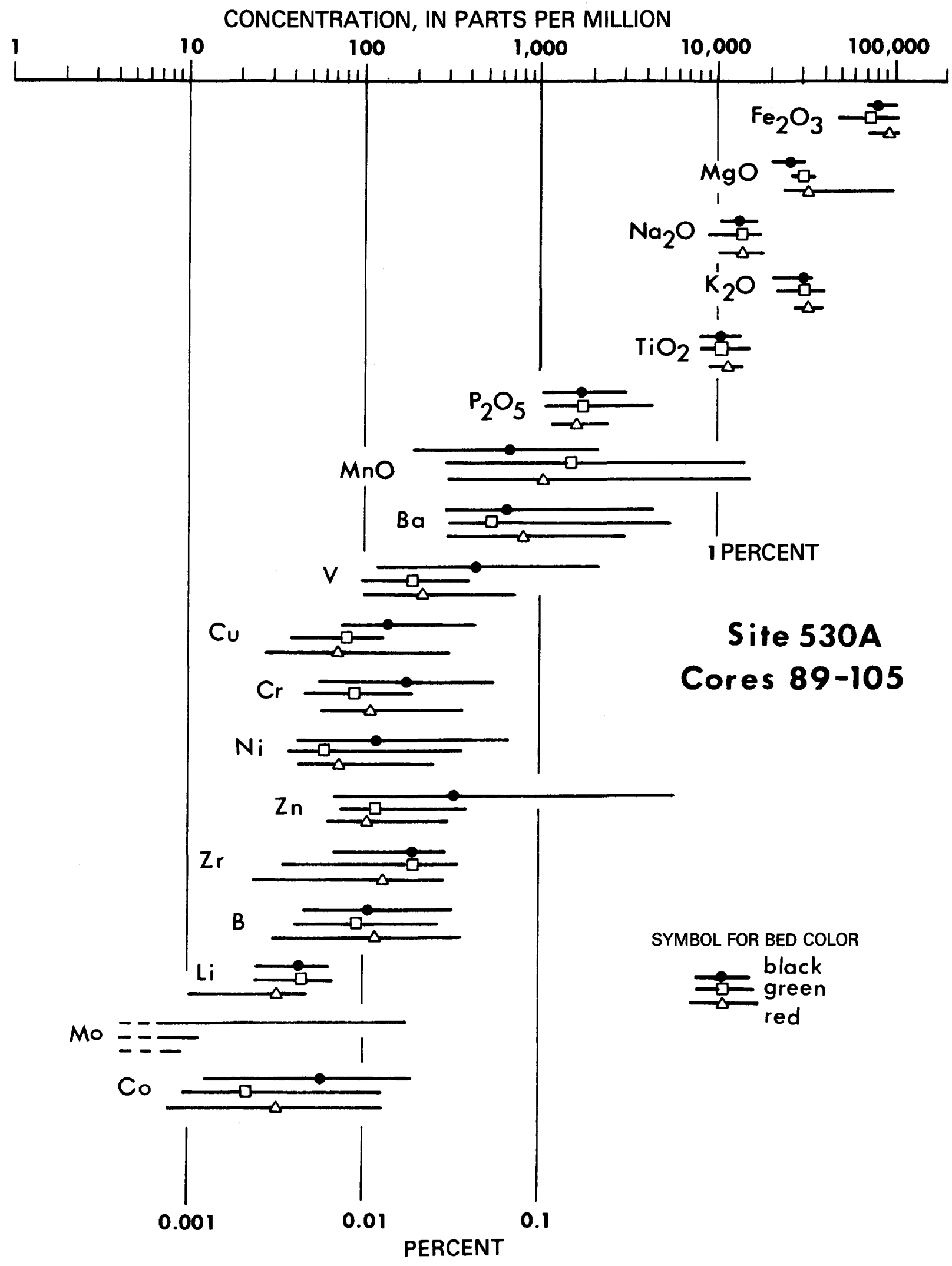

Figure 6. Observed range (length of bar) and geometric mean (symbol) of concentrations of major-element oxides and trace elements in samples of red (open triangle) and green (open square) claystone and black shale (solid circle) from Deep Sea Drilling Project site 530, cores 87-105. 
black, green, and red Cretaceous strata are contrasted below, and their geochemistry and metal accumulation rates are compared with those of modern anoxic sediments.

The enrichment of certain trace elements-especially $\mathrm{Cu}, \mathrm{Zn}, \mathrm{Mo}, \mathrm{V}, \mathrm{Ni}$, and $\mathrm{Cr}$-in sediments and rocks enriched in organic matter has been reported by many investigators (for example, Tourtelot, 1964; Wedepohl, 1964; Brongersma-Sanders, 1965; Calvert and Price, 1970; Vine and Tourtelot, 1969, 1970; Volkov and Fomina, 1974; Lange and others, 1978; Chester and others, 1978; Leinen and Stakes, 1979; Brongersma-Sanders and others, 1980; Dean and Gardner, 1982; Dean and Parduhn, 1984). The association of high trace-element concentrations with organic matter may reflect the concentration of these elements by organisms (bioconcentration), by chemical sorption and precipitation with organic detritus, clays, and so forth falling through the water column, or formation of sulfides under anoxic conditions created by a flux of excess OC. Marine plankton concentrate trace elements, especially $\mathrm{Ba}$, $\mathrm{Pb}, \mathrm{Ni}, \mathrm{Cu}, \mathrm{Zn}, \mathrm{Mn}$, and $\mathrm{Fe}$ (Vinogradov, 1953; Goldberg, 1957; Boyle and Lynch, 1968; Knauer and Martin, 1973; Martin and Knauer, 1973; Vinogradova and Kovalskiy, 1962; Boström and others, 1974; Chester and others, 1978; Moore and Boström, 1978; Leinen and Stakes, 1979; Collier and Edmond, 1984), suggesting that bioconcentration is a potentially important mechanism for incorporation of certain trace elements in OC-rich marine sediments. The great effectiveness of the adsorption of trace metals by clay minerals and organic matter, however, and coprecipitation of trace metals, particularly as sulfide minerals, suggests that these processes also may play an important role in the removal of trace metals from seawater (Tourtelot, 1964, 1979; Volkov and Fomina, 1974; Holland, 1979).

From studies of the minor-element compositions of contemporaneous Upper Cretaceous marine and nonmarine shales in the western interior of the United States, Tourtelot (1964) found that element concentrations were consistently higher in the marine shales. He concluded that sorption and syngenetic mineral formation in the marine environment were important, if not the most important, processes affecting the minor element content of shales. The final minor element composition is thus the result of cycles of sorption-desorption and (or) precipitationdissolution as the sediments are subjected to varying chemical conditions in depositional and diagenetic environments. The greatest control is probably exerted by oxidationreduction conditions during diagenesis. Vine and Tourtelot (1970) also concluded that sorption processes are important in metal enrichment in black shales, but suggested that some prior concentration of metals from seawater (for example, by bioconcentration) was required. They stated that the availability of metals in the various solutions with which the organic matter comes in contact throughout its history is probably the most significant factor in determining metal enrichment, and that interstitial pore fluids are probably the most important of these solutions.
If thin beds of black shale are interstratified with other lithologies, they may become sinks for elements mobilized and transported in pore waters during compaction (Berner 1969, 1975). The importance of interbedded more-reduced and less-reduced strata on the migration and accumulation of trace elements and the relative mobility of different elements under reducing conditions was pointed out by Dean and Parduhn (1984) for Cretaceous black shale interbedded with red and green claystone in the Angola basin at DSDP site 530. This 160-m-thick interbedded sequence is Albian through ConiacianSantonian in age and represents the upper part of midCretaceous black-shale deposition in the Atlantic. The sequence contains 260 beds of black shale which average 5.4 weight percent $\mathrm{OC}$, compared with less than 0.5 percent for red and green claystones in the sequence (Meyers and others, 1984). Geometric-mean concentrations of trace elements from each lithology show that concentrations of $\mathrm{As}, \mathrm{Cd}, \mathrm{Co}, \mathrm{Cr}, \mathrm{Cu}, \mathrm{Mo}, \mathrm{Ni}, \mathrm{Pb}, \mathrm{V}$, and $\mathrm{Zn}$ are all higher in black shales than in red and green claystones (fig. 6). Concentrations of $\mathrm{Ba}$ and Fe generally are higher in red claystone than in green claystone and black shale. Concentrations of manganese generally are higher in green claystone than red claystone, and much lower in black shale. Dean and Gardner (1982) found the same general relationships in cycles of black shale and green and red claystone from DSDP site 367 off northwest Africa; Cr, Mo, Ni, Zn, and $\mathrm{V}$ were enriched in black shale, whereas $\mathrm{Co}$ and $\mathrm{Cu}$ were of about equal concentrations in all lithologies (fig. 7).

The maximum concentrations of elements in the site 530 black shales, however, are not all at the same depth (fig. 8). Concentrations of $\mathrm{V}$ and $\mathrm{Cu}$ (as well as $\mathrm{Cd}, \mathrm{Zn}$, and Mo, not shown in fig. 8) are highest in the part of the section where black shale beds are most abundant. Concentrations of several other trace elements, especially $\mathrm{Ni}, \mathrm{Ba}$, and $\mathrm{Co}$ (not shown in fig. 8) are higher in black shales in the upper part of the section. These differences may be related to differences in amount and type of organic matter in the black shale beds. Data of Deroo and others (1984; fig. 8) show that the black shale beds in the upper part of the section contain more organic matter (higher percentage of $\mathrm{OC}$ ) and that this organic matter contains more lipid-rich marine organic matter (higher $\mathrm{H}$-index).

Brumsack (1980) analyzed 38 samples of Cretaceous black shale from the Atlantic that had more than 1 percent OC (average of 6.12 percent; table 2) and compared the element concentrations in these black shales to those from 11 samples of associated lithologies that contained $0.5-1.0$ percent organic carbon and 38 samples of associated lithologies that contained less than 0.5 percent $\mathrm{OC}$. His results showed that $\mathrm{Cu}, \mathrm{Cr}, \mathrm{Mo}, \mathrm{Ni}$, and $\mathrm{Zn}$ were enriched in $\mathrm{OC}$-rich beds relative to associated OC-poor beds. Iron and manganese concentrations were highest in black and red beds. Table 2 compares Brumsack's (1980) data with those from site 530 (Dean and Parduhn, 1984). The mean values for samples from site 


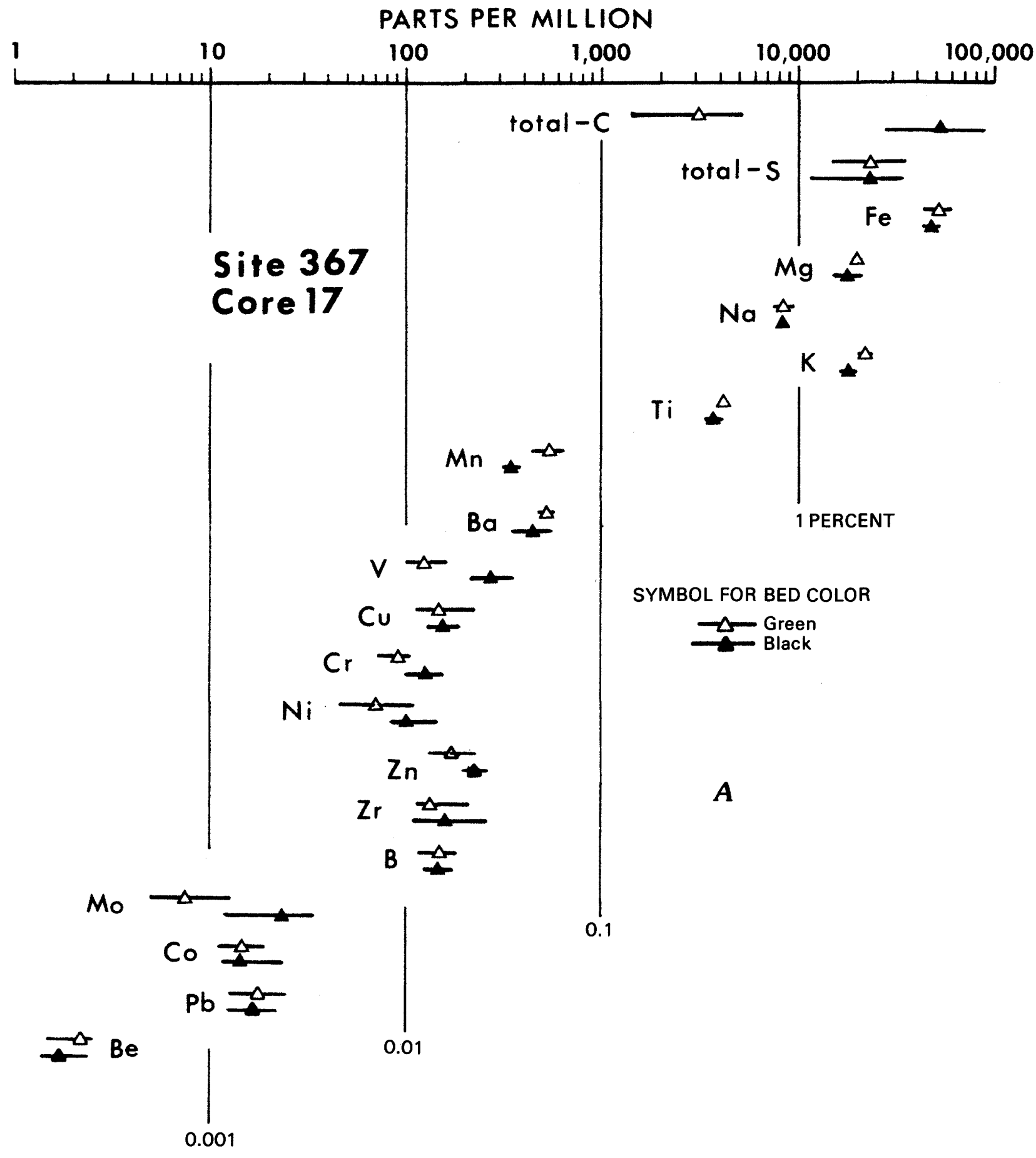

\section{PERCENT}

530 given by Dean and Parduhn and plotted in figure 6 are geometric means which are more realistic measures of central tendency because trace element concentrations usually have frequency distributions that more closely approximate log-normal than normal distributions. In table 2 , however, the site 530 data are expressed as arithmetic means for purposes of comparison. The average concentrations of $\mathrm{Cr}, \mathrm{Cu}, \mathrm{Ni}$, and $\mathrm{Pb}$ in both sets of black shale samples are comparable, whereas
Brumsack's (1980) average concentrations of Mo, V, and $\mathrm{Zn}$ are about twice those of the site 530 black shales; concentrations of $\mathrm{Ba}, \mathrm{Cd}$, and $\mathrm{Co}$ are higher in site 530 black shales. Some of these differences may reflect analytical uncertanties, but, in general, Cretaceous black shales from the Atlantic are similarly enriched in trace elements.

Compared with modern anoxic sediments from a variety of environments, the site 530 black shales are at least as enriched or more enriched in $\mathrm{Ba}, \mathrm{Cd}, \mathrm{Co}, \mathrm{Cr}$, 


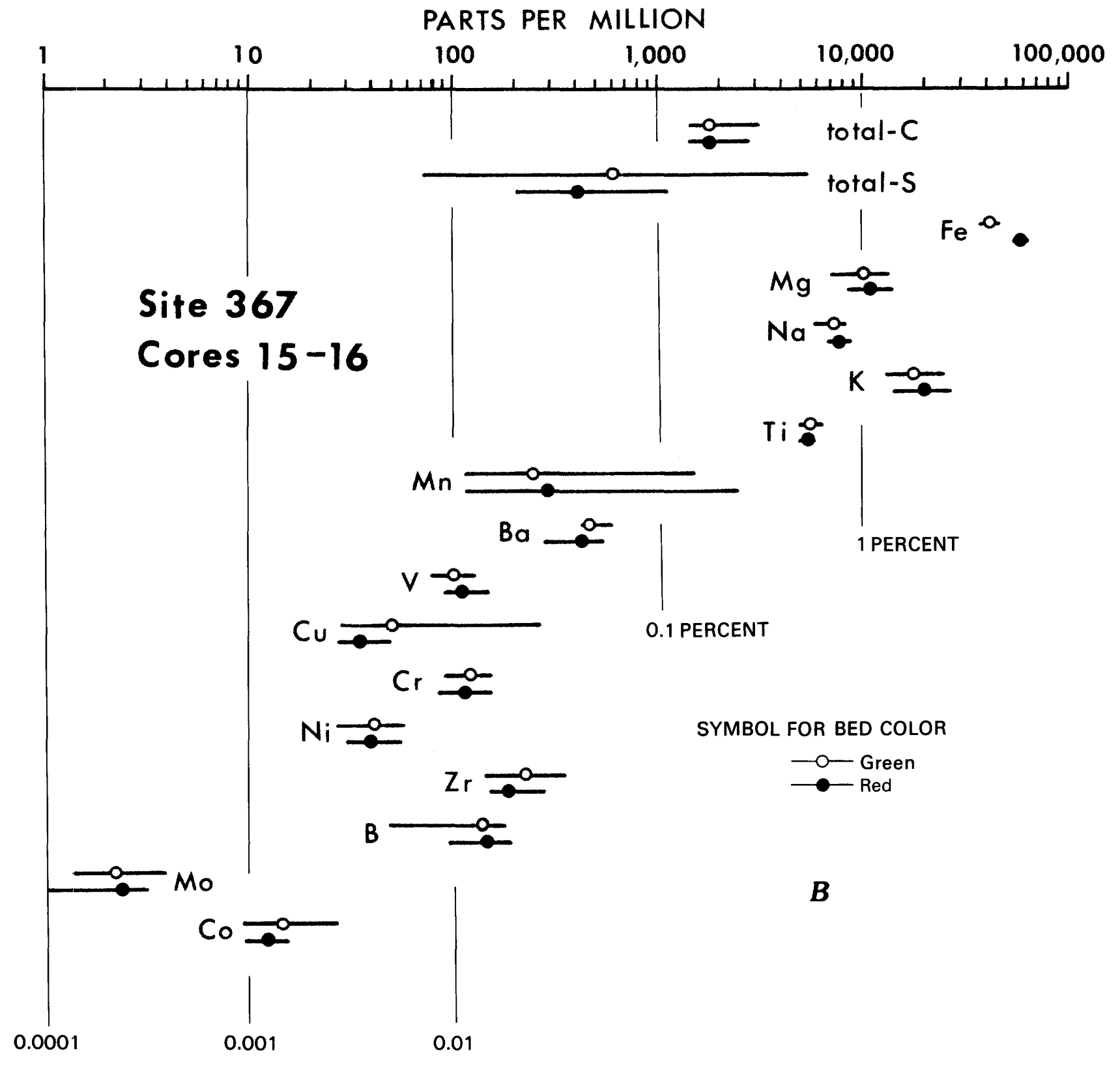

\section{PERCENT}

Figure 7 (above and facing page). A, Observed range (length of bar) and geometric mean (symbol) of concentrations of major-element oxides and trace elements on a carbonate-free basis for samples of interbedded black shale (solid triangle), and green claystone (open triangle), from Deep Sea Drilling Project site 367, core 17. B, Observed range (length of bar) and geometric mean (symbol) of concentrations of major-element oxides and trace elements on a carbonate-free basis for samples of interbedded green (open circle) and red (solid circle) claystone from Deep Sea Drilling Project site 367, cores 15 and 16.

$\mathrm{Cu}, \mathrm{Ni}, \mathrm{Pb}, \mathrm{V}$, and $\mathrm{Zn}$ (on a carbonate-free basis; table 2). In general, concentrations of trace elements in site $\mathbf{5 3 0}$ deep-water black shales, as well as most of those reported by Brumsack (1980) and Dean and Gardner (1982), are significantly higher than those in sediments from modern anoxic environments from the Black Sea and Saanich Inlet central basin (table 2). These two modern anoxic environments have anoxic water columns above the sediment rather than only anoxic sedimentinterstitial waters. The ranges and mean concentrations of most trace elements in site 530 black shales also are larger than those in very OC-rich green muds deposited within an intense oxygen-minimum zone in Walvis Bay, South West Africa (table 2).

Enrichments of Cd, Mo, Ni, Co, and $\mathrm{Zn}$ can be related to enhanced supply and preservation of organic 

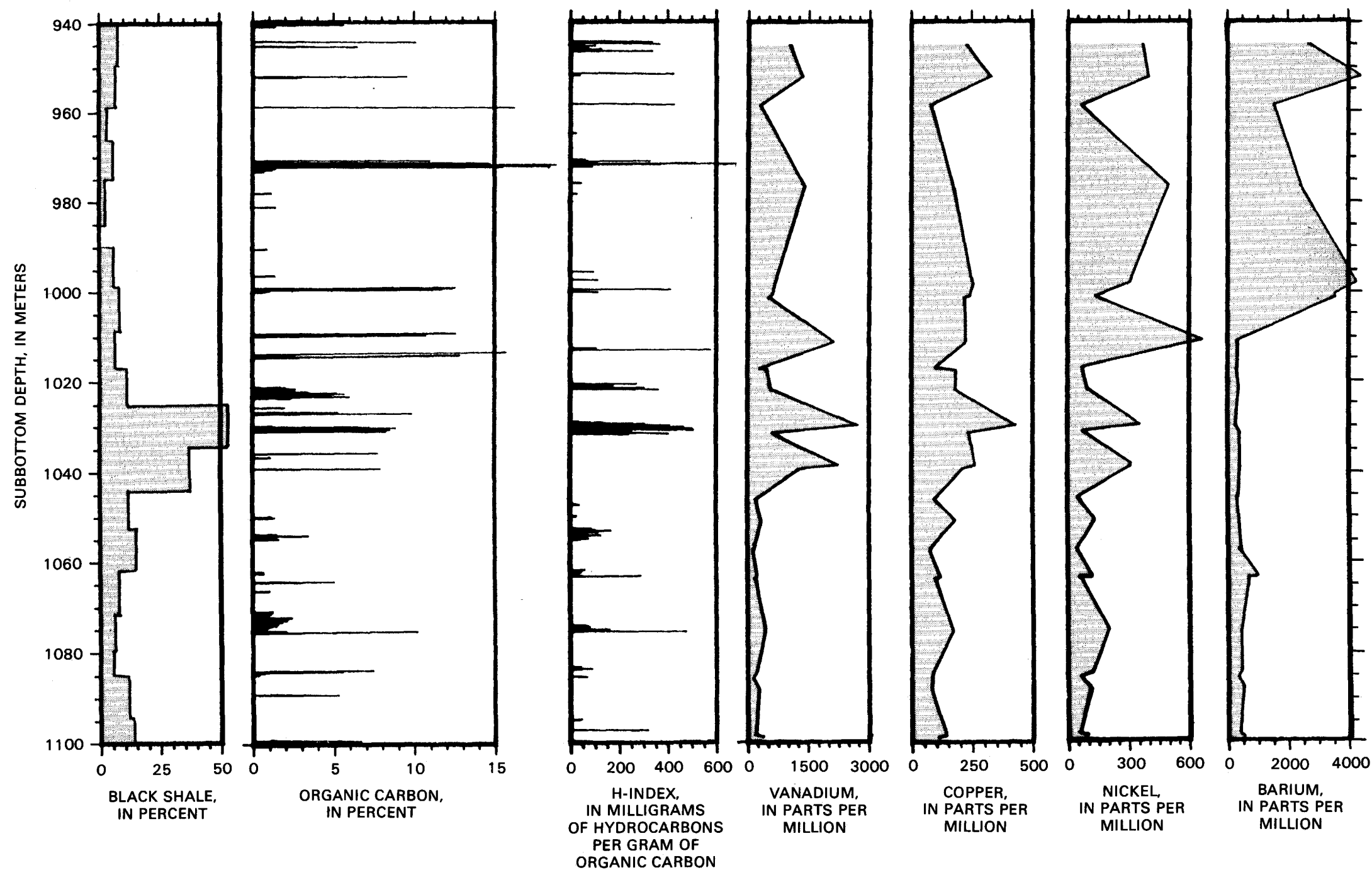

Figure 8. Plots of carbonate-free (cf) concentrations (in parts per million) versus depth for $\mathrm{V}, \mathrm{Cu}, \mathrm{Ni}$, and Ba in samples of black shale from Deep Sea Drilling Project site 530, southern Angola basin (from Dean and Parduhn, 1984). Percentage of black shale beds in each 9.5-meter core is shown. Values of percent organic carbon and hydrogen index $(\mathrm{H}$-index, in milligrams of hydrocarbons per gram of organic carbon) are from Deroo and others (1984). 
matter (see, for example, Bruland, 1980), with subsequent liberation during decomposition of the organic matter and scavenging by sulfides during early diagenesis in anoxic sediment. The high concentrations of zinc and cobalt also may have been supplied directly to the sediment as metal sulfide particles produced in an anoxic, sulfide-rich water column as in the modern anoxic Black Sea (see for example, Spencer and others, 1972; Brewer and Spencer, 1974), but other evidence suggests that the black shales at site 530, and probably in much of the Cretaceous Atlantic Ocean, were not deposited under an entirely anoxic water column.

A possible example of trace element enrichment by pore waters in oxidized sediment overlying reduced sediment was recovered at DSDP site 105 in the North American basin of the western North Atlantic Ocean. Here, the middle Cretaceous black shale unit is overlain by Upper Cretaceous-lower Tertiary red and green clays (Lancelot and others, 1972). This unit has been recovered at eight other sites in the North American basin, and is interpreted as having been deposited in an oxygenated, pelagic deep-sea environment similar to that presently accumulating pelagic clays in the central North Pacific (Jansa and others, 1979). Lancelot and others (1972) considered that the multicolored clays at site 105 were enriched in certain heavy metals, especially $\mathrm{Mn}, \mathrm{Zn}, \mathrm{Cu}$, $\mathrm{Pb}, \mathrm{Cr}, \mathrm{Ni}$, and $\mathrm{V}$, and that this enrichment was a result of hydrothermal volcanic exhalations. If the analyses of the site 105 multicolored clays by Lancelot and others (1972) are compared with analyses of modern and ancient deep-sea sediments and rocks from a wide variety of environments (table 2, fig. 7), however, the site 105 clays are clearly not enriched in any elements, even when compared with modern pelagic red clay and Creteceous red claystones from other Atlantic sites. On the other hand, bands enriched in goethite, manganese oxides, and sphalerite in the site 105 multicolored clays do require explanation. Because iron, manganese, and certain trace elements, particularly the transition elements, are easily mobilized under reducing conditions, Arthur (1979b) proposed that much of the excess iron and manganese in some bands within the site 105 multicolored clays was derived from upward diffusion of dissolved ions and advection of pore waters from compaction of black shales underlying the multicolored clays. When the chemically reduced ions derived from the underlying black shales reached a sufficiently oxidizing interface within the multicolored clays or at the sediment/water interface, iron and (or) manganese oxides precipitated in response to lower solubilities under increased Eh conditions. Authur (1979b) suggested that the sphalerite, which is mainly at the base of the multicolored clay sequence, also originated by upward diffusion of zinc from the underlying black shales.

For each $9.5-\mathrm{m}$ cored interval in the black-shalebearing sequence at site 530, mass accumulation rates
(MAR; $\mathrm{g} / \mathrm{cm}^{2} / \mathrm{m}$.y.) were calculated for bulk sediment, for each different colored lithology, for $\mathrm{OC}$, for $\mathrm{Zn}, \mathrm{Cr}$, and $\mathrm{Ni}$ in each different colored lithology, and for the sum of each of the three trace elements (table 3). Mass accumulation rates were calculated (table 3) using estimates of the percentages of black, red, and green beds in the recovered part of each $9.5-\mathrm{m}$ cored interval, biostratigraphically determined accumulation rates and porosity (Hay and others, 1984), and an average grain density of $2.7 \mathrm{~g} / \mathrm{cm}^{3}$. The MAR for OC varies from 0 to $28 \mathrm{~g} / \mathrm{cm}^{2} / \mathrm{m}$.y. As expected, maximum values for $\mathrm{OC}$ and trace element MARs occur in cores 97 and 98 where black shales are much more abundant than in any other part of the section (fig. 8). Maximum MARs for $\mathrm{Zn}, \mathrm{Cr}$, and $\mathrm{Ni}$ in black shale beds are $1.5,0.22$, and 0.11 $\mathrm{g} / \mathrm{cm}^{2} / \mathrm{m} . \mathrm{y}$., respectively, in cores 97 and 98 . MARs for these elements are all about $0.01-0.02 \mathrm{~g} / \mathrm{cm}^{2} / \mathrm{m}$.y. in black shale beds in the lower part of the black shale sequence, and $0.01-0.4 \mathrm{~g} / \mathrm{cm}^{2} / \mathrm{m}$.y. in the upper part of the sequence (table 3 ). The changes in zinc MAR are the most extreme. Maximum values of total MARs (all lithologies) for $\mathrm{Zn}, \mathrm{Cr}$, and $\mathrm{Ni}$ are 1.57, 0.67, and 0.41 $\mathrm{g} / \mathrm{cm}^{2} / \mathrm{m}$.y., respectively, and only the maximum for zinc occurs in the zone of maximum black shale concentration in cores 97 and 98 . Total MARs for all three elements are uniformly low in the lower part of the black shale section and relatively high in the upper part of the section (cores 87 to 96 ).

In comparison, Leinen and Stakes (1979) calculated average MARs for $\mathrm{Zn}$ and $\mathrm{Ni}$ of $0.17 \mathrm{~g} / \mathrm{cm}^{2} / \mathrm{m} . \mathrm{y}$. and $0.08 \mathrm{~g} / \mathrm{cm}^{2} / \mathrm{m} . y$. , respectively, for sediment on the crest of the East Pacific rise, and $0.06 \mathrm{~g} / \mathrm{cm}^{2} / \mathrm{m} . \mathrm{y}$. and 0.03 $\mathrm{g} / \mathrm{cm}^{2} / \mathrm{m} . y$. , respectively, for pelagic sediment in the eastern equatorial Pacific Ocean. The average MARs of Leinen and Stakes (1979) are somewhat higher than the average MARs of site 530 black shales, but lower than total MARs in all cores except those in the lower part of the section. As expected, the percentages of total MAR for each element that are contributed by black shale are highest in cores 97 and 98 . Black shales, however, also contribute significant proportions of the total MARs for $\mathrm{Zn}$ and $\mathrm{Ni}$ in cores above 96 (as much as 62 percent of the zinc MAR in core 87), although black shales comprise less than 8 percent of this part of the section.

Site 530 probably is an example of the lower limit of trace-element accumulation in Cretaceous black shales. The OC accumulation rates are low (maximum of 28 $\mathrm{g} / \mathrm{cm}^{2} / \mathrm{m}$.y.) compared with that of other Atlantic Cretaceous black shale sequences. For example, Arthur and Natland (1979) calculated that OC in the Aptian-lower Albian black shale sequence at site 361 in the Cape basin accumulated at an average rate of $258 \mathrm{~g} / \mathrm{cm}^{2} / \mathrm{m} . y$., and that the $\mathrm{OC}$ in lower to middle Albian black, dolomitic sapropels and marly limestones accumulated at rates of about $500 \mathrm{~g} / \mathrm{cm}^{2} / \mathrm{m} . \mathrm{y}$. We have calculated that $\mathrm{OC}$ in Albian-Turonian black shales at site 367 in 
Table 3. Site 530, mass accumulation rates of selected components in red, green, and black lithologies [OC, organic carbon; leaders (---) indicate no analyses for that core]

\begin{tabular}{|c|c|c|c|c|c|c|c|c|c|c|c|c|c|c|c|c|}
\hline \multirow{2}{*}{$\begin{array}{c}\text { Core } \\
\text { No. }\end{array}$} & \multicolumn{2}{|c|}{ Depth interval (m) } & \multirow{2}{*}{$\begin{array}{c}\text { Recovery } \\
(\mathrm{cm})\end{array}$} & \multicolumn{3}{|c|}{ Colored beds (percent) } & \multicolumn{4}{|c|}{ Percentage in black beds ${ }^{2}$} & \multicolumn{3}{|c|}{ Percentage in red beds ${ }^{2}$} & \multicolumn{3}{|c|}{ Percentage in green bed $s^{2}$} \\
\hline & From & To & & Black & Red & Green & $\mathrm{oc}^{1}$ & $\mathrm{Zn}$ & $\mathrm{Cr}$ & Ni & $\mathrm{Zn}$ & $\mathrm{Cr}$ & $\mathrm{Ni}$ & $\mathrm{Zn}$ & $\mathrm{Cr}$ & Ni \\
\hline 87 & 940 & 949 & 703 & 8 & 72 & 20 & 6.8 & 0.180 & 0.029 & 0.036 & 0.010 & 0.011 & 0.004 & 0.008 & 0.015 & 0.010 \\
\hline 88 & 949 & 958 & 448 & 6 & 74 & 20 & 8.5 & .140 & .045 & .039 & .007 & .011 & .004 & .013 & .019 & .005 \\
\hline 89 & 958 & 967 & 922 & 3 & 87 & 10 & 10.0 & .140 & .020 & .040 & .025 & .025 & .015 & .013 & .017 & .006 \\
\hline 90 & 967 & 976 & 446 & 5 & 85 & 10 & 9.0 & .110 & .018 & .049 & .020 & .020 & .010 & .013 & .015 & .008 \\
\hline 91 & 976 & 985 & 547 & 0 & 95 & 5 & --- & --- & -- & --- & .011 & .010 & .006 & .015 & .015 & .034 \\
\hline 92 & 985 & 990 & 0 & --- & --- & --- & --- & --- & -- & --- & -- & -- & -- & -- & -- & --- \\
\hline 93 & 990 & 999 & 918 & 4 & 90 & 6 & 1.0 & .014 & .025 & .030 & .007 & .008 & .006 & .016 & .012 & .007 \\
\hline 94 & 999 & 1,008 & 273 & 6 & 79 & 15 & 7.1 & .042 & .025 & .015 & .007 & .008 & .006 & .016 & .012 & .007 \\
\hline 95 & 1,008 & 1,017 & 656 & 5 & 80 & 15 & 9.6 & .009 & .092 & .065 & .009 & .009 & .007 & .031 & .012 & .005 \\
\hline 96 & 1,017 & 1,026 & 795 & 9 & 45 & 46 & 3.0 & .023 & .033 & .008 & .009 & .009 & .009 & .014 & .008 & .006 \\
\hline 97 & 1,026 & 1,035 & 607 & 52 & 0 & 48 & 5.1 & .275 & .040 & .006 & -- & --- & -- & .013 & .010 & .005 \\
\hline 98 & 1,035 & 1,044 & 501 & 36 & 0 & 64 & 5.0 & .300 & .016 & .030 & -- & --- & --- & .024 & .007 & .006 \\
\hline 99 & 1,044 & 1,053 & 735 & 9 & 20 & 71 & 1.7 & .019 & .034 & .009 & .009 & .009 & .008 & .007 & .007 & .006 \\
\hline 100 & 1,053 & 1,062 & 672 & 12 & 25 & 66 & 1.7 & .012 & .020 & .010 & .009 & .009 & .008 & .010 & .008 & .006 \\
\hline 101 & 1,062 & 1,071 & 995 & 5 & 35 & 60 & 3.0 & .013 & .042 & .012 & .009 & .009 & .009 & .010 & .010 & .006 \\
\hline 102 & 1,071 & 1,080 & 800 & 3 & 70 & 25 & 3.9 & .013 & .027 & .020 & .006 & .006 & .004 & .010 & .010 & .005 \\
\hline 103 & 1,080 & 1,085 & 600 & 2 & 60 & 37 & 3.5 & .014 & .008 & .011 & .006 & .006 & .004 & .010 & .006 & .005 \\
\hline 104 & 1,085 & 1,094 & 790 & 8 & 0 & 94 & 2.9 & .012 & .010 & .010 & -- & -- & -- & .010 & .009 & .008 \\
\hline 105 & 1,094 & 1,102 & 800 & 10 & 20 & 72 & 4.0 & .014 & .010 & .005 & .009 & .006 & .008 & .008 & .008 & .005 \\
\hline
\end{tabular}




\begin{tabular}{|c|c|c|c|c|c|c|c|c|c|c|c|c|c|c|c|c|c|}
\hline \multirow{4}{*}{$\begin{array}{r}\text { Core } \\
\text { No. }\end{array}$} & \multicolumn{17}{|c|}{ Mass accumulation rate (in grams per square centimeter per million years) } \\
\hline & \multirow{2}{*}{\multicolumn{8}{|c|}{ Claystone beds }} & \multirow{2}{*}{\multicolumn{6}{|c|}{$\frac{\text { Element in colored } \text { bed }^{4}}{\text { Red }}$ Green }} & \multirow{2}{*}{\multicolumn{3}{|c|}{ Total }} \\
\hline & & & & & & & & & & & & & & & & & \\
\hline & Bulk ${ }^{3}$ & Black & Red & Green & OC & $\mathrm{Zn}$ & $\mathrm{Cr}$ & Ni & $\mathrm{Zn}$ & $\mathrm{Cr}$ & Ni & $\mathrm{Zn}$ & $\mathrm{Cr}$ & $\mathrm{Ni}$ & $\mathrm{Zn}$ & $\mathrm{Cr}$ & N1 \\
\hline 87 & 2,786 & 223 & 2,006 & 557 & 15.2 & 0.401 & 0.065 & 0.080 & 0.200 & 0.221 & 0.080 & 0.045 & 0.084 & 0.056 & 0.646 & 0.369 & 0.216 \\
\hline 88 & 2,786 & 167 & 2,062 & 557 & 14.2 & .234 & .075 & .065 & .144 & .227 & .082 & .072 & .106 & .028 & .451 & .408 & .176 \\
\hline 89 & 2,786 & 84 & 2,424 & 279 & 8.4 & .117 & .017 & .033 & .606 & .606 & .364 & .036 & .047 & .017 & .759 & .670 & .414 \\
\hline 90 & 2,786 & 139 & 2,368 & 279 & 12.5 & .153 & .025 & .068 & .474 & .474 & .237 & .036 & .042 & .022 & .663 & .540 & .327 \\
\hline 91 & 2,786 & 0 & 2,647 & 139 & -- & -- & -- & -- & .291 & .265 & .159 & .021 & .021 & .047 & .312 & .286 & .206 \\
\hline 92 & -- & 0 & 0 & 0 & 0 & -- & -- & -- & -- & --- & -- & -- & --- & -- & --- & -- & -- \\
\hline 93 & 2,786 & 111 & 2,507 & 167 & 1.1 & .016 & .028 & .033 & .176 & .201 & .150 & .027 & .020 & .012 & .218 & .249 & .196 \\
\hline 94 & 2,786 & 167 & 2,201 & 418 & 11.9 & .070 & .042 & .025 & .154 & .176 & .132 & .067 & .050 & .029 & .291 & .268 & .186 \\
\hline 95 & 1,049 & 52 & 839 & 157 & 5.0 & .005 & .048 & .034 & .076 & .076 & .059 & .049 & .019 & .008 & .129 & .143 & .101 \\
\hline 96 & 1,049 & 94 & 472 & 483 & 2.8 & .022 & .031 & .008 & .042 & .042 & .042 & .068 & .039 & .029 & .132 & .112 & .079 \\
\hline 97 & 1,049 & 545 & 0 & 504 & 27.8 & 1.500 & .218 & .033 & --- & --- & --- & .065 & .050 & .025 & 1.565 & .268 & .058 \\
\hline 98 & 1,049 & 378 & 0 & 671 & 18.9 & 1.133 & .060 & .113 & --- & --- & -- & .161 & .047 & .040 & 1.294 & .107 & .153 \\
\hline 99 & 1,049 & 94 & 210 & 745 & 1.6 & .018 & .032 & .008 & .019 & .019 & .017 & .052 & .052 & .045 & .089 & .103 & .070 \\
\hline 100 & 1,049 & 126 & 262 & 692 & 2.1 & .015 & .025 & .013 & .024 & .024 & .021 & .069 & .055 & .042 & .108 & .104 & .077 \\
\hline 101 & 1,049 & 52 & 367 & 629 & 1.6 & .007 & .022 & .006 & .033 & .033 & .033 & .063 & .063 & .038 & .103 & .118 & .076 \\
\hline 102 & 1,049 & 31 & 734 & 262 & 1.2 & .004 & .008 & .006 & .044 & .044 & .029 & .026 & .026 & .013 & .074 & .079 & .049 \\
\hline 103 & 1,049 & 21 & 629 & 388 & .7 & .003 & .002 & .002 & .038 & .038 & .025 & .039 & .023 & .019 & .080 & .063 & .047 \\
\hline 104 & 1,049 & 84 & 0 & 986 & 2.4 & .010 & .008 & .008 & -- & -- & -- & .099 & .089 & .079 & .109 & .097 & .087 \\
\hline 105 & 1,049 & 105 & 210 & 755 & 4.2 & .015 & .010 & .005 & .019 & .013 & .017 & .060 & .060 & .038 & .094 & .084 & .060 \\
\hline
\end{tabular}

${ }^{1}$ Average percentage of organic carbon (OC) in black shale beds in each core is based on data of Deroo and others (1984) and Meyers and others (1984).

${ }^{2}$ Data of Dean and Parduhn (1984).

${ }^{3}$ Mass accumulation rate (MAR) for bulk sediment $=$ (sedimentation rate in meters per million years) $\times 100(1-$ porosity $/ 100) \times$ grain density $($ Thiede and Rea, 1981$)$ where sedimentation rate $=15.4$ meters per million years for cores 87-94 and 5.8 for cores $95-105$. Porosity $=33$ percent for all cores, and grain density is assumed to be $2.7 \mathrm{~g} / \mathrm{cm}^{3}$. Sedimentation rates and porosity from Hay and others (1984). MAR for OC = MAR of black beds $\times$ (percent OC/100) for each core.

${ }^{4}$ MAR for trace elements $=$ MAR of each colored bed $\times$ (percentage of trace element in each colored bed $/ 100$ ). 
the southeastern North Atlantic off northwest Africa accumulated at rates of about $460 \mathrm{~g} / \mathrm{cm}^{2} / \mathrm{m}$.y. using measured OC, porosity, and sedimentation-rate data of Lancelot and others (1978). For site 367, $\mathrm{Zn}$ and $\mathrm{Ni}$ MARs of 1.16 and $0.53 \mathrm{~g} / \mathrm{cm}^{2} / \mathrm{m} . y$. , respectively, were calculated using average $\mathrm{Zn}$ and Ni concentrations of 390 and $180 \mathrm{ppm}$, respectively (data of Lange and others, 1978). Maximum concentrations of OC and trace elements in the black shale section at site 367 occur in cores 18 and 19. Our unpublished analyses of 16 samples from these two cores show average zinc and nickel concentrations of 1280 and $246 \mathrm{ppm}$, respectively, and MARs of 3.8 and $0.73 \mathrm{~g} / \mathrm{cm}^{2} / \mathrm{m} . \mathrm{y}$., respectively. These values clearly are at least one order of magnitude higher than those in pelagic clays studied by Leinen and Stakes (1979). The trace element MARs for site 367 also are higher than those estimated for modern anoxic deep-basin sediments from the Black Sea (table 4), although the MARs for OC are about the same as those for site 367 .

Black shales obviously were an important sink for trace metals in the Cretaceous Atlantic Ocean. The concepts and observations mentioned here deserve further research and may ultimately explain much of the variability in metal enrichment in black shales in general. Studies of major and trace element geochemistry of black shale sequences, in conjunction with studies of amount and type of sulfur and OC, and changes in sedimentation rate, also are needed.

\section{MODELS OF DEPOSITION}

\section{Bottom-water oxygenation}

Interbedding of sediments alternately rich and poor in organic matter can be the result of either fluctuating preservation of organic matter or fluctuating rate of supply of organic matter. Differential preservation can result if bottom waters at the site of accumulation are alternately oxic and anoxic (or near-anoxic). Therefore, alternating periods of oxygen-deficient and relatively well oxygenated bottom waters may be required if the site of accumulation is on a basin floor. Cyclic variation in amount of organic matter deposited at a continental margin site can be explained by cyclic fluctuations in the thickness and intensity of a midwater oxygen-minimum layer. Both depositional models (basin deoxygenation and expansion and intensification of an oxygen-minimum layer) have been proposed to explain the accumulation of OC-rich strata (see, for example, Schlanger and Jenkyns, 1976; Ryan and Cita, 1977; Fischer and Arthur, 1977; Thiede and van Andel, 1977; Arthur and Schlanger, 1979). Both models require almost no dissolved oxygen in part of the water column as a result of reduced advection of oxygenated water and (or) increased supply of organic matter, and both models imply that reducing conditions in the sediments (and therefore the increased degree of preservation of organic matter) are the result of anoxic or near-anoxic conditions in the overlying waters.

Black, laminated, OC-rich Cretaceous strata are so widespread in the Atlantic that the closed-basin model has been proposed as the most likely analog for the Early to middle Cretaceous South and North Atlantic basins. The implication is that a stable salinity stratification existed, either because of lower salinity surface water with bottom water of more normal salinity as in the modern Black Sea, or because of normal-salinity surface water with more-saline bottom water, which led to increased residence time of deep-water masses and gradual oxygen depletion with or without increased surface productivity. Higher-salinity bottom water would have a lower oxygen solubility which, together with an increased residence time, would result in greater oxygen depletion. The salinity-stratification model is made even more plausible by the fact that isolated Atlantic basins were accumulating great thicknesses of evaporites in the Late Jurassic and again in the Aptian, and therefore probably were more saline as well as more stagnant in the Early Cretaceous. In contrast, Brass and others (1982) suggested that the sinking of warm, saline bottom water produced over warm, arid, extensive shelf areas could generate more vigouous bottom-water turnover rates that may have been as high as those of modern thermohaline deep circulation. Model studies by Southam and others (1982) suggest that a totally anoxic water column in the open ocean is unlikely because of the delicate balance between oxygen demand and supply to deeper waters and nutrient upwelling to support surface productivity. The Black Sea sediment record, however, is proof that rapid variations in oxygenation and anoxia can occur in large, isolated basins (Deuser, 1974; Degens and Stoffers, 1976).

\section{Supply of organic carbon to sediments}

All the interbedding of more-reduced and lessreduced strata by fluctuating deoxygenation of bottom waters is difficult to explain, particularly in deep-basin settings. Most of the Jurassic and Cretaceous strata in the Atlantic contain abundant evidence that they were deposited in well-oxygenated bottom waters with at least some benthic infauna; only the interbedded, darkcolored, OC-rich lithologies, which are a minor part of the total middle Cretaceous stratigraphic record, suggest anaerobic depositional conditions because they commonly are laminated and apparently unbioturbated. Ekdale (1980) showed that trace-fossil diversity varies within Cretaceous deep-water oxidation-reduction cycles, decreasing in OC-rich beds. Chondrites, a shallowburrowing, branching ichnofossil, is typically the last trace fossil found at the transition between a green and 
Table 4. Concentrations of major-element oxides (in percent) and trace elements (in parts per million) and mass accumulation rate for modern and ancient Black Sea sediments

[Leaders (---) indicate no analyses. Mass accumulation rates (MAR) ${ }^{3}$ are in grams per square centimeter per million years $\left.\left(\mathrm{g} / \mathrm{cm}^{2} / \mathrm{m} . \mathrm{y}.\right)\right]$

\begin{tabular}{|c|c|c|c|c|c|c|}
\hline \multirow[b]{2}{*}{$\begin{array}{l}\text { Element } \\
\text { or } \\
\text { oxide }\end{array}$} & \multicolumn{3}{|c|}{ Modern Black Sea sediments ${ }^{1}$} & \multicolumn{3}{|c|}{ Ancient Black Sea sapropels ${ }^{2}$} \\
\hline & $\begin{array}{c}\text { Mean } \\
\text { bulk } \\
\text { sediment }\end{array}$ & $\begin{array}{c}\text { Mean } \\
\text { carbonate- } \\
\text { free sediment }\end{array}$ & $\mathrm{MAR}^{3}$ & $\begin{array}{c}\text { Mean } \\
\text { bulk } \\
\text { sediment }\end{array}$ & $\begin{array}{l}\text { Mean } \\
\text { carbonate-free } \\
\text { sediment }\end{array}$ & $\operatorname{MAR}^{3}$ \\
\hline \multicolumn{7}{|c|}{ Major elements and oxides } \\
\hline $\mathrm{SiO}_{2}$ & 28.6 & 50.9 & 2,860 & 43.4 & 49.9 & 6,510 \\
\hline $\mathrm{Al}_{2} \mathrm{O}_{3}$ & 7.66 & 11.3 & 766 & 12.6 & 14.6 & 1,890 \\
\hline $\mathrm{Fe}_{2} \mathrm{O}_{3}$ & 4.46 & 7.87 & 446 & 6.07 & 6.97 & 910 \\
\hline Mg0 & 2.15 & 2.93 & 215 & 2.15 & 2.87 & 377 \\
\hline $\mathrm{CaO}$ & 24.7 & --- & 2,470 & 7.20 & $\rightarrow--$ & 1,080 \\
\hline${ }^{4} \mathrm{CaCO}_{3}$ & 44.1 & --- & 4,410 & 12.9 & -- & 1,935 \\
\hline $\mathrm{Na}_{2} \mathrm{O}$ & 1.05 & 1.60 & 105 & 2.37 & 2.72 & 356 \\
\hline $\mathrm{K}_{2} \mathrm{O}$ & 1.53 & 2.72 & 153 & 2.54 & 2.92 & 381 \\
\hline $\mathrm{TiO}_{2}$ & .23 & .57 & 23 & .57 & .65 & 86 \\
\hline $\mathrm{MnO}^{2}$ & .06 & .10 & 6.1 & .09 & .10 & 14 \\
\hline $\mathrm{S}$ & 2.8 & 6.0 & 280 & 4.1 & 4.7 & 615 \\
\hline C & 2.6 & 4.8 & 260 & 6.2 & 7.1 & 930 \\
\hline $\mathrm{P}_{2} \mathrm{O}_{5}$ & .31 & .70 & 31 & .17 & .20 & 24 \\
\hline \multicolumn{7}{|c|}{ Trace elements } \\
\hline$B^{5}$ & 70 & 118 & 0.7 & 215 & 242 & 3.2 \\
\hline $\mathrm{Ba}_{5}$ & 280 & 537 & 2.8 & 569 & 639 & 8.5 \\
\hline $\mathrm{Co}^{5}$ & 27 & 49 & .27 & 37 & 42 & .56 \\
\hline $\mathrm{Cr}$ & 115 & 145 & 1.15 & 168 & 192 & 2.52 \\
\hline $\mathrm{Cu}_{5}$ & 43 & 88 & .43 & 108 & 123 & 1.62 \\
\hline $\mathrm{Ga}^{5}$ & 13 & 24 & .13 & 28 & 31 & .42 \\
\hline $\mathrm{Li}^{5}$ & 90 & 90 & .90 & 92 & 103 & 1.38 \\
\hline Mo & 17 & 36 & .17 & 84 & 95 & 1.26 \\
\hline $\mathrm{Ni}$ & 120 & 200 & 1.20 & 151 & 172 & 2.27 \\
\hline $\mathrm{Pb}$ & 8 & 14 & .08 & 12 & 14 & .18 \\
\hline $\mathrm{Rb}$ & 64 & 111 & .64 & 127 & 145 & 1.91 \\
\hline$v^{5}$ & 188 & 316 & 1.88 & 378 & 425 & 5.67 \\
\hline $\mathrm{Y}$ & 6 & 12 & .05 & 17 & 20 & .26 \\
\hline $\mathrm{Zn}$ & 55 & 121 & .55 & 120 & 138 & 1.80 \\
\hline $\mathrm{Zr}$ & 53 & 118 & .53 & 112 & 129 & 1.68 \\
\hline
\end{tabular}

'Data for top $20 \mathrm{~cm}$ in Black Sea cores 1432 and 1462 (Hirst, 1974).

${ }^{2}$ Data for old Black Sea sapropels (3,000 to 7,000 yr BP) (Hirst, 1974).

${ }^{3}$ Mass accumulation rates (MAR) (grams per square centimeter per million years) are based on the mean bulk-sediment concentrations of elements or oxides, an average sediment accumulation rate of 9 $\mathrm{cm}$ per 1,000 yr for modern Black Sea sediments, an average sediment accumulation rate of $15 \mathrm{~cm}$ per $1,000 \mathrm{yr}$ for old Black Sea sapropels (data of Ross and Degens, 1974), and a dry bulk density of 1.1 gram per cubic centimeter (Keller, 1974).

${ }^{4}$ Percent $\mathrm{CaCO}_{3}$ was calculated from percent $\mathrm{CaO}$.

${ }^{5}$ Data for $\mathrm{B}, \mathrm{Co}, \mathrm{Ga}, \mathrm{Li}$, and $\mathrm{V}$ are for core 1432 only. 
a black bed, and the first to colonize the bottom following the deposition of laminated black clays. Changes in trace-fossil diversity suggest that at least some of the oxidation-reduction cycles may be due to a change in bottom-water oxygen concentration at or above the sediment-water interface. Interbedding of oxic-anoxic strata in the North Atlantic began in the Jurassic and continued at least into the Eocene; however, only the Lower to middle Cretaceous and Eocene strata contain more than 1 percent OC. It is not difficult to visualize abrupt changes in bottom-water circulation in a restricted basin such as the Early Cretaceous Atlantic Ocean, but it is difficult to imagine total stagnation of the Atlantic during the Late Cretaceous and Tertiary.

We therefore favor a third depositional model to explain many examples of interbedded more-reduced and less-reduced strata in which varying diagenetic oxidationreduction conditions in the sediments are caused by varying oxygen demand within the sediments, largely in response to varying rates of accumulations of marine and (or) terrestrial organic detritus. This model does not necessitate major changes in the oxygen content of the bottom water, only that the supply of organic matter increases, either by periodic increases in surface productivity or by periodic redeposition of organic matter in the deep basin from sites on the outer shelf or slope where more organic matter is preserved in sediments, for example, under an oxygen-minimum zone. Similar environmental interpretations of cyclic facies of the Jurassic of Yorkshire, United Kingdom, were made by Morris (1979) and Demaison and Moore (1980).

If the rate of supply of organic matter is low, the bottom waters will be more or less well oxygenated, the zero-oxygen isopleth will be at some distance below the sediment-water interface, and red clay will accumulate. If the rate of supply of organic matter is higher, the bottom waters still will be more or less well oxygenated, but the increased oxygen demand in the sediments, mainly from the increased decomposition of the organic matter, will result in a zero-oxygen isopleth at or near the sediment-water interface, and green, reduced clay will accumulate. If the rate of accumulation of organic matter is so great that the sediments are completely anoxic and reduced, the zero-oxygen isopleth may be some distance above the sediment-water interface, and $\mathrm{H}_{2} \mathrm{~S}$ accumulates locally in the bottom waters. The extent of deoxygenation of the bottom waters would be controlled by the rate of oxygen consumption, the rate of $\mathrm{H}_{2} \mathrm{~S}$ production, the rate of oxygen supply to the bottom waters, the strength of bottom currents (advection of oxygen), and the rate of sedimentation. The sluggish circulation of the bottom waters and (or) the extreme drawdown of oxygen by oxidation of $\mathrm{OC}$ in the water column would aid in the accumulation of $\mathrm{H}_{2} \mathrm{~S}$, but the primary cause of anoxic conditions is the high rate of supply of organic matter and concomitant high biological oxygen demand within the sediments. The black color is due mainly to organic matter and FeS. The FeS would eventually be converted to $\mathrm{FeS}_{2}$ (pyrite or marcasite) which would tend to lighten the color of the sediments. Maturation of the organic matter, however, would tend to darken the sediments such that the black muds probably become black or at least dark-gray shales through increasing thermal alteration and diagenesis. If the initial deposition resulted in an interbedding of layers more and less enriched in organic matter but otherwise homogeneous, migration of $\mathrm{SO}_{4}^{2-}$ into layers enriched in organic matter to replace $\mathrm{SO}_{4}^{2-}$ consumed by sulfate reduction would produce local concentrations of $\mathrm{FeS}$ and an intensification of color differences (Berner, 1969). With time, these local sulfide concentrations would produce concentrations of pyrite at the boundary between interbeds of more- and less-OC-rich mud rocks.

One problem with this model is how the OC supply to deep-water sediment can increase without creating an excess of production over consumption of $\mathrm{OC}$ in the water column. In the modern ocean, less than 0.1 percent of the OC produced survives to a depth of $4,000 \mathrm{~m}$ (Müller and Suess, 1979, 1980) because of high rates of consumption and oxidation in the water column. Changes in surface productivity alone probably could not account for OC enrichment in the black shales without concomitant depletion of dissolved oxygen in the bottom waters. Enough OC, however, could be supplied periodically to cause interbedding of green and red sediment because such changes in oxidation state are found in Holocene oceanic deep-water sediments (Lynn and Bonatti, 1965; McGeary and Damuth, 1973; Gardner and others, 1982).

Figure 9 (facing page). Illustrations showing how influx of terrigenous organic matter, surface-water organic productivity, upwelling, and turbidity currents may contribute to accumulation and redeposition of sediments containing varying amounts of organic carbon and, therefore, ranging in color from red to black.

A, Example of a period of moderate supply of organic detritus from autochthonous-marine and terrigenous sources and moderate upwelling resulting in accumulation of green sediment in shelf areas, sediment with high concentrations of organic carbon, perhaps black in color, within the $\mathrm{O}_{2}$ minimum zone, and dominantly red clays in the deep basin. Such conditions might be representative of the Late Cretaceous (for example, Santonian-Coniacian) in the Atlantic Ocean.

$B$, Example of a period of rapid rate of supply of organic detritus and stronger upwelling resulting in an expanded and more intense $\mathrm{O}_{2}$-minimum zone that may include much of the water mass and allow organic-carbon (OC)-sediment rich in carbon to accumulate over a much greater area and provide a greater source area for supply of OC-rich sediment to the deep basin by downslope transport. Such conditions might be representative of periods of accumulation of OC-rich strata in the Atlantic Ocean (Aptian-Albian and Cenomanian-Turonian). 

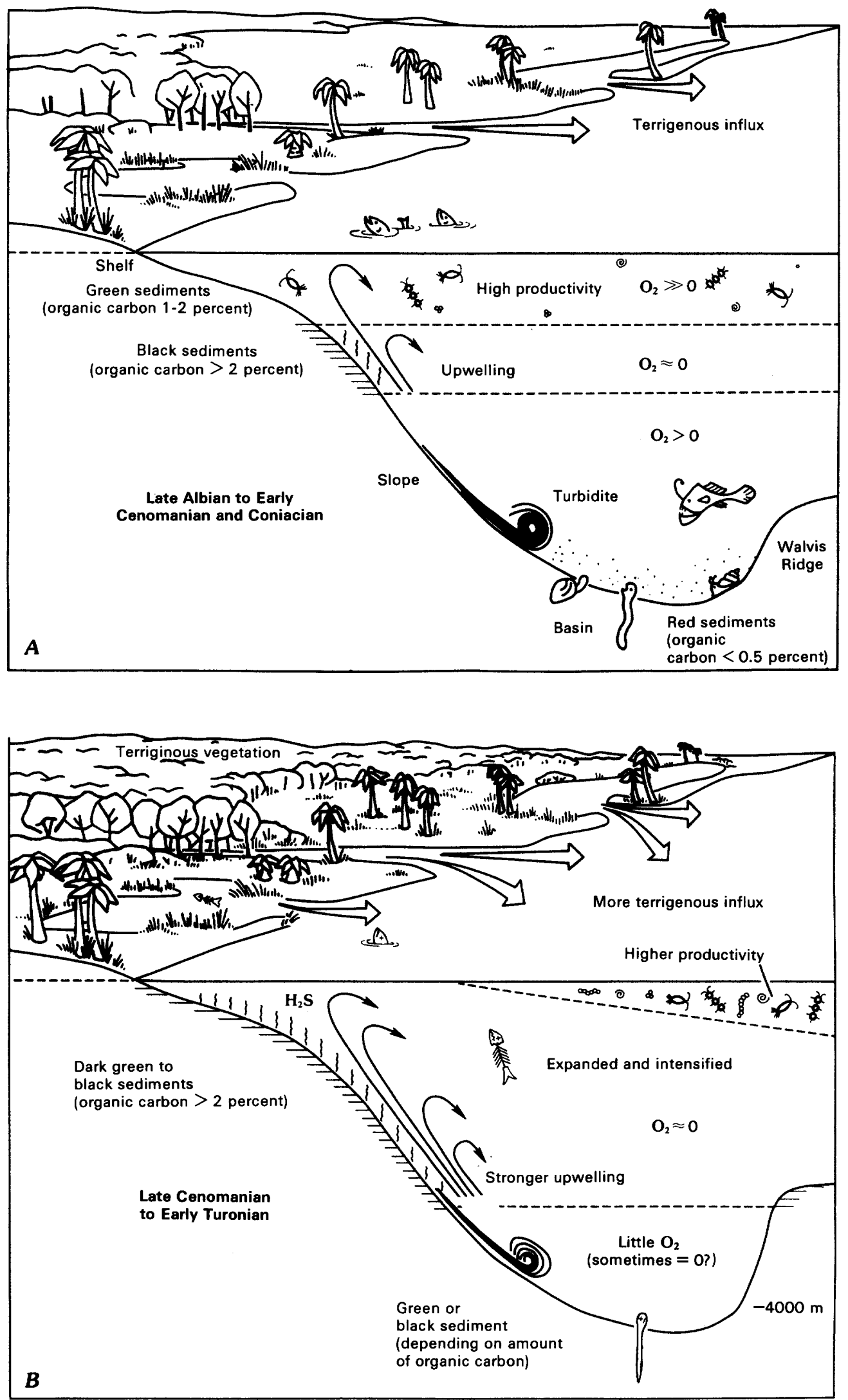
Presumably the periodicity in the initial OC-preservation would be aided by periodic increases in sedimentation rate (Heath and others, 1977; Müller and Suess, 1979) which could also explain the red and green cycles.

From the preceding discussion, it is apparent that the origin of interbedded more- and less-reduced lithologies with variable amounts of organic matter and variable amounts of pelagic, hemipelagic, and terrestrial sediment is complex and probably is not due to any one simple process. Figure 9 is a diagram of many of the variables during a period of time of accumulation of less organic matter (fig. 9A; for example, AlbianCenomanian), and during a period of accumulation of more organic matter (fig. 9B; Aptian-Albian or Cenomanian-Turonian). The main variables are the rate of influx of terrigenous sediment and organic matter and surface-water productivity. The amounts of organic matter from these two sources (terrigenous and marine) in turn determine the thickness and intensity of a mid-water oxygen-minimum zone. Surface-water productivity is determined, at least in part, by the intensity of upwelling of nutrient-rich water from the oxygen-minimum zone. Another variable is the frequency and magnitude of turbidity currents. Holding this variable constant and assuming that turbidity currents were more or less continuously redepositing shallow-water or slope-derived, continental-margin sediment to deeper sites, accumulation at these deeper water sites was a combination of pelagic, hemipelagic, and turbiditic processes.

In the situation shown diagrammatically in figure $9 A$, surface-water productivity is fairly high so that a midwater oxygen minimum exists. Shelf sediments consist largely of terrigenous clastic material and organic matter with some contributions from authochthonous marine organic matter and biogenic calcareous and siliceous debris. Sediment that accumulated where the continental margin intersected the oxygen-minimum zone are OCrich, black, and laminated where the dissolved oxygen concentration was zero throughout a sufficient thickness of the water column. The composition of redeposited sediment depends on local sources. Slope sediments along arid continental margins that are characterized by coastal upwelling are primarily fine grained and rich in carbonate or biogenic silica (for example, sites 398, 400, 402, and 370). Sediment accumulating in well-oxygenated bottomwater environments are mostly red clay. Locally, green clay interbeds exist that represent periods of accumulation of slightly higher concentrations of organic matter, high enough to consume all the dissolved oxygen within the sediment and impart a green color (mainly from reduced iron) to the sediment, but not enough to have a marked effect on the benthic fauna. The result is interbedded red and green clay units that are both intensely bioturbated.

In the situation shown diagrammatically in figure $9 B$, there is higher surface-water productivity in response to a greater supply of nutrients from more intense upwelling. In addition, an increase in the influx of terrigenous organic matter takes place as a result of a rise in sea level and (or) an increase in amount of terrestrial vegetation. This increased supply of organic matter from marine and (or) terrestrial sources increases the oxygen demand in the water column and in the sediments which causes an expansion and intensification of the oxygen minimum zone. As a result, sediment accumulating along the continental margin is more reduced and contains more organic matter. This sediment covers a much greater area. Because of the presence of more sediment that contains more organic matter available for down-slope transport into deeper-water environments, the basin sediment also is more reduced and contains more organic matter. In extreme cases, when bottom waters are delicately poised at a low oxygen level, oxygen-deficient conditions may extend into deeper waters, but most of the time the bottom-water mass is sufficiently oxic to support at least a benthic epifauna. The resulting sediment facies consist of dark-green to black, OC-rich sediment deposited in continental-margin settings and interbedded green and black, OC-rich basinal sediment. Sediment deposited in either the continental margin or basinal environments at times of extreme oxygen deficiency may be laminated, indicating complete elimination of the benthic fauna.

\section{CONCLUSIONS}

1. Most of the organic matter in OC-rich Cretaceous strata in the western and northern North Atlantic Ocean is of terrestrial origin, whereas most of the organic matter in equivalent strata in the southeastern North Atlantic and South Atlantic is of marine origin. Mixtures of terrestrial and marine organic matter, however, are common in both the North and South Atlantic.

2. Periodicities of the oxidation-reduction cycles usually range from 20,000 to 100,000 years per cycle and average about $40,000-50,000$ years per cycle. These cycles may be due to climatic forcing, similar to Cenozoic climate-induced depositional cycles, but they may also be due, in part, to periodic sediment redeposition.

3. Local concentrations of sulfide, sulfate, and carbonate minerals usually are produced by diagenetic oxidation-reduction reactions. These reactions are generally related to anaerobic decomposition of organic matter. Phosphate is not always enriched in deep-water black shales, and no phosphate minerals have been reported from these strata.

4. Certain trace elements, especially $\mathrm{Cd}, \mathrm{Cu}, \mathrm{Zn}$, $\mathrm{Mo}, \mathrm{V}, \mathrm{Ni}$, and $\mathrm{Cr}$, are enriched in OC-rich strata. This enrichment may be due to the uptake of these elements by clays and organic matter and (or) to their coprecipitation with sulfide minerals under reducing conditions. The enrichments may reflect deposition of sediment under anoxic conditions in the deep sea, or they may be 
inherited from the composition of organic matter originally deposited upslope under low-oxygen conditions and subsequently redeposited in deeper water.

5. Compactional dewatering of some black shale sequences resulted in upward diffusion of some reduced metal ions after deposition of high concentrations of organic matter, resulting in anoxic conditions within the sediment. Slowly deposited, oxidized claystones overlying some black shale sequences are enriched in metals, particularly $\mathrm{Fe}, \mathrm{Mn}, \mathrm{Zn}$, and $\mathrm{Cu}$, relative to normal pelagic clays; this enrichment may be due to upward migration of metals from the underlying black shale.

6 . The origin of interbedded more- and less-reduced lithologies containing varying amounts of organic matter and varying amounts of pelagic, hemipelagic, and terrigenous sediment is complex and probably is not due to any one process. The main variables are the rate of influx of terrigenous sediment and organic matter and surfacewater productivity. Variations in rate of supply of these two sources of organic matter from shallow-water areas to deeper, basinal sites of accumulation produced cyclic interbeds of more-reduced and less-reduced lithologies. During several periods of time (for example, AptianAlbian and Cenomanian-Turonian), a coincidence of several climatic and oceanographic factors apparently resulted in maximum production and preservation of organic matter in deep-sea environments that otherwise were fairly well oxygenated and were preserving lesser amounts of organic matter. Bottom-water anoxia may have occurred during these periods of maximum accumulation of OC-rich strata, but the commonly observed cyclic interbeds of green and black strata are mainly the result of diagenetic fluctuations in oxidation-reduction potential in the sediment in response to fluctuation in amount of organic debris being deposited, regardless of source. Much of the organic debris may have been transported to basinal sites from continental-margin settings within oxygen-minimum zones by turbidity currents.

\section{REFERENCES CITED}

Anderson T. F., Arthur, M. A., and Holser, W. T., 1982, Organic carbon and sulfur in black shales and secular variations in $\delta^{13} \mathrm{O}$ and $\delta^{34} \mathrm{~S}$ : Geological Society of America Abstracts with Programs, v. 14, no. 7, p. 433.

Arthur, M. A., 1979a, North Atlantic Cretaceous black shales; the record at site 398 and a brief comparison with other occurrences, in Sibuet, J-C., Ryan, W. B. F., and others, Initial reports of the Deep Sea Drilling Project, v. 47, part 2: Washington, D.C., U.S. Government Printing Office, p. 719-751.

$1979 \mathrm{~b}$, Origin of Upper Cretaceous multicolored claystones of the western Atlantic, in Tucholke, B. E., Vogt, P. R., and others, Initial reports of the Deep Sea Drilling Project, v. 43: Washington, D.C., U.S. Government Printing Office, p. 417-420.
1982, The carbon cycle-Controls on atmospheric $\mathrm{CO}_{2}$ and climate in the geologic past, in Berger, W. H., and Crowell, J. C., eds., Prepleistocene climates: National Academy of Sciences-National Research Council Geophysical Study Group Publication, p. 55-67.

Arthur, M. A., and Dean, W. E., 1986, Cretaceous paleoceanography of the western North Atlantic Ocean, in Vogt, P. R., and Tucholke, B. E., eds., The geology of North America, Volume M-The western North Atlantic region: Boulder, Colo., Geological Society of America, p. 617-630.

Arthur, M. A., Dean, W. E., Bottjer, D., and Scholle, P. A., 1984, Rhythmic bedding in Mesozoic-Cenozoic pelagic carbonate sequences; the primary and diagenetic origin of Milankovitch-like cycles, in Berger, A., Imbrie, J., Hays, J. D., Kukla, G., and Saltzman, B., eds., Milankovitch and climate, part 1: Amsterdam, Reidel Publishing Co., p. 191-222.

Arthur, M. A., Dean, W. E., and Schlanger, S. O., 1985, Variations in the global carbon cycle during the Cretaceous related to climate, volcanism, and changes in atmospheric $\mathrm{CO}_{2}$, in Sundquist, E. T. and Broecker, W. S., eds., The carbon cycle and atmospheric $\mathrm{CO}_{2}$ : Natural variations Archean to Present: American Geophysical Union Monograph 32, p. 504-529.

Arthur, M. A., Dean, W. E., and Stow, D. A. V., 1984, Models for the deposition of Mesozoic-Cenozoic fine-grained OCrich sediment in the deep sea, in Stow, D. A. V., and Piper, D. J., eds., Fine-grained sediments, processes and products: Geological Society of London Special Publication, p. 527-559.

Arthur, M. A., and Fischer, A. G., 1977, Upper Cretaceous-Paleocene magnetic stratigraphy at Gubbio, Italy; I. Lithostratigraphy and sedimentology: Geological Society of America Bulletin, v. 88, p. 367-389.

Arthur, M. A., and Natland, J. H., 1979, Carbonaceous sediments in the North and South Atlantic, the role of salinity in stable stratification of early Cretaceous basins, in Talwani, M., Hay, W. W., and Ryan, W. B. F., eds., Deep drilling results in the Atlantic Ocean--Continental margins and paleoenvironment: Washington, American Geophysical Union, Maurice Ewing Series, v. 3, p. 375-401.

Arthur, M. A., and Schlanger, S. O., 1979, Cretaceous "oceanic anoxic events" as causal factors in development of reefreservoired giant oilfields: American Association of Petroleum Geologists Bulletin, v. 63, p. 870-885.

Baker, P. A., and Kastner, M., 1981, Constraints on the formation of sedimentary dolomite: Science, v. 213, p. 214-216.

Baturin, G. N., 1972, Phosphorus in interstitial waters of sediments of the southeastern Atlantic: Oceanology, v. 12, p. 849-855.

Baturin, G. N. Kochenov, A. V., and Petelin, V. P., 1970, Phosphorite formation on the shelf of South West Africa: Lithology and Mineral Resources, v. 3, p. 266-276.

Bender, M. L., and Heggie, D. T., 1984, Fate of organic carbon reaching the sea floor; a status report: Geochimica et Cosmochimica Acta, v. 48, p. 977-986.

Berner, R. A., 1969, Migration of iron and sulfur within anaerobic sediments during early diagenesis: American Journal of Science, v. 267, p. 19-42. 
1970, Sedimentary pyrite formation: American Journal of Science, v. 268, p. 1-23.

1971, Principles of chemical sedimentology: New York, Mc-Graw-Hill, 240 p.

1974, Kinetic models for the early diagenesis of nitrogen, sulfur, phosphorous, and silicon in anoxic marine sediments, in Goldberg, E. D., ed., The sea, v. 5, Marine chemistry: New York, Wiley, p. 427-449.

1975, Diagenetic models of dissolved species in the interstitial waters of compacting sediments: American Journal of Science, v. 275, p. 88-96.

1978, Sulfate reduction and the rate of deposition of marine sediments: Earth and Planetary Science Letters, v. 37 , p. $492-498$.

1980, Early diagenesis-A theoretical approach: Princeton, Princeton University Press, 241 p.

1982, Burial of organic carbon and pyrite sulfur in the modern ocean; its geochemical and environmental significance: American Journal of Science, v. 282, p. 451-473.

1984, Sedimentary pyrite formation; an update: Geochimica et Cosmochimica Acta, v. 48, p. 605-615.

Berner, R. A., and Raiswell, R., 1983, Burial of organic carbon and pyrite sulfur in sediments over Phanerozoic time; a new theory: Geochimica et Cosmochimica Acta, v. 47, p. 855-862.

Bolli, H. M., Ryan, W. B. F., and others, 1978, Initial reports of the Deep Sea Drilling Project, v. 40: Washington, D.C., U.S. Government Printing Office, 1079 p.

Boström, K., Joensuu, O., and Bröhm, I., 1974, Plankton-Its composition and its significance as a source of pelagic sediments: Chemical Geology, v. 14, p. 255-271.

Boyle, R. W., and Lynch, J. J., 1968, Speculations on the source of zinc, cadmium, lead, copper, and sulfur in Mississippi Valley and similar types of lead-zinc deposits: Economic Geology, v. 63, p. 421-422.

Brass, G. W., Southam, J. R., and Peterson, W. H., 1982, Warm saline bottom water in the ancient ocean: Nature, v. 296, p. 620-623.

Brewer, P. G., and Spencer, D. W., 1974, Distribution of some trace elements in Black Sea and their flux between dissolved and particulate phases, in Degens, E. T. and Ross, D. A., eds., The Black Sea-Geology, chemistry and biology: American Association of Petroleum Geologists Memoir 20, p. 137-143.

Briskin, M., and Schreiber, B. C., 1978, Authigenic gypsum in marine sediments: Marine Geology, v. 28, p. 37-49.

Broecker, W. S., and Van Donk, J., 1970, Insolation changes, ice volumes and the $\mathrm{O}^{18}$ record in deep-sea cores: Review of Geophysics and Space Physics, v. 8, p. 169-198.

Brongersma-Sanders, M., 1965, Metals of Kupferschiefer supplied by normal seawater: Geologisches Rundschau, v. 55, p. $365-375$.

Brongersma-Sanders, M., Stephan, K. M., Kwee, T. G., and de Bruin, M., 1980, Distribution of minor elements in cores from the South West Africa shelf with notes on plankton and fish mortality: Marine Geology, v. 37, p. 91-132.

Bruland, K. W., 1980, Oceanographic distributions of cadmium, zinc, nickel, and copper in the North Pacific: Earth and Planetary Science Letters, v. 47, p. 176-198.

Brumsack, H. J., 1980, Geochemistry of Cretaceous black shales from the Atlantic Ocean (DSDP legs 11, 14, 36, and 41): Chemical Geology, v. 31, p. 1-25.
Calvert, S. E., 1976, The mineralogy and geochemistry of nearshore sediments, in Riley, J. P., and Chester, R., eds., Chemical oceanography, 2d ed.: New York, Academic Press, v. 6 , p. $187-280$.

Calvert, S. E., and Price, N. B., 1970, Minor metal contents of recent organic-rich sediment off South West Africa: Nature, v. 227, p. 593-595.

Chester, R., and Asten, S. R., 1976, Geochemistry of deep-sea sediments, in Riley, J. P., and Chester, R., eds., Chemical oceanography, 2d ed.: New York, Academic Press, v. 6, p. 281-390.

Chester, R., Griffiths, A., and Stoner, J. H., 1978, Minor metal content of surface seawater particulates and organic-rich shelf sediments: Nature, v. 275, p. 308-309.

Church, T. M., 1979, Marine barite, in Burns, R. G., ed., Marine minerals: Washington, Mineralogical Society of America Short Course Notes, v. 6, p. 180-210.

Claypool, G. E., and Kaplan, I. R., 1974, The origin and distribution of methane in deep-sea sediments, in Kaplan, I. R., ed., Natural gases in marine sediments: New York, Plenum Press, p. 94-129.

Collier, Robert, and Edmond, John, 1984, The trace element geochemistry of marine biogenic particulate matter: Progresses in Oceanography, v. 13, p. 113-199.

Cronan, D. S., 1974, Authigenic minerals in deep-sea sediments, in Goldberg, E. D., ed., The sea, v. 5, Marine chemistry: New York, Wiley-Interscience, p. 491-525.

Curtis, C. D., 1980, Diagenetic alteration in black shales: Journal of the Geological Society of London, v. 137, p. 189-194.

Dean, W. E., Arthur, M. A., Stow, D. A. V., 1984, Origin and geochemistry of Cretaceous deep-sea black shales and multicolored claystones, with emphasis on Deep Sea Drilling Project site 530, southern Angola basin, in Hay, W. W., Sibuet, J.-C., and others, Initial reports of the Deep Sea Drilling Project, v. 75: Washington, D.C., U.S. Government Printing Office, p. 819-844.

Dean, W. E., and Gardner, J. V., 1982, Origin and geochemistry of redox cycles of Jurassic to Eocene age, Cape Verde basin (DSDP site 367), continental margin of northwest Africa, in Schlanger, S. O., and Cita, M. B., eds., Nature and origin of Cretaceous organic carbon-rich facies: London, Academic Press, p. 55-78.

Dean, W. E., Gardner, J. V., and Cepek, P., 1981, Tertiary carbonate-dissolution cycles in the Sierra Leone rise, eastern equatorial Atlantic Ocean: Marine Geology, v. 39, p. 81-101.

Dean, W. E., Gardner, J. V., Jansa, L. F., Cepek, P., Seibold, E., 1978, Cyclic sedimentation along the continental margin of northwest Africa, in Lancelot, Y., Seibold, E., and others, Initial reports of the Deep Sea Drilling Project, v. 41: Washington, D.C., U.S. Government Printing Office, p. 965-986.

Dean, W. E., and Parduhn, N. L., 1984, Inorganic geochemistry of sediments and rocks recovered at DSDP sites 530 and 532, southern Angola basin and Walvis ridge, in Hay, W. W., Sibuet, J.-C., and others, Initial reports of the Deep Sea Drilling Project, v. 75: Washington, D.C., U.S. Government Printing Office, p. 923-953.

Dean, W. E., and Schreiber, B. C., 1978, Authigenic barite, leg 41 Deep Sea Drilling Project, in Lancelot, Y., Seibold, E., and others, Initial reports of the Deep Sea Drilling Project, v. 41: Washington, D.C., U.S. Government Printing Office, p. 915-931. 
Dean, W. E., Thiede, J., and Claypool, G. E., 1981, Origin of organic carbon-rich mid-Cretaceous limestones, MidPacific Mountains and southern Hess rise, in Vallier, $\mathrm{T}$. L., Thiede, J., and others, Initial reports of the Deep Sea Drilling Project, v. 62: Washington, D.C., U.S. Government Printing Office, p. 877-890.

Demaison, G. J., and Moore, G. T., 1980, Anoxic environments and oil source bed genesis: American Association of Petroleum Geologists Bulletin, v. 64, p. 1179-1209.

Degens, E. T., and Stoffers, P., 1976, Stratified waters as a key to the past: Nature, v. 263, p. 22-27.

Deroo, G., Herbin, J. P., and Huc, A. Y., 1984, Organic geochemistry of Cretaceous black shales from DSDP site 530, leg 75, eastern South Atlantic, in Hay, W. W., Sibuet, J.-C., and others, Initial reports of the Deep Sea Drilling Project, v. 75: Washington, D.C., U.S. Government Printing Office, p. 983-999.

Deuser, W. G., 1974, Evolution of anoxic conditions in the Black Sea during the Holocene, in Degens, E. T., and Ross, D. A., eds., The Black Sea-Geology, chemistry and biology: American Association of Petroleum Geologists Menoir 20, p. 133-136.

Dick, H., von der, Rullkötter, J., and Welte, D. H., 1983, Content, type, and thermal evolution of organic matter in sediments from the eastern Falkland Plateau, Deep Sea Drilling Project, leg 71, in Ludwig, W. J., Krasheninnikov, V., and others, Initial reports of the Deep Sea Drilling Project, v. 71, part 2: Washington, D.C., U.S. Government Printing Office, p. 1015-1032.

Donnelly, T. W., and Merrill, L., 1977, The scavenging of magnesium and other chemical species by biogenic opal in deep-sea sediments: Chemical Geology, v. 19, p. 167-186.

Ekdale, A. A., 1980, Trace fossils and stagnation of deep-sea basins [abs.]: American Association of Petroleum Geologist Bulletin, v. 64, p. 704.

Fischer, A. G., and Arthur, M. A., 1977, Secular variations in the pelagic realm, in Cook, H. E., and Enos, P., eds., Deep water carbonate environments: Society of Economic Paleontologists and Mineralogists Special Publication 25, p. 19-50.

Friedman, G. M., and Murata, K. J., 1979, Origin of dolomite in Miocene Monterey Shale and related formations in the Temblor Range, California: Geochimica et Cosmochimica Acta, v. 43, p. 1357-1365.

Froelich, P. N., Bender, M. L., Luedtke, N. A., Heath, G. R., and deVries, T., 1982, The marine phosphorus cycle: American Journal of Science, v. 282, p. 474-511.

Froelich, P. N., Klinkhammer, G. P., Bender, M. L., Luedtke, N. A., Heath, G. R., Cullen, D., Dauphin P., Hammond, D., Hartman, B., and Maynard, V., 1979, Early oxidation of organic matter in pelagic sediments of the eastern equatorial Atlantic-Suboxic diagenesis: Geochimica et Cosmochimica Acta, v. 43, p. 1075-1090.

Fuchs, G., Thaur, R., Ziegler, H., and Stichler, W., 1979, Carbon isotope fractionation by Methanobacterium thermoautotrophicum: Archiv für Microbiologie, v. 120, p. 135-139.

Gardner, J. V., 1975, Late Pleistocene carbonate dissolution cycles in the eastern equatorial Atlantic, in Sliter, W. V., Bé, A. W. H., and Berger, W. H., eds., Dissolution of deep-sea carbonates: Cushman Foundation for Foraminiferal Research, Special Publication 13, p. 129-141.
1982, High-resolution carbonate and organic-carbon stratigraphies for the late Neogene and Quaternary from the western Caribbean and eastern equatorial Pacific, in Prell, W. L., Gardner, J. V., and others, Initial reports of the Deep Sea Drilling Project, v. 68: Washington, D.C., U.S. Government Printing Office, p. 347-364.

Gardner, J. V., Dean, W. E., Klise, D. H., and Baldauf, J. G., 1982, A climate-related oxidizing event in deep-sea sediment from the Bering Sea: Quaternary Research, v. 18, p. 91-107.

Gardner, J. V., Dean, W. E., and Wilson, C., 1984, Carbonate and organiccarbon cycles and the history of upwelling at DSDP site 532, Walvis ridge, South Atlantic Ocean, in Hay, W. W., Sibuet, J.-C., and others, Initial reports of the Deep Sea Drilling Project, v. 75: Washington, D.C., U.S. Government Printing Office, p. 905-921.

Gilbert, D., 1984, Organic facies variations in the Mesozoic South Atlantic, in Hay, W. W., Sibuet, J.-C., and others, Initial reports of the Deep Sea Drilling Project, v. 75: Washington, D.C., U.S. Government Printing Office, p. $1035-1049$.

Glenn, C., and Arthur, M. A., 1982, Deposition of black shales and the cycling of oceanic phosphate: Geological Society of America Abstracts with Programs, v. 14, no. 7, p. 497.

Goldberg, E. D., 1957, Biogeochemistry of trace metals, in Hedgepath, J. W., ed., Treatise on marine ecology and paleoecology, v. 1, Ecology: Geological Society of America Memoir 67, p. 345-357.

Goldhaber, M. B., Aller, R. C., Cochran, J. K., Rosenfeld, J. K., Martens, C. S., and Berner, R. A., 1977, Sulfate reduction, diffusion, and bioturbation in Long Island Sound sediments; Report of the Foam Group: American Journal of Science, v. 277, p. 193-237.

Goldhaber, M. B., and Kaplan, I. R., 1974, The sulfur cycle in the sea, in Goldberg, E. D., ed., The sea, v. 5, Marine chemistry: New York, John Wiley, p. 569-655.

1975, Controls and consequences of sulfate reduction rates in recent marine sediments: Soil Science, v. 119 , p. 42-55.

1980, Mechanisms of sulfur incorporation and isotope fractionation during early diagenesis in sediments of the Gulf of California: Marine Chemistry, v. 9 , p. 95-143.

Hay, W. W., Sibuet, J.-C., and others, 1984, Initial reports of the Deep Sea Drilling Project, v. 75: Washington, D.C., U.S. Government Printing Office, $1302 \mathrm{p}$.

Hays, J. D., Imbrie, J., and Shackleton, N. J., 1976, Variations in the Earth's orbit-Pacemaker of the ice ages: Science, v. 194, p. 1121-1132.

Heath, G. R., Moore, T. C., and Dauphin, J. P., 1977, Organic carbon in deep-sea sediments, in Anderson, N. R., and Malahoff, A., eds., The fate of fossil fuel $\mathrm{CO}_{2}$ in the oceans: New York, Plenum Press, p. 605-625.

Heath, G. R., Moore, T. C., and van Andel, T. H., 1977, Carbonate accumulation and dissolution in the equatorial Pacific during the past $\mathbf{4 5}$ million years, in Anderson, $\mathrm{N}$. R., and Malahoff, A., eds., The fate of fossil fuel $\mathrm{CO}_{2}$ in the oceans: New York, Plenum Press, p. 627-639.

Hein, J. R., O'Neil, J. R., and Jones, M. G., 1979, Origin of authigenic carbonates in sediments from the deep Bering Sea: Sedimentology, v. 26, p. 681-705. 
Hirst, D. M., 1974, Geochemistry of sediments from eleven Black Sea cores, in Degens, E. T., and Ross, D. A., eds., The Black Sea-Geology, chemistry and biology: American Association of Petroleum Geologists Memoir 20, p. 430-455.

Holland, H. D., 1979, Metals in black shales-A reassessment: Economic Geology, v. 74, p. 1676-1680.

Jansa, L. F., Enos, P., Tucholke, B. E., Gradstein, F. M., and Sheridan, R. E., 1979, Mesozoic-Cenozoic sedimentary formations of the North Atlantic basin, western North Atlantic, in Talwani, M., Hay, W. W., and Ryan, W. B. F., eds., Deep drilling results in the Atlantic Ocean; continental margins and paleoenvironment: Washington, D.C., American Geophysical Union, Maurice Ewing Series, v. 3, p. 1-57.

Jansa, L. F., Gardner, J. V., and Dean, W. E., 1978, Mesozoic sequences of the central North Atlantic, in Lancelot, Y., Seibold, E., and others, Initial reports of the Deep Sea Drilling Project, v. 41: Washington, D.C., U.S. Government Printing Office, p. 991-1031.

Jorgensen, B. B., 1977, The sulfur cycle of a coastal marine sediment (Limfjorden, Denmark): Limnology and Oceanography, v. 22, p. 814-832.

Keller, G. H., 1974, Mass physical properties of some western Black Sea sediments, in Degens, E. T., and Ross, D. A., eds., The Black Sea-Geology, chemistry, and biology: American Association of Petroleum Geologists Memoir 20, p. 332-337.

Kelts, K., and McKenzie, J., 1982, Diagenetic dolomite formation in Quaternary anoxic diatomaceous muds of Deep Sea Drilling Project leg 64, Gulf of California, in Curray, J. R., Moore, D. G., and others, Initial reports of the Deep Sea Drilling Project, v. 64: Washington, D.C., U.S. Govenment Printing Office, p. 553-570.

Kendrick, J. W., 1979, Geochemical studies of black clays from leg 43, Deep Sea Drilling Project, in Tucholke, B., Vogt, P., and others, Initial reports of the Deep Sea Drilling Project, v. 43: Washington, D.C., U.S. Government Printing Office, p. 633-642.

Knauer, G. A., and Martin, J. H., 1973, Seasonal variations of cadmium, copper, manganese, lead, and zinc in water and phytoplankton in Monterey Bay, California: Limnology and Oceanography, v. 18, p. 597-604.

Krom, M. D., and Berner, R. A., 1981, The diagenesis of phosphorus in a nearshore marine sediment: Geochimica et Cosmochimica Acta, v. 45, p. 207-216.

Lancelot, Y., Hathaway, J. C., and Hollister, C. D., 1972, Lithology of sediments from the western North Atlantic, leg 11, Deep Sea Drilling Project, in Hollister, C. D., Ewing, J. I., and others, Initial reports of the Deep Sea Drilling Project, v. 11: Washington, D.C., U.S. Government Printing Office, p. 901-950.

Lancelot, Y., Seibold, E., and others, 1978, Initial reports of the Deep Sea Drilling Project, v. 41: Washington, D.C., U.S. Government Printing Office, 1259 p.

Lange, J., Wedepohl, K. H., Heinrichs, H., and Gohn, E., 1978, Notes about the specific chemical composition of "black shales" from site 367 (leg 41), in Lancelot, Y., Seibold, E., and others, Initial reports of the Deep Sea Drilling Project, v. 41: Washington, D.C., U.S. Government Printing Office, p. 875-877.

Leinen, M., and Stakes, D., 1979, Metal accumulation rates in the central equatorial Pacific during Cenozoic time: Geological Society of America Bulletin, v. 90, p. 357-375.
Leventhal, J. S., 1983, An interpretation of carbon and sulfur relationships in Black Sea sediments as indicators of environments of deposition: Geochimica et Cosmochimica Acta, v. 47, p. 133-138.

Lynn, D. C., and Bonatti, E., 1965, Mobility of manganese in diagenesis of deep-sea sediments: Marine Geology, v. 3, p. 457-474.

Manheim, F. T., 1961, A geochemical profile in the Baltic Sea: Geochimica et Cosmochimica Acta, v. 25, p. 52-71.

1976, Intersitial waters of marine sediments, in Riley, J. P., and Chester, R., eds., Chemical oceanography, $2 \mathrm{~d}$ ed., v. 6,: New York, Academic Press, p. 115-186.

Martens, C. S., and Berner, R. A., 1974, Methane production in the interstitial waters of sulfate-depleted marine sediments: Science, v. 185, p. 1167-1169.

Martin, J. H., and Knauer, G. A., 1973, The elemental composition of plankton: Geochimica et Cosmochimica Acta, v. 37, p. 1639-1653.

Matthews, R. K., 1974, Dynamic stratigraphy: Englewood Cliffs, N.J., Prentice-Hall, 370 p.

Matthews, R. K., and Poore, R. Z., 1980, Tertiary $\delta^{13} \mathrm{C}$ record and glacioeustatic sea-level fluctuations: Geology, v. 8, p. 501-504.

McCave, I. N., 1979, Depositional features of organic black and green mudstones at DSDP sites 386 and 387, western North Atlantic, in Tucholke, B. E., Vogt, P. R., and others, Initial reports of the Deep Sea Drilling Project, v. 43: Washington, D.C., U.S. Government Printing Office, p. 411-416.

McGeary, D. F. R., and Damuth, J. E., 1973, Postglacial iron-rich crusts in hemipelagic deep-sea sediment: Geological Society of America Bulletin, v. 84, p. 1201-1212.

Meyers, P. A., Brassell. S. C., and Huc, A. Y., 1984, Geochemistry of organic carbon in South Atlantic sediments from Deep Sea Drilling Project leg 75, in Hay, W. W., Sibuet, J.-C., and others, Initial reports of the Deep Sea Drilling Project, v. 75: Washington, D.C., U.S. Government Printing Office, p. 967-981.

Moore, C., and Boström, K., 1978, The elemental composition of lower marine organisms: Chemical Geology, v. 23, p. 1-9.

Morris, K. A., 1979, A classification of Jurassic marine shale sequences: an example from the Toarcian (Lower Jurassic) of Great Britain: Paleogeography, Paleoclimatology, and Paleoecology, v. 26, p. 117-120.

Müller, P. S., and Suess, E., 1979, Productivity, sedimentation rate, and sedimentary organic carbon content in the oceans: DeepSea Research, v. 26, p. 1347-1362.

Nesteroff, W. D., 1973, Petrography and mineralogy of sapropels, in Ryan, W. B. F., Hsu, K. J., and others, Initial reports of the Deep Sea Drilling Project, v. 13: Washington, D.C., U.S. Government Printing Office, p. 713-720.

Nissenbaum, A., Presley, B. J., and Kaplan, I. R., 1972, Early diagenesis in a reducing fjord, Saanich Inlet, British Columbia-I. Chemical and isotopic changes in major components of interstitial water: Geochimica et Cosmochimica Acta, v. 36, p. 1007-1027.

Oremland, R. S., and Taylor, B. F., 1978, Sulfate reduction and methanogenesis in marine sediments: Geochimica et Cosmochimica Acta, v. 42, p. 209-214.

Pedersen, T. F., and Price, N. B., 1982, The geochemistry of manganese carbonate in Panama basin sediments: Geochimica et Cosmochimica Acta, v. 46, p. 59-68. 
Pisciotto, K. E., and Mahoney, J. J., 1981, Isotopic survey of diagenetic carbonates, Deep Sea Drilling Project, leg 63, in Yeates, R. S., and Haq, B. U., Initial reports of the Deep Sea Drilling Project, v. 63: Washington, D.C., U.S. Government Printing Office, p. 595-610.

Presley, B. J., Culp, J., Petrowski, C., and Kaplan, I. R., 1973, Interstitial water studies, leg 15 , major ions $\mathrm{Br}, \mathrm{Mn}, \mathrm{NH}_{3}$, $\mathrm{Li}, \mathrm{B}, \mathrm{Si}$, and $\mathrm{C}^{13}$, in Heezen, B. C., MacGregor, I. G., and others, Initial reports of the Deep Sea Drilling Project, v. 20: Washington, D.C., U.S. Government Printing Office, p. 55-60.

Presley, B. J., Kolodny, Y., Nissenbaum, A., and Kaplan, I. R., 1972, Early diagenesis in a reducing fjord, Saanich Inlet, British Columbia-II. Trace element distribution in interstitial water and sediment: Geochimica et Cosmochimica Acta, v. 36, p. 1073-1090.

Redfield, A. C., 1958, The biological control of chemical factors in the environment: American Scientist, v. 46, p. 206226.

Rice, D. D., and Claypool, G. E., 1981, Generation, accumulation, and resource potential of biogenic gas: American Association of Petroleum Geologists Bulletin, v. 65, p. 5-25.

Ross, D. A., and Degens, E. T., 1974, Recent sediments of Black Sea, in Degens, E. T., and Ross, D. A., eds., The Black Sea--Geology, chemistry, and biology: American Association of Petroleum Geologists Memoir 20, p. 183-199.

Ruddiman, W. F., 1971, Pleistocene sedimentation in the equatorial Atlantic; Stratigraphy and faunal paleoclimatology: Geological Society of America Bulletin, v. 82, p. 283-302.

Ryan, W. B. F., and Cita, M. B., 1977, Ignorance concerning episodes of oceanwide stagnation: Marine Geology, v. 23, p. 197-215.

Schlanger, S. O., and Jenkyns, H. C., 1976, Cretaceous oceanic anoxic events-Causes and consequences: Geologie en Mijnbouw, v. 55, p. 179-184.

Scholle, P. A., and Arthur, M. A., 1980, Carbon-isotopic fluctuations in pelagic limestones; potential stratigraphic and petroleum exploration tool: American Association of Petroleum Geologists Bulletin, v. 64, p. 67-87.

Sclater, J. G., Hellinger, S., and Tapscott, C., 1977, The paleobathymetry of the Atlantic Ocean from the Jurassic to the present: Journal of Geology, v. 85, p. 509-552.

Seisser, W. G., and Rogers, J., 1976, Authigenic pyrite and gypsum in South West African continental slope sediments: Sedimentology, v. 23, p. 567-577.

Sholkovitz, E., 1973, Interstitial water chemistry of the Santa Barbara basin sediments: Geochimica et Cosmochimica Acta, v. 37, p. 2043-2073.

Sheridan, R. E., Gradstein, F. M., and others, 1982, Early history of the Atlantic ocean and gas hydrates on the Blake outer ridge; Results of the Deep Sea Drilling Project leg 76: Geological Society of America Bulletin, v. 93, p. 876-885.

Southam, J. R., Peterson, W. H., and Brass, G. W., 1982, Dynamics of anoxia: Palaeogeography, Palaeoclimatology, and Palaeoecology, v. 40, p. 183-198.

Spencer, D. W., Brewer, P. G., and Sachs, P. L., 1972, Aspects of the distribution and composition of suspended matter in the Black Sea: Geochimica et Cosmochimica Acta, v. 36, p. 71-86.
Suess, E., 1976, Nutrients near the depositional interface, in McCave, I. N., ed., The benthic boundary layer: New York, Plenum Press, p. 57-79.

1979, Mineral phases formed in anoxic sediments by microbial decomposition of organic matter: Geochimica et Cosmochimica Acta, v. 43, p. 339-352.

1981, Phosphate regeneration from sediments of the Peru continental margin by dissolution of fish debris: Geochimica et Cosmochimica Acta, v. 45, p. 577-588.

Summerhayes, C. P., 1981, Organic facies of middle Cretaceous black shales in deep North Atlantic: American Association of Petroleum Geologists Bulletin, v. 65, p. 2364-2380.

Thiede, J., and Rea, D. K., 1981, Mass accumulation rates of Barremian to Recent biogenic sediments from the MidPacific Mountains (Deep Sea Drilling Project site 463) and Hess rise (sites 464, 465, and 466), central North Pacific Ocean, in Thiede, J., Vallier, T. L., and others, Initial reports of the Deep Sea Drilling Project, v. 62: Washington, D.C., U.S. Government Printing Office, p. 637-652.

Thiede, J., and van Andel, T. H., 1977, The paleoenvironment of anaerobic sediments in the late Mesozoic South Atlantic Ocean: Earth and Planetary Science Letters, v. 33, p. 301-309.

Thierstein, H. R., 1979, Paleooceanographic implications of organic carbon and carbonate distribution in Mesozoic deep-sea sediments, in Talwani, M., Hay, W. W., and Ryan, W. B. F., eds., Deep drilling results in the Atlantic Ocean; continental margins and paleoenvironment: Washington, D.C., American Geophysical Union, Maurice Ewing Series, v. 3, p. 249-274.

Tissot, B., Deroo, G., and Herbin, J. P., 1979, Organic matter in Cretaceous sediments of the North Atlantic; contributions to sedimentology and paleogeography, in Talwani, M., Hay, W., and Ryan, W. B. F., eds., Deep drilling in the Atlantic Ocean; continental margins and paleoenvironment: Washington, D.C., American Geophysical Union, Maurice Ewing Series 3, p. 362-374.

Tissot, B., Demaison, G., Masson, P., Delteil, J. R., and Combaz, A., 1980, Paleoenvironment and petroleum potential of middle Cretaceous black shales in Atlantic basins: American Association of Petroleum Geologists Bulletin, v. 64, p. 2051-2063.

Toth, D. J., and Lerman, A., 1977, Organic matter reactivity and sedimentation rates in the ocean: American Journal of Science, v. 277, p. 465-485.

Tourtelot, H. A., 1964, Minor-element composition and organic carbon content of marine and nonmarine shales of Late Cretaceous age in the western interior of the United States: Geochimica et Cosmochimica Acta, v. 28, p. $1579-1604$.

1979, Black shale-Its deposition and diagenesis: Clays and Clay Minerals, v. 27, p. 313-321.

Tucholke, B. E., and Vogt, P. R., 1979, Western North Atlantic; sedimentary evolution and aspects of tectonic history, in Tucholke, B. E., Vogt, P. R., and others, Initial reports of the Deep Sea Drilling Project, v. 43: Washington, D.C., U.S. Government Printing Office, p. 791-825.

Vine, J. D., and Tourtelot, E. B., 1969, Geochemical investigations of some black shales and associated rocks: U.S. Geological Survey Bulletin, 1314-A, 43 p.

1970 , Geochemistry of black shale deposits-A summary report: Economic Geology, v. 65, p. 253-272. 
Vinogradov, A. P., 1953, The elementary chemical composition of marine organisms: Sears Foundation for Marine Research Memoir 2, $647 \mathrm{p}$.

Vinogradova, Z. A., and Kovalskiy, U. V., 1962, Elemental composition of the Black Sea plankton: Akademiya Nauk S.S.S.R. Doklady, v. 147, p. 1458-1460 [in Russian].

Volkov, I. I., and Fomina, L. S., 1974, Influences of organic materials and processes of sulfide formation on distribution of some trace elements in deep-water sediments of Black Sea, in Degens, E. T., and Ross, D. A., eds., The Black Sea-Geology, chemistry, and biology: American Association of Petroleum Geologists Memoir 20, p. $457-476$.
Wedepohl, K. H., 1964, Untersuchung am Kupferschiefer in nordwest Deutchland; ein Beitrag zur Deutung der Genese bituminoger Sediment: Geochimica et Cosmochimica Acta, v. 28, p. 305-364.

Weissert, H., 1981, The environment of deposition of black shales in the Early Cretaceous; an ongoing controversy, in Warme, J. F., Douglas, R. G., and Winterer, E. L., eds., The Deep Sea Drilling Project; a decade of progress: Society of Economic Paleontologists and Mineralogists Special Publication 32, p. 547-560.

Zen, E-An, 1959, Mineralogy and petrography of marine bottom sediment samples off the coast of Peru and Chile: Journal of Sedimentary Petrology,v. 29, p. 513-539. 


\title{
Limestone Diagenesis-Some Geochemical Considerations
}

By LYNTON S. LAND, Department of Geological Sciences, University of Texas at Austin, Austin, Texas 78713

\section{CONTENTS}

\author{
Abstract 130 \\ Introduction 130 \\ Limestone diagenesis $\mathbf{1 3 0}$ \\ Meteoric stabilization of shallow-water sediments $\mathbf{1 3 0}$ \\ Burial diagenesis of chalk 132 \\ Intermediate situations $\mathbf{1 3 5}$ \\ Conclusions 135 \\ References cited 135
}

\section{FIGURES}

1. Scatter plot of $\delta^{13} \mathrm{C}$ and $\delta^{18} \mathrm{O}$ for Holocene sediments and Pleistocene limestones 133

2. Strontium and oxygen isotopic changes during diagenesis of Miocene chalk, northern Jamaica 134 


\section{Abstract}

Carbonate sediments are deposited as metastable assemblages of aragonite, $\mathrm{Mg}$-calcite, and (or) Ca-rich dolomite. The transformation of such assemblages of metastable minerals toward rocks composed of stable assemblages of pure calcite and ideal dolomite (stabilization) takes place continuously, but episodically, until the rocks are destroyed by weathering or metamorphism. Stabilization in surficial environments, especially those associated with meteoric recharge, dominates limestone diagenesis. Geochemical techniques have not yet evolved to the stage where environments of diagenesis can be uniquely determined.

\section{INTRODUCTION}

Experimental work in the 1950's established the basic phase equilibria for the system $\mathrm{CaCO}_{3}-\mathrm{MgCO}_{3}$. Calcite was demonstrated to be thermodynamically stable with respect to aragonite over all normal (not tectonically overpressured) burial conditions (Jamieson, 1953). Dolomite was shown to be stable with respect to the assemblage calcite + magnesite (Graf and Goldsmith, 1955; Goldsmith and Heard, 1961). The finding that modern shallowwater carbonate sediments are composed of the metastable minerals aragonite and magnesian calcite (Mg-calcite) was first met with skepticism. It has become clear, however, that these metastable minerals formed the precursor sediment for many ancient limestones and that massive stabilization reactions are necessary (accompanying or in addition to compaction and cementation) to form carbonate rocks from metastable precursor sediments.

The concept of progressive, stepwise stabilization (that is, the transformation of metastable mineral assemblages toward stable assemblages), first proposed by Ostwald (1911, p. 444), dominates all aspects of diagenesis, not only the diagenesis of carbonate sediments. Most sediments are deposited as metastable assemblages of minerals which transform by stepwise stabilization as temperature and fluid compositions change during diagenesis. The question is: can the temperature and fluid compositions which induce the diagenetic changes be documented?

Although the mineralogy of lower Paleozoic shallow-water sediment (especially carbonate mud) is unknown, we do know that metastable phases existed. Early molluscs were composed of aragonite just as most are today, and early marine aragonite cements and ooids did indeed form (Sandberg, 1983). There is growing evidence that either calcite or Mg-calcite may have been much more common components of lower Paleozoic sediment than was aragonite (Wilkinson, 1982). PostPaleozoic carbonate sediments probably had a mineralogy not too dissimilar from today's sediment - that is, about two-thirds aragonite and one-third $\mathrm{Mg}$-calcite. Skeletal pelagic sediment, which first appears abundantly in the Mesozoic, has always been composed of calcite, yet it too is subjected to stabilization reactions.

\section{LIMESTONE DIAGENESIS}

Recognizing that overlap exists, carbonate sediments can conveniently be subdivided into shallow-water sediment, initially composed of Mg-calcite and aragonite, and pelagic sediment composed primarily of calcite. The stabilization of sediment dominated by aragonite and $\mathrm{Mg}$ calcite to limestone composed of calcite is commonly, but not necessarily universally, accomplished by early influx of meteoric water. Pelagic sediment, in contrast, is compacted or transformed by convection-dominated burial diagenesis in sea water. These two diagenetic realms, (1) nearly open-system meteoric dissolution-precipitation, and (2) more nearly closed-system stabilization dominated by compaction, are the "end member" processes that form the basis for the present discussion.

\section{Meteoric stabilization of shallow-water sediments}

The stabilization of aragonite and $\mathrm{Mg}$-calcite as the result of the influx of meteoric water has been intensively studied in Pleistocene limestones. Unfortunately, too many authors have used these examples as actualistic models for ancient limestone diagenesis without realizing the sample bias which has been introduced by the complexity of Pleistocene eustatic sea-level changes. Most early studies concentrated on Pleistocene rocks subareally exposed on the coasts of tropical and subtropical land masses (for example, Bermuda, Gross, 1964; Barbados, Matthews, 1968; the Red Sea, Gavish and Friedman, 1969; Jamaica, Land and Epstein, 1970). These sediments were deposited during interglacial highstands of sea level, especially at $+5 \mathrm{~m}, 120,000$ years ago (see, for example, Harmon and others, 1981). All these deposits have been in the vadose zone (the unsaturated zone above the water table) for most of their history. Many early studies were therefore biased toward vadose meteoric, rather than phreatic meteoric diagenesis. Diagenesis within phreatic ground-water lenses certainly dominates most limestone diagenesis, yet few studies of Pleistocene diagenesis deal with it, except where extensive uplift has occurred, because drilling is commonly required to obtain samples. Moreover, the rapid oscillations of sea level during the Pleistocene did not deposit extensive tabular beds, nor did they allow large-scale, stable, steady-state, meteoricphreatic systems to be established. The overprinting of early Pleistocene phreatic events by later sea-level oscillations, which crested near the position of modern sea level, further complicates the identification and interpretation of phreatic events. 
Studies of Holocene phreatic-meteoric diagenesis are rare (see, for example, Halley and Harris, 1979; Budd, 1985 ) because the modern rise of sea level has been so rapid that only small quantities of sediment have been generated. Most modern carbonate sediment has been deposited below present-day sea level. Insufficient time has been available for extensive coastal recharge to permeate most modern sediments. Land (1973a) and Steinen and Matthews (1973), in addressing phreatic as opposed to vadose diagenesis, concluded that diagenesis in the phreatic zone is much more rapid than in the vadose zone. Phreatic-meteoric diagenesis produces both replacement and cementation textures more similar to ancient limestones than does vadose diagenesis. Extrapolating Holocene stabilization and cementation rates observed in the Schooner Cays, Budd (1985) estimated that phreaticmeteoric diagenesis could accomplish destruction of all metastable aragonite and generate a limestone composed of calcite in less than 50,000 years.

Petrographic and geochemical data typically show large changes in whole-rock elemental and isotopic chemistry and in the chemistry of individual components during alternation to calcite. Depletion in strontium, magnesium, ${ }^{13} \mathrm{C}$, and ${ }^{18} \mathrm{O}$ are typically observed. The stabilization of aragonite and $\mathrm{Mg}$-calcite takes place in relatively open aqueous systems by dissolutionreprecipitation. Although various words have been used to describe the processes (for example, inversion (incorrectly!), neomorphism, recrystallization, incongruent solution), it is convenient to categorize reactions as proceeding either by replacement or by wholesale dissolution. In reality, replacement is simply dissolution, with subsequent precipitation soon afterward, commonly by "templating" the phase which is being dissolved in submicroscopic voids. Thus, it is clear why replacement need not occur in truly open chemical systems. The degree of fluid communication between local solutions causing dissolution, those causing precipitation, and the larger reservoir of water from which they are all derived may vary considerably depending on such factors as local rock permeability, fluid flow rates, diffusion gradients, and crystal nucleation rates. Precipitated (replacement) crystals may form far from equilibrium with the bulk-water reservoir and be affected strongly by the chemistry of the phase which is being dissolved (Brand and Veizer, 1980, 1981).

A good example of this problem is the stabalization of high-strontium marine aragonite found in corals, modern ooids, and some marine cements (but not molluscs). This kind of aragonite typically has strontium contents of 7,000-10,000 ppm (parts per million), and $\delta^{18} \mathrm{O}$ values of about -2 to -4 per mil (PBD). An "equilibrium" marine aragonite, assuming $25^{\circ} \mathrm{C}$ and $\delta^{18} \mathrm{O}$ seawater $=+1$ per mil, should contain about $8,200 \mathrm{ppm}$ strontium and have a $\delta^{18} \mathrm{O}$ value of -2.5 per mil (PDB). Natural departures from "equilibrium" are caused by local variations in temperature, $\delta^{18} \mathrm{O}$ of the water, kinetic factors, and "vital effects" in the case of skeletal precipitates. Pleistocene aragonite replaced by calcite (that is, displaying relict textures such that wholesale dissolution can be ruled out) varies from 140 to $2,000 \mathrm{ppm}$ strontium, and from -0.5 to -3.7 per mil $\delta^{18} \mathrm{O}$ (Land, 1973b; Land and Epstein, 1970; Martin and others, 1986). Calcite in equilibrium with coastal meteoric water $\left(25^{\circ} \mathrm{C}, \delta^{18} \mathrm{O}\right.$ water $=-3.5$ per mil) should have a $\delta^{18} \mathrm{O}$ value of about -5 per mil and a strontium content of less than $200 \mathrm{ppm}$. Clearly, most of the calcite which diagenetically replaced Pleistocene aragonite is not in equilibrium with an open meteoric system. Almost all replacement calcite seems to form in partly open systems, the "openness" of which was locally highly variable (Pingitore, 1976), and locally related to the permeability of the allochem being replaced (Martin and others, 1986). Calcite that formed from aragonite in a rigorously closed system has not been identified. At the present state of the art, modeling (see, for example, Morrow and Mayers, 1978) has not yet proceeded to the point that this process can be quantitatively duplicated mathematically. Modeling of diagenesis (including all other phases), using both carbon and oxygen isotopes (and strontium isotopes for some samples) and several trace elements ( $\mathrm{Sr}, \mathrm{Mg}, \mathrm{Mn}, \mathrm{Fe}$ ) simultaneously holds considerable promise for the future.

In an example from Permian rocks, Given and Lohmann (1985, p. 430) proposed that nonluminescent calcite replaced aragonite and $\mathrm{Mg}$-calcite marine cements in a "low water/rock, "closed' system" such "that the isotopic signature of the nonluminescent calcite also represents the original isotopic composition of the marine cement." They did not demonstrate, however, that the replacement took place in a system strictly closed to cations such as strontium and magnesium. A comparison of the reservoir sizes between calcite and water in a rock of reasonable porosity demonstrates that whereas the reservoirs of carbon and cations in the rock overwhelms the carbon $\left(\mathrm{HCO}_{3}^{-}\right)$and cation reservoirs in the pore water, the reservior of oxygen is more nearly of the same size. Therefore, the oxygen isotope composition of calcite will be most sensitive to alteration during diagenesis. If the oxygen isotope composition is strictly conserved during diagenesis, no other component can be modified whatsoever. It is impossible to convert strontium-rich aragonite or Mg-calcite to strontium- and magnesium-depleted calcite and rigorously conserve the oxygen isotope composition of the precursor phase.

It is possible, however, to alter a primary aragonite or $\mathrm{Mg}$-calcite component to calcite, either by advective or diffusive diagenesis, and cause no change in the $\delta^{18} \mathrm{O}$. If diagenesis takes place by slow stabilization in seawater (Saller, 1984), the oxygen isotope composition of the calcite replacement product might be identical to the precursor aragonite or $\mathrm{Mg}$-calcite, whereas the cation content might be quite different. In this situation, however, the $\delta^{18} \mathrm{O}$ of the replacement calcite is in no sense 
"original." It is the same as the original phase only by happenstance in that diagenesis (stabilization) occurred in the same solution (seawater) from which the metastable phase initially precipitated. Given and Lohmann (1985) did not document a composition for primary Permian marine cement; rather, they documented the conditions of diagenesis, which may have been induced by ${ }^{18} \mathrm{O}-$ depleted Permian seawater (Given and Lohmann, 1985) or by meteoric water (Given and Lohmann, 1986).

Many authors have emphasized the depletion of Pleistocene limestones in ${ }^{13} \mathrm{C}$ with increased diagenesis (Allen and Matthews, 1977, 1982) and the correlation between $\delta^{18} \mathrm{O}$ and $\delta^{13} \mathrm{C}$ (fig. 1). Although these observations are correct, they are almost all based on sampling rocks which have been subaereally exposed (that is, immediately adjacent to soils) for varying lengths of time. Soil carbon dioxide depleted in ${ }^{13} \mathrm{C}$ because of oxidation of organic matter is produced during vadose diagenesis in semitropical (humid) climates. A similar large-scale input of organic-derived carbon dioxide is not to be expected in an arid climate (few plants), or during phreatic diagenesis in which the carbon reservoir in the rocks is dominant. Additionally, the incorporation of significant amounts of organic ( ${ }^{13} \mathrm{C}$-depleted) carbon in carbonate cement is not limited to oxidation associated with soils. In fact, the isotopic signature of vadose diagenesis (depletion in ${ }^{13} \mathrm{C}$ and ${ }^{18} \mathrm{O}$ ) can be nearly identical to that of burial cementation of some sequences, such as the Texas Gulf Coast Teritary (Land, 1984; Lundegard and others, 1984). ${ }^{13} \mathrm{C}$-depleted cements are neither unique to or necessarily characteristic of vadose diagenesis.

Many Pleistocene and older limestones composed completely of calcite are still inhomogeneous in their distribution of trace elements and stable isotopes (see, for example, Benson and Matthews, 1971, their fig. 5; Prezbindowski, 1984, his figs. 7 and 8). Such inhomogeneities can provide valuable clues to diagenetic processes; but the inhomogeneous nature of the crystals indicates that they have not yet fully stabilized. The capacity for continued stabilization continues to exist until thermal metamorphism homogenizes (or destroys) the limestone.

\section{Burial diagenesis of chalk}

Although many authors have assumed calcite to be a stable constituent of limestones, it clearly need not be. Small differences in magnesium or strontium concentration, for example, significantly change the solubility of calcite. Given geologic times for reaction, the more soluble phases, even though they are only slightly more soluble, do react. Schlanger and Douglas (1974) usefully expressed this idea in the form of a "diagenetic potential." Small, trace-element-rich crystals have more "diagenetic potential" (they are more soluble) than large pure crystals, all other things being equal.
Pelagic chalk consists of a mixture of skeletal components dominated by coccoliths and pelagic foraminifera. Each taxon exhibits slightly different skeletal microarchitecture and skeletal chemistry (see, for example, Savin and Stehli, 1974), and pelagic sediment is highly inhomogeneous even though an X-ray diffraction pattern shows it to be pure calcite (aragonitic pteropods are ignored in this discussion because their extreme "diagenetic potential" is obvious; Berner and Honjo, 1981). The Deep Sea Drilling Program has demonstrated that carbonate ooze transforms into chalk and that chalk transforms into limestone with increasing burial. The process occurs by "solution-compaction" (Scholle, 1977) as more soluble components dissolve (aided by increased overburden pressure) and reprecipitate "locally." Suprisingly, massive chemical changes in both the trace element composition and isotopic composition of the chalk occur as burial diagenesis proceeds. In some cases, the burial diagenesis of chalk is indistinguishable on the basis of oxygen isotope and strontium content from meteoric diagenesis (fig. 2; Land, 1979).

During burial diagenesis of chalk, trace elements such as strontium clearly must be removed from the compacting system by diffusion and (or) fluid flow. The depletion in ${ }^{18} \mathrm{O}$ toward the bottom of some chalk sections (fig. 2) cannot be due solely to replacement at elevated temperatures, but must involve introduction of ${ }^{18} \mathrm{O}$-depleted (and ${ }^{87} \mathrm{Sr}$-depleted, Elderfield and others, 1982) water from beneath (Land, 1980, his fig. 3), probably driven by thermal convection. Even though the fluids participating in burial diagenesis of deep-sea chalk sequences are introduced at the bottom of the section (and at high temperatures), the chemistry of limestones that result strikingly resemble chalk sequences altered by meteoric water. Cretaceous chalk exposed by submarine erosion is also replaced by a Sr-depleted (but not ${ }^{18} \mathrm{O}$ depleted, because of the cold temperatures) calcitereaction rind in essentially unmodified seawater (Schlager and James, 1978).

What is important here is that although the "diagenetic potential" of calcite chalk is much smaller than that of sediment composed of aragonite and $\mathrm{Mg}$ calcite, stabilization still occurs, albeit over a much longer time. By analogy, the burial diagenesis of platform carbonate sequences (where solution compaction is accomplished by megascopic stylolitization) can almost certainly continue long after the original mineralogy of the sediments has been converted to calcite. Using currently available data, it may be impossible to distinguish early surficial meteoric diagenesis from burial compaction.

Scholle and Halley (1985) advocated burial diagenesis of platform carbonate sequences as being of considerably greater significance than has been previously recognized. They pointed out (p. 312) that some studies of Pleistocene diagenesis concluded "that there has been little or no net addition of carbonate material to the 


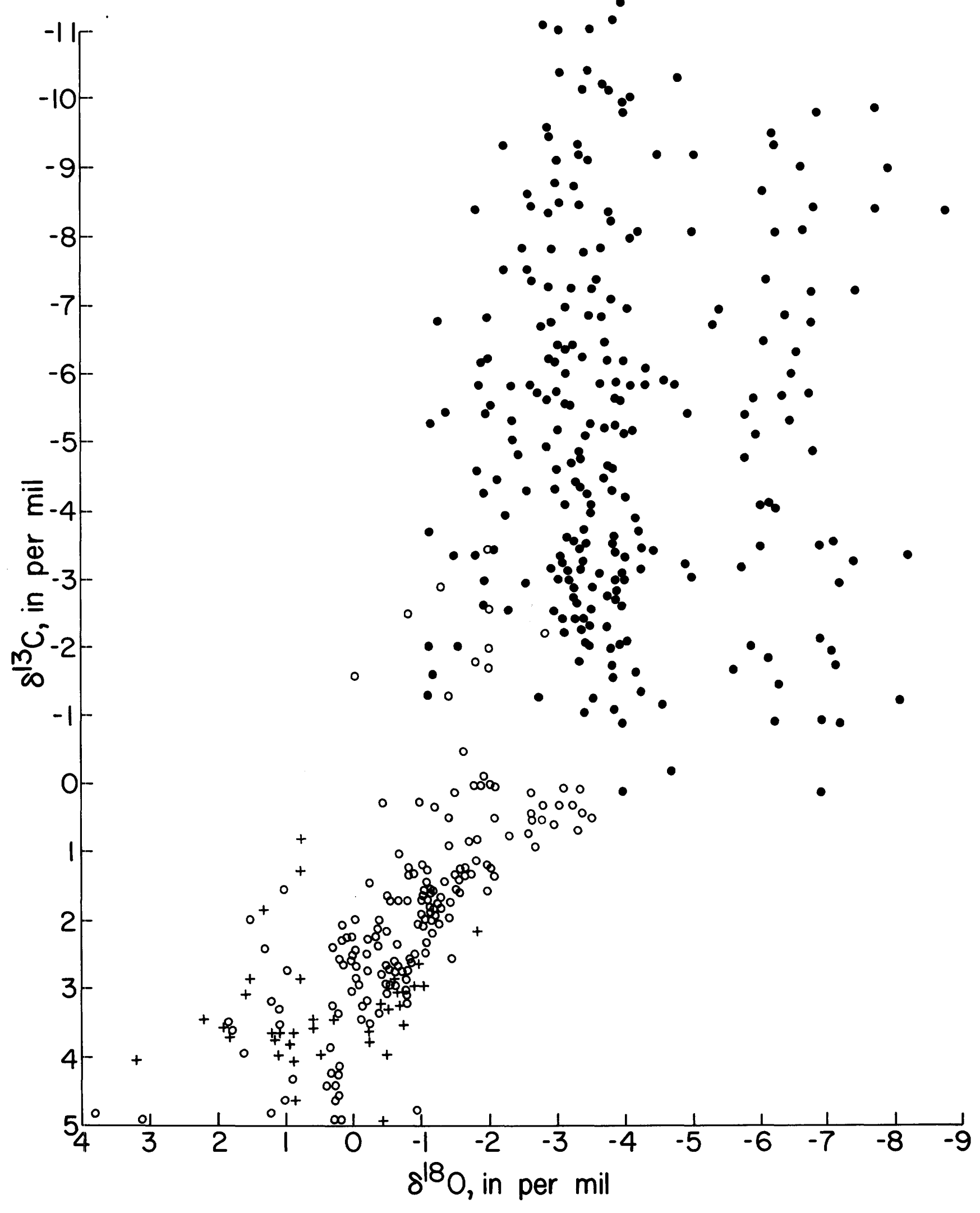

Figure 1. Scatter plot of $\delta^{13} \mathrm{C}$ and $\delta^{18} \mathrm{O}$ for unlithified bulk Holocene sediment (open circle), lithified bulk Holocene sediment (plus sign), and Pleistocene limestones altered by meteoric water (closed circle). Data summarized from numerous sources, cited in Land, (in press). The large depletion in ${ }^{13} \mathrm{C}$ is due to strong bias toward samples dominated by vadose diageneis. Samples with $\delta^{18} \mathrm{O}$ more enriched than -5 per mil are from temperate climates, samples with $\delta^{18} \mathrm{O}$ more depleted than -5 per mil are from tropical climates. 


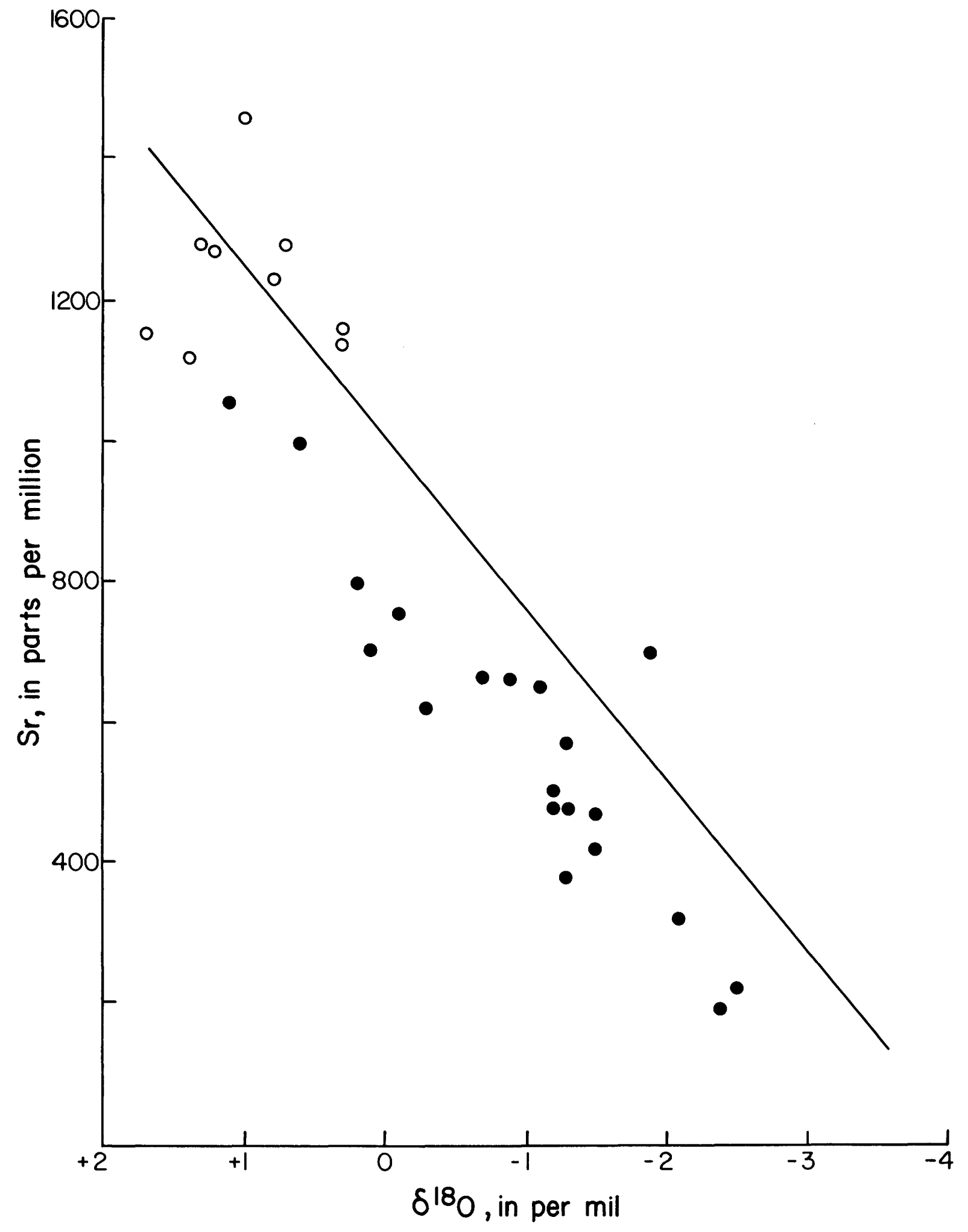

Figure 2. Strontium and oxygen isotopic changes during diagenesis of Miocene chalk, northern Jamaica. Open circles are from marine chalk which has never been subareally exposed. Solid circles are from subareally exposed samples. The line is generalized from Matter and others (1975) for Shatsky rise limestones recovered by JOIDES, which have never been subareally exposed. The similarity between subareal meteoric and marine burial diagenesis of chalk is striking. 
section despite as much as 120,000 years of near-surface alteration.' Here again, as in interpreting ${ }^{13} \mathrm{C}$, some commonly studied Pleistocene rocks are not good actualistic models for ancient limestones. Scholle and Halley emphasized that the 120,000-year-old Miami Oolite has lost substantially no porosity compared with modern ooids. This fact is not surprising because the rock has been exposed for at least 110,000 years in the vadose zone where gravitational removal of dissolved $\mathrm{CaCO}_{3}$ is the dominant process. Scholle and Halley (1985) ignored data which clearly demonstrate that significant porosity reduction can take place in meteoric phreatic lenses. In addition to the examples from Barbados and Bonaire cited by Scholle and Halley, the Pleistocene Hope Gate Formation of Jamaica not only consists of 37 percent dolomite, but has an average porosity of 5 percent (Land, 1973c, his tables 3 and 1). Low-porosity limestones can indeed form without burial compaction.

\section{Intermediate situations}

If shallow-water carbonate sediments are buried quickly or isolated from recharge zones, they enter the subsurface in a highly metastable state. Their diagenesis thus differs substantially from sediments that were converted to calcite by recharging meteoric water.

Reeckmann (1981) documented such a sequence in which updip grainstones were massively altered by meteoric influx while down-dip wackestones were relatively unaltered. If the sequence she studied were to be buried, continued stabilization of the down-dip wackestones would be inevitable. Burial-driven stabilization of the down-dip rocks could result in a very different type of diagenesis than the meteoric stabilization that is exhibited by the updip rocks. Burial stabilization has been invoked by Moore and Druckman (1981) for the Jurassic Smackover of the Gulf Coast and convincingly documented by Saller (1984) for the subsurface Tertiary limestones of Enewetak atoll. The opposing view, that stabilization of the Jurassic Smackover limestones to calcite was accomplished in contemporaneous meteoric systems, was espoused by Wagner and Matthews (1982a), Wagner and Matthews (1982b), Wagner and Matthews (1983), and Humphrey and others (1986). Clearly, the stabilization of aragonite-Mg-calcite assemblages in other than surficial meteoric hydrogeochemical environments needs additional attention, both from a theoretical (modeling) perspective, and from additional well-studied examples.

\section{CONCLUSIONS}

Current knowledge of diagenesis is highly biased toward those environments which have been intensively studied, especially the vadose alteration of Pleistocene grainstones. Burial diagenesis is only currently receiving the attention it deserves, but it is hardly "out of mind" (Scholle and Halley, 1985). If studied critically (Prezbindowski, 1984), burial diagenesis rarely approaches the importance of early marine and meteoric diagenesis in molding limestones petrographically or chemically. Most authors have accepted the fact that thick platform sequences accumulate at net rates of about $50 \mathrm{~m} / \mathrm{Ma}$, more than an order of magnitude more slowly than analogous modern carbonate sediments accumulate (Fisher, 1969). Therefore, meteoric infiltration is inevitable under most circumstances as shallow-water carbonate sediments "shoal up" to sea level, and it is not surprising that meteoric diagenesis dominates the diagenesis of carbonates. In contrast, the diagenesis of shales and many sandstones is dominated by thermally driven processes during burial. There is no question that subsurface compaction and stylolitization on a range of scales can accomplish considerable mass transfer during the diagenesis of limestones; however, just as the degree of openness of the chemical system which prevails during aragonite or $\mathbf{M g}$-calcite stabilization is argued, the degree of openness of compacting limestone (or dolomite, Land, 1985 ) sequences is unproven. Geochemistry has the potential to unravel these problems and to document the fluid compositions and temperatures that prevail during diagenesis. But quantitative studies which integrate a variety of different techniques are needed, coupled with rigorous mathematical models, to quantify diagenetic environments in a convincing manner.

\section{REFERENCES CITED}

Allen, J. R., and Matthews, R. K., 1977, Carbon and oxygen isotopes as diagenetic and stratigraphic tools-Surface and subsurface data, Barbados, West Indies: Geology, v. 5, p. 16-20.

1982, Isotope signatures associated with early meteoric diagenesis: Sedimentology, v. 29, p. 797-817.

Benson, L. V., and Matthews, R. K., 1971, Electron microprobe studies of magnesium distribution in carbonate cements and recrystallized skeletal grainstones from the Pleistocene of Barbados, West Indies: Journal of Sedimentary Petrology, v. 41 , p. $1018-1025$.

Berner, R. A., and Honjo, S., 1981, Pelagic sedimentation of aragonite-Its geochemical significance: Science, v. 211, p. 940-942.

Brand, U., and Veizer, J., 1980, Chemical diagenesis of a multicomponent carbonate system-1, Trace elements: Journal of Sedimentary Petrology, v. 50, p. 1219-1236.

1981, Chemical diagenesis of a multicomponent carbonate system -2, Stable isotopes: Journal of Sedimentary Petrology, v. 51, p. 987-997.

Budd, D. A., 1985, Freshwater phreatic diagenesis of Holocene ooid sands, Schooner Cays, Bahamas: Austin, Texas, University of Texas, Austin, Ph. D. dissertation, 491 p. 
Elderfield, H., Gieskes, J. M., Baker, P. A., Oldfield, R. K., Hawkesworth, C. J., and Miller, R., $1982,{ }^{87} \mathrm{Sr} /{ }^{86} \mathrm{Sr}$ and ${ }^{18} \mathrm{O} /{ }^{16} \mathrm{O}$ ratios, interstitial water chemistry and diagenesis in deep-sea carbonate sediments of the Ontong Java plateau: Geochimica et Cosmochimica Acta, v. 46, p. 2259-2268.

Fisher, A. G., 1969, Geological time-distance rates-The Bubnoff unit: Geological Society of America Bulletin, v. 80, p. 549-552.

Gavish, E., and Friedman, G. M., 1969, Progressive diagenesis in Quaternary to Late Tertiary carbonate sedimentsSequence and time scale: Journal of Sedimentary Petrology, v. 39 , p. $980-1006$.

Given, R. K., and Lohmann, K. C., 1985, Derivation of the original isotopic composition of Permian marine cements: Journal of Sedimentary Petrology, v. 55, p. 430-439.

1986, Isotopic evidence for the early meteoric diagenesis of the reef facies, Permian reef complex of west Texas and New Mexico: Journal of Sedimentary Petrology, v. 56, p. 183-193.

Goldsmith, J. R., and Heard, H. C., 1961, Subsolidus phase relations in the system $\mathrm{CaCO}_{3}-\mathrm{MgCO}_{3}$ : Journal of Geology, v. 69 , p. $45-74$.

Graf, D. L., and Goldsmith, J. R., 1955, Some hydrothermal syntheses of dolomite and protodolomite: Journal of Geology, v. 64, p. 173-186.

Gross, M. G., 1964, Variations in the $\mathrm{O}^{18} / \mathrm{O}^{16}$ and $\mathrm{C}^{13} / \mathrm{C}^{12}$ ratios of diagenetically altered limestones in the Bermuda Islands: Journal of Geology, v. 72, p. 170-194.

Halley, R. B., and Harris, P. M., 1979, Freshwater cementation of a 1,000-year-old oolite: Journal of Sedimentary Petrology, v. 49 , p. $969-987$.

Harmon, J. R., Land, L. S., Mitterer, R. M., Garrett, P., Schwarcz, H. P., and Larson, G. J., 1981, Bermuda sea level during the last interglacial: Nature, v. 289 , p. 481-483.

Humphrey, J. D., Ransom, K. L., and Matthews, R. K., 1986, Early meteoric diagenetic control of upper Smackover production, Oaksfield, Louisiana: American Association of Petroleum Geologists Bulletin, v. 70, p. 70-85.

Jamieson, J. C., 1953, Phase equilibrium in the system calcitearagonite: Journal of Chemical Physics, v. 21, p. 1385-1390.

Land, L. S., 1973a, Phreatic versus vadose diagenesis of limestones-Evidence from a fossil water table: Sedimentology, v. 20, p. 175-183.

1973b, Holocene meteoric dolomitization of Pleistocene limestones, north Jamaica: Sedimentology, v. 20, p. 411-424.

1973c, Contemporaneous dolomitization of Middle Pleistocene reefs by meteoric water: Bulletin of Marine Science, v. 32, p. 64-92.

1979, Chert-chalk diagenesis; the Miocene Island slope of north Jamaica, Journal of Sedimentary Petrology, v. 49, p. 223-232.

1980, The isotopic and trace element geochemistry of dolomite; the state of the art, in Zenger, D. H., Dunham, J. B., and Ethington, R. L., eds., Concepts and models of dolomitization, Society of Economic Paleontologists and Mineralogists Special Publication 28, p. 87-110.

1985, The origin of massive dolomite: Journal of Geological Education, v. 33, p. 112-125.

in press, The carbon and oxygen isotopic chemistry of surficial Holocene shallow marine carbonate sediment and Quarternary limestone and dolomite, in Fontes, J. Ch., and
Fritz, P., eds., Handbook of environmental isotope geochemistry, v. 3: New York, Elsevier.

Land, L. S., and Epstein, S., 1970, Late Pleistocene diagenesis and dolomitization, Sedimentology, v. 14, p. 187-200.

Lundegard, P. D., Land, L. S., and Galloway, W. E., 1984, The problem of secondary porosity-Frio Formation (Oligocene), Texas Gulf Coast: Geology, v. 7, p. 399-402.

Matter, A. R., Douglas, R. G., and Perch-Nielsen, K., 1975, Fossil preservation, geochemistry, and diagenesis of pelagic carbonates from Shatsky rise, northwest Pacific, in Initial reports of the Deep Sea Drilling Project, v. 32: Washington, D.C., U.S. Government Printing Office, p. 891-919.

Martin, G. D., Wilkinson, B. H., and Lohmann, K. C., 1986, The role of skeletal porosity in aragonite neomorphismStrombus and Montastrea from the Pleistocene Key Largo limestone, Florida: Journal of Sedimentary Petrology, v. 50, p. 194-203.

Matthews, R. K., 1964, Carbonate diagenesis-Equilibration of sedimentary mineralogy to the subaerial environmentCoral Cap of Barbados, West Indies: Journal of Sedimentary Petrology, v. 38, p. 1110-1119.

Moore, C. H., and Druckman, K., 1981, Burial diagenesis and porosity evolution, Upper Jurassic Smackover, Arkansas and Louisiana: American Association of Petroleum Geologists Bulletin, v. 65, p. 597-628.

Morrow, D. W., and Mayers, I. R., 1978, Simulation of limestone diagenesis-A model based on strontium depletion: Canadian Journal of Earth Sciences, v. 15, p. 376-396.

Ostwald, W., 1911, Lehrbuch der Allgemeinen Chemie: v. 2, pt. 2: Leipzig, W. Englemann, 1188 p.

Pingitore, N. E., Jr., 1976, Vadose and phreatic diagenesisProcesses, products and their recognition in corals: Journal of Sedimentary Petrology, v. 46, p. 985-1006.

Prezbindowski, D. R., 1984, Burial cementation-Is it important? A case study, Stuart City trend, south-central Texas, in Schneidermann, N., and Harris, P. M., eds., Carbonate cements: Society of Economic Paleontologists and Mineralogists Special Publication 36, p. 241-264.

Reeckmann, S. A., 1981, Relationships between lithology and diagenesis and a limestone-marl facies transition-An electron microprobe study: Sedimentology, v. 28, p. 643-652.

Saller, A. H., 1984, Diagenesis of Cenozoic limestones on Enewetak atoll: Baton Rouge, Louisiana, Louisiana State University, Ph. D. dissertation, 363 p.

Sandberg, P. A., 1983, An oscillating trend in Phanerozoic nonskeletal carbonate mineralogy: Nature, v. 305, p. 19-22.

Savin, S. M., and Stehli, F. G., 1974, Interpretation of oxygen isotope paleotemperature measurements-Effect of the $\mathrm{O}^{18} / \mathrm{O}^{16}$ ratio of sea water, depth stratification of foraminifera, and selective solution, in Les méthodes quantitatives d'étude des variations du climat au cours du Pléistocene: Colloques Internationaux du Centre Nationale Recherche Société, Nombre 219, p. 183-191.

Schlager, W., and James, N. P., 1978, Low-magnesian calcite limestones forming at the deep-sea floor, Tongue of the Ocean, Bahamas: Sedimentology, v. 25, p. 675-702.

Schlanger, S. O., and Douglas, R. G., 1974, The pelogic oozechalk transition and its implications for marine stratigraphy, in Hsu, K. J., and Jenkyns, H. C., eds., Pelagic sedimentsOn land and under the sea: International Association of Sedimentologists Special Publication 1, p. 117-148. 
Scholle, P. A., 1977, Chalk diagenesis and its relation to petroleum exploration-Oil from chalks, a modern miracle?: American Association of Petroleum Geologists Bulletin, v. 61, p. $982-1009$.

Scholle, P. A., and Halley, R. B., 1985, Burial diagenesis-Out of sight, out of mind!, in Schneidermann, N., and Harris, P. M., eds., Carbonate cements: Society of Economic Paleontologists and Mineralogists Special Publication 36, p. 309-334.

Steinen, R. K., and Matthews, R. K., 1973, Phreatic versus vadose diagenesis-Stratigraphy and mineralogy of a cored borehole on Barbados, West Indies: Journal of Sedimentary Petrology, v. 43, p. 1012-1020.
Wagner, P. D., and Matthews, R. K., 1982a, Porosity preservation in the upper Smackover (Jurassic) carbonate grainstone, Walker Creek field, Arkansas-Response of paleophreatic lenses to burial processes: Journal of Sedimentary Petrology, v. 52 , p. $3-18$.

1982b, Reply to discussion of Moore and Brock: Journal of Sedimentary Petrology, v. 52, p. 24-26.

1983, Reply to comments of Michell-Tapping and Chimene: Journal of Sedimentary Petrology, v. 53, p. 321-322.

Wilkinson, B. W., 1982, Cyclic cratonic carbonates and Phanerozoic calcite seas: Journal of Geological Education, v. 30, p. 189-203. 


$$
\text { . }
$$




\section{A Comparative Study of the Dissolution and Crystal Growth Kinetics of Calcite and Aragonite}

By EURYBIADES BUSENBERG, U.S. Geological Survey, MS 432, National Center, Reston, Virginia 22092, and

L. NIEL PLUMMER, U.S. Geological Survey, MS 432, National Center, Reston, Virginia 22092

\section{CONTENTS}

Abstract 141

Introduction 141

Acknowledgments 141

Plummer, Wigley, and Parkhurst model for the dissolution of calcite 141

Experimental 143

Procedures 143

Analytical methods 144

Gas, gas mixtures, and $\mathrm{P}_{\mathrm{CO}_{2}} 144$

Calcites and aragonites used 144

Summary of the aqueous model 144

Calculations 145

Experimental results for calcite and aragonite dissolution and crystal

growth 146

Forward reactions 146

Backward reactions 147

Backward reactions in $\mathrm{KOH}$ solutions 150

Backward reactions in $\mathrm{KHCO}_{3}$ solutions 150

Backward reactions in $\mathrm{CaCl}_{2}$ solutions 151

Backward reactions in $\mathrm{KHCO}_{3}-\mathrm{KOH}$ solutions 152

Backward reactions in $\mathrm{Ca}\left(\mathrm{HCO}_{3}\right)_{2}$ solutions 155

The dissolution region $\mathbf{1 5 6}$

The precipitation region 160

The backward rate constant $k_{4} \quad 160$

Effects of stirring on rate 161

Comparison of the kinetics of dissolution and precipitation of calcite and aragonite 163

Comparison of the dissolution kinetics of calcite and aragonite with dolomite 163

Summary and conclusions 166

References cited 168 
1-11. Graphs showing:

1. Rate of dissolution of calcite and aragonite as function of $\mathrm{pH} \mathbf{1 4 7}$

2. Dissolution rates of aragonite and calcite as function of $\mathrm{pH}$ and $\mathrm{P}_{\mathrm{CO}_{2}} 148$

3. Backward rate effects of hydroxyl ion activity 151

4. Rates of calcite dissolution in the absence and presence of bicarbonate ion activities 153

5. Effect of $\mathrm{HCO}_{3}^{-}$activites on calcite and aragonite dissolution $\mathbf{1 5 6}$

6. Effect of $\mathrm{CaCl}_{2}$ concentrations on the rate of dissolution of calcite 158

7. Effect of $\mathrm{CO}_{3}{ }^{2-}$ activity on rates of dissolution of calcite and aragonite 159

8. Rate of dissolution and growth of calcite minus $k_{1} a_{\mathrm{H}+}$ and activity product of $\mathrm{Ca}^{2+}$ and $\mathrm{HCO}_{3}^{-} 161$

9. Dissolution of calcite and aragonite as function of $-\log (1-\Omega) \quad 165$

10. Dissolution and precipitation rates of calcite and aragonite $\mathbf{1 6 6}$

11. Comparison of dissolution and precipitation rates of calcite and aragonite 167

\section{TABLES}

1. Description of the calcium carbonate used, locality, and source of sample 145

2. Composition and surface areas of the samples used 146

3. Rate constants that can be used to calculate the rate of dissolution and crystal growth of calcite and aragonite 149

4. Procedures used to evaluate the backward reactions $\mathbf{1 5 0}$

5. Observed and calculated minus log rates of dissolution of aragonite as a function of $\mathrm{pH}$ and $\mathrm{CO}_{2} \quad 152$

6. Observed and calculated $-\log$ rates of dissolution of calcite as a function of $\mathrm{pH}$ and $\mathrm{CO}_{2} \quad 154,155$

7. Observed and calculated rates of dissolution of calcite and aragonite in $\mathrm{CaCl}_{2}$ solutions 157

8. Observed and calculated log rates of dissolution of calcite and aragonite in $\mathrm{KHCO}_{3}-\mathrm{KOH}$ solutions 160

9. Observed and calculated $\log$ rates of dissolution and crystal growth of aragonite in $\mathrm{Ca}\left(\mathrm{HCO}_{3}\right)_{2}$ solutions 162,163

10. Observed and calculated log rates of dissolution and crystal growth of calcite in $\mathrm{Ca}\left(\mathrm{HCO}_{3}\right)_{2}$ solutions 164 


\section{Abstract}

The dissolution and crystal-growth kinetics of calcite and aragonite were studied in pure water and in the presence of $\mathrm{HCl}, \mathrm{CaCl}_{2}, \mathrm{KHCO}_{3}$, and $\mathrm{KOH}$ at various $\mathrm{CO}_{2}$ partial pressures and at $25^{\circ} \mathrm{C}$. In $\mathrm{CO}_{2}-\mathrm{H}_{2} \mathrm{O}$ solutions, the forward rate of reaction $\left(R_{0}\right)$ of the $\mathrm{CaCO}_{3}$ minerals is described by

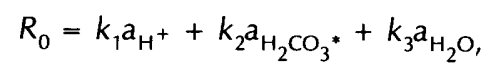

where $k_{1}, k_{2}$, and $k_{3}$ are rate constants. In the presence of $\mathrm{Ca}^{2+}, \mathrm{HCO}_{3}{ }^{-}, \mathrm{CO}_{3}{ }^{2-}$, or $\mathrm{OH}^{-}$species far from equilibrium, the forward rate decreases due to backward reactions. The backward rate contribution of these four ions is described by a Langmuir isotherm and is equal to $R_{b(i)}=R_{0} a_{i} /\left(A_{i}\right.$ $\left.+B_{i} a_{i}\right)$, where $R_{b(i)}$ is the backward rate contribution of the ith species, $A$ and $B$ are rate constants, and $a_{i}$ is the activity of the $i$ th species. Combined, $R=R_{0}-R_{b}$ describes the net rate of dissolution $(R)$ of calcite and aragonite in a wide range of solution compositions. The dissolution equation can be used in the $\Omega(\Omega=\mid A P / K)$ range of 0.0 to about 0.6 for calcite and aragonite, where IAP is the ion activity product and $K$ is the equilbrium constant.

The rate of crystal growth of calcite and aragonite was investigated in $\mathrm{Ca}\left(\mathrm{HCO}_{3}\right)_{2}$ solutions at $\mathrm{CO}_{2}$ partial pressures of $10^{-3.5}$ to 1 atmosphere and is described by the equation

$$
R=k_{4}\left(\mathrm{CE}-\mathrm{a}_{\mathrm{Ca}^{2}}{ }^{2+\mathrm{a}_{\mathrm{HOO}_{3}}}\right)^{-},
$$

where $k_{4}$ and $c$ are constants and $E$ is the equilibrium activity product of $\mathrm{Ca}^{2+}$ and $\mathrm{HCO}_{3}{ }^{-}$of the $\mathrm{CaCO}_{3}$ polymorph at the bulk $\mathrm{CO}_{2}$ partial pressure. This crystal growth equation accurately describes the rate of precipitation of calcite in the $\Omega$ range of 1.5 to more than 100 and aragonite in the $\Omega$ range of 2.0 to more than 100. A Freundlich isotherm describes the undersaturation region near equilibrium in the $\Omega$ range of 0.6 to 1.0 for calcite and aragonite. A similar Freundlich equation may describe the supersaturated region near equilibrium in the $\Omega$ range of 1.0 to 1.45 for calcite and 1.0 to 2.0 for aragonite.

The rates of dissolution of aragonite are slightly greater than for calcite in solutions of the same composition; however, the rate of crystal growth of aragonite is significantly slower than that of calcite in supersaturated $\mathrm{Ca}\left(\mathrm{HCO}_{3}\right)_{2}$ solutions. These kinetic factors may explain the near absence of aragonite in freshwater environments. The same forward rate equation can be used to describe the dissolution of dolomite except that the rates are half order with respect to $\mathrm{H}^{+}, \mathrm{H}_{2} \mathrm{CO}_{3}{ }^{*}$, and $\mathrm{H}_{2} \mathrm{O}$. The rates of dissolution of dolomite are 100 times slower than those of calcite and aragonite, and relatively small concentrations of $\mathrm{HCO}_{3}{ }^{-}$can almost completely stop dolomite dissolution far from "equilibrium."

\section{INTRODUCTION}

Understanding the time-space relationships of the diagenesis of carbonate sediments and rocks requires fundamental knowledge of the kinetics and mechanisms of reactions at the surfaces of calcite, aragonite, and dolomite. An extensive literature on the solution kinetics of calcite was reviewed by Plummer and others (1979) and compared with results and predictions based on a model of calcite dissolution (Plummer and others, 1978). The dissolution model (reviewed later) was derived from experiments in the $\mathrm{CO}_{2}-\mathrm{HCl}-\mathrm{H}_{2} \mathrm{O}$ system. Most predicted rates were found to agree within a factor of 20 of the observed literature values and many within a factor of two or better over widely varying chemical conditions beyond those investigated by Plummer and others (1978). Near-equilibrium predicted dissolution rates were found to be systematically faster than the observed. The effects of small additions of as much as a few millimoles of salts such as $\mathrm{CaCl}_{2}$ and $\mathrm{KHCO}_{3}$ were largely accounted for via thermodynamic corrections calculated by the aqueous model used to define the saturation state of the bulk solution and the calcite surface equilibrium $\mathrm{pH}$ (both essential factors in the dissolution model). No data exist, however, on the effects of higher concentrations of added salts. Reddy and others (1981) showed that measured rates of crystal growth of calcite in calcium bicarbonate solutions were closely predicted by the dissolution model at $\mathrm{CO}_{2}$ partial pressures of 0.03 to 0.30 atm (atmosphere), but again larger departures were found near equilibrium. No studies of the dissolution and crystal growth kinetics of aragonite in $\mathrm{CO}_{2}-\mathrm{H}_{2} \mathrm{O}$ solutions are known, although the dissolution kinetics of dolomite was recently investigated by Busenberg and Plummer (1982).

The present study examines more closely the effects of larger concentrations (as much as $2 \mathrm{M}$ ) of $\mathrm{CaCl}_{2}$, $\mathrm{KHCO}_{3}, \mathrm{~K}_{2} \mathrm{CO}_{3}$ and $\mathrm{KOH}$ on the dissolution kinetics of calcite and aragonite far from equilibrium in $\mathrm{CO}_{2}-\mathrm{H}_{2} \mathrm{O}$ solutions at $25^{\circ} \mathrm{C}$. The work of Reddy and others (1981) has been extended to a wider range of $\mathrm{P}_{\mathrm{CO}_{2}}$ and supersaturation in an investigation of the crystal growth rate of calcite and aragonite in $\mathrm{Ca}\left(\mathrm{HCO}_{3}\right)_{2}$ solutions. Also, the dissolution of calcite and aragonite has been studied in detail near equilibrium in an attempt to interpret departures from the dissolution model. Finally, the dissolution mechanisms of calcite and aragonite are compared with Busenberg and Plummer's (1982) recent study of the mechanisms of dissolution of dolomite.

\section{Acknowledgments}

The authors are grateful to Eric T. Sundquist and Michael M. Reddy for their careful reviews of the manuscript and their many useful comments.

\section{PLUMMER, WIGLEY, AND PARKHURST MODEL FOR THE DISSOLUTION OF CALCITE}

Plummer and others (1978) studied the kinetics of dissolution of Iceland spar calcite in dilute solutions far 
from equilibrium as a function of $\mathrm{pH}, \mathrm{P}_{\mathrm{CO}_{2}}$ and temperature using the $\mathrm{pH}$-stat method. The dissolution behavior of calcite "near" equilibrium was evaluated using the free-drift method. The experimental procedures of these methods were described in detail by these authors. The results of their investigation suggested that three independent (but simultaneous) forward reactions and one backward reaction give rise to the observed overall rate.

At low $\mathrm{pH}$ and in the absence of $\mathrm{CO}_{2}$ the dissolution rate was found to be proportional to the activity of hydrogen ion in the bulk solution. At high $\mathrm{pH}$ in the near absence of hydrogen ions and $\mathrm{CO}_{2}$, the forward rate was constant. In the intermediate $\mathrm{pH}$ range, the rate increased in proportion to the $\mathrm{CO}_{2}$ partial pressure. The forward rate for the dissolution of calcite $\left(R_{0}\right)$ was given by the expression:

$$
R_{0}=k_{1} a_{\mathrm{H}^{+}}+k_{2} a_{\mathrm{H}_{2} \mathrm{CO}_{3}^{*}}+k_{3} a_{\mathrm{H}_{2} \mathrm{O}},
$$

where $k_{1}, k_{2}$ and $k_{3}$ are rate constants dependent on temperature, and $\mathrm{H}_{2} \mathrm{CO}_{3}^{*}$ is equal by convention to $\mathrm{H}_{2} \mathrm{CO}_{3}^{\circ}+\mathrm{CO}_{2(\text { aq) }}$. The units of rate are in $\mathrm{mmol} \cdot \mathrm{cm}^{-2} \cdot \mathrm{s}^{-1}$ of calcite dissolved. The temperature dependences of the forward rate constants at 1,800 revolutions per minute of Plummer and others (1978) are given by the following expressions:

$$
\begin{aligned}
& \log k_{1}=0.198-444 / T \\
& \log k_{2}=2.84-2,177 / T, \text { and } \\
& \log k_{3}=1.10-1,737 / T,
\end{aligned}
$$

where $T$ is temperature in Kelvins. The Arrhenius activation energies were found to be about 2, 10, and 7.9 $\mathrm{kcal} \cdot \mathrm{mol}^{-1}$ for $k_{1}, k_{2}$, and $k_{3}$, respectively.

Using the free-drift method, Plummer and others (1978) found a direct relationship between the activity product of $\mathrm{Ca}^{2+}$ and $\mathrm{HCO}_{3}^{-}$and the decrease in the net rate relative to the forward rate given by equation 1 . The backward rate $\left(R_{b}\right)$ was given by:

$$
R_{b}=k_{4} a_{\mathrm{Ca}^{2}}+a_{\mathrm{HCO}_{3}^{-}},
$$

where $k_{4}$ is a rate constant. Equations 1 and 5 were combined to yield the overall rate $(R)$ for the dissolution of calcite,

$$
R=k_{1} a_{\mathrm{H}^{+}}+k_{2} a_{\mathrm{H}_{2} \mathrm{CO}_{3}^{*}}+k_{3} a_{\mathrm{H}_{2} \mathrm{O}}-\mathrm{k}_{4} a_{\mathrm{Ca}^{2}} a_{\mathrm{HCO}_{3}^{-*}}
$$

A significant achievement of the mechanistic model of calcite dissolution of Plummer and others (1978) was the theoretical derivation of the rate constant $k_{4}$ using a reaction mechanism model. This dissolution model is an extension of the adsorption heterogeneous reaction model of Mullin (1972). It assumes that a thin, relatively immobile surface layer exists between the surface of the crystal and the shear layer (the hydrodynamic boundary layer), and that the reactions occur on a small number of sites on the mineral surface. The model assumes that the reaction of surface $\mathrm{CaCO}_{3}$ with $\mathrm{H}^{+}$is much faster than reaction with $\mathrm{H}_{2} \mathrm{CO}_{3}^{*}$ and $\mathrm{H}_{2} \mathrm{O}$. The model then assumes that the flux of bulk solution $\mathrm{H}_{2} \mathrm{O}$ and $\mathrm{CO}_{2}$ across the boundary layer is faster than the heterogeneous reaction at the mineral surface. Therefore, the activities of $\mathrm{H}_{2} \mathrm{O}$ and $\mathrm{H}_{2} \mathrm{CO}_{3}^{*}$ at the mineral surface are about the same as their bulk solution activities. Because the $\mathrm{H}^{+}$ flux across the boundary layer is slower than the heterogeneous surface reaction, the activity of $\mathrm{H}^{+}$the surface layer is assumed to be the equilibrium (saturation) value at the bulk solution $\mathrm{CO}_{2}$ partial pressure.

For the backward reactions to occur, interaction of the boundary layer reactants and products with the surface layer is necessary. Several steps may be involved in the interaction of the boundary layer ions with the solid surface. The initial step may involve a collision of $\mathrm{CaHCO}_{3}^{+}$with the surface layer anions $\mathrm{CO}_{3}^{2-}, \mathrm{HCO}_{3}^{-}$, and $\mathrm{OH}^{-}$and the formation of an uncharged growth unit on the surface. A second step may involve dehydration and incorporation of the growth unit into the crystal lattice. The reactions can be written to show the relationship between the boundary layer ( 0 ) and the surface layer $(s)$ ions for the forward reactions:

$$
\begin{aligned}
& \mathrm{CaCO}_{3}+\mathrm{H}_{(0)}^{+} \rightarrow \mathrm{Ca}_{(s)}^{2+}+\mathrm{HCO}_{3(s)}^{-}, \\
& \mathrm{CaCO}_{3}+\mathrm{H}_{2} \mathrm{CO}_{3(0)}^{\circ} \rightarrow \mathrm{Ca}_{(s)}^{2+}+2 \mathrm{HCO}_{3(s)}^{-} \text {, and } \\
& \mathrm{CaCO}_{3}+\mathrm{H}_{2} \mathrm{O}_{(0)} \rightarrow \mathrm{Ca}_{(s)}^{2+}+\mathrm{HCO}_{3(s)}^{-}+\mathrm{OH}_{(s)}^{-}
\end{aligned}
$$

For the backward reaction between $\mathrm{CaHCO}_{3}{ }^{+}{ }_{(0)}$ and the surface layer anion $\mathrm{CO}_{3}^{2-}(s)$,

$$
\mathrm{CaHCO}_{3}{ }_{(0)}+\mathrm{CO}_{3(s)}^{2-} \rightarrow \mathrm{CaCO}_{3}+\mathrm{HCO}_{3(s)}^{-} \text {. }
$$

This reaction can be simplified to read:

$$
\mathrm{CaHCO}_{3}{ }_{(0)}^{+} \rightarrow \mathrm{CaCO}_{3}+\mathrm{H}^{+}{ }_{(s)} .
$$

The other backward reactions involved are:

$$
\begin{gathered}
\mathrm{CaHCO}_{3}{ }^{+}(0) \\
\mathrm{CaHCO}_{3}{ }^{+}{ }_{(0)}+\mathrm{OH}_{(s)}^{-} \rightarrow \mathrm{HCO}_{3}^{-}{ }_{(s)}^{-} \rightarrow \mathrm{CaCO}_{3}+\mathrm{H}_{2} \mathrm{O}_{(s)} \text {, and } \\
\mathrm{H}_{2} \mathrm{CO}_{3}{ }_{(s)}^{\circ} .
\end{gathered}
$$

The rates of reaction from equations 7-9 can be written:

$$
\begin{aligned}
& R_{0(1)}=k_{1}^{\prime} a_{\mathrm{H}_{(0)}^{+}}-k_{4}^{\prime} a_{\mathrm{CaHCO}_{3}{ }_{(0)}^{+}}, \\
& R_{0(2)}=k_{2} a_{\mathrm{H}_{2} \mathrm{CO}_{3}{ }_{(0)}^{\circ}}-k_{4} a_{\mathrm{CaHCO}_{3}{ }_{(0)}^{+}} a_{\mathrm{HCO}_{3}^{-}(s)} \text {, and } \\
& R_{0(3)}=k_{3} a_{\mathrm{H}_{2} \mathrm{O}_{(0)}}-k_{4} a_{\mathrm{CaHCO}_{3}{ }_{(0)}} a_{\mathrm{OH}^{-}{ }_{(s)}} \text {. }
\end{aligned}
$$


The total rate of dissolution is equal to

$$
R=R_{0(1)}+R_{0(2)}+R_{0(3)}
$$

Because the surface layer is assumed to be in equilibrium with the calcite surface, the net rate of reaction of the surface species is zero. From the assumption that calcite reacts fast with $\mathrm{H}^{+}$and more slowly with $\mathrm{H}_{2} \mathrm{CO}_{3}^{*}$ and $\mathrm{H}_{2} \mathrm{O}$, the surface layer activities of $\mathrm{H}_{2} \mathrm{CO}_{3}^{*}$ and $\mathrm{H}_{2} \mathrm{O}$ are about the same as their bulk fluid activities, but significantly different for $\mathrm{H}^{+}$. Therefore, $k_{2}^{\prime} a_{\mathrm{H}_{2} \mathrm{CO}_{3(0)}^{*}}$ and $k_{3}^{\prime} a_{\mathrm{H}_{2} \mathrm{O}_{(0)}}$ can be replaced by $k_{2} a_{\mathrm{H}_{2} \mathrm{CO}_{3(b)}^{*}}$ and $k_{3} a_{\mathrm{H}_{2} \mathrm{O}_{(b)}}$, where the subscript $(b)$ designates bulk solution. At low $\mathrm{pH}$, the relationship

$$
k_{1}\left(a_{\mathrm{H}_{(0)}^{+}}-a_{\mathrm{H}_{(b)}^{+}}\right) \approx k_{1} a_{\mathrm{H}_{(b)}^{+}}
$$

is a good approximation. At high $\mathrm{pH}$ the $k_{1}^{\prime} a_{\mathrm{H}_{(0)}^{+}}$term is small in comparison to the other two forward terms and can be neglected. From equations 14-16,

$$
k_{4}=k_{4}^{\prime}+k_{4}^{\prime \prime} a_{\mathrm{HCO}_{3(s)}^{-}}+k_{4}^{\prime \prime \prime} a_{\mathrm{OH}_{(s)}^{-}} .
$$

Because the backward and forward terms must be equal at equilibrium as required by the principle of microscopic reversibility, equations $14-16$ yield:

$k_{4}^{\prime}=\frac{k_{1}^{\prime} K_{2}}{K_{C}}, k_{4}^{\prime \prime}=\frac{k_{2} K_{2}}{K_{C} K_{1}}$, and $k_{4}^{\prime \prime \prime}=\frac{k_{3} K_{2}}{K_{C} K_{W}}$

where $K_{2}, K_{W}$, and $K_{C}$ are equilibrium constants for the reactions: $\mathrm{HCO}_{3}^{-}=\mathrm{H}^{+}+\mathrm{CO}_{3}^{2-} ; \mathrm{H}_{2} \mathrm{O}=\mathrm{H}^{+}+\mathrm{OH}^{-}$; and $\mathrm{CaCO}_{3}$ (calcite) $=\mathrm{Ca}^{2+}+\mathrm{CO}_{3}^{2-}$. Substituting equation 20 into equation 19 gives

$$
k_{4}=\frac{K_{2}}{K_{\mathrm{C}}}\left\{k_{1}^{\prime}+\frac{1}{a_{\mathrm{H}_{(s)}^{+}}}\left[k_{2} a_{\mathrm{H}_{2} \mathrm{CO}^{*}(b)}+k_{3} a_{\mathrm{H}_{2} \mathrm{O}_{(b)}}\right]\right\}
$$

The backward rate constant $k_{4}$ can be calculated from equation 21 by replacing $k_{1}^{\prime}$ with the experimentally determined value $k_{1}$.

The model assumes that $k_{2}^{\prime}=k_{2}$ and $k_{3}^{\prime}=\mathrm{k}_{3}$, and that the bulk activities of $\mathrm{H}_{2} \mathrm{CO}_{3}^{*}$ and $\mathrm{H}_{2} \mathrm{O}$ are the same as the surface values. With these approximations, the theoretical temperature and $\mathrm{P}_{\mathrm{CO}_{2}}$ dependence of $k_{4}$ can be calculated. The Plummer, Wigley, and Parkhurst (1978) model for calcite dissolution has been used to explain the results of many published dissolution studies (Plummer and others, 1979) and to calculate the rates of precipitation of calcite from supersaturated calcium bicarbonate solutions (Reddy and others, 1981). The model has also been used to quantify other experimental and natural phenomena involving calcite dissolution and precipitation (Dreybrodt, 1980, 1981a, 1981b, 1981c; House, 1981a, 1981b).

\section{EXPERIMENTAL}

Because the work of Plummer and others (1978) was based only on dissolution measurements of calcite in the presence of $\mathrm{CO}_{2}-\mathrm{H}_{2} \mathrm{O}-\mathrm{HCl}$, a new study was made to determine the rates of dissolution and growth of the polymorphs, calcite and aragonite, at $25^{\circ} \mathrm{C}$ and a stirring rate of 260 revolutions per minute in the presence of $\mathrm{CO}_{2}-\mathrm{H}_{2} \mathrm{O}-\mathrm{HCl}-\mathrm{KHCO}_{3}-\mathrm{KOH}-\mathrm{CaCl}_{2}$. The single crystals used were suspended with platinum wires in the reaction vessels containing solutions of known composition. Every effort was made to maintain a constant composition of the solution by limiting the change in weight to $0.1-0.2 \mathrm{mg}$, by using large volumes of solution $(800$ milliliters) and by maintaining the $\mathrm{pH}$ constant (to \pm 0.03 $\mathrm{pH}$ units). All reference to the rate constants $k_{1}, k_{2}$, and $k_{3}$ listed here pertain to new revised values determined in this experimental study.

\section{Procedures}

All experiments were performed in jacketed oneliter Pyrex reaction vessels maintained at $25^{\circ} \mathrm{C} \pm 0.05^{\circ} \mathrm{C}$ with Haake (Model FE and FK2) constant temperature circulating pumps ${ }^{1}$. In experiments performed at less than $\mathrm{pH} 4$ or greater than $\mathrm{pH} 9$, changes in $\mathrm{pH}$ caused by the dissolution of $\mathrm{CaCO}_{3}$ crystals were less than 0.03 $\mathrm{pH}$ units. These low $\mathrm{pH}$ changes were achieved by using large volumes of solution ( 800 millileters) and dissolving small amounts of $\mathrm{CaCO}_{3}(0.1-0.2 \mathrm{mg})$. In the $\mathrm{pH}$ range 4-9, the $\mathrm{pH}$ was maintained to within $0.03 \mathrm{pH}$ units by adding dilute $\mathrm{HCl}$ into the reaction vessels with $\mathrm{pH}$-stats (Radiometer $\mathrm{pH}$ meter PHM 64, titrator TTT 60, and autoburette ABU 13).

Experiments were performed using (1) single crystals, and (2) particles or powders. The first type of material consisted of single crystals, cleavage rhombohedrons (calcite), or aragonite crystals cut into welldefined geometrical shapes. The crystals were reacted with dilute $\mathrm{HCl}$ and washed several times with distilled water before initial use. These crystals were suspended with platinum wires into the reaction vessels, and the rates of dissolution or crystallization were determined by weight loss or gain of the samples. The crystals were washed carefully with deionized water immediately after each experiment, dried between 10 and $60 \mathrm{~min}$ at $110^{\circ} \mathrm{C}$ and

'Use of trade and company names is for descriptive purposes only and does not imply endorsement by the U.S. Geological Survey. 
allowed to cool overnight before weighing. Differences in weight used to calculate rates were determined with a Mettler electronic balance (Model ME22-BA25-BE22) with an accuracy of better than $2 \mu \mathrm{g}$. Weight losses were checked by chemical analysis of the Ca released into the known volume of solution. Excellent agreement was found between these two methods. A more detailed account of the procedures used is given by Busenberg and Plummer (1982). The surface areas of the crystals were calculated from the dimensions and the geometrical shape of the crystals and ranged from about 2 to $10 \mathrm{~cm}^{2}$.

In the second group of experiments, rates were measured in stirred suspensions. These experiments were used mainly to study dissolution near equilibrium. The material used in some experiments were size-sorted fragments of calcite and aragonite. The surface areas were calculated from the sizes and geometry of the fragments by the method described by Plummer and others (1978). Size-sorted oolites of aragonite were used in some experiments. The surface area was calculated from the mean diameter of the spheres. Two oolite samples, $\mathrm{Cl}$ and $\mathrm{C} 2$, (table 1) had calculated surface areas of 85.6 and 56.4 $\mathrm{cm}^{2} \cdot \mathrm{g}^{-1}$, respectively. About $20 \mathrm{~g}$ of oolite sample was used per experiment. Other materials used in batch experiments were reagent-grade calcite powder (J. T. Baker Chemical Co., No. 5-1294), and a pure synthetic aragonite powder prepared and aged in artificial seawater at $75^{\circ} \mathrm{C}$ (Plummer and Busenberg, 1982). The BET surface areas of the two powders were $0.19 \mathrm{~m}^{2} \cdot \mathrm{g}^{-1}$ for the calcite and $1.2 \mathrm{~m}^{2} \cdot \mathrm{g}^{-1}$ for the aragonite. Reaction progress in the batch experiments was calculated from changes in $\mathrm{pH}$ or $\mathrm{Ca}$ of the solution as a function of time.

\section{Analytical methods}

The Ca released in the free-drift experiments was determined from aliquots filtered through $0.45-\mu \mathrm{m}$ membrane filters, and obtained at regular intervals throughout the experiments. Calcium was determined by ethylenediamine tetraacetic acid (EDTA) using calcein as the endpoint indicator by the procedure of Diehl (1964). The EDTA was standardized with a primary $\mathrm{CaCO}_{3}$ standard (J. T. Baker Chemical Co., Ultrex $\mathrm{CaCO}_{3}$ No. 4-4918), and the EDTA concentration was determined with an accuracy of better than 0.1 percent. The accuracy of $\mathrm{Ca}$ analyses was better than 0.5 percent. The Ca released from single crystals was determined by standard atomic absorption procedures using a Perkin-Elmer Corporation Model 503 instrument. Strontium and magnesium were also determined by standard atomic absorption procedures.

The $\mathrm{pH}$ was measured with Radiometer Model PHM 64, Orion Research, Inc. Model 801 and Fluke Model 8800A instruments. Radiometer Cat. No. GK 2104C and Orion Research Model 81-0200 combination $\mathrm{pH}$ electrodes were used. The electrodes were standardized with $4.01 \pm 0.01,6.86 \pm 0.01$, and, when necessary, $9.18 \pm 0.01$ Fisher Scientific Co. buffers.

\section{Gas, gas mixtures, and $\mathbf{P}_{\mathrm{CO}_{2}}$}

$\mathrm{CO}_{2}, \mathrm{~N}_{2}$, and $\mathrm{CO}_{2}-\mathrm{N}_{2}$ gas mixtures prepared by Air Products, Inc. were used in all the experiments. Analysis of some of the mixtures by gas chromatography indicated that the actual compositions were well within one percent of the stated compositions. Before bubbling the gas into the reaction vessel, all gases were bubbled through deionized water at the same temperature as the reaction vessel to saturate the gas with water vapor. The $\mathrm{CO}_{2}$ partial pressure was calculated from the measured room barometric pressure $(B)$ using the equation:

$$
P_{\mathrm{CO}_{2}}=\frac{B-V+0.4 h / D}{760} \cdot X_{\mathrm{Co}_{2}}
$$

where $B$ is the measured barometric pressure in millimeters $\mathrm{Hg}$, corrected for temperature and latitude; $V$ is the saturation vapor pressure of water, in millimeters of $\mathrm{Hg}$, at the experimental temperature; $h$ is the depth in millimeters of the gas bubbler in the reaction vessel; $D$ is the specific gravity of mercury (13.6); and $X_{\mathrm{Co}_{2}}$ is the volume fraction of $\mathrm{CO}_{2}$ in the gas (Plummer and Busenberg, 1982).

\section{Calcites and aragonites used}

A description of the calcites and aragonites used in this study is given in table 1 . Table 2 is a compilation of $\mathrm{Sr}$ and $\mathrm{Mg}$ concentrations, surface areas, and weights of the samples used per 800 milliliters of solution.

\section{Summary of the aqueous model}

Plummer and Busenberg (1982) evaluated the equilibrium constants for the system $\mathrm{CaCO}_{3}-\mathrm{CO}_{2}-\mathrm{H}_{2} \mathrm{O}$ between $0^{\circ}$ and $90^{\circ} \mathrm{C}$ and determined the solubility constants of calcite and aragonite over a wide range of $\mathrm{CO}_{2}$ partial pressures in this temperature range. The same aqueous model and data base are used in this paper. The necessary reactions and the logarithms of the equilibrium constants for this system at $25^{\circ} \mathrm{C}$ (Plummer and Busenberg, 1982) are as follows:

$$
\begin{array}{lll}
\mathrm{H}_{2} \mathrm{O}(\mathrm{aq}) & =\mathrm{H}^{+}+\mathrm{OH}^{-} & \log K_{\mathrm{W}}=-13.992 \\
\mathrm{CO}_{2}(\mathrm{~g}) & =\mathrm{CO}_{2}(\mathrm{aq}) & \log K_{\mathrm{H}}=-1.468 \\
\mathrm{CO}_{2}(\mathrm{aq})+\mathrm{H}_{2} \mathrm{O} & =\mathrm{HCO}_{3}^{-}+\mathrm{H}^{+} \log K_{1}=-6.352
\end{array}
$$


Table 1. Description of the calcium carbonate used and locality and source of samples

\begin{tabular}{|c|c|c|c|c|}
\hline Sample & Mineral & Description & Locality & Source \\
\hline A & Aragonite----- & $\begin{array}{l}\text { Pseudohexagonal twin crystal, } \\
1 \text { by } 4 \mathrm{~cm} \text {, clear. }\end{array}$ & Aragon, Spain-..-- & $\begin{array}{l}\text { Peter C. Avery, } \\
\text { SUNY at Buffalo, } \\
\text { Buffalo, N.Y. }\end{array}$ \\
\hline B & Aragonite----- & $\begin{array}{l}\text { Pseudohexagonal twin crystals, } \\
2.5 \text { by } 3 \mathrm{~cm} \text {, translucent, } \\
\text { gray. }\end{array}$ & Bastennes, France----- & $\begin{array}{l}\text { Ward's Natural } \\
\text { Science Establish- } \\
\text { ment, Inc., } \\
\text { Rochester, N.Y. }\end{array}$ \\
\hline M, M1 & Aragonite----- & $\begin{array}{l}\text { Pseudohexagonal twin crystals, } \\
3 \text { by } 3 \mathrm{~cm} \text {, translucent, } \\
\text { light gray. }\end{array}$ & $\begin{array}{l}\text { Molina de Aragon, } \\
\text { Spain. }\end{array}$ & $\begin{array}{l}\text { Ward's Natural } \\
\text { Science Establish- } \\
\text { ment, Inc., } \\
\text { Rochester, N.Y. }\end{array}$ \\
\hline N & Aragonite----- & $\begin{array}{l}\text { Pseudohexagonal twin crystals, } \\
0.8 \text { by } 1 \mathrm{~cm} \text {, translucent. }\end{array}$ & Artesia, N. Mex.--_: & $\begin{array}{l}\text { Walter F. White, } \\
\text { U.S. Geological } \\
\text { Survey, } \\
\text { Towson, Md. }\end{array}$ \\
\hline$S$ & Aragonite----- & $\begin{array}{l}\text { Massive, fine grained, } \\
\text { opaque, white. }\end{array}$ & $\begin{array}{l}\text { Compton Mallet, } \\
\text { Somerset, United } \\
\text { Kingdom. }\end{array}$ & $\begin{array}{l}\text { Peter G. Avery, } \\
\text { SUNY at Buffalo, } \\
\text { Buffalo, N.Y. }\end{array}$ \\
\hline $\mathrm{C} 1, \mathrm{C} 2$ & Aragonite----- & 0ölites--- & $\begin{array}{l}\text { Stablized oölite } \\
\text { bar--North of } \\
\text { Andros Island, } \\
\text { Bahamas. }\end{array}$ & $\begin{array}{l}\text { Randolph Steinen, } \\
\text { University of } \\
\text { Connecticut, } \\
\text { Storrs, Conn. }\end{array}$ \\
\hline AA & Aragonite----- & $\begin{array}{l}\text { Synthetic, needles } \\
\text { prepared in artificial } \\
\text { seawater at } 75^{\circ} \mathrm{C} \text {. }\end{array}$ & & Present paper. \\
\hline
\end{tabular}

$$
\begin{aligned}
& \mathrm{HCO}_{3}^{-}=\mathrm{H}^{+}+\mathrm{CO}_{3}^{2-} \quad \log K_{2}=-10.329(26) \\
& \mathrm{Ca}^{2+}+\mathrm{HCO}_{3}^{-}=\mathrm{CaHCO}_{3}^{+} \quad \log \mathrm{K}_{\mathrm{CaHCO}_{3}^{+}}=\quad 1.11
\end{aligned}
$$

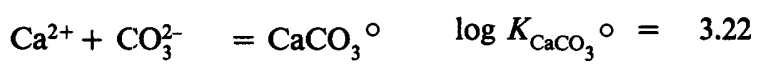

$$
\begin{aligned}
& \mathrm{Ca}^{2+}+\mathrm{OH}^{-}=\mathrm{CaOH}^{+} \quad \log K_{\mathrm{CaOH}^{+}}=1.3 \\
& \mathrm{CaCO}_{3 \text { (calcit) }}=\mathrm{Ca}^{2+}+\mathrm{CO}_{3}^{2-} \log K_{\mathrm{C}}=-8.480 \\
& \mathrm{CaCO}_{3 \text { (aragonite) }}=\mathrm{Ca}^{2+}+\mathrm{CO}_{3}^{2-} \log K_{\mathrm{A}}=-8.336
\end{aligned}
$$

Individual ion-activity coefficients were calculated using the modified version of the extended Debye-Hückel equation given by Truesdell and Jones (1974). The activity coefficient of $\mathrm{CaHCO}_{3}{ }^{+}$was assumed to be equal to that of $\mathrm{HCO}_{3}^{-}$. Individual ion activities of uncharged species were calculated from the expression of Reardon and Langmuir (1976). A detailed evaluation of the aqueous model used and equilibrium constants can be found in Plummer and Busenberg (1982.)

\section{Calculations}

For single crystals suspended into the various solutions, rates were calculated from the changes in weight using the equation

$$
R=(W / G) /(t \times S)
$$

where $R$ is the rate in $\mathrm{mmol} \cdot \mathrm{cm}^{-2} \cdot \mathrm{s}^{-1}, W$ is the weight gained or lost in milligrams, $G$ is the gram formula weight of calcite or aragonite in $\mathrm{mg} \cdot \mathrm{mmol}^{-1}, t$ is the duration of the experiment in seconds, and $S$ is the surface area in square centimeters. Equation 32 was also used to obtain 
Table 2. Compositions and surface areas of the samples used

[Leaders (---) indicate not determined; ppm, parts per million; $\mathrm{cm}^{2}$, square centimeters; and $\mathrm{mL}$, milliliters]

\begin{tabular}{|c|c|c|c|c|c|}
\hline Sample & $\begin{array}{l}\text { Strontium } \\
(\mathrm{ppm})\end{array}$ & $\begin{array}{l}\text { Magnesium } \\
(\mathrm{ppm})\end{array}$ & $\begin{array}{c}\text { Total } \\
\text { surface } \\
\text { area } \\
\left(\mathrm{cm}^{2}\right)\end{array}$ & $\begin{array}{c}\text { Surface } \\
\text { area } \\
\left(\mathrm{cm}^{2} / \mathrm{g}\right)\end{array}$ & $\begin{array}{l}\text { Weight } \\
\text { of } \\
\text { (g/800 mL } \\
\text { solution) }\end{array}$ \\
\hline$A$ & 700 & 9.0 & $3.0-3.7$ & -- & $-\infty$ \\
\hline B & 720 & 5.2 & $2.0-5.5$ & -- & $-\infty$ \\
\hline$M$ & 660 & 12 & $2.3-6.7$ & -- & $\ldots$ \\
\hline$N$ & 720 & 23 & $4.0-4.4$ & - &.- \\
\hline 0 & 160 & 21 & $2.7-4.8$ &.-- & --- \\
\hline$S$ & 64 & 1 & $5.3-6.4$ & -- & -- \\
\hline $\mathrm{C} 2$ & 930 & 87 & --- & 56.4 & $20-35$ \\
\hline $\mathrm{Cl}$ & 940 & 92 & $\ldots$ & 85.6 & $5-20$ \\
\hline$A A$ & 15 & 53 &.- & 12,000 & 2.0 \\
\hline M1 & 660 & 12 & -- & 190 & 7.0 \\
\hline$C M$ & -- & -- & $3-10$ & -- & -- \\
\hline$C A$ & 10 & 9 & --- & 1,900 & 5.0 \\
\hline
\end{tabular}

rate from the analytical data; here, $W$ represents the total calcium released in the solution in milligrams, and $G$ the weight of calcium per mole of calcite or aragonite in $\mathrm{mg} \cdot \mathrm{mmol}^{-1}$.

Two procedures were used to calculate rates from the free-drift runs. In runs in which pH was measured as a function of time, rates were calculated by the stepwise central-difference method similar to that of Plummer and Wigley (1976) and Plummer and others (1978). For the free-drift runs in which $\mathrm{Ca}$ was measured as a function of time, the experimental $\mathrm{Ca}$ data were fitted to the equation:

$$
\mathrm{Ca}=A+B t+C t^{0.5}+D \log t+E t^{0.33},
$$

where $A, B, C, D$, and $E$ are fitted parameters for a given run and $t$ is time. Rates were obtained by differentiation of equation 33 at regular time intervals.

\section{EXPERIMENTAL RESULTS FOR CALCITE AND ARAGONITE DISSOLUTION AND CRYSTAL GROWTH}

\section{Forward reactions}

Figure 1 shows the effect of bulk solution $\mathrm{H}^{+}$ activity on the dissolution rate of single aragonite and calcite crystals in the near absence of $\mathrm{CO}_{2}\left(\mathrm{~N}_{2}\right.$ atmosphere) and calcium between $\mathrm{pH} 2\left(\mathrm{HCl}-\mathrm{H}_{2} \mathrm{O}\right)$ and $11\left(\mathrm{KOH}-\mathrm{H}_{2} \mathrm{O}\right)$. The slope of $\log$ rate as a function of $\mathrm{pH}$ is -1.0 between $\mathrm{pH} 2$ and 4.5 . In this $\mathrm{pH}$ range, the hydrogen ion dependence of the forward rate is then

$$
R_{\mathrm{H}^{+}}=k_{1} a_{\mathrm{H}^{+}} .
$$

Figure 1 shows a region between $\mathrm{pH} 5$ and 9 where the rate is independent of $\mathrm{pH}$ in the absence of $\mathrm{CO}_{2}$. In this region both $\mathrm{H}^{+}$and $\mathrm{OH}^{-}$are nearly absent (their activities do not exceed $10^{-5} \mathrm{~mol} \cdot \mathrm{L}^{-1}$ ), and the forward rate is constant according to:

$$
R_{\mathrm{H}_{2} \mathrm{O}}=k_{3}
$$

The region of decreasing rate at $\mathrm{pH}$ values greater than 9.5 has been interpreted as backward reaction between the mineral surface and $\mathrm{OH}^{-}$and will be treated in a later section of this paper.

Figure $2 \mathrm{~A}$ shows the effect of increasing $\mathrm{CO}_{2}$ partial pressure on the forward rate for aragonite. This effect was evaluated for both aragonite and calcite using:

$$
R_{\mathrm{H}_{2} \mathrm{CO}_{3}^{*}}=R_{0}-\left(R_{\mathrm{H}^{+}}+R_{\mathrm{H}_{2} \mathrm{O}}\right)
$$

which is obtained by rearranging equation 1 . The forward rate dependence of $\mathrm{R}_{\mathrm{H}_{2} \mathrm{CO}_{3}}$ was found to be directly proportional to the $\mathrm{CO}_{2}$ partial pressure for aragonite, similar to that found earlier for calcite (Plummer and others, 1978):

$$
R_{\mathrm{H}_{2} \mathrm{CO}_{3} *}=k_{2} a_{\mathrm{H}_{2} \mathrm{CO}_{3} *}
$$

Figure $2 B$ is a comparison of the results for calcite and aragonite. The calculated values for $k_{1}$ and $k_{2}$ for calcite and aragonite are identical within experimental error (table 3). The apparent larger value for the total forward rate $\left(R_{0}\right)$ on figure $2 B$ results from the larger $k_{3}$ constant for aragonite.

The total forward rate far from equilibrium observed for both calcite and aragonite in $\mathrm{CO}_{2}-\mathrm{H}_{2} \mathrm{O}$ solutions obeys the equation given by Plummer and others (1978), 


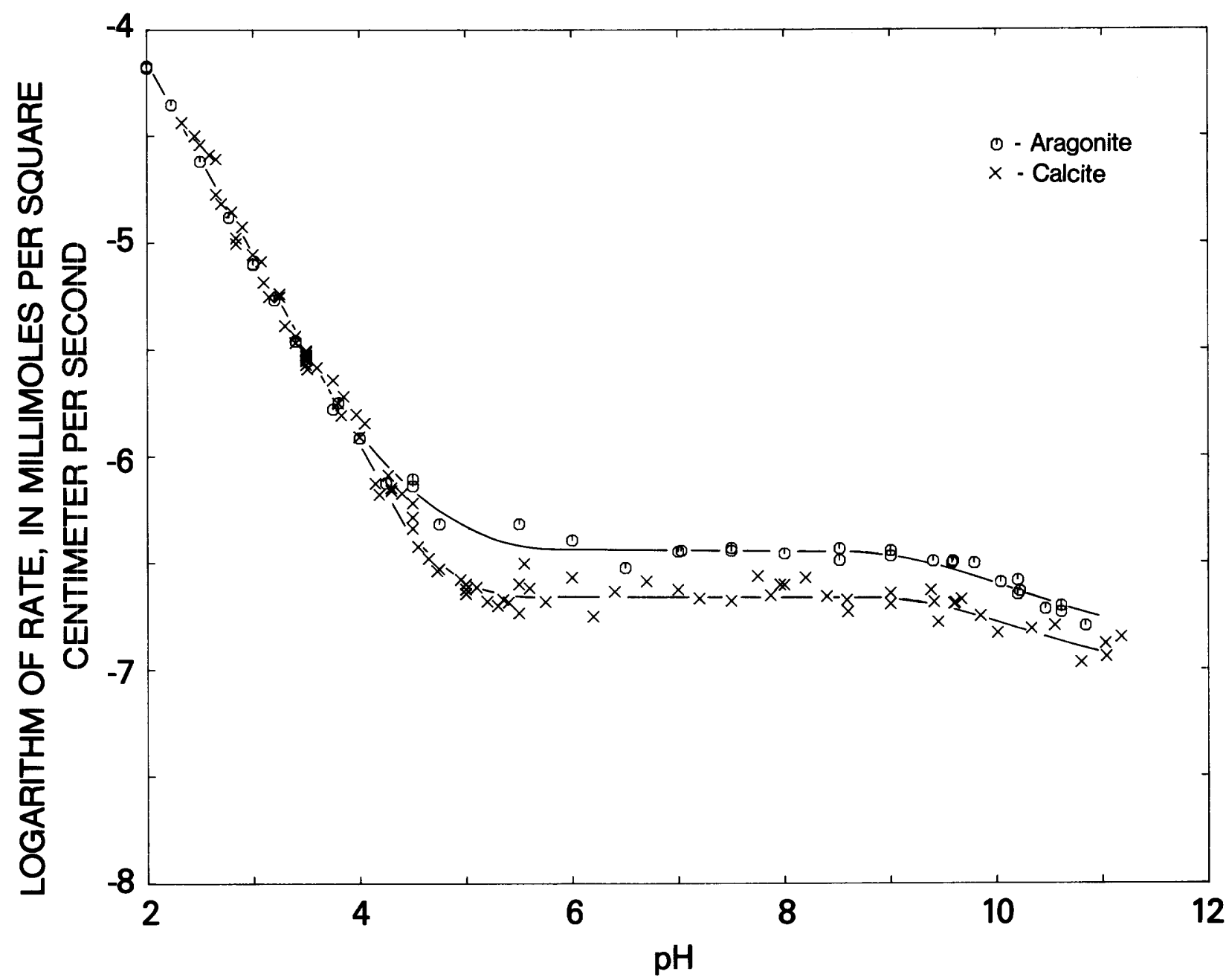

Figure 1. Dissolution rates of calcite and aragonite single crystals as a function of $\mathrm{pH}$ in near absence of $\mathrm{CO}_{2}\left(\mathrm{~N}_{2}\right.$ atmosphere) far from equilibrium.

$$
R_{0}=k_{1} a_{\mathrm{H}^{+}}+k_{2} a_{\mathrm{H}_{2} \mathrm{CO}_{3}}+k_{3} a_{\mathrm{H}_{2} \mathrm{O}}
$$

where the rate constants $k_{1}, k_{2}$, and $k_{3}$ are given in table 3 for the present experimental conditions.

\section{Backward reactions}

In the model of Plummer and others (1978), the backward rate is interpreted as a reaction between bulk solution $\mathrm{CaHCO}_{3}{ }^{+}$and negative surface sites (eqs. 1113); however, positive sites in addition to negative sites exist on the calcite and aragonite surfaces. Foxall and others (1979) showed that the surface positive sites on calcite in aqueous solutions are mainly $\mathrm{Ca}^{2+}$ and that the $\mathrm{Ca}^{2+}$-anion pair rather than the $\mathrm{H}^{+}-\mathrm{OH}^{-}$pair are the surface-potential determining ions for calcite. Therefore, backward reactions between the positive surface sites and bulk solution anions should also occur. All the other possible backward reactions between the surface and ions not included in the reactions given by equations 10-13 in the system $\mathrm{Ca}^{2+}-\mathrm{H}_{2} \mathrm{O}-\mathrm{CO}_{2}$ are evaluated in the next few sections of this paper.

To isolate and determine the backward rate effects of individual species, the solution parameters $\left(\mathrm{pH}, \mathrm{P}_{\mathrm{CO}_{2}}\right.$, and composition) were adjusted so as to eliminate or minimize the effects of all other interfering ions. If this was not possible, the combined backward rate effects of more than one species were determined. The backward rate effect of the species of interest was calculated by subtracting all the effects of the other interfering ions. The assumption that backward rates are additive is implied by the procedures used. Our results suggest that this additive assumption is valid in dilute solutions, but may be less reliable in complex concentrated solutions and when the saturation $\Omega$ for calcite and aragonite exceeds 0.6 in pure $\mathrm{Ca}\left(\mathrm{HCO}_{3}\right)_{2}$ solutions. The failure may result 

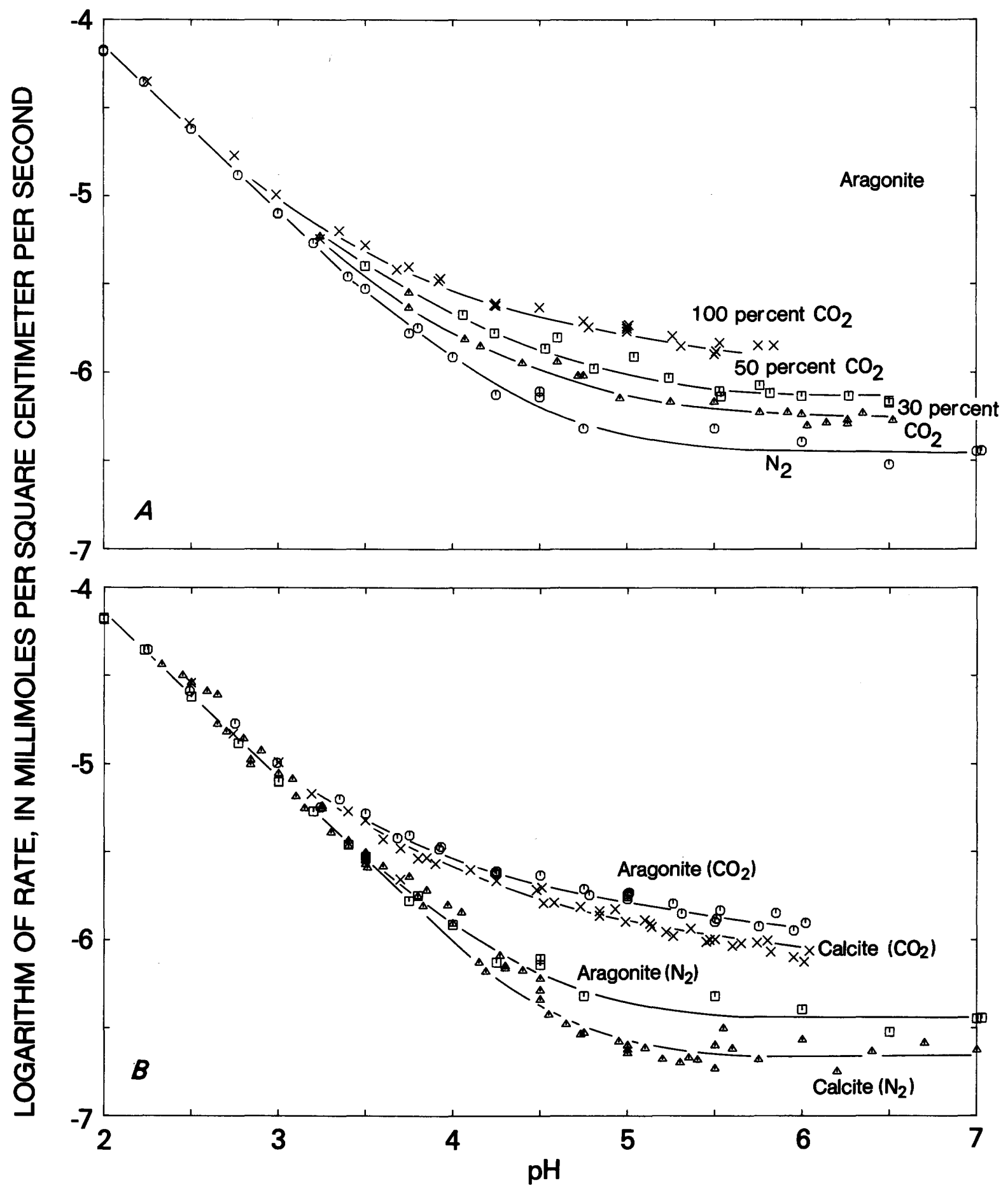

Figure 2. Dissolution rates of single crystals of $A$, aragonite as a function of $\mathrm{pH}$ and gas composition (numerical values represent mole percent $\mathrm{CO}_{2}$ in the $\mathrm{CO}_{2}-\mathrm{N}_{2}$ gas mixtures) far from equilibrium, and $B$, calcite and aragonite as a function of $\mathrm{pH}$, in near absence of $\mathrm{CO}_{2}\left(\mathrm{~N}_{2}\right.$ atmosphere) and 100 percent $\mathrm{CO}_{2}$ far from equilibrium.

from the inability of the model to account for ion-ion and ion-surface interactions.

The effects of $\mathrm{OH}^{-}, \mathrm{HCO}_{3}^{-}, \mathrm{Ca}^{2+}$, and $\mathrm{CO}_{3}^{2-}$ procedures and experimental conditions used are outlined in table 4. Presumably, the first step in all backward reactions involves the adsorption of a reactive ion into the surface from the bulk solution. If the rate of backward reaction is directly proportional to the activity of the adsorbate and the adsorption is described by some isotherm, a direct relationship will exist between the bulk solution concentration of the ion and the isotherm that will be defined by the changes in the theoretical forward 
Table 3. Rate constants used to calculate the rate of dissolution (equations 53 and 54) and crystal growth (equation 56) of calcite and aragonite

[Unit of rate calculated from, constants is $\mathrm{mmol} \cdot \mathrm{cm}^{-2} \cdot \mathrm{s}^{-1} ; \mathrm{m}, \mathrm{molar}$ ]

\begin{tabular}{|c|c|c|c|c|c|c|}
\hline & Rate consta & & & Arag & ite & \\
\hline & ${ }^{1} \log k_{1}$ & & & & & \\
\hline & $\log k_{2}$ & -4 & & & & \\
\hline & $\log k_{3}$ & -6 & & & & \\
\hline & $k_{4}$ & ${ }^{2} \mathrm{Eq}$ & ion 21 & & & \\
\hline & c & & & & & \\
\hline & ${ }^{3} \log k_{5}$ & & & & & \\
\hline & $n$ & 0 & & & & \\
\hline & & Calcite & & & nite & Concentration \\
\hline$i$ & $A_{i}$ & $B_{i}$ & & & $B_{i}$ & \\
\hline $4 \mathrm{Ca}^{2+}$ & 0.0025 & $0.09\left[10+2^{(9-p H)}\right]$ & 0.00 & $\mathrm{pH}$ ] & $0.10\left[10+2^{(9-p H)}\right]$ & $0-0.3 \mathrm{M}$ \\
\hline $\mathrm{OH}^{-}$ & 0.00014 & 2.0 & 0.00 & & 2.0 & $<\mathrm{pH} 11.2$ \\
\hline $\mathrm{HCO}_{3}$ & 0.01 & 1.65 & 0.00 & & 1.65 & $0-0.1 \mathrm{M}$ \\
\hline $\mathrm{HCO}_{3}$ & 0.05 & 1.0 & 0.04 & & 0.96 & $0.1-2.0 \mathrm{M}$ \\
\hline $\mathrm{CO}_{3}^{2^{-}}$ & 0.000001 & 4.5 & 0.00 & & 17.2 & $\left({ }^{5}\right)$ \\
\hline
\end{tabular}

${ }^{1}$ At a stirring rate of 260 revolutions per minute.

${ }^{2} k_{4}$ is a function of $\mathrm{P}_{\mathrm{CO}_{2}}$ as given theoretically by equation 21 , the experimental value of $k_{4}$ for aragonite is the theoretical value of calcite divided by 2.14

${ }^{3}$ Formula can be used between pH 4 and 10 and $\mathrm{Ca}^{2+}>0.1$ molar.

${ }^{4}$ For 0.96 atmospheres $\mathrm{P}_{\mathrm{CO}_{2}}$.

${ }^{5}$ Concentration ranges are 0 to $0.2 \mathrm{M}$ and 0 to $0.05 \mathrm{M}$ for calcite and aragonite, respectively.

rate given by equation 1 . To obey an adsorption isotherm, the backward reaction rate will have to be proportional to the fraction of the surface sites covered by the adsorbate. The rates of reaction in the presence and absence of the adsorbate are given by $R$ and $R_{0}$, respectively. The effect of an adsorbate on the rate can be expressed by the ratio $\left(R_{0}-R\right) / R_{0}$ which is proportional to the fraction of adsorption sites occupied by the adsorbate. The fraction of adsorption sites free from the adsorbate is then proportional to $R / R_{0}$.

The Langmuir isotherm equation (Langmuir, 1918) states that

$$
\theta=b X /(1+b x)
$$

where $\theta$ is the fraction of adsorption sites covered by the adsorbate, $b$ is a constant, and $X$ is the concentration of the adsorbate in solution. Because $\left(1-R / R_{0}\right)$ is proportional to $\theta$,

$$
\left(1-R / R_{0}\right)=a \theta=a b X /(1+b X),
$$

where $a$ is a constant. Dividing by $X$ and taking the reciprocal,

$$
X_{i} /\left(1-R / R_{0}\right)=A_{i}+B_{i} X_{i}
$$

where the subscript $i$ represents species $i, A$ is equal to the constant $1 / a b$, and $B$ is a second constant equal to $1 / a$. Equation 41 describes a straight line and is a common representation of a Langmuir isotherm. Inasmuch as the chemical reaction on the surface depends on activity rather than concentration, the problem involves chemisorption and $X_{i}$ should be replaced by the activity of the $i$ th adsorbed species in equation 41 . The rate of the initial adsorption reaction can be obtained by rearranging equation $\mathbf{4 1}$ as follows: 
Table 4. Procedures used to evaluate the backward reactions

[Concentrations are in moles $(\mathrm{mol})$ per liter $(\mathrm{L}) ; \mathrm{CO}_{2}$ partial pressures are in atmospheres]

\begin{tabular}{|c|c|c|c|c|}
\hline $\begin{array}{c}\text { Ion } \\
i\end{array}$ & $\begin{array}{l}\text { Solution } \\
\text { preparation }\end{array}$ & $\mathrm{pH}$ & $\mathrm{P}_{\mathrm{CO}_{2}}$ & $\begin{array}{l}\text { Equation used to } \\
\text { evaluate backward rate }\end{array}$ \\
\hline $\mathrm{OH}^{-}$ & $\mathrm{KOH}$ added. & $8-11 \cdot 3$ & $\begin{array}{l}\mathrm{P}_{\mathrm{CO}_{2}} \text { about } 0 ; \\
\text { bubbled } \mathrm{N}_{2}\end{array}$ & $\mathrm{R}_{\mathrm{OH}^{-}}=\mathrm{R}_{\mathrm{O}}-\mathrm{R}$ \\
\hline $\mathrm{HCO}_{3}^{-}$ & $\begin{array}{l}\mathrm{KHCO}_{3} \text { added } \\
0-2 \mathrm{~mol} / \mathrm{L} .\end{array}$ & $\begin{array}{l}\text { Determined by } \\
\text { composition } \\
\text { and } \mathrm{P}_{\mathrm{CO}} \\
4-7.4\end{array}$ & $\begin{array}{l}\text { Variable, determined } \\
\text { by composition of } \\
\text { the gas bubbled in } \\
\text { the solution. } \\
0.96-0.03 \text {. }\end{array}$ & $\mathrm{R}_{\mathrm{HCO}_{3}}{ }^{-}=\mathrm{R}_{\mathrm{O}}-\mathrm{R}-\mathrm{R}_{\mathrm{OH}^{-}}^{-}$ \\
\hline $\mathrm{Ca}^{2+}$ & $\mathrm{CaCl}_{2}$ added. & $4-10$ & $\begin{array}{l}\mathrm{P}_{\mathrm{CO}_{2}} \text { about } 0 ; \\
\text { bubbled } \mathrm{N}_{2} .\end{array}$ & $\mathrm{R}_{\mathrm{Ca}^{2+}}{ }^{2+} \mathrm{R}_{0}-\mathrm{R}-\mathrm{R}_{\mathrm{OH}^{-}}$ \\
\hline $\mathrm{CO}_{3}^{2-}$ & $\begin{array}{l}\mathrm{KHCO}_{3}-\mathrm{KOH} \\
\text { added. }\end{array}$ & $\begin{array}{r}\text { Adjusted to } 9.8 \\
\text { by adding } \mathrm{KOH} \text {. }\end{array}$ & Closed system. & $\mathrm{R}_{\mathrm{CO}_{3}}{ }^{2-}=\mathrm{R}_{\mathrm{O}}-\mathrm{R}-\mathrm{R}_{\mathrm{OH}^{-}}$ \\
\hline
\end{tabular}

${ }^{1} R=$ experimental rate of dissolution of calcite or aragonite. $R_{0}=$ theoretical forward rate calculated from equation 1 . $R_{\mathrm{i}}=$ backward rate of the $i$ th species.

$$
R=R_{0}-R_{0} a_{\mathrm{i}} /\left(A_{i}+B_{i} a_{i}\right)
$$

The backward rate contribution $\left(R_{b}\right)$ of adsorbed species is equal to

$$
R_{b(i)}=R_{0} a_{\mathrm{i}} /\left(A_{i}+B_{i} a_{i}\right),
$$

where $R_{b}=R_{0}-R$. Langmuir isotherm equations similar to equation 41 were used by Sjoberg (1978) and Reddy (1977) and Reddy and Wang (1980) to describe backward rate effects and inhibition by various ions in the dissolution or precipitation of calcite, respectively. The logical sequence that must be used to evaluate the backward rate constants in the system $\mathrm{Ca}^{2+}-\mathrm{H}_{2} \mathrm{O}-\mathrm{CO}_{2}$ (table 4) is followed in the next sections of this paper.

\section{Backward reactions in $\mathrm{KOH}$ solutions}

At $\mathrm{pH}$ values greater than about 9.5 , as shown in figure 1 , the observed forward rate decreased below the rate predicted by equation 1 . The decrease in rate can be explained as a backward reaction between the surface and adsorbed $\mathrm{OH}^{-}$. This reaction may be written:

$$
\mathrm{CaHCO}_{3}{ }_{(s)}+\mathrm{OH}_{(a d s)}^{-} \rightarrow \mathrm{CaCO}_{3}+\mathrm{H}_{2} \mathrm{O}_{(\mathrm{s})},
$$

where the subscripts ( $a d s)$ and $(s)$ denote adsorbed and surface species, respectively. If the backward reaction rate is proportional to the activity of the adsorbate and the adsorption follows the Langmuir equation, a plot of $X /\left(1-R / R_{0}\right)$ as a function of $X$ will yield a straight line with a slope equal to $B$ and an intercept equal to $A$ (eq. 41). Such a plot, strongly suggesting a direct relationship between the amount of $\mathrm{OH}^{-}$absorbed and the backward-reaction rate, is shown on figure 3. Also, a single Langmuir relation for $\mathrm{OH}^{-}$applies equally to both calcite and aragonite dissolution.

The experimental results, including the observed and calculated rates as a function of $\mathrm{pH}$ and $\mathrm{P}_{\mathrm{CO}_{2}}$, are given in tables 5 and 6 for aragonite and calcite, respectively.

\section{Backward reactions in $\mathrm{KHCO}_{3}$ solutions}

A significant backward reaction between the surface of aragonite and calcite and $\mathrm{HCO}_{3}^{-}$(0) was observed above $\mathrm{pH} 5$ at $\mathrm{P}_{\mathrm{CO}_{2}}$ of 0.1 to 1.0. Figure 4 shows the extent of this backward reaction on calcite dissolution at $0.96 \mathrm{~atm} \mathrm{CO}_{2}$. The solid line represents the forward rates calculated from equation 38 and the constants of table 3, which exclude the $\mathrm{HCO}_{3}{ }^{-}$effect. For $a_{\mathrm{HCO}_{3}}{ }^{-}$ values greater than $10^{-3}$, the calcite dissolution rate is below that calculated by equation 38 (fig. 4). Similar results were obtained for aragonite. The high $\mathrm{HCO}_{3}{ }^{-}$ activities were obtained by adding $\mathrm{KHCO}_{3}$ salt.

The observed decrease in the forward rate due to added $\mathrm{KHCO}_{3}$ may have resulted from the following reactions:

$$
\begin{aligned}
& \mathrm{Ca}_{(s)}^{2+}+\mathrm{HCO}_{3^{-}(a d s)}^{-} \rightarrow \mathrm{CaCO}_{3}+\mathrm{H}^{+}{ }_{(s)}, \\
& \mathrm{CaHCO}_{3(s)}^{+}+\mathrm{HCO}_{3^{-}(a d s)}^{-} \rightarrow \mathrm{CaCO}_{3}+\mathrm{H}_{2} \mathrm{CO}_{3(s)} \text {, and } \\
& \left.\mathrm{CaOH}^{+}{ }_{(s)}+\mathrm{HCO}_{3_{(a d s)}^{-}} \rightarrow \mathrm{CaCO}_{3}+\mathrm{H}_{2} \mathrm{O}_{(s)}\right)^{.}
\end{aligned}
$$




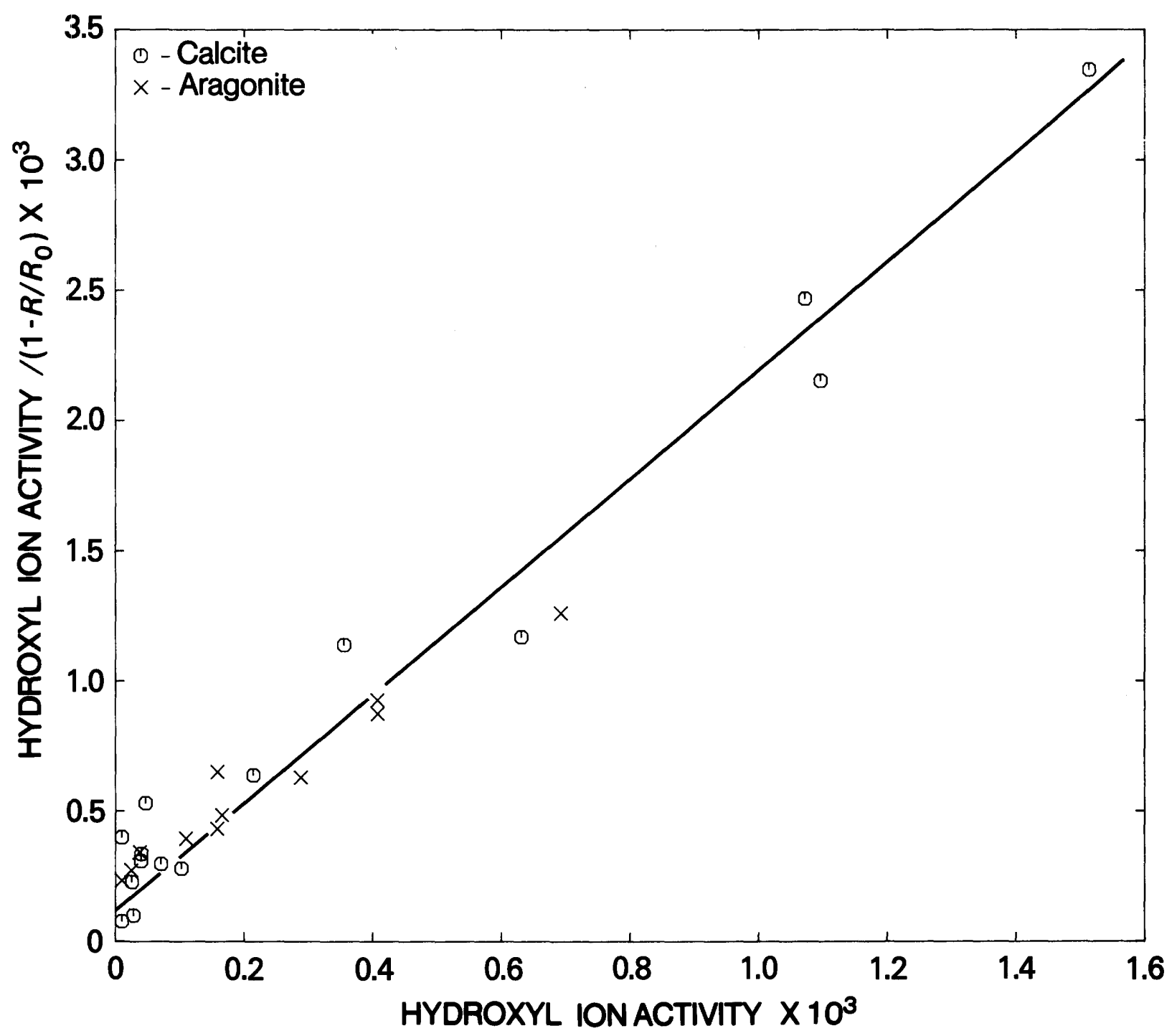

Figure 3. Langmuir isotherm showing backward rate effects of hydroxyl-ion activity $\left(\mathrm{a}_{\mathrm{OH}^{-}}\right)$for calcite and aragonite single crystals.

Reaction 45 was probably the most important because $\mathrm{Ca}^{2+}$ is the most common cation on calcite and aragonite surfaces in aqueous solutions (Foxall and others, 1979); reactions 46 and 47 probably occurred to a lesser extent. Two Langmuir isotherms are required to describe the backward rate effects of $\mathrm{HCO}_{3}^{-}$; the first describes the backward rate for $\mathrm{HCO}_{3}^{-}$in the activity range 0 to 0.1 , and the second, at activities greater than 0.1 (fig. 5). The isotherms were independent of $\mathrm{P}_{\mathrm{CO}_{2}}$ as shown by the data given in tables 4 and 5 for aragonite and calcite, respectively. The rate constants are presented in table 3.

\section{Backward reactions in $\mathrm{CaCl}_{2}$ solutions}

The decrease in forward rate caused by the presence of $\mathrm{Ca}^{2+}$ in the bulk solution may have resulted from the following two reactions:

$$
\mathrm{HCO}_{3(s)}^{-}+\mathrm{Ca}^{2+}(a d s) \rightarrow \mathrm{CaCO}_{3}+\mathrm{H}_{(s)}^{+}
$$

and

$$
\mathrm{CO}_{3(s)}^{2-}+\mathrm{Ca}^{2+}{ }_{(a d s)} \rightarrow \mathrm{CaCO}_{3} .
$$

Both of these reactions probably occurred simultaneously; however, it is reasonable to expect that under differing conditions of surface $\mathrm{pH}$ (that is, surface $\mathrm{P}_{\mathrm{CO}_{2}}$ ), one reaction may have been significantly more important than the other. At high and intermediate activities of $\mathrm{H}^{+}$in the stability fields of $\mathrm{H}_{2} \mathrm{CO}_{3}{ }^{*}$ and $\mathrm{HCO}_{3}^{-}(s)$ it is reasonable to assume that $\mathrm{HCO}_{3}^{-}{ }_{(s)}^{-}$is significantly higher than $\mathrm{CO}_{3(s)}^{2-}$ and that the reaction represented by equation 48 dominates the backward rate contribution due 
Table 5. Observed (Obs.) and calculated (Calc.) -log rates of dissolution of aragonite as a function of $\mathrm{pH}$ and $\mathrm{CO}_{2}$ partial pressure

[Unit of rate is $\mathrm{mmol} \cdot \mathrm{cm}^{-2} \cdot \mathrm{sec}^{-1}: \mathrm{pH}$ was adjusted by addition of $\mathrm{HCl}, \mathrm{KOH}$, or $\mathrm{KHCO}_{3}$. Omega value of the solutions was near zero]

\begin{tabular}{|c|c|c|c|c|c|c|c|c|c|c|c|c|c|c|c|c|c|}
\hline Run & Sample & $\mathrm{pH}$ & $\mathrm{P}_{\mathrm{CO}_{2}}$ & $\begin{array}{l}\text { Obs. } \\
\text {-log } \\
\text { rate }\end{array}$ & $\begin{array}{l}\text { Calc. } \\
\text {-log } \\
\text { rate }\end{array}$ & Run & Sample & $\mathrm{pH}$ & ${ }^{\mathrm{P}_{\mathrm{CO}}}$ & $\begin{array}{l}\text { Obs. } \\
\text {-log } \\
\text { rate }\end{array}$ & $\begin{array}{l}\text { Calc. } \\
\text {-log } \\
\text { rate }\end{array}$ & Run & Sample & $\mathrm{pH}$ & ${ }^{P_{C O}}$ & $\begin{array}{l}\text { Obs. } \\
\text {-log } \\
\text { rate }\end{array}$ & $\begin{array}{l}\text { Calc. } \\
\text {-log } \\
\text { rate }\end{array}$ \\
\hline $\begin{array}{r}3 \\
265 \\
9 \\
6 \\
8\end{array}$ & $\begin{array}{l}O-2 \\
A-1 \\
M-1 \\
M-2 \\
N-1\end{array}$ & $\begin{array}{l}2.00 \\
2.00 \\
2.23 \\
2.50 \\
2.77\end{array}$ & $\begin{array}{l}0.0000 \\
0.0000 \\
0.0000 \\
0.0000 \\
0.0000\end{array}$ & $\begin{array}{l}4.17 \\
4.18 \\
4.35 \\
4.62 \\
4.88\end{array}$ & $\begin{array}{l}4.06 \\
4.05 \\
4.29 \\
4.56 \\
4.82\end{array}$ & $\begin{array}{l}111 \\
126 \\
115 \\
130 \\
129\end{array}$ & $\begin{array}{l}A-3 \\
A-1 \\
A-2 \\
A-3 \\
A-1\end{array}$ & $\begin{array}{l}4.16 \\
4.40 \\
4.60 \\
4.72 \\
4.75\end{array}$ & $\begin{array}{l}0.2843 \\
0.2848 \\
0.2843 \\
0.2860 \\
0.2860\end{array}$ & $\begin{array}{l}5.85 \\
5.95 \\
5.94 \\
6.02 \\
6.02\end{array}$ & $\begin{array}{l}5.85 \\
5.94 \\
6.00 \\
6.02 \\
6.03\end{array}$ & $\begin{array}{l}53 \\
59 \\
81 \\
48 \\
58\end{array}$ & $\begin{array}{l}S-1 \\
M-2 \\
0-2 \\
N-1 \\
B-1\end{array}$ & $\begin{array}{r}4.24 \\
4.25 \\
4.25 \\
.4 .50 \\
4.75\end{array}$ & $\begin{array}{l}0.9588 \\
0.9572 \\
0.9625 \\
0.9585 \\
0.9572\end{array}$ & $\begin{array}{l}5.62 \\
5.62 \\
5.61 \\
5.63 \\
5.71\end{array}$ & $\begin{array}{l}5.63 \\
5.63 \\
5.63 \\
5.68 \\
5.72\end{array}$ \\
\hline $\begin{array}{r}7 \\
16 \\
2 \\
13 \\
12\end{array}$ & $\begin{array}{l}B-1 \\
0-1 \\
S-1 \\
N-1 \\
M-1\end{array}$ & $\begin{array}{l}3.75 \\
3.80 \\
4.00 \\
4.25 \\
4.50\end{array}$ & $\begin{array}{l}0.0000 \\
0.0000 \\
0.0000 \\
0.0000 \\
0.0000\end{array}$ & $\begin{array}{l}5.78 \\
5.75 \\
5.91 \\
6.13 \\
6.14\end{array}$ & $\begin{array}{l}5.72 \\
5.77 \\
5.92 \\
6.08 \\
6.21\end{array}$ & $\begin{array}{l}127 \\
114 \\
132 \\
119 \\
128\end{array}$ & $\begin{array}{l}A-3 \\
N-1 \\
N-1 \\
S-1 \\
A-2\end{array}$ & $\begin{array}{l}6.00 \\
6.03 \\
6.14 \\
6.26 \\
6.26\end{array}$ & $\begin{array}{l}0.2848 \\
0.2843 \\
0.2860 \\
0.2848 \\
0.2848\end{array}$ & $\begin{array}{l}6.24 \\
6.30 \\
6.28 \\
6.29 \\
6.27\end{array}$ & $\begin{array}{l}6.22 \\
6.23 \\
6.25 \\
6.28 \\
6.28\end{array}$ & $\begin{array}{l}75 \\
68 \\
57 \\
67 \\
82\end{array}$ & $\begin{array}{l}M-2 \\
A-2 \\
A-2 \\
A-1 \\
O-1\end{array}$ & $\begin{array}{l}5.26 \\
5.31 \\
5.50 \\
5.51 \\
5.53\end{array}$ & $\begin{array}{l}0.9585 \\
0.9592 \\
0.9572 \\
0.9592 \\
0.9625\end{array}$ & $\begin{array}{l}5.79 \\
5.85 \\
5.90 \\
5.88 \\
5.83\end{array}$ & $\begin{array}{l}5.80 \\
5.81 \\
5.85 \\
5.85 \\
5.86\end{array}$ \\
\hline $\begin{array}{l}25 \\
10 \\
34 \\
35 \\
37\end{array}$ & $\begin{array}{l}S-1 \\
S-1 \\
N-1 \\
S-1 \\
N-1\end{array}$ & $\begin{array}{l}7.00 \\
7.03 \\
7.50 \\
7.50 \\
8.00\end{array}$ & $\begin{array}{l}0.0000 \\
0.0000 \\
0.0000 \\
0.0000 \\
0.0000\end{array}$ & $\begin{array}{l}6.45 \\
6.44 \\
6.44 \\
6.43 \\
6.46\end{array}$ & $\begin{array}{l}6.46 \\
6.46 \\
6.46 \\
6.46 \\
6.46\end{array}$ & $\begin{array}{r}102 \\
94 \\
104 \\
100 \\
96\end{array}$ & $\begin{array}{l}B-1 \\
A-2 \\
A-1 \\
S-1 \\
M-2\end{array}$ & $\begin{array}{l}4.24 \\
4.53 \\
4.60 \\
4.81 \\
5.04\end{array}$ & $\begin{array}{l}0.4600 \\
0.4791 \\
0.4765 \\
0.4791 \\
0.4799\end{array}$ & $\begin{array}{l}5.78 \\
5.86 \\
5.80 \\
5.98 \\
5.91\end{array}$ & $\begin{array}{l}5.80 \\
5.87 \\
5.88 \\
5.92 \\
5.95\end{array}$ & $\begin{array}{l}65 \\
51 \\
80 \\
60 \\
56\end{array}$ & $\begin{array}{l}M-1 \\
S-2 \\
N-1 \\
A-1 \\
A-1\end{array}$ & $\begin{array}{l}6.25 \\
6.30 \\
6.35 \\
6.51 \\
6.74\end{array}$ & $\begin{array}{l}0.9592 \\
0.9587 \\
0.9625 \\
0.9593 \\
0.9572\end{array}$ & $\begin{array}{l}5.97 \\
6.02 \\
6.02 \\
6.04 \\
6.16\end{array}$ & $\begin{array}{l}6.05 \\
6.06 \\
6.07 \\
6.10 \\
6.13\end{array}$ \\
\hline $\begin{array}{r}32 \\
33 \\
21 \\
22 \\
444\end{array}$ & $\begin{array}{l}B-1 \\
M-2 \\
0-1 \\
M-2 \\
M-1\end{array}$ & $\begin{array}{l}8.52 \\
8.52 \\
9.00 \\
9.00 \\
9.40\end{array}$ & $\begin{array}{l}0.0000 \\
0.0000 \\
0.0000 \\
0.0000 \\
0.0000\end{array}$ & $\begin{array}{l}6.49 \\
6.43 \\
6.44 \\
6.47 \\
6.49\end{array}$ & $\begin{array}{l}6.46 \\
6.46 \\
6.46 \\
6.46 \\
6.46\end{array}$ & $\begin{array}{r}106 \\
98 \\
109 \\
101 \\
108\end{array}$ & $\begin{array}{l}A-2 \\
A-3 \\
M-1 \\
O-1 \\
N-1\end{array}$ & $\begin{array}{l}5.24 \\
5.53 \\
5.54 \\
5.76 \\
5.82\end{array}$ & $\begin{array}{l}0.4765 \\
0.4607 \\
0.4574 \\
0.4791 \\
0.4574\end{array}$ & $\begin{array}{l}6.03 \\
6.11 \\
6.14 \\
6.07 \\
6.12\end{array}$ & $\begin{array}{l}5.98 \\
6.03 \\
6.04 \\
6.07 \\
6.09\end{array}$ & $\begin{array}{l}61 \\
72 \\
79 \\
78 \\
77\end{array}$ & $\begin{array}{l}A-2 \\
S-2 \\
M-2 \\
M-1 \\
A-2\end{array}$ & $\begin{array}{l}6.74 \\
6.88 \\
6.99 \\
7.07 \\
7.20\end{array}$ & $\begin{array}{l}0.9593 \\
0.9585 \\
0.9625 \\
0.9625 \\
0.9625\end{array}$ & $\begin{array}{l}6.09 \\
6.24 \\
6.26 \\
6.22 \\
6.37\end{array}$ & $\begin{array}{l}6.13 \\
6.23 \\
6.30 \\
6.37 \\
6.47\end{array}$ \\
\hline $\begin{array}{l}453 \\
447 \\
450 \\
446 \\
454\end{array}$ & $\begin{array}{l}M-2 \\
M-1 \\
M-2 \\
M-2 \\
A-2\end{array}$ & $\begin{array}{r}9.58 \\
9.59 \\
9.79 \\
10.04 \\
10.20\end{array}$ & $\begin{array}{l}0.0000 \\
0.0000 \\
0.0000 \\
0.0000 \\
0.0000\end{array}$ & $\begin{array}{l}6.50 \\
6.49 \\
6.50 \\
6.59 \\
6.65\end{array}$ & $\begin{array}{l}6.46 \\
6.46 \\
6.46 \\
6.46 \\
6.46\end{array}$ & $\begin{array}{r}99 \\
107 \\
95 \\
105 \\
91\end{array}$ & $\begin{array}{l}N-1 \\
A-3 \\
S-2 \\
M-2 \\
M-1\end{array}$ & $\begin{array}{l}6.00 \\
6.27 \\
6.50 \\
6.50 \\
2.25\end{array}$ & $\begin{array}{l}0.4607 \\
0.4765 \\
0.4799 \\
0.4765 \\
0.9600\end{array}$ & $\begin{array}{l}6.13 \\
6.13 \\
6.17 \\
6.16 \\
4.35\end{array}$ & $\begin{array}{l}6.14 \\
6.20 \\
6.26 \\
6.26 \\
4.30\end{array}$ & $\begin{array}{l}76 \\
87 \\
89\end{array}$ & $\begin{array}{l}A-1 \\
A-3 \\
A-1\end{array}$ & $\begin{array}{l}7.26 \\
7.62 \\
7.81\end{array}$ & $\begin{array}{l}0.9625 \\
0.9600 \\
0.9600\end{array}$ & $\begin{array}{l}6.48 \\
6.63 \\
7.02\end{array}$ & $\begin{array}{l}6.52 \\
6.85 \\
7.06\end{array}$ \\
\hline $\begin{array}{l}445 \\
124 \\
118 \\
122 \\
133\end{array}$ & $\begin{array}{l}A-2 \\
B-1 \\
S-2 \\
N-1 \\
A-2\end{array}$ & $\begin{array}{r}10.84 \\
3.24 \\
3.75 \\
3.75 \\
4.07\end{array}$ & $\begin{array}{l}0.0000 \\
0.2848 \\
0.2848 \\
0.2848 \\
0.2860\end{array}$ & $\begin{array}{l}6.80 \\
5.23 \\
5.55 \\
5.63 \\
5.81\end{array}$ & $\begin{array}{l}6.48 \\
5.24 \\
5.63 \\
5.63 \\
5.81\end{array}$ & $\begin{array}{l}46 \\
47 \\
85 \\
45 \\
52\end{array}$ & $\begin{array}{l}B-1 \\
M-2 \\
S-2 \\
M-1 \\
0-1\end{array}$ & $\begin{array}{l}3.50 \\
3.68 \\
3.75 \\
3.92 \\
3.93\end{array}$ & $\begin{array}{l}0.9585 \\
0.9585 \\
0.9609 \\
0.9585 \\
0.9588\end{array}$ & $\begin{array}{l}5.28 \\
5.42 \\
5.40 \\
5.48 \\
5.47\end{array}$ & $\begin{array}{l}5.34 \\
5.43 \\
5.47 \\
5.54 \\
5.54\end{array}$ & & & & & & \\
\hline
\end{tabular}

to $\mathrm{Ca}_{(a d s)}^{2+}$. Similar reasoning can be used to define the region of low activity of $\mathrm{H}^{+}$in the stability field of $\mathrm{CO}_{3}^{2-}$ as the region where reaction 49 predominates. Our data are insufficient to evaluate the surface $\mathrm{CO}_{2}$ partial pressure and to calculate the exact $\mathrm{HCO}_{3(s)}^{-}$to $\mathrm{CO}_{3(s)}^{2-}$ ratio. All results for calcite and aragonite are presented in table 7 .

Figure 6 shows the effect of bulk solution $\mathrm{pH}$ on the backward reaction between $\mathrm{Ca}^{2+}$ and calcite under nitrogen atmosphere. As the bulk solution $\mathrm{pH}$ increased from 4 to 9, the surface $\mathrm{P}_{\mathrm{CO}_{2}}$ likely decreased and $\mathrm{CO}_{3(s)}^{2-}$ became came increasingly more important in the surface speciation. The changes in backward rate shown on figure 5 reflect these changes in surface speciation of calcite. The experimental data and the calculated effects of $\mathrm{Ca}^{2+}$ (dashed lines, fig. 6) are in good agreement. The solid.line represents the forward rate in the absence of backward reactions as given by equation 38 and the constants of table 3. Similar results were obtained for aragonite, and the constants of equation 41 describing the $\mathrm{Ca}^{2+}$ effect for both calcite and aragonite are given in table 3.

\section{Backward reactions in $\mathrm{KHCO}_{3}-\mathrm{KOH}$ solutions}

The stability field of $\mathrm{CO}_{3}^{2-}$ ion begins at $\mathrm{pH}$ of 10.3 and is beyond the $\mathrm{pH}$ range of most natural environments. 


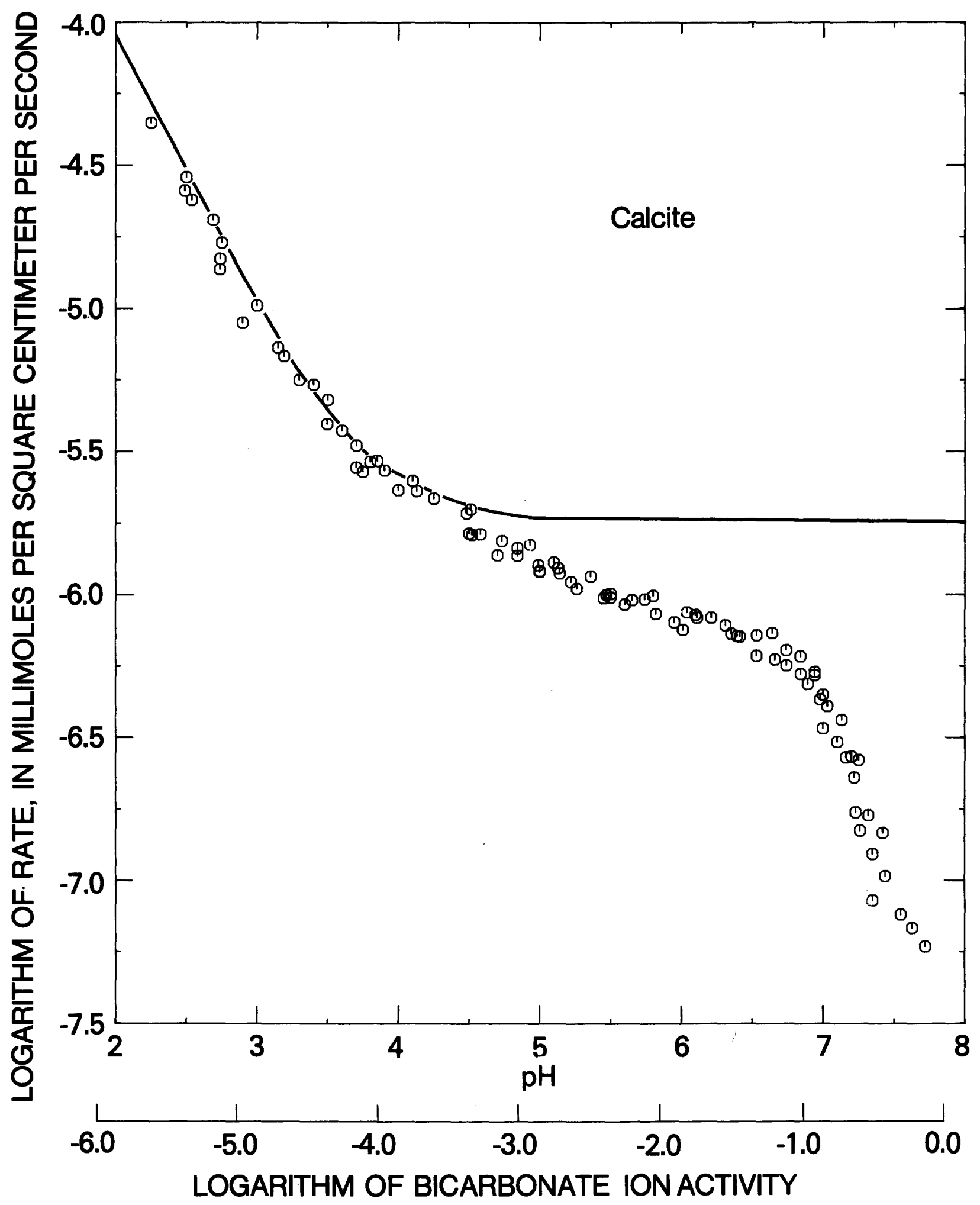

Figure 4. Dissolution rates of calcite single crystals in absence (solid line) and presence of different bicarbonate ion activities $\left(\mathrm{a}_{\mathrm{HCO}_{3}}{ }^{-}\right)$and 0.96 atmosphere $\mathrm{CO}_{2}$ partial pressure far from equilibrium. For experimental conditions, $\mathrm{pH} .=7.84+$ $\log \mathrm{a}_{\mathrm{HCO}_{3}}{ }^{-}$ 
Table 6. Observed (Obs.) and calculated (Calc.) - log rates of dissolution of calcite as a function of $\mathrm{pH}$ and $\mathrm{CO}_{2}$ partial pressure [Unit of rate is $\mathrm{mmol} \cdot \mathrm{cm}^{-2} \cdot \mathrm{sec}^{-1}$; $\mathrm{pH}$ was adjusted by addition of $\mathrm{HCl}, \mathrm{KOH}$, or $\mathrm{KHCO}_{3}$. Omega value of the solutions was about zero]

\begin{tabular}{|c|c|c|c|c|c|c|c|c|c|c|c|c|c|c|c|c|c|}
\hline Run & Sample & $\mathrm{pH}$ & ${ }^{\mathrm{P}} \mathrm{CO}_{2}$ & $\begin{array}{l}\text { Ous. } \\
\text {-log } \\
\text { rate }\end{array}$ & $\begin{array}{l}\text { Calc. } \\
\text {-log } \\
\text { rate }\end{array}$ & Run & Sample & $\mathrm{pH}$ & $\mathrm{P}_{\mathrm{CO}_{2}}$ & $\begin{array}{l}\text { Obs. } \\
\text {-log } \\
\text { rate }\end{array}$ & $\begin{array}{l}\text { Calc. } \\
\text {-log } \\
\text { rate }\end{array}$ & Run & Sample & $\mathrm{pH}$ & $\mathrm{P}^{\mathrm{P}} \mathrm{O}_{2}$ & $\begin{array}{l}\text { Obs. } \\
\text {-log } \\
\text { rate }\end{array}$ & $\begin{array}{l}\text { Calc. } \\
\text {-log } \\
\text { rate }\end{array}$ \\
\hline $\begin{array}{r}369 \\
3 \\
25 \\
30 \\
368\end{array}$ & $\begin{array}{r}16 \\
1 \\
2 \\
2 \\
17\end{array}$ & $\begin{array}{l}2.33 \\
2.45 \\
2.50 \\
2.59 \\
2.65\end{array}$ & $\begin{array}{l}0.0000 \\
0.0000 \\
0.0000 \\
0.0000 \\
0.0000\end{array}$ & $\begin{array}{l}4.44 \\
4.50 \\
4.54 \\
4.59 \\
4.77\end{array}$ & $\begin{array}{l}4.39 \\
4.51 \\
4.56 \\
4.65 \\
4.71\end{array}$ & $\begin{array}{l}236 \\
286 \\
275 \\
287 \\
308\end{array}$ & $\begin{array}{l}10 \\
13 \\
11 \\
14 \\
19\end{array}$ & $\begin{array}{l}5.00 \\
5.10 \\
5.20 \\
5.30 \\
5.35\end{array}$ & $\begin{array}{l}0.0000 \\
0.0000 \\
0.0000 \\
0.0000 \\
0.0000\end{array}$ & $\begin{array}{l}6.60 \\
6.61 \\
6.68 \\
6.70 \\
6.67\end{array}$ & $\begin{array}{l}6.49 \\
6.52 \\
6.54 \\
6.56 \\
6.56\end{array}$ & $\begin{array}{l}474 \\
488 \\
473 \\
489 \\
472\end{array}$ & $\begin{array}{l}15 \\
13 \\
14 \\
14 \\
13\end{array}$ & $\begin{array}{l}4.53 \\
4.72 \\
4.78 \\
4.87 \\
4.98\end{array}$ & $\begin{array}{l}0.0991 \\
0.0979 \\
0.0991 \\
0.0979 \\
0.0991\end{array}$ & $\begin{array}{l}6.15 \\
6.28 \\
6.27 \\
6.33 \\
6.37\end{array}$ & $\begin{array}{l}6.21 \\
6.28 \\
6.30 \\
6.34 \\
6.37\end{array}$ \\
\hline $\begin{array}{r}4 \\
26 \\
1 \\
31 \\
32\end{array}$ & $\begin{array}{l}2 \\
1 \\
1 \\
1 \\
2\end{array}$ & $\begin{array}{l}2.65 \\
2.70 \\
2.80 \\
2.84 \\
2.84\end{array}$ & $\begin{array}{l}0.0000 \\
0.0000 \\
0.0000 \\
0.0000 \\
0.0000\end{array}$ & $\begin{array}{l}4.61 \\
4.82 \\
4.85 \\
5.00 \\
4.98\end{array}$ & $\begin{array}{l}4.71 \\
4.76 \\
4.86 \\
4.89 \\
4.89\end{array}$ & $\begin{array}{r}293 \\
290 \\
28 \\
288 \\
302\end{array}$ & $\begin{array}{r}9 \\
22 \\
2 \\
15 \\
13\end{array}$ & $\begin{array}{l}5.40 \\
5.50 \\
5.50 \\
5.55 \\
5.60\end{array}$ & $\begin{array}{l}0.0000 \\
0.0000 \\
0.0000 \\
0.0000 \\
0.0000\end{array}$ & $\begin{array}{l}6.68 \\
6.73 \\
6.60 \\
6.50 \\
6.62\end{array}$ & $\begin{array}{l}6.57 \\
6.58 \\
6.58 \\
6.59 \\
6.59\end{array}$ & $\begin{array}{l}490 \\
215 \\
216 \\
217 \\
218\end{array}$ & $\begin{array}{r}15 \\
9 \\
10 \\
11 \\
12\end{array}$ & $\begin{array}{l}4.99 \\
5.00 \\
5.00 \\
5.00 \\
5.00\end{array}$ & $\begin{array}{l}0.0979 \\
0.0989 \\
0.0989 \\
0.0989 \\
0.0989\end{array}$ & $\begin{array}{l}6.35 \\
6.46 \\
6.48 \\
6.41 \\
6.38\end{array}$ & $\begin{array}{l}6.37 \\
6.37 \\
6.37 \\
6.37 \\
6.37\end{array}$ \\
\hline $\begin{array}{r}363 \\
24 \\
2 \\
358 \\
367\end{array}$ & $\begin{array}{r}11 \\
1 \\
2 \\
22 \\
15\end{array}$ & $\begin{array}{l}2.90 \\
3.00 \\
3.08 \\
3.10 \\
3.15\end{array}$ & $\begin{array}{l}0.0000 \\
0.0000 \\
0.0000 \\
0.0000 \\
0.0000\end{array}$ & $\begin{array}{l}4.92 \\
5.05 \\
5.08 \\
5.18 \\
5.25\end{array}$ & $\begin{array}{l}4.95 \\
5.05 \\
5.13 \\
5.15 \\
5.20\end{array}$ & $\begin{array}{l}289 \\
303 \\
291 \\
301 \\
277\end{array}$ & $\begin{array}{l}16 \\
14 \\
23 \\
12 \\
15\end{array}$ & $\begin{array}{l}5.75 \\
6.00 \\
6.20 \\
6.40 \\
6.70\end{array}$ & $\begin{array}{l}0.0000 \\
0.0000 \\
0.0000 \\
0.0000 \\
0.0000\end{array}$ & $\begin{array}{l}6.68 \\
6.57 \\
6.75 \\
6.63 \\
6.58\end{array}$ & $\begin{array}{l}6.60 \\
6.61 \\
6.62 \\
6.62 \\
6.63\end{array}$ & $\begin{array}{l}491 \\
471 \\
492 \\
493 \\
470\end{array}$ & $\begin{array}{l}16 \\
12 \\
17 \\
18 \\
11\end{array}$ & $\begin{array}{l}5.20 \\
5.28 \\
5.35 \\
5.51 \\
5.57\end{array}$ & $\begin{array}{l}0.0979 \\
0.0991 \\
0.0979 \\
0.0979 \\
0.0991\end{array}$ & $\begin{array}{l}6.37 \\
6.33 \\
6.50 \\
6.55 \\
6.47\end{array}$ & $\begin{array}{l}6.43 \\
6.45 \\
6.47 \\
6.51 \\
6.53\end{array}$ \\
\hline $\begin{array}{r}362 \\
11 \\
357 \\
14 \\
15\end{array}$ & $\begin{array}{r}10 \\
1 \\
21 \\
2 \\
1\end{array}$ & $\begin{array}{l}3.25 \\
3.25 \\
3.30 \\
3.40 \\
3.40\end{array}$ & $\begin{array}{l}0.0000 \\
0.0000 \\
0.0000 \\
0.0000 \\
0.0000\end{array}$ & $\begin{array}{l}5.25 \\
5.24 \\
5.39 \\
5.47 \\
5.43\end{array}$ & $\begin{array}{l}5.29 \\
5.29 \\
5.34 \\
5.43 \\
5.43\end{array}$ & $\begin{array}{l}304 \\
292 \\
280 \\
305 \\
628\end{array}$ & $\begin{array}{r}15 \\
24 \\
9 \\
16 \\
13\end{array}$ & $\begin{array}{l}7.00 \\
7.20 \\
7.50 \\
7.75 \\
7.87\end{array}$ & $\begin{array}{l}0.0000 \\
0.0000 \\
0.0000 \\
0.0000 \\
0.0000\end{array}$ & $\begin{array}{l}6.62 \\
6.66 \\
6.68 \\
6.56 \\
6.65\end{array}$ & $\begin{array}{l}6.63 \\
6.63 \\
6.63 \\
6.63 \\
6.63\end{array}$ & $\begin{array}{l}494 \\
469 \\
495 \\
231 \\
232\end{array}$ & $\begin{array}{r}19 \\
10 \\
20 \\
9 \\
10\end{array}$ & $\begin{array}{l}5.62 \\
5.78 \\
5.78 \\
6.00 \\
6.00\end{array}$ & $\begin{array}{l}0.0979 \\
0.0991 \\
0.0979 \\
0.0985 \\
0.0985\end{array}$ & $\begin{array}{l}6.50 \\
6.52 \\
6.57 \\
6.60 \\
6.61\end{array}$ & $\begin{array}{l}6.54 \\
6.58 \\
6.58 \\
6.64 \\
6.64\end{array}$ \\
\hline $\begin{array}{r}89 \\
90 \\
95 \\
111 \\
112\end{array}$ & $\begin{array}{l}1 \\
2 \\
7 \\
7 \\
8\end{array}$ & $\begin{array}{l}3.50 \\
3.50 \\
3.50 \\
3.50 \\
3.50\end{array}$ & $\begin{array}{l}0.0000 \\
0.0000 \\
0.0000 \\
0.0000 \\
0.0000\end{array}$ & $\begin{array}{l}5.55 \\
5.53 \\
5.57 \\
5.52 \\
5.50\end{array}$ & $\begin{array}{l}5.53 \\
5.53 \\
5.53 \\
5.53 \\
5.53\end{array}$ & $\begin{array}{r}629 \\
19 \\
276 \\
306 \\
630\end{array}$ & $\begin{array}{r}14 \\
2 \\
12 \\
17 \\
15\end{array}$ & $\begin{array}{l}7.96 \\
8.00 \\
8.20 \\
8.40 \\
8.59\end{array}$ & $\begin{array}{l}0.0000 \\
0.0000 \\
0.0000 \\
0.0000 \\
0.0000\end{array}$ & $\begin{array}{l}6.60 \\
6.60 \\
6.57 \\
6.66 \\
6.67\end{array}$ & $\begin{array}{l}6.63 \\
6.63 \\
6.63 \\
6.64 \\
6.64\end{array}$ & $\begin{array}{l}233 \\
234 \\
431 \\
266 \\
468\end{array}$ & $\begin{array}{r}11 \\
12 \\
11 \\
10 \\
9\end{array}$ & $\begin{array}{l}6.00 \\
6.00 \\
6.02 \\
6.07 \\
6.27\end{array}$ & $\begin{array}{l}0.0985 \\
0.0985 \\
0.0983 \\
0.0988 \\
0.0991\end{array}$ & $\begin{array}{l}6.57 \\
6.56 \\
6.61 \\
6.61 \\
6.59\end{array}$ & $\begin{array}{l}6.64 \\
6.64 \\
6.64 \\
6.66 \\
6.70\end{array}$ \\
\hline $\begin{array}{r}114 \\
119 \\
120 \\
5 \\
366\end{array}$ & $\begin{array}{r}2 \\
7 \\
8 \\
1 \\
14\end{array}$ & $\begin{array}{l}3.50 \\
3.50 \\
3.50 \\
3.51 \\
3.60\end{array}$ & $\begin{array}{l}0.0000 \\
0.0000 \\
0.0000 \\
0.0000 \\
0.0000\end{array}$ & $\begin{array}{l}5.54 \\
5.51 \\
5.50 \\
5.59 \\
5.58\end{array}$ & $\begin{array}{l}5.53 \\
5.53 \\
5.53 \\
5.54 \\
5.62\end{array}$ & $\begin{array}{l}307 \\
294 \\
631 \\
274 \\
624\end{array}$ & $\begin{array}{r}18 \\
17 \\
16 \\
10 \\
9\end{array}$ & $\begin{array}{l}8.60 \\
9.00 \\
9.00 \\
9.38 \\
9.41\end{array}$ & $\begin{array}{l}0.0000 \\
0.0000 \\
0.0000 \\
0.0000 \\
0.0000\end{array}$ & $\begin{array}{l}6.73 \\
6.69 \\
6.64 \\
6.63 \\
6.68\end{array}$ & $\begin{array}{l}6.64 \\
6.66 \\
6.66 \\
6.69 \\
6.69\end{array}$ & $\begin{array}{l}432 \\
187 \\
188 \\
189 \\
190\end{array}$ & $\begin{array}{r}12 \\
9 \\
10 \\
11 \\
12\end{array}$ & $\begin{array}{l}6.54 \\
6.66 \\
6.66 \\
6.66 \\
6.66\end{array}$ & $\begin{array}{l}0.0983 \\
0.0989 \\
0.0989 \\
0.0989 \\
0.0989\end{array}$ & $\begin{array}{l}6.53 \\
6.65 \\
6.66 \\
6.64 \\
6.62\end{array}$ & $\begin{array}{l}6.74 \\
6.75 \\
6.75 \\
6.75 \\
6.75\end{array}$ \\
\hline $\begin{array}{r}361 \\
22 \\
83 \\
356 \\
365\end{array}$ & $\begin{array}{r}9 \\
1 \\
2 \\
20 \\
13\end{array}$ & $\begin{array}{l}3.75 \\
3.80 \\
3.83 \\
3.85 \\
3.97\end{array}$ & $\begin{array}{l}0.0000 \\
0.0000 \\
0.0000 \\
0.0000 \\
0.0000\end{array}$ & $\begin{array}{l}5.64 \\
5.75 \\
5.80 \\
5.72 \\
5.80\end{array}$ & $\begin{array}{l}5.75 \\
5.79 \\
5.82 \\
5.84 \\
5.94\end{array}$ & $\begin{array}{l}295 \\
625 \\
627 \\
626 \\
278\end{array}$ & $\begin{array}{l}18 \\
10 \\
12 \\
11 \\
13\end{array}$ & $\begin{array}{l}9.45 \\
9.60 \\
9.61 \\
9.67 \\
9.85\end{array}$ & $\begin{array}{l}0.0000 \\
0.0000 \\
0.0000 \\
0.0000 \\
0.0000\end{array}$ & $\begin{array}{l}6.78 \\
6.69 \\
6.69 \\
6.67 \\
6.75\end{array}$ & $\begin{array}{l}6.70 \\
6.72 \\
6.72 \\
6.73 \\
6.76\end{array}$ & $\begin{array}{l}191 \\
192 \\
193 \\
194 \\
438\end{array}$ & $\begin{array}{r}9 \\
10 \\
11 \\
12 \\
18\end{array}$ & $\begin{array}{l}6.66 \\
6.66 \\
6.66 \\
6.66 \\
6.84\end{array}$ & $\begin{array}{l}0.0987 \\
0.0987 \\
0.0987 \\
0.0987 \\
0.0983\end{array}$ & $\begin{array}{l}6.60 \\
6.61 \\
6.61 \\
6.53 \\
6.64\end{array}$ & $\begin{array}{l}6.75 \\
6.75 \\
6.75 \\
6.75 \\
6.77\end{array}$ \\
\hline $\begin{array}{r}12 \\
360 \\
355 \\
21 \\
364\end{array}$ & $\begin{array}{r}2 \\
24 \\
19 \\
2 \\
12\end{array}$ & $\begin{array}{l}4.00 \\
4.05 \\
4.15 \\
4.19 \\
4.27\end{array}$ & $\begin{array}{l}0.0000 \\
0.0000 \\
0.0000 \\
0.0000 \\
0.0000\end{array}$ & $\begin{array}{l}5.91 \\
5.84 \\
6.13 \\
6.18 \\
6.09\end{array}$ & $\begin{array}{l}5.96 \\
6.00 \\
6.07 \\
6.10 \\
6.16\end{array}$ & $\begin{array}{l}296 \\
279 \\
297 \\
298 \\
281\end{array}$ & $\begin{array}{l}19 \\
14 \\
20 \\
21 \\
16\end{array}$ & $\begin{array}{l}10.01 \\
10.33 \\
10.55 \\
10.80 \\
11.03\end{array}$ & $\begin{array}{l}0.0000 \\
0.0000 \\
0.0000 \\
0.0000 \\
0.0000\end{array}$ & $\begin{array}{l}6.83 \\
6.81 \\
6.79 \\
6.97 \\
6.88\end{array}$ & $\begin{array}{l}6.78 \\
6.84 \\
6.86 \\
6.89 \\
6.91\end{array}$ & $\begin{array}{l}433 \\
268 \\
439 \\
440 \\
455\end{array}$ & $\begin{array}{l}13 \\
12 \\
19 \\
20 \\
19\end{array}$ & $\begin{array}{l}7.05 \\
7.21 \\
7.22 \\
7.50 \\
7.68\end{array}$ & $\begin{array}{l}0.0983 \\
0.0988 \\
0.0983 \\
0.0983 \\
0.0985\end{array}$ & $\begin{array}{l}6.56 \\
6.60 \\
6.64 \\
6.66 \\
6.91\end{array}$ & $\begin{array}{l}6.79 \\
6.79 \\
6.79 \\
6.80 \\
6.81\end{array}$ \\
\hline $\begin{array}{r}283 \\
18 \\
359 \\
354 \\
273\end{array}$ & $\begin{array}{r}10 \\
2 \\
23 \\
18 \\
9\end{array}$ & $\begin{array}{l}4.30 \\
4.30 \\
4.40 \\
4.50 \\
4.50\end{array}$ & $\begin{array}{l}0.0000 \\
0.0000 \\
0.0000 \\
0.0000 \\
0.0000\end{array}$ & $\begin{array}{l}6.16 \\
6.15 \\
6.17 \\
6.22 \\
6.34\end{array}$ & $\begin{array}{l}6.18 \\
6.18 \\
6.24 \\
6.29 \\
6.29\end{array}$ & $\begin{array}{l}300 \\
299 \\
487 \\
479 \\
486\end{array}$ & $\begin{array}{l}11 \\
10 \\
12 \\
20 \\
11\end{array}$ & $\begin{array}{r}11.04 \\
11.18 \\
3.16 \\
3.27 \\
3.33\end{array}$ & $\begin{array}{l}0.0000 \\
0.0000 \\
0.0981 \\
0.0990 \\
0.0981\end{array}$ & $\begin{array}{l}6.94 \\
6.85 \\
5.04 \\
5.10 \\
5.27\end{array}$ & $\begin{array}{l}6.91 \\
6.91 \\
5.20 \\
5.30 \\
5.35\end{array}$ & $\begin{array}{l}270 \\
448 \\
456 \\
449 \\
272\end{array}$ & $\begin{array}{l}10 \\
12 \\
20 \\
13 \\
12\end{array}$ & $\begin{array}{l}7.80 \\
7.81 \\
7.92 \\
8.04 \\
8.12\end{array}$ & $\begin{array}{l}0.0986 \\
0.0985 \\
0.0985 \\
0.0985 \\
0.0986\end{array}$ & $\begin{array}{l}7.15 \\
6.93 \\
7.14 \\
7.25 \\
7.48\end{array}$ & $\begin{array}{l}6.81 \\
6.81 \\
7.01 \\
7.14 \\
7.22\end{array}$ \\
\hline $\begin{array}{r}17 \\
282 \\
23 \\
284 \\
36\end{array}$ & $\begin{array}{r}1 \\
9 \\
2 \\
11 \\
2\end{array}$ & $\begin{array}{l}4.50 \\
4.55 \\
4.65 \\
4.73 \\
4.75\end{array}$ & $\begin{array}{l}0.0000 \\
0.0000 \\
0.0000 \\
0.0000 \\
0.0000\end{array}$ & $\begin{array}{l}6.28 \\
6.42 \\
6.48 \\
6.54 \\
6.53\end{array}$ & $\begin{array}{l}6.29 \\
6.32 \\
6.37 \\
6.40 \\
6.41\end{array}$ & $\begin{array}{l}485 \\
478 \\
484 \\
477 \\
483\end{array}$ & $\begin{array}{r}10 \\
19 \\
9 \\
18 \\
24\end{array}$ & $\begin{array}{l}3.50 \\
3.52 \\
3.68 \\
3.77 \\
3.82\end{array}$ & $\begin{array}{l}0.0981 \\
0.0990 \\
0.0981 \\
0.0990 \\
0.0981\end{array}$ & $\begin{array}{l}5.46 \\
5.36 \\
5.65 \\
5.52 \\
5.60\end{array}$ & $\begin{array}{l}5.50 \\
5.52 \\
5.66 \\
5.73 \\
5.78\end{array}$ & $\begin{array}{l}457 \\
450 \\
265 \\
267 \\
269\end{array}$ & $\begin{array}{r}21 \\
14 \\
9 \\
11 \\
9\end{array}$ & $\begin{array}{l}8.16 \\
8.28 \\
5.60 \\
6.90 \\
7.30\end{array}$ & $\begin{array}{l}0.0985 \\
0.0985 \\
0.2964 \\
0.2962 \\
0.2959\end{array}$ & $\begin{array}{l}7.35 \\
7.60 \\
6.36 \\
6.42 \\
6.62\end{array}$ & $\begin{array}{l}7.26 \\
7.42 \\
6.39 \\
6.54 \\
6.55\end{array}$ \\
\hline $\begin{array}{l}285 \\
235 \\
236 \\
241 \\
235\end{array}$ & $\begin{array}{r}12 \\
9 \\
10 \\
10 \\
9\end{array}$ & $\begin{array}{l}4.95 \\
5.00 \\
5.00 \\
5.00 \\
5.00\end{array}$ & $\begin{array}{l}0.0000 \\
0.0000 \\
0.0000 \\
0.0000 \\
0.0000\end{array}$ & $\begin{array}{l}6.58 \\
6.64 \\
6.60 \\
6.62 \\
6.64\end{array}$ & $\begin{array}{l}6.48 \\
6.49 \\
6.49 \\
6.49 \\
6.49\end{array}$ & $\begin{array}{l}476 \\
482 \\
475 \\
481 \\
480\end{array}$ & $\begin{array}{l}17 \\
23 \\
16 \\
22 \\
21\end{array}$ & $\begin{array}{l}4.00 \\
4.13 \\
4.23 \\
4.37 \\
4.47\end{array}$ & $\begin{array}{l}0.0990 \\
0.0981 \\
0.0991 \\
0.0981 \\
0.0981\end{array}$ & $\begin{array}{l}5.81 \\
5.80 \\
5.96 \\
6.01 \\
6.13\end{array}$ & $\begin{array}{l}5.91 \\
5.99 \\
6.06 \\
6.13 \\
6.18\end{array}$ & $\begin{array}{l}271 \\
403 \\
405 \\
400 \\
374\end{array}$ & $\begin{array}{l}11 \\
16 \\
18 \\
20 \\
22\end{array}$ & $\begin{array}{l}7.63 \\
4.50 \\
5.14 \\
5.83 \\
6.53\end{array}$ & $\begin{array}{l}0.2959 \\
0.4711 \\
0.4711 \\
0.4693 \\
0.4725\end{array}$ & $\begin{array}{l}6.99 \\
5.92 \\
6.12 \\
6.26 \\
6.37\end{array}$ & $\begin{array}{l}6.93 \\
5.97 \\
6.18 \\
6.33 \\
6.39\end{array}$ \\
\hline
\end{tabular}

Possible reactions between calcite and aragonite surface sites and $\mathrm{CO}_{3(a d s)}^{2-}$ are:

$\mathrm{Ca}^{2+}(s)+\mathrm{CO}_{3}^{2-}(a d s) \rightarrow \mathrm{CaCO}_{3}$,

$\mathrm{CaOH}^{+}{ }_{(s)}+\mathrm{CO}_{3}^{2-}{ }_{(a d s)} \rightarrow \mathrm{CaCO}_{3}+\mathrm{OH}_{(s)}^{-}$, and (51)
$\mathrm{CaHCO}_{3(s)}^{+}+\mathrm{CO}_{3}^{2-}(a d s) \rightarrow \mathrm{CaCO}_{3}+\mathrm{HCO}_{3(s)}^{-}$

Of these, reaction 50 is probably the most important. The contribution of the $\mathrm{CO}_{3}^{2-}(a d s)$ to the backward reaction was evaluated at $\mathrm{pH} 9.8$ in solutions ranging from $10^{-4}$ to $0.3 \mathrm{M}$ total carbon. The rates for calcite as a function of the total dissolved carbon in solution is shown in 
Table 6. Observed (Obs.) and calculated (Calc.) -log rates of dissolution of calcite as a function of $\mathrm{pH}$ and $\mathrm{CO}_{2}$ partial pressure--Continued

\begin{tabular}{|c|c|c|c|c|c|c|c|c|c|c|c|c|c|c|c|c|c|}
\hline Run & Sample & $\mathrm{pH}$ & $\mathrm{P}^{\mathrm{PO}_{2}}$ & $\begin{array}{l}\text { Obs. } \\
\text {-log } \\
\text { rate }\end{array}$ & $\begin{array}{l}\text { Calc. } \\
\text {-log } \\
\text { rate }\end{array}$ & Run & Sample & pH & ${ }^{\mathrm{P}} \mathrm{CO}_{2}$ & $\begin{array}{l}\text { Obs. } \\
\text {-log } \\
\text { rate }\end{array}$ & $\begin{array}{l}\text { Calc. } \\
\text {-log } \\
\text { rate }\end{array}$ & Run & Sample & pH & $\mathrm{P}_{\mathrm{CO}_{2}}$ & $\begin{array}{l}\text { Obs. } \\
\text {-log } \\
\text { rate }\end{array}$ & $\begin{array}{l}\text { Calc. } \\
\text {-log } \\
\text { rate }\end{array}$ \\
\hline $\begin{array}{l}383 \\
388 \\
410 \\
375 \\
411\end{array}$ & $\begin{array}{l}15 \\
20 \\
10 \\
23 \\
11\end{array}$ & $\begin{array}{l}6.80 \\
6.81 \\
6.98 \\
7.05 \\
7.06\end{array}$ & $\begin{array}{l}0.4737 \\
0.4700 \\
0.4684 \\
0.4725 \\
0.4684\end{array}$ & $\begin{array}{l}6.30 \\
6.37 \\
6.32 \\
6.48 \\
6.31\end{array}$ & $\begin{array}{l}6.39 \\
6.40 \\
6.40 \\
6.40 \\
6.40\end{array}$ & $\begin{array}{r}322 \\
53 \\
323 \\
324 \\
50\end{array}$ & $\begin{array}{r}22 \\
2 \\
16 \\
20 \\
2\end{array}$ & $\begin{array}{l}3.19 \\
3.30 \\
3.40 \\
3.50 \\
3.50\end{array}$ & $\begin{array}{l}0.9955 \\
0.9791 \\
1.0025 \\
0.9959 \\
0.9772\end{array}$ & $\begin{array}{l}5.17 \\
5.25 \\
5.27 \\
5.32 \\
5.40\end{array}$ & $\begin{array}{l}5.14 \\
5.22 \\
5.29 \\
5.36 \\
5.36\end{array}$ & $\begin{array}{l}339 \\
417 \\
340 \\
261 \\
341\end{array}$ & $\begin{array}{r}19 \\
13 \\
20 \\
9 \\
21\end{array}$ & $\begin{array}{l}6.01 \\
6.04 \\
6.10 \\
6.11 \\
6.21\end{array}$ & $\begin{array}{l}0.9799 \\
0.9892 \\
0.9799 \\
0.9885 \\
0.9799\end{array}$ & $\begin{array}{l}6.12 \\
6.06 \\
6.07 \\
6.08 \\
6.08\end{array}$ & $\begin{array}{l}6.12 \\
6.11 \\
6.12 \\
6.12 \\
6.12\end{array}$ \\
\hline $\begin{array}{l}412 \\
381 \\
389 \\
390 \\
376\end{array}$ & $\begin{array}{l}12 \\
13 \\
21 \\
22 \\
24\end{array}$ & $\begin{array}{l}7.17 \\
7.30 \\
7.40 \\
7.44 \\
7.52\end{array}$ & $\begin{array}{l}0.4684 \\
0.4737 \\
0.4700 \\
0.4700 \\
0.4725\end{array}$ & $\begin{array}{l}6.47 \\
6.60 \\
6.72 \\
6.80 \\
7.14\end{array}$ & $\begin{array}{l}6.55 \\
6.65 \\
6.75 \\
6.79 \\
6.88\end{array}$ & $\begin{array}{l}325 \\
245 \\
326 \\
247 \\
246\end{array}$ & $\begin{array}{r}15 \\
9 \\
21 \\
11 \\
10\end{array}$ & $\begin{array}{l}3.60 \\
3.70 \\
3.70 \\
3.70 \\
3.70\end{array}$ & $\begin{array}{l}0.9959 \\
0.9859 \\
0.9955 \\
0.9857 \\
0.9859\end{array}$ & $\begin{array}{l}5.43 \\
5.66 \\
5.48 \\
5.36 \\
5.40\end{array}$ & $\begin{array}{l}5.42 \\
5.48 \\
5.48 \\
5.48 \\
5.48\end{array}$ & $\begin{array}{l}342 \\
424 \\
262 \\
343 \\
465\end{array}$ & $\begin{array}{l}22 \\
20 \\
10 \\
23 \\
17\end{array}$ & $\begin{array}{l}6.31 \\
6.35 \\
6.39 \\
6.41 \\
6.48\end{array}$ & $\begin{array}{l}0.9799 \\
0.9876 \\
0.9885 \\
0.9799 \\
0.9849\end{array}$ & $\begin{array}{l}6.11 \\
6.14 \\
6.14 \\
6.15 \\
7.26\end{array}$ & $\begin{array}{l}6.13 \\
6.13 \\
6.13 \\
6.13 \\
6.13\end{array}$ \\
\hline $\begin{array}{l}382 \\
399 \\
395 \\
398 \\
394\end{array}$ & $\begin{array}{l}14 \\
15 \\
11 \\
14 \\
10\end{array}$ & $\begin{array}{l}7.75 \\
2.47 \\
2.70 \\
2.82 \\
3.03\end{array}$ & $\begin{array}{l}0.4737 \\
0.4884 \\
0.4885 \\
0.4884 \\
0.4885\end{array}$ & $\begin{array}{l}7.30 \\
4.55 \\
4.68 \\
4.87 \\
5.02\end{array}$ & $\begin{array}{l}7.18 \\
4.52 \\
4.74 \\
4.85 \\
5.05\end{array}$ & $\begin{array}{r}248 \\
39 \\
327 \\
309 \\
328\end{array}$ & $\begin{array}{r}12 \\
2 \\
19 \\
20 \\
14\end{array}$ & $\begin{array}{l}3.70 \\
3.75 \\
3.80 \\
3.85 \\
3.90\end{array}$ & $\begin{array}{l}0.9857 \\
0.9965 \\
0.9959 \\
0.9892 \\
0.9959\end{array}$ & $\begin{array}{l}5.41 \\
5.57 \\
5.53 \\
5.53 \\
5.56\end{array}$ & $\begin{array}{l}5.48 \\
5.50 \\
5.53 \\
5.55 \\
5.58\end{array}$ & $\begin{array}{l}460 \\
459 \\
466 \\
461 \\
344\end{array}$ & $\begin{array}{r}24 \\
23 \\
18 \\
9 \\
24\end{array}$ & $\begin{array}{l}6.49 \\
6.49 \\
6.49 \\
6.49 \\
6.53\end{array}$ & $\begin{array}{l}0.9867 \\
0.9867 \\
0.9849 \\
0.9867 \\
0.9879\end{array}$ & $\begin{array}{l}6.13 \\
6.26 \\
8.12 \\
6.03 \\
6.21\end{array}$ & $\begin{array}{l}6.13 \\
6.13 \\
6.13 \\
6.13 \\
6.13\end{array}$ \\
\hline $\begin{array}{l}393 \\
397 \\
396 \\
404 \\
392\end{array}$ & $\begin{array}{r}9 \\
13 \\
12 \\
17 \\
24\end{array}$ & $\begin{array}{l}3.49 \\
3.91 \\
4.31 \\
4.63 \\
4.89\end{array}$ & $\begin{array}{l}0.4885 \\
0.4884 \\
0.4885 \\
0.4907 \\
0.4885\end{array}$ & $\begin{array}{l}5.39 \\
5.62 \\
5.78 \\
5.95 \\
6.02\end{array}$ & $\begin{array}{l}5.42 \\
5.71 \\
5.89 \\
6.01 \\
6.10\end{array}$ & $\begin{array}{r}43 \\
310 \\
66 \\
65 \\
311\end{array}$ & $\begin{array}{r}2 \\
21 \\
2 \\
4 \\
22\end{array}$ & $\begin{array}{l}4.00 \\
4.10 \\
4.10 \\
4.13 \\
4.25\end{array}$ & $\begin{array}{l}0.9950 \\
0.9892 \\
0.9847 \\
0.9847 \\
0.9890\end{array}$ & $\begin{array}{l}5.63 \\
5.60 \\
5.60 \\
5.64 \\
5.66\end{array}$ & $\begin{array}{l}5.62 \\
5.66 \\
5.66 \\
5.68 \\
5.72\end{array}$ & $\begin{array}{l}418 \\
345 \\
263 \\
419 \\
346\end{array}$ & $\begin{array}{r}14 \\
9 \\
11 \\
15 \\
10\end{array}$ & $\begin{array}{l}6.53 \\
6.64 \\
6.66 \\
6.74 \\
6.74\end{array}$ & $\begin{array}{l}0.9892 \\
0.9879 \\
0.9884 \\
0.9892 \\
0.9879\end{array}$ & $\begin{array}{l}6.14 \\
6.13 \\
6.23 \\
6.25 \\
6.19\end{array}$ & $\begin{array}{l}6.13 \\
6.13 \\
6.13 \\
6.13 \\
6.13\end{array}$ \\
\hline $\begin{array}{l}427 \\
391 \\
428 \\
401 \\
429\end{array}$ & $\begin{array}{r}23 \\
23 \\
24 \\
21 \\
9\end{array}$ & $\begin{array}{l}5.25 \\
5.38 \\
5.54 \\
5.67 \\
5.73\end{array}$ & $\begin{array}{l}0.4917 \\
0.4884 \\
0.4917 \\
0.4889 \\
0.4917\end{array}$ & $\begin{array}{l}6.16 \\
6.15 \\
6.21 \\
6.25 \\
6.23\end{array}$ & $\begin{array}{l}6.20 \\
6.23 \\
6.27 \\
6.29 \\
6.30\end{array}$ & $\begin{array}{r}312 \\
44 \\
313 \\
253 \\
315\end{array}$ & $\begin{array}{r}23 \\
1 \\
24 \\
9 \\
10\end{array}$ & $\begin{array}{l}4.48 \\
4.50 \\
4.51 \\
4.52 \\
4.58\end{array}$ & $\begin{array}{l}0.9890 \\
0.9950 \\
0.9890 \\
0.9834 \\
0.9892\end{array}$ & $\begin{array}{l}5.72 \\
5.79 \\
5.70 \\
5.79 \\
5.79\end{array}$ & $\begin{array}{l}5.80 \\
5.81 \\
5.81 \\
5.82 \\
5.83\end{array}$ & $\begin{array}{l}347 \\
264 \\
377 \\
348 \\
378\end{array}$ & $\begin{array}{r}11 \\
12 \\
9 \\
12 \\
10\end{array}$ & $\begin{array}{l}6.84 \\
6.84 \\
6.89 \\
6.94 \\
6.94\end{array}$ & $\begin{array}{l}0.9879 \\
0.9884 \\
0.9868 \\
0.9879 \\
0.9868\end{array}$ & $\begin{array}{l}6.28 \\
6.22 \\
6.31 \\
6.27 \\
6.28\end{array}$ & $\begin{array}{l}6.28 \\
6.28 \\
6.32 \\
6.36 \\
6.36\end{array}$ \\
\hline $\begin{array}{l}430 \\
413 \\
402 \\
414 \\
406\end{array}$ & $\begin{array}{r}10 \\
9 \\
19 \\
10 \\
22\end{array}$ & $\begin{array}{l}5.85 \\
6.04 \\
6.09 \\
6.28 \\
6.50\end{array}$ & $\begin{array}{l}0.4917 \\
0.4946 \\
0.4907 \\
0.4946 \\
0.4879\end{array}$ & $\begin{array}{l}6.25 \\
6.26 \\
6.30 \\
6.25 \\
6.37\end{array}$ & $\begin{array}{l}6.32 \\
6.34 \\
6.35 \\
6.36 \\
6.37\end{array}$ & $\begin{array}{r}52 \\
314 \\
316 \\
255 \\
317\end{array}$ & $\begin{array}{r}1 \\
9 \\
11 \\
11 \\
12\end{array}$ & $\begin{array}{l}4.70 \\
4.73 \\
4.84 \\
4.84 \\
4.93\end{array}$ & $\begin{array}{l}0.9791 \\
0.9890 \\
0.9892 \\
0.9834 \\
0.9896\end{array}$ & $\begin{array}{l}5.86 \\
5.81 \\
5.84 \\
5.86 \\
5.82\end{array}$ & $\begin{array}{l}5.87 \\
5.88 \\
5.91 \\
5.92 \\
5.94\end{array}$ & $\begin{array}{l}425 \\
384 \\
370 \\
349 \\
379\end{array}$ & $\begin{array}{l}21 \\
16 \\
18 \\
13 \\
11\end{array}$ & $\begin{array}{l}6.98 \\
7.00 \\
7.00 \\
7.03 \\
7.10\end{array}$ & $\begin{array}{l}0.9876 \\
0.9792 \\
0.9843 \\
0.9868 \\
0.9868\end{array}$ & $\begin{array}{l}6.37 \\
6.35 \\
6.47 \\
6.39 \\
6.52\end{array}$ & $\begin{array}{l}6.40 \\
6.41 \\
6.41 \\
6.44 \\
6.51\end{array}$ \\
\hline $\begin{array}{l}415 \\
407 \\
408 \\
416 \\
409\end{array}$ & $\begin{array}{r}11 \\
23 \\
24 \\
12 \\
9\end{array}$ & $\begin{array}{l}6.55 \\
6.64 \\
6.75 \\
6.76 \\
6.86\end{array}$ & $\begin{array}{l}0.4946 \\
0.4879 \\
0.4879 \\
0.4946 \\
0.4879\end{array}$ & $\begin{array}{l}6.27 \\
6.37 \\
6.39 \\
6.23 \\
6.31\end{array}$ & $\begin{array}{l}6.37 \\
6.38 \\
6.38 \\
6.38 \\
6.38\end{array}$ & $\begin{array}{l}329 \\
454 \\
452 \\
453 \\
464\end{array}$ & $\begin{array}{r}9 \\
18 \\
16 \\
17 \\
16\end{array}$ & $\begin{array}{l}4.99 \\
5.00 \\
5.00 \\
5.00 \\
5.00\end{array}$ & $\begin{array}{l}0.9818 \\
0.9853 \\
0.9853 \\
0.9853 \\
0.9849\end{array}$ & $\begin{array}{l}5.90 \\
5.83 \\
5.86 \\
5.81 \\
6.15\end{array}$ & $\begin{array}{l}5.96 \\
5.96 \\
5.96 \\
5.96 \\
5.96\end{array}$ & $\begin{array}{l}350 \\
371 \\
380 \\
351 \\
426\end{array}$ & $\begin{array}{l}14 \\
19 \\
12 \\
15 \\
22\end{array}$ & $\begin{array}{l}7.13 \\
7.16 \\
7.20 \\
7.22 \\
7.23\end{array}$ & $\begin{array}{l}0.9868 \\
0.9843 \\
0.9868 \\
0.9868 \\
0.9876\end{array}$ & $\begin{array}{l}6.44 \\
6.57 \\
6.57 \\
6.64 \\
6.76\end{array}$ & $\begin{array}{l}6.54 \\
6.57 \\
6.61 \\
6.63 \\
6.64\end{array}$ \\
\hline $\begin{array}{l}420 \\
434 \\
421 \\
435 \\
436\end{array}$ & $\begin{array}{l}16 \\
14 \\
17 \\
15 \\
16\end{array}$ & $\begin{array}{l}6.95 \\
7.07 \\
7.15 \\
7.16 \\
7.29\end{array}$ & $\begin{array}{l}0.4938 \\
0.4913 \\
0.4938 \\
0.4913 \\
0.4913\end{array}$ & $\begin{array}{l}6.39 \\
6.46 \\
6.44 \\
6.54 \\
6.61\end{array}$ & $\begin{array}{l}6.38 \\
6.39 \\
6.53 \\
6.54 \\
6.65\end{array}$ & $\begin{array}{r}462 \\
463 \\
45 \\
67 \\
256\end{array}$ & $\begin{array}{r}10 \\
11 \\
2 \\
3 \\
12\end{array}$ & $\begin{array}{l}5.00 \\
5.00 \\
5.00 \\
5.00 \\
5.10\end{array}$ & $\begin{array}{l}0.9849 \\
0.9849 \\
0.9950 \\
0.9724 \\
0.9834\end{array}$ & $\begin{array}{l}5.92 \\
6.03 \\
5.92 \\
5.92 \\
5.89\end{array}$ & $\begin{array}{l}5.96 \\
5.96 \\
5.96 \\
5.96 \\
5.99\end{array}$ & $\begin{array}{l}385 \\
372 \\
352 \\
386 \\
373\end{array}$ & $\begin{array}{l}17 \\
20 \\
16 \\
18 \\
21\end{array}$ & $\begin{array}{l}7.25 \\
7.26 \\
7.32 \\
7.35 \\
7.35\end{array}$ & $\begin{array}{l}0.9792 \\
0.9843 \\
0.9868 \\
0.9792 \\
0.9843\end{array}$ & $\begin{array}{l}6.58 \\
6.83 \\
6.77 \\
6.91 \\
7.07\end{array}$ & $\begin{array}{l}6.67 \\
6.69 \\
6.75 \\
6.79 \\
6.79\end{array}$ \\
\hline $\begin{array}{l}422 \\
437 \\
441 \\
423 \\
442\end{array}$ & $\begin{array}{l}18 \\
17 \\
21 \\
19 \\
22\end{array}$ & $\begin{array}{l}7.38 \\
7.40 \\
7.48 \\
7.58 \\
7.69\end{array}$ & $\begin{array}{l}0.4938 \\
0.4913 \\
0.4874 \\
0.4938 \\
0.4874\end{array}$ & $\begin{array}{l}6.88 \\
6.76 \\
7.06 \\
7.16 \\
7.16\end{array}$ & $\begin{array}{l}6.74 \\
6.76 \\
6.84 \\
6.95 \\
7.10\end{array}$ & $\begin{array}{l}318 \\
331 \\
330 \\
258 \\
332\end{array}$ & $\begin{array}{l}13 \\
11 \\
10 \\
10 \\
12\end{array}$ & $\begin{array}{l}5.13 \\
5.14 \\
5.22 \\
5.26 \\
5.36\end{array}$ & $\begin{array}{l}0.9896 \\
0.9818 \\
0.9818 \\
0.9885 \\
0.9818\end{array}$ & $\begin{array}{l}5.91 \\
5.92 \\
5.95 \\
5.98 \\
5.94\end{array}$ & $\begin{array}{l}5.99 \\
6.00 \\
6.01 \\
6.02 \\
6.04\end{array}$ & $\begin{array}{l}353 \\
387 \\
445 \\
446 \\
447\end{array}$ & $\begin{array}{r}17 \\
19 \\
9 \\
10 \\
11\end{array}$ & $\begin{array}{l}7.42 \\
7.44 \\
7.55 \\
7.63 \\
7.72\end{array}$ & $\begin{array}{l}0.9868 \\
0.9792 \\
0.9749 \\
0.9749 \\
0.9749\end{array}$ & $\begin{array}{l}6.83 \\
6.99 \\
7.12 \\
7.17 \\
7.23\end{array}$ & $\begin{array}{l}6.89 \\
6.93 \\
7.11 \\
7.29 \\
7.55\end{array}$ \\
\hline $\begin{array}{r}443 \\
444 \\
319 \\
41 \\
55\end{array}$ & $\begin{array}{r}23 \\
24 \\
18 \\
1 \\
2\end{array}$ & $\begin{array}{l}7.79 \\
7.87 \\
2.50 \\
2.54 \\
2.69\end{array}$ & $\begin{array}{l}0.4874 \\
0.4874 \\
0.9959 \\
0.9965 \\
0.9801\end{array}$ & $\begin{array}{l}6.93 \\
7.46 \\
4.54 \\
4.62 \\
4.69\end{array}$ & $\begin{array}{l}7.25 \\
7.41 \\
4.54 \\
4.57 \\
4.71\end{array}$ & $\begin{array}{r}257 \\
333 \\
336 \\
49 \\
259\end{array}$ & $\begin{array}{r}9 \\
13 \\
16 \\
1 \\
11\end{array}$ & $\begin{array}{l}5.45 \\
5.47 \\
5.50 \\
5.50 \\
5.60\end{array}$ & $\begin{array}{l}0.9885 \\
0.9818 \\
0.9801 \\
0.9763 \\
0.9885\end{array}$ & $\begin{array}{l}6.01 \\
6.00 \\
6.00 \\
6.01 \\
6.03\end{array}$ & $\begin{array}{l}6.05 \\
6.06 \\
6.06 \\
6.07 \\
6.08\end{array}$ & & & & & & \\
\hline $\begin{array}{r}320 \\
40 \\
54 \\
321 \\
42\end{array}$ & $\begin{array}{r}23 \\
1 \\
1 \\
17 \\
2\end{array}$ & $\begin{array}{l}2.74 \\
2.74 \\
2.90 \\
3.00 \\
3.15\end{array}$ & $\begin{array}{l}0.9955 \\
0.9965 \\
0.9801 \\
0.9959 \\
0.9965\end{array}$ & $\begin{array}{l}4.83 \\
4.86 \\
5.05 \\
4.99 \\
5.14\end{array}$ & $\begin{array}{l}4.76 \\
4.76 \\
4.90 \\
4.98 \\
5.11\end{array}$ & $\begin{array}{l}335 \\
334 \\
260 \\
337 \\
338\end{array}$ & $\begin{array}{l}15 \\
14 \\
12 \\
17 \\
18\end{array}$ & $\begin{array}{l}5.65 \\
5.74 \\
5.80 \\
5.82 \\
5.95\end{array}$ & $\begin{array}{l}0.9801 \\
0.9801 \\
0.9885 \\
0.9801 \\
0.9801\end{array}$ & $\begin{array}{l}6.02 \\
6.02 \\
6.00 \\
6.07 \\
6.10\end{array}$ & $\begin{array}{l}6.08 \\
6.09 \\
6.10 \\
6.10 \\
6.11\end{array}$ & & & & & & \\
\hline
\end{tabular}

figure 7. Line 1 in figure 7 represents the forward rate $\left(R_{0}\right)$ for the dissolution of calcite in the absence of backward reactions. The calculated rates as $R_{\mathrm{OH}^{-}}, R_{\mathrm{HCO}_{3}}$, and $R_{\mathrm{CO}_{3}^{2-}}$ effects are subtracted successively from $R_{0}$ and represented by lines 2,3 , and 4 , respectively, as a function of log activity $\mathrm{CO}_{3}^{2-}$ The calculated rate (line 4) agrees well with the experimental points for calcite. The experimental and calculated rates for calcite and aragonite are given in table 8 as a function of the total molarity of $\mathrm{CO}_{3}^{2-}$.

\section{Backward reactions in $\mathrm{Ca}\left(\mathrm{HCO}_{3}\right)_{2}$ solutions}

No single model describes the rates of dissolution of calcite and aragonite in $\mathrm{Ca}\left(\mathrm{HCO}_{3}\right)_{2}$ solutions in the saturation region of 0.0 to $1.0 \Omega$. The Plummer, Wigley, 


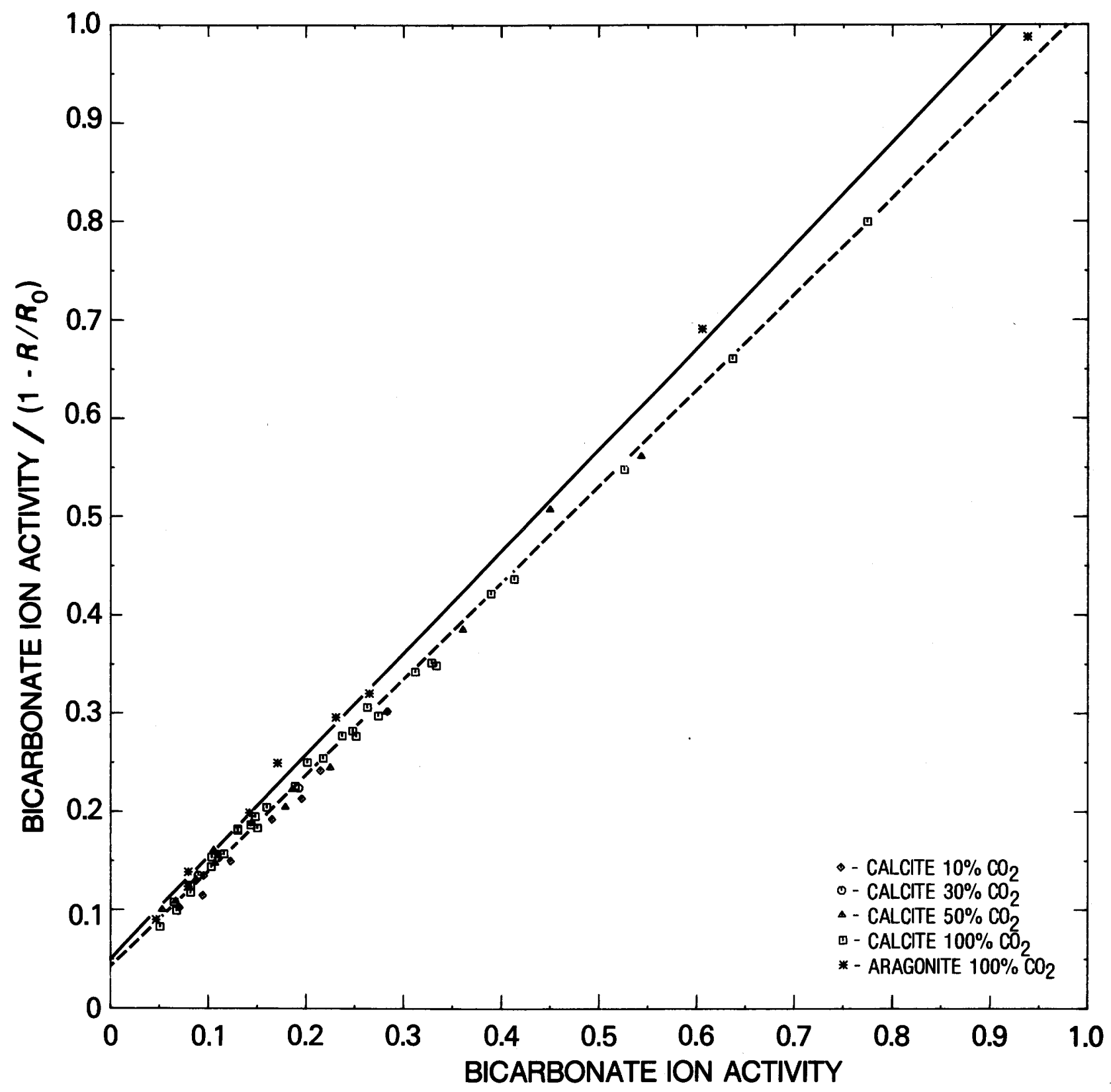

Figure 5. Langmuir isotherm showing backward rate effects of bicarbonate ion activities $\left(\mathrm{a}_{\mathrm{HCO}_{3}}{ }^{-}\right)$for calcite and aragonite single crystals at different gas compositions (numerical values represent mole percent $\mathrm{CO}_{2}$ in the $\mathrm{CO}_{2}-\mathrm{N}_{2}$ gas mixtures) far from equilibrium.

and Parkhurst model describes accurately the rate of dissolution of calcite and aragonite in the saturation region of 0.005 to $0.90 \Omega$. The model fails to predict accurately rates very far from equilibrium and particularly very near equilibrium. The Plummer, Wigley, and Parkhurst model can predict reasonably accurate crystal growth rates above $\Omega$ of 1.5 but not near equilibrium (Reddy and others, 1981). The hybrid model incorporating many features of the model of Plummer, Wigley, and Parkhurst used in the present paper can describe accurately rates in the saturation region of $0.0-0.6 \Omega$ for both calcite and aragonite. This model fails in the saturation region of 0.6-1.0 $\Omega$. An additional deficiency of the models its failure to predict rates of crystal growth from supersaturated solution. An asset of the model is its ability to predict rate far from equilibrium in relatively complex (mixed salt) solutions.

\section{The dissolution region}

Figure 8 shows the rate of dissolution and precipitation of single crystals of calcite as a function of the 
Table 7. Observed (Obs.) and calculated (Calc.) log rates of dissolution of calcite and aragonite in $\mathrm{CaCl}_{2}$ solutions as a function of $\mathrm{pH}$

[Concentrations are in $\mathrm{mmol} \cdot \mathrm{L}^{-1}$; rate is in $\mathrm{mmol} \cdot \mathrm{cm}^{-2} \cdot \mathrm{sec}^{-1}$ ]

\begin{tabular}{|c|c|c|c|c|c|c|c|c|c|c|c|}
\hline \multicolumn{6}{|c|}{ Calcite } & \multicolumn{6}{|c|}{ Aragonite } \\
\hline Run & Sample & $\mathrm{CaCl}_{2}$ & $\mathrm{pH}$ & $\begin{array}{l}\text { Obs. } \\
\text { log } \\
\text { rate }\end{array}$ & $\begin{array}{l}\text { Calc. } \\
\text { log } \\
\text { rate }\end{array}$ & Run & Sample & $\mathrm{CaCl}_{2}$ & $\mathrm{pH}$ & $\begin{array}{l}\text { Obs. } \\
\text { log } \\
\text { rate }\end{array}$ & $\begin{array}{l}\text { Calc. } \\
\text { log } \\
\text { rate }\end{array}$ \\
\hline $\begin{array}{r}15 \\
16 \\
5 \\
6 \\
1\end{array}$ & $\begin{array}{l}24 \\
23 \\
19 \\
20 \\
9\end{array}$ & $\begin{array}{l}0.0005 \\
0.0005 \\
0.0010 \\
0.0010 \\
0.0010\end{array}$ & $\begin{array}{l}8.60 \\
8.60 \\
6.00 \\
6.00 \\
7.00\end{array}$ & $\begin{array}{l}-6.77 \\
-6.81 \\
-6.76 \\
-6.62 \\
-6.74\end{array}$ & $\begin{array}{l}-6.78 \\
-6.78 \\
-6.66 \\
-6.66 \\
-6.72\end{array}$ & $\begin{array}{l}39 \\
73 \\
74 \\
41 \\
76\end{array}$ & $\begin{array}{l}M-6 \\
M-3 \\
B-9 \\
A-1 \\
B-8\end{array}$ & $\begin{array}{l}0.0010 \\
0.0010 \\
0.0010 \\
0.0010 \\
0.0010\end{array}$ & $\begin{array}{l}6.00 \\
6.80 \\
6.80 \\
7.00 \\
7.00\end{array}$ & $\begin{array}{l}-6.39 \\
-6.62 \\
-6.60 \\
-6.58 \\
-6.59\end{array}$ & $\begin{array}{l}-6.55 \\
-6.57 \\
-6.57 \\
-6.57 \\
-6.57\end{array}$ \\
\hline $\begin{array}{l}2 \\
11 \\
12 \\
17 \\
18\end{array}$ & $\begin{array}{l}10 \\
9 \\
10 \\
22 \\
21\end{array}$ & $\begin{array}{l}0.0010 \\
0.0010 \\
0.0010 \\
0.0010 \\
0.0010\end{array}$ & $\begin{array}{l}7.00 \\
7.40 \\
7.50 \\
8.85 \\
8.85\end{array}$ & $\begin{array}{l}-6.77 \\
-6.74 \\
-6.75 \\
-6.93 \\
-6.82\end{array}$ & $\begin{array}{l}-6.72 \\
-6.75 \\
-6.76 \\
-6.90 \\
-6.90\end{array}$ & $\begin{array}{l}28 \\
77 \\
78 \\
33 \\
34\end{array}$ & $\begin{array}{l}B-4 \\
M-5 \\
B-7 \\
M-3 \\
B-7\end{array}$ & $\begin{array}{l}0.0010 \\
0.0010 \\
0.0010 \\
0.0010 \\
0.0010\end{array}$ & $\begin{array}{l}7.37 \\
8.00 \\
8.00 \\
8.00 \\
8.00\end{array}$ & $\begin{array}{l}-6.61 \\
-6.58 \\
-6.66 \\
-6.73 \\
-6.66\end{array}$ & $\begin{array}{l}-6.57 \\
-6.58 \\
-6.58 \\
-6.58 \\
-6.58\end{array}$ \\
\hline $\begin{array}{r}34 \\
35 \\
7 \\
8 \\
31\end{array}$ & $\begin{array}{l}9 \\
10 \\
21 \\
22 \\
22\end{array}$ & $\begin{array}{l}0.0100 \\
0.0100 \\
0.0100 \\
0.0100 \\
0.0100\end{array}$ & $\begin{array}{l}5.00 \\
5.00 \\
6.00 \\
6.00 \\
7.00\end{array}$ & $\begin{array}{l}-6.67 \\
-6.68 \\
-6.84 \\
-6.90 \\
-7.00\end{array}$ & $\begin{array}{l}-6.59 \\
-6.59 \\
-6.80 \\
-6.80 \\
-6.94\end{array}$ & $\begin{array}{l}79 \\
25 \\
26 \\
62 \\
65\end{array}$ & $\begin{array}{l}M-6 \\
N-1 \\
B-3 \\
B-1 \\
A-2\end{array}$ & $\begin{array}{l}0.0010 \\
0.0010 \\
0.0010 \\
0.0100 \\
0.0100\end{array}$ & $\begin{array}{l}9.00 \\
9.00 \\
9.00 \\
6.00 \\
6.00\end{array}$ & $\begin{array}{l}-6.78 \\
-6.58 \\
-6.64 \\
-6.65 \\
-6.63\end{array}$ & $\begin{array}{l}-6.58 \\
-6.58 \\
-6.58 \\
-6.73 \\
-6.73\end{array}$ \\
\hline $\begin{array}{l}3 \\
30 \\
13 \\
14 \\
22\end{array}$ & $\begin{array}{l}11 \\
21 \\
11 \\
12 \\
15\end{array}$ & $\begin{array}{l}0.0100 \\
0.0100 \\
0.0100 \\
0.0100 \\
0.0100\end{array}$ & $\begin{array}{l}7.00 \\
7.00 \\
7.50 \\
7.50 \\
8.00\end{array}$ & $\begin{array}{l}-7.03 \\
-6.92 \\
-7.00 \\
-7.15 \\
-7.08\end{array}$ & $\begin{array}{l}-6.94 \\
-6.94 \\
-7.02 \\
-7.02 \\
-7.12\end{array}$ & $\begin{array}{l}45 \\
46 \\
44 \\
50 \\
35\end{array}$ & $\begin{array}{l}N-1 \\
B-8 \\
B-9 \\
B-6 \\
M-4\end{array}$ & $\begin{array}{l}0.0100 \\
0.0100 \\
0.0100 \\
0.0100 \\
0.0100\end{array}$ & $\begin{array}{l}6.85 \\
6.85 \\
7.30 \\
8.00 \\
8.00\end{array}$ & $\begin{array}{l}-6.82 \\
-6.84 \\
-6.86 \\
-6.88 \\
-6.70\end{array}$ & $\begin{array}{l}-6.82 \\
-6.82 \\
-6.86 \\
-6.92 \\
-6.92\end{array}$ \\
\hline $\begin{array}{l}25 \\
23 \\
24 \\
26 \\
20\end{array}$ & $\begin{array}{l}19 \\
16 \\
18 \\
20 \\
18\end{array}$ & $\begin{array}{l}0.0100 \\
0.0100 \\
0.0100 \\
0.0100 \\
0.0100\end{array}$ & $\begin{array}{l}8.00 \\
8.00 \\
8.00 \\
8.00 \\
8.82\end{array}$ & $\begin{array}{l}-7.15 \\
-7.01 \\
-7.07 \\
-7.14 \\
-7.11\end{array}$ & $\begin{array}{l}-7.12 \\
-7.12 \\
-7.12 \\
-7.12 \\
-7.30\end{array}$ & $\begin{array}{l}36 \\
47 \\
23 \\
59 \\
60\end{array}$ & $\begin{array}{l}B-8 \\
N-2 \\
A-2 \\
M-1 \\
B-1\end{array}$ & $\begin{array}{l}0.0100 \\
0.0100 \\
0.0100 \\
0.1000 \\
0.1000\end{array}$ & $\begin{array}{l}8.00 \\
8.00 \\
9.00 \\
5.00 \\
5.00\end{array}$ & $\begin{array}{l}-6.75 \\
-6.89 \\
-6.95 \\
-6.67 \\
-6.58\end{array}$ & $\begin{array}{l}-6.92 \\
-6.92 \\
-6.97 \\
-6.59 \\
-6.59\end{array}$ \\
\hline $\begin{array}{r}21 \\
40 \\
9 \\
10 \\
37\end{array}$ & $\begin{array}{l}17 \\
15 \\
23 \\
24 \\
18\end{array}$ & $\begin{array}{l}0.0100 \\
0.1000 \\
0.1000 \\
0.1000 \\
0.1000\end{array}$ & $\begin{array}{l}8.82 \\
5.00 \\
6.00 \\
6.00 \\
7.00\end{array}$ & $\begin{array}{l}-7.17 \\
-6.73 \\
-7.09 \\
-7.06 \\
-7.27\end{array}$ & $\begin{array}{l}-7.30 \\
-6.67 \\
-6.91 \\
-6.91 \\
-7.10\end{array}$ & $\begin{array}{l}67 \\
72 \\
31 \\
32 \\
37\end{array}$ & $\begin{array}{l}M-2 \\
B-2 \\
M-2 \\
B-6 \\
M-5\end{array}$ & $\begin{array}{l}0.1000 \\
0.1000 \\
0.1000 \\
0.1000 \\
0.1000\end{array}$ & $\begin{array}{l}5.10 \\
6.10 \\
7.00 \\
7.00 \\
8.00\end{array}$ & $\begin{array}{l}-6.61 \\
-6.86 \\
-6.98 \\
-6.88 \\
-7.21\end{array}$ & $\begin{array}{l}-6.63 \\
-6.85 \\
-7.05 \\
-7.05 \\
-7.31\end{array}$ \\
\hline $\begin{array}{r}4 \\
28 \\
29 \\
33 \\
38\end{array}$ & $\begin{array}{l}13 \\
11 \\
12 \\
23 \\
14\end{array}$ & $\begin{array}{l}0.1000 \\
0.1000 \\
0.1000 \\
0.1000 \\
0.1000\end{array}$ & $\begin{array}{l}7.00 \\
7.00 \\
7.00 \\
7.50 \\
8.00\end{array}$ & $\begin{array}{l}-7.23 \\
-7.20 \\
-7.27 \\
-7.35 \\
-7.45\end{array}$ & $\begin{array}{l}-7.10 \\
-7.10 \\
-7.10 \\
-7.21 \\
-7.33\end{array}$ & $\begin{array}{l}38 \\
21 \\
22\end{array}$ & $\begin{array}{l}B-9 \\
A-1 \\
B-1\end{array}$ & $\begin{array}{l}0.1000 \\
0.1000 \\
0.1000\end{array}$ & $\begin{array}{l}8.00 \\
9.00 \\
9.00\end{array}$ & $\begin{array}{l}-7.18 \\
-7.33 \\
-7.45\end{array}$ & $\begin{array}{l}-7.31 \\
-7.62 \\
-7.62\end{array}$ \\
\hline $\begin{array}{l}32 \\
19 \\
39 \\
27 \\
36\end{array}$ & $\begin{array}{l}15 \\
19 \\
15 \\
9 \\
21\end{array}$ & $\begin{array}{l}0.1000 \\
0.1000 \\
0.1000 \\
0.1000 \\
0.3000\end{array}$ & $\begin{array}{l}8.50 \\
8.86 \\
9.00 \\
9.00 \\
5.00\end{array}$ & $\begin{array}{l}-7.71 \\
-7.72 \\
-7.85 \\
-7.85 \\
-6.81\end{array}$ & $\begin{array}{l}-7.45 \\
-7.55 \\
-7.58 \\
-7.58 \\
-6.69\end{array}$ & & & & & & \\
\hline
\end{tabular}

activity product of $\mathrm{Ca}^{2+}$ and $\mathrm{HCO}_{3}^{-}$at $\mathrm{P}_{\mathrm{CO}_{2}}=0.96 \mathrm{~atm}$. The effect of $\mathrm{pH}$ on rate was eliminated by subtracting $k_{1} a_{\mathrm{H}}+$ from the observed rate. Figure 8 is divided into dissolution (undersaturated part) and crystal growth (oversaturated part) segments. The dissolution segment can be subdividec into two dissolution regions.

In dissolution region I, the observed rates are equal to the forward rates (eq. 1) minus the backward rate contributions of $\mathrm{Ca}^{2+}, \mathrm{HCO}_{3}^{-}, \mathrm{CO}_{3}^{2-}$, and $\mathrm{OH}^{-}$(eq. 43). The contributions of $\mathrm{OH}^{-}$and $\mathrm{CO}_{3}^{2-}$ at the solution conditions are negligible. The equation describing rate is then

$$
R=R_{0}\left(1-\sum \frac{a_{i}}{A_{i}+B_{i} a_{i}}\right)
$$

where $R_{0}$ is the forward rate in the absence of all 


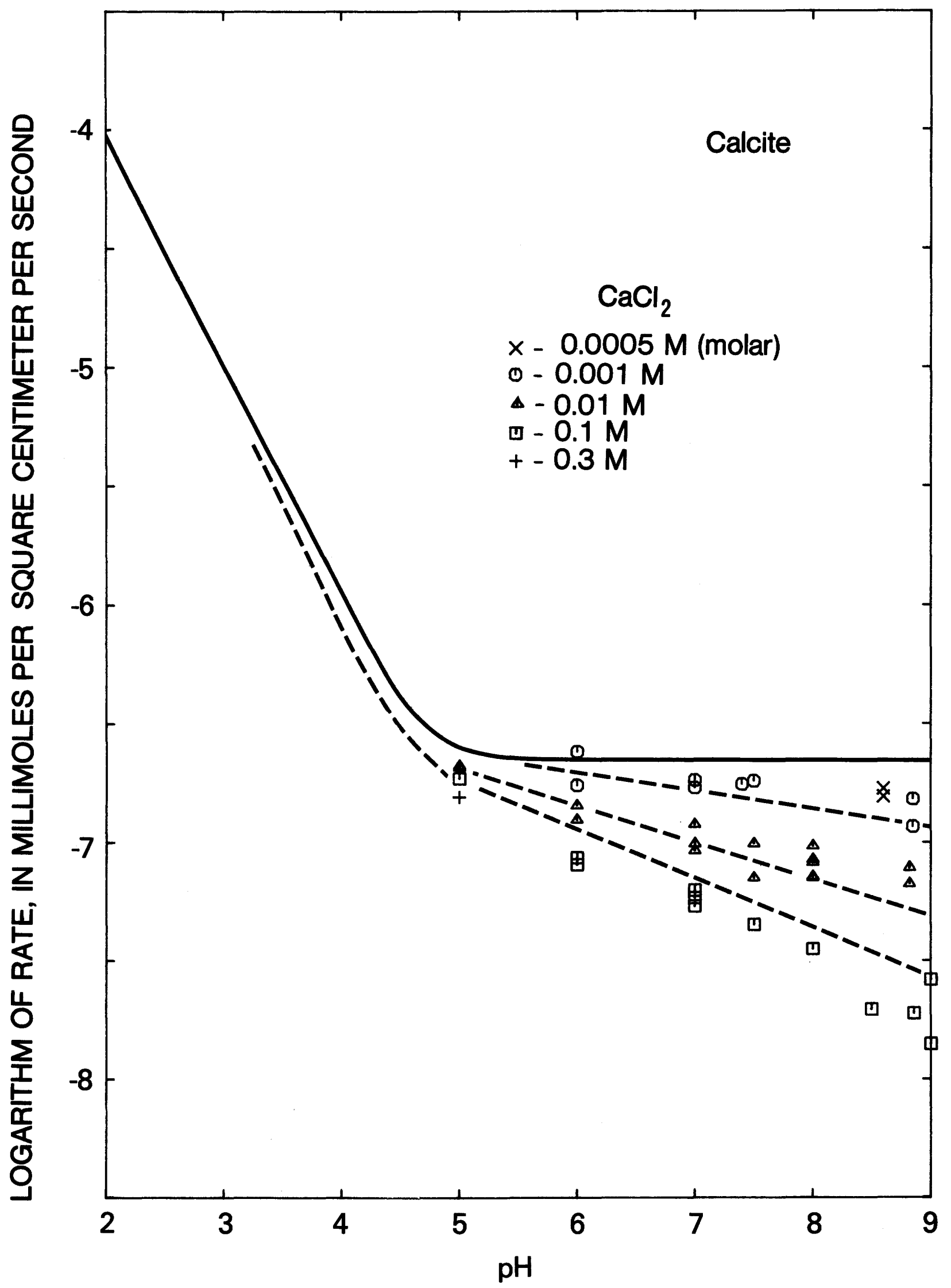

Figure 6. Effect of different $\mathrm{CaCl}_{2}$ concentrations on rate of dissolution of calcite single crystals far from equilibrium. Solid line is calculated rate in absence of $\mathrm{CaCl}_{2}$ (eq. 38). Dashed lines are rates calculated from equation 42 and constants of table 3 . 


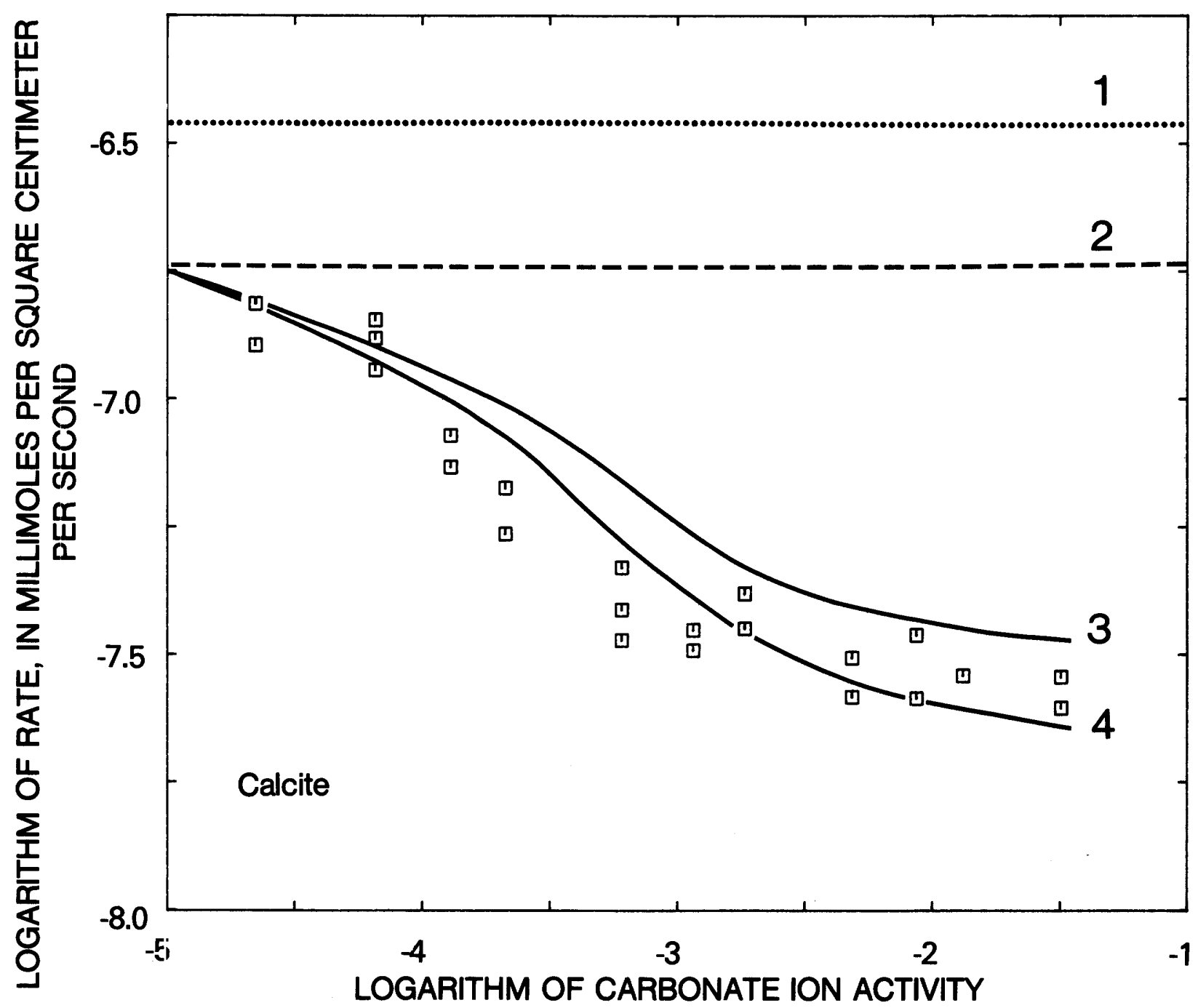

Figure 7. Dissolution rates of single crystals of calcite and aragonite as function of activity of carbonate ion (a $\mathrm{CO}_{3}{ }^{2-)}$. Lines 1, 2, 3, and 4 represent $\log R_{0^{\prime}} \log \left(R_{0}-R_{\mathrm{OH}^{-}}\right), \log \left(R_{0}-R_{\mathrm{OH}^{-}}-R_{\mathrm{HCO}_{3}}{ }^{-}\right)$, and $\log \left(R_{0}-R_{\mathrm{OH}^{-}}-R_{\mathrm{HCO}_{3}}{ }^{-} R_{\mathrm{CO}_{3}^{2-}}\right)$, respectively.

backward reactions (eq. 1), $A$ and $B$ are Langmuir isotherm constants (table 3 ), and $a_{i}$ represents the activity of the ith ions in the solutio:1. The experimental data, saturation, and experimental and calculated rates are presented in tables 9 and 10 for aragsonite and calcite, respectively.

In dissolution region II $(1>\Omega>0.6)$ the observed rates in $\mathrm{Ca}\left(\mathrm{HCO}_{3}\right)_{2}$ solution follow the empirical equation:

$$
R=k_{5}(1-\Omega)^{n}
$$

where $k_{5}$ and $n$ are constants and $\Omega$ is the ratio $I A P / K$, where $I A P$ is the ion activity product of $\mathrm{CaCO}_{3}$ in solution and $K$ is the equilibrium constant. Equation 54 was first used by Morse (1978) and Morse and others (1979) to describe the dissolution of calcite and aragonite near equilibrium in sea water. Sundquist (1979) proposed that
$\mathrm{CO}_{3}^{2-}$ can be substituted for $\Omega$ in equation 54 . This form of the equation does not fit our data as well and is not used in this paper.

Taking the logarithm of equation 54,

$$
\log R=\log k_{5}+n \log (1-\Omega),
$$

which is the equation of a straight line. Figure 9 is a plot of aragonite and calcite data near equilibrium; the last point in this illustration has an $\Omega$ value of 0.992 .

Equation 54 resembles a Freundlich isotherm (Adamson, 1976). The relationship $(1-\Omega)$ could conceivably describe the decrease in the number of sites with high enough free energy to initiate backward reactions near equilibrium. This equation is valid for the system $\mathrm{Ca}^{2+}-\mathrm{H}_{2} \mathrm{O}-\mathrm{CO}_{2}$ from $\Omega$ of 0.6 to at least 0.99 for both calcite and aragonite. The rate constants needed to 
Table 8. Observed (Obs.) and calculated (Calc.) log rates of dissolution of calcite $(\mathrm{C})$ and aragonite $(\mathrm{A})$ in $\mathrm{KHCO}_{3}-\mathrm{KOH}$ solutions as a function of total carbon in solution

[Rates were calculated using equation 51 and constants of table 3. Units of concentration and rate are $\mathrm{mmol} \cdot \mathrm{L}^{-1}$ and $\mathrm{mmol} \cdot \mathrm{cm}^{-2} \cdot \mathrm{sec}^{-1}$, respectively]

\begin{tabular}{|c|c|c|c|c|c|c|}
\hline Run & Sample & $\begin{array}{r}\text { Total } \\
\text { carbon }\end{array}$ & $\mathrm{pH}$ & $\begin{array}{l}\text { Obs. } \\
\text { log } \\
\text { rate }\end{array}$ & $\begin{array}{l}\text { Calc. } \\
\text { log } \\
\text { rate }\end{array}$ & Phase \\
\hline $\begin{array}{l}22 \\
23 \\
18 \\
20 \\
21\end{array}$ & $\begin{array}{l}22 \\
24 \\
17 \\
19 \\
20\end{array}$ & $\begin{array}{l}0.0001 \\
0.0001 \\
0.0003 \\
0.0003 \\
0.0003\end{array}$ & $\begin{array}{l}9.80 \\
9.80 \\
9.80 \\
9.80 \\
9.80\end{array}$ & $\begin{array}{l}-6.89 \\
-6.81 \\
-6.88 \\
-6.94 \\
-6.85\end{array}$ & $\begin{array}{l}-6.83 \\
-6.83 \\
-6.90 \\
-6.90 \\
-6.90\end{array}$ & $\begin{array}{l}C \\
C \\
C \\
C \\
C\end{array}$ \\
\hline $\begin{array}{l}16 \\
17 \\
11 \\
12 \\
10\end{array}$ & $\begin{array}{l}13 \\
14 \\
23 \\
24 \\
22\end{array}$ & $\begin{array}{l}0.0006 \\
0.0006 \\
0.0010 \\
0.0010 \\
0.0030\end{array}$ & $\begin{array}{l}9.80 \\
9.80 \\
9.80 \\
9.80 \\
9.80\end{array}$ & $\begin{array}{l}-7.13 \\
-7.07 \\
-7.26 \\
-7.17 \\
-7.41\end{array}$ & $\begin{array}{l}-6.98 \\
-6.98 \\
-7.05 \\
-7.05 \\
-7.25\end{array}$ & $\begin{array}{l}C \\
C \\
C \\
C \\
C\end{array}$ \\
\hline $\begin{array}{l}14 \\
15 \\
9 \\
13 \\
7\end{array}$ & $\begin{array}{l}11 \\
12 \\
19 \\
10 \\
17\end{array}$ & $\begin{array}{l}0.0030 \\
0.0030 \\
0.0060 \\
0.0060 \\
0.0100\end{array}$ & $\begin{array}{l}9.80 \\
9.80 \\
9.80 \\
9.80 \\
9.80\end{array}$ & $\begin{array}{l}-7.33 \\
-7.47 \\
-7.45 \\
-7.49 \\
-7.45\end{array}$ & $\begin{array}{l}-7.25 \\
-7.25 \\
-7.37 \\
-7.37 \\
-7.45\end{array}$ & $\begin{array}{l}C \\
C \\
C \\
C \\
C\end{array}$ \\
\hline $\begin{array}{l}8 \\
6 \\
4 \\
5 \\
3\end{array}$ & $\begin{array}{l}18 \\
16 \\
12 \\
14 \\
11\end{array}$ & $\begin{array}{l}0.0100 \\
0.0300 \\
0.0600 \\
0.0600 \\
0.1000\end{array}$ & $\begin{array}{l}9.80 \\
9.80 \\
9.80 \\
9.80 \\
9.80\end{array}$ & $\begin{array}{l}-7.38 \\
-7.51 \\
-7.46 \\
-7.59 \\
-7.54\end{array}$ & $\begin{array}{l}-7.45 \\
-7.55 \\
-7.58 \\
-7.58 \\
-7.60\end{array}$ & $\begin{array}{l}C \\
C \\
C \\
C \\
C\end{array}$ \\
\hline $\begin{array}{l}1 \\
2 \\
1 \\
2 \\
3\end{array}$ & $\begin{array}{l}9 \\
10 \\
M-6 \\
A-1 \\
A-2\end{array}$ & $\begin{array}{l}0.3000 \\
0.3000 \\
0.0001 \\
0.0003 \\
0.0006\end{array}$ & $\begin{array}{l}9.80 \\
9.80 \\
9.80 \\
9.80 \\
9.80\end{array}$ & $\begin{array}{l}-7.54 \\
-7.61 \\
-6.62 \\
-6.84 \\
-6.86\end{array}$ & $\begin{array}{l}-8.30 \\
-8.30 \\
-6.73 \\
-6.74 \\
-6.76\end{array}$ & $\begin{array}{l}C \\
C \\
A \\
A \\
A\end{array}$ \\
\hline $\begin{array}{l}4 \\
5 \\
10 \\
11 \\
8\end{array}$ & $\begin{array}{l}M-1 \\
B-4 \\
N-2 \\
B-7 \\
N-1\end{array}$ & $\begin{array}{l}0.0010 \\
0.0010 \\
0.0030 \\
0.0030 \\
0.0060\end{array}$ & $\begin{array}{l}9.80 \\
9.80 \\
9.80 \\
9.80 \\
9.80\end{array}$ & $\begin{array}{l}-6.99 \\
-6.97 \\
-7.11 \\
-7.04 \\
-7.02\end{array}$ & $\begin{array}{l}-6.78 \\
-6.78 \\
-6.87 \\
-6.87 \\
-6.98\end{array}$ & $\begin{array}{l}A \\
A \\
A \\
A \\
A\end{array}$ \\
\hline $\begin{array}{l}9 \\
6 \\
7 \\
13 \\
14\end{array}$ & $\begin{array}{l}B-6 \\
M-2 \\
B-5 \\
M-5 \\
M-7\end{array}$ & $\begin{array}{l}0.0060 \\
0.0100 \\
0.0100 \\
0.0300 \\
0.0300\end{array}$ & $\begin{array}{l}9.80 \\
9.80 \\
9.80 \\
9.80 \\
9.80\end{array}$ & $\begin{array}{l}-7.04 \\
-7.31 \\
-7.13 \\
-7.21 \\
-7.09\end{array}$ & $\begin{array}{l}-6.98 \\
-7.09 \\
-7.09 \\
-7.47 \\
-7.47\end{array}$ & $\begin{array}{l}A \\
A \\
A \\
A \\
A\end{array}$ \\
\hline 12 & $M-3$ & 0.1000 & 9.80 & -7.21 & -8.60 & A \\
\hline
\end{tabular}

evaluate equation 54 at 0.96 atm $\mathrm{CO}_{2}$ partial pressure are given on table 3 . The effects of $\mathrm{P}_{\mathrm{CO}_{2}}$ (if any) on the rate constants have not been evaluated.

A problem with using an empirical equation such as equation 54 is that the values of $k_{5}$ and $n$ vary with the composition of the aqueous solution. For example, in seawater Morse and other (1979) found a value of $n$ for aragonite of 2.93 which compares with our values of
1.161 in calcium bicarbonate solutions (table 3) near equilibrium.

\section{The precipitation region}

The kinetics of precipitation of calcite and aragonite on single crystals at various $\mathrm{P}_{\mathrm{CO}_{2}}$ was investigated. The supersaturated solutions were prepared as described by Reddy and other (1981) with the exception of dissolving vaterite rather than calcite to obtain the supersaturated solutions. Single crystals of aragonite and calcite were suspended in the stirred metastable solutions and the rate of crystallizations determined from the weight gained. The phase forming on aragonite was carefully checked by staining (Friedman, 1959), optical microscopy, and $\mathrm{X}$-ray diffraction to make sure it was aragonite. No calcite as detected forming on aragonite single crystals. The results are shown in figures 8 and 10.

Two precipitation regions were recognized and are shown in figure 8 . The rate of growth of calcite and aragonite in precipitation region I can presumably be described by equation 54; however, we were unable to evaluate these constants because of the extremely slow rates of precipitation and the metastable nature of the supersaturated solutions.

In precipitation region II, the rate of $\mathrm{CaCO}_{3}$ growth is proportional to the activity product of $\mathrm{Ca}^{2+}$ and $\mathrm{HCO}_{3}^{-}$. The rate expression that describes the precipitation of both calcite and aragonite is:

$$
R=k_{4}\left(c E-a_{\mathrm{Ca}^{2}+} a_{\mathrm{HCO}_{3}}\right),
$$

where $k_{4}$ and $c$ are constants, and $E$ is the equilibrium product of $\mathrm{Ca}^{2+}$ and $\mathrm{HCO}_{3}^{-}$for the appropriate $\mathrm{CaCO}_{3}$ polymorph at the bulk solution $\mathrm{CO}_{2}$ partial pressure. Equation 56 was found to be valid for $\mathrm{CO}_{2}$ partial pressures from $10^{-3.5}$ to 0.96 atm and for calcite in the $\Omega$ range of 1.5 to more than 100 and aragonite in the $\Omega$ range of 2.0 to more than 100 . In terms of $\Omega$, an alternative form of equation 56 is:

$$
R=\frac{k_{4} K}{K_{2}} a_{H^{+}(e q)}\left(c-\Omega \frac{a_{H^{+}}}{a_{\mathrm{H}^{+}(e q)}}\right),
$$

where $K$ is the equilibrium constant for calcite or aragonite, the subscript $(e q)$ refers to the equilibrium value, and $K_{2}$ is given by equation 26 . The experimental results for both calcite and aragonite are shown in figure 10.

\section{The backward rate constant $\boldsymbol{k}_{4}$}

Plummer and others(1978) experimentally determined the rate constant $k_{4}$ of calcite for a large number 


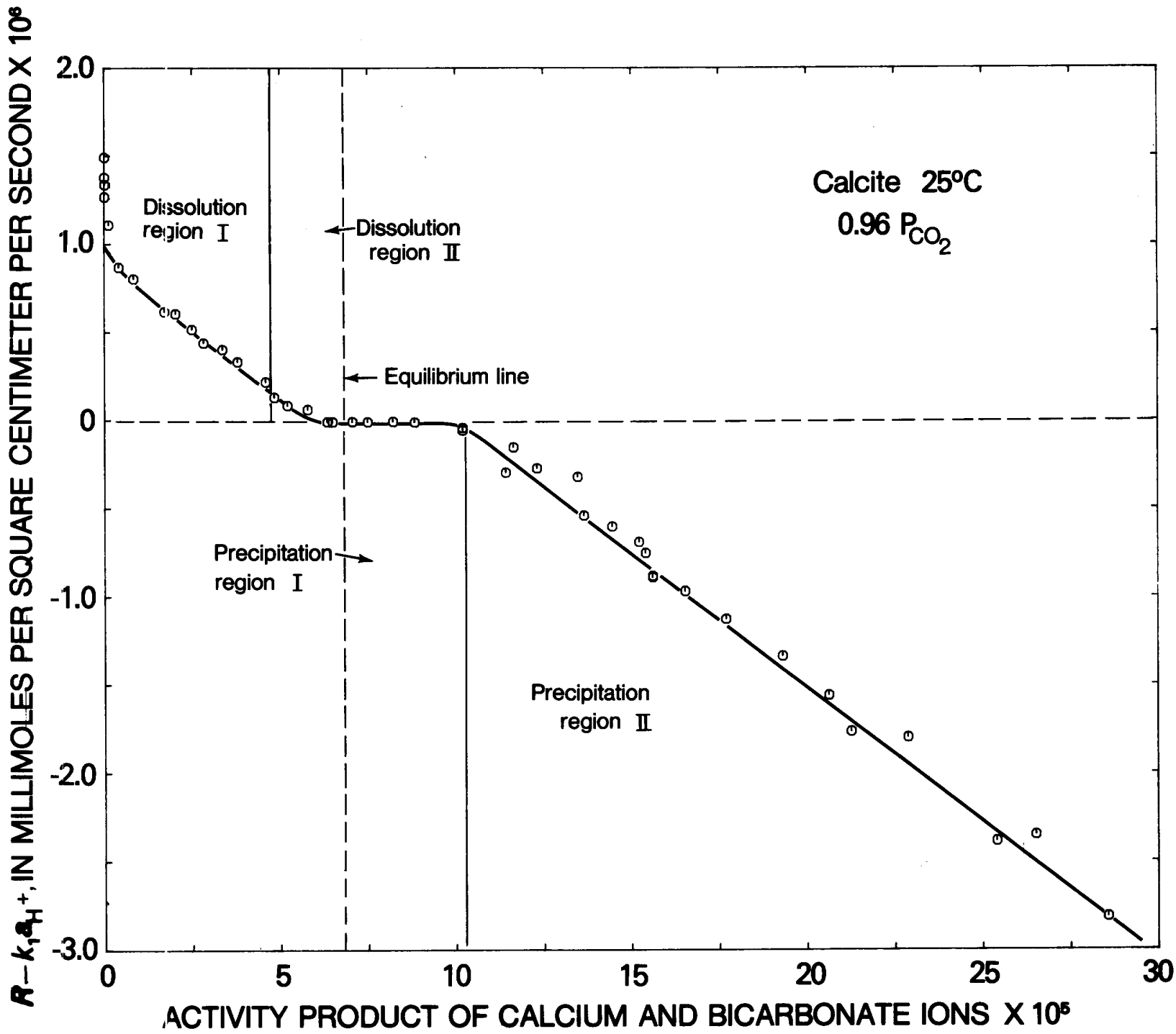

Figure 8. Obse ved rate of dissolution and growth of calcite single crystals minus $k_{1} a_{H^{+}}$as function of activity product of $\mathrm{Ca}^{2+}$ and $\mathrm{HCO}_{3}{ }^{-}$at $0.96 \mathrm{P}_{\mathrm{CO}_{2}}$. See text for details.

of $\mathrm{CO}_{2}$ partial pressures. They also evaluated this constant theoretically rising equation 21 and found close agreement with the experiemental results. The theoretical value of $k_{4}$ for calcite as a function of $\mathrm{CO}_{2}$ partial pressure can be calculated from equation 21 and is given in Plummer and others (1978). The value for $k_{4}$ calculated for aragonite from figure 10 is about half the theoretical value of calcite and about three times smaller than the theoretical value for aragonite calulated from equation 21 at $0.96 \mathrm{~atm}$ $\mathrm{CO}_{2}$ partial pressure. These values suggest that kinetic factors favor the growth of calcite at the expense of aragonite in supersaturated $\mathrm{Ca}\left(\mathrm{HCO}_{3}\right)_{2}$ solutions.

\section{Effects of stirring on rates}

The effects of stirring on the rate constant $k_{1}$ are large and have been well documented by Plummer and others (1979). In the present study, experiments were performed to determine the stirring effects on the rate constants $k_{2}$ and $k_{3}$ in pure $\mathrm{CO}_{2}-\mathrm{H}_{2} \mathrm{O}$ solutions before the large backward reaction effects of $\mathrm{Ca}^{2+}$ an $\mathrm{HCO}_{3}{ }^{-}$ were recognized; the results are, therefore, ambiguous. The values of $k_{1}$ and $k_{2}$ obtained for both calcite and aragonite via the weight loss method (table 3 ) are the same, which are expected if the $\mathrm{H}^{+}$and $\mathrm{CO}_{2}$ reactions were transport controlled. A new study of stirring dependence in a different part of dissolution region $I$ is required to resolve this question. The rate constant $k_{3}$ of aragonite is 1.4 times greater than that of calcite under the same hydrodynamic conditions, strongly suggesting that the water reaction is not predominantly transport controlled for the two $\mathrm{CaCO}_{3}$ polymorphs. 
Table 9. Observed (Obs.) and calculated (Calc.) log rates of dissolution and crystal growth of aragonite in $\mathrm{Ca}\left(\mathrm{HCO}_{3}\right)_{2}$ solutions

[Units of concentration and rate are $\mathrm{mmol} \cdot \mathrm{kg}^{-1}$ and $\mathrm{mmol} \cdot \mathrm{cm}^{-2} \cdot \mathrm{sec}^{-1}$, respectively. Rates of dissolution and crystal growth were calculated using equations 51 and 54, respectively, and the constants in table 3. Crystal growth rates are in square brackets; leaders (--), indicate values not calculated]

\begin{tabular}{|c|c|c|c|c|c|c|c|c|c|c|c|c|c|c|c|}
\hline Run & Sample & $\mathrm{Ca}$ & $\begin{array}{l}\mathrm{Log} \\
\mathrm{P}_{\mathrm{CO}_{2}}\end{array}$ & $\begin{array}{c}\text { Calc. } \\
\text { pH }\end{array}$ & Omega & $\begin{array}{l}\text { Obs. } \\
\text { log } \\
\text { rate }\end{array}$ & $\begin{array}{l}\text { Calc. } \\
\text { log } \\
\text { rate }\end{array}$ & Run & Sample & $\mathrm{Ca}$ & $\begin{array}{l}\mathrm{Log} \\
\mathrm{P}_{\mathrm{CO}_{2}}\end{array}$ & $\begin{array}{c}\text { Calc. } \\
\text { pH }\end{array}$ & Omega & $\begin{array}{l}\text { Obs. } \\
\text { log } \\
\text { rate }\end{array}$ & $\begin{array}{l}\text { Calc. } \\
\text { log } \\
\text { rate }\end{array}$ \\
\hline $\begin{array}{l}22 \\
23 \\
24 \\
20 \\
21\end{array}$ & $\begin{array}{l}N-2 \\
M-5 \\
M-4 \\
A-2 \\
M-2\end{array}$ & $\begin{array}{l}0.582 \\
0.582 \\
0.582 \\
1.120 \\
1.120\end{array}$ & $\begin{array}{l}-0.016 \\
-0.016 \\
-0.016 \\
-0.016 \\
-0.016\end{array}$ & $\begin{array}{l}4.88 \\
4.88 \\
4.88 \\
5.16 \\
5.16\end{array}$ & $\begin{array}{l}0.0004 \\
0.0004 \\
0.0004 \\
0.0026 \\
0.0026\end{array}$ & $\begin{array}{l}-5.77 \\
-5.88 \\
-5.80 \\
-5.84 \\
-5.88\end{array}$ & $\begin{array}{l}-5.80 \\
-5.80 \\
-5.80 \\
-5.89 \\
-5.89\end{array}$ & $\begin{array}{l}32 \\
40 \\
41 \\
46 \\
47\end{array}$ & $\begin{array}{l}M-2 \\
M-2 \\
A-1 \\
M-1 \\
M-5\end{array}$ & $\begin{array}{l}5.000 \\
5.560 \\
5.560 \\
5.940 \\
5.940\end{array}$ & $\begin{array}{l}-0.540 \\
-0.540 \\
-0.540 \\
-0.539 \\
-0.539\end{array}$ & $\begin{array}{l}6.29 \\
6.34 \\
6.34 \\
6.36 \\
6.36\end{array}$ & $\begin{array}{l}0.5008 \\
0.6602 \\
0.6602 \\
0.7813 \\
0.7813\end{array}$ & $\begin{array}{l}-7.19 \\
-7.65 \\
-6.86 \\
-7.14 \\
-8.23\end{array}$ & $\begin{array}{l}-6.75 \\
-- \\
-\end{array}$ \\
\hline $\begin{array}{l}12 \\
13 \\
11 \\
14 \\
7\end{array}$ & $\begin{array}{l}M-1 \\
M-5 \\
A-1 \\
M-2 \\
N-1\end{array}$ & $\begin{array}{l}2.620 \\
2.620 \\
3.720 \\
3.720 \\
3.790\end{array}$ & $\begin{array}{l}-0.016 \\
-0.016 \\
-0.016 \\
-0.016 \\
-0.016\end{array}$ & $\begin{array}{l}5.51 \\
5.51 \\
5.65 \\
5.65 \\
5.66\end{array}$ & $\begin{array}{l}0.0270 \\
0.0270 \\
0.0692 \\
0.0692 \\
0.0726\end{array}$ & $\begin{array}{l}-6.04 \\
-6.04 \\
-5.95 \\
-6.12 \\
-5.98\end{array}$ & $\begin{array}{l}-6.07 \\
-6.07 \\
-6.18 \\
-6.18 \\
-6.19\end{array}$ & $\begin{array}{l}66 \\
67 \\
60 \\
61 \\
42\end{array}$ & $\begin{array}{l}M-1 \\
M-5 \\
N-1 \\
M-3 \\
M-1\end{array}$ & $\begin{array}{r}9.930 \\
9.930 \\
11.390 \\
11.390 \\
12.380\end{array}$ & $\begin{array}{l}-0.539 \\
-0.539 \\
-0.539 \\
-0.539 \\
-0.540\end{array}$ & $\begin{array}{l}6.56 \\
6.56 \\
6.62 \\
6.62 \\
6.65\end{array}$ & $\begin{array}{l}2.8848 \\
2.8848 \\
4.0584 \\
4.0584 \\
5.0012\end{array}$ & $\begin{array}{l}{[-6.70]} \\
{[-7.43]} \\
{[-6.62]} \\
{[-6.85]} \\
{[-6.45]}\end{array}$ & $\begin{array}{l}{[-8.17]} \\
{[-8.17]} \\
{[-6.94]} \\
{[-6.94]} \\
{[-6.70]}\end{array}$ \\
\hline $\begin{array}{l}8 \\
3 \\
4 \\
6 \\
9\end{array}$ & $\begin{array}{l}M-4 \\
A-2 \\
M-1 \\
M-2 \\
M-7\end{array}$ & $\begin{array}{l}3.790 \\
4.630 \\
4.630 \\
5.780 \\
5.780\end{array}$ & $\begin{array}{l}-0.016 \\
-0.016 \\
-0.016 \\
-0.016 \\
-0.016\end{array}$ & $\begin{array}{l}5.66 \\
5.74 \\
5.74 \\
5.83 \\
5.83\end{array}$ & $\begin{array}{l}0.0726 \\
0.1231 \\
0.1231 \\
0.2195 \\
0.2197\end{array}$ & $\begin{array}{l}-6.01 \\
-6.08 \\
-6.23 \\
-6.37 \\
-6.34\end{array}$ & $\begin{array}{l}-6.19 \\
-6.27 \\
-6.27 \\
-6.37 \\
-6.37\end{array}$ & $\begin{array}{l}43 \\
37 \\
50 \\
51 \\
29\end{array}$ & $\begin{array}{l}M-6 \\
M-4 \\
N-1 \\
M-6 \\
A-1\end{array}$ & $\begin{array}{l}12.380 \\
13.370 \\
15.000 \\
15.000 \\
15.650\end{array}$ & $\begin{array}{l}-0.540 \\
-0.540 \\
-0.539 \\
-0.539 \\
-0.540\end{array}$ & $\begin{array}{l}6.65 \\
6.68 \\
6.73 \\
6.73 \\
6.74\end{array}$ & $\begin{array}{l}5.0012 \\
6.0409 \\
7.9752 \\
7.9752 \\
8.8633\end{array}$ & $\begin{array}{l}{[-6.68]} \\
{[-6.54]} \\
{[-6.16]} \\
{[-6.15]} \\
{[-6.29]}\end{array}$ & $\begin{array}{l}{[-6.70]} \\
{[-6.53]} \\
{[-6.35]} \\
{[-6.35]} \\
{[-6.29]}\end{array}$ \\
\hline $\begin{array}{l}2 \\
5 \\
15 \\
10 \\
1\end{array}$ & $\begin{array}{l}A-1 \\
N-2 \\
A-2 \\
M-6 \\
M-3\end{array}$ & $\begin{array}{l}6.780 \\
6.780 \\
7.390 \\
8.480 \\
9.510\end{array}$ & $\begin{array}{l}-0.016 \\
-0.016 \\
-0.016 \\
-0.016 \\
-0.016\end{array}$ & $\begin{array}{l}5.89 \\
5.89 \\
5.93 \\
5.98 \\
6.03\end{array}$ & $\begin{array}{l}0.3313 \\
0.3313 \\
0.4135 \\
0.5867 \\
0.7824\end{array}$ & $\begin{array}{l}-6.39 \\
-6.30 \\
-6.59 \\
-7.10 \\
-7.37\end{array}$ & $\begin{array}{l}-6.46 \\
-6.46 \\
-6.52 \\
-6.62 \\
---\end{array}$ & $\begin{array}{l}30 \\
44 \\
45 \\
84 \\
83\end{array}$ & $\begin{array}{l}M-1 \\
A-1 \\
M-2 \\
M-2 \\
B-2\end{array}$ & $\begin{array}{l}15.650 \\
17.700 \\
17.700 \\
17.940 \\
18.820\end{array}$ & $\begin{array}{l}-0.540 \\
-0.539 \\
-0.539 \\
-0.545 \\
-0.545\end{array}$ & $\begin{array}{l}6.74 \\
6.79 \\
6.79 \\
6.80 \\
6.82\end{array}$ & $\begin{array}{r}8.8633 \\
11.8914 \\
11.8914 \\
12.4640 \\
13.9765\end{array}$ & $\begin{array}{l}{[-6.27]} \\
{[-6.11]} \\
{[-6.17]} \\
{[-5.90]} \\
{[-6.07]}\end{array}$ & $\begin{array}{l}{[-6.29]} \\
{[-6.14]} \\
{[-6.14]} \\
{[-6.13]} \\
{[-6.07]}\end{array}$ \\
\hline $\begin{array}{l}17 \\
19 \\
16 \\
18 \\
64\end{array}$ & $\begin{array}{l}M-3 \\
N-1 \\
A-1 \\
M-1 \\
M-6\end{array}$ & $\begin{array}{l}14.260 \\
14.260 \\
15.630 \\
15.630 \\
16.920\end{array}$ & $\begin{array}{l}-0.015 \\
-0.016 \\
-0.015 \\
-0.016 \\
-0.016\end{array}$ & $\begin{array}{l}6.18 \\
6.18 \\
6.22 \\
6.22 \\
6.25\end{array}$ & $\begin{array}{l}2.1349 \\
2.1367 \\
2.6706 \\
2.6728 \\
3.2402\end{array}$ & $\begin{array}{l}{[-7.98]} \\
{[-8.37]} \\
{[-7.36]} \\
{[-7.30]} \\
{[-6.55]}\end{array}$ & $\begin{array}{l}{[-7.56]} \\
{[-7.56]} \\
{[-7.02]} \\
{[-7.02]} \\
{[-7.08]}\end{array}$ & $\begin{array}{l}96 \\
97 \\
81 \\
82 \\
77\end{array}$ & $\begin{array}{l}M-1 \\
M-6 \\
M-6 \\
M-7 \\
M-5\end{array}$ & $\begin{array}{l}19.090 \\
19.090 \\
19.680 \\
20.650 \\
20.720\end{array}$ & $\begin{array}{l}-0.541 \\
-0.541 \\
-0.545 \\
-0.545 \\
-0.545\end{array}$ & $\begin{array}{l}6.82 \\
6.82 \\
6.84 \\
6.85 \\
6.86\end{array}$ & $\begin{array}{l}14.3264 \\
14.3264 \\
15.5472 \\
17.4292 \\
17.5695\end{array}$ & $\begin{array}{l}{[-5.76]} \\
{[-5.92]} \\
{[-5.87]} \\
{[-6.02]} \\
{[-6.12]}\end{array}$ & $\begin{array}{l}{[-6.06]} \\
{[-6.06]} \\
{[-6.03]} \\
{[-5.98]} \\
{[-5.98]}\end{array}$ \\
\hline $\begin{array}{l}65 \\
68 \\
69 \\
58 \\
59\end{array}$ & $\begin{array}{l}M-7 \\
M-2 \\
B-1 \\
A-2 \\
M-2\end{array}$ & $\begin{array}{l}16.920 \\
18.290 \\
18.290 \\
18.360 \\
18.360\end{array}$ & $\begin{array}{l}-0.016 \\
-0.016 \\
-0.016 \\
-0.016 \\
-0.016\end{array}$ & $\begin{array}{l}6.25 \\
6.28 \\
6.28 \\
6.28 \\
6.28\end{array}$ & $\begin{array}{l}3.2402 \\
3.9101 \\
3.9101 \\
3.9462 \\
3.9462\end{array}$ & $\begin{array}{l}{[-6.92]} \\
{[-6.35]} \\
{[-6.56]} \\
{[-6.31]} \\
{[-6.49]}\end{array}$ & & $\begin{array}{l}78 \\
92 \\
93 \\
79 \\
80\end{array}$ & $\begin{array}{ll}\text { B-1 } & 2 \\
M-5 & 2 \\
B-2 & 2 \\
M-4 & 2 \\
N-2 & 2\end{array}$ & $\begin{array}{l}20.720 \\
21.140 \\
21.140 \\
21.520 \\
21.520\end{array}$ & $\begin{array}{l}-0.545 \\
-0.541 \\
-0.541 \\
-0.545 \\
-0.545\end{array}$ & $\begin{array}{l}6.86 \\
6.86 \\
6.86 \\
6.87 \\
6.87\end{array}$ & $\begin{array}{l}17.5695 \\
18.2552 \\
18.2552 \\
19.2175 \\
19.2175\end{array}$ & $\begin{array}{l}{[-5.95]} \\
{[-6.02]} \\
{[-5.91]} \\
{[-5.95]} \\
{[-6.06]}\end{array}$ & $\begin{array}{l}{[-5.98]} \\
{[-5.96]} \\
{[-5.96]} \\
{[-5.94]} \\
{[-5.94]}\end{array}$ \\
\hline $\begin{array}{l}85 \\
62 \\
63 \\
73 \\
76\end{array}$ & $\begin{array}{l}M-1 \\
N-2 \\
M-4 \\
M-2 \\
N-1\end{array}$ & $\begin{array}{l}19.900 \\
20.150 \\
20.150 \\
20.680 \\
20.820\end{array}$ & $\begin{array}{l}-0.023 \\
-0.016 \\
-0.016 \\
-0.023 \\
-0.023\end{array}$ & $\begin{array}{l}6.32 \\
6.32 \\
6.32 \\
6.33 \\
6.34\end{array}$ & $\begin{array}{l}4.8618 \\
4.9330 \\
4.9330 \\
5.3299 \\
5.4164\end{array}$ & $\begin{array}{l}{[-5.95]} \\
{[-6.47]} \\
{[-6.33]} \\
{[-6.08]} \\
{[-6.22]}\end{array}$ & $\begin{array}{l}{[-6.25]} \\
{[-6.25]} \\
{[-6.19]} \\
{[-6.18]}\end{array}$ & $\begin{array}{l}88 \\
89 \\
161 \\
159 \\
160\end{array}$ & $\begin{array}{l}N-1 \\
M-4 \\
N-2 \\
B-1 \\
M-7\end{array}$ & $\begin{array}{r}23.180 \\
23.180 \\
1.015 \\
2.000 \\
2.000\end{array}$ & $\begin{array}{r}0.541 \\
-0.541 \\
-1.012 \\
-1.012 \\
-1.012\end{array}$ & $\begin{array}{l}6.89 \\
6.89 \\
6.11 \\
6.39 \\
6.39\end{array}$ & $\begin{array}{r}22.6847 \\
22.6847 \\
0.0195 \\
0.1277 \\
0.1277\end{array}$ & $\begin{array}{c}{[-5.72]} \\
{[-5.83]} \\
-6.70 \\
-6.61 \\
-6.77\end{array}$ & $\begin{array}{l}{[-5.87]} \\
{[-5.87]} \\
-6.48 \\
-6.63 \\
-6.63\end{array}$ \\
\hline $\begin{array}{l}74 \\
75 \\
72 \\
71 \\
94\end{array}$ & $\begin{array}{l}A-2 \\
M-3 \\
A-1 \\
M-1 \\
M-2\end{array}$ & $\begin{array}{l}21.030 \\
21.100 \\
21.610 \\
21.770 \\
23.100\end{array}$ & $\begin{array}{l}-0.023 \\
-0.023 \\
-0.023 \\
-0.023 \\
-0.018\end{array}$ & $\begin{array}{l}6.34 \\
6.34 \\
6.35 \\
6.35 \\
6.37\end{array}$ & $\begin{array}{l}5.5476 \\
5.5918 \\
5.9191 \\
6.0240 \\
6.8689\end{array}$ & $\begin{array}{l}{[-6.33]} \\
{[-6.38]} \\
{[-6.04]} \\
{[-5.97]} \\
{[-5.92]}\end{array}$ & $\begin{array}{l}{[-6.16]} \\
{[-6.15]} \\
{[-6.11]} \\
{[-6.09]} \\
{[-5.99]}\end{array}$ & $\begin{array}{l}157 \\
158 \\
155 \\
156 \\
146\end{array}$ & $\begin{array}{l}M-5 \\
N-1 \\
M-2 \\
B-2 \\
B-1\end{array}$ & $\begin{array}{c}3.060 \\
3.060 \\
4.010 \\
4.010 \\
5.060\end{array}$ & $\begin{array}{l}-1.012 \\
-1.012 \\
-1.012 \\
-1.012 \\
-1.011\end{array}$ & & $\begin{array}{l}0.4037 \\
0.4037 \\
0.8284 \\
0.8284 \\
1.5207\end{array}$ & $\begin{array}{c}-6.95 \\
-6.75 \\
-7.02 \\
-7.04 \\
{[-8.46]}\end{array}$ & $\begin{array}{l}-6.77 \\
-6.77 \\
-- \\
--\end{array}$ \\
\hline $\begin{array}{l}95 \\
90 \\
91 \\
86 \\
87\end{array}$ & $\begin{array}{l}A-2 \\
B-1 \\
M-7 \\
A-1 \\
M-3\end{array}$ & $\begin{array}{l}23.100 \\
23.140 \\
23.140 \\
23.170 \\
23.170\end{array}$ & $\begin{array}{l}-0.018 \\
-0.018 \\
-0.018 \\
-0.018 \\
-0.018\end{array}$ & $\begin{array}{l}6.37 \\
6.37 \\
6.37 \\
6.37 \\
6.37\end{array}$ & $\begin{array}{l}6.8689 \\
6.8971 \\
6.8971 \\
6.9183 \\
6.9183\end{array}$ & $\begin{array}{l}{[-6.27]} \\
{[-6.00]} \\
{[-6.17]} \\
{[-5.90]} \\
{[-6.16]}\end{array}$ & $\begin{array}{l}{[-5.99]} \\
{[-5.99]} \\
{[-5.99]} \\
{[-5.99]} \\
{[-5.99]}\end{array}$ & $\begin{array}{l}147 \\
144 \\
145 \\
148 \\
142\end{array}$ & $\begin{array}{l}M-7 \\
A-2 \\
M-4 \\
N-2 \\
A-1\end{array}$ & $\begin{array}{l}5.060 \\
6.080 \\
6.080 \\
6.700 \\
8.060\end{array}$ & $\begin{array}{l}-1.011 \\
-1.011 \\
-1.011 \\
-1.011 \\
-1.011\end{array}$ & $\begin{array}{l}6.77 \\
6.84 \\
6.84 \\
6.88 \\
6.95\end{array}$ & $\begin{array}{l}1.5207 \\
2.4453 \\
2.4453 \\
3.1362 \\
5.0129\end{array}$ & $\begin{array}{l}{[-8.05]} \\
{[-7.83]} \\
{[-7.88]} \\
{[-7.82]} \\
{[-6.82]}\end{array}$ & $\begin{array}{l}-\overline{[} \\
{[-7.97]} \\
{[-7.97]} \\
{[-7.83]} \\
{[-6.95]}\end{array}$ \\
\hline $\begin{array}{l}56 \\
57 \\
38 \\
39 \\
35\end{array}$ & $\begin{array}{l}A-1 \\
M-1 \\
M-7 \\
A-2 \\
N-2\end{array}$ & $\begin{array}{r}23.530 \\
23.530 \\
1.060 \\
1.060 \\
2.000\end{array}$ & $\begin{array}{l}-0.016 \\
-0.016 \\
-0.540 \\
-0.540 \\
-0.540\end{array}$ & $\begin{array}{l}6.38 \\
6.38 \\
5.66 \\
5.66 \\
5.92\end{array}$ & $\begin{array}{l}7.1343 \\
7.1343 \\
0.0074 \\
0.0074 \\
0.0432\end{array}$ & $\begin{array}{c}{[-6.33]} \\
{[-6.00]} \\
-6.40 \\
-6.31 \\
-6.35\end{array}$ & $\begin{array}{l}{[-5.96]} \\
-6.27 \\
-6.27 \\
-6.40\end{array}$ & $\begin{array}{l}143 \\
140 \\
141 \\
153 \\
154\end{array}$ & $\begin{array}{l}M-3 \\
M-5 \\
N-1 \\
A-2 \\
M-4\end{array}$ & $\begin{array}{r}8.060 \\
10.010 \\
10.010 \\
10.980 \\
10.980\end{array}$ & $\begin{array}{l}-1.011 \\
-1.011 \\
-1.011 \\
-1.012 \\
-1.012\end{array}$ & $\begin{array}{l}6.95 \\
7.04 \\
7.04 \\
7.08 \\
7.08\end{array}$ & $\begin{array}{r}5.0129 \\
8.6181 \\
8.6181 \\
10.8519 \\
10.8519\end{array}$ & $\begin{array}{l}{[-6.73]} \\
{[-6.55]} \\
{[-6.54]} \\
{[-6.37]} \\
{[-6.40]}\end{array}$ & $\begin{array}{l}{[-6.95]} \\
{[-6.57]} \\
{[-6.57]} \\
{[-6.45]} \\
{[-6.45]}\end{array}$ \\
\hline $\begin{array}{l}33 \\
34 \\
54 \\
55 \\
52\end{array}$ & $\begin{array}{l}N-1 \\
M-3 \\
M-4 \\
M-2 \\
N-2\end{array}$ & $\begin{array}{l}3.000 \\
3.000 \\
3.250 \\
3.250 \\
3.510\end{array}$ & $\begin{array}{l}-0.540 \\
-0.540 \\
-0.539 \\
-0.539 \\
-0.539\end{array}$ & $\begin{array}{l}6.09 \\
6.09 \\
6.12 \\
6.12 \\
6.15\end{array}$ & $\begin{array}{l}0.1295 \\
0.1295 \\
0.1600 \\
0.1600 \\
0.1965\end{array}$ & $\begin{array}{l}-6.33 \\
-6.39 \\
-6.49 \\
-6.41 \\
-6.67\end{array}$ & $\begin{array}{l}-6.52 \\
-6.52 \\
-6.55 \\
-6.55 \\
-6.58\end{array}$ & $\begin{array}{l}138 \\
139 \\
151 \\
152 \\
149\end{array}$ & $\begin{array}{l}M-2 \\
B-2 \\
A-1 \\
M-3 \\
M-1\end{array}$ & $\begin{array}{l}11.900 \\
11.900 \\
11.980 \\
11.980 \\
13.110\end{array}$ & $\begin{array}{l}-1.011 \\
-1.011 \\
-1.012 \\
-1.012 \\
-1.012\end{array}$ & $\begin{array}{l}7.11 \\
7.11 \\
7.11 \\
7.11 \\
7.14\end{array}$ & $\begin{array}{l}13.1957 \\
13.1957 \\
13.4392 \\
13.4392 \\
16.7382\end{array}$ & $\begin{array}{l}{[-6.37]} \\
{[-6.40]} \\
{[-6.26]} \\
{[-6.24]} \\
{[-6.08]}\end{array}$ & $\begin{array}{l}{[-6.36]} \\
{[-6.36]} \\
{[-6.35]} \\
{[-6.35]} \\
{[-6.26]}\end{array}$ \\
\hline $\begin{array}{l}53 \\
36 \\
48 \\
49 \\
31\end{array}$ & $\begin{array}{l}M-7 \\
M-5 \\
A-2 \\
M-3 \\
A-2\end{array}$ & $\begin{array}{l}3.510 \\
3.980 \\
4.010 \\
4.010 \\
5.000\end{array}$ & $\begin{array}{l}-0.539 \\
-0.540 \\
-0.539 \\
-0.539 \\
-0.540\end{array}$ & $\begin{array}{l}6.15 \\
6.20 \\
6.20 \\
6.20 \\
6.29\end{array}$ & $\begin{array}{l}0.1965 \\
0.2750 \\
0.2797 \\
0.2797 \\
0.5008\end{array}$ & $\begin{array}{l}-6.70 \\
-6.86 \\
-6.77 \\
-6.80 \\
-7.15\end{array}$ & $\begin{array}{l}-6.58 \\
-6.63 \\
-6.63 \\
-6.63 \\
-6.75\end{array}$ & $\begin{array}{l}150 \\
136 \\
137 \\
110 \\
108\end{array}$ & $\begin{array}{ll}M-6 & 1 \\
M-1 & 1 \\
M-6 & 1 \\
N-2 & \\
B-1 & \end{array}$ & $\begin{array}{r}13.110 \\
14.010 \\
14.010 \\
4.060 \\
5.040\end{array}$ & $\begin{array}{l}-1.012 \\
-1.011 \\
-1.011 \\
-1.545 \\
-1.545\end{array}$ & $\begin{array}{l}7.14 \\
7.17 \\
7.17 \\
7.21 \\
7.30\end{array}$ & $\begin{array}{r}16.7382 \\
19.6176 \\
19.6176 \\
2.8761 \\
5.0430\end{array}$ & $\begin{array}{l}{[-6.13]} \\
{[-6.04]} \\
{[-6.06]} \\
{[-8.06]} \\
{[-7.31]}\end{array}$ & $\begin{array}{l}{[-6.26]} \\
{[-6.19]} \\
{[-6.19]} \\
{[-8.97]} \\
{[-7.10]}\end{array}$ \\
\hline
\end{tabular}


Table 9. Observed (Obs.) and calculated (Calc.) log rates of dissolution and crystal growth of aragonite in $\mathrm{Ca}\left(\mathrm{HCO}_{3}\right)_{2}$ solutions-Continued

\begin{tabular}{|c|c|c|c|c|c|c|c|}
\hline Run 5 & Semple & $\mathrm{Ca}$ & $\begin{array}{l}\mathrm{Log} \\
\mathrm{P}_{\mathrm{CO}_{2}}\end{array}$ & $\begin{array}{l}\text { Calc. } \\
\mathrm{pH}\end{array}$ & Omega & $\begin{array}{l}\text { Obs. } \\
\text { log } \\
\text { rate }\end{array}$ & $\begin{array}{l}\text { Calc. } \\
\text { log } \\
\text { rate }\end{array}$ \\
\hline $\begin{array}{l}109 \\
106 \\
107 \\
104 \\
105\end{array}$ & $\begin{array}{l}M-7 \\
t-2 \\
N-4 \\
t-1 \\
M-3\end{array}$ & $\begin{array}{l}5.040 \\
6.030 \\
6.030 \\
7.000 \\
7.000\end{array}$ & $\begin{array}{l}-1.545 \\
-1.545 \\
-1.545 \\
-1.545 \\
-1.545\end{array}$ & $\begin{array}{l}7.30 \\
7.37 \\
7.37 \\
7.43 \\
7.43\end{array}$ & $\begin{array}{r}5.0430 \\
7.9791 \\
7.9791 \\
11.6258 \\
11.6258\end{array}$ & $\begin{array}{l}{[-7.01]} \\
{[-6.66]} \\
{[-6.87]} \\
{[-6.57]} \\
{[-6.57]}\end{array}$ & $\begin{array}{l}{[-7.10]} \\
{[-6.77]} \\
{[-6.77]} \\
{[-6.58]} \\
{[-6.58]}\end{array}$ \\
\hline $\begin{array}{l}102 \\
103 \\
100 \\
101 \\
98\end{array}$ & $\begin{array}{l}N-5 \\
N-1 \\
N-2 \\
E-2 \\
N-1\end{array}$ & $\begin{array}{l}7.700 \\
7.700 \\
8.940 \\
8.940 \\
9.980\end{array}$ & $\begin{array}{l}-1.545 \\
-1.545 \\
-1.545 \\
-1.545 \\
-1.545\end{array}$ & $\begin{array}{l}7.46 \\
7.46 \\
7.52 \\
7.52 \\
7.56\end{array}$ & $\begin{array}{l}14.7480 \\
14.7480 \\
21.3151 \\
21.3151 \\
27.8624\end{array}$ & $\begin{array}{l}{[-6.43]} \\
{[-6.32]} \\
{[-6.18]} \\
{[-6.51]} \\
{[-6.07]}\end{array}$ & $\begin{array}{l}{[-6.47]} \\
{[-6.47]} \\
{[-6.32]} \\
{[-6.32]} \\
{[-6.22]}\end{array}$ \\
\hline $\begin{array}{l}99 \\
123 \\
121 \\
122 \\
119\end{array}$ & $\begin{array}{l}N-6 \\
N-2 \\
\mathrm{E}-1 \\
\mathrm{M}-7 \\
\mathrm{~A}-2\end{array}$ & $\begin{array}{l}9.980 \\
2.000 \\
3.010 \\
3.010 \\
3.950\end{array}$ & $\begin{array}{l}-1.545 \\
-2.545 \\
-2.545 \\
-2.545 \\
-2.545\end{array}$ & $\begin{array}{l}7.56 \\
7.91 \\
8.07 \\
8.07 \\
8.18\end{array}$ & $\begin{array}{r}27.8624 \\
4.0933 \\
11.8039 \\
11.8039 \\
23.1848\end{array}$ & $\begin{array}{l}{[-6.14]} \\
{[-7.30]} \\
{[-6.50]} \\
{[-6.56]} \\
{[-6.26]}\end{array}$ & $\begin{array}{l}{[-6.22]} \\
{[-7.43]} \\
{[-6.66]} \\
{[-6.66]} \\
{[-6.38]}\end{array}$ \\
\hline $\begin{array}{l}120 \\
134 \\
135 \\
132 \\
133\end{array}$ & $\begin{array}{l}M-4 \\
A-2 \\
M-4 \\
B-1 \\
M-7\end{array}$ & $\begin{array}{l}3.950 \\
3.990 \\
3.990 \\
4.500 \\
4.500\end{array}$ & $\begin{array}{l}-2.545 \\
-2.543 \\
-2.543 \\
-2.543 \\
-2.543\end{array}$ & $\begin{array}{l}8.18 \\
8.18 \\
8.18 \\
8.22 \\
8.22\end{array}$ & $\begin{array}{l}23.1848 \\
23.6539 \\
23.6539 \\
31.6017 \\
31.6017\end{array}$ & $\begin{array}{l}{[-6.27]} \\
{[-6.34]} \\
{[-6.41]} \\
{[-5.99]} \\
{[-6.04]}\end{array}$ & $\begin{array}{l}{[-6.38]} \\
{[-6.37]} \\
{[-6.37]} \\
{[-6.26]} \\
{[-6.26]}\end{array}$ \\
\hline $\begin{array}{l}130 \\
131 \\
128 \\
129 \\
115\end{array}$ & $\begin{array}{l}A-1 \\
M-3 \\
M-1 \\
M-5 \\
M-5\end{array}$ & $\begin{array}{l}5.050 \\
5.050 \\
5.610 \\
5.610 \\
5.960\end{array}$ & $\begin{array}{l}-2.543 \\
-2.543 \\
-2.543 \\
-2.543 \\
-2.545\end{array}$ & $\begin{array}{l}8.26 \\
8.26 \\
8.30 \\
8.30 \\
8.32\end{array}$ & $\begin{array}{l}41.4876 \\
41.4876 \\
52.9141 \\
52.9141 \\
60.9786\end{array}$ & $\begin{array}{l}{[-5.94]} \\
{[-6.05]} \\
{[-5.82]} \\
{[-5.99]} \\
{[-5.98]}\end{array}$ & $\begin{array}{l}{[-6.17]} \\
{[-6.17]} \\
{[-6.08]} \\
{[-6.08]} \\
{[-6.04]}\end{array}$ \\
\hline $\begin{array}{l}116 \\
126 \\
127 \\
113 \\
114\end{array}$ & $\begin{array}{l}N-1 \\
M-6 \\
N-1 \\
M-2 \\
B-2\end{array}$ & $\begin{array}{l}5.960 \\
5.970 \\
5.970 \\
6.950 \\
6.950\end{array}$ & $\begin{array}{l}-2.545 \\
-2.543 \\
-2.543 \\
-2.545 \\
-2.545\end{array}$ & $\begin{array}{l}8.32 \\
8.32 \\
8.32 \\
8.38 \\
8.38\end{array}$ & $\begin{array}{l}60.9786 \\
60.9620 \\
60.9620 \\
85.8562 \\
85.8562\end{array}$ & $\begin{array}{l}{[-5.82]} \\
{[-5.77]} \\
{[-5.74]} \\
{[-5.74]} \\
{[-5.93]}\end{array}$ & $\begin{array}{l}{[-6.04]} \\
{[-6.04]} \\
{[-6.04]} \\
{[-5.93]} \\
{[-5.93]}\end{array}$ \\
\hline $\begin{array}{l}124 \\
125 \\
166 \\
167 \\
180\end{array}$ & $\begin{array}{l}M-2 \\
B-2 \\
A-2 \\
M-4 \\
M-7\end{array}$ & $\begin{array}{l}7.400 \\
7.400 \\
1.000 \\
1.000 \\
1.500\end{array}$ & $\begin{array}{l}-2.543 \\
-2.543 \\
-3.519 \\
-3.519 \\
-3.519\end{array}$ & $\begin{array}{l}8.40 \\
8.40 \\
8.57 \\
8.57 \\
8.72\end{array}$ & $\begin{array}{r}98.0406 \\
98.0406 \\
4.9308 \\
4.9308 \\
13.4562\end{array}$ & $\begin{array}{l}{[-5.60]} \\
{[-5.81]} \\
{[-7.11]} \\
{[-6.93]} \\
{[-6.46]}\end{array}$ & $\begin{array}{l}{[-5.89]} \\
{[-5.89]} \\
{[-7.17]} \\
{[-7.17]} \\
{[-6.58]}\end{array}$ \\
\hline $\begin{array}{l}178 \\
179 \\
164 \\
165 \\
176\end{array}$ & $\begin{array}{l}N-1 \\
B-8 \\
A-1 \\
M-3 \\
M-2\end{array}$ & $\begin{array}{l}1.750 \\
1.750 \\
2.000 \\
2.000 \\
2.250\end{array}$ & $\begin{array}{l}-3.519 \\
-3.519 \\
-3.519 \\
-3.519 \\
-3.519\end{array}$ & $\begin{array}{l}8.78 \\
8.78 \\
8.82 \\
8.82 \\
8.86\end{array}$ & $\begin{array}{l}19.3214 \\
19.3214 \\
26.1761 \\
26.1761 \\
33.9502\end{array}$ & $\begin{array}{l}{[-6.36]} \\
{[-6.37]} \\
{[-6.19]} \\
{[-6.29]} \\
{[-6.27]}\end{array}$ & $\begin{array}{l}{[-6.43]} \\
{[-6.43]} \\
{[-6.32]} \\
{[-6.32]} \\
{[-6.22]}\end{array}$ \\
\hline $\begin{array}{l}177 \\
174 \\
175 \\
172 \\
173\end{array}$ & $\begin{array}{l}B-1 \\
B-2 \\
M-5 \\
A-1 \\
M-3\end{array}$ & $\begin{array}{l}2.250 \\
2.500 \\
2.500 \\
2.750 \\
2.750\end{array}$ & $\begin{array}{l}-3.519 \\
-3.519 \\
-3.519 \\
-3.519 \\
-3.519\end{array}$ & $\begin{array}{l}8.86 \\
8.89 \\
8.89 \\
8.92 \\
8.92\end{array}$ & $\begin{array}{l}33.9502 \\
42.5737 \\
42.5737 \\
51.9797 \\
51.9797\end{array}$ & $\begin{array}{l}{[-6.54]} \\
{[-6.53]} \\
{[-6.53]} \\
{[-6.02]} \\
{[-6.02]}\end{array}$ & $\begin{array}{l}{[-6.22]} \\
{[-6.15]} \\
{[-6.15]} \\
{[-6.08]} \\
{[-6.08]}\end{array}$ \\
\hline $\begin{array}{l}162 \\
163 \\
170 \\
171 \\
168\end{array}$ & $\begin{array}{l}M-1 \\
M-6 \\
A-2 \\
M-4 \\
M-1\end{array}$ & $\begin{array}{l}3.000 \\
3.000 \\
3.250 \\
3.250 \\
3.500\end{array}$ & $\begin{array}{l}-3.519 \\
-3.519 \\
-3.519 \\
-3.519 \\
-3.519\end{array}$ & $\begin{array}{l}8.95 \\
8.95 \\
8.97 \\
8.97 \\
8.99\end{array}$ & $\begin{array}{l}62.1056 \\
62.1056 \\
72.8949 \\
72.8949 \\
84.2951\end{array}$ & $\begin{array}{l}{[-5.79]} \\
{[-5.92]} \\
{[-6.01]} \\
{[-6.28]} \\
{[-5.58]}\end{array}$ & $\begin{array}{l}{[-6.02]} \\
{[-6.02]} \\
{[-5.97]} \\
{[-5.97]} \\
{[-5.92]}\end{array}$ \\
\hline 169 & $15-6$ & 3.500 & -3.519 & 8.99 & 84.2951 & {$[-5.71]$} & {$[-5.92]$} \\
\hline
\end{tabular}

\section{Comparison of the kinetics of dissolution and precipitation of calcite and aragonite}

Figure 11 is a comparison of the kinetics of dissolution and precipitation of calcite and aragonite at 0.96 atm $\mathrm{CO}_{2}$ partial pressure in $\mathrm{Ca}\left(\mathrm{HCO}_{3}\right)_{2}$ solutions. As shown, the rates of dissolution are comparable (those of aragonite slightly faster), but the rates of precipitation are significantly different (aragonite precipitates significantly slower than calcite). Three factors contribute to this large difference in the rates of precipitation of these two $\mathrm{CaCO}_{3}$ minerals. First, the solubility of aragonite is greater than that of calcite; thus, the equilibrium points are not the same (fig. 11). Second, $k_{4}$ of aragonite is smaller than that of calcite. Third, the intercept of the backward rate line with the zero rate line (fig. 11) differs for the two minerals, occurring at $\Omega$ values of 1.45 and 2.0 for calcite and aragonite, respectively, over the range of $\mathrm{P}_{\mathrm{CO}_{2}}$ investigated. In terms of our rate equations, these three factors favor the precipitation of calcite at the expense of aragonite in $\mathrm{Ca}\left(\mathrm{HCO}_{3}\right)_{2}$ solutions. Supersaturation $(\Omega)$ of at least 1.45 for calcite and 2.0 for aragonite are necessary before the rate becomes proportional to the activity product of $\mathrm{Ca}^{2+}$ and $\mathrm{HCO}_{3}{ }^{-}$. Below these supersaturation values, backward reactions probably occur only at higher energy sites.

Even though both calcite and aragonite can precipitate from dilute supersturated solutions, the rate of formation of calcite is significantly faster than that of aragonite under comparable conditions. The rate of dissolution of aragonite from undersaturated solutions is slightly faster than that of calcite. These two kinetic processes may explain the near absence of aragonite in natural fresh water environments at low temperatures.

\section{Comparison of the dissolution kinetics of calcite and aragonite with dolomite}

The model describing the dissolution of dolomite (Busenberg and Plummer, 1982) is similar to that for calcite and aragonite. The main difference between the $\mathrm{CaCO}_{3}$ minerals and dolomite is the presence of two different components in dolomite that behave as separate entities on the surface. The rate of reaction is rapid for the $\mathrm{CaCO}_{3}$ component of dolomite, but significantly slower for the $\mathrm{MgCO}_{3}$ component; thus, the surface becomes enriched with the $\mathrm{MgCO}_{3}$ component. The rate determining step in dolomite dissolution is the removal of the $\mathrm{MgCO}_{3}$ component from the surface.

The forward reaction mechanisms for dolomite dissolution have been interpreted as two consecutive steps in three parallel reactions. For the $\mathrm{CaCO}_{3}$ minerals, there are only three parallel reactions. The generalized forward equation for the dissolution of all three minerals is: 
Table 10. Observed (Obs.) and calculated (Calc.) rates of dissolution and crystal growth of calcite in $\mathrm{Ca}\left(\mathrm{HCO}_{3}\right)_{2}$ solutions

[Units of concentration and rate are $\mathrm{mmol} \cdot \mathrm{kg}^{-1}$ and $\mathrm{mmol} \cdot \mathrm{cm}^{-2} \cdot \mathrm{sec}^{-1}$, respectively. Rates of dissolution and crystal growth were calculated using equations 51 and 54, respectively, and the constants in table 3. Crystal growth rates are in square brackets; leaders (---), indicate values not calculated]

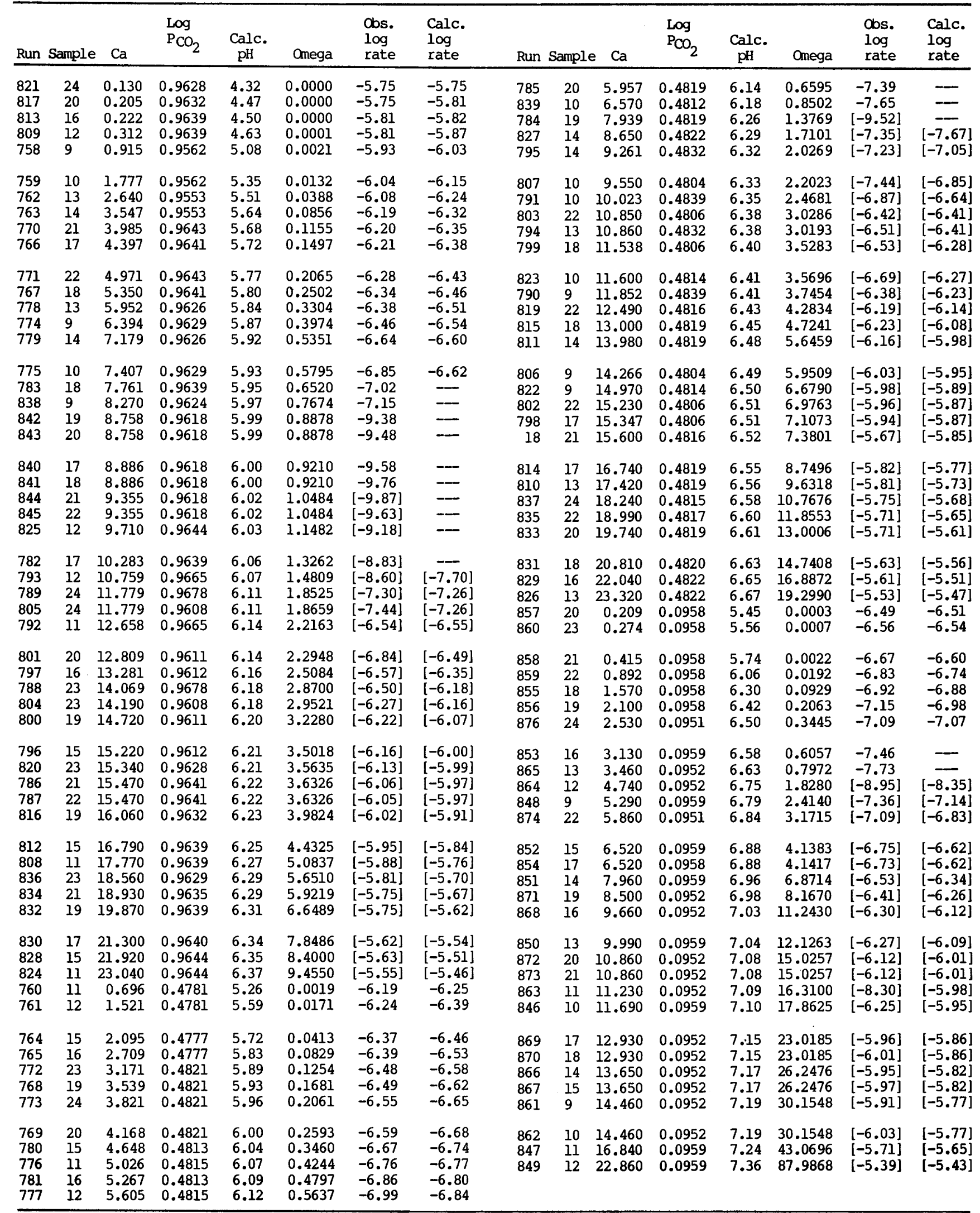




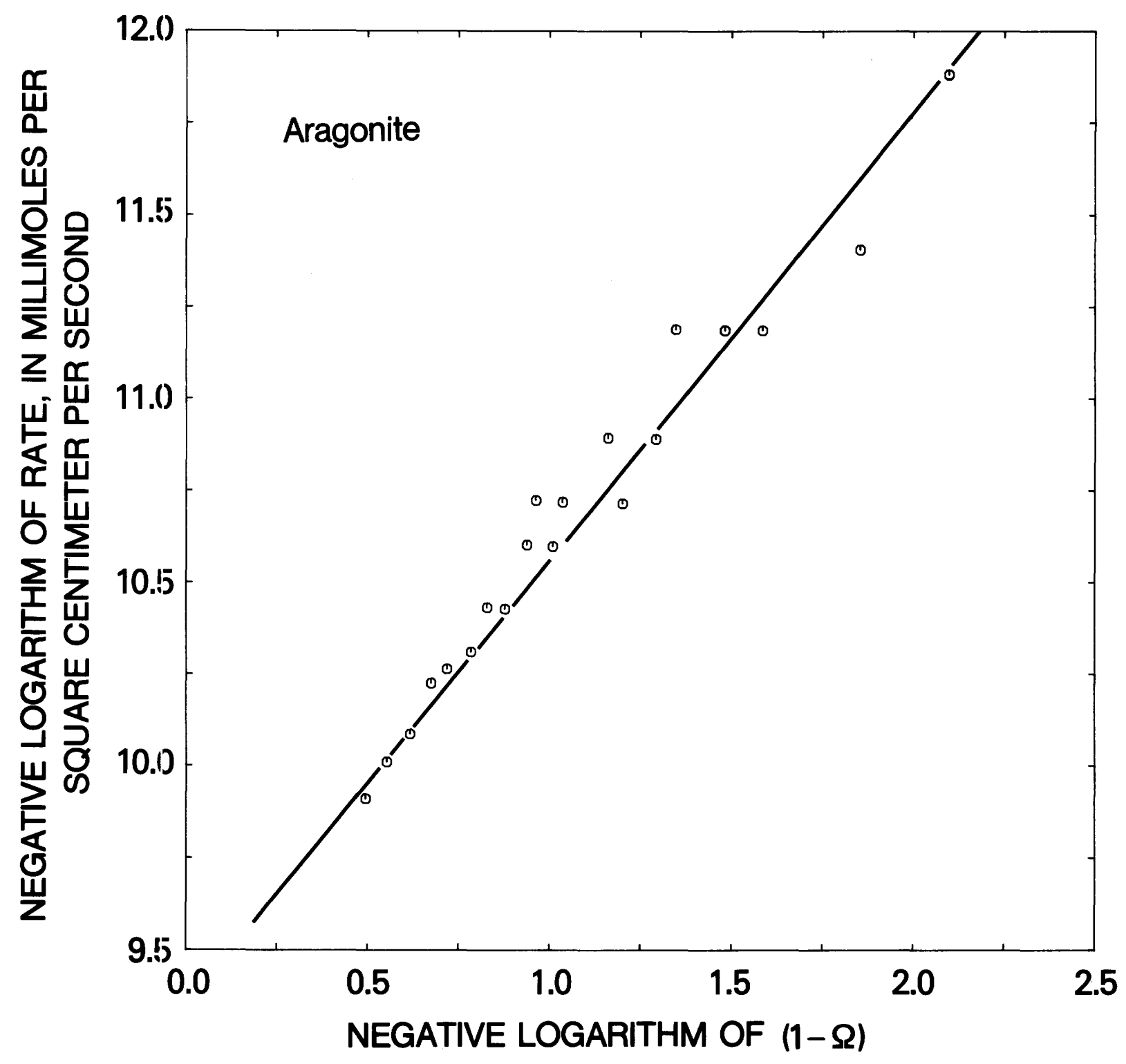

Figure 9. Dissolution rates of calcite and aragonite as function of $-\log (1-\Omega)$ near equilibrium. Rate was determined from measurement of $\mathrm{pH}$ in free-drift experiments between $\Omega$ of 0.6 and 0.99 .

$$
R_{0}=k_{1} a_{\mathrm{H}^{+}}^{n}+k_{2} a_{\mathrm{H}_{2} \mathrm{CO}_{3}}^{n}+k_{3} a_{\mathrm{H}_{2}}^{n} \text {, }
$$

where $n$ is 1 for calcite and aragonite and 0.5 for dolomite. The rate-limiting step in dolomite, the removal of the $\mathrm{MgCO}_{3}$ component, give rise to the observed half-order kinetic:; at $25^{\circ} \mathrm{C}$.

The forward rate constants $k_{1}, k_{2}$, and $k_{3}$ for dolomite are highly variable among different dolomite samples. Under identical experimental conditions, the rate constants vary by as much as one order of magnitude between different samples. Clear hydrothermal dolomites dissolve much more slowly than do imperfect cloudy crystals, and the rates probably vary as a function of crystal defect density. No differences in forward rate constants were observed between synthetic and seven natural aragonites from different locations and origins. Similarly, no differences in rate were observed between a natural and two different synthetic calcites.

No reversible backward reactions were observed for dolomites. The most important backward reaction in dolomites results from the reaction of adsorbed $\mathrm{HCO}_{3}{ }^{-}$with positive sites at the surface. This reaction effectively stops dissolution far from "equilibrium" and can be described by a Langmuir isotherm. Our results show that the rate of dissolution of dolomite in extremely dilute solutions is about 100 times slower than that of calcite and aragonite. Relatively low concentrations of $\mathrm{HCO}_{3}^{-}$can almost completely stop the dissolution of dolomite far from "equilibrium." Our combined results on the dissolution of dolomite suggest that reversible dolomite-solution equilibrium 


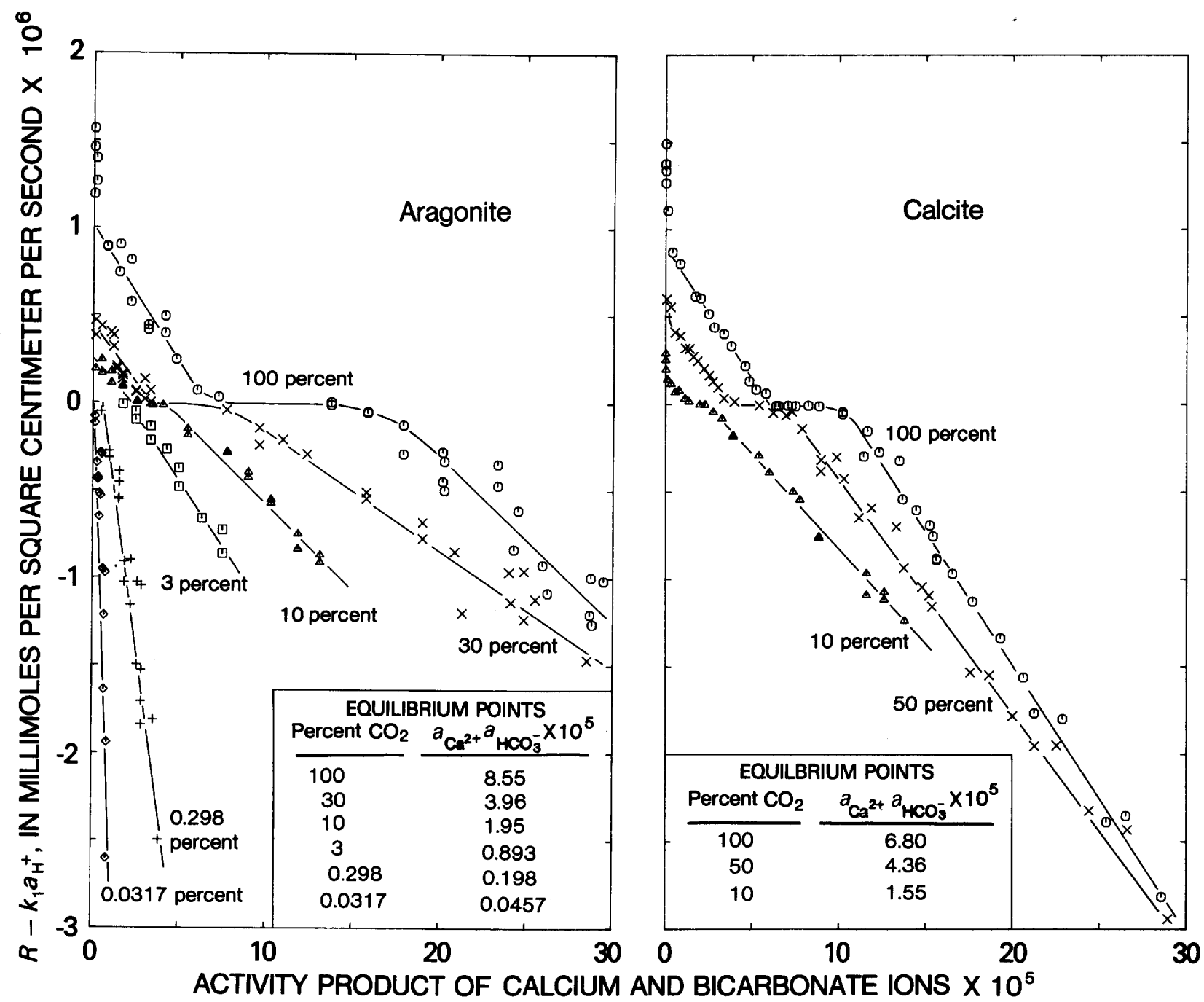

Figure 10. Dissolution and precipitation rates of calcite and aragonite as function of $R-k_{1} a_{H^{+}}$, gas composition (numerical values represent mole percent $\mathrm{CO}_{2}$ in the $\mathrm{CO}_{2}-\mathrm{N}_{2}$ gas mixtures), and activity product of $\mathrm{Ca}^{2+}$ and $\mathrm{HCO}_{3}{ }^{-}$. Each point represents an independent measurement of weight gain or weight loss of single crystal of aragonite or calcite.

cannot be achieved in the laboratory at less than $45^{\circ} \mathrm{C}$. Backward reactions have been demonstrated that can form calcite and aragonite in calcium bicarbonate solutions.

\section{SUMMARY AND CONCLUSIONS}

This paper presents experimental results, at $25^{\circ} \mathrm{C}$, of (1) dissolution of calcite and aragontie in $\mathrm{CO}_{2}-\mathrm{H}_{2} \mathrm{O}$ $\mathrm{HCl}-\mathrm{KHCO}_{3}-\mathrm{KOH}-\mathrm{CaCl}_{2}-\mathrm{Ca}\left(\mathrm{HCO}_{3}\right)_{2}$ solutions, and (2) crystal growth of calcite and aragonite in $\mathrm{Ca}\left(\mathrm{HCO}_{3}\right)_{2}$ solutions. In $\mathrm{CO}_{2}-\mathrm{H}_{2} \mathrm{O}$ solutions far from equilibrium, the rate of dissolution of $\mathrm{CaCO}_{3}$ is described by

$$
R_{0}=k_{1} \mathrm{a}_{\mathrm{H}^{+}}+k_{2} a_{\mathrm{H}_{2} \mathrm{CO}_{3}}+k_{3} a_{\mathrm{H}_{2} \mathrm{O}},
$$

where the rate constants $k_{1}, k_{2}$, and $k_{3}$ are given in table 3 for the experimental conditions. With the addition of single salts of $\mathrm{KOH}, \mathrm{KHCO}_{3}, \mathrm{~K}_{2} \mathrm{CO}_{3}$, or $\mathrm{CaCl}_{2}$ far from equilibrium, the rate of dissolution decreases, and the change in rate of dissolution is accounted for by Langmuir isotherms for $\mathrm{OH}^{-}, \mathrm{HCO}_{3}^{-}, \mathrm{CO}_{3}^{2-}$, and $\mathrm{Ca}^{2+}$ on the calcite or aragonite surface. The decrease in rate is attributed to backward reactions between adsorbed species and surface species and is described by terms of the form $R_{b}=R_{0} a_{i} /\left(A_{i}+B_{i} a_{i}\right)$ for the $i$ th species adsorbing. Values of $A$ and $B$ for $\mathrm{OH}^{-}, \mathrm{HCO}_{3}^{-}, \mathrm{CO}_{3}^{2-}$, and $\mathrm{Ca}^{2+}$ are given in table 3 . The backward adsorption isotherms appear to be additive during dissolution in the range 0 to $0.6 \Omega$ corresponding to the rate equation

$$
R=R_{0}\left(1-\sum \frac{a_{i}}{A_{i}+B_{i} a_{i}}\right)
$$

For example, the backward reaction term, $k_{4} a_{\mathrm{Ca}^{2}}+a_{\mathrm{HCO}_{3}}{ }^{-}$ 


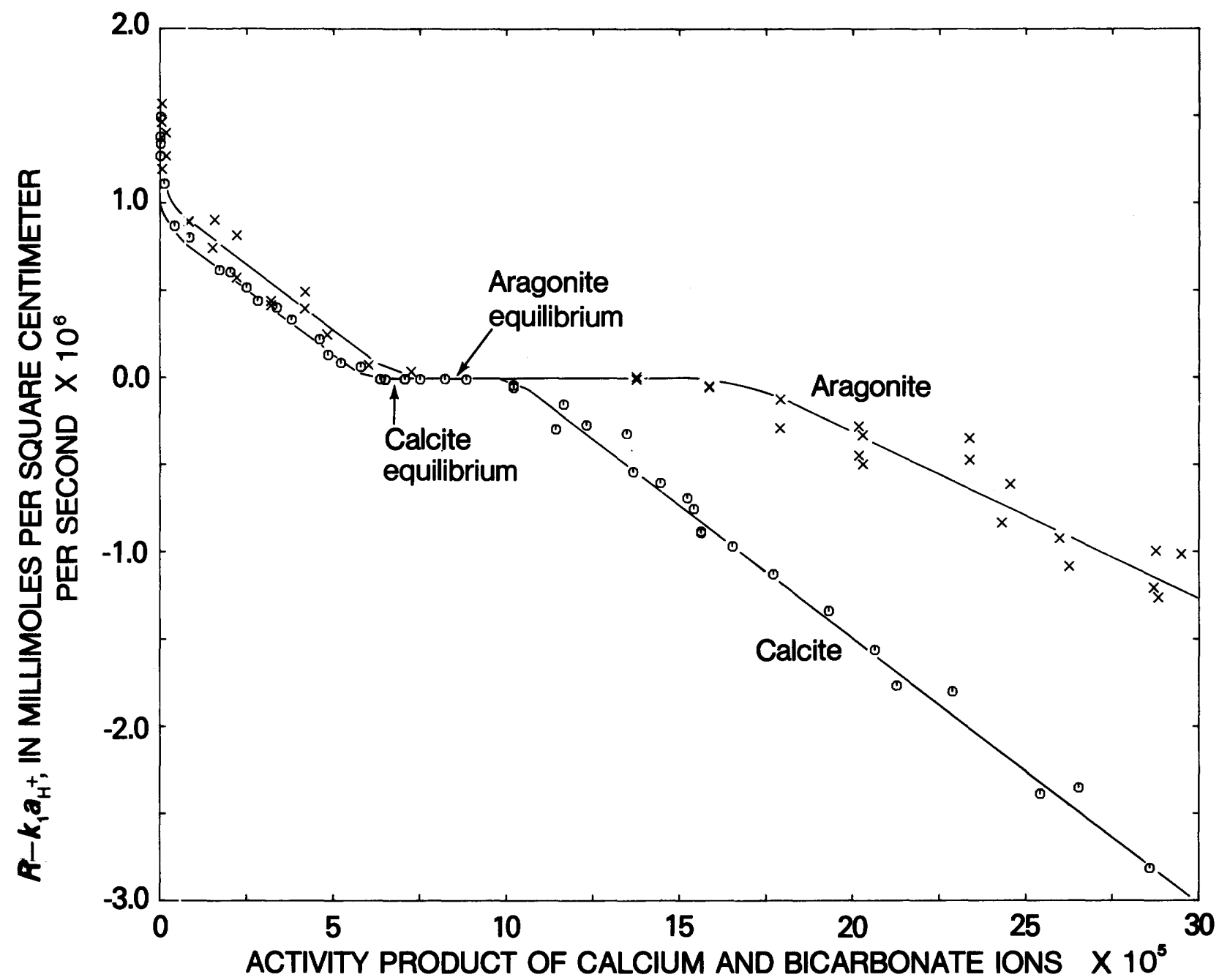

Figure 11. Comparison of dissolution and precipitation rates of calcite and aragonite single crystals as function of activity product of $\mathrm{Ca}^{2+}$ and $\mathrm{HCO}_{3}{ }^{-}$at $0.96 \mathrm{P}_{\mathrm{CO}_{2}}$. Note that rates of precipitation of calcite are significantly faster than those of aragonite, whereas aragonite dissolves only slightly faster than calcite.

of Plummer and others (1978) is completely accounted for by summing two backward reaction isotherm expressions (for $\mathrm{Ca}^{2+}$ and $\mathrm{HCO}_{3}{ }^{-}$were determined separately in $\mathrm{CaCl}_{2}$ and $\mathrm{KHCO}_{3}$ solutions) in describing dissolution rate in $\mathrm{Ca}\left(\mathrm{HCO}_{3}\right)_{2}$ solutions to $\Omega$ of 0.6 . Conceivably, every bulk solution species that can react with surface sites to produce calcite or aragonite does so and contributes to the overall observed backward rate. Bulk solution anions and cations precipitate in this process. The inital step in all back reatctions may always involve the adsorption of the reactive species into the Helmholtz layer. The next step may be the reaction between the adsorbate and the surface reactive sites. This reaction was found to be proportional to the activity of the adsorbate.

In $\mathrm{Ca}\left(\mathrm{HCO}_{3}\right)_{2}$ solutions at undersaturations higher than $\Omega$ of 0.6 , the isotherm relations are no longer simply additive, and we have found that an empirical relation $R=k_{5}(1-\Omega)^{n}$ adequately describes dissolution rate to equilibrium. The constants $k_{5}$ and $n$ are given in table 3 for calcite and aragonite in $\mathrm{Ca}\left(\mathrm{HCO}_{3}\right)_{2}$ solutions, but in general these constants are expected to depend on composition of the solution. A similar empirical relation may describe growth of calcite and aragonite near equilibrium. In supersaturated $\mathrm{Ca}\left(\mathrm{HCO}_{3}\right)_{2}$ solutions of $\Omega=1.5$ to more than 100 for calcite and 2.0 to more than 100 for aragonite, the rate of crystal growth is given by

$$
R=k_{4}\left(c E-a_{\mathrm{Ca}^{2}}+a_{\mathrm{HCO}_{3}}\right)
$$

over the range of $\mathrm{P}_{\mathrm{CO}_{2}}$ investigated $\left(10^{-3.5}\right.$ to $\left.1.0 \mathrm{~atm}\right)$.

Our results show that kinetic factors account for the absence of aragonite in fresh-water environments. In subsaturated water aragonite dissolves faster than calcite, and in supersaturated waters we have found that calcite grows significantly faster than aragonite. 


\section{REFERENCES CITED}

Adamson, A. W., 1976, Physical chemistry of surfaces [3d ed.]: New York, Wiley, 698 p.

Busenberg, E., and Plummer, L. N., 1982, The kinetics of dissolution of dolomite in $\mathrm{CO}_{2}-\mathrm{H}_{2} \mathrm{O}$ systems at $1.5^{\circ}$ to $65^{\circ} \mathrm{C}$ and 0 to $1 \mathrm{~atm} \mathrm{P}_{\mathrm{CO}_{2}}$ : American Journal of Science, v. 282 , p. $45-78$.

Diehl, H., 1964, Calcein, calmagite, and o, o'-dihydroyazobenzene. Titrimetric, colorimetric, and fluorometric reagents for calcium and magnesium: Columbus, Ohio, The G. Frederick Smith Chemical Co., 24 p.

Dreybrodt, W., 1980, Deposition of calcite from thin films of natural calcareous solutions and the growth of speleothems: Chemical Geology, v. 29, p. 89-105.

1981a, Mixing corrosion in $\mathrm{CaCO}_{3}-\mathrm{CO}_{2}-\mathrm{H}_{2} \mathrm{O}$ systems and its role in the karstification of limestone areas: Chemical Geology, v. 32, p. 221-236.

$1981 \mathrm{~b}$, The kinetics of calcite precipitation from thin films of calcareous solutions and the growth of speleothems; revisited: Chemical Geology, v. 32, p. 237-245. $1981 \mathrm{c}$, Kinetics of the dissolution of calcite and its applications to karstification: Chemical Geology, v. 31, p. 245-269.

Foxall, T., Peterson, G. C., Rendall, H. M., and Smith, A. L., 1979, Charge determination at calcium salt/aqueous solution interface: Journal of the Chemical Society, Faraday Transactions I, v. 75, p. 1034-1039.

Friedman, G. M., 1959, Identification of carbonate minerals by staining methods: Journal of Sedminentary Petrology, v. 29 , p. 87-97.

House, W. A., 1981a, Kinetics of crystallization of calcite from calcium bicarbonate solutions: Journal of the Chemical Society, Faraday Transactions I, v. 77, p. 341-359.

$1981 b$, An experimental investigation of carbon dioxide adsorption during calcite precipitation: Colloids and Surfaces, v. 2, p. 119-131.

Langmuir, I., 1918, The adsorption of gases on plane surfaces of glass, mica, and platinum: Journal of the American Chemical Society, v. 40, p. 1361-1403.

Morse, J. W., 1978, Dissolution kinetics of calcum carbonate in sea water. V. Effects of natural inhibitors and the position of the chemical lysocline: American Journal of Science, v. 274 , p. $638-647$.

Morse, J. W., Kanel, J. D., and Harris, K., 1979, Dissolution kinetics of calcium carbonate in seawater. VII. The dissolution kinetics of aragonite and pteropod tests: American Journal of Science, v. 9, p. 488-502.
Mullin, J.W., 1972, Crystallization [2d ed.]: Cleveland, Ohio, CRC Press, 415 p.

Plummer, L. N., and Busenberg, E., 1982, The solubilities of calcite, aragonite, and vaterite in $\mathrm{CO}_{2}-\mathrm{H}_{2} \mathrm{O}$ solutions between $0^{\circ}$ and $90^{\circ} \mathrm{C}$, and an evaluation of the aqueous model fore the system $\mathrm{CaCO}_{3}-\mathrm{CO}_{2}-\mathrm{H}_{2} \mathrm{O}$ : Geochimica et Cosmochimica Acta, v. 46, p. 1011-1040.

Plummer, L. N., and Wigley, T. M. L., 1976, The dissolution of calcite in $\mathrm{CO}_{2}$-saturated solutions at $25^{\circ} \mathrm{C}$ and 1 atmosphere total pressure: Geochimica et Cosmochimica Acta, v. 40, p. 191-202.

Plummer, L. N., Wigley, T. M. L., and Parkhurst, D. L., 1978, The kinetics of calcite dissolution in $\mathrm{CO}_{2}$-water systems at $5^{\circ}$ to $60^{\circ}$ and 0.0 to $1.0 \mathrm{~atm} \mathrm{CO}_{2}$ : American Journal of Science, v. 278, p. 179-216.

1979 , Critical review of the kinetics of calcite dissolution and precipitation, in Jenne, E. A., ed., Chemical modeling in aqueous systems: American Chemical Society Symposium Series 93, p. 537-573.

Reardon, E. J., and Langmuir, D., 1976, Activity coefficients of $\mathrm{MgCO}_{3}{ }^{\circ}$ and $\mathrm{CaSO}_{4}{ }^{\circ}$ ion pairs as a function of ionic strength: Geochimica et Cosmochimica Acta, v. 40, p. 549-554.

Reddy, M. M., 1977, Crystallization of calcium carbonate in the presence of trace concentrations of phosphoruscontaining anions. I. Inhibition by phosphate and glycerophosphate at $\mathrm{pH} 8.8$ and $25^{\circ} \mathrm{C}$ : Journal of Crystal Growth, v. 41, p. 287-295.

Reddy, M. M., Plummer, L. N., and Busenberg, E., 1981, Crystal growth of calcite from calcium bicarbonate solutions at constant $\mathrm{P}_{\mathrm{CO}_{2}}$ and $25^{\circ} \mathrm{C}$; A test of a calcite dissolution model: Geochimica et Cosmochimica Acta, v. 45, p. 1281-1289.

Reddy, M. M., and Wang, K. K., 1980, Crystallization of calcium carbonate in the presence of metal ions. I. Inhibition by magnesium ion at $\mathrm{pH} 8.8$ and $25^{\circ} \mathrm{C}$ : Journal of Crystal Growth, v. 50, p. 470-480.

Sjöberg, E. L., 1978, Kinetics and mechanism of calcite dissolution in aqueous solutions at low temperatures: Acta Universitasis Stockholmiensis, v. 32, p. 1-95.

Sundquist, E. T., 1979, Carbon dioxide in the ocean-Some effects on sea water and carbonate sediments: Boston, Mass., Harvard University $\mathrm{Ph}$. D. thesis, $352 \mathrm{p}$.

Truesdell, A. H., and Jones, B. F., 1974, WATEQ, A computer program for calculating chemical equilibria of natural waters: U.S. Geological Survey Journal of Research, v. 2, p. 233-248. 


\title{
Effect of Magnesium lons on
}

\section{Calcium Carbonate Nucleation and Crystal Growth in Dilute Aqueous Solutions at $25^{\circ} \mathrm{C}$}

\author{
By MICHAEI_ M. REDDY, U.S. Geological Survey, Box 25046, Denver Federal Center, \\ MS 407, Denver, Colorado 80225
}

\section{CONTENTS}

\author{
Abstract 170 \\ Introduction $\mathbf{1 7 0}$ \\ Materials and methods $\mathbf{1 7 0}$ \\ Results and discussion 171 \\ Nucleation in labile solutions $\mathbf{1 7 2}$ \\ Nucleation in metastable solutions \\ Calcite-seeded crystallization $\mathbf{1 7 5}$ \\ Approach to calcite equilibrium 176 \\ Conclusions 17! \\ References cited 182
}

\section{FIGURES}

1. Plot of calcite supersaturation versus time for calcium carbonate precipitates from stirred and quiescent labile solutions 171

2. Scanning electron micrographs of calcium carbonate precipitates from stirred and unstirred solutions 172,173

3-8. Plots:

3. Number of nucleation particles and induction interval versus calcite supersaturation for precipitation without and with magnesium ions 176, 177

4. Calcium carbonate nucleation rate versus calcite supersaturation in solution without and with magnesium ions 178

5. Calcite srystallization reduced-rate constant as a function of concentration of magnesium ion in solution $\mathbf{1 7 9}$

6. Langmuir isotherm plot of $k_{0} /\left(k_{0}-k\right)$ versus reciprocal of magnesium ion concentration 179

7. Solution calcite supersaturation versus time for calcite-seeded crystallization without and with magnesium ions 180

8. Steady-itate supersaturation versus initial total magnesium ion concentration and initial seed-crystal concentration 181

\section{TABLES}

1. Initial solution concentration and calcite supersaturation values for calcium carbonate nucleation from labile-supersaturated solutions at $\mathrm{pH} \quad 10.3 \quad \mathbf{1 7 2}$

2. Calcium carbonate nucleation in presence and absence of magnesium ion at $25^{\circ} \mathrm{C} \quad 174$

3. Experimental sonditions, seed-crystal concentrations, and rate constants for calcite growth in the presence and absence of magnesium ion 178 


\section{Abstract}

Calcium carbonate formation has been examined within a range of solution supersaturations and magnesium-to-calcium ratios. Potentiometry, turbidimetry, and chemical analysis were used to monitor changes in solution composition; solid phases were characterized by optical and scanning electron microscopy, specific surface area measurements, and X-ray diffractometry. Nucleation rates, particle numbers, precipitate composition, and crystal morphology were found to be a function of supersaturation level, solution hydrodynamics, and magnesium ion concentration. The crystallization of calcite from metastable supersaturated solutions was studied using a seededgrowth technique. Under all conditions, calcite crystallization rates were proportional to the square of relative supersaturation and were controlled by a surface reaction. Kinetic analysis demonstrated that the observed reduction in the rate of calcite crystallization in the presence of magnesium ion resulted from a decrease in the reaction rate constant. This observed reduction was consistent with a Langmuir adsorption model, implying that the inhibition mechanism involved reversible adsorption of magnesium ions at growth sites on the calcite crystal surface. The formation of an epitaxial magnesium-rich surface phase was not significant. Crystallization experiments generally did not reach calcite equilibrium. Supersaturation at the termination of these experiments depended on the initial magnesium ion concentration and seed crystal-to-solution ratio, demonstrating a kinetically controlled reaction.

\section{INTRODUCTION}

Rates and mechanisms of carbonate mineral reactions in surface and subsurface waters are of considerable interest in low-temperature aqueous geochemistry and are important aspects of diagenesis in sedimentary rocks. Heterogeneous reactions of calcium carbonate have been studied extensively (Reddy, 1978, and references therein). Several investigators have demonstrated the importance of kinetic factors in the approach of carbonate minerals to equilibrium and the influence of kinetic inhibitors on the formation and dissolution of carbonate minerals. Magnesium ion has commonly been cited as a mediator of calcium carbonate mineral kinetics. For example, Thorstenson and Plummer $(1977,1978)$ and Berner $(1978)$ examined the influence of magnesium ion on the formation of calcium carbonate over a range of natural and experimental conditions; however, relatively little is known about the reaction rates or mechanistic details of this inhibitory process.

Calcite-seeded growth in moderately supersaturated solutions follows a parabolic rate equation in both the presence and absence of magnesium ion (Reddy, 1978). In these experiments, magnesium ion reduced the rate of calcite crystallization by a mechanism involving the blockage of growth sites on the crystal surface. No evidence was obtained to support the hypothesis that a magnesiumrich surface phase formed during crystallization. Reddy and Nancollas (1976) reported that high concentrations of dissolved magnesium ion markedly influenced the formation of calcium carbonate by spontaneous precipitation.

In the present study, the formation of calcium carbonate has been characterized by chemical analysis, potentiometry, X-ray diffraction, and optical and electron microscopic methods over a wide range of supersaturation and solid/solution ratios in the presence and absence of magnesium ion. Supersaturation, $\Omega_{c}$, is herein defined as the calcium carbonate ion activity product (IAP) divided by the calcite thermodynamic solubility product, $\left(K_{s p}\right)$, that is, $\Omega_{c}=I A P / K_{s p}$.

Supersaturation values are commonly divided into two classes: labile solutions and metastable solutions. This differentiation is based on the time required to form a precipitate in the solution. Labile solutions have high supersaturations; nucleation occurs within a brief (typically a few seconds) interval after solution preparation. Metastable solutions, on the other hand, have intermediate supersaturations; nucleation follows a specific well-defined interval, $t_{I}$ (referred to as the induction interval), typically from a minimum of several minutes to several hours. Designation of supersaturation values for each class is dependent on the mineral being studied and the experimental conditions. For calcium carbonate, labile solutions have supersaturations greater than 100 , and metastable solutions have supersaturations less than 100. Metastable solutions can be prepared with low supersaturation values (5-7), which do not nucleate within 24 hours. These metastable solutions are used for seededgrowth experiments.

\section{MATERIALS AND METHODS}

Grade-A glassware, reagent-grade chemicals, and deionized, distilled water filtered through Millipore $^{1}$ filters were used in all experiments. Prior to each experiment, reagent solutions were filtered through prewashed $0.22-\mu \mathrm{m}$ Millipore filters to minimize the presence of heteronuclei.

Details of the nucleation experiments in labilesupersaturated solutions have been presented elsewhere (Reddy and Nancollas, 1976). These solutions were prepared by mixing thermostated sodium carbonate and calcium chloride solutions in a large reaction vessel as rapidly as possible. The progress of the precipitation reaction was followed by the analyses of filtered samples withdrawn from the reaction cell. The calcium concentration in the filtered aliquots was determined by ethylene-diamine tetraacetic acid (EDTA) titration with a micrometer buret in the presence of a Calcine indicator.

\footnotetext{
${ }^{1}$ Use of trade and company names is for descriptive purposes only and does not imply endorsement by the U. S. Geological Survey.
} 
Magnesium ion analyses were performed in the same manner (by difference) with the appropriate indicator (Eriochrome Black T). Total carbonate concentrations in solution were calculated from dilution of stock solution and separately from titration of the filtrate with $0.01 \mathrm{~N}$ sulfuric acid.

$\mathrm{pH}$ was measured at $25.00 \pm 0.02^{\circ} \mathrm{C}$ with a Corning Model $12 \mathrm{pH}$ meter, a Sargent Combination Electrode, and a Sargent Model SP recorder. Electrodes were calibrated prior to and following each experiment with National Bureau of Standards standard buffer solutions at $\mathrm{pH} 6.865(0.025 \mathrm{M}$ potassium dihydrogen phosphate, $0.025 M$ disodium hydrogen phosphate) and pH $9.18(0.01$ $M$ sodium borate) at $25^{\circ} \mathrm{C}$.

The preparation of metastable supersaturated solutions has been described previously (Reddy, 1978). Calcium, magnesium, and total carbonate concentrations determined by analysis of the metastable solution shortly after preparation agreed with the concentration values calculated from the dilution of stock solution. Solution $\mathrm{pH}$ was monitored continuously, and turbidity was determined by a light-scattering technique on aliquots withdrawn from time to time during the nucleation experiments. Estimates of the length of the induction period from $\mathrm{pH}$ and turbiclity measurements agreed within 5 percent for the same experiment.

Precipitates for chemical and X-ray diffraction analysis and for optical and electron microscopy were obtained by filtering 10 to 500 milliliters of the growth suspension through a $0.22-\mu \mathrm{m}$ Millipore filter, followed by air-drying. Precipitates on the filter surface were coated with carbon and gold and examined by scanning electron microscopy (SEM) using an ETEC Autoscan instrument. Dried precipitates for optical microscopy were slurried in a small amount of ethylene glycol and examined with a Zeiss RA microscope. Specific surface areas of calcium carbonate precipitates were determined with a Quantachrome Monosorb surface-area analyzer. X-ray diffraction (XRD) analyses were done using Ni-filtered $\mathrm{CuK} \alpha$ radiation with a Sicmens diffractometer or with a DebyeScherrer powder camera with a Norelco X-ray generator.

Seeded-grow $1 \mathrm{~h}$ experiments began by inoculating a stirred supersaturated solution with a known weight of calcite seed at seed concentrations of 0.05 to $0.5 \mathrm{~g} / \mathrm{L}$ for magnesium-free solutions. Inasmuch as the rate of formation of calcite ir. solutions containing magnesium ion can be considerably slower than in magnesium-free solutions, two modifications of this laboratory scheme were adopted for selected experiments. Several runs used seed crystal concentrations greater than $0.5 \mathrm{~g} / \mathrm{L}$ to enhance calcite formation and the approach to equilibrium. Other runs were reinoculated with calcite seeds after a specific growth interval, and the subsequent reaction was followed to completion.

Several measurements of the crystallization rate in seeding solutions employed a constant $\mathrm{pH}$ of 9 using the
Radiometer pH stat system: TTT2 titrator, titrograph, ABU 12 autoburet, a closed reaction cell with stirrer, and separate $\mathrm{pH}$ and reference electrodes.

\section{RESULTS AND DISCUSSION}

\section{Nucleation in labile solutions}

Ionic concentrations and supersaturations were calculated from the measured $\mathrm{pH}$ and from the total calcium and carbonate concentrations by using massaction and mass-balance equations (Reddy, 1978) (table 1). The solubility product of calcite and the stability constants of $\mathrm{CaCO}_{3}$ and $\mathrm{CaHCO}_{3}{ }^{+}$were taken from Jacobson and Langmuir (1974). Supersaturation dropped rapidly in continuously stirred labile solutions; visible onset of precipitation occurred within 2-10 seconds of mixing (fig. 1). Initial pHs of 10.4 decreased to 9.5

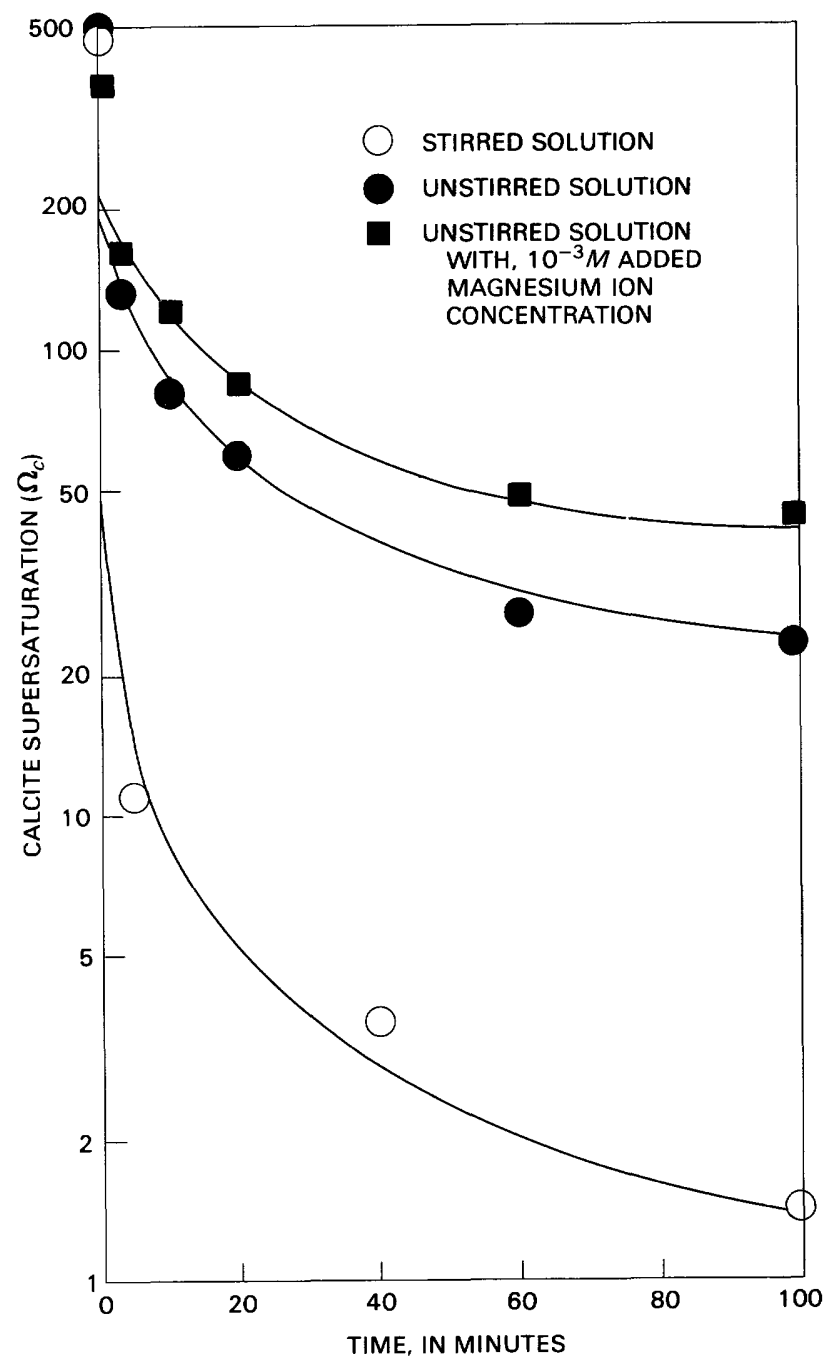

Figure 1. Calcite supersaturation $\left(\Omega_{c}\right)$ versus time for calcium carbonate nucleation from stirred and quiescent labile solutions. 
Table 1. Initial solution concentrations and calcite supersaturation values $\left(\Omega_{c}\right)$ for calcium carbonate nucleation from labilesupersaturated solutions at $\mathrm{pH} 10.3$

[Total carbonate concentration $5 \times 10^{-3} \mathrm{M}$ at $25^{\circ} \mathrm{C}$. Leaders (--) indicate no added magnesium ion; $\Omega_{c}$, supersaturation]

\begin{tabular}{|c|c|c|c|c|c|c|}
\hline \multirow{3}{*}{$\begin{array}{c}\text { Experi- } \\
\text { ment }\end{array}$} & \multicolumn{6}{|c|}{ Initial concentration (moles per liter $\times 10^{4}$ ) } \\
\hline & \multicolumn{2}{|c|}{ Total } & \multirow[b]{2}{*}{$\mathrm{Ca}^{2+}$} & \multirow[b]{2}{*}{$\mathrm{CO}_{3}{ }^{2-}$} & \multirow[b]{2}{*}{$\mathrm{CaCO}_{3}^{\circ}$} & \multirow[b]{2}{*}{$\Omega_{c}$} \\
\hline & $\mathrm{Ca}^{2+}$ & $\mathrm{Mg}^{2+}$ & & & & \\
\hline $\begin{array}{r}13 \\
15 \\
7 \\
8\end{array}$ & $\begin{array}{l}50 \\
54 \\
54 \\
55\end{array}$ & $\begin{array}{c}--- \\
1 \\
---\end{array}$ & $\begin{array}{l}26.83 \\
28.83 \\
29.57 \\
31.16\end{array}$ & $\begin{array}{l}17.16 \\
16.81 \\
16.16 \\
16.42\end{array}$ & $\begin{array}{l}21.82 \\
22.47 \\
22.25 \\
22.13\end{array}$ & $\begin{array}{l}462 \\
476 \\
471 \\
468\end{array}$ \\
\hline $\begin{array}{r}9 \\
11 \\
12 \\
13\end{array}$ & $\begin{array}{l}53 \\
53 \\
46 \\
58\end{array}$ & $\begin{array}{l}1 \\
--- \\
10 \\
---\end{array}$ & $\begin{array}{l}30.25 \\
29.65 \\
24.63 \\
33.72\end{array}$ & $\begin{array}{l}16.05 \\
16.12 \\
20.30 \\
15.63\end{array}$ & $\begin{array}{l}22.45 \\
22.30 \\
17.54 \\
23.97\end{array}$ & $\begin{array}{l}475 \\
472 \\
371 \\
508\end{array}$ \\
\hline
\end{tabular}

${ }^{1}$ Experiments 3 and 5 were stirred continuously during precipitation; all other experiments were quiescent after intial mixing.

during the first 10 minutes of reaction and to 8.6 during the first 100 minutes. Long-term solution pH's approached 8.2. The total calcium concentration dropped from $5 \times$ $10^{-3} M$ to a steady-state value of less than $1 \times 10^{-3} \mathrm{M}$ within 5 minutes of mixing and solutions rapidly approached calcite equilibrium. In unstirred experiments, the calcium concentration dropped more slowly with time; the experiments approached a steady-state calcium carbonate IAP significantly greater than that for calcite equilibrium (fig. 1). IAP's during this phase of the precipitation reaction may correspond to the steady-state values of the initially formed precipitate.

The initial precipitate had characteristics of a noncrystalline or microcrystalline material. X-ray diffraction patterns had only a few broad peaks, and examination by optical microscopy showed submicrometer, isotropic particles. In many experiments, however, vaterite and calcite were identified in the XRD pattern, and under the microscope the samples consisted of a mixture of birefringent crystals in a submicrometer-size, optically isotropic matrix. By SEM, most of these initial precipitates were seen to consist of uniform, submicrometer-size, spherical particles that displayed no euhedral character (fig. 2). Specific surface areas calculated for these initial precipitates agreed well with the measured value of $15 \mathrm{~m}^{2} / \mathrm{g}$.

The formation of calcium carbonate polymorphs and their subsequent transformation and incorporation of magnesium ion differed between the stirred and unstirred solutions, suggesting that the processes occurring during or shortly after calcium carbonate nucleation from highly supersaturated solutions were influenced by solution hydrodynamics. For example, both the change in total calcium concentration and the nucleation particles number (the number of particles formed in the supersaturated solution) differed between the stirred and unstirred solutions. Particle number differences were most pronounced for calcite rhombs and vaterite spheres. The precipitates that formed in stirred solutions did not appear to have a noncrystalline component (figs. $2 B$ and $2 D$ ), presumably because of the rapid transformation of any such material that did form. Scanning electron micrographs of precipitates collected on filters showed that in stirred solutions, containing low concentrations of magnesium ion, calcite rhombs and vaterite spheres formed in nearly equal numbers. The recrystallization of what may have initially been noncrystalline material and unstable polymorphs of $\mathrm{CaCO}_{3}$ yielded calcite with a uniform, twinned-rhombohedral morphology and a narrow size distribution (figs. $2 C$ and $2 E$ ). XRD, optical microscopy, and SEM demonstrated that for concentrations of dissolved magnesium ion at or less than $10^{-4} M$, the final crystalline product was calcite. Sufficiently high concentrations of magnesium ion $\left(10^{-3} \mathrm{M}\right)$ caused the percentage of vaterite spheres to increase relative to calcite rhombs.

The degree of incorporation of magnesium ion in the precipitate varied with the presence or absence of stirring and with the initial magnesium concentration. Initial total concentrations of magnesium ion were selected to eliminate the formation of magnesium carbonate phases. Magnesium-to-calcium ratios thus were low, ranging from 0.2 to 0.02 in the initial solution. The calcium ion concentration decreased markedly during precipitation, whereas the magnesium ion concentration changed only slightly. Thus, as the precipitation experiment approached equilibrium the magnesium-to-calcium ratio in the solution increased. For an initial unstirred solution containing $1 \times 10^{-3} M$ total concentration of magnesium ion, the precipitate contained about 1 percent magnesium. Experiment 12 (table 1) yielded a precipitate containing 1 mole percent magnesium ion 3 minutes after the onset of nucleation. Four subsequent analyses of the precipitate at intervals over the next 100 minutes showed that the mole percent magnesium decreased to 0.7 percent. Precipitation from a similar solution that had an initial concentration of magnesium ion of $5 \times 10^{-4} \mathrm{M}$ showed 0.7 mole percent magnesium in the precipitate 3 minutes after nucleation, whereas after 10 minutes the magnesium

Figure 2 (facing page). Scanning electron micrographs of calcium carbonate precipitates from stirred and unstirred solutions. $A$, unstirred solution, 3 minutes after nucleation. $T_{M g}=$ $5 \times 10^{-4} \mathrm{M}$. B, stirred solution, 5 minutes after nucleation, no added magnesium ion. $C$, as in $B$ but 1 day after nucleation. $D$, stirred solution, 5 minutes after nucleation. $T_{\mathrm{Mg}}=1 \times 10^{-4}$ $M$. $E$, as in $D$ but 1 day following nucleation. Bar marker is one micrometer long. 

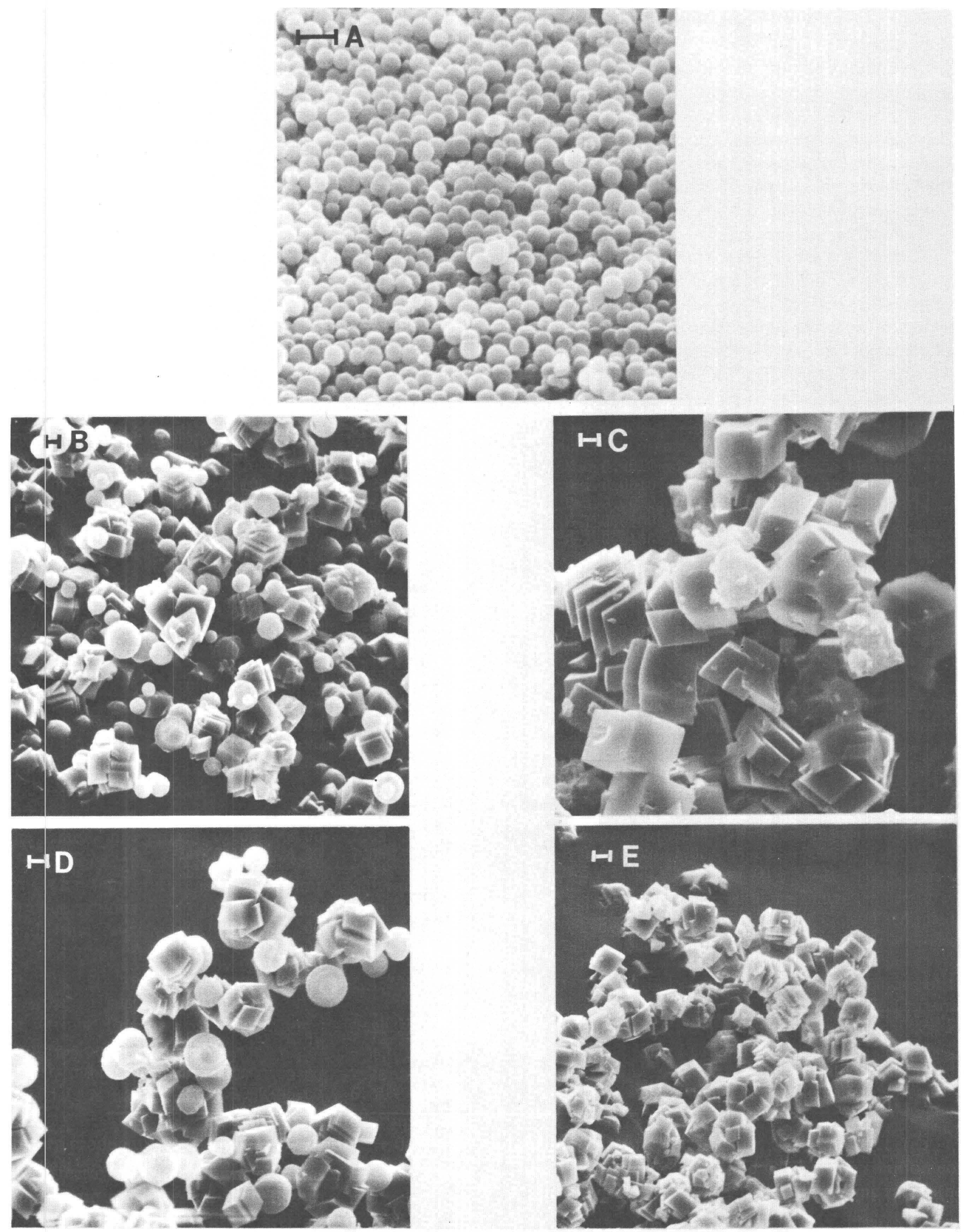
content of the precipitate had decreased slightly to 0.6 mole percent.

Continuous stirring following nucleation yielded precipitates with somewhat higher magnesium ion contents. Experiment 2, which was equivalent to experiment 12 except that it was unstirred, produced an initial precipitate that contained 2.3 mole percent magnesium 5 minutes after nucleation. The magnesium content of the precipitate decreased to 1.6 mole percent within the first 100 minutes of reaction.

In each nucleation experiment (stirred and unstirred) that was sampled successively during the reaction, the magnesium content of the initial precipitate was at a maximum. As the precipitate aged, its magnesium content decreased, typically several tenths of 1 percent over the course of the experiment. In contrast, the precipitates that formed in the sealed-bottle experiments showed higher magnesium contents at the termination of the reaction. Inasmuch as copius amounts of calcium carbonate precipitated in the first few minutes of the reaction, changes in the magnesium ion content of the precipitate were probably due in large part to transformation and recrystallization processes.

The variation in the magnesium content of the precipitate during the formation of $\mathrm{CaCO}_{3}$ may be due to a number of factors. The reaction rate is important because at high rates of precipitation (at the start of reaction) more magnesium was incorporated in the precipitate than later in the reaction when the reaction rates were significantly lower. This observation is in agreement with that of Berner (1978), who reported that experiments at high supersaturation and high precipitation rates produced calcites richer in magnesium. The incorporation of magnesium during the precipitation of calcium carbonate may have involved polymorphs other than calcite which have dissimilar magnesium ion distribution coefficients, thus leading to a variation in the distribution coefficient with changing polymorph composition.

Long-term experiments involved the recrystallization of the calcium carbonate precipitate in a solution having a magnesium-to-calcium ratio significantly higher than that at the initiation of the precipitation. Thus, because of the higher ratio, magnesium ion may have been incorporated into the precipitate either via a solid state exchange of surface magnesium or by the formation of a magnesium-rich surface phase.

\section{Nucleation in metastable solutions}

The nucleation and subsequent crystallization of calcium carbonate in stirred, metastable-supersaturated solutions (table 2) formed less complex precipitates than those that formed from labile-supersaturated solutions. Lower initial supersaturations in metastable solutions reduced the amount of initial noncrystalline precipitate
Table 2. Calcium carbonate nucleation without and with magnesium ion at $25^{\circ} \mathrm{C}$

[Leaders (--) indicate no added magnesium ion; $\Omega_{c}$, supersaturation; $t_{I}$ induction interval, in seconds]

\begin{tabular}{|c|c|c|c|c|c|c|}
\hline \multirow[b]{2}{*}{$\begin{array}{l}\text { Experi- } \\
\text { ment }\end{array}$} & \multicolumn{3}{|c|}{$\begin{array}{l}\text { Total initial concentration } \\
\text { (moles per liter) } \times 10^{4}\end{array}$} & \multirow[b]{2}{*}{$\mathrm{pH}$} & \multirow[b]{2}{*}{${ }^{\Omega_{C}}$} & \multirow[b]{2}{*}{$\underline{t} I$} \\
\hline & $\mathrm{Ca}^{2+}$ & $\mathrm{Mg}^{2+}$ & $\mathrm{CO}_{3}{ }^{2-}$ & & & \\
\hline 3 & 26.64 & --- & 41.39 & 8.565 & 27.8 & 480 \\
\hline 4 & 13.32 & -- & 41.39 & 8.567 & 15.5 & 2,100 \\
\hline 6 & 33.30 & -- & 41.39 & 8.502 & 29.2 & 420 \\
\hline 7 & 13.32 & -- & 41.39 & 8.654 & 18.6 & 1,500 \\
\hline 8 & 26.64 & -- & 41.39 & 8.505 & 24.5 & 660 \\
\hline 9 & 33.30 & --- & 41.38 & 8.545 & 32.0 & 300 \\
\hline 12 & 46.62 & --- & 41.38 & 8.448 & 33.9 & 300 \\
\hline 13 & 6.66 & -- & 41.38 & 8.832 & 14.2 & 4,500 \\
\hline 16 & 19.98 & --- & 41.38 & 8.647 & 26.1 & 720 \\
\hline M2 & 40.05 & 3.214 & 41.64 & 8.585 & 39.9 & 300 \\
\hline M3 & 26.70 & 2.142 & 41.64 & 8.665 & 34.2 & 450 \\
\hline M4 & 13.35 & 1.071 & 41.64 & 8.830 & 25.6 & 960 \\
\hline M12 & 43.74 & 15.01 & 41.55 & 8.419 & 28.7 & 1,050 \\
\hline M14 & 26.05 & 25.91 & 41.64 & 8.523 & 22.4 & 1,740 \\
\hline M17 & 52.09 & 51.82 & 41.64 & 8.302 & 22.6 & 1,680 \\
\hline M22 & 6.34 & 12.75 & 41.69 & 8.725 & 13.9 & 8,640 \\
\hline M25 & 50.00 & 252.09 & 41.71 & 8.135 & 10.7 & 15,120 \\
\hline M27 & 72.67 & 385.34 & 41.71 & 8.025 & 10.8 & 15,600 \\
\hline
\end{tabular}

and led to smaller amounts of unstable polymorphs. Direct nucleation (that is, crystal formation from an initially supersaturated solution without intervention of an antecedent) appeared to be important in the development of the ultimate crystal assemblage.

The predominate crystalline components of the precipitate, over a range of magnesium ion concentrations and supersaturations, were vaterite and aragonite. The formation of calcite from the metastable solutions was retarded. Some aged solutions, containing low concentrations of magnesium ion, developed calcite as a final precipitate. In these experiments, initially formed vaterite transformed to calcite during the course of the experiment. Precipitates from solutions containing high concentrations of magnesium ion were aragonite.

An abrupt change in solution $\mathrm{pH}$ and turbidity was used to identify calcium carbonate nucleation. The time required to initiate this change after the component solutions were mixed was considered to be the induction interval $\left(t_{T}\right)$. At low supersaturations, changes in the solution $\mathrm{pH}$ and turbidity during nucleation were less pronounced. Induction intervals and the number of particles formed during nucleation (particles per milliliter) exhibited little systematic variation with changing magnesium ion concentration (fig. 3).

Both the induction interval and the number of particles per milliliter followed a log-log linear relationship with calcite supersaturation; the best-fit line for solutions containing magnesium ion lay slightly above that for the magnesium-free solution (fig. 3). The presence of magnesium ion in the supersaturated solutions lengthened the induction interval and led to a larger number of 
nucleation particles. Nucleation rates, defined as $N / t_{I}$, were thus used to identify the metastable region of calcium carbonate supersaturation and to quantify the influence of magnesium ion on this region (fig. 4).

As discussed previously, metastable solutions can be divided into two groups: (1) those having a very small nucleation rate, and (2) those having a measurable nucleation rate, with subsequent crystalline phase formation in a specific time interval $t_{r}$. A rate of 50 particles per cubic centimeter per second has been chosen as the boundary between these two regions. For the experiments shown in figure 4 , the calcium carbonate metastable region extends from $\Omega_{c}=1$ to $\Omega_{c}=10$. Inasmuch as the presence of magnesium ion increased both the induction interval and the nucleation particle number in roughly the same proportion, magnesium ion did not appear to have altered the calcium carbonate nucleation rate appreciably.

\section{Calcite-seeded crystallization}

The initial conditions for calcite-seeded growth experiments are given in table 3. Typical plots of the concentration of calcium in solution and $\mathrm{pH}$ against time for calcite growth in the presence and absence of magnesium ion illustrate that seed crystals induced immediate crystal growth. Total calcium concentrations and solution $\mathrm{pH}$ 's demonstrate that magnesium ions did not prevent crystallization, but that they reduced the calcite crystallization rate markedly. The role of magnesium ions is most clearly shown with the second addition of seed crystal to solutions with the high magnesium-ion concentration. Initially, the concentration of calcium in solution decreased only slightly, but if more seeds were added the growth rate nearly equaled that of the magnesium-free control reaction. The formation of calcite from supersaturated solutions with a high concentration of magnesium ions was thus kinetically inhibited and proceeded only when sufficient reactive surfaces were available. Magnesium exhibited no marked changes in solution concentration during the course of the reaction. The crystallization rates followed an expression found to hold in earlier work (Reddy, 1978):

$$
d N / d t=k s N^{2},
$$

where $N$ is the amount of calcium carbonate in moles per liter at time $t$ (from the start of the reaction by addition of seed crystal) in minutes to be precipitated to reach (calcite) equilibrium; $d N / d t$ is the calcite crystallization reaction rate; $k$ in [(moles per liter) $\times$ minutes $\times$ milligrams of seed crystal per liter $]^{-1}$ is the crystal growth-rate constant; and $s$ in milligrams of seed per liter is the added seed concentration and is proportional to the surface area available for growth.
Analysis of the data for the seeded crystallization experiments was facilitated by use of an integrated form of equation 1 :

$$
N^{-1}-N_{0}^{-1}=k s t,
$$

where $N_{0}$ (the initial theoretical crystal yield) is calcite (moles per liter) to be precipitated from the stable supersaturated solution at the time of seed inoculation. Linear plots of $N^{-1}-N_{0}^{-1}$ versus time demonstrate the validity of equation 2 (Reddy, 1978) for interpreting the experimental results. Rate constants for calcite crystallization in solutions with and without magnesium ion are listed in table 3 . The parabolic dependence of the crystal growth rate (the $N^{2}$ term in equation 1) is consistent with a calcite crystallization mechanism involving a ratelimiting surface reaction step at the crystal face (Reddy, 1978).

Equation 2 enables a quantitative description to be made of the influence of magnesium ion on calcite crystallization kinetics. Plots of $N^{-1}-N_{0}^{-1}$ versus time showed a decrease in slope ( $k s$ from equation 2 ) with increasing magnesium ion concentration. The influence of magnesium ion on the calcite crystallization rate was compared for different experiments by plotting the reduced reactionrate constant, $k / k_{0}$ (where $k$ is for solutions containing magnesium ion and $k_{0}$ is for magnesium-free control experiments), as a function of the magnesium ion concentration (fig. 5). This plot presents the data shown in table 3 as well as two sets of published data. The good agreement of the four independent sets of experimental results is evidence of the reliability of the seeded-growth technique. Rate-constant reduction occurred at magnesium ion concentrations of $10^{-5} M$; pronounced decrease in the rate constant was evident above $2 \times 10^{-4} M$. Previous investigations have shown that calcite growth-rate reduction follows a Langmuir-type adsorption model (Reddy, 1978). If this treatment is appropriate, the crystallization rate constant in the presence and absence of magnesium ion is

$$
k_{0} /\left(k_{0}-k\right)=1+k_{2}\left(k_{1} T_{\mathrm{Mg}^{2+}}\right)^{-1}
$$

where $k_{1}$ and $k_{2}$ are the adsorption and desorption rate constants, respectively, for magnesium ion at the growth sites on the crystal surface, and $T_{\mathrm{Mg}^{2+}}$ is the total concentration of dissolved magnesium ion. A linear relationship between $k_{0} /\left(k_{0}-k\right)$ and the reciprocal of the total magnesium ion concentration (fig. 6) demonstrates that the Langmuir adsorption isotherm model described the inhibition satisfactorily. This agreement over a wide range of solid to solution ratios implies that inhibition of calcite growth was due to the adsorption of magnesium ion at growth sites on the crystal surface. 


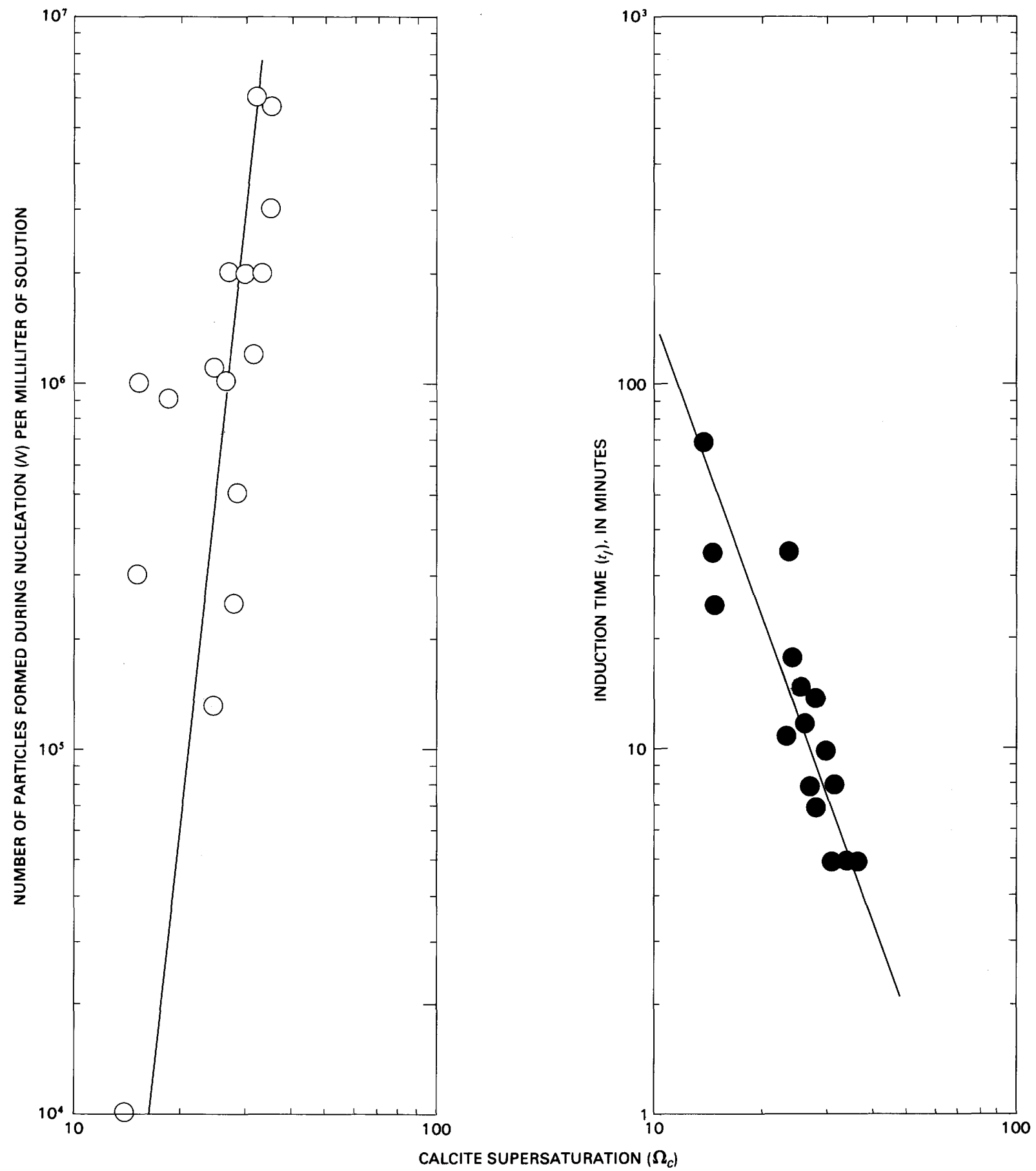

Figure 3 (above and facing page). Number of nucleation particles and induction interval versus calcite supersaturation for precipitation without and with magensium ions.

\section{Approach to calcite equilibrium}

Whereas an adsorption mechanism is compatible with calcite growth-rate inhibition by magnesium ion during most of the reaction, equation 1 does not describe the crystallization process near equilibrium. In the absence of magnesium ion, and at an intermediate seed-crystal concentration, calcite equilibrium was attained within 100 minutes of reaction. In the presence of magnesium ion, even with significantly higher seed concentration, the crystallization did not reach calcite equilibrium (fig. 7). In several experiments, the solution composition after extended reaction time changed only slightly and appeared to approach steady-state calcite supersaturations 

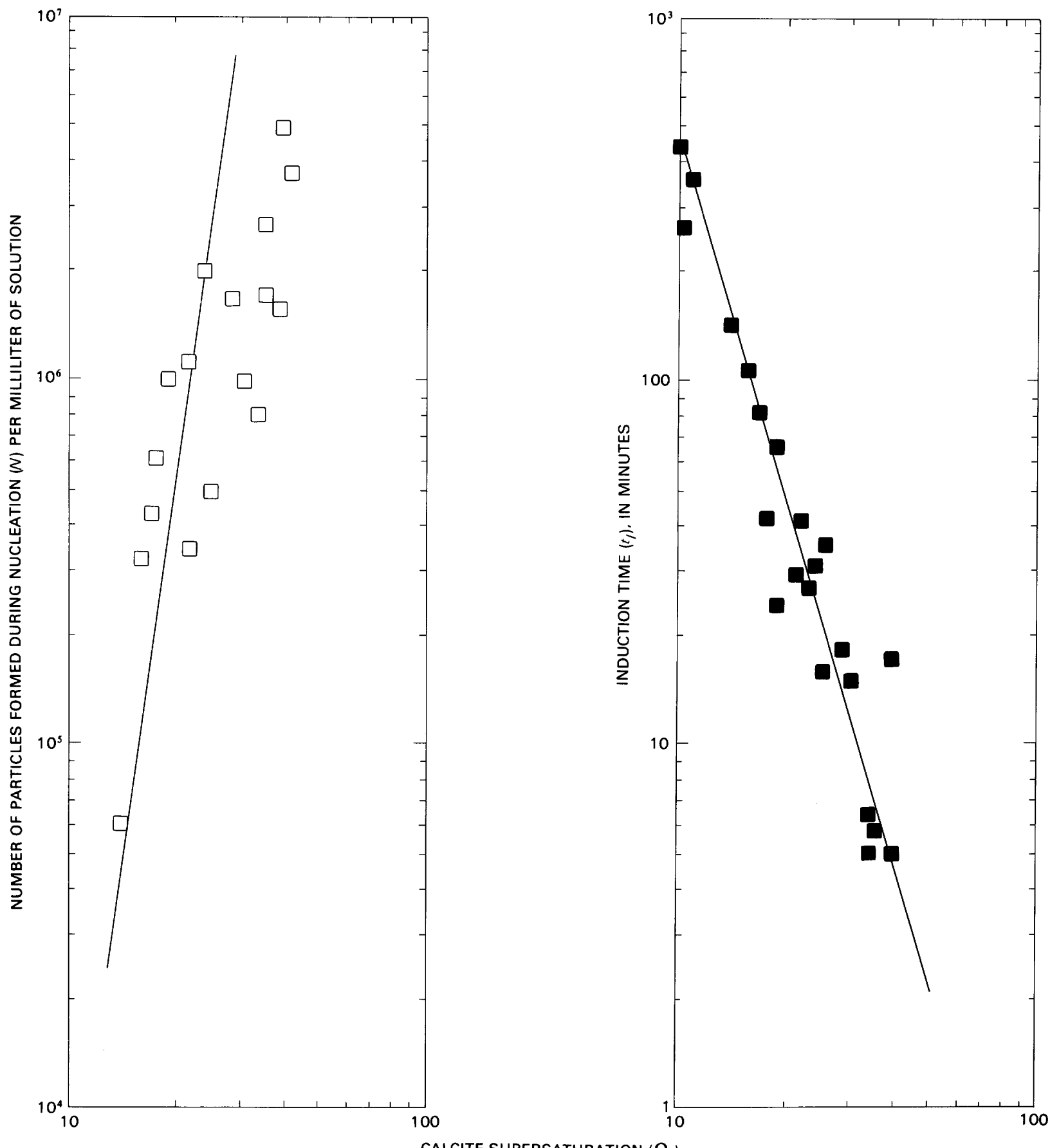

significantly greater than equilibrium. This steady-state calcite supersaturation value was related to both the initial magnesium ion concentration and the seed-crystal concentration (fig. 8). Changes in the concentration of magnesium ion during calcite growth were not statistically significant over the initial phase of the reaction. Longterm equilibration and successive seed additions, however, led to the loss of magnesium ion from solution.

Steady-state supersaturation, the saturation value approached in solutions at long reaction times, was clearly related to magnesium-ion concentration (fig. 7). At higher magnesium-ion concentrations, steady-state supersaturation was higher. With a second addition of seeds, new steady-state supersaturations were reached which were closer to calcite equilibrium. Steady-state supersaturation values for several replicate experiments at intermediate seed concentrations were in good agreement. Crystallization experiments, at similar seed-crystal concentrations, exhibited steady-state supersaturation, which was a function of the log magnesium ion concentration (fig. 8). This 
Table 3. Experimental conditions, seed crystal concentrations (s), and rate constants $(k)$ for calcite growth in the presence and absence of magnesium ion

[ $s$ in milligrams per liter; rate constant $(k)$ in (moles per liter) '(minutes) ' (milligrams of seed per liter)]

\begin{tabular}{|c|c|c|c|c|c|c|c|c|}
\hline \multirow{3}{*}{$\begin{array}{c}\text { Experi- } \\
\text { ment }\end{array}$} & \multicolumn{4}{|c|}{$\begin{array}{l}\text { Initial concentration of ions in } \\
\text { solution (moles per liter) } \times 10^{4}\end{array}$} & \multirow[b]{3}{*}{$\mathrm{CO}_{3}{ }^{2-}$} & \multirow[b]{3}{*}{$\mathrm{pH}$} & \multirow[b]{3}{*}{$\underline{s}$} & \multirow[b]{3}{*}{$\underline{k}$} \\
\hline & \multicolumn{3}{|c|}{ Total } & \multirow[b]{2}{*}{$\mathrm{Ca}^{2+}$} & & & & \\
\hline & $\mathrm{Ca}^{2+}$ & $\mathrm{Mg}^{2+}$ & $\mathrm{CO}_{3}{ }^{2-}$ & & & & & \\
\hline $\begin{array}{l}S C-1 \\
S C-2 \\
S M-1 \\
S M-2 \\
S M-3\end{array}$ & $\begin{array}{l}2.258 \\
2.238 \\
2.315 \\
2.172 \\
2.078\end{array}$ & $\begin{array}{l}0 \\
0 \\
10.979 \\
10.979 \\
5.227\end{array}$ & $\begin{array}{l}40.97 \\
40.97 \\
40.97 \\
40.97 \\
38.62\end{array}$ & $\begin{array}{l}1.874 \\
1.848 \\
1.924 \\
1.837 \\
1.749\end{array}$ & $\begin{array}{l}2.307 \\
2.357 \\
2.393 \\
2.394 \\
2.279\end{array}$ & $\begin{array}{l}9.01 \\
9.02 \\
9.00 \\
9.00 \\
9.02\end{array}$ & $\begin{array}{c}248 \\
24.8 \\
1247 \\
1247 \\
2327\end{array}$ & $\begin{array}{l}1.40 \\
1.42 \\
0.0124 \\
0.0084 \\
0.020\end{array}$ \\
\hline $\begin{array}{l}\text { SM-4 } \\
\text { SM-5 } \\
36 \\
38 \\
40\end{array}$ & $\begin{array}{l}2.243 \\
2.197 \\
1.862 \\
2.297 \\
2.165\end{array}$ & $\begin{array}{c}2.233 \\
5.723 \\
0 \\
13.08 \\
6.066\end{array}$ & $\begin{array}{l}40.97 \\
40.97 \\
41.86 \\
42.30 \\
39.86\end{array}$ & $\begin{array}{l}1.875 \\
1.828 \\
1.679 \\
2.031 \\
1.938\end{array}$ & $\begin{array}{l}2.288 \\
2.382 \\
1.035 \\
1.385 \\
1.262\end{array}$ & $\begin{array}{l}9.00 \\
9.01 \\
8.638 \\
8.736 \\
8.736\end{array}$ & $\begin{array}{r}249 \\
248 \\
249 \\
1370 \\
2410\end{array}$ & $\begin{array}{l}0.162 \\
0.037 \\
1.49 \\
0.0012 \\
0.025\end{array}$ \\
\hline
\end{tabular}

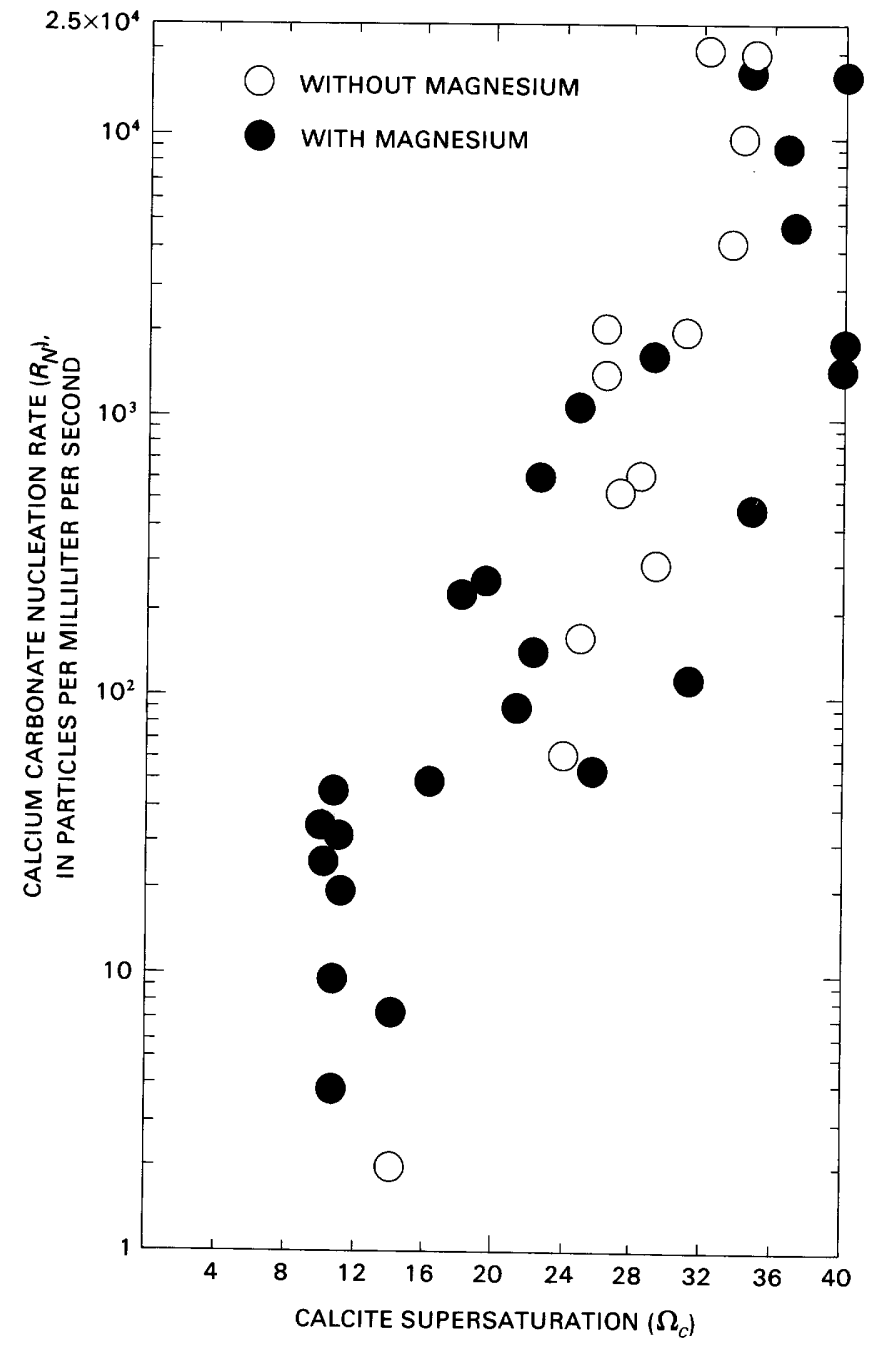

Figure 4. Calcium carbonate nucleation rate versus calcite supersaturation in solutions without and with magnesium ions. situation may have arisen because of irreversible adsorption of magnesium ion on the calcite surface forming localized areas of a magnesium-rich phase. This explanation is consistent with the suggestion of Fajans (1931) that an ionic species is strongly adsorbed on a crystalline solid if that species forms an insoluble compound with opposite charged ions of the crystal structure. A quantitative description of this process is difficult to develop on a theoretical basis, because the incorporation of magnesium ion during growth led to changing surface properties with time. The incorporation of magnesium ion (or subsequent exclusion from a growth phase) may have been a function of growth rate. During rapid crystallization, ions may be incorporated in a crystal by a process that does not correspond to simple adsorption (Adamson, 1960). Such adsorption would be accompanied by surface exchange. In the present experiments, magnesium ions may have been continually taken up or released as each growth layer came into exchange equilibrium with the substrate crystal and the solution. The final steady-state supersaturation value decreased linearly (fig. 8) with increasing log of the seed concentration.

Other authors have emphasized the kinetic restrictions associated with the heterogenous reactions of aqueous calcium carbonate in the presence of magnesium ion. For example, Thorstenson and Plummer $(1977,1978)$ termed the steady-state solution composition in such systems "stochiometric saturation." The solid phase in contact with this solution remains invariant, even though it may be part of a continuous compositional series. They proposed that the magnesium content of solid calcium carbonate should be governed primarily by the activity product of calcium and carbonate ions in solution. From the thermodynamic requirements of stoichiometric saturation, the solution magnesium-to-calcium ratio should not be a major regulating factor in determining 


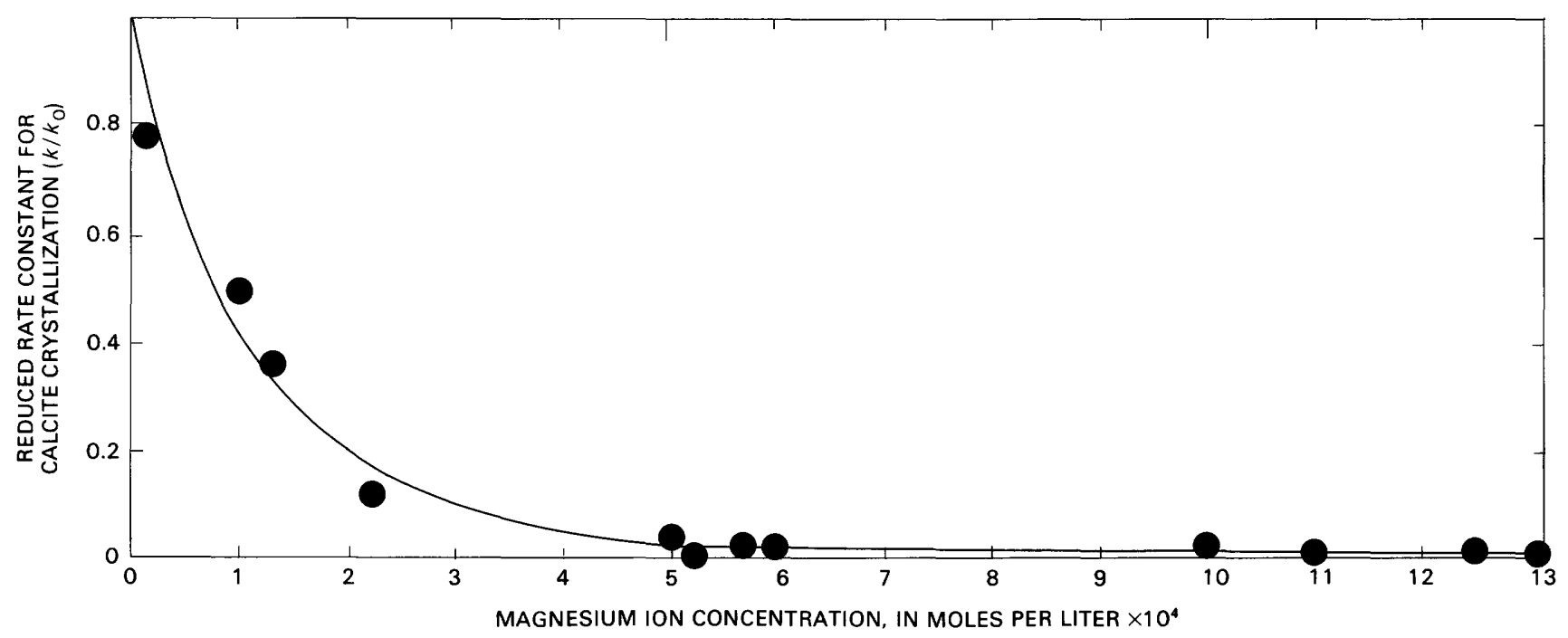

Figure 5. Calcite crystallization reduced-rate constant $\left(k / k_{0}\right)$ as a function of the concentration of magnesium ion in solution.

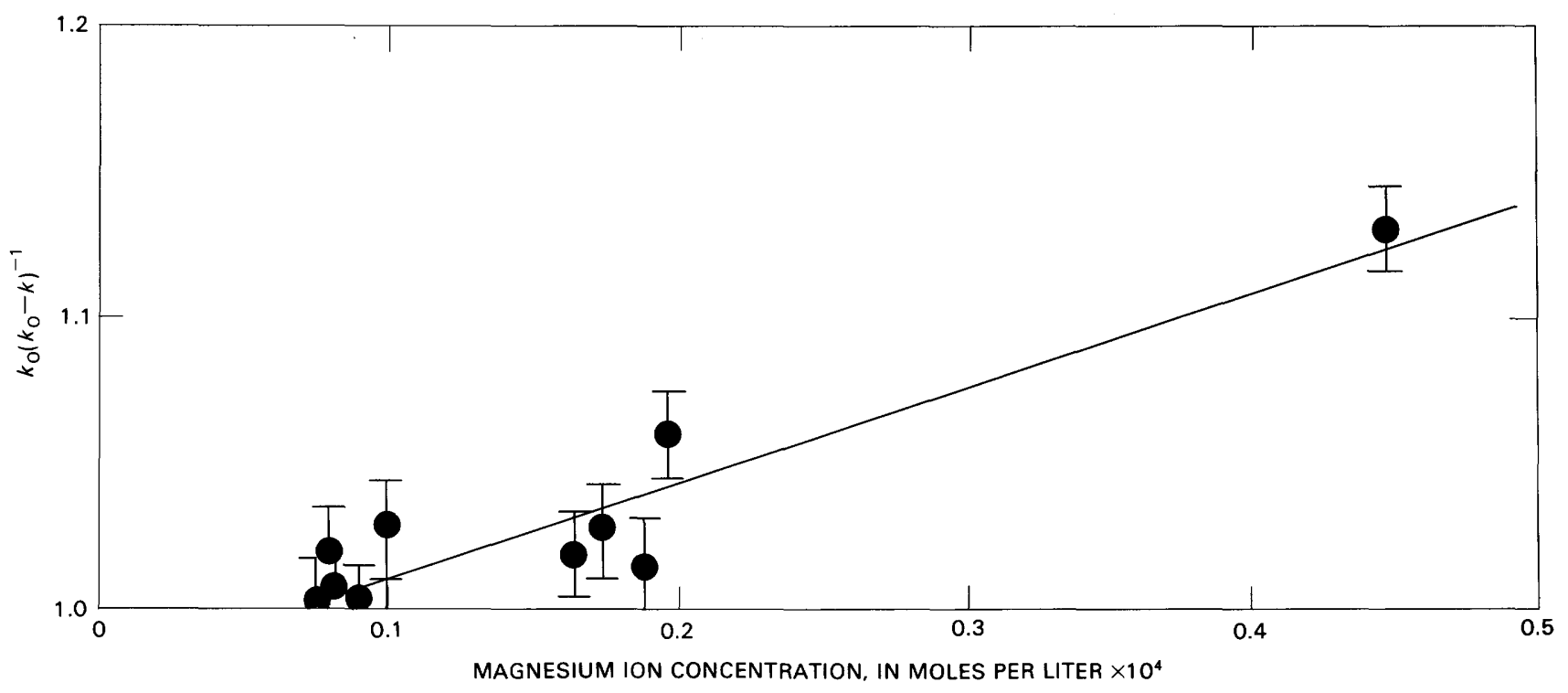

Figure 6. Langmuir isotherm plot of $k_{0} /\left(k_{0}-k\right)$ versus the reciprocal of the magnesium ion concentration.

the composition of the solid phase. Results obtained in the seeded-crystallization experiments are consistent with the hypothesis of Thorstenson and Plummer, because calcite containing little or no magnesium ion formed over the range of experimental conditions used.

Berner (1978), in discussing the magnesium content of calcite precipitated from seawater, emphasized that the composition of the solid phase is controlled by kinetic factors, and that it does not represent exchange equilibrium of calcium and magnesium ions between seawater and calcite. Morse and others (1979) observed a magnesium calcite growth onto a calcite crystal suspended in seawater. This incorporation of magnesium in the growth phase in the seawater experiments differs from the dilute solution results presented in this paper. The differences may be due in part to the higher ionic strength of the seawater medium or to naturally occurring calcite-growth inhibitors present in seawater, which could have facilitated the formation of magnesium calcite. Additional work on the comparison of laboratory and field calcium carbonate formation kinetics seems needed.

\section{CONCLUSIONS}

Diagenetic transformations of sedimentary carbonate minerals arise from numerous processes including calcium carbonate nucleation and crystal growth. Results obtained in this study demonstrate that calcium carbonate mineral formation was characterized reliably and reproducibly over a range of magnesium ion concentrations. Both magnesium ion distribution and calcium carbonate 


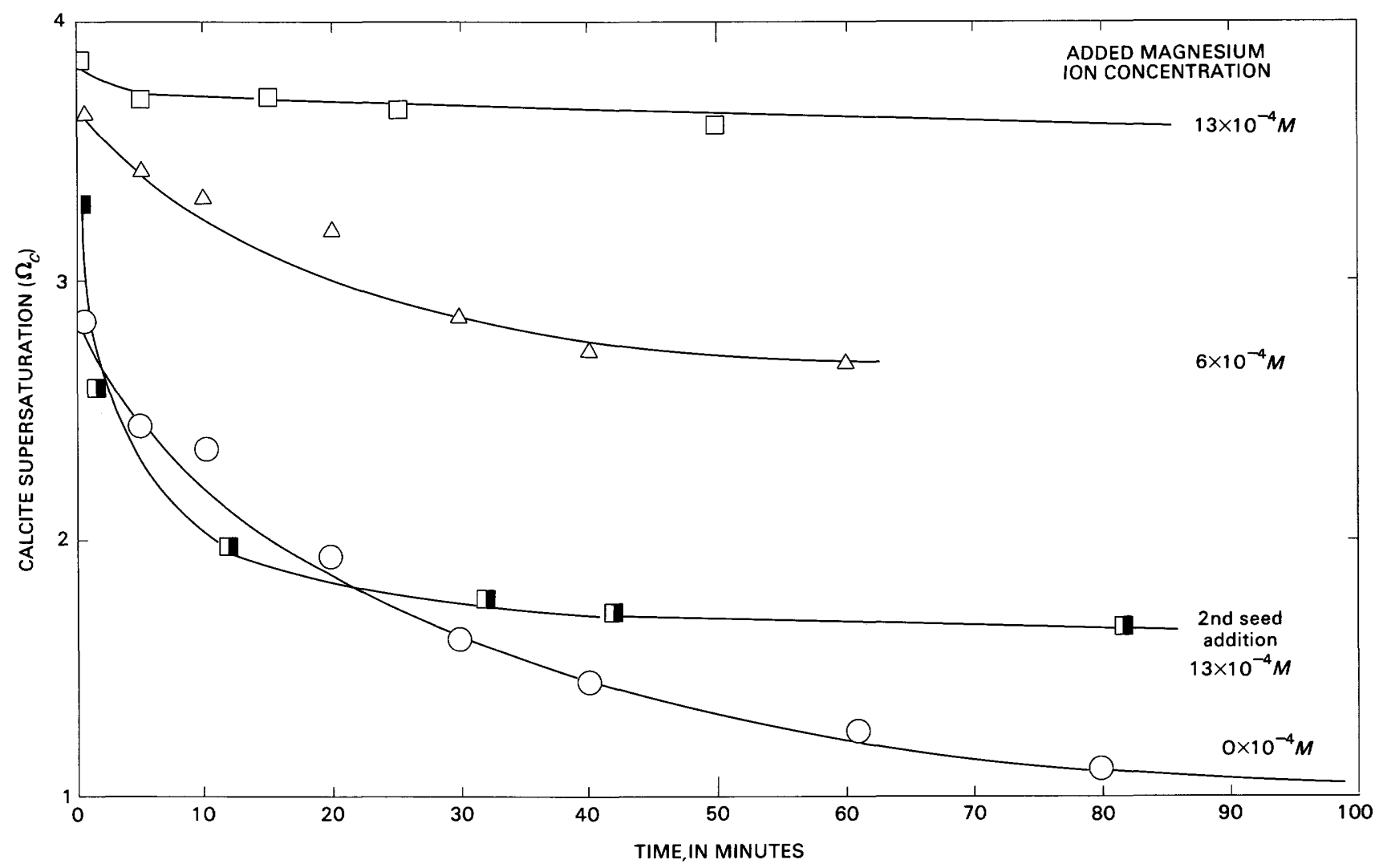

Figure 7. Calcite supersaturation versus time for calcite-seeded crystallization without and with magnesium ions.

formation exhibited systematic variations over a wide range of calcium carbonate formation rates and supersaturations.

Solution supersaturation, hydrodynamics, magnesium ion concentration, and reaction path were involved in regulating the course of calcium carbonate formation. Supersaturation level was of paramount importance in the experiments examined here. At high supersaturations nucleation proceeded rapidly, yielding an unstable and reactive initial precipitate, which rapidly transformed to more stable carbonate minerals. Solution hydrodynamics and the concentration of magnesium ion had a secondary influence on the nucleation reaction at high supersaturation.

At intermediate supersaturations (10-40) the influence of supersaturation on the precipitation reaction was also important: nucleation particle number and induction interval followed a log-log linear relationship with supersaturation. As observed at high supersaturation, magnesium-ion concentration level had a secondary influence on the rate and course of reaction. High magnesium-ion concentrations regulated the polymorphic composition of the final $\mathrm{CaCO}_{3}$ precipitate.

For calcite-seeded growth from metastable solutions (supersaturations of less than 10 ), nucleation processes were unimportant. The growth rate followed a second-order rate equation, consistent with a surface reaction rate-determining step. Magnesium ion reduced calcite formation under these conditions by blocking growth sites on the seed crystal surface. Variation of the reaction rate constant with magnesium ion concentration is consistent with a Langmuir adsorption isotherm model. Because many sediment reactions occur in metastable solutions, the quantitative description of the influence of magnesium ion on the calcite crystallization rate may be useful in interpreting field observations. Additional support for a kinetic mechanism for the retardation of the growth rate of calcite by magnesium ion is that the steady-state supersaturation, reached at the apparent end of the crystallization experiment, was a function of the experimental solution-tosolid ratio. The formation of a magnesium-containing surface phase did not appear to be associated with the mechanism of magnesium ion inhibition of calcite crystal growth.

Bathurst (1983) pointed out several puzzling aspects of carbonate cement mineralogy which may be clarified by a fuller understanding of the chemical processes involved in calcite crystal growth. Cement formation and dissolution reactions are regulated in large measure by the solution concentration of magnesium ion; however, supersaturation levels and the presence of a reactive growth surface can be more influential than magnesium ion concentration in some situations. 


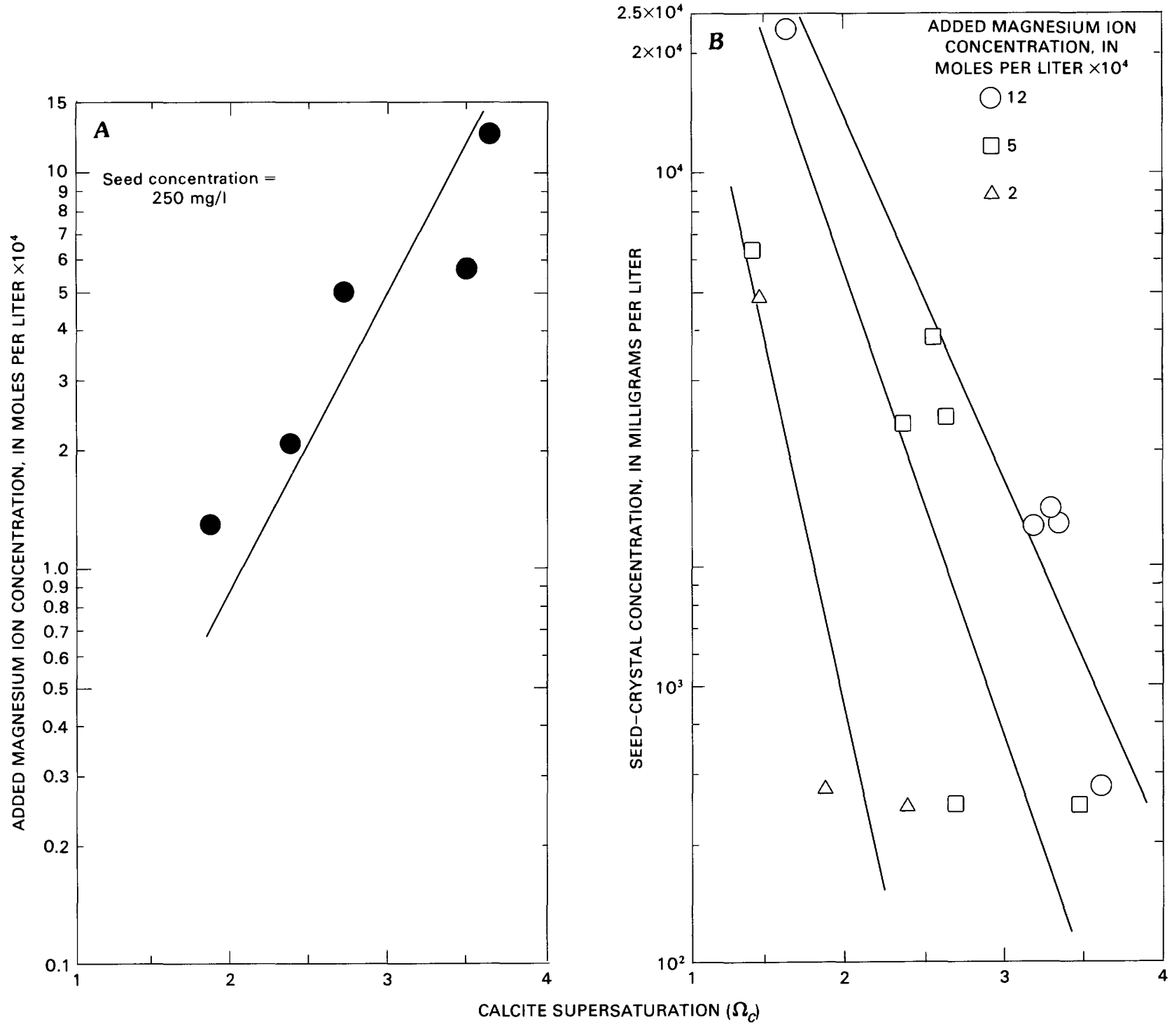

Figure 8. Steady-state calcite supersaturation versus $(A)$ initial total magnesium-ion concentration and $(B)$ initial seed-crystal concentration.

As an example of the application of laboratory results to a field situation, consider the formation of lowmagnesian calcite from marine sediments that have been uplifted and bathed in fresh water. Mackenzie and others (1983) summarized the results of numerous investigations which showed magnesium loss and fabric retention during freshwater diagenesis of high-magnesian calcites. This reaction depends strongly on solution supersaturation level and the presence of crystallization inhibitors. Although the high-magnesian calcites are less stable than low-magnesian calcite, the transformation from the unstable phase to the stable phase was not observed until the sediment pore water changed from a marine to a freshwater composition.

It is unclear whether the rate-limiting step in the transformation is the dissolution or the crystallization process. If the crystallization reaction is rate-limiting and calcite supersaturation values are fixed by the solubility of the high-magnesian calcite, calcite will not form until the solution concentration of magnesium ion decreases to a value consistent with an appreciable calcite growth rate. If a minimum necessary rate constant is assumed to be 1 percent of the value in the absence of magnesium ion, from the data in table 3 , the magnesium concentration associated with this calcite growth-rate constant is about 1-2 millimoles of magnesium ion per liter. To reduce a seawater magnesium-ion concentration to this value requires a 50-fold dilution, a value consistent with circulation of a low-magnesium fresh water in the uplifted sediment. Conversion rates would also be regulated by hydrodynamic factors, including the pore-water flushing rate.

The observed microstructure retention during the transformation implies low-solution supersaturations and 
low growth rates. Release of magnesium ion to the pore water during recrystallization will limit supersaturation and growth rates at the microstructure level.

The important point concerning the application of laboratory studies to carbonate-sediment diagenesis is that information about the mechanism of magnesium ion regulation of carbonate-sediment diagenetic reactions is available. Laboratory studies, such as those presented in this paper, give reliable, quantitative estimates of the influence of magnesium ion on mineralogical changes that occur in sediments. Additional work is needed to extend these results to actual sedimentary environments.

\section{REFERENCES CITED}

Adamson, A. W., 1960, Physical chemistry of surfaces: New York, Wiley-Interscience Publishers, $629 \mathrm{p}$.

Bathurst, R. G. C., 1983, Early diagenesis of carbonate sediments, in Parker, A., and Sellwood, B. W., eds., Sediment diagenesis: Boston, Mass., D. Reidel Publishing Company, p. 349-377.

Berner, R. A., 1978, Discussion-Equilibrium, kinetics, and the precipitation of magnesium calcite from seawater: American Journal of Science, v. 278, p. 1475-1477.

Fajans, Kasimir, 1931, Radio elements and isotopes; chemical forces and optical properties of substances: New York, McGraw-Hill, $125 \mathrm{p}$.
Jacobson, R. L., and Langmuir, D., 1974, Dissociation constants of calcite and $\mathrm{CaHCO}_{3}^{+}$from 0 to $50^{\circ} \mathrm{C}$ : Geochimica et Cosmochimica Acta, v. 38, p. 301-318.

Mackenzie, F. T., Bischoff, W. D., Bishop, F. C., Loijens, M., Schoonmaker, J., and Wollast, R., 1983, Magnesian calcites-Low-temperature occurrence, solubility, and solidsolution behavior, in Reeder, R. J., ed., CarbonatesMineralogy and chemistry: Washington, D.C., Mineralogical Society of America Reviews in Mineralogy, v. 11, p. 97-144.

Morse, J. W., Mucci, A., Walter, L. M., and Kaminsky, M. S., 1979, Magnesium interaction with the surface of calcite in seawater: Science, v. 205, p. 904-905.

Reddy, M. M., 1978, Kinetic inhibition of calcium carbonate formation by wastewater constituents, in Rubin, A. J., ed., The chemistry of wastewater technology: Ann Arbor, Michigan, Ann Arbor Science Publishers, Inc., p. 31-58.

Reddy, M. M., and Nancollas, G. H., 1976, The crystallization of calcium carbonate-IV. The effect of magnesium, strontium and sulfate ions: Journal of Crystal Growth, v. 35, p. 33-38.

Thorstenson, D. C., and Plummer, L. N., 1977, Equilibrium criteria for two-component solids reacting with fixed composition in an aqueous phase-Example, the magnesium calcites: American Journal of Science, v. 277, p. 1203-1223.

1978, Discussion:-Equilibrium criteria for twocomponent solids reacting with fixed composition in an aqueous phase-Example, the magnesium calcites: American Journal of Science, v. 278, p. 1478-1488. 


\title{
Authigenic Potassium Feldspar in Ribbon Rocks of the Cambrian-Conococheague Limestone, Western Maryland
}

By PAUL P. HEARN, Jr., U.S. Geological Survey, MS 957, National Center, Reston, Virginia 22092, ROY C. LINDHOLM, George Washington University, 2021 G Street N.W., Washington, D.C. 20002, and

JOHN F. SUTTER, U.S. Geological Survey, MS 981, National Center, Reston, Virginia 22092

\section{CONTENTS}

\author{
Abstract 185 \\ Introduction 185 \\ Methods 186 \\ Results and discussion 186 \\ Petrography of ribbon rocks $\mathbf{1 8 6}$ \\ Accessory minerals $\mathbf{1 8 8}$ \\ Microprobe analyses 189 \\ Chemistry of insoluble residues 190 \\ X-ray diffraction mineralogy 190 \\ Evidence of interstitial brines 190 \\ Thermochemical and mass-balance considerations 192 \\ Timing of feldspathization 193 \\ Conclusions 195 \\ References cited 195
}

\section{FIGURES}

1. Map of study area showing locations of outcrops where samples were collected 185

2-3. Photographs:

2. Ribbon rock in outcrop, showing dolostone and limestone interbeds 186

3. Slabbed sample of ribbon rock, showing detail of individual dolostone and limestone interbeds 186

4. Photomicrograph of interface between individual fine-grained dolostone and coarser-grained limestone interbeds 187

5-8. Scanning electron micrographs:

5. Adjacent dolostone and limestone interbeds, showing differences in grain size and microporosity of dolostone 187

6. Adjacent dolostone and limestone interbeds taken with backscattered electron detector 188

7. Adjacent dolostone and limestone interbeds showing electronexcited cathodoluminescence of detrital phases 188

8. Detrital quartz and potassium feldspar, showing relative luminescent intensity 189

9. Diagram showing analyses of ethylenediamine tetraacetic acid-insoluble residues of individual limestone and dolostone interbeds 191 
10. X-ray diffractograms of ethylenediamine tetraacetic acid-insoluble residue, showing characteristic reflections of fine-grained potassium feldspar in dolostone interbeds, sand-size potassium feldspar with overgrowths in limestone interbeds, and detrital cores of potassium feldspar grains from limestone interbeds following removal of overgrowths by dissolution in dilite hydrofluoric acid 192

11. Scanning electron micrograph of halite daughter crystal in fluid inclusion cavity in calcite breached during polishing 193

12. Plot of ${ }^{40} \mathrm{Ar} /{ }^{39} \mathrm{Ar}$ age spectra for detrital potassium feldspar with overgrowths and detrital grains whose overgrowths had been removed by dissolution in 5 percent hydrofluoric acid, generalized age spectra for each, and synthetic age spectra for overgrowths alone

\section{TABLES}

1. Microprobe analyses of potassium feldspar 189

2. Representative chlorine and bromine analyses of dolostone and limestone interbeds 192 
Abstract

Thin alternating beds of coarse-grained limestone and finegrained dolostone, commonly known as ribbon rock, are a characteristic lithology in the Cambrian Conococheague Limestone of western Maryland as well as in other lower Paleozoic carbonate rocks of the central Appalachian basin. The depositional environment of these rocks has been interpreted as a mixed sand-mud tidal flat. Abundant potassium feldspar has been identified in both the limestone and dolostone interbeds; on the basis of cathodoluminescence properties, high potassium/rubidium and potassium/barium ratios, and chemical purity, much of this feldspar is believed to be authigenic.

Authigenic potassium feldspar in the limestones occurs as overgrowths on sand-size grains of detrital microcline and orthoclase; the total potassium feldspar content of this lithology averages 9 weight percent. In contrast, potassium feldspar in the dolostones occurs as a matrix of intergrown clay and siltsize grains, and comprises as much as 30 weight percent of these interbeds. This fine-grained feldspar appears to be the product of the metasomatism of preexisting clay minerals.

Simple mass-balance calculations indicate that the authigenic potassium feldspar could not have formed isochemically, but had to involve the movement of multiple pore volumes of potassium-bearing fluids through these rocks. Bulk-rock chlorine/bromine ratios and the presence of halite daughter crystals in some fluid inclusions suggest that these fluids were brines with salinities considerably greater than seawater. ${ }^{40} \mathrm{Ar} /{ }^{39} \mathrm{Ar}$ age spectrum analyses of overgrowths on detrital grains indicate that the authigenic potassium feldspar is Late Pennsylvanian-Early Permian in age. These results strongly suggest that the authigenic potassium feldspar in the Conococheage Limestone resulted from the mobilization and migration of basinal brines during the Alleghanian orogeny.

\section{INTRODUCTION}

Thin, interbedded dololutites and pelleted limestones (ribbon rocks) are a common subfacies in lower Paleozoic carbonate rocks throughout the central Appalachian basin. Their presence, together with stromatolites, mudcracks, flat-pebble conglomerates, and other diagnostic sedimentary structures, indicates deposition in a shallow-platform lagoon-tidal flat complex, which is believed to have paralleled the Middle Cambrian to Middle Ordovician mainland for several thousand miles (Reinhardt and Hardie, 1976). Ribbon rocks were apparently formed by sedimentation in a zone transitional between supratidal mudflats and subtidal to intertidal sand flats. Demicco and Mitchell (1982) described the sedimentary processes recorded in these rocks as a wave and current "turn-on, turn-off" system, where alternating high- and low-energy conditions produced layers of rippled sand draped by laminae of fine silt and mud. The extensive occurrence of this lithology is attributable to both the low slope and the rapid subsidence of the broad carbonate shelf, which allowed short-term changes in current and wave energy to be recorded and preserved in sediments over a large area.
Numerous occurrences of authigenic potassium feldspar (K-feldspar) in lower Paleozoic rocks of the Appalachian basin have been described during the past 50 years (see, for example, Daly, 1912; Tester and Atwater, 1934; Berg, 1954; Woodard, 1972). Much of this work was summarized by Buyce and Friedman (1975), who recognized authigenic K-feldspar as a characteristic component of the Cambrian-Ordovician rocks that formed on the east-facing shelf of the proto-Atlantic Ocean. The common association of authigenic K-feldspar with dolomitized sequences of tidal-flat carbonates led some workers to suggest that the feldspar was the product of early diagenesis (Mazzullo, 1976). The results of our work, however, suggest that the authigenic K-feldspar in the Conococheague Limestone formed some 200 million years after deposition due to the migration of tectonically mobilized brines.

This paper describes the results of petrographic and geochemical analyses of Conococheague ribbon rocks and suggests a scenario for the formation of authigenic Kfeldspar. Although limited in scale, the study should serve as a basis for reconstructing the diagenetic history of similar carbonate units elsewhere in the Appalachian basin.

The study area is located about $15 \mathrm{~km}$ west of Hagerstown, Maryland, south of the town of Clear Spring (fig. 1). Samples were collected from outcrops (fig. 2) exposed along the tracks of the Western Maryland Railroad.

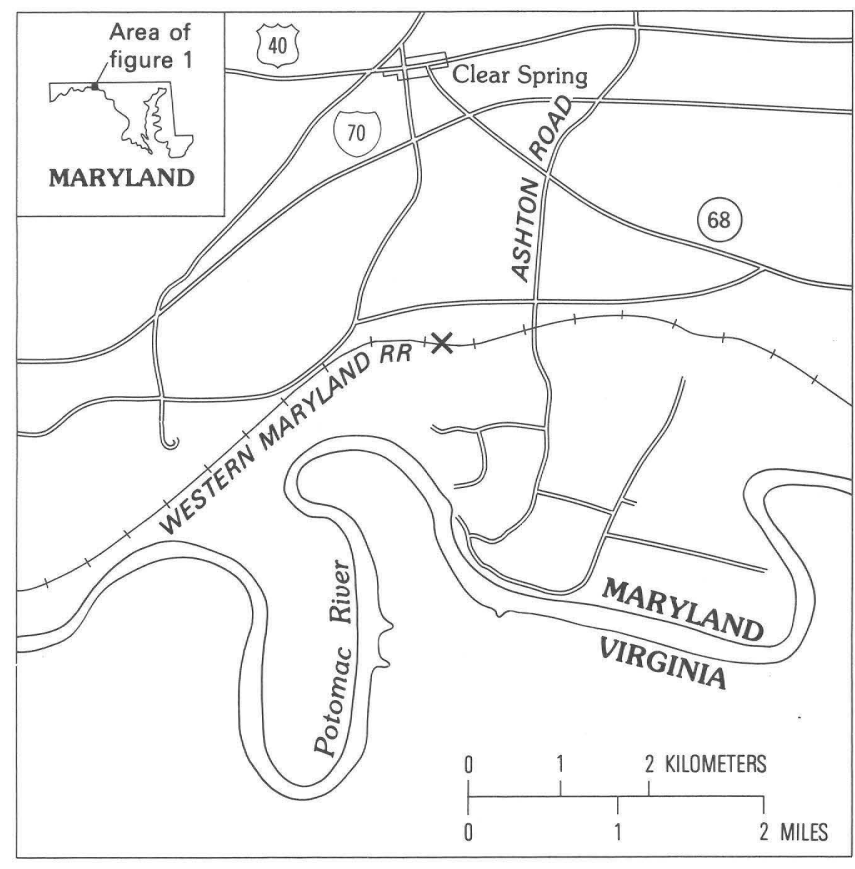

Figure 1. Study area, showing location of outcrop (X) where samples were collected. 


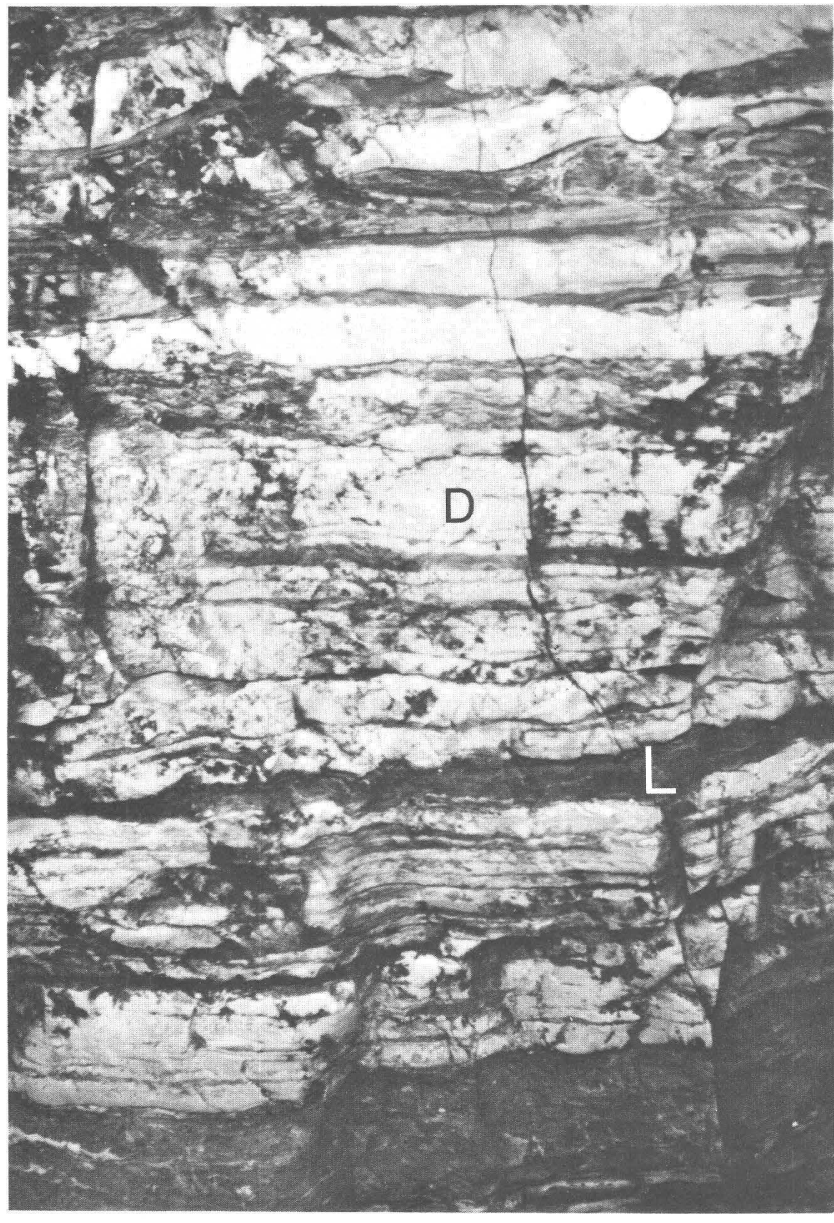

Figure 2. Ribbon rock in outcrop, showing dolostone (D) and limestone (L) interbeds. Note dime in upper right-hand corner for scale.

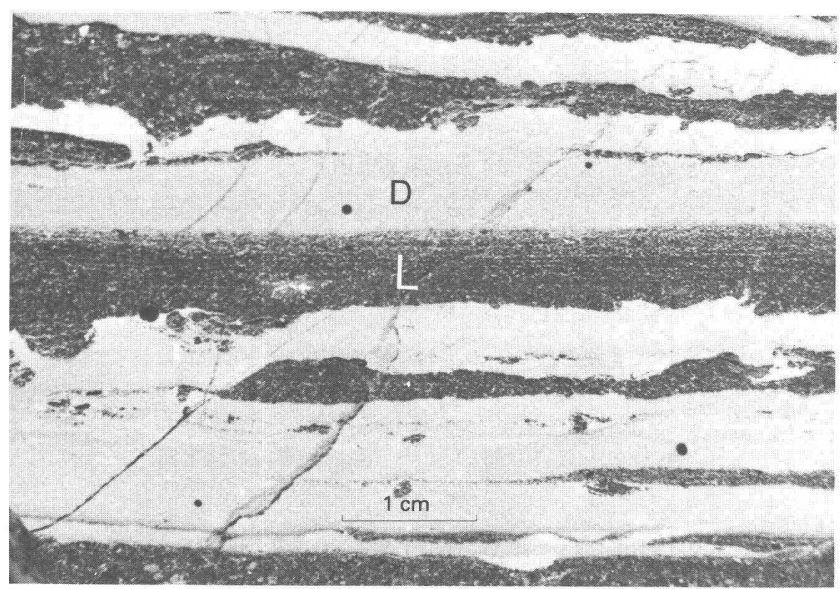

Figure 3. Slabbed sample of ribbon rock, showing detail of individual dolostone (D) and limestone (L) interbeds.

\section{METHODS}

A single oriented sample (fig. 3) about $20 \mathrm{~cm}$ in vertical thickness was chiseled from the outcrop shown in figure 2. Uncovered, oil-polished thin sections oriented normal to the bedding plane were prepared covering the entire vertical sequence in the sample. Subsamples of individual limestone and dolostone interbeds were separated with a rock saw. The noncarbonate fraction of samples was separated by boiling crushed samples in a solution of trisodium ethylenediamine tetraacetic acid (EDTA), as described by Glover (1961); the weight percent insoluble residue was determined gravimetrically.

$\mathrm{X}$-ray diffraction analysis of bulk samples and $\mathrm{K}$-feldspar separates was performed on a Diano XRD-5 $\mathrm{X}$-ray diffractometer ${ }^{1}$, using copper radiation and a graphite monochrometer. The potassium content of the insoluble residues was determined by wavelength-dispersive X-ray fluorescence (XRF) on a Diano model 8600 automated XRF spectrometer; rubidium and barium were determined by energy-dispersive XRF on a Kevex model 0700 automated XRF spectrometer. Polished thin sections were examined with an ETEC Autoscan scanning electron microscope (SEM) equipped with an EDAX 9100 $\mathrm{X}$-ray analyzer; quantitative analyses of major elements of feldspars were made using an ARL SEMQ electron microprobe.

Age-estimates for authigenic overgrowths in pure mineral separates of $\mathrm{K}$-feldspar were made using the ${ }^{40} \mathrm{Ar} /{ }^{39} \mathrm{Ar}$ incremental-heating technique (Merrihue and Turner, 1966; Dalrymple and Lanphere, 1971; Lanphere and Dalrymple, 1974). This technique produces a series of dates, or age spectra, by releasing argon gas from a sample in steps of increasing temperatures. In contrast to the conventional potassium-argon method, the incremental-heating technique can yield information about argon loss due to thermal events or argon gained by the diagenetic addition of potassium during the history of the sample.

\section{RESULTS AND DISCUSSION}

\section{Petrography of ribbon rocks}

The contrasting textures of the dolostone and limestone interbeds are shown in the photomicrograph in figure 4. The transition upward from limestone to dolostone is usually gradual, reflecting a slow decrease in current and wave energy. In contrast, the transition upward from dolostone to limestone is sharp, indicating an abrupt increase in energy and the partial erosion of the underlying mud.

${ }^{1}$ Use of trade and company names is for descriptive purposes only and does not imply endorsement by the U.S. Geological Survey. 
Dolostone layers range in thickness from $1 \mathrm{~mm}$ to $3 \mathrm{~cm}$. A typical interbed contains about 50 percent dolomite and 25 percent $\mathrm{K}$-feldspar, the remainder being quartz, calcite, and minor pyrite. Oxidation of pyrite causes the dolostone to weather to a grayish orange, but

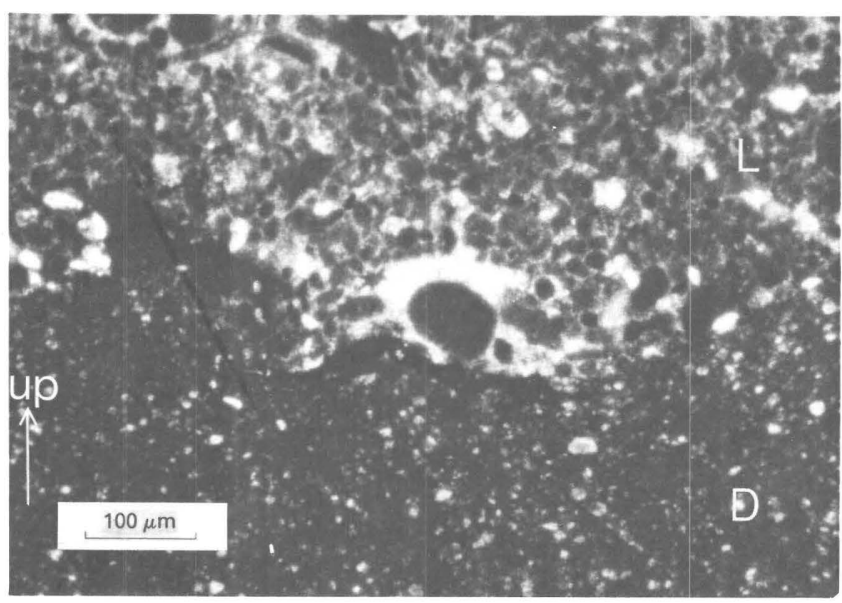

Figure 4. Photomicrograph of interface between individual fine-grained dolostone (D) and coarser pelleted limestone (L) interbeds. freshly broken surfaces are medium-dark gray. The dolomite is finely crystalline; rhomb sizes range from 20 to $50 \mu \mathrm{m}$. Quartz grains are about the same size. Kfeldspar appears in thin section as dark-brown, clay- and silt-size grains which form the matrix of the dolostones.

Limestone layers range in thickness from 2 to $5 \mathrm{~mm}$ and are finely laminated. Both weathered and fresh surfaces are dark gray. In the thicker layers, the limestone is a medium-grained calcarenite cemented by sparry calcite. The allochems are mostly intraclasts, but pellets, ooids, and biogenic fragments are also common. In the thinner layers the limestone is a micaceous, medium- to coarse-grained calcilutite cemented by sparry calcite; the allochems are dominantly pellets. K-feldspar occurs as discrete sand-size grains, most of which have overgrowths. Subequal amounts of sand-size quartz are also present.

The SEM micrograph shown in figure 5, taken with a secondary electron detector, reveals several textural features. The difference in grain size between K-feldspars in the limestone and dolostone layers is clear. Differences in polishing hardness have caused feldspar, quartz, and accessory mineral grains in the limestone to stand out in

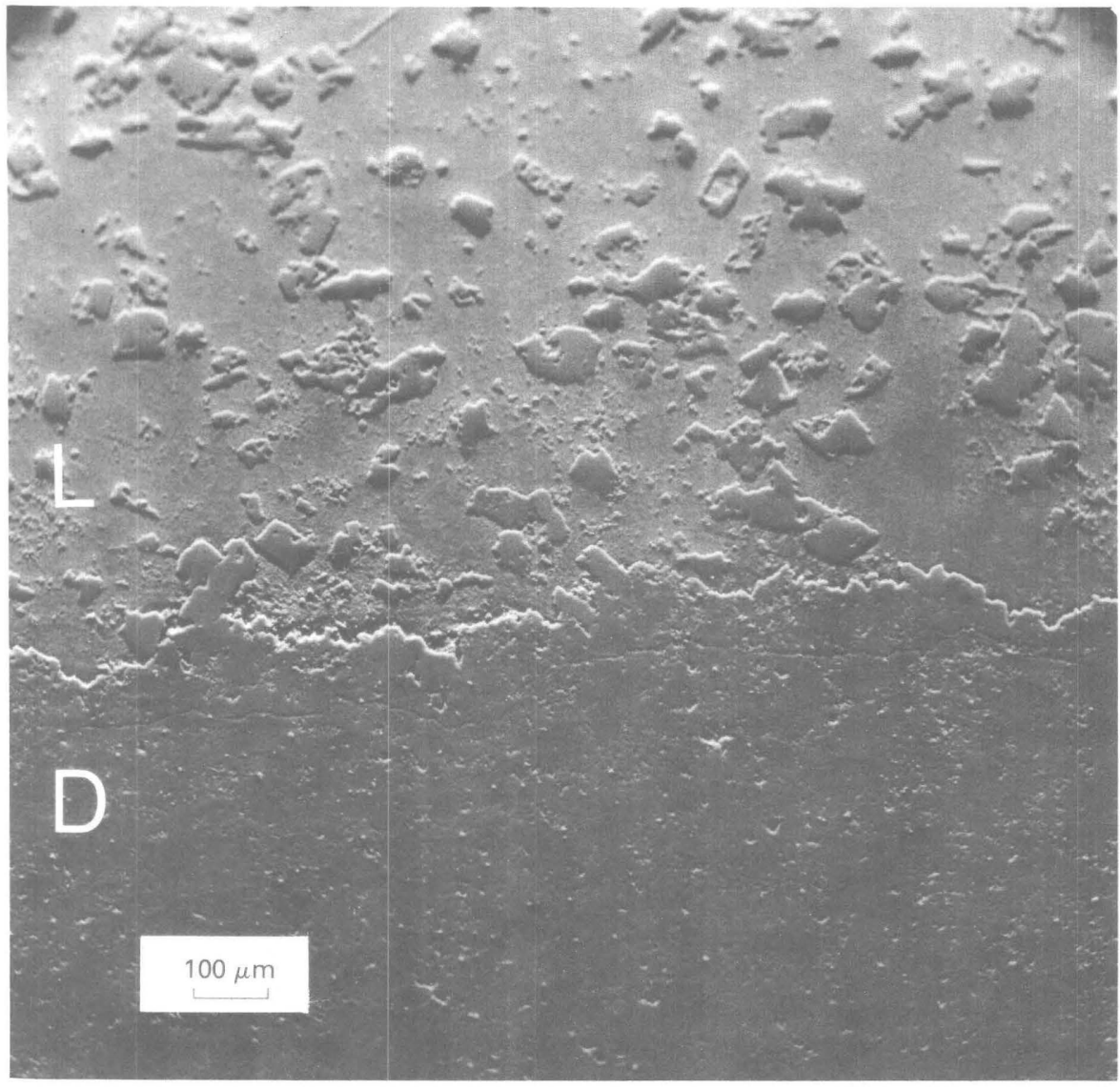

Figure 5. Scanning electron micrograph (secondary electron excitation) of adjacent dolostone and limestone interbeds showing difference in grain size and microporosity of dolostone. 


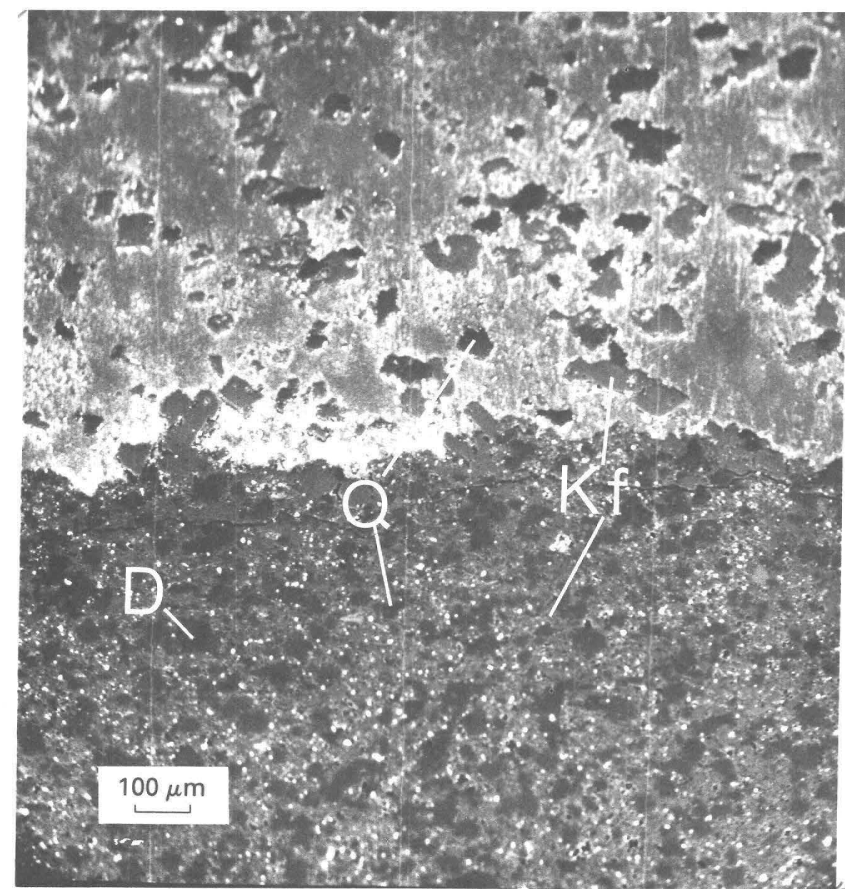

Figure 6. Scanning electron micrograph of adjacent dolostone and limestone interbeds taken with backscattered electron detector. Grain brightness is proportional to average atomic weight.

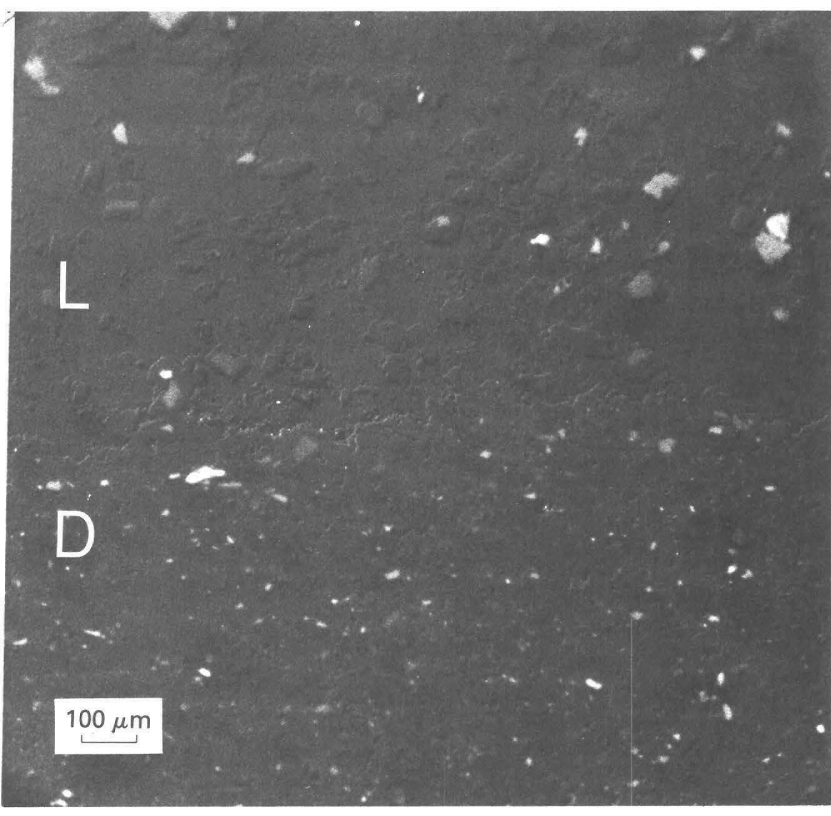

Figure 7. Scanning electron micrograph of adjacent dolostone and limestone interbeds showing electron-excited cathodoluminescence of detrital phases.

defects in igneous $\mathrm{K}$-feldspars act as activators, causing them to luminesce under an electron beam.

Luminescing detrital cores and nonluminescing authigenic overgrowths are readily apparent in the limestone interbeds in CL images (fig. 7). Differences in luminescent intensity and the apparent lack of a detrital core in some grains is due to the relatively shallow $(\sim 1$ $\mu \mathrm{m})$ depth from which cathodoluminescence can be detected. K-feldspar in the dolostone is also a mixture of luminescing and nonluminescing grains. In contrast to the limestone interbeds, however, the fine-grained, matrix-forming $\mathrm{K}$-feldspar shows no evidence of having precipitated around preexisting detrital grains; rather it appears to be an alteration product of clay minerals.

Nonluminescing overgrowths on quartz grains were observed in both the limestone and dolostone interbeds (fig. 8), but they were less well developed and present on fewer grains than were overgrowths of K-feldspar.

\section{Accessory minerals}

Accessory minerals were identified on the basis of chemical composition and morphology by SEM/EDX. The accessory suite includes muscovite, zircon, monazite, titanium oxide, apatite, pyrite, and siderite. Zircon, (1971) suggested that certain trace elements or structural 


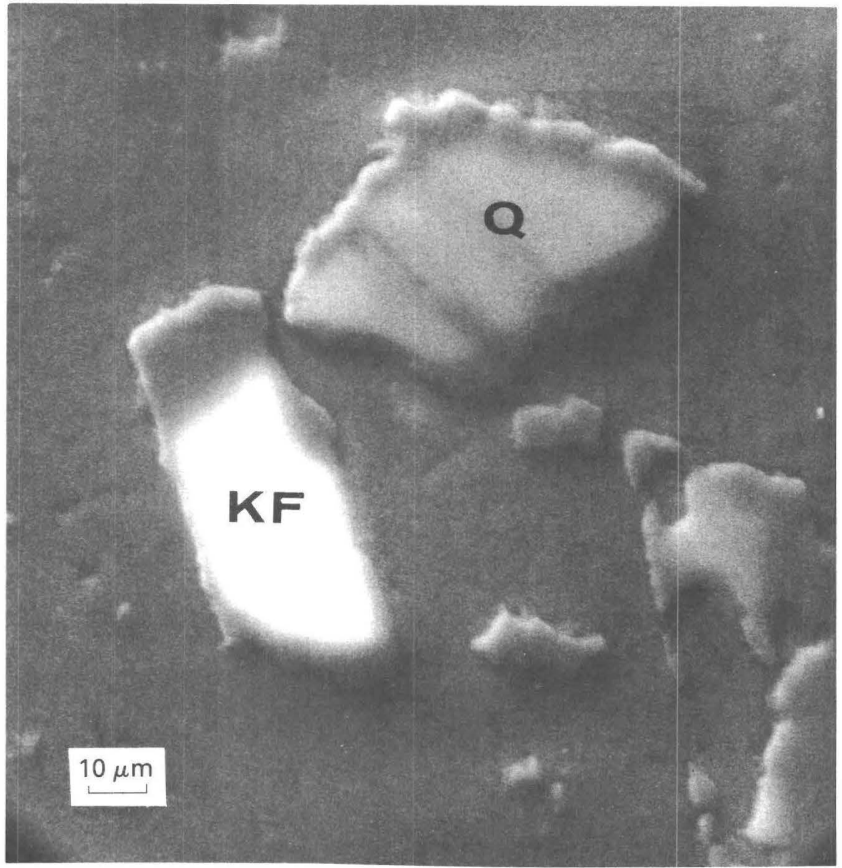

Figure 8. Scanning electron micrograph (cathodoluminescence detector) showing relative luminescent intensity of detrital quartz (Q) and potassium feldspar (KF). titanium oxide, monazite, and apatite were found only in limestone interbeds; pyrite and siderite were found in both lithologies but were more abundant in the dolostones. Pyrite and siderite are almost certainly secondary and indicate reducing conditions. These phases commonly coexist with organic matter and may reflect the former presence of stromatolitic algae. Apatite and titanium oxide could be either detrital or secondary. Zircon and monazite, however, are most probably detrital, and, together with detrital K-feldspar, quartz, and muscovite, they suggest that the siliciclastic material in these rocks was derived from the craton to the west.

\section{Microprobe analyses}

$\mathrm{K}$-feldspars in both limestone and dolostone interbeds were analyzed in polished and carbon-coated thin sections. Igneous K-feldspar was distinguished from authigenic K-feldspar on the basis of luminescence or nonluminescence under the electron beam. The average compositions of authigenic and igneous K-feldspar from each lithology are given on table 1 .

Table 1. Microprobe analyses of potassium feldspars (averages based on analyses of 10 grains)

[Leaders (---) indicate absent or undetermined]

\begin{tabular}{|c|c|c|c|c|c|c|c|c|}
\hline \multirow[b]{2}{*}{$\begin{array}{c}\text { Type of } \\
\text { potassium feldspar }\end{array}$} & \multicolumn{7}{|c|}{ Oxide (in percent) } & \multirow[b]{2}{*}{ Total } \\
\hline & $\mathrm{SiO}_{2}$ & $\mathrm{Al}_{2} \mathrm{O}_{3}$ & $\mathrm{~K}_{2} \mathrm{O}$ & $\mathrm{Na}_{2} \mathrm{O}$ & $\mathrm{CaO}$ & $\mathrm{FeO}$ & $\mathrm{BaO}$ & \\
\hline $\begin{array}{l}\text { Detrital cores, in } \\
\text { limestones }\end{array}$ & 63.93 & 18.55 & 15.64 & 0.61 & 0.65 & 0.01 & 0.39 & 99.78 \\
\hline $\begin{array}{l}\text { Authigenic } \\
\text { overgrowths, on } \\
\text { potassium feldspars } \\
\text { in limestones- }\end{array}$ & 64.15 & 18.82 & 15.89 & .14 & .81 & .02 & .10 & 99.74 \\
\hline $\begin{array}{l}\text { Detrital, in } \\
\text { dolostones- }\end{array}$ & 65.20 & 18.62 & 15.04 & .48 & .57 & --- & .44 & 100.35 \\
\hline $\begin{array}{l}\text { Authigenic, in } \\
\text { dolostones }\end{array}$ & 64.15 & 18.14 & 14.96 & .19 & .55 & --- & .21 & 98.20 \\
\hline $\begin{array}{l}\text { Average composition } \\
\text { of } 5 \text { authigenic } \\
\text { microclines } \\
\text { reported by } \\
\text { Kastner (1971) }\end{array}$ & 64.84 & 18.67 & 16.96 & .08 & .01 & --- & --- & 100.56 \\
\hline $\begin{array}{l}\text { Theoretical } \\
\text { composition- }\end{array}$ & 64.76 & 18.32 & 16.92 & --- & --- & --- & --- & 100 \\
\hline
\end{tabular}


Although the chemical composition of authigenic $\mathrm{K}$-feldspar in the Conococheague Limestone is closer to the theoretical end-member composition than most igneous K-feldspars (Deer and others, 1967), authigenic $\mathrm{K}$-feldspar in these rocks still contains significant amounts of impurities relative to the pure specimens analyzed by Kastner (1971). The low potassium values are probably due to the presence of small amounts of albite and anorthite and the substitution of barium for potassium. This explanation is consistent with the findings of Ali and Turner (1982), who reported an inverse relationship between potassium and barium-sodium contents in microprobe traverses across $\mathrm{K}$-feldspar overgrowths. The low totals obtained for authigenic K-feldspar in the dolostones may possibly be due to the presence of organic matter or structural water. The presence of remnant organic matter in the dolostones is quite possible, if not likely, based on the algal stromatolites present in nearby strata and the reducing conditions suggested by the occurrence of pyrite and siderite. The presence of water as both finely disseminated fluid inclusions and as structurally bound $\mathrm{H}_{3} \mathrm{O}^{+}$is plausible in light of recent infrared studies of igneous feldspars (Solomon and Rossman, 1982), where values were reported for fluid-inclusion and structurally bound water as high as 1.0 and 0.80 percent, respectively.

Microprobe results reveal no significant differences between authigenic K-feldspar in limestone and dolostone interbeds. Authigenic K-feldspar in both lithologies are noticeably depleted in sodium and barium relative to igneous K-feldspar. This depletion would be expected in the typically purer authigenic phases. Calcium values, however, show no appreciable difference between authigenic and detrital phases. Calcium in the K-feldspar in the limestone interbeds could not have been contributed by carbonate inclusions, as these zones were easily identified and avoided during analysis. The contribution of carbonate to calcium values in analyses of feldspars in dolostones is uncertain.

\section{Chemistry of insoluble residues}

The total amount of K-feldspar (authigenic and detrital) in each sample was estimated from the potassium content of the insoluble residue and the average potassium content of K-feldspars determined by the electron probe. The assumption that all the potassium was located in $\mathrm{K}$ feldspar is justified on the basis of petrographic and XRD analyses.

Both rubidium and barium commonly substitute for potassium in feldspars. This substitution is less pronounced at low temperatures; hence authigenic $\mathrm{K}$-feldspar is depleted in rubidium and barium relative to hightemperature polymorphs. For this reason, potassium/ rubidium $(\mathrm{K} / \mathrm{Rb})$ and potassium/barium $(\mathrm{K} / \mathrm{Ba})$ ratios can be used to distinguish samples containing appreciable authigenic K-feldspar.

The results of the insoluble residue analyses are shown for samples of three limestone and three dolostone interbeds in figure 9. Dolostone interbeds contain two to three times more insoluble residue than limestone interbeds. Potassium/rubidium and $\mathrm{K} / \mathrm{Ba}$ ratios are significantly greater than the range of values reported for igneous rocks and igneous K-feldspars. Potassium/ rubidium ratios indicate no difference between insoluble residues of dolostone and limestone interbeds, whereas the $\mathrm{K} / \mathrm{Ba}$ ratios are noticeably lower in limestone residues, due to an enrichment in barium. The reason for this enrichment is not clear. Excess barium could be present as finely disseminated barite. Although barite was not detected in these samples, it has been identified in the Conococheague Limestone at another location (unpublished data from this laboratory).

\section{X-Ray diffraction analysis}

X-ray diffraction (XRD) analyses of EDTA-soluble residues show the noncarbonate fraction of the Conococheague ribbon rocks to be dominated by K-feldspar, with lesser amounts of quartz. Minor amounts of muscovite were identified in some samples. Monoclinic and triclinic K-feldspars were distinguished by the XRD criteria of Goldsmith and Laves (1954); the presence of a single 131 reflection is indicative of monoclinic Kfeldspar, whereas a $131-1 \overline{3} 1$ doublet suggests the presence of triclinic K-feldspar. XRD patterns of insoluble residues of dolostone interbeds show only a single 131 monoclinic reflection, whereas patterns of limestone interbeds show a 131 monoclinic reflection flanked by less intense triclinic 131 and $1 \overline{3} 1$ reflections (fig. 10). XRD patterns of detrital grains whose overgrowths have been removed by dissolution in dilute hydrofluoric acid also show both monoclinic and triclinic reflections, but the intensity of the monoclinic reflection is substantially reduced. These results suggest that the authigenic K-feldspar in both the dolostone and limestone interbeds is monoclinic, and that the detrital cores of grains with overgrowths are a mixture of triclinic and monoclinic K-feldspar.

\section{Evidence of interstitial brines}

Authigenic K-feldspar has commonly been reported in conjunction with rock features indicating hypersaline conditions (Fuchtbauer, 1972; Buyce and Friedman, 1975). The Conococheague Limestone is characterized by several features, most notably stromatolites and mudcracks, which are suggestive of a sabkha-like environment 

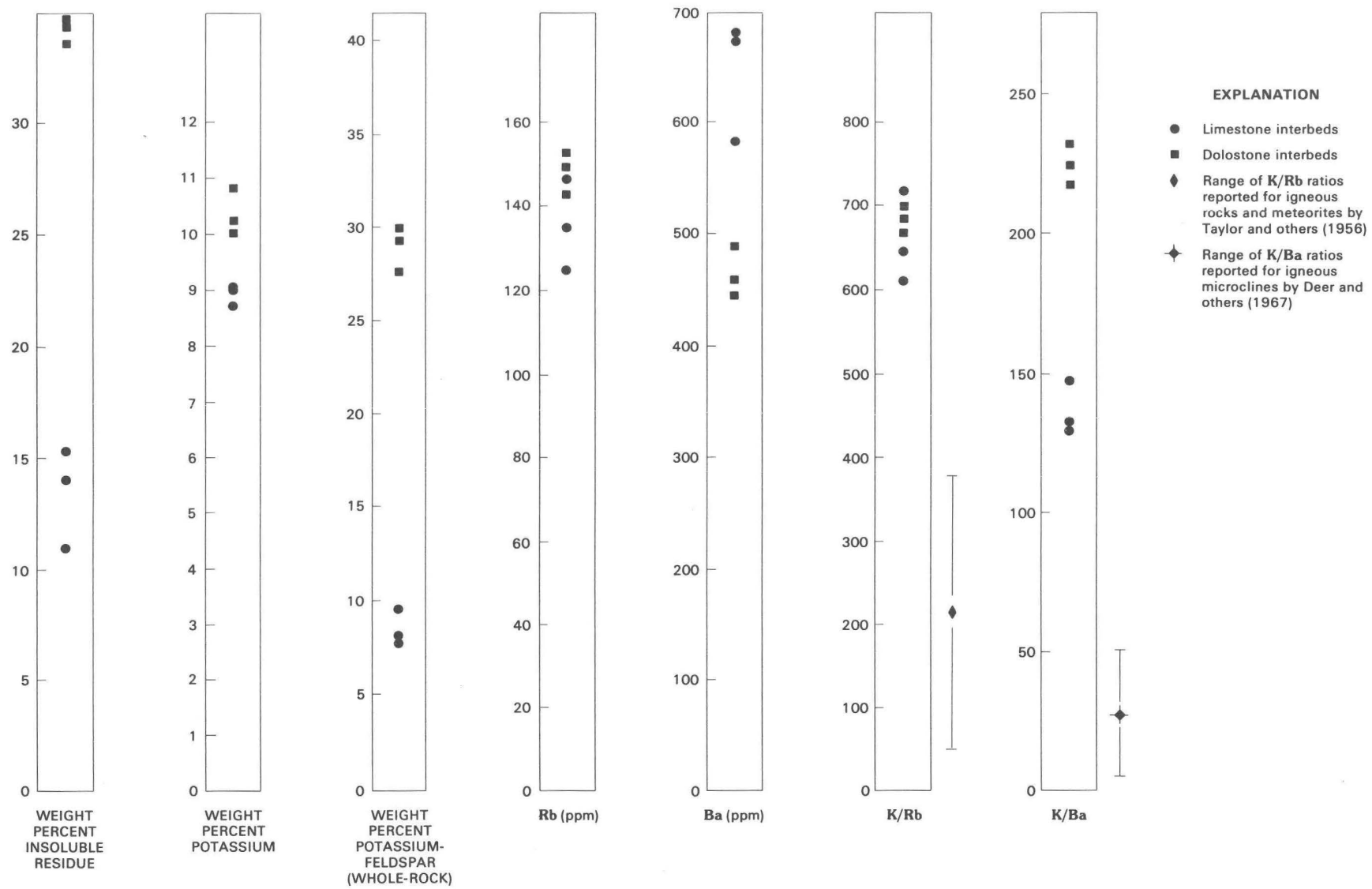

Figure 9. Analyses of insoluble residues after ethylenediamine tetraaretic acid treatment of individual limestone and dolostone interbeds. 

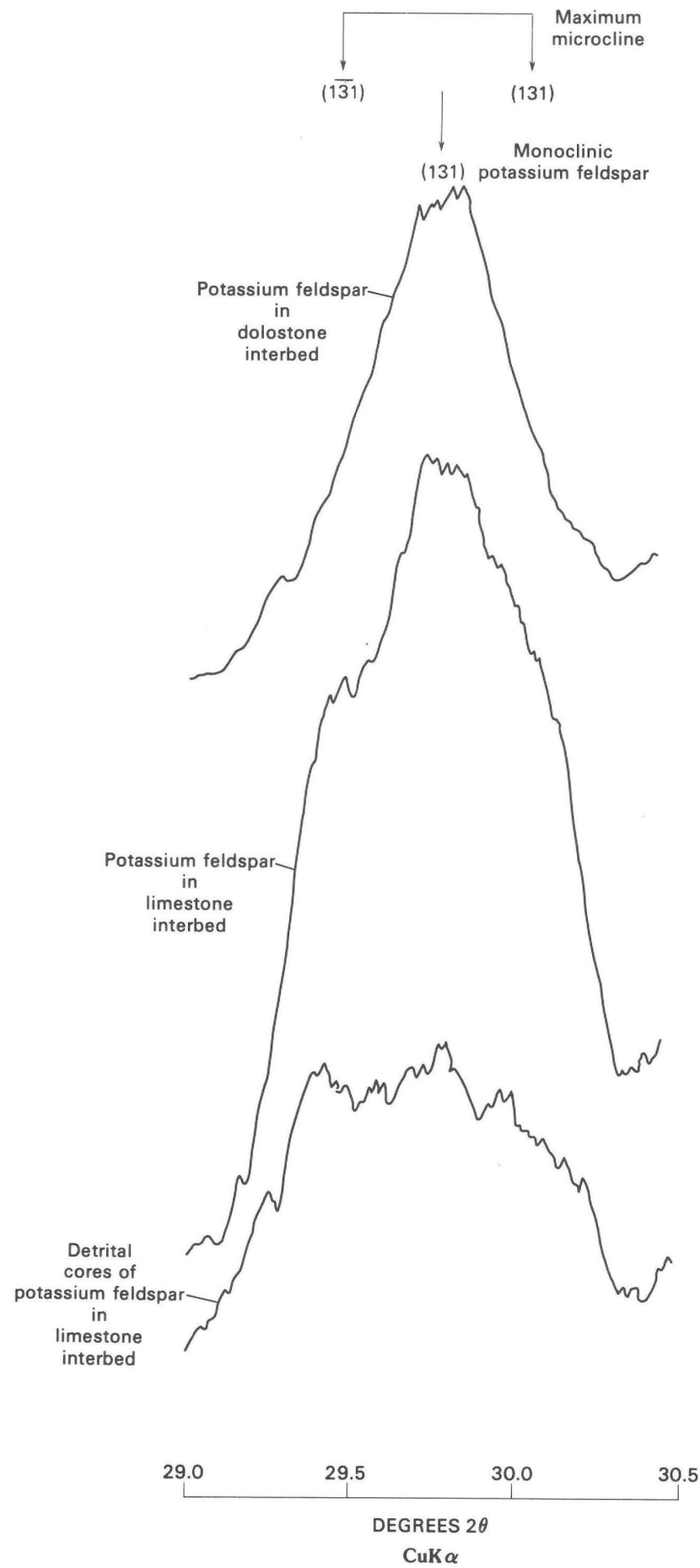

Figure 10. Partial X-ray diffractograms of ethylenediamine tetraacetic acid-insoluble residues, showing characteristic reflections of fine-grained potassium feldspar in dolostone interbeds, sand-size potassium feldspar with overgrowths in limestone interbeds, and detrital cores of potassium feldspar grains from limestone interbeds following removal of overgrowths by dissolution in dilute hydrofluoric acid. Positions of characteristic reflections taken from Wright (1968). (CuK $\alpha$ radiation). exposed to periodic dessication. Other evidence indicates the former presence of interstitial fluids with salinities appreciably greater than normal seawater. The ratio of chloride to bromine was used by Carpenter (1978) to evaluate the history of oilfield brines. Because bromine does not precipitate during the evaporation of seawater and is progressively concentrated in the residual brine, the chlorine/bromine $(\mathrm{Cl} / \mathrm{Br})$ ratio is an indicator of the degree of evaporative concentration which a fluid has undergone. Experiments have shown that brines produced from the evaporation of seawater should have $\mathrm{Cl} / \mathrm{Br}$ ratios ranging from 182 to 70 during the initial stages of halite precipitation (Zherebtsova and Volkova, 1966). $\mathrm{Cl} / \mathrm{Br}$ ratios for bulk samples of limestone and dolostone interbeds, which are assumed to reflect the composition of fluid inclusions, range from 111 to 140 (table 2). These data suggest that these rocks contained a brine which was concentrated by evaporation well past the point of saturation with respect to halite. This conclusion is supported by the presence of daughter crystals of halite in a few fluid inclusion cavities in calcite exposed during polishing (fig. 11). The crystals are too large to have been precipitated by evaporation after the inclusions were breached, indicating that they were in equilibrium with the trapped fluids.

Table 2. Representative chlorine and bromine analyses of dolostone and limestone interbeds.

[Analysts: J. Gillison and C. Palmer Analyses in parts per million]

\begin{tabular}{cccc}
\hline Interbed & $\mathrm{Cl}$ & $\mathrm{Br}$ & $\mathrm{Cl} / \mathrm{Br}$ \\
\hline Dolostone: & 200 & 1.7 & 118 \\
& 260 & 2.3 & 113 \\
& 240 & 2.0 & 120 \\
Limestone: & 190 & 1.6 & 119 \\
& 210 & 1.5 & 140 \\
& 200 & 1.8 & 111 \\
\hline
\end{tabular}

\section{Thermochemical and mass-balance considerations}

The data of Helgeson (1974) indicate that a brine in equilibrium with both $\mathrm{K}$-feldspar and albite should have a potassium/sodium $(\mathrm{K} / \mathrm{Na})$ activity ratio of 0.18 at $300^{\circ} \mathrm{C}$ and 0.06 at $200^{\circ} \mathrm{C}$. Extrapolation of Helgeson's data to $100^{\circ} \mathrm{C}$ yields an equilibrium ratio of 0.02 . Solutions having $\mathrm{K} / \mathrm{Na}$ activity ratios higher than the value for a given temperature should be supersaturated with 


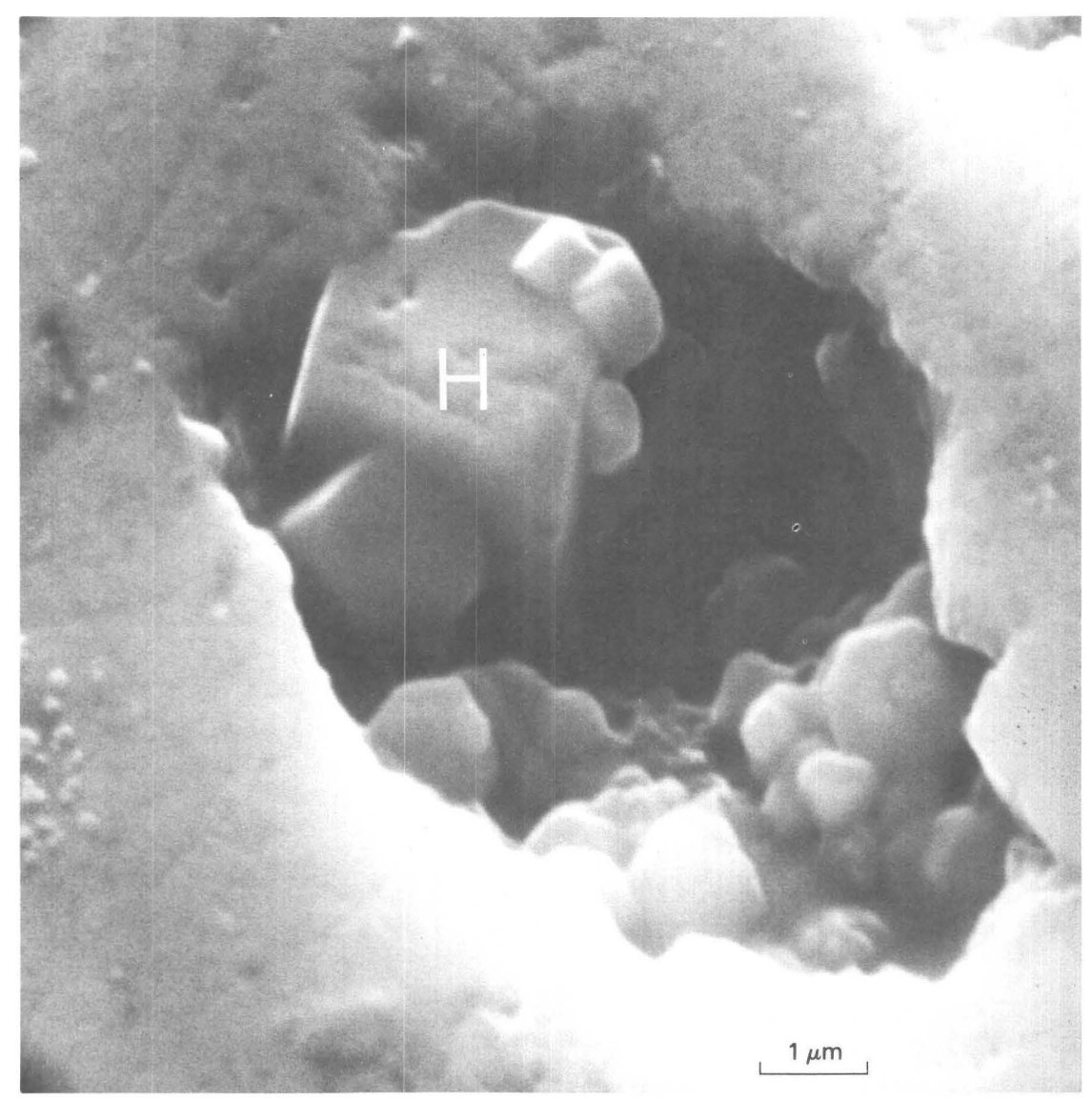

Figure 11. Scanning electron micrograph of halite daughter crystal in fluid inclusion cavity in calcite breached during polishing. Smaller crystals probably represent residue from evaporation of fluid.

respect to K-feldspar. According to the data of Zherebtsova and Volkova (1966), the evaporation of seawater should produce a brine with a $\mathrm{K} / \mathrm{Na}$ activity ratio of 0.02 at the first point of gypsum precipitation, and ratios of 0.04 to 0.17 during the initial stages of halite precipitation. Conodont alteration indices (Epstein and others, 1977) indicate that the maximum temperatures experienced by the Conococheague Limestone were in the range of $200^{\circ}$ to $250^{\circ} \mathrm{C}$. Thus, the precipitation of $\mathrm{K}$ feldspar at these temperatures in a brine supersaturated with respect to halite is feasible from a thermochemical standpoint.

Simple mass-balance calculations indicate that the observed mass of authigenic $\mathrm{K}$-feldspar could not have formed isochemically, but had to have involved a flux of potassium-bearing fluids through these rocks. A typical dolostone interbed in the Conococheague Limestone contains in excess of 25 weight percent $\mathrm{K}$-feldspar (see fig. 9). Estimates from cathodoluminescence images indicate that at least 75 percent of this $\mathrm{K}$-feldspar is authigenic.
Accordingly, 1 cubic centimeter of dolostone should contain about $80 \mathrm{mg}$ of diagenetic potassium. If the initial sediment had a porosity of 0.70 and the pore fluids were supersaturated with respect to halite, less than $12 \mathrm{mg}$ of dissolved potassium would have been available to participate in diagenetic reactions. Even if the initial siliciclastic mud in these interbeds was pure illite, there would not have been sufficient potassium for the Kfeldspar to have formed isochemically. Rather, the feldspathization had to involve the migration of multiple pore volumes of fluid through the rocks.

\section{Timing of feldspathization}

Initially, a ${ }^{40} \mathrm{Ar} /{ }^{39} \mathrm{Ar}$ age spectrum was generated from a sample of $\mathrm{K}$-feldspar grains having authigenic overgrowths. The overgrowths were then removed from 


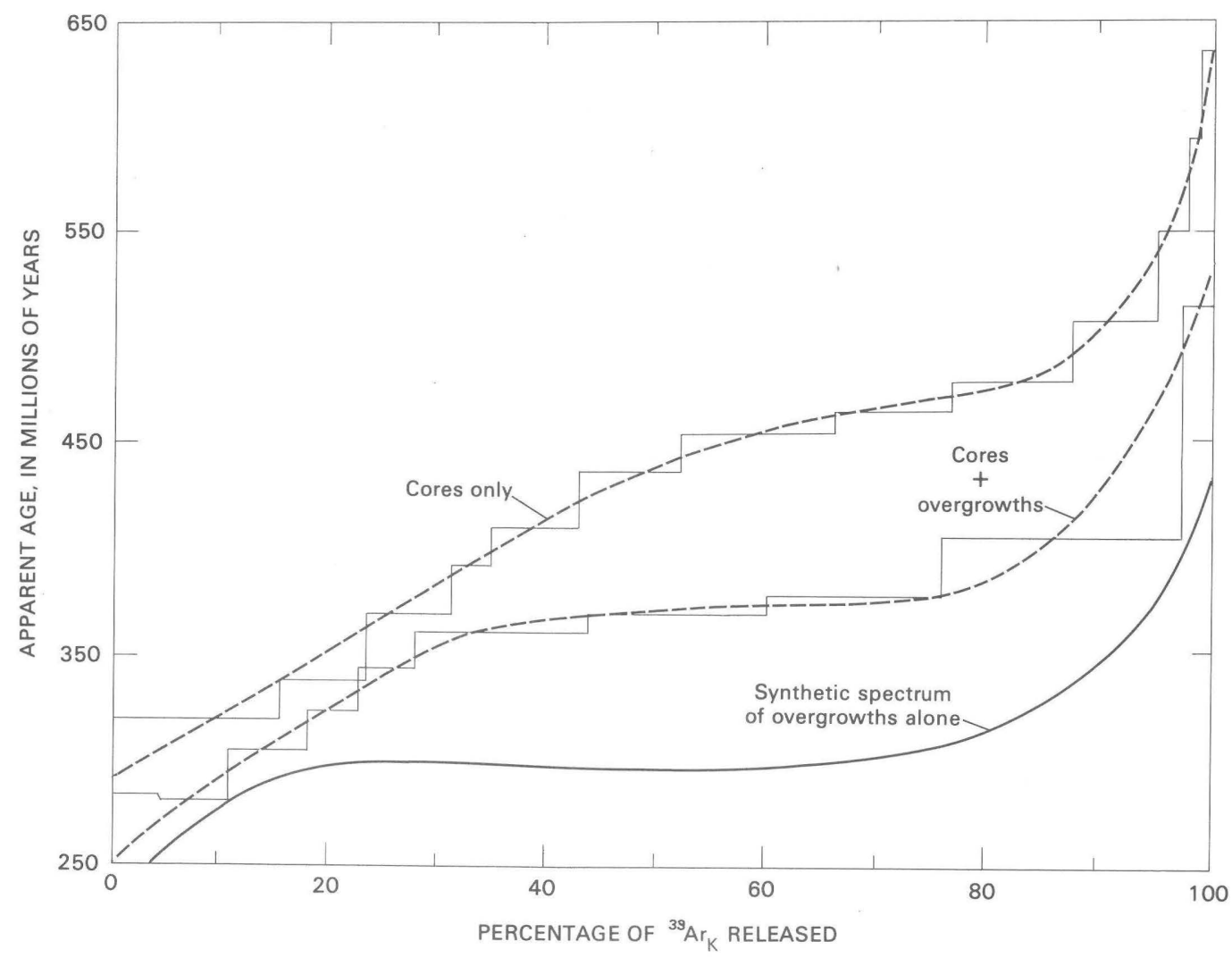

Figure 12. ${ }^{40} \mathrm{Ar} /{ }^{39} \mathrm{Ar}$ age spectra for detrital potassium feldspar grains with overgrowths and detrital grains whose overgrowths had been removed by dissolution in 5 percent hydrofluoric acid (step-like patterns), generalized age spectra for each (smooth dashed curves), and synthetic age spectrum for overgrowths alone (solid curve) obtained by subtracting one generalized age spectrum from the other.

a second split of this sample by dissolution in a 5 percent solution of hydrofluoric acid and a second ${ }^{40} \mathrm{Ar} /{ }^{39} \mathrm{Ar}$ age-spectrum analysis performed. The results of these two experiments are shown in figure 12. To obtain an approximate age spectrum for the authigenic overgrowths alone, a smooth curve was fitted to both of the experimentally produced age spectra and the "cores + overgrowths" curve subtracted from the "cores only" curve. Because estimates from cathodoluminescence images indicated that 45 to 50 percent of these grains were authigenic, no weighting factors were applied. The resulting synthetic curve is an approximation of the age spectrum that would result from the analysis of overgrowths alone if such a sample could be analyzed.

The synthetic age spectrum for overgrowths alone shows an age plateau at about 300 million years, indicating a Late Pennsylvanian-Early Permian age for the authigenic overgrowths. In addition, the age spectra of the "cores only" and "cores + overgrowths" indicate that the detrital K-feldspars still retain some portion of their predepositional history. Inasmuch as the core Kfeldspar fragments are partly monoclinic, this age spectrum indicates that the sample was not heated above $250^{\circ} \mathrm{C}$ following deposition, because above this temperature monoclinic K-feldspar loses all of its accumulated radiogenic ${ }^{40} \mathrm{Ar}$ (Harrison and Mc-Dougall, 1982). This conclusion is consistent with the estimates of thermal history based on conodont alteration indices.

The interpretation of the last 30-35 percent of the argon released from the samples is more difficult, as argon begins to exsolve in the argon-extraction apparatus at the temperatures represented by these steps on the age spectrum (Harrison and Mc-Dougall, 1982). The subtraction of the upper portion of these age spectra is probably not justifiable; probably only the first $65-70$ percent of the argon released represents true volume diffusion loss.

The conclusion that the authigenic K-feldspar is Late Pennsylvanian-Early Permian in age is consistent with reports of low-temperature secondary magnetization 
with late Carboniferous pole positions in early to middle Paleozoic rocks of the central Appalachians (McCabe and others, 1983). These authors showed that this magnetization is not due to the thermal resetting of a detrital component, but rather is the result of the precipitation of secondary magnetite that was contemporaneous with folding, that is, Carboniferous in age.

\section{CONCLUSIONS}

We believe that the unusually large quantities of authigenic K-feldspar in ribbon rocks of the Conococheague Limestone reflect a chemical event associated with the mobilization and migration of basinal brines during the Alleghanian orogeny. This conclusion is supported by ${ }^{40} \mathrm{Ar} /{ }^{39} \mathrm{Ar}$ age determinations on authigenic $\mathrm{K}$ feldspar overgrowths, petrographic and chemical evidence for the presence of hypersaline brines, and mass-balance and thermochemical calculations. The extensive nature of stratigraphically equivalent and lithologically similar carbonate units throughout the Appalachians and numerous reports of authigenic $\mathrm{K}$-feldspar in these rocks suggests that orogenic activity may have been responsible for brine migration throughout the entire basin. Accordingly, the results of this study may have important implications for research on oil and gas migration pathways and the evolution of brine-derived mineral deposits.

\section{REFERENCES CITED}

Ali, A. D., and Turner, P., 1982, Authigenic K-feldspar in the Bromsgrove Sandstone Formation (Triassic) of central England: Journal of Sedimentary Petrology, v. 52, p. 187-197.

Berg, R., 1954, Franconia Formation of Minnesota and Wisconsin: Geological Society of America Bulletin, v. 65, p. 857-882.

Buyce, M. R., and Friedman, G. M., 1975, Significance of authigenic $\mathrm{K}$-feldspar in Cambrian-Ordovician carbonate rocks of the Proto-Atlantic shelf in North America: Journal of Sedimentary Petrology, v. 45, p. 808-821.

Carpenter, A. B., 1978, Origin and chemical evolution of brines in sedimentary basins: Oklahoma Geological Survey Circular 79, p. 60-77.

Daly, R. A., 1912, Stratigraphy and structure of the Clarke Range, in American Cordillera-Forty-ninth parallel: Geological Society of Canada Memoir 38, p. 47-57.

Dalrymple, G. B., and Lanphere, M. A., $1971,{ }^{40} \mathrm{Ar} /{ }^{39} \mathrm{Ar}$ technique of $\mathrm{K} / \mathrm{Ar}$ dating-A comparison with the conventional technique: Earth and Planetary Science Letters, v. 12 , p. $300-308$.
$1974,{ }^{40} \mathrm{Ar} /{ }^{39} \mathrm{Ar}$ age spectra of some undisturbed terrestrial samples: Geochimica et Cosmochimica Acta, v. 38 , p. $715-738$.

Deer, W. A., Howie, R. A., and Zussman, J., 1967, An introduction to the rock-forming minerals: New York, John Wiley and Sons, $528 \mathrm{p}$.

Demicco, R. V., and Mitchell, R. W., 1982, Facies of the great American bank in the central Appalachians, in P. L. Lyttle, ed., Central Appalachian geology: NE-SE Geological Society of America 1982 Field Trip Guidebooks, p. 171-266.

Epstein, A. G., Epstein, J. B., and Harris, L. D., 1977, Conodont color alteration-An index to organic metamorphism: U.S. Geological Survey Professional Paper 995, 27 p.

Fuchtbauer, Hans, 1972, Influence of salinity on carbonate rocks in the Zechstein Formation, northwestern Germany: UNESCO, 1972, Geology of saline deposits, Proceedings of the Hanover Symposium, 1968, p. 23-31.

Glover, E. D., 1961, Method of solution of calcareous materials using the complexing agent, EDTA: Journal of Sedimentary Petrology, v. 31, p. 622-626.

Goldsmith, J. R., and Laves, F., 1954, The microcline-sanidine stability relations: Geochimica et Cosmochimica Acta, v. 5, p. 1-19.

Harrison, T. M., and Mc-Dougall, I., 1982, The thermal significance of potassium feldspar K-Ar ages inferred from ${ }^{40} \mathrm{Ar} /{ }^{39} \mathrm{Ar}$ age spectrum results: Geochimica et Cosmochimica Acta, v. 46, p. 1811-1820.

Helgeson, H. C., 1974, Chemical interaction of feldspars and aqueous solutions, in W. S. Mackenzie and J. Zussman, eds., The feldspars: Proceedings of a NATO Advanced Study Institute, p. 184-217.

Kastner, M., 1971, Authigenic feldspars in carbonate rocks: American Mineralogist, v. 56, p. 1403-1442.

Lanphere, M. A., and Dalrymple, G. B., 1971, A test of the ${ }^{40} \mathrm{Ar} /{ }^{39} \mathrm{Ar}$ age spectrum technique on some terrestrial materials: Earth and Planetary Science Letters, v. 12, p. 359-372.

Mc-Cabe, C., Van der Voo, R., Peacor, D. R., Scotese, C. R., and Freeman, R., 1983, Diagenetic magnetite carries ancient yet secondary remanence in some Paleozoic sedimentary carbonates: Geology, v. 11, p. 221-223.

Mazzullo, S. J., 1976, Significance of authigenic K-feldspar in Cambrian-Ordovician carbonate rocks of the Proto-Atlantic Shelf in North America-A discussion: Journal of Sedimentary Petrology, v. 46, p. 1035-1040.

Merrihue, C., and Turner, G., 1966, Potassium-argon dating by activation with fast neutrons: Journal of Geophysical Research, v. 71, p. 2852-2857.

Reinhardt, J., and Hardie, L. A., 1976, Selected examples of carbonate sedimentation, Lower Paleozoic of Maryland: Guidebook for the 1976 Northeast-Southeast Joint Section Meeting of the Geological Society of America, Geological Society of America Guidebook 5, 53 p.

Solomon, G. C., and Rossman, G. R., 1982, Water in feldspars: Geological Society of America Abstracts with Program, p. 622 . 
Taylor, S. R., Emilius, C. H., and Exley, C. S., 1956, Some anomalous $K / R b$ ratios in igneous rocks and their petrological significance: Geochimica et Cosmochimica Acta, v. 10, p. 224-229.

Tester, A. C., and Atwater, G. I., 1934, The occurrence of authigenic K-feldspars in sediments: Journal of Sedimentary Petrology, v. 4, p. 23-31.

Woodard, H. H., 1972, Syngenetic sanidine beds from the Middle Ordovician St. Peter Sandstone: Wisconsin Journal of Geology, v. 80, p. 323-332.
Wright, T. L., 1968, X-ray and optical study of alkali feldspar-II. An X-ray method for determining the composition and structural state from measurement of $2 \theta$ values for three reflections: American Mineralogist, v. 53, p. 88-104.

Zherebtsova, I. K., and Volkova, N. N., 1966, Experimental study of the behavior of trace elements in the process of natural solar evaporation of Black Sea water and Sasyk-Sivash brine: Geochemistry International, v. 3, p. 656-670. 


\title{
Diagenesis of the Todilto Limestone Member of the Wanakah Formation, Chama Basin, New Mexico
}

\author{
By JENNIE L. RIDGLEY, U.S. Geological Survey, Box 25046, Denver Federal \\ Center, MS 916, Denver, Colorado 80225
}

\section{CONTENTS}

Abstract 198

Introduction 198

Methods of study 198

Depositional textures 198

Diagenetic alterations 199

Micritization 199

Types of cementation 199

Authigenic evaporites 199

Calcite replacement of evaporites 199

Dolomite and dedolomitization 201

Stylolitization $\mathbf{2 0 2}$

Conclusions 205

References cited 205

\section{FIGURES}

1. Map showing sample localities and structural features, southern part of Chama basin, New Mexico 199

2. Photomicrographs showing micritization, early cementation, authigenic evaporites 200

3. Photomicrographs showing calcite replacement of evaporites, dolomite, dedolomite, stylolites 202, 203

4. Cross plot of bulk density versus compensated neutron porosity 204 


\section{Abstract}

The Middle Jurassic Todilto Limestone Member of the Wanakah Formation in the Chama basin, north-central New Mexico, is dominantly a carbonate-gypsum sequence. Preliminary petrographic studies indicate that most of the carbonates in the southern part of the basin were originally deposited as carbonate mud that contained little bioclastic and detrital material. Diagenetic alteration of these sediments has resulted in a variety of textures. Early stages of diagenesis are marked by incomplete cementation of the sediments and micritization of biotic debris. Fine-grained mosaics of calcite crystals were precipitated as cement, partially or totally filling the pore spaces between detrital, larger carbonate, and bioclastic grains. Later stages of diagenesis are marked by the formation of moldic porosity followed by various stages of cementation by sparry calcite. Closure of vugs and voids by later stages of calcite cement is also apparent. Much of the later calcite is ferroan, in contrast to early calcite cements which are nonferroan. Authigenic gypsum or anhydrite crystals fill pore spaces within the sediment or replace the micrite. Locally some authigenic gypsum has been replaced by calcite. Some of the originally bedded gypsum has also been partially to totally replaced by sparry calcite. Minor dolomitization of both the micrite and sparry calcite occurred during late-stage diagenesis. Much of this dolomite has been subsequently dedolomitized. Clay minerals, quartz, organic material, and iron-rich minerals are concentrated along the boundaries of horizontal, vertical, and network stylolites.

\section{INTRODUCTION}

In the Chama basin of north-central New Mexico, the Middle Jurassic Todilto Limestone Member of the Wanakah Formation (Condon and Huffman, in press) overlies the Entrada Sandstone and is overlain by an upper unnamed clastic member of the Wanakah Formation (Ridgley, 1977). The Todilto consists of a carbonateevaporite sequence containing local interbedded sandstone and mudstone. The carbonate and clastic rocks form the lower part of the member and are continuous throughout the basin. The evaporites form the upper part of the member and locally may be absent from large areas of the basin. The carbonates consist of multistage calcite and minor remnant dolomite; the evaporites consist of gypsum at the surface and anhydrite in the subsurface. The carbonate facies may be further subdivided into a basal platy, laminated limestone, a middle crinkly limestone, and an upper microfragmental brecciated limestone. Where the limestone section is overlain by gypsum, the crinkly limestone is a more rhythmically bedded sequence of limestone and gypsum. The brecciated limestone is generally present only where there is no overlying gypsum; however, locally it has been found within the more massive gypsum facies.

Preliminary petrographic studies of 36 samples from the carbonate facies from the southern part of the
Chama basin (fig. 1) were made to ascertain the original mode of deposition and the subsequent diagenetic alterations of these facies. These samples were originally collected at random for use in other studies, and thus, the position of the samples are not tied to measured sections. The results of this study represent the first detailed petrographic depositional and diagenetic data to be published on the Todilto Limestone Member. For the purposes of this paper diagenetic alterations include all those changes that occur between the time of deposition and the time that conditions of metamorphism occur (Murray and Pray, 1965).

\section{METHODS OF STUDY}

Samples used in this study were originally collected for isotope analysis from widely spaced outcrop localities in the southern part of the Chama basin (fig. 1). These samples are from representative sections of the platy, crinkly, and brecciated carbonate facies and the gypsum and rhythmically bedded limestone-gypsum evaporite facies. Thin sections of each sample were examined with the petrographic microscope; rock chips from selected samples were examined with a scanning electron microscope (SEM) in order to identify the relationships of diagenetic minerals at the greater resolution capability of the SEM.

To check for the presence of dolomite, thin sections were stained with a combined solution of alizarin red-S and potassium ferricyanide (Dickson, 1965). This technique permits the distinction of calcite and dolomite and indicates the distribution of ferrous iron between these two minerals. It does not, however, indicate the amount of iron present in ferroan calcite or ferroan dolomite.

\section{DEPOSITIONAL TEXTURES}

Petrographic and SEM examination indicate that in most samples much of the carbonate was deposited originally as micrite or microcrystalline carbonate mud (1-4 $\mu \mathrm{m})$ with a low content of allochem and terrigenous components (less than 10 percent). The allochem components are pellets, superficial ooliths, bioclastic fragments, and glauconite grains. The terrigenous components are quartz and detrital clays. The allochem components occur singly or in clusters; the terrigenous components occur singly, but more commonly have been concentrated along later stylolite boundaries. In contrast, a few samples contain a higher proportion of terrigenous material (between 10 and 50 percent) and may be classified as sandy or silty micrites and calcilutites (Folk, 1959). In these samples, the terrigenous components, generally quartz and detrital clays, are concentrated along laminae less than $1 \mathrm{~mm}$ thick. The silty micrites and 


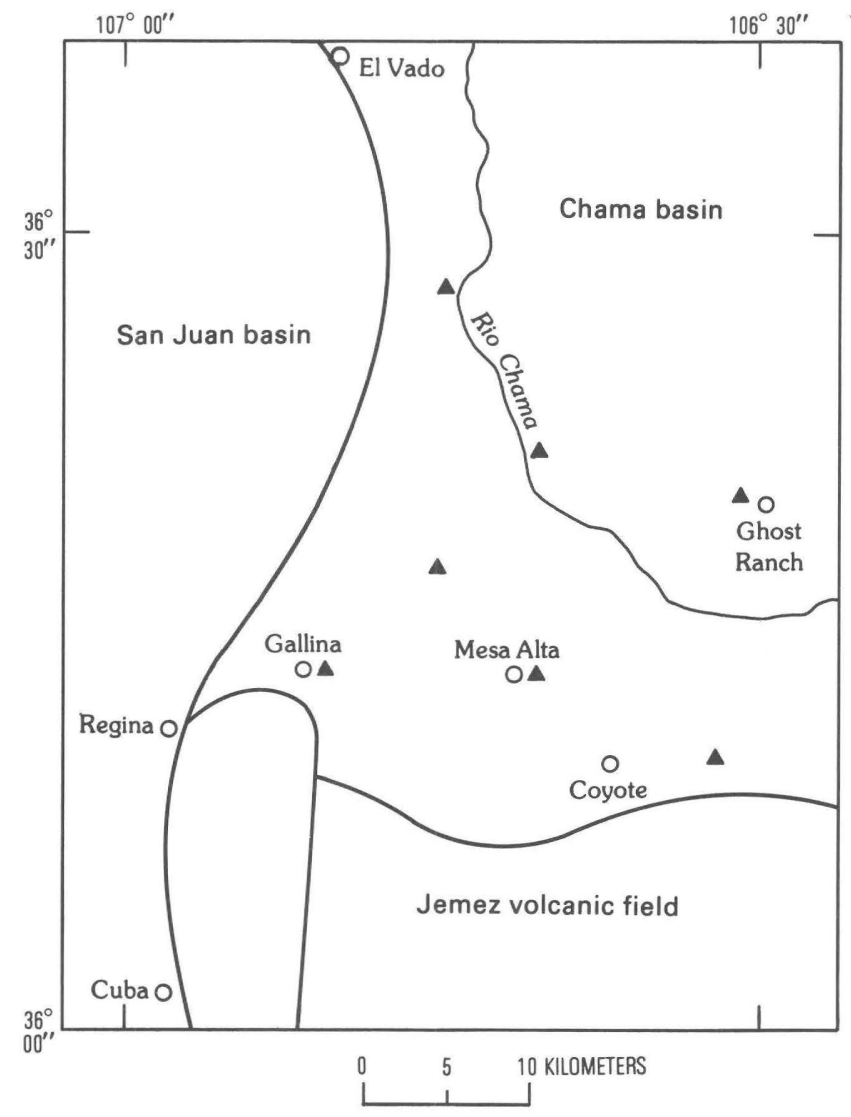

Figure 1. Index map of the southern part of the Chama basin, New Mexico. Triangles represent sample localities. Heavy lines separate adjacent structural features.

calcilutites commonly occur with thin interbedded sandstones or mudstones that are locally present in the basal platy and middle crinkly facies. Petrographic observations indicate that for most of the samples the original depositional fabric has been altered or obscured by subsequent diagenesis.

\section{DIAGENETIC ALTERATIONS}

Several types of diagenetic events have been recognized and are discussed separately as follows.

\section{Micritization}

One of the earliest diagenetic events was the micritization of bioclastic shell material (fig. $2 A$ ). Micritization took place by the repeated boring of shell material by algae and the subsequent infilling of empty bores with micritic carbonate (Bathurst, 1966). The result of this process was the formation of a micrite envelope that surrounds the remaining shell material.

\section{Types of cementation}

Cements in the carbonate and clastic rocks of the Todilto are of various ages. The earliest type of cement is rim cement around grains, especially where allochem and terrigenous grains are moderately to densely packed. The rim cements occur as fibrous fringing cements and are especially abundant around pellets and superficial ooliths (fig. 2B). The rim cements also occur as mosaics of small crystals around quartz grains and calcite grains greater than $4 \mu \mathrm{m}$.

Other types of cements precipitated at various stages of lithification of the carbonates. Some cements fill pore spaces that formed by the dissolution of bioclasts (fig. $2 A$ ) and evaporite nodules. Other cements fill intergranular pore space, late fractures, and voids formed when evaporite minerals dissolved. Late calcite cements are commonly ferroan, in contrast to early calcite cements which are nonferroan.

\section{Authigenic evaporites}

Examination of thin sections and rock chips and field relations of the carbonate-evaporite rocks indicate the presence of primary bedded and later authigenic evaporites. To date, gypsum and anhydrite are the only evaporite minerals that have been identified. Authigenic gypsum and anhydrite replace micrite (figs. $2 C, 2 D$, and $2 E)$; replacement began prior to complete lithification. Gypsum also occurs as an authigenic precipitate in open pore space (fig. $2 F$ ).

Two forms of authigenic gypsum and anhydrite replace partially lithified micrite. In one, anhydrite grew as euhedral crystals $(0.08-0.4 \mathrm{~mm}$ in length), either singly or in clusters. Presently, in the rhythmically bedded crinkly limestone facies these euhedral crystal volumes are occupied by masses of tiny gypsum crystals $(3-50 \mu \mathrm{m})$ (fig. 2C). This textural relationship suggests that the anhydrite either dissolved and created moldic porosity that was subsequently filled by numerous small gypsum crystals or that during hydration the single anhydrite crystals were replaced by many small gypsum crystals.

In the other form, gypsum grew as lath-shaped crystals of various sizes $(0.2-0.08 \mathrm{~mm}$ in length) from numerous point sources within the partially lithified micrite. These lath-shaped crystals grew at a variety of angles to one another and eventually coalesced to form nodular gypsum or masses of gypsum enclosing remnant micrite patches (figs. $2 D$ and $2 E$ ). The gypsum in these masses is both displacive and replacive. It is displacive in that it pushed aside carbonate laminae and stylolites as the nodules grew. It is replacive in that it incorporated some of the previously deposited carbonate as it grew (figs. $2 D$ and $2 E$ ). This particular type of diagenetic alteration is characteristic of the rhythmically bedded limestonegypsum facies that are overlain by more massive gypsum.

\section{Calcite replacement of evaporites}

Gypsum replaced by calcite is present in all facies but is most abundant where overlying gypsum is absent. 

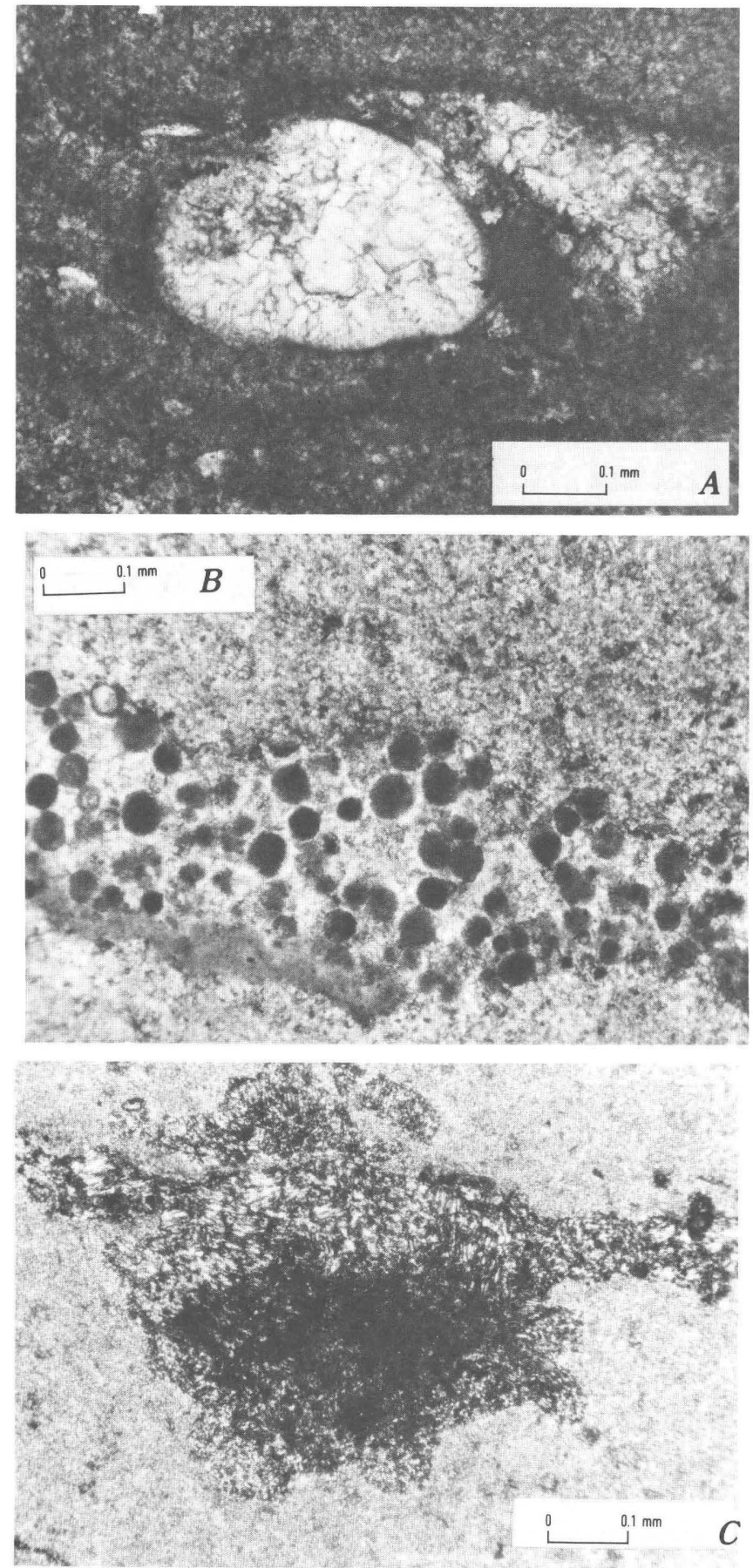
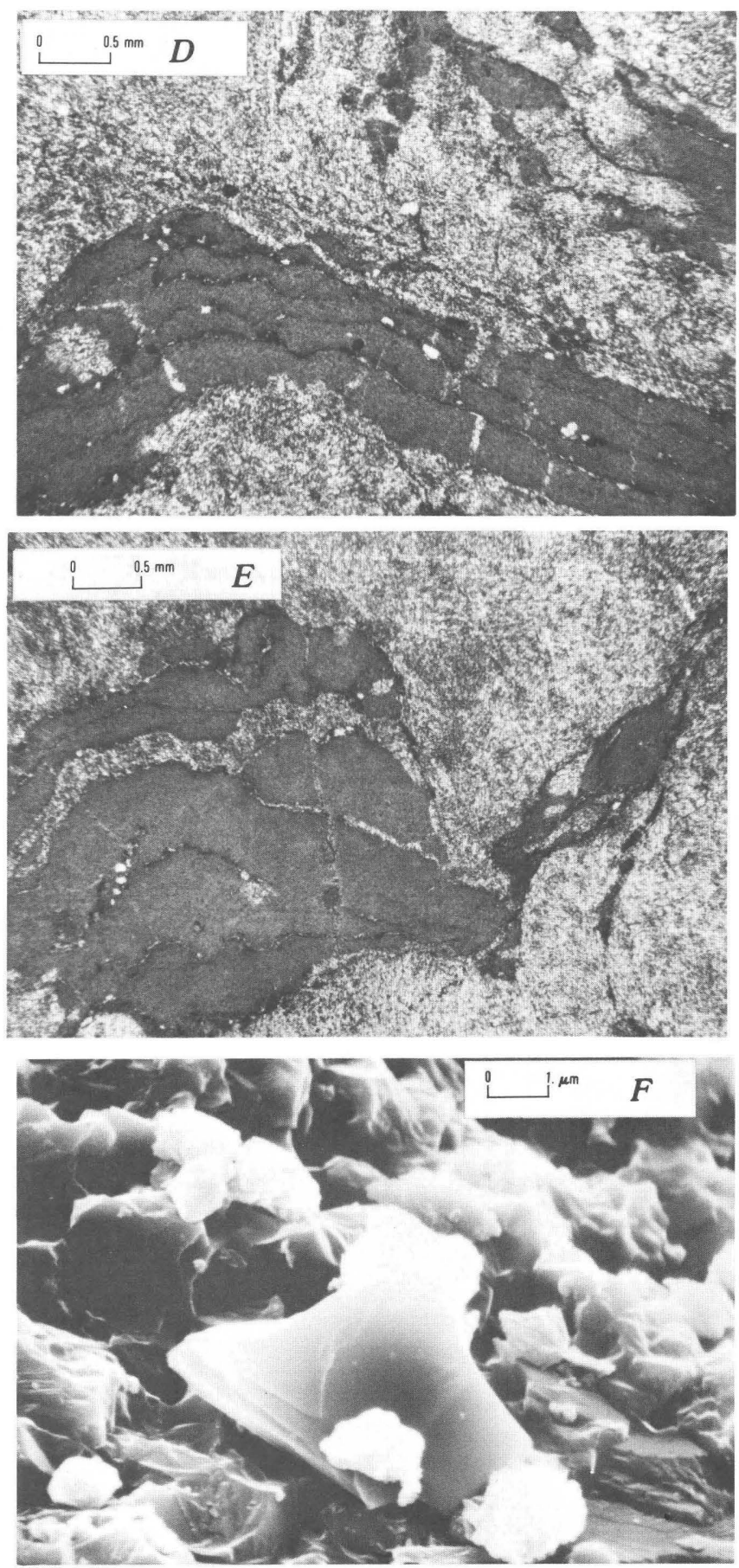

Figure 2. Photomicrographs of micritization, early cementation, and authigenic evaporites. A, Micritized bioclast. Probable ostracode shell replaced with micritic envelope. Sometime after formation of the micrite envelope the remaining fossil was leached. Later sparry calcite cement filled the interior. Crossed nicols. Field of view $1.0 \mathrm{~mm}$. B, Early radial rim cement of calcite around pellets or superficial ooliths. Light areas around ooliths or pellets are the radial rim cement which has undergone some neomorphism. Field of view $1.0 \mathrm{~mm}$. C, Gypsum replacement of anhydrite. Cluster of euhedral grains set around large euhedral area occurs in micrite. Euhedral grains, once anhydrite, are now filled with mosaics of small gypsum crystals. Field of view 1.0 mm. $D$, Gypsum replacement of micrite. Lath-shaped gypsum (lighter areas) replacing micrite (center dark mass and dark wispy areas above). Dark wavy bands are stylolites. Fractures oriented perpendicular to stylolites are filled with gypsum. Field of view 5.1 $\mathrm{mm}$. E, Gypsum replacement of micrite. Lath-shaped gypsum (lighter areas) replaces micrite (dense gray areas at left and right). Dark bands are microstylolites with quartz grains (clear grains) along seams. Field of view $5.1 \mathrm{~mm}$. F, Scanning electron micrograph of authigenic gypsum. Gypsum (large light-gray grain in center) probably precipitated in pore. Later quartz and calcite overgrowth can be seen near bottom of crystal. Field of view $12 \mu \mathrm{m}$. 
Many of the resulting textures mimic textures produced by the growth of authigenic anhydrite or gypsum (fig. $3 A$ ). For example, in the brecciated facies large areas of sparry calcite contain patches of original micrite in a pattern similar to that seen where gypsum has replaced portions of the original micrite (compare figs. $2 D$ and $2 E$ to fig. $3 A$ ). These patches of micrite do not appear to be supported by framework or matrix, but rather appear to float within the sparry calcite areas. Thus, the micrite patches are not true breccia clasts and the sparry calcite that surrounds them is not totally cement. Most of the sparry calcite crystals are replacements of gypsum by calcite. Occasional relict gypsum within the large sparry calcite crystals is evidence of replacement rather than dissolution followed by precipitation of cement in the resulting void. Invariably large, single calcite crystals have patchy extinction and contain inclusions that may be gypsum along crystallographic boundaries. Also, the manner in which many of the sparry calcite crystals interlock resembles the random interlocking pattern seen in larger gypsum laths.

One principal difference between the calcite and gypsum replacement textures is the presence of more quartz in the calcite. Some of this quartz undoubtedly was part of the original sediment; the remainder appears to be authigenic. The authigenic quartz commonly occurs as crystals with well-defined terminations and hexagonal outlines or as fibrous chalcedony. The presence of authigenic quartz in these rocks and the textural relations between the quartz and calcite suggest the presence of former evaporite minerals (Friedman, 1980).

Calcite also occurs as mosaics of crystals (about 1-3 $\mu \mathrm{m}$ in width) filling well-defined euhedral volumes (fig. 3B; see also, Stapor, 1968) that were once occupied by gypsum or anhydrite. This diagenetic texture is more abundant in the brecciated facies. As was noted previously, similar euhedral volumes in the bedded, crinkly limestone facies contain mosaics of gypsum crystals. Whether the calcite actually replaced the gypsum or whether the gypsum was selectively leached and the resulting moldic porosity cemented with mosaics of calcite crystals has not been determined. Similar textures in the Permian Tansill Formation, Texas and New Mexico, were described by Lucia (1961) as representing either direct calcite replacement of gypsum or anhydrite or precipitation of calcite in voids created by the leaching of these evaporite minerals.

Direct calcite replacement of primary bedded anhydrite or gypsum was also observed (fig. $3 C$ ). In figure $3 C$, the large sparry calcite is cloudy, and remnants of gypsum and crystal shape reminiscent of gypsum are apparent.

\section{Dolomite and dedolomitization}

Several authors (for example, Rawson, 1980; Stapor, 1968) who have studied the Todilto have commented on the lack of dolomite; however, Gabelman (1970) reported finding a minor amount of dolomite in the Todilto at the Flat Top uranium mine near Grants, New Mexico. His identification of dolomite was based on the lack of reaction of portions of the limestone to weak solutions of hydrochloric acid. In the present study, petrographic and SEM examination of thin sections and rock chips found only minor amounts of dolomite. The presence of dolomite in the Todilto is also suggested by the results obtained by plotting bulk density against compensated neutron porosity. The values were obtained by interpretation of density and compensated neutron-porosity data formation shown on compensated neutron-density logs of holes that penetrate the Todilto Limestone Member in the east-central part of the San Juan basin. Several of these cross plots are shown in figure 4. Successive changes in composition, from the base to the top of the member, are shown for each hole. These compositional changes suggest the presence of anhydrite and mixtures of dolomite and limestone.

In the Todilto the dolomite generally occurs as remnant patches in micrite and microspar matrix (fig. $3 D$ ). A minor amount of dolomite was also observed in one thin section in the form of overgrowths on gypsum crystals present within micrite patches. The rest of the dolomite occurs as remnants within large sparry calcite crystals, some of which formed as replacement of evaporites.

The age relations of the dolomite are not totally clear. Groundmass dolomite of rhombic and anhedral shape replaces micrite and microspar and may have formed early, perhaps contemporaneous with primary evaporite precipitation. The remnant dolomite in the large sparry calcite crystals may have formed somewhat later under different geochemical conditions. The presence of zoned dolomite, later dedolomitized, indicates fluctuations in the geochemical environment. The remnant dolomite may have formed as partial replacement of gypsum and was subsequently incorporated in the calcite when it replaced the gypsum; however, no detectable dolomite was found in the coarse gypsum patches in the two thin sections of highly gypsiferous limestone examined. An alternative explanation is that early in the diagenetic history of the limestone calcite began to replace the gypsum as a result of fluctuation in calcite-gypsum solubilities (Wigley, 1973). This calcite was then subsequently partially dolomitized.

The minor amount of dolomite present is attributed to extensive dedolomitization-that is, replacement of dolomite by calcite. Dedolomitization is a diagenetic process that occurs at low temperature and low partial pressure of carbon dioxide and is apparently promoted by the dissolution of sulfates, in particular gypsum (de Groot, 1967; Yanat'eve, 1955). It is therefore a near-surface process related to present exposure or past unconformities. Dedolomitization of the Todilto Limestone Member may be a recent phenomenon related to present exposure; 
however, some dedolomitization may have occurred shortly after early burial when the ground-water chemistry changed. Pipiringos and O'Sullivan (1978) and Lupe (1981) postulated the presence of an unconformity at the top of the Summerville Formation-Wanakah Formation interval-the immediately overlying formationthroughout this and adjacent regions. This unconformity, however, is not readily apparent at the outcrop. Examination of core of the Todilto from the central part of the depositional basin might help resolve the age of the dedolomitization.

Evidence for dedolomitization is seen in a variety of textures. In most thin sections some matrix calcite occurs as rhombic or incomplete rhombohedral crystals. These crystals may be primary or they may represent replacement of dolomite. Calcite replacement of zoned dolomite is also apparent (fig. $3 E$ ). In several thin sections clotted or pseudomicropelletal texture is present (fig. $3 F$ ) which is similar to the grumeleuse texture reported by Cayeux (1935). Evamy (1967) suggested that some clotted textures might be due to the dedolomitization of cloudy-center dolomite described by Murray (1964).

Another type of dedolomitization texture observed was the progressive replacement of dolomite crystals by calcite. This process led to the formation of irregular remnants of dolomite within the original crystal. Complete replacement of the dolomite crystals may have resulted in a texture that is difficult to distinguish from that of the original limestone. Similar textures of dedolomitized dolomitic limestones were noted by Munn and Jackson (1980, fig. 2, plate 1) in their examination of the Lower Carboniferous Hoptonwood and Matlock Formations, Wirksworth, United Kingdom. They reported the progressive replacement of dolomite by calcite that began with selective replacement at the margins or along planes of crystallographic weakness, such as cleavages, and culminated in partial or total replacement. This type of dedolomitization texture was most noticeable in the upper $2 \mathrm{~m}$ of the limestones and was considered to be related to present-day weathering.

\section{Stylolitization}

The formation of microstylolites is, perhaps, the most striking visible form of diagenetic alteration in the Todilto Limestone Member. Horizontal, vertical, and inclined stylolites are all present, although horizontal stylolites predominate. The microstylolite seams are generally less than $0.1 \mathrm{~mm}$ thick; suture amplitudes are also usually less than $0.1 \mathrm{~mm}$. Residual material concentrated along the stylolite seam consists of clay minerals, quartz, organic material, and iron-bearing minerals. The morphology of the stylolites is varied. Simple or primitive wavelike types, sutured types, and sharp-peaked types,

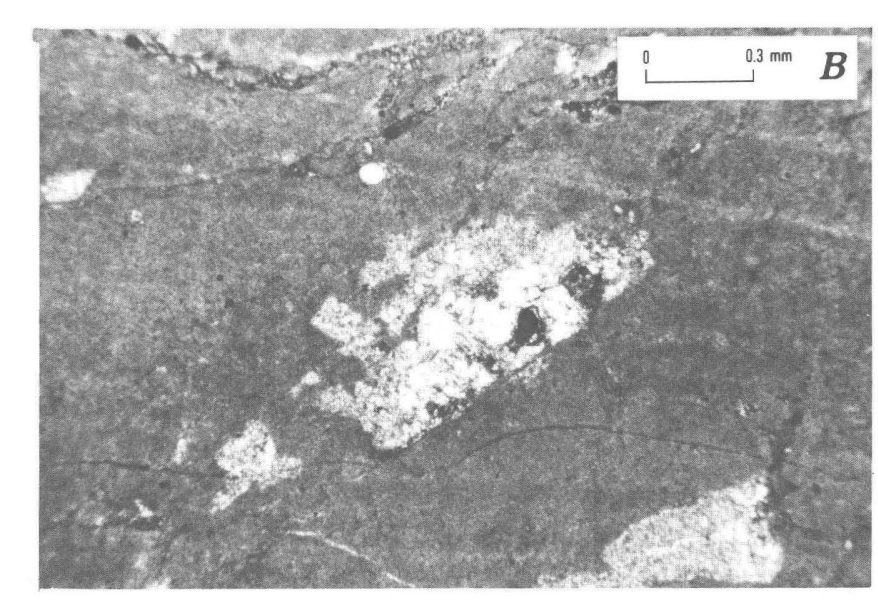

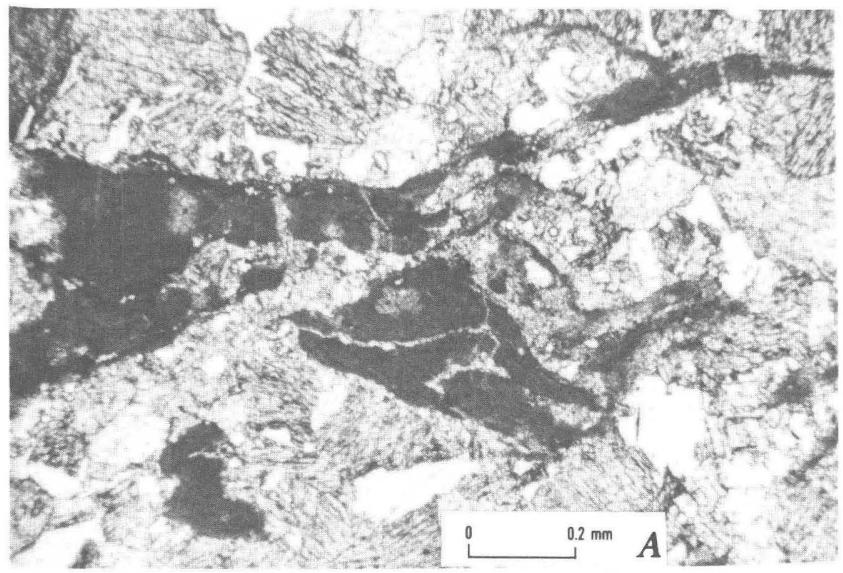

Figure 3. Photomicrographs of calcite replacement of evaporites, dolomite, dedolomite, and stylolites. A, calcite replacement of gypsum. Darker patches and wisps are original micrite. Sparry calcite (light area) is for the most part replacement of gypsum, although some may represent cement. Most of the calcite shows patchy extinction and remnants of gypsum. Sparry calcite fills fractures in micrite near center of photograph. Circular areas in center are bubbles; clear patches are voids. Field of view 1.64 $\mathrm{mm}$. B, Calcite filling euhedral volumes once occupied by anhydrite crystals. Large lath-shaped area near the center of the photograph and clusters of smaller euhedral volumes are now filled with mosaics of small calcite crystals or large sparry calcite crystals. This assemblage may represent calcite replacement of anhydrite or gypsum or calcite cement filling voids that resulted from leaching of anhydrite. Crossed nicols. Field of view $2.5 \mathrm{~mm}$. C, Calcite replacement of bedded evaporites. Micrite layers (dark areas) 

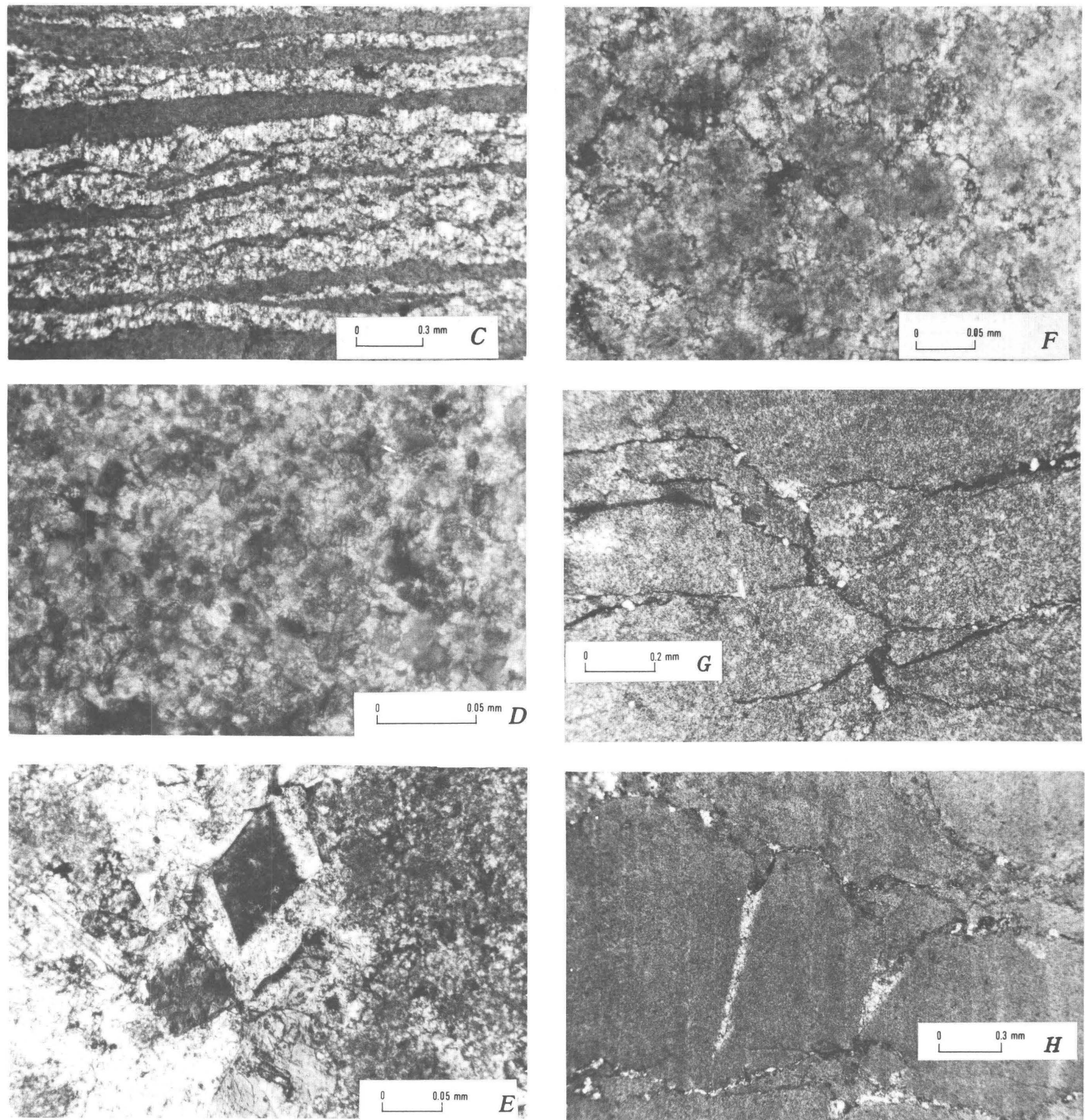

interbedded with sparry calcite (light areas) that has replaced primary evaporites. Field of view $2.5 \mathrm{~mm}$. D, Groundmass dolomite in micrite. Light areas are dolomite, quartz, and late kaolinite overgrowths. Dark areas are micrite. Dolomite replaced part of the micrite and has subsequently been partly dedolomitized. Field of view $0.26 \mathrm{~mm}$. E, Calcite replacement of zoned dolomite. Crossed nicols. Field of view $0.41 \mathrm{~mm}$. F, Clotted or grumeleuse texture due to dedolomitization of cloudy-center dolomite. Thin, dark, irregular band between grains may be due to pressure solution. Field of view $0.41 \mathrm{~mm}$. G, Network microstylolites. Residual material of clay, organic material, iron-rich minerals, and quartz are concentrated along stylolite seams. Field of view 1.64 mm. $H$, Tension gashes or extension fractures. Coarse sparry calcite fills wedge-shaped fractures that begin at stylolite seams (dark wavy bands). Field of view $2.5 \mathrm{~mm}$. 


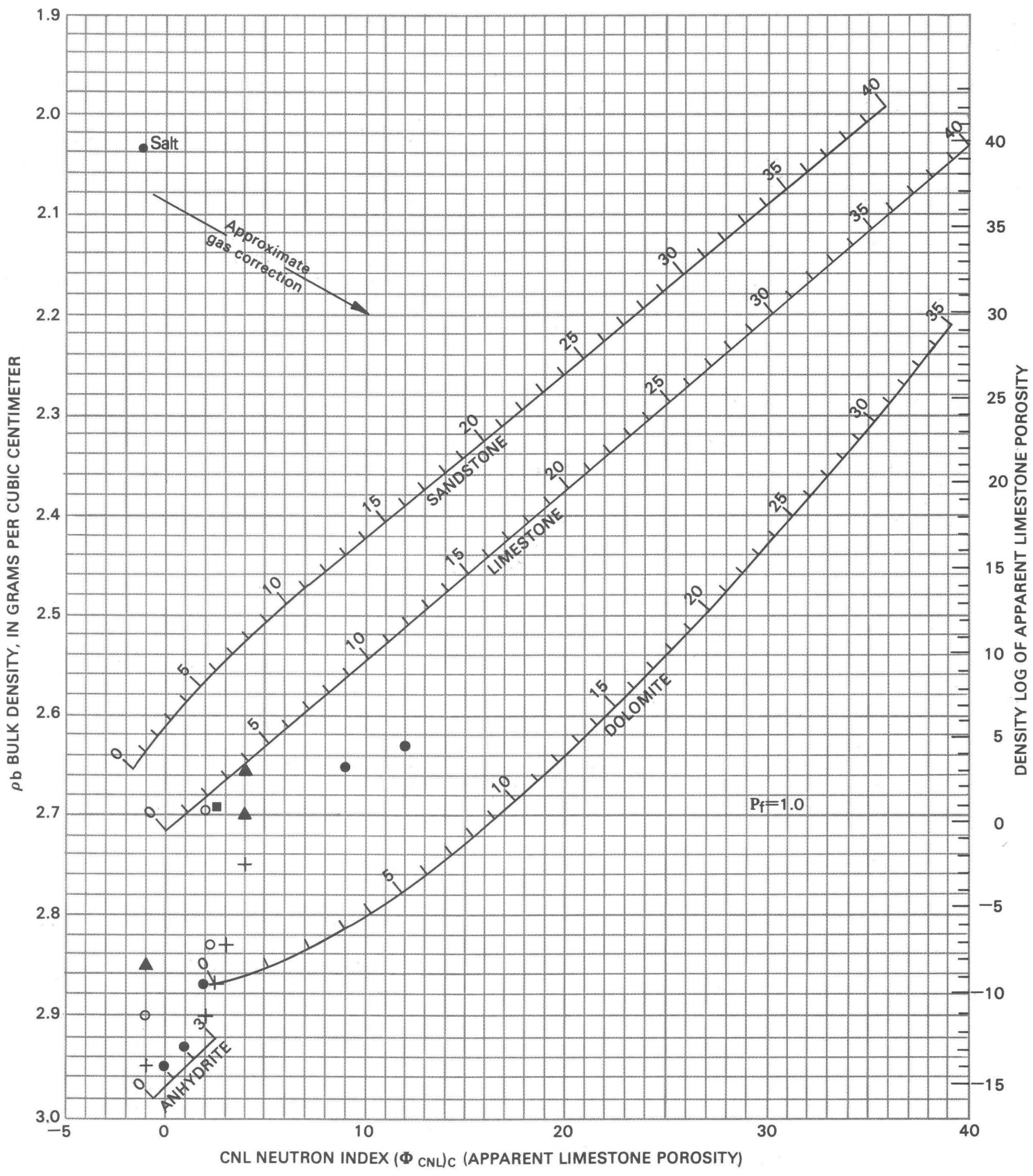

Figure 4 (above and facing page). Cross plot of bulk density versus compensated neutron porosity for several holes that penetrated the Todilto Limestone Member of the Wanakah Formation. Bulk density and compensated neutron porosity values shown were obtained from examination of density and compensated neutron porosity and formation density porosity logs. Successive vertical changes in composition from base to top of formation for each hole are shown as occurring from top to bottom of the figure. Base diagram is from Schlumberger (1972) and is for freshwater, liquid-filled holes. 
LOCATION OF DRILL HOLES IN THE TODILTO LIMESTONE MEMBER OF THE WANAKAH FORMATION, CHAMA BASIN, NEW MEXICO

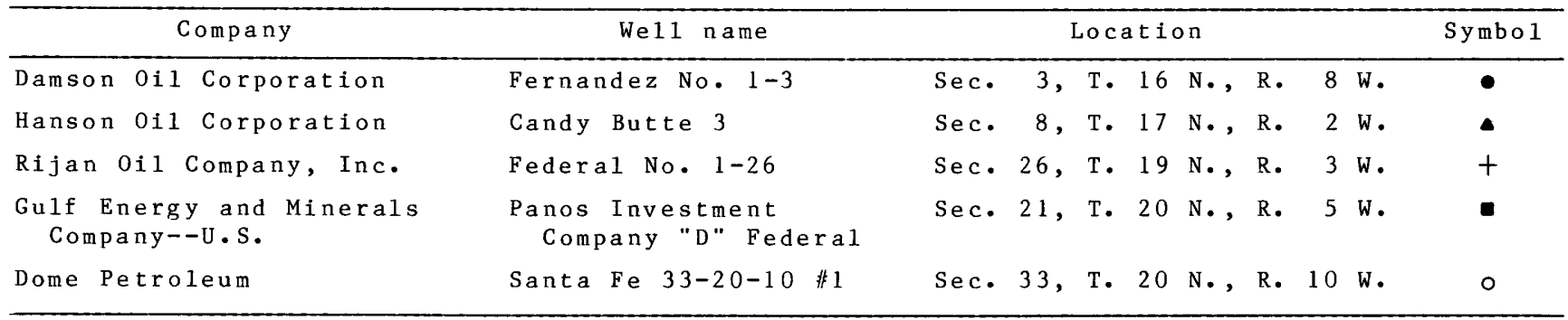

as defined by Park and Schot (1968, fig. 1), are present. Subparallel horizontal and vertical stylolites were noted in some thin sections; in others, interconnecting networks of stylolites are more common (fig. 3G). These network stylolites are similar to those discussed by Park and Schot (1968; fig. 5), who suggested that they might be of tectonic origin.

Associated with many of the stylolites, but particularly with the network type, are fractures that are nearly perpendicular to the seam. These fractures are filled with sparry calcite and originate at a peak or valley of the stylolite seam. Many of these fractures are wedge shaped; they are wider where they abut against the seam (fig. $3 H$ ). Fractures extending from a single stylolite seam in opposite directions are not uncommon. Choukroune (1969) called these types of fractures tension gashes and stated that they were related to the same stress conditions that formed the stylolites.

More recently, Nelson (1979) redefined "tension gashes" as extension fractures and concurred with Choukroune's theory of origin. Nelson (1981) further suggested that the pattern of stylolites with extension fractures are similar to stress patterns produced in laboratory triaxial compression and extension tests and are therefore of probable tectonic origin. He envisioned these types of stylolite patterns as having been produced by a slow tectonic process operating on soluble rocks being compacted in one direction and extended in another direction at $90^{\circ}$.

Complete evaluation of the stylolite patterns and time of formation will require more detailed study; however, certain observations as to timing of stylolite formation suggest that it began during early burial. In the bedded crinkly limestone, remnant patches of micrite enclosed within the growing gypsum contain stylolites of various forms (figs. $2 D$ and $2 E$ ). Some of these stylolites contain gypsum-filled fractures oriented perpendicular to the seam (fig. $2 D$ ). Locally, the stylolites extend out from the micrite into the gypsum. They may completely cross the gypsum, where the gypsum mass is small, or terminate within it. This phenomenon suggests that the growing gypsum was unable to incorporate all the seam material as it grew and not that late stylolites cut across the gypsum. Thus, the formation of stylolites appears to have preceded the formation of the gypsum that replaced the micrite.

\section{CONCLUSIONS}

These preliminary studies indicate a varied and complex diagenetic history for the Todilto Limestone Member of the Wanakah Formation. The most important diagenetic alterations are a complex cementation history, dolomitization followed by dedolomitization, an evaporite replacement of carbonates and subsequent carbonate replacement of these evaporites, and an early formation of stylolites. This preliminary study lays the groundwork for the future investigations needed to explain more fully the diagenetic history of the Todilto Limestone Member.

\section{REFERENCES CITED}

Bathurst, R. G. C., 1976, Carbonate sediments and their diagenesis: New York, Elsevier, 658 p.

Cayeux, L., 1935, Les roches sedimentaires de France; les roches carbonatees: Paris, Masson, 463 p.

Choukroune, P., 1969, An example of mesoscopic analyses of concentric folding in limestone series: Tectonophysics, v. 7, p. 57-70.

Condon, S. M., and Huffman, A. C., in press, Revisions in nomenclature of the Middle Jurassic Wanakah Formation, northwest New Mexico and northeast Arizona: U.S. Geological Survey Bulletin 1633-A.

de Groot, K., 1967, Experimental dedolomitization: Journal of Sedimentary Petrology, v. 37, p. 1216-1220.

Dickson, J. A. D., 1965, A modified staining technique for carbonates in thin section: Nature, v. 205, p. 587.

Evamy, B. D., 1967, Dedolomitization and the development of rhombohedral pores in limestone: Journal of Sedimentary Petrology, v. 37, p. 1204-1215.

Folk, R. L., 1959, Practical petrographic classification of limestones: American Association of Petroleum Geologists Bulletin, v. 43, p. 1-38.

Friedman, G. M., 1980, Dolomite is an evaporite mineral; Evidence from the rock record and from sea marginal ponds of the Red Sea: Society of Economic Paleontologists and Mineralogists Special Publication 28, p. 69-80. 
Gabelman, J., 1970, The Flat Top uranium mine, Grants, New Mexico: U.S. Atomic Energy Commission, RME-4112, 81 p.

Lucia, F. J., 1961, Dedolomitization in the Tansill (Permian) Formation: Geological Society of America Bulletin, v. 72, p. 1107-1110.

Lupe, R. D., 1981, Stratigraphic sections of subsurface Jurassic rocks in the San Juan basin, New Mexico, Colorado, Utah, and Arizona: U.S. Geological Survey Oil and Gas Chart 118.

Munn, D., and Jackson, D. E., 1980, Dedolomitization of Lower Carboniferous dolostone in the Wirksworth area, Derbyshire, England: Geological Magazine, v. 117, p. 607-612.

Murray, R. C., 1964, Preservation of primary structures and fabrics in dolomite, in Imbrie, J., and Newell, N. D., eds., Approaches to paleoecology, 1st ed.: New York, Wiley and Sons, 432 p.

Murray, R. C., and Pray, L. C., 1965, Dolomitization and limestone diagenesis-An introduction: Society of Economic Paleontologists and Mineralogists Special Publication 13, p. 1-2.

Nelson, R. A., 1979, Natural fracture systems, description and classification: American Association of Petroleum Geologists Bulletin, v. 63, p. 2214-2221.

1981, Significance of fracture sets associated with stylolite zones: American Association of Petroleum Geologists Bulletin, v. 65 , p. 2417-2425.

Park, W. C., and Schot, E. H., 1968, Stylolites; their nature and origin: Journal of Sedimentary Petrology, v. 38, p. 175-191.
Pipiringos, G. N., and O'Sullivan, R. B., 1978, Principal unconformities in Triassic and Jurassic rocks, western interior United States-A preliminary survey: U.S. Geological Professional Paper 1035-A, 29 p.

Rawson, R. R., 1980, Uranium in Todilto Limestone (Jurassic) of New Mexico-Example of a sabkha-like deposit, in Rautman, C., compiler, Geology and mineral technology of the Grants uranium region 1979: New Mexico Bureau of Mines and Mineral Resources Memoir 38, p. 304-312.

Ridgley, J. L., 1977, Stratigraphy and depositional environments of Jurassic-Cretaceous rocks in the southwest part of the Chama Basin, New Mexico: New Mexico Geological Society Guidebook, 28th Field Conference, San Juan Basin III, p. 153-158.

Schlumberger, 1972, Log interpretation charts: Houston, Texas, Schlumberger Limited, 92 p.

Stapor, F. W., 1968, Stratigraphy of the Todilto Formation in the Ghost Ranch area, New Mexico: Madison, Wisconsin, University of Wisconsin, M.S. thesis, $75 \mathrm{p}$.

Wigley, T. M. L., 1973, Chemical evolution of the system calcitegypsum-water: Canadian Journal of Earth Science, v. 10, p. 306-315.

Yanat'eva, O. K., 1955, Effect of aqueous solutions of gypsum on dolomite in the presence of carbon dioxide: Doklady Akadimiya Nauk S.S.S.R., v. 101, p. 911-912. 


\title{
Mineralogy and Stable Isotope Geochemistry of Carbonate and Sulfate Minerals in Diagenetically Altered Tertiary and Cretaceous Sandstones, Uinta Basin, Utah
}

By JANET K. PITMAN, U.S. Geological Survey, Box 25046, DFC, MS 916, Denver, Colorado 80225,

MARTIN B. GOLDHABER, U. S. Geological Survey, Box 25046, DFC, MS 916, Denver, Colorado 80225, and

THOMAS D. FOUCH, U.S. Geological Survey, Box 25046, DFC, MS 916, Denver, Colorado 80225

\section{CONTENTS}

\author{
Abstract 208 \\ Introduction 208 \\ Acknowledgments 208 \\ Methods 208 \\ Geology 209 \\ Whole-rock mineralogy 209 \\ Carbonate mineralogy and diagenesis $\mathbf{2 1 2}$ \\ Porosity development $\mathbf{2 1 2}$ \\ Stable isotopes $\mathbf{2 1 4}$ \\ Carbon isotopes 214 \\ Oxygen isotopes 216 \\ Dolomite 217 \\ Summary $\mathbf{2 1 7}$ \\ References cited $\mathbf{2 1 7}$
}

FIGURES

1. Index map of Uinta basin, Utah, showing location of Natural Buttes field 208

2. Chart showing correlation of major Tertiary and Cretaceous rock units in Uinta basin, Utah 210

3. Ternary diagram showing mineralogic composition of sandstones in cored part of Wasatch and Tuscher Formations 211

4. Photomicrographs of authigenic anhydrite, iron-free and iron-bearing carbonate, and associated dissolution features in the Wasatch and Tuscher Formations 213

5. Crossplot showing $\delta^{13} \mathrm{C}_{\mathrm{PDB}}$ versus $\delta^{18} \mathrm{O}_{\mathrm{PDB}}$ for carbonate grains and cement in sandstones from the Tuscher and Wasatch Formations 216

TABLE

1. Stable isotope data for calcite, dolomite, and anhydrite in sandstones from the Wasatch and Tuscher Formations 215 


\section{Abstract}

Nonmarine Tertiary and Cretaceous sandstones in the Uinta Basin, Utah, have been extensively modified by the formation of a carbonate mineral assemblage composed of ironfree calcite, ferroan calcite, dolomite, and ankerite. Iron-free calcite was the earliest carbonate to form followed by ferroan calcite which is now the most abundant carbonate phase. Most of the calcite appears to have formed during early burial before significant compaction had taken place.

The $\delta^{13} \mathrm{C}$ compositions of calcite in the Tuscher Formation vary between -3.1 and -8.1 per mil. The source of heavy carbon (near -3 per mil) was dissolved marine carbonate that was derived locally from depositional waters. In the Wasatch Formation, $\delta^{13} \mathrm{C}$ values are distinctly light, ranging from -5.2 to -10.6 per mil. The isotopically light carbon may have been derived from atmospheric $\mathrm{CO}_{2}$ or it may have originated from organic matter in kerogenous shales, as $\delta^{34} \mathrm{~S}$ values $(+30$ per mil average) for associated anhydrite are similar to those for organic matter and pyrite in the Eocene Green River Formation.

$\delta^{18} \mathrm{O}$ compositions of calcite are similar in the Tuscher (-9.7 to -14.2 per mil) and Wasatch Formations (-9.4 to -13.1 per mil). These data suggest that the variation in pore-water composition was a more important factor than the effects of temperature with increasing burial depth in determining $\delta^{18} \mathrm{O}$ systematics.

\section{INTRODUCTION}

Thick sequences of nonmarine Tertiary and Cretaceous rocks in the eastern part of the Uinta Basin, Utah, are unconventional reservoirs for large amounts of natural gas (fig. 1). Individual sandstones have undergone extensive postdepositional mineral alteration that resulted in the formation of authigenic carbonate and minor anhydrite. This paper is a study of the carbonate and sulfate mineral assemblage that characterizes the lower Tertiary Wasatch and Upper Cretaceous Tuscher Formations. The recognition of individual carbonate phases and the diagenetic environment in which they formed is important in reconstructing the burial history of the sandstones. The purpose of the paper is to (1) identify and describe the discrete carbonate mineral phases that are present in Tertiary and Cretaceous sandstones, (2) present data for carbon and oxygen isotope compositions of carbonate grains and cement, and (3) discuss the origin of carbonate and its relation to the occurrence of anhydrite.

\section{Acknowledgments}

We thank Lisa Pratt for her helpful suggestions and critical review of the manuscript. Isotope analyses were performed by Global Geochemistry Corp. The U.S. Geological Survey research was supported by a grant from the U.S. Department of Energy.
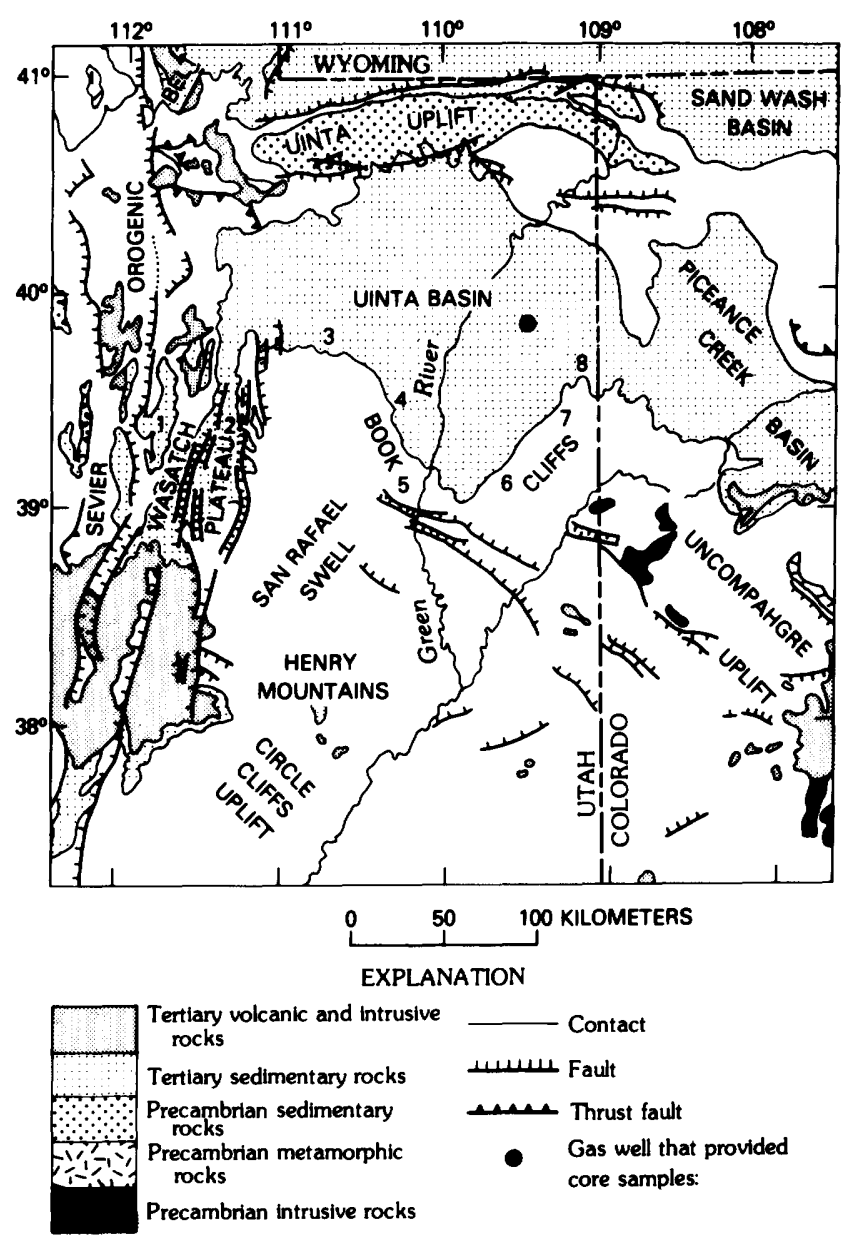

Figure 1. Index map of Uinta basin, Utah, showing location of Natural Buttes field.

\section{METHODS}

About 80 sandstone samples from the CIGE Natural Buttes 21 well were analyzed for their mineralogic composition and diagenetic character using standard $\mathrm{X}$-ray diffraction and petrographic techniques. Cored intervals that were sampled included the Wasatch Formation between 1,342 and $1,373 \mathrm{~m}(4,389$ and 4,508 ft) and the Tuscher Formation between 1,586 and 2,227 m $(6,350$ and $6,509 \mathrm{ft})$. In thin section, mineral abundances were determined by counting 300 grains per section. Each section was impregnated with blue epoxy and stained with alizarin red-S and potassium ferricyanide to differentiate between individual carbonate phases. Scanning electron microscopy was used to identify authigenic minerals on the basis of their morphology.

Carbon and oxygen isotope compositions of carbonate minerals were determined for 27 samples by Global Geochemistry Corporation. ${ }^{1}$ All samples were

\footnotetext{
${ }^{1}$ Use of company names is for descriptive purposes only and does not imply endorsement by the U.S. Geological Survey.
} 
first treated with Clorox to minimize contamination from reactive organic compounds. For samples that contained both calcite and dolomite-ankerite, an attempt was made to collect $\mathrm{CO}_{2}$ from each of the two carbonate fractions based upon the relative reactivity of calcite and dolomite in 100-percent $\mathrm{H}_{3} \mathrm{PO}_{4}$ (Walters and others, 1972). Carbon dioxide was collected after 6, 30, and 102 hours of reaction time at $25^{\circ} \mathrm{C}$. The 30 -hour aliquot representing mixed calcite and dolomite was discarded. The 6- and 102-hour aliquots were assumed to represent the calcite and dolomite-ankerite fractions, respectively. Dolomite data were not corrected for the difference in fractionation factor between 100-percent $\mathrm{H}_{3} \mathrm{PO}_{4}$ and dolomite compared with calcite (Land, 1980). Carbon $\left({ }^{13} \mathrm{C} /{ }^{12} \mathrm{C}\right)$ and oxygen $\left({ }^{18} \mathrm{O} /{ }^{16} \mathrm{O}\right)$ stable isotope ratios are reported as $\delta^{13} \mathrm{C}$ and $\delta^{18} \mathrm{O}$ values with units in parts per thousand (per mil) relative to the PDB standard (Cretaceous belemnite from the Peedee Formation). The samples chosen for isotope analyses were studied petrographically in more detail than the rest of the samples.

Four samples of anhydrite were analyzed for $\delta^{34} \mathrm{~S}$. Anhydrite was dissolved in $6 \mathrm{~N} \mathrm{HCl}$; sulfate was precipitated as $\mathrm{BaSO}_{4}$ which was decomposed directly to $\mathrm{SO}_{2}$ for analysis of the sulfur isotope ratio. The barite was purified by reaction with hot, alkaline sodium carbonate. The resulting sodium sulfate solution was reprecipitated as $\mathrm{BaSO}_{4}$ and decomposed to $\mathrm{SO}_{2}$ to determine $\delta^{34} \mathrm{~S}$.

\section{GEOLOGY}

Nonmarine rocks of the lower Tertiary Wasatch Formation and Upper Cretaceous Tuscher Formation in the Uinta Basin, Utah, were deposited over a time span of 25-30 million years in subaqueous depositional settings that record the evolution from a Late Cretaceous marine foreland trough to an internally drained Tertiary hydrographic basin (Fouch and others, 1983). This transition occurred in response to Laramide tectonism during late Maestrichtian and early Paleocene time. Accompanying Laramide deformation was widespread erosion, which is reflected in a regional unconformity that separates Cretaceous from Tertiary strata. Locally, the unconformity represents a hiatus of about 15 million years (Fouch and others, 1983). The stratigraphic and age relations between the Wasatch and Tuscher Formations and adjacent rock units are shown in figure 2.

In the eastern part of the Uinta Basin, the upper part of the Wasatch Formation is composed of finegrained lenticular sandstones that contain small-scale cross beds. Commonly the sandstones contain red coloration and are interbedded with variegated mudstones and shales. Some sandstone beds locally are conglomeratic. The presence of numerous red sandstone beds as well as their stratification and grain size indicate that these rocks formed from sediment deposited in deltaic plain environments peripheral to ancient Lake Uinta. Fouch (1975) and Ryder and others (1976) showed that the upper part of the Wasatch Formation in the eastern part of the basin is gradational with lacustrine rocks of the Eocene Green River Formation. Much of the Wasatch Formation also is temporally equivalent to rocks between the middle and carbonate markers of the Eocene Green River Formation that have yielded abundant gas and some liquid hydrocarbons in the north-central and southeastern parts of the basin (Fouch, 1981; Pitman and others, 1982).

The Tuscher Formation of the Mesa Verde Group contains fine-grained gray and brown sandstone (some beds are calcareous), gray-green sandstone, minor fossil mollusk debris, and carbonaceous and coaly shale beds. The sandstone units are laterally discontinuous and formed from sediments deposited in sinuous streams on the lower part of an alluvial braidplain (Fouch and others, 1983). The Tuscher Formation contains large amounts of thermogenic gas in the western and central parts of the basin where the rocks are deeply buried. In the eastern part of the basin, large amounts of early thermal gas are stratigraphically trapped in diagenetically altered lenticular sandstones (Pitman and others, 1987). The origin and distribution of rocks in the Wasatch and Tuscher Formations at Natural Buttes have been discussed in more detail by Pitman and others (1987).

\section{WHOLE-ROCK MINERALOGY}

On the basis of petrographic and X-ray diffraction examination, fine-grained, moderately sorted to wellsorted sandstones in the Wasatch Formation are feldsparrich, ranging from lithic arkoses to feldspathic litharenites (fig. 3). Sandstones in the Tuscher Formation generally are finer grained than those in the Wasatch and contain more quartz. These sandstones range between feldspathic litharenites and litharenites (fig. 3). Variations in mineralogic composition between the units reflect admixtures of sediment eroded from Laramide highlands that lay south and east of the Uinta Basin. Tertiary and Cretaceous rocks of interest in this study are similar in mineralogic composition to fluvial sandstones studied by Keighin and Fouch (1981), Pitman and others (1982), Stanley and Collinson (1979), Zawiskie and others (1982), and Lawton (1983).

Sandstones in the Wasatch and Tuscher Formations contain different amounts of framework grains, matrix material, pore-filling and replacement cements, and clay minerals. Monomineralic quartz, feldspar, and a variety of sedimentary lithic fragments and minor igneous fragments constitute the detrital fraction of the sandstones. Quartz grains commonly are angular to subrounded and contain euhedral syntaxial overgrowths 


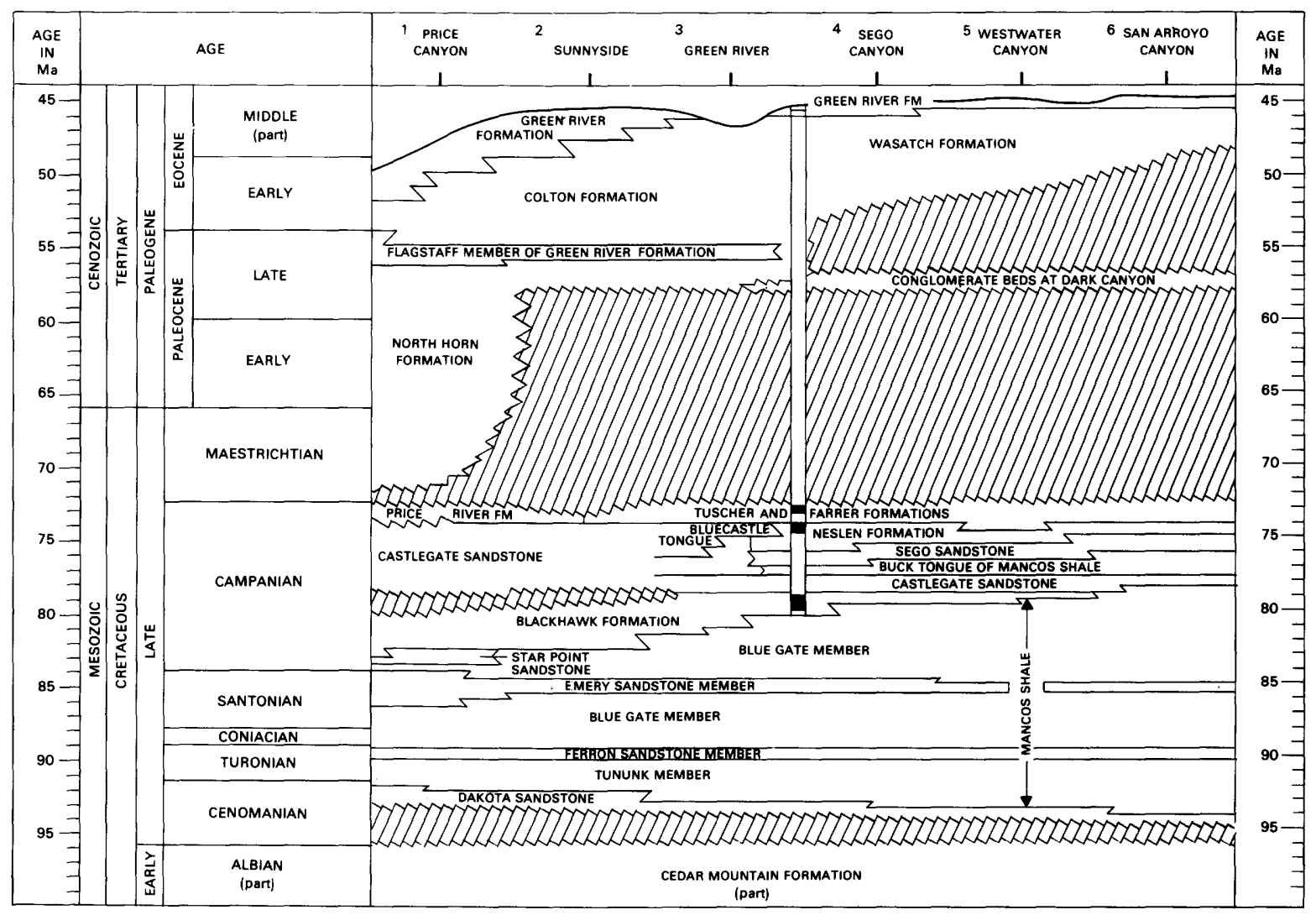

Figure 2. Correlation of major Tertiary and Cretaceous rock units in Uinta basin, Utah, modified from Fouch and others (1983). See figure 1 for location of sections shown in columns 1-8. Drill hole represented in column 5 has been projected southward to coeval rocks exposed near Green River. Dark sections of hole represent cored intervals. 


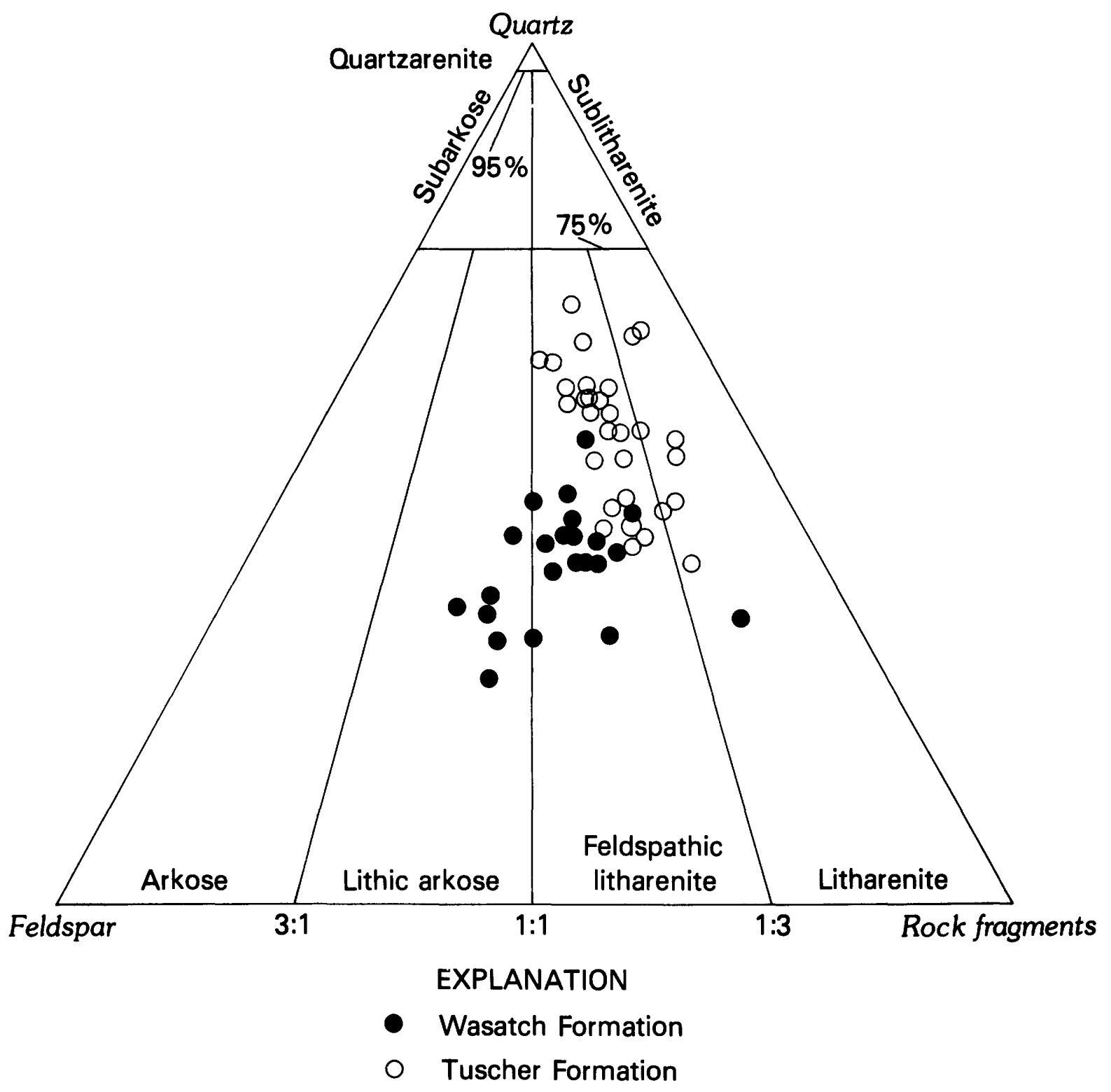

Figure 3. Ternary diagram (modified from Folk, 1974) showing mineralogic composition of sandstones in cored part of Wasatch and Tuscher Formations.

that are embayed due to dissolution associated with replacement carbonate and clay minerals. Feldspar is dominantly plagioclase, although smaller yet significant amounts of potassium feldspar are also present. Feldspar grains, particularly the potassium varieties, are weathered or show the effects of chemical alteration due to carbonate replacement and dissolution. Sedimentary rock fragments are of diverse origin and include sand-size, partly abraded carbonate clasts (mostly dolomite), and rhombic, detrital(?) dolomite grains which commonly contain an anhedral rim of ankerite.

Authigenic mineral cement, common to most sandstones, includes secondary silica as syntaxial quartz overgrowths, a mineralogically complex carbonate assemblage, and local barite and anhydrite. Authigenic carbonate minerals fill primary and secondary pores and replace framework grains, principally feldspar. Pervasive dissolution features and relicts of undissolved carbonate are evidence that authigenic carbonate formerly occupied much of the intergranular and intragranular porosity.

Authigenic clay minerals in sandstones consist of different proportions of kaolinite, illite, mixed-layer illite/smectite, and chlorite. Small amounts of corrensite are present in sandstones of the Wasatch Formation. Kaolinite typically occurs as well-crystallized booklets in secondary dissolution pores that are lined with fibrous illite or mixed-layer illite/smectite. Chlorite, usually associated with illite, forms pseudohexagonal platelets 
that are oriented perpendicular to grain surfaces. Corrensite may be associated with volcanic lithic fragments.

\section{CARBONATE MINERALOGY AND DIAGENESIS}

Sandstones in the Wasatch and Tuscher Formations in the eastern part of the Uinta basin have had a complex diagenetic history. The formation of several generations of carbonate during burial altered the sandstone fabric more than other diagenetic events. X-ray diffraction analysis and thin-section staining for iron content revealed a carbonate mineral assemblage composed of iron-free calcite, ferroan calcite, dolomite, and minor to trace amounts of ankerite. In most sandstones, ferroan calcite is the dominant carbonate cement and makes up between 0 and 35 percent of the mineral fraction. The relative abundance of iron-free calcite was not estimated because this mineral occurs only as isolated relicts in dissolution pores. Dolomite and small amounts of ankerite vary in abundance from 0 to 15 percent. Because detrital and authigenic dolomite are complexly intergrown, these percentages are only approximate. Textural relations between the individual carbonate phases and other mineral constituents in the sandstones are shown in figure 4.

Iron-free calcite was the earliest carbonate to form in Tertiary and Cretaceous sandstones and was followed by ferroan calcite which is now the most abundant carbonate phase. Iron-free calcite occurs in intergranular pores as isolated relicts of grains and cement which commonly are surrounded by ferroan calcite. The iron-free calcite commonly displays polysynthetic twinning, indicating that the mineral formed soon after deposition. During early burial, leaching of iron-free calcite locally may have created secondary porosity that was later recemented by ferroan calcite.

Ferroan calcite partly to completely replaces framework grains, particularly feldspar and rock fragments, and fills intergranular pores. Occurrences of ferroan calcite commonly are syntaxial with relict ironfree calcite grains and cement. Where ferroan calcite is widespread, it forms a fine- to coarse-crystalline, poikilotopic cement that encloses detrital framework grains which were typically not subjected to mechanical compaction or chemical alteration prior to its emplacement. Within cemented areas, detrital quartz rarely exhibits quartz overgrowths and feldspar grains commonly are angular and fresh in appearance, implying that they were protected from alteration by chemically active pore-fluids.

The distribution of ferroan calcite is highly variable; it is most widespread in sandstones that contain clastic carbonate grains or where there is evidence for preexisting iron-free calcite cement. Remnants of iron-free calcite surrounded by optically continuous ferroan calcite suggest that ferroan calcite either grew by nucleating on detrital carbonate grains and remnants of iron-free calcite cement or by incompletely replacing early-formed ironfree calcite. The relative abundance of ferroan calcite in Tertiary and Cretaceous sandstones may reflect the existence of these nucleation sites for carbonate growth. Patchy ferroan calcite, common in many sandstones, suggests that dissolution removed most of the replacment cement.

Authigenic dolomite in the sandstones is relatively rare and is distributed as minor anhedral pore-filling and replacement cement. Ankerite occurs in relatively small amounts as anhedral syntaxial rims surrounding dolomite grains. The relations between grains and cement suggest that the formation of ankerite required preexisting detrital dolomite grains for its growth; most ankerite probably formed along with the dolomite clasts from the source area.

Coarse-crystalline anhydrite and barite occur locally in sandstones of the Wasatch Formation as replacement minerals. Anhydrite typically forms large poikilotopic crystals that surround detrital grains and replace carbonate cement and secondary quartz overgrowths. The textural relations between the sulfate minerals and the other mineral cements suggest that anhydrite and barite formed during a later stage of diagenesis, following the precipitation of carbonate and silica cement.

\section{POROSITY DEVELOPMENT}

The relative abundance of ferroan calcite in sandstones appears to reflect initial sandstone porosity and permeability. Coarser grained, cleaner sandstones tended to be relatively permeable and permitted the circulation of large volumes of reactive fluids and, hence, more complete mineral reaction. In contrast, finer-grained sandstones and siltstones typically were less permeable. Mineral reactions were slower in these rocks due to retarded fluid circulation rates.

Many sandstones in the Wasatch and Tuscher Formations show moderate to high porosity which resulted in part from the dissolution of calcite that formerly occupied many intergranular and intragranular pores. Partly dissolved feldspar grains containing relicts of ferroan calcite, corroded quartz overgrowth and grain boundaries, and isolated remnants of iron-free and ferroan calcite cement in pores are common in many of the sandstones and are evidence for dissolution of preexisting carbonate.

A possible explanation for carbonate dissolution may be changes in pore-water chemistry that occurred when waters of low $\mathrm{pH}$ came in contact with the sandstones. Physiochemical conditions that promoted dissolution probably existed during periods of subaerial erosion associated with the formation of the Cretaceous-Tertiary 

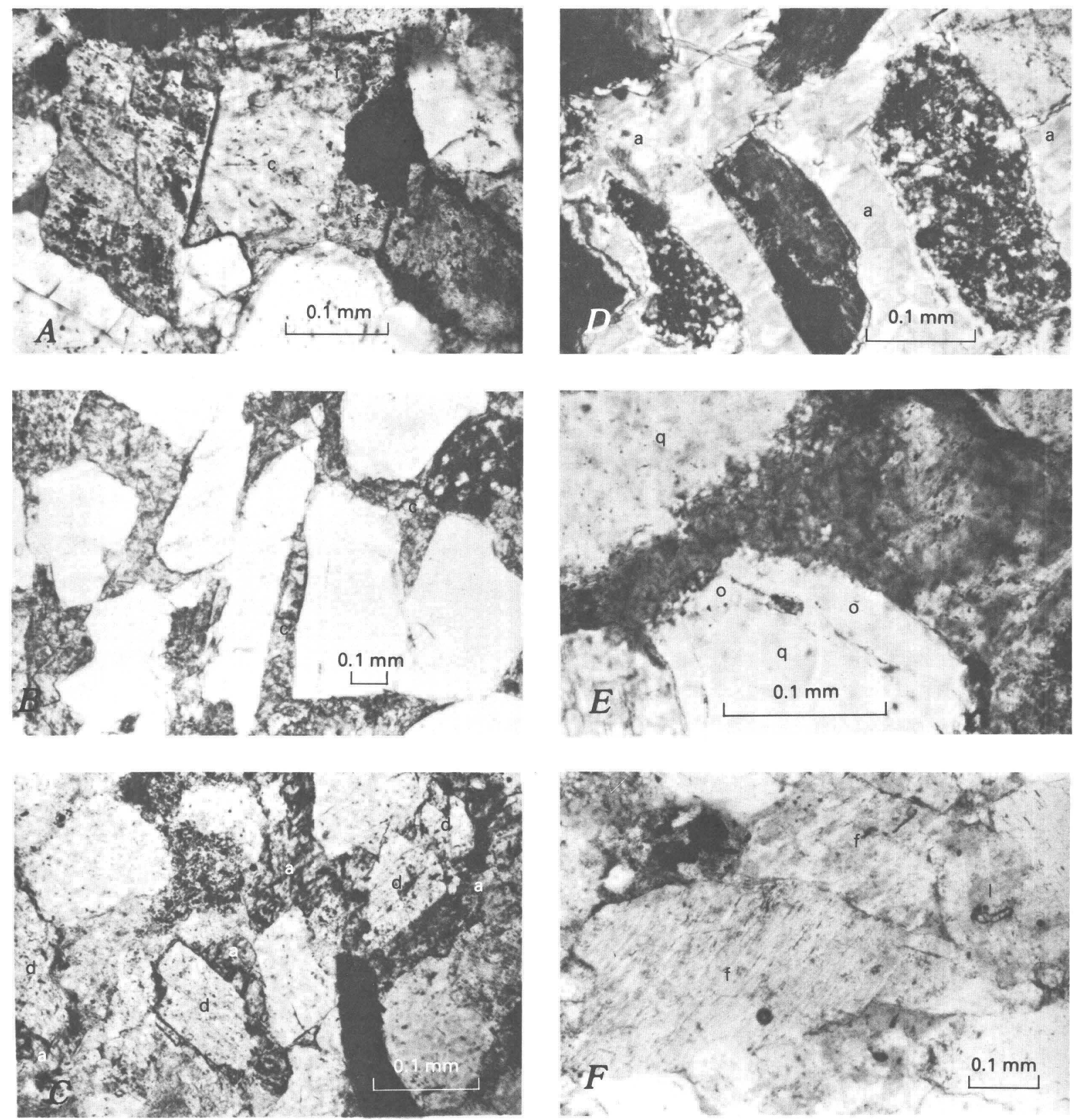

Figure 4. Photomicrographs of authigenic anhydrite, iron-free and iron-bearing carbonate, and associated dissolution features in the Wasatch and Tuscher Formations.

A, Early iron-free calcite (c) surrounded by late-formed ferroan-calcite ( $f$ ).

$B$, Early diagenetic, poikilotopic ferroan calcite (c) enclosing detrital unaltered quartz grains.

C, Detrital abraded dolomite fragments (d) surrounded by optically continuous ankerite (a).

$D$, Poikilotopic anhydrite (a) replacing framework grains in mineral cements.

E, Embayed quartz grain (q) and overgrowth (o) boundaries caused by dissolution of replacement carbonate.

$F$, Partly dissolved feldspar grains $(f)$ and lithic fragment $(I)$ that resulted from leaching of replacement carbonate.

unconformity and during hydrocarbon generation. During periods of regional tectonism, exposed sandstone beds that were being eroded were exposed to ground waters of low $\mathrm{pH}$ which were capable of dissolving carbonate. Meteoric waters moved into the subsurface via these porous sandstones and possibly incipient fractures where they intermingled with migrating formation fluids. Mixing of waters of different chemistry may have created an environment at depth favorable for the dissolution of carbonate. During diagenesis, the production of $\mathrm{CO}_{2}$ in response to the degradation of organic matter and the expulsion of interlayer shale waters during burial 
compaction also may have contributed to the dissolution of carbonate.

In some sandstones there is no evidence of extensive carbonatization. Either the observed porosity is of primary origin, which seems unlikely, or it is secondary and was caused by the direct dissolution of framework grains, such as feldspar and unstable lithic fragments.

\section{STABLE ISOTOPES}

Carbon and oxygen isotope compositions were determined separately for selected samples of ferroan calcite and mixtures of dolomite and subordinate ankerite from the Wasatch and Tuscher Formations (table 1). $\delta^{13} \mathrm{C}$ values for calcite from the Wasatch range from -5.2 to -10.6 per mil, and $\delta^{18} \mathrm{O}$ values range from -9.4 to -13.1 per mil. One calcite sample from the Wasatch Formation, U80TF249, is unusually light in carbon and heavy in oxygen compared with the other samples.

In the older Tuscher Formation, $\delta^{13} \mathrm{C}$ values for calcite range from -3.1 to -8.1 per mil and $\delta^{18} \mathrm{O}$ ranges from -9.7 to -14.2 per mil. Two samples, Sandia 8 and Sandia 13, have unusually light isotope values relative to the other samples, with $\delta^{13} \mathrm{C}=-7.6$ and -8.1 per mil and $\delta^{18} \mathrm{O}=-12.9$ and -14.2 per mil, respectively. These isotope compositions are similar to those of calcite in the Wasatch Formation.

The isotope compositions of dolomite are fairly constant for both the Wasatch and Tuscher Formations. Values range from -0.5 to -4.2 per mil for $\delta^{13} \mathrm{C}$ and from -5.5 to -8.8 per mil for $\delta^{18} \mathrm{O}$. The dolomite fractions for the Sandia 8 and Sandia 13 samples from the Tuscher are enriched in the light isotopes of carbon and oxygen compared with the other samples.

A crossplot of $\delta^{13} \mathrm{C}$ and $\delta^{18} \mathrm{O}$ values for the calcite and dolomite fractions is shown in figure 5. These data reveal that the isotope compositions of calcite in the Wasatch (with the exception of sample U80TF249) fall along a linear trend that is distinct from the trend along which all but the two anomalous calcite values for the Tuscher cluster. Isotope values for the dolomite-ankerite fraction plot along a separate trend. Distinct isotopic trends for calcite in Tertiary and Cretaceous sandstones indicate that the fluids which diagenetically altered these sediments had quite different isotope compositions. The initial porosity and permeability of individual sandstone beds controlled fluid migration pathways and water-rock interaction and, thus, the degree of isotope exchange between carbonate and water.

\section{Carbon isotopes}

Carbon isotope compositions for ferroan calcite in the Wasatch Formation are consistently more negative than those for calcite in the older Tuscher Formation. $\delta^{13} \mathrm{C}$ values, from -5 to -10 per mil in the Wasatch, may reflect a component of atmospheric carbon, or more likely, an influx of organically derived carbon that was produced during bacterial degradation of organic matter. Petrographic analysis indicates that most of the carbonate in the Wasatch Formation formed early in the burial history; thus, some dissolved carbonate for carbonate precipitation may have been generated from the bacterial oxidation of organic matter during the early stages of diagenesis. It is also possible that at some later diagenetic stage, a small fraction of dissolved $\mathrm{HCO}_{3}$ formed during nonbacterial (catagenic) methane production; however, this is uncertain inasmuch as sequences of lacustrine shale interbedded with Wasatch strata generally did not reach the early stages of thermal maturity with respect to hydrocarbon generation until late in the burial history.

One calcite sample from the Wasatch Formation (U80TF249) contains unusually light $\delta^{13} \mathrm{C}(-10.6$ per mil) compared with the $\delta^{13} \mathrm{C}$ of the other samples and is displaced from the $\delta^{13} \mathrm{C}$ versus $\delta^{18} \mathrm{O}$ trend line shown in figure 5. This isotope composition may reflect a sandstone characterized by a high water:rock ratio and isotope exchange due to an influx of water (possibly from a different source) that contained a large proportion of isotopically light carbon, or it may represent a local effect of a larger than average abundance of organic matter indigenous to that sample.

Isotopically light $\delta^{13} \mathrm{C}$ compositions for calcite in the Wasatch Formation may possibly be related to the sulfate mineral anhydrite that occurs locally in some sandstones. Calcite in rocks that contain anhydrite typically is displaced toward lighter $\delta^{13} \mathrm{C}$ (and $\delta^{18} \mathrm{O}$ ) ratios compared with calcite in rocks devoid of anhydrite (fig. 5). Markedly light $\delta^{13} \mathrm{C}$ compositions for calcite in sandstones containing anhydrite suggest that the precipitation or recrystallization of calcite may have been associated with the formation of anhydrite.

$\delta^{34} \mathrm{~S}$ compositions for anhydrite in sandstones with associated isotopically light $\delta^{13} \mathrm{C}$ calcite are consistently heavy, averaging +30.3 per mil (table 1 ). These values are close to the $\delta^{34} \mathrm{~S}$ compositions reported by Harrison and Thode (1958), Mauger (1972), Cole and Picard (1981), Smith and Young (1983), and D. E. Anders and P. Gerrild (U.S. Geological Survey, Denver, Colorado, written commun., 1980) for both organic and pyrite sulfur in kerogen-rich rocks of the lacustrine Green River Formation. $\delta^{34} \mathrm{~S}$ values of anhydrite, however, are dissimilar to typical sulfates present in weathering environments. The apparent relation between the isotope composition of sulfate sulfur in Wasatch beds and organic and pyrite sulfur in lacustrine shales of the Green River Formation suggests that fluids derived from kerogenous shale beds in the Green River may have migrated during burial into nearby porous and permeable 
Table 1. Stable isotope data for calcite, dolomite, and anhydrite in sandstones from the Wasatch and Tuscher Formations

[Asterisks $\left(^{*}\right)$, anomalous samples; isotope values, per mil; leaders (---), not determined]

\begin{tabular}{|c|c|c|c|c|c|c|}
\hline \multirow{2}{*}{$\begin{array}{c}\text { Sample } \\
\text { No. }\end{array}$} & \multirow{2}{*}{$\begin{array}{l}\text { Depth } \\
\text { (feet) }\end{array}$} & \multirow{2}{*}{$\begin{array}{c}\text { Anhydrite } \\
\delta^{34} S\end{array}$} & \multicolumn{2}{|c|}{ Calcite } & \multicolumn{2}{|c|}{ Dolomite } \\
\hline & & & $\delta^{13} C_{P D B}$ & $\delta^{18} 0_{P D B}$ & ${ }^{13} C_{P D B}$ & $\delta^{18} 0_{\text {PDB }}$ \\
\hline \multicolumn{7}{|c|}{ Wasatch Formation } \\
\hline $\begin{array}{r}\text { U80TF240 } \\
\text { U80TF248 } \\
\text { *U80TF249 } \\
\text { U80TF253 } \\
\text { U80TF256 }\end{array}$ & $\begin{array}{l}4402.7 \\
4415.7 \\
4416.4 \\
4443.0 \\
4458.9\end{array}$ & $\begin{array}{l}--- \\
--- \\
--- \\
---\end{array}$ & $\begin{array}{r}-5.4 \\
-7.0 \\
-10.6 \\
-6.5 \\
-5.3\end{array}$ & $\begin{array}{r}-12.4 \\
-12.5 \\
-9.4 \\
-11.8 \\
-10.7\end{array}$ & $\begin{array}{l}-2.0 \\
-4.2 \\
-1.7 \\
-2.4 \\
-1.5\end{array}$ & $\begin{array}{l}-7.0 \\
-7.9 \\
-5.3 \\
-7.9 \\
-6.9\end{array}$ \\
\hline $\begin{array}{l}\text { U80TF } 261 \\
\text { U80TF263 } \\
\text { U80TF268 } \\
\text { Sandia } 6 \\
\text { U80TF270 }\end{array}$ & $\begin{array}{l}4463.0 \\
4465.0 \\
4470.0 \\
4486.8 \\
4487.0\end{array}$ & $\begin{array}{c}+30.8 \\
+28.7 \\
--- \\
--- \\
+31.5\end{array}$ & $\begin{array}{l}-7.6 \\
-8.5 \\
-5.2 \\
-5.3 \\
-7.9\end{array}$ & $\begin{array}{l}-12.6 \\
-13.1 \\
-10.8 \\
-10.9 \\
-12.1\end{array}$ & $\begin{array}{l}-3.7 \\
-3.1 \\
-1.3 \\
-2.3 \\
-0.8\end{array}$ & $\begin{array}{l}-8.8 \\
-8.0 \\
-6.8 \\
-7.9 \\
-6.1\end{array}$ \\
\hline \multicolumn{7}{|c|}{ Tuscher Formation } \\
\hline $\begin{array}{r}\text { U80TF272 } \\
\text { U80TF275 } \\
\text { U80TF } 277 \\
\text { *Sandia } 8\end{array}$ & $\begin{array}{l}5406.0 \\
6423.7 \\
5425.0 \\
5469.0\end{array}$ & $\begin{array}{l}--- \\
--- \\
---\end{array}$ & $\begin{array}{l}-3.7 \\
-3.4 \\
-3.9 \\
-7.6\end{array}$ & $\begin{array}{r}-10.9 \\
-9.8 \\
-11.6 \\
-12.9\end{array}$ & $\begin{array}{l}-1.3 \\
-0.5 \\
-0.8 \\
-3.8\end{array}$ & $\begin{array}{r}-6.6 \\
-5.5 \\
-6.0 \\
-12.4\end{array}$ \\
\hline $\begin{array}{r}\text { U80TF279 } \\
\text { U80TF284 } \\
\text { *Sandia } 13 \\
\text { U80TF294 }\end{array}$ & $\begin{array}{l}6472.8 \\
5487.0 \\
6507.0 \\
6510.0\end{array}$ & $\begin{array}{l}--- \\
--- \\
--- \\
---\end{array}$ & $\begin{array}{l}-3.1 \\
-3.1 \\
-8.1 \\
-3.1\end{array}$ & $\begin{array}{r}-9.9 \\
-9.7 \\
-14.2 \\
-10.5\end{array}$ & $\begin{array}{l}-1.3 \\
-1.1 \\
-8.2 \\
-0.7\end{array}$ & $\begin{array}{r}-7.5 \\
-7.1 \\
-18.0 \\
-6.8\end{array}$ \\
\hline
\end{tabular}

strata of the Wasatch Formation. Smith and others (1964) showed that sulfur in the Green River occurs only in a reduced state, as pyrite and organic sulfur. Hence, to derive sulfur for anhydrite, the oxidation of reduced sulfur was required to form sulfate. This process suggests that oxygenated meteoric waters may have played a role in the formation of anhydrite in Wasatch sandstones.

Another possibility is that the oxidation of sulfur involved the oxidation of organic matter to soluble carbonate species. If this were true, isotopically light organic carbon was remobilized into adjacent sandstone beds of the Wasatch Formation and precipitated as carbonate. Such a mechanism could explain the isotopically light carbonate in sandstone beds containing anhydrite and can also account for the formation of a smaller component of isotopically light calcite in sandstones devoid of anhydrite.

Most $\delta^{13} \mathrm{C}$ compositions for calcite in the Tuscher Formation are isotopically heavy (near -3 per mil) compared with those for calcite in the Wasatch Formation, indicating that dissolved biogenic carbon was only a minor carbon source for these carbonates. Similar $\delta^{13} \mathrm{C}$ values throughout the Tuscher suggest that the calcite precipitated from a large reservoir of dissolved carbonate of nearly constant isotope composition. The isotopically heavy carbon can be attributed largely to dissolved carbonate species of marine origin that were derived locally from depositional waters. Calcite with light carbonisotope signatures typically is absent in the Tuscher despite the presence of interbedded carbonaceous and coaly shales.

$\delta^{13} \mathrm{C}$ and $\delta^{18} \mathrm{O}$ compositions for the two calcite samples in the Tuscher Formation (Sandia 8 and Sandia 13) that are isotopically light compared with those of the other samples, closely correspond to the carbon and oxygen values that characterize the average isotope composition of calcite in the Wasatch Formation. Petrographic analysis revealed that isotopically light calcite in the Tuscher formed during early diagenesis in sandstones that had high initial porosity and permeability. Thus, this early calcite probably formed locally from reactive fluids that were similar in isotope composition to those that deposited calcite in the Wasatch. 


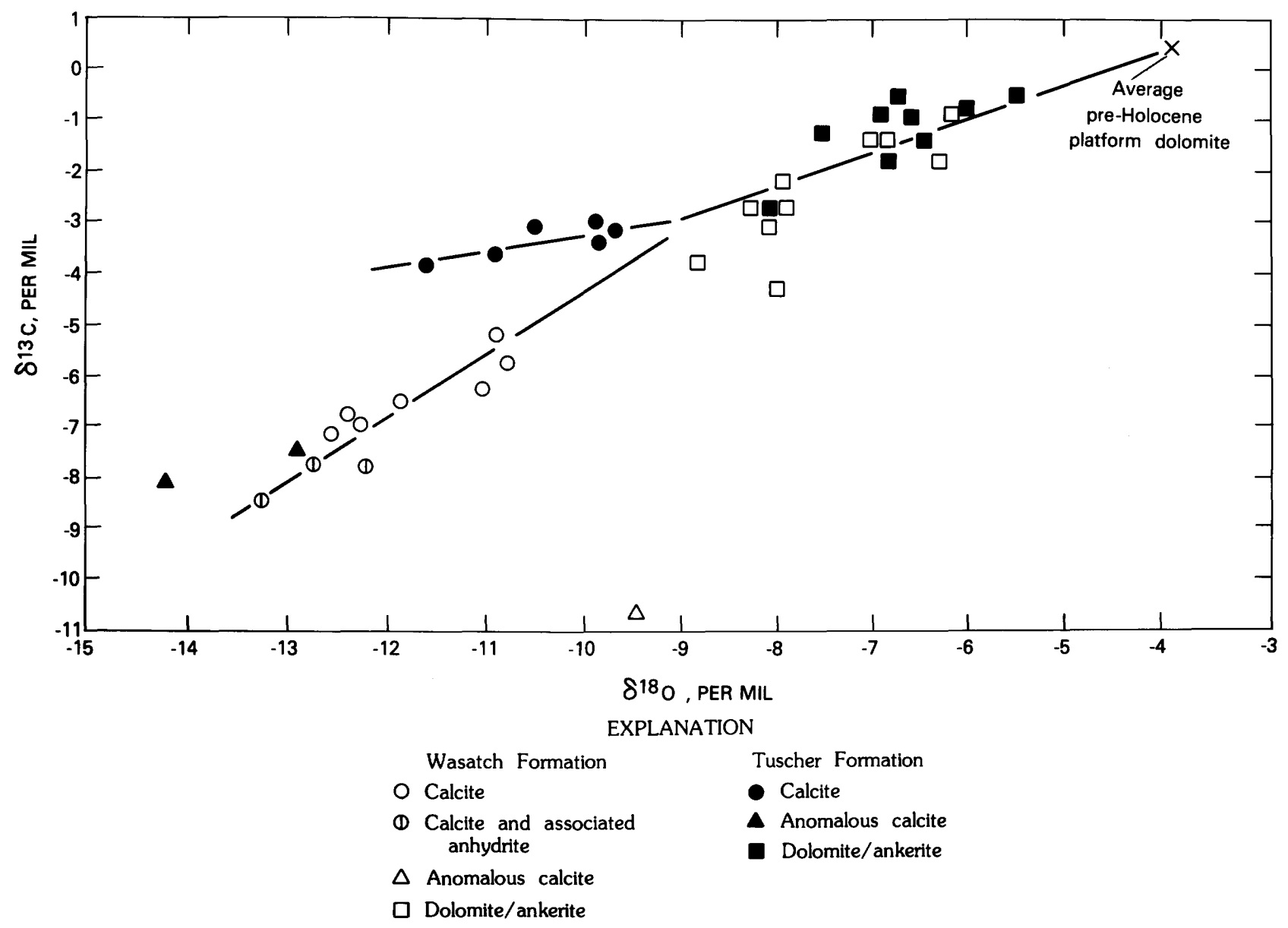

Figure 5. Crossplot showing $\delta^{13} \mathrm{C}_{\mathrm{PDB}}$ versus $\delta^{18} \mathrm{O}_{\mathrm{PDB}}$ for carbonate grains and cement in sandstones from the Tuscher and Wasatch Formations.

\section{Oxygen isotopes}

The $\delta^{18} \mathrm{O}$ compositions of calcite in sandstones of the Wasatch and Tuscher Formations are similar to those of diagenetic carbonate cement in sandstones such as have been reported by Hudson (1977) and Pitman and others (1982). The range, between -9.4 and -14.2 per mil, can be attributed either to the influence of isotopically light meteoric waters during diagenesis (Rothe and others, 1974) or to variations in temperature with increasing depth of burial which caused a decrease in the fractionation between the oxygen of carbonate ions and water.

The $\delta^{18} \mathrm{O}$ compositions for calcite in the Wasatch are, on the average, nearly identical to those for calcite in the older Tuscher Formation. The expected general trend of decreasing $\delta^{18} \mathrm{O}$ compositions with increasing burial depth and age of rock is not apparent, suggesting that temperature was not the major influence governing the isotope composition of oxygen during carbonate diagenesis. If temperature had been an important factor, $\delta^{18} \mathrm{O}$ values for calcite should be systematically lighter with increasing depth of burial. An inverse relation between $\delta^{18} \mathrm{O}$ composition and burial depth suggests that a flux of isotopically light pore waters through permeable horizons was a more important factor than depth of burial and temperature in determining ${ }^{18} \mathrm{O}$ systematics.

The two calcite samples from the Tuscher with unusually light $\delta^{18} \mathrm{O}$ compositions $(-12.9$ and -14.2 per mil) and the three samples from the Wasatch containing anhydrite probably reflect enhanced interaction with meteoric water related to high initial sandstone permeability coupled with reactions involving an input of organically derived aqueous $\mathrm{CO}_{2}$. Much of the Wasatch apparently was influenced by meteoric water, inasmuch as the isotope compositions of calcite in sandstones with associated anhydrite plot on the same linear trend as those for calcite in sandstones with no anhydrite. 


\section{Dolomite}

The trend of $\delta^{13} \mathrm{C}$ and $\delta^{18} \mathrm{O}$ ratios for dolomite in Tertiary and Cretaceous sandstones extrapolates close to the approximate isotope composition of average marine dolomite (near zero per mil; fig. 5). Petrographic analysis indicated that the dolomite fraction in both formations contains abundant detrital dolomite and minor authigenic dolomite and ankerite. The similar isotope compositions of dolomite-ankerite in the two formations are attributed principally to a detrital component of these minerals common to both.

The two dolomite samples in the Tuscher Formation (Sandia 8 and Sandia 13) that are isotopically light relative to the other samples may reflect the presence of early authigenic dolomite and possibly ankerite, inasmuch as each contains an unusually high amount of these minerals.

\section{SUMMARY}

The formation of a carbonate mineral assemblage composed of iron-free calcite, ferroan calcite, dolomite, and ankerite significantly modified Tertiary and Cretaceous sandstones in the Uinta basin, Utah. Iron-free calcite occurs as relicts and was the earliest carbonate to form. Ferroan calcite followed the precipitation of ironfree calcite and now is the dominant cement. Commonly, ferroan calcite forms a poikilotopic cement that occludes pores and replaces framework grains. Locally dissolved ferroan calcite reflects either a late stage of diagenesis due to the expulsion of interlayer shale waters, the production of $\mathrm{CO}_{2}$ during degradation of organic matter, or the influx of meteoric water during a period of erosion. Dolomite and ankerite occur principally as detrital grains and less commonly as authigenic pore-filling cement.

Stable isotope analysis of carbonate grains and cement indicate that calcite in the Tertiary Wasatch Formation formed from fluids that were of lighter isotope composition than fluids that precipitated calcite in the older Cretaceous Tuscher Formation. Isotopically light carbon in calcite from both formations is attributed primarily to an influx of organic carbon derived from nearby beds of lacustrine shale in the Green River Formation. $\delta^{34} \mathrm{~S}$ compositions of anhydrite from sandstones in the Wasatch that contain calcite enriched in ${ }^{13} \mathrm{C}$ support this interpretation, inasmuch as they are similar to compositions reported for organic and pyrite sulfur in the Green River Formation. Isotopically heavy $\delta^{13} \mathrm{C}$ values approach zero per mil in the Tuscher, reflecting a marine origin except locally where there was an influx of isotopically light meteoric water. $\delta^{18} \mathrm{O}$ values for calcite in the Wasatch are similar to those for calcite in the Tuscher, suggesting that variations in pore-water composition rather than the effects of temperature with increasing burial depth controlled oxygen composition. Carbon and oxygen isotope ratios of dolomite in the Wasatch and Tuscher Formations approximate the trend of marine dolomites. This relationship suggests that a component of detrital dolomite is common to both formations.

\section{REFERENCES CITED}

Cole, R. D., and Picard, M. D., 1981, Sulfur-isotope variations in marginal lacustrine rocks of the Green River Formation, Colorado and Utah: Society of Economic Paleontologists and Mineralogists Special Publication 31, p. 261-275.

Folk, R. L., 1974, Petrology in sedimentary rocks: Austin, Texas, Hemphill's Publishing Company, 182 p.

Fouch, T. D., 1975, Lithofacies and related hydrocarbon accumulations in Tertiary strata of the western and central Uinta basin, Utah, in Bolyard, D. W., ed., Symposium on deep drilling frontiers in the central Rocky Mountains: Rocky Mountain Association of Geologists Bulletin, p. 163-173.

1981, Chart showing distribution of rock types, lithologic groups and depositional environments for some lower Tertiary and Upper Cretaceous rocks from outcrops at Willow Creek-Indian Canyon through the subsurface of the Duchesne and Altamont oil fields, southwest to northcentral parts of the Uinta basin, Utah: U.S. Geological Survey Oil and Gas Investigations Chart OC-81, 2 sheets.

Fouch, T. D., Lawton, T. F., Nichols, D. J., Cashion, W. B., and Cobban, W. A., 1983, Patterns and timing of synorogenic sedimentation in Upper Cretaceous rocks of central and northeast Utah, in Reynolds, M., and Dolly, E., eds., Mesozoic paleogeography of west-central United States: Society of Economic Paleontologists and Mineralogists, Rocky Mountain Section Symposium 2, p. 305-334.

Harrison, A. G., and Thode, H. G., 1958, Sulphur isotope abundances in hydrocarbons and source rocks of Uinta Basin, Utah: American Association of Petroleum Geologists Bulletin, v. 42, p. 2642-2649.

Hudson, J. D., 1977, Stable isotopes and limestone lithification: Geological Society of London Journal, v. 133, p. 637-660.

Keighin, C. W., and Fouch, T. D., 1981, Depositional environments and diagenesis of some nonmarine Upper Cretaceous reservoir rocks, Uinta basin, Utah, in Ethridge, F. G., and Flores, R. M., eds., Recent and ancient nonmarine depositional environments; Models for exploration: Society of Economic Paleontologists and Mineralogists Special Publication 31, p. 109-125.

Land, L. S., 1980, The isotopic and trace element geochemistry of dolomite; The state of the art: Society of Economic Paleontologists and Mineralogists Special Publication 28, p. 87-110.

Lawton, T. F., 1983, Late Cretaceous fluvial systems and the age of foreland uplifts in central Utah, in Lowell, J. D., and Gries, R., eds., Rocky Mountain Foreland basin and uplifts: Denver, Colorado, Rocky Mountain Association of Geologists, p. 181-199. 
Mauger, R. L., 1972, A sulphur isotope study of bituminous sands from the Uinta basin, Utah: 24th International Geological Congress Proceedings, Comptes Rendus, sec. 5., p. 19-27.

Pitman, J. K., Fouch, T. D., and Goldhaber, M. B., 1982, Depositional setting and diagenetic evolution of some Tertiary unconventional reservoir rocks, Uinta basin, Utah: American Association of Petroleum Geologists Bulletin, v. 66, p. 1581-1596.

Pitman, J. K., Anders D. A., Fouch T. D., and Nichols D. J., 1987, Depositional environments, diagenesis, and hydrocarbon potential of nonmarine Upper Cretaceous and lower Tertiary rocks, eastern Uinta basin, Utah, in Spencer, C. W., and Mast, R. F., eds., Geology of tight gas reservoirs: American Association of Petroleum Geologists Studies in Geology 24, p. 235-252.

Rothe, P., Hoefs, J., and Sonne, V., 1974, The isotopic composition of Tertiary carbonates from the Mainz basin, an example of isotopic fractionations in "closed basins": Sedimentology, v. 21, p. 373-395.

Ryder, R. T., Fouch, T. D., and Elison, J. H., 1976, Early Ter- tiary sedimentation in the western Uinta Basin, Utah: Geological Society of America Bulletin, v. 87, p. 496-512.

Smith, J. W., Young, N. B., and Lawlor, D. L., 1964, Direct determination of sulfur forms in Green River oil shale: Analytical Chemistry, v. 36, p. 618-622.

Smith, J. W., and Young, N. B., 1983, Stratigraphic variation of sulfur isotopes in Colorado corehole number 1, in Gary, J. H., ed., Sixteenth oil shale symposium proceedings: Golden, Colorado, Colorado School of Mines, p. 176-188.

Stanley, K. O., and Collinson, J. W., 1979, Depositional history of the Paleocene-lower Eocene Flagstaff Limestone and coeval rocks, central Utah: American Association of Petroleum Geologists Bulletin, v. 63, p. 311-323.

Walters, L. J., Jr., Claypool, G. E., and Choquette, P. W., 1972, Reaction rates and $\delta^{18} \mathrm{O}$ variation for the carbonatephosphoric acid preparation method: Geochimica et Cosmochimica Acta, v. 36, p. 129-140.

Zawiskie, J., Chapman, D., and Alley, R., 1982, Depositional history of the Paleocene-Eocene Colton Formation, northcentral Utah: Utah Geological Association Bulletin, v. 10, p. 273-284. 


\title{
Diagenetic Relationships in a Hydrocarbon-Productive Chalk-the Cretaceous Niobrara Formation
}

By RICHARD M. POLLASTRO, U.S. Geological Survey, Box 25046, Denver Federal Center, MS 960, Denver, Colorado 80225, and PETER A. SCHOLLE, Southern Methodist University, Dallas, Texas 75275

\section{CONTENTS}

\author{
Abstract 221 \\ Introduction 221 \\ Acknowledgments 222 \\ Stratigraphy and hydrocarbon production 222 \\ Methods of study 222 \\ Samples 222 \\ Analytical methods 223 \\ Results and discussion 224 \\ Porosity, chalk fabric, and oxygen isotopes 224 \\ Mineralogy 226 \\ Detrital-diagenetic relations 226 \\ Nature and origin of regularly interstratified chlorite/smectite $\mathbf{2 3 0}$ \\ Geologic and economic implications 230 \\ Summary and conclusions $\mathbf{2 3 3}$ \\ References cited $\mathbf{2 3 3}$
}

\section{FIGURES}

1. Index map and cross section of wells studied, Denver basin, eastern Colorado 223

2. Plots showing weight percentage of insoluble residue as a function of frequency in chalk samples 224

3. Plots showing porosity versus depth in cores studied 225

4. Scanning electron micrographs showing progressive cementation during burial 226

5-7. Plots of:

5. Whole-rock oxygen isotopes versus burial depth 227

6. Composition of mixed-layer illite/smectite in Pierre Shale and insoluble residue from chalk of Niobrara Formation versus burial depth 228

7. Composition of mixed-layer illite/smectite versus depth in residues and bentonites 229

8-10. X-ray diffraction traces of:

8. Mixture of random and ordered illite/smectite in Niobrara insoluble residue $\mathbf{2 3 0}$

9. Kaolinitic bentonites showing presence of regularly interstratified mixed-layer illite/smectite and chlorite/smectite in Niobrara strata $\mathbf{2 3 1}$

10. $<2-\mu \mathrm{m}$ fraction of aluminous bentonite showing evidence for the presence of interlayer aluminum complexes $\mathbf{2 3 2}$ 
11. Regional petrophysical facies map of Niobrara Formation 233

12. Paleotherm map of Niobrara Formation in the Denver basin based on degree of ordering of mixed-layer illite/smectite in bentonites 234

TABLE

1. Names, locations, status, core intervals, and bottom-hole temperatures of wells studied 222 


\section{Abstract}

An understanding of diagenesis is critical in predicting reservoir or source-rock potential of the Niobrara Formation because the primary properties of the chalks and calcareous shales have been greatly modified by burial. Porosity and isotope composition of the chalks are consistently related to burial depth (or paleoburial depth) and thermal history. Initial porosities of 60 percent or more have been reduced by progressive cementation to about 25 percent with $1 \mathrm{~km}$ of burial and to less than 10 percent with burial depth of about $2 \mathrm{~km}$ or more. The oxygen isotope composition of the whole rock reflects these changes with shifts to progressively more negative $\delta^{18} 0$ values with greater burial.

The clay mineral composition and degree of ordering of mixed-layer illite/smectite $(\mathrm{I} / \mathrm{S})$ clay in bentonite beds and insoluble residues from the chalks can also be related to porosity loss due to increasing temperatures with burial depth. Although the starting composition of I/S clay originally deposited in chalk residues was highly variable, the expandability and range of expandability of the I/S became increasingly more limited with greater burial. A systematic increase in the percentage of illite-like layers in the I/S of bentonites as well as a progressive increase in the degree of ordering of $\mathrm{I} / \mathrm{S}$ was noted in more deeply buried samples. Regularly interstratified chlorite/smectite $(\mathrm{C} / \mathrm{S})$ was also formed in aluminous bentonites at elevated temperatures and pressures during deep burial $\left(>100^{\circ} \mathrm{C}\right)$. The composition and degree of ordering of $\mathrm{I} / \mathrm{S}$ and the occurrence of $\mathrm{C} / \mathrm{S}$ in bentonites are in good agreement with the level of maturation of kerogen and hydrocarbons within the Niobrara Formation, Denver basin. The clay minerals can, therefore, be used as geothermometers for predicting indigenous biogenic gas and thermogenic oil from the Niobrara. These depth-dependent relationships also suggest that parts of the Denver basin were more deeply buried in the past than formerly thought and (or) had paleogeothermal gradients higher than those of today.

\section{INTRODUCTION}

Natural gas and oil are produced from the organicrich chalk beds of the Upper Cretaceous Niobrara Formation in eastern Colorado and northwestern Kansas. Because of the increased production of oil and gas from these pelagic sediments during the past 15 years (Scholle, 1977a, 1977b; Pollastro and Scholle, 1984), the diagenetic alteration of chalk has received considerable attention. Although most scientific studies have focused on the diagenesis of the chalk itself, few have looked at the diagenesis of clay minerals or other inorganic components within insoluble residues or bentonites from the chalk.

Chalks are fine-grained limestones (micrites) composed largely of calcareous nannofossils, called coccoliths, and lesser amounts of calcareous microfossils, such as Foraminfera and calcispheres. Chalk forms only where organisms that form these calcareous tests can live in the overlying water and where the rate of input is low from clastic terrigenous material or other carbonate grains which might otherwise overwhelm and mask the nannofossils and microfossils (Scholle, 1977a).

Chalks formed from coccoliths and tests of planktonic Foraminifera are composed of chemically stable low-magnesium calcite and have inherently low permeability due to their very small average grain size. These two factors combine to make chalk fairly stable under near-surface conditions. Chalk oozes can be deposited with as much as $60-80$ percent porosity. Dewatering and initial mechanical compaction (grain reorientation and breakage) of a chalk ooze typically reduce this initially high porosity to about 50 percent under relatively shallow burial (Schlanger and Douglas, 1974). Scholle (1977a) showed that further loss in porosity in chalk is due to pressure solution of calcium carbonate at grain contacts and along solution seams as the chalk is subjected to an increase in lithostatic pressure due to depth of burial. This calcium carbonate is then reprecipitated locally at sites of lower differential stress (such as open pores). Permeability in chalks also decreases linearly with porosity (Scholle, 1977a). These relationships have been demonstrated in the Niobrara Formation by Lockridge and Scholle (1978).

The chalks of the Niobrara Formation contain a relatively large amount of insoluble residue. The insoluble residue consists chiefly of both detrital and authigenic clay minerals, quartz, pyrite, plagioclase feldspars, and organic matter (Pollastro, 1981a; Pollastro and Martinez, 1985). Numerous bentonite beds are also common throughout most of the Niobrara strata (Hattin, 1976, 1981; Kauffman, 1977; Pollastro, 1981a, 1981b). Studies of clay-rich rocks have demonstrated specific depth-dependent mineralogical changes (see reviews by Weaver, 1979; Hower, 1981). In particular, clay-mineral assemblages and their extent of diagenetic reaction have been used as geothermometers for determining maximum paleotemperature in sedimentary rocks (Hoffman and Hower, 1979; Pollastro and Bader, 1983; Pollastro and Scholle, 1984). The most significant reaction within the clay-mineral assemblages of deeply buried clay-rich rocks is the conversion of smectite to illite through a mixed-layer illite/smectite (I/S) series. Pollastro (1985) discussed the nature of the I/S reaction within the Niobrara of the Denver basin.

The present paper focuses on post-depositional diagenetic relations within a single chalk lithofacies of the Niobrara Formation, Denver basin, Colorado. In the cores studied, the petrophysical properties, fabric, and oxygen isotope composition of the chalk are consistently related to burial depth. In addition, the composition and ordering of I/S clay show a similar progression of diagenesis with burial and temperature (or paleoburial and paleotemperature). These relationships, when combined with studies of organic geochemistry and maturation, demonstrate how chalk and clay-mineral diagenesis can be used as a predictive tool in regional paleogeographic and economic reconstructions. 


\section{Acknowledgments}

The manuscript benefited greatly from critical reviews by Leonard G. Schultz and Donald L. Gautier. We also thank Dudley Rice and the late John Hower for their helpful discussions.

\section{STRATIGRAPHY AND HYDROCARBON PRODUCTION}

Chalk and chalky shale of the Niobrara Formation (Coniacian-Campanian) were deposited over a wide area of the Western Interior of the United States in a relatively shallow epicontinental seaway during an overall transgressive episode. The Niobrara Formation of eastern Colorado and adjacent areas consists of two members: the lower, Fort Hays Limestone Member consists of 12-26 m of highly bioturbated chalk and chalky shale; the upper and major part of the Niobrara Formation, represented by the Smoky Hill Chalk Member, consists of about 150$200 \mathrm{~m}$ of gray to dark-gray chalky shale and locally massive chalk beds apparently deposited under poorly oxygenated conditions (Arthur and others, 1985).

Gas production comes from relatively pure chalk beds (that is, containing a small acid-insoluble fraction) at the top of the Smoky Hill Member. The productive interval is informally referred to as the "Beecher Island zone" (Lockridge, 1977). This uppermost, relatively "clean" chalk unit, ranging from about 6 to $15 \mathrm{~m}$ in thickness, was deposited over a large region. Using subsurface geophysical logs, Hann (1981) correlated the Beecher Island zone from outcrops along the Front Range near Fort Collins, Colorado, across the Denver basin to the outcrops in west-central Kansas described by Hattin and Cobban (1977). Biostratigraphic and radiometric studies of such widespread lithofacies of the Niobrara cyclothem are believed to represent time-equivalent sediments (Kauffman, 1977). These uppermost chalk beds are overlain by a thick section of bentonitic Pierre Shale that serves as the seal for the reservoir. Most of the hydrocarbons produced from the Niobrara are believed to have been generated from type II organic matter within the Niobrara itself (Rice and Claypool, 1981; Rice, 1984).

\section{METHODS OF STUDY}

\section{Samples}

This paper contains data on Niobrara samples collected from numerous well cores and several outcrops. Most of the data, however, were obtained from core samples of five wells recovered from three specific depths along the eastern flank of the Denver basin, eastern Colorado. The origin, geochemistry, and maturity of organic matter and hydrocarbons from the cores of these same wells were described by Rice and Claypool (1981) and Rice (1984).

The names, locations, uncorrected bottom-hole temperatures, and depths of the cores recovered from these wells are listed in table 1 . Their approximate locations and a simplified cross-section are shown in figure 1. The cores recovered from these five wells only included the hydrocarbon-productive "Beecher Island zone."

About 150 samples of chalk and chalky shale and 15 samples of bentonite beds were collected from core from the five wells listed in table 1. Analytical work consisted of porosity measurements, examination of chalk textures and mineralogical components by scanning electron microscopy (SEM), $\mathrm{HCl}$-insoluble residue determinations, whole-rock oxygen isotope analyses, and $\mathrm{X}$-ray powder diffraction (XRD) analyses of whole-rock

Table 1. Names, locations, status, core interval, and uncorrected bottom-hole log temperatures of wells studied

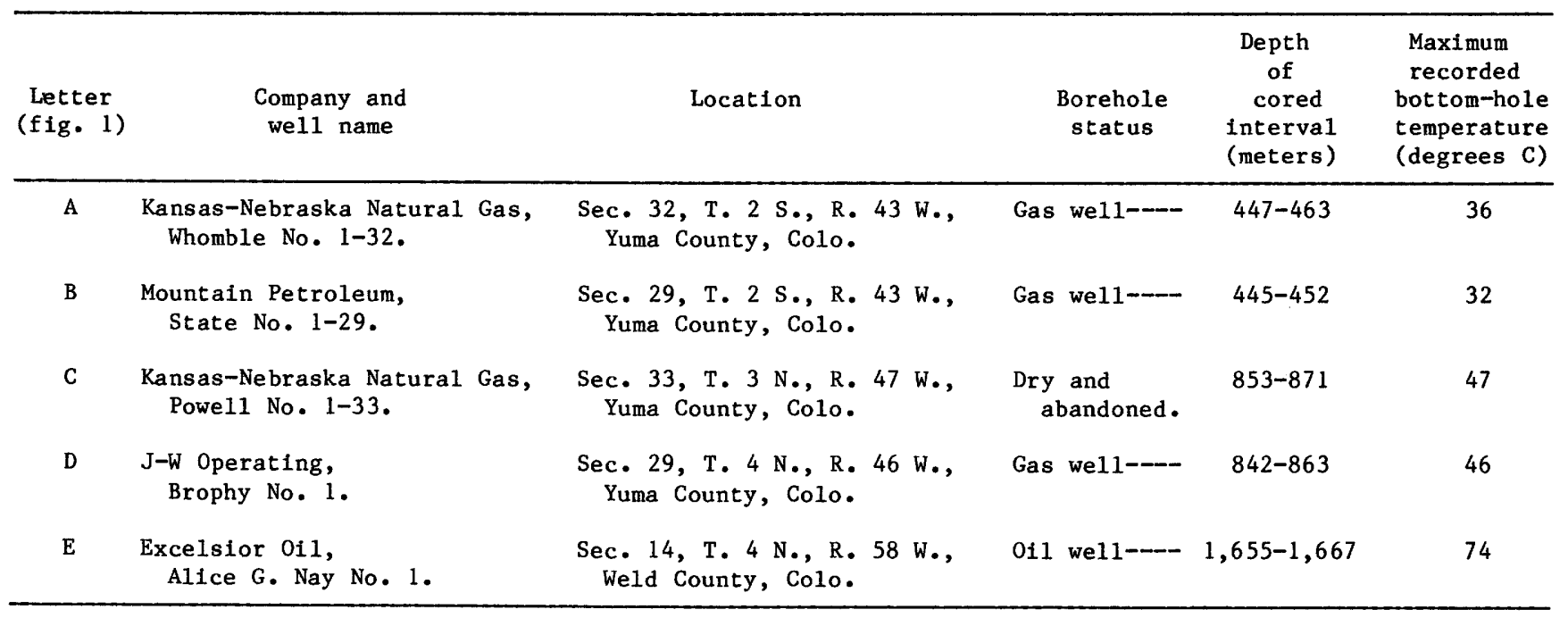



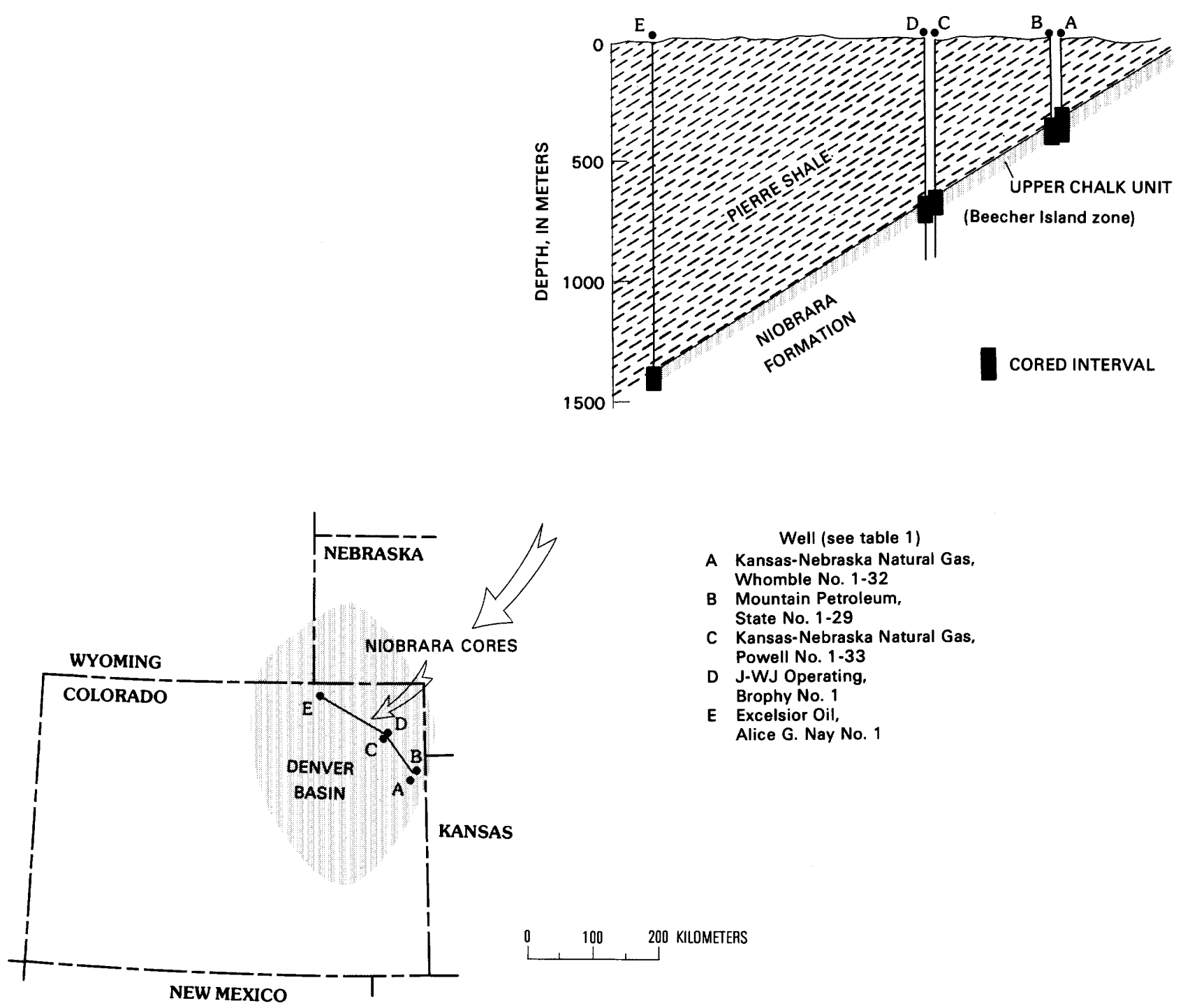

Figure 1. Index map and cross section of wells studied, Beecher Island zone, Niobrara Formation, Denver basin, eastern Colorado.

chalk, shale, and bentonite, chalk insoluble residue, and the $<2-\mu \mathrm{m}$ and $<0.5-\mu \mathrm{m}$ oriented fractions of the residues, shales, and bentonites. In addition, about 200 samples of bentonite were analyzed from outcrop and other core of the Niobrara in the Denver basin and adjacent areas.

\section{Analytical methods}

About 140 porosity measurements were made on 2.5-cm (1-inch) coreplugs by bulk-density versus volume analyses. Samples collected from cores and outcrops for mineralogy and geochemistry were washed to remove contaminants, dried, and ground to $<35$ mesh $(0.5 \mathrm{~mm})$. Several splits of each sample were taken for various analysis.
Calcite was dissolved in $1 \mathrm{~N} \mathrm{HCl}$; the residue was filtered and washed immediately after effervescence stopped to minimize solution of other minerals. The insoluble residue was dried overnight at $65^{\circ} \mathrm{C}$, the weight percentage of the residue was determined, and a small portion of the residue was spot-checked with $6 \mathrm{~N} \mathrm{HCl}$ for undissolved carbonate.

The mineralogy of the acid-insoluble residues, shales, and bentonite beds was first established by XRD analyses of randomly oriented whole rock or residue material and oriented aggregates of the $<2-\mu \mathrm{m}$ (equivalent spherical diameter) fraction. Oriented mounts were prepared by a modified filter-membrane-peel technique (Pollastro, 1982). Semiquantitative XRD analysis of the whole rock or whole insoluble residue was made by comparing the peak intensities for unknown samples with 
those from prepared mixtures of concentrated Niobrara material, insofar as possible, and following the procedures outlined by Schultz (1964) and Hoffman (1976), with minor modification. Semiquantitative analyses of the clay fraction were made following the procedure outlined by Schultz (1964).

Composition and ordering of I/S clay was determined on oriented, ethylene glycol-saturated specimens of the $\langle 0.5-\mu \mathrm{m}$ fraction. The patterns were interpreted using the methods of Reynolds and Hower (1970). Ordering types were defined using the "Reichweite" (R) notation, as described by Reynolds (1980), where "R" signifies the most distant layer in an interstratified sequence that affects the probability of occurrence of the final layer. Diffractograms indicate that most naturally occurring I/S falls into one of three ordering types of interstratification (Reynolds and Hower, 1970), namely, (1) random $I / S(R=0)$, (2) allevardite or short-range ordered $I / S(R=1)$, and (3) Kalkberg or long-range ordered $I / S(R \geqslant 3)$.

Whole-rock oxygen isotope analysis was performed using standard techniques (Craig, 1957). Isotope results are reported in per mil deviation from the PeeDee belemnite (PDB) using the standard $\delta$ notation:

$$
\delta^{18} \mathrm{O}=\frac{{ }^{18} \mathrm{O} /{ }^{16} \mathrm{O} \text { sample }-{ }^{18} \mathrm{O} /{ }^{16} \mathrm{O} \text { standard }}{{ }^{18} \mathrm{O} /{ }^{16} \mathrm{O} \text { standard }} \times 1000 .
$$

Relative increases of ${ }^{18} \mathrm{O} /{ }^{16} \mathrm{O}$ (increased values of $\delta^{18} \mathrm{O}$ ) are referred to in this paper as "more positive" or "heavier". Analogously, decreases in the ${ }^{18} \mathrm{O} /{ }^{16} \mathrm{O}$ ratio are termed "more negative" or "lighter". Studies in our laboratory and those in cooperation with M. A. Arthur (University of Rhode Island, Kingston, Rhode Island) have found that the most reliable whole-rock oxygen isotope values for evaluating chalk diagenesis are those determined from chalks containing less than 35 weight percent insoluble residue. Therefore, all isotope analyses were determined from chalks having this restriction.

\section{RESULTS AND DISCUSSION}

\section{Porosity, chalk fabric, and oxygen isotopes}

The acid-insoluble residue of 156 core samples from the five wells from the Beecher Island zone (table 1) averaged 30 percent by weight. The range of the percentage of insoluble residue as a function of frequency is shown in figure 2. Variations in the insoluble residue content within the chalk can be explained by fluctuations in the amount of both terrigenous and volcanic detritus that was added to the sediment (Pollastro, 1981a) and by temporal variations in biological productivity in the Cretaceous water column (Arthur and others, 1985).

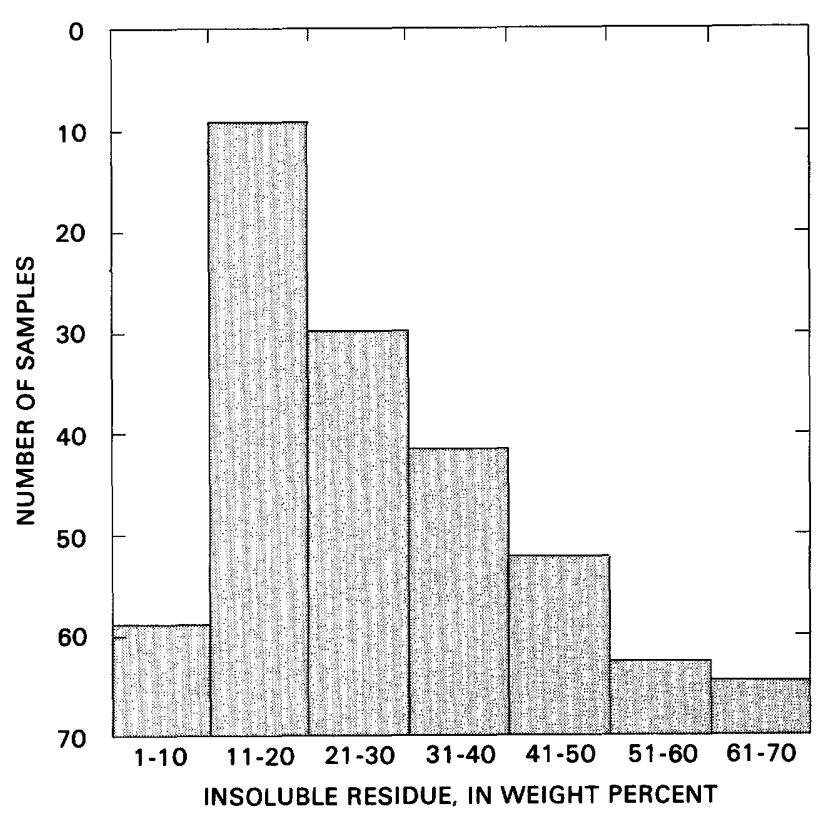

Figure 2. Frequency plot of $\mathrm{HCl}$-insoluble residue from 156 core samples of Beecher Island zone chalk, Niobrara Formation.

Measurements on 142 samples from the five wells described in this report (fig. 3) show that the average porosity of the Beecher Island zone decreases from 39 percent in the shallowest wells at about $460 \mathrm{~m}$ depth to 27 percent at about $850 \mathrm{~m}$ depth, to 9 percent in the Alice G. Nay well at $1,650 \mathrm{~m}$ depth. These porosities are in good agreement with those calculated from borehole density logs by Lockridge and Scholle (1978, fig. 6). Porosity loss and alteration of the original chalk fabric due to progressive cementation during burial diagenesis are illustrated in the scanning electron micrographs (fig. 4) of relatively clean chalk from the three depths. Because the amount of insoluble residue in these chalks affects the porosity and chalk fabric (Scholle, 1977a; Pollastro and Martinez, 1985), only chalks containing about 15 weight percent insoluble residue were used in the comparison. The chalk from the Whomble well at $460 \mathrm{~m}$ depth (fig. $4 A$ ) contained coccoliths and rhabdolith spines which showed little or no alteration of their primary biogenic textures by cementation. Extremely high microporosity (40 percent) was noted at shallow depth. The chalk from the Powell well at $850 \mathrm{~m}$ (fig. $4 B$ ) was slightly more altered by pressure solution and cementation. Some of the fossil grains in this sample were interpenetrated due to chemical compaction. Rhombs of sparry calcite cement as overgrowths were also present; the porosity was about 30 percent. The typical fabric of the chalk from the Alice G. Nay well at $1,650 \mathrm{~m}$ depth is shown in figure $4 C$. Euhedral crystals produced by overgrowth cementation are ubiquitous and have reduced the matrix porosity to about 9 percent. Only a 


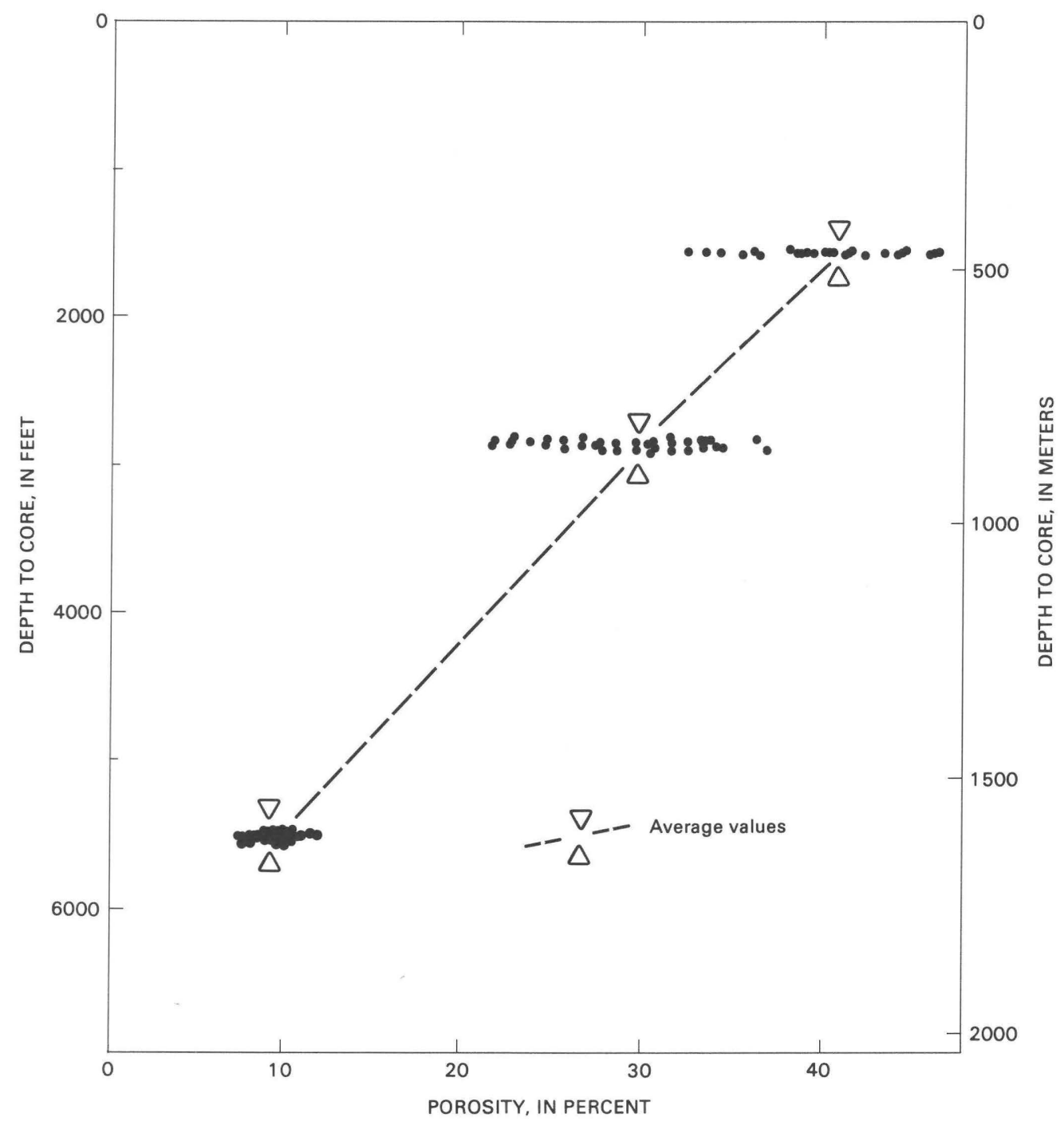

Figure 3. Plot of porosity versus depth in the Beecher Island zone of the Niobrara Formation in the five wells studied. Porosity values were determined from $2.5-\mathrm{cm}$ (1-inch) core plugs by bulkdensity versus volume measurement. Dashed line connects average porosity from each core group. Analysis performed on total of 142 samples.

few recognizable traces of the original biogenic grains were noted.

Plots of porosity versus insoluble residue content in chalks of the Niobrara show that porosity is higher in relatively clean carbonate beds than in beds with a high shale content (Pollastro and Martinez, 1985). At greater burial depths, pressure solution (that is, carbonate dissolution and transfer) was more active in beds with high shale content. As in stylolite formation, the dissolved carbonate from shaly beds in chalk was probably redeposited in the cleaner, adjacent limestone. Upon continued burial and cementation, this process further depleted shaly beds of carbonate and further enriched the carbonate-rich chalk beds. This process may have continued until the porosity of chalk was reduced to the extent at which the original porosity relations were reversed; that is, the adjacent shales may retain higher clay microporosities than the adjacent "clean" chalk carbonate at great depths.

Figure 5 shows the relations between present burial depth and whole-rock oxygen isotope values from 32 samples of chalk. The dashed line connects the average porosity from each core-depth group of samples. Oxygen isotope values are progressively more negative (or lighter) with greater burial and porosity loss. These values are a function of the isotope composition of the water and the temperature at which the carbonate cements were precipitated (see Garlick, 1969 for review of oxygen isotope analysis). The observed shift in isotope values was a result of the dissolution of coccoliths and Foraminifera and the reprecipitation of this carbonate as cement from pore fluids at elevated subsurface temperatures. These shifts presumably took place in a semi-closed system (that is, one dominated by expulsion of in-place pore fluids). 

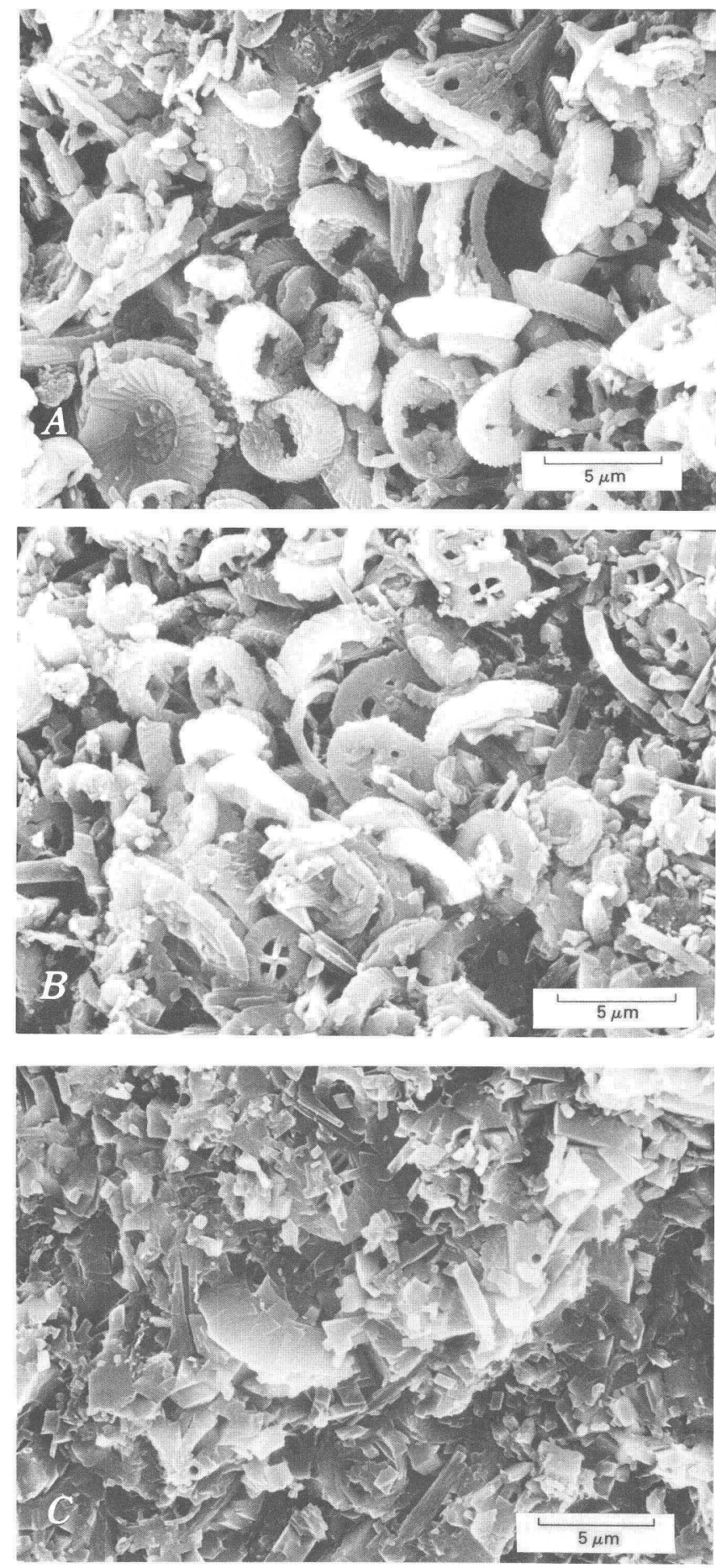

Figure 4. Scanning electron micrographs showing progressive cementation of Niobrara Formation chalk during burial. All samples contain about 15 weight percent $\mathrm{HCl}$-insoluble residue. Typical fabric of chalk from depths of: $A, 460 \mathrm{~m}$, porosity about 40 percent; $B, 850 \mathrm{~m}$, porosity about 30 percent; $C, 1,650 \mathrm{~m}$, porosity about 9 percent.

Initial oxygen isotope values of modern marine carbonate deposits range from +2.0 to -2.0 per mil (PDB) (Milliman, 1974). The unusually negative starting values (projected to zero burial) of the Niobrara most likely reflect the influence of "fresh", isotopically "light" surface waters draining into the restricted epicontinental seaway (Arthur and others, 1985). Oxygen isotope analyses of chalks, combined with other geochemical data, support the concept that cementation was a gradual process throughout the burial history of the rock and that these cements were derived internally by selective dissolution (Scholle, 1977a).

\section{Mineralogy}

\section{Detrital-diagenetic relations}

The composition and degree of ordering of I/S in insoluble residues of chalk and chalky shale from the Niobrara Formation and shale and calcareous shale from the Pierre Shale (Whomble No. 1 well) are shown in figure 6 along with the composition of the I/S from bentonite beds. Fabric, porosity, and whole-rock oxygen isotope values of the chalk from the Whomble well indicate that the core was not buried to depths much greater than present; therefore, the original clay mineralogy and claymineral composition of $\mathrm{I} / \mathrm{S}$ in these strata probably did not change significantly. Core from the Whomble No. 1 well included about $7 \mathrm{~m}$ of the lowermost Sharon Springs Member of the Pierre Shale, which immediately overlies the Beecher Island zone of the Niobrara Formation. The approximate contact, or transition, between the two formations is shown by the dashed line in figure 6 . The left part of figure 6 represents the weight percentage of insoluble residue, or the "shaliness" of the sample. The right part shows the percentage of expandable layers (or percentage of illite layers) in I/S and the general nature of interstratification of the I/S.

Illite/smectite in bentonites from both the Sharon Springs shale and Beecher Island zone chalk contained about 10 percent illite layers. The I/S in shale from the Sharon Springs Member was randomly interstratified $(\mathrm{R}=0)$ and had a composition range of $20-55$ percent illite layers. The more illitic I/S clay of the Sharon Springs Member occurred at the transition between the two formations. The I/S in the residues of chalk from the Niobrara were typically more illitic and ordered (40-70 percent illite layers) than the I/S of the overlying Pierre Shale. Exceptions (for example, sample 32) include zones of chalk which contained a significant admixture of altered volcanic ash (see Pollastro, 1981a). The relationship between the composition of I/S in the more calcareous versus the less calcareous samples from the present study is the opposite of that reported by Nadeau and Reynolds (1981a). We suggest that these differences in I/S are not related to rock chemistry, as suggested by Nadeau and Reynolds (1981a), but to the origins of the I/S clay, as will be discussed later. 


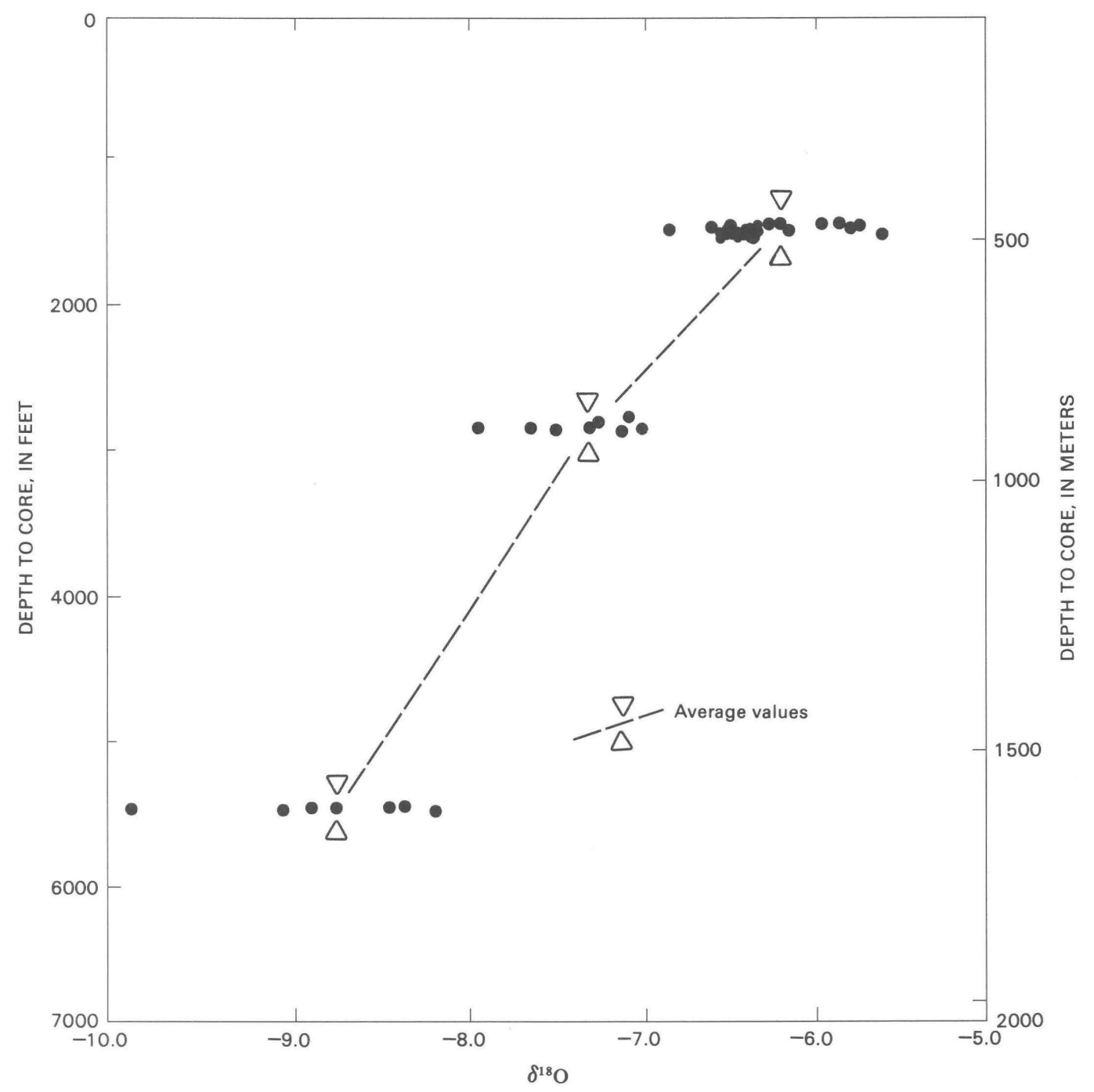

Figure 5. Plot of whole-rock oxygen isotope ratios (relative to Pedee belemnite standard) versus burial depth. All samples contained less than 35 percent $\mathrm{HCl}$-insoluble material. Dashed line connects average isotope ratio from each core group.

Differences in the composition of I/S clay between the uppermost Niobrara and lowermost Pierre strata were probably due to variations in origin and provenance at the close of upper Smoky Hill time to the onset of deposition of the Pierre Shale. Although the Niobrara Formation represents an overall major transgressive cycle during the Cretaceous, the upper Smoky Hill strata were deposited during a regressive phase (Hancock and Kauffman, 1979; Hattin, 1981). The more illitic (less expandable) I/S in the uppermost Smoky Hill strata (fig. 6) probably resulted from a dominant influx of reworked I/S clay as terrigenous detritus deposited from the west and, perhaps, a minor component from the east. Little volcanic activity occurred during late Smoky Hill (Beecher Island) time, as evidenced by the presence of only a few thin bentonites and small amounts of altered airfall ash in chalk zones containing authigenic kaolinite and highly expandable I/S (Pollastro, 1981a).
The start of the next major transgression, the Claggett cyclothem, was coincident with a change from the chalky shale and chalk of the Niobrara Formation to the dark gray Pierre Shale (McGookey, 1972), represented here as the Sharon Springs Member. The basal $10 \mathrm{~m}$ of the Sharon Springs Member of the Pierre Shale contained numerous bentonite beds, including the Ardmore Bentonite Beds. This 2-m-thick bed or series of beds is an excellent time-stratigraphic marker unit in the Upper Cretaceous section of this region, and, in the subsurface, produces a distinctive low resistivity reading on electric logs (Shurr, 1980). The thickness and wide extent of this marker bentonite throughout the northern part of the Pierre seaway is evidence of large-scale volcanism, whose apparent locus was in the Elkhorn Mountains of westcentral Montana. Major volcanic eposodes during the Cretaceous have been linked to major transgressive events (Nadeau and Reynolds, 1981b). Increasing volcanism 


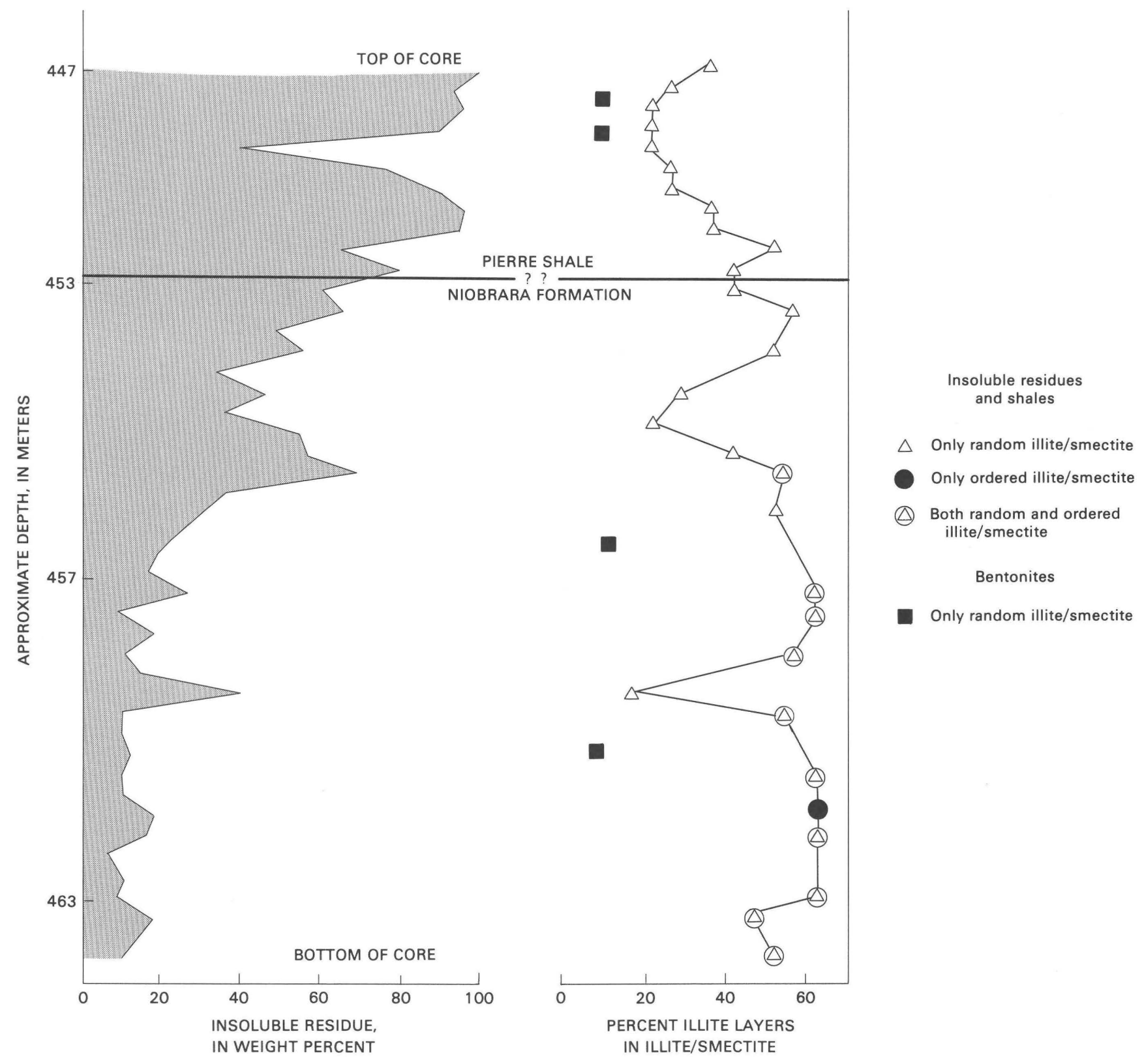

Figure 6. Plot of amount of insoluble residue and composition of mixed-layer illite/smectite (I/S) clay versus depth from core of Whomble No. 1 well (460 m depth). Dashed lines represent samples for which I/S ratio could not be determined.

during early Sharon Springs deposition explains the differences in composition of I/S for these units. Large volumes of highly expandable clay, formed from relatively fresh volcanic material over a short marine residence time, were deposited in the Sharon Springs Member. Voluminous, highly expandable I/S clay overwhelmed the much less expandable I/S clay (reworked from older, more illitic, terrigenous sources) that typically dominated in insoluble residues of chalk from the uppermost Smoky Hill strata.

As in most deeply buried clay-rich rocks, the most significant reaction in the clay-rich insoluble residues and bentonite beds of the Niobrara chalks was the conversion of smectite to illite in the I/S. The bulk mineralogy of the acid-insoluble residues from Niobrara chalks typically consisted of various amounts of clay minerals, quartz, pyrite, gypsum, anhydrite, plagioclase feldspar, and, locally, zeolites. Although the bulk mineralogy of the insoluble residues and bentonite beds varied, no depth-related diagenetic trends were evident. Clay minerals in these insoluble residues and bentonites, however, showed signs of depth diagenesis. The dominant clay mineral in more than 90 percent of the samples studied was I/S. The compositions of the I/S from the insoluble residues and bentonites of the Niobrara Formation and Pierre Shale in these wells are summarized in figure 7 . I/S in chalk residues of the 


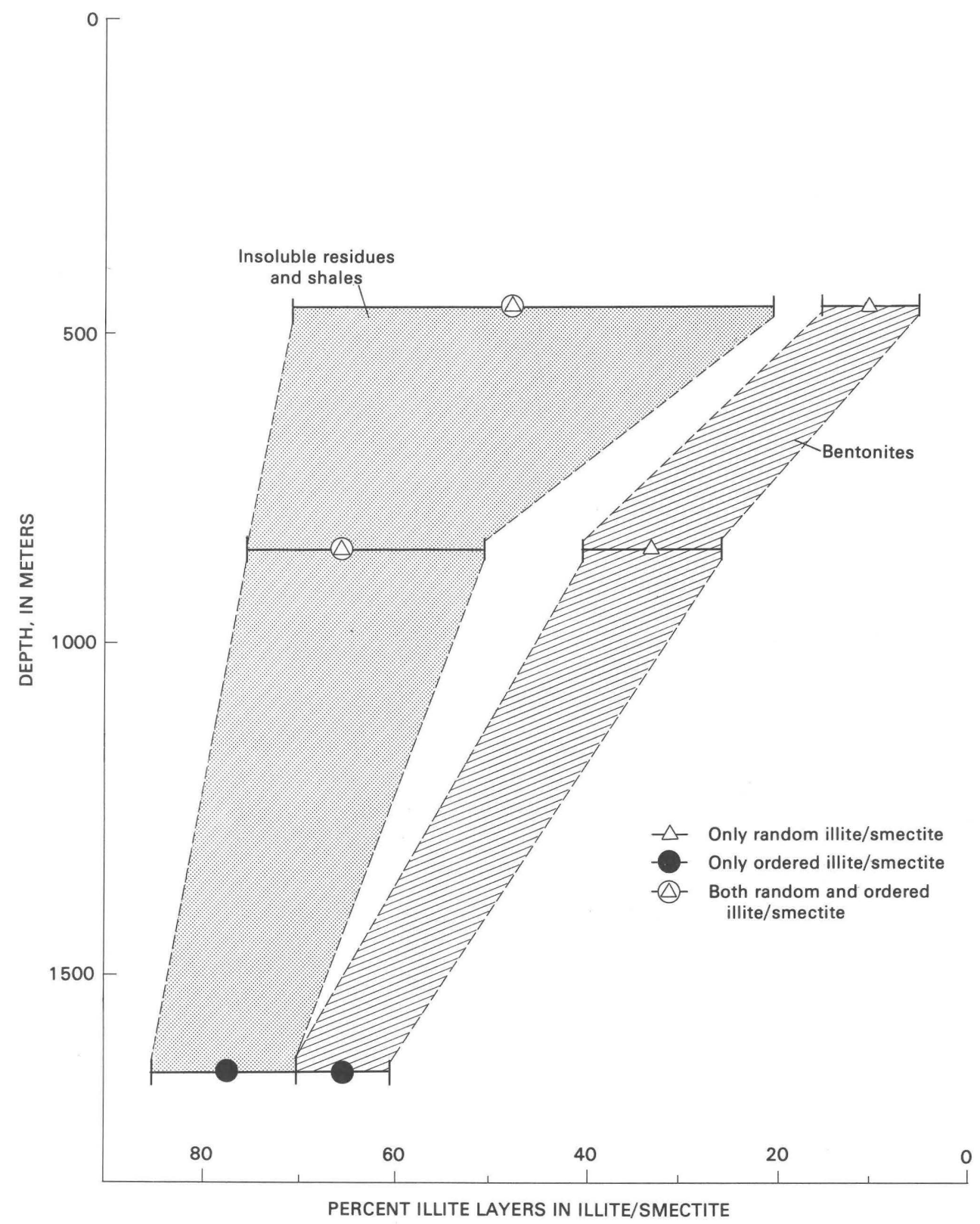

Figure 7. Plot of composition of mixed-layer illite/smectite versus depth in residues and bentonites of Niobrara Formation and Pierre Shale from five wells studied.

shallow $(450 \mathrm{~m})$ cores was randomly $(\mathrm{R}=0)$ and shortrange ordered $(R=1, R=2)$ interstratified, with compositions ranging from 20 to 70 percent illite layers. The bentonites, however, contained only randomly interstratified $(\mathrm{R}=0) \mathrm{I} / \mathrm{S}$ and few (less than 15 percent) or no illite layers. Insoluble residues from chalk of the two wells at intermediate depths $(860 \mathrm{~m})$ also contained both random and short-range ordered I/S ranging in composition from 50 to 75 percent illite layers. In many insoluble residue samples both ordered and random I/S were distinguished in the XRD pattern of glycolated materials (fig. 8). Bentonites from these wells at $860 \mathrm{~m}$ depth contained random I/S having about 30-35 percent illite layers.

In the deepest core from the Alice G. Nay No. 1 well (a well at 1,650 $\mathrm{m}$ with oil shows), the I/S from chalk residues was both short- and long-range ordered $(R>0)$ and ranged in composition from 70 to 85 percent illite layers. Regularly interstratified $\mathrm{C} / \mathrm{S}$ was also identified in one of the residues. Bentonites from this core contained short-range ordered I/S having about 65 percent illite layers. In four of the five bentonites sampled from this well, the I/S coexisted with a iron-rich $\mathrm{C} / \mathrm{S}$.

Insoluble residues of the chalk contained I/S of many different origins. The I/S had variable compositions and degrees of ordering. With increased temperature due to burial, the range in composition of I/S became more limited as a result of the extent of diagenetic reaction; that is, smectite layers in highly expandable I/S of insoluble 


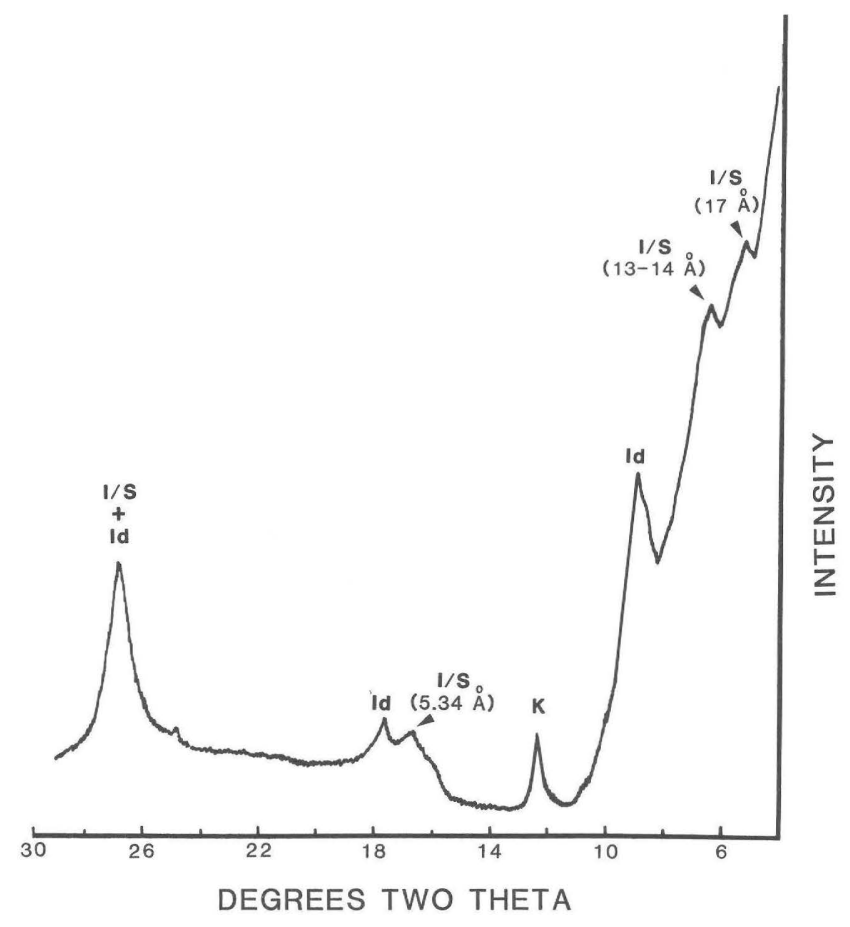

Figure 8. X-ray powder diffraction pattern of oriented, ethylene glycol-treated, $<0.5-\mu \mathrm{m}$ fraction from Niobrara Formation insoluble residue ( $460 \mathrm{~m}$ depth) showing mixture of random 17-Å and ordered (about 13- $\AA$ ) mixed-layer illite/smectite (I/S). Id, discrete illite; K, kaolinite. CuK $\alpha$ radiation.

residues were unstable under deeper burial conditions and were, therefore, converted to illite layers, resulting in a narrower overall range in composition of I/S in deeper cores. In a detailed analysis of the abundance and morphology of clay minerals in these residues, Pollastro (1985) showed that the smectite-to-illite reaction involved cannibalization of smectite layers and the conservation of aluminum and potassium, to produce a more illitic I/S clay.

In bentonites, the starting composition of the I/S precursor was completely or nearly completely expandable smectite. With increasing temperature due to burial, the $\mathrm{I} / \mathrm{S}$ in bentonites became progressively more illitic, maintaining its narrow composition range, and, at about 60 percent illite layers, the I/S transformed from random to short-range ordered. Rettke (1981) reported similar results for I/S in cores of the Dakota Formation of the Denver basin. Thus, the I/S that formed in thin, clean, discrete bentonites within Niobrara strata, where starting compositions were nearly fixed and where little or no detrital clays were present, was found to be the best indicator of the extent of diagenetic reaction and, therefore, the most useful for clay-mineral geothermometry.

\section{Nature and origin of regularly interstratified chlorite/smectite}

The five bentonites recovered from the Alice G. Nay well at a depth of about $1,650 \mathrm{~m}$ were highly kaolinitic (fig. 9). The only differences among the four bentonites that contained $\mathrm{C} / \mathrm{S}$ and the one that contained no $\mathrm{C} / \mathrm{S}$ were the thickness of the beds and the abundance and distribution of associated pyrite. The four bentonites that contained $\mathrm{C} / \mathrm{S}$ were about $2-3 \mathrm{~mm}$ thick and contained as much as $50-60$ percent pyrite distributed throughout the beds. The bentonite that contained no $\mathrm{C} / \mathrm{S}$ was about $1 \mathrm{~cm}$ thick and had only 15 percent pyrite that was concentrated chiefly along the outer edges of the bed.

Kaolinite-rich bentonites from the Niobrara typically contained I/S having abundant hydroxy-Al interlayers. The hydroxy-Al interlayers were recognized on XRD patterns of oriented specimens (heated to $300^{\circ} \mathrm{C}$ ) by abnormally large basal spacings (fig. 10). In these samples, $\mathrm{Al}^{3+}$, rather than $\mathrm{Na}^{+}$and $\mathrm{Ca}^{2+}$, was the principal interlayer cation. Gill and others (1972) also found that several bentonites from the Sharon Springs Member of the lower Pierre Shale and upper portion of the Niobrara Formation in western Kansas are kaolinitic, that the smectite comprising the remainder of the clay fraction tends to be the beidellitic variety containing hydroxy-Al interlayers, and that these features seem to be most strongly developed in thinner bentonite beds.

The $\mathrm{C} / \mathrm{S}$ in these bentonites probably formed at elevated temperatures $\left(>90^{\circ} \mathrm{C}\right.$, Hoffman and Hower, 1979 ; Kubler, 1973) and pressures during deep burial from aluminous, dioctahedral I/S and (or) kaolinite in the bentonites reacting with iron-rich fluids. Bentonites within the chalk probably acted as primary seams for migration of solutions, similar to stylolites, during deep burial. Solution transfer of iron-rich fluids along impermeable bentonite beds caused extensive late pyritization and the formation of the $\mathrm{C} / \mathrm{S}$ phase. Some iron and magnesium may have been derived from the octahedral layers of smectite during its diagenetic conversion to illite. The samples could not be purified for an accurate determination of the 060 reflection, however, from the reaction described previously, the $\mathrm{C} / \mathrm{S}$ was probably an iron-rich, dioctahedral variety (tosudite?). Similar products have been synthesized in laboratory experiments by Velde (1977) and Eberl (1978).

\section{GEOLOGIC AND ECONOMIC IMPLICATIONS}

The diagenetic relationships identified in this study have been used to produce generalized predictive maps for hydrocarbon reservoir and source rock studies of the Niobrara Formation. Based on porosity versus presentday burial and paleoburial relationships, porosity can be predicted for chalk facies of the Niobrara Formation across the Western Interior (fig. 11). Clay mineral assemblages are commonly used as geothermometers (Hoffman and Hower, 1979; Weaver, 1979; Pollastro and Bader, 1983; Pollastro and Barker, 1984) and, therefore, provide a temperature record of a potential source rock. The conversion of randomly interstratified $I / S(R=0)$ to $I / S$ with 


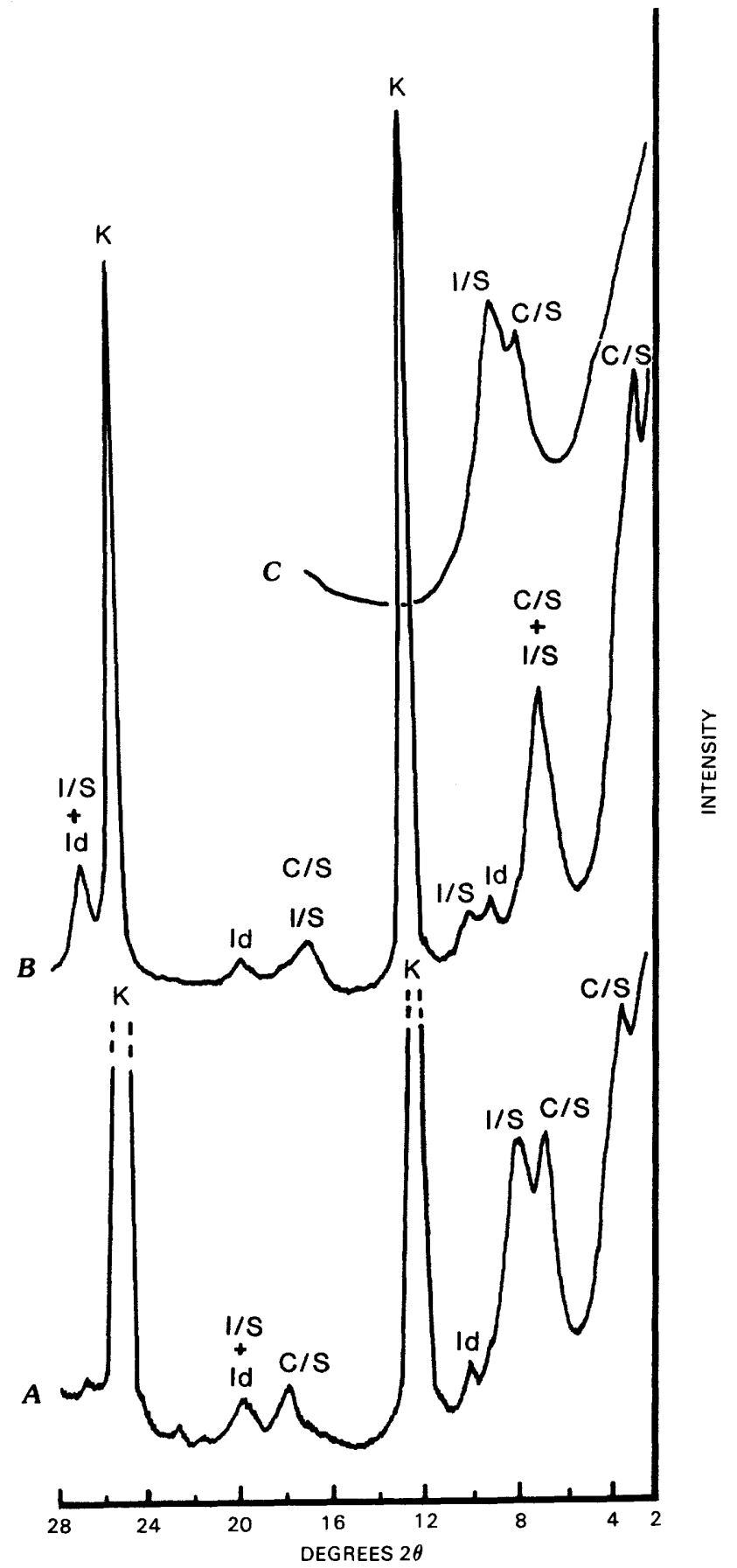

Figure 9. X-ray powder diffractograms of air-dried (A), ethylene glycol-treated $(B)$, and heated to $550^{\circ} \mathrm{C}(\mathrm{C})$ oriented specimens of $<2-\mu \mathrm{m}$ fraction of bentonite from Alice G. Nay No. 1 well $(1,650$ $\mathrm{m})$. Abundant kaolinite (K) and a regularly interstratified chlorite/smectite (C/S) phase coexist with ordered illite/smectite (I/S). Id, discrete illite. CuK $\alpha$ radiation. 


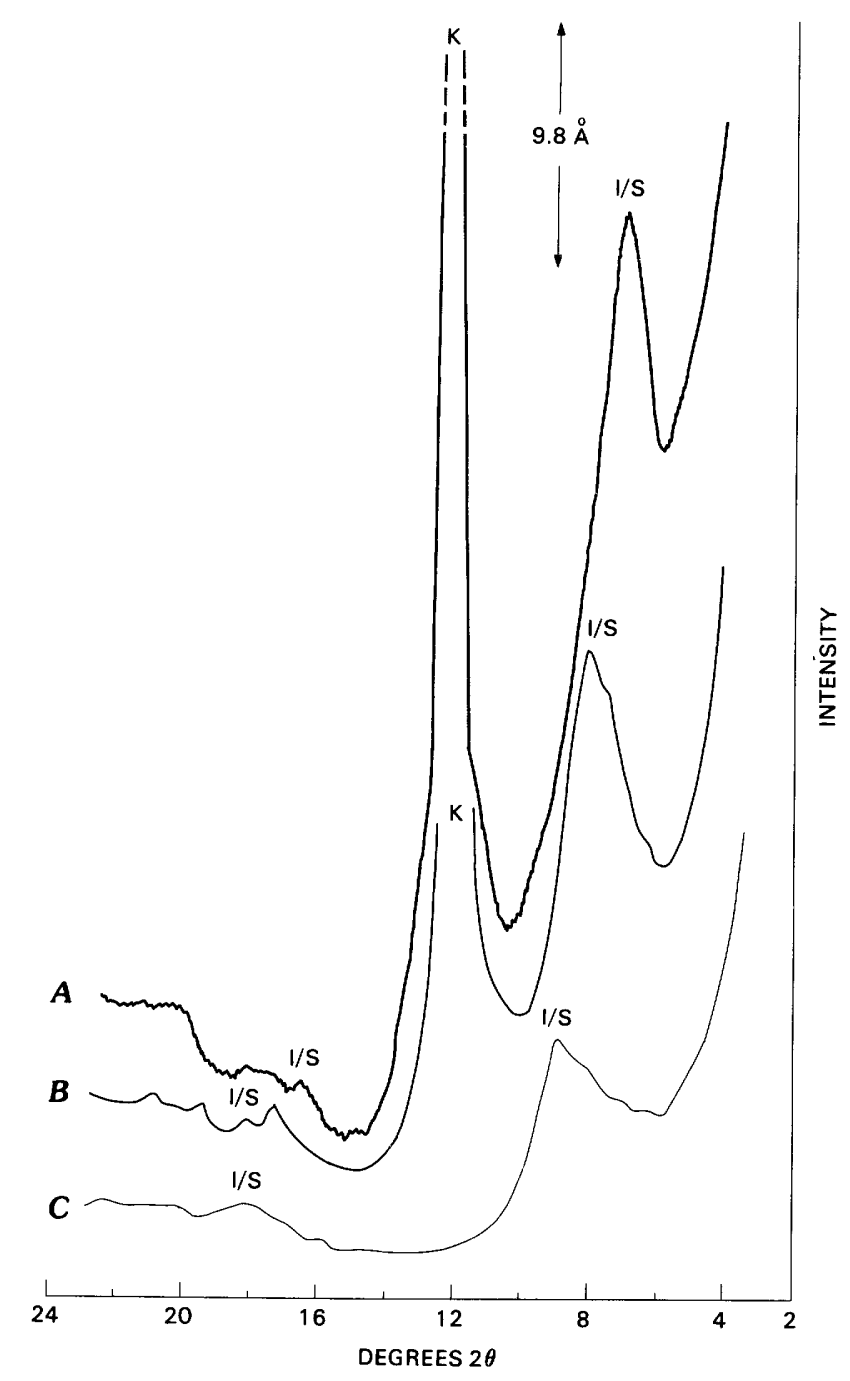

Figure 10. X-ray powder diffractograms of treated, oriented mounts of $<2-\mu \mathrm{m}$ fraction of aluminous bentonite in Niobrara Formation strata of the Alice G. Nay No. 1 core showing evidence upon heating of abundant interlayer aluminum complexes. $A$, ethylene glycol-treated; $B$, heated at $300^{\circ} \mathrm{C} ; \mathrm{C}$, heated at $550^{\circ} \mathrm{C}$. I/S, mixed-layer illite/smectite; K, kaolinite. CuK $\alpha$ radiation.

short-range ordered interstratification $(\mathrm{R}=1)$ occurs at about $100^{\circ} \mathrm{C}$, as does the formation of $\mathrm{C} / \mathrm{S}$ in buried Cretaceous sandstones and shales (Velde, 1973; Hoffman and Hower, 1979; Weaver, 1979). The appearance of either or both of these ordered interstratified clay minerals and the disappearance of randomly interstratified I/S in thin bentonite beds of the Niobrara can be used as geothermometers.

Coincidently, the lower temperature limit for the generation of thermogenic oil is also about $100^{\circ} \mathrm{C}$ (Tissot and Welte, 1978). The $100^{\circ} \mathrm{C}$ paleotherm map of figure 12 was drawn using the composition and degree of ordering of $\mathrm{I} / \mathrm{S}$ in bentonites from numerous Niobrara and lower Pierre Shale outcrop and core samples and with the aid of structure contour and isopach maps of the Denver basin. Although this map was produced from a limited distribution of samples, it suggests that the Niobrara in parts of the Denver basin and adjacent areas was buried much deeper in the past (as compared with its presentday depths) and (or) was subjected to a higher geothermal gradient than that which exists today.

Conversely, bentonites from some outcrop localities in figure 12 indicate that the Niobrara remained under relatively shallow burial conditions during the development of the basin, perhaps due to the presence of an early basin hinge zone or to significant differences in thickness of the overlying section. 


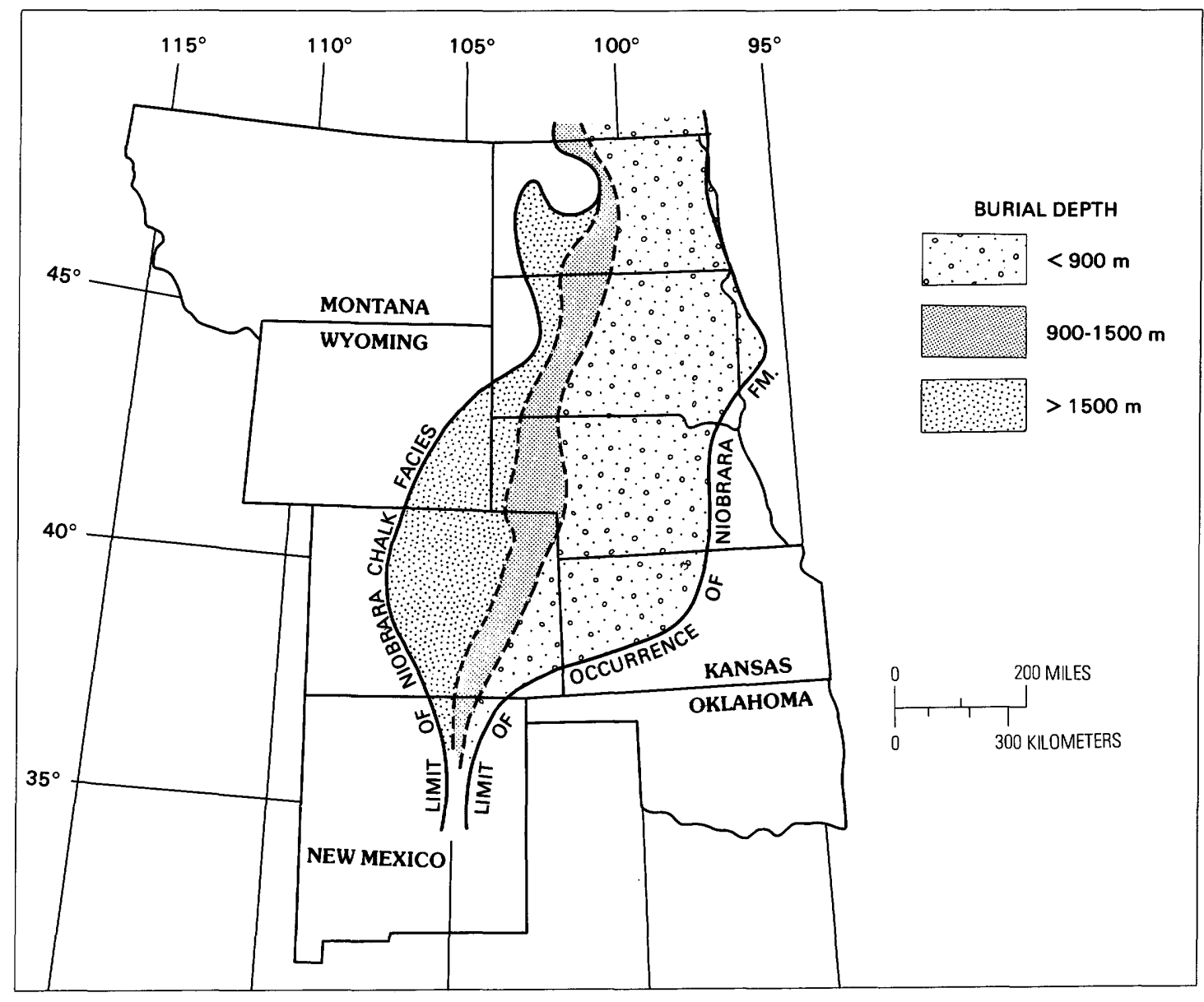

Figure 11. Regional distribution of predicted porosity in chalk facies of the Niobrara Formation. Patterns show thickness of total post-Niobrara Cretaceous overburden. Area buried to $1,000 \mathrm{~m}$ or less should contain chalks with more than 35 percent average porosity. Area buried to 1,000-1,200 $\mathrm{m}$ should have about 30-35 percent average porosity.

\section{SUMMARY AND CONCLUSIONS}

Studies of inorganic diagenesis and reservoir and source-rock properties of hydrocarbon-productive chalk from the Niobrara Formation present a comprehensive model of burial diagenesis. Progressive loss in porosity and negative shifts in the whole-rock oxygen isotope composition of the chalk can be explained by progressive cementation due to pressure solution and reprecipitation of carbonate with increased burial. The composition and ordering of I/S clay in bentonites and insoluble residues showed a progressive transformation with increased burial depth and porosity loss. Although the starting composition of the I/S in chalk at the time of deposition, or shortly after, was highly variable, the expandability range became increasingly limited and shifted toward more illitic compositions with greater burial. The I/S in bentonites, however, retained a narrow range of composition, became increasingly more illitic with depth, and converted from random to ordered interstratification at about $100^{\circ} \mathrm{C}$. Regularly ordered C/S may have formed in these aluminous bentonites in the presence of iron-rich fluids under deep burial conditions.

Because of these consistent relations to burial depth (or paleoburial depth) and the broad, uniform facies of the chalk, reliable paleogeographic reconstructions and economic predictions can be made.

\section{REFERENCES CITED}

Arthur, M. A., Dean, W. E., Pollastro, R. M., Claypool, G. E., and Scholle, P. A., 1985, Comparative geochemical and mineralogical studies of two cyclic transgressive pelagic limestone units, Cretaceous Western Interior basin, U.S., in Pratt, L. M., Kauffman, E. G., and Zelt, F. B., eds., Fine-grained deposits and biofacies of the Cretaceous Western Interior seaway-Evidence for cyclic sedimentary processes: SEPM Field Trip Guidebook No. 4, p. 16-27.

Craig, H., 1957, Isotopic standards for carbon and oxygen and correction factors for mass spectrometric analysis of carbon dioxide: Geochimica et Cosmochimica Acta, v. 12, p. 133-149. 


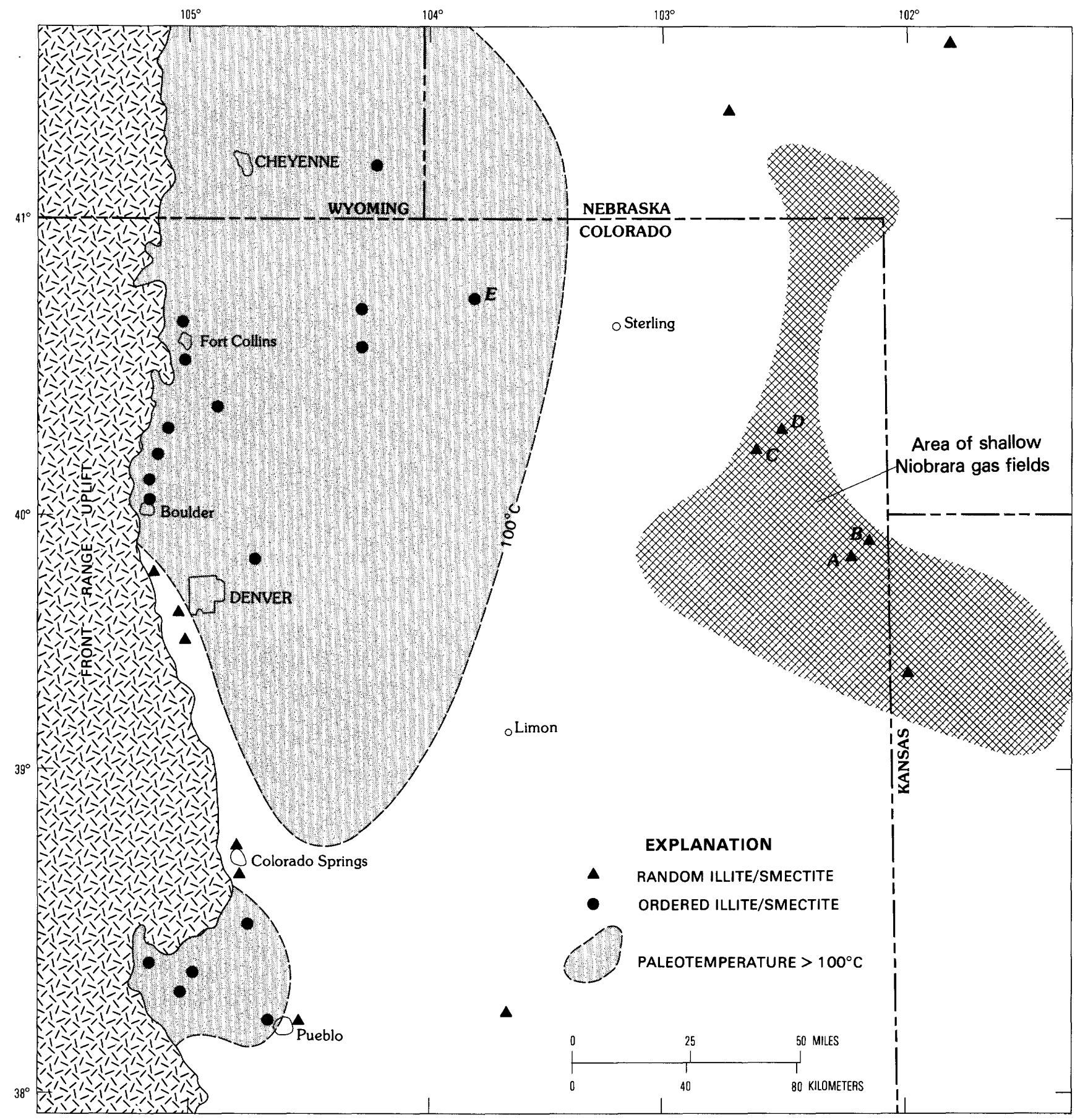

Figure 12. Paleotherm map of Denver basin showing parts of the Niobrara Formation where temperatures may have been greater than $100^{\circ} \mathrm{C}$. Paleotemperatures are estimated from model proposed by Hoffman and Hower (1979) and are based on degree of ordering in mixed-layer illite/smectite from bentonite beds in the Niobrara Formation and lower Pierre Shale.

Eberl, D. D., 1978, Reaction series for dioctahedral smectites: Clays and Clay Minerals, v. 26, p. 327-340.

Garlick, G. D., 1969, The stable oxygen isotopes of oxygen, in Wedepohl, K. W., ed., Handbook of geochemistry, v. 2: New York, Springer-Verlag, p. 8B1-27.

Gill, J. R., and Cobban, W. A., 1966, Regional unconformity in Late Cretaceous, Wyoming, in Geological Survey research 1966: U.S. Geological Survey Professional Paper 550-B, p. B-20-B-27.
Gill, J. R., Cobban, W. A., and Schultz, L. G., 1972, Stratigraphy and composition of the Sharon Springs Member of the Pierre Shale in western Kansas: U.S. Geological Survey Professional Paper 728, $54 \mathrm{p}$.

Hann, M. L., 1981, Petroleum potential of the Niobrara Formation in the Denver basin: Colorado and Kansas: Fort Collins, Colorado, Colorado State University, M.S. thesis, $260 \mathrm{p}$. 
Hancock, J. M., and Kauffman, E. G., 1979, The great transgressions of the Late Cretaceous: Journal of the Geological Society of London, v. 136, p. 175-186.

Hattin, D. E., 1981, Petrology of Smoky Hill Member, Niobrara Chalk (Upper Cretaceous), in type area, western Kansas: American Association of Petroleum Geologists Bulletin, v. 65 , p. $831-849$.

Hattin, D. E., and Cobban, W. A., 1977, Upper Cretaceous stratigraphy and paleoecology of western Kansas: The Mountain Geologist, v. 14, p. 175-217.

Hoffman, Janet, 1976, Regional metamorphism and K-Ar dating of clay minerals in Cretaceous sediments of the disturbed belt of Montana: Cleveland, Ohio, Case Western Reserve University, Ph. D. thesis, 266 p.

Hoffman, Janet, and Hower, John, 1979, Clay mineral assemblages as low grade metamorphic indicators-Application to the thrust faulted disturbed belt of Montana, U.S.A., in Scholle, P. A., and Schluger, P. K., eds., Aspects of diagenesis: Society of Economic Paleontologists and Mineralogists Special Publication 26, p. 55-79.

Hower, John, 1981, Shale diagenesis, in F. J. Longstaffe, ed., Short course handbook 7: Mineralogical Association of Canada, p. 60-80.

Kauffman, E. G., 1977, Geological and biological overviewWestern Interior Cretaceous basin: The Mountain Geologist, v. 14 , p. $75-99$.

Kubler, Bernard, 1973, La corrensite, indicateur possible de milieux de sedimentation et du degré, de transformation d'un sediment: Centres Recherches Pau Bulletin, v. 7, p. 543-556.

Lockridge, J. P., 1977, Beecher Island field, Yuma County, Colorado, in Exploration frontiers of the central and southern Rockies: Rocky Mountain Association of Geologists, Symposium Guidebook, p. 271-279.

Lockridge, J. P., and Scholle, P. A., 1978, Niobrara gas in eastern Colorado and northwestern Kansas, in Pruit, J. D., and Coffin, P. E., eds., Energy resources of the Denver basin: Rocky Mountain Association of Geologists, Symposium Guidebook, p. 35-49.

McGookey, D. P., coordinator, 1972, Cretaceous System, in Geologic atlas of the Rocky Mountain region: Denver, Colorado, Rocky Mountain Association of Geologists, p. 190-228.

Milliman, J. D., 1974, Marine carbonates: New York, SpringerVerlag, $375 \mathrm{p}$.

Nadeau, P. H., and Reynolds, R. C., Jr., 1981a, Burial and contact metamorphism in the Mancos Shale: Clays and Clay Minerals, v. 29, p. 249-259.

1981b, Volcanic components in pelitic sediments: Nature, v. 294 , p. $72-74$.

Pollastro, R. M., 1981a, Authigenic kaolinite and associated pyrite in chalk of the Cretaceous Niobrara Formation, eastern Colorado: Journal of Sedimentary Petrology, v. 51, p. 53-562.

1981b, Clay-mineral diagenesis within a fine-grained, marine, hydrocarbon-bearing, carbonate sequence-Evidence from the Cretaceous Niobrara Formation [abs.]: Program and abstracts, 18th annual meeting, The Clay Minerals Society, 30th Annual Clay Minerals Conference, Urbana, Illinois, p. 13.

1982, A recommended procedure for the preparation of oriented clay-mineral specimens for X-ray diffraction
analysis-Modifications to Drever's filter-membrane peel technique: U.S. Geological Survey Open-File Report 8271, $24 \mathrm{p}$.

1985, Mineralogical and morphological evidence for the formation of illite at the expense of illite/smectite: Clays and Clay Minerals, v. 33, p. 265-274.

Pollastro, R. M., and Bader, J. W., 1983, Clay-mineral relationships in some low-permeability hydrocarbon reservoirs and their use as predictive resource tools [abs.]: American Association of Petroleum Geologists Bulletin, v. 67, p. 536.

Pollastro, R. M., and Barker, C. E., 1984, Geothermometry from clay minerals, vitrinite reflectance, and fluid inclusionsApplications to the thermal and burial history of rocks cored from the Wagon Wheel No. 1 well, Green River basin, Wyoming, in Law, B. E., ed., Geological characteristics of low-permeability Upper Cretaceous and Lower Tertiary rocks of the Pinedale anticline area, Sublette County, Wyoming: U.S. Geological Survey Open-File Report 84-743, p. 78-94.

Pollastro, R. M., and Martinez, C. J., 1985, Mineral, chemical, and textural relationships in rhythmic-bedded, hydrocarbonproductive chalk of the Niobrara Formation, Denver basin, Colorado: The Mountain Geologist, v. 22, p. 55-63.

Pollastro, R. M., and Scholle, P. A., 1984, Hydrocarbon exploration, development from low-permeability chalks-Upper Cretaceous Niobrara Formation, Rocky Mountains region: Oil and Gas Journal, v. 82, no. 17, p. 138-145.

Rettke, R. C., 1981, Probable burial diagenetic and provenance effects on Dakota Group clay mineralogy, Denver basin: Journal of Sedimentary Petrology, v. 51, p. 541-551.

Reynolds, R. C., 1980, Interstratified clay minerals, in Brindley, G. W. and Brown, G., eds., Crystal structures of clay minerals and their X-ray identification: London, Mineralogical Society, p. 249-303.

Reynolds, R. C., Jr., and Hower, John, 1970, The nature of interlayering in mixed-layer illite-montmorillonite: Clays and Clay Minerals, v. 18, p. 25-36.

Rice, D. D., 1984, Relation of hydrocarbon occurrence to thermal maturity of organic matter in the Upper Cretaceous Niobrara Formation, eastern Denver basin-Evidence of biogenic versus thermogenic origin of hydrocarbons, in Woodward, Jane, Meissner, F. F., and Clayton, J. L., eds., Hydrocarbon source rocks of the greater Rocky Mountain region: Rocky Mountain Association of Geologists, p. 365-368.

Rice, D. D., and Claypool, G. E., 1981, Generation, accumulation, and resource potential of biogenic gas: American Association of Petroleum Geologists Bulletin, v. 65, p. 5-25.

Schlanger, S. O., and Douglas, R. G., 1974, Pelagic ooze-chalklimestone transition and its implications for marine stratigraphy, in Hsu, K. J., and Jenkyns, H. C., eds., Pelagic sediments-On land and under the sea: International Association of Sedimentology Special Publication 1, p. 117-148.

Scholle, P. A., 1977a, Chalk diagenesis and its relation to petroleum exploration; oil from chalks, a modern miracle?: American Association of Petroleum Geologists Bulletin, v. 61, p. $982-1009$.

1977b, Current oil and gas production from North American Upper Cretaceous chalks: U.S. Geological Survey Circular 767, $51 \mathrm{p}$. 
Schultz, L. G., 1964, Quantitative interpretation of mineralogical composition from X-ray and chemical data for the Pierre Shale: U.S. Geological Survey Professional Paper 391-C, $31 \mathrm{p}$.

Shurr, G. W., 1980, Geologic setting of the Pierre Shale (Upper Cretaceous) in the northern Great Plains: U.S. Geological Survey Open-File Report 80-675, 8 p.

Tissot, B. P., and Welte, D. H., 1978, Petroleum formation and occurrence: Springer-Verlag, New York, 538 p.

Velde, Bruce, 1973, Phase equilibria for dioctahedral expan- dable phases in sediments and sedimentary rocks, in Serratosa, J. M., ed., Proceedings of the International Clay Conference, Madrid, Spain, 1972: Madrid, Spain, Division of Sciences, National Research Council, p. 235-248.

1977, A proposed phase diagram for illite, expanding chlorite, corrensite and illite-montmorillonite mixed-layer minerals: Clays and Clay Minerals, v. 25, p. 264-270.

Weaver, C. E., 1979, Geothermal alteration of clay minerals and shales-Diagenesis: Office of Nuclear Waste Isolation Technical Report 21, 176 p. 


\section{Burial Diagenesis of Sandstones}

\section{by RAYMOND SIEVER, Department of Earth and Planetary Sciences Harvard University, Cambridge, Massachusetts 02138}

\section{CONTENTS}

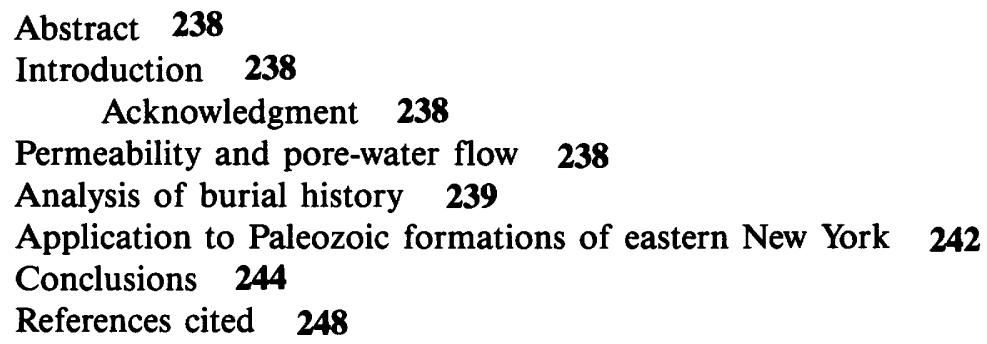

\section{FIGURES}

1. Chart showing stages of burial diagenesis of sandstones $\mathbf{2 4 0}$

2. Sedimentation diagrams for sandstones that have been buried, uplifted, partially eroded, and reburied 241

3. Time-temperature diagram showing generalized yield curves for slow diagenetic reaction 243

4. Time-temperature curve for pelagic siliceous ooze deposited on spreading sea floor above and below carbonate compensation zone $\mathbf{2 4 4}$

5-7. Sedimentation diagrams:

5. Paleozoic formations in eastern New York 245

6. Diagenetic phases in Esopus Shale $\mathbf{2 4 6}$

7. Diagenetic phases in Slide Mountain Sandstone $\mathbf{2 4 7}$ 
Abstract

The burial diagenesis of sandstones is controlled chiefly by the generally permeable nature of sands that allows extensive flow of pore waters at various stages of the process. The flow is driven by expression of compaction water from muddy sediments in the sands, by infiltration of meteoric water under hydrostatic head from an elevated recharge region, by convection transfer from deeper, warmer regions to shallower, cooler ones, and by movement of water produced by dehydration reactions. The chemical driving force behind much of the alteration of detrital components is the chemical instability of many of these materials, especially those of volcaniclastic origin. A second major control is the increase in temperature and pressure that accompanies deep burial under a range of geothermal gradients that differ according to the tectonic position of the rocks. The use of sedimentation diagrams, the estimation of paleogeotherms from tectonic history, and the reconstruction of time-temperature curves has shown that the diagenesis (as derived from petrography) of three Paleozoic formations in eastern New York State is a function of the duration of and the temperatures that prevailed during their burial.

\section{INTRODUCTION}

An explosion of research has taken place on the diagenesis of all types of sediments, ranging from the diagenesis of carbonates, which has become an integral part of understanding their deposition, to that of clastic sediments. Studies of the diagenesis of sandstones have been sparked by exploration for oil and gas and the necessity to understand reservoir properties to enhance oil recovery. As a result, we have learned much that is new and rediscovered much that we knew before. New to the study of sandstone diagenesis is the emphasis on burial effects in various basins, especially on the increase in temperature and pressure that affects the course of cementation and authigenesis. This paper emphasizes those kinds of changes, although it will of necessity treat in passing other aspects of the subject, knowledge of which is required before we can sort out the effects of burial from the many other controls.

\section{Acknowledgment}

Part of this work was done under the auspices of NSF Grant EAR-82-12261.

\section{PERMEABILITY AND PORE-WATER FLOW}

The important aspect of sandstones that sets them apart from mudstones and many other lithologies is the generally high porosity and permeability that characterize the original sediment and that allow the traversal of pore waters at various times in the sediment's history, barring complete cementation or alteration and loss of permeability. We now understand that not only are arenites of all kinds permeable, but the original turbidites that later may become matrix-rich graywackes are also permeable, at least throughout much of their early history. One of the major aspects of sandstone diagenesis, therefore, is the decrease in permeability that may come from diagenesis. One route is the deformation and alteration of rock fragments, that, if extensive enough, convert a lithic arenite into a wacke or graywacke. Another route is the precipitation of mineral cements that occlude pore space. Purely physical compaction is minor for most sandstones; most of the compaction stems from pressure solution or diagenetic dissolution that locally produces as a consequence secondary porosity (Schmidt and McDonald, 1979).

Inasmuch as permeability makes possible movements of pore waters, to understand the nature and extent of diagenetic reactions we need to know flow rates. These rates depend on both permeability and the nature of the flow that results from a hydrostatic head or convective motion. The hydrostatic head arises typically from the recharging rim of a sedimentary basin. Convective flow is produced by geothermal gradients that are high enough (Wood and Hewett, 1982), most dramatically where an intrusion has taken place at depth (Kastner and Siever, 1983).

Another source for flow is the water of compaction that is expressed from the entire sedimentary column, primarily from the muddy, fine-grained sediments. Much of this water is expressed early in a sandstone's history, when it is near the top of the section where it acts as a conduit for still compacting muds and carbonates. After moderate burial the rate of compaction decreases drastically and the effect diminishes. At greater depths the water liberated by dehydration reactions (Surdam and Boles, 1979), such as the transformation of smectite to illite (Hower and others, 1976), may move through sandstones.

The boundary value for flow rates is zero when there is no flow drive or the permeability becomes vanishingly small. At this point reactions within a sandstone become completely isochemical and dependent solely on molecular diffusion for transport. The flow rate becomes zero when the sandstone becomes sealed by an impermeable cap and base, which may lead to overpressuring, another disturbance in a sediment's history. Here, the sandstone itself remains permeable, and the isochemical reactions within it are governed by diffusion. The perfect small-scale examples of isochemical reactions in an overpressured formation that remain to be studied are sandstone ripples encased in a shale matrix. The flow rate will go to zero if and when the sandstone itself becomes internally sealed by cementation or alteration of rock fragments to matrix.

As flow rates approach zero, the length of time required for cementation rises steeply (Pettijohn and 
others, 1972, p. 397-398). Indeed, the question arises how can a completely cemented sedimentary quartzite form in any reasonable geological period of time except at higher temperatures, where pressure drives may overcome the declining permeability.

Even without overpressuring or complete cementation, the flow rate becomes zero if there is no pressure head whatsoever, due to a perfectly level ground-water potential surface in the basin. If the geothermal gradient is too low, convection-driven flow is absent. A section impoverished in fine-grained sediments does not compact significantly, and little water will be expressed.

The chemical driving force of diagenetic reactions is the chemical instability of detrital or chemically precipitated components. Reactions between phases that are not in equilibrium, such as smectite and potassium feldspar or two different plagioclases, are examples. At most sedimentary temperatures chemical reactions are heterogeneous and involve solids and the pore solution. Polymorphic inversions, such as aragonite to calcite or opalA to opal-CT, are affected by the pore solution if the mechanism is recrystallization by dissolution and reprecipitation. If pore water does not move, such reactions slowly proceed by diffusion. The trend to equilibrium produces a stable mineral assemblage in equilibrium with the pore-water solution. Such seems to be true for older shales that have a chlorite-illite-quartz-albite assemblage. If such completely isochemical changes were common, each formation with a different set of detrital components would form its own stable assemblage in terms of both the phases present and different proportions of the phases that reflect different bulk chemical compositions. The fact that in most sections we see no such wide variation in composition suggests that in sandstones, at least, few courses of diagenesis are controlled chiefly by isochemical reactions.

More to the point are those diagenetic reactions brought about by movements of pore waters from one region to another. Pore waters may achieve a particular composition as a result of dissolution of a mineral in one place and the flow transport elsewhere of the solute. The flow of the solute might produce a precipitation reaction in another region. The most common example is that of the infiltration of meteoric waters into near-surface formations. Such waters aggressively weather carbonates and unstable silicates and sulfides. One result is the dissolution of detrital plagioclase, an important process in many sandstones (Land and Dutton, 1978). Invasion by meteoric waters may take place shortly after deposition, when an alluvial sandstone is still exposed periodically as a recharge region for an aquifer and later when, as a result of erosion and unconformity higher in the section, the sandstone is once again brought into the region of downward movement of ground water.

Other movements of water are those related to circulation in deeper formations and those driven by compaction, dehydration, or convection. Regardless of the cause, these waters move from regions of higher temperature and pressure towards those of lower temperature and pressure, higher in the section. In the course of this mass transfer, components sensitive to such temperature changes, including most of the common elements, will move. The most common example of such a component is quartz, whose solubility, rate of dissolution, and precipitation as a function of temperature are well known. Waters at a given depth that are saturated with respect to quartz cool as they move upwards in the column and thus become supersaturated with respect to quartz. As they traverse sandstones with abundant quartz detritus, they find the seed surfaces they need for precipitation. The opposite may be true of calcite, which decreases in solubility with the increase in temperature and pressure that follows most geothermal and lithostatic pressure gradients. Thus, the replacement of quartz by calcite at depth and the reverse nearer the surface should be expected as a consequence of the changes in solubility of these two minerals as they are buried. Although these reactions may take place, exactly how and where they happen in specific formations is still difficult to assess. In the examples cited, mass transport is helped by diffusion, which operates in the same way to transfer solutes from regions of dissolution to regions of precipitation, although much more slowly.

\section{ANALYSIS OF BURIAL. HISTORY}

The stages of burial diagenesis of sandstones are shown in figure 1 by means of a flow chart showing how various waters affect a detrital assemblage to produce diverse diagenetic materials. The course of early diagenesis, including the reaction of minerals with the water of the environment and the effects of bioturbation, was discussed by Berner (1980). Deep burial assemblages are affected more by deeper water movements than by shallower ones along temperature and pressure gradients. Finally, the formation may be part of a later uplifted section and again infiltrated by meteoric water which results in reversible changes, such as temperature and pressure decrease, decementation, and kaolinization.

Siever (1983a) quantitatively analyzed depth of burial and increase in temperature by use of sedimentation diagrams and by estimation of paleogeotherms. Figure 2 shows an idealized example of one such diagram drawn for a formation that is buried, compacted, uplifted, partially eroded, and then buried again. The sequence of geological events for this formation is plotted on the diagram, which shows the locus of the formation with respect to the sediment-water interface as a function of postdepositional time. Plotting the burial history at a single point gives a one-dimensional view of the sedimentary column as it changes with postdepositional time. 


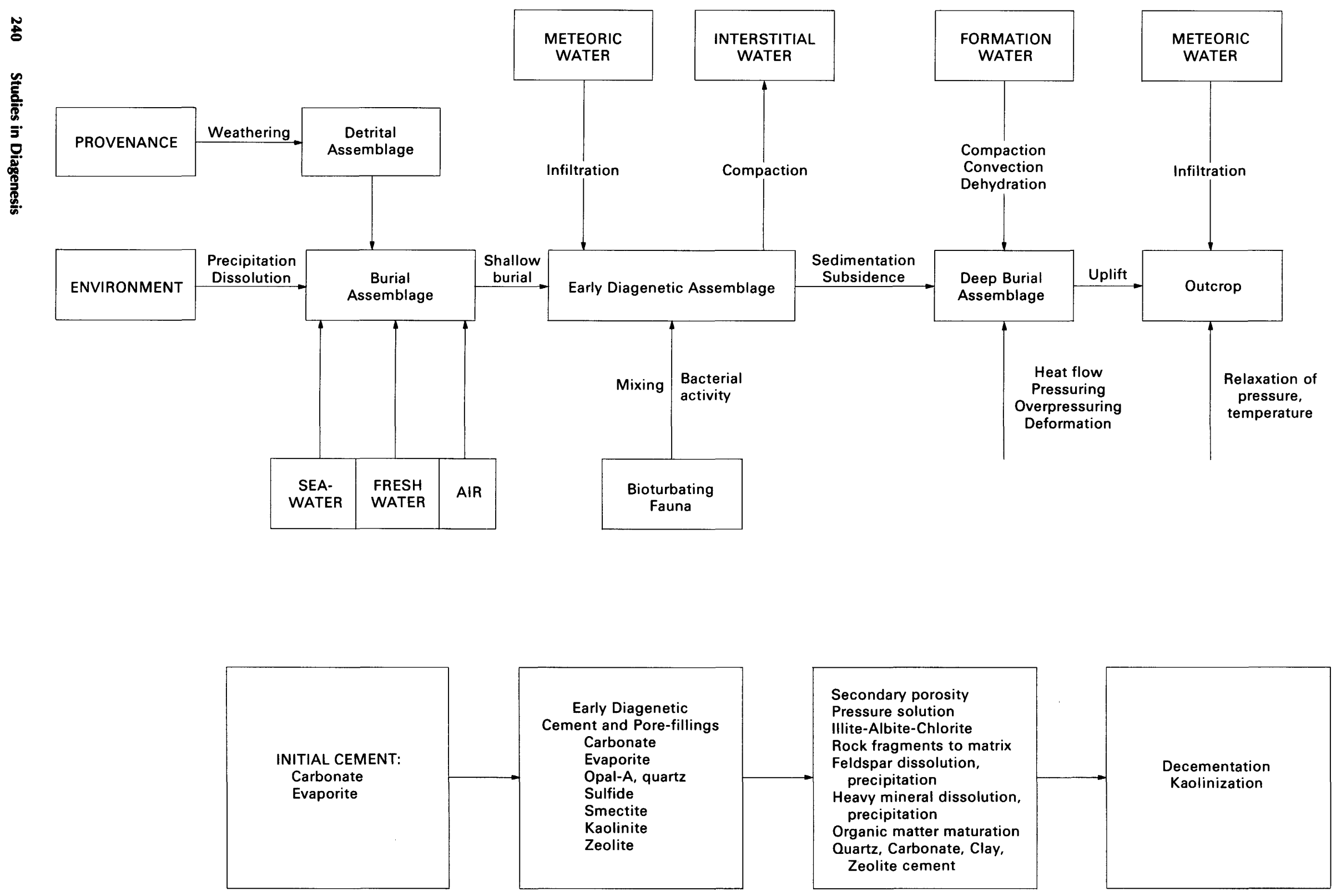

Figure 1. Stages of burial diagenesis of sandstones, showing the effect of various waters on detrital assemblages. Boxes show assemblages produced by the processes indicated by the arrows. 


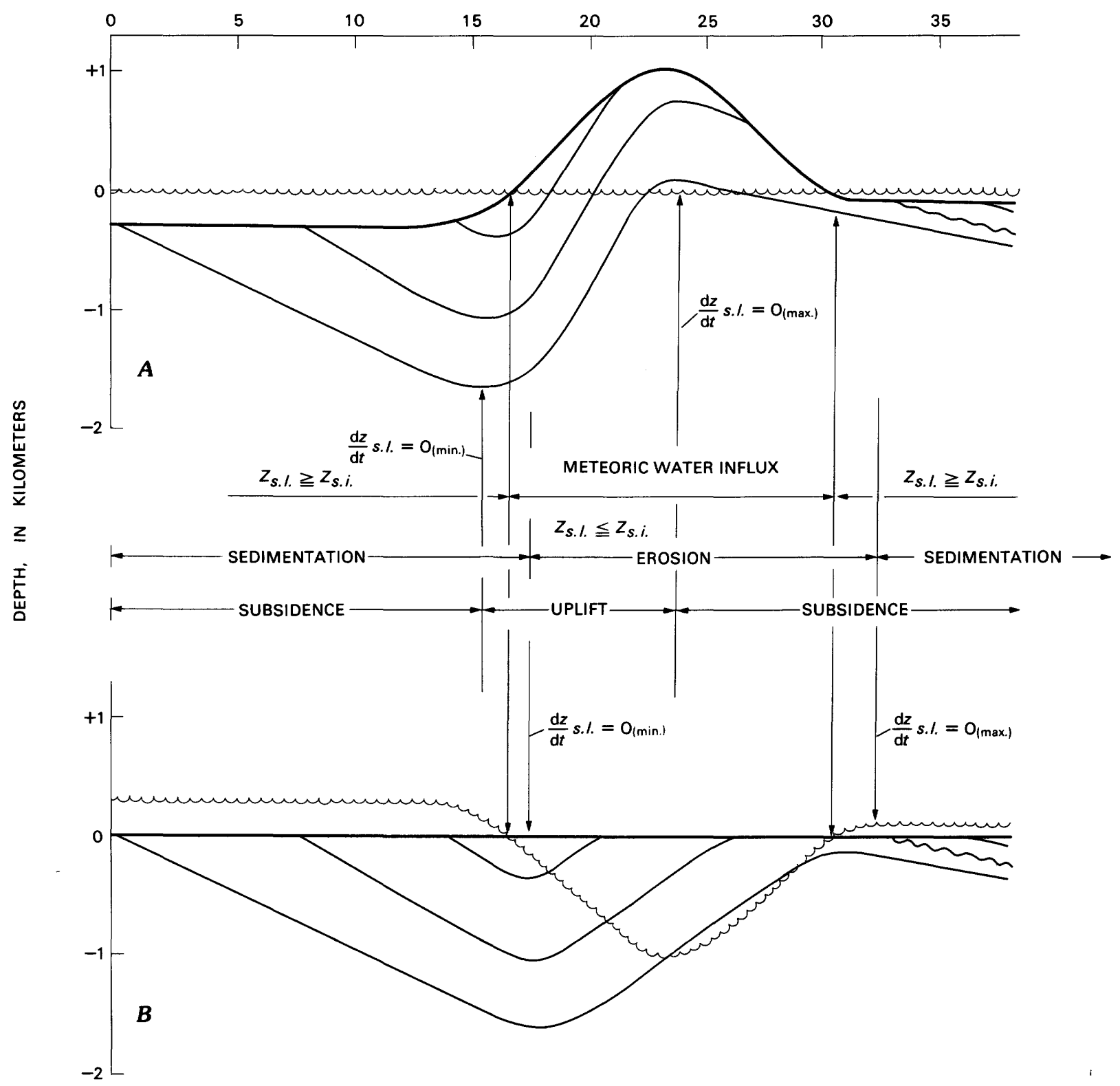

\section{EXPLANATION}

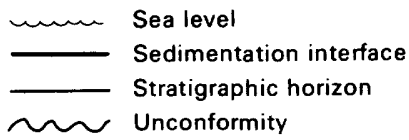

Figure 2. Sedimentation diagrams for sandstones that have been buried, uplifted, partially eroded, and reburied. $A$, plotted with reference to sea level at zero $\left(z_{s l}\right)$. B, plotted with reference to the sediment-water or sediment-air interface as zero $\left(z_{s, i}\right)$. (Modified from Siever, 1983a). Times are when values of $\mathrm{dz} / \mathrm{dt}$, the differential of depth (referred to either sediment-water interface or sea level) with respect to time, are at maxima or minima and are shown correlated with relative values of $z-s .1$. and $z-s . i$. and burial stages.

Of particular importance for diagenesis is the time of meteoric water influx during an erosional interval.
To get the background for the causes and effects of pore-water movements, the paleogeotherms for this 
diagram must be estimated (Siever, 1983a). The geothermal gradient is a function of heat flow, thermal conductivity of the rock column, temperature of the thermal boundary layer at the sediment-water or air-water interface, and nonequilibrium heat lag during sedimentation or uplift. Each of these quantities will be time dependent. Heat flow changes in response to tectonic changes. Thermal conductivity changes with diagenetic changes in porosity. The temperature of the thermal boundary layer changes in response to physical oceanographic variables, paleolatitude changes caused by continental drift, and (or) global climatic changes. Heat lag changes with sedimentation and subsidence rates, and heat transfer changes by convection of ground waters. None of these factors can be precisely calculated from current imprecise geological data, but they do not vary widely. Hence, we may make general estimates of these quantities that allow a calculation of the gradient at any given postdepositional time.

Perhaps the most important aspect in reconstructing paleogeotherms is the insight we get on the rates of slow diagenetic reactions that characterize sandstone diagenesis. Most diagenetic reactions take place at less than $100^{\circ} \mathrm{C}$, and almost all take place at less than about $200^{\circ} \mathrm{C}$. In this temperature region, the transformations of clay minerals, zeolites, feldspars, and other silicates rarely go to completion except after very long times. Thus, reaction kinetics are important in deducing reaction yields as functions of time and temperature. Frequently, the Arrhenius equation is used, which relates the change in a reaction rate constant to an increase in temperature and defines the activation energy as an exponential:

$$
\frac{\mathrm{d}(\ln k)}{\mathrm{d} T}=\frac{E_{a}}{R T^{2}} .
$$

If $E_{a}$ is not temperature dependent, the integrated form may be used:

$$
k=A \exp \left[-\frac{E_{a}}{R T}\right]
$$

where $k$ is the reaction rate constant, $E_{a}$ is the activation energy, $R$ is the gas constant per mole, $T$ is temperature (in Kelvins), and $A$ an integration constant (commonly called the "frequency factor"). Although the Arrhenius equation is convenient and applicable to a remarkably large number of common, fast laboratory reactions, it is clearly not applicable to many diagenetic reactions in which the activation energies may not be constant with temperature, that is, where the reaction mechanisms are different in different temperature regions. Yet, this equation has been shown to be a good approximation for at least one clay mineral transformation that has been studied experimentally (Eberl and Hower, 1976).

Whether or not the specific equation holds, the general form does, and it leads to yield curves such as those shown in figure 3 , a plot of time versus temperature. Also shown in figure 3 are the normal ranges of sedimentation rates and geothermal gradients, which can also be represented on a time-temperature graph because temperature and burial are both related to the rate at which a formation is buried. On this same kind of graph a series of diagenetic transformations together with a burial curve translated into time versus temperature has been plotted in figure 4 . In this figure, the transition from opal-A to opal-CT to quartz for 80 percent yields is shown for a siliceous oceanic sediment (Siever, 1983b). This reconstruction is for a sediment that was deposited on a ridge flank, well above the carbonate compensation depth (CCD), then subsided along a general plate-contraction path (Parsons and Sclater, 1977) to a position below the CCD and then to an abyssal plain, a typical path followed by many Pacific Ocean sediments. The temperatures shown are deduced from oceanic heat-flow measurements adjusted for distance from a ridge and for an average pelagic sedimentation rate. The phase transitions are drawn from kinetics of the transformations as experimentally determined by Kastner and others (1977) and inferred from occurrences in drill holes of the Deep Sea Drilling Program (Kastner, 1981). Such a matching of reaction kinetics and burial history allows the prediction of phases to be expected at any given postdepositional time.

\section{APPLICATION TO PALEOZOIC FORMATIONS OF EASTERN NEW YORK}

The combined use of sedimentation diagrams, paleogeotherms, and petrographic data leads to the kind of diagenetic history reconstructions shown in figures 5-7. These curves are taken for a point in eastern New York just west of the Catskill Mountains front. Abundant information is available on the stratigraphic succession in this area, and the diagenesis of several formations has been mapped from petrographic information (Siever and Hager, 1981). Sedimentation diagrams for four formations are shown in figure 5, one each for the Late Cambrian (Potsdam Sandstone), the Early Devonian (Esopus Shale), the Late Devonian (Slide Mountain Sandstone, Rickard, 1975), and a Pennsylvanian sandstone inferred by extrapolation to have been deposited and eroded in the late Paleozoic. All these formations are plotted with respect to the sediment-water or sediment-air interface; the position of sea level is estimated from the environment of deposition of each formation. The major tectonic events of the Paleozoic in this region-the Taconic, Acadian, and Allegheny orogenies-are shown above the curve. The stratigraphic succession records subsidence and sedimentation during the Cambrian and Ordovician of a shallow shelf, deepening to a pre-Taconic turbidite basin, probably a marginal sea or back-arc basin. After the Taconic orogeny, the region was uplifted and eroded, followed by a resumption of shallow-shelf subsidence in the Early Devonian. This shelf condition gave way to rapid subsidence and sedimentation of a thick Upper Devonian 


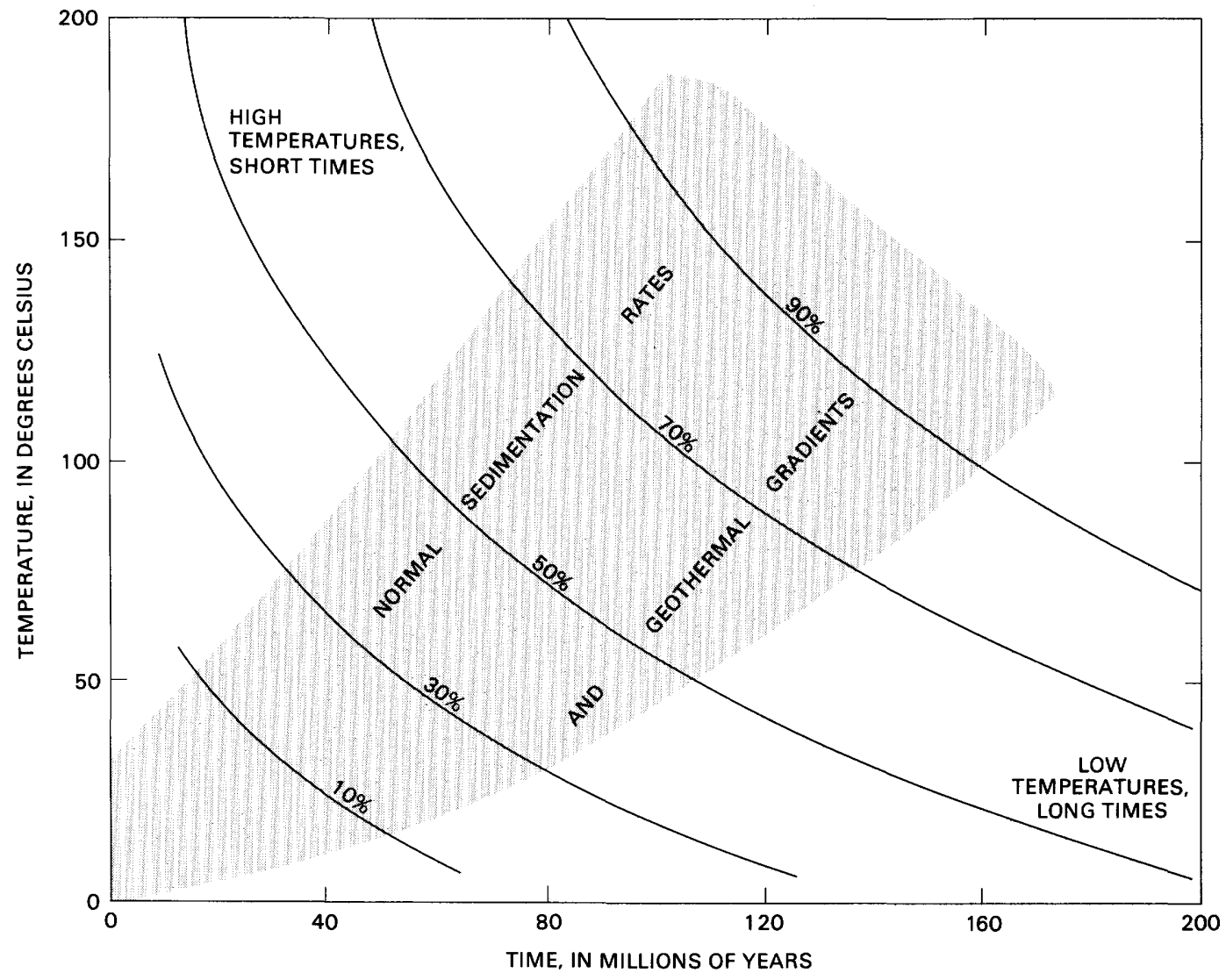

Figure 3. Time-temperature diagram showing generalized yield curves (in percent) for a hypothetical, typical, slow diagenetic reaction. Region of normal sedimentation-burial rates and geothermal gradients is stippled. (Modified from Siever, 1983a.)

clastic wedge associated with the Acadian orogeny. The post-Acadian clastic influx continued until the uplift associated with the Allegheny orogeny at the end of the Paleozoic.

At the top of figure 5 these tectonic conditions are translated into heat-flow and paleogeothermal gradients. Following the Allegheny orogeny Triassic-Jurassic rifting began. The westernmost extent of the rift zone is within $100 \mathrm{~km}$ of the area considered here and thus might have exerted some minor influence in heating the crust in the eastern Catskill region. Following the heating and crustal extension of the Triassic-Jurassic, the crust has had a long history of attenuating heat flow and has evolved slowly to its present average continental value.

The diagenetic consequences of these events for the Potsdam Sandstone, based in part on the petrographic work of Sahakian (1963), are plotted below the sedimentation curve in figure 5. Carbonate cement was precipitated during early diagenesis and was accompanied by a small amount of physical compaction of the sand and associated silty and muddy facies. The calcite cement seems to have been the result of the inception of carbonate precipitation conditions on a low-latitude shallow shelf, which, shortly after deposition of the Potsdam, led to the deposition of the largely carbonate facies of the Upper Cambrian and Lower Ordovician. Authigenic feldspar in the Potsdam is one of the early cements and is probably the result of burial to as much as $0.5 \mathrm{~km}$ in pore waters dominated by marine waters. These pore waters would have been altered by early diagenesis in which the $\mathrm{pH}$ remained about 8 , the cation activities increased slightly, and silica activity increased, making possible the precipitation of authigenic feldspars as proposed by Kastner and Siever (1979). At about the same time, with the beginning of deeper burial, pressure solution of quartz began and steadily increased during later burial. Pressure solution is clearly a function of both pressure and temperature increase. At some time near the end of the Ordovician, perhaps during a higher heat flow regime, burial would have exceeded $2 \mathrm{~km}$, and the increased temperatures would have initiated the conversion of various species of smectite detritus to illite and chlorite. The reaction may have involved some small amount of dissolution of detrital feldspar and growth of albite as the stable illite-chloritealbite-quartz assemblage came into being. By the end of the Paleozoic, about $\mathbf{3 0 0}$ million years after deposition, enough time had elapsed at temperatures characteristic of burial to $3-4 \mathrm{~km}$ for complete conversion to the stable assemblage found today-calcite-albite-illite-choritequartz. Since then, no changes have taken place.

The next formation, the Lower Devonian Esopus Formation, illustrates a somewhat different history (fig. 6). 


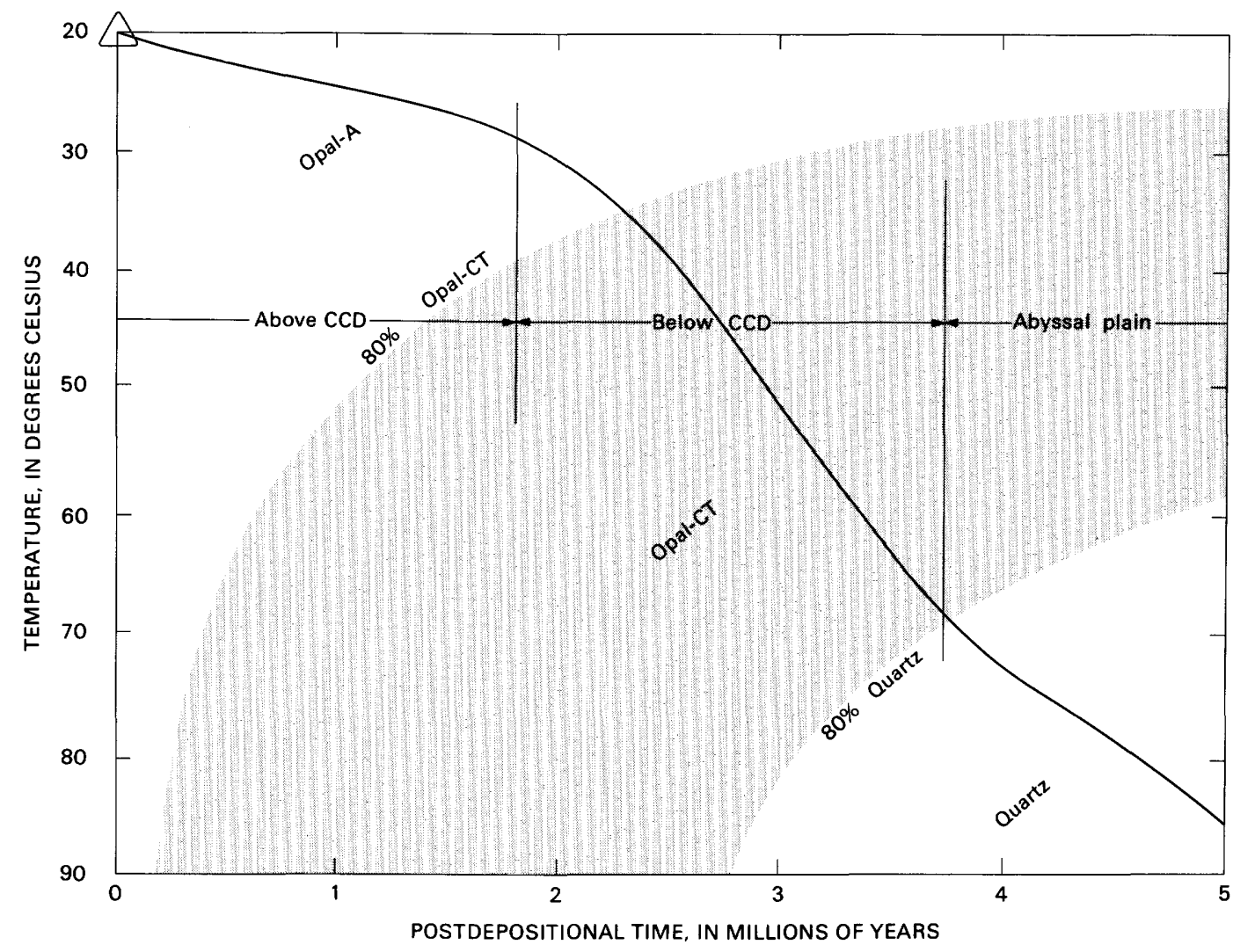

Figure 4. Time-temperature curve for a pelagic siliceous ooze deposited on spreading sea floor above and below carbonate compensation depth (CCD) and beneath abyssal turbidite plain. Phase transitions of silica polymorphs are for 80 percent yields. Stippled area covers time-temperature region in which opal-CT is an abundant silica phase. (Modified from Siever, 1983b.)

Its sedimentation curve is simpler, but the starting detrital and chemical assemblage - a siliceous, carbonate-rich, siliciclastic mud-predisposed it to a different course (Rehmer, 1976). The early events were carbonate cementation, possibly by recrystallized faunal elements, and the formation of concretions. At the same time, compaction was proceeding and the opal-A of sponge spicules and perhaps some radiolarians was converting to opal-CT. Rapid burial under the later Devonian clastic wedge followed, and in a few tens of millions of years the Esopus was buried to a depth of more than $2 \mathrm{~km}$. Physical compaction was largely completed by this time, and opal-CT was converted to quartz. Further burial to depths greater than $3 \mathrm{~km}$ resulted in the growth of the illite-chlorite-albite assemblage and the embrittlement of the shale that led to its dominant fracture pattern found well away from any tectonic deformation zone. By the early Mesozoic, the diagenetic changes in the Esopus Shale were complete and yielded the present assemblage of carbonate (cement and concretions), quartz (cement and chert layers), albite, illite, and chlorite.

The Upper Devonian sandstone had yet another diagenetic history stemming from its detrital assemblage of quartz, feldspars, and rock fragments of a supracrustal, nonvolcanic suite (Burtner, 1964). Its sedimentation diagram shows a simple burial history of subsidence beneath the thick clastic wedge followed by Mesozoic uplift and erosion (fig. 7). Hematite cement was one of the early diagenetic additions to this deltaic plain sand as the sand physically compacted slightly in the first few million years after its deposition. The abundant rock fragments of argillaceous and low-grade metamorphic rocks would have begun to deform and alter as rapid burial started. Similar to the other formations in this succession, the conversion of detrital smectite, kaolinite, and other clay minerals to the illite-chlorite suite would have begun. Carbonate cement seems to have been introduced at this time, perhaps as a result of downward pore-water movements that transported $\mathrm{HCO}_{3}^{-}$and $\mathrm{Ca}^{2+}$ into higher temperature regions where they were less soluble and precipitated.

\section{CONCLUSIONS}

The examples given here are representative of the effects of burial on three somewhat different, moderately deeply buried Paleozoic formations in a continental margin setting. The course of diagenesis was controlled first by the composition of the detritus and environmental 
TIME, IN MILLIONS OF YEARS BEFORE PRESENT
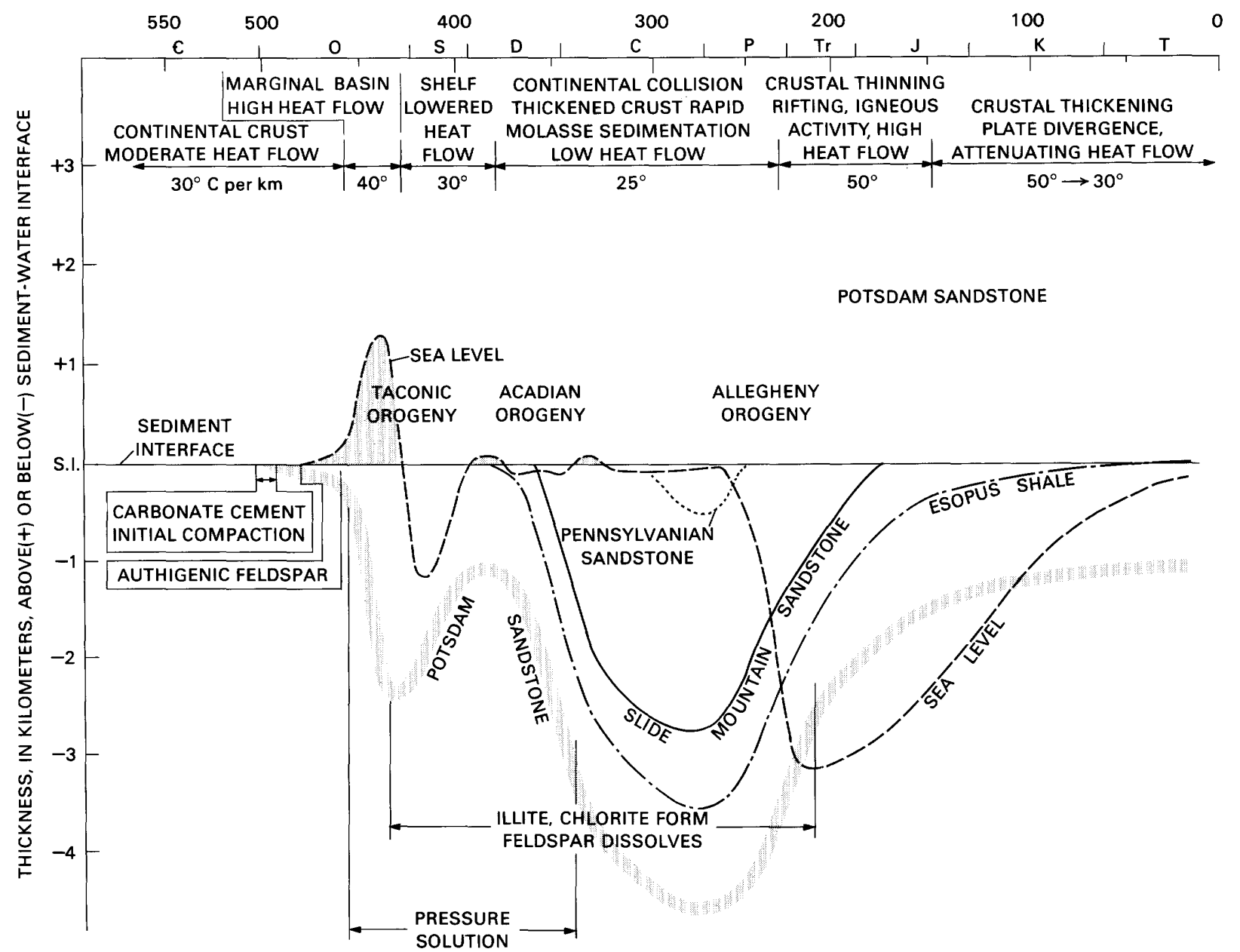

Figure 5. Sedimentation diagram for Paleozoic formations in eastern New York just west of Catskill Mountains front. Depths below the sediment interface are shown for four formations: the Upper Cambrian Potsdam Sandstone, the Lower Devonian Esopus Shale, the Upper Devonian Slide Mountain Sandstone, and a Middle Pennsylvanian Allegheny sandstone. C, Cambrian; O, Ordovician; S, Silurian; D, Devonian; C, Carboniferous; P, Permian; Tr, Triassic; J, Jurassic; K, Cretaceous; T, Tertiary. Below time scale are place tectonic interpretations for appropriate time intervals of the Catskill front region of eastern New York State and estimated geothermal gradient values for these time intervals (in degrees Celsius per kilometer). Curve for sea level was inferred from sedimentologic and stratigraphic reconstructions of sedimentary environments. Time intervals when sea level was above sediment-water interface, corresponding to time of marine sedimentation, are stippled between sea-level curve and zero reference line for sediment-water interface. Diagenetic phases shown are for Potsdam Sandstone.

chemical additions; that is, kinds and amounts of feldspars, carbonate, clay minerals, and rock fragments. The course of early diagenesis was controlled by the chemistry of interstitial water, whether marine or subaerial. Under subaerial conditions infiltration of meteoric waters may have been significant in the early alteration of detrital minerals and the addition of cements. Deeper burial diagenesis was controlled by the rate at which the sediment was transported to higher temperature and pressure regimes. Here, faster kinetics of slow reactions took over and, given even relatively short times at deep burial, resulted in extensive alterations, such as the formation of the stable silicate assemblage, illite-chloritealbite-quartz.
The application of sedimentation diagrams and paleogeotherms in a context of chemical kinetics is the guide to a quantitative as well as a qualitative evaluation of the postdepositional time at which a given yield of diagenetic product can be achieved. Study of recent sedimentary deposits allows us to catch some of the faster diagenetic reactions. The examples given here are of nonvolcaniclastic sandstones. The course of diagenesis of volcaniclastic sands genetically associated with plate convergences involves many different phases and types of diagenetic paragenesis, examples of which were given by Galloway (1974) and discussed by Surdam and Boles (1979). A complete picture of the range of burial diagenesis of sandstones must include sandstones of all the 


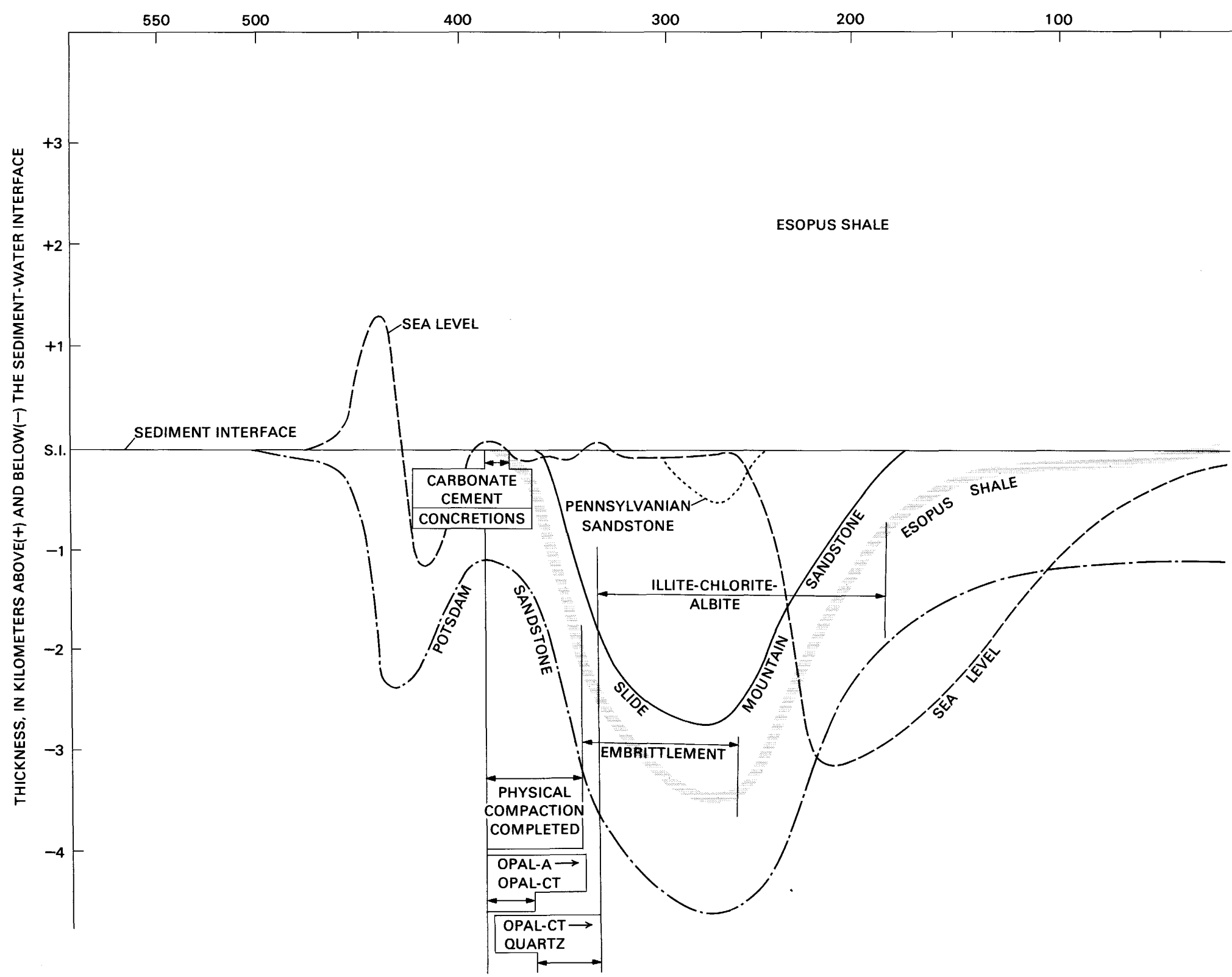

Figure 6. Sedimentation diagram showing diagenetic phases in Esopus Shale. 


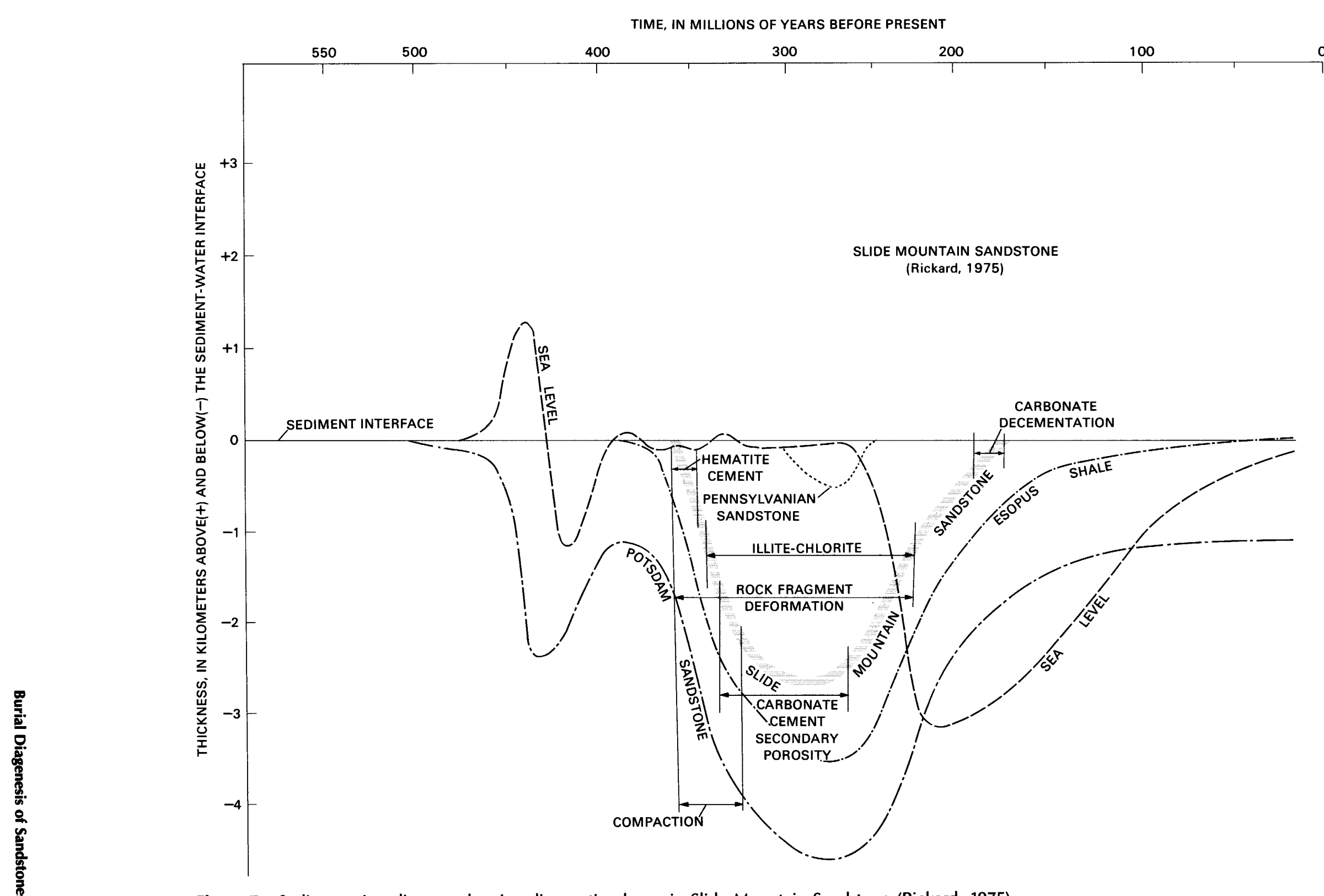

Figure 7. Sedimentation diagram showing diagenetic phases in Slide Mountain Sandstone (Rickard, 1975). 
types in different provenances genetically related to plate tectonic environments (Dickinson and Suczek, 1979) and how the diagenetic history of these deposits is subsequently affected by plate tectonic movement as manifested through paleogeothermal gradients (Siever, 1979). To pursue this goal requires the modal mineralogy of diagenetic components of sandstones so that reaction yields can be compared with products. We need to compare different formations in the same burial sequence to see the effects of varying depths of burial. This should be paired with studies of one formation at various depths. Above all, we must reconstruct the burial history as accurately as possible, for that will allow the deductions of paleohydrology coupled to reaction kinetics that will ultimately lead to a predictive capability for sandstone diagenesis.

\section{REFERENCES CITED}

Berner, R. A., 1980, Early Diagenesis: Princeton, Princeton University Press, 214 p.

Burtner, R., 1964, Paleocurrent and petrographic analysis of the Catskill facies of southeastern New York and northeastern Pennsylvania: Cambridge, Massachusetts, Harvard University Ph. D. thesis, $221 \mathrm{p}$.

Dickinson, W. R., and Suczek, C. A., 1970, Plate tectonics and sandstone compositions: American Association of Petroleum Geologists Bulletin, v. 63, p. 2164-2182.

Eberl, D. D., and Hower, J., 1976, The kinetics of illite formation: Geological Society of America Bulletin, v. 87, p. 1326-1330.

Galloway, W. E., 1974, Deposition and diagenetic alteration of sandstone in northeast Pacific arc-related basins; Implications for graywacke genesis: Geological Society of America Bulletin, v. 85, p. 379-390.

Hower, J., Eslinger, E., Hower, M. F., and Perry, E. A., 1976, Mechanisms of burial metamorphism of argillaceous sediment, mineralogical and chemical evidence: Geological Society of America Bulletin, v. 87, p. 725-737.

Kastner, M., 1981, Authigenic silicates in deep-sea sediments; Formation and diagenesis, in, Emiliani, C., ed., The sea, v. 7, The oceanic lithosphere: New York, Wiley, p. 915-980.

Kastner, M., Keene, J. B., and Gieskes, J. M., 1977, Diagenesis of siliceous oozes-I. Chemical controls on the rate of opal-A to opal-CT transformation-An experimental study: Geochemica et Cosmochimica Acta, v. 41, p. 1041-1059.
Kastner, M., and Siever, R., 1979, Low temperature feldspars in sedimentary rocks: American Journal of Science, v. 279, p. 435-479.

Kastner, M., and Siever, R., 1983, Siliceous sediments of the Guaymas basin; The effect of high thermal gradients on diagenesis: Journal of Geology v. 91, p. 629-641.

Land, L. S., and Dutton, S. P., 1978, Cementation of a Pennsylvanian deltaic sandstone; Isotopic data: Journal of Sedimentary Petrology, v. 48, p. 1167-1176.

Parsons, B., and Sclater, J. G., 1977, An analysis of the variation of ocean floor heat flow and bathymetry with age: Journal of Geophysical Research, v. 82, p. 803-827.

Pettijohn, F. J., Potter, P. E., and Siever, R., 1972, Sand and sandstone: Heidelberg, New York, Springer-Verlag, 618 p.

Rehmer, J., 1976, Petrology of the Esopus Shale (Lower Devonian), New York and adjacent states: Cambridge, Massachusetts, Harvard University Ph. D. thesis, 288 p.

Rickard, L. V., 1975, Correlation of the Silirian and Devonian rocks in New York State: New York State Museaum and Science Service, Map and Chart Series 24, p. 1-16.

Sahakian, A., 1963, Paleocurrent sudy of the Potsdam Sandstone of New York and Quebec: Cambridge, Massachusetts, Harvard University $\mathrm{Ph}$. D. thesis, 94 p.

Schmidt, V., and McDonald, D. A., 1979, The role of secondary porosity in the course of sandstone diagenesis, in Scholle, P. A., and Schluger, P. R., eds., Aspects of diagenesis: Society of Economic Paleontologists and Mineralogists Special Publication 26, p. 175-207.

Siever, R., 1979, Plate tectonic controls on diagenesis: Journal of Geology, v. 87, p. 127-155.

Siever, R., 1983a, Burial history and diagenetic reaction kinetics: American Association of Petroleum Geologist Bulletin, v. 67, p. 684-689.

1983b, Evolution of chert at active and passive continental margins, in Iijima, A., Hein, J. R., and Siever, R., eds., Siliceous deposits in the Pacific region: New York, Elsevier, p. 7-24.

Siever, R., and Hager, J. R., 1981, Paleogeography, tectonics and thermal history of some Atlantic margin sediments, in Kerr, J. W., ed., North Atlantic borderlands: Canadian Society of Petroleum Geologists Memoir, v. 11, p. 95-117.

Surdam, R. C., and Boles, J. R., 1979, Diagenesis of volcanic sandstones, in Scholle, P. A., and Schluger, P. R., eds., Aspects of diagenesis: Society of Economic Paleontologists and Mineralogists Special Publication 26, p. 227-242.

Wood, J. R., and Hewett, T. A., 1982, Fluid convection and mass transfer in porous sandstones-A theoretical model: Geochimica et Cosmochimica Acta, v. 46, p. 1707-1713. 


\title{
Diagenesis of the Morrison Formation, Smith Lake Uranium District, McKinley County, New Mexico
}

By NEIL S. FISHMAN, U.S. Geological Survey, Box 25046, DFC, MS 939, Denver, Colorado 80225, and

RICHARD L. REYNOLDS, U.S. Geological Survey, Box 25046, DFC, MS 964, Denver, Colorado 80225

\section{CONTENTS}

\author{
Abstract 251 \\ Introduction 251 \\ Acknowledgments 251 \\ Geologic and geochemical setting 251 \\ Geology 251 \\ Geochemistry 253 \\ Organic material 253 \\ Methods 254 \\ Paragenetic relations 254 \\ Alterations preceding emplacement of organic material 254 \\ Organic material and associated alterations 256 \\ Alterations following emplacement of organic material $\mathbf{2 5 8}$ \\ Discussion 259 \\ References cited 262
}

FIGURES

1-3. Maps showing:

1. Location of Smith Lake district $\mathbf{2 5 2}$

2. Smith Lake district and structural setting of Mariano Lake and Ruby orebodies $\mathbf{2 5 3}$

3. Sampling and core localities at Mariano Lake and Ruby deposits 255

4. Diagram of diagenetic alterations in sandstones that host the Mariano

Lake and Ruby uranium deposits 256

5-6. Scanning electron micrographs:

5. Early authigenic pyrite in embayed areas of detrital quartz 257

6. Authigenic, smectite-rich mixed-layer illite/smectite 257

7-10. Photomicrographs showing:

7. Detrital plagioclase dissolved along crystallographic planes $\mathbf{2 5 7}$

8. Detrital sanidine in which central core has dissolved to leave secondary void $\mathbf{2 5 7}$

9. Authigenic potassium feldspar overgrowth on detrital microcline $\mathbf{2 5 7}$

10. Organic material partly filling intergranular pore in host rock 257

11. Scanning electron micrograph showing distribution of uranium, vanadium, silicon, and aluminum in organic material 259

12-13. Photomicrographs showing:

12. Organic material coating grains and filling intergranular pores $\mathbf{2 6 0}$

13. Organic material intimately mixed with euhedral pyrite $\mathbf{2 6 0}$ 
14. Histogram of sulfur isotope values of $\mathrm{FeS}_{2}$ minerals from Mariano Lake and Ruby deposits 260

15. Scanning electron micrograph of authigenic vanadiferous chlorite 260

16. Photomicrograph of dissolved iron-titanium oxide, with titanium oxide remnants 261

17. Histogram of carbon isotope values of authigenic calcite from Mariano Lake and Ruby deposits 261

18. Photomicrograph of kaolinite replacement of calcite 261

19-20. Scanning electron micrographs:

19. Authigenic native selenium 261

20. Probable authigenic goethite coating native selenium 261 


\section{Abstract}

Petrographic and geochemical studies have revealed a complex diagenetic history for sandstone units within the lower part of the Brushy Basin Member of the Morrison Formation (Jurassic) in the southern San Juan basin, New Mexico. Underground mine and core samples were obtained from the Mariano Lake and Ruby uranium mines, which are about $5 \mathrm{~km}$ apart in the Smith Lake uranium district. The host sandstones of the two deposits have undergone similar diagenetic alterations except that authigenic calcite is abundant at the Ruby locality and rare at the Mariano Lake locality. Early in the diagenetic history of the host sandstones, solutions bearing soluble organic species deposited noncellular organic material that coats detrital grains and fills some voids. The organic material localized and concentrated uranium (chiefly as a urano-organic complex) to form uranium orebodies that also have high concentrations of vanadium, chiefly as vanadiferous chlorite, and sulfur, chiefly as void-filling pyrite and marcasite. The $\delta^{34} S$ values for both iron disulfides range from -29.4 to -41.6 per mil. Organic-rich solutions were also probably responsible for extensive destruction of detrital titanomagnetite and ilmenite grains.

Diagenetic alterations preceding the introduction of the organic material include the precipitation of small (less than $10 \mu \mathrm{m})$, euhedral pyrite crystals and framboidal pyrite which differ only slightly in isotopic composition $\left(\delta^{34} S\right.$ values range from -11.0 to -38.2 per mil) from the later void-filling pyrite and marcasite. In addition, precipitation of smectite-rich, mixedlayer illite/smectite clays, dissolution of some detrital feldspars, and precipitation of quartz and feldspar overgrowths also preceded emplacement of the organic material. Following precipitation of the organic material and associated uranium, calcite $\left(\delta^{13} \mathrm{C}\right.$ values range from -7.4 to -12.5 per mil), barite, dolomite, and kaolinite formed as interstitial cements. Subsequent oxidation of parts of the orebodies led to the replacement of iron disulfides by iron oxides and hydroxides, the precipitation of native selenium, and a minor redistribution of iron disulfide, uranium, and iron oxide(?) minerals. The light sulfur-isotope values strongly suggest a biogenic origin for the iron disulfide minerals, and the light carbon-isotope values of calcite suggest that oxidized organic carbon was incorporated into calcite.

\section{INTRODUCTION}

The sequence of diagenetic alterations in sandstones that contain uranium orebodies record geochemical and hydrologic conditions during and after the formation of these orebodies. In this paper we outline the diagenetic evolution of two sandstones containing uranium orebodies-the Mariano Lake and Ruby orebodies-in the Brushy Basin Member of the Jurassic Morrison Formation along the southern margin of the San Juan basin, New Mexico. These two deposits comprise much of the mineralization in the Smith Lake district of the Grants uranium region (fig. 1), the major uranium-producing region in the United States (Chenoweth and Holen, 1980).
Petrographic observations and chemical data are integrated with isotope data to place important constraints on the nature and timing of uranium mineralization in these sandstones and to help identify factors responsible for preservation of the orebodies. Additionally, these studies provide a broad picture of diagenetic patterns in some Brushy Basin sandstones in the central part of the Grants uranium region, a relatively unstudied area.

\section{Acknowledgments}

We are grateful to Jacques F. Robertson and Martin B. Goldhaber of the U.S. Geological Survey for their many helpful discussions of the material in this report and to Jacques F. Robertson for providing additional samples from the Ruby deposit. We thank Robert A. Zielinski for his help in preparing fission-track maps. Mark Stanton and Jim Nishi provided valuable laboratory assistance. We appreciate access to the Mariano Lake mine granted by Gulf Mineral Resources Corporation and to the Ruby mine granted by Western Nuclear Corporation. Robert A. Zielinski and Christine E. Turner-Peterson provided many helpful comments and suggestions in their critical reviews of this manuscript.

\section{GEOLOGIC AND GEOCHEMICAL SETTING}

\section{Geology}

Uranium deposits of the Grants uranium region occur primarily in sandstones of the Westwater Canyon and Brushy Basin Members of the Morrison Formation. In northwest New Mexico the Westwater Canyon Member is composed chiefly of several fluvial sandstone "packages" which were deposited on an aggrading alluvial plain (Turner-Peterson and others, 1980; Turner-Peterson, 1986). The overlying Brushy Basin Member is composed chiefly of lacustrine mudstones and interbedded lenticular sandstones; many of the sandstones are compositionally and texturally similar to those of the Westwater Canyon Member (Craig and others, 1955; Turner-Peterson, 1986; Bell, 1986). Brushy Basin mudstone units were deposited along the margins and within a saline, alkaline lake (Bell, 1986; Turner-Peterson, 1985; Turner-Peterson and Fishman, 1986).

The sandstones at the Mariano Lake and Ruby localities are, for the most part, the lowermost sandstones in the Brushy Basin Member. It is not known if these sandstones are part of a continuous sand body or if they are separate bodies. Because sandstones in the Brushy Basin Member are typically lenticular and discontinuous, the sandstones at the two localities are considered here to be two distinct sand bodies. 


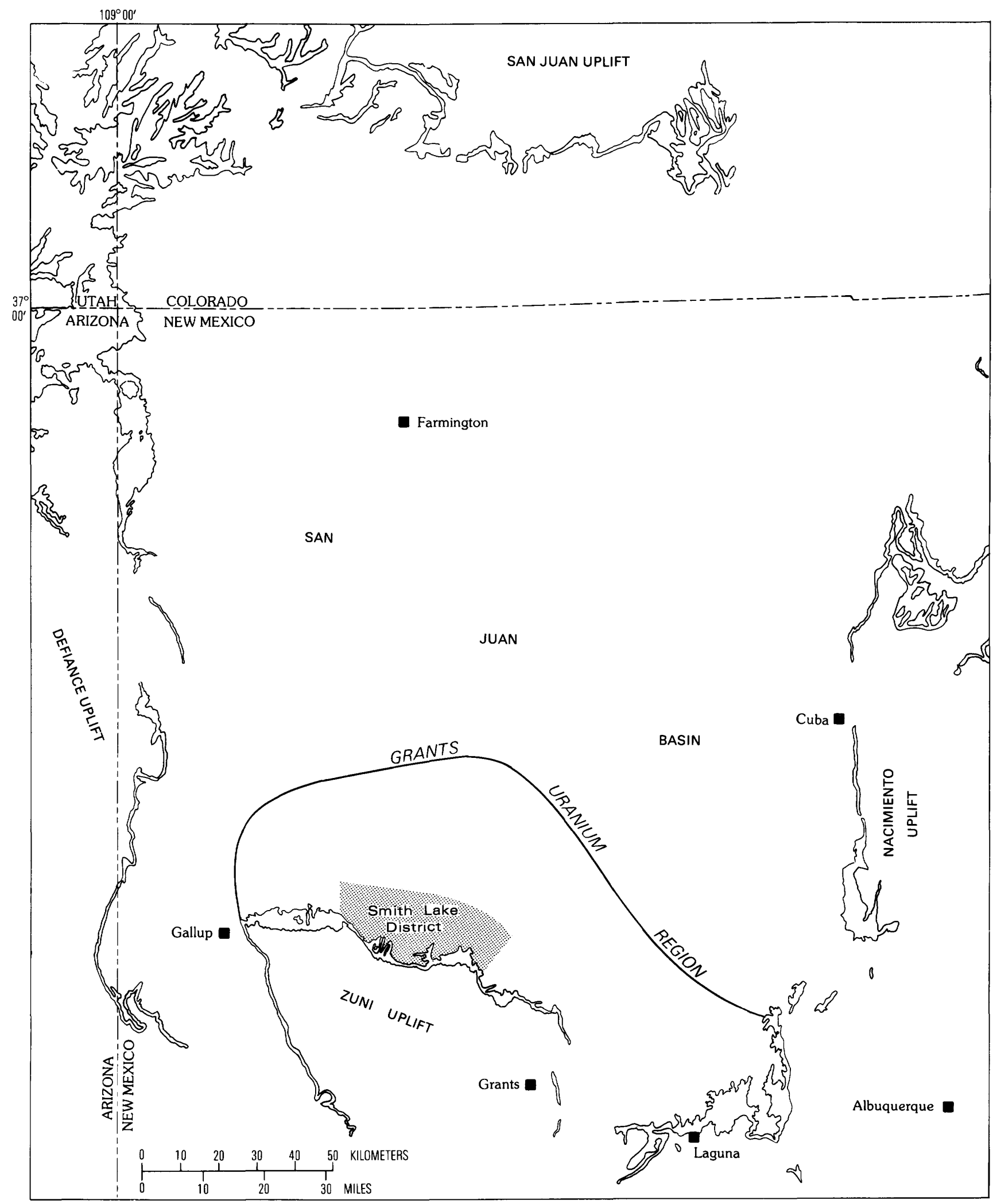

Figure 1. Index map showing location of Smith Lake district (stippled) in Grants uranium region, San Juan basin, New Mexico. Lines represent outcrops of the Morrison Formation. 
The host sandstones are fairly well to poorly sorted, medium- to coarse-grained arkoses. In both deposits, uranium is intimately associated with a noncellular organic material that partly impregnates the host rock (Fishman and Reynolds, 1982; this study). This association is typical of the primary (tabular) uranium deposits in the Grants uranium region (Granger and others, 1961; Adams and others, 1978) and is expressed as a positive correlation between whole-rock abundances of organic carbon and uranium and as a directly observed spatial association of organic matter and uranium (see later discussion).

The Mariano Lake deposit is in the trough, and the Ruby deposit is on the south flank of the same syncline (fig. 2). The axial trend of the syncline is approximately perpendicular to the present hydrologic and paleohydrologic gradient which is from south to north into the San Juan basin (Craig and others, 1955). The structural setting appears to have had different influences on groundwater flow and subsequent diagenetic alterations in the two deposits, as discussed later.

\section{Geochemistry}

Locally, both deposits occur on or near the chemically reduced side of a poorly defined, regional reductionoxidation or "redox" boundary. Such a configuration has led previous investigators to conclude that the orebodies originated in the late Tertiary by the concentration of uranium from oxidation-reduction processes along a migrating redox interface (Place and others, 1980; Ristorcelli, 1980; Saucier, 1980). Although some deposits elsewhere in the region have undoubtedly formed by such processes, they are essentially devoid of the organic material that characterizes primary (tabular) uranium deposits (Granger and others, 1961; Squyres, 1980; Fishman and Reynolds, 1983) and are considered secondary in origin, uranium having been remobilized from preexisting primary (tabular) deposits (Saucier, 1980; Ludwig and others, 1982). Therefore, the coexistence of organic material with uranium at the Mariano Lake and Ruby deposits indicates a primary (tabular) origin relatively unmodified by later oxidation-reduction recyling.

\section{Organic material}

Organic material in the host sandstones is an abundant authigenic constituent and exerts obvious control on the localization of uranium mineralization. The organic material occurs as a noncellular (Hatcher and others, 1986) substance which coats detrital grains and fills some primary voids and secondary voids formed by early diagenetic processes (Fishman and Reynolds, 1982). The organic material imparts a dark brown or black color to the host sandstone. The organic material was introduced post-depositionally, probably as a soluble or colloidal organic species (see Squyres, 1980; Leventhal, 1980) and

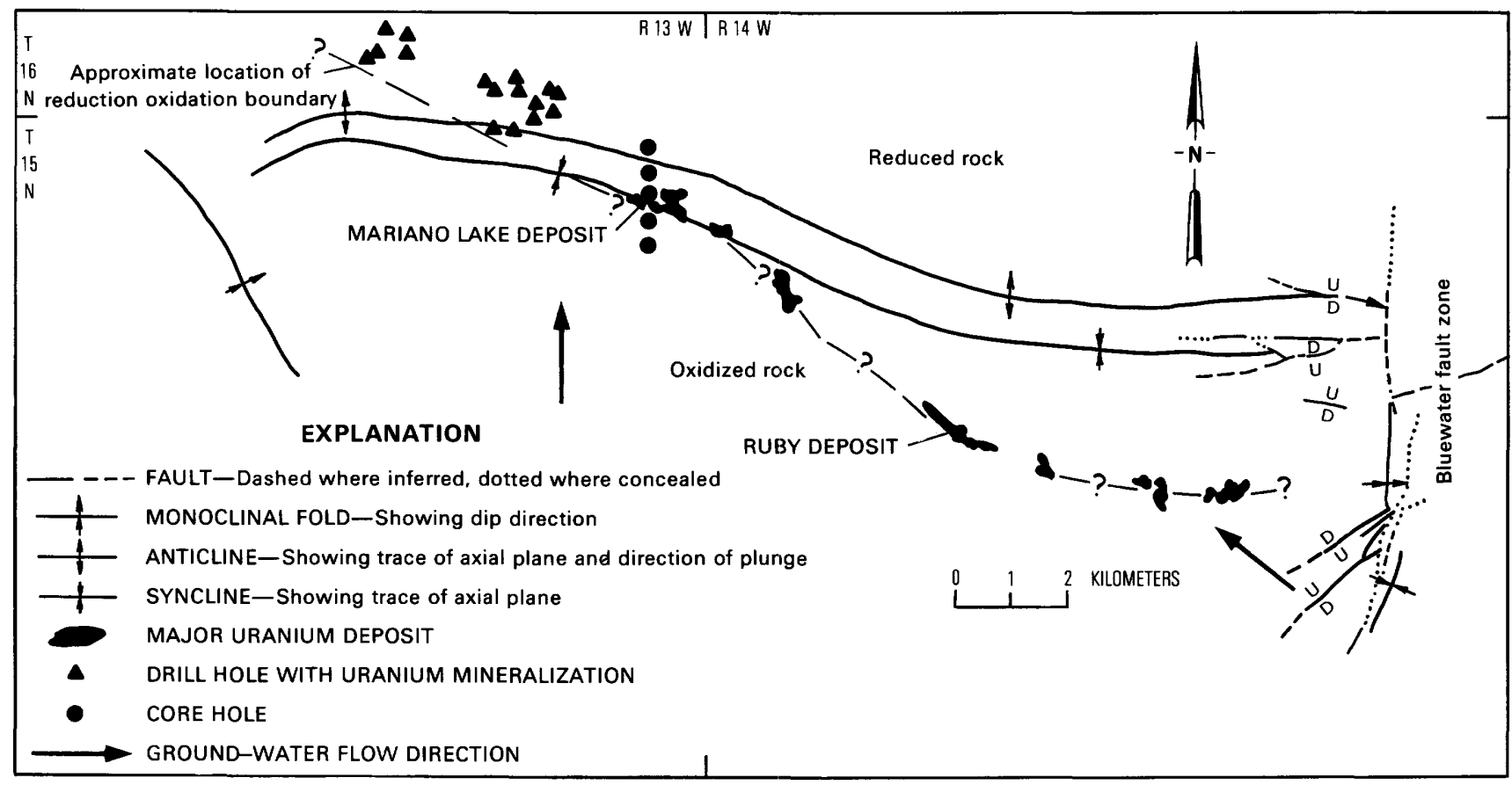

Figure 2. Plan map of part of the Smith Lake district (stippled area in figure 1), showing structural setting of Mariano Lake and Ruby orebodies (modified from Green and Jackson, 1975; Robertson and Jackson, 1975; J. F. Robertson, U.S. Geological Survey, Denver, Colo., written commun., 1981). The location of oxidized rock, reduced rock, and the approximate location of the reduction-oxidation (redox) boundary are also shown. 
was localized in the host rocks in undulatory layers that are generally subparallel to stratification and elongate parallel to sedimentary trends (see Granger and others, 1961; Fishman and others, 1985).

The original chemical structure and isotopic composition of the organic material has possibly been modified by radiation bombardment, oxidation, and aging. As a result, attempts to identify the exact source of the organic material are indeterminate (see Leventhal, 1980); however, recent studies suggest that the organic material was originally a humic substance (Hatcher and others, 1986) which was probably derived from the decomposition of vegetal matter (Schnitzer and Kahn, 1972; Hatcher and others, 1986). That the original organic material is more likely a humic substance than, perhaps, an oil-related substance is also suggested from laboratory experiments which indicate that modern humic substances concentrate uranium (Szalay, 1964), whereas oil and some oil-related substances apparently do not (Moore, 1954; Erickson and others, 1954; Hyden, 1961). The localizing mechanism for the organic species is poorly understood. Granger (1968) proposed that the organic material precipitated at the interface between solutions containing the soluble organic species and a cation-bearing ground water. In contrast, Fishman and Turner-Peterson (1986) proposed that the cations necessary to precipitate the organic material were "scavenged" from detrital grains, especially detrital magnetite and ilmenite.

\section{METHODS}

For this study, 129 samples (mineralized and unmineralized samples) were collected from 26 different sites at the Mariano Lake mine (fig. $3 A$ ) and 53 samples (mineralized and unmineralized) from 19 sites at the Ruby mine (fig. $3 B$ ). In addition, 100 samples of the ore-bearing sandstone were obtained from seven cores drilled by Gulf Mineral Resources Corporation. The trend of the core fence was approximately north-south; cores 3 and 4 penetrated mineralized ground. Cores 1 and 2 were drilled south of and cores 5-7 north of the Mariano Lake orebody.

After drying, part of each mine sample was used for chemical analyses which included uranium by a delayed neutron technique, vanadium by $\mathrm{X}$-ray fluorescence, and carbon and sulfur by induction furnace techniques. The complete geochemical data are summarized in Pierson and others (1983). In addition, a heavy-mineral separate of each sample was obtained by established procedures using high-density liquids. A representative portion of each heavy-mineral separate was then imbedded in epoxy, and the mount was polished for petrographic study using vertically reflected light under oil. Petrographic observations using both transmitted and vertically reflected light were also made on polished thin sections.
Clay minerals were identified by X-ray diffraction measurements of oriented mounts of the $<2-\mu \mathrm{m}$ size material. Clay minerals and other alterations were observed using a scanning electron microscope (SEM) equipped with an energy dispersive X-ray spectrometer (EDX) for determining elemental compositions. Additionally, X-ray "dot maps," used to determine the distribution of elements at selected sites on polished thin sections and grain mounts, were made with the SEM.

Fission-track images of the concentration and distribution of uranium in $\mathbf{1 0}$ thin sections were developed in muscovite mica overlays (Zielinski and Rosholt, 1978).

Sulfur-isotope compositions of iron disulfide minerals were determined by mass spectrometric measurements of samples prepared by methods outlined in Bailey and Smith (1972) on selected samples characterized by a single authigenic iron disulfide textural type or generation (see following discussion). The sulfur isotope compositions $\left(\delta^{34} \mathrm{~S}\right)$ of $\mathrm{FeS}_{2}$ minerals are expressed as the per-mil difference between the ratio of ${ }^{32} \mathrm{~S} /{ }^{34} \mathrm{~S}$ in the sample to that of a standard (Cañon Diablo troilite). The carbon-isotope compositions $\left(\delta^{13} \mathrm{C}\right)$ of authigenic calcite were determined by mass spectrometric measurements of $\mathrm{CO}_{2}$ released upon digestion of the sample in phosphoric acid. The carbon-isotope compositions $\left(\delta^{13} \mathrm{C}\right)$ are expressed as the per-mil difference between the ratio of ${ }^{13} \mathrm{C} /{ }^{12} \mathrm{C}$ in the sample to those of a standard (Belemnitella americana from the Cretaceous Pedee Formation, South Carolina).

\section{PARAGENETIC RELATIONS}

The sandstones that host the Mariano Lake and Ruby deposits have had a similar diagenetic history (fig. 4). It is convenient to divide the paragenetic sequence determined for the two sandstones into three groups: (1) alterations that preceded emplacement of the organic material (pre-ore), (2) alterations associated with emplacement of the organic material and associated uranium (ore), and (3) subsequent alterations (post-ore).

\section{Alterations preceding emplacement of organic material}

Paragenetic relations reveal that precipitation of pyrite was the first alteration in the sandstones. This early authigenic pyrite (pre-ore $\mathrm{FeS}_{2}$ ), identified both petrographically and with the SEM, commonly occurs as euhedral crystals (less than $10 \mu \mathrm{m}$ across) or aggregates of crystals perched on detrital grain surfaces or within small embayed areas on the grain surface (fig. 5). Framboidal pyrite is also present in both deposits, and some may have precipitated early in the alteration history of the host sandstones. An origin involving bacterial 

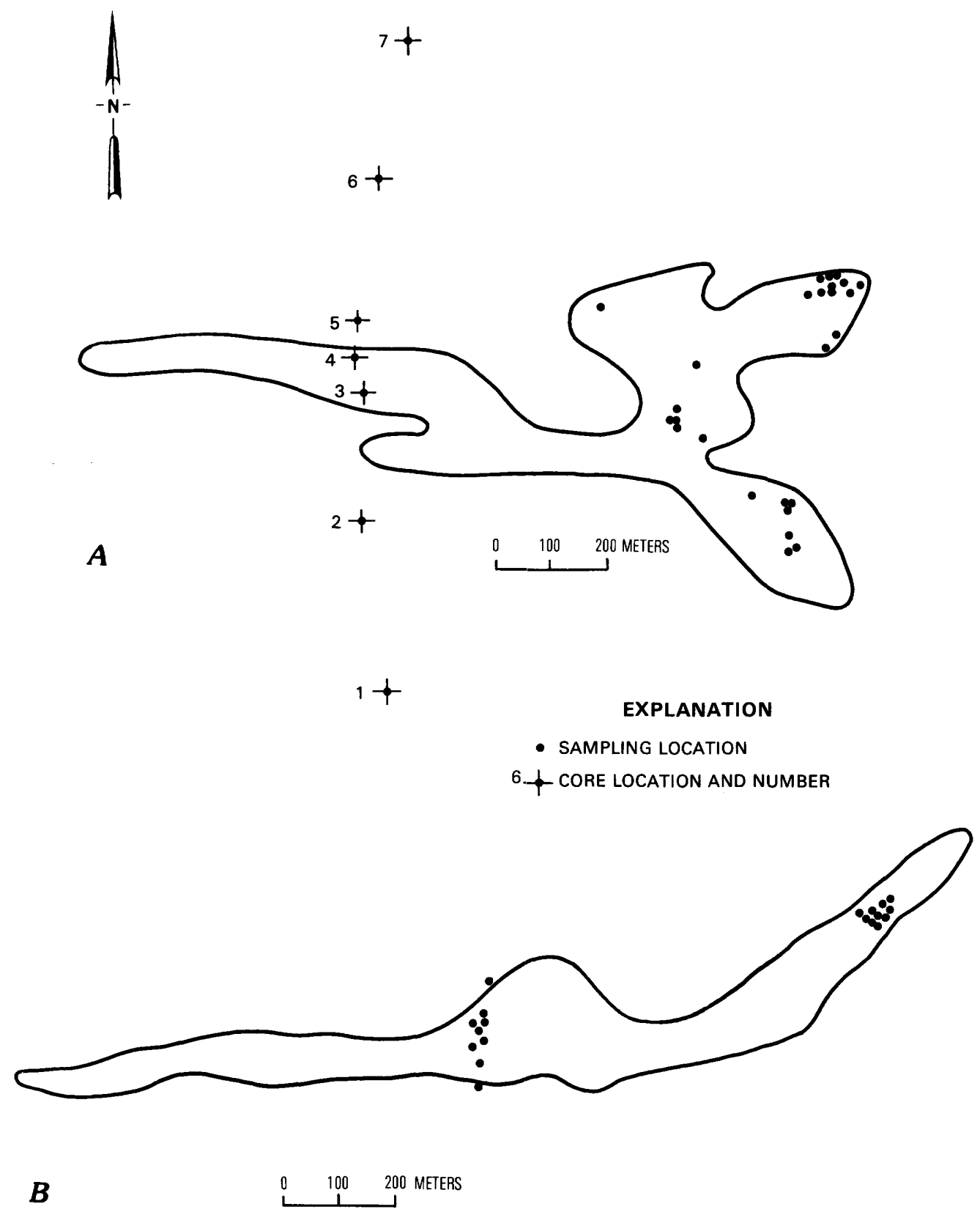

Figure 3. Map showing sampling and core locations at $A$, the Mariano Lake deposit (deposit outline modified from Sachdev, 1980), and B, sampling locations at Ruby deposit. Outlined area marks the extent of mine workings.

sulfate reduction is possible for framboidal pyrite (Berner, 1970); such bacterial control probably also resulted in isotope fractionation (Goldhaber and others, 1978) yielding the isotopically light sulfur which was incorporated into these pre-ore $\mathrm{FeS}_{2}$ minerals $\left(\delta^{34} \mathrm{~S}\right.$ values range from -11.0 to -38.4 per mil).

Authigenic clays, which coat some detrital grains and surround early pyrite, display an interlocking honeycomb network with minor crenulated surfaces when observed with an SEM (fig. 6). The texture and morphology of the early clays are similar to authigenic smectite-rich clays described by Wilson and Pittman (1977). X-ray diffraction analyses of host-sandstone samples revealed the presence of smectite-rich, mixed-layer illite/smectite clays containing 20-30 percent illite layers (as determined by the technique of Reynolds and Hower, 1970), which corroborates the clay identification made on the basis of morphology.

Dissolution of some detrital feldspars followed the precipitation of mixed-layer clays. The absence of mixedlayer clays in voids left by feldspar dissolution suggests that the clays formed prior to dissolution. Those feldspars displaying extensive dissolution features include plagioclase (fig. 7) and some potassium feldspars (fig. 8). Identification of the type of potassium feldspar that was dissolved was difficult due to extensive alteration of these 


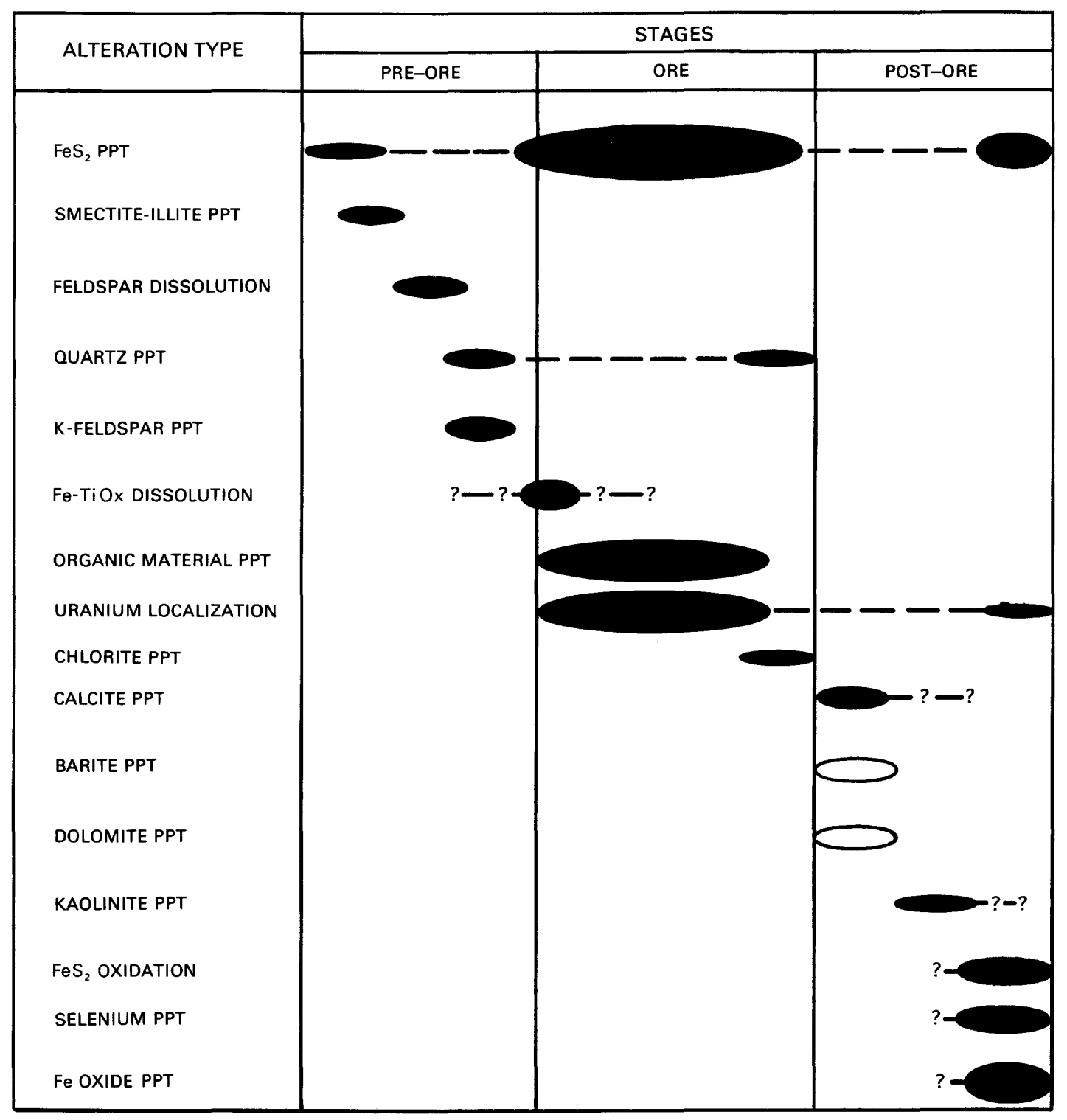

Figure 4. Summary of diagenetic alterations in sandstones that host the Mariano Lake and Ruby uranium deposits. Open ellipses indicate uncertain paragenetic relationships between barite and dolomite with respect to calcite. Ppt, precipitation.

grains; however, these grains were probably originally unstable under diagenetic conditions, and were possibly sanidine. Orthoclase and microcline generally show no evidence of dissolution. Potassium feldspar dissolution appears to have proceeded from the core of the grain outward, whereas plagioclase dissolution proceeded from the grain surface inward, in part controlled by cleavage and (or) twin planes.

Quartz and feldspar overgrowths also formed prior to emplacement of organic material. Electron microprobe analyses reveal the presence of $\mathrm{K}, \mathrm{Al}$, and $\mathrm{Si}$ in these authigenic feldspars. Void-filling authigenic feldspars are morphologically rhombic (observed in SEM studies), similar to the authigenic feldspars observed and identified by Sibley (1978) as adularia. The overgrowths observed in our studies occur on detrital orthoclase and microcline grains. Additionally, authigenic adularia(?) occurs in secondary voids in detrital feldspars (Fishman and Reynolds, 1982). Both authigenic quartz and adularia(?) enclose previously formed pyrite and are in turn coated by organic material (fig. 9).

\section{Organic material and associated alterations}

Noncellular organic material is extremely abundant in ore zones, commonly comprising more than 10 percent by volume (Fishman and Reynolds, 1982) of the host rock. Petrographic observations indicate that the organic material completely coats detrital grain surfaces, except along original intergranular contacts (fig. 10), and fills some primary and secondary voids. Because it is an abundant 


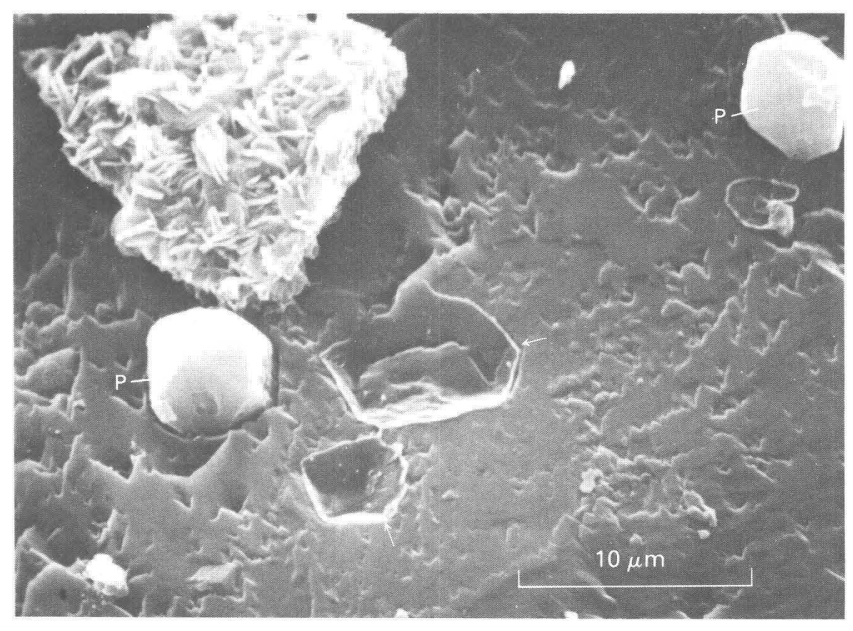

Figure 5. Scanning electron micrograph of early authigenic pyrite $(P)$ in small embayed areas on detrital quartz grain. Arrows mark positions of pyrite grains that were plucked during mount preparation. Material in upper left corner comprises later authigenic phases.

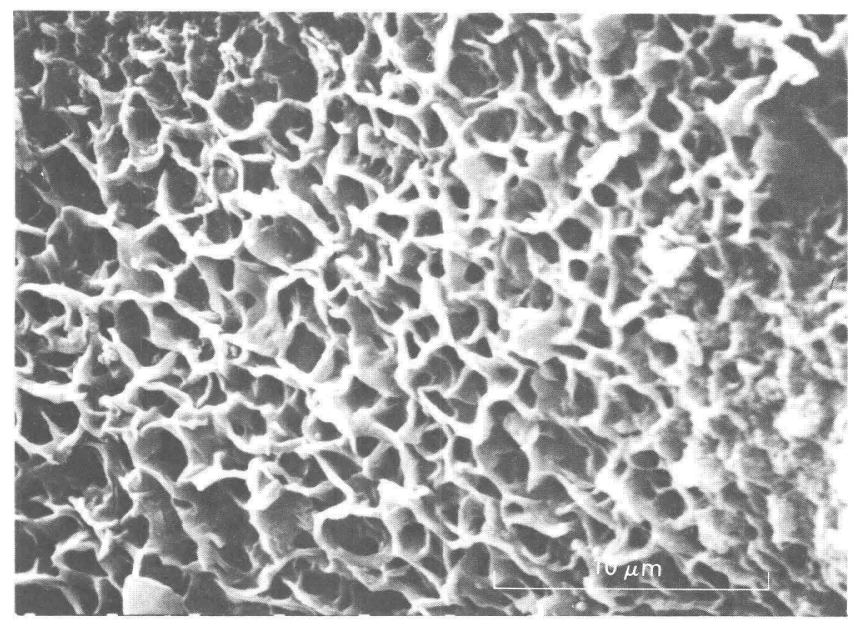

Figure 6. Scanning electron micrograph of authigenic, smectite-rich, mixed-layer smectite/illite clays.

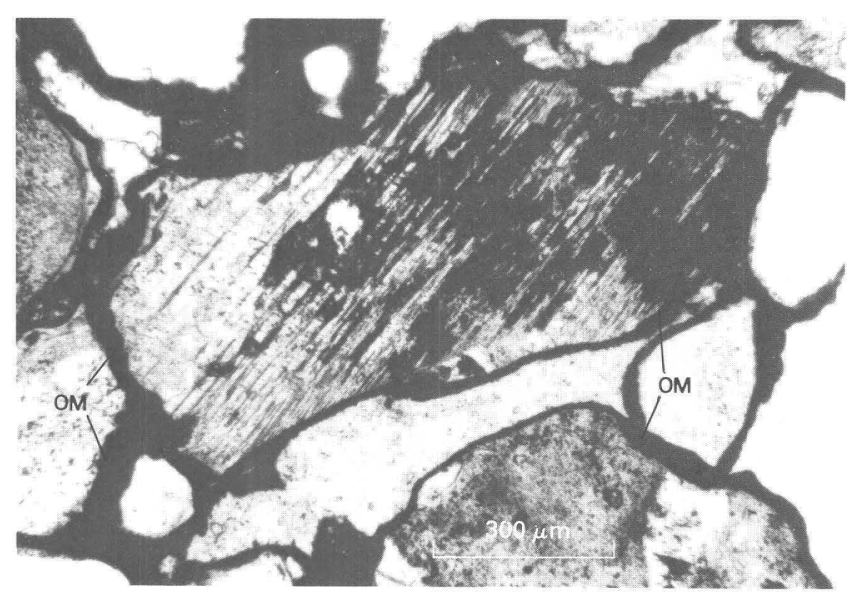

Figure 7. Photomicrograph of detrital plagioclase grain dissolved along crystallographic planes. Dissolved areas are filled with later introduced organic material $(\mathrm{OM})$ which also coats detrital grain surfaces.

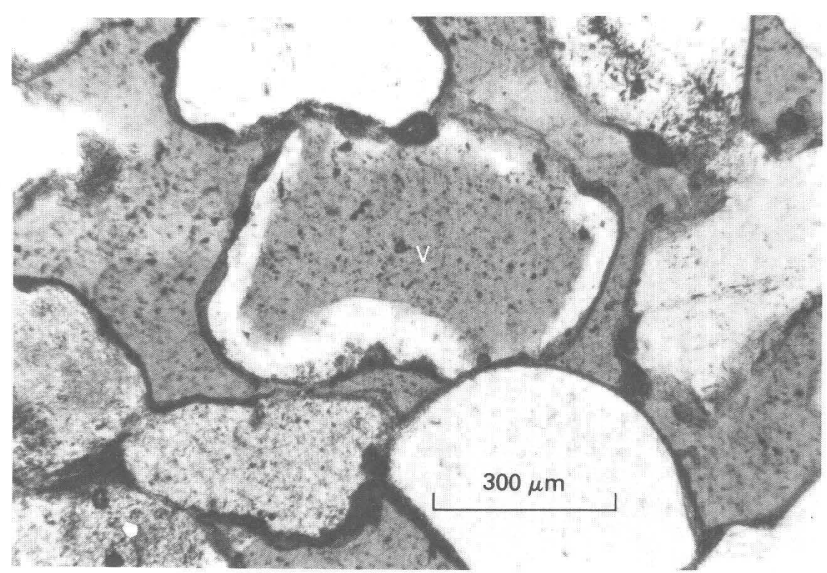

Figure 8. Photomicrograph of detrital potassium feldspar grain in which central core was dissolved resulting in secondary void (V).

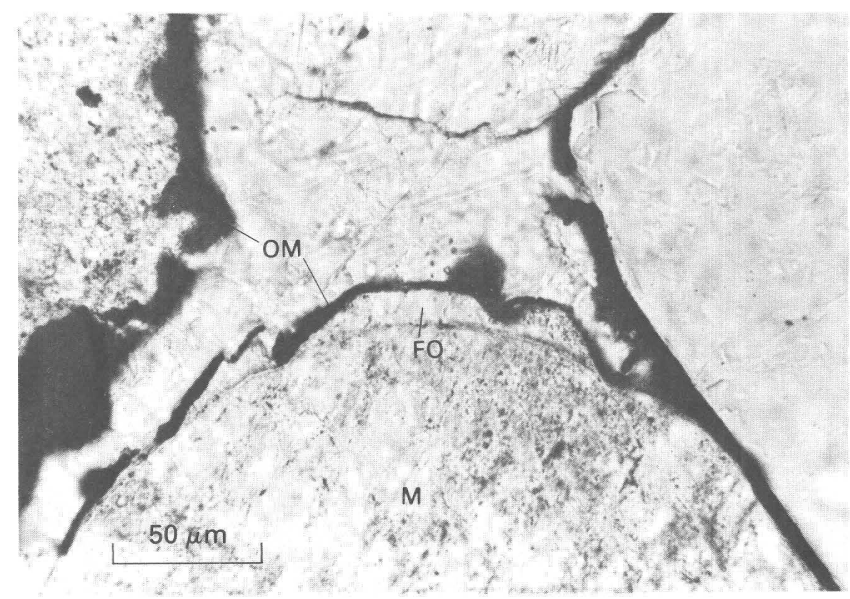

Figure 9. Photomicrograph of authigenic potassium feldspar (adularia(?)) overgrowth (FO) on detrital microcline (M) grain. Note organic material (OM) which coats overgrowth as well as detrital grain surfaces.

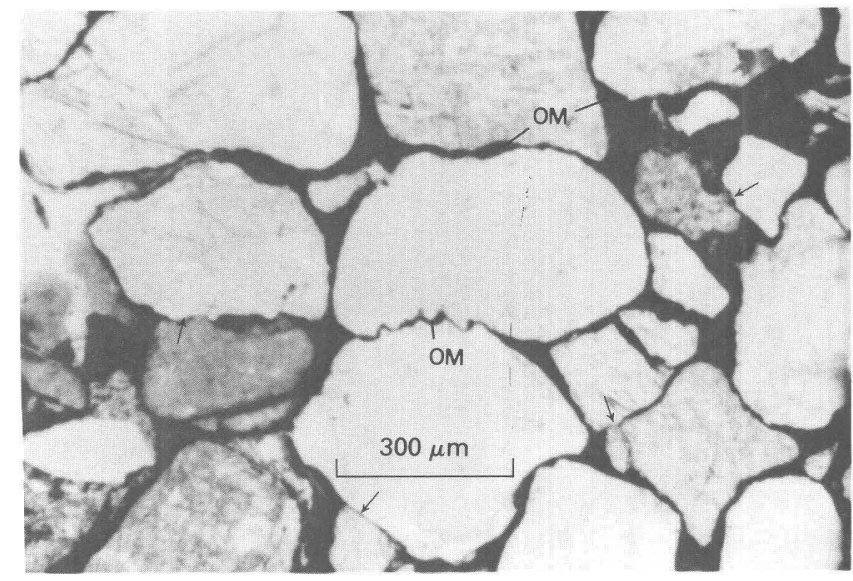

Figure 10. Photomicrograph of organic material $(O M)$ partly filling intergranular pores in host rock. Note presence of organic material along sutured grain contacts near center of photo. Original intergranular contacts are few (arrows) and noted by absence of organic material. 
authigenic constituent and commonly fills voids, the organic material has probably reduced the transmissivity of the host rock in ore zones. The presence of organic material between neighboring grains which display long, concave-convex, and sutured grain contacts-all of which are contacts that resulted from compaction of the host rocks - suggests that organic material was emplaced prior to major compaction.

When viewed under vertically reflected light in oil, the organic material ranges in color from light gray-brown to very dark brown and commonly displays various reflectivities. SEM-EDX dot maps indicate that variations in $\mathrm{Al}, \mathrm{Si}$, and $\mathrm{V}$ contents correspond to organic material with lower reflectivities (fig. 11). Fission-track maps (fig. 12) and SEM-EDX dot maps (fig. 11) reveal that uranium is rather homogeneously distributed throughout the organic material that coats grains and fills some voids and thereby is not responsible for different organic-material reflectivities. Nearly all the uranium in both deposits is in the noncellular organic material; some such uranium is in the uranium silicate coffinite, which was identified in the claysize fraction (less than $2 \mu \mathrm{m}$ ) by X-ray diffraction. Uranium occurrences other than as coffinite or uranoorganic associations are minor.

Abundant pyrite and marcasite (ore-stage $\mathrm{FeS}_{2}$ minerals) are intimately mixed with uraniferous organic material (fig. 13), suggesting coprecipitation. Framboidal pyrite also occurs within organic material. The isotopic composition of ore-stage $\mathrm{FeS}_{2}$ is light (-29.4 to -41.6 per mil; fig. 14) and suggests an origin related to bacterial sulfate reduction (Goldhaber and others, 1978). SEMEDX and electron microprobe analyses reveal that $\mathrm{FeS}_{2}$ minerals associated with the organic material commonly contain selenium. Textural relationships between the $\mathrm{FeS}_{2}$ minerals and the organic material suggest that $\mathrm{FeS}_{2}$ minerals continued to precipitate after emplacement of the organic material.

Semiquantitative X-ray diffraction analyses reveal that chlorite is enriched in zones containing noncellular organic material. The chlorite, as observed with the SEM (fig. 15), occurs as platelets or rosettes, commonly intergrown with microcrystalline quartz, coating organic material. SEM-EDX analyses also indicate that the chlorite of ore zones ubiquitously contains vanadium. In addition, SEM-EDX analyses reveal that uranium is also commonly associated with the chlorite. Morphologically similar chlorite occurs in unmineralized rock of the host sandstone, but it is subordinate to other clay minerals (P. B. Blackmon, U.S. Geological Survey, Denver, Colo., written commun., 1980) and contains no detectable vanadium or uranium.

In ore zones and in the host rock adjacent to ore zones, detrital iron-titanium (Fe-Ti) oxide grains (principally magnetite, titanomagnetite, and ilmenite) have been extensively altered; iron has been preferentially removed, leaving remnant Fe-Ti-oxide or Ti-oxide. The residual Ti-oxide typically mimics the crystallographically controlled positions of ilmenite (fig. 16) in a parent titanomagnetite grain (Ramdohr, 1980). Iron-titanium oxide grain alteration undoubtedly resulted from postdepositional processes because the observed delicate morphologies of dissolved grains are unlikely to have survived sediment transport and deposition. The altered Fe-Ti-oxide grains closely resemble those described by Adams and others (1974) who suggested that destruction of detrital Fe-Ti-oxide grains resulted from solutions containing dissolved organic species. Similar solutions are probably responsible for the destruction of detrital Fe-Ti-oxide grains in the sandstones that host the Mariano Lake and Ruby deposits. Organic material in some partly dissolved Fe-Ti-oxide grains indicates that at least some, and possibly most dissolution preceded the emplacement of organic material.

\section{Alterations following emplacement of organic material}

Alterations following emplacement of organic material include the precipitation of calcite, barite, dolomite, kaolinite, $\mathrm{FeS}_{2}$ minerals, native selenium, uranium minerals, and ferric oxides (goethite(?)). Most of these alterations have been noted in volumetrically minor amounts in both deposits with one notable exception. Calcite is common at the Ruby locality where it occurs in and around ore zones, whereas calcite is rare at the Mariano Lake locality and is confined to ore zones. Calcite commonly fills remaining primary and secondary voids, and single calcite crystals commonly envelop several detrital grains. The carbon-isotope composition of the calcite from both deposits ranges from -7.5 to -12.8 per mil (fig. 17).

Minor amounts of dolomite and barite are present. Dolomite was observed only at the Mariano Lake deposit, whereas barite was noted at both deposits. Dolomite occurs as small rhombs filling some post-ore voids, whereas barite occurs as large masses enveloping detrital grains.

Kaolinite is present in ore zones and in the surrounding rock at both localities. The kaolinite fills some interstitial voids and replaces calcite (fig. 18) and other authigenic minerals in ore zones.

The remaining alterations which followed the emplacement of organic material have been noted chiefly along the southern edges of the deposits and in scattered localities throughout the deposits. Such alterations were likely in response to the encroachment of oxygenated ground waters from the south and southeast (see fig. 2). $\mathrm{FeS}_{2}$ minerals have been altered to ferric oxides and hydroxides. Native selenium, identified petrographically and by X-ray diffraction, and observed with the SEM, occurs as a separate phase (fig. 19) intergrown with a third 

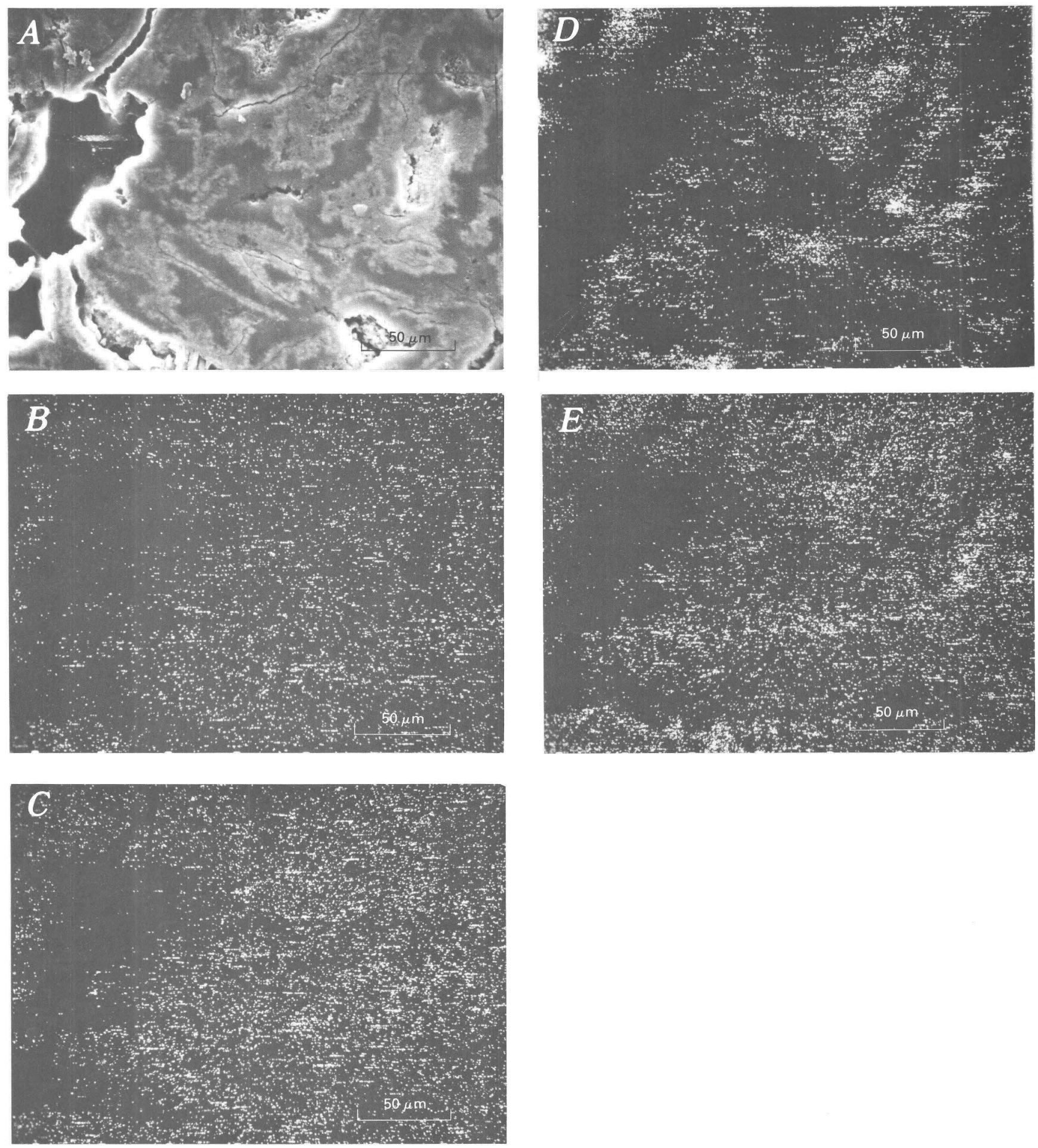

Figure 11. Scanning electron micrographs of $A$, multireflective organic material; and SEM-EDX and dot maps showing the distribution of $B$, uranium in the same organic material; $C$, vanadium; $D$, silicon; and $E$, aluminum.

generation of $\mathrm{FeS}_{2}$ minerals or intergrown with uranium minerals which precipitated late in the alteration process. Microcrystalline iron oxides (goethite(?)) coat chlorite, kaolinite, and native selenium (fig. 20) in ore zones and in oxidized rock.

\section{DISCUSSION}

Organic material was emplaced in the host sandstones of the Mariano Lake and Ruby deposits early in the paragenetic sequence of diagenetic alterations but 


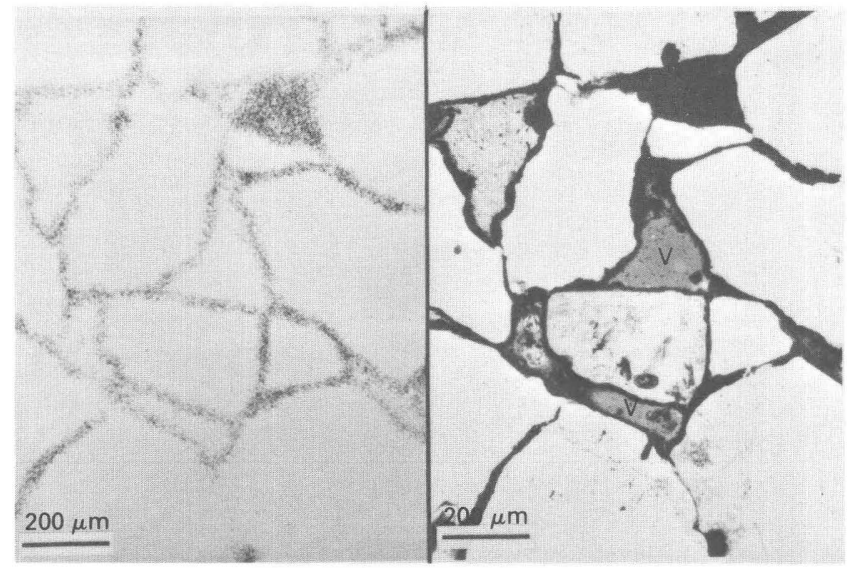

Figure 12. Photomicrograph (right side) of organic material coating grains and filling some intergranular pores and corresponding fission-track map (left side). Note that uranium (which produced the "tracks") is evenly distributed throughout with the organic material. Remaining voids (V) are noted.

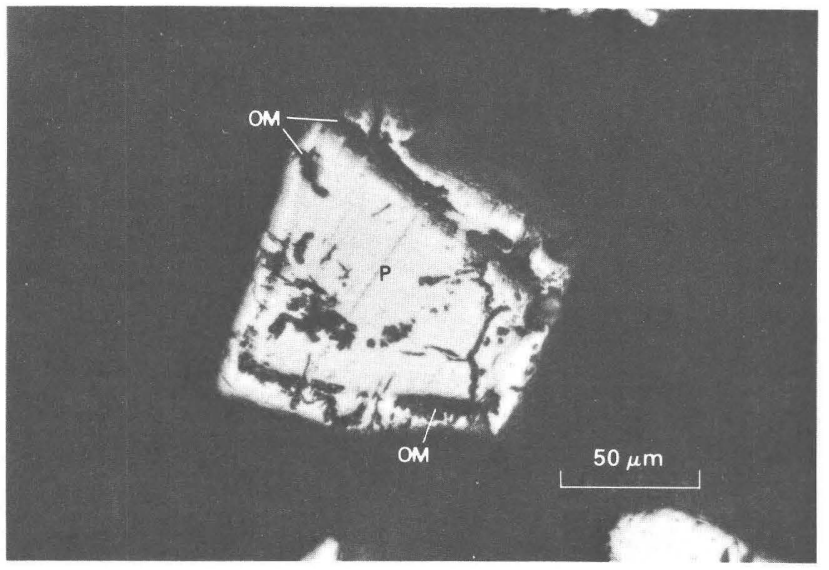

Figure 13. Photomicrograph of organic material (OM) intimately mixed with grain of euhedral pyrite $(P)$.

followed the precipitation of volumetrically minor preore pyrite, mixed-layer clays, and quartz and feldspar overgrowths and the selective dissolution of detrital feldspars and iron-titanium oxide grains. The introduction of organic material, however, preceded major burial compaction of the host sandstone; an early introduction of organic material is consistent with the 100 m.y. minimum ages determined for the Mariano Lake and Ruby ores by uranium-lead isotope methods (Ludwig and others, 1984). This conclusion is also consistent with evidence from other orebodies in the Grants uranium region indicating that lenses of organic material were truncated by pre-Dakota erosion (Nash and Kerr, 1966) and that the emplacement of organic material was partly controlled by pre-Dakota folds (Moench and Schlee, 1967).

The intimate spatial association of uranium with organic material indicates that the organic material played

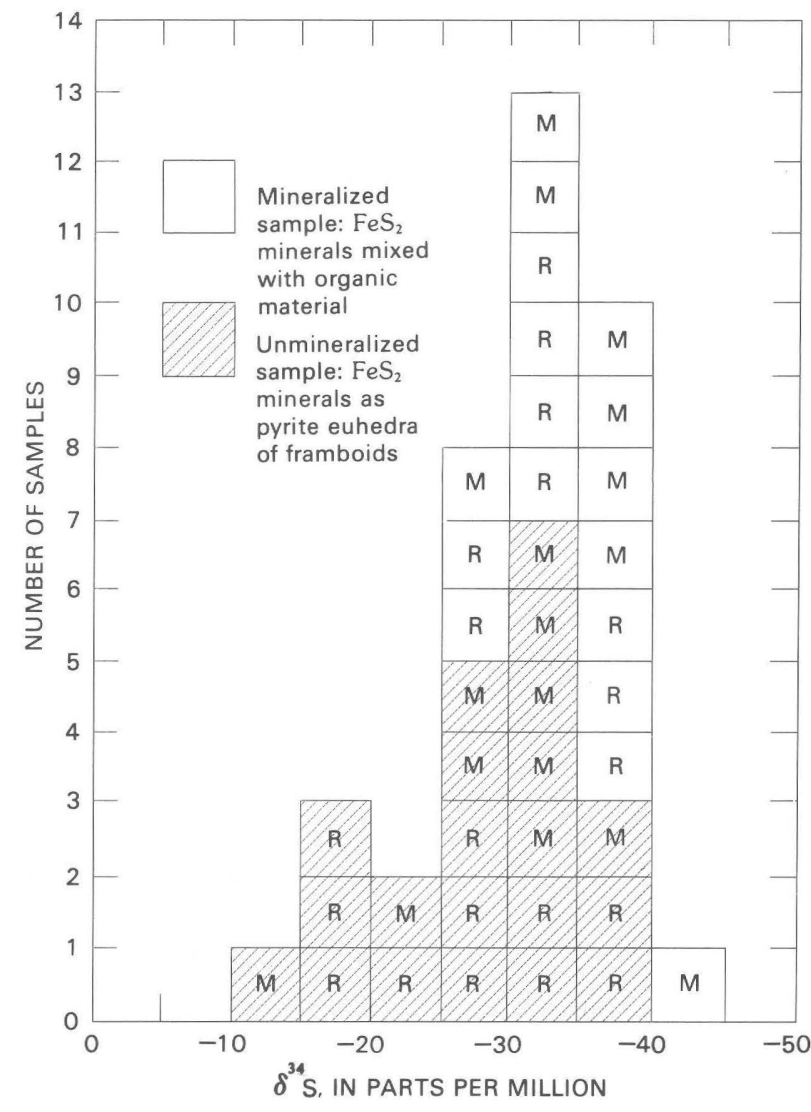

Figure 14. Histogram of sulfur isotope values of $\mathrm{FeS}_{2}$ minerals from Mariano Lake (M) and Ruby (R) deposits.

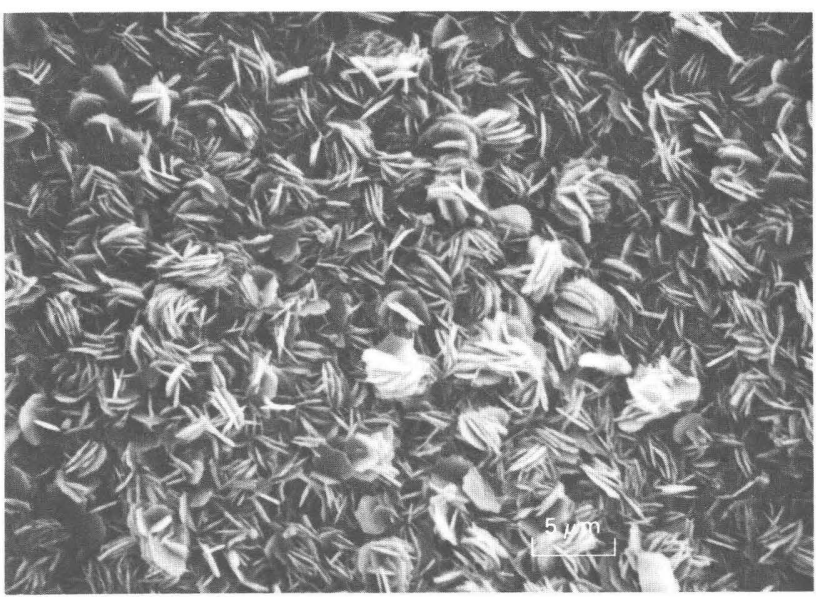

Figure 15. Scanning electron micrograph of authigenic vanadiferous chlorite.

a crucial role in localizing and concentrating uranium at the Mariano Lake and Ruby localities. The occurrence of uraniferous organic material completely enclosed by $\mathrm{FeS}_{2}$ minerals (fig. 13) suggests a simultaneous precipitation. The enrichment of uranium in the organic material after the formation of the enclosing $\mathrm{FeS}_{2}$ mineral is difficult to envision. 


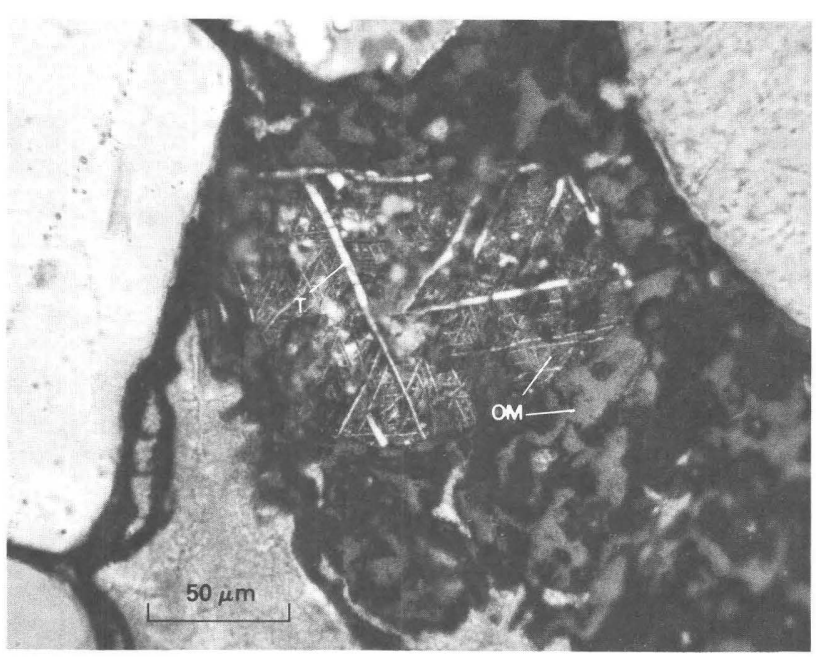

Figure 16. Photomicrograph of dissolved iron-titanium oxide, with titanium oxide remnants $(T)$. Organic material $(O M)$ partly fills grain and fills interstices.

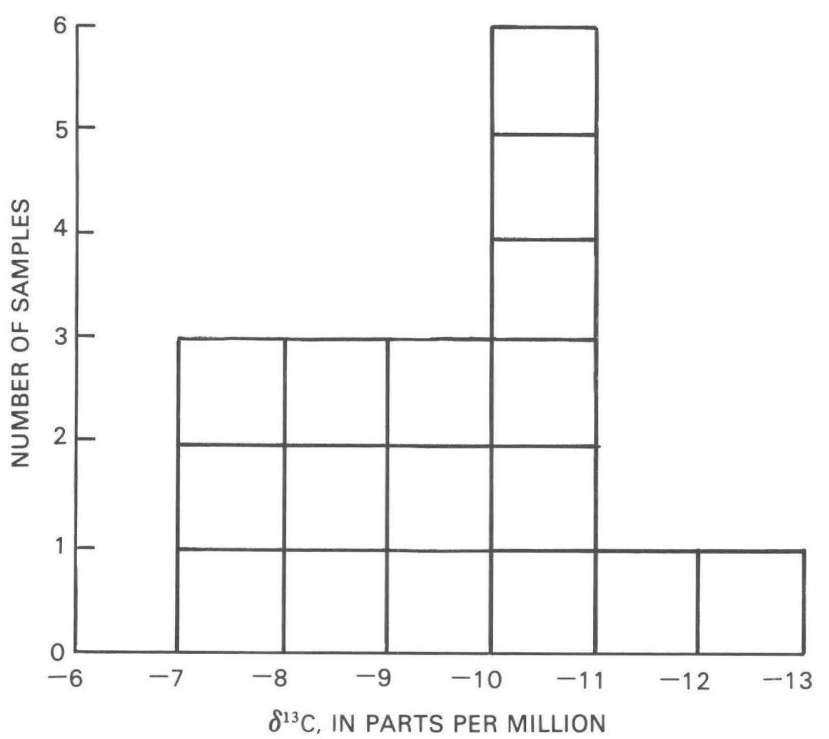

Figure 17. Histogram of carbon-isotope values of authigenic calcite from Mariano Lake and Ruby deposits.

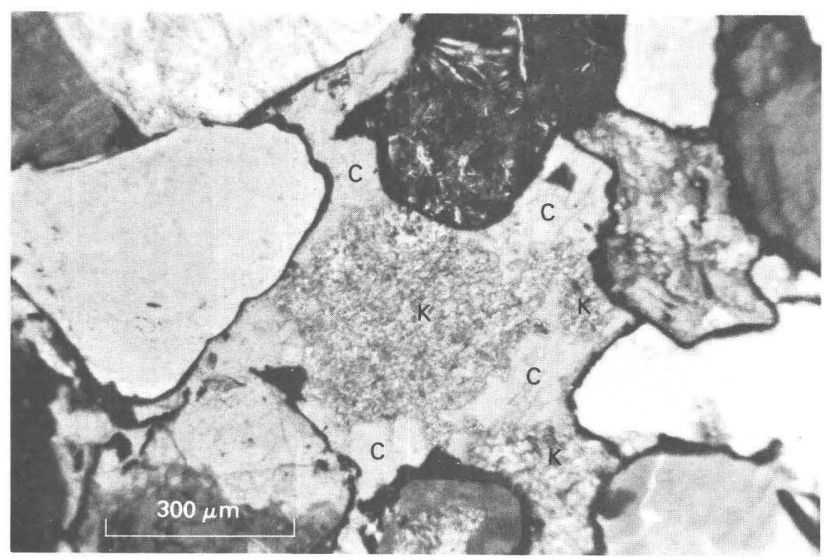

Figure 18. Photomicrograph of kaolinite (K) replacement of calcite (C).

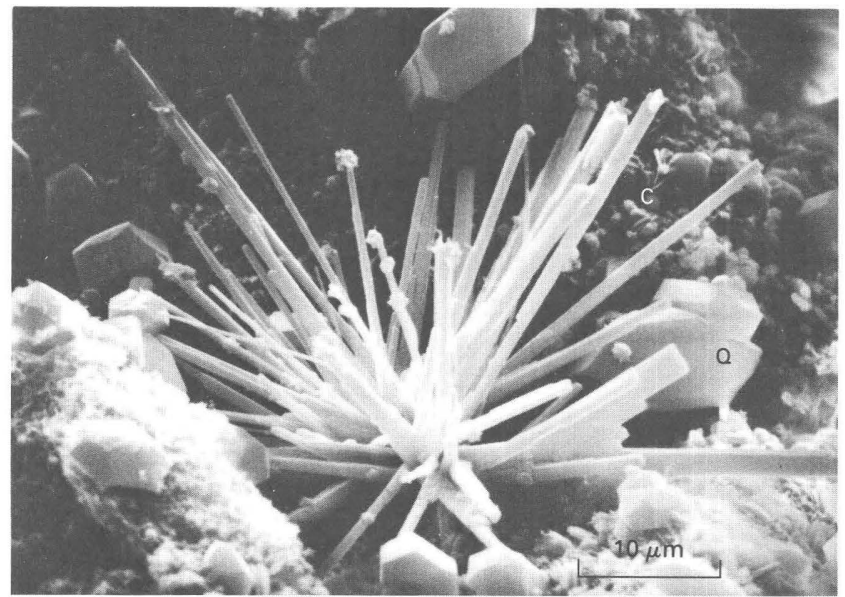

Figure 19. Scanning electon micrograph of authigenic native selenium (bladed material), superimposed on previously precipitated Q, quartz and C, chlorite.

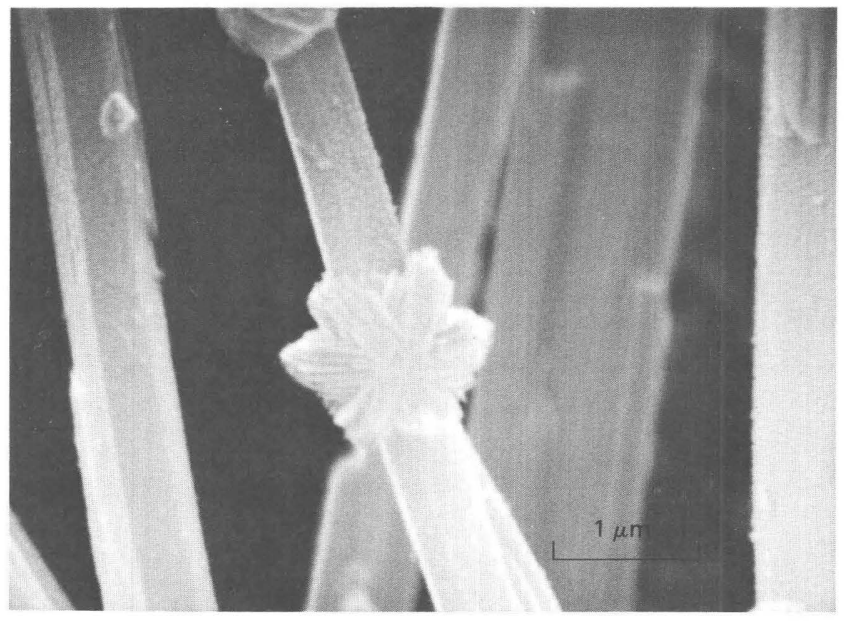

Figure 20. Scanning electon micrograph of iron mineral (based on SEM-EDX analyses), possibly authigenic goethite, in part coating native selenium (expanded view of part of fig. 19).

The enrichment of chlorite in ore zones of the Ruby and Mariano Lake deposits is a distinctive feature commonly noted in other primary deposits in the Grants uranium region (Granger, 1962; Brookins, 1975). Also, chlorite enrichment is spatially and temporally related to uranium mineralization at other localities within the Morrison Formation in Utah (Northrup and others, 1981).

Chlorite in the uranium mineralized zones of the Mariano Lake and Ruby localities and in other uranium deposits in the Morrison sandstones is commonly vanadiferous (Foster, 1959; Brookins, 1975; Northrup and others, 1981). The vanadium probably resides in the "brucite" interlayer of the chlorite crystal structure (Northrop and others, 1981). In contrast, the large size of uranium or uranyl ions relative to that of the cation sites within the chlorite crystal structure probably precludes the presence of uranium in the chlorite (C. G. Whitney, U.S. Geological Survey, Denver, Colo., oral commun., 1982). 
The association of uranium with chlorite in the ore zones of the Mariano Lake and Ruby localities may possibly be due to adsorption of uranium or uranium-rich organic material on the chlorite or possibly to the presence of submicroscopic uranium minerals intergrown with the chlorite. The enrichment of chlorite in ore zones and the anomalously high vanadium content of such chlorite suggests that chlorite precipitation may be spatially and temporally related to uranium mineralization.

The encroachment of oxygenated ground waters from the south during late Tertiary time (Saucier, 1980) may account for many of the post-mineralization alterations in both deposits. Oxidative destruction of $\mathrm{FeS}_{2}$ minerals resulted in the replacement of $\mathrm{FeS}_{2}$ minerals by ferric oxides and hydroxides and also in the liberation of $\mathrm{S}, \mathrm{Fe}$, and Se. The redistribution of these elements led to the reprecipitation of $\mathrm{FeS}_{2}$ minerals and native selenium. The oxidizing ground waters were probably also responsible for the redistribution of minor amounts of uranium and iron as uranium minerals and ferric oxides late in the paragenetic alteration sequence.

The formation of calcite at both localities clearly postdated emplacement of the organic material and may be genetically related to the Tertiary oxidation event. The light carbon-isotope composition of the calcite suggests that the carbonate carbon was partly derived from the oxidation of organic material (see Hoefs, 1973; Leventhal, 1980). Calcite formation at the Ruby locality was more extensive than at the Mariano Lake locality and may be related to more severe oxidation of some of the original Ruby ore zone.

Whatever its origin, the calcite may have been important in preserving the Ruby deposit by greatly lowering the transmissivity of the ore-bearing sandstone, thereby partly blocking passage of oxidizing ground waters. The minor amount of calcite at the Mariano Lake deposit suggests different conditions for the preservation of that orebody. Stagnation of ground waters or deflection of ground-water flow patterns in the synclinal trough may have retarded or diverted the ingress of potentially destructive oxidizing ground waters.

\section{REFERENCES CITED}

Adams, S. S., Curtis, H. S., and Hafen, P. L., 1974, Alteration of detrital magnetite-ilmenite in continental sandstones of the Morrison Formation, New Mexico, in Formation of uranium deposits: Vienna, International Atomic Energy Agency, p. 219-253.

Adams, S. S., Curtis, H. S., Hafen, P. L., and Salek-Nejad, H., 1978, Interpretation of postdepositional processes related to the formation and destruction of the Jackpile-Paguate uranium deposit, northwest New Mexico: Economic Geology, v. 73, p. 1635-1654.

Bailey, S. A., and Smith, J. W., 1972, Improved method for the preparation of sulfur dioxide from barium sulfate for isotope ratio studies: Analytical Chemistry, v. 44, p. 1542-1543.
Bell, T. E., 1986, Depositional and diagenetic trends in the Brushy Basin and upper Westwater Canyon Members of the Morrison Formation, northwest New Mexico, in TurnerPeterson, C. E., Santos, E. S., and Fishman, N. S., eds., A basin analysis case study-The Morrison Formation, Grants uranium region, New Mexico: American Association of Petroleum Geologists Studies in Geology 22, p. 77-92.

Berner, R. A., 1970, Sedimentary pyrite formation: American Journal of Science, v. 268, p. 1-23.

Brookins, D. G., 1975, Uranium in deposits of the Grants, New Mexico mineral belt: Grand Junction, Colorado, U.S. Energy Research and Development Administration OpenFile Report GJBX-16 (76), 153 p.

Chenoweth, W. L., and Holen, H. K., 1980, Exploration in Grants uranium region since 1963, in Rautman, C. A., compiler, Geology and mineral technology of the Grants uranium region 1979: New Mexico Bureau of Mines and Mineral Resources Memoir 38, p. 17-21.

Craig, L. C., Holmes, C. N., Cadigan, R. A., Freeman, V. L., Mullens, T. E., and Weir, G. W., 1955, Stratigraphy of the Morrison and related Formations, Colorado Plateau region-A preliminary report: U.S. Geological Survey Bulletin 1009-E, p. 125-168.

Erickson, R. L., Myers, A. T., and Horr, C. A., 1954, Association of uranium and other metals with crude oil, asphalt, and petroliferous rock: American Association of Petroleum Geologists Bulletin, v. 38, no. 10, p. 2200-2218.

Fishman, N. S., and Reynolds, R. L., 1982, Origin of the Mariano Lake uranium deposit, McKinley County, New Mexico: U.S. Geological Survey Open-File Report 82-888, $52 \mathrm{p}$.

Fishman, N. S., and Reynolds, R. L., 1983, Geochemical characteristics of the Church Rock 1 and 1 East uranium deposits, Grants uranium region, New Mexico: U.S. Geological Survey Open-File Report 83-194, 36 p.

Fishman, N. S., Reynolds, R. L., and Robertson, J. F., 1985, Uranium mineralization in the Smith Lake district of Grants uranium region, New Mexico: Economic Geology, v. 80, p. $1348-1364$.

Fishman, N. S., and Turner-Peterson, C. E., 1986, Cation scavenging-An alternative to a brine for humic acid precipitation in tabular uranium ore, in Dean, W. A., ed., Proceedings of the Denver Region Exploration Geologists Society Symposium, Organics and ore deposits, Denver, Colorado, 1985, p. 197-204.

Foster, M. D., 1959, Chemical study of mineralized clays: U.S. Geological Survey Professional Paper 320, p. 121-132.

Goldhaber, M. B., Reynolds, R. L., and Rye, R. O., 1978, Origin of a south Texas roll-type uranium deposit. II. Sulfide petrology and sulfur isotope studies: Economic Geology, v. 73 , p. $1690-1705$.

Granger, H. C., 1962, Clays in the Morrison Formation and their spatial relationship to the uranium deposits at Ambrosia Lake, New Mexico: U.S. Geological Survey Professional Paper 450-D, p. D15-D20.

1968, Localization and control of uranium deposits in the southern San Juan basin mineral belt, New MexicoAn hypothesis: U.S. Geological Survey Professional Paper 600-B, p. B60-B70.

Granger, H. C., Santos, E. S., Dean, B. G. and Moore, F. B., 1961, Sandstone-type uranium deposits at Ambrosia Lake, New Mexico-An interim report: Economic Geology, v. 56, p. $1179-1210$. 
Green, M. W., and Jackson, T. J., 1975, Geologic map of the Mariano Lake quadrangle, McKinley County, New Mexico: U.S. Geological Survey Open-File Report 75-261, 5 p.

Hatcher, P. G., Spiker, E. C., Orem, W. H., Romankiw, L. A., Szeverenyi, N. M., and Maciel, G. E., 1986, Organic geochemical studies of uranium-associated organic matter from the San Juan basin-A new approach using solid-state ${ }^{13} \mathrm{C}$ nuclear magnetic resonance, in Turner-Peterson, C. E., Santos, E. S., and Fishman, N. S., eds., A basin analysis case study-The Morrison Formation, Grants uranium region, New Mexico: American Association of Petroleum Geologists Studies in Geology 22, p. 171-184.

Hoefs, J., 1973, Stable isotope geochemistry: New York, SpringerVerlag, $143 \mathrm{p}$.

Hyden, H. J., 1961, Uranium and other metals in crude oil, Part B: U.S. Geological Survey Bulletin 1100, p. 17-97.

Leventhal, J. S., 1980, Organic geochemistry and uranium in the Grants mineral belt, in Rautman, C. A., compiler, Geology and mineral technology of the Grants uranium region 1979: New Mexico Bureau of Mines and Mineral Resources Memoir 38, p. 75-84.

Ludwig, K. R., Rubin, Bruce, Fishman, N. S., and Reynolds, R. L., 1982, U-Pb ages of uranium ores in the Church Rock uranium district, New Mexico: Economic Geology, v. 77, no. 6, p. 1942-1945.

Ludwig, K. R., Simmons, K. R., and Webster, J. D., 1984, U-Pb isotope systematics and apparent ages of uranium ores, Ambrosia Lake and Smith Lake districts, Grants mineral belt, New Mexico: Economic Geology, v. 79, p. 322-337.

Moench, R. H., and Schlee, J. S., 1967, Geology and uranium deposits of the Laguna district, New Mexico: U.S. Geological Survey Professional Paper 519, 117 p.

Moore, G. W., 1954, Extraction of uranium from aqueous solution by coal and some other materials: Economic Geology, v. 49 , p. $652-658$.

Nash, J. T., and Kerr, P. F., 1966, Geologic limitations on the age of uranium deposits in the Jackpile sandstone, New Mexico: Economic Geology, v. 61, p. 1283-1287.

Northrup, H. R., Whitney, C. G., and Goldhaber, M. B., 1981, Clay mineralogy of uranium deposits, Henry Mountains, Utah: Program with abstracts, 30th Annual Clay Minerals Conference, Urbana, Illinois, p. 15.

Pierson, C. T., Spirakis, C. S., and Robertson, J. F., 1983, Comparison of abundances of chemical elements in mineralized and unmineralized sandstone of the Brushy Basin Member of the Morrison Formation, Smith Lake district, Grants uranium region, New Mexico: U.S. Geological Survey OpenFile Report 83-818, 45 p.

Place, J. T., Della Valle, R. S., and Brookins, D. G., 1980, Mineralogy and geochemistry of Mariano Lake uranium deposit, Smith Lake district, in Rautman, C. A., compiler, Geology and mineral technology of the Grants uranium region 1979: New Mexico Bureau of Mines and Mineral Resources Memoir 38, p. 172-184.

Ramdohr, P., 1980, The ore minerals and their intergrowths; volume 2: New York, Pergamon Press, $1205 \mathrm{p}$.

Reynolds, R. C., and Hower, John, 1970, The nature of interlayering in mixed-layered illite/montomorillonite: Clays and Clay Minerals, v. 18 , p. $26-36$.

Ristorcelli, S. J., 1980, Geology of eastern Smith Lake ore trend, Grants mineral belt, in Rautman, C. A., compiler, Geology and mineral technology of the Grants uranium region 1979: New Mexico Bureau of Mines and Mineral Resources Memoir 38, p. 145-152.
Robertson, J. F., and Jackson, T. J., 1975, Geologic and structural contour maps of the Hosta Butte quadrangle, McKinley County, New Mexico: U.S. Geological Survey OpenFile Report 75-302, 6 p.

Sachdev, S. C., 1980, Mineralogical variation across Mariano Lake roll-type uranium deposit, McKinley County, New Mexico, in Rautman, C. A., compiler, Geology and mineral technology of the Grants uranium region 1979: New Mexico Bureau of Mines and Mineral Resources Memoir 38, p. 162-171.

Saucier, A. E., 1980, Tertiary oxidation in Westwater Canyon Member of Morrison Formation, in Rautman, C. A., compiler, Geology and mineral technology of the Grants uranium region 1979: New Mexico Bureau of Mines and Mineral Resources Memoir 38, p. 116-121.

Schnitzer, M. A., and Kahn, S. U., 1972, Humic substances and the environment: New York, Marcel Dekker, 327 p.

Sibley, D. F., 1978, K-feldspar cement in the Jacobsville Sandstone: Journal of Sedimentary Petrology, v. 48, no. 3, p. 983-986.

Squyres, J. B., 1980, Origin and significance of organic matter in uranium deposits of Morrison Formation, San Juan basin, New Mexico, in Rautman, C. A., compiler, Geology and mineral technology of the Grants uranium region, 1979: New Mexico Bureau of Mines and Mineral Resources Memoir 38, p. 86-97.

Szalay, A., 1964, Cation exchange properties of humic acids and their importance in the geochemical enrichment of $\mathrm{UO}_{2}{ }^{2+}$ and other cations: Geochimica et Cosmochimica Acta, v. 28 , p. $1605-1614$.

Turner-Peterson, C. E., 1985, Lacustrine-humate model for primary uranium ore deposits, Grants uranium region, New Mexico: American Association of Petroleum Geologists Bulletin, v. 69, no. 11, p. 1999-2020.

1986, Fluvial sedimentology of a major uranium-bearing sandstone-A study of the Westwater Canyon Member of the Morrison Formation, San Juan basin, New Mexico, in Turner-Peterson, C. E., Santos, E. S., and Fishman, N. S., eds., A basin analysis case study-The Morrison Formation, Grants uranium region, New Mexico: American Association of Petroleum Geologists Studies in Geology 22, p. 47-76.

Turner-Peterson, C. E., and Fishman, N. S., 1986, Geologic synthesis and genetic models for uranium mineralization in the Morrison Formation, Grants uranium region, New Mexico, in Turner-Peterson, C. E., Santos, E. S., and Fishman, N. S., eds., A basin analysis case study-The Morrison Formation, Grants uranium region, New Mexico: American Association of Petroleum Geologists Studies in Geology 22, p. 357-388.

Turner-Peterson, C. E., Gundersen, L. C., Francis, D. S., and Aubrey, W. M., 1980, Fluvio-lacustrine sequences in the Upper Jurassic Morrison Formation and the relationship of facies to tabular uranium ore deposits in the Poison Canyon area, Grants mineral belt, New Mexico, in Turner-Peterson, C. E., ed., Uranium in sedimentary rocks-Application of the facies concept to exploration: Rocky Mountain Section of Economic Paleontologists and Mineralogists, p. 177-211.

Wilson, M. D., and Pittman, E. D., 1977, Authigenic clays in sandstones; Recognition and influence on reservoir properties and paleoenvironmental analysis: Journal of Sedimentary Petrology, v. 47, p. 3-31.

Zielinski, R. A., and Rosholt, J. N., 1978, Uranium in waters and aquifer rocks at the Nevada Test Site, Nye County, Nevada: U.S. Geological Survey Journal of Research, v. 6, no. 4, p. 489-498. 



\title{
Diagenesis and Uranium Mineralization in the Westwater Canyon Member of the Morrison Formation, Grants Uranium Region, Northwestern New Mexico
}

\author{
By PAULA L. HANSLEY, U.S. Geological Survey, Box 25046, \\ Denver Federal Center, MS 916, Denver, Colorado 80225
}

\section{CONTENTS}

\author{
Abstract 267 \\ Introduction 267 \\ Geologic setting 267 \\ Materials and methods 267 \\ Description of major diagenetic phases and alterations 268 \\ Epigenetic organic matter 269 \\ Uranium ore $\mathbf{2 7 0}$ \\ Sulfides $\mathbf{2 7 0}$ \\ Clay minerals 270 \\ Chlorite 271 \\ Feldspars 272 \\ Silica minerals 273 \\ Carbonates 274 \\ Sulfates 274 \\ Iron oxides 274 \\ Etched grains 274 \\ Paragenesis and geochemistry of diagenetic alterations 275 \\ Conclusions 278 \\ References cited 278
}

\section{FIGURES}

1. Regional map showing locations of cored drill holes and major uranium deposits in the Grants uranium region, New Mexico $\mathbf{2 6 8}$

2. Cross section of cored holes showing stratigraphic positions of uranium mineralization 269

3. Photomicrograph of a sandstone impregnated with epigenetic carbonaceous uranium ore $\mathbf{2 7 0}$

4. Photomicrograph of altered iron-titanium oxide grain filled with epigenetic carbonaceous uranium ore $\mathbf{2 7 0}$

5. Scanning electron micrograph of botryoidal coffinite and coffinite crystals 271

6. Scanning electron micrograph of authigenic "honeycomb" illite/smectite and adularia 271

7-9. Photomicrographs showing:

7. Kaolinite replacement of authigenic barite within detrital plagioclase grain 271

8. Kaolinite surrounding remnant primary uranium ore $\mathbf{2 7 1}$

9. Chlorite rim on partly dissolved detrital plagioclase feldspar grain 272 
10. Scanning electron micrograph showing the relation between chlorite and illite/smectite $\mathbf{2 7 2}$

11-14. Photomicrographs showing:

11. Detrital potassium feldspar grain with thin albite rim superseded by potassium feldspar overgrowth $\mathbf{2 7 2}$

12. Potassium feldspar overgrowth that supersedes chlorite rim $\mathbf{2 7 3}$

13. Stages in the dissolution of a detrital plagioclase grain and formation of a "hollow" potassium feldspar grain 273

14. Detrital twinned plagioclase grain replaced marginally by potassium feldspar 274

15. Scanning electron micrograph of uranium ore that embays a euhedral quartz overgrowth $\mathbf{2 7 4}$

16. Photomicrograph showing two generations of authigenic silica as overgrowths on a detrital quartz grain 274

TABLE

1. Paragenesis of major authigenic phases and diagenetic alterations in the Westwater Canyon Member of the Morrison Formation near Crownpoint, New Mexico 275 


\section{Abstract}

Petrologic studies of core from the Grants uranium region of the southwestern San Juan basin have revealed that the uranium-bearing Westwater Canyon Member of the Morrison Formation (Upper Jurassic) has had a more complex diagenetic history than has previously been documented. Petrographic data suggest that most uranium enrichment occurred after precipitation of epigenetic organic matter and before significant compaction.

Authigenic phases characteristic of ore zones include epigenetic uranium-bearing, carbonaceous matrix (primary ore), euhedral pyrite, and rosette chlorite. Alterations in the stratigraphic interval containing uranium ore, but not necessarily restricted to mineralized strata, include leached iron-titanium oxides, skeletalized plagioclase feldspars, and authigenic titanium dioxide, quartz, potassium feldspar, albite, ordered mixed-layer illite/smectite (I/S), edge-to-face chlorite, kaolinite, ferroan and nonferroan carbonates, and sulfates. Below the mineralized interval, postdepositional alterations are less complex: sulfate, carbonate, and smectite are the most common interstitial materials. Above the mineralized interval, smectite is the dominant authigenic phase.

Most diagenetic alterations occurred during primary mineralization in Late Jurassic to Early Cretaceous time and during widespread leaching of framework grains and authigenic cements in the Tertiary Period. Sandstones in the Westwater Canyon Member are characterized by multiple generations of authigenic minerals, many of which form distinct alteration patterns throughout cores taken from a line of drillholes that transect the Grants uranium region. Alteration patterns suggest that mineralizing solutions originated in part from compaction of fine-grained units in the overlying Brushy Basin Member. In the deeper cores, chemically etched heavy minerals and I/S form a distinct alteration zone that may be the result of reactions caused by the incursion of a warm fluid from deeper in the basin. Chlorite-dominated alteration zones in barren sandstone units in the Westwater Canyon Member that are stratigraphically equivalent to ore-bearing units may possibly represent sites of previous accumulations of primary (carbonaceous) uranium ore.

\section{INTRODUCTION}

Inasmuch as uranium in the Morrison Formation (Upper Jurassic) is present in large part as a result of diagenetic processes, interpretation of the postdepositional history of this formation is crucial to understanding the genesis of sedimentary uranium deposits in the Grants uranium region, New Mexico. To study diagenesis in the Morrison, core was collected from seven drill holes that were positioned in a line perpendicular to the southeastwardly trend of uranium deposits in the Grants uranium region and parallel to the northeastwardly direction of the dip of the Morrison Formation (fig. 1). Some holes were located on trend with known orebodies, and others were positioned where no mineralization was thought to be present. In this way, comparisons could be made between diagenetic alterations in mineralized strata and those in unmineralized strata; previous studies have focused almost entirely on uranium-bearing rocks (Adams and Saucier, 1981). The present paper summarizes the results of new petrologic studies of the cores; the reader is referred to Hansley (1986b) for a description of regional alteration patterns and a discussion of models for uranium mineralization in the Morrison Formation.

\section{GEOLOGIC SETTING}

In the study area, interbedded massive sandstone and thin mudstone units of the Westwater Canyon Member of the Morrison Formation are underlain by less massive sandstone units of the Recapture Member and overlain by the predominantly fine-grained, tuffaceous Brushy Basin Member. Sediments of the Recapture and Westwater Canyon Members were deposited by meandering and braided streams that flowed in a northeast to southeast direction in the San Juan basin in Late Jurassic time (Turner-Peterson, 1986). The overlying Brushy Basin Member is composed of fine-grained, tuffaceous lacustrine units (Bell, 1983, 1986) that interfinger locally with the upper part of the Westwater Canyon Member. The Morrison is underlain by the Middle Jurassic Wanakah Formation (Condon and Peterson, 1986) and is separated from the overlying Upper Cretaceous Dakota Sandstone by a regional unconformity.

Because the uranium ore (more than $200 \mathrm{ppm}$ uranium) found in the cores was entirely in the Westwater Canyon Member (fig. 2), this unit became the focus of the present study. Sandstones in the Westwater Canyon are chiefly subangular to subrounded, medium- to coarsegrained, moderately to well-sorted lithic arkoses and subarkoses with poor to excellent porosity (Steele, 1984).

\section{MATERIALS AND METHODS}

Paragenetic relations were established with a petrographic microscope by examining polished sections and thin sections impregnated with blue epoxy and stained with sodium cobaltinitrate for potassium feldspar identification. Selected samples were studied using a Cambridge 250 Mark 2 scanning electron microscope (SEM) equipped with an energy-dispersive X-ray unit (EDX) and an ARL electron microprobe equipped with wavelengthdispersive and energy-dispersive X-ray attachments ${ }^{1}$. Aluminum-coated polished thin sections were examined with the electron microprobe to verify the presence of carbon. Identification of ferroan carbonates was made using the staining techniques outlined by Dickson (1965)

\footnotetext{
${ }^{1}$ Use of trade and company names is for descriptive purposes and does not imply endorsement by the U.S. Geological Survey.
} 


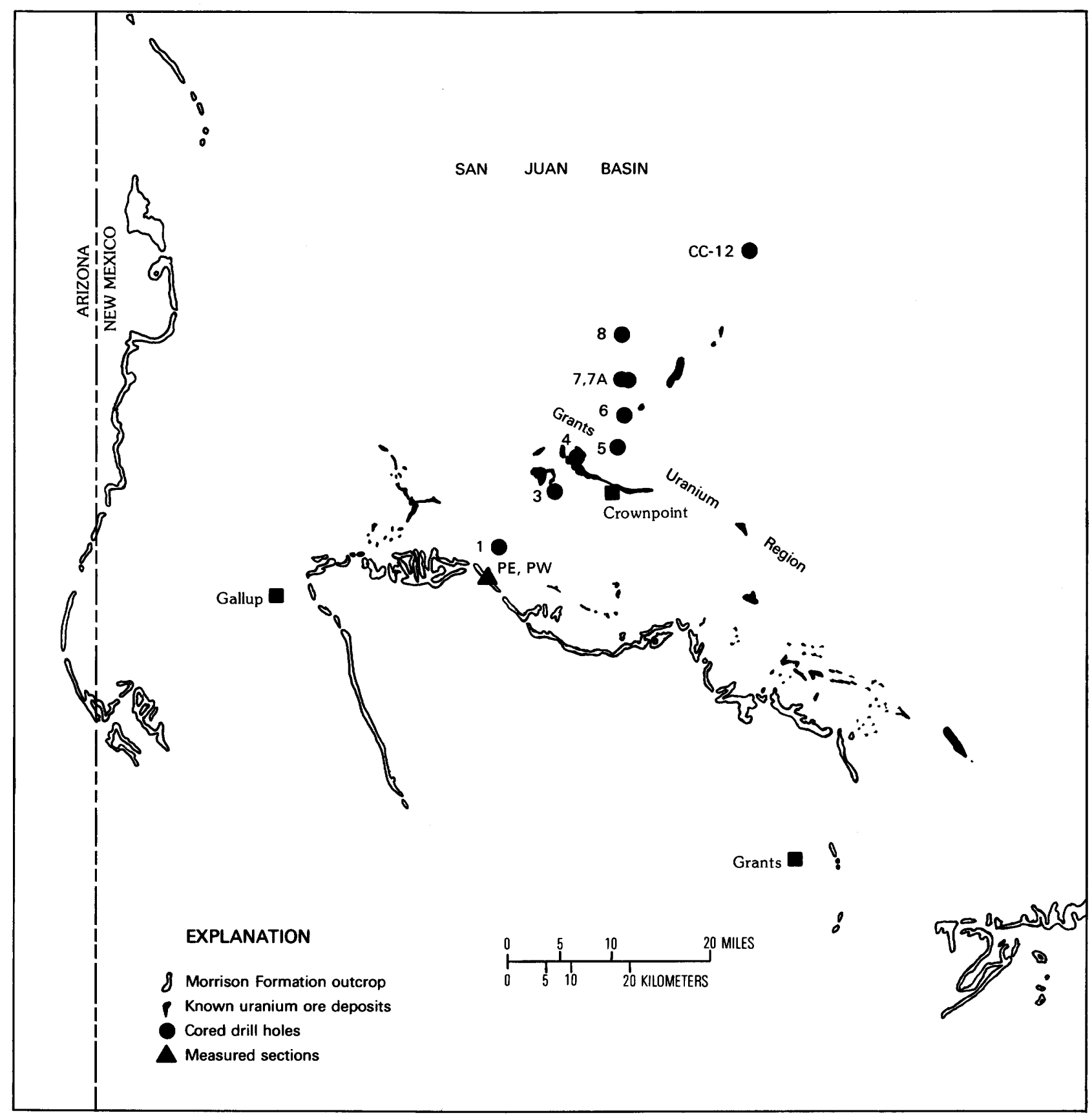

Figure 1. Locations of cored drill holes and major uranium deposits in the Grants uranium region, northwestern New Mexico.

and Hutchison (1974). Clay minerals were identified by X-ray diffraction with a Picker diffractometer using the $<1-\mu \mathrm{m}$ fraction of each sample (Whitney, 1986), and the authigenic nature of the clay minerals was verified by SEM examination of selected samples.

\section{DESCRIPTION OF MAJOR DIAGENETIC PHASES AND ALTERATIONS}

The complexity and diversity of diagenetic alterations are more pronounced in the Westwater Canyon than in the overlying Brushy Basin and underlying Recapture Members, both of which have had relatively simple postdepositional histories. The Brushy Basin contains few sandstone units; these units are characterized by a smectite matrix cemented by minor calcite and silica. The Recapture sandstone units contain nonferroan calcite, anhydrite, and smectite. The major diagenetic alterations in upper fine- to medium-grained sandstones of the Westwater Canyon Member are described in this section, and interpretations relating to the paragenesis of authigenic phases and to the geochemistry of diagenetic fluids are presented in the following section. 


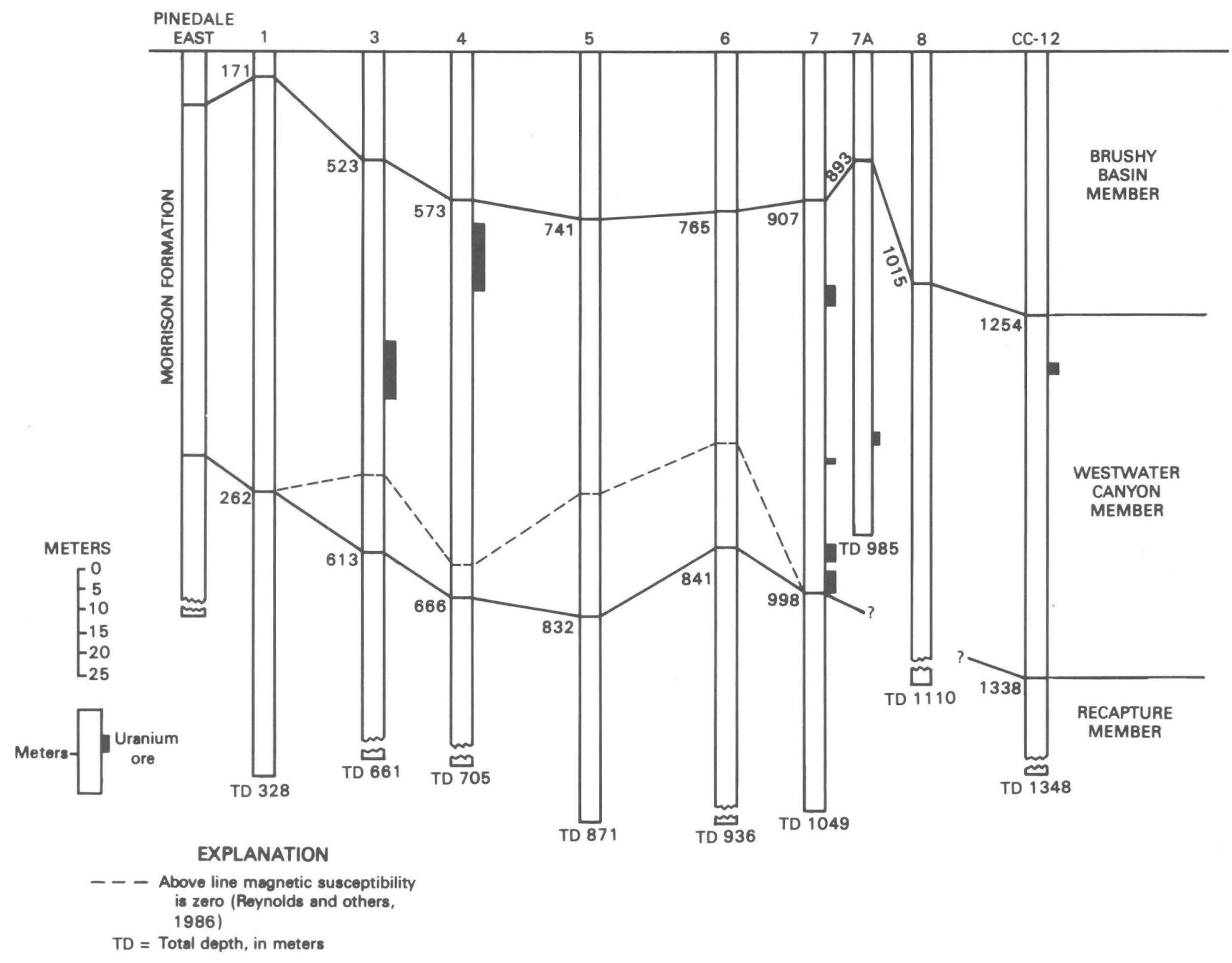

Figure 2. Cross section of cored holes (see fig. 1) showing stratigraphic positions of uranium mineralization.

\section{Epigenetic organic matter}

Most epigenetic organic matter in the Westwater Canyon Member has been mineralized with uranium. The organic matter forms grain coatings, fills primary pores, and lacks observable cellular structure. The origin of the organic matter has been an enigma. Due to radiation damage, the structure of the organic matter cannot be determined by conventional pyrolysis techniques (Leventhal, 1980). Recent nuclear magnetic resonance data, however, suggest that the organic material was derived from degraded plant material or humate (Hatcher and others, 1986). The humate may have been intrinsic to the Westwater Canyon Member, which contains abundant detrital (cellular) plant material from which humic acids may have been derived. On the other hand, fluids carrying organic acids may have migrated into Westwater Canyon sandstones from adjacent organic-rich mudstone facies of the Brushy Basin Member during compaction (Turner-Peterson and others, 1980; Fishman and others, 1984). In either case, the humate was dissolved by moderately high-pH fluids derived from the early alteration of abundant volcanic ash in the upper part of the Morrison Formation. Subsequently, these humic acid-bearing solutions migrated through the sandstones and deposited the humate as matrix in the sandstones.

In sandstones impregnated with uraniferous, carbonaceous matrix, floating framework grains and tangential grain contacts are common (fig. 3), and most irontitanium oxide grains have been totally replaced by humate (fig. 4). In strata where iron-titanium oxides have been leached of iron and replaced by organic matter, magnetic susceptibility approaches zero (Reynolds and others, 1986) (fig. 2). Authigenic euhedral pyrite and titanium dioxides are associated with these altered grains. 


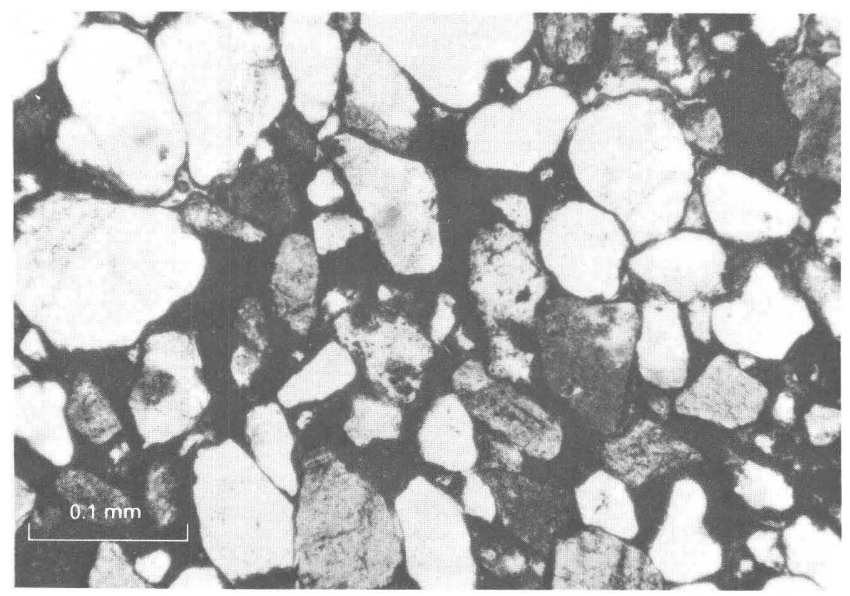

Figure 3. Photomicrograph of sandstone impregnated with epigenetic carbonaceous uranium ore.

\section{Uranium ore}

Two basic types of uranium ore have been recognized in the Grants uranium region: primary ore and redistributed ore. For the most part, primary ore is composed of a mixture of uranium and epigenetic humate that occurs as grain coatings and fills primary pores in the fluvial sandstones (Granger and others, 1961; Fishman and Reynolds, 1986). Primary orebodies are usually tabular, blanketlike deposits that may be suspended in the host sandstone without apparent relation to structure or bedding. Commonly, no discrete uranium minerals can be detected in the primary ore, leading to the conclusion that uranium resides in urano-organic complexes. Radiogenic ages $(\mathrm{U} / \mathrm{Pb})$ indicate that primary uranium mineralization occurred about 130 to 110 m.y. ago or during Late Jurassic to Early Cretaceous time (Ludwig and others, 1984). Redistributed (secondary) ore formed by the destruction of primary orebodies, that is, by the oxidation of organic material and subsequent redistribution of the uranium as secondary deposits. In general, the distance from primary to redistributed deposits is only a few hundred meters. Most redistribution took place during the late Tertiary as a direct result of Late Cretaceousearly Tertiary (Laramide) uplift, when oxidizing fluids migrated from exposed outcrops along the southern margin of the basin downdip through Morrison sandstones (Saucier, 1980).

In the present study, uranium was noted as a mixture of primary (carbonaceous) and redistributed or secondary (carbon-poor) ore (Hansley, 1986b). Uranium in most primary ore appears to be present as formless (even under the SEM), noncrystalline material, and elemental X-ray fluorescence (dot) maps of the ore revealed that uranium is concentrated on the margins of carbonaceous material (Hansley, 1986b). Scanning electron microscopy of some primary ore zones, however, showed

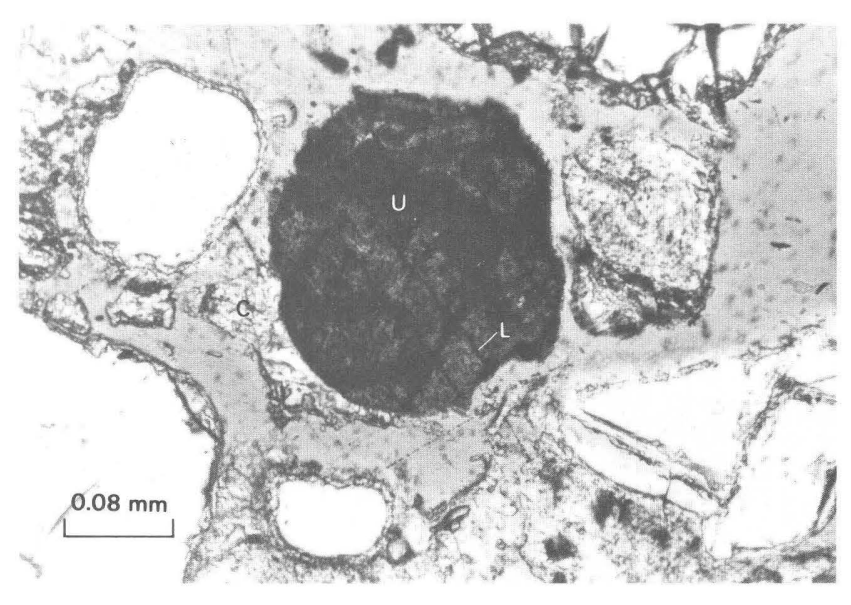

Figure 4. Photomicrograph of altered iron-titanium oxide grain filled with epigenetic carbonaceous uranium ore (U). Relict ilmenite lamellae (L) are now titanium dioxide. Post-ore calcite cement (C) is at lower left of grain. Sample 3-1866; ore zone; transmitted and reflected light.

that uranium is contained in microbotryoidal material, which was found to be a mixture of cryptocrystalline coffinite $(<1 \mu \mathrm{m}$ in size) and carbonaceous matrix (fig. 5). $\mathrm{X}$-ray diffraction patterns of this material contain weak coffinite peaks, and electron microprobe analyses showed that carbon was present. X-ray fluorescence (dot) maps revealed that uranium is coextensive with silicon rather than carbon. This carbon is presumed to be organic carbon because of a lack of calcium or other cations in the $\mathrm{X}$-ray fluorescence spectrum.

Secondary uranium ore contains less organic matter and more coffinite than does primary ore. In cores 7 and $7 \mathrm{a}$, groups of tetragonal coffinite crystals are intergrown with and apparently embay primary ore, and in core 4, micrometer-size, cigar-shaped coffinite crystals protrude from a carbonaceous, uranium-bearing substrate (Hansley, 1986b).

\section{Sulfides}

Pyrite is the most common sulfide in these sandstones, although minor marcasite and sphalerite are present. Anhedral pyrite in the upper part and locally in the lowermost sandstones of the Westwater Canyon Member totally cements millimeter-size areas of framework grains, which contain no observable diagenetic alterations. The most abundant morphological variety of pyrite, however, is found almost exclusively in ore-bearing intervals. Here, it occurs as euhedral grains that are commonly intergrown with primary uranium ore. Euhedral pyrite also occurs on top of corroded barite cement and as framboids on rosette chlorite.

\section{Clay minerals}

Both smectite and ordered, interstratified illite/smectite $(\mathrm{I} / \mathrm{S})$ occur as detrital grain coatings that display a characteristic honeycomb texture under the SEM (fig. 6). 


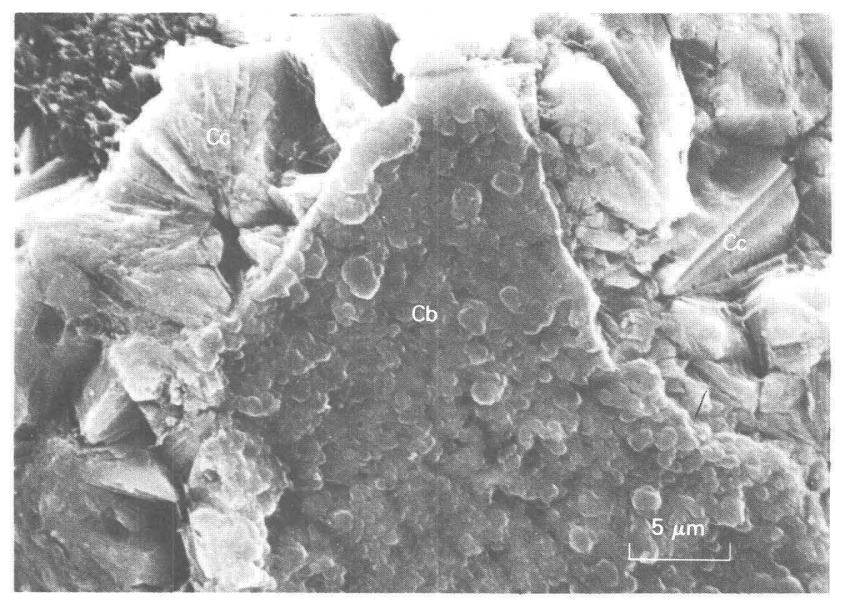

Figure 5. Scanning electron micrograph of botryoidal coffinite (Cb) and coffinite crystals (Cc). Sample 7-3259; ore zone.

When viewed with the SEM, the more illitic clays display delicate wispy growths on grain boundaries, and X-ray fluorescence spectra show the presence of potassium. Clay mineral analyses and identifications presented in this report were performed by G. Whitney (see Whitney, 1986). The I/S was identified by the presence of non-integrally spaced peaks that shifted position upon glycolation (Reynolds and Hower, 1970). It varies in expandability (that is, percentage of smectite layers) from 10 to 70 percent; most samples are 40-50 percent expandable and are perfectly ordered. Some X-ray diffractograms exhibited superlattice reflections at about $27 \AA$.

Pure (100 percent expandable) smectite is confined to unmineralized intervals in the Westwater Canyon Member in core 1 and to the Brushy Basin and Recapture Members in the other cores; ordered I/S is sandwiched between these smectite-bearing layers in both mineralized and barren sandstone units throughout the Westwater Canyon Member in cores 3-7a. The mixed-layer clay becomes increasingly illitic in a basinward direction in the cores of the present study (Whitney, 1986).

Coarse plates of kaolinite occur as scattered books in pores and are most abundant in cores 1-4 near the basin margin. Kaolinite embays most other authigenic phases (fig. 7) and contains remnants of primary uranium ore (fig. 8). Some skeletal plagioclase grains are filled with kaolinite, but some fresh plagioclase grains are surrounded by pores containing clumps of kaolinite.

\section{Chlorite}

Both edge-to-face and rosette chlorite occur in the Westwater Canyon Member. Edge-to-face chlorite aggregates are present chiefly as grain coatings in both mineralized and unmineralized strata. Rosette chlorite, on

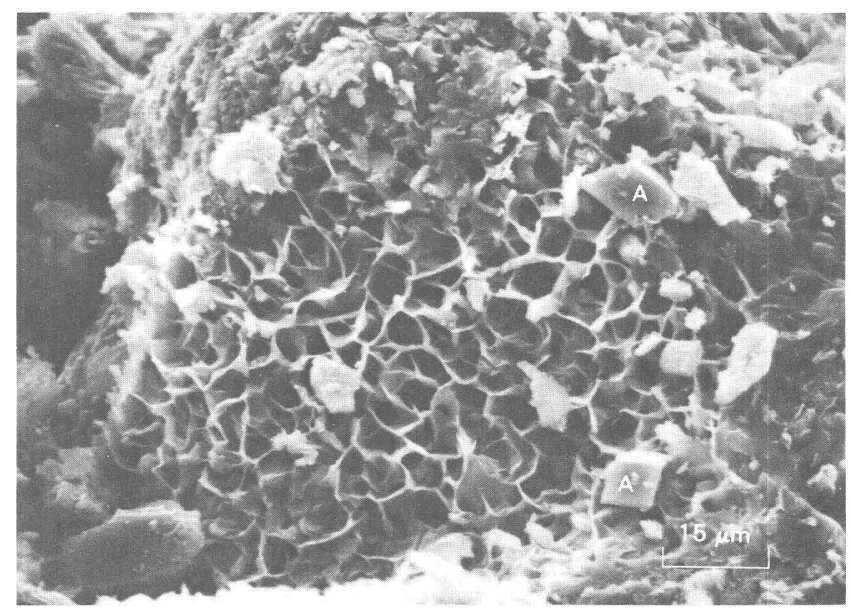

Figure 6. Scanning electron micrograph of authigenic "honeycomb" illite/smectite and adularia (A). Sample 7-3259; ore zone.

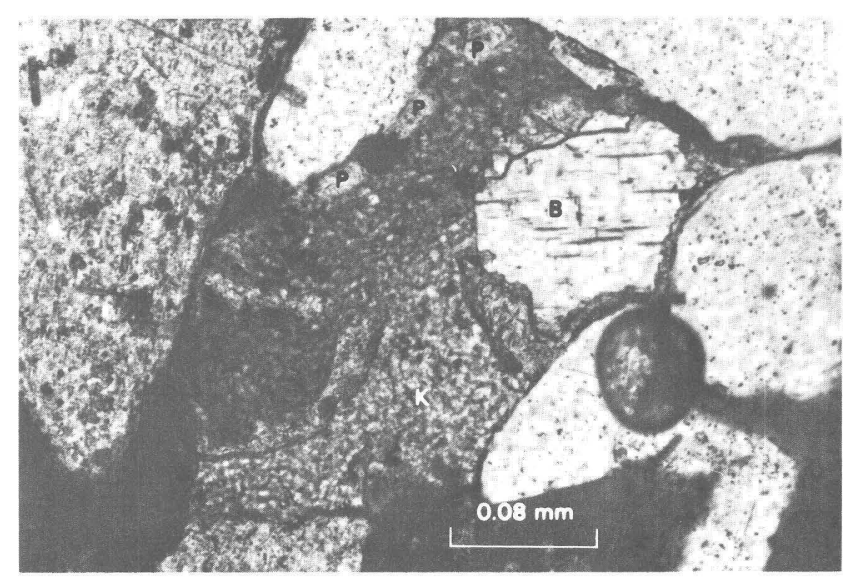

Figure 7. Photomicrograph of kaolinite (K) replacement of authigenic barite (B) within detrital plagioclase grain (P). Sample 7-3303; barren zone; plane-polarized light.

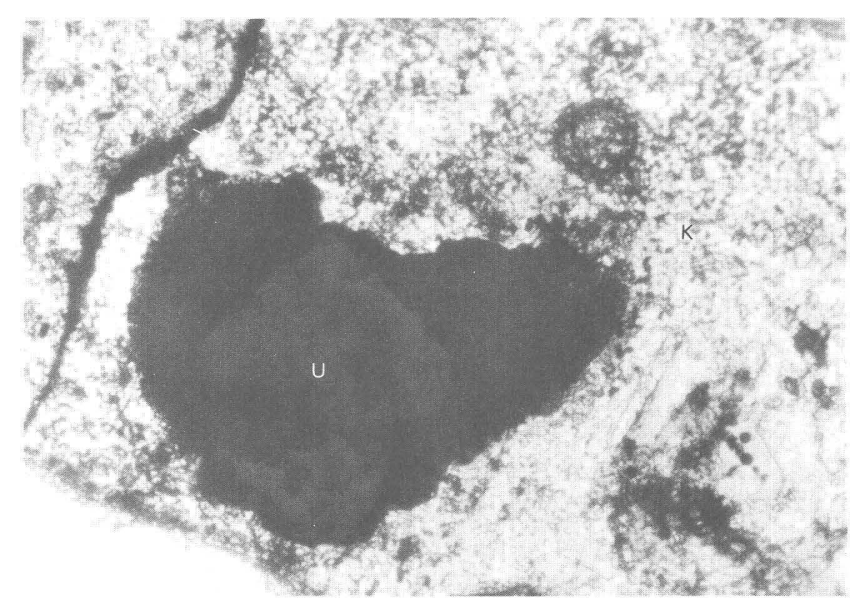

Figure 8. Photomicrograph of kaolinite $(\mathrm{K})$ that surrounds remnant primary uranium ore (U). Grain coatings (G) are uraniferous. Sample 3-1866; ore zone; plane-polarized light. 
the other hand, forms clumps of plates in pores and pore throats in both barren and mineralized sandstones. Edgeto-face chlorite (1) lines pores that are filled with sulfate or carbonate cements, (2) is overgrown by authigenic potassium feldspar, and (3) forms rims on skeletal plagioclase grains (fig. 9). Rosette chlorite occurs on quartz overgrowths and in pores associated with micrometer-size adularia and idiomorphic quartz. Rosette chlorite and I/S commonly coexist in the same pore (fig. 10).

Both types of chlorite are commonly intergrown with and form overgrowths on primary ore. Where ore (primary) contains the most organic carbon, chlorite is rare; where ore (secondary?) is depleted in organic carbon, chlorite is abundant. Irregular millimeter-sized areas in the lower part of the Brushy Basin Member are interpreted to have been plant fragments, because electron microprobe analyses show that these carbon-rich areas have been partially replaced by iron-rich chlorite (data not shown here).

\section{Feldspars}

Several types of feldspar alterations have taken place in the Westwater Canyon Member: plagioclase grains are partly to totally dissolved; authigenic potassium feldspar occurs as overgrowths and idiomorphic crystals in pores; potassium feldspar has replaced the margins of plagioclase grains; and albite has replaced plagioclase and formed overgrowths on all feldspar varieties. In the upper part of the Westwater Canyon Member, particularly in cores closest to the basin margin, the dissolution of plagioclase has resulted in widespread moldic porosity (Hansley, 1984). Plagioclase has also been dissolved in the other (basinward) cores, but remnants of grains are totally albitized.

Albitized feldspar grains occur throughout the Westwater Canyon Member but are most common in the upper parts of cores closest to the center of the basin (Hansley, 1984, 1986b). Skeletal plagioclase grains are preferentially albitized, and completely albitized skeletal plagioclase grains were found in core 8 . Thin $(<5 \mu \mathrm{m})$ albite rims occur on both detrital plagioclase and perthitic feldspars in optical continuity with the sodic portions of these grains. In addition, the albite rims underlie potassium feldspar overgrowths (fig. 11), particularly in cores 5 and 6 . The albite rims are interpreted to be authigenic, because they are not present at grain contacts. Albite overgrowths on plagioclase are most common in core 8 .

Electron microprobe and universal stage analyses of authigenic potassium feldspar overgrowths (fig. 12) revealed that the feldspar is a type of adularia, specifically a potassic sanidine with a disordered structure and a low, variable optic angle (Hansley, 1984; 1986b; Smith, 1974). Potassium feldspar overgrowths are most abundant in the upper part of the Westwater Canyon Member in

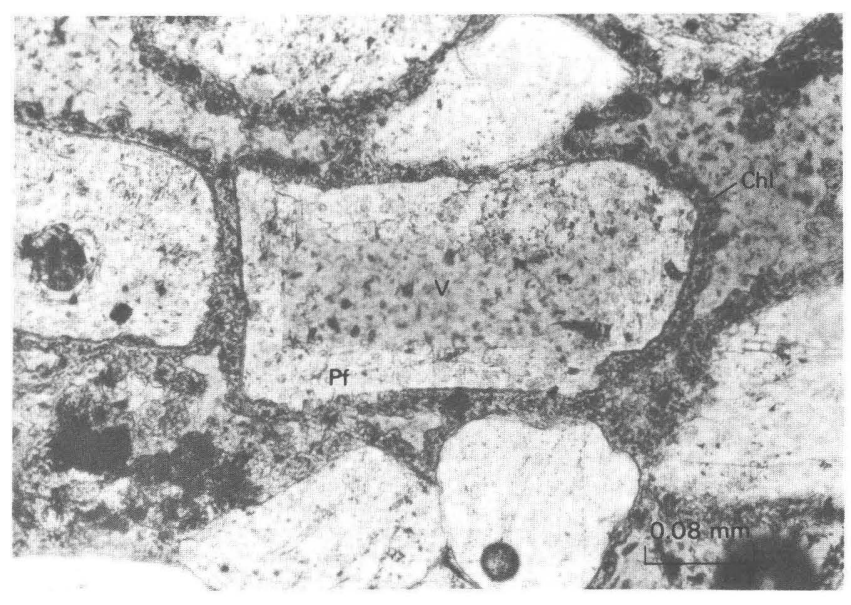

Figure 9. Photomicrograph of chlorite rim (Chl) on partly dissolved detrital plagioclase feldspar grain (Pf). Note that chlorite rim occurs at grain contacts. V, void. Sample 4-1972; barren zone; plane-polarized light.

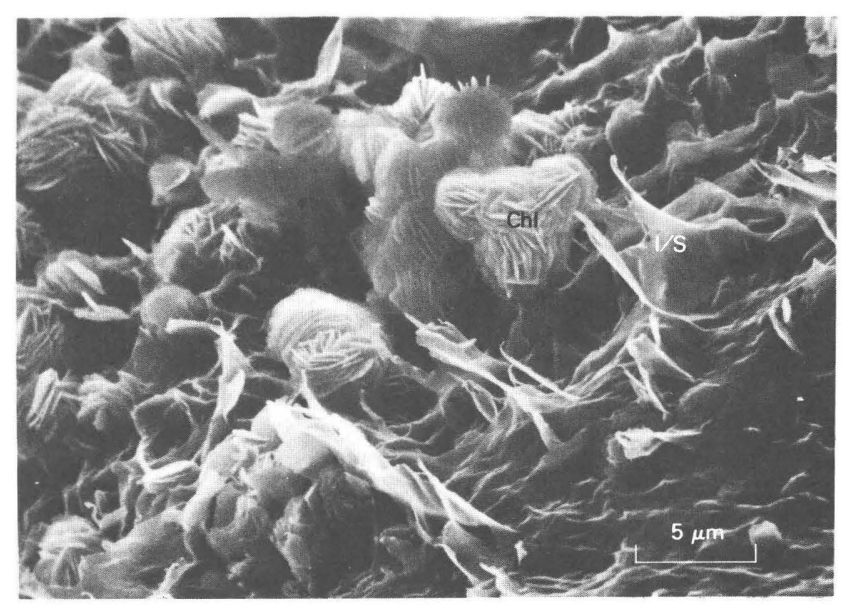

Figure 10. Scanning electron micrograph showing relation between rosette chlorite (Chl) and illite/smectite (I/S). Sample 31868; ore zone.

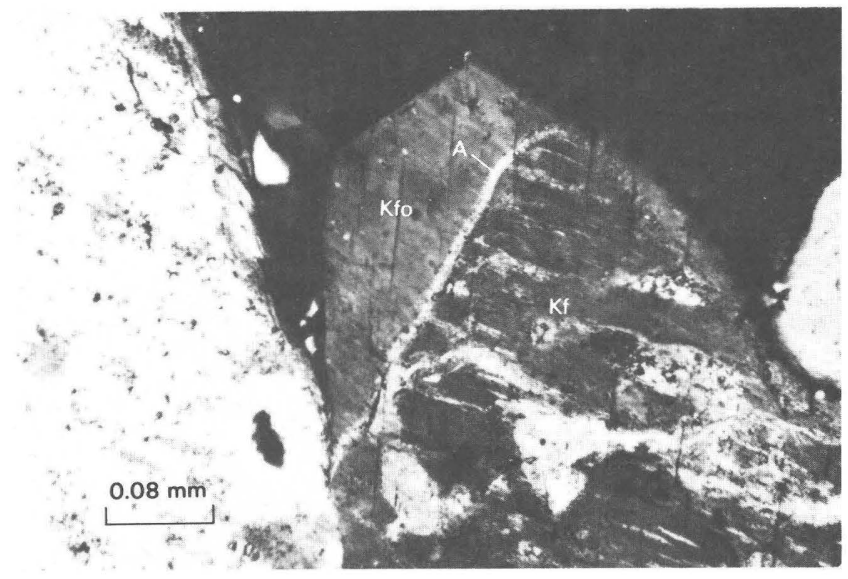

Figure 11. Photomicrograph of detrital potassium feldspar grain (Kf) with thin albite rim (A) superseded by potassium feldpar overgrowth (Kfo). Sample 6-2604; barren zone; crossed polarizers. 


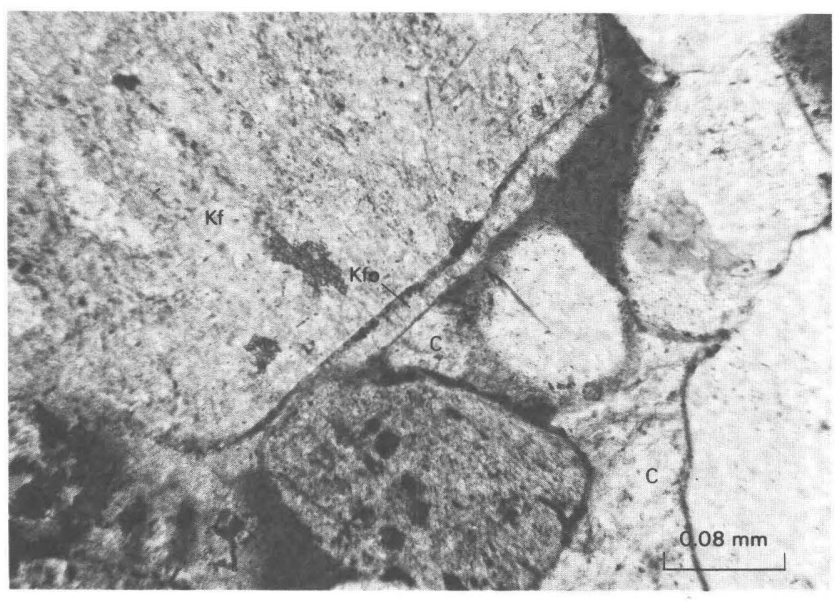

Figure 12. Photomicrograph of detrital potassium feldspar (Kf) with potassium feldspar overgrowth (Kfo) that supersedes chlorite rim (Chl). Later calcite cement (C) fills pore. $\mathrm{V}$, void. Sample 8-3129; barren zone; plane-polarized light.

unmineralized cores 5 and 6 and in mineralized core 7; they were not found in cores 1 and 8. Cryptocrystalline adularia is commonly intergrown with rosette chlorite and idiomorphic quartz in barren sandstone intervals.

All hollow potassium feldspar grains in the Morrison Formation were identified by Austin (1980) as detrital sanidine; however, in the present study, most hollow sanidine grains were found to have been overgrowths on preexisting detrital plagioclase grains that had been dissolved during diagenesis (fig. $13 A-C$ ). None of these hollow grains showed cathodoluminescence, indicating that they are authigenic (Kastner and Siever, 1979), and electron microprobe analyses revealed that they are nearly pure, stoichiometric $\mathrm{KAlSi}_{3} \mathrm{O}_{8}$ (Hansley, 1984). Detrital sanidine, which occurs throughout these volcaniclastic sandstones, shows extensive dissolution features and enrichment of potassium at the expense of sodium around dissolution voids. Many detrital plagioclase grains are replaced marginally by potassium feldspar (fig. 14), which is composed of intergrown adularia crystals that have different optical orientations.

\section{Silica minerals}

Authigenic silica is ubiquitous in the upper part of the Westwater Canyon Member. As many as four generations of authigenic silica cement were observed in the same

Figure 13. Photomicrographs showing stages of dissolution of detrital plagioclase grain and formation of "hollow" potassium feldspar grain:

A, Detrital plagioclase $(\mathrm{Pf})$ with euhedral potassium feldspar overgrowth (Kfo) (sample 6-2624, barren);
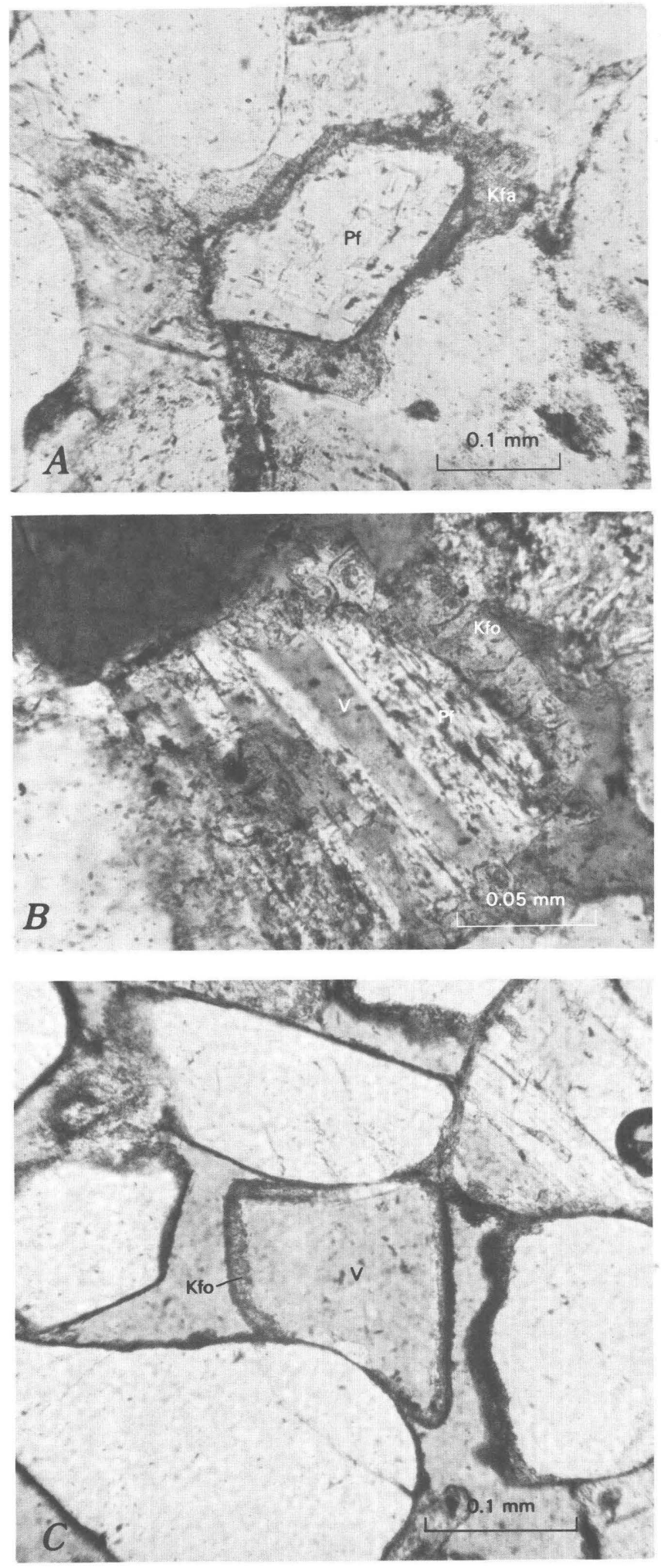

$B$, partially dissolved plagioclase grain ( $\mathrm{Pf}$ ) with dissolution voids (V) and potassium feldspar overgrowth (Kfo) (sample 7-3129, barren); and

$C$, potassium feldspar overgrowth (Kfo) surrounding a void (V) where a detrital plagioclase grain $(\mathrm{Pf})$ once occurred (sample 3-1833, barren). All photomicrographs taken in plane-polarized light. 
pore. The most common form of authigenic silica is quartz overgrowths that may underlie or, commonly, overlie grain coatings of primary uranium ore (fig. 15). Double quartz overgrowths have been noted on the same detrital quartz grain (fig. 16). Other types of authigenic silica are (1) microcrystalline idiomorphic quartz that occurs with rosette chlorite and adularia in the pores of unmineralized sandstone units, and (2) noncrystalline silica that forms spheres (opal-CT(?)) associated with coffinite in cores 7 and $7 \mathrm{a}$.

\section{Carbonates}

Several generations of nonferroan and ferroan carbonates occur in the Westwater Canyon Member. Minor amounts of nonferroan calcite cement occur inside concretions; however, most nonferroan calcite fills pores rimmed with primary ore and chlorite (see fig. 9). Nonferroan calcite embays primary ore and is, in turn, embayed locally by ferroan calcite and ankerite. Ferroan calcite and ankerite contain inclusions of carbonaceous uranium ore in cores 7 and $7 a$.

\section{Sulfates}

Anhydrite and barite occur as interstitial cements and as infillings or replacements of detrital plagioclase (see fig. 7). Anhydrite is common in the deeper parts of cores $5-7$, but it is rare in the other cores. Barite occurs sporadically throughout all cores. Both sulfates embay other authigenic phases with the exception of kaolinite. In core $7 \mathrm{a}$, barite cement is pink due to oxidized pyrite inclusions, and the barite is overgrown with euhedral pyrite crystals.

\section{Iron oxides}

Thin hematitic rims occur on iron-titanium oxide grains below the magnetic susceptibility line (see fig. 2), and hematite is present inside reduced mudstone nodules. Hematite rosettes occur inside dissolution cavities in skeletal plagioclase and on chlorite rosettes in core 4.

\section{Etched grains}

Deep chemical etching has produced cubic and dodecahedral faces on detrital almandine-spessartine garnets in certain stratigraphic intervals within the Westwater Canyon Member (Hansley, 1986a). Deeply etched staurolite grains occur in the same zone. Garnets are rounded, not etched, in the overlying Brushy Basin and the underlying Recapture Members. The sharpness

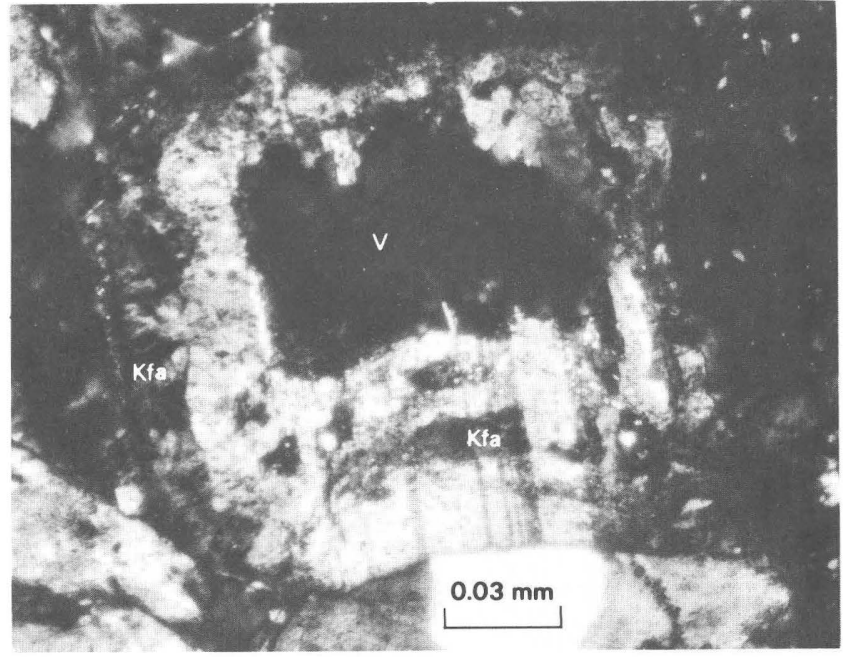

Figure 14. Photomicrograph of detrital, skeletal twinned plagioclase grain replaced marginally by authigenic potassium feldspar (Kfa). V, void.

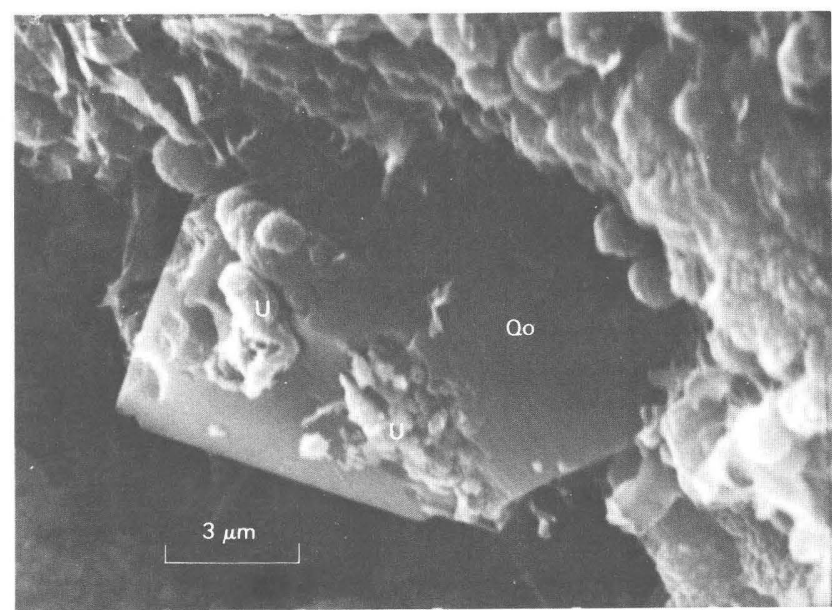

Figure 15. Scanning electron micrograph of uranium ore (U) that embays euhedral quartz overgrowth (Qo). Sample 7-3259; ore zone.

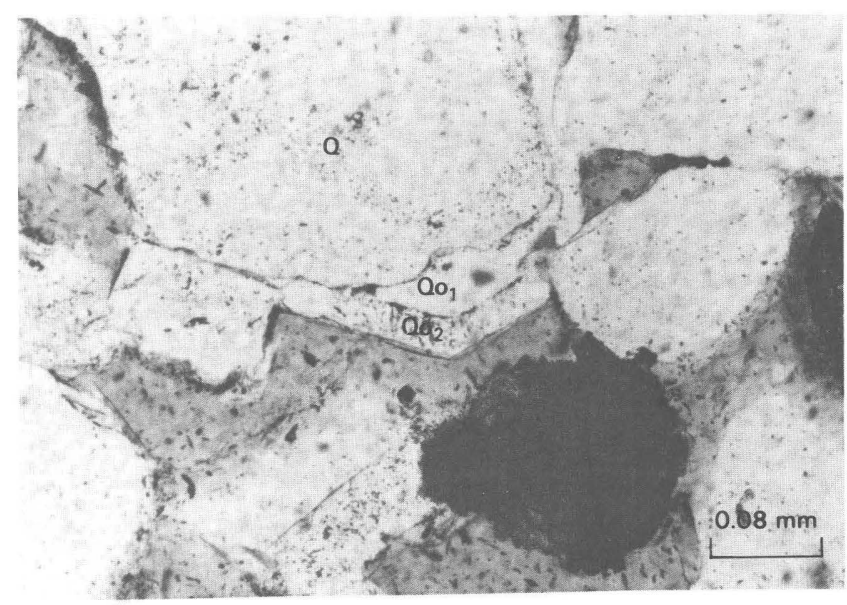

Figure 16. Photomicrograph showing two generations of authigenic silica $\left(\mathrm{Qo}_{1}, \mathrm{Qo}_{2}\right)$ as overgrowths on detrital quartz grain (Q). Sample 5-2802, barren zone; crossed polarizers. 
of the etched surfaces and the limited distribution of etched grains preclude a detrital origin for these textures (Hansley, 1983; Hansley, 1985; Hansley, 1986a). The zone of deeply etched garnets coincides with the zone of ordered $\mathrm{I} / \mathrm{S}$ in the core fence.

\section{PARAGENESIS AND GEOCHEMISTRY OF DIAGENETIC ALTERATIONS}

A paragenetic sequence for the Westwater Canyon Member based on the information presented in this report appears in table 1 . The relationships of various authigenic phases to each other and to uranium ore are discussed in the following paragraphs. The chemistry and temperatures of interstitial fluids are inferred based on the observed petrology.

During early diagenesis, the chemistry of pore water in the upper part of the Morrison Formation was controlled largely by the dissolution of tremendous volumes of volcanic ash that fell into streams and lakes in the area of the San Juan basin during Late Jurassic time. Due to hydrolysis and dissolution of the ash, the resultant pore waters were buffered to a moderately basic $\mathrm{pH}$. Where organic matter was present in mudstones and in fluvial channels, the early (pre-compaction) geochemical environment was reducing. The occurrence of ferric oxides in many parts of the Morrison, however, suggests that conditions were at least mildly oxidizing in some units. Smectite and minor anhedral pyrite, nonferroan calcite, quartz overgrowths, and kaolinite precipitated before significant compaction and the emplacement of primary ore. Early diagenetic kaolinite is interpreted to be that which occurs within volcanic rock fragments.

Many alterations-especially those involving feldspars and iron-titanium oxides - that are most intense near the top of the Westwater Canyon Member suggest that fluids migrated into the Westwater Canyon from overlying Brushy Basin units. The optimum time for downward fluid migration was during early diagenesis, when the fine-grained Brushy Basin sediments were compacted. Movement of fluids from fine-grained Brushy Basin units into the coarser and more permeable sandstones in the upper part of the Westwater Canyon Member was first suggested by Turner-Peterson and others (1980) based on detailed sedimentologic studies.

The near-zero magnetic susceptibility that is directly related to iron-titanium oxide alteration in the upper part of the Westwater Canyon Member has been attributed to the early postdepositional movement of organic acidbearing solutions through the sandstones (Reynolds and others, 1986; Adams and Saucier, 1981). Euhedral pyrite and titanium dioxides, chiefly anatase, were products of iron-titanium oxide diagenesis. The paucity of uranium within carbonized iron-titanium oxides and the enrichment of uranium on the margins of these altered grains imply that most uranium was introduced after emplacement of the organic material. This observation contradicts earlier studies that concluded uranium and carbon were precipitated at the same time, based on a uranium:carbon ratio of 1:1 (by weight) in many ore zones (Leventhal, 1980; Adams and Saucier, 1981).

Table 1. Paragenesis of major authigenic phases and diagenetic alterations in the Westwater Canyon Member of the Morrison Formation near Crownpoint, New Mexico

[Dashed lines indicate tentative interpretations]

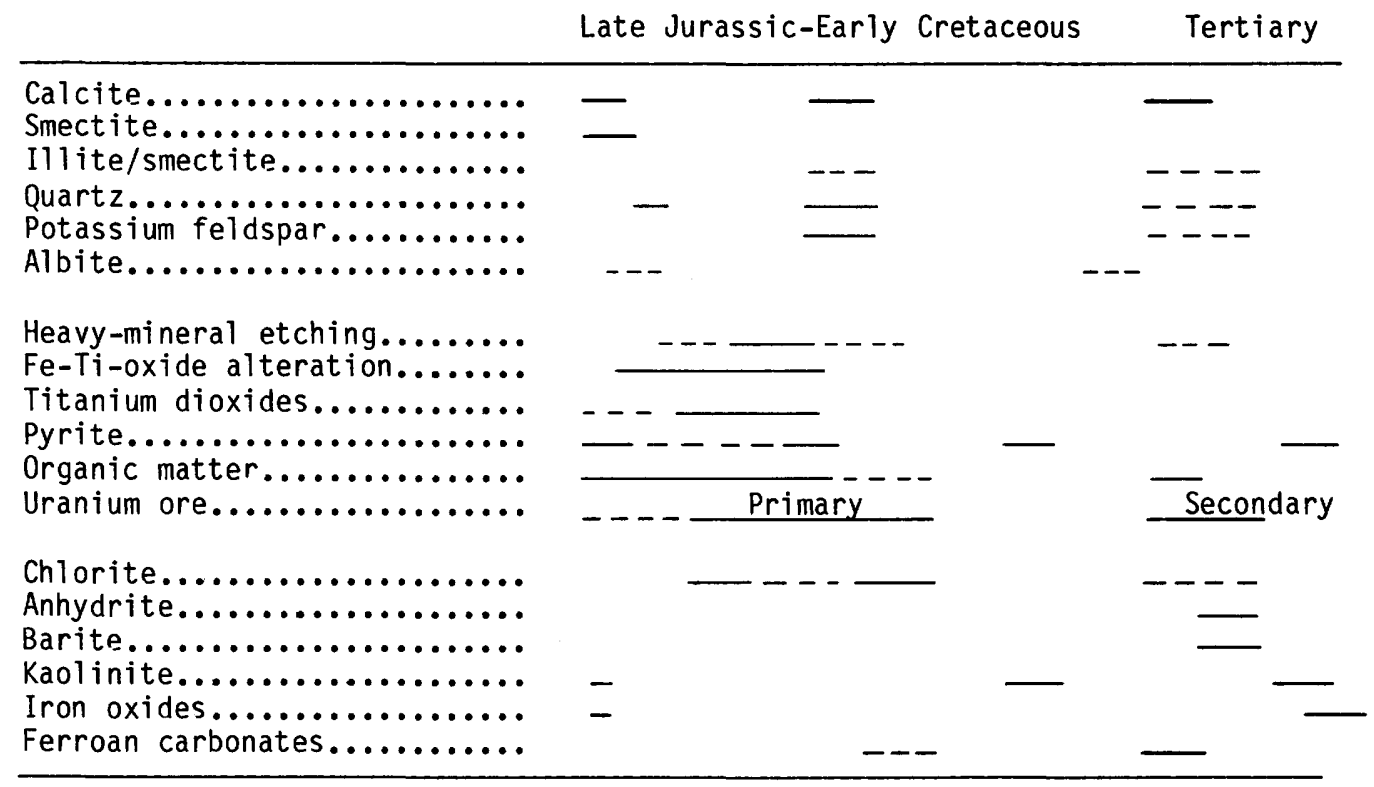


Primary uranium mineralization occurred during early diagenesis when the inferred hydrologic communication between the two members would have taken place. Fluids migrating through the Westwater Canyon Member, possibly enriched by solutions migrating out of the Brushy Basin units, carried soluble humic acids and uranium to sites of precipitation. In this way, tabular primary ore deposits were formed. Additional uranium enrichment apparently occurred after the deposition of epigenetic humate as uranium-bearing solutions continued to migrate into humate-rich zones, where the uranium was continually reduced and precipitated in and around the margins of humate-impregnated areas. Multiple generations of authigenic phases in ore-bearing strata reflect the extended duration of the mineralization event.

The presence of coffinite and opal-CT(?) in some orebodies suggests that uranium and silicon traveled together in solution as a hydroxy-uranyl-silicate complex. Such a complex is stable at low temperatures in neutral to mildly alkaline solutions in which the carbonate activity is less than the silica activity (Yermolayev and others, 1965). The silica activity was apparently high during early diagenesis due to the dissolution of volcanic ash and possibly stabilized the hydroxy-uranyl-silicate complex. According to Hemingway (1982), a high silica activity (at least $10^{-3.5}$ ) favors the formation of coffinite over uraninite. The cryptocrystalline coffinite that is coextensive with carbonaceous matrix may have formed in part during primary mineralization where silica activity was high and in part during later diagenesis when extensive dissolution of aluminosilicates occurred. A later generation of coffinite is represented by coarse-grained coffinite that has replaced primary (carbonaceous) ore in cores 7 and $7 \mathrm{a}$. This coffinite may have formed as a result of recrystallization of cryptocrystalline coffinite in the primary ore.

The widespread occurrence of altered tuffs and bentonites in the upper part of the Morrison Formation suggest that smectite was an alteration product of rhyolitic volcanic ash (Brookins, 1975). Sometime during later diagenesis, smectite probably transformed to I/S as is suggested by the similarity in textures of the smectite and the I/S and by the occurrence of both clay minerals on detrital grain rims. Because primary uranium ore and most other authigenic phases commonly overlie I/S (Fishman and Reynolds, 1986), the mixed-layer clays probably formed during early diagenesis. Random I/S may form at temperatures as low as $60^{\circ} \mathrm{C}$; however, an ordered structure requires temperatures of at least $100^{\circ} \mathrm{C}$ (Perry and Hower, 1970).

Organic acids may have facilitated the illitization reaction at temperatures less than $60^{\circ} \mathrm{C}$ (Brookins, 1975) by reducing ferric to ferrous iron in the smectite, a process that creates a charge deficiency in the structure (Perry and Hower, 1970) and that has been demonstrated to be a viable process by Eslinger and others (1979). This negative charge can be balanced by the incorporation of potassium as an interlayer cation into the structure. High potassium activity due to the dissolution of abundant rhyolitic volcanic ash may have also promoted early transformation of smectite to I/S. Recent studies suggest that unusual solution chemistry, such as extremely high potassium activity in a saline, alkaline lake environment, promotes the transformation of smectite to $I / S$ at temperatures less than $60^{\circ} \mathrm{C}$ (Singer and Stoffers, 1980).

Ordering of mixed-layer clays, as mentioned previously, requires higher temperatures. The highest temperature that the Morrison Formation could have attained due to burial diagenesis is about $65^{\circ} \mathrm{C}$ according to the inferred geothermal gradient of $20^{\circ} \mathrm{C} / \mathrm{km}$ (Scott, 1986), because the Morrison was buried to a depth of only about $2000 \mathrm{~m}$ during the mid-Tertiary. Even if burial had been deep enough to produce a temperature of $100^{\circ} \mathrm{C}$, the restricted occurrence of the ordered clays still cannot be explained. An alternative explanation is that a warm fluid migrated updip through the Westwater Canyon Member and caused the transformation of smectite to ordered I/S (Whitney, 1986) during maximum burial in the mid-Tertiary when oil is known to have been generated in the San Juan basin (Rice, 1983). The presence of a warm fluid is also indicated by oxygen and deuterium isotope data on the I/S clay minerals (Northrop and Whitney, 1985). This hypothesis also accounts for the restriction of ordered clays to the Westwater Canyon Member. Warmer temperatures would also have favored albitization of plagioclase, because temperatures of $100^{\circ} \mathrm{C}$ are thought by Boles (1982) to be required for albitization, based on his studies of sediments in the Gulf Coast region. The close correspondence between the etched garnet and I/S zones indicates that the etching of garnets may have also resulted from reactions involving a higher temperature fluid (Hansley, 1985).

Several chemical factors may have interacted, therefore, to promote illitization of smectite during early diagenesis of these sandstones, but ordering of the I/S probably occurred later in diagenesis due to increased temperature.

Most kaolinite formed late in diagenesis, although minor kaolinite formed as an alteration of rock fragments during early diagenesis. Some skeletal plagioclase grains are partly replaced(?) by kaolinite, but fresh plagioclase grains within nests of kaolinite suggest that the alteration of feldspars was not the only source for aluminum and silica in the kaolinite (Austin, 1980).

The abundance of pyrite in ore zones has been attributed to the reducing environment caused by humic material. During early diagenesis, sulfate was reduced by anaerobic microbial activity, and the reduced sulfur combined with iron to form pyrite (Leventhal, 1980). The paucity of pyrite and abundance of sulfate in cores 7 and 7 a suggest that oxidation of pyrite may have led to sulfate precipitation. Overgrowths of euhedral pyrite on barite 
imply a resulfidization or re-reduction of these sandstones. This later reduction may have been associated with redistribution of uranium into roll-type deposits along an oxidation-reduction front (Rhett, 1980).

Chlorite precipitated prior to significant grain dissolution, because partly dissolved grains have chlorite rims that outline the original grain boundaries. Rosette chlorite and I/S were probably cogenetic phases (Whitney, 1986), although paragenetic relations between the two phases are ambiguous. Etched garnets within chlorite rims and rosette chlorite on etched surfaces suggest that edge-to-face chlorite precipitated before rosette chlorite, and therefore, represents an earlier stage of chlorite formation.

The superposition of chlorite rosettes on primary uranium ore and intergrowths of chlorite and ore suggest that the chlorite formed during mineralization or, alternatively, was a later alteration product of primary ore. This latter hypothesis is favored by the following petrographic observations: in primary ore zones, ore coats grain rims; in barren rock surrounding primary ore zones, chlorite coats the detrital grains, thus filling the same niche as the primary ore in the ore zones. In high-grade primary ore, which is generally deficient in chlorite, vanadium was detected in areas where organic carbon was present; where chlorite rosettes are abundant, the chlorite is vanadiferous (Whitney, 1986). Thus, the vanadium in the organic matter was probably incorporated into the chlorite structure during diagenesis of the organic matter.

Inclusions of primary uranium ore within ankerite cement suggest that ferroan carbonates also formed during the alteration of carbonaceous uranium ore. Supporting this interpretation by indicating that some of the carbonate carbon was derived from organic carbon are light $\delta^{13} \mathrm{C}$ values $(-8$ to -12$)$ for ankerite (Hansley, 1986b) and similar light $\delta^{13} \mathrm{C}$ values for calcite from ore zones in the Ambrosia Lake District in the Grants uranium region (Leventhal, 1980).

Delicate remnants of plagioclase grain rims show no effects of mechanical compaction; thus, some burial was apparently attained before dissolution took place. Furthermore, plagioclase skeletalization apparently postdated the formation of primary ore, because ore rarely occurs within skeletal plagioclase grains, and, in areas totally impregnated with ore, plagioclase grains are generally unaltered. Chlorite rims on the edges of skeletal plagioclase grains and around the edges of moldic pores containing plagioclase remnants indicate that plagioclase dissolved after chlorite precipitated. Plagioclase skeletalization postdated the formation of potassium feldspar overgrowths, because skeletal grains commonly occur totally within the overgrowths.

Recent experiments on the dissolution of silicates indicate that organic acids are probably the best naturally occurring solvents of aluminosilicate minerals (Surdam and others, 1984). During the mid-Tertiary, solutions containing organic acids and carbon dioxide (as carbonic acid) were produced during the maturation of humate. These solutions were probably responsible for extensive dissolution of framework grains and cement and the development of moldic secondary porosity in the Westwater Canyon Member. Because plagioclase remnants are commonly albitized, albitization either predated or was coincident with plagioclase dissolution. Albitization of the plagioclase remnants probably served to stabilize the skeletal grains. If warm fluids did indeed migrate updip through the Westwater Canyon Member during deepest burial, the increased temperature would have hastened the maturation of the organic material and, thus, would have facilitated production of organic acids.

Both authigenic albite and analcime occur in dissolution voids within altered plagioclase grains in core 8. Because zeolites commonly form as alteration products of volcanic glass in saline, alkaline lacustrine environments, the analcime may have formed indirectly as an alteration product of volcanic glass; however, because analcime has not been observed coexisting with unaltered volcanic ash, it is therefore thought to form from a precursor zeolite, such as clinoptilolite (Hay, 1966). During subsequent burial diagenesis, analcime probably transformed to albite (Liou, 1971). In geochemical studies of the Grants uranium region, Della Valle (1981) found that sodium was somewhat enriched in the upper part of the Westwater Canyon Member. These data suggest that sodium may have been derived from altered tuff beds in the overlying lacustrine facies of the Brushy Basin Member. Because of the close spatial association of skeletal plagioclase and authigenic albite, however, some sodium was probably derived locally from alteration of detrital plagioclase grains.

Potassium feldspar probably formed after the formation of the primary uranium ore, because overgrowths of this mineral supersede (post-ore) chlorite grain rims (see fig. 12). In addition, where primary ore coats detrital grains, the ore does not occur on potassium feldspar overgrowths (Hansley, 1986b).

The various stages of authigenic silica formation suggest that pulses of silica-saturated pore waters migrated through these sandstones. These pore waters may have been derived from the compaction of tuffaceous lacustrine sediments in the overlying and intertonguing Brushy Basin Member, as has been suggested by Turner-Peterson and others (1980) and Turner-Peterson (1986). Silica may have precipitated when these alkaline waters mixed with formation waters of lower $\mathrm{pH}$ and/or encountered accumulations of organic matter in the Westwater Canyon Member. In addition, some silica was probably derived by the dissolution of detrital silicates and volcanic ash in the Westwater Canyon Member itself.

Widespread post-ore oxidation of primary uranium ore during the late Tertiary (Saucier, 1980) obliterated evidence of earlier diagenetic reactions. At this time 
meteoric water flowed from recharge areas along the southern margin of the basin through Westwater Canyon sandstone units toward the center of the basin. Oxidized ore zones occur in cores closest to the basin margin. Petrographic evidence for a late oxidizing event includes relicts of carbonate and sulfate cements, remnants of uraniferous and carbonaceous matrix, hematite rosettes on chlorite, and floating detrital grains in enlarged pores. During the leaching process, coarse crystalline kaolinite precipitated in pores and within leached grains. Some coarse, void-filling coffinite probably formed at this time, when the organic matter associated with primary ore oxidized to carbon dioxide, and uranium formed soluble uranyl complexes, which precipitated as secondary ore in reduced zones downdip. Uranium-lead apparent ages of near zero indicate that redistribution may be occurring at the present time (Ludwig and others, 1982).

\section{CONCLUSIONS}

Diagenetic alterations in both mineralized and barren sandstone units of the Westwater Canyon Member of the Morrison Formation in the Grants uranium region are more complex than alterations in underlying and overlying members. The complexity can be attributed largely to processes associated with both primary uranium mineralization and the later alteration of primary (carbonaceous) ore, because most diagenetic alterations occur in mineralized strata or in rocks stratigraphically equivalent to mineralized strata. Alteration patterns suggest that some fluids migrated into the Westwater Canyon Member from overlying mudstones in the Brushy Basin Member, and the presence of certain authigenic phases (such as ordered I/S, etched garnets, and albite) confined to the Westwater Canyon implies that warm fluids migrated updip through the Westwater Canyon sandstones perhaps during the mid-Tertiary. Finally, during the late Tertiary, oxidizing fluids that migrated downdip from exposed outcrops caused extensive alteration of primary ore deposits and redistributed uranium into organic-poor secondary deposits. Both Tertiary events were responsible for the formation of widespread secondary porosity through the dissolution of grains and cements.

As the organic matter in primary ore altered during diagenesis due to microbial activity, warm(?) temperatures, and oxidizing solutions, chlorite, ferroan carbonates, and coffinite apparently precipitated in its place. Therefore, as was first suggested by Squyres (1980), chlorite-bearing assemblages in barren strata may represent former sites of primary ore accumulation. If this hypothesis is correct, primary orebodies may have once been more widespread in the Grants uranium region.

\section{REFERENCES CITED}

Adams, S. S., and Saucier, A. E., 1981, Geology and recognition criteria for uraniferous humate deposits, Grants uranium region, New Mexico: U.S. Department of Energy report GJBX-2(81), $225 \mathrm{p}$.

Austin, S. R., 1980, Dissolution and authigenesis of feldspars, in Rautman, C. A., compiler, Geology and mineral technology of the Grants uranium region 1979: New Mexico Bureau of Mines and Mineral Resources Memoir 38, p. 107-115.

Bell, T. E., 1983, Deposition and diagenesis of the Brushy Basin and upper Westwater Canyon Members of the Morrison Formation in northwest New Mexico and its relationship to uranium mineralization: Berkeley, University of California, Ph.D. dissertation, 102 p.

Bell, T. E., 1986, Deposition and diagenesis in the Brushy Basin and upper part of the Westwater Canyon Member of the Morrison Formation, San Jaun basin, New Mexico, in Turner-Peterson, C. E., Santos, E. S., and Fishman, N. S., eds., A basin analysis case study-The Morrison Formation, Grants uranium region, New Nexico: American Association of Petroleum Geologists Studies in Geology 22, p. 77-92.

Boles, J. R., 1982, Active albitization of plagioclase, Gulf Coast Tertiary: American Journal of Science, v. 282, p. 165-180.

Brookins, D. G., 1975, The Grants mineral belt, New MexicoComments on the coffinite-uraninite relationship, probable clay mineral reactions, and pyrite formation, in Woodward, L. A., and Northrop, S. A., eds., Tectonic and mineral resources of southwestern North America: New Mexico Geological Society Special Publication No. 6, p. 158-166.

Condon, S. M., and Peterson F., 1986, Stratigraphy of Middle and Upper Jurassic rocks in the San Juan Basin; historical perspective, current ideas, and remaining problems, in Turner-Peterson, C. E., Santos, E. S., and Fishman, N.S., eds., A basin analysis case study-The Morrison Formation, Grants uranium region, New Mexico: American Association of Petroleum Geologists Studies in Geology 22, p. 7-26.

Della Valle, R. S., 1981, Geochemical studies of the Grants mineral belt, New Mexico: Albuquerque, N. Mex., University of New Mexico, Ph. D. dissertation, 450 p.

Dickson, J. A., 1965, A modified staining technique for carbonates in thin section: Nature, v. 205, no. 497, p. 587.

Eslinger, E. V., Highsmith, P., Albers, D., and DeMayo, B., 1979 , Role of iron reduction in the conversion of smectite to illite in bentonites in the Disturbed Belt, Montana: Clays and Clay Minerals, v. 27, p. 327-338.

Fishman, N. S., and Reynolds, R. L., 1986, Diagenesis of the Morrison Formation, Smith Lake uranium district, McKinley County, New Mexico, in Mumpton, F. A., ed., Studies in diagenesis: U.S. Geological Survey Bulletin 1578, p. 239-254.

Fishman, N. S., Reynolds, R. L., and Robertson, J. R., 1985, Uranium mineralization in the Smith Lake district of the Grants uranium region, New Mexico: Economic Geology, v. 80 , p. $1348-1364$. 
Fishman, N. S., Turner-Peterson, C. E., and Reynolds, R. L., 1984, Alteration of magnetite and ilmenite in Upper Jurassic Morrison Formation, San Juan basin, New MexicoRelationship to facies and primary uranium mineralization [abs]: American Association of Petroleum Geologists Bulletin, v. 66, no. 7, p. 937.

Granger, H. C., Santos, E. S., Dean, B. G., and Moore, F. B., 1961, Sandstone-type uranium deposits at Ambrosia Lake, New Mexico-An interim report: Economic Geology, v. 56 , no. 7 , p. $1179-1209$.

Hansley, P. L., 1983, The nonopaque detrital heavy mineralogy of the Morrison Formation near Crownpoint, San Juan basin, New Mexico: U.S. Geological Survey Open-file Report 83-191, 44 p.

1984, Feldspar alteration patterns in the Upper Jurassic Morrison Formation, northwestern New Mexico [abs]: Society of Economic Paleontologists and Mineralogists Annual Midyear Meeting, Technical Program, v. 1, p. 37.

1985, A zone of chemically etched garnets in the Upper Jurassic Morrison Formation, northwestern New MexicoAn indicator of a unique diagenetic fluid? [abs]: Society of Economic Paleontologists and Mineralogists Annual Midyear Meeting, Technical Program, v. 2, p. 39.

1986a, The relationship of detrital, nonopaque heavy minerals to diagenesis and provenance of the Morrison Formation, southwestern San Juan basin, New Mexico, in Turner-Peterson, C. E., Santos, E. S., and Fishman, N.S., eds., A basin analysis case study-The Morrison Formation, Grants uranium region, New Mexico: American Association of Petroleum Geologists Studies in Geology 22, p. 257-276.

1986b, Regional diagenetic trends and uranium mineralization in the Morrison Formation across the Grants uranium region, New Mexico, in Turner-Peterson, C. E., Santos, E. S., and Fishman, N.S., eds., A basin analysis case study-The Morrison Formation, Grants uranium region, New Mexico: American Association of Petroleum Geologists Studies in Geology 22, p. 277-302.

Hatcher, P. G., Spiker, E. C., Orem, W. H., Romankiw, L. A., Szeverenyi, N. M., and Maciel, G. E., 1986, Organic geochemical studies of uranium-associated organic matter from the San Juan basin-A new approach using solid-state ${ }^{13} \mathrm{C}$ nuclear magnetic resonance, in Turner-Peterson, C. E., Santos, E. S., and Fishman, N.S., eds., A basin analysis case study-The Morrison Formation, Grants uranium region, New Mexico: American Association of Petroleum Geologists Studies in Geology 22, p. 171-184.

Hay, R. L., 1966, Zeolites and zeolitic reactions in sedimentary rocks: Geologic Society of America Special Paper 85, $130 \mathrm{p}$.

Hemingway, B. S., 1982, Thermodynamic properties of selected uranium compounds and aqueous species at $298.15 \mathrm{~K}$ and 1 bar and at higher temperatures. Preliminary models for the origin of coffinite deposits: U.S. Geological Survey Open-file Report 82-619, 60 p.

Hutchison, C. S., 1974, Laboratory handbook of petrographic techniques: New York, Wiley, 527 p.

Kastner, M., and Siever, R., 1979, Low temperature feldspars in sedimentary rocks: American Journal of Science, v. 279, p. 435-479.
Leventhal, J. S., 1980, Organic geochemistry and uranium in Grants mineral belt, in Rautman C. A., compiler, Geology and mineral technology of the Grants uranium region 1979: New Mexico Bureau of Mines and Mineral Resources Memoir 38, p. 75-85.

Liou, J. G., 1971, Analcime equilibria: Lithos, v. 4, p. 389-402.

Ludwig, K. R., Rubin, B., Fishman, N. S., and Reynolds, R. L., 1982, U-Pb ages of uranium ores in the Church Rock district, New Mexico: Economic Geology, v. 77, p. 1942-1945.

Ludwig, K. R., Simmons, K. R., and Webster, J. D., 1984, U$\mathrm{Pb}$ isotope systematics and apparent ages of uranium ores, Ambrosia Lake and Smith Lake districts, Grants mineral belt, New Mexico: Economic Geology, v. 79, p. 322-337.

Northrop, H. R., and Whitney, G., 1985, Sediment-hosted ore deposits; Genetic processes inferred from the mineralogic, chemical, and isotopic composition of clay minerals, in USGS research on mineral resources-1985, Program and abstracts: U.S. Geological Survey Circular 949, p. 38-39.

Perry, E., and Hower, J., 1970, Burial diagenesis in Gulf Coast pelitc sediments: Clays and Clay Minerals, v. 18, p. 165-177.

Reynolds, R. C., and Hower, J., 1970, The nature of layering in mixed-layer illite-montmorillonites: Clays and Clay Minerals, v. 18, p. 25-36.

Reynolds, R. L., Fishman, N. S., Scott, J. H., and Hudson, M. E., 1986, Iron-titanium oxide minerals and magnetic susceptibility anomalies in the Mariano Lake-Lake Valley cores-Constraints on conditions of uranium mineralization in the Morrison Formation, San Juan basin, New Mexico, in Turner-Peterson, C. E., Santos, E. S., and Fishman, N.S., eds., A basin analysis case study-The Morrison Formation, Grants uranium region, New Mexico: American Association of Petroleum Geologists Studies in Geology 22, p. 303-314.

Rhett, D. W., 1980, Heavy-mineral criteria for subsurface uranium exploration, San Juan basin, New Mexico, in Rautman, C. A., compiler, Geology and mineral technology of the Grants uranium region 1979: New Mexico Bureau of Mines and Mineral Resources Memoir 38, p. 202-207.

Rice, D. D., 1983, Relation of natural gas composition to thermal maturity and source rock type in San Juan basin, northwestern New Mexico and southwestern Colorado: American Association of Petroleum Geologists Bulletin, v. 67, n. 8, p. 1199-1218.

Saucier, A. E., 1980, Tertiary oxidation in Westwater Canyon Member of Morrison Formation, in Rautman, C. A., compiler, Geology and mineral technology of the Grants uranium region 1979: New Mexico Bureau of Mines and Mineral Resources Memoir 38, p. 116-121.

Scott, J. H., 1986, Analysis of geophysical well logs from the Mariano Lake-Lake Valley drilling project, San Juan basin, New Mexico, in Turner-Peterson, C. E., Santos, E. S., and Fishman, N.S., eds., A basin analysis case study-The Morrison Formation, Grants uranium region, New Mexico: American Association of Petroleum Geologists Studies in Geology 22, p. 241-256.

Singer, A., and Stoffers, P., 1980, Clay mineral diagenesis in two East African lake sediments: Clay Minerals, v. 15, p. 291-307.

Smith, J. V., 1974, Feldspar minerals, v. 1, Crystal structure and physical properties: New York, Springer-Verlag, 627 p. 
Squyres, J. B., 1980, Origin and significance of organic matter in uranium deposits of Morrison Formation, San Juan basin, New Mexico, in Rautman, C. A., compiler, Geology and mineral technology of the Grants uranium region 1979: New Mexico Bureau of Mines and Mineral Resources Memoir 38, p. 86-97.

Steele, B. A., 1984, Preliminary report on the petrography of the Upper Jurassic Morrison Formation, Mariano LakeLake Valley drilling project, McKinley County, New Mexico: U.S. Geological Survey Open-file Report 84-170, 43 p.

Surdam, R. C., Boese, S. W., and Crossey, L. J., 1984, The chemistry of secondary porosity, in McDonald, D. A., and Surdam, R. C., eds., Clastic diagenesis: American Association of Petroleum Geologists Memoir 37, p. 127-149.

Turner-Peterson, C. E., 1986, Fluvial sedimentology of a major uranium-bearing sandstone; A study of the Westwater Canyon Member of the Morrison Formation, San Juan basin, New Mexico, in Turner-Peterson, C. E., Santos, E. S., and Fishman, N.S., eds., A basin analysis case study-The Morrison Formation, Grants uranium region, New Mexico: American Association of Petroleum Geologists Studies in Geology 22, p. 47-76.
Turner-Peterson, C. E., Gunderson, L. C., Francis, D. S., and Aubrey, W. M., 1980, Fluvio-lacustrine sequences in the Upper Jurassic Morrison Formation and the relationship of facies to tabular uranium ore deposits in the Poison Canyon area, Grants mineral belt, New Mexico, in TurnerPeterson, C. E., ed., Uranium in sedimentary rocksApplication of the facies concept to exploration: Rocky Mountain section, Society of Economic Paleontologists and Mineralogists, p. 177-211.

Whitney, G., 1986, Petrology of clay minerals in the subsurface Morrison Formation near Crownpoint, southern San Jaun basin, New Mexico-An interim report, in Turner-Peterson, C. E., Santos, E. S., and Fishman, N.S., eds., A basin analysis case study-The Morrison Formation, Grants uranium region, New Mexico: American Association of Petroleum Geologists Studies in Geology 22, p. 315-330.

Yermolayev, N. P., Zhidikova, A. P., and Zarinskiy, V. A., 1965, Transport of uranium in aqueous solutions in the form of complex silicate ions: Geokhimiya, no. 7, p. 813-826. 


\title{
Diagenesis and the Sources of the Ore-Forming Fluids, Tony M. Vanadium-Uranium Deposit, Henry Structural Basin, Utah
}

\author{
BY H. ROY NORTHROP, MARTIN B. GOLDHABER, C. GENE WHITNEY, \\ FRED PETERSON, RICHARD L. REYNOLDS, and JOHN A. CAMPBELL, \\ U.S. Geological Survey, Box 25046, Denver Federal Center, MS 963, \\ Denver, Colorado 80225
}

\section{CONTENTS}

\section{Abstract 282}

Introduction 282

Acknowledgments 282

Geologic setting $\mathbf{2 8 2}$

Stratigraphy and lithology 282

Age of mineralization $\mathbf{2 8 2}$

Temperature of mineralization $\mathbf{2 8 2}$

Experimental methods 283

Results 284

Mineralogy of the deposits $\mathbf{2 8 4}$

Stable isotope geochemistry $\mathbf{2 8 4}$

Discussion 286

Conclusions 289

References cited $\mathbf{2 8 9}$

\section{FIGURES}

1. Map of Henry basin showing location of Tony M. mine 283

2-3. Charts showing:
2. Distribution of ore-stage dolomite $\mathbf{2 8 4}$

3. $\delta^{18} \mathrm{O}$ values of calcite and dolomite $\mathbf{2 8 5}$

4-5. Histograms of:
4. $\delta^{18} \mathrm{O}$ values of calcite and dolomite $\mathbf{2 8 5}$

5. Calculated $\delta^{18} \mathrm{O}$ and $\delta \mathrm{D}$ values of waters in equilibrium with clay minerals 286

6-8. Charts showing:

6. Calculated $\delta^{18} \mathrm{O}$ versus $\delta \mathrm{D}$ composition of waters in equilibrium with authigenic clay minerals 286

7. Variation of calculated $\delta^{18} \mathrm{O}$ values of water in equilibrium with authigenic clay minerals with depth 287

8. Time versus rate of formation of ore horizon $\mathbf{2 8 8}$

In Memoriam

H. Roy Northrop $3 / 9 / 48-6 / 24 / 87$ 


\begin{abstract}
Tabular-type vanadium-uranium deposits occur in the Upper Jurassic Morrison Formation in the Henry structural basin, Utah. Mineralization took place at and immediately below an interface between a basin-derived brine and meteoric water. Based on isotopic compositions calculated from authigenic clay minerals, one of the two waters appears to have been a connate basinal brine, and was probably derived from dewatering of the evaporite-mudflat sediments subjacent to the mineralized strata. The other solution appears to have been meteoric water that migrated downward through the superjacent sediments shortly after their deposition. Vanadium and uranium, soluble in their $4+$ and $6+$ valance states, respectively, were carried in the meteoric water, were reduced at and immediately below the brine-meteoric water interface, and were precipitated as coffinite, vanadium-rich chlorite, and vanadium oxyhydroxide.
\end{abstract}

\section{INTRODUCTION}

Genetic models for the formation of tabular-type vanadium-uranium deposits of the Colorado Plateaus province have been proposed by many workers (see Thamm and others, 1981; Finch, 1967 for a history). Of all these models, only Fischer (1947), Shawe (1956), and Granger (1976) proposed ore deposition at the interface between a brine and fresh water. Key data to support this brine-interface model or any of the proposed genetic models have been lacking until our work.

This paper summarizes chemical, mineralogic, and isotopic data from one tabular-type vanadium-uranium deposit, the Tony M. orebody in the Henry basin in southcentral Utah. It focuses on data that constrain the sources of the waters involved in the ore-forming process and emphasizes the role of diagenesis in the formation of this deposit. More detailed reports on this subject have been published elsewhere (see Northrop and others, in press a, in press b; Goldhaber and others, in press; Northrop and Goldhaber, in press).

\section{Acknowledgments}

Plateau Resources Ltd. allowed unlimited access to both core and mine samples and shared insight and ideas that made this study possible.

\section{GEOLOGIC SETTING}

\section{Stratigraphy and lithology}

The Tony M. vanadium-uranium deposit is hosted by fluvial sandstones of the Salt Wash Member of the Upper Jurassic Morrison Formation in the Henry structural basin, Utah (fig. 1; and Peterson, 1980). In general, the orebody is typical of tabular vanadium-uranium deposits of the Colorado Plateaus province and consists of two (or locally three) closely spaced vanadium-uranium-rich layers separated by an interval barren of uranium but enriched in vanadium (Carpenter, 1980). The package of rocks containing the uranium ore zones and the vanadium-rich, uranium-poor (barren) zones is referred to as the mineralized interval. The tabular (peneconcordant) mineralized interval crosses stratigraphic boundaries at a shallow angle and climbs stratigraphically to the northeast down the inferred paleohydrologic gradient (Peterson, 1978, 1980). The westernmost part of the Tony M. orebody intersects a lower bounding mudstone, the Tidwell Member of the Morrison Formation; the remainder of the orebody is suspended within sandstones of the Salt Wash. The mineralized interval contains anomalous concentrations of organic matter (dominantly detrital plant debris), magnesium, molybdenum, selenium, aluminum, and isotopically light pyritic sulfur, in addition to the vanadium and uranium (Carpenter, 1980; Northrop, 1982).

\section{Age of mineralization}

Attempts to date the vanadium-uranium mineralization in the Henry basin have been disappointing. Uranium-lead ages are all discordant, apparently minimum ages, that constrain the time of mineralization to latest Jurassic or earliest Cretaceous, but allow ages approaching that of the host rocks (K. R. Ludwig, U.S. Geological Survey, Denver, Colorado, written commun., 1982). Rb-Sr ages determined on the authigenic chlorites indicate the same time period, but the chlorite appears to have remained an open system with respect to strontium, resulting in large errors and unreliable ages (K. R. Ludwig, oral commun., 1984). Geologic constraints (Peterson, 1978 , 1980; Northrop, 1982) suggest that the vanadiumuranium mineralization took place early in the diagenetic history of the host rock. Petrographic observations of Goldhaber and others (in press) support this suggestion.

\section{Temperature of mineralization}

In recent years considerable evidence has accumulated to indicate that vanadium-uranium mineralization took place at low temperatures (see, for example, Nash and others, 1981). With respect to the Tony M. orebody, additional evidence supporting low-temperature mineralization includes the presence of ore-stage bacteriogenic pyrite (Carpenter, 1980; Northrop, 1982; Goldhaber and others, in press); such sulfate-reducing bacteria live at temperatures less than $80^{\circ} \mathrm{C}$. The occurrence of pre-ore smectite (Northrop, 1982) suggests that these rocks probably have never been subjected to temperatures greater than about $60^{\circ} \mathrm{C}$ (Reynolds, 1980). Geologic reconstruction 


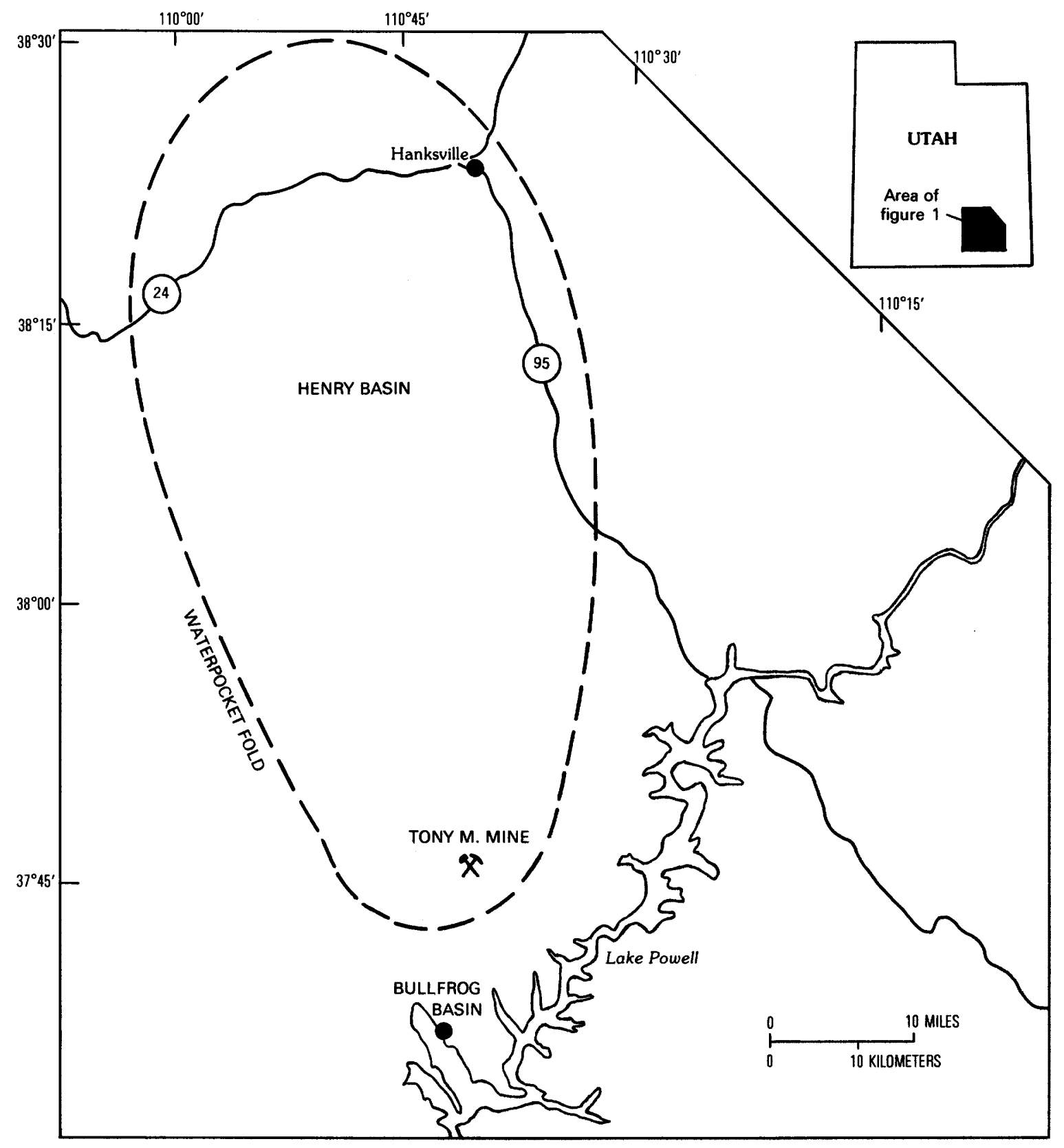

Figure 1. Map showing margin (dashed line) of the Henry basin, south-central Utah, which is a doubly plunging syncline, that forms a structurally closed basin. Also shown is location of Tony M. mine, in the Salt Wash Member of the Upper Jurassic Morrison Formation. Circled numbers, State highways.

of the sediment pile (Peterson, 1980) places the maximum depth of burial for the mineralized interval at less than 1 kilometer. Thus, at any reasonable geothermal gradient, vanadium and uranium must have been deposited at temperatures less than $50^{\circ} \mathrm{C}$. Temperaturedependent, stable-isotope data are presented here for $25^{\circ} \mathrm{C}$; however, differences in the actual temperature, within the described constraints, will not change their interpretation.

\section{EXPERIMENTAL METHODS}

All samples were obtained from cores drilled below the static water table. Bulk samples were disaggregated by hand in a mortar and pestle. Oxygen isotope analyses of carbonate minerals were made on these disaggregated samples. Clay mineral separations were made by soaking the disaggregated samples in distilled water and sonifying them to separate the clay-size particles from other 
phases. The clay fraction (less than 2 micrometer $(\mathrm{m} \mu)$ ) was then separated by centrifugation. Oriented slides were prepared for X-ray diffraction analysis using the method described by Drever (1973). Clay-size fractions were prepared for oxygen and hydrogen isotope analyses using the techniques described by Clayton and Mayeda (1963) and Savin and Epstein (1970). Oxygen isotope analyses of dolomites were made after first separating calcite from dolomite by the extraction procedure of Walters and others (1972). All isotope data are presented in the familiar delta $(\delta)$ notation, relative to Standard Mean Ocean Water (SMOW) (oxygen and hydrogen), PeeDee Formation Belemnite (PDB) (carbon), and Canyon Diablo Troilite (CDT) (sulfur).

\section{RESULTS}

\section{Mineralogy of the deposit}

Based on petrographic, scanning electron microscopic (including energy-dispersive X-ray analysis), and microprobe analyses, the uranium in the Tony $\mathbf{M}$. orebody is predominantly as the mineral coffinite. Vanadium is present in the mineralized interval both as an oxide mineral and in a vanadium-bearing chlorite (Whitney and Northrop, in press), which is the dominant clay mineral in the mineralized interval. Vanadium-rich, interstratified chlorite/smectite is laterally continuous with the mineralized interval, but areally beyond the economic limits of the orebody. Below the mineralized interval the predominant authigenic clay mineral is interstratified illite/smectite containing more than 75 per cent expandable layers. The predominant clay minerals above the mineralized interval are kaolinite in sandstones and smectite in bentonitic horizons. Smectite, in both the Tidwell and unmineralized Salt Wash Members, predates mineralization, whereas the kaolinite postdates the mineralization.

Pore-filling carbonate minerals include pre-ore and post-ore calcite and ore-stage dolomite that occurs as a micritic cement within the mineralized interval and as euhedral rhomboids above the mineralized interval (Goldhaber and others, in press). The dolomite content of the host rock increases systematically upward from the mineralized interval and reaches a maximum about 6 meters above the mineralized interval. On the other hand, the dolomite content of the mineralized interval is low and represents a local minimum in the dolomite content of the host rock (fig. 2) (Northrop and others, in press a).

\section{Stable isotope geochemistry}

The $\delta^{18} \mathrm{O}$ of the dolomite cements decreases upward from the zone of minimum dolomite in the mineralized interval, through the zone of maximum dolomite

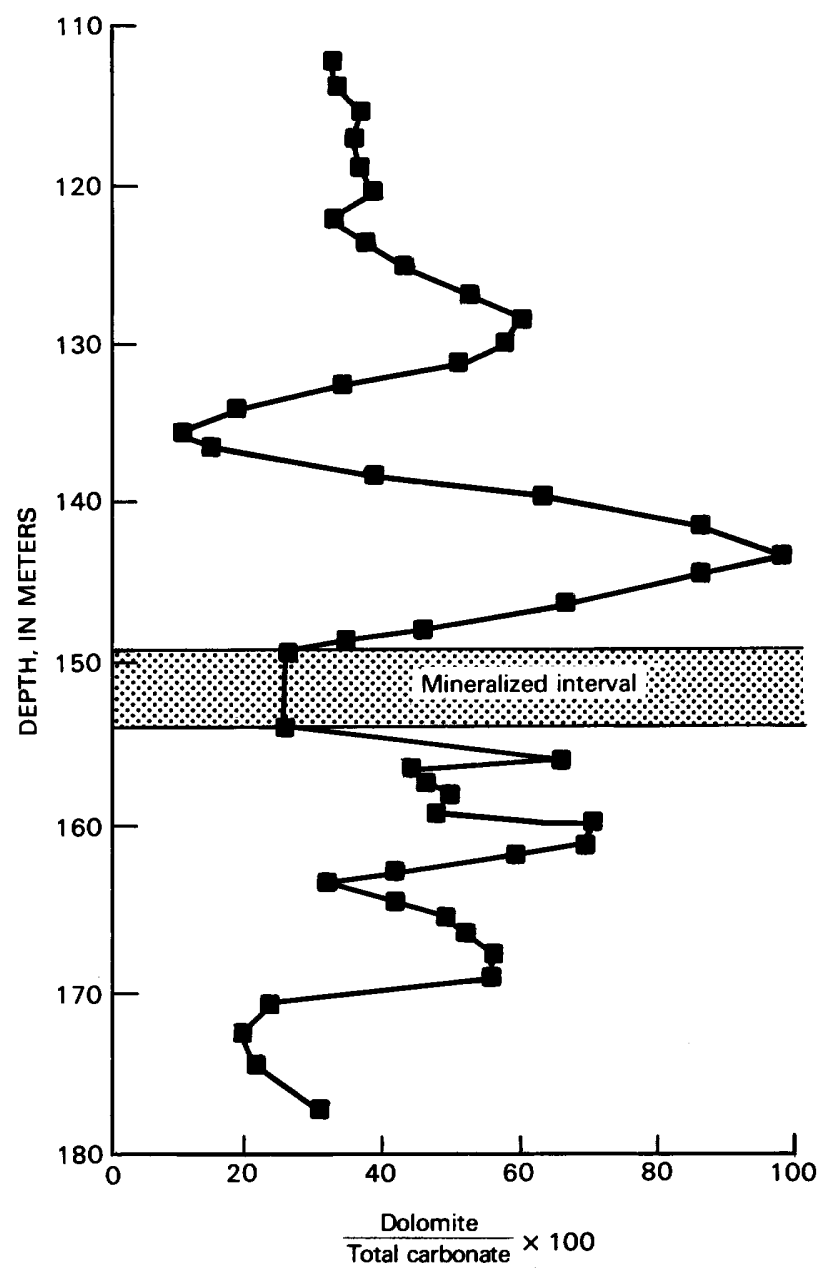

Figure 2. Distribution of authigenic, ore-stage dolomite cement in core $3 \mathrm{C}$, which penetrated the mineralized interval of the Tony $M$. orebody. Dolomite abundance is shown as per cent of total carbonate that is dolomite, as determined semiquantatively by $\mathrm{X}$-ray diffraction.

above the mineralized interval (fig. 3). Oxygen isotope values of the dolomite in the mineralized interval are between +19 and +22 per mil (SMOW) and decrease to between +17 and +18.5 per mil in the zone of maximum dolomite content directly above the mineralized interval. Values between +14 and +16 per mil (SMOW) were found in the low-dolomite, unmineralized Salt Wash at greater distances above the mineralized interval.

The $\delta^{18} \mathrm{O}$ composition of pre- and post-ore calcite from the Salt Wash ranges from +15 to +18.5 per mil (SMOW), consistent with a diagenetic environment dominated by meteoric water (Keith and Weber, 1964) (fig. 4). In contrast, the $\delta^{18} \mathrm{O}$ composition of the bedded limestones in the underlying marine Summerville Formation and in the evaporite-dominated basal Tidwell Member of the Morrison Formation ranges from +16.4 to +30 per mil, more typical of marine and marine-evaporite conditions of formation (fig. 4). The $\delta^{18} \mathrm{O}$ values of the 


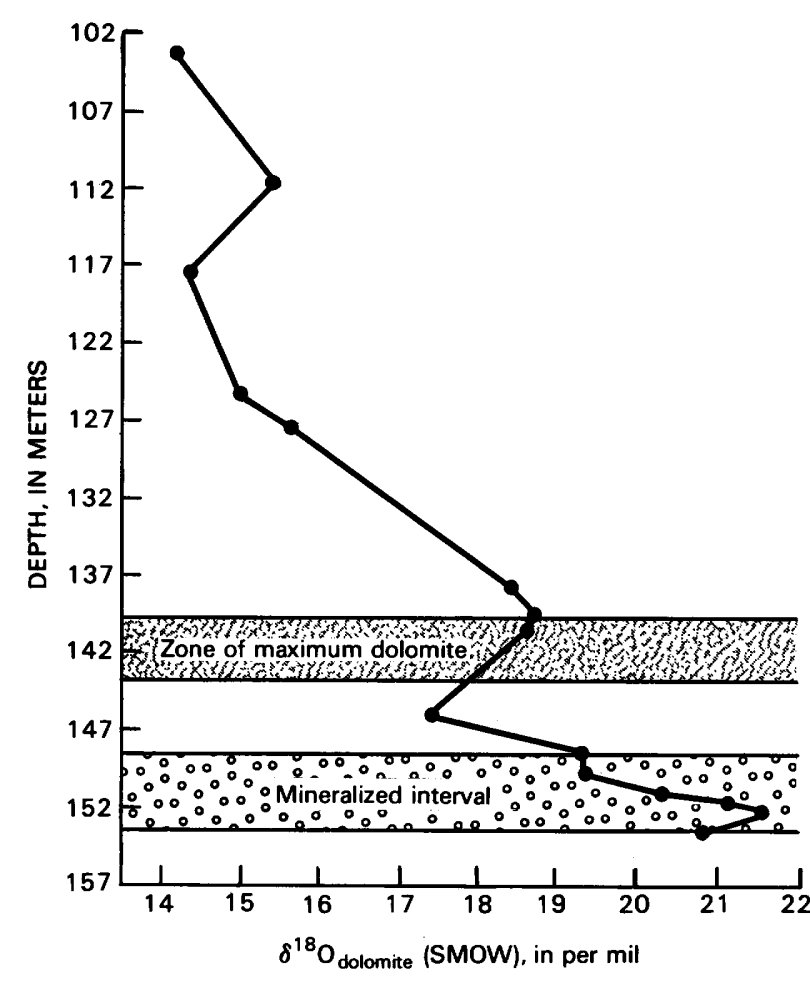

Figure 3. The $\delta^{18} \mathrm{O}$ values of dolomite versus depth in core $3 C$, Tony $M$. orebody. Dolomite maximum superjacent to the mineralized interval and the mineralized interval are shown for reference. SMOW, Standard Mean Ocean Water. dolomites in the mineralized interval of the Tony $M$. orebody are also in this range. Even though the range of values for each population is fairly large, calcite in both the Summerville Formation and Tidwell Member of the Morrison Formation and dolomite in the mineralized interval are all isotopically heavier than dolomite in the unmineralized rock and heavier than the pre- and postore calcites. The existence of these two populations of oxygen isotopes in carbonate minerals requires two waters of different oxygen isotopic composition. These specific isotope signatures imply that one water was meteoric and that the other was seawater.

The oxygen and hydrogen isotopic composition of waters in equilibrium with various clay minerals was determined using calculated isotopic compositions of individual clay phases (Northrop and Goldhaber, in press). The clay-size fraction itself was always a mixture of two or more different clay minerals; hence, the isotopic compositions of these fractions were meaningless. End-member isotopic compositions, however, could be solved graphically by plotting $\delta^{18} \mathrm{O}$ or $\delta \mathrm{D}$ versus the abundance of either clay phase for two-phase mixtures. End-member isotopic compositions for three-phase mixtures were calculated using the solutions of the two-phase mixtures together with a series of isotope mass-balance equations, solved simultaneously. The isotopic compositions of waters in equilibrium with clay minerals define two distinct populations (figs. $5 A, B$, and 6). One population, having $\delta^{18} \mathrm{O}$ values greater than -4 per mil and $\delta \mathrm{D}$ values greater than -30 per mil, included all the samples from

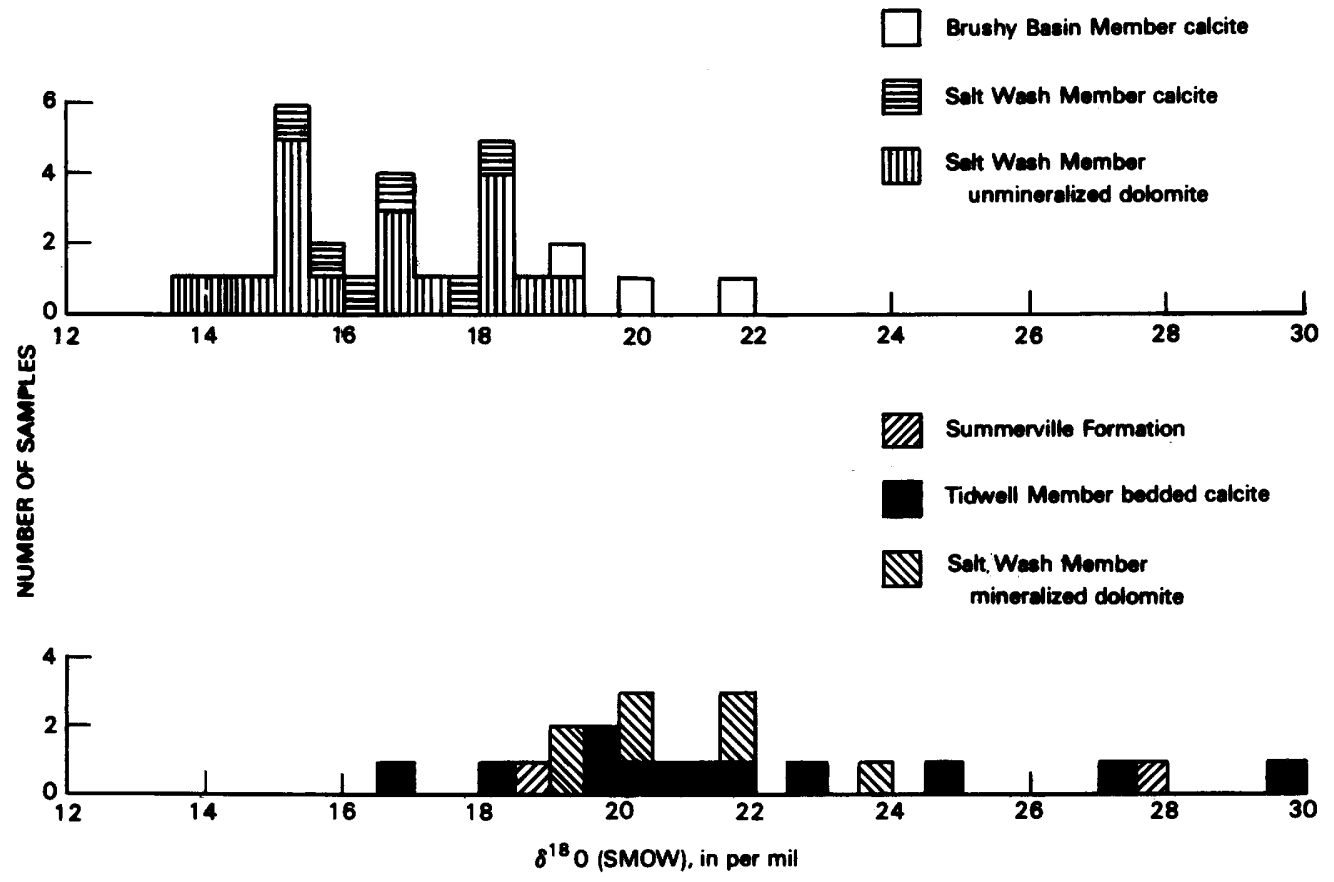

Figure 4. Histograms of calcite and dolomite $\delta^{18} \mathrm{O}$ values from the Jurassic Summerville Formation and Tidwell, Salt Wash, and Brushy Basin Members of the Morrison Formation in the Henry basin, Utah. SMOW, Standard Mean Ocean Water. 

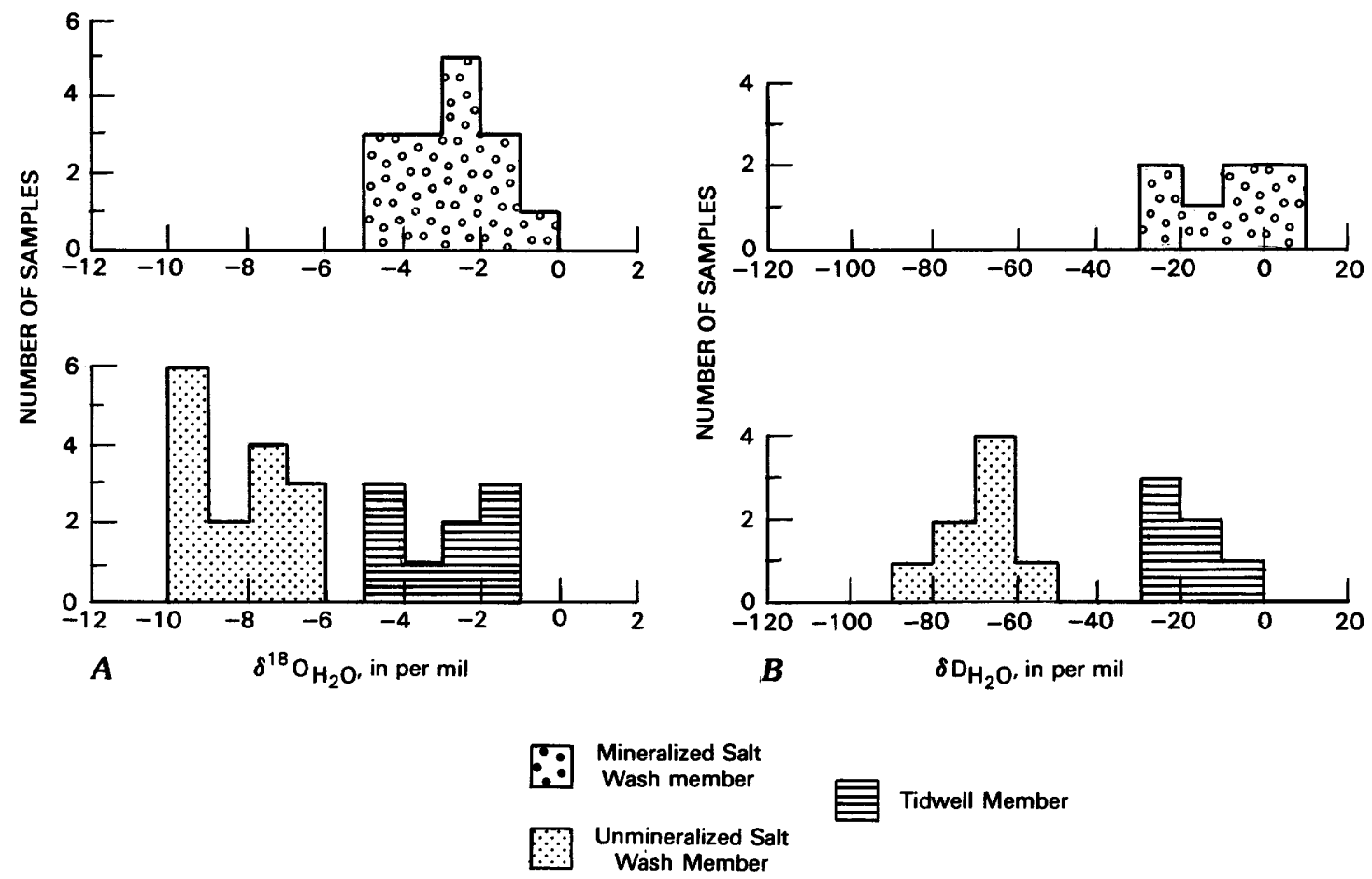

Figure 5. The $\delta^{18} \mathrm{O}(\mathrm{A})$ and $\delta \mathrm{D}(\mathrm{B})$ composition of waters calculated to have been in equilibrium (at $25^{\circ} \mathrm{C}$ ) with authigenic clay minerals from the Salt Wash and Tidwell Members of the Morrison Formation, Henry basin, Utah (Northrop and others, in press b).

the mineralized interval and the Tidwell Member below the mineralized interval. The other population, having $\delta^{18} \mathrm{O}$ values less than -6 per mil and $\delta \mathrm{D}$ values less than -60 per mil, included all the unmineralized samples from the Salt Wash Member. The boundary between these two populations corresponds to the top of the mineralized interval in the Tony M. orebody (fig. 7). Over a vertical interval of about 2 meters the $\delta^{18} \mathrm{O}$ of the calculated waters decreased from about -3 to -9 per mil, and the $\delta \mathrm{D}$ of the waters decreased from -25 to -65 per mil.

\section{DISCUSSION}

During Jurassic time, the Henry basin was a tectonically evolving, doubly plunging syncline. Variable rates of subsidence within the basin actively created intrabasinal folding (Peterson, 1980, 1984). Continued subsidence resulted in a continuous addition to the sediment pile within the basin, which was accompanied by compaction and eventually dewatering of the deeper sediments of the Jurassic Morrison Formation. Evolving intrabasinal structures further influenced sedimentation and basin hydrology. Within this sedimentological regime, relatively small lakes with anoxic bottom waters existed. These lakes appear to have been responsible for the local preservation of detrital plant debris (Peterson, 1980). This plant debris later served as a food source for sulfate-reducing bacteria, the actions of which appear to have provided the reductant for the vanadium and uranium (Northrop

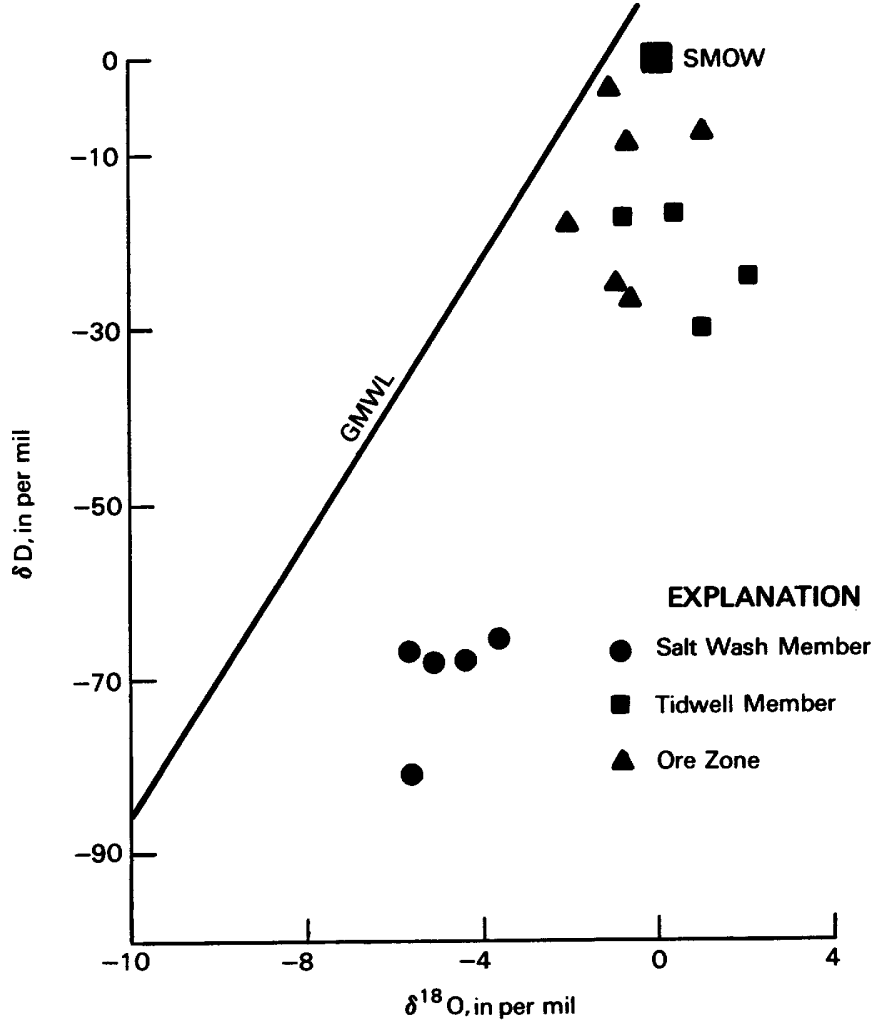

Figure 6. $\delta^{18} \mathrm{O}$ versus $\delta \mathrm{D}$ composition of waters, calculated from authigenic clay minerals from the Salt Wash and Tidwell Members of the Morrison Formation, core 3C, Henry basin, Utah (Northrop and others, in press b). Global Meteoric Water Line (GMWL) (Craig, 1961) shown for reference. Standard Mean Ocean Water (SMOW) is standard against which values are reported. 


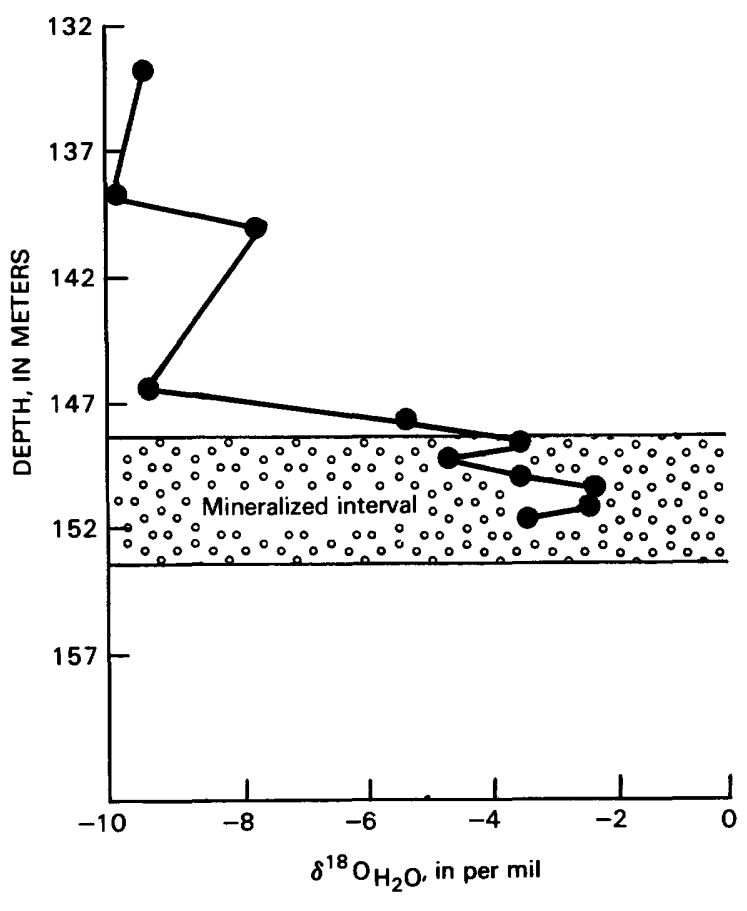

Figure 7. Variation of $\delta^{18} \mathrm{O}$ of waters calculated from authigenic clay minerals versus depth in core $3 C$, Tony $M$. orebody. Mineralized interval is shown for reference.

and others, in press a; Goldhaber and others, in press).

The oxygen and hydrogen isotopic composition of waters calculated to be in equilibrium with authigenic clay minerals in the unmineralized Salt Wash have values typical of meteoric waters (fig. 6); these values are slightly enriched in ${ }^{18} \mathrm{O}$ with respect to meteoric water when compared with the global meteoric water line (GMWL) defined by Craig (1961). This "oxygen shift" (see, for example, Taylor, 1976) predictably resulted from the migration of meteoric water down through the recently deposited pile of sediment containing abundant volcanic ash. The difference in hydrogen isotope values between the calculated waters and modern meteoric water is consistent with the well-documented tectonic extension and northerly migration of the western United States since the Jurassic (Parrish and others, 1982). The $\delta^{18} \mathrm{O}$ values of the pre- and post-ore calcite and the dolomite in the unmineralized zone are typical of carbonate cements formed from meteoric ground waters (Keith and Weber, 1964).

The similarity of the isotopic composition of waters calculated from the authigenic clay minerals in the mineralized interval and Tidwell Member to that of seawater (SMOW; fig. 6) indicates that seawater was a likely source for that water; however, brines coexisting with closedbasin evaporites also have $\delta \mathrm{D}$ and $\delta^{18} \mathrm{O}$ values in the same range. The basal Tidwell Member in the structurally closed Henry basin contains such evaporites (Peterson 1978, 1980); moreover, the Tidwell Member has always been considered to be of terrestrial origin. Because the $\delta^{34} \mathrm{~S}, \delta^{13} \mathrm{C}$, and $\delta^{18} \mathrm{O}$ values of sulfate and carbonate minerals in the Tidwell evaporites (Northrop, 1982) are sufficiently close to those of seawater, distinguishing water source is impossible from the existing data. Regardless of whether the water was of marine or terrestrial evaporite origin, the isotopic composition of the authigenic clay minerals in the Tidwell Member and in the mineralized interval indicates that these minerals formed in equilibrium with the same highly saline connate waters. This link between the mineralized interval and the underlying Tidwell can also be seen in the $\delta^{18} \mathrm{O}$ values of the dolomites, the magnesium content of authigenic clay minerals, and the sodium content of the pore-filling phases throughout the Tidwell and Salt Wash Members (Northrop 1982; Northrop and others, in press a, in press b).

Thorium:uranium ratios and the vanadium content of the unmineralized Morrison Formation in the Henry basin indicate that the likely source of the vanadium and uranium for these deposits was the overlying Salt Wash and Brushy Basin Members (Northrop, 1982; Northrop and others, in press a). The oxygen isotopic composition of dolomite in the mineralized interval and of the vanadium-bearing chlorite indicate that the vanadium and uranium-bearing phases formed within the brine. This mode of origin requires that the vanadium and uranium were transported by the meteoric water and that they were removed from solution at the boundary between the two waters. The mineralizing process, as reflected by the vanadium-uranium content of the rock, was most intense immediately below the brine-meteoric water interface and decreased in intensity downward for 1-3 meters below that interface (Carpenter, 1980; Northrop, 1982). This vanadium-uranium pattern, as well as the $\mathrm{Mg}$ :Fe ratios in authigenic clay minerals (Northrop and others, in press b) are repeated at each uranium ore-horizon within the mineralized interval in the Tony M. orebody, as well as in the other orebodies in the Henry basin (Northrop and others, in press a; Goldhaber and others, in press). This systematic pattern requires that each uranium ore-horizon within the mineralized interval formed at different times near a static (or nearly static) interface that moved periodically to successively higher stratigraphic levels rather than simultaneously during a single mineralizing episode.

Dolomite maxima, one of which is laterally continuous for more than 5 kilometers above each mineralized interval in rocks wherein calcite otherwise predominates requires either dedolomitization of the entire Salt Wash (except for these dolomite-rich peneconcordant layers) or dolomitization of thin tabular layers. The sabka model of dolomitization, whereby dolomite forms preferentially in the fluid-mixing zone (see, for example, Hsu and Siegenthaler, 1969; Atwood and Bubb, 1970; Folk and Land, 1975; Magaritz and others, 1980) between a magnesium-rich brine and meteoric water is our preferred 
explanation. The systematic decrease in $\delta^{18} \mathrm{O}$ values of the dolomite from within to 10 meters above the mineralized interval supports fluid mixing in this zone. Evidence of such a mixing interval cannot be seen from the clay mineral data because ore-stage clay minerals are absent above the mineralized interval.

The Tidwell and Salt Wash Members in the Henry basin contain four identified stratigraphic levels at which brine-meteoric water interfaces were stable. Three of these contain potentially economic vanadium-uranium concentrations (Northrop and others, in press a; Goldhaber and others, in press). Based on vanadium and uranium contents of natural waters (Granger and Warren, 1978; Langmuir, 1978) and the solubility limits of vanadium and uranium in the same solution (Hostetler and Garrels, 1962), the time necessary to form an average ore-horizon can be calculated. The flow rate of the meteoric water that carried the vanadium and uranium to the site of mineralization, and the efficiency of the mineralizing process to concentrate vanadium and uranium are the rate-limiting steps. The rate of change in the position of the brine-meteoric water interface can also be calculated, based on Peterson's (1980) suggested tectonic movements of 0.01 to 0.02 millimeters per year. This calculation obviously assumes that the interface position is tied to the geologic evolution of the Henry basin. The sample calculation shown in figure 8 illustrates that transport times for vanadium and uranium, in the range of tens-of-thousands of years, are sufficiently long to have formed the ore zone during the time the brine-meteoric water interface migrated upwards through the thickness of this ore zone.

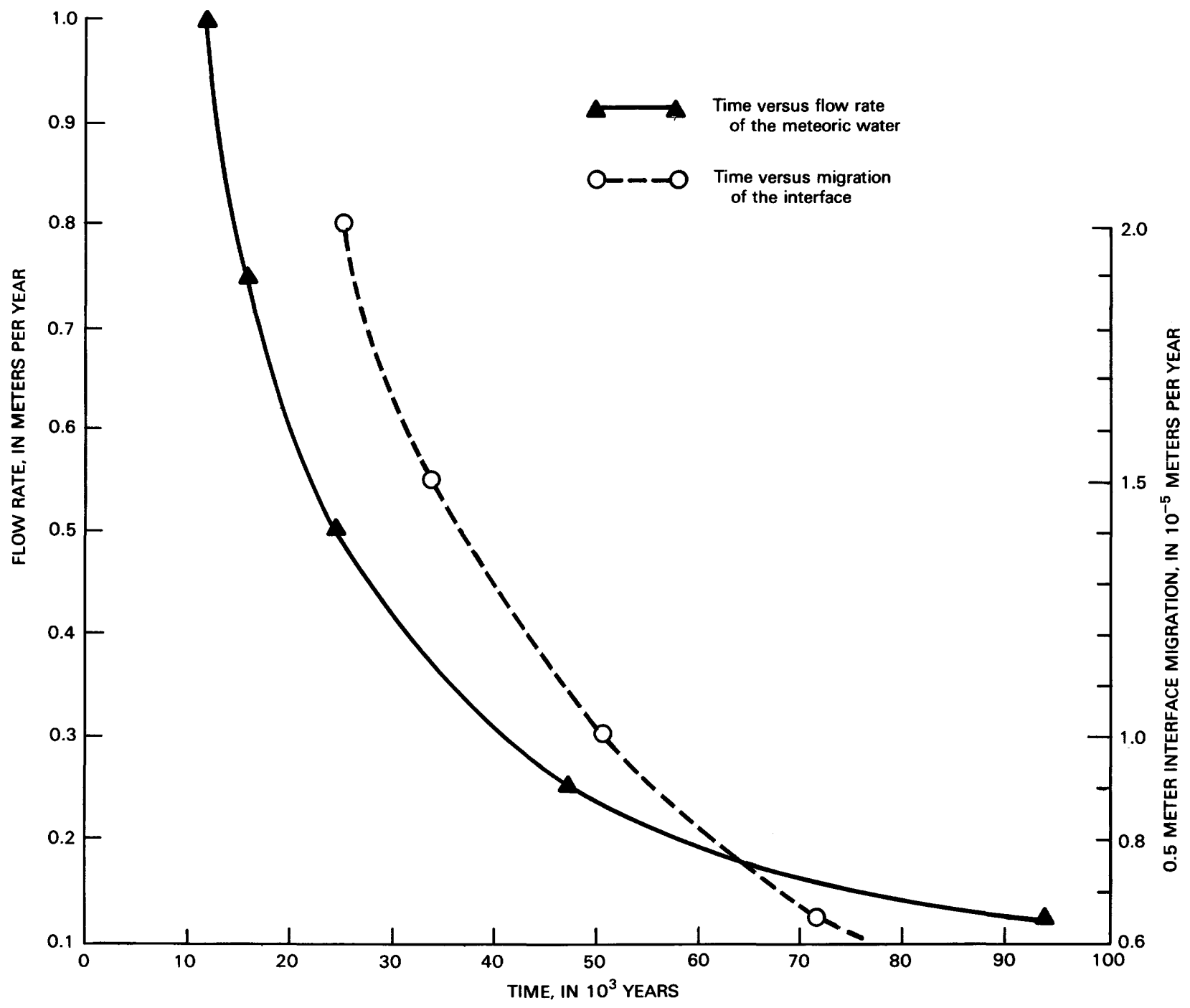

Figure 8. Plot showing time versus rate plot of formation of a typical ore-horizon, $0.5 \mathrm{~m}$ thick containing 9,750 parts per million (ppm) vanadium and 1,500 ppm uranium. Starting water for this calculation contained 85 parts per billion (ppb) uranium and $552 \mathrm{ppb}$ vanadium. We have assumed that 75 percent of the vanadium and uranium in the starting water was removed by the precipitation reactions. Vanadium to uranium molar ratio shown (6.5:1) is typical of the Tony M. orebody (Carpenter, 1980; Northrop, 1982). 


\section{CONCLUSIONS}

The calculated isotopic composition of waters from which authigenic minerals in the Tony $\mathbf{M}$. orebody formed indicate that vanadium-uranium mineralization took place at the boundary between two isotopically distinct waters. The oxygen and hydrogen isotope data place constraints on the sources of the waters involved in the mineralizing process. The lower fluid appears to have been a connatebasin brine, derived at least in part from the Tidwell Member of the Morrison Formation within the Henry basin. The upper fluid was meteoric water, migrating downward through the superjacent strata. In this structurally closed basin, the brine occupied the deepest permeable horizons and formed a stable interface with the overlying meteoric waters. A stable interface within the same stratigraphic interval must have existed for sufficient periods of time for vanadium-uranium mineralization to have occurred at and directly below the interface. Immediately above the interface was a thin (about 10 meters) zone of mixing of the two waters. Most of the authigenic, ore-stage dolomite precipitated in the mixing zone.

\section{REFERENCES CITED}

Atwood, D. K., and Bubb, J. N., 1970, Distribution of dolomite in a tidal flat environment, Sugarloaf Key, Florida: Journal of Sedimentary Petrology, v. 78, p. 499-505.

Carpenter, D. J., 1980, Elemental, isotopic and mineralogic distributions within a tabular-type uranium-vanadium deposit, Henry Mountains mineral belt, Garfield County, Utah: M.S. thesis, Golden, Colorado, Colorado School of Mines, $156 \mathrm{p}$.

Clayton, R. N., and Mayeda, T. K., 1963, The use of bromine pentafluoride in the extraction of oxygen from oxides and silicates for isotopic analysis: Geochimica et Cosmochimica Acta, v. 27, p. 43-52.

Craig, Harmon, 1961, Isotopic variations in meteoric waters: Science, v. 133, p. 1702-1703.

Drever, J. I., 1973, The preparation of oriented clay mineral specimens for X-ray diffraction analysis by a filter-membranes peel technique: American Mineralogist, v. 58, p. 553-554.

Finch, W. I., 1967, Geology of epigenetic uranium deposits in sandstones in the United States: U.S. Geological Survey Professional Paper 538, 121 p.

Fischer, R. P., 1947, Deposits of vanadium-bearing sandstone, in Vanderwilt, J. W., ed., Mineral resources of Colorado: Colorado Mineral Resources Board, p. 451-456.

Folk, R. L., and Land, L. S., 1975, Mg/Ca ratios and salinity; two controls over crystallization of dolomite: American Association of Petroleum Geologists Bulletin, v. 59, p. 60-68.

Goldhaber, M. B., Reynolds, R. L., Campbell, J. A., Wanty, R. D., Grauch, R. I., and Northrop, H. R., in press, Genesis of the tabular-type vanadium-uranium deposits, Henry structural basin, Utah. Part II. Mechanism of ore and gangue mineral formation at the interface between brine and meteoric water: Economic Geology.
Granger, H. C., 1976, Fluid flow and ionic diffusion and their roles in the genesis of sandstone-type uranium ore bodies, U.S. Geological Survey Open-File Report 76-454, 26 p.

Granger, H. C., and Warren, C. G., 1978, Some speculations on the genetic geochemistry and hydrology of roll-type uranium deposits: Wyoming Geological Association Annual Conference, 30th Guidebook, p. 349-361.

Hostetler, P. B., and Garrels, R. M., 1962, Transportation and precipitation of uranium and vanadium at low temperatures, with special reference to sandstone-type uranium deposits: Economic Geology, v. 57, p. 137-167.

Hsu, K. J., and Siefenthaler, C., 1969, Preliminary experiments on hydrodynamic movements induced by evaporation and their bearing on the dolomite problem: Sedimentology, v. 12 , p. $11-25$.

Keith, M. L., and Weber, J. N., 1964, Carbon and oxygen isotopic composition of selected limestones and fossils: Geochimica et Cosmochimica Acta, v. 28, p. 1782-1816.

Langmuir, D., 1978, Uranium solution-mineral equilibria with application to sedimentary ore deposits: Geochimica et Cosmochimica Acta, v. 42, p. 547-569.

Magaritz, M., Goldenberg, L., Kafri, U., and Arad, A., 1980, Dolomite formation in the seawater-freshwater interface: Nature, v. 287 , p. 622-624.

Nash, J. T., Granger, H. C., and Adams, S. S., 1981, Geology and concepts of genesis of important types of uranium deposits: Economic Geology, 75th Anniversary Vol., p. 63-116.

Northrop, H. R., 1982, Origin of the tabular-type vanadiumuranium deposits in the Henry structural basin, Utah: Ph.D. thesis, Golden, Colorado, Colorado School of Mines, $340 \mathrm{p}$.

Northrop, H. R., and Goldhaber, M. B., in press, The chemical, mineralogic, and stable isotopic composition of the Morrison Formation in the Henry structural basin, Utah: U.S. Geological Survey Open-File Report.

Northrop, H. R., Goldhaber, M. B., Landis, G. P., and Unruh, J. W., in press a, Genesis of the tabular-type vanadiumuranium deposits of the Henry basin, Utah. Part I. Geochemical and mineralogical evidence for the source of the ore-forming fluids: Economic Geology.

Northrop, H. R., Goldhaber, M. B., Whitney, C. G., Landis, G. P., and Rye, R. O., in press b, Genesis of the tabular-type vanadium-uranium deposits of the Henry basin, Utah. Part III. The mineralogy and geochemistry of clay minerals as evidence of mineralization: Economic Geology.

Parrish, J. T., Zeigler, A. M., and Scotese, C. R., 1982, Rainfall patterns and the distribution of coals and evaporites in the Mesozoic and Cenozoic: Palaeo, v. 40, p. 67-101.

Peterson, Fred, 1978, Measured sections of the lower Member and Salt Wash Member of the Morrison Formation (Upper Jurassic) in the Henry Mountains mineral belt of southern Utah: U.S. Geological Survey Open-File Report 78-1094, $95 \mathrm{p}$.

Peterson, Fred, 1980, Sedimentology as a strategy for uranium exploration: Concepts gained from analysis of a uraniumbearing depositional sequence in the Morrison Formation of south-central Utah, in Turner-Peterson, C.E., ed., Uranium in sedimentary rocks-Application of the facies concept to exploration: Denver, Colorado, Rocky Mountain Section, Society of Economic Paleoentologists and Mineralogists, p. 65-126. 
1984, Fluvial sedimentation on a quivering cratonInfluence of slight crustal movements on fluvial processes, Upper Jurassic Morrison Formation, western Colorado Plateau: Sedimentary Geology, v. 38, p. 21-49.

Reynolds, R. C., 1980, Interstratified clay minerals: in Brindley, G. W. and Brown, G., eds., Crystal structures of clay minerals and their X-ray identification: London, Mineralogical Society, p. 249-303.

Savin, S. M., and Epstein, S., 1970, The oxygen and hydrogen geochemistry of clay minerals: Geochimica et Cosmochimica Acta, v. 34, p. 25-42.

Shawe, D. R., 1956, Significance of roll ore bodies in genesis of uranium-vanadium deposits of the Colorado Plateau, in Page, L. R., Stocking, H. E., and Smith, H. B., compilers, Contributions to the geology of uranium and thorium: U.S. Geological Survey Professional Paper 300, p. 239-241.
Taylor, H. P. Jr., 1976, Oxygen isotope studies of hydrothermal mineral deposits, in Barnes, H. L., ed., Geochemistry of hydrothermal ore deposits: New York, Holt, Rinehart and Winston, p. 109-142.

Thamm, J. K., Kovschak, A. A., Jr., and Adams, S. S., 1981, Geology and recognition criteria for sandstone uranium deposits of the Salt Wash type, Colorado Plateau province: Final Report for U.S. Department of Energy, GJBX-6(81), $117 \mathrm{p}$.

Walters, L. J., Jr., Claypool, G. E., and Choquette, P. W., 1972, Reaction rates and $\delta^{18} \mathrm{O}$ variation for the carbonatephosphoric acid preparation method: Geochimica et Cosmochimica Acta, v. 36, p. 129-140.

Whitney, Gene, and Northrop, H. R., 1986, Vanadium chlorite from a sandstone-hosted vanadium-uranium deposit, Henry basin, Utah: Clays and Clay Minerals, v. 34, p. 488-495. 


\title{
Clay Mineral Diagenesis in Lacustrine Sediments
}

\author{
By BLAIR F. JONES, U.S. Geological Survey, National Center, MS 432, 12201 \\ Sunrise Valley Drive, Reston, Virginia 22092
}

\section{CONTENTS}

Abstract 292

Introduction 292

Acknowledgments 292

Observation and analytical evidence 292

Mechanisms of clay structural transformation 293

Chemical and mineralogical changes 293

Phase relations 295

Conclusions 298

References cited 298

\section{FIGURES}

1. Diagram of stability relations of hydrous magnesium silicates with respect to solution activities as calculated from thermodynamic data 297

2. Diagram of stability relations of hydrous magnesium and sodium-magnesium silicates as estimated from thermodynamic data and natural occurrences 298, 299

\section{TABLES}

1. Calculated structural formulas of lacustrine mixed-layer magnesium smectities 294

2. Stability reactions for sesquioxide-free hydrous magnesium silicates 296 


\section{Abstract}

Recent investigations of the geochemical evolution of waters and associated sediments in saline lake systems indicate that reactions involving silica or silicates remove major cations from solution. These studies have confirmed earlier observations by George Millot on ancient lacustrine deposits; he found that silica and cations in smectite clays. increase relative to alumina from basin margin to center. Mineralogical and chemical data from Lake Abert in south-central Oregon, the Amargosa Desert in southern Nevada, and Great Salt Lake, Utah, indicate that solute loss of $\mathrm{K}, \mathrm{Mg}$, and $\mathrm{Si}$ is commonly associated with the formation of a clay mineral component that increases with the proportion of solution to detrital solid, that is, the proportion of water to sediment inflow. Available evidence suggests that diagenesis in saline and perhaps freshwater sediments includes any or all of the following mechanisms in general sequence: hydrolysis of primary silicates (especially pyroclastic material), exchange and fixation of cations in interlayer positions in preexisting 2:1 silicate layers, and subsequent reaction with silica to form wholly authigenic interstratifications. The detailed structure of the final product depends on the hydrologic environment and its influence on $\mathrm{pH}$, solute silica, and alkali/ferromagnesium ratios.

\section{INTRODUCTION}

As with the marine environment, there has long been speculation as to what extent depositional conditions in lakes are reflected in the alteration or diagenesis of clays in lacustrine sediments. Garrels and Mackenzie (1967) presented the classic model of the development of alkaline, saline (so-called "soda") lakes by evaporative concentration of drainage from crystalline rock terranes. They proposed the direct precipitation of sepiolite from lake waters as the principal control on the concentration of silica (and magnesium) in solution. Similarly, Gac and others (1977), following the indications of Carmouze (1976), used an evaporative concentration model to postulate the authigenic formation of smectite in Lake Chad in central Africa. From their examination of the $<2-\mu \mathrm{m}$-size materials remaining after the experimental evaporation of Chari River inflow water, Gac and others (1977) suggested that the amount of smectite had increased over what was in the original suspended sediment. Jones and Bowser (1978), however, concluded that definitive mineralogical evidence was lacking for authigenesis of clays in freshwater lake sediments. The present paper examines the evidence for and the mechanisms of clay mineral diagenesis in saline, alkaline, and perhaps also freshwater lacustrine environments.

\section{Acknowledgments}

I thank the manuscript reviewers, Gene Whitney and L. V. Benson, and those who offered help and encouragement to the work: M. W. Bodine, R. G. Deike, D. D. Eberl, H. P. Eugster, J. Hower, B. Hudner, C. Moss, S. L. Rettig, R. J. Spencer, D. C. Thorstenson, A. H. Weir, and especially Betty Jones.

\section{OBSERVATION AND ANALYTICAL EVIDENCE}

In his 1964 treatise on the geology of clays, Georges Millot reviewed the clay mineral parageneses of alkaline lakes and marine basins and concluded that the "montmorillinoid" clays found in them were largely diagenetically transformed or authigenic in origin, processes that he termed "neoformation by addition." He noted a geochemical sequence in deposits of closed basins (or "confined environment deposits"): the most aluminous clays were at the periphery; they were succeeded by more magnesian smectites basinward; and sepiolite was found at the center. More recent studies of the geochemical evolution of waters in closed basins have documented the reaction of solutes with silica or silicates, processes that exert a significant influence on the solute budget of lake systems (Jones and VanDenburgh, 1966; VanDenburgh, 1975; Al Droubi and others, 1980; Eugster and Jones, 1979). Subsequent studies of recent lacustrine sediments at Lake Abert, Ore. (Jones and Weir, 1983), and Great Salt Lake, Utah (Spencer, 1982), have confirmed the sequence of more magnesian clay compositions basinward, and have associated it with increasingly saline conditions.

Although Millot's sequence can be simply related to silicate mineral solubility, evidence from modern and ancient lacustrine deposits indicates that the authigenic formation of clay minerals in a lake environment takes place far more commonly by diagenetic alteration of preexisting material than by direct precipitation of a new phase from solution. This phenomenon seems to be a function of the relative insolubilities of the hydroxides of major elements that compose the common clay mineral assemblages. Thus, colloidal aluminous or iron-rich particles may constitute the fundamental reactive base for the development of authigenic silicates. At the same time, silica can be accumulated in sediments by organisms or by inorganic precipitation as a result of evaporative concentration of a dilute water. Although uncommon, examples of direct reaction of sesquioxide with silica in relatively dilute water do exist. For example, at Lake Chad in central Africa, Pedro and others (1978) suggested that smectite formed by the reaction of silica with ironrich detrital particles contributed by the principal stream inflow. At Lake Malawi (Lake Nyasa), Africa, Müller and Förstner (1973) identified nontronite, which they interpreted as a product of the reaction of iron-bearing pore fluids with diatomite silica.

Based on the solubility of pure compounds, the next most insoluble precipitate-after alkaline earth 
carbonate-expected from the concentration of most natural waters would be some form of magnesium silicate (Jones and VanDenburgh, 1966; Al Droubi and others, 1980; Eugster and Jones, 1979). Detailed mineralogic examinations of sediments from modern saline lakes or playas in the United States (Droste, 1961; Güven and Kerr, 1966; Jones and others, 1972) have not identified sepiolite. Wollast and others (1968), in their study of sepiolite precipitation, noted that if "reactive aluminous phases" are present in sediment, a magnesium-aluminosilicate will form instead of sepiolite. Transformation of preexisting clays seems especially favored where the proportion of sediment to water is high and where the solute content is significant (that is, in typical saline lakes or playas). This type of diagenesis yields the same basinward compositional trend of increasing silica and magnesium that is expected from direct precipitation, as shown by the sequence of smectite compositions from the Lake Chad sediments reported by Carmouze and others (1977). Such transformations appear to be facilitated by the high reactivity of cryptocrystalline pyroclastics (Deike and Jones, 1980).

\section{Mechanisms of clay structural transformation}

Devitrification of volcanic glass typically results in the formation of dioctahedral smectite by complete hydration of the glass and subsequent leaching of variable amounts of silica and cations. Depending somewhat on the chemical heterogeneity of the glassy pyroclastic materials, some interstratification of the smectite may result from subaerial weathering and degradation during transport to the lacustrine depositional basin (Jones and Weir, 1983). Poor crystallinity or structural disorder in the cryptocrystalline smectite is probably the result of (1) the short-range order of the original volcanic glass, or (2) the extensive protonation of fundamental structural bonds in 2:1 silicate layers (Hem and Lind, 1974).

In addition to changes related to hydrolysis, the conditions resulting from organic degradation in lake-bottom sediments can cause the reduction of smectite iron, thereby accounting for the uptake of potassium or other ions in interlayer sites. Such a process was proposed by Singer and Stoffers (1980) for the formation of illite from smectite in sediment cores from Lake Albert (Zaire-Uganda) and Lake Manyara (Tanzania), east Africa; this same process can account for potassium enrichment and incipient illitization of smectite at Lake Abert (Jones and Weir, 1983). Singer and Stoffers (1980) concluded that the uptake of potassium into phyllosilicates is accompanied by the replacement of $\mathrm{Mg}$ for octahedral $\mathrm{Fe}^{3+}$, similar to the mechanism proposed by Drever (1971) for clay sediments in marine reducing environments. The experiments of Heller-Kallai and Rozenson (1978) with magnesium sulfide solutions, however, show that the reduction of iron in iron-bearing smectite leads initially to simple (and reversible) layer-charge increase (or to the formation of a degraded clay phase with increased ionexchange capacity), rather than directly to octahedral substitution of magnesium for iron, as suggested by Drever (1971). The lack of such direct octahedral substitution is more consistent with evidence for the uptake of potassium earlier than magnesium at Lake Abert (Jones and Weir, 1983) and Great Salt Lake (Spencer, 1982).

\section{Chemical and mineralogical changes}

Along with the ubiquitous carbonate deposition that accompanies increased salinity in lakes, the depletion of magnesium relative to solutes that are more conservative in solution has been documented in the geochemical evolution of most closed basin waters (Jones and VanDenburgh, 1966; Eugster and Jones, 1979). In many basins, magnesium depletion can be attributed to its incorporation in carbonate phases, but, as noted at Lake Abert (Jones and Weir, 1983) and Great Salt Lake (Spencer, 1982), magnesium is generally enriched in lake-sediment clay fractions as well. Magnesium solute depletion begins by the exchange of magnesium onto clays for calcium (which precipitates as $\mathrm{CaCO}_{3}$ ), and it apparently continues by the interlayer uptake of $\mathrm{Mg}(\mathrm{OH})^{+}$or by the intergrading of chloritic layers in smectite (probably facilitated by the reduction of octahedral iron as noted previously). Magnesium has been shown to be the predominant exchangeable cation in clays from Lake Abert (Jones and Weir, 1983) and the Amargosa Desert (Eberl and others, 1982), as well as from Lake Manyara (Singer and Stoffers, 1980). After magnesium exchange, these magnesium interlayers then react with noncrystalline silica to form interstratified kerolite, as has been suggested in the Lake Abert and Amargosa Desert deposits.

This reaction is similar to that of clay mineral authigenesis by fixation of silica on a metal hydroxide layer, as shown experimentally by Caillère and Hénin (1961). Indeed, much of the authigenic magnesium silicates found in lake deposits probably formed by the interstratification of (1) 9.6- $\AA$, nonexpanding trioctahedral kerolite; or (2) very low charge, nearly trioctahedral, stevensite domains and preexisting, perhaps largely dioctahedral smectite. The average structural formulas calculated for these interstratified minerals show that most of the layer charge arises from octahedral vacancies rather than tetrahedral substitution. Hence, the expanding component is termed stevensite rather than saponite, according to the criteria of Faust and others (1959). Brindley (1955) first recognized that stevensites may contain talclike layers, and Brindley and Kao (1980) noted the development of expanded basal spacings and (or) mixed layering with the experimental addition of equivalent $\mathrm{Mg}$ and $\mathrm{OH}$ to beidellite. 
Average structural formulas based on the 22 negative charges of a normal smectite formula for suspected trioctahedral-dioctahedral mixed-layer materials in both modern and ancient lacustrine sediments are listed in table 1. The hydrochemical environment of these clays ranged from highly saline (Great Salt Lake) to somewhat brackish (Lake Chad), but presumably all associated waters were neutral to alkaline (for example, the $\mathrm{pH}$ of Lake Abert commonly reaches 10 ). The most magnesiumrich examples from each location are given for the modern lake sediments, whereas a range is presented in the formulas for the early Tertiary Green River and the Pliocene-Pleistocene Amargosa Desert materials. Larger proportions of sesquioxides in smectites from predominantly nonvolcanic terrane suggest a saponite-type (tetrahedral) layer charge similar to the Great Salt Lake material.

The modern lake sediments that provided the clay compositions given in table 1 are all from closed basins maintained by surface water inflow that provides a source of colloidal detritus. Spencer's (1982) and the author's findings suggest that the Great Salt Lake clay chemistry can be obtained simply by the addition of magnesium silicate to inflow river clay. Likewise, the formula given by Carmouze (1976) was obtained by subtracting the Chari River smectite composition from the analysis of the Lake Chad mineral. The Green River material of Dyni (1976) was apparently also formed in a similar physical setting, whereas the stevensite of Tettenhorst and Moore (1978) probably resulted from a saline lake environment

Table 1. Average structural formulas ${ }^{1}$ for lacustrine mixed-layer magnesium smectite, in atoms per 22 negative charge

[n.r., Not reported]

\begin{tabular}{|c|c|c|c|c|c|c|c|c|}
\hline & \multicolumn{2}{|c|}{ Tetahedral } & \multicolumn{5}{|c|}{ Octahedral } & \multirow{2}{*}{$\begin{array}{l}\text { Inter- } \\
\text { layer } \\
x_{+}\end{array}$} \\
\hline & Si & $\mathrm{Al}$ & $\mathrm{Mg}$ & $\mathrm{Al}$ & $\mathrm{Fe}^{3+}$ & Li & Sum & \\
\hline \multicolumn{9}{|c|}{ Ancient sediments } \\
\hline \multicolumn{9}{|l|}{$\begin{array}{l}\text { Green River Formation: } \\
\text { Dyni (1976) }\end{array}$} \\
\hline $\begin{array}{l}\text { Unadjusted.............. } \\
\text { Adjusted for }\end{array}$ & 3.85 & 0.15 & 1.67 & 0.49 & 0.27 & 0.04 & 2.47 & 0.50 \\
\hline $\begin{array}{l}\text { celadonite............. } \\
\text { adjusted for }\end{array}$ & 3.82 & .18 & 1.77 & .45 & .29 & .04 & 2.55 & .39 \\
\hline $\begin{array}{l}i l 1 i t e . . . . \cdots \cdots \cdots \cdots \\
\text { Tettenhorst and }\end{array}$ & 3.96 & .04 & 2.03 & .21 & .27 & .05 & 2.56 & .47 \\
\hline $\begin{array}{l}\text { Moore }(1978) . \ldots \ldots \ldots \ldots \\
\text { Bradley and Fahey }\end{array}$ & 4.00 & .0 & 2.67 & .07 & .03 & n. $r$. & 2.77 & .32 \\
\hline $\begin{array}{l}\text { (1962)........................ } \\
\text { Amargosa Desert: }\end{array}$ & 3.98 & .02 & 2.81 & .06 & .04 & .04 & 2.95 & .04 \\
\hline $\begin{array}{l}\text { Fairbanks Butte }{ }^{2} \\
\text { Eberl and others }(1982)\end{array}$ & 3.95 & .05 & 1.77 & .41 & .27 & $n \cdot r$. & 2.45 & .46 \\
\hline Kerolite/stevensite...... & 3.96 & .04 & 2.72 & .07 & .03 & .09 & 2.91 & .21 \\
\hline $\begin{array}{l}\text { Kerolite................. } \\
\text { Morocco (ghassoulite): }\end{array}$ & 3.94 & .03 & 3.01 & $: 0$ & .01 & n. $r$. & 3.02 & .15 \\
\hline $\begin{array}{l}\text { Millot (1954) (Ke............. } \\
\text { Amboseli basin (kerolite): }\end{array}$ & 3.98 & .02 & 2.69 & .08 & .05 & .10 & 2.92 & .21 \\
\hline $\begin{array}{l}\text { Stoessell and Hay } \\
\quad(1978) \ldots \ldots \ldots \ldots \ldots \ldots \ldots \\
\text { Lake Tecopa: }\end{array}$ & 3.91 & .04 & 2.99 & .04 & .0 & n. $r$. & 2.99 & .22 \\
\hline $\begin{array}{l}\text { Starkey and Blackmon } \\
\quad(1979) \ldots \ldots \ldots \ldots \ldots \ldots \ldots\end{array}$ & 3.90 & .10 & 2.20 & .28 & .12 & .10 & 2.70 & .41 \\
\hline \multicolumn{9}{|c|}{ Modern sediments } \\
\hline $\begin{array}{l}\text { Lake Abert: } \\
\text { Jones and Weir (1983)....... } \\
\text { Lake Chad: } \\
\text { Tardy and others }\end{array}$ & 3.90 & 0.10 & 1.85 & 0.39 & 0.30 & n. $r$. & 2.54 & 0.38 \\
\hline$(1974) \ldots \ldots \ldots \ldots \ldots \ldots$ & 4.00 & .0 & 1.90 & .51 & .16 & $n \cdot r$. & 2.55 & .19 \\
\hline $\begin{array}{l}\text { Carmouze }(1976) \ldots \ldots \ldots \ldots \ldots \\
\text { Walker Lake: }\end{array}$ & 4.00 & .0 & 1.99 & .24 & .12 & 3.11 & 2.46 & .45 \\
\hline $\begin{array}{l}\text { Spencer (1977)............. } \\
\text { Great Salt Lake: }\end{array}$ & 3.43 & .57 & 1.27 & .63 & .51 & $n \cdot r$. & 2.41 & .58 \\
\hline 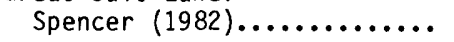 & 3.63 & .37 & 1.67 & .51 & .36 & $n \cdot r$. & 2.54 & .41 \\
\hline
\end{tabular}


that was significantly isolated from detrital influx. On the other hand, the more magnesium-rich clays of the Amargosa Desert, Nev. (Eberl and others, 1982), and the Amboseli basin, Kenya (Stoessel and Hay, 1978), were formed under conditions of sustained spring inflow, which also provided a minimum of transported detritus. The final product was an almost pure trioctahedral 2:1 layer phase (kerolite), in addition to sepiolite. Although good textural evidence exists for the coalescent nucleation of sepiolite (Khoury, 1979), trioctahedral 2:1 phyllosilicates appear to require preexisting sheetstructure substrata, presumably because the true phyllosilicate structure does not as readily accommodate water of hydration (see Güven and Carney, 1979).

Thus, the only silicate phases that nucleate directly from natural silica-rich surface waters appear to be sepiolite and magadiite, the latter at considerably higher salinity than the former. A chemical "combination" of these two phases, loughlinite (or "soda-sepiolite"), has been described from the saline facies of the Wyoming Green River Formation (Fahey and others, 1960), but was interpreted as a product of postdepositional diagenesis. A facility for direct nucleation of chain-structure clay minerals from aqueous fluids has been demonstrated by the ready precipitation of sepiolite from laboratory solutions (Siffert and Wey, 1962; Wollast and others, 1968), and the observation of magadiite precipitating in playa ponds (Rooney and others, 1969), as well as in laboratory vessels (Bricker, 1969).

The only areas where both phases have been reported in the same stratigraphic interval are in the Pliocene-Pleistocene beds of ancient Lake Tecopa, Calif., downstream from the Amargosa Desert in the Amargosa River drainage (Starkey and Blackmon, 1979). By studying these occurrences and those of sepiolite reported in the literature, Starkey and Blackmon (1979) concluded that precipitation took place only where aluminum (and presumably iron also) was low or absent. They referred to the observation of Wollast and others (1968) that sepiolite was usually associated with carbonate sediments where aluminum content was very low. They also noted that colloidal silica has great affinity for solute magnesium and suggested that diatom debris may be a substrate for the formation of magnesium silicate. This was confirmed in the study of authigenic stevensite formation at Pastos Grandes playa, Bolivia, by Badaut and Risacher (1983). Although Starkey and Blackmon (1979) related Lake Tecopa magadiite to local soda-rich springs, the paucity of detrital or solute sesquioxide and the reaction of $\mathrm{Na}^{+}$with colloidal silica were also likely factors in its formation. The bulk of the clay in the Lake Tecopa sediments was termed lithium saponite by Starkey and Blackmon; however, according to the formula calculated from their analysis (table 1), this smectite is similar to the stevensite-rich interstratified clay from the Amargosa Desert, where it probably originated.

\section{PHASE RELATIONS}

Pertinent hydrologic conditions for silicate authigenesis in the lacustrine environment are reflected in phase relations for low-temperature magnesium silicates, as shown on activity-activity diagrams. The controlling equations for the principal phases in the systems $\mathrm{MgO}$ $\mathrm{SiO}_{2}-\mathrm{H}_{2} \mathrm{O}$ and $\mathrm{MgO}-\mathrm{Na}_{2} \mathrm{O}-\mathrm{SiO}_{2}-\mathrm{H}_{2} \mathrm{O}$ are given in table 2. The first two equations describe the simple precipitation or dissolution of sepiolite and talc (or kerolite), respectively. The second pair of equations represents the conversion of sepiolite to talc (or kerolite) at constant activity of $\mathrm{SiO}_{2(\text { aq) }}$ or $\mathrm{H}_{2} \mathrm{O}$ (for a plot of $\mathrm{a}_{\mathrm{Mg}^{2+}} / \mathrm{a}_{\mathrm{H}^{+}}^{2}$ versus $\mathrm{SiO}_{2 \text { (aq) }}$, as in fig. 1). The third pair of equations shows the sodium addition necessary to form aluminum-free smectite (stevensite) from either sepiolite or talc (kerolite) at constant activity of $\mathrm{SiO}_{2 \text { (aq) }}$ (for the plot of $\mathrm{a}_{\mathrm{Mg}^{2+}} / \mathrm{a}_{\mathrm{H}^{+}}^{2}$ versus $\mathrm{a}_{\mathrm{Na}^{+}} / \mathrm{a}_{\mathrm{H}^{+}}$, as in fig. 2). The final equation illustrates the precipitation of serpentine (chrysotile). For the construction of the activity-activity diagrams, available thermodynamic data were taken from the sources listed for the computer program WATEQ (Truesdell and Jones, 1974). Although the emphasis here is on silicate solubility in the sesquioxide ( $\mathrm{Al}, \mathrm{Fe}$ )-free system, dashed lines and parenthetical mineral names have been added to figure 1 to suggest stability fields for appropriate aluminous phases at representative sodium concentrations and at saturation with noncrystalline $\mathrm{Fe}(\mathrm{OH})_{3}$.

The solubility boundaries of figure 1 clearly illustrate the closed-system metastability of sepiolite relative to talc even if allowance is made for variable crystallinity (such as the disorder in the hydrated kerolite analog of talc) by calculation from the range of free energy of formation data determined for talc by Bricker and others (1973) and Hemley and others (1977) and for sepiolite by Wollast and others (1968). If the precipitation mechanism in nature, however, is primarily through addition of magnesium to preexisting colloidal silica, the low ratio of magnesium to silicon can be expected to favor the initial formation of sepiolite over talc (or kerolite). A rise in solution $\mathrm{pH}$ accompanying the degassing of $\mathrm{CO}_{2}$ from spring discharge, organic respiration, or evaporative concentration of sediment-free surface waters should promote the direct precipitation of either phase. Stable ground-water inflow, buffering of an alkaline $\mathrm{pH}$ by carbonate precipitation, and a preexisting mineral substrate, however, apparently aid in overcoming kinetic dehydration or nucleation barriers to kerolite formation. Long-standing ground-water discharge of appropriate composition into an evaporative shallow lake or marsh environment has led to substantive formation of both sepiolite and kerolite/stevensite in the Amargosa Desert (Khoury, 1979; Khoury and others, 1982; Eberl and others, 1982) and the Amboseli basin (Stoessell and Hay, 1978). Traces of a 7- $\AA$ reflection on X-ray diffractograms from both locales suggest that even chrysotile may form 
Table 2. Stability reactions for sesquioxide-free hydrous magnesium silicates ${ }^{1}$

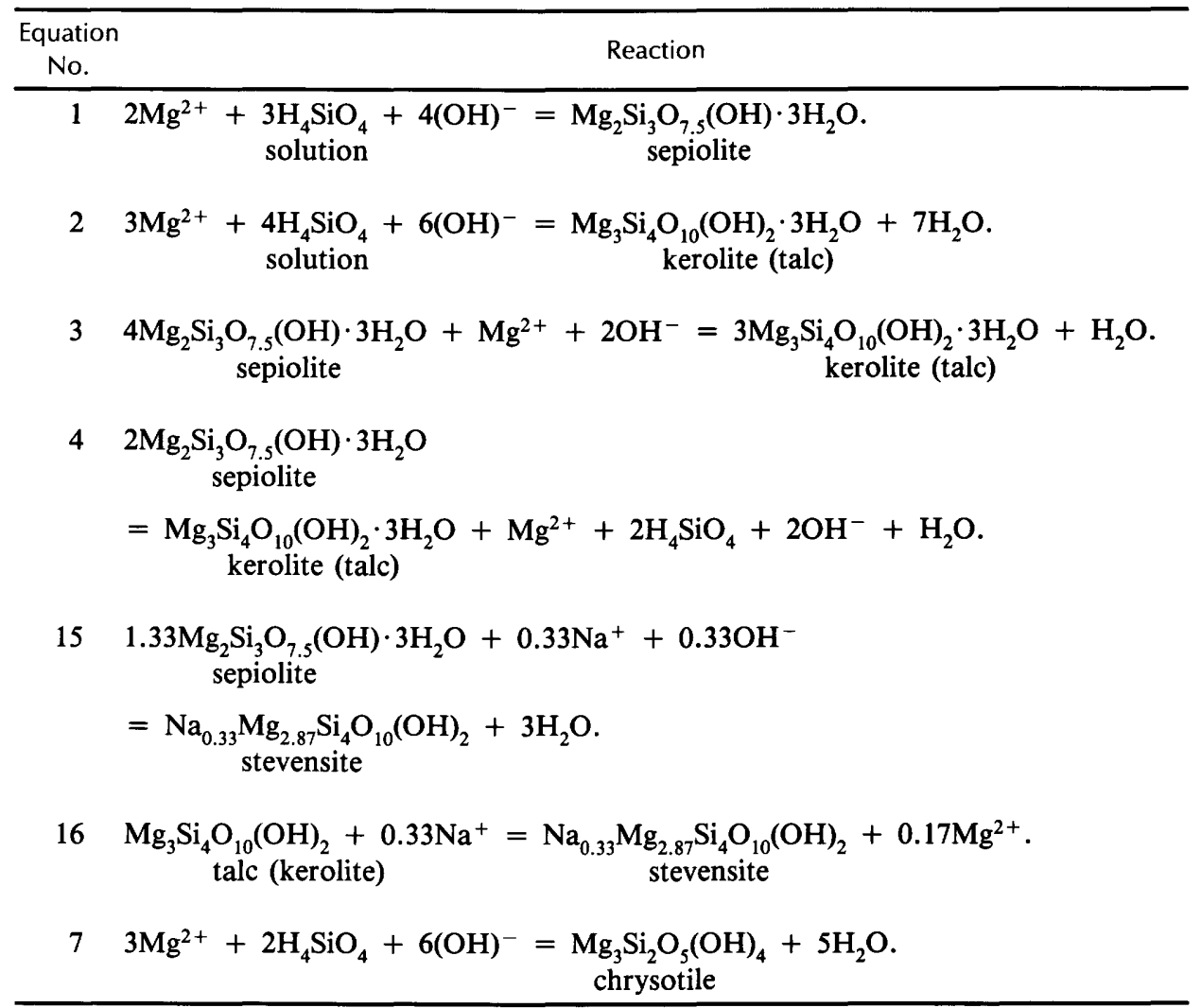

\footnotetext{
${ }^{1}$ These equations have been written for end-member octahedral deficiency in sesquioxide-free smectite structures at constant activity of $\mathrm{SiO}_{2(\mathrm{aq})}$ to illustrate the stevensite definition according to seat of layer charge as discussed in the text. As described, natural stevensites typically have low layer charge (Faust and others, 1959), which is consistent with the apparent interstratification of smectite and talc or kerolite layers, and can range through kerolite/stevensite interstratifications to nearly pure kerolite.
}

if evaporatively induced $\mathrm{pH}$ and solute increase are more rapid than mineral precipitation. Despite initial metastability in the formation of sepiolite, the boundary derived from equation 4 shown in the upper right part of figure 1 suggests that the sepiolite may actually be stablized at sufficiently high levels of all three factors, that is, $\mathrm{pH}$, magnesium concentrations, and silica concentrations at constant $\mathrm{a}_{\mathrm{H}_{2} \mathrm{O}}$.

The effects of sodium concentration at silica contents appropriate to glass saturation are considered in figure 2. The metastability of sepiolite and lack of stability data for pure stevensite makes the precise location of these field boundaries conjectural; however, the lower limit of the sepiolite field (and that for noncrystalline talc/kerolite, as well) at $-\log \mathrm{SiO}_{2(\text { (aq) }}=3$ was derived from the appropriate curve of figure 1 , and the upper limit was estimated. The lower concentration limit of the stevensite field was drawn to correspond with the $\mathrm{a}_{\mathrm{Na}^{+}} / \mathrm{a}_{\mathrm{H}^{+}}=1$ condition of equation 5 , but the higher $\mathrm{a}_{\mathrm{Na}^{+}} / \mathrm{a}_{\mathrm{H}^{+}}$estimate is based on analyses of Amargosa Desert waters. The slopes of the other stevensite field boundaries were derived from the stoichiometry of equation 6 and the dissolution of the phase. With the addition of sesquioxide, a smectite-chlorite boundary can be estimated that roughly bisects the stevensite field.

The phase relations at constant silica depicted on figure 2 correspond well with the hydrochemical environments observed for magnesium silicate precipitation and diagenesis. Thus, sepiolite precipitation can be expected primarily from relatively dilute waters-as in the Amboseli basin (Stoessell and Hay, 1978) or the Amargosa Desert (Khoury, 1979; Khoury and others, 1982)-whereas at the same locale kerolite may have formed from evaporatively induced, somewhat higher $\mathrm{pH}$ and $\mathrm{Mg}$-content solutions with decreasing $\mathrm{SiO}_{2(\mathrm{aq})}$. Kerolite has been identified as a precipitate from Stewart Springs, Calif., in waters with $\mathrm{a}_{\mathrm{Mg}^{2+}} / \mathrm{a}_{\mathrm{H}^{+}}^{2}=18.77$ $(\mathrm{pH}=12.2)$ and $\log$ total aqueous silica equal to -4.23 (I. Barnes, U.S. Geological Survey, Menlo Park, Calif., written commun., 1981).

The normal dominance of sodium in continental brackish or saline waters (Jones, 1966) should indicate the preference for the expandable smectite (stevensite) according to figure 2 . Indeed, this result corresponds with the paucity of pure magnesium silicates in closed-basin lake or playa sediments (Droste, 1961). The suggestion of kerolite/smectite interstratification in Lake Abert sediments (Weir and Jones, 1978; Jones and Weir, 1983) 


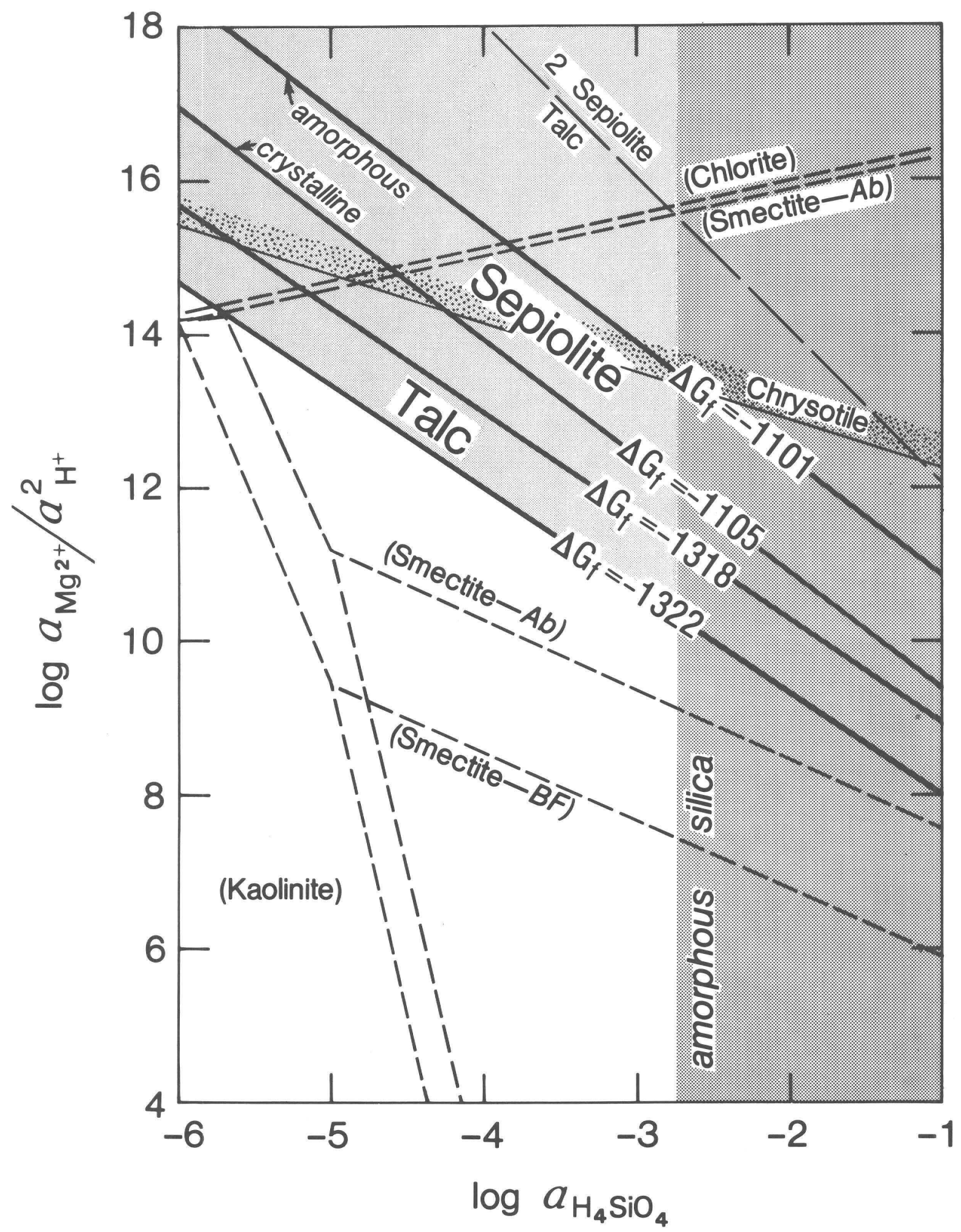

Figure 1. Stability relations for hydrous magnesium silicates with respect to solute activities, as calculated from thermodynamic data cited in text. Shaded regions correspond in sesquioxide-free system to supersaturation with solid phases, either Mg-silicate (light shade) or noncrystalline (amorphous) silica (darker shade). Field boundaries for sepiolite and talc correspond to equations 1 and 2, respectively, in table 2 and are drawn for stability of both noncrystalline (amorphous) and crystalline forms with appropriate free energy of formation values given in kilocalories per mole. Similar estimate is given in shading of chrysotile boundary, which corresponds to equation 7 of table 2. Long-dashed line resulting from calculations based on equation 4 of table 2 is shown in upper right of diagram. Double-dashed boundaries, one each for $\mathrm{a}_{\mathrm{Na}^{+}} / \mathrm{a}_{\mathrm{H}^{+}}$values of 6.0 and 8.0, are given for sesquioxide-bearing phases at saturation with noncrystalline $\mathrm{Fe}(\mathrm{OH})_{3}$, assuming $\mathrm{Al}$ is conserved. Stability regions for these phases (chlorite, smectites, and kaolinite) are labeled on the appropriate side of the two short-dashed boundaries. Smectite-Ab and smectite-BF refer to Kittrick's Aberdeen and Belle Fourche, S. Dak., montmorillonites, respectively. Stability constants are modified from Truesdell and Jones (1974). 
and the recognition of kerolite/stevensite interstratification in the Amargosa Desert deposits (Eberl and others, 1982) indicate that the upper boundary of the stevensite field on figure 2 is diffuse. The slope of this boundary is consistent with a trend toward increased interstratification of kerolite with smectite as the salinity and $\mathrm{pH}$ rise in alkaline saline lakes such as Lake Abert. A corresponding 1:1 increase in solution magnesium and sodium content on evaporative concentration would mark an oblique path across the talc-smectite boundary. Similarly, the evidence for formation of chloritic intergrades prior to kerolite interstratification (Jones and Weir, 1983) is consistent with the lower position of a smectite-chlorite boundary depicted for a sesquioxide-bearing system.

\section{CONCLUSIONS}

In summary, the diagenesis of clay minerals in lacustrine sediments involves primarily the uptake of potassium, magnesium, and silica from lake waters through the reaction of the dissolved elements with preexisting particulate material. The reactions appear to proceed in sequential steps, as follows:

1. Hydrolysis of pyroclastics or detrital sesquioxide to form hydroxide colloids, intergrades, or incipient, largely dioctahedral 2:1 layers;

2. Exchange of cations for the calcium lost by carbonate precipitation, and organically induced reduction of iron to increase phyllosilicate layer charge and to fix interlayer cations, initially potassium, but also magnesium, perhaps as hydroxide polymers; and

3. Reaction of magnesium (hydroxide?) with silica from pore fluids, diatomaceous debris, or glassy pyroclastics to form trioctahedral kerolite and (or) stevensite interstratification.

These reactions seem to operate in many hydrologic systems over a wide range of salinity. Pure kerolite is associated with precipitated sepiolite and carbonate, and is apparently restricted to areas of relatively dilute ground-water discharge with an absence of reactive detritus. The higher solute sodium content of brackish or saline lakes favors the development of stevensite, especially where detrital input is restricted.

\section{REFERENCES CITED}

Al Droubi, A., Fritz, B., Gac, J. Y., and Tardy, Y., 1980, Generalized residual alkalinity concept; application to prediction of the chemical evolution of natural waters by evaporation: American Journal of Science, v. 280, p. 560-572.

Badaut, D., and Risacher, F., 1983, Authigenic smectite on diatom frustules in Bolivian saline lakes: Geochimica et Cosmochimica Acta, v. 47, p. 363-375.

Bradley, W. H., and Fahey, J. J., 1962, Occurrence of stevensite in the Green River Formation of Wyoming: American Mineralogist, v. 47, p. 996-998.

Bricker, O. P., 1969, The stability constants and free energies of formation of magadiite and kenyaite at $25^{\circ} \mathrm{C}$ and one atmosphere total pressure: American Mineralogist, v. 54, p. 1026-1033.

Bricker, O. P., Nesbitt, H. W., and Gunter, W. D., 1973, The stability of talc: American Mineralogist, v. 58, p. 64-72.

Brindley, G. W., 1955, Stevensite, a montmorillonite-type mineral showing mixed-layer characteristics: American Mineralogist, v. 40, p. 239-247.

Brindley, G. W., and Kao, C. C., 1980, Formation, compositions, and properties of hydroxy- $\mathrm{Al}$ and hydroxy-Mg montmorillonite: Clays and Clay Minerals, v. 28, p. 435-443.

Caillère, S., and Hénin, S., 1961, Vues d'ensemble sur le problème de la synthèse des minéraux phylliteux à basse température: Colloques Internationaux du Centre National de la Recherche Scientifique, v. 105, p. 31-43.

Carmouze, J. P., 1976, La régulation hydrogéochemique du lac Tchad: Travaux et Documents de L'Office de la Recherche Scientifique et Technique Outre-Mer, no. 58, 418 p.

Carmouze, J. P., Pedro, G., and Berrier, J., 1977, Sur la nature des smectites de néoformtion du lac Tchad et leur distribution spatiele en fonction des conditions hydrogéochemiques: Comptes Rendu Academy Science Français, sér. D., v. 284, p. $615-618$.

Deike, R. G., and Jones, B. F., 1980, Provenance, distribution and alteration of volcanic sediments in a saline alkaline lake; chapter 14, in A. Nissenbaum, ed., Hypersaline brines and evaporitic environments: Amsterdam, Elsevier Publishing Co., p. 167-193.

Drever, J. I., 1971, Magnesium-iron replacement in clay minerals in anoxic marine sediments: Science, v. 172, p. 1334-1336.

Droste, J. B., 1961, Clay mineral composition of sediments in some desert lakes in Nevada, California, and Oregon: Science, v. 113, p. 1928.

Figure 2. (facing page) Stability relations of hydrous magnesium and sodium-magnesium silicates as estimated from thermodynamic data cited in text, as well as from natural occurrences. Fields of supersaturation are labeled according to appropriate mineral phase. Solid boundaries outline most probable stability fields, whereas long-dashed lines suggest possible limits for occurrence of low-soda minerals. Short-dashed boundaries indicate actual stable extension of talc (kerolite) field, which would preclude formation of sepiolite. Region of kerolite/stevensite mixed-layer development is suggested for upper stability boundary of stevensite. For sesquioxide-bearing system, chlorite-smectite boundary is shown by short dashes; it was calculated from same data as for figure 1 with log $\mathrm{SiO}_{2(\mathrm{aq})}$ equal to -3.02 . Smectite-Ab refers to Kittrick's Aberdeen montmorillonite in Truesdell and Jones (1974). 


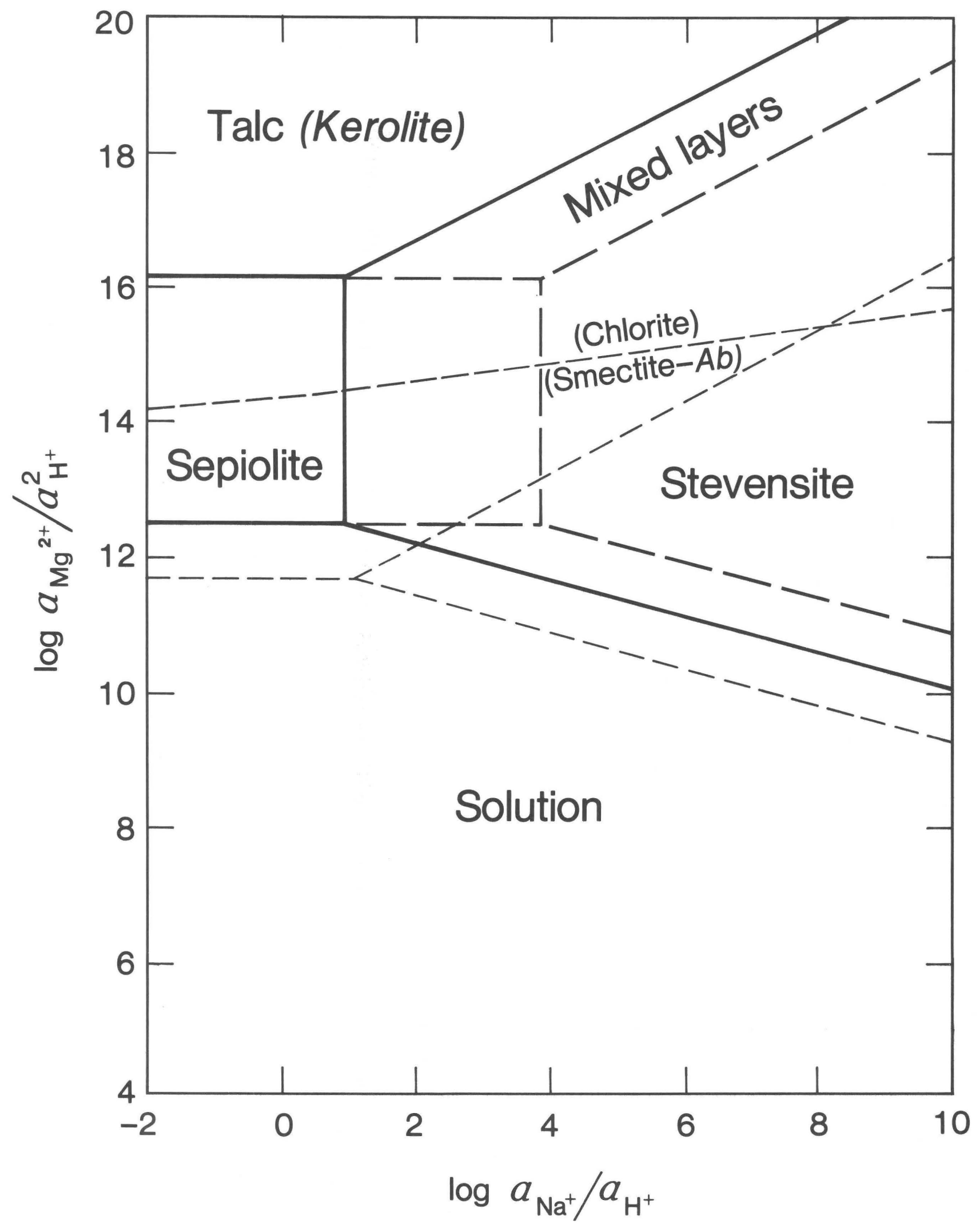


Dyni, J. R., 1976, Trioctahedral smectite in the Green River Formation, Duchesne County, Utah: U.S. Geological Survey Professional Paper 967, 14 p.

Eberl, D. E., Jones, B. F., and Khoury, H. N., 1982, Mixed-layer kerolite/stevensite from the Amargosa Desert, Nevada: Clays and Clay Minerals, v. 30, p. 321-326.

Eugster, H. P., and Jones, B. F., 1979, Behavior of major solutes during closed-basin brine evolution: Americal Journal of Science, v. 279, p. 609-631.

Fahey, J. J., Ross, M., and Axelrod, J. M. 1960, Loughlinite, a new hydrous sodium magnesium silicate: American Mineralogist, v. 45, p. 270-281.

Faust, G. T., Hathaway, J. C., and Millot, G., 1959, A restudy of stevensite and allied minerals: American Mineralogist v. 44, p. $342-370$.

Gac, J. Y., Al Droubi, A., Fritz, B., and Tardy, Y., 1977, Geochemical behavior of silica and magnesium during the evaporation of waters in Chad: Chemical Geology, v. 19, p. 215-228.

Garrels, R. M., and Mackenzie, F. T., 1967, Origin of the chemical composition of some springs and lakes, in W. Stumm, ed., Equilibrium concepts in natural water systems: American Chemical Society Advances in Chemistry, v. 67, p. 222-242.

Güven, N., and Carney, L. L., 1979, The transformation of sepiolite to stevensite and the effect of added chlorides and hydroxides: Clays and Clay Minerals, v. 27, p. 253-260.

Güven, N., and Kerr, P. F., 1966, Selected Great Basin playa clays: American Mineralogist, v. 51, p. 1056-1067.

Heller-Kallai, L., and Rozenson, I., 1978, Removal of magnesium from interstitial waters in reducing environmentsThe problem reconsidered: Geochimica et Cosmochimica Acta, v. 42, p. 1907-1909.

Hem, J., and Lind, C., 1974, Kaolinite synthesis at $25^{\circ} \mathrm{C}$ : Science, v. 184 , p. $1171-1173$.

Hemley, J. J., Montoya, J. W., Christ, C. L., and Hostettler, P. B., 1977, Mineral equilibria in the $\mathrm{MgO}-\mathrm{SiO}_{2}-\mathrm{H}_{2} \mathrm{O}$ system; I. Talc-chrysotile-forsterite-brucite stability relations: American Journal of Science, v. 277, p. 322-351.

Jones, B. F., 1966, Geochemical evolution of closed basin waters in the western Great Basin, in Rau, J. I., ed., Northern Ohio Geological Society, 2nd symposium on salt: v. 2, p. 181-200.

Jones, B. F., and Bowser, C. J., 1978, The mineralogy and related chemistry of lake sediments, ch. 7, in Lerman, A., ed., Lakes; chemistry, geology, physics: New York, SpringerVerlag, p. 179-235.

Jones, B. F., and VenDenburgh, A. S., 1966, Geochemical influences on the chemical character of closed lakes, in Symposium of Garda, Hydrology of lakes and reservoirs: International Association of Scientific Hydrology Publication 70 , p. $435-446$.

Jones B. F., VanDenburgh, A. S., Deike, R. G., Rettig, S. L., and Truesdell, A. H., 1972, Mineralogy of some sediments from alkaline saline lakes: International Clay Conference Program and Abstracts, Madrid, p. 80-81.

Jones, B. F., and Weir, A. H., 1983, Clay minerals of Lake Abert, an alkaline, saline lake: Clays and Clay Minerals, v. 31, p. 161-172.

Khoury, H. N., 1979, Mineralogy and chemistry of some unusual clay deposits in the Amargosa Desert, southern Nevada: Urbana, Ill., University of Illinois, Ph. D. thesis, 171 p.
Khoury, H. N., Eberl, D. D., and Jones, B. F., 1982, Origin of clays from the Amargosa Desert, Nevada: Clays and Clay Minerals, v. 30, p. 327-336.

Millot, G., 1954, La Ghassoulite, pôle magnésian de la série des montmorillonites: Comptes Rendu Academy Science Français, v. 238, p. 257-259.

Géologie des Argiles: Masson et Cie., Paris ("Geology of Clays," translated by W. Farrand and H. Paquet: New York, Springer-Verlag, 1970, 429 p.)

Müller, G., and Förstner, U., 1973, Recent iron ore formation in Lake Malawi, Africa: Mineralium Deposita, v. 8 , p. 278-290.

Pedro, G., Carmouze, J. P., and Velde, B., 1978, Peloidal nontronite formation in recent sediments of Lake Chad: Chemical Geology, v. 23, p. 139-149.

Rooney, T. P., Jones, B. F., and Neal, J. T., 1969, Magadiite from Alkali Lake, Oregon: American Mineralogist, v. 54, p. 1034-1043.

Siffert, B., and Wey, R., 1962, Synthèse d'une sépiolite à température ordinaire: Comptes Rendu Academy Science Français, v. 254, p. 1460-1463.

Singer, A., and Stoffers, P., 1980, Clay mineral diagenesis in two East African lake sediments: Clay Minerals, v. 15, p. 291-307.

Spencer, R. J., 1977, Silicate and carbonate sediment-water relationships in Walker Lake, Nevada: Reno, Nev., University of Nevada, M.S. thesis, 98 p.

1982, The geochemical evolution of Great Salt Lake: Baltimore, Maryland, Johns Hopkins University, Ph. D. thesis, $308 \mathrm{p}$.

Starkey, H. C., and Blackmon, P. D., 1979, Clay mineralogy of Pleistocene Lake Tecopa, Inyo County, California: U.S. Geological Survey Professional Paper 1061, 34 p.

Stoessell, R. K., and Hay, R. L., 1978, The geochemical origin of sepiolite and kerolite at Amboseli, Kenya: Contributions to Mineralogy and Petrology, v. 65, p. 255-267.

Tardy, Y., Cheverry, C., and Fritz, B., 1974, Néoformation d'une argile magnésienne dans less dépressionns interdunaires du lac Tchad; Application aux domains de stabilité des phyllosilicates alumineaux, magnésiens, et ferrifères: Comptes Rendu Academy Science Français, v. 278, p. 1999-2002.

Teague, T. T., 1981, Authigenic silicates and carbonates in playa and related deposits from the Amargosa Desert, Nevada: Berkeley, Calif., University of California, M.S. thesis, 78 p.

Tettenhorst, R., and Moore, G. E., Jr., 1978, Stevensite oolites from the Green River Formation of central Utah: Journal of Sedimentary Petrology, v. 48, p. 587-594.

Truesdell, A. H., and Jones, B. F., 1974, WATEQ, a computer program for calculating chemical equilibria of natural waters: U.S. Geological Survey Journal of Research, v. 2, p. 238-248.

VanDenburgh, A. S., 1975, Solute balance at Abert and Summer Lakes, south-central Oregon: U.S. Geological Survey Professional Paper 502-C, 29 p.

Weir, A. H., and Jones, B. F., 1978, Clay minerals in the sediments of a saline lake: International Clay Conference, Program and Abstracts, Oxford, United Kingdom, p. 301.

Wollast, R., MacKenzie, F. T., and Bricker, O. P., 1968, Experimental precipitation and genesis of sepiolite at earthsurface conditions: American Mineralogist, v. 53, p. 1645-1662. 


\title{
Zeolitic Diagenesis of Tuffs in an Upper Miocene Lacustrine Deposit Near Durkee, Baker County, Oregon
}

\author{
By ARTHUR J. GUDE, 3rd, and RICHARD A. SHEPPARD, \\ U.S. Geological Survey, Denver Federal Center, MS 917, Denver, Colorado 80225
}

\section{CONTENTS}

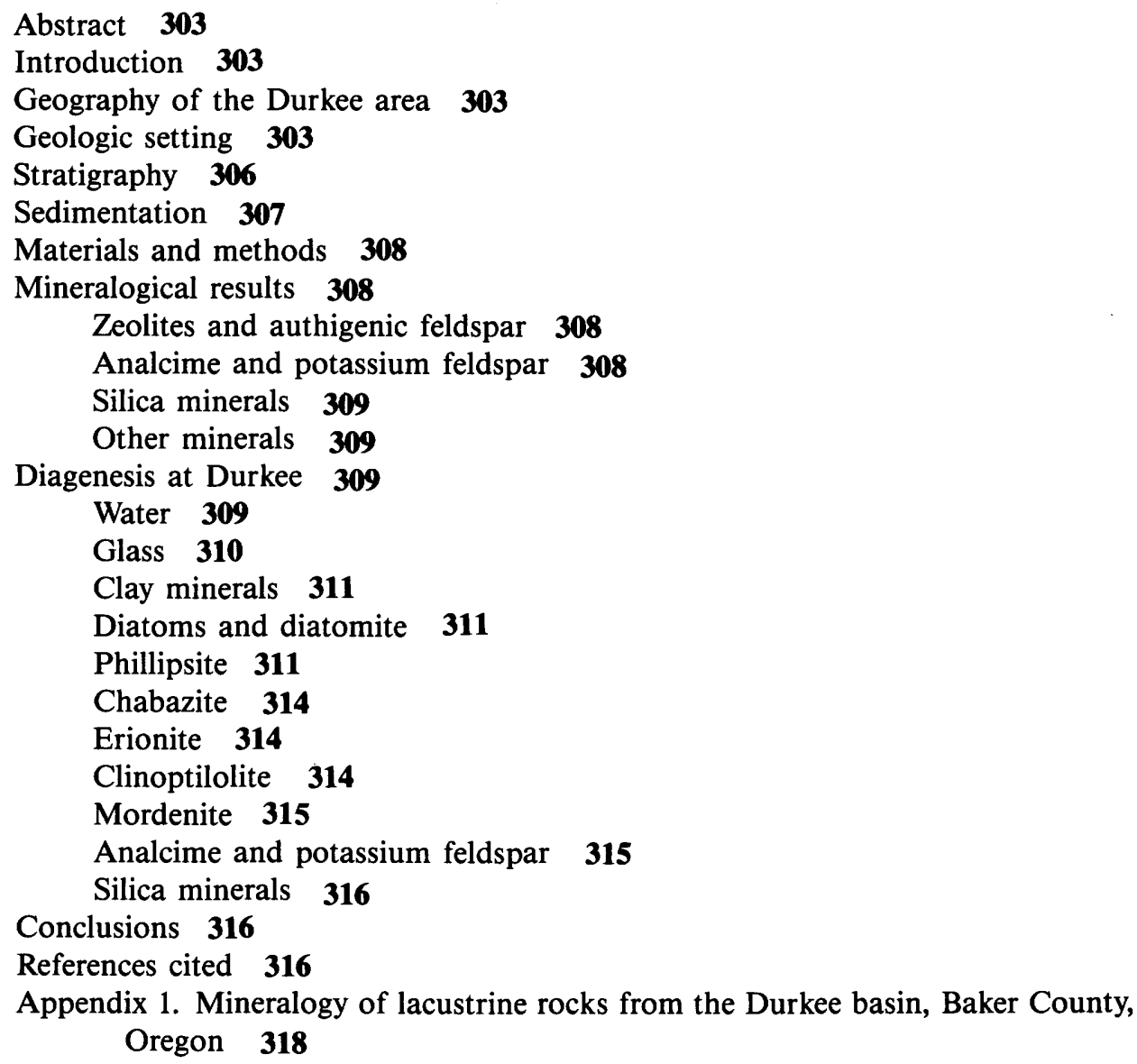

1. Map of late Miocene lacustrine basin showing sampled localities and geology at Durkee, Oregon 304, 305

2. Schematic diagram of a stratigraphic cross section of the Durkee basin 306

3. Composite columnar section of Durkee lacustrine and fluvial rocks $\mathbf{3 0 7}$

4-6. Photographs:

4. View looking northwest from locality 30 across an eroded amphitheatre $\mathbf{3 0 7}$

5. Salt casts and raindrop imprints on underside of an altered tuff at locality 7, Durkee, Oregon 308

6. Ripple-marked bed on surface of an altered tuff at locality 65, Durkee, Oregon $\mathbf{3 1 0}$ 
7-16. Scanning electron micrographs:

7. Partly eroded glass fragment $\mathbf{3 1 0}$

8. Smectite coating surface of glass fragment $\mathbf{3 1 1}$

9. Spherical rosettes of phillipsite and clinoptilolite 311

10. Chabazite on clay lining in relict shards $\mathbf{3 1 4}$

11. Chabazite on a mat of smectite lining a shard 314

12. Chabazite from locality SD-4-16, Durkee, Oregon 314

13. Erionite, chabazite, and clay in cavity between shards 315

14. Erionite on chabazite 315

15. Clinoptilolite coexisting with erionite 315

16. Mordenite ribbons and filaments 315

\section{TABLES}

1. Paragenesis of authigenic minerals at Durkee, Oregon 309

2. Chemical and physical data for shards from three fresh vitric tuffs from Durkee basin, Oregon $\mathbf{3 1 0}$

3. Diatom species and varieties at Durkee, Baker County, Oregon 312, 313 


\section{Abstract}

Authigenic zeolites derived from siliceous tuffs deposited in a late Miocene saline, alkaline lake near Durkee, Oregon, formed diagenetically at low pressure and temperature. Here, several rhyolitic air-fall and reworked tuffs and an ash-flow tuff are interbedded with diatomite, mudstone, sandstone, siltstone, and conglomerate. The zeolites chabazite, erionite, and clinoptilolite are common in the altered tuffs; minor amounts of analcime, phillipsite, and mordenite have been recognized as have authigenic potassium feldspar, silica minerals, and clay minerals. The diagenetically formed zeolites and authigenic potassium feldspar are restricted to an $18-\mathrm{km}^{2}$ area in the southeastern part of the $120-\mathrm{km}^{2}$ ancient lake. Altered tuffs have been recognized only in the middle and lower $135 \mathrm{~m}$ of the exposed 350-m section in the deepest part of the lake basin. Fresh vitric tuffs are interbedded with a thick diatomite in the upper part of the stratigraphic section. The $102-\mathrm{km}^{2}$ area of the basin bordering the zeolitic alteration zone contains tuffs equivalent to the zeolitic beds but which still contain relatively fresh glass. Reactions between silicic vitric tuffs and alkaline, saline-lake basin waters $(\mathrm{pH}>9)$ probably account for the observed generalized paragenetic sequence: glass $\rightarrow$ smectite $\rightarrow$ phillipsite $\rightarrow$ chabazite $\rightarrow$ erionite $\rightarrow$ clinoptilolite $\rightarrow$ mordenite, and then any of these zeolites $\rightarrow$ analcime $\rightarrow$ potassium feldspar. Evidence for the required high salinity and alkalinity are the saline mineral crystal molds observed in many altered tuffs and the Magadi-type chert found in a zeolitic tuff and mudstone unit.

\section{INTRODUCTION}

Zeolites, clay minerals, silica minerals, and potassium feldspar of diagenetic origin are common in many Cenozoic volcanogenic lacustrine rocks. A model for the alteration pattern of siliceous tuffs in such deposits has been developed from studies of the Tecopa-Shoshone area, California; the Mud Hills near Barstow, California; and the Wikieup area, Arizona (Sheppard and Gude, 1968, 1969, 1973a). Other lake deposits with similar histories are known in this country and elsewhere, such as in the rift valleys of east-central Africa (Surdam and Eugster, 1976). Features which characterize these deposits are: (1) beds of siliceous vitric tuffs that were deposited in saline, alkaline, closed-basin lakes, and (2) near-surface temperatures and pressures that prevailed during the alteration of the volcanic ash (glass).

During mid-Tertiary time, a restricted, intermontane lacustrine basin near the present-day site of Durkee, Baker County, Oregon, received nearly continuous input of volcanic sediment (Prostka, 1967). Sporadically, however, the valley outlet at the south end was dammed, forming a lake, the level of which fluctuated when the dam breached and redeveloped. During the frequent times of desert climate, the lake often was shallow enough to allow playas to form. Rigorous evaporation conditions in the playas concentrated dissolved salts in the water and developed the high salinity and alkalinity which elsewhere are known to alter tuffaceous material to zeolites (Sheppard and Gude, 1968, 1969, 1973a). At other times the lake was fresh to slightly brackish; diatomites and other facies characteristic of such lacustrine environments can be noted today interfingered and interbedded with the zeolitic formations. The actual alteration of volcanic glass to zeolites at Durkee was limited to a small, $18-\mathrm{km}^{2}$ area in the southeastern part of the $120-\mathrm{km}^{2}$ basin. Here, the lake ponded at the choked outlet, and the buildup of high salinity and alkalinity was not diluted by freshwater mixing. At least 20 distinct zeolitic tuffs have been found in this area, one of which is as much as $4 \mathrm{~m}$ thick and consists locally of nearly monomineralic chabazite.

The interplay between fluvial and lacustrine environments in the Durkee deposit, and the relations between the zeolitic tuffs and freshwater assemblages of diatomites and "unaltered" volcanic glass, are more complex than in most of the saline, alkaline lake deposits of zeolites heretofore described. These relationships and the unusual thickness of the chabazite beds suggest that a detailed analysis of the low-temperature, low-pressure mineral reactions that took place in this deposit would add substantially to our understanding of diagenesis in volcanogenic lacustrine rocks. The present paper describes the occurrence and mineral chemistry of the zeolites, clays, and other authigenic minerals in the lacustrine rocks of the Durkee basin and relates these phases to the diagenetic history of the area.

\section{GEOGRAPHY OF THE DURKEE AREA}

Durkee is well known to zeolite investigators as the type locality of erionite (Eakle, 1898; Staples, 1957; Staples and Gard, 1959; Sheppard and Gude, 1975). It is a small hamlet on the Burnt River in eastern Oregon (fig. $1 \mathrm{~A}$ ) where Interstate Highway 84 and the Union Pacific Railroad transect the basin. The highway provides easy access from Baker, $42 \mathrm{~km}$ to the northwest. Tributary streams to the Burnt River cut badland-type gullies down through the soft lake sediments. Veneers of gravel, formed during two Quaternary cycles, are draped over parts of the exhumed lake sediments and onto the stream benches and valley floors. Scattered remnants of unaltered Mazama ash are present in perched Holocene stream channels.

\section{GEOLOGIC SETTING}

The geology of the area is shown in detail on a 15minute geologic map of the Durkee quadrangle by Prostka (1967) who delineated all but the westernmost part of the late Miocene lacustrine basin and the surrounding rocks. The older rocks, which are as much as $650 \mathrm{~m}$ above 


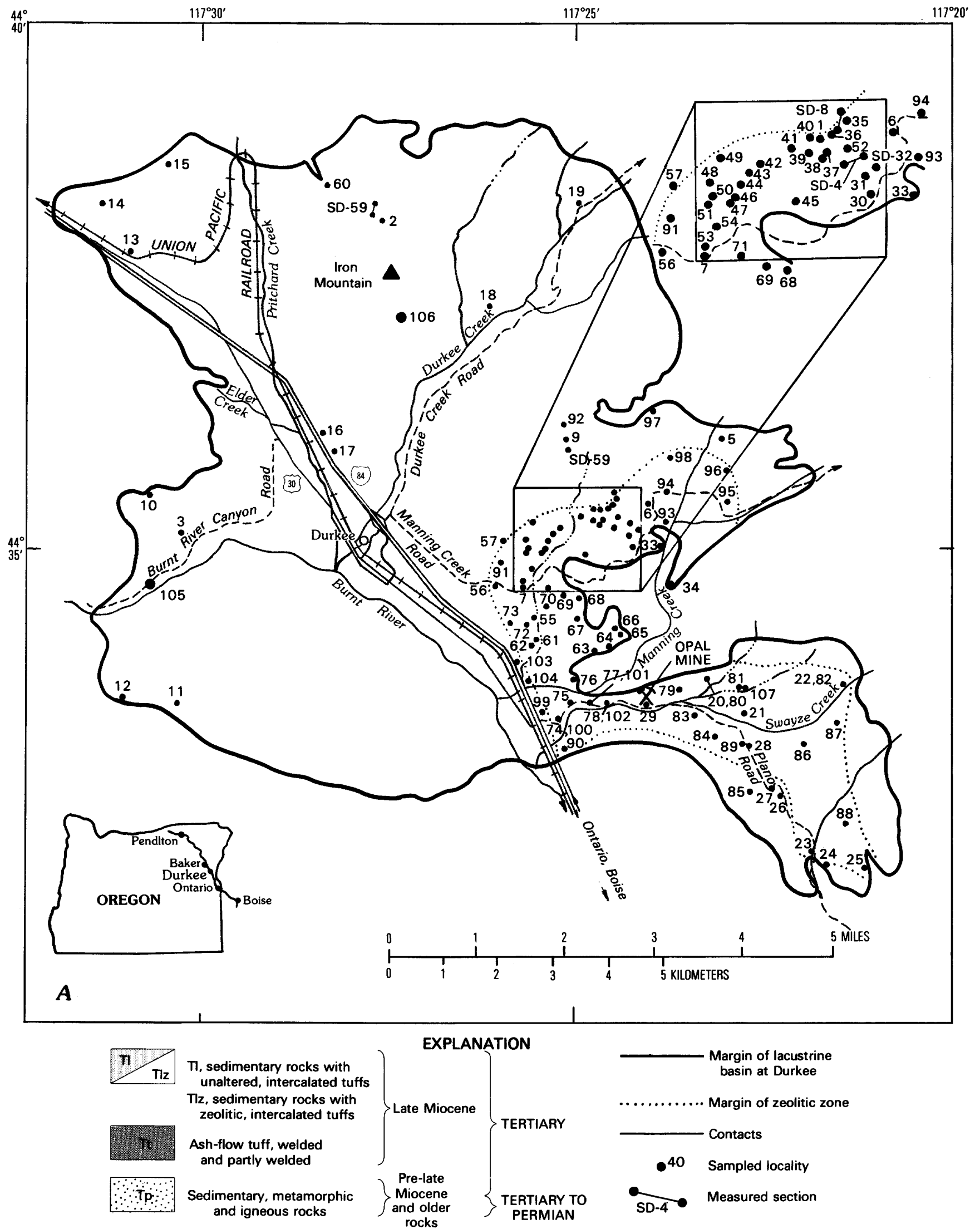

Figure 1 (above and facing page). Late Miocene lacustrine basin showing sampled localities $(A)$ and geology $(B)$ at Durkee, Oregon. 


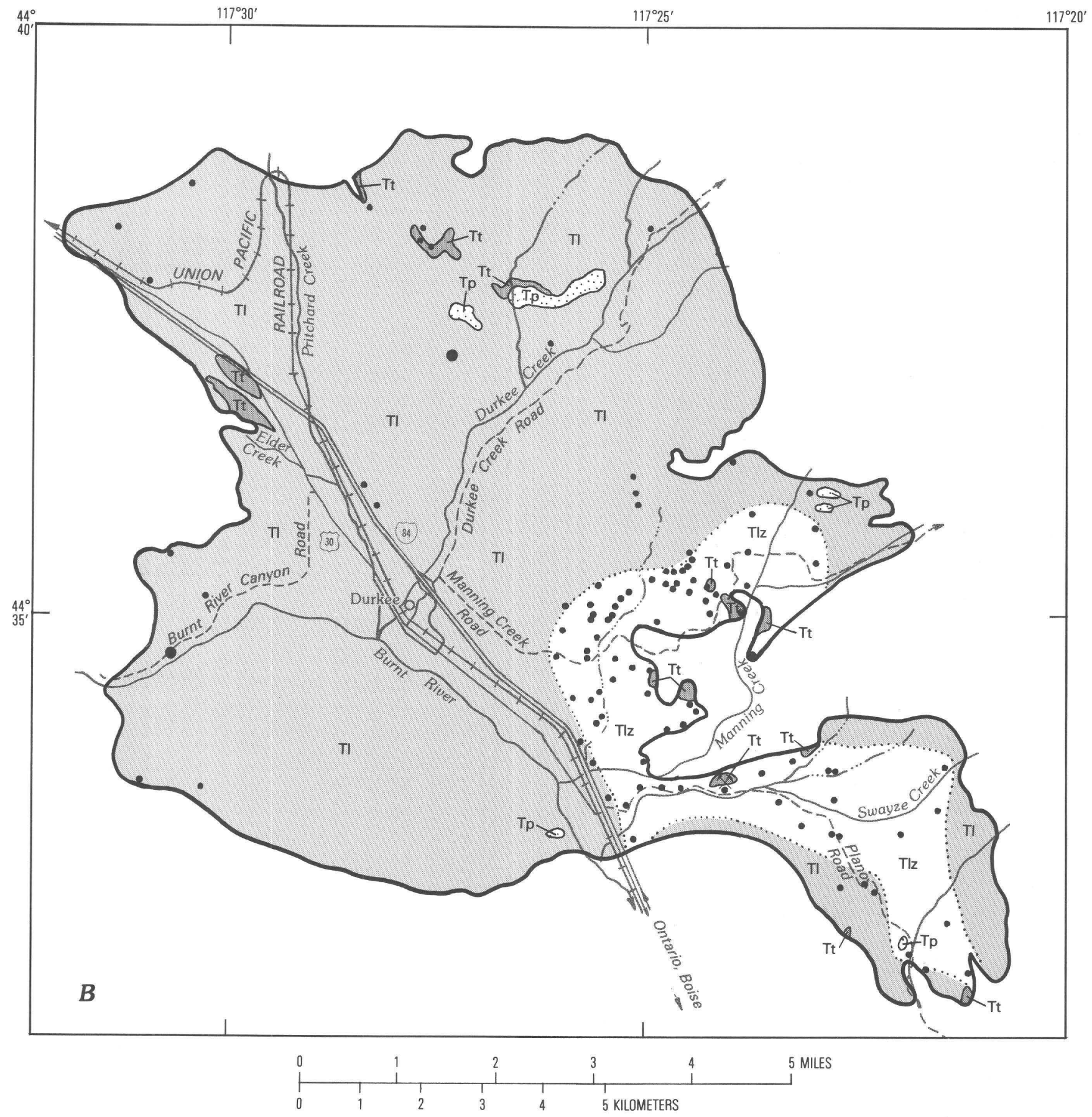

the basin floor, are Permian argillites and greenschists on the north and east and Triassic phyllites and marble on the south. Some Triassic gabbro and patches of the Miocene Columbia River Basalt Group are present in the older rocks. Iron Mountain, which rises as a monadnock about $25 \mathrm{~m}$ above the valley just west of Durkee Creek, is a conspicuous mass of the Columbia River Basalt.

Figure $1 B$, which was modified from the maps of Prostka (1967) and Gilluly (1937), shows the sampled localities, the location of measured sections, and the approximate boundary between unaltered, fresh, glassbearing lacustrine rocks and the rocks containing diagenetic zeolites. A few sample localities away from the zeolite area, where a trace amount of zeolite was found, are not included. These isolated localities represent detached microenvironments in which the immediate surrounding water attained the required geochemistry to react with the tuffaceous material. The result is the miniscule amount of the same zeolites found in the nearby zeoliterich deposits.

Sediments derived from older rocks are present as detrital grains in the lacustrine mudstones, siltstones, sandstones, and conglomerates and as minor amounts of quartz, plagioclase, and amphibole minerals in the 
intercalated tuffs. Silicic vitric material, commonly referred to as "volcanic ash," was contributed from the fallout plumes of nearby volcanic centers and is present as finegrained bubble-wall tuffaceous material in the mud, silt, and sandstones and as coarser pumice fragments in some conglomerate units. Major Plinian eruptive events formed the relatively clean, distinctive vitric tuffs by direct airfall, and reworked ash rapidly swept into the lake from the surrounding hillsides.

These tuff units are mostly thin-bedded layers $1-25 \mathrm{~cm}$ thick. Several composite units that are uniform in appearance are as much as $3 \mathrm{~m}$ thick. A single "welded ash-flow" unit, hereafter called "welded tuff," as much as 15 m thick, occurs at or near the base of the lacustrine beds and is the only basinwide unit that can be used as a reliable stratigraphic marker bed. Except where the welded tuff is present, correlation of beds across the basin is nearly impossible.

A set of east-west normal faults with displacements of as much as $10 \mathrm{~m}$ is shown on Prostka's map (1967). Abundant shorter and smaller displacement en echelon faults were noted in the field, but are too numerous to show in figure 1. Erosion has obliterated outcrops of many of the thin-bedded sedimentary tuffs, especially where the tuffs are in diatomaceous or mudstone sequences.

The Durkee zeolite deposit differs from other Tertiary saline, alkaline lakes in that the perquisite saline,

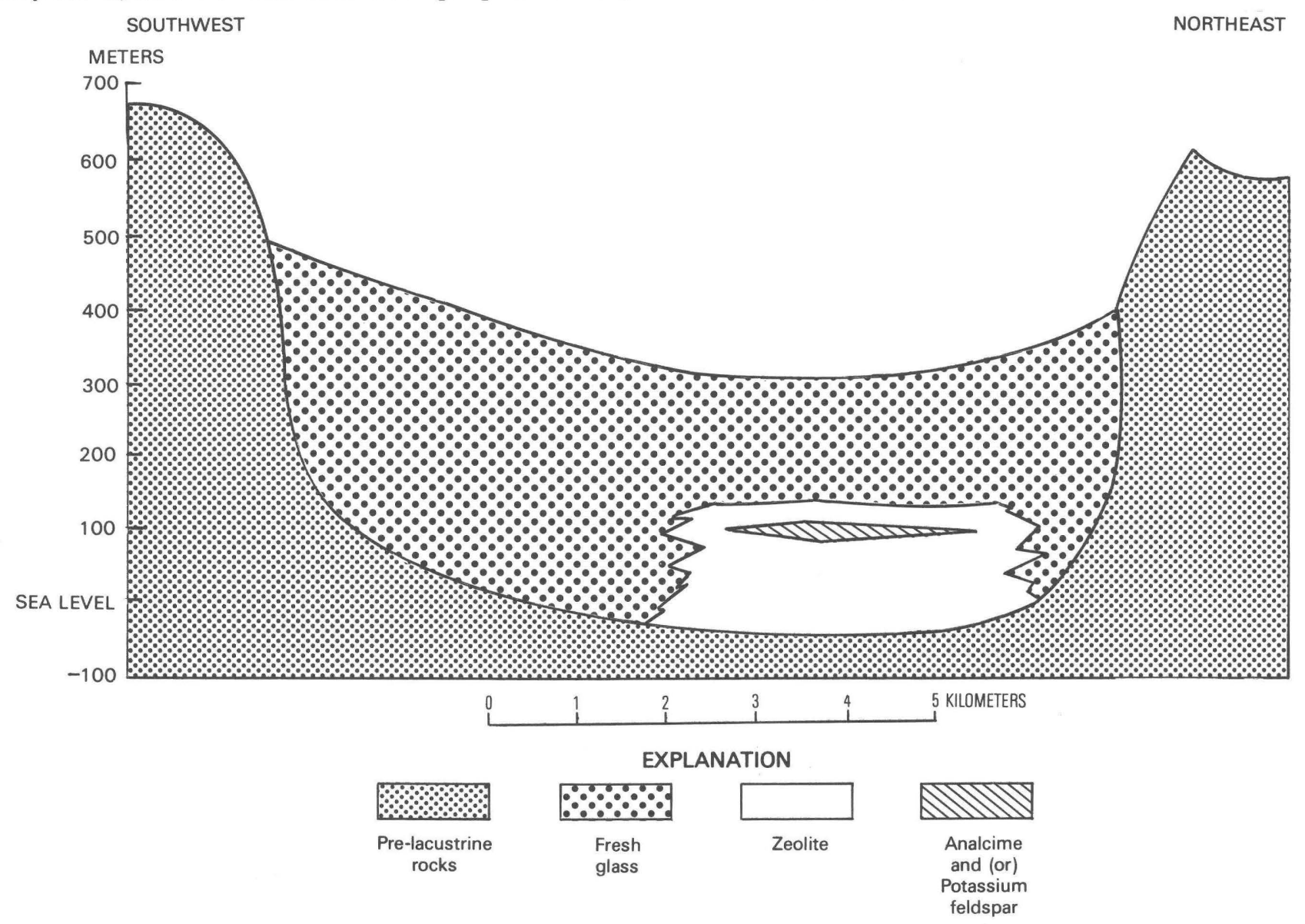

alkaline water formed as an encapsulated body in a fresh water or slightly brackish water lake with a flourishing diatom population.

Figure 2 is a schematic diagram across the deep southeastern part of the basin. It shows our concept of the pattern of alteration at Durkee based on field observations and laboratory analyses. The encapsulated zeolite zone is shown before erosion removed the immediately overlying rocks. The diatomite and fresh tuffs probably covered the core area, because unaltered diatomaceous rocks are juxtaposed with zeolitic units in faulted masses deep within the central part of the basin.

A composite columnar section, figure 3 , shows the approximate sequence of the various rock units. No single exposure displays the uninterrupted section. Therefore, we were not able to make precise correlation between separated sections. The middle part of the diagram depicts a section in which continuity of the beds above the zeolite-bearing rock and the overlying freshwater units is diffuse and only an approximation. Three measured sections-SD-4, SD-32, and SD-8were used (fig. 1A).

\section{STRATIGRAPHY}

Figure 2. Schematic diagram of a stratigraphic cross section of the Durkee basin. 


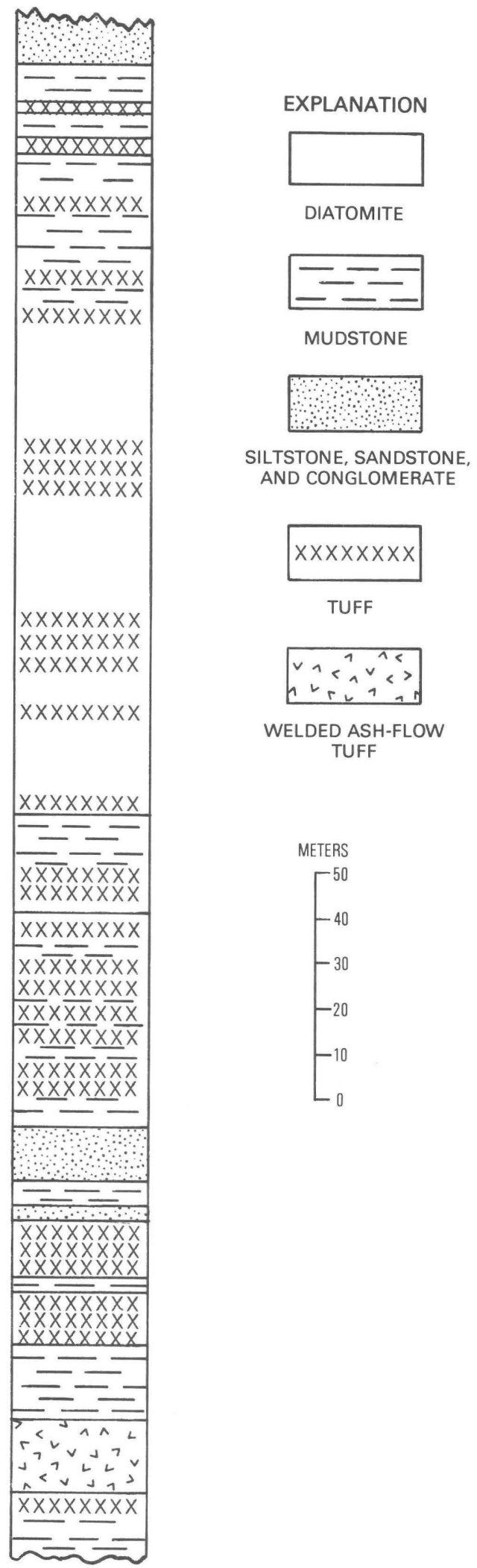

Figure 3. Composite columnar section of Durkee lacustrine and fluvial rocks.

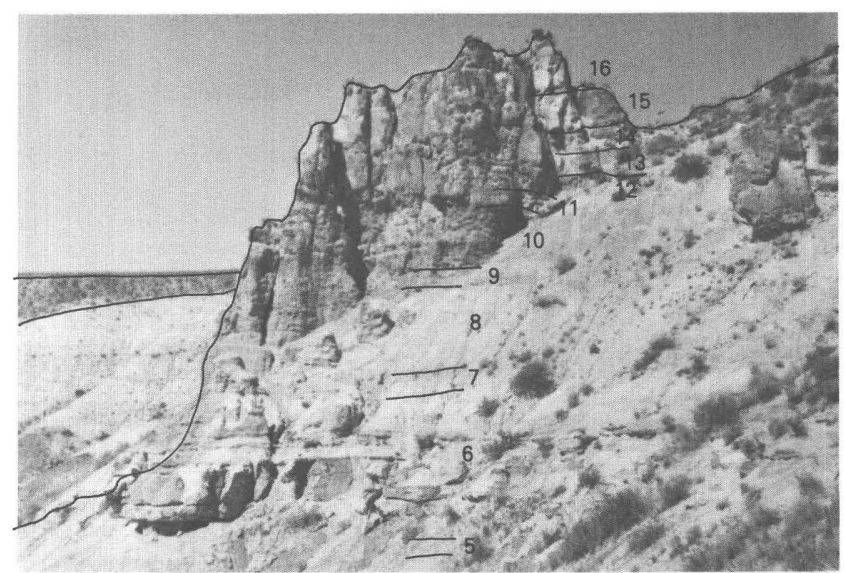

Figure 4. View looking northwest from locality D-30 across an eroded amphitheatre. Resistant beds and pinnacles are in zeolitized part of the basin. Freshwater diatomaceous section is in background, on left. Person in lower middle is shown for scale. Numbers are those of units in measured section SD-4 (see appendix 1).

\section{SEDIMENTATION}

Tuffs that are altered to zeolites generally form resistant beds which are readily recognized in the predominantly mudstone sequences that filled the basin. Of the approximately $350 \mathrm{~m}$ of section that was measured, less than 25 percent of the total thickness, including the welded tuff, is recognizable as tuff beds. Calcareous or silicified tuffaceous units found outside the altered area commonly mimic the resistant zeolitic tuff beds. In the lower part of the stratigraphic section where composite tuff units or closely spaced intercalated tuffs are present and the alteration is complete, the resistant beds form prominent cliffs and free-standing pinnacles. Figure 4 is a view northwest across an eroded amphitheater floored by the welded tuff and walled by sheer cliffs and spires composed of the thick tuffs measured in section SD-4. Figure 5 is a panoramic view showing most of the lacustrine beds north of Interstate 84, taken from a site $1 \mathrm{~km}$ east of Durkee, looking northeast up Durkee Creek.

The light-colored rocks in the left background of figure 4 are the thick diatomites and diatomaceous mudstones and tuffs depicted in figure 2 that overlie the prominent resistant beds and pinnacles of the zeolite zone seen in the foreground. Several nearly fresh vitric tuffs measured in the middle of section SD-8 probably are lateral equivalents of tuffs measured in sections SD-4 and SD-32 in which they are completely altered to zeolites. Correlations, as noted above, were difficult to make, especially in the poorly preserved outcrops of unaltered rocks such as seen in figure 4 . 


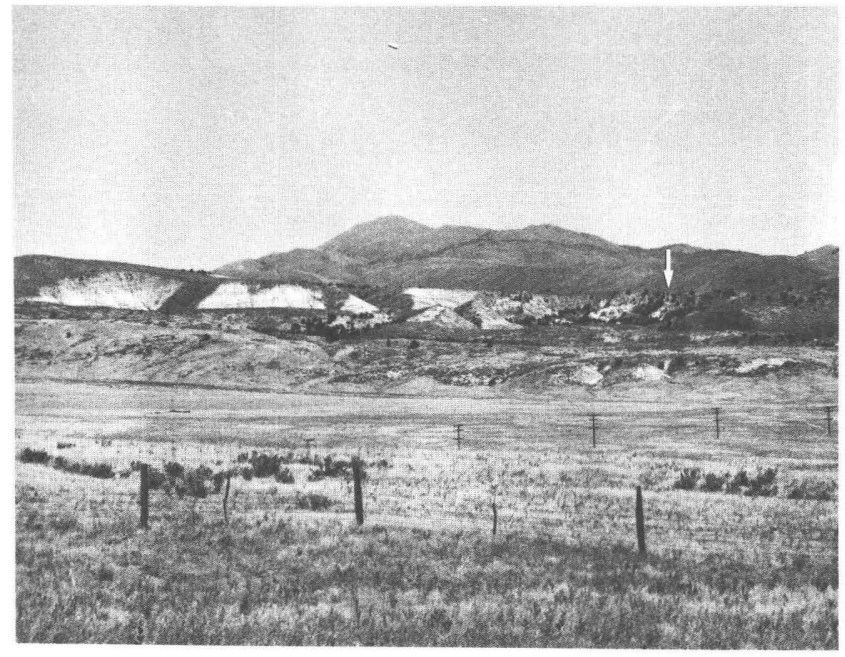

Figure 5. View to northeast from site about $1 \mathrm{~km}$ east of Durkee, Oregon showing light-colored diatomite exposed at the head of eroding gullies. Arrow indicates amphitheater (fig. 4).

\section{MATERIALS AND METHODS}

Appendix 1 is a compilation of the sample descriptions made from field notes and the mineralogy determined in the laboratory. All sample-collecting localities are shown in figure 1. Most samples were collected at tuff outcrops where the zeolite alteration appeared to be most intense; however, some samples were collected away from the main zeolite zone to examine the mineralogy of comparable tuffs in obvious freshwater areas of the basin. Multiple specimens were generally collected at a single site where lithologic differences were visible within a sampled unit. In addition, subsamples were prepared in the laboratory if close inspection revealed apparent mineralogical or lithological differences that were not noticed at the outcrop.

From about 100 field sites, about 380 separate specimens were examined. A conventional X-ray powder diffraction (XRD) pattern using monochromatic $\mathrm{CuK} \alpha_{1}$ radiation and a horizontal scanning diffractometer was made for each specimen handpacked in a back-loaded aluminum holder. The relative abundance of each mineral identified in a single specimen was estimated in parts-often from comparison of the visually integrated pattern of each identified phase on the XRD record. Unaltered glass, opaline silica, and some poorly crystalline or very fine grained clay minerals were estimated with less certainty because of the broad and diffuse nature of the XRD scattering.

Selected specimens were examined in thin section, in immersion oils by optical microscopy using a polarizing petrographic microscope, and by scanning electron microscopy (SEM). For SEM, specimens were mounted with silver paste on 3.2-cm Cambridge-type stubs and sputter coated with gold or gold-palladium. The SEM images were produced with Cambridge Stereoscan S-180 and Stereoscan $250 \mathrm{MK} 2$ instruments ${ }^{1}$. Chemical analyses of shards from three vitric tuffs from the Durkee basin were made by conventional rock analysis techniques by Elaine L. Brandt (U.S. Geological Survey, Denver, Colo.).

\section{MINERALOGICAL RESULTS}

The locality, description, and mineralogical composition of all samples examined are listed in appendix 1.

\section{Clay minerals}

Although the clay mineralogy in these samples was not studied rigorously, three categories of materials were recognized based on the prominent basal XRD reflections near 10 and $14 \AA$. Some of the $14-\AA$ smectite and the 10 - $\AA$ mixed-layer clays may be authigenic; however, the 7- $\AA$ clay found in a few samples is most likely detrital in origin. The 7-A phase was found only in samples collected away from the zeolitic area or in clearly identified detrital-rich samples at the boundary between the zeolitic and the freshwater units. Samples from mudstones, siltstones, sandstones, or conglomerates which showed a 10-Å peak probably contain detrital mica rather than an authigenic illite or mixed-layer clay.

\section{Zeolites and authigenic feldspar}

Other than analcime, which is discussed later with potassium feldspar, the five zeolites derived from the siliceous vitric tuffs were generally present in mixed assemblages or, less commonly, in nearly monomineralic beds. A group of two or three zeolite varieties in a single specimen was common. Seven samples were found to contain four zeolites, and one, sample D-30K, contained five zeolites including analcime. Clinoptilolite was the zeolite most frequently found; erionite was next followed by chabazite, phillipsite, and mordenite.

\section{Analcime and potassium feldspar}

Five of the six zeolites found at Durkee were authigenically formed by the alteration of the vitric tuffs. Analcime has not been shown conclusively to have formed

\footnotetext{
${ }^{1}$ Use of trade and company names is for descriptive purposes only and does not imply endorsement by the U.S. Geological Survey.
} 
from glass here at Durkee, nor in any other lacustrine setting. A precursor zeolite, such as any of the other five zeolites present at Durkee, is apparently required for the development of analcime (Sheppard and Gude, 1973b).

Potassium feldspar, like analcime, was also formed from a precursor zeolite at Durkee. The zeolite mineral may have been any of the five diagenetically derived from glass, or it may have been analcime. Potassium feldspar has not been found directly associated with siliceous vitric material in any of the saline, alkaline lake deposits examined to date. The particular variety of feldspar found at Durkee has chemical and crystallographic properties which set it apart from feldspars found in more classic igneous environments (see Sheppard and Gude, 1973b). These authigenic potassium feldspars may contain as much as 1 percent $\mathrm{B}_{2} \mathrm{O}_{3}$ substituting for $\mathrm{Al}_{2} \mathrm{O}_{3}$ (Sheppard and Gude, 1965), and have nearly the stoichiometric amount of $\mathrm{K}_{2} \mathrm{O}$ required for a sanidine; thus, they contain almost no $\mathrm{Na}_{2} \mathrm{O}$. The unit.cell of these potassium feldspars is always distorted in the $a$-axis dimension that is predicted for a nearly pure sanidine (Sheppard and Gude, 1973). The euhedral monciclinic crystals formed at Durkee are $2-10 \mu \mathrm{m}$ in size.

\section{Silica minerals}

Two silica phases present at Durkee that are clearly part of the diagenetic process are opal-CT and Magaditype chert. The latter material was found only at locality $\mathrm{D}-107$. Some of the quartz found at Durkee is authigenic and is easily recognized in petrographic thin sections. Most of the quartz determined by XRD is detrital or pyrogenic and had no part in the lacustrine diagenesis of the tuffs.

\section{Other minerals}

Other minerals listed in appendix 1 are mostly clastic detritus or late-formed calcite or gypsum. Dolomite in a thin bed outside the south end of the zeolite zone is probably not part of the glass-to-zeolite diagenetic process. Similarly, apatite found in a thin bed in an isolated outcrop, also near the south end of the lake beds, is an unexplained anomaly.

\section{DIAGENESIS AT DURKEE}

"Zeolitic diagenesis" is almost a redundant phrase, especially when it is used to denote a process such as that in a setting like Durkee. Diagenesis at shallow-lake water temperatures and surface ambient pressures yield zeolites if the required water geochemistry and fresh siliceous vitric
Table 1. Paragenesis of authigenic minerals at Durkee, Oregon [Modified from Gude and Sheppard, 1978; earliest minerals listed on left]

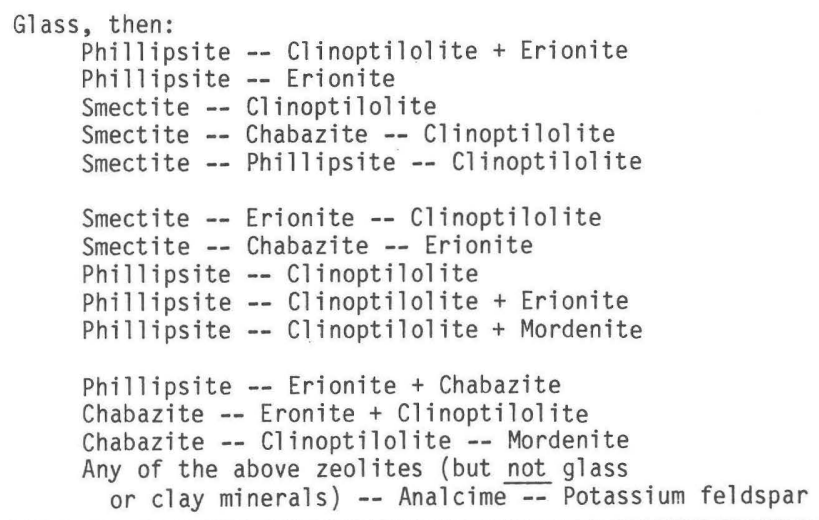

tuff are present. The generalized sequence of formation (modified from Gude and Sheppard, 1978) of zeolites and associated authigenic silicate minerals is glass $\rightarrow$ smectite $\rightarrow$ phillipsite $\rightarrow$ chabazite $\rightarrow$ erionite $\rightarrow$ clinoptilolite $\rightarrow$ mordenite and then any of the preceding zeolites $\rightarrow$ analcime $\rightarrow$ potassium feldspar. Table 1 gives the detailed paragenetic sequence for the authigenic minerals found at Durkee. It was assembled from petrographic microscope studies, XRD mineral identifications (appendix 1), and SEM data supplemented with energy dispersive X-ray spectroscopy (EDX). The following discussions are phaseby-phase descriptions for the evidence of diagenesis.

\section{Water}

No residual formational or interstitial water from the late Miocene lake at Durkee has been found. Thus, assumptions about the water geochemistry have been based on studies of modern lakes such as Lake Magadi, Kenya (Surdam and Eugster, 1976); Owens and Searles Lakes, California (Smith, 1966); and Teels Marsh, Nevada (Surdam and Mariner, 1971); and from extensive work by Jones $(1965,1966)$ and Jones and others $(1967,1977)$ on lakes in northern California and southern Oregon. In addition to these present-day analogs, certain inferences about water chemistry can be made from field and laboratory observations.

At Durkee and other lacustrine basins (Sheppard and Gude, 1968, 1969, 1973a), crystal molds and casts are present that have the morphology of gaylussite or pirssonite, which are soluble sodium carbonatebicarbonate minerals. Similar minerals have been found on playa lake bottoms in saturated brines of modern "soda lakes" (Smith and Friedman, 1986). During rapid sediment filling of such a lake, clay-size detritus would cover the crystals of the sodium minerals, and thus produce the crystal molds. 


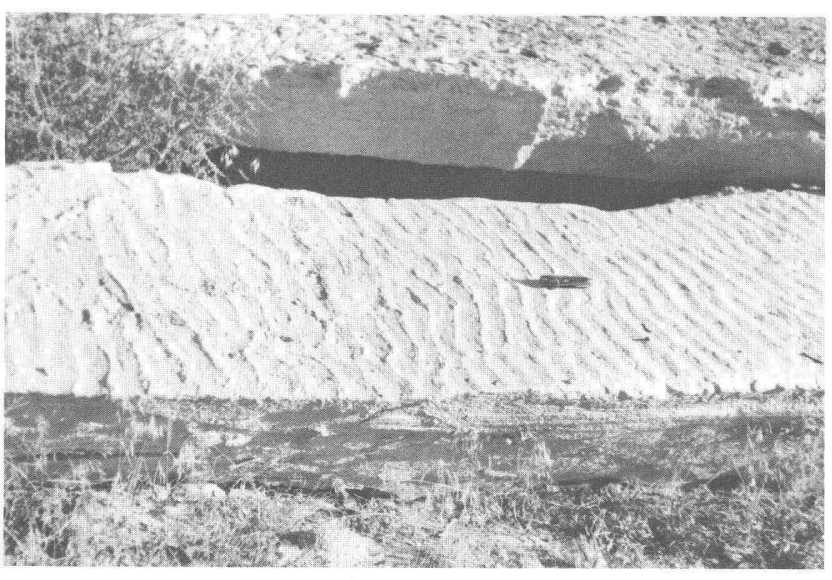

Figure 6. Ripple-marked bed on surface of an altered tuff at locality D-65, Durkee, Oregon (knife is about $7.5 \mathrm{~cm}$ long).

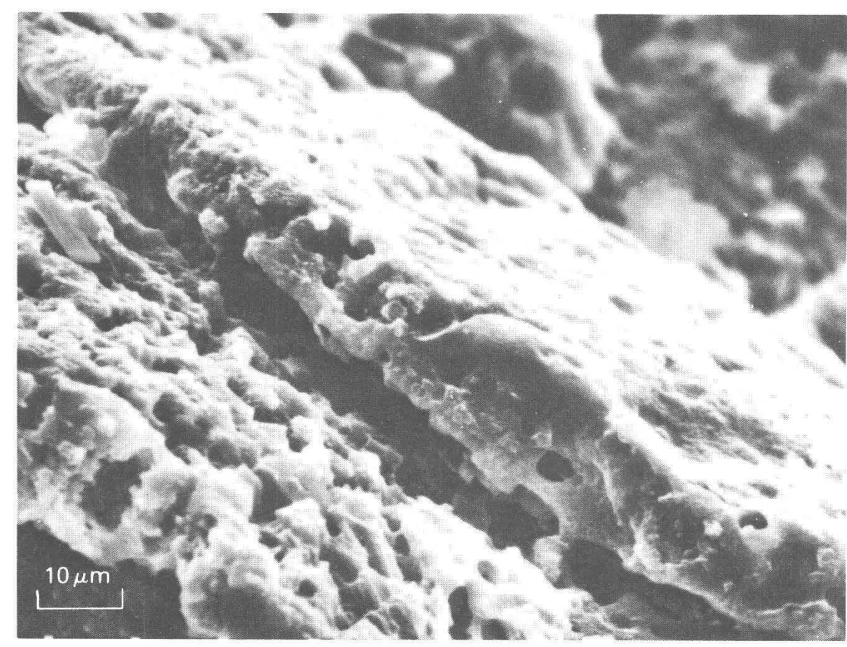

Figure 7. Scanning electron micrograph of partly etched glass fragment, from sample SD-4-3GX, Durkee, Oregon.

Crystals casts of an unidentified mineral found on the underside of a tuff were collected at several localities at Durkee. The deposition of these crystals was sufficiently widespread within the zeolite area for this tuff unit to serve as a local marker bed. Well-preserved, ripplemarked beds (fig. 6) are additional evidence of a shallowwater, playa-lake deposition.

\section{Glass}

Early Pliocene volcanic events supplied the silicic vitric airfall ash, with each tuff having a slightly different composition. Table 2 gives conventional silicate rock analyses and measured indices of refraction for three tuffs which are representative of those in the Durkee basin.
Table 2. Chemical and physical data for shards from three fresh vitric tuffs from Durkee basin, Oregon

[Elaine L. Brandt, analyst]

\begin{tabular}{|c|c|c|c|}
\hline \multicolumn{4}{|c|}{ Conventional rock analyses (weight percent) } \\
\hline Sample No.1.............. & 1 & 2 & 3 \\
\hline $\mathrm{SiO}_{2}$ & 73.33 & 71.67 & 68.12 \\
\hline $\mathrm{Al}_{2} \mathrm{O}_{3}$ & 11.71 & 11.78 & 13.77 \\
\hline $\mathrm{Fe}_{2} \mathrm{O}_{3}$ & 0.64 & 0.71 & 0.77 \\
\hline $\mathrm{FeO}$ & 0.29 & 1.24 & 1.04 \\
\hline $\mathrm{Mg} 0$ & 0.11 & 0.19 & 0.34 \\
\hline $\mathrm{CaO}$ & 0.35 & 0.81 & 1.18 \\
\hline $\mathrm{Na}_{2} \mathrm{O}$ & 2.62 & 2.21 & 3.75 \\
\hline $\mathrm{K}_{2} \mathrm{O}$ & 5.76 & 5.04 & 4.14 \\
\hline $\mathrm{H}_{2} \mathrm{O}^{+}$ & 4.33 & 5.42 & 5.57 \\
\hline $\mathrm{H}_{2} \mathrm{O}-$ & 0.24 & 0.17 & 0.22 \\
\hline $\mathrm{TiO}_{2}$ & 0.11 & 0.38 & 0.39 \\
\hline $\mathrm{P}_{2} \mathrm{O}_{5}$ & 0.01 & 0.03 & 0.07 \\
\hline MnO & 0.08 & 0.04 & 0.07 \\
\hline $\mathrm{Cl}$ & 0.07 & 0.03 & 0.15 \\
\hline $\mathrm{F}$ & 0.07 & 0.08 & 0.05 \\
\hline Subtotal.......... & 99.72 & 99.80 & 99.63 \\
\hline Less $0 . \ldots . . . . . .$. & 0.05 & 0.04 & 0.05 \\
\hline Total............. & 99.67 & 99.76 & 99.58 \\
\hline Index of refraction... & 1.497 & 1.503 & 1.508 \\
\hline Shard morphology...... & $\begin{array}{l}40-50 \% \\
\text { pumice. }\end{array}$ & $\begin{array}{l}\text { A11 platy } \\
\text { bubble-wal1. }\end{array}$ & $\begin{array}{l}10-20 \% \\
\text { pumice. }\end{array}$ \\
\hline
\end{tabular}

lField numbers are as on figure 1.

1. Field No. 9D, Lab. Serial No. D-103730.

2. Field No. SD-8-11C, Lab. Serial No. D-103732.

3. Field No. SD-8-9A, Lab. Serial No. D-103733.

The morphology of the glass shards also varied from place to place. We were unable to collect matched samples from a single tuff unit which showed the compositional change from fresh glass to a completely altered zeolitic tuff. Thus, no data are available from Durkee to document the change in chemistry during diagenesis. Figure 7 is a scanning electron micrograph showing a partly dissolved glass fragment from a specimen taken at the top of the welded tuff. The glass material removed by the highly saline, alkaline water may have formed a gel, which then crystallized to a zeolite (Surdam and Mariner, 1971). Alternatively, in the absence of direct evidence such as entrapped water or gel, the dissolved glass components may have precipitated directly to a zeolite from solution. According to field and laboratory observation by Surdam and Eugster (1976), the composition of the water and the glass and the $\mathrm{pH}$ of the solutions may determine which alkalic zeolite forms. The exact paragenesis 


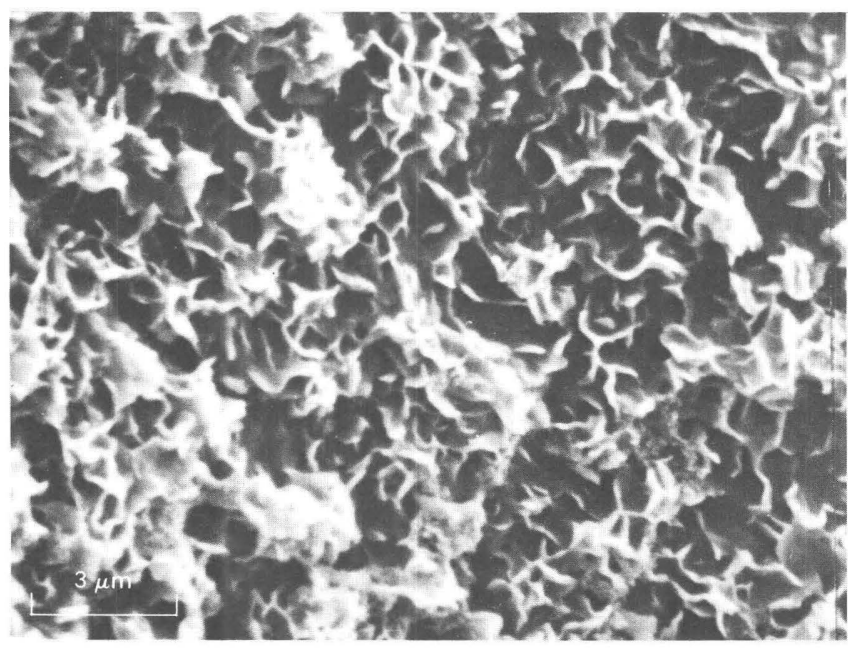

Figure 8. Scanning electron micrograph showing smectite coating the surface of a glass fragment, from sample SD-43GY, Durkee, Oregon.

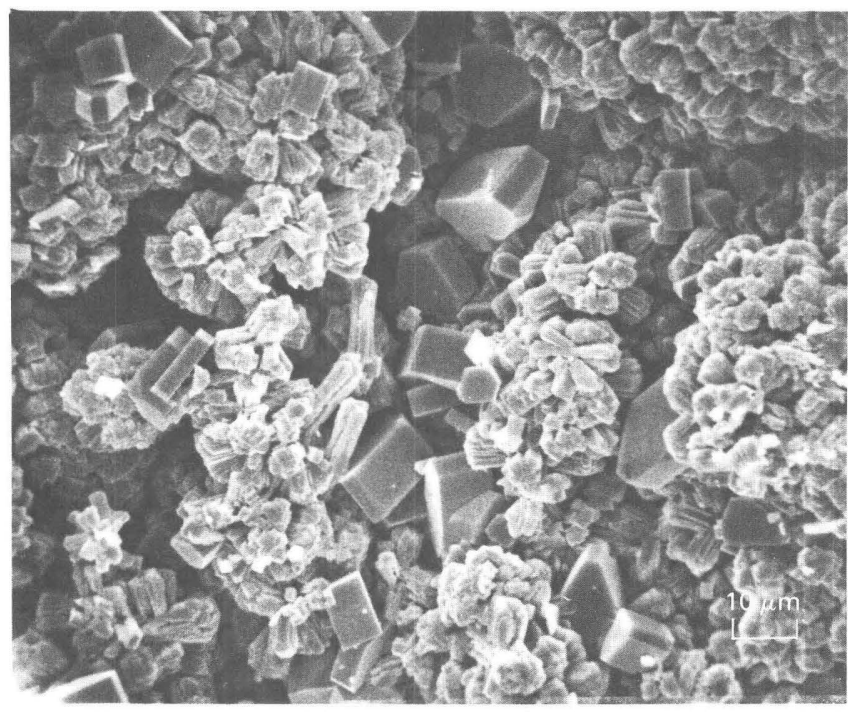

Figure 9. Scanning electron micrograph showing spherical rosettes of phillipsite $(\mathrm{Ph})$ and clinoptilolite $(\mathrm{Cp})$, from sample SD8-6C, Durkee, Oregon.

cannot as yet be predicted in modern closed-lake systems, but the series reported here for the Durkee deposits fits the patterns studied in other lakes.

\section{Clay minerals}

Smectite is ubiquitous in the altered tuffs in the Durkee basin, where it was generally the first formed mineral phase found as a thin coating on partly altered glass shards (fig. 8). This clay layer can be seen petrographically to outline relict shard textures after the zeolitic alteration was complete and no glass remained. Hay, (1963, p. 249) demonstrated that "Alteration of glass to montmorillonite (is) *** a hydrolysis reaction" during his work on zeolites in the middle Tertiary John Day Formation. More recently, Dibble and Tiller (1981) showed that kinetic processes are important factors in the glass-clay-zeolitefeldspar diagenesis and can explain the brief time needed to deposit the thin clay layers.

Detailed study of clay-mineralogy diagenesis, other than determining the presence of three broad categories based on the low-angle, strong XRD maxima as $14-\AA$, $10-\AA$, or $7-\AA$ clays has not been done at Durkee. XRD methods can detect small quantities of well-crystallized phases; however, the clay minerals at Durkee are not only poorly crystalline, but also are present in minute amounts, thus making detection by XRD in multiphase samples nearly impossible. Scanning electron microscopy provides a useful means of examining such materials; figure 8 and other illustrations for the separate zeolite minerals show the typical smectite morphology.

\section{Diatoms and diatomite}

Diatomite beds and interbedded units of sandstone, siltstone, mudstone, and airfall tuff dominate the lacustrine sequence in most of the Durkee basin. The lightcolored units visible in outcrops at the eroding heads of gullies and in road cuts (fig. 4) are chiefly diatomite. Eight samples from three localities were submitted to G. W. Andrews for examination and determination of the diatoms present. Two of the samples collected in the zeolitized area (fig. $1 B$ ) contained no diatoms, even though approximately correlative units a few tens of meters away beyond the limit (fig. $1 B$ ) of zeolitic alteration are diatomites. Presumably, the alkaline water within the zeolite area was capable of dissolving the tests of diatoms that may have been present, or diatoms did not thrive in such saline alkaline solutions.

Table 3 lists about 60 varieties of diatoms and their relative abundance found in the six diatomite-rich specimens (G. W. Andrews, U.S. Geological Survey, National Museum, Washington, D.C., written commun., 1971). Recent paleontological diatom investigations in the Durkee basin by J. Platt Bradbury (U.S. Geological Survey, Denver, Colo., oral commun., 1985) support most of the findings of G. W. Andrews and have provided a certain age as late Miocene.

\section{Phillipsite}

Phillipsite was observed in thin section as the first zeolite to have formed in the deposits at Durkee. This is the pattern found by Sheppard and Gude (1968, 1969, 1973a) for such zeolite alteration of volcanic glass in saline, alkaline lake deposits. Figure 9 is an SEM photograph of rosettes and $10-\mu \mathrm{m}$ elongate bundles of 
Table 3. Diatom species and varieties at Durkee, Baker County, Oregon

[Relative frequency indicated by: A, abundant, C, common, R, rare; leaders (---) indicate none found. Analysts: G. W. Andrews and J. P. Bradbury, U.S. Geological Survey]

Field No. (see fig. 1 , and appendix 1)...................

USGS diatom local ity No.....................................

6365

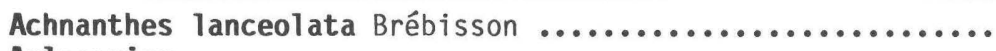

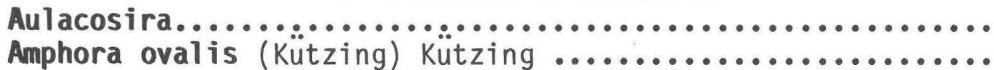

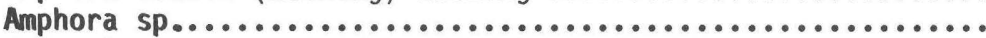

Caloneis sp.

Cocconeis placentula var. lineata (Ehrenberg) Cleve..........

Cocconeis placentula Ehrenberg.............................

Cymatopleura solea (Brébisson) W. Smith......................

Cymbella mexicana (Ehrenberg) A. Schmidt

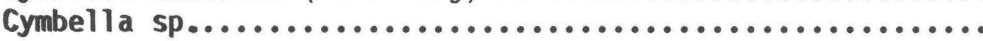

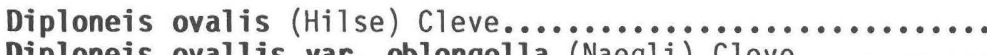

Diploneis ovallis var. oblongella (Naegli) Cleve.............

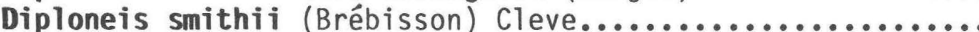

Diploneis sp.............................................

Epithemia sorex Kützing

6365

Epithemia sorex var. gracillis Hustedt...

Epithemia sp A.

Epithemia sp...............................................

Eunotia serra Ehrenberg...................................

Eunotia valida Hustedt.

Eunotia sp................................................

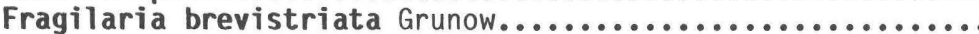

Fragilaria leptostauron (Ehrenberg) Hustedt..................

Fragilaria leptostauron var. dubia (Grunow) Hustedt..........

Fragilaria leptostauron var. dubia Grunow.................

Fragilaria leptostauron var. A. .

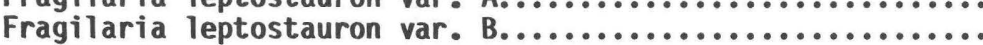

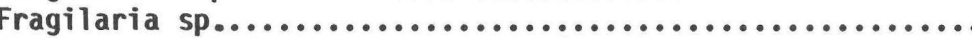

Gomphonema intricatum var. vibrio (Ehrenberg) Cleve..........

Gomphonema sp. A..................................

Gomphonema sp. B.

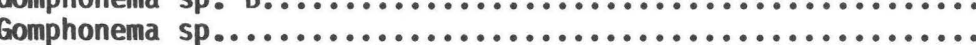

Hantzschia amphioxys (Ehrenberg) Ralfs.....................

Navicula amphibola Cleve.

Navicula lacustris Gregory................................

\begin{tabular}{|c|c|c|c|c|c|c|c|}
\hline --- & --- & --- & --- & -- & --- & $\mathrm{R}$ & $\mathrm{R}$ \\
\hline --- & C & $A$ & $A$ & -- & $R$ & $\AA$ & A \\
\hline $\mathrm{R}$ & $\mathrm{R}$ & $\mathrm{R}$ & --- & $R$ & --- & $\mathrm{R}$ & --- \\
\hline --- & --- & C & C & -- & --- & -- & --- \\
\hline $\mathrm{R}$ & --- & $\mathrm{R}$ & $R$ & $\cdots$ & --- & $R$ & -- \\
\hline --- & --- & --- & --- & -- & --- & -- & R \\
\hline--- & --- & $R$ & C & --1 & $R$ & $R$ & -- \\
\hline $\mathrm{R}$ & $\mathrm{R}$ & $\mathrm{R}$ & ---- & --1 & ---- & $R$ & --- \\
\hline C & C & C & $R$ & -- & C & C & C \\
\hline$R$ & $R$ & $R$ & --- & -- & --- & $\cdots$ & -- \\
\hline C & C & C & $R$ & $R$ & $R$ & C & C \\
\hline$R$ & --- & $R$ & --- & --- & --- & -- & --- \\
\hline C & $C$ & C & $\mathrm{R}$ & -- & --- & $R$ & --- \\
\hline--- & --- & $R$ & --- & --- & --- & -- & --- \\
\hline $\mathrm{R}$ & C & C & C & $R$ & C & C & C \\
\hline --- & ---- & --- & --- & --- & --- & C & --- \\
\hline --- & --- & --- & --- & --- & --- & -- & $\mathrm{R}$ \\
\hline C & --- & --- & -- & -- & --- & -- & -- \\
\hline $\mathrm{R}$ & $\mathrm{R}$ & --- & --- & -- & --- & -- & --- \\
\hline --- & --- & --- & --- & --- & --- & $\mathrm{R}$ & --- \\
\hline ---- & --- & --- & --- & -- & $R$ & -- & --- \\
\hline C & C & --- & --- & -- & --- & -- & --- \\
\hline --- & C & --- & --- & --- & --- & -- & --- \\
\hline --- & --- & --- & --- & -- & --- & --1 & C \\
\hline C & --- & C & --- & $R$ & $\mathrm{R}$ & $R$ & --- \\
\hline --- & --- & --- & --- & -- & --- & -- & $R$ \\
\hline --- & --- & --- & --- & -- & --- & -- & R \\
\hline --- & --- & --- & --- & -- & --- & -- & $R$ \\
\hline--- & --- & --- & --- & -- & --- & $\mathrm{R}$ & --- \\
\hline--- & --- & --- & --- & $\mathrm{R}$ & --- & - & --- \\
\hline --- & --- & --- & --- & $R$ & --- & - & --- \\
\hline --- & --- & --- & --- & -- & $\mathrm{R}$ & -- & --- \\
\hline C & --- & --- & --- & --- & --- & -- & --- \\
\hline --- & --- & $\mathrm{R}$ & --- & $\mathrm{R}$ & --- & $R$ & --- \\
\hline C & C & --- & $R$ & $R$ & $\mathrm{R}$ & C & C \\
\hline
\end{tabular}


Navicula oblonga Kützing

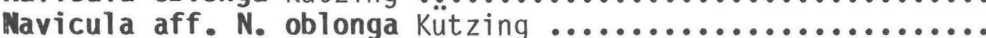

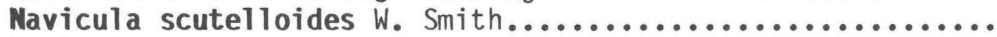

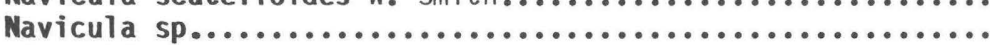

Nitzschia spo.

Opephora martyi Héribana

Pinnularia borealis Ehrent

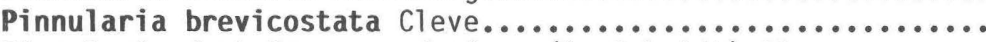

Pinnularia dactylus.var. dariana (A. Schmidt) Cleve.........

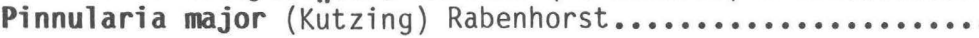

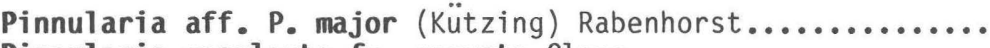

Pinnularia mesolepta fo. angusta Cleve..................

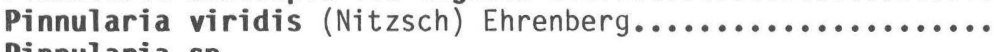

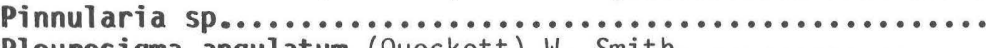

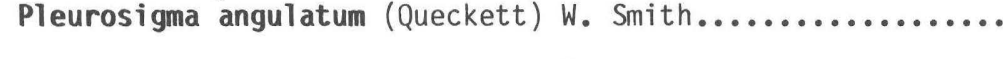

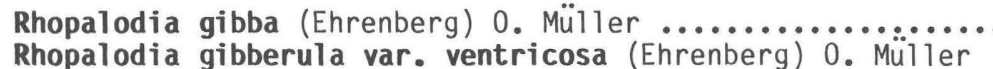

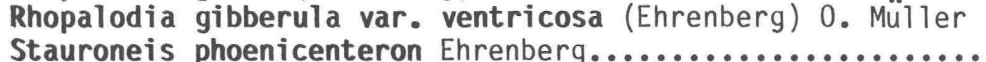

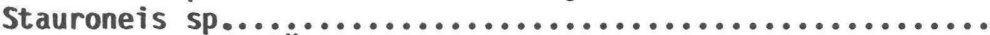

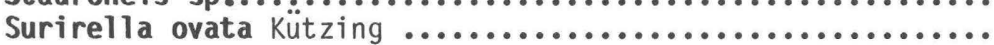

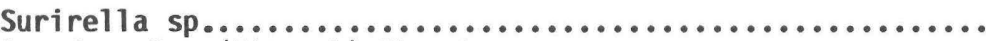

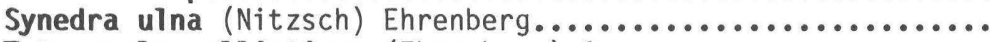

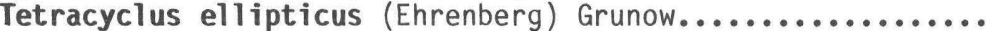

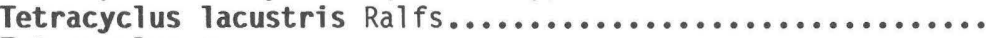

Tetracyclus sp..................................

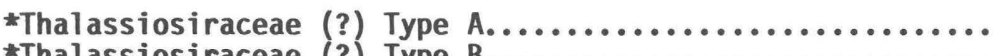

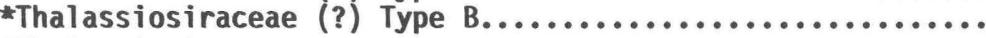

C ---

R

R

$--$

--

---

$-$

$\mathrm{R}$

---

$--$

$-\cdots$

R

--.

$-$

C

$---$

$---$

C

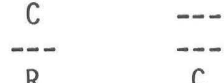

$\cdots$

$\begin{array}{ll}-1 & -1 \\ --- & --\end{array}$

C

Mineralogy (see appendix 1). Estimated abundance reported as parts in ten

Mineralogy (see appendix 1). Estimated abundance reported as parts in ten

R $\quad R$

$C$
--
$R$
$R$

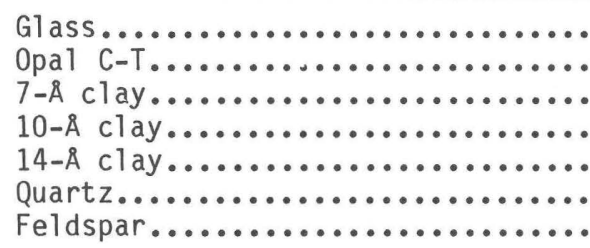

$\begin{array}{ccc}--- & --- & -- \\ --- & --- & --- \\ --- & --- & -- \\ 1 & 1 & 1 \\ --- & 2 & 5 \\ 5 & 4 & 3 \\ 4 & 3 & 1\end{array}$

$\begin{array}{cc}5 & --- \\ 1 & --- \\ 1 & --- \\ 2 & 2 \\ --- & 3 \\ --- & 3 \\ 1 & 2\end{array}$

5
---
--
1
2
2
Trace

$\begin{array}{cc}--- & 2 \\ --- & --- \\ --- & -- \\ 1 & 3 \\ 4 & 1 \\ 4 & 2 \\ 1 & 2\end{array}$

*The discoid centric diatoms in the Durkee deposits are undescribed genera and species of the family Thalassiosiraceae, apparently

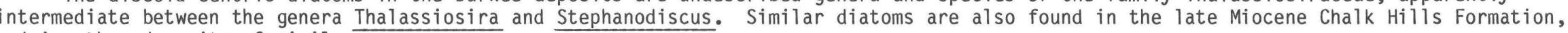
and in other deposits of similar age. 


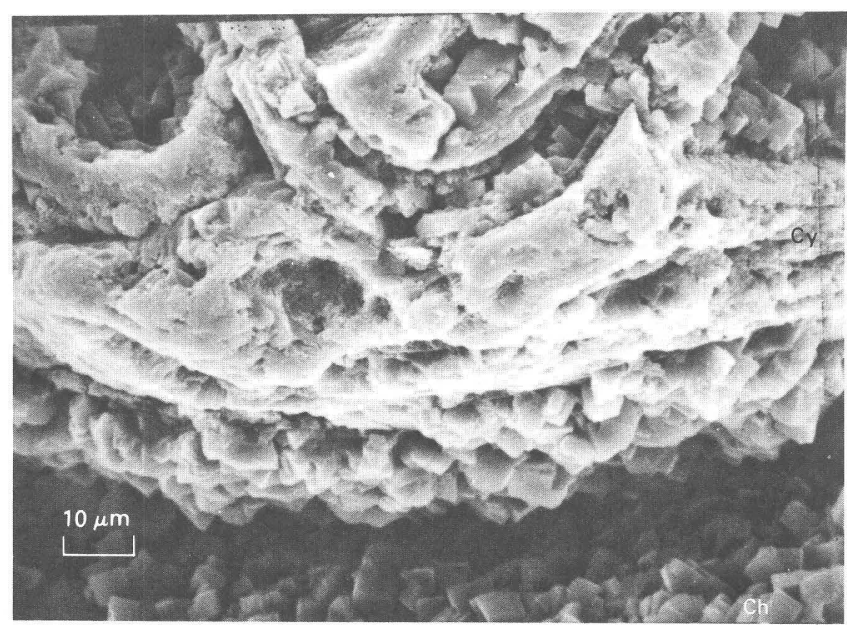

Figure 10. Scanning electron micrograph of chabazite (Ch) on clay (Cy) lining in relict shards from sample SD-4-2, Durkee, Oregon.

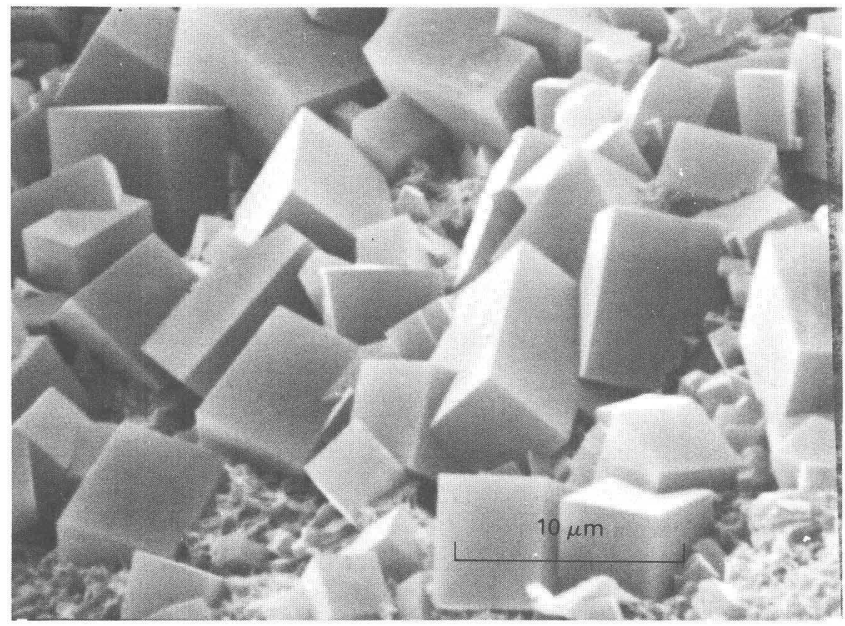

Figure 11. Scanning electron micrograph of chabazite on a mat of smectite lining a shard, from sample SD-4-16, Durkee, Oregon.

phillipsite which appear to have formed earlier than the perched crystals of clinoptilolite.

The scarcity of phillipsite is probably due to rapidly changing diagenetic conditions. After phillipsite formed, the $\mathrm{pH}$ of the reacting waters probably increased (Surdam and Sheppard, 1978, p. 149) which favored the formation of the other zeolites in the paragenetic sequence shown in table 1 .

\section{Chabazite}

Chabazite from Durkee was described by Gude and Sheppard (1978). The SEMs in figures 10 and 11 are new to the present study and show chabazite on mats of

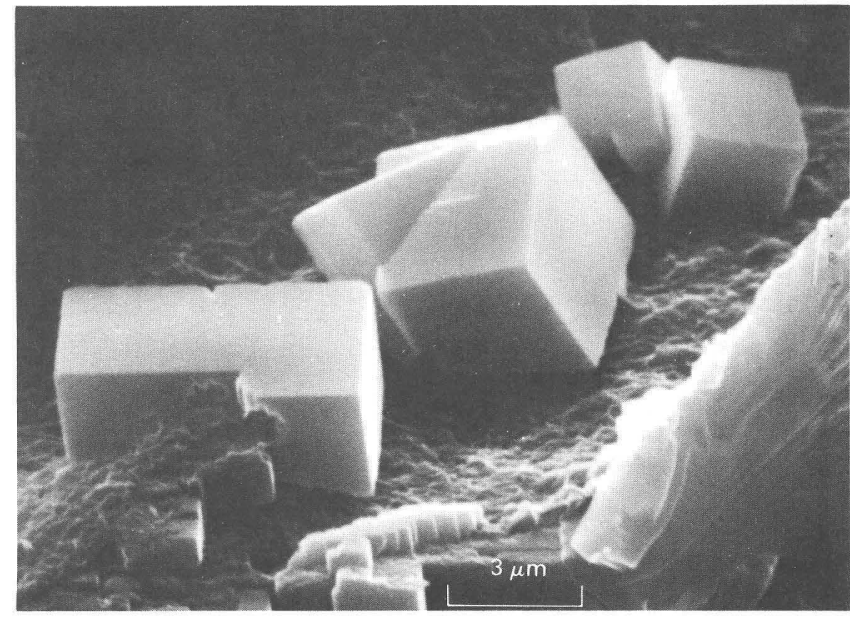

Figure 12. Scanning electron micrograph of chabazite from sample SD-4-16, Durkee, Oregon, showing twinning habit and late-formed smectite (bottom left) encroaching on a chabazite crystal (from Gude and Sheppard, 1978).

smectite which formed by the alteration of glass shard walls. Figure 12 (from Gude and Sheppard, 1978) shows the twinning habit that is common for chabazite from the tuffs deposited in the saline, alkaline lakes. Chabazite beds as seen at measured section SD-4 are commonly massive and nearly monomineralic through as much as a $15-\mathrm{m} \mathrm{sec}-$ tion. This is a restricted occurrence, however, and chabazite has not been formed in such large quantities in outcrops away from this area.

\section{Erionite}

Durkee, at locality D-29 on Swayze Creek, is the type locality (Eakle, 1898) for the original woolly variety of erionite. Erionite in tuffs in the Durkee lake beds first reported by Sheppard and Gude (1975) is now known to be one of the common zeolites in the basin. It clearly formed later than chabazite as is seen in figures 13 and 14. The woolly crystal habit found at the type locality has not been seen elsewhere in the Durkee area. Elongate, 40$\mu \mathrm{m}$ rods of erionite, commonly in bundles of parallel needles, is the common form in the lacustrine tuffs as shown in figure 13.

\section{Clinoptilolite}

Although clinoptilolite is widespread in the zeolitic areas at Durkee, it has not been found in monomineralic units more than a few centimeters thick. Erionite coexisting with clinoptilolite can be seen in figure 15. Clinoptilolite crystals, nearly 1-mm wide, were readily observed with a field hand lens at one sample locality, D-66c. Here, 


\section{Silica minerals}

Quartz, opal-CT, and Magadi-type chert have been identified at Durkee. Authigenic quartz that formed after clinoptilolite has been noted by optical microscopy only in sample D-62A. At least 30 other samples may contain authigenic quartz without detrital minerals such as plagioclase, amphibole, and clay minerals. Opaline silica was noted at many sample localities, but it was generally associated with the diatomite. Magadi-type chert found at a single locality (D-107) was not directly related to any tuff unit.

\section{CONCLUSIONS}

Diagenesis at Durkes has produced on 18- to 20$\mathrm{km}^{2}$ zeolite deposit in a restricted part of late Miocene lacustrine beds which are present in a $120-\mathrm{km}^{2}$ basin. The geochemical requirements of high salinity and alkalinity were apparently developed in a part of an ancient lake. Diatoms flourished in the surrounding lake where freshwater streams entered the lake margins. Zeolitic alteration of the siliceous vitric tuffs occurred near the narrow sediment-dammed outlet. The preservation of the altered zeolitic core area in an otherwise freshwater-lake sedimentary basin indicates a rapid kinetic process that may have taken place in a sheltered cove of the lake. The reaction of saline, alkaline, closed-basin waters with the vitroclastic material was able to proceed at temperatures and pressures of a desert-floor shallow lake, surrounded by a growing deposit of diatoms that coexisted with the formation of the authigenic zeolites.

\section{REFERENCES CITED}

Dibble, W. E., Jr., and Tiller, W. A., 1981, Kinetic model of zeolite paragenesis in tuffaceous sediments: Clays and Clay Minerals, v. 29, p. 323-330.

Eakle, A. S., 1898, Erionite, a new zeolite: American Journal of Science, v. 155, p. 66-68.

Gilluly, J., 1937, Geology and mineral resources of the Baker quadrangle, Oregon: U.S. Geological Survey Bulletin 879, $119 \mathrm{p}$.

Gude, A. J., 3rd, and Sheppard, R. A., 1978, Chabazite in siliceous tuffs of a Pliocene lacustrine deposit near Durkee, Baker County, Oregon: U.S. Geological Survey Journal of Research, v. 6, p. 467-472.

Hay, R. L., 1963, Stratigraphy and zeolite diagenesis of the John Day Formation of Oregon: University of California Publications in Geological Science, v. 42, p. 199-265.

Jones, B. F., 1965, The hydrology and mineralogy of Deep Springs Lake, Inyo County, California: U.S. Geological Survey Professional Paper 502-A, 56 p.
1966, Geochemical evolution of closed basin waters in the western Great Basin, in Rau, J. F., ed., Second symposium on salt: Ohio Geological Society, v. 1, p. 189-200.

Jones, B. F., Eugster, H. P., and Rettig, S. L., 1977, Hydrochemistry of the Lake Magadi basin, Kenya: Geochimica et Cosmochimica Acta, v. 41, p. 53-72.

Jones, B. F., Rettig, S. L., and Eugster, H. P. 1967, Silicate in alkaline brines: Science, v. 158, p. 1310-1314.

Prostka, H. J., 1967, Preliminary geologic map of the Durkee quadrangle, Oregon: Oregon Department of Geology and Mineral Industries Geological Map GMS-3, text 8 p.

Smith, G. I., 1966, Geology of Searles Lake, in Rau, J. F., ed., Second symposium on salt: Northern Ohio Geological Society, v. 1, p. 167-180.

Smith, G. I., and Friedman, Irving, 1986, Seasonal diagenetic changes in salts of Owens Lake, 1970-77, in Mumpton, F. A., ed., Studies in diagenesis: U.S. Geological Survey Bulletin 1578, 21-29.

Sheppard, R. A., and Gude, A. J., 3rd, 1965, Potash feldspar of possible economic value in the Barstow Formation, San Bernardino County, California: U.S. Geological Survey Circular 500,7 p.

1968, Distribution and genesis of authigenic silicate minerals in tuffs of Pleistocene Lake Tecopa, Inyo County, California: U.S. Geological Survey Professional Paper 597, $38 \mathrm{p}$.

1969, Diagenesis of tuffs in the Barstow Formation, Mud Hills, San Bernardino County, California: U.S. Geological Survey Professional Paper 634, 35 p.

1973a, Zeolites and associated authigenic silicate minerals in tuffaceous rocks of the Big Sandy Formation, Mohave County, Arizona: U.S. Geological Survey Professional Paper $830,36 \mathrm{p}$.

1973b, Boron-bearing potassium feldspar of authigenic origin in closed-basin deposits: U.S. Geological Survey Journal of Research, v. 1, no. 4, p. 377-382.

1975, Distribution of zeolites in Pliocene lacustrine rocks, Durkee basin, Baker County, Oregon: Geological Society of America Abstracts with Programs, v. 7, no. 3, p. 374.

Staples, L. W., 1957, X-ray study of erionite, a fibrous zeolite [abs.]: Geological Society of America Bulletin, v. 68, p. 1847.

Staples, L. W., and Gard, J. A., 1959, The fibrous zeolite erionite, its occurrence, unit cell, and structure: Mineralogical Magazine, v. 32, p. 261-281.

Surdam, R. C., and Mariner, R. H., 1971, The genesis of phillipsite in Recent tuffs at Teels Marsh, Nevada: Geological Society of America Abstracts with Programs, v. 3, p. 725 .

Surdam, R. C., and Eugster, H. P., 1976, Mineral reactions in the sedimentary deposits of the Lake Magadi region, Kenya: Geological Society of America Bulletin, v. 87, no. 12, p. 1739-1752.

Surdam, R. C., and Sheppard, R. A., 1978, Zeolites in saline, alkaline-lake deposits, in Sand, L. B., and Mumpton, F. A., eds., Natural zeolites-Occurrence, properties, use: Elmsford, New York, Pergamon Press, p. 149. 


\section{APPENDIX 1}


Notes and definitions:

Sample number (first column) combines the locality number (given in the spanner head) and the unit or bed number (or 1etter). Thus, sample D-1C-2 is from locality D1 and 1s unit $C$ plus subunit 2. All localities are shown on figure 1. Unit is used here to mean a stratigraphic piece (1ithology) of a measured section. Bed is used to mean a change of lithology within a

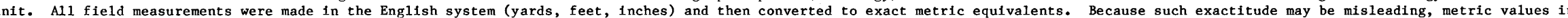

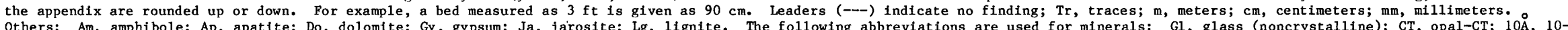
Others: Am, amphíbole; Ap, apat1te; Do, dolomite; Gy, gypsum; Ja, jarosite; Lg, lignite. The following abbreviations are used for minerals: Gl, glass (noncrystalline); CT, opal-CT; 10
angstrom clay; 14A, 14-angstrom clay; Ph, phillipsite; Ch, chabazite; Er, erionite; Cp, clinoptilolite; Mo, mordenite; An, analcime; KF, potassium feldspar; Qtz, quartz; PF, plagioclase eldspar; Cl, calcite.

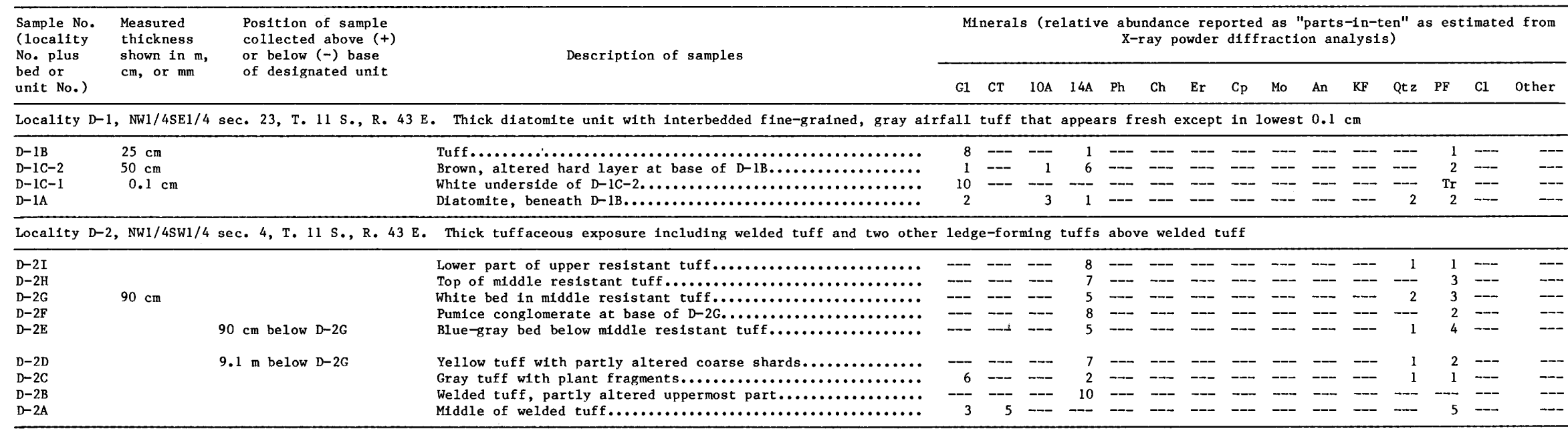

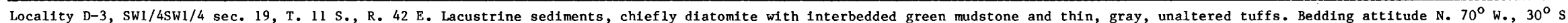

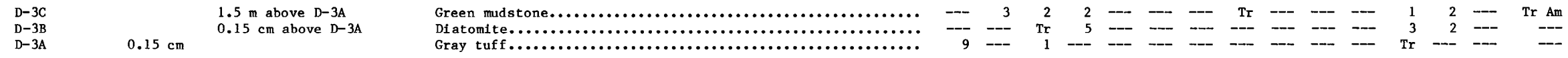
Locality SD-4, SE1/4SE1/4 sec. 23, T. 11 S., R. $43 \mathrm{E}$. Measured section. Bedding attitude N. $70^{\circ}$ W., $16^{\circ}$ N.

\begin{tabular}{|c|c|c|c|c|c|c|c|c|c|c|c|c|c|c|c|c|c|c|}
\hline$S D-4-16$ & $4.0 \mathrm{~m}$ & $+2.5 \mathrm{~m}$ & $\begin{array}{l}\text { Yellow, thick-bedded, massive tuff with vitric shard } \\
\text { texture; top of unit eroded. }\end{array}$ & -- & --- & --- & $\operatorname{Tr}$ & -- & 10 & $\operatorname{Tr}$ & -- & -- & --- & --- & --- & $\cdots$ & -- & $\cdots$ \\
\hline SD-4-15 & $2.0 \mathrm{~m}$ & & 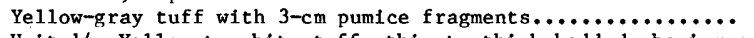 & -- & --- & --- & 9 & -- & 1 & $\rightarrow$ & -- & --- & --- & --- & -- & -- & -- & -- \\
\hline SD-4-14 & $1.7 \mathrm{~m}$ & & Unit 14--Yellow to white tuff, thin to thick bedded, having co & oarse & shard & textu & are: & & & & & & & & & & & \\
\hline $\begin{array}{l}\text { SD-4-14B } \\
S D-4-14 A\end{array}$ & & $+1.4 \mathrm{~m}$ & 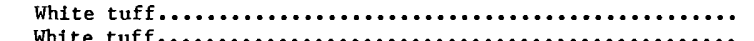 & -- & --- & --- & - & -- & 10 & $\mathrm{Tr}$ & $\mathrm{Tr}$ & -- & --- & --- & $\cdots$ & $=--$ & $\overline{--}$ & -- \\
\hline $\begin{array}{l}S D-4-14 A \\
S D-4-13\end{array}$ & $1.7 \mathrm{~m}$ & $+90 \mathrm{~cm}$ & 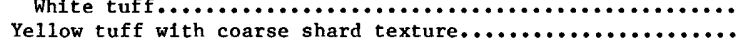 & $\cdots$ & -- & $\overline{--}$ & $\begin{array}{r}2 \\
\mathrm{Tr}\end{array}$ & - & 7 & $\begin{aligned} 1 \\
---\end{aligned}$ & $\begin{array}{c}\operatorname{Tr} \\
3\end{array}$ & -- & --- & - & -- & -- & -- & 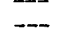 \\
\hline SD-4-12 & $1.4 \mathrm{~m}$ & & $\begin{array}{l}\text { Brown tuffaceous mudstone, conchoidal fracture; abundant } \\
\text { white cavity fillings. }\end{array}$ & --- & --- & --- & 7 & --- & 1 & --- & -- & -- & $\cdots$ & -- & 1 & 1 & -- & \\
\hline SD-4-11 & $1.8 \mathrm{~m}$ & & $\begin{array}{l}\text { Yellow tuff, medium thick to thick bedded; locally with } \\
\text { white opal segregations. }\end{array}$ & -- & --- & -- & -- & -- & 5 & 1 & 4 & --- & -- & $\cdots$ & -- & --- & -- & -- \\
\hline SD-4-10 & $3.8 \mathrm{~m}$ & & $\begin{array}{l}\text { Brown tuffaceous mudstone, crudely bedded; many small } \\
\text { cavities filled with white crystals. }\end{array}$ & $\cdots$ & $\cdots$ & $\cdots$ & 5 & -- & $\mathrm{Tr}$ & --- & 1 & --- & --- & --- & -- & 4 & $\cdots$ & - \\
\hline SD-4-9 & $8 \mathrm{~cm}$ & & $\begin{array}{l}\text { Yellow tuff, with one bed consisting of pumice fragments } \\
\text { as wide as } 2 \mathrm{~cm} \text {. }\end{array}$ & - & -- & $\cdots$ & 1 & -- & 3 & --- & 1 & -- & $\cdots$ & - & --- & 5 & -- & \\
\hline SD-4-8 & $4 \mathrm{~m}$ & & $\begin{array}{l}\text { Brown tuff, punky with crude bedding, coarser near base; } \\
\text { many pumice fragments. }\end{array}$ & -- & -- & -- & $\operatorname{Tr}$ & --- & 8 & -- & 2 & --- & -- & -- & -- & -- & -- & \\
\hline
\end{tabular}




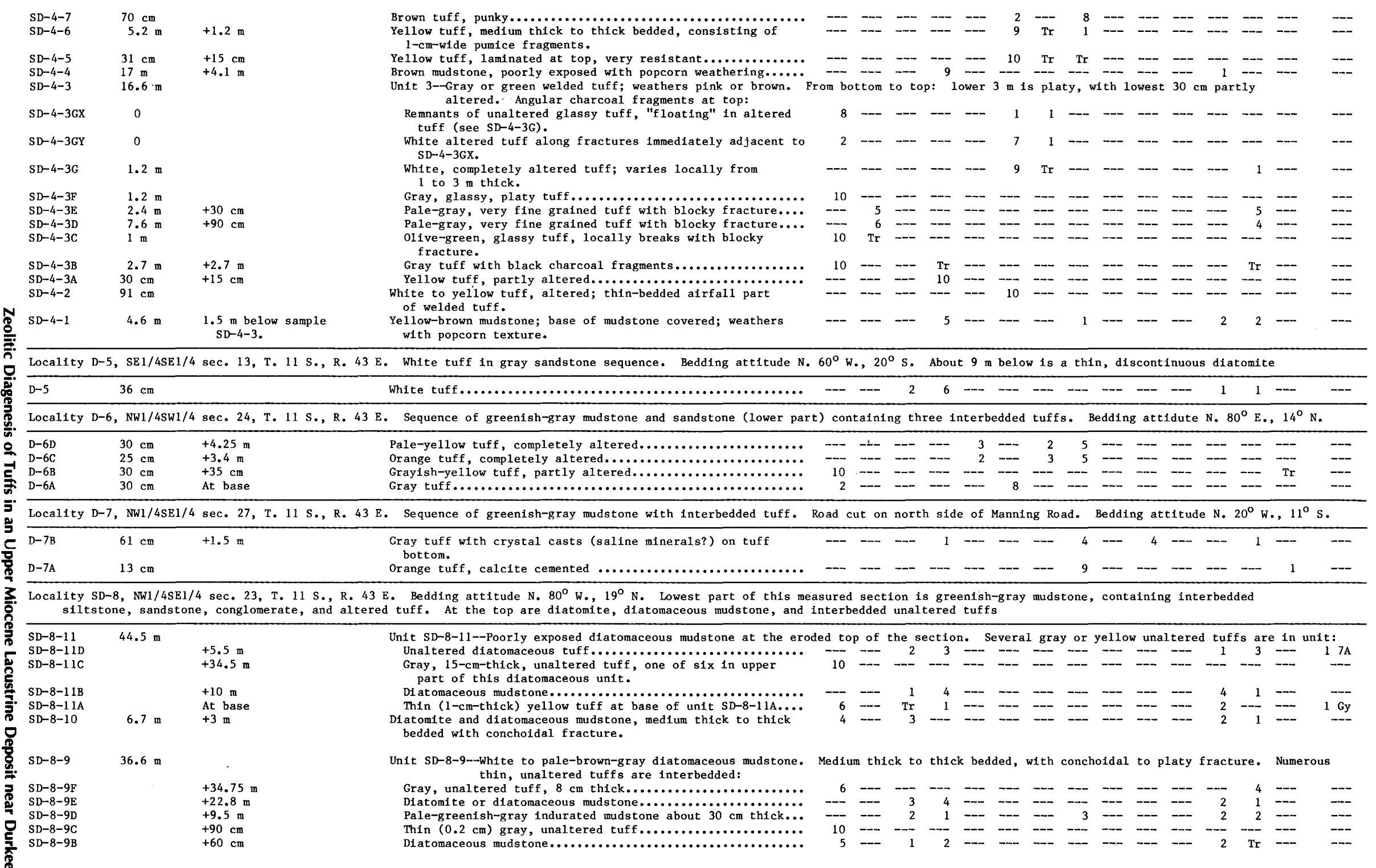


Append1x 1. Mineralogy of lacustrine rocks from the Durkee basin, Baker County, Oregon--Continued

\begin{tabular}{|c|c|c|c|c|c|c|c|c|c|c|c|c|c|c|c|c|c|c|}
\hline \multirow{2}{*}{$\begin{array}{l}\text { Sample No. } \\
\text { (locallty } \\
\text { No. plus } \\
\text { bed or } \\
\text { unit No.) }\end{array}$} & \multirow{2}{*}{$\begin{array}{l}\text { Measured } \\
\text { thickness } \\
\text { shown in m, } \\
\mathrm{cm} \text {, or } \mathrm{mm}\end{array}$} & \multirow{2}{*}{$\begin{array}{l}\text { Position of sample } \\
\text { collected above }(+) \\
\text { or below }(-) \text { base } \\
\text { of designated unit }\end{array}$} & \multirow{2}{*}{ Description of samples } & \multicolumn{15}{|c|}{$\begin{array}{c}\text { Minerals (relative abundance reported as "parts-in-ten" as estimated from } \\
\text { X-ray powder diffraction analysis) }\end{array}$} \\
\hline & & & & G1 & Cr & 10A & $14 \mathrm{~A}$ & $\mathrm{Ph}$ & Ch & Er & $C_{p}$ & Mo & An & $\mathrm{KF}$ & Qtz & $\mathrm{PF}$ & $\mathrm{C} 1$ & Other \\
\hline \multicolumn{19}{|c|}{ Locality SD-8--Continued } \\
\hline $\begin{array}{l}\text { SD-8-9A } \\
\text { SD-8-8 }\end{array}$ & $22.1 \mathrm{~m}$ & At base & $\begin{array}{c}\text { Thin }(2.5 \mathrm{~cm}) \text { gray unaltered tuff............................. } \\
\text { Unit SD-8-8--Pale-brown-gray mudstone with conchoidal to platy } \\
\text { Mudstone is medium thick to thick bedded: }\end{array}$ & $\begin{array}{l}10 \\
\text { fract }\end{array}$ & $\begin{array}{cc}--- \\
\text { ture; }\end{array}$ & --- & $-\overline{11} \mathrm{y} \mathrm{cc}$ & contai & ns ab & undan & it ost & tracod & ds and & rare & clan & ms. & --- & --- \\
\hline $\begin{array}{l}S D-8-8 F \\
S D-8-8 E\end{array}$ & & $+21.3 \mathrm{~m}$ & & --- & --- & $\begin{array}{r}2 \\
---\end{array}$ & 3 & $\overrightarrow{--}$ & -- & $-\cdots$ & -- & - & - & -- & 3 & 2 & $\overline{---}$ & $\overline{---}$ \\
\hline $\begin{array}{l}S D-8-8 E \\
S D-8-8 D\end{array}$ & & $\begin{array}{l}+9.1 \mathrm{~m} \\
+8.2 \mathrm{~m}\end{array}$ & $\begin{array}{l}\text { Brown sandstone, fine grained....................................... } \\
\text { White, upper tuffaceous mudstone with } 2-\text { to } 5 \text {-cm-thick } \\
\text { sandstones; ostracods are in upper parts. }\end{array}$ & 10 & --- & --- & -5 & --- & -- & -- & --- & --- & -- & --- & --- & $\operatorname{Tr}$ & --- & -- \\
\hline$S D-8-8 C$ & & & Brown, lower tuffaceous mudstone, part of SD-8-8D........ & 10 & $\cdots$ & --- & --- & -- & --- & --- & --- & --- & --- & --- & $\operatorname{Tr}$ & $\operatorname{Tr}$ & --- & $\overline{\operatorname{Tr}}-\overline{\mathrm{Am}}$ \\
\hline$-8-8 \mathrm{~B}$ & & $+7.6 \mathrm{~m}$ & Mudstone with ostracods and clams......................... & --- & --- & 3 & 3 & -- & -- & --- & -- & -- & -- & --- & 3 & 1 & --- & Tr Am \\
\hline SD-8-8A & & $+5.5 \mathrm{~m}$ & Thin $(10-\mathrm{cm}-\mathrm{thick})$ white tuff $\ldots \ldots \ldots \ldots \ldots \ldots \ldots \ldots \ldots$ & --- & --- & -- & 1 & --- & -- & 3 & 6 & -- & -- & -- & -- & - & $\cdots$ & \\
\hline $\begin{array}{l}\text { SD-8-7 } \\
\text { SD-8-6 }\end{array}$ & $\begin{array}{c}5 \mathrm{~m} \\
14.3 \mathrm{~m}\end{array}$ & $+2.4 \mathrm{~m}$ & $\begin{array}{l}\text { Brown sandstone, with thin mudstone and conglomerate beds... } \\
\text { Unit SD-8-6--Gray to greenish-gray mudstone containing thin sil }\end{array}$ & $\begin{array}{l}--- \\
1 \text { tston }\end{array}$ & ne and & $\begin{array}{l}\text { Tr } \\
\text { sanc }\end{array}$ & idstone & ne bed & s:- & --- & 2 & --- & --- & --- & 3 & 2 & -- & 3 Am \\
\hline SD-8-6I & & & $\begin{array}{l}\text { Pale-orange tuff forms top of unit SD-8-6. This sample } \\
\text { is at the top of the } 35-\mathrm{cm}-\text { thick tuff. }\end{array}$ & -- & --- & -- & $\operatorname{Tr}$ & --- & -- & 5 & 5 & --- & -- & -- & --- & -- & $-\cdots$ & -- \\
\hline SD-8-6H & & & Sample from middle of tuff $($ see SD-8-6I) $\ldots \ldots \ldots \ldots \ldots \ldots \ldots$ & --- & --- & --- & --- & -- & --- & 4 & 6 & --- & --- & -- & --- & $\cdots$ & -- & --- \\
\hline $0-8-6 \mathrm{G}$ & & & Sample from base of tuff $($ see $S D-8-61) \ldots \ldots \ldots \ldots \ldots \ldots \ldots$ & --- & --- & -- & --- & --- & 5 & 2 & 3 & --- & --- & --- & --- & -- & $\cdots$ & --- \\
\hline SD-8-6F & & $+9.5 \mathrm{~m}$ & White tuff, $1 \mathrm{~cm}$ thick $\ldots \ldots \ldots \ldots \ldots \ldots \ldots \ldots \ldots \ldots \ldots \ldots \ldots \ldots \ldots \ldots$ & -- & -- & --- & 1 & 3 & -- & 3 & 3 & --- & -- & --- & -- & $\cdots$ & $\cdots$ & -- \\
\hline SD-8-6E & & $+8.2 \mathrm{~m}$ & 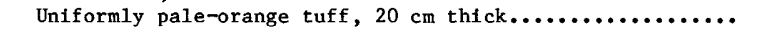 & --- & --- & -- & -- & --- & -- & 10 & --- & -- & --- & --- & -- & -- & -- & --- \\
\hline SD-8-6D & & $+5.8 \mathrm{~m}$ & Gray upper part of $30-\mathrm{cm}$-thick tuff $\ldots \ldots \ldots \ldots \ldots \ldots \ldots$ & --- & --- & $\operatorname{Tr}$ & $\mathrm{Tr}$ & - & --- & 9 & --- & --- & --- & --- & 1 & --- & --- & --- \\
\hline SD-8-6C & & & Yellow lowe & -- & $\ldots-$ & --- & 1 & 5 & --- & - & 3 & --- & --- & --- & $\operatorname{Tr}$ & 1 & --- & --- \\
\hline SD-8-6B & & $+4.9 \mathrm{~m}$ & 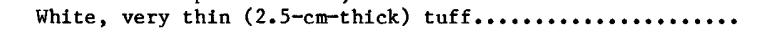 & -- & $-\cdots$ & -- & $\mathrm{Tr}$ & 4 & $\cdots$ & 2 & 3 & $-\cdots$ & -- & -- & -- & & --- & -- \\
\hline SD-8-6A & & $-1.5 \mathrm{~m}$ & 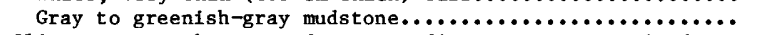 & --- & -- & -- & $\operatorname{Tr}$ & 3 & -- & -- & $\operatorname{Tr}$ & --- & -- & --- & 5 & & -- & --- \\
\hline$S D-8-5$ & $4 \mathrm{~m}$ & & $\begin{array}{l}\text { 01ive-green to brown sandstone, medium to coarse grained, } \\
\text { very poorly consolidated. }\end{array}$ & --- & --- & -- & -- & $\rightarrow$ & $-\cdots$ & --- & $\operatorname{Tr}$ & --- & --- & -- & 5 & 4 & --- & $1 \mathrm{Am}$ \\
\hline $\begin{array}{l}S D-8-4 \\
S D-8-4 B\end{array}$ & $3.7 \mathrm{~m}$ & & $\begin{array}{l}\text { y mudstone that has conchoidal fracture } \\
\text { thick, at top of unit } S D-8-4 \ldots \ldots \ldots\end{array}$ & when & fresh. & Tr $\mathrm{Sc}$ & Some th & thin & uffs & in up & per ${ }_{2}^{p}$ & part: & $\ldots$ & $\cdots$ & 4 & - & --- & 1 Gy \\
\hline$S D-8-4 A$ & & $+1.5 \mathrm{~m}$ & 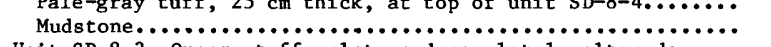 & --- & --- & $\operatorname{Tr}$ & -- & --- & --- & --- & I & --- & 5 & 2 & 1 & 1 & --- & $-1-$ \\
\hline SD-8- & $1.7 \mathrm{~m}$ & & Unit SD-8-3--Orange tuff, platy and completely altered: & & & & & & & & & & & & & & & \\
\hline$S D-8-3 C$ & & & 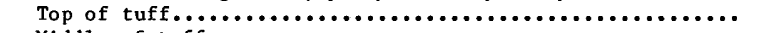 & --- & --- & 1 & 1 & --- & 1 & --- & --- & -- & 4 & 3 & --- & $\ldots$ & $\cdots$ & $\overline{---}$ \\
\hline$S D-8-3$ & & & 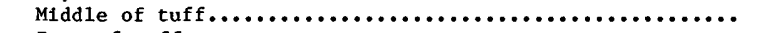 & -- & -- & $\operatorname{Tr}$ & $\operatorname{Tr}$ & --- & 1 & --- & --- & --- & 5 & & -- & --- & -- & 1 Gy \\
\hline SD-8-3A & & & 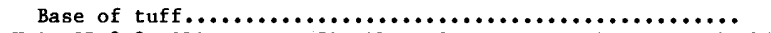 & -- & -- & 1 & $\operatorname{Tr}$ & --- & --- & -- & -- & $\cdots$ & 5 & 4 & $\cdots$ & --- & --- & Tr Ja \\
\hline $\begin{array}{l}\text { SD-8-2 } \\
\text { SD-8-2D }\end{array}$ & $8.5 \mathrm{~m}$ & & $\begin{array}{l}\text { Unit SD-8-2--0live-green fissile mudstone; contains several thi } \\
\text { Thin tuff or tuffaceous mudstone in the upper } 1 \mathrm{~m} \text { of } \\
\text { this unit. }\end{array}$ & in, al & 1tered & tuf & fs: & 3 & 2 & --- & --- & --- & -- & --- & 3 & -- & --- & \\
\hline 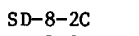 & & $+5.5 \mathrm{~m}$ & Uppermost of two thin $(2.5-\mathrm{cm}-$ thick $)$ orange tuffs......... & --- & --- & -- & $\cdots$ & 4 & -- & 1 & 3 & --- & -- & - & --- & --- & $\cdots$ & 2 Gy \\
\hline SD-8- & & & st of two tuffs $($ see SD-8-2C) $\ldots \ldots \ldots \ldots \ldots \ldots$ & --- & --- & --- & --- & 4 & --- & $\operatorname{Tr}$ & 6 & & --- & -- & --- & & & \\
\hline $\begin{array}{l}S D-8- \\
S D-8-\end{array}$ & 10.3 & $+5.2 \mathrm{~m}$ & 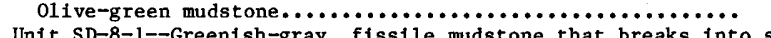 & $--\overline{1}$ & --- & 1 & $\operatorname{Tr}$ & --- & -- & $\cdots$ & -- & -- & --- & --- & 1 & 3 & 3 & $27 \mathrm{~A}$ \\
\hline SD-8-1 & $10.3 \mathrm{~m}$ & & $\begin{array}{l}\text { Unit SD-8-1--Greenish-gray, fissile mudstone that breaks into } \\
\text { in the upper part of the unit: }\end{array}$ & small & & & & & & & & & & & & & & \\
\hline & & +10.2 & sugary tuff near top of unit $\ldots \ldots \ldots \ldots \ldots \ldots \ldots \ldots$ & $-\ldots$ & -- & --- & -- & 1 & -- & $\operatorname{Tr}$ & 9 & -- & --- & --- & --- & --- & --- & $-\cdots$ \\
\hline $\begin{array}{l}S D-8-1 B \\
S D-8-1 A\end{array}$ & & $\begin{array}{l}+8.2 \mathrm{~m} \\
+4 \mathrm{~m}\end{array}$ & Orange tuff, $10.2 \mathrm{~cm}$ thick $\ldots \ldots \ldots \ldots \ldots \ldots \ldots \ldots \ldots \ldots \ldots \ldots \ldots \ldots \ldots \ldots$ & --- & --- & -- & --- & $=$ & -- & $\operatorname{Tr}$ & 10 & -- & -- & -- & --- & $-\overline{T r}$ & -- & --- \\
\hline SD-8-1A & & $+4 \mathrm{~m}$ & Mudstone........................... & -- & & & & & $\cdots$ & 1 & 2 & & $\cdots$ & & & & & \\
\hline
\end{tabular}

Locallty D-9, SWl/4SWl $/ 4 \mathrm{sec}$. 14, T. 11 S., R. 43 E. Exposure is a 2.1 -m-thick gray tuff stratigraphically above SD-8. Bedding attitude $\mathrm{N}$. $75^{\circ}$ E., $5^{\circ} \mathrm{N}$. The tuff is fine to medium bedded, and cross-bedded. About $9 \mathrm{~m}$ of greenish-gray mudstone are above $\mathrm{D}-9$. Below $\mathrm{D}-9$ are about $45.7 \mathrm{~m}$ of pale-gray mudstone, sandstone, and diatomaceous mudstone

\begin{tabular}{|c|c|c|c|c|c|c|c|c|c|c|c|c|c|c|c|c|c|}
\hline D-9E & $+3 \mathrm{~m}$ & 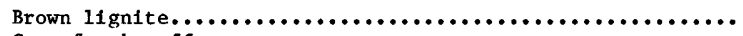 & 9 & --- & --- & 1 & --- & --- & --- & --- & --- & --- & - & --- & - & -- & $\ddot{---}$ \\
\hline D-9D & $+1 \mathrm{~m}$ & 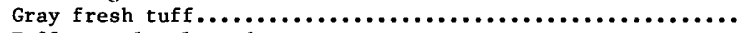 & 7 & -- & --- & 2 & -- & --- & --- & --- & --- & --- & --- & 1 & $\operatorname{Tr}$ & --- & --- \\
\hline D-9C & $+46 \mathrm{~cm}$ & Tuff, part1y a1tered....................... & 8 & -- & --- & 2 & -- & --- & -- & -- & -- & -- & -- & -- & - & -- & - \\
\hline $\begin{array}{l}D-9 B \\
D-9 A\end{array}$ & At base & 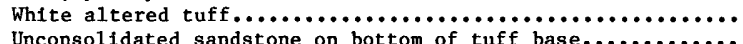 & --- & -- & $\overline{\mathrm{Tr}}$ & 10 & --- & --- & $\overline{-}$ & $\overline{---}$ & -- & -- & $\overline{---}$ & --- & $-\overline{5}$ & -- & $2 \overline{\mathrm{Am}}$ \\
\hline
\end{tabular}


Local1ty D-11, SE1/4SE1/4 sec. 36, T. $11 \mathrm{~S}$, , R. $42 \mathrm{E}$. Thin tuff is present in a brownish-gray mudstone and siltstone sequence

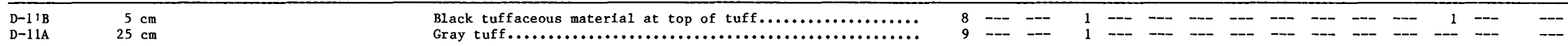

Locality D-12, NW1/4SW1/4 sec. 36, T. 11 S., R. 42 E. Ridge-forming tufa deposit

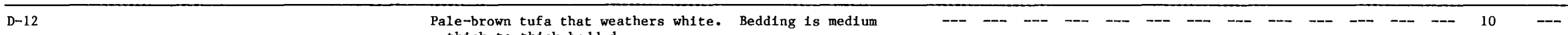
thick to thick bedded.

Loca11ty D-13, SE1/4SW1/4 sec. 1, T. 11 S., R. 42 E. Road-cut exposure of the western part of the Durkee lacustrine beds. Bedding attitude N. $10^{\circ}$ E., $22^{\circ}$ E.

$\mathrm{D}-13 \mathrm{C}$

$\mathrm{D}-13 \mathrm{~B}$

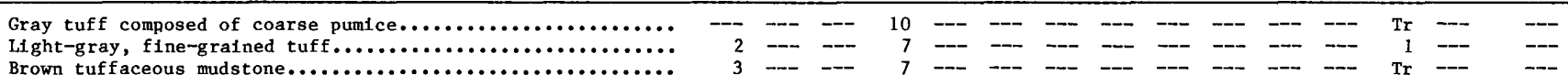

(10.-Pumice tuff in a waxy, clayey matrix................... 6 ---

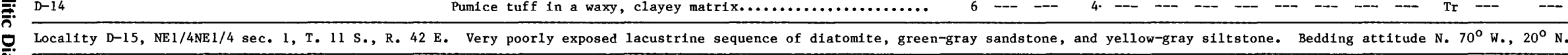
Sandstone..........................................

$D-15 A$ Diatomite.

Locality D-16, SWl $/ 4 \mathrm{SE} 1 / 4 \mathrm{sec} .17$, T. 11 S., R. 43 E. Two thick tuffs, probably similar to tuffs at D-9. Good exposure 1 f freeway road cut. Bedding attitude N. $40^{\circ}$ W., $18^{\circ}$ N.

$\rightarrow-16 \mathrm{~B}$

豪 $D-16 A$ Upper brown-gray tuff rests conformably on lower tuff;
locally cross-bedded.

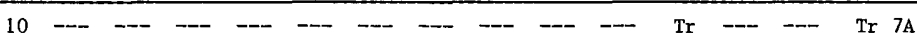

Gray-brown lower tuff, collected near middle of bed........ 10 -..

Locality D-17, NW1/4NE1/4 sec. 20, T. 11 S., R. 43 E. Excellent quarry exposure. Bedding attitude N. $35^{\circ}$ W., $16^{\circ}$ N. Section is 1 ower than the tuffs at D- 16

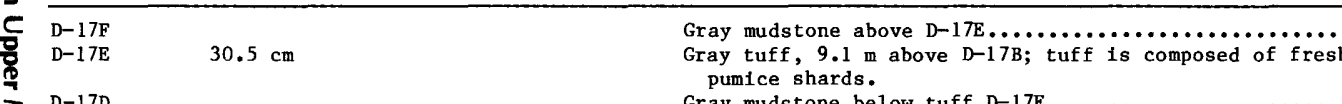

$3-17 D$

$\mathrm{D}-17 \mathrm{C}$

D-17A

Gray nudstone below tuff $\mathrm{D}-17 \mathrm{E}$

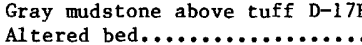

Gray mudstone below D-17B

Locality D-18, NE1/4SW1/4 sec. 10, T. $11 \mathrm{~S} .$, R. 43 E. Sequence of pale-gray to yellow-gray diatomaceous beds. A 2.5 -cm-thick yellow bed beneath gray siltstones is at top of hill

D-18C

D-18B

हैं $\mathrm{D}-18 \mathrm{~A}$

Diatomite, $4.6 \mathrm{~m}$ above $\mathrm{D}-18 \mathrm{~B}$

Gray siltstone.

Locality D-19, SE $1 / 4 \mathrm{NW} 1 / 4 \mathrm{sec} .21$, T. 11 S., R. 43 E. Sequence of pale-gray and yellow diatomaceous sediments sim1lar to those at 1ocality D-18

$\stackrel{D-19 B}{D-19 A}$

Sequence of pale-gray and yellow diatomaceous sediments sim1lar to those at locallty D-18

(D-19A

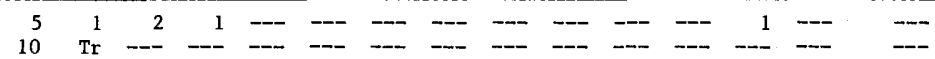

$\begin{array}{llllllllllllllll}--- & -- & 1 & 5 & --- & --- & --- & --- & -- & --- & -- & 3 & 1 & -- & - & -\end{array}$

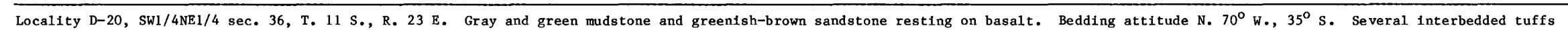

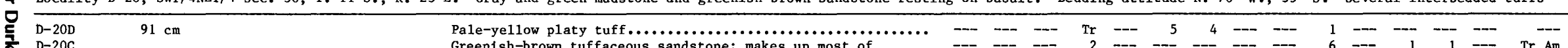


Appendix 1. Mineralogy of lacustrine rocks from the Durkee basin, Baker County, Oregon--Continued

Sample No. Measured Position of samp1e

$\begin{array}{lll}\text { Sample No. } & \text { Measured } & \text { Position of sample } \\ \text { (locality } & \text { thickness } & \text { collected above }(+)\end{array}$

$\begin{array}{lll}\text { No. plus } & \text { shown } 1 \mathrm{n} \mathrm{m}, & \text { or below }(-) \text { base } \\ \text { bed or } & \mathrm{cm} \text {, or } \mathrm{mm} & \text { of designated unit }\end{array}$

unit No.)

Locality D-20--Continued

D-20B 2.5

\begin{tabular}{ll}
$\mathrm{D}-20 \mathrm{~B}$ & $2.5 \mathrm{~cm}$ \\
$\mathrm{D}-20 \mathrm{~A}$ & $0.6 \mathrm{~cm}$ \\
\hline
\end{tabular}

(n)

Description of samples

Minerals (relative abundance reported as "parts-in-ten" as estimated from $\mathrm{X}$-ray powder diffraction ana1ysis)

\begin{tabular}{lllllllllllllll} 
G1 & CT & $10 \mathrm{~A}$ & $14 \mathrm{~A}$ & $\mathrm{Ph}$ & $\mathrm{Ch}$ & $\mathrm{Er}$ & $\mathrm{CP}$ & $\mathrm{Mo}$ & $\mathrm{An}$ & $\mathrm{KF}$ & $\mathrm{Qtz}$ & $\mathrm{PF}$ & $\mathrm{Cl}$ & other \\
\hline
\end{tabular}

Locality D-21, NE1/4NW1/4 sec. 6, T. 12 S., R. 44 E. Poor exposure. Greenish-gray mudstone contains two thin orange tuffs

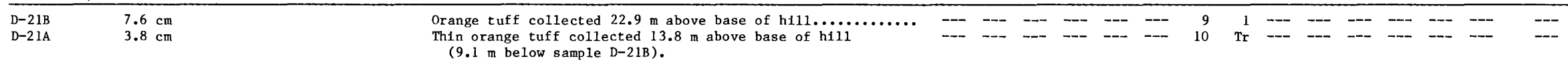

Locality D-22, SE1/4SW1/4 sec. 32, T. 11 S., R. 44 E. Thick-bedded, poorly sorted sandstone, locally caliche cemented. D-82 was recollected at locality D-22

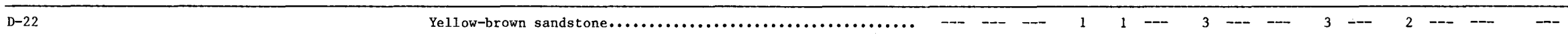
Locality D-23, NE1/4SE1/4 sec. 7, T. 12 S., R. 44 E. Poorly exposed, green mudstone containing an interbedded tuff

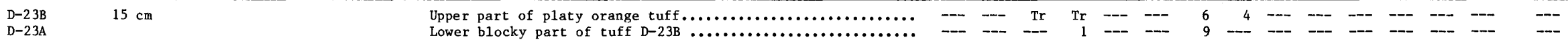

Locality D-24, SWl $/ 4$ SWl $/ 4$ sec. 8, T. 12 S., R. 44 E. Tuff, lower 1 n section than D-23. Bedding attitude N. $85^{\circ}$ E., $28^{\circ}$ N.

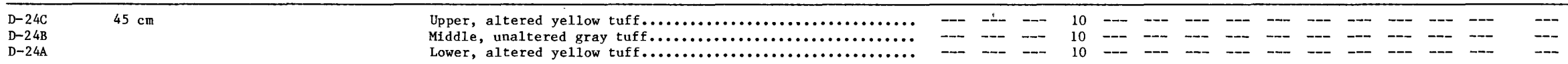

Locality D- 25, SWl $/ 4 \mathrm{SE} 1 / 4 \mathrm{sec} .8$, T. $12 \mathrm{~S}$, R. 44 E. Gray, partly altered tuff low in lacustrine section, about 7-8 $\mathrm{m}$ above welded tuff, 1n a brown mudstone

D-25B

$\mathrm{D}-25 \mathrm{~A}$

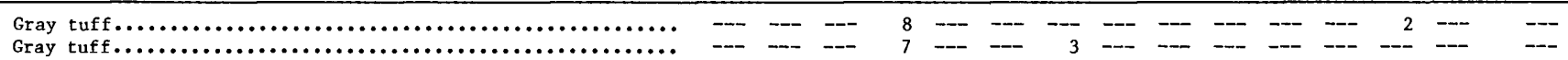

Locality D-26, NW1/4NE1/4 sec. 7, sec. 7, T. 12 S., R. 44 E. Thin tuff in a gray or slightly diatomaceous mudstone sequence

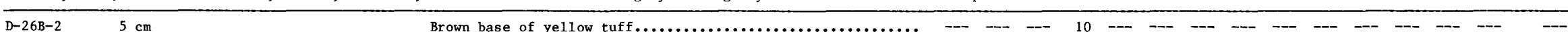

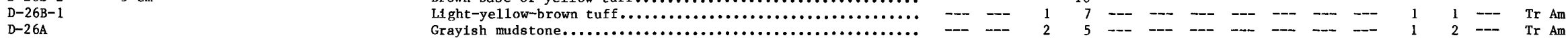

Locality D-27, SWI/4SE $1 / 4$ sec. 6, T. 12 S., R. 44 E. Thick, pale-gray diatomaceous mudstone

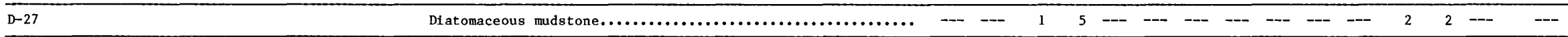

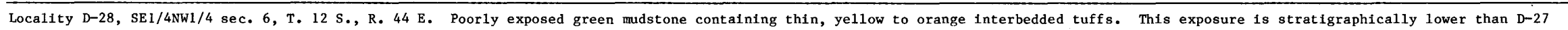

\begin{tabular}{|c|c|c|c|c|c|c|c|c|c|c|c|c|c|c|c|c|c|}
\hline $\mathrm{D}-28 \mathrm{E}$ & $0.5 \mathrm{~cm}$ & 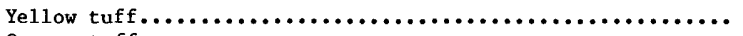 & -- & -- & -- & --- & --- & -- & 10 & -- & --- & --- & --- & --- & -- & --- & --- \\
\hline$D-28 D$ & $7 \mathrm{~cm}$ & 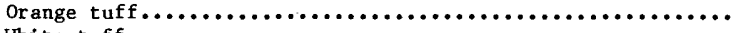 & --- & -- & --- & --- & --- & --- & 10 & --- & --- & $-\infty$ & --- & --- & --- & --- & -- \\
\hline D-28C & $2.5 \mathrm{~cm}$ & 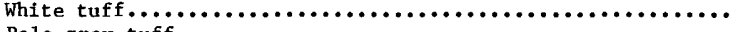 & --- & -- & --- & - & 2 & --- & 8 & -- & -- & -- & --- & --- & -- & $\cdots$ & --- \\
\hline$D-28 B$ & $15 \mathrm{~cm}$ & 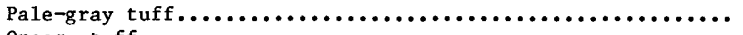 & -- & $\cdots$ & --- & $\operatorname{Tr}$ & --- & - & 10 & $-\ldots$ & --- & --- & $\cdots$ & $\operatorname{Tr}$ & -- & $-\infty$ & -- \\
\hline D-28A & 10 & 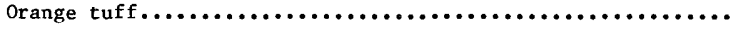 & --- & - & --- & -- & -- & --- & 10 & -- & --- & -- & --- & -- & -- & -- & --- \\
\hline
\end{tabular}

Locality D-29, SW1/4SW1/4 sec. 36, T. $11 \mathrm{~S} .$, R. $43 \mathrm{E}$. Opal-mine quarry and type locality of erionite. Quarry is in welded tuff and is immediately overlain by a thick sequence of tuffs interbedded in mudstone, sandstone, siltstone, and tuffaceous mudstone. Quarry entrance is covered by slumped rubble

D-2

$45 \mathrm{~cm}$

Yellow tuff, upper part; separated by $15 \mathrm{~m}$ of slope
cover above bed $\mathrm{D}-29 \mathrm{C}$.

--- 

Lower part of yellow tuff in bed $\mathrm{D}-29 \mathrm{E} \ldots \ldots \ldots \ldots \ldots \ldots \ldots$
Green-gray mudstone and siltstone with a thin fissile
tuff (tuff sampled). tuffaceous sandstone.
Yellow lapill1 tuff jus

just above welded tuff at quarry entrance.
Miscellaneous collection of specimens of type erionite from quarry rubble and waste dump.
Brown and green-brown sandstone, conglomerate, and

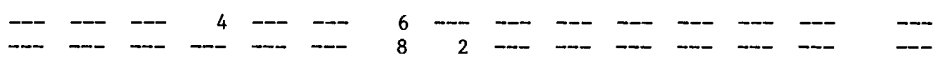

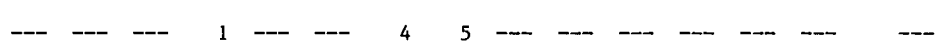

$$
\begin{aligned}
& \text {--- } \\
& \text {--- }
\end{aligned}
$$

Locality D-30, NE1/4NE1/4 sec. 26 , T. 11 S., R. 43 E. Fault-detached sequence of brown mudstone and siltstone with interbedded white to pale-gray or brown tuffs. Most tuffs are coated

\begin{tabular}{|c|c|c|c|c|c|c|c|c|c|c|c|c|c|c|c|c|c|c|}
\hline D-30L & & $4 \mathrm{~cm}$ above bed $\mathrm{D}-30 \mathrm{~K}$ & Greenish-gray tuffaceous siltstone...$\ldots \ldots \ldots \ldots \ldots \ldots \ldots \ldots$ & - & -- & 1 & 1 & -- & 1 & $\operatorname{Tr}$ & --- & --- & - & -- & $-\ldots$ & 5 & $-\cdots$ & $2 \mathrm{Am}$ \\
\hline $\mathrm{D}-30 \mathrm{~K}$ & $1 \mathrm{~cm}$ & $7.6 \mathrm{~m}$ above bed $\mathrm{D}-30 \mathrm{~J}$ & Gray tuffaceous siltstone.................................... & -- & -- & -- & $\operatorname{Tr}$ & 2 & 2 & 2 & 2 & -- & 2 & --- & -- & --- & --- & -- \\
\hline D-30J & $75 \mathrm{~cm}$ & & 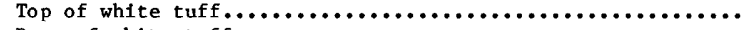 & -- & --- & & $\operatorname{Tr}$ & -- & 8 & 2 & -- & -- & -- & - & -- & --- & --- & $\cdots$ \\
\hline D-30I & & $12.19 \mathrm{~cm}$ above bed $\mathrm{D}-30 \mathrm{H}$ & Base of white tuff $\ldots \ldots \ldots \ldots \ldots \ldots \ldots \ldots \ldots \ldots \ldots \ldots \ldots \ldots \ldots$ & $\cdots$ & -- & 1 & $\operatorname{Tr}$ & - & 6 & 2 & 1 & -- & -- & --- & -- & - & -- & -- \\
\hline D-30H & $1.5 \mathrm{~m}$ & & Top of white tuff with multiple bedding.$\ldots \ldots \ldots \ldots \ldots \ldots \ldots$ & --- & --- & 1 & 1 & -- & 2 & 3 & 3 & $\cdots$ & $\cdots$ & $-\infty$ & -- & --- & --- & -- \\
\hline D-30G & & & 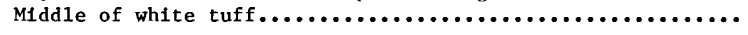 & -- & -- & $\operatorname{Tr}$ & $\operatorname{Tr}$ & -- & & 6 & 4 & -- & -- & -- & -- & - & -- & - \\
\hline D-30F & & $4.57 \mathrm{~m}$ above bed $\mathrm{D}-30 \mathrm{E}$ & Base of white tuff....... & --- & --- & 1 & $\operatorname{Tr}$ & --- & 5 & -- & 4 & --- & --- & --- & --- & --- & --- & --- \\
\hline D-30E-1 & & $1.22 \mathrm{~m}$ above bed base & s material.... & --- & --- & --- & $\operatorname{Tr}$ & --- & 8 & 2 & $\operatorname{Tr}$ & --- & --- & --- & --- & -- & --- & Tr Gy \\
\hline $\mathrm{D}-30 \mathrm{E}-2$ & & & Green tuff $\ldots \ldots \ldots \ldots \ldots \ldots \ldots \ldots \ldots \ldots \ldots \ldots \ldots \ldots$ & $-\cdots$ & -- & $\cdots$ & 1 & $\cdots$ & 7 & 2 & $\operatorname{Tr}$ & -- & - & - & $\cdots$ & -- & $-\cdots$ & $\operatorname{Tr}$ Gy \\
\hline $\mathrm{D}-30 \mathrm{E}-3$ & & & 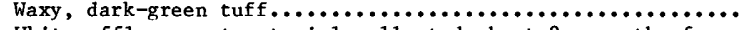 & -- & --- & -- & 5 & -- & 1 & 3 & 1 & --- & -- & --- & --- & -- & -- & $\operatorname{Tr}$ Gy \\
\hline D-30D & & & $\begin{array}{l}\text { White efflorescent material collected about } 9 \mathrm{~m} \text { north of } \\
\text { samples collected at } \mathrm{D}-30 \mathrm{~A} \text { and } 30 \mathrm{~B} \text {. }\end{array}$ & $\cdots$ & -- & -- & - & -- & 4 & 3 & 3 & --- & -- & --- & -- & $\cdots$ & -- & Tr Gy \\
\hline $\mathrm{D}-30 \mathrm{C}-$ & & & 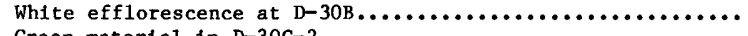 & -- & -- & -- & -- & -- & 1 & 3 & 5 & -- & -- & -- & -- & --- & - & 1 Gy \\
\hline D-30C-1 & & & mater1a1 in $\mathrm{D}-30 \mathrm{C}-2, \ldots \ldots \ldots \ldots \ldots \ldots \ldots \ldots \ldots \ldots \ldots \ldots \ldots \ldots \ldots \ldots \ldots \ldots$ & -- & --- & --- & & -- & 2 & 4 & 4 & -- & & & & -- & - & \\
\hline D-30B & $1.75 \mathrm{~m}$ & $46 \mathrm{~cm}$ above base & Lowest tuff in sequence at locality $\mathrm{D}-30 \ldots \ldots \ldots \ldots \ldots$ & - & -- & -- & $-\overline{T r}$ & $-\bar{T}$ & 3 & 3 & 3 & - & & & & --- & & Gy \\
\hline$D-30 A$ & & & Base of lowest tuff bed $D-30 B \ldots \ldots \ldots \ldots \ldots \ldots \ldots \ldots$ & & -- & --- & $\operatorname{Tr}$ & $\operatorname{Tr}$ & 5 & 3 & 2 & $\cdots$ & 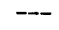 & -1 & . & -- & & \\
\hline
\end{tabular}
with a white, powdery efflorescence. Th1s sequence appears to be higher in section than that at locality SD-4 and may be equivalent to lower part of sequence at locality SD-8
withere

Locality D-31, SE1/4SE1/4 sec. 23, T. 11 S., R. 43 E. Thick unit of ye11ow tuffs equivalent to tuffs at SD-4-13, $-14,-15$, and -16

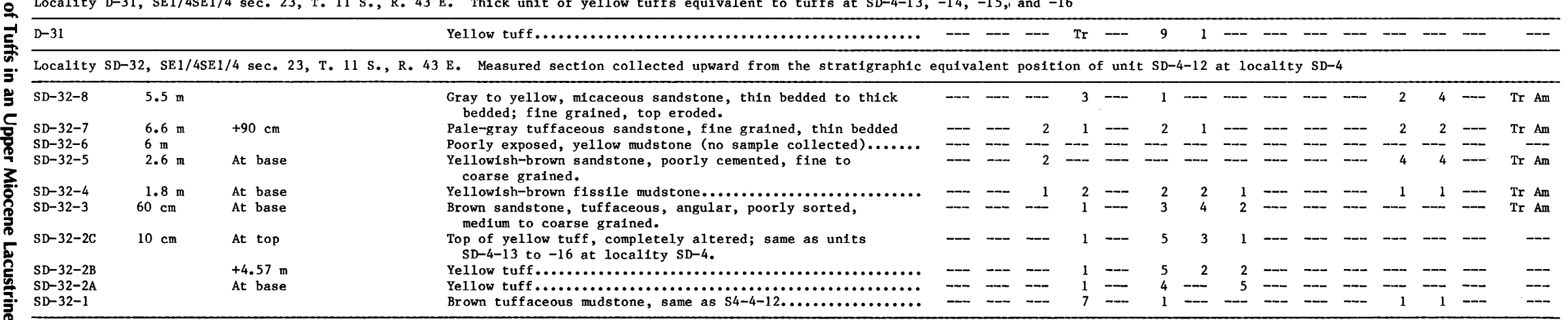
$\mathrm{SD}-32-1$

Locality D-33, NW1 $/ 4 \mathrm{NWl} / 4 \mathrm{sec}$. 25

\begin{tabular}{|c|c|c|c|c|c|c|c|c|c|c|c|c|c|c|c|c|c|}
\hline $\begin{array}{l}D-33-1 \\
D-33-2\end{array}$ & $\begin{array}{l}\text { Yellow tuff .... } \\
\text { White patches in }\end{array}$ & yeilow tuff & $\overline{--}$ & $\overline{--}$ & $\overline{--}$ & $\begin{array}{r}\operatorname{Tr} \\
1\end{array}$ & - & $\begin{array}{l}9 \\
6\end{array}$ & $\begin{aligned} 1 \\
---\end{aligned}$ & $\underset{3}{\operatorname{Tr}}$ & $\overline{--}$ & $\overline{---}$ & $\overline{--}$ & -- & $\overline{-}$ & $\overline{--}$ & $\overline{--}$ \\
\hline
\end{tabular}
base of the welded tuff

Locallty D-34, NE1/4SW1/4 sec. 25, T. $11 \mathrm{~S} .$, R. 43 E. Welded tuff. Doorly exposed lacustrine sediments below

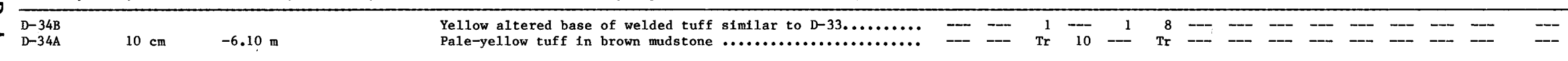


Appendix 1. Mineralogy of lacustrine rocks from the Durkee basin, Baker County, Oregon--Continued

\begin{tabular}{|c|c|c|c|c|c|c|c|c|c|c|c|c|c|c|c|c|c|c|}
\hline \multirow{2}{*}{$\begin{array}{l}\text { Sample No. } \\
\text { (locality } \\
\text { No. plus } \\
\text { bed or } \\
\text { unit No.) }\end{array}$} & \multirow{2}{*}{$\begin{array}{l}\text { Measured } \\
\text { thickness } \\
\text { shown in m, } \\
\mathrm{cm}, \text { or } \mathrm{mm}\end{array}$} & \multirow{2}{*}{$\begin{array}{l}\text { Position of sample } \\
\text { collected above }(+) \\
\text { or below }(-) \text { base } \\
\text { of designated unit }\end{array}$} & \multirow{2}{*}{ Description of samples } & \multicolumn{15}{|c|}{$\begin{array}{c}\text { Minerals (relative abundance reported as "parts-1n-ten" as estimated from } \\
\text { X-ray powder diffraction analysis) }\end{array}$} \\
\hline & & & & G1 & ст & $10 \mathrm{~A}$ & $14 \mathrm{~A}$ & $\mathrm{Ph}$ & $\mathrm{Ch}$ & Er & $\mathrm{Cp}$ & Mo & An & $\mathrm{KF}$ & Qtz & $\mathrm{PF}$ & $\mathrm{Cl}$ & Other \\
\hline \multicolumn{19}{|c|}{ Locality D- $35, \mathrm{NW1} / 4 \mathrm{SE} 1 / 4 \mathrm{sec} .23$, T. $11 \mathrm{~S} .$, R. $43 \mathrm{E}$. Sequence of thin tuffs similar to SD-8-6C and $-6 \mathrm{D}$} \\
\hline $\begin{array}{l}D-35 D \\
D-35 C-3\end{array}$ & $0.5 \mathrm{~cm}$ & & 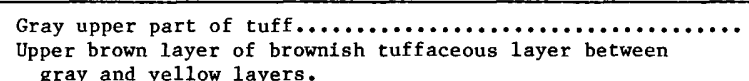 & -- & -- & 1 & -- & --- & -- & $\stackrel{9}{3}$ & $\begin{array}{r}\mathrm{Tr} \\
3\end{array}$ & -- & $-\overline{--}$ & -- & --- & --- & -- & $\operatorname{Tr} \overline{---}$ \\
\hline $\begin{array}{l}D-35 C-2 \\
D-35 C-1\end{array}$ & $2 \mathrm{~mm}$ & & 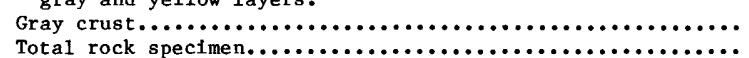 & --- & -- & $\stackrel{2}{\mathrm{Tr}}$ & 1 & $\begin{array}{l}2 \\
4\end{array}$ & -- & $\frac{2}{3}$ & $\begin{array}{l}3 \\
3\end{array}$ & --- & --- & --- & -- & -- & --- & -- \\
\hline D-35B-4 & $1 \mathrm{~mm}$ & & $\begin{array}{l}\text { Yellow lower part of tuff sequence } \mathrm{D}-35 ; \mathrm{D}-35 \mathrm{~B} 4 \text { is gray } \\
\text { top layer of lower yellow part. }\end{array}$ & --- & --- & 1 & 3 & 3 & --- & 1 & 2 & -- & -- & -- & -- & --- & -- & $\operatorname{Tr} G y$ \\
\hline $\begin{array}{l}D-35 B-3 \\
D-35 B-2\end{array}$ & $5 \mathrm{~mm}$ & & 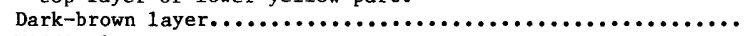 & --- & -- & -- & 6 & 2 & --- & --- & 2 & -- & -- & --- & --- & -- & --- & $\operatorname{Tr}$ Gy \\
\hline $\begin{array}{l}D-35 B-2 \\
D-35 B-1\end{array}$ & $2 \mathrm{~mm}$ & & 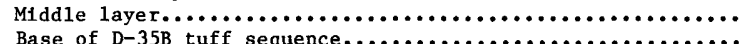 & $\ldots$ & -- & $-\overline{1}$ & $\mathrm{Tr}_{3}$ & 6 & $\overline{--}$ & --- & $\begin{array}{l}4 \\
2\end{array}$ & - & $\overline{---}$ & $\overline{---}$ & $\overline{--}$ & $\overline{--}$ & $\overline{---}$ & $\overline{\operatorname{Tr}} \mathrm{Gy}$ \\
\hline $\mathrm{D}-35 \mathrm{~A}$ & & & Grayish-green ${ }^{2}$ & -- & --- & 1 & 2 & --- & -- & -.- & 5 & --- & --- & -- & 2 & -- & --- & 11 - \\
\hline
\end{tabular}

Locality D-36, NW1/4SE1/4 sec. 23, T. 11 S., R. 43 E. Thick tuff sequence of gray and orange beds with subconchoidal, platy fracture. Same un1t as unit SD-8-3 at locality SD-8, but

\begin{tabular}{|c|c|c|c|c|c|c|c|c|c|c|c|c|c|c|c|c|c|c|}
\hline $\mathrm{D}-36 \mathrm{E}$ & $2.4 \mathrm{~m}$ & & 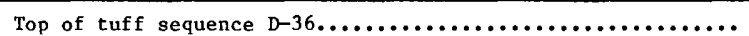 & --- & --- & $\operatorname{Tr}$ & --- & --- & --- & -- & -- & $\ldots$ & 5 & 5 & -- & -- & -- & --- \\
\hline D-36D & & $+1.98 \mathrm{~m}$ & Tuff & --- & -- & - & --- & -- & -- & --- & --- & --- & 5 & 5 & --- & --- & 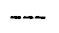 & -- \\
\hline$D-36 C-2$ & $5 \mathrm{~mm}$ & & 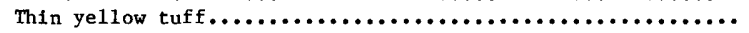 & --- & --- & 1 & $\cdots$ & -- & --- & --- & -- & --- & 5 & 4 & -- & -- & -- & --- \\
\hline$D-36 C-1$ & & $+1.07 \mathrm{~m}$ & 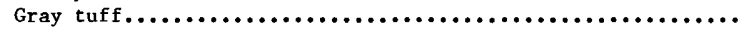 & --- & -- & -- & -- & --- & $\cdots$ & $\cdots$ & -- & --- & 6 & 4 & --- & --- & --- & -- \\
\hline D-36B-2 & $1 \mathrm{~mm}$ & $+35.6 \mathrm{~cm}$ & 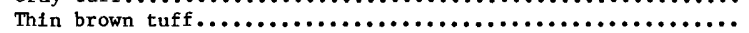 & --- & $-\ldots$ & 1 & -- & -- & --- & --- & $-\ldots$ & --- & 4 & 5 & --- & --- & --- & -- \\
\hline $\mathrm{D}-36 \mathrm{~B}-1$ & & & 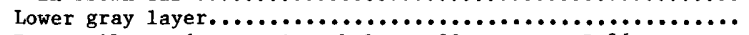 & - & -- & 1 & 1 & -- & --- & --- & -- & --- & 4 & 4 & -- & --- & -- & --- \\
\hline $\mathrm{D}-36 \mathrm{~A}$ & & & Brown silty mudstone, just below tuff sequence $D-36 . . . \ldots \ldots . .$. & --- & $---_{\text {i }}$ & 1 & $-\cdots$ & --- & --- & -- & -- & --- & 4 & 5 & -- & --- & -- & -- \\
\hline
\end{tabular}

Locality D-37, SW1/4SE1/4 sec. 23, T. 11 S., R. 43 E. Same tuff as unit SD-8-3. A basalt on the southwest side of this gully drops the tuff below the drainage

\begin{tabular}{|c|c|c|c|c|c|c|c|c|c|c|c|c|c|c|c|c|c|}
\hline $\begin{array}{l}D-37 C \\
D-37 B \\
D-37 A\end{array}$ & $1.5 \mathrm{~m}$ & 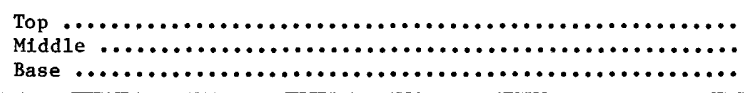 & $\overline{---}$ & $\begin{array}{l}--- \\
--- \\
--\end{array}$ & $\overline{---}$ & --- & --- & --- & -- & $\begin{array}{r}\operatorname{Tr} \\
--- \\
--\end{array}$ & $\overline{---}$ & $\begin{array}{l}9 \\
9 \\
9\end{array}$ & $\begin{array}{l}1 \\
1 \\
1\end{array}$ & $\overline{---}$ & $\overline{\mathrm{Tr}}$ & $\begin{array}{l}--- \\
--- \\
--\end{array}$ & -- \\
\hline Locality & 14 sec. & The sequence below the tuff is & greeni & sh-gr & ay mu & idstone & e and & sand & Istone & & & & & & & & \\
\hline $\begin{array}{l}\mathrm{D}-38 \mathrm{C}-2 \\
\mathrm{D}-38 \mathrm{C}-1 \\
\mathrm{D}-38 \mathrm{~B} \\
\mathrm{D}-38 \mathrm{~A}-2 \\
\mathrm{D}-38 \mathrm{~A}-1\end{array}$ & $1.5 \mathrm{~m}$ & 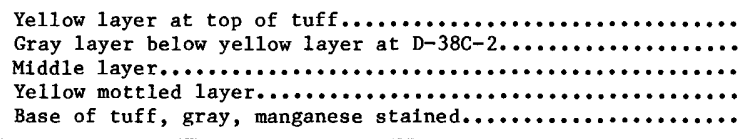 & $\begin{array}{l}--- \\
\overline{--} \\
--\end{array}$ & $\begin{array}{l}--- \\
-- \\
--\end{array}$ & $\begin{array}{r}-\mathrm{Tr} \\
-\mathrm{Tr} \\
1\end{array}$ & $\begin{array}{l}--- \\
--- \\
--\end{array}$ & $\begin{array}{l}--- \\
-- \\
---\end{array}$ & --- & - & $\begin{array}{l}--- \\
--- \\
---\end{array}$ & $\begin{array}{l}-- \\
-\cdots \\
---\end{array}$ & $\begin{array}{l}5 \\
5 \\
3 \\
2 \\
1\end{array}$ & $\begin{array}{l}5 \\
5 \\
7 \\
8 \\
8\end{array}$ & $\begin{array}{l}-- \\
-- \\
-- \\
--\end{array}$ & \begin{tabular}{c}
-- \\
-- \\
\hdashline $\mathrm{Tr}$
\end{tabular} & $\begin{array}{l}-- \\
- \\
-- \\
--\end{array}$ & $\begin{array}{l}-- \\
-- \\
-- \\
--\end{array}$ \\
\hline (2) & 19, SW1 $/ 4$ SE $1 / 4$ sec. & E. Same tuff unit as SD-8-3 & & & & & & & & & & & & & & & \\
\hline $\begin{array}{l}D-39 C \\
D-39 B \\
D-39 A\end{array}$ & $90 \mathrm{~cm}$ & $\begin{array}{l}\text { Top } \\
\text { Midd1e } \\
\text { Base, }\end{array}$ & $\begin{array}{l}--- \\
-- \\
--\end{array}$ & $\overline{---}$ & $\begin{array}{r}\operatorname{Tr} \\
\operatorname{Tr} \\
--\end{array}$ & $\overline{---}$ & $\overline{--}$ & $\overline{---}$ & $\begin{array}{l}--- \\
---\end{array}$ & $\overline{--}$ & $\ddot{--}$ & $\begin{array}{l}9 \\
9 \\
9\end{array}$ & $\begin{array}{l}1 \\
\operatorname{Tr} \\
\operatorname{Tr}\end{array}$ & $\begin{array}{r}\mathrm{Tr} \\
1 \\
1\end{array}$ & $\overline{---}$ & $\overline{--}$ & --- \\
\hline
\end{tabular}

Locality D-40, NW1/4SE1/4 sec. 23 , T. $11 \mathrm{~S}$, R. $43 \mathrm{E}$. Gray, glassy, unaltered tuff in a diatomite sequence equivalent to the upper part of section measured at locality SD-8

\begin{tabular}{|c|c|c|c|c|c|c|c|c|c|c|c|c|c|c|c|c|c|}
\hline $\mathrm{D}-40 \mathrm{~B}$ & $30 \mathrm{~cm}$ & 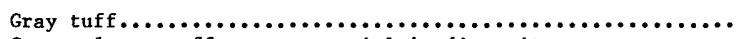 & 10 & --- & --- & --- & --- & -- & --- & --- & -- & --- & --- & --- & $\operatorname{Tr}$ & -- & --- \\
\hline D-40A-4 & & Gray, glassy tuffaceous material in diatomite sequence...... & 10 & --- & -- & --- & $\cdots$ & --- & -- & -- & $\cdots$ & --- & -- & -- & $\operatorname{Tr}$ & --- & --- \\
\hline $\begin{array}{l}D-40 A-3 \\
D-40 A-2\end{array}$ & $\begin{array}{l}2 \mathrm{~mm} \\
0.5 \mathrm{~cm}\end{array}$ & 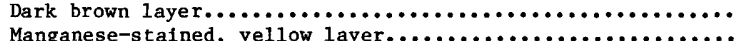 & 9 & $\overline{---}$ & $\frac{1}{2}$ & -- & $\overline{---}$ ( & --- & 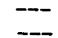 & -- & --- & --- & 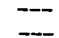 & 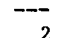 & $\mathrm{Tr}$ & --- & 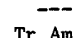 \\
\hline $\mathrm{D}-40 \mathrm{~A}-1$ & $3 \mathrm{~cm}$ & Pale-ye11 & 8 & - & --- & -- & --- & $-\infty$ & -- & -- & -- & --- & -- & 1 & 1 & $\ldots$ & If \\
\hline
\end{tabular}


Locality D-41, SE1/4SWl $/ 4$ sec. 23, T. 11 S., R. 43 E. Sequence of greenish-gray and red mudstones with two interbedded tuffs equivalent to bed sampled at SD-8-6E and SD-8-6G to -6 I

\begin{tabular}{|c|c|c|c|c|c|c|c|c|c|c|c|c|c|c|c|c|c|c|}
\hline $\mathrm{D}-41 \mathrm{~F}$ & $30 \mathrm{~cm}$ & & $\begin{array}{l}\text { Upper tuff, poor1y exposed, probably equivalent to bed } \\
\text { sampled at SD-8-6I. }\end{array}$ & $-\cdots$ & --- & -- & --- & -- & --- & 5 & 4 & 1 & --- & --- & --- & & & - \\
\hline$D-41 E$ & $61 \mathrm{~cm}$ & Top & Lower tuff, multibedded, orange....................... & --- & --- & --- & --- & -- & -- & 10 & $\cdots$ & --- & -- & --- & -- & & & - \\
\hline$D-41 \mathrm{D}$ & & $\begin{array}{l}+36 \mathrm{~cm} \\
+23 \mathrm{~cm}\end{array}$ & (.................. & $\overline{--}$ & 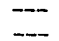 & -- & --- & --- & -- & 10 & ---8 & --- & --- & --- & -- & - & & - \\
\hline$D-41 \mathrm{~B}$ & & $+15 \mathrm{~cm}$ & Tuff & --- & --- & $\operatorname{Tr}$ & $\operatorname{Tr}$ & --- & --. & 2 & 8 & --- & -- & --- & $\ldots$ & & & - \\
\hline$-41 \mathrm{~A}-2$ & $5 \mathrm{~cm}$ & Base & 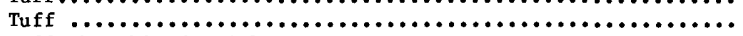 & -- & --- & -- & $\mathrm{Tr}$ & --- & --- & --- & 10 & --- & --- & -- & --- & & & - \\
\hline$D-41 \mathrm{~A}-1$ & $6 \mathrm{~mm}$ & Base bottom & Tuff, hornblende r1ch $\ldots . \ldots \ldots \ldots \ldots \ldots \ldots \ldots \ldots \ldots \ldots$ & --- & -- & -- & -- & -- & -- & --- & 9 & --- & --- & --- & -- & & & - \\
\hline
\end{tabular}

Local1ty D-42, SW1/4Sw1/' sec. 23, T. 11 S., R. 43 E. Two orange tuffs, same as at locality D-41

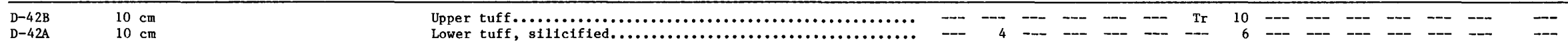
Locality D-43, SWI $/ 4 \mathrm{SWl} / 4$ sec. 23 , T. 11 S., R. $43 \mathrm{E}$. Thick ye1low to orange tuff, equivalent to bed sampled at SD-8-3. Bedding attitude N. $10^{\circ} \mathrm{E}$., $10^{\circ}$ W. Tuff over11es a sequence of greenish-gray sandstone and siltstone

\begin{tabular}{|c|c|c|c|c|c|c|c|c|c|c|c|c|c|c|c|c|c|c|}
\hline $\begin{array}{l}D-43 C \\
D-43 B \\
D-43 A\end{array}$ & $1.2 \mathrm{~m}$ & $\begin{array}{l}\text { Top } \\
\text { MIdd1e } \\
\text { Base }\end{array}$ & 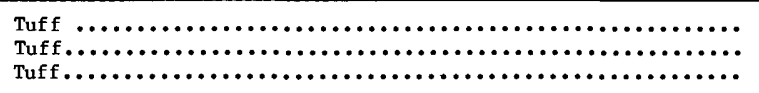 & --- & --- & $\begin{array}{l}-- \\
--- \\
--\end{array}$ & $\begin{array}{l}-- \\
--- \\
--\end{array}$ & $\overline{--}$ & $\begin{array}{r}-- \\
10 \\
10\end{array}$ & $\begin{array}{l}-- \\
\operatorname{Tr}\end{array}$ & $\begin{array}{r}10 \\
2 \\
\mathrm{Tr}\end{array}$ & --- & $\overline{---}$ & $\begin{array}{l}--- \\
--- \\
---\end{array}$ & --- & $\begin{array}{l}-- \\
--- \\
--\end{array}$ & $\overline{---}$ & $\begin{array}{l}--- \\
---\end{array}$ \\
\hline $\begin{array}{l}D-44 B \\
D-44 A\end{array}$ & $30 \mathrm{~cm}$ & $\begin{array}{l}\text { Top } \\
\text { Base }\end{array}$ & 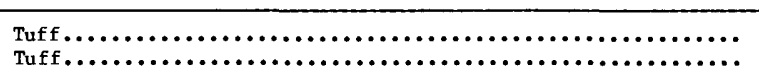 & -- & -- & -- & -- & $\begin{array}{c}\mathrm{Tr} \\
---\end{array}$ & $\begin{array}{r}2 \\
---\end{array}$ & $\begin{array}{l}8 \\
8\end{array}$ & $--\overline{2}$ & -- & $\overline{--}$ & --- & --- & -- & -- & $-\overline{-}$ \\
\hline$D-45 B$ & $3 \mathrm{~m}$ & & $\begin{array}{l}\text { Pale-yellow bedded tuff in brown mudstone; an unknown } \\
\text { distance above bed } \mathrm{D}-45 \mathrm{~A} \text {. } \\
\text { Upper yellow altered part of welded tuff................ }\end{array}$ & $\ldots$ & +- & -- & 1 & --- & 5 & 3 & 1 & --- & -- & -- & -- & -- & $\frac{\text { พ. }}{---}$ & $\operatorname{Tr} G y$ \\
\hline
\end{tabular}

Locality D-46, NE1/4NE1/4 sec. 27, T. 11 S., R. $43 \mathrm{E}$. Tuff, equivalent to tuff at locality D- 43 , in a sequence of green sandstone and siltstone. Bedding attitude N. $40^{\circ}$ W., $18^{\circ}$ SW. Many small faults at locality D- 46

$\begin{array}{lll}\mathrm{D}-46 \mathrm{C} & 1.1 \mathrm{~m} \quad \text { Top }\end{array}$

$\begin{array}{llll}\mathrm{D}-46 \mathrm{C} & 1.1 \mathrm{~m} & \text { Top } & \text { Ye11 ow tuff. } \\ \mathrm{D}-46 \mathrm{~B} & & \text { Middle } & \text { Yellow tuff. } \\ \mathrm{D}-46 \mathrm{~A}-2 & & \text { Yellow }\end{array}$

$D-46 \mathrm{~A}-1$

Base botton

Yhite tuff

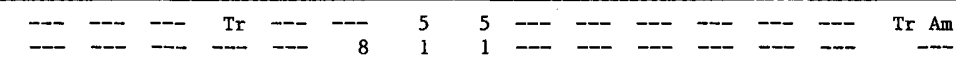

Loca1ity D-47, NE1/4NE1/4 sec. 27, T. 11 S., R. 43 E. Tuff w1th blocky to subconchotdal fracture. Stratigraphic relation to other localities 1s unknown

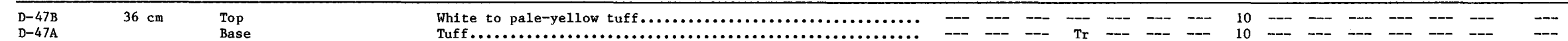

Local1ty D-48, NE1/4NE $1 / 4$ sec. 27, T. 11 S., R. $43 \mathrm{E}$. Several tuff s in a green mudstone sequence

D-48F $\quad 36 \mathrm{~cm} \quad$ Upper beds in unit

$\begin{array}{lll}\mathrm{D}-48 \mathrm{E} & 8 \mathrm{~cm} & \text { Base } 5 \mathrm{~m} \text { above bed } \mathrm{D}-48 \mathrm{D} \\ \mathrm{D}-48 \mathrm{D} & 8.5 \mathrm{~m} \text { above bed } \mathrm{D}-48 \mathrm{C} \\ \mathrm{D}-48 \mathrm{C} & 7 \mathrm{~cm} & 1.2 \mathrm{~m} \text { above bed } \mathrm{D}-48 \mathrm{~B}\end{array}$

$\begin{array}{lll}\mathrm{D}-48 \mathrm{~B} & 15 \mathrm{~cm} & \begin{array}{l}\text { Upper part } \\ \mathrm{D}-48 \mathrm{~A}\end{array} \\ \end{array}$

. $D-48 A$

Yellow tuff, highest in sequence........................

................

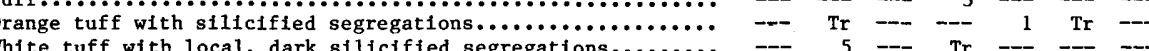

Tuff bed lowe with local, dark silicified segregations..........

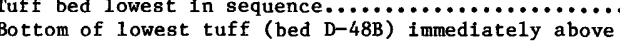
underlying green silicenous mudstone.

Locality D-49, SE1/4SE $1 / 4 \mathrm{sec} .22$, T. $11 \mathrm{~S}$, R..43 E. Several tuffs in a green1sh-gray mudstone

D-49X

Gray tuff highest in top part of sequence

$\begin{array}{ll}46 \mathrm{~cm} & 1.5 \mathrm{~m} \text { above bed } \mathrm{D}-49 \mathrm{~J} \\ 90 \mathrm{~cm} & 0.6 \mathrm{~m} \text { above bed } \mathrm{D}-49 \mathrm{I}\end{array}$

Gray tuff highest in top part of sequence $\ldots \ldots \ldots \ldots \ldots . . .$.

--- ---

$\operatorname{Tr}=---$

$\begin{array}{rrrrrrr}10 & --- & -- & -- & -- & --- & -- \\ 6 & -- & --- & --- & 1 & -- & -- \\ 9 & -- & --- & --- & --- & -- & -\end{array}$

ב--

Brown tuffaceous sandstone.

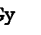


Appendix 1. Mineralogy of lacustrine rooks from the Durkee basin, Baker County, Oregon--Continued

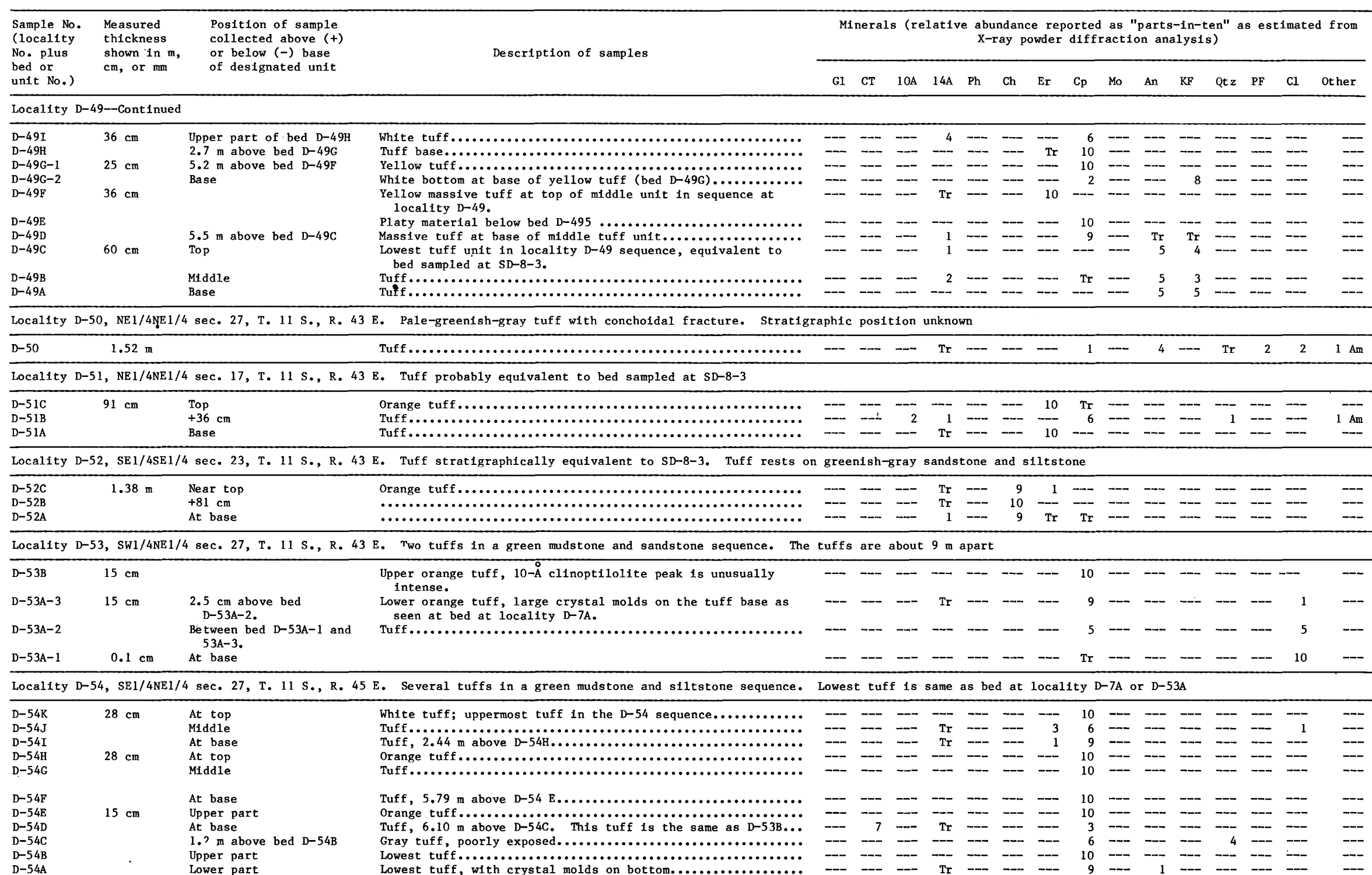


Locality D-55, SE1/4SE $1 / 4$ sec. 27, T. 11 S., R. 43 E. Greenish-gray mudstone sequence, containing a yellow tuff midway up the slope. Bedding attitude N. $50^{\circ}$ W., $23^{\circ}$ SW. The tuff is medium bedded and ripple bedded. This may be the same unit as seen at SD-8-3. Prominent tufa unit caps hil1

\begin{tabular}{|c|c|c|c|c|c|c|c|c|c|c|c|c|c|c|c|c|c|c|}
\hline D-55F & & & $\begin{array}{l}\text { Tufa, brown resistant bed capping hill; locally contains } \\
\text { cavities with quartz crystals. }\end{array}$ & --- & --- & --- & $\operatorname{Tr}$ & -- & -- & -- & $-\cdots$ & -- & -- & -- & 1 & -- & 9 & --- \\
\hline D-55E & $5 \mathrm{~cm}$ & $2.4 \mathrm{~m}$ above bed $\mathrm{D}-55 \mathrm{D}$ & 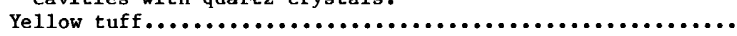 & --- & --- & --- & --_- & --- & --- & 10 & $\operatorname{Tr}$ & --- & --- & --- & -- & -- & -- & \\
\hline D-55D & $1.6 \mathrm{~m}$ & At top & 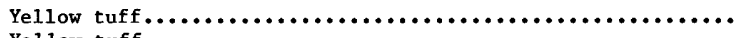 & -- & --- & -- & $\operatorname{Tr}$ & --- & -- & - & 1 & -- & -- & -- & 9 & -- & -- & $\operatorname{Tr} A$ \\
\hline D-55C & & $+1.3 \mathrm{~m}$ & 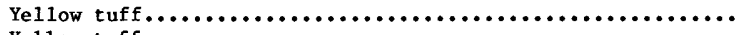 & -- & - & --- & $\operatorname{Tr}$ & -- & -- & 10 & - & -- & $\cdots$ & -- & -- & - & $-\cdots$ & - \\
\hline $\begin{array}{l}D-55 B \\
D-55 A\end{array}$ & & $\begin{array}{l}+76 \mathrm{~cm} \\
\text { At base }\end{array}$ & 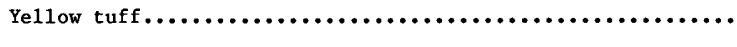 & $\overline{---}$ & --- & $\because-$ & $\begin{array}{r}\operatorname{Tr} \\
1\end{array}$ & -- & -- & $\begin{array}{r}10 \\
4\end{array}$ & $--{ }_{5}$ & - & -- & -- & --- & - & -- & -- \\
\hline
\end{tabular}

Locality D-56, NE1/4SW1/4 sec. 27, T. 11 S., R. 43 E. Poor exposure in road cut south of dirt road. Bedding attitude N. $30^{\circ} \mathrm{W} ., 25^{\circ} \mathrm{W}$. Two tuffs are in th1s sequence

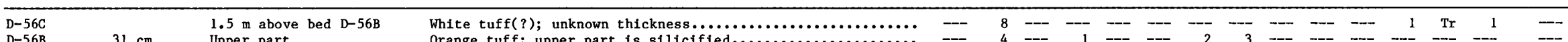

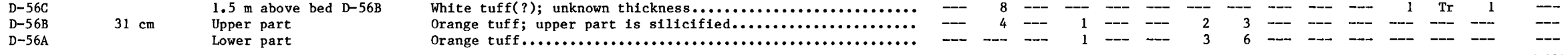

Locality D-57, NE1/4NW1/4 sec. 27 , T. 11 S., R. 43 E. Poorly exposed diatomaceous mudstone sequence. Iron-stained f1oat from a tuff(?) is on upper part of h111

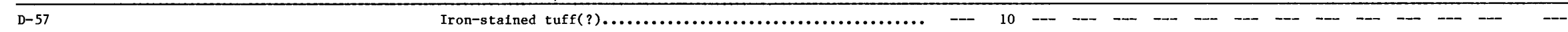

Local1ty SD-58, NW1/4NW1/4 sec. 23, T. 11 S., R. 43 E. Measured section collected upward from valley floor at 1ocal1ty D-9. Bedding att1tude N. $50^{\circ}$ W., $14^{\circ}$ NW.

\begin{tabular}{|c|c|c|c|c|c|c|c|c|c|c|c|c|c|c|c|c|c|c|}
\hline SD-58-10 & & $12.04 \mathrm{~m}$ & $\begin{array}{l}\text { Light-brown, silty and sandy mudstone, poorly exposed; top } \\
\text { is unconformably(?) overlain by gravels. }\end{array}$ & --- & -- & -- & $\mathrm{Tr}$ & --- & --- & -- & -- & - & -- & -- & 10 & $\mathrm{Tr}$ & -- & --- \\
\hline SD-58-9 & $5.6 \mathrm{~m}$ & $1.08 \mathrm{~m}$ & $\begin{array}{l}\text { Greenish-gray mudstone, poorly exposed; popcorn weathered } \\
\text { surface; } 1 \text { ifgnite bed at base of unit D-58-9 was } \\
\text { re-collected at same place as bed D-9E at locality D-9. }\end{array}$ & (8) & -- & $\cdots$ & $\mathrm{Tr}$ & --- & --- & -- & --- & -- & --- & --- & 1 & 1 & - & -- \\
\hline SD-58-8 & $2.9 \mathrm{~m}$ & & Diatomaceous mudstone; poor1y exposed....................... & (10) & --- & --- & --- & -- & -- & -- & -- & -- & -- & -- & $\mathrm{Tr}$ & -- & $\cdots$ & -- \\
\hline SD-58-7 & $2.1 \mathrm{~m}$ & & $\begin{array}{l}\text { Pale-gray tuff, mostly pumice shards, multiple bedded and } \\
\text { cross bedded. (Re-collected from same locality as D-9.) } \\
\text { No sample collected. }\end{array}$ & -- & --- & -- & -- & --- & -- & --- & --- & -- & -- & --- & & --- & -- & -- \\
\hline SD-58-6 & $5.5 \mathrm{~m}$ & $+1.2 \mathrm{~m}$ & $\begin{array}{l}\text { Brownish-gray, tuffaceous mudstone and siltstone sequence, } \\
\text { white, 1.5-cm-thick layer collected. }\end{array}$ & 3 & -- & $\operatorname{Tr}$ & 6 & -- & --- & -- & 1 & -- & -- & -- & -- & $\operatorname{Tr}$ & -- & -- \\
\hline $\begin{array}{l}\text { SD-58-5 } \\
\text { SD-58-4 }\end{array}$ & $\begin{array}{l}3.4 \mathrm{~m} \\
9.6 \mathrm{~m}\end{array}$ & $\begin{array}{l}\text { Middle of this unit } \\
+7.8 \mathrm{~m}\end{array}$ & $\begin{array}{l}\text { Gray tuff, poorly exposed, abundant detrital material....... } \\
\text { Brownish-gray tuffaceous mudstone, with diatomaceous } \\
\text { mudstone. }\end{array}$ & 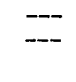 & $\overline{---}$ & $\begin{array}{c}\operatorname{Tr} \\
1\end{array}$ & $\begin{array}{l}1 \\
3\end{array}$ & --- & --- & $\overline{---}$ & --- & --- & --- & -- & $\overline{\operatorname{Tr}}$ & $\begin{array}{l}9 \\
6\end{array}$ & $\overline{---}$ & $\stackrel{--}{--}$ \\
\hline $\begin{array}{l}\text { SD-58-3 } \\
\text { SD-58-3C }\end{array}$ & $25.9 \mathrm{~m}$ & $+24.1 \mathrm{~m}$ & $\begin{array}{l}\text { Brownish-gray, very poorly exposed mudstone with an unaltered } \\
\text { Tuffaceous, mudstone, resistant layer, with abundant } \\
\text { gypsum veinlets; no sample collected. }\end{array}$ & tuff & at bas & ise of & unit: & $\therefore$ & --- & -- & - & -- & -- & -- & -- & $\cdots$ & --- & --- \\
\hline SD-58-3B & & $+7.8 \mathrm{~m}$ & 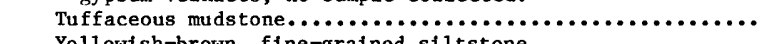 & -- & -- & 2 & $\mathrm{Tr}$ & -- & --- & $=$ & -- & -- & -- & -- & 1 & 5 & -- & $27 \mathrm{~A}$ \\
\hline $\begin{array}{l}\mathrm{SD}-58-3 \mathrm{~A} \\
\mathrm{SD}-58-2\end{array}$ & $10.8 \mathrm{~m}$ & $\begin{array}{l}+5.3 \mathrm{~m} \\
+4.6 \mathrm{~m}\end{array}$ & 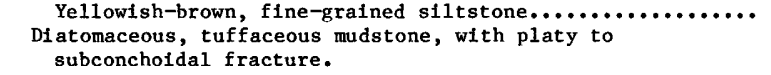 & $\begin{array}{l}6 \\
5\end{array}$ & $-\overline{1}$ & $\overline{\mathrm{Tr}}$ & $\begin{array}{l}1 \\
3\end{array}$ & -- & +- & $\overline{\mathrm{Tr}}$ & -- & -- & --- & -- & -- & $\begin{array}{l}3 \\
1\end{array}$ & --- & $\operatorname{Tr} 7 \mathrm{~A}$ \\
\hline $\begin{array}{l}\text { SD-58-1 } \\
\text { SD-58-1C }\end{array}$ & $\begin{array}{c}12.3 \mathrm{~m} \\
7 \mathrm{~cm}\end{array}$ & & $\begin{array}{l}\text { Pale-gray, diatomaceous mudstone unit; poorly exposed, with s } \\
\text { Gray unaltered tuff, thin }(7 \mathrm{~cm}) \text { at top of unit. No } \\
\text { sample collected. }\end{array}$ & ubconc & choida & 11 frac & cture: & :- & -- & -- & --- & --- & --- & -- & -- & -- & -- & -- \\
\hline $\begin{array}{l}\text { SD-58-1B } \\
\text { SD-59-1A }\end{array}$ & $10 \mathrm{~cm}$ & $\begin{array}{l}+5.2 \mathrm{~m} \\
\text { At base of measured } \\
\text { section. }\end{array}$ & 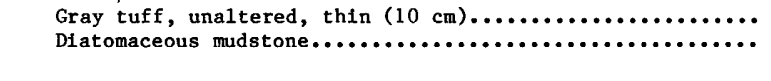 & $\begin{array}{l}8 \\
3\end{array}$ & --- & $\begin{array}{l}\mathrm{Tr} \\
\mathrm{Tr}\end{array}$ & $\begin{array}{r}\mathrm{Tr} \\
3\end{array}$ & -- & $\overline{--}$ & $\because$ & $\overline{---}$ & -- & 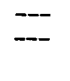 & -- & $-\overline{3}$ & $\begin{array}{l}2 \\
1\end{array}$ & $\overline{---}$ & $\overline{--}$ \\
\hline & & & & & & & & & & & & & & & & & & \\
\hline SD-59-5 & $5.2 \mathrm{~m}$ & & $\begin{array}{l}\text { Tuff, sandy tuff, and lapill1 tuff, very resistant ledge } \\
\text { former; re-collected from locality D2, bed D-2I; top of } \\
\text { unit unconformable with overlying gravel; no sample } \\
\text { collected. }\end{array}$ & -- & -- & - & - & --- & --- & -- & --- & --- & -- & --- & -- & --- & -- & --- \\
\hline SD-59-4 & $11.7 \mathrm{~m}$ & $+7.2 \mathrm{~m}$ & $\begin{array}{l}\text { Yellow, altered sandy conglomeratic tuff; very poorly } \\
\text { exposed. }\end{array}$ & 6 & -- & -- & 3 & --- & --- & --- & -- & -- & -- & -- & -- & 1 & - & $\cdots$ \\
\hline
\end{tabular}


Appendix 1. Mineralogy of 1acustrine rocks from the Durkee basin, Baker County, Oregon--Continued

\begin{tabular}{|c|c|c|c|c|c|c|c|c|c|c|c|c|c|c|c|c|c|c|}
\hline \multirow{2}{*}{$\begin{array}{l}\text { Sample No. } \\
\text { (locality } \\
\text { No. plus } \\
\text { bed or } \\
\text { unit No.) }\end{array}$} & \multirow{2}{*}{$\begin{array}{l}\text { Measured } \\
\text { thickness } \\
\text { shown in } \mathrm{m}, \\
\mathrm{cm} \text {, or } \mathrm{mm}\end{array}$} & \multirow{2}{*}{$\begin{array}{l}\text { Position of sample } \\
\text { collected above }(+) \\
\text { or below }(-) \text { base } \\
\text { of designated unit }\end{array}$} & \multirow{2}{*}{ Description of samples } & \multicolumn{15}{|c|}{$\begin{array}{c}\text { Minerals (relative abundance reported as "parts-in-ten" as estimated from } \\
\text { X-ray powder diffraction analysis) }\end{array}$} \\
\hline & & & & G1 & Ст & $10 \mathrm{~A}$ & $14 \mathrm{~A}$ & $\mathrm{Ph}$ & $\mathrm{Ch}$ & Er & $C_{p}$ & Mo & An & $\mathrm{KF}$ & Qtz & $\mathrm{PF}$ & $\mathrm{Cl}$ & other \\
\hline \multicolumn{19}{|c|}{ Locality SD-59--Continued } \\
\hline SD-59-3 & $10.4 \mathrm{~m}$ & & $\begin{array}{l}\text { Tuff, lapilli tuff, and sandy tuff, resistant ledge } \\
\text { former; collected from locality } \mathrm{D}-2 \text {, beds } \mathrm{D}-2 \mathrm{~F} \text {, } \\
-2 \mathrm{G} \text {, and }-2 \mathrm{H} \text {. }\end{array}$ & --- & --- & -- & -- & -- & --- & -- & -- & -- & --- & --- & -- & --- & -- & --- \\
\hline $\begin{array}{l}\text { SD-59-2 } \\
\text { SD-59-2C }\end{array}$ & $27.3 \mathrm{~m}$ & $+23.1 \mathrm{~m}$ & 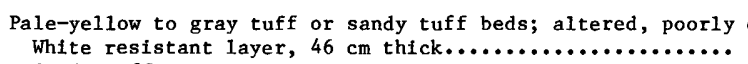 & $\begin{array}{c}\text { expose } \\
8\end{array}$ & d: & --- & 2 & -- & --- & --- & --- & -- & --- & --- & --- & --- & --- & -- \\
\hline $\mathrm{SD}-59-2 \mathrm{~B}$ & & $+7.6 \mathrm{~m}$ & Sandy tuff & 7 & $\mathrm{Tr}$ & --- & 3 & --- & --- & --- & --- & --- & -- & --- & $\operatorname{Tr}$ & $\mathrm{Tr}$ & -- & -- \\
\hline$S D-59-2 A$ & & $+2.7 \mathrm{~m}$ & 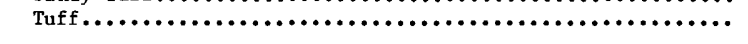 & 6 & 1 & -- & $\operatorname{Tr}$ & --- & -- & --- & -- & --- & --- & --- & 1 & $\operatorname{Tr}$ & --- & --- \\
\hline SD-59-1 & & & Gray welded tuff weathers brown, very resistant, base not exp & osed: & & & & & & & & & & & & & & \\
\hline $\begin{array}{l}\text { SD }-59-1 C \\
\text { SD-59-1B }\end{array}$ & & $+1.5 \mathrm{~m}$ & Welded tuff, partly altered............................. & 10 & -- & - & $\mathrm{Tr}$ & -- & --- & --- & $\overline{--}$ & -- & --- & --- & -- & - & --- & -- \\
\hline SD-59-1A & & $3.3 \mathrm{~m}$ below top & $\begin{array}{l}\text { Welded tuff, glassy, perlitic part; from middle of } \\
\text { altered part. }\end{array}$ & $\begin{array}{l}9 \\
9\end{array}$ & $\overline{1}$ & - & $\begin{array}{l}\mathrm{Tr} \\
\mathrm{Tr}\end{array}$ & -- & -- & --- & - & $\overline{--}$ & -- & -- & -- & $\begin{array}{c}1 \\
-\end{array}$ & $\overline{---}$ & -- \\
\hline
\end{tabular}

Locality D-60, NW1/4NE $1 / 4 \mathrm{sec} .5$, T. 11 S., R. 43 E. Mudstone containing interbedded tuff between basalt and welded tuff

\begin{tabular}{|c|c|c|c|c|c|c|c|c|c|c|c|c|c|c|c|c|c|c|}
\hline D-60D & & Base of welded tuff & Welded tuff $\ldots \ldots \ldots \ldots \ldots$ & 10 & --- & --- & --- & --- & $-\cdots$ & -- & --- & -- & -- & -- & - & --- & -- & --- \\
\hline $\mathrm{D}-60 \mathrm{C}$ & $77 \mathrm{~cm}$ & & Gray pumice tuff, bedded; at base of welded tuff............. & --- & 8 & -- & 2 & -- & --- & --- & -- & -- & --- & -- & --- & --- & -- & --- \\
\hline D-60B & & & 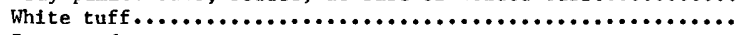 & -- & 8 & --- & 1 & -- & --- & --- & -- & -- & - & -- & --- & 1 & --- & --- \\
\hline $\mathrm{D}-60 \mathrm{~A}$ & $15.8 \mathrm{~m}$ & & 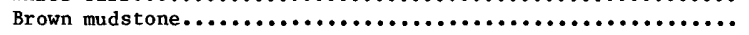 & --- & 6 & --- & 3 & --- & --. & --- & --- & --- & --- & --- & $\operatorname{Tr}$ & 1 & $\ldots$ & --- \\
\hline
\end{tabular}

\section{D-60A $15.8 \mathrm{~m}$}

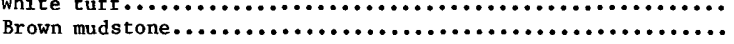

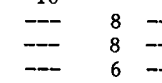

Locality D-61, NE1/4NE1/4 sec. 34, T. 11 S., R. 43 E. Thin, very resistant tuff, partly silified, except lowest part which is entirely silicified. Bedding attitude N. $70^{\circ}$ W., $12^{\circ}$ s.

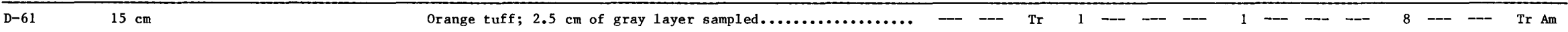
Locality D-62, NE1/4NE1/4 sec. 34, T. 11 S., R. $43 \mathrm{E}$. Green mudstone sequence, similar to that at locality D-61, but collected tuff is stratigraphically higher than tuff at locality D-61. Bedding attitude $\mathrm{N} .60^{\circ}$ w., $16^{\circ} \mathrm{s}$

\begin{tabular}{|c|c|c|c|c|c|c|c|c|c|c|c|c|c|c|c|c|c|c|}
\hline$D-62 C$ & $2.5 \mathrm{~cm}$ & Upper part & $\begin{array}{l}\text { Orange and white tuff, collected } 90 \mathrm{~m} \text { south of locality } \\
\text { D-61, and atratigraphically lower. }\end{array}$ & -- & 2 & -- & $\operatorname{Tr}$ & -- & -- & -- & 8 & -- & -- & -- & $\cdots$ & --- & - & - \\
\hline $\begin{array}{l}D-62 B \\
D-62 A\end{array}$ & $7.62 \mathrm{~cm}$ & $\begin{array}{l}\text { At base of bed D- } 62 \mathrm{C} \\
\text { Lower part }\end{array}$ & $\begin{array}{l}\text { Tuff } \ldots \ldots \ldots \ldots \ldots \ldots \ldots \ldots \ldots \ldots \ldots \ldots \ldots \ldots \ldots \ldots \ldots \ldots \ldots \\
\text { Gray, lower part of orange tuff; this tuff is } \\
\text { stratigraphically above that at locality } D-61 .\end{array}$ & --- & -- & $\cdots$ & $\ddot{--}$ & -- & -- & -- & $\begin{array}{r}10 \\
5\end{array}$ & 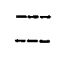 & $\because-$ & $\overline{-}$ & $\overline{5}$ & -- & --- & 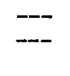 \\
\hline
\end{tabular}

Locallty D-63, NE $1 / 4$ NW1/4 sec. 35, T. 11 S., R. 43 E. Two thin tuffs in a green mudstone sequence, about $12 \mathrm{~m}$ apart

\begin{tabular}{|c|c|c|c|c|c|c|c|c|c|c|c|c|c|c|c|c|c|c|}
\hline $\begin{array}{l}D-63 C \\
D-63 B \\
D-63 A\end{array}$ & $\begin{array}{l}10.2 \mathrm{~cm} \\
7.62 \mathrm{~cm}\end{array}$ & $\begin{array}{l}12.2 \mathrm{~m} \text { above bed } \mathrm{D}-63 \mathrm{~B} \\
\text { Upper part } \\
\text { At base of bed } \mathrm{D}-63\end{array}$ & 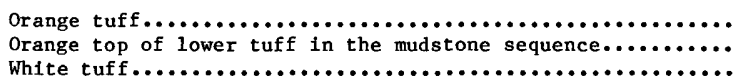 & $\overline{-\cdots}$ & $-\overline{3}$ & $\overline{\mathrm{Tr}}$ & $\begin{array}{r}\mathrm{Tr} \\
2 \\
\mathrm{Tr}\end{array}$ & $\overline{--}$ & $\overline{---}$ & $\begin{array}{r}10 \\
4 \\
--\end{array}$ & 4 & $\ddot{--}$ & $\overline{---}$ & $=$ & $\cdots$ & - & {$[-$} & $\operatorname{Tr}$ Gy \\
\hline
\end{tabular}
Locallty D-64, NW1/4NE1/4 sec. 35, T. 11 S., R. 43 E. Tuff equivalent to that at locality D-7, with crystal casts on underside of tuff base

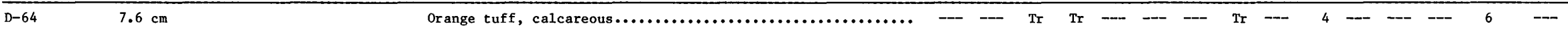
Locality D-65, NE1/4NE1/4 sec. 35, T.11 S., R. 43 E. Tuff, with ripple-marked, massive base; thin bedded and ripple bedded at top, in greenish-gray mudstone

\begin{tabular}{|c|c|}
\hline $\begin{array}{l}D-65 B \\
D-65 A\end{array}$ & $20.3 \mathrm{~cm}$ \\
\hline
\end{tabular}


Locality D-66, SWl/4SE $1 / 4$ sec. 26, T. 11 S., R. $43 \mathrm{E}$. Thick, multiple-bedded tuff overlying siltstone and sandstone. Bedding attitude N. $75^{\circ}$ E., $15^{\circ}$ S. May be equivalent to bed D-55A at locality D-55

\begin{tabular}{|c|c|c|c|c|c|c|c|c|c|c|c|c|c|c|c|c|c|c|}
\hline D-66F & & $91 \mathrm{~cm}$ above bed $\mathrm{D}-66 \mathrm{E}$ & $\begin{array}{l}\text { Yellow tuff in poorly exposed sequence with mudstone } \\
\text { interbedding. }\end{array}$ & -- & --- & $\operatorname{Tr}$ & 1 & --- & -- & --- & 9 & -- & --- & --- & -- & --- & -- & -- \\
\hline D-66E & & $91 \mathrm{~cm}$ above bed $\mathrm{D}-66 \mathrm{D}$ & 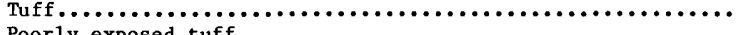 & -- & --- & -- & 1 & -- & $\cdots$ & $-\cdots$ & 9 & $-\cdots$ & $-\overline{-}$ & $-\overline{--}$ & -- & --- & --- & --- \\
\hline $\begin{array}{l}D-66 D \\
D-66 C\end{array}$ & $15 \mathrm{~cm}$ & $15.2 \mathrm{~cm}$ above bed $\mathrm{D}-66 \mathrm{C}$ & 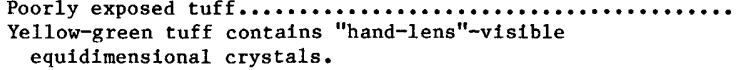 & -- & -- & $-\overline{--}$ & 1 & -- & -- & -- & $\begin{array}{r}10 \\
9\end{array}$ & $\overline{---}$ & --- & -- & -- & -- & -- & $-\overline{-}$ \\
\hline $\begin{array}{l}D-66 \mathrm{~B} \\
\mathrm{D}-66 \mathrm{~A}\end{array}$ & $\begin{array}{l}30 \mathrm{~cm} \\
23 \mathrm{~cm}\end{array}$ & & Tuff & --- & -- & -- & $\begin{array}{r}\mathrm{Tr} \\
2\end{array}$ & --- & --- & -- & $\begin{array}{r}10 \\
8\end{array}$ & $=-$ & --- & --- & --- & -- & -- & -- \\
\hline
\end{tabular}
Locality D- 67, SE $1 / 4$ SW1 $/ 4$ sec. 26, r. 11 S., R. 43 E. Sequence of green siltstone, sandstone, and conglomerate. Bedding attitude N. $85^{\circ}$ W., $27^{\circ}$ s. Conglomerate 18 made up most1y of
gray schist and quartzite

D-67B

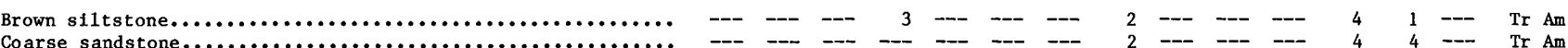
calfty D- $68, \mathrm{NE} 1 / 4 \mathrm{SWl} / 4 \mathrm{sec} .26$, T. $11 \mathrm{~S} .$, R. $43 \mathrm{E}$. Tuffs in brown mudstone sequence. Bedding attitude N. $70^{\circ}$ W., $17^{\circ} \mathrm{s}$. Tuffs are multiple-bedded; thickness is unknown but is at least
$1.8 \mathrm{~m}$

\begin{tabular}{lll}
\hline D-68C & Upper part & White to pale-yellow tuff \\
$\mathrm{D}-68 \mathrm{~B}$ & Middle part & Fine-grained tuff $\ldots \ldots \ldots \ldots \ldots$
\end{tabular}

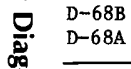
Fine-grained tuff

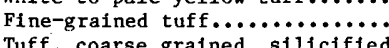

Locallty D-69, NW1/4SWl/4 sec. 26, T. $11 \mathrm{~S}$, R. 43 E. Collection of fragments of vertabrate fossils from gray siltstone above welded tuf

क. D-69

No samples collected, except fossils...................

Locality D-70, NE1/4SE1/4 sec. 27, T. 11 S., R. 43 E. Tuff sequence, poor1y exposed

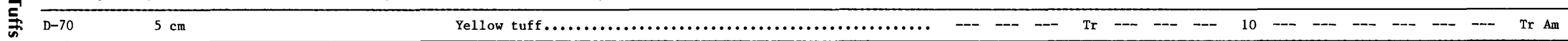

5. Locality D-71, NW1/4SW1/4 sec. 26, T. 11 S., R. 43 E. Poorly exposed tuff overlain by green siltstone. Tuff 1s probably the same as that at $10 c a 11 t y$ D- 55

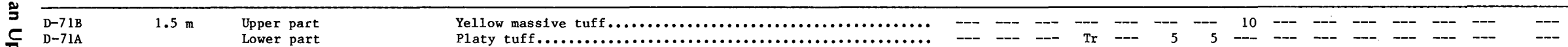

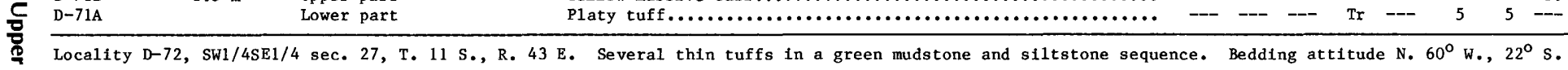

3. $8 \mathrm{~cm}$

$\begin{array}{lr}20 \mathrm{~cm} \\ \mathrm{D}-72 \mathrm{C} & 10 \mathrm{c} \\ \mathrm{D}-72 \mathrm{~B} & 5 \\ \mathrm{D}-72 \mathrm{~A} & 5\end{array}$

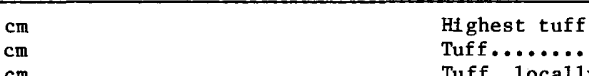

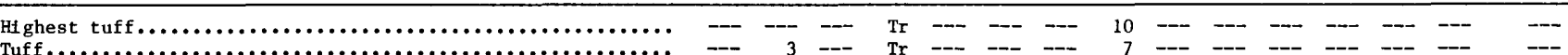

Locallty D-73, SW1/4SE1/4 sec. 27, T. 11 S., R. 43 E. Tuff in a green mudstone sequence. Lower part of tuff is silicified

D-73

SW1/4SE1/4 sec. 27 ,

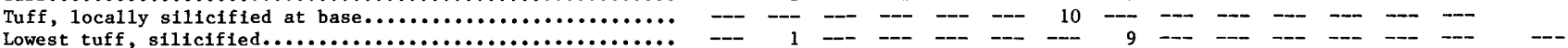

Locality D-74, SW1/4SW1/4 sec. 35, T. 11 S., R. $43 \mathrm{E}$

$\nabla$ $-74 \mathrm{D} \quad 4 \mathrm{~cm}$

$\mathrm{D}-74 \mathrm{D}$
$\mathrm{D}-74 \mathrm{C}$
$\mathrm{D}-74 \mathrm{~B}$

$\mathrm{D}-74 \mathrm{~B}$
$\mathrm{D}-74 \mathrm{~A}$

$4 \mathrm{~cm}$
$8 \mathrm{~cm}$

$3 \mathrm{~cm} \quad$ Top

Bap

Locality D-75, Center of Sw1/4 sec. 35, T. 11 s.; R. tuffs are above and below the thickest, collected tuf

$\begin{array}{lll}\mathrm{D}-75 \mathrm{C} & 15 \mathrm{~cm} & \text { Top. } \\ \mathrm{D}-75 \mathrm{~B} & 20 & \mathrm{~cm}\end{array}$

$\begin{array}{lll}\mathrm{D}-75 \mathrm{~B} & 20 \mathrm{~cm} & \text { Middl } \\ \mathrm{D}-75 \mathrm{~A} & 20 \mathrm{~cm} & \text { Base }\end{array}$

Mase

Gray and green mudstone sequence containing thin tuffs. Bedding attitude N. $60^{\circ}$ W., $10^{\circ} \mathrm{s}$.

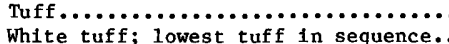

White tuff; lowest tuff
Orange base of bed $\mathrm{D}-74 \mathrm{~B}$

(1) --- $\begin{array}{llllllllllllll} & -- & 1 & --- & --- & --- & -- & --- & --- & -- & 1 & 2 & --- & 5 \text { Ap }\end{array}$

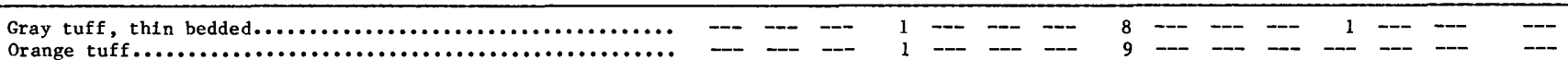

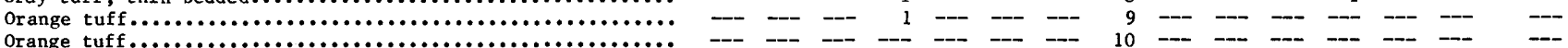


Appendix 1. Mineralogy of lacustrine rocks from the Durkee basin, Baker County, Oregon--Continued

Sample No. Measured

(locality thicked Position of sample

No. plus collected above $(+)$

unit No.)

Description of samples

Minerals (relative abundance reported as "parts-in-ten" as estimated from X-ray powder diffraction analysis)

Lality D-76, SE1/4NW1/4 sec. 35, T. 11 S., Ro 43 E. Sequence of yellow and greenish-yellow sandstone, conglomerate, tuffaceous sandstone, and sandy tuff. Bedding attitude $\mathrm{N}$, $35^{\circ} \mathrm{W}$. $18^{\circ}$ SW. Pre-Tertiary rocks crop out just east of D-76. Exposure is in bank of irrigation ditch where the rancher, Earl Sutter, found vertebrate fossil bones. The authors did not find fossils, but borrowed the specimens from Mr. Sutter for examination

D-7

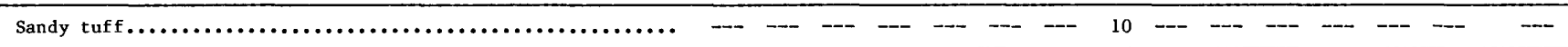

Locality D-77, SE1/4SW1/4 sec. 35, T. 11 S., R. 43 E. Thick tuff in a gray mudstone sequence. Re-collected the following year in more detail as D-101

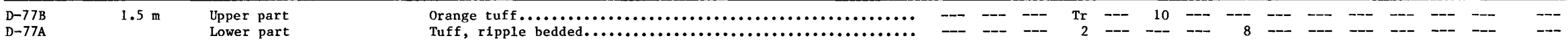
Locality D-78, SW1/4SE1/4 sec. 35, T. $11 \mathrm{~S}$, R. $43 \mathrm{E}$. Thin tuff in greenish-yellow mudstone. Bedding attitude $\mathrm{N} .80^{\circ} \mathrm{W}, 1^{\circ} \mathrm{s}$. White to pale-gray tufa is about $3 \mathrm{~m}$ above the tuff and may be unconformable on the lake beds. The tufa was not sampled. Tuff was re-collected as localtty D-102

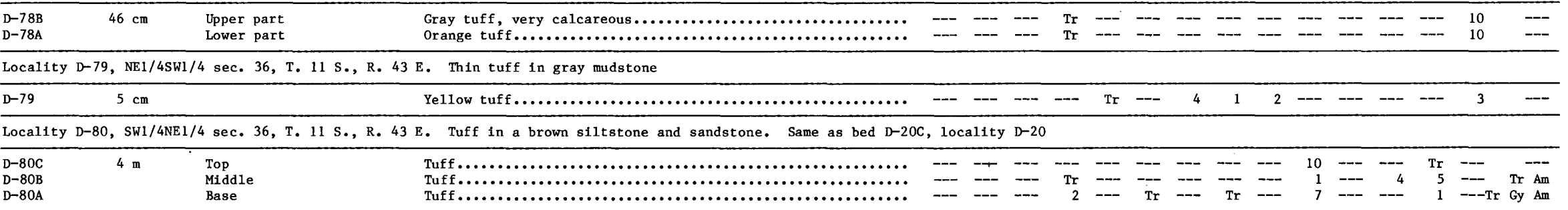

Locality D-81, SW1/4SW1/4 sec. 31, T. 11 S., R. 44 E. Tuff in greenish-gray mudstone, at locality D-107. Next hill west of D-81 is same sequence as that at locality D-20

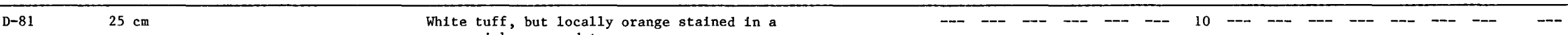
greenish-gray mudstone.

Locality D-82, SWI/4SE1/4 sec. 32 , T. 11 S., R. 44 E. See a1so local1ty D-22

D-82

Brown sandstone......................................

Locality D-83, SW1/4SW1/4 sec. 36, T. 11 S., R. 44 E. Several thin tuffs in a greenish-gray mudstone. Bedding attitude N. $10^{\circ}$ W., $22^{\circ}$ SW.

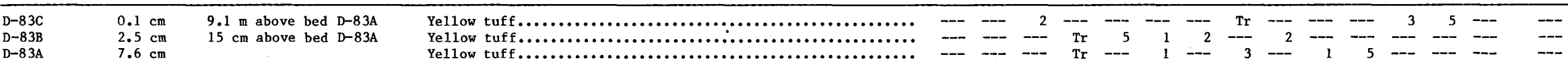

Locality D-84, SW1/4NW1/4 sec. 6, T. 12 S., R. 44 E. Thin tuff in a greenish-gray mudstone. Bedding attitude N. $25^{\circ}$ W., $26^{\circ}$ sW.

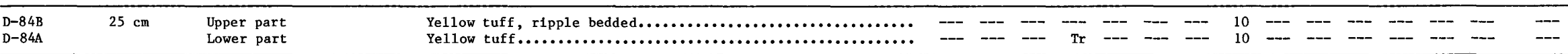

Locality D- 85 , SE $1 / 4 \mathrm{SW} 1 / 4 \mathrm{sec} .6$, T. $12 \mathrm{~S}$, , R. $44 \mathrm{E}$. Thick pale-gray to white diatomaceous mudstone and diatomite. Bedding attitude N. $30^{\circ}$ W., $14^{\circ}$ SW.

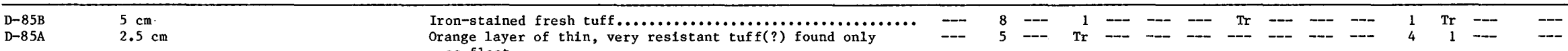
as float. 
Localfty D-86, SE $1 / 4 \mathrm{NE} 1 / 4 \mathrm{sec} .6$, T. 12 S., R. $44 \mathrm{E}$. Thin tuff in a green mudstone and sandstone

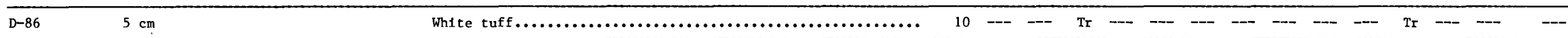

Locality D-87, NE1/4NW1/4 sec. 6, T. 12 S., R. 44 E. Sandstone, $12.1 \mathrm{~m}$ thick, coarse grained with cross-bedding. Bedding att1tude N. $5^{\circ}$ E., $12^{\circ}$ E.

\begin{tabular}{|c|c|c|c|c|c|c|c|c|c|c|c|c|c|c|c|c|c|}
\hline D-87C & Upper part & 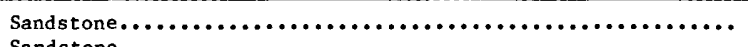 & --- & -- & --- & 1 & -- & --- & -- & 4 & -- & -- & --- & 3 & 2 & -- & --- \\
\hline $\begin{array}{l}\text { D-87B } \\
\text { D-87A }\end{array}$ & $\begin{array}{l}\text { Middle part } \\
\text { Lower part }\end{array}$ & 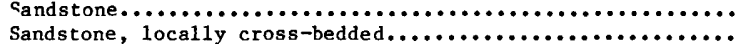 & $\overline{---}$ & $\overline{---}$ & -- & $\begin{array}{l}\mathrm{Tr} \\
\mathrm{Tr}\end{array}$ & -- & $\overline{--}$ & --- & $\begin{array}{l}1 \\
1\end{array}$ & $\overline{--}$ & $\overline{---}$ & -- & $\begin{array}{l}5 \\
5\end{array}$ & $\begin{array}{l}4 \\
2\end{array}$ & -- & $\begin{array}{ll}\operatorname{Tr} & \mathrm{Am} \\
2 & \mathrm{Am}\end{array}$ \\
\hline
\end{tabular}

Locality D-88, SE1/4NW1/4 sec. 8, T. 12 s., R. 44 E. Thick $(30.4 \mathrm{~m})$ pale-gray to yellow sandstone similar to sandstone at $10 \mathrm{cality} \mathrm{D-87.} \mathrm{Bedding} \mathrm{attitude} \mathrm{N.} 30^{\circ}$ W., $8^{\circ}$ NE.

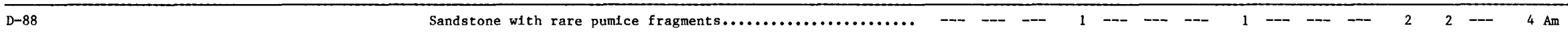
Locality D-89, SE1/4NW1/4 sec. 6 , T. 12 S., R. 44 E. Tuff collected as float in a green mudstone sequence, probably similar to bed D-28A at locality D-28

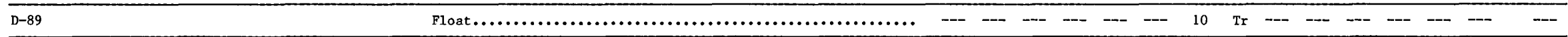
Locality D-90, SE1/4NW1/4 sec. 2, T. 12 S., R. 43 E. Thick tuffaceous unit that breaks with a conchoidal fracture D-90 Pale-green tuffaceous unit.

8 Localtty D-91, SE1/4NW1/4 sec. 27, T. 11 S., R. 45 E. Thin tuffs clearly seen in a poor exposure of partially covered mudstone in lower part of sequence and diatomite in upper part

त्रें

\begin{tabular}{|c|c|c|c|c|c|c|c|c|c|c|c|c|c|c|c|c|c|c|}
\hline $\begin{array}{l}D-91 D \\
D-91 C\end{array}$ & & $76 \mathrm{~m}$ above bed $\mathrm{D}-91 \mathrm{~B}$ & Gray, resistant sandstone overlying bed $D-91 c \ldots \ldots \ldots \ldots \ldots$ & $\because-$ & $-\overline{4}$ & 1 & $\because-$ & -- & -- & -- & 1 & $\because--$ & -- & -- & 2 & 5 & --- & $1 \mathrm{Am}$ \\
\hline $\begin{array}{l}D-91 C \\
D-91 B\end{array}$ & $\begin{array}{ll}3 \mathrm{~cm} \\
1 \mathrm{~cm}\end{array}$ & $7.6 \mathrm{~m}$ above bed $\mathrm{D}-91 \mathrm{~B}$ & $\begin{array}{l}\text { Gray tuff.......................................................... } \\
\text { Gray, varied calcareous unit, immediately overlying bed } \\
\text { D-9IA. }\end{array}$ & -- & $-{ }^{4}$ & -- & -- & - & -- & -- & 2 & - & -- & -- & 3 & - & 5 & -- \\
\hline D-91A & $8 \mathrm{~cm}$ & & Gray tuff in lower part of sequence; rat tooth marks on & --- & 4 & -- & --- & -- & - & -- & 6 & -- & -- & $\cdots$ & -- & $-\cdots$ & $\mathrm{T}$ & --- \\
\hline
\end{tabular}

D-91A $8 \mathrm{c}$ weathered surfaces.

Locality D-92, SWl/4SW1/4 sec. 14 , T. 11 S., R. 43 E. Contact between pale-gray diatomite to the south and reddish-brown siltstone, sandstone, and conglomerate to the north. Contact apality D-92, SWl/4SW1/4 sec. 14 , T. 11 S., R. $43 \mathrm{E}$. Contact between pale-gray diatomite to the
appears to be a nearly vertical fault (north side down) with an attitude of N. $80^{\circ} \mathrm{W} ., 70^{\circ} \mathrm{N}$. D-92 No sample.

Locality D-93, SE1/4SW1/4 sec. 24, T. 11 S., R. 43 E. Poorly exposed tuffs in a sequence that is mostly siltstone and sandstone

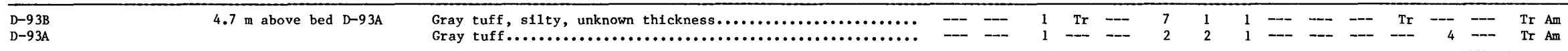

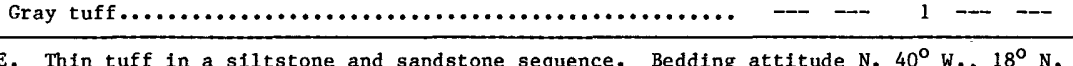

Locality D-94, NE1/4SWl/4 sec. 24, T. $11 \mathrm{~S} ., \mathrm{R} .43 \mathrm{E}$. Thin tuff in a siltstone and sandstone sequence. Bedding attitude N. $40^{\circ} \mathrm{W} ., 18 \mathrm{~N}$.

D-94 10 c Cream-colored tuff, locally cross-bedded...

Locality D-95, NE1/4SE1/4 sec. 24, T. $11 \mathrm{~S}$., R. $43 \mathrm{E}$. Thin tuffs in a mudstone and siltstone sequence

D-95E-1 $2.5 \mathrm{~cm} \quad 4.5 \mathrm{~m}$ above bed D-95D White tuff with raindrop prints on base; upper surface

$\begin{array}{lrl}D-95 E-2 & 1 \mathrm{~mm} & \text { At base } \\ \mathrm{D}-95 \mathrm{D} & 10 \mathrm{~cm} & 4.5 \mathrm{~m} \text { above bed } \mathrm{D}-95 \mathrm{C}\end{array}$

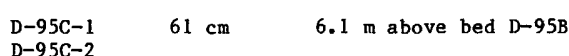

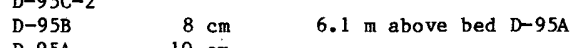

White tuff with
very irregular.

Thin black layer at bottom of tuff...............................

bed $D-7 \mathrm{~A}$, locality $\mathrm{D}-7$.

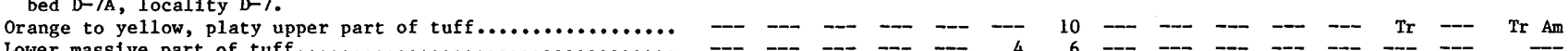

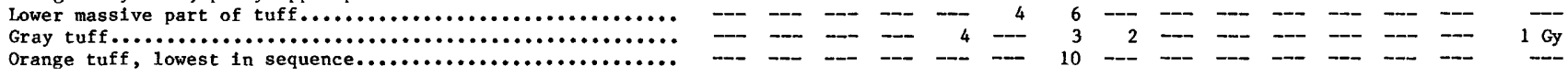

Localtty D-96, SE1/4NE1/4 sec. 24, T. $11 \mathrm{~s} .$, R. $43 \mathrm{E}$. Th1n tuffs in mudstone sequence 1dentical to that at locality D-95

D-96

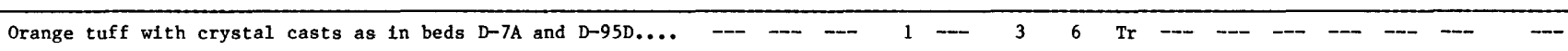


Append1x 1. Mineralogy of 1acustrine rocks from the Durkee basin, Baker County, Oregon--Continued

\begin{tabular}{|c|c|c|c|c|}
\hline \multirow{2}{*}{$\begin{array}{l}\text { Sample No. } \\
\text { (locallty } \\
\text { No. plus } \\
\text { bed or } \\
\text { unit No.) }\end{array}$} & \multirow{2}{*}{$\begin{array}{l}\text { Measured } \\
\text { thickness } \\
\text { shown } 1 \mathrm{n} \mathrm{m}, \\
\mathrm{cm}, \text { or } \mathrm{mm}\end{array}$} & \multirow{2}{*}{$\begin{array}{l}\text { Position of sample } \\
\text { collected above }(+) \\
\text { or below }(-) \text { base } \\
\text { of designated unit }\end{array}$} & \multirow[t]{2}{*}{ Description of samples } & $\begin{array}{c}\text { Minerals (relative abundance reported as "parts-in-ten" as estimated from } \\
\text { X-ray powder diffraction analysis) }\end{array}$ \\
\hline & & & & \\
\hline
\end{tabular}

unit No.) $\quad \mathrm{cm}$, or $\mathrm{mm}$ of designate

Locality D- $97, \mathrm{NW} 1 / 4 \mathrm{NW1} / 4 \mathrm{sec} .13$, T. $11 \mathrm{~S} .$, R. $43 \mathrm{E}$. Bedding attitude N. 70 W., $24^{\circ} \mathrm{N}$. Thick, unaltered tuff overlain by gravels; probably the same as that in unit SD-58- 7 at locality SD-42

\begin{tabular}{|c|c|c|c|c|c|c|c|c|c|c|c|c|c|c|c|c|c|c|}
\hline$D \rightarrow 97$ & $1.5 \mathrm{~m}$ & & 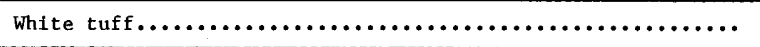 & 10 & --- & --- & $\operatorname{Tr}$ & --- & --- & --- & --- & --- & --- & --- & --- & --- & --- & --- \\
\hline & & & & & & & & & & & & & & & & & & \\
\hline $\begin{array}{l}D-98 \mathrm{~F} \\
D-98 \mathrm{E}\end{array}$ & $51 \mathrm{~cm}$ & $\begin{array}{l}\text { Upper part } \\
3 \mathrm{~m} \text { above bed } \mathrm{D}-98 \mathrm{D}\end{array}$ & 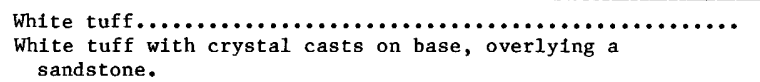 & $\begin{array}{r}10 \\
---\end{array}$ & --- & --- & -- & --- & Tr & $\begin{array}{r}\mathrm{Tr} \\
8\end{array}$ & -- & --- & --- & --- & --- & --- & --- & -- \\
\hline$-98 \mathrm{D}$ & $25 \mathrm{~cm}$ & thove bed $\mathrm{D}-98 \mathrm{C}$ & White and orange mottled tuff $\ldots \ldots \ldots \ldots \ldots \ldots \ldots \ldots \ldots \ldots$ & --- & --- & -- & $\operatorname{Tr}$ & --- & 3 & 4 & 3 & --- & -- & -- & --- & --- & -- & $\operatorname{Tr}$ Gy \\
\hline $\begin{array}{l}\text { D-98C } \\
\text { D-98B }\end{array}$ & $\begin{array}{l}10 \mathrm{~cm} \\
36 \mathrm{~cm}\end{array}$ & $\begin{array}{l}5 \mathrm{~m} \text { above bed } \mathrm{D}-98 \mathrm{~B} \\
7 \mathrm{~m} \text { above bed } \mathrm{D}-98 \mathrm{~A}\end{array}$ & 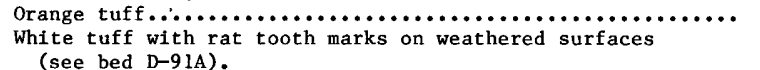 & -- & --- & --- & $\begin{array}{r}2 \\
\operatorname{Tr}\end{array}$ & 3 & $\begin{array}{l}3 \\
2\end{array}$ & $\begin{array}{l}2 \\
1\end{array}$ & $\begin{array}{r}3 \\
--\end{array}$ & $\begin{array}{l}--- \\
--\end{array}$ & --- & --- & --- & --- & $-\overline{--}$ & --- \\
\hline D-98A & $30 \mathrm{~cm}$ & & White tuff, lowest in sequence $\ldots \ldots \ldots \ldots \ldots \ldots \ldots \ldots \ldots . . .$. & --- & -- & -- & 2 & 2 & 1 & 2 & 3 & --- & $\cdots$ & --- & -- & - & -- & -- \\
\hline
\end{tabular}

Locality D-99, SE1/4SE1/4 sec. 34, T. 11 S., R. $43 \mathrm{E}$. Thin bed of phosphatic rock in brown mudstone; same as that at bed D-74D at 1ocality D-74. Just north of D-99 an east-west fault places the mudstone in contact with a pale gray diatomite

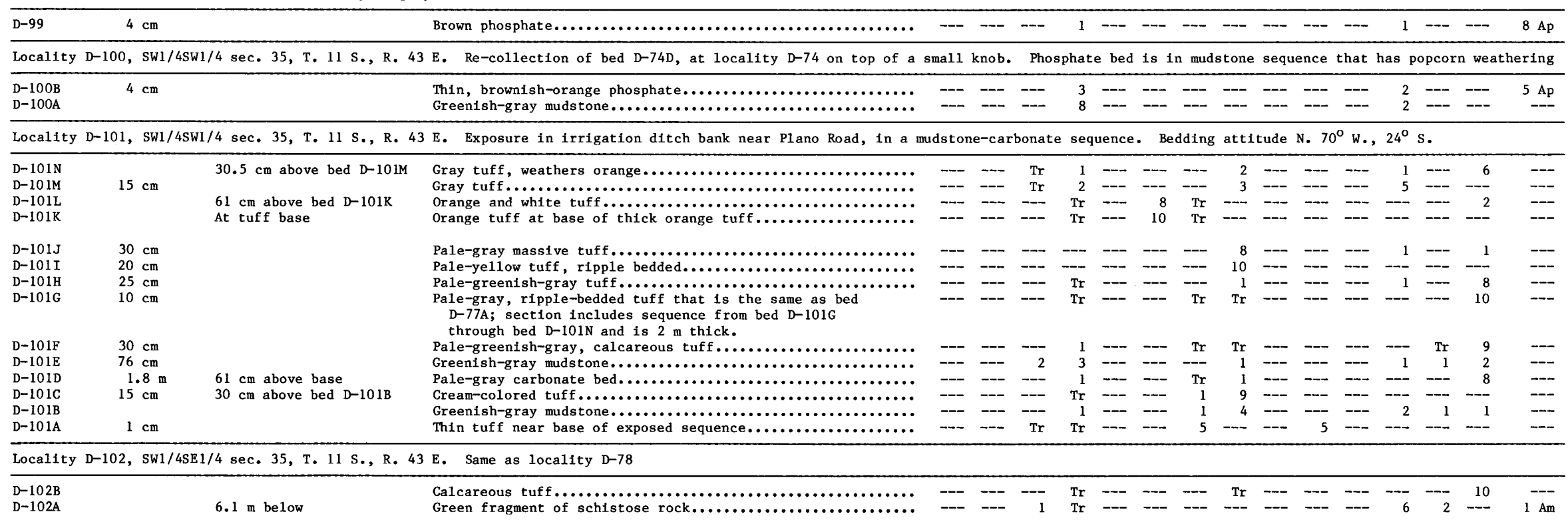


Locality D-103, SW1/4NE1/4 sec. 34, T. 11 S., R. 43 E. Sequence of greenish-gray mudstone containing a thin tuff and a thin dolomite bed

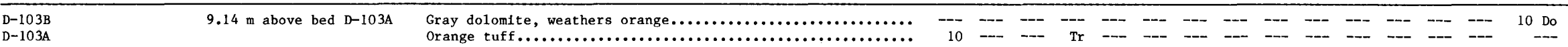

Loca11ty D-104, NE1/4SE1/4 sec. 34, T. 11 S., R. 43 E. Sequence of poor1y exposed mudstone and tuff

D-104

Gray tuff..........................................

Locality D- 105 , NW1/4SE1/4 sec. 25, T. 11 S., R. 42 E. Sequence of diatomite and an unaltered tuff. Bedding att1tude N. $45^{\circ}$ w., $30^{\circ}$ S.

Gray tuff......................................

10 - - - - - -

Locality D-106, NE1/4SWl/4 sec. 9, T. 11 S., R. 43 E. Thin, unaltered tuff on the flank of Iron Mountain in a pinkish-brown siltstone, sandstone, and cong1omerate sequence

$10 \mathrm{~cm}$

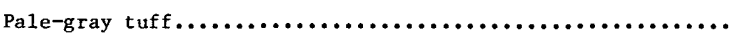

Locality D-107, SWI/4SWl/4 sec. 31, T. 11 S., R. 44 E. Chert bed in mudstone sequence about 90 m east and downslope from 1ocallty D-81

\begin{tabular}{|c|c|c|c|c|c|c|c|c|c|c|c|c|c|c|c|c|c|}
\hline $\begin{array}{l}D-107 Z \\
D-107 Y\end{array}$ & $\begin{array}{l}15 \mathrm{~cm} \\
2.4 \mathrm{~cm}\end{array}$ & $\begin{array}{l}\text { Chert bed, Magadi-type ( }(\text { ), dark gray } \ldots \ldots \ldots \ldots \ldots \ldots \ldots \ldots \\
\text { Magadi-type chert, float from below bed } \mathrm{D}-81 \mathrm{z} ; \text {; gray } \\
\text { translucent, with petrified wood. }\end{array}$ & $\overline{--}$ & --- & --- & -- & --- & --- & --- & --- & $=-$ & --- & -- & $\begin{array}{l}10 \\
10\end{array}$ & --- & $\overline{--}$ & --- \\
\hline
\end{tabular}





\title{
Magadi-Type Chert-A Distinctive Diagenetic Variety From Lacustrine Deposits
}

\author{
By RICHARD A. SHEPPARD, U.S. Geological Survey, Box 25046, Denver \\ Federal Center, MS 939, Denver, Colorado 80225, and \\ ARTHUR J. GUDE 3rd, U.S. Geological Survey, Box 25046, Denver Federal \\ Center, MS 917, Denver, Colorado 80225
}

\section{CONTENTS}

Abstract $\quad 336$

Introduction $\mathbf{3 3 6}$

Acknowledgments 336

Occurrences of Magadi-type chert in the United States 336

Description of the chert $\mathbf{3 3 6}$

Textural characteristics 339

Petrographic characteristics 339

$\mathrm{X}$-ray diffraction characteristics
Chemical composition 341

Genesis of the chert $\mathbf{3 4 2}$

Significance of Magadi-type chert 344

References cited $\mathbf{3 4 5}$

\section{FIGURES}

1. Map showing occurrences of Magadi-type chert in sedimentary rocks of the United States $\mathbf{3 3 7}$

2-6. Photographs:

2. Thin bed of Magadi-type chert in zeolitic tuff near Paradise Valley, Nevada 339

3. Platy Magadi-type chert from lacustrine facies of Gila Conglomerate near Buckhorn, New Mexico 339

4. Lobate nodule of Magadi-type chert from upper Tertiary lacustrine deposits near Paradise Valley, Nevada $\mathbf{3 4 0}$

5. Magadi-type chert from lacustrine facies of Gila Conglomerate near Buckhorn, New Mexico 340

6. Lobate nodule of Magadi-type chert from "Rome beds" near Rome, Oregon $\mathbf{3 4 0}$

7-10. Photomicrographs of interior of Magadi-type chert showing:

7. Aggregate of interlocking, irregular, fine chalcedony 341

8. Irregular patch of spherulitic chalcedony 341

9. Vague, ellipsoidal bodies of chalcedony 342

10. Filling of crystal mold by chalcedony, finely crystalline quartz, and coarsely crystalline quartz $\mathbf{3 4 2}$

11. X-ray diffraction traces of well-crystallized quartz and Magadi-type chert $\mathbf{3 4 3}$

\section{TABLES}

1. Occurrences of Magadi-type chert in the conterminous United States

2. Semiquantitative spectrographic analyses of Magadi-type chert 344

3. Minerals associated with strata containing Magadi-type chert 345 


\begin{abstract}
Chert that formed from magadiite $\left(\mathrm{NaSi}_{7} \mathrm{O}_{13}(\mathrm{OH})_{3} \cdot 3 \mathrm{H}_{2} \mathrm{O}\right)$ or other hydrous sodium silicate minerals was first described in 1967 by H. P. Eugster, who observed it in upper Pleistocene lacustrine deposits at Lake Magadi, Kenya. Since then, this distinctive chert of inorganic origin has been recognized in other Pleistocene lacustrine deposits of the Eastern Rift Valley in Kenya and Tanzania and in many lacustrine deposits of Jurassic to Pleistocene age in the United States. Magadi-type chert is especially common in the upper Cenozoic deposits of the Basin and Range province. The chert occurs chiefly as thin, discontinuous beds or as plates or nodules of irregular shape. Typically, the chert is dense, homogeneous, and translucent and has a thin, soft, white, opaque rind. Most of the chert consists of finely crystalline chalcedonic quartz, but the rind may consist of chalcedony and (or) various types of silicate or aluminosilicate minerals. This chert is known to have formed only in deposits of saline and highly alkaline lakes of the sodium carbonatebicarbonate type. The chert did not precipitate directly from the lake water or brine; rather, it formed during early diagenesis from a primary precipitate of magadiite or some other hydrous sodium silicate mineral. The conversion to chert from these precursor minerals involved a loss of sodium and water and a reduction in volume. The distinctive surface reticulation and soft-sediment deformation features of the chert were produced during the conversion. Magadi-type chert is an excellent indicator of past environmental conditions, and its recognition can also be a valuable prospecting tool for locating evaporites, zeolites, and fluorite in continental sedimentary deposits.
\end{abstract}

\section{INTRODUCTION}

Nodular and bedded cherts are common throughout the geologic record, and many occur in marine deposits (Pettijohn, 1975). The origin of most of these cherts has been ascribed either to biochemical accumulations or to silicification of carbonate rocks. Magadi-type chert, that is, chert that formed from magadiite $\left(\mathrm{NaSi}_{7} \mathrm{O}_{13}(\mathrm{OH})_{3} \cdot 3 \mathrm{H}_{2} \mathrm{0}\right)$ or other hydrous sodium silicate minerals, was first described by Eugster $(1967,1969)$ from the upper Pleistocene lacustrine deposits of Lake Magadi, Kenya. Although the cherts at Lake Magadi had previously been recognized and described by Baker (1958), their origin was not known until Eugster's investigations. Hay (1968) described nodules of Magadi-type chert in Pleistocene lacustrine deposits at Lake Magadi and at Lake Natron and Olduvai Gorge in Tanzania.

Magadi-type chert was first reported in the United States from the Eocene Green River Formation of Wyoming by Eugster and Surdam (1971) and later from numerous localities in lacustrine rocks of Pleistocene to Jurassic age in Wyoming by Surdam and others (1972). Subsequently, chert believed to have formed from a magadiite precursor was reported from Pliocene lacustrine deposits in southeastern Oregon and southwestern New Mexico (Sheppard and Gude, 1974) and in central Nevada
(Sheppard and Gude, 1980). Nodular varieties of Magaditype chert are prized by rock collectors and lapidaries and are appropriately called snakeskin agates.

Recognition of Magadi-type chert in the Cambrian Observatory Hill Beds in south-central Australia recently helped White and Youngs (1980) interpret the depositional environment as a saline, alkaline lake. This interpretation of these Cambrian rocks is the first record of alkaline, lacustrine sedimentation in the Cambrian System of Australia and necessitates a reevaluation of existing concepts of Cambrian geography and tectonics in central Australia.

This present report provides a catalog of the occurrences of Magadi-type chert in the United States; several of the occurrences have not been previously reported. In addition, the morphological, mineralogical, and chemical characteristics of the chert are described to aid further discoveries, and the significance of the chert is discussed with respect to the interpretation of the depositional environment of the host rocks and to the potential use of the chert as a guide for locating other valuable mineral deposits.

\section{Acknowledgments}

We thank R. L. Hay for providing samples of chert from the east African lacustrine deposits and R. C. Surdam for providing samples of chert from the Green River Formation of Wyoming.

\section{OCCURRENCES OF MAGADI-TYPE CHERT IN THE UNITED STATES}

Occurrences of Magadi-type chert are shown in figure 1 and are listed in table l. Except for the locality in South Carolina, the known occurrences of Magadi-type chert are in the Western United States, particularly in the Basin and Range province. Occurrences are especially numerous in Wyoming, probably because a special effort was made to search for deposits in that State. The chert has been identified in rocks that range in age from Jurassic to Pleistocene, except that no occurrence of Cretaceous age has been found. More than half the occurrences are in rocks of Miocene or younger age.

\section{DESCRIPTION OF THE CHERT}

Magadi-type chert occurs as thin beds or as irregular plates or nodules, but nodular varieties are most common. Thin beds have been reported from the Green River Formation (Eugster and Surdam, 1971) and the Moonstone Formation (Mariner, 1971) in Wyoming and from the "Rome beds" in Oregon (Sheppard and Gude, 1974). We have also recognized thin beds of Magadi-type chert in a lacustrine facies of the Gila Conglomerate near Buckhorn, 


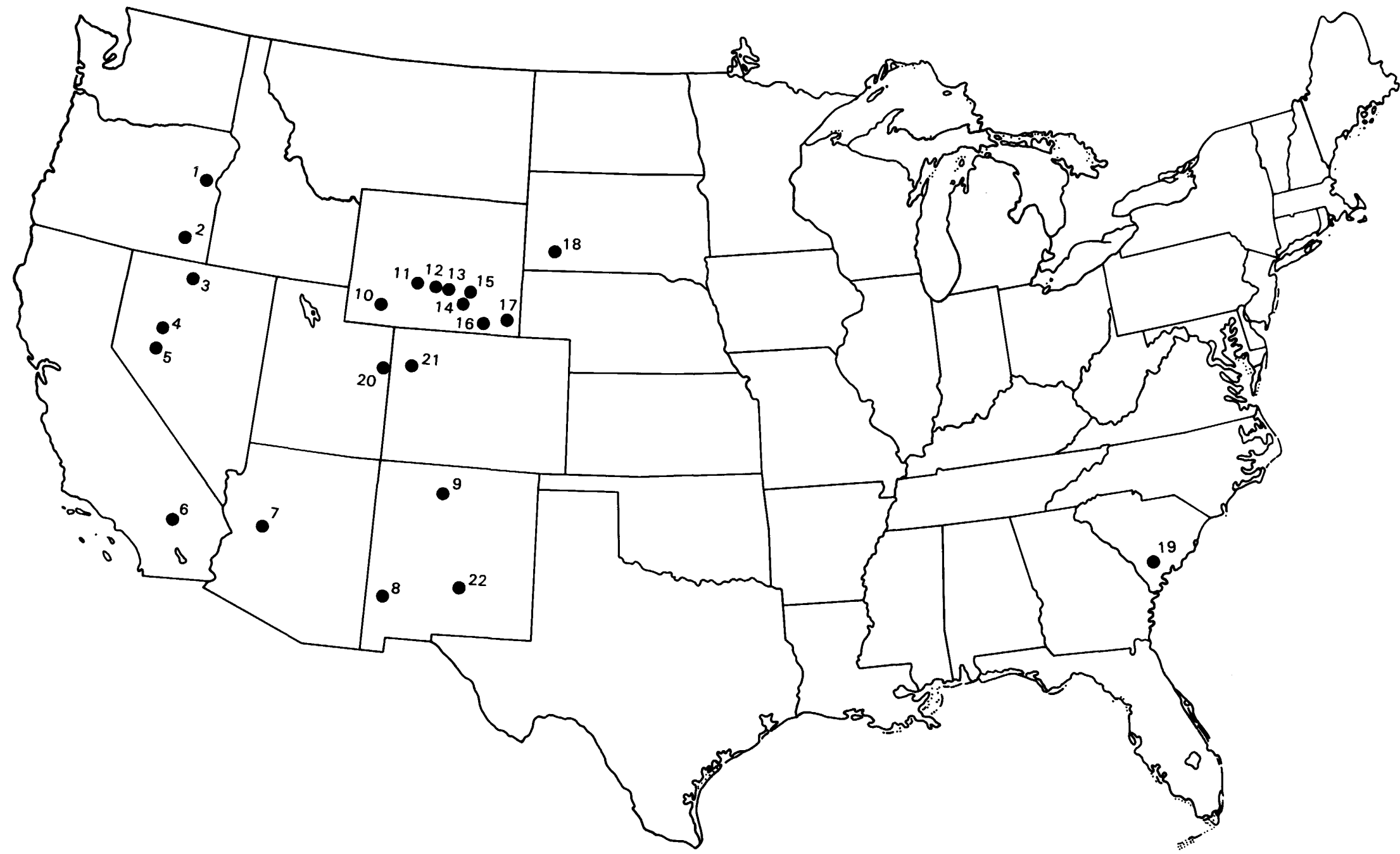

Figure 1. Occurrences of Magadi-type chert in sedimentary rocks of conterminous United States. Data for numbered localities are given in table 1. 
Table 1. Occurrences of Magadi-type chert in the conterminous United States

[Locality numbers are shown in figure 1. Asterisk (*) indicates localities at which identification of chert as Magadi-type is tentative]

Locality $\quad$ occurrence $\quad$ References

1. Near Durkee, sec. 31, T. 11 s., R. 44 E., Baker County, oregon.

2. Near Rome, Malheur County, Oregon.

3. Near Paradise Valley, sec. 17 T. 41 N., R. 43 E., Humboldt County, Nevada.

4. Near Dixle Valley, sec. 7, T. 24 N., R. 38 E., Churchil1 County, Nevada.

5. Near Eastgate, Churchil1 County, Nevada.

6. Near Hector, sec. 35, T. 8 N., R. 5 E., San Bernardino County, California.

7. Near Bismarck Mesa, sec. 11 , T. 13 N., R. 6 W., Yavapai County, Arizona.

8. Near Buckhorn, Grant County, New Mexico.

9. Near Coyote, Rio Arriba County, New Mexico.*

10. Near Green River, Sweetwater County, Wyoming.

11. Near Green Cove, Fremont County, Wyoming.

12. Near White Ridge, Natrona County, Wyoming.

13. Near the Bug Ranch headquarters, Natrona County, Wyoming.

14. Near Nelson Springs, Carbon County, Wyoming.

15. Chalk Mountain, Carbon County, Wyoming.

16. Near Buckeye Creek, Albany County, Wyoming.

17. Along Horse Creek, Laramie County, Wyoming.

18. Near Sheep Mountain Table, sec. 2, T. 4 S., R. 13 E., Pennington County, South Dakota.*

19. Near Orangeburg, Orangeburg County, South Carolina.

20. Near Dragon, sec. 13, T. 12 s., R. 25 E., Uintah County, Utah.

21. Near Greasewood Gulch, sec. 31, T. 1 S., R. 96 W., Rio Blanco County, Colorado.

22. Near Carrizozo, sec. 21 , T. 9 S., R.10 E., Lincoln County, New Mexico.
Unnamed lacustrine rocks of Pliocene age.

"Rome beds" of Pliocene age.

Unnamed lacustrine rocks of Miocene or Pliocene age.

Unnamed lacustrine rocks of Cenozoic age.

Monarch Mill Formation of Pliocene age.

Unnamed lacustrine rocks of Miocene or Pliocene age.

Unnamed lacustrine rocks of Miocene or Pliocene age.

Lacustrine rocks in the Gila Conglomerate of Pliocene or Pleistocene age.

Pedernal Chert Member of the Abiquiu Tuff of Miocene age.

Wilkins Peak Member of the Green River Formation of Eocene age.

Wagon Bed Formation of Eocene age--

Moonstone Formation of P1iocene age.

Bug Formation of Pleistocene age--

Unnamed lacustrine rocks of Cenozotc age.

Lacustrine rocks of the White River Group of 01igocene age.

Morrison Formation of Jurassic age.

Unnamed lacustrine rocks of Miocene age.

Brule Formation of oligocene age--

McBean Formation of Eocene age--

Douglas Creek Member of the Green Rfver Formation of Eocene age.

Garden Gulch Member of the Green River Formation of Eocene age.

Unnamed lacustrine rocks of late Tertiary or Pletstocene age.
This report.

Sheppard and Gude (1974).

This report.

R. H. Mariner, U.S. Geological Survey, 345 Middlefield Road, Menlo Park, California 94025 (oral commun., 1981).

Sheppard and Gude (1980)

This report.

This report.

Sheppard and Gude (1974).

Santos and others (1975).

Surdam and others (1972).

Surdam and others (1972).

Mariner (1971).

Surdam and others (1972).

Surdam and others (1972).

Surdam and others (1972).

Surdam and others (1972).

Surdam and others (1972).

W. H. Raymond, U.S. Geological Survey, Box 25046, DFC, MS 921 , Denver, Colorado 80225 (oral commun., 1981).

Houser (1982).

R. C. Johnson, U.S. Geological Survey, Box 25046, DFC, MS 939 Lakewood, Colorado 80225 (oral commun., 1982).

R. C. Johnson, U. S. Geological Survey, Box 25046, DFC, MS 939 Denver, Colorado 80225 (oral Commun., 1984).

R. H. Weber, New Mexico Bureau of Mines and Mineral Resources, Socorro, New Mexico 87801 (oral commun., 1984). 
New Mexico, and in unnamed lacustrine rocks of Miocene or Pliocene age near Paradise Valley, Nevada (table 1). The beds are $0.1-15 \mathrm{~cm}$ thick, but are generally less than $2 \mathrm{~cm}$ thick (fig. 2) and are commonly discontinuous and contorted. Platy chert (fig. 3 ) is generally less than $1 \mathrm{~cm}$ thick and is locally transitional into beds or nodules. Both bedded and platy varieties of Magadi-type chert have external and internal textures that are similar to the more common nodular variety described below. Nodules of chert vary greatly in shape and size, although most are irregular, lobate, and $2-18 \mathrm{~cm}$ in the longest dimension (fig. 4). The shortest dimension of the nodules is generally perpendicular to bedding. At some localities, the nodules are confined to a single layer; but at other places, the chert nodules are distributed vertically through as much as $1 \mathrm{~m}$ of mudstone or zeolitic mudstone.

Angular chips of Magadi-type chert occur in a channel sandstone of the Moonstone Formation in the NE $1 / 4$ sec. 30, T. 30 N., R. 89 W., at White Ridge, Wyoming (table 1 , locality 12). At this locality, the same stratigraphic interval contains abundant thin beds and plates of chert in brownish-gray mudstone. The chert in place in the mudstone and the epiclastic chert in the sandstone appear identical. These relationships indicate that the conversion to chert was relatively rapid, and that the thin, siliceous beds in the mudstone were already chert before being eroded, transported, and incorporated in a penecontemporaneous sandstone. Similar occurrences of chert fragments in intraformational gravel or sandstone were described by Hay (1968) at Olduvai Gorge, Tanzania, and by Eugster (1969) at Lake Magadi, Kenya.

\section{Textural characteristics}

Most of the Magadi-type chert, whether bedded, platy, or nodular, is dense, homogeneous, and milky to translucent; it generally has a thin, soft, opaque, white coating or rind. Although most of the dense chert is light gray, some is dark gray, black, greenish brown, or reddish brown. Laminations or concentric color bands are rare in the chert. The white rinds are $0.1-5 \mathrm{~mm}$ thick, but most are $1 \mathrm{~mm}$ or less thick.

Perhaps the most distinctive feature of the Magaditype chert is the surface reticulation (figs. 3 and 4). The spacing of the reticulate pattern is commonly $0.5-4 \mathrm{~mm}$, and the reticulation generally extends through the white rind and into the underlying dense chert. This characteristic reticulation led rock collectors and lapidaries to describe nodular varieties of the chert as "snakeskin agate" (Sheppard and Gude, 1974, p. 625), and the peculiar texture has also been termed "crocodile skin" (White and Youngs, 1980 , p. 1281). Superimposed on the reticulation of some cherts is a much larger scale pattern of cracks, such as that shown in figure 5. These larger cracks extend deeper into the chert than the surface reticulation.

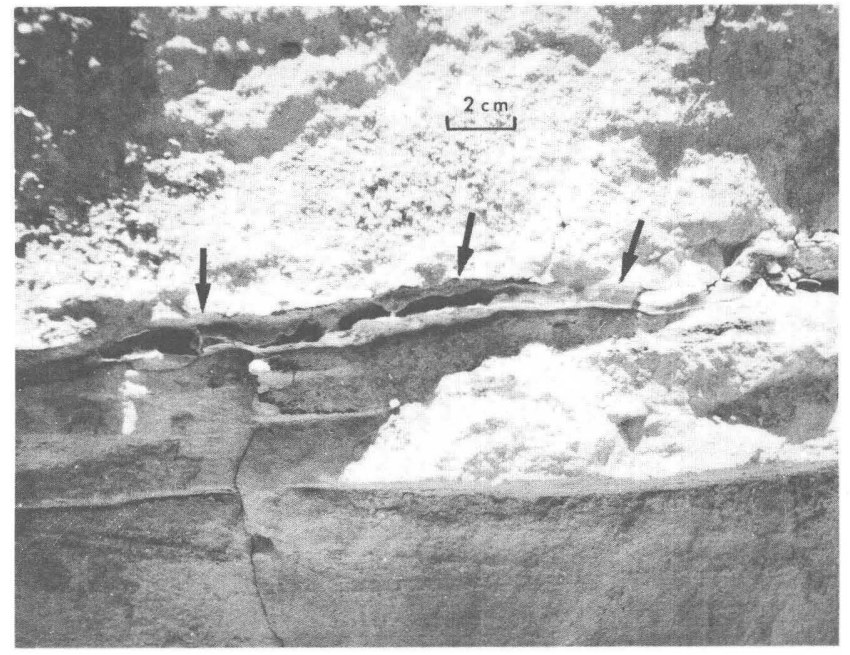

Figure 2. Thin bed of Magadi-type chert (arrows) in zeolitic tuff near Paradise Valley, Nevada (table 1, locality 3). Note thin, white rind and dark, dense interior.

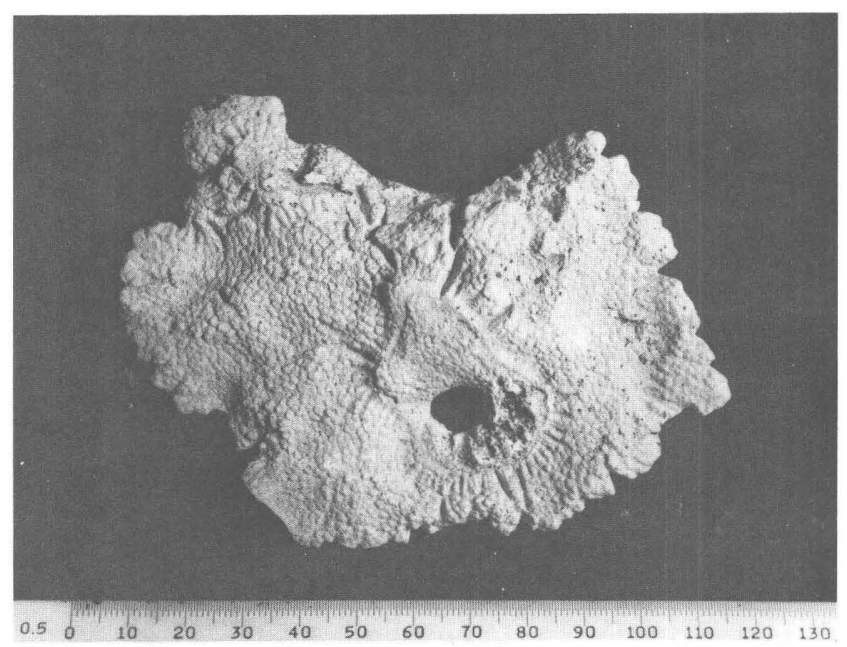

Figure 3. Platy Magadi-type chert from lacustrine facies of Gila Conglomerate near Buckhorn, New Mexico (table 1, locality 8), showing surface reticulation. Scale is in units of $0.5 \mathrm{~mm}$.

Crystal molds (fig. 6) are common on the surfaces of some chert but are less common in the interior of the chert. Although some crystal molds are too deformed to be identified, molds from nodules in the "Rome beds" resemble gaylussite or pirssonite (Sheppard and Gude, 1974), and other molds in chert from the Moonstone Formation resemble trona (Surdam and others, 1972). Generally, those cherts that have crystal molds on the surface lack the characteristic surface reticulation.

\section{Petrographic characteristics}

Examination of thin sections of the dense chert shows that it consists mainly of an aggregate of interlocking, irregular, fine grains of chalcedony (fig. 7). Individual grains 
range in size from less than $2 \mu \mathrm{m}$ to about $40 \mu \mathrm{m}$, but most are less than $25 \mu \mathrm{m}$. All the chalcedony exhibits anomalous extinction and is length slow. The mean index of refraction of the chalcedony is betweem 1.53 and 1.54 and is distinctly lower than that of quartz. Some chert contains rare veinlets or relatively large patches of fibrous chalcedony which is coarser grained than that of the matrix. The chert from Bismarck Mesa, Arizona (table 1, locality 7) contains veinlets and large patches of spherulitic chalcedony (fig. 8). The spherulites are as much as $250 \mu \mathrm{m}$ in size and are length slow.

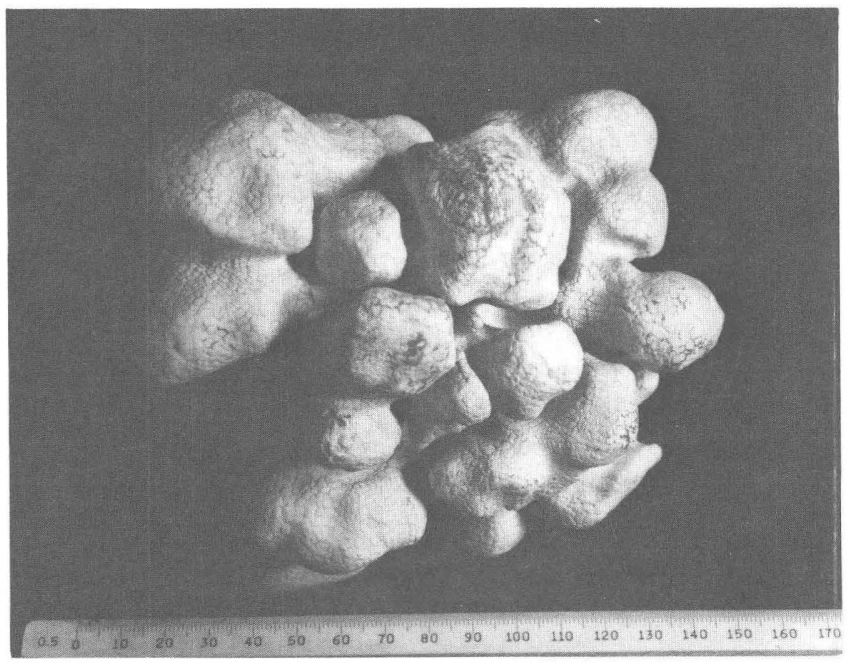

Figure 4. Large, lobate nodule of Magadi-type chert from upper Tertiary lacustrine deposit near Paradise Valley, Nevada (table 1, locality 3), showing surface reticulation. Scale is in units of $0.5 \mathrm{~mm}$.

Some of the Magadi-type chert from Rome, Oregon (table 1, locality 2) and Eastgate, Nevada (table 1, locality 5) contain abundant, but vague, ellipsoidal bodies of chalcedony that are recognizable under crossed nicols (fig. 9). These bodies are $0.03-1.4 \mathrm{~mm}$ in their longest dimension and characteristically consist of a very fine grained core (less than $2 \mu \mathrm{m}$ in grain size) and a coarser, fibrous rim. Some ellipsoidal bodies also show a vague concentric structure within the cores. The fibrous chalcedony rims of the bodies are length fast, in contrast to all the other chalcedony examined. Inasmuch as most of the magadiite in lacustrine deposits is spherulitic and about the same size as the ellipsoidal bodies in the chert (Eugster, 1967; Hay, 1968), these chalcedonic bodies are probably relicts of the original magadiite.

Crystal molds in some of the Magadi-type cherts are filled or partly filled with a variety of materials. For example, crystal molds in some chert nodules from the "Rome beds" of southeastern Oregon (Sheppard and Gude, 1974) are filled with chalcedony, quartz, and calcite. A thin layer of length-slow chalcedony lines the molds and is followed inwardly by finely crystalline, granular quartz, and then by coarsely crystalline quartz (fig. 10). Some of the coarse

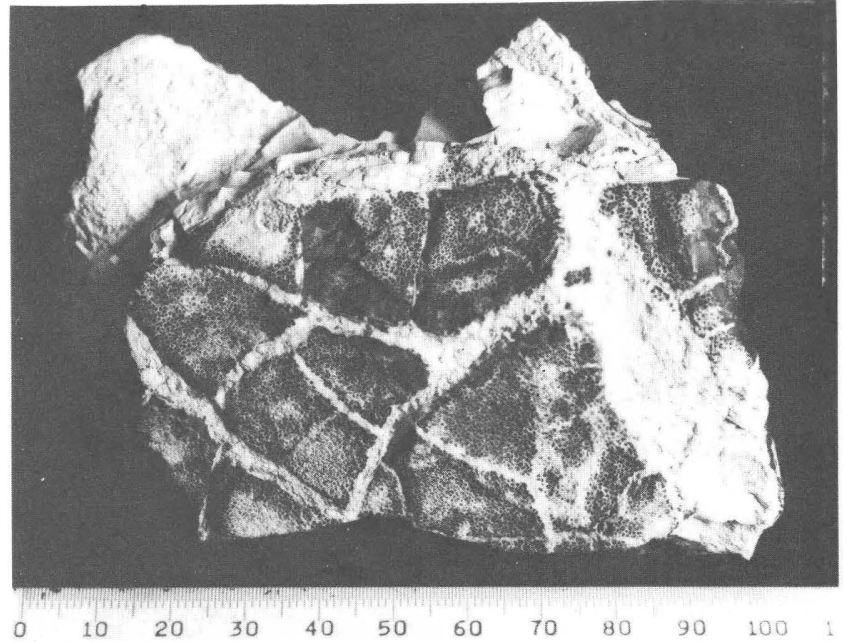

Figure 5. Magadi-type chert from lacustrine facies of Gila Conglomerate near Buckhorn, New Mexico (table 1, locality 8), showing larger-scale pattern of cracks superimposed on surface reticulation. Scale is in units of $0.5 \mathrm{~mm}$.

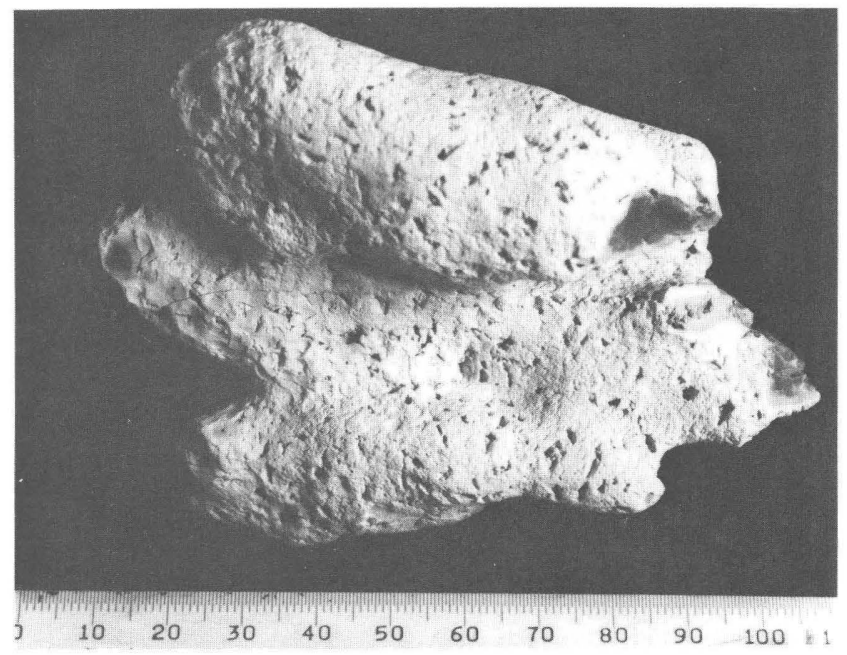

Figure 6. Lobate nodule of Magadi-type chert from "Rome beds" near Rome, Oregon (table 1, locality 2), showing deformed crystal molds on surface. Note dark, dense chert beneath thin, white rind. Scale is in units of $0.5 \mathrm{~mm}$.

quartz shows crystal faces where it projects into a still unfilled cavity. This sequence is the same in all molds, and calcite, where present, postdates the coarse quartz.

\section{X-ray diffraction characteristics}

X-ray powder diffractometer (XRD) patterns of the dense chert confirm the presence of quartz but show some significant differences (fig. 11). The ratio of intensities of the 101 peak to the 100 peak for well-crystallized quartz is about 4, but this ratio for most of the Magadi-type cherts is 6-8. Also, the XRD patterns of the dense chert generally 


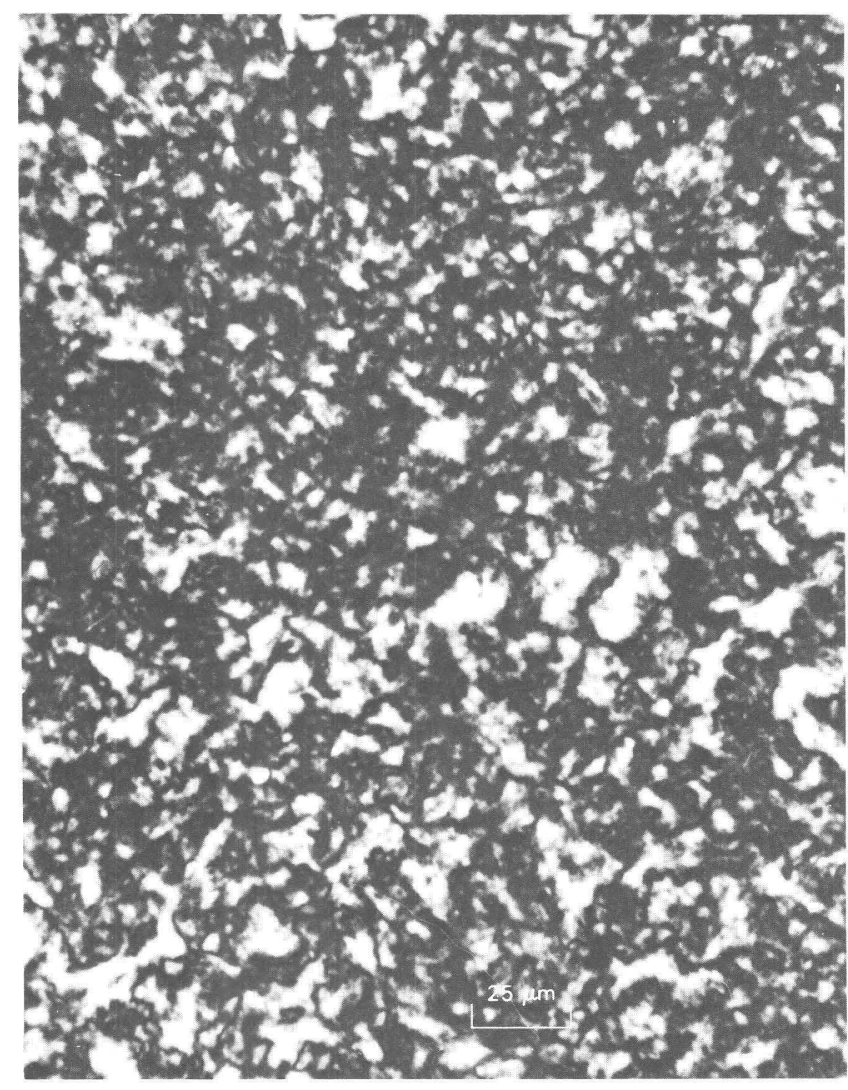

Figure 7. Photomicrograph of interior of chert nodule showing aggregate of interlocking, irregular, fine grains of chalcedony. Nodule is from "Rome beds" (table 1, locality 2). Crossed nicols.

show weak, relatively broad peaks at the following $d$ spacings: $4.40-4.44,3.08-3.11,2.86-2.88$, and $2.53-2.55 \AA$. These peaks have not been identified, but we have also recognized them in chert from the Pleistocene deposits at Lake Magadi, Kenya, and at Lake Natron and Olduvai Gorge, Tanzania. Inasmuch as the cherts consist mainly of silica (table 2), this unidentified phase may be a "new" silica mineral. Two of the above $d$ spacings are identical to those of an unidentified silica(?) phase reported by Hay (1970) from chert nodules at Olduvai Gorge. XRD patterns of the dense chert from deposits older than Oligocene lack peaks of the unidentified phase, and the ratio of intensities of the 101 peak to the 100 peak is close to that of quartz. Thus, with increasing age, the chalcedony and the unidentified phase seem to convert to quartz.

The thin, white rinds on the Magadi-type chert consist mainly of an aggregate of irregular grains of chalcedony that are more finely crystalline than the chalcedony of the dense part of the chert. Most of the chalcedony is less than $2 \mu \mathrm{m}$ in grain size and appears milky in reflected light. Our XRD studies of the rinds show that some contain, in addition to chalcedony, one or more of the following minerals: calcite, clinoptilolite (a common siliceous zeolite), silhydrite $\left(3 \mathrm{SiO}_{2} \cdot \mathrm{H}_{2} \mathrm{O}\right)$, and opal-CT. All these constituents are probably diagenetic. Several specimens of platy

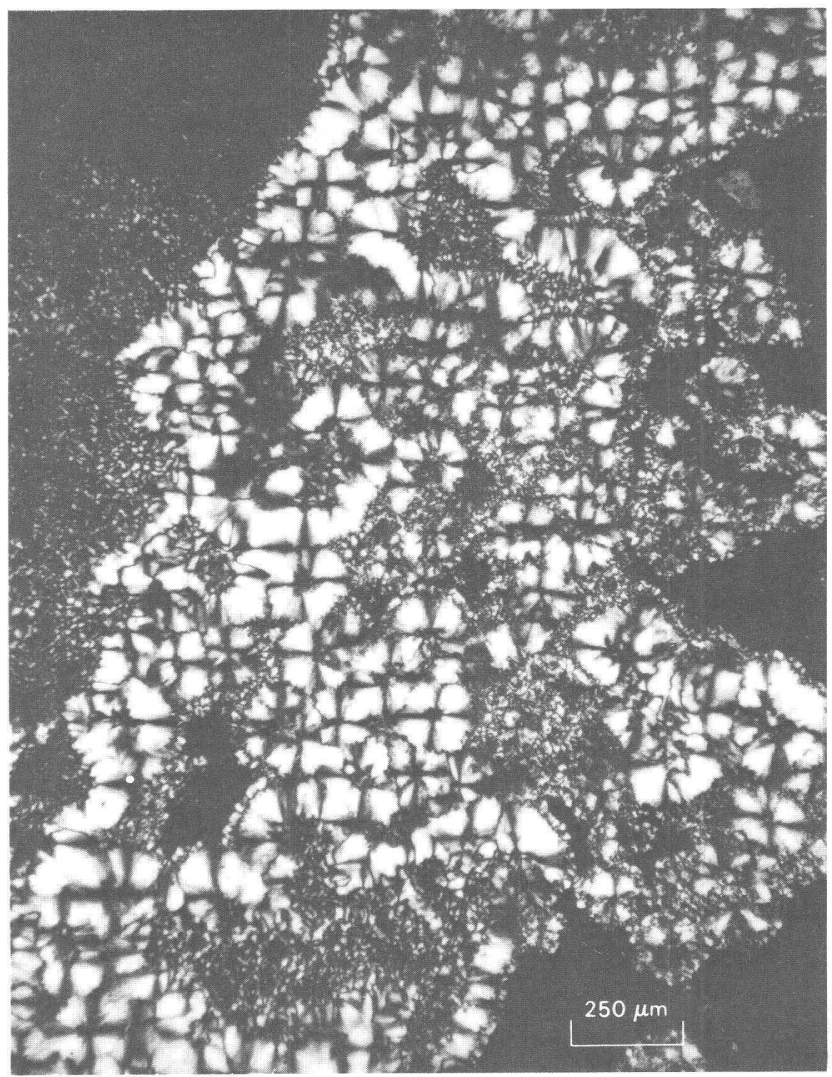

Figure 8. Photomicrograph of interior of chert nodule showing irregular patch of spherulitic chalcedony. Nodule is from upper Tertiary lacustrine deposit at Bismarck Mesa, Arizona (table 1, locality 7). Crossed nicols.

Magadi-type chert from the Pliocene Moonstone Formation (table 1, locality 12) have rinds that consist only of silhydrite. Prior to our recognition of the silhydrite in these rinds, the only known occurrence of this mineral was near Trinity Center, California, where it has formed from an unusual spring deposit of magadiite (Gude and Sheppard, 1972). XRD studies by Hay (1968) of the rinds of nodules of Magadi-type chert from the upper Pleistocene lacustrine deposits at Lake Natron, Tanzania, have shown the presence of one or more of the following minerals: magadiite, kenyaite $\left(\mathrm{NaSi}_{11} \mathrm{O}_{20.5}(\mathrm{OH})_{4} \cdot 3 \mathrm{H}_{2} \mathrm{O}\right)$, quartz, clinoptilolite, and erionite (a zeolite). Also, Eugster (1969) recognized magadiite and kenyaite in the coatings on chert from the upper Pleistocene deposits at Lake Magadi. It is significant that magadiite and other hydrous sodium silicate minerals are absent from cherts in deposits older than late Pleistocene. Apparently, the magadiite and similar minerals have reacted during diagenesis to form silica or aluminosilicate phases.

\section{CHEMICAL COMPOSITION}

Standard chemical analyses were not performed during this study on any of the Magadi-type cherts, but semiquantitative spectrographic analyses of the chert from six 


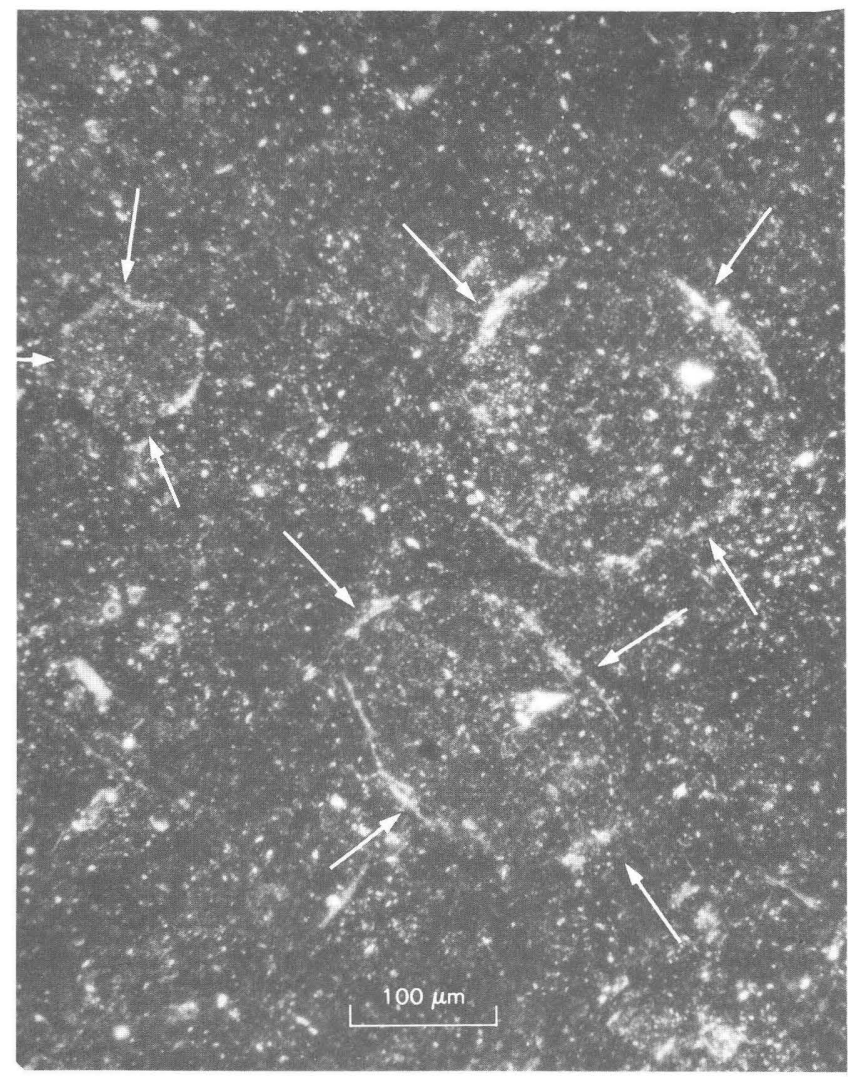

Figure 9. Photomicrograph of interior of chert nodule showing vague, ellipsoidal bodies (arrows) of chalcedony that probably are relicts of original magadiite. Nodule is from "Rome beds" (table 1, locality 2). Crossed nicols.

localities are given in table 2 . These analyses indicate that the cherts contain only minor constituents other than $\mathrm{SiO}_{2}$. The most abundant impurity is calcium which is probably in minor calcite. The cherts also undoubtedly contain a small quantity of water, although no determination or loss on ignition was made. The uranium content of the chert is about $1-46 \mathrm{ppm}$, and these values are not considered anomalous (R. A. Zielinski, U.S. Geological Survey, Box 25046, DFC, MS 424, Denver, Colorado 80225 , oral commun., 1981).

\section{GENESIS OF THE CHERT}

Magadiite $\left(\mathrm{NaSi}_{7} 0_{13}(\mathrm{OH})_{3} \cdot 3 \mathrm{H}_{2} 0\right)$, the presumed precursor for most of the Magadi-type chert, is known to precipitate in alkaline lakes, particularly those of the sodium carbonate-bicarbonate variety (Eugster, 1967; Rooney and others, 1969; Surdam and Eugster, 1976). Jones and others (1967) determined that these brines in closed basins in volcanic terranes of Oregon and Kenya have a pH as high as 11 and $\mathrm{SiO}_{2}$ contents as high as 2,700 ppm. Thus, brines of this type are capable of storing substantial amounts of silica in solution. Dilution of these silicarich brines by freshwater is an obvious mechanism for the

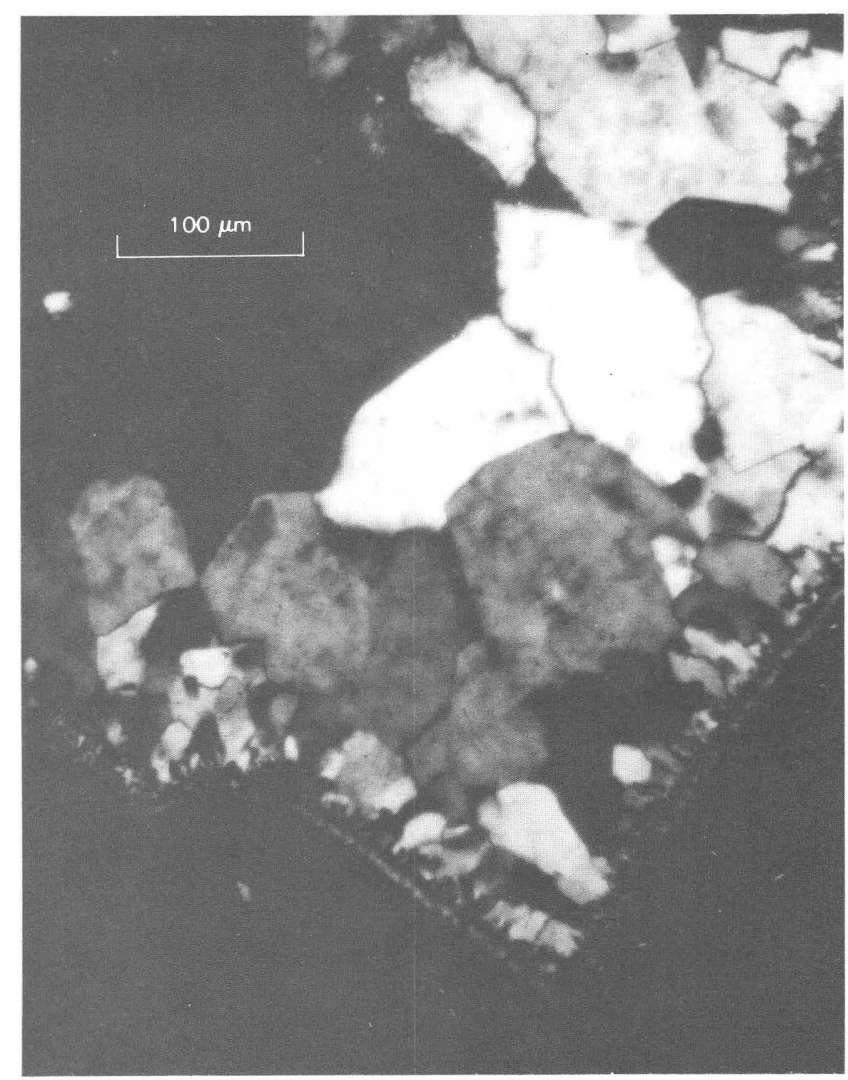

Figure 10. Photomicrograph of interior of chert nodule showing filling of crystal mold. Thin layer of chalcedony lines mold and is followed inwardly by finely crystalline, granular quartz, and then by coarsely crystalline quartz. Nodule is from "Rome beds" (table 1, locality 2). Crossed nicols.

precipitation of magadiite (Eugster, 1967). Freshwater flooding of silica-rich, alkaline lake water may cause a stratified condition. Magadiite could then precipitate at the interface between the freshwater and the saline, alkaline water because of the lowering of the $\mathrm{pH}$. Solubility studies by Bricker (1969) have shown that any mechanism that decreases the $\mathrm{pH}$ could cause the precipitation of magadiite from silica-rich, alkaline brines. Thus, some process other than freshwater dilution could cause magadiite to precipitate. For example, biogenically produced $\mathrm{CO}_{2}$ could reduce the pH of the brine (Eugster, 1969). Hay (1968) also suggested that simple evaporative concentration of the brine could lead to magadiite precipitation.

Most of the Magadi-type cherts, including beds, plates, and nodules, exhibit features indicative of soft-sediment deformation. Because the precursor magadiite is soft and plastic (Eugster, 1967), it is susceptible to deformation under slight loads. Typical features of the chert, such as contorted bedding, protrusions on nodules and plates, and extrusion forms, were probably produced by plastic deformation of the magadiite prior to its conversion to chert.

The conversion of magadiite to chert during diagenesis involves a loss of sodium and water as well as a 


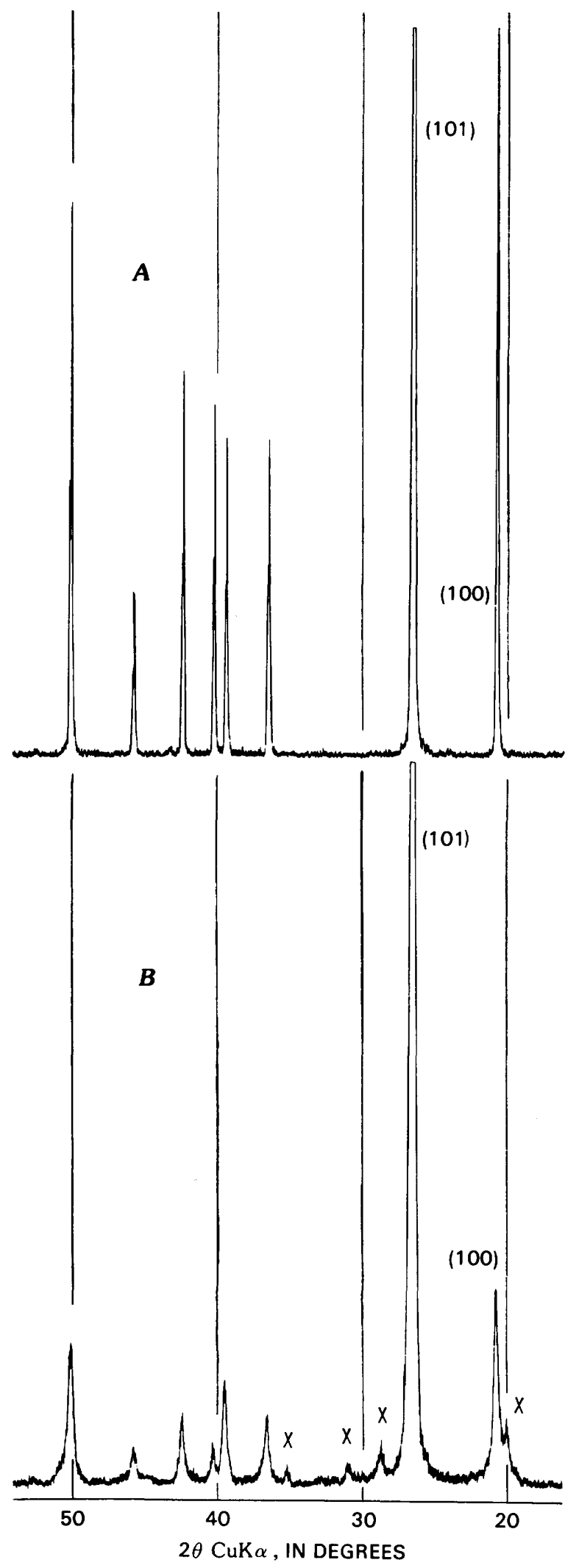

Figure 11. Comparison of X-ray diffractometer traces of well-crystallized quartz $(A)$ with Magadi-type chert from Gila Conglomerate near Buckhorn, New Mexico (B) (table 1 , locality 8 ). Note difference in ratios of intensities decrease in the volume of the solid phase. Two possible equations for the conversion are:

$$
\begin{aligned}
& \mathrm{NaSi}_{7} \mathrm{O}_{13}(\mathrm{OH})_{3} \cdot 3 \mathrm{H}_{2} \mathrm{O}+\mathrm{H}^{+} \rightarrow 7 \mathrm{SiO}_{2}+5 \mathrm{H}_{2} \mathrm{O}+\mathrm{Na}^{+} \\
& \text {magadiite chert } \\
& \underset{\text { magadiite }}{\mathrm{NaSi}_{7} \mathrm{O}_{13}(\mathrm{OH})_{3} \cdot 3 \mathrm{H}_{2} \mathrm{O}} \rightarrow \underset{\text { chert }}{7 \mathrm{SiO}_{2}}+\underset{\mathrm{H}_{2} \mathrm{O}}{4 \mathrm{Na}^{+}}+\mathrm{OH}^{-} .
\end{aligned}
$$

and

The chemical parameters of the interstitial fluids that may control the conversion of magadiite to chert are suggested by these two equations and include (1) a decrease of the $\mathrm{pH},(2)$ a decrease in the activity of sodium, (3) a decrease in the activity of silica, and (4) a decrease in the activity of water-caused perhaps by an increase in the salinity of the interstitial fluids. Eugster (1969) favored a decrease of the $\mathrm{pH}$ and the activity of sodium to account for the conversion at Lake Magadi. These decreases could be accomplished simultaneously by leaching of the magadiite by percolating meteoric water. Hay (1970), however, attributed the conversion of magadiite to chert at Lake Magadi and Olduvai Gorge to a decrease in the activity of silica, possibly caused by the sorption or reaction of silica with clay minerals. Subsequent oxygen isotope studies on east African cherts by O'Neil and Hay (1973) suggested that the conversion took place in fluids of widely varying salinities and chemical activity $\left(a_{\mathrm{Na}^{+}}: a_{\mathrm{H}^{+}}\right)$ratios. Inasmuch as the conversion of magadiite to chert is a dehydration reaction, relatively high temperatures at or near the land surface would also favor the conversion.

The actual diagenetic process for the conversion is still poorly understood, and our studies of the Magaditype chert in lacustrine deposits of the United States have not shed additional light on which parameter or combination of parameters was the driving force for the conversion of magadiite or other hydrous sodium silicate minerals to chert. Eugster (1969) suggested that kenyaite or noncrystalline silica may be an intermediate product in the conversion, but we found neither field nor petrographic evidence to confirm this intermediate step. We, therefore, assume that the chert formed directly from magadiite by a solution-precipitation mechanism. The conversion apparently took place in a relatively short time. The minimum time necessary for the conversion in the east African lacustrine deposits was probably a few hundred to a few thousand years (Hay, 1968; Eugster, 1969). As described, the presence of chert chips in an intraformational channel sandstone in the Moonstone Formation of Wyoming indicates that the conversion from magadiite to chert was rapid. Also, the fact that magadiite has not been reported from lacustrine deposits older than late Pleistocene is evidence for relatively rapid conversion.

of 101 peak to 100 peak. Peaks of unidentified phase in Magaditype chert are indicated by $\mathrm{X}^{\prime} \mathrm{s}$. 
Table 2. Semiquantitative spectrographic analyses of Magadi-type chert

[Analyst: N. M. Conklin. Results are to be identified with geometric brackets whose boundaries are 1.2, $0.83,0.56,0.38,0.26,0.18,0.12$, and so forth but are reported arbitrarily as midpoints of these brackets, $1.0,0.7,0.5,0.3,0.2,0.15,0.1$, and so forth. The precision of a reported value is approximately plus or minus one bracket at 68-percent confidence, or two brackets at 95-percent confidence. G, greater than 10 percent; $\mathrm{L}$, detected but below limit of determination; $\mathrm{N}$, not detected]

\begin{tabular}{|c|c|c|c|c|c|c|}
\hline $\begin{array}{l}\text { Lab. No. } \cdots \\
\text { Fieid No. } \\
\text { Locality No. }\end{array}$ & $\begin{array}{c}\text { D } 235863 \\
\text { FAM- } 78 \\
2\end{array}$ & $\begin{array}{l}\text { D235867 } \\
\text { LHO-10-15 } \\
3\end{array}$ & $\begin{array}{c}D 235866 \\
E 5-12 J \\
5\end{array}$ & $\begin{array}{l}\text { D235868 } \\
\text { BMK-3 } \\
7\end{array}$ & $\begin{array}{c}\text { D235864 } \\
\text { BNM-13B } \\
8\end{array}$ & $\begin{array}{c}\text { D235870 } \\
\text { M00-2A } \\
12\end{array}$ \\
\hline \multicolumn{7}{|c|}{ Weight percent } \\
\hline $\begin{array}{l}\mathrm{Si} \\
\mathrm{Al} \\
\mathrm{Fe} \\
\mathrm{Mg}\end{array}$ & $\begin{array}{l}\mathrm{G} \\
0.002 \\
\mathrm{~L}^{.07}\end{array}$ & $\begin{array}{l}G \\
0.07 \\
.03 \\
.003\end{array}$ & $\begin{array}{l}G \\
0.07 \\
.07 \\
.003\end{array}$ & $\begin{array}{l}f_{1} \\
0.07 \\
.07 \\
.03\end{array}$ & $\begin{array}{l}G \\
0.05 \\
.07 \\
.001\end{array}$ & $\begin{array}{l}G \\
0.03 \\
.07 \\
.007\end{array}$ \\
\hline $\begin{array}{l}\mathrm{Ca} \\
\mathrm{Na} \\
\mathrm{K} \\
\mathrm{Ti} \\
\mathrm{P}\end{array}$ & $\stackrel{N}{N}_{N^{.03}}^{.0003}$ & $\mathrm{~N}_{\mathrm{N}}^{.07}$ & $\mathrm{~N}^{.07}$ & $\mathrm{~N}_{\mathrm{N}}^{.07}$ & $N_{N}^{.07}$ & $\mathrm{~N}^{.07}$ \\
\hline \multicolumn{7}{|c|}{ Parts per million } \\
\hline $\begin{array}{l}\mathrm{Ag} \\
\mathrm{B} \\
\mathrm{Ba} \\
\mathrm{Cr} \\
\mathrm{Cu} \\
\mathrm{Mn}\end{array}$ & $\begin{array}{c}0.5 \\
15 \\
30 \\
N \\
15 \\
7\end{array}$ & $\begin{array}{r}N \\
70 \\
70 \\
N \\
70 \\
10\end{array}$ & $\begin{array}{c}N \\
100 \\
30 \\
1.5 \\
30 \\
15\end{array}$ & $\begin{array}{c}0.5 \\
150 \\
30 \\
7 \\
30 \\
15\end{array}$ & $\begin{array}{r}N \\
300 \\
15 \\
N \\
20 \\
10\end{array}$ & $\begin{array}{c}0.5 \\
30 \\
30 \\
1.5 \\
30 \\
7\end{array}$ \\
\hline $\begin{array}{l}S r \\
u^{1} \\
y \\
Y b \\
Z r\end{array}$ & $\begin{array}{l}\mathrm{N} \\
1.35 \\
10 \\
L \\
10\end{array}$ & $\begin{array}{l}N \\
5.76 \\
N \\
N \\
L\end{array}$ & $\begin{array}{l}7 \\
4.16 \\
N \\
N \\
10\end{array}$ & $\begin{array}{c}150 \\
14.3 \\
N \\
N \\
L\end{array}$ & $\begin{array}{c}N \\
17.9 \\
N \\
N \\
15\end{array}$ & $\begin{array}{c}15 \\
46.4 \\
L \\
L \\
15\end{array}$ \\
\hline
\end{tabular}

${ }^{1}$ Uranium determined by delayed neutron activation analysis by H. T. Millard, Jr., F. Luman, and B. Keaten.

Magadi-type chert inherited several features from the original magadiite. These features include (1) the lobate form and protrusions of the nodular and platy chert that were produced by plastic deformation of the magadiite prior to conversion to chert, (2) the relicts of magadiite spherulites, (3) the molds of saline minerals, and (4) the rare rinds containing silhydrite that so far has been described as forming only from magadiite (Gude and Sheppard, 1972). The characteristic surface reticulation of most Magadi-type chert is apparently due to the volume reduction during the conversion of magadiite to chert. Except for the silhydrite, these features are identical with those of chert known to have formed from magadiite, and they seem to be unique to chert of this derivation (Surdam and others, 1972).

\section{SIGNIFICANCE OF MAGADI-TYPE CHERT}

The occurrence of Magadi-type chert in sedimentary rocks is indicative of an alkaline, lacustrine depositional environment. In order to store enough silica in solution for the precipitation of magadiite, the $\mathrm{pH}$ of the lake water probably has to be at least 9.5 (Surdam and others, 1972). All the occurrences of chert, magadiite, and kenyaite in the Pleistocene deposits of east Africa studied by Hay (1968) were attributed to strata of saline, alkaline lakes that were rich in dissolved sodium carbonate- bicarbonate. Theoretical considerations led Drever (1974) to suggest that magadiite could precipitate from sea water in the absence of silica-secreting organisms; however, magadiite has not been recognized in marine sediments.

Inasmuch as the Magadi-type chert appears to be indicative of a saline, alkaline depositional environment, certain other minerals, which are common in such envronments and have economic potential, may be expected to occur in the same strata as the chert. These minerals include evaporite minerals, such as trona, nahcolite, and borate minerals, zeolites, potassium feldspar, fluorite, and, possibly, lithium-bearing clay minerals. Some, such as the evaporite minerals, are primary precipitates from the lake brine, whereas others, such as the zeolites and potassium feldspar, are diagenetic and generally result from the reaction of volcanic glass with the interstitial brine. Those zeolites that have been identified in strata containing Magadi-type chert are analcime, chabazite, clinoptilolite, erionite, mordenite, and phillipsite. Table 3 shows the presence or absence of these potentially economic minerals at nearly half of the Magaditype chert localities listed in table 1 . Because the chert is easily recognized by its distinctive appearance and because the chert resists weathering, Magadi-type chert is a valuable prospecting guide for locating these minerals in lacustrine deposits. It is also an important indicator of past geologic environments of lacustrine sedimentary formations. 
Table 3. Minerals associated with strata containing Magaditype chert

[X, present; 0 , looked for but not found; leaders (---), not looked for]

\begin{tabular}{|c|c|c|c|c|c|}
\hline $\begin{array}{l}\text { Locality } \\
\quad \text { No. } \\
\text { (table 1) }\end{array}$ & $\begin{array}{c}\text { Saline minerals } \\
\text { or molds of } \\
\text { saline minerals }\end{array}$ & Zeolites & $\begin{array}{l}\text { Potassium } \\
\text { feldspar }\end{array}$ & Fluorite & $\begin{array}{l}\text { Lithium- } \\
\text { bearing } \\
\text { clay }\end{array}$ \\
\hline 1 & $x$ & $x$ & $x$ & 0 & --- \\
\hline 2 & $x$ & $x$ & $x$ & $x$ & --- \\
\hline 3 & 0 & $x$ & $x$ & 0 & -.. \\
\hline 5 & $x$ & $x$ & $x$ & $x$ & --- \\
\hline 6 & $x$ & $x$ & 0 & 0 & $x$ \\
\hline 7 & 0 & $x$ & $x$ & 0 & $x$ \\
\hline 8 & 0 & $x$ & $x$ & $x$ & $x$ \\
\hline 10 & $x$ & $x$ & $x$ & $x$ & -- \\
\hline 12 & $x$ & $x$ & 0 & 0 &.- \\
\hline
\end{tabular}

\section{REFERENCES CITED}

Baker, B. H., 1958, Geology of the Magadi area: Geological Survey of Kenya Report 42, 81 p.

Bricker, O. P., 1969, Stability constants and Gibbs free energies of formation of magadiite and kenyaite: American Mineralogist, v. 54, p. 1026-1033.

Drever, J. I., 1974, Geochemical model for the origin of Precambrian banded iron formations: Geological Society of America Bulletin, v. 85, p. 1099-1106.

Eugster, H. P., 1967, Hydrous sodium silicates from Lake Magadi, Kenya: precursors of bedded chert: Science, v. 157 , p. $1177-1180$.

1969, Inorganic bedded cherts from the Magadi area, Kenya: Contributions to Mineralogy and Petrology, v. 22, p. 1-31.

Eugster, H. P., and Surdam, R. C., 1971, Bedded cherts in the Green River Formation: Geological Society of America Abstracts with Programs, v. 3, no. 7, p. 559-560.

Gude, A. J., 3d, and Sheppard, R. A., 1972, Silhydrite, $3 \mathrm{SiO}_{2} \cdot \mathrm{H}_{2} \mathrm{O}$, a new mineral from Trinity County, California: American Mineralogist, v. 57, p. 1053-1065.

Hay, R. L., 1968, Chert and its sodium-silicate precursors in sodium-carbonate lakes of east Africa: Contributions to Mineralogy and Petrology, v. 17, p. 255-274.
1970, Silicate reactions in three lithofacies of a semi-arid basin, Olduvai Gorge, Tanzania: Mineralogical Society of America Special Paper 3, p. 237-255.

Houser, B. B., 1982, Chert derived from magadiite in the middle Eocene McBean Formation, South Carolina: Geological Society of America Abstracts with Programs, v. 14, nos. 1 and 2 , p. 27.

Jones, B. F., Rettig, S. L., and Eugster, H. P., 1967, Silica in alkaline br..ses: Science, v. 158, p. 1310-1314.

Mariner, R. H., 1971, Experimental evaluation of authigenic mineral reactions in the Pliocene Moonstone Formation: Laramie, Wyoming, University of Wyoming, Ph.D. dissertation, 133 p.

O'Neil, J. R., and Hay, R. L., $1973,{ }^{18} \mathrm{O} /{ }^{16} \mathrm{O}$ ratios in cherts associated with the saline lake deposits of East Africa: Earth and Planetary Science Letters, v. 19, p. 257-266.

Pettijohn, F. J., 1975, Sedimentary rocks (3d ed.): New York, Harper and Row, 628 p.

Rooney, T. P., Jones, B. F., and Neal, J. T., 1969, Magadiite from Alkali Lake, Oregon: American Mineralogist, v. 54, p. 1034-1043.

Santos, E. S., Hall, R. B., and Weisner, R. C., 1975, Mineral resources of the San Pedro Parks Wilderness and vicinity, Rio Arriba and Sandoval Counties, New Mexico: U.S. Geological Survey Bulletin 1385-C, 29 p.

Sheppard, R. A., and Gude, A. J., 3rd, 1974, Chert derived from magadiite in a lacustrine deposit near Rome, Malheur County, Oregon: U.S. Geological Survey Journal of Research, v. 2 , no. 5 , p. $625-630$.

1980, Diagenetic fluorite in the Eastgate zeolite deposit, Churchill County, Nevada: U.S. Geological Survey Open-File Report 80-506, 8 p.

Surdam, R. C., and Eugster, H. P., 1976, Mineral reactions in the sedimentary deposits of the Lake Magadi region, Kenya: Geological Society of America Bulletin, v. 87, p. 1739-1752.

Surdam, R. C., Eugster, H. P., and Mariner, R. H., 1972, Magaditype chert in Jurassic and Eocene to Pleistocene rocks, Wyoming: Geological Society of America Bulletin, v. 83, p. 2261-2266.

White, A. H., and Youngs, B. C., 1980, Cambrian alkali playalacustrine sequence in the northeastern Officer basin, South Australia: Journal of Sedimentary Petrology, v. 50, p. 1279-1286. 


\title{
Salt-Induced Diagenesis of Argillaceous Sediments \\ By CHARLES W. HOLMES, U.S. Geological Survey, MS 972, Denver Federal Center, Denver, Colorado 80225
}

\section{CONTENTS}

\author{
Abstract 349 \\ Introduction 349 \\ Geologic background 349 \\ Methods 351 \\ Core and sample selection $\mathbf{3 5 1}$ \\ Water chemistry 351 \\ Solid-phase chemistry $\mathbf{3 5 1}$ \\ Results 353 \\ Pore-water chemistry $\mathbf{3 5 3}$ \\ Mineralogy 355 \\ Discussion and conclusions $\mathbf{3 5 7}$ \\ Summary 361 \\ References cited 361
}

\section{FIGURES}

1-3. Maps showing:

1. Location of cores used in study 349

2. Rates of sedimentation in northern Gulf of Mexico $\mathbf{3 5 0}$

3. Percentage of foraminifera in sand fraction of surficial sediments in northern Gulf of Mexico $\mathbf{3 5 0}$

4. Plot of carbon percentage of surficial sediments and oxygen content of waters versus depth in northern Gulf of Mexico 351

5. Contour map of top of salt structure in northwestern Gulf of Mexico showing relationship of boreholes to salt mass $\mathbf{3 5 2}$

6. Seismic profiles over salt structure penetrated by borehole $66 \mathbf{3 5 2}$

7. Seismic profiles over salt structure on lower continental slope showing positions of boreholes 112 and 123353

8-23. Plots:

8. Grain-size distribution of sediments from core 114 versus depth $\mathbf{3 5 3}$

9. Chlorinity of extracted pore water from core 114 versus depth 354

10. Chlorinity of water-leached extract from dry sample of core 114 versus depth 354

11. Chlorinity of extracted pore water from core 66 versus depth 354

12. Chlorinity of water-leached extract from dry sample from core 123 versus depth 355

13. $\mathrm{Na} / \mathrm{Cl}$ ratio of water-leached extract from core 114 versus depth 355

14. $\mathrm{K} / \mathrm{Cl}$ ratio of water-leached extract from core 114 versus depth 356

15. Percentage of carbonate of sediments from core 114 versus depth 356

16. $\mathrm{Ca} / \mathrm{Mg}$ ratio of carbonate fraction of sediments from core 114 versus depth 356 
8-23. Plots-Continued.

17. Total organic carbon of dry sample from core 114 versus depth 357

18. $\delta^{13} \mathrm{C}$ in carbonate fraction versus carbonate content and $\delta^{13} \mathrm{C}$ of organic fraction versus total organic content of sediments from core $114 \quad 357$

19. "Authigenic" iron and manganese of sediments from core 114 versus depth 358

20. Total nitric acid-leached zinc of sediments from core 114 versus depth 358

21. Ratio of total acid-leached zinc and "authigenic" zinc of sediments from core 114 versus depth 359

22. X-ray diffraction patterns of $<2-\mu \mathrm{m}$ size fractions of sediments from core 114 versus depth 359

23. X-ray diffraction patterns of $<2-\mu \mathrm{m}$ size fractions of sediments from core 66 versus depth 359

24. Diagram showing metal distribution in "typical" nodule in cores immediately above salt cap rock 360 


\section{Abstract}

Geochemical data from ten 300-m boreholes on the outer continental shelf and slope in the northwestern Gulf of Mexico document diagenetic changes caused by processes activated by salt intrusions. Two of four boreholes on the shelf and a borehole on the slope were drilled in sediments of Quaternary age that overlie salt structures. The other boreholes were drilled on the flank of salt structures, but also penetrated sediments of Quaternary age. In those sediments overlying salt, the abundance of expandable clay minerals (smectite) compared with that of nonexpandable clay minerals (illite) decreased with depth. Correspondingly, the total organic carbon and carbonate content and the ${ }^{13} \mathrm{C}$ content of the organic material also decreased with depth. Clay transformations, caused by the heat from the salt, released a significant amount of intercellular water (200 liters per cubic meter). This water dissolved the leading edge of the salt stock, producing a brine and creating a residual of anhydrite between the sediments and the salt. The constituents of the brine reacted with the sediment above salt, causing further clay-mineral transformations. The sulfate in the brine reacted with the organic material, producing sulfides, carbonate species, and additional water. The additional water dissolved more salt and accelerated the diagenetic processes. Where the anhydrite cap intruded a layer of abundant organic material, such as a hydrocarbon accumulation, the diagenetic processes produced the limestone-gypsumanhydrite sequence that is common in the cap rock of many salt structures in the Gulf of Mexico.

\section{INTRODUCTION}

Sixty-eight cores were obtained by the Shell Development Corporation on the upper slope and shelf edge of the northern Gulf of Mexico. Ten of these cores were selected for geochemical analysis. The selection was made to have the broadest representative sample of the upper slope and shelf edge. From these 10 cores, 1,500 samples were analyzed for 30 elements by the semiquantative spectrographic method of the U.S. Geological Survey (Grimes and Marranzino, 1968). The most notable result was the discovery of anomalous concentrations of $\mathrm{Zn}, \mathrm{Pb}$, and $\mathrm{Mn}$ in the sediments above salt structures on the upper continental slope. The sediments above salt on the lower slope and those immediately adjacent to salt structures, however, had concentrations of these and other metals in the normal range for marine sediments. To define the cause of the anomalies, six cores were selected for further chemical and mineralogical analyses: three boreholes penetrated salt (two on the upper slope, and one on the lower slope), and three were on the flanks of salt intrusions (fig. 1).

\section{GEOLOGIC BACKGROUND}

The continental slope of the northern Gulf of Mexico is an area of moderate to high sedimentation rates (Holmes and Booth, 1980) (fig. 2). This sedimentologic pattern has prevailed throughout the latter part of the Quaternary Period although glacial episodes have caused local increases. The sediments are dominated by contributions from the Mississippi River and reflect the texture and mineralogy of its drainage basin. Much organic material is also incorporated within these deposits. Part of this material was derived from the watershed of the river and is dominated by plant material; however, a significant fraction was derived from the water column and has a high proteinaceous content. An index of the marine component of the organic material is the foraminiferal content of the sand-size fraction of the sediments

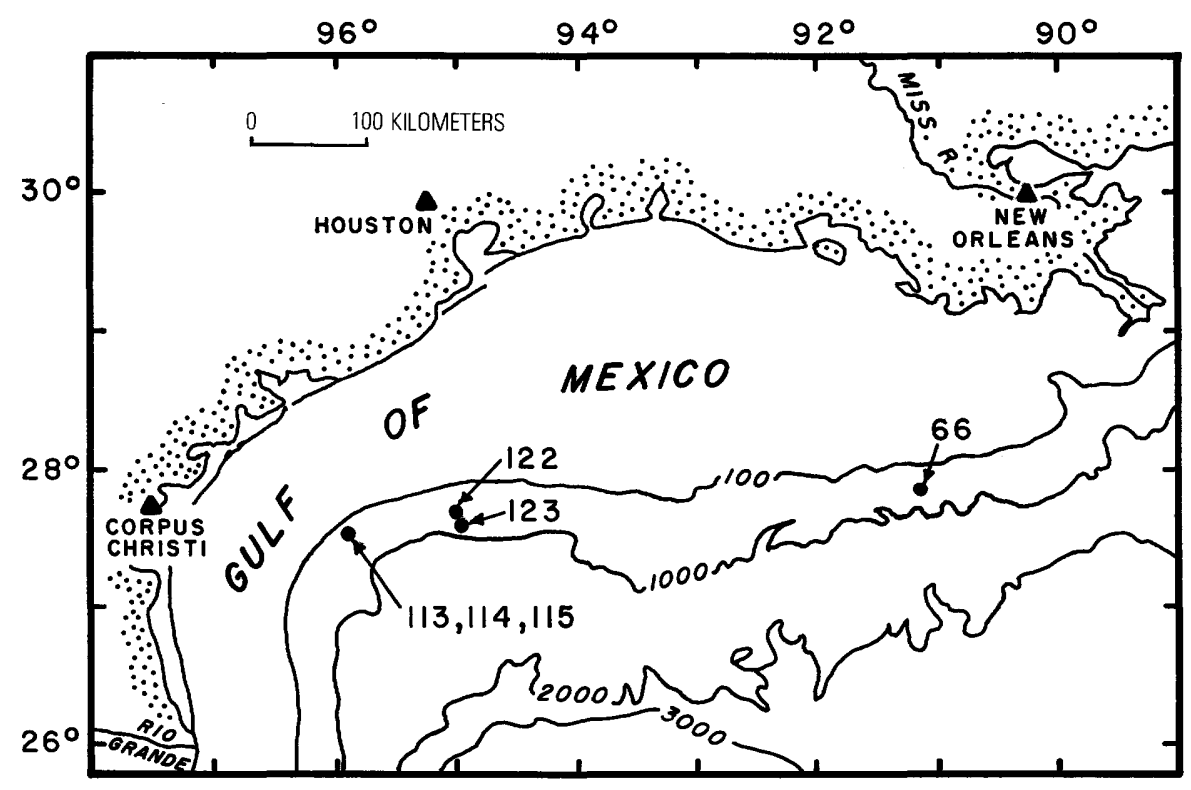

Figure 1. Location (solid circles) of cores used in study. Depth contours are in meters. 
(fig. 3), which is greater at the shelf edge and on the upper slope than on the central shelf. The oxygen minimum within the water column coincides with the sediment with the highest total organic content on the upper slope (fig. 4). The zone of reduced oxygen varies with sea level, oceanic circulation, and climatic changes, but the presence of the unoxidized organic matter in the upper-slope sediments suggests that the oxygen-poor zone has been about in the same position with respect to sea level throughout much of the Neogene Period.
A thick salt layer exists under the thick wedge of clastic material in the northern Gulf of Mexico. Due to isostatic disequilibrium and differential loading, the salt has been squeezed into the overlying sediments. The piercement activity has progressed basinward with time; the youngest activity is presently along the outer part of the slope. Gussow (1968) argued that the initiation of salt diapirism was triggered by heat after a critical loading factor was reached. Based on the internal mineralogical composition and the structure of the salt bodies, he

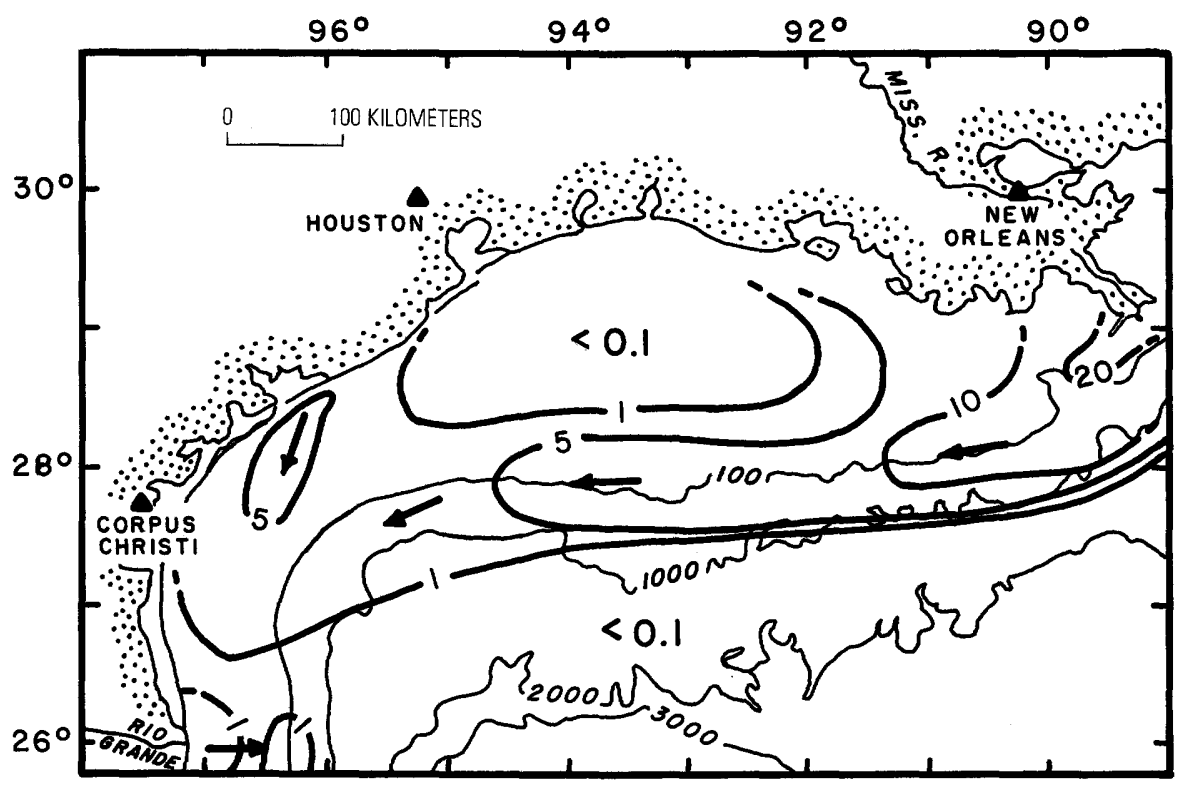

Figure 2. Rates of sedimentation (heavy contours) in the northern Gulf of Mexico. Rates were estimated by the ${ }^{210} \mathrm{~Pb}$ method, and are given in millimeters per year. Depths (light contours) are in meters. Arrows indicate direction of sediment transport. Data are from Holmes and Booth (1980).

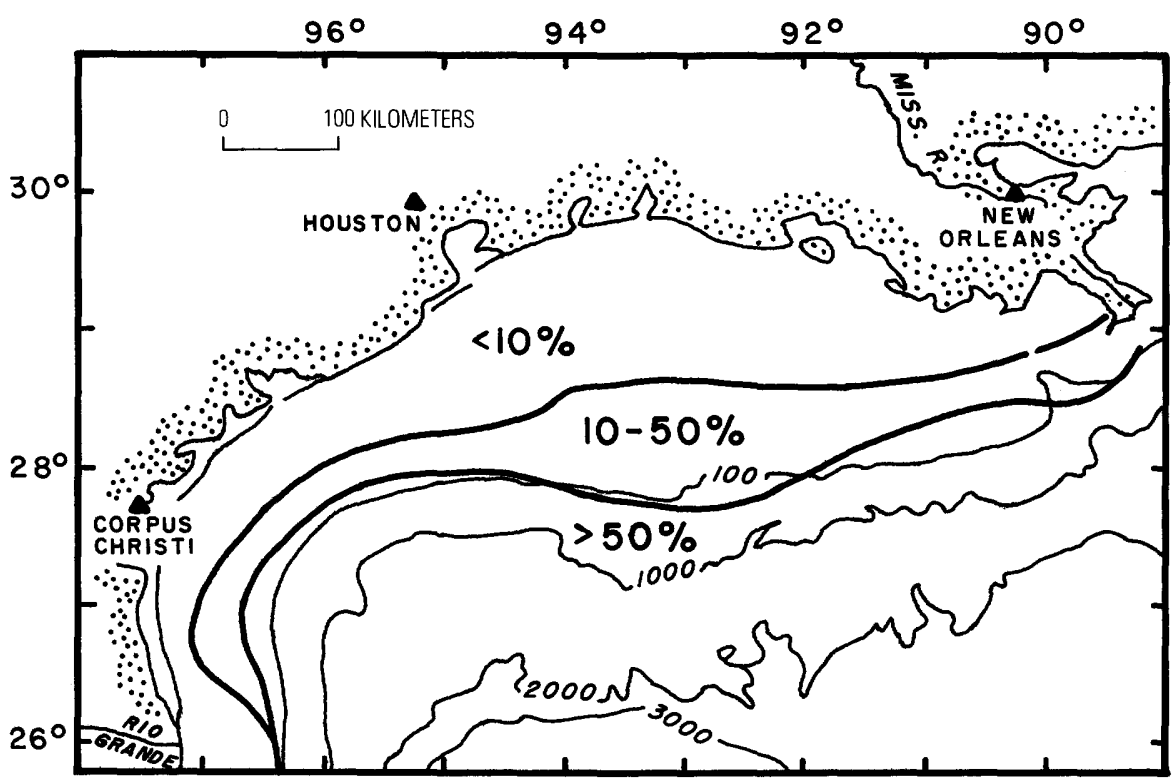

Figure 3. Percentage of foraminifera in sand fraction of surficial sediments in northern Gulf of Mexico. Depth contours are in meters. 

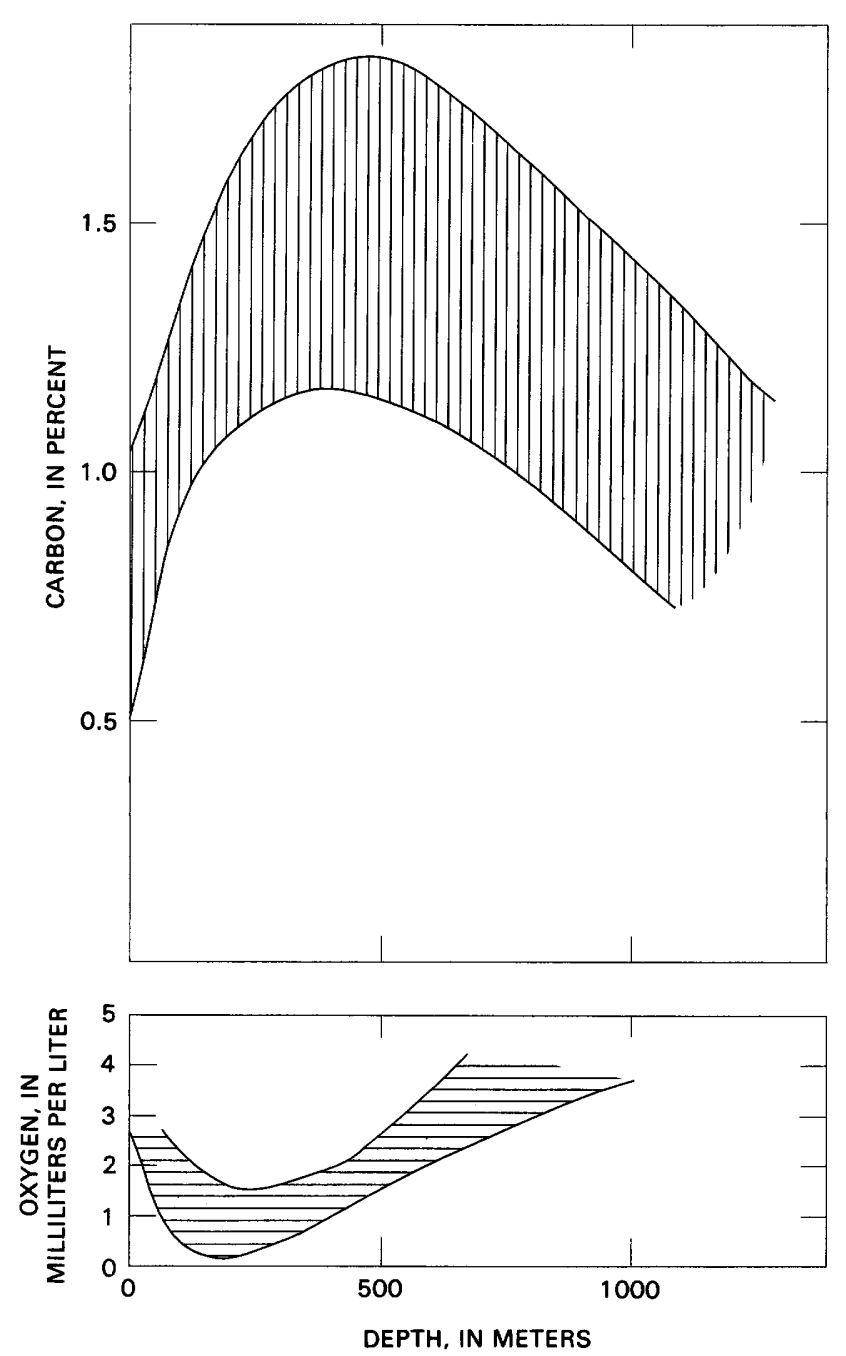

Figure 4. Carbon percentage of surficial sediments and oxygen content of waters versus depth in northern Gulf of Mexico. Carbon data are based on 150 analyses of slope and outershelf cores. Oxygen profiles were made in summer. Oxygen minimum may be higher during this sampling period than in late winter and spring when floods in Mississippi River watershed increase productivity levels in the northern Gulf of Mexico (Holmes and Booth, 1980). Thus, maximum carbon percentage and oxygen minimum may be in better agreement during periods of maximum sediment influx.

suggested that the emplacement took place rapidly at a temperature that exceeded $300^{\circ} \mathrm{C}$. This argument is strengthened by the presence of high thermal gradients associated with salt structures. Such a thermal environment must significantly affect the diagenetic processes in the sediments surrounding the intrusion.

\section{METHODS}

\section{Core and sample selection}

Of the six cores selected for detailed analyses, the three associated with a salt structure in the northwestern
Gulf of Mexico received the most attention (fig. 5) because of (1) their high lead and zinc contents, (2) the availability of good samples of cap rock, (3) the continuity of cores, and (4) the availability of pore-water data from the core on the crest of the dome. The borehole drilled on the crest of the dome, site 114 (water depth $=250 \mathrm{~m}$ ), penetrated a granular anhydrite cap (Lehner, 1969). Borehole 113 was drilled on the updip flank and borehole 115 on the downdip flank of the same structure (fig. 5). All cores had exceptionally high recoveries of 77,88 , and 70 percent, respectively. In the central Gulf, site 66 (water depth $=198 \mathrm{~m}$ ) was examined because it also penetrated salt (fig. 6), and although only a few samples were available for analysis, pore-water data were available (Manheim and Bischoff, 1969). The two remaining borings were made on a structure lower on the slope; site 123 was made on the crest of the structure, and site 122 was on the updip flank (fig. 7). These sites were selected because the sediments had been intruded by salt in the recent geologic past (Gussow, 1968; Lehner, 1969).

\section{Water chemistry}

As mentioned previously, pore-water data collected immediately after the cores were taken were available for cores 114 and 66 (Manheim and Bishoff, 1969). An attempt was made to obtain complementary water chemistry on 600 samples from these cores by measuring the amount of water-soluble $\mathrm{Ca}^{2+}, \mathrm{Mg}^{2+}, \mathrm{Na}^{+}, \mathrm{K}^{+}$, and $\mathrm{Cl}^{-}$. These analyses were made by leaching a $20-\mathrm{g}$ (gram) sample of finely powdered sediments with $500 \mathrm{~mL}$ (milliliters) of deionized water. The cations were determined by atomic absorption methods, whereas chlorine was determined by the standard Mohr titration technique. Although the water-leach procedure is subject to complete dissolution or partial dissolution of material not in the original pore water, comparison of ratios of ions in the water-leach extract and the original pore water (Manheim and Bischoff, 1969) suggests that this effect was not particularly significant for sodium and potassium.

\section{Solid-phase chemistry}

To assess the geochemical variations in the solid phases, the metal content of the "authigenic" phases (that is, ferromanganese coatings, carbonates, and adsorbed phases), the metal content of all nonsilicate phases, and the mineralogical composition of the clay fraction were determined. Atomic absorption methods were used to analyze 550 samples for "authigenic" $\mathrm{Fe}, \mathrm{Mn}, \mathrm{Mg}, \mathrm{Ca}$, $\mathrm{Zn}$, and $\mathrm{Pb}$. The samples were dried, ground in an agate mortar, and shaken for approximately 12 hours in a 50$\mathrm{mL}$ solution of $1 M$ hydroxylamine-hydrochloric and 


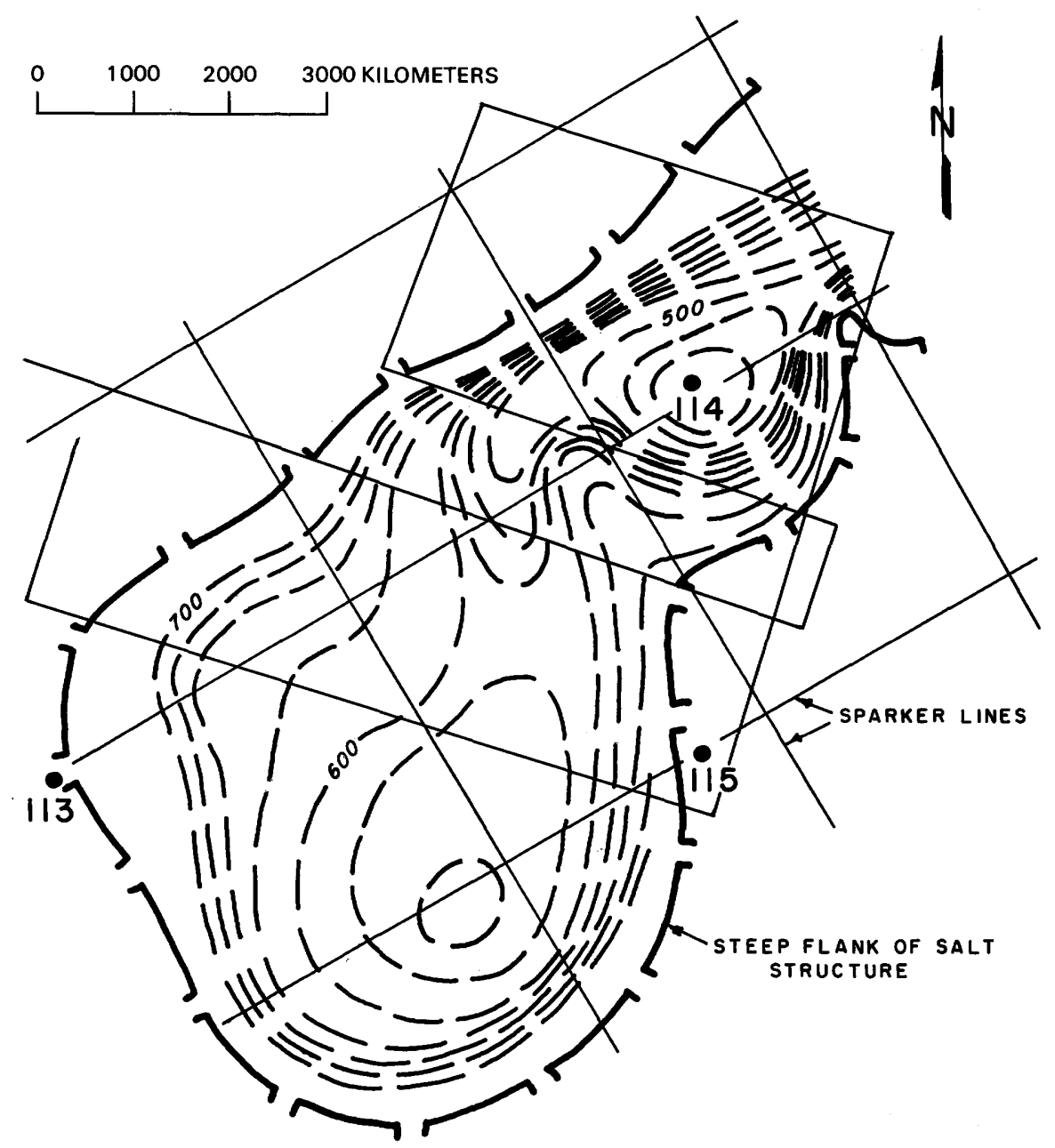

Figure 5. Contour (dashed lines) map of top of salt structure in northwestern Gulf of Mexico showing relationship of boreholes 113, 114, and 115 (solid dots; fig. 1) to salt mass. Data from Lehner (1969). Sparker lines are track lines of geophysical survey ship. Contour interval, 25 meters.

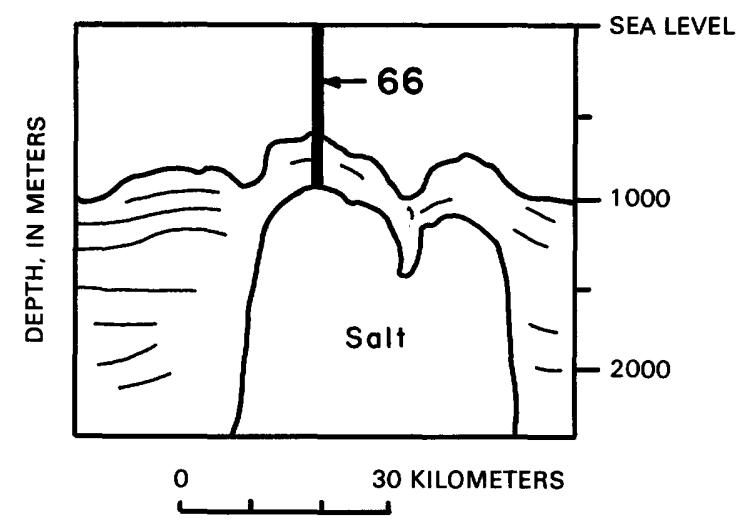

Figure 6. Seismic profile over salt structure penetrated by borehole 66 (see fig. 1). Lines represent major reflectors.

25 percent $(\mathrm{V} / \mathrm{V})$ acetic acid. This procedure dissolves non-silicate ferromanganese and carbonate minerals and extracts the adsorbed trace elements, but it does not affect detrital silicates or sulfides (Chester and Hughes, 1967). Replicate analyses of 10 percent of the samples established that the error of this method was less than 10 percent.

Atomic absorption was also used to measure these same elements released from the solid phases by hot, concentrated nitric acid. Here, a 5-g, finely ground sample was shaken in a heating block for 4 hours. This process dissolves the same phases as the preceeding process as well as sulfides, sulfates, and some detrital silicates (Holmes 1977a). Clay mineralogy was determined by the method outlined by Carroll (1970). Some samples were also analyzed by J. C. Hathaway (U.S. Geological Survey, Woods Hole, Mass.). Selected samples were also analyzed for the amount of organic carbon and carbonate; the sediment texture was determined by procedures outlined by Griffins (1967). The carbon isotope analyses were performed by B. B. Bernard, Texas A\&M University, College Station, Texas. 


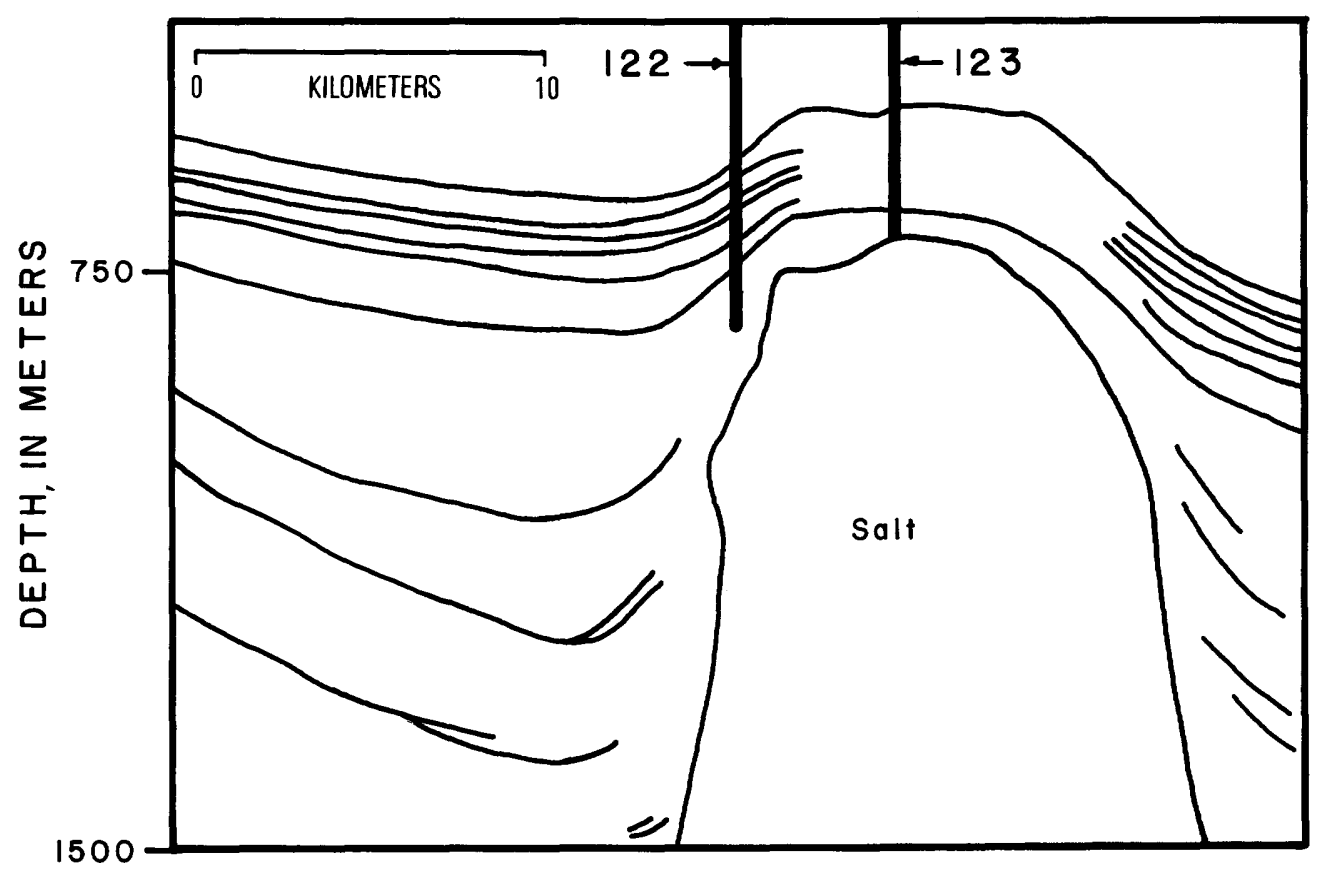

Figure 7. Seismic profile over salt structure on lower continental slope showing positions of boreholes 122 and 123 (see fig. 1). Lines represent major reflectors.

\section{RESULTS}

The slope sediments, as determined by textural analyses, are silty clays (fig. 8). Throughout the sediment column the coarse fraction (greater than $62 \mathrm{~mm}$ ) contained both foraminifera and detrital material. For the most part, foraminifera dominated except for those layers deposited as a single event (turbidites?). At the present time, a rich pteropod ooze is being deposited on top of the structure from which core 114 was taken (Holmes, 1977a) and accounts for the greater amount of "sand" at the surface of the core.

\section{Pore-water chemistry}

Pore water extracted from the sediments overlying the salt structures increased in salinity linearly with depth. In core 114 (fig. 9), the salinity of the pore water in the sediments immediately above the cap rock approached halite saturation. Chloride values from the water-leach experiments (fig. 10) confirm the linear trend and further support the concept of linear solid-state diffusion of the chloride component suggested by Manheim and Bishoff (1969). In core 66, a similar trend was found but the chloride concentrations were much lower (fig. 11). The pore water at this site, however, contained more bromine and potassium than at site 114, suggesting an origin from a salt mass containing latestage evaporites. In contrast to these two sites, the chloride values from site 123 showed no clear trend

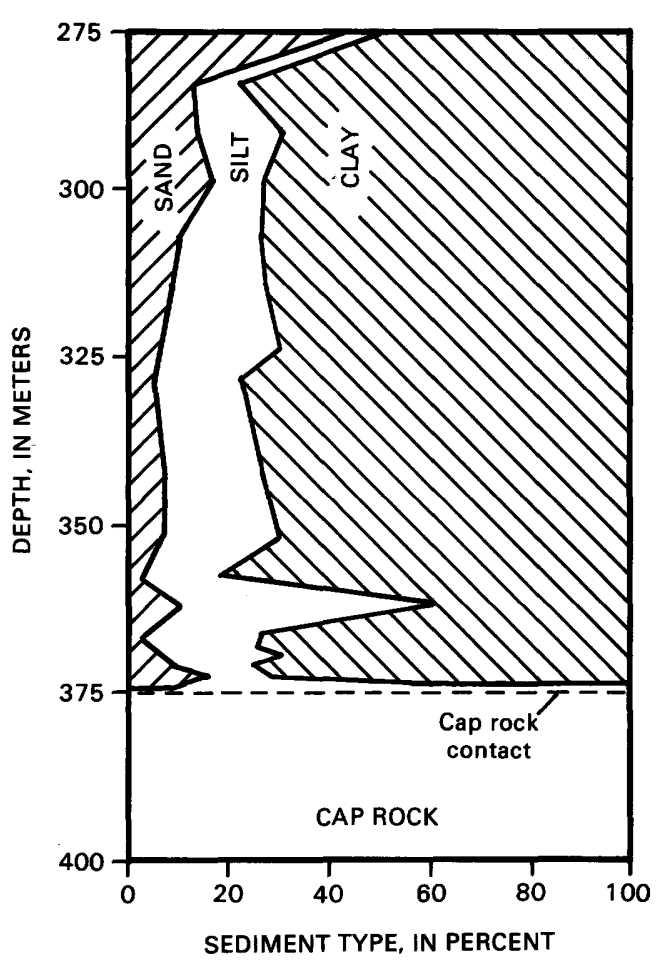

Figure 8. Grain-size distribution of sediments from core 114 (see fig. 1) versus depth.

(fig. 12). A computer-generated "best-fit" line through the data points suggests a linear trend.

A plot of the $\mathrm{Na} / \mathrm{Cl}$ molar ratio in the water-leached extract from site 114 against depth shows two trends 


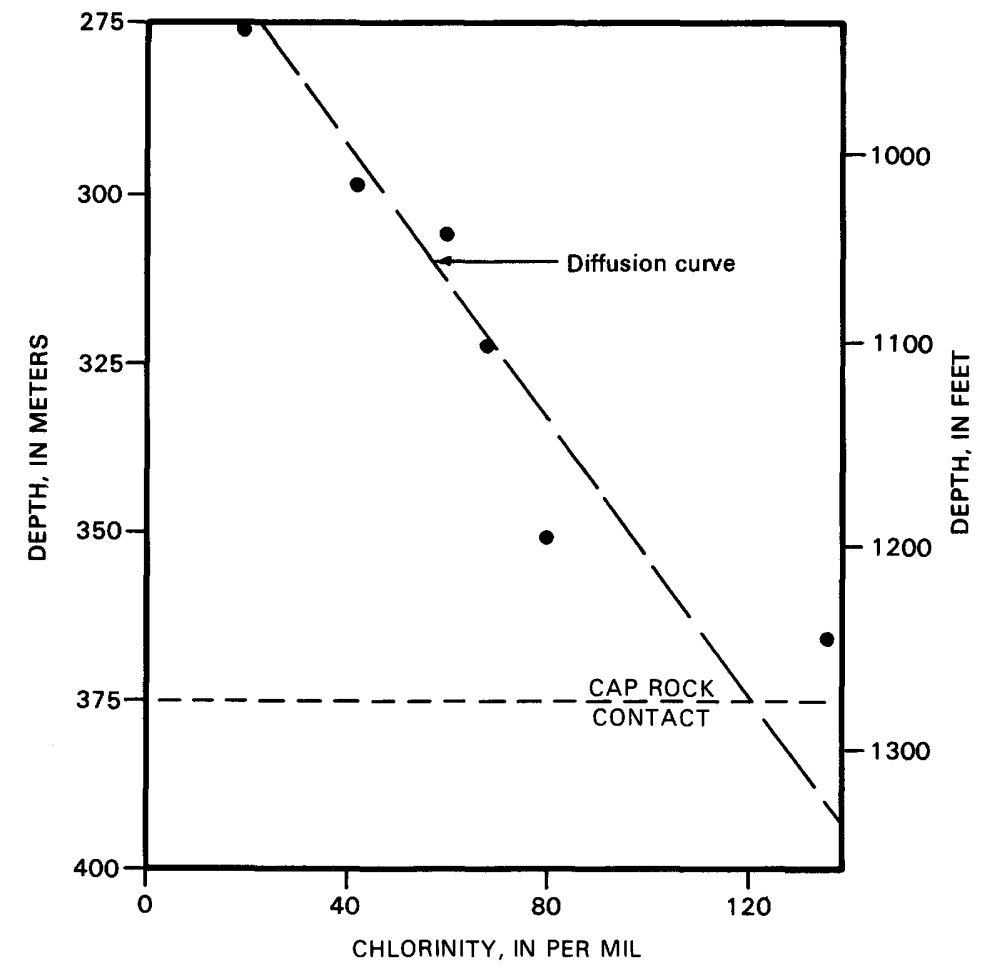

Figure 9. Chlorinity of extracted pore water from core 114 (see fig. 1) versus depth. Diffusion curve is theoretical curve if solid-state diffusion were active.

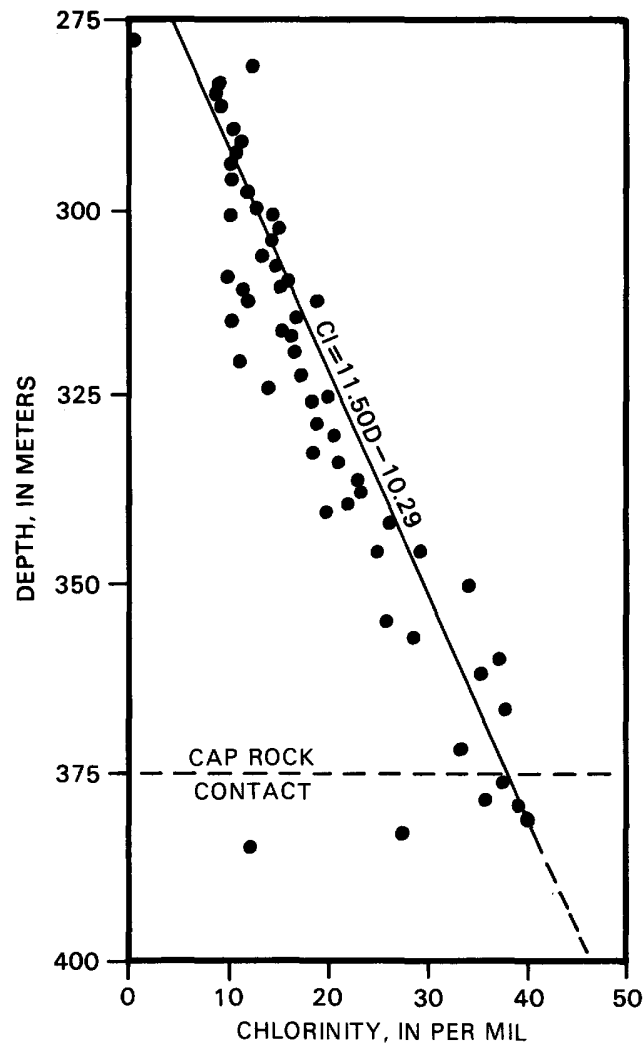

Figure 10. Chlorinity of waterleached extract from dry sample of core 114 (see fig. 1) versus depth. Line is best-fit line.

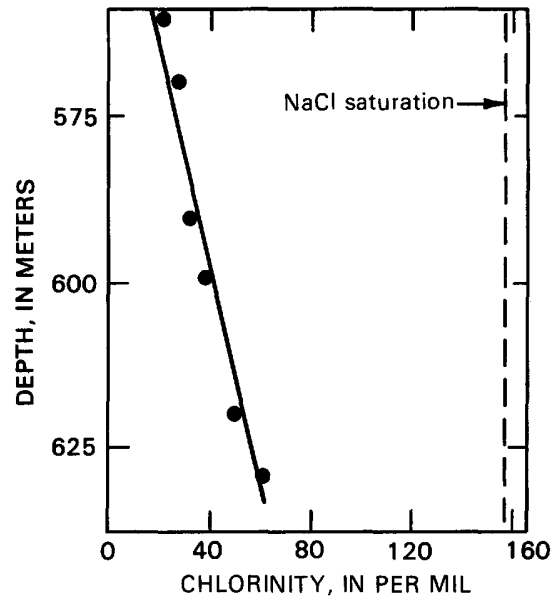

Figure 11. Chlorinity of extracted pore water from core 66 (see fig. 1) versus depth (modified from Manheim and Bishoff, 1969). $\mathrm{NaCl}$ saturation is given for comparison.

(fig. 13). In the lower part of the sedimentary column, immediately above the cap rock, the $\mathrm{Na} / \mathrm{Cl}$ ratio was similar to that of seawater (about 0.7). From this level to about the $325-\mathrm{m}$ level, the ratio increased linearly and then was constant at about 1.0 to the sediment-water interface. The $\mathrm{K} / \mathrm{Cl}$ ratio (fig. 14) was the reverse, being constant at about 0.06 from the top of the cap rock to the $325-\mathrm{m}$ level, from where it increased more or less linearly to 


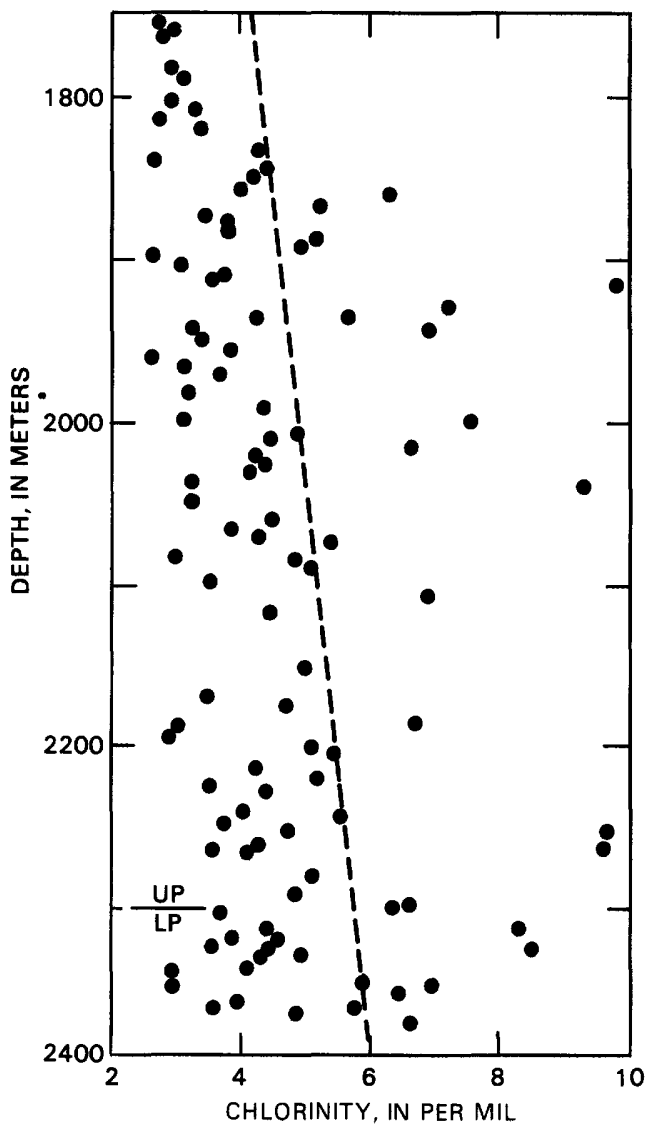

Figure.12. Chlorinity of water-leached extract from dry sample from core 123 (see fig. 1) versus depth. Depth of transition is shown between upper Pleistocene (UP) and lower Pleistocene (LP) as reported by Lehner (1969). Dashed line is best-fit regression line.

the top of the sediment column. Too few samples were examined from core 66 to define trends, and in core 123 and cores from the flanks of the salt intrusions no changes in these ratios with depth were noted.

The carbonate fraction of the sediment at site 114 ranged from 1 percent in the lower portions of the sedimentary column to more than 20 percent at the sediment-water interface (fig. 15). The shape of the curve closely parallels the $\mathrm{K} / \mathrm{Cl}$ curve. The $\mathrm{Ca} / \mathrm{Mg}$ ratio of the carbonate fraction also parallels the $\mathrm{K} / \mathrm{Cl}$ ratio, increasing from 2 in the lower portion of the sediment column to 20 at the top (fig. 16). The organic carbon content, an index of the total organic material in the sediments, ranged from 0.8 to 1.6 percent and had a distribution similar to that of the carbonate component (fig. 17). The carbon in the carbonate fraction and in noncarbonate material was isotopically lighter in the sediments that had a minimum of each component (fig. 18). Thus, both fractions were lighter isotopically in the lower part

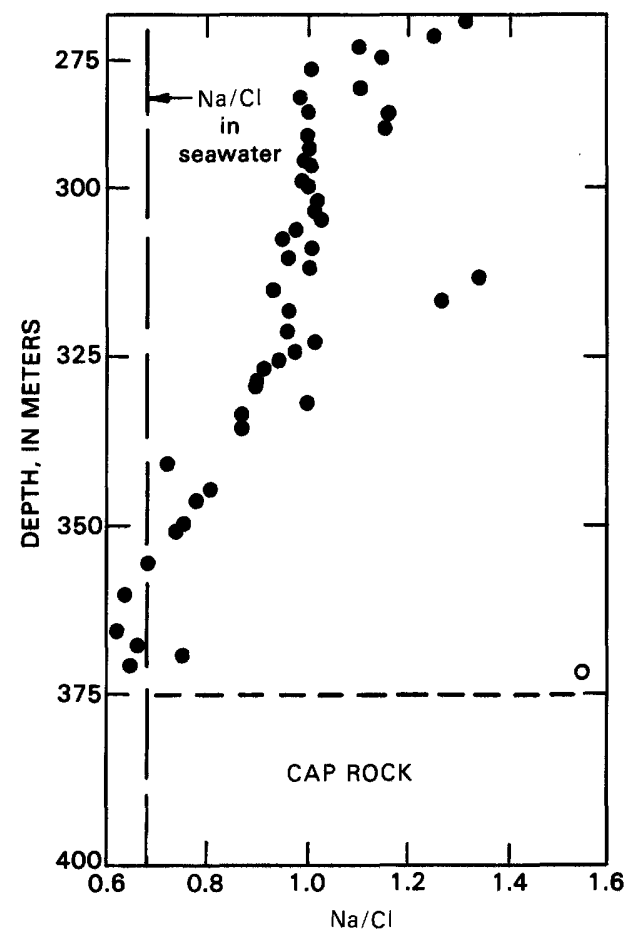

Figure 13. Molar $\mathrm{Na} / \mathrm{Cl}$ ratio of the waterleached extract from core 114 (see fig. 1) versus depth. Vertical dashed line is molar ratio of $\mathrm{Na} / \mathrm{Cl}$ of normal seawater. Horizontal dashed line is contact between sediment and cap rock.

of the sediment column than near the sediment-water interface.

The iron content of the sediments increased linearly with depth from a low of 0.2 percent at the sedimentwater interface to 1.6 percent in the sediments immediately above the cap rock. Manganese was nearly constant throughout the core, but increased logarithmically in the zone immediately above the cap rock (fig. 19). Frank T. Manheim (U.S. Geological Survey, Woods Hole, Mass., oral commun., 1982) reported that the pore water immediately above the cap rock contained $90 \mathrm{ppm}$ (parts per million) manganese, coinciding with the high manganese concentrations in the sediments. The maximum total zinc content of the sediments was near the $325-\mathrm{m}$ level and averaged 1,000 ppm. Some samples retained more than $2,000 \mathrm{ppm}$ zinc (fig. 20). The ratio of hydroxylamine-hydrochloride-soluble zinc to the amount of zinc soluble in "hot" nitric acid was minimum near the $325-\mathrm{m}$ level, suggesting that the zinc in this zone was present in a stable form, probably as a sulfide.

\section{Mineralogy}

The mineralogy of the reactive minerals, the clay minerals, changed with depth at two sites above the salt 


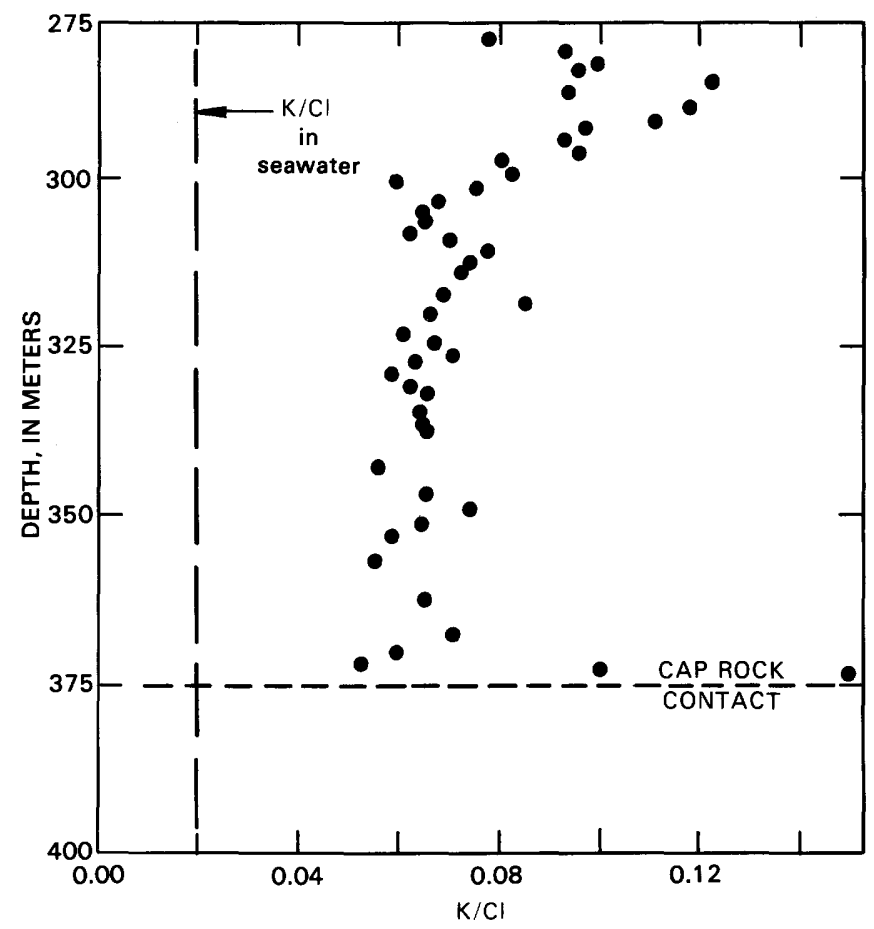

Figure 14. Molar $\mathrm{K} / \mathrm{Cl}$ ratio of the water-leached extract from core 114 (see fig. 1) versus depth. Vertical dashed line is molar $\mathrm{K} / \mathrm{Cl}$ ratio of normal seawater. Horizontal dashed line is contact between sediment and cap rock.

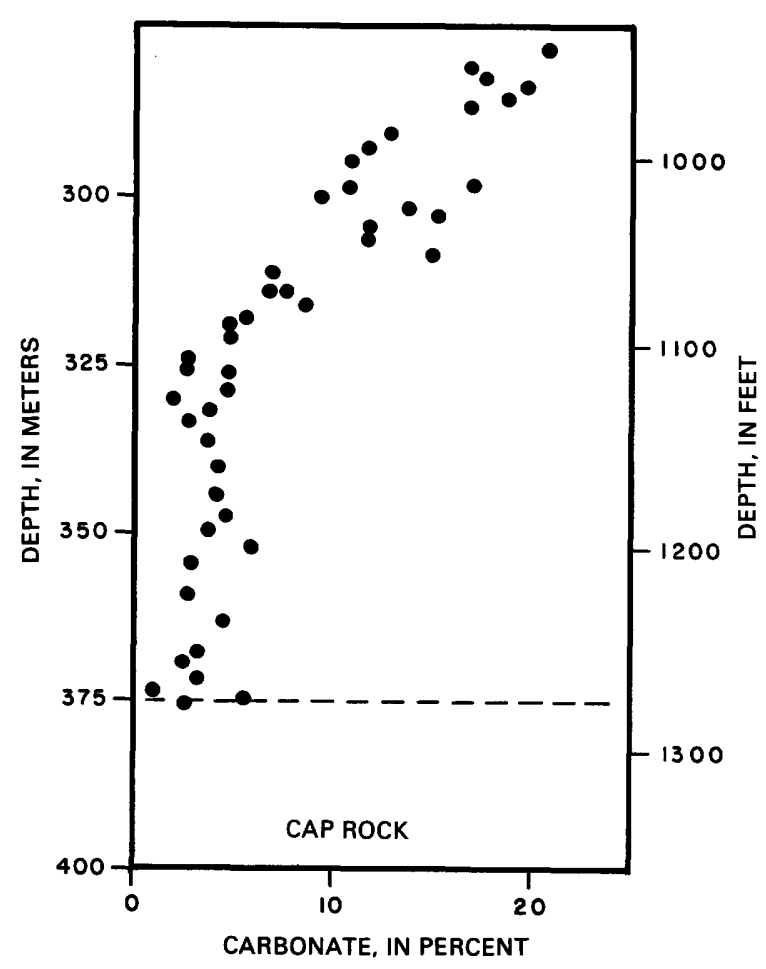

Figure 15. Carbonate percentage of sediments from core 114 (see fig. 1) versus depth. Horizontal dashed line is contact between sediment and cap rock.

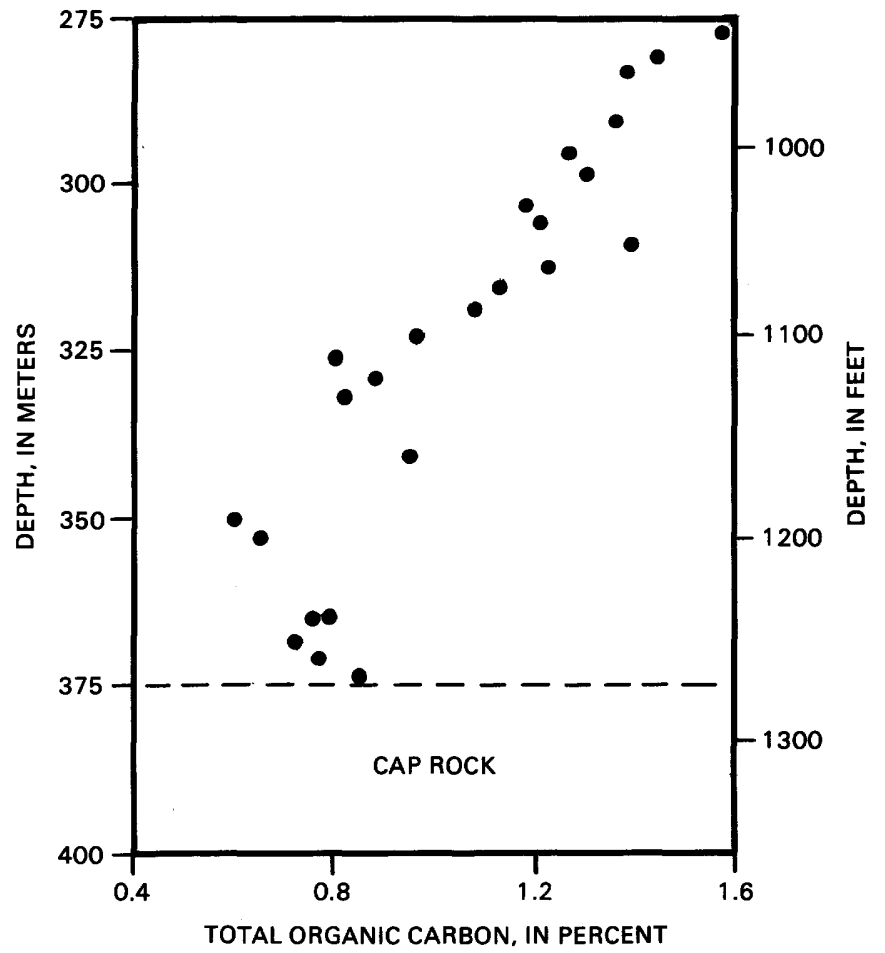

Figure 16. Total organic carbon of dry sample, in weight percent, from core 114 (see fig. 1) versus depth. Horizontal dashed line is contact between sediment and cap rock. 


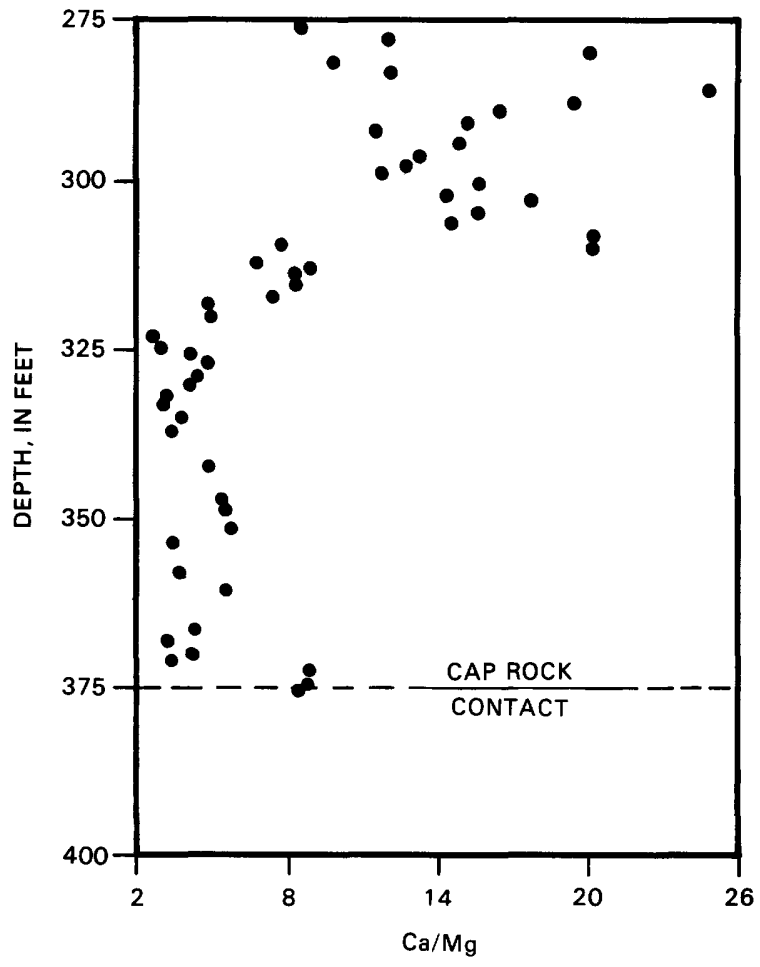

Figure 17. Molar $\mathrm{Ca} / \mathrm{Mg}$ ratio of carbonate fraction of sediments from core 114 (see fig. 1) versus depth. Horizontal dashed line is contact between sediment and cap rock.

on the upper slope (figs. 22 and 23). At both sites (114 and 66), the amount of the 10 - $\AA$ phases increased with respect to those clay minerals with higher basal spacings. In core 114 , chlorite was detected in a sample immediately above the cap rock (J. Hathaway, U.S. Geological Survey, Woods Hole, Mass., written commun., 1974). These mineralogical changes are common in deeply buried Tertiary sediments of the Gulf Coast (Burst, 1969), but have not been previously reported at these shallow depths.

In the sediments immediately above the salt intrusion on the upper slope, nodular bodies are common (fig. 24). Most of these bodies consist of a rust-colored rind with a central core of buff to white crystals. From $\mathrm{X}$-ray diffraction examination, the central core contains bassanite $\left(\mathrm{CaSO}_{4} \cdot 1 / 2 \mathrm{H}_{2} \mathrm{O}\right)$, jarosite $\left(\mathrm{KFe}_{3}\left(\mathrm{SO}_{4}\right)_{2}(\mathrm{OH})_{6}\right)$, rhombic sulfur, and a small amount of pyrite. Semiquantitative elemental analyses of these minerals and the rind indicate abnormal amounts of $\mathrm{Mo}$, Co, and $\mathrm{Mn}$ with respect to the surrounding sediments.

\section{DISCUSSION AND CONCLUSIONS}

Diagenic processes act throughout a large temporal spectrum, but for conceptual convenience diagenesis is considered to occur either "early" or "late". These terms are necessarily vague due to the complex nature of conditions that must be present to produce a chemical or mineralogical change in the sediment.
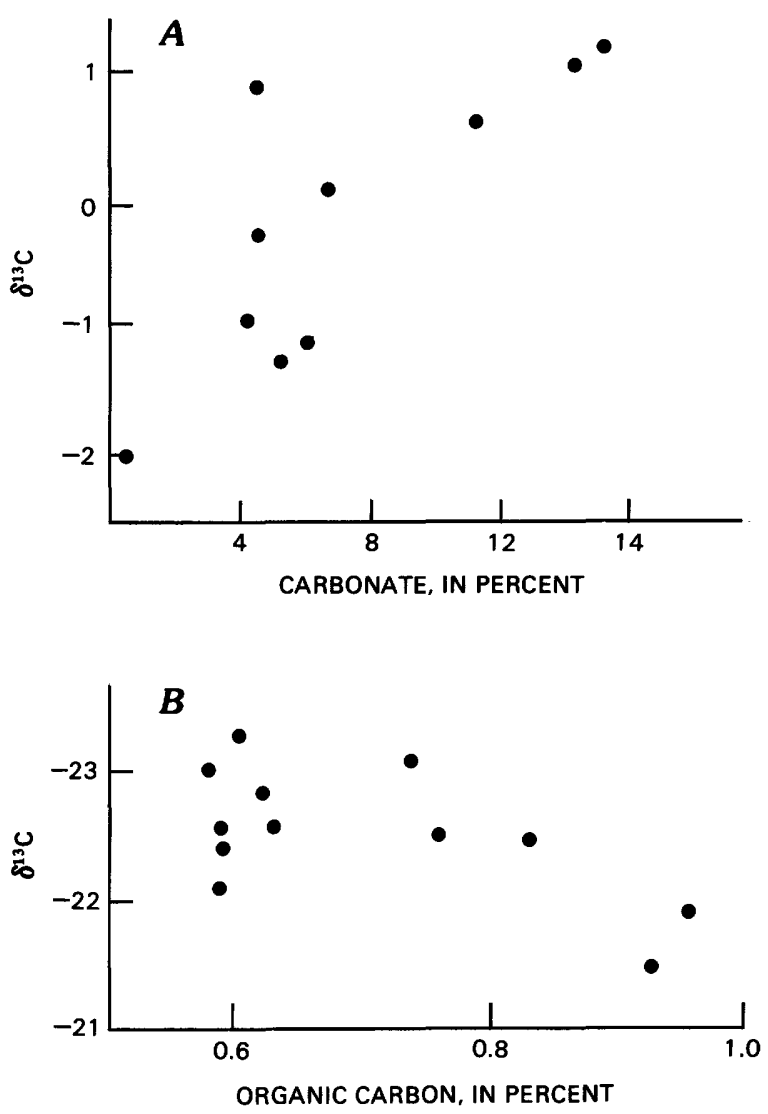

Figure 18. $A, \delta^{13} \mathrm{C}$ of carbonate fraction versus carbonate percentage of sediments from core $114 . B, \delta^{13} \mathrm{C}$ of organic fraction versus total organic content of sediments from core 114 (see fig. 1). The more negative the number, the lighter the carbon mass (that is, the less ${ }^{13} \mathrm{C}$ in sample).

The degradation of organic material in the sediment is one of the most important factors determining the environmental conditions of early diagenesis. The complex nature of the organic substances which make up the total organic content affects their rate of decomposition; for example, proteinaceous substances oxidize quicker than cellulosic substances. Organic oxidation, however, changes the oxidation-reduction potential, the alkalinity of the pore water, the sulfate concentration, and the oxygen content of a sedimentary environment so that the degree of completeness of the organic degradation directly affects the diagenetic processes. Inasmuch as oxygen is necessary for this reaction, the limiting factor in the degradation process is the availability of this element. In the marine subaqueous environment, oxygen is supplied by the following species (in order of importance):

$$
\mathrm{O}_{2}>\mathrm{NO}_{3}>\mathrm{MnO}, \mathrm{FeOOH}>\mathrm{SO}_{4} \text { (Berner, 1971). }
$$

In most sediments, free oxygen and the oxygen bound as nitrate are rapidly consumed by oxidation. The oxides of manganese and iron react slowly, which leaves the sulfate concentration as the limiting factor. This species plays a dual role, supplying oxygen for oxidation of organic 


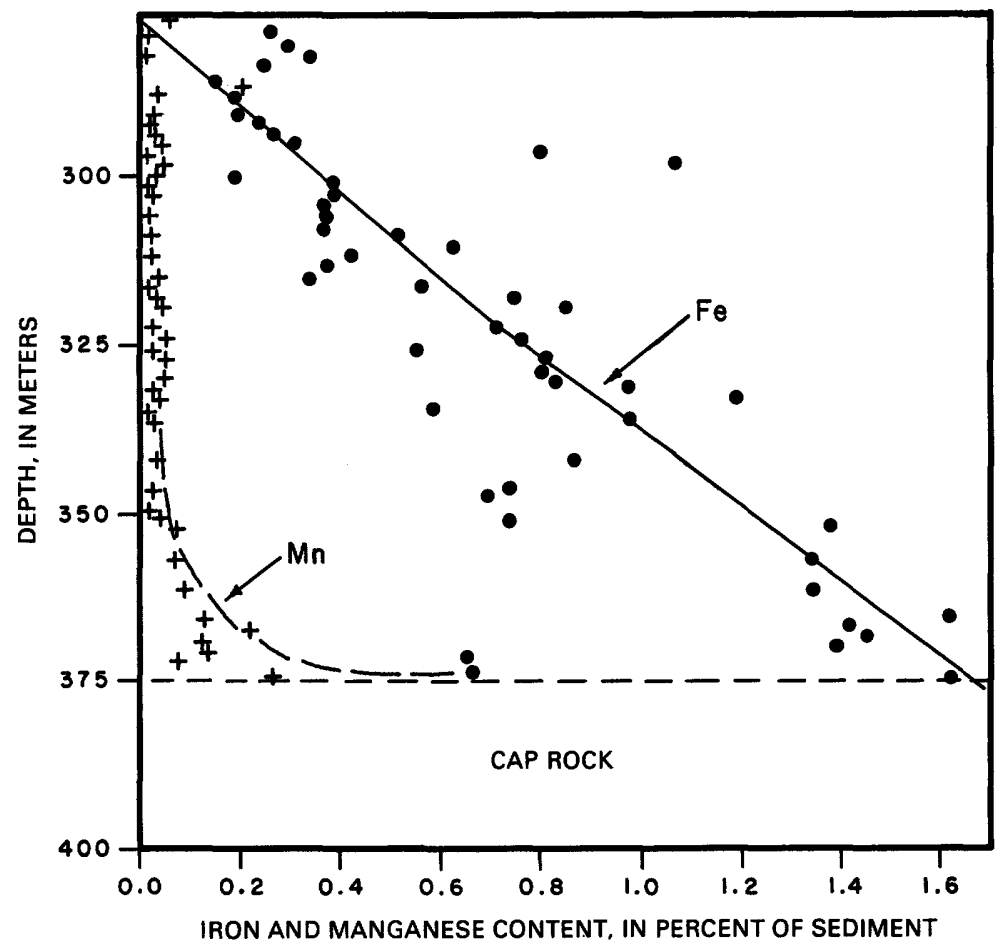

Figure 19. "Authigenic" iron (plus sign) and manganese (solid circle), in percent, of sediment from core 114 (see fig. 1) versus depth. Horizontal dashed line is contact between sediment and cap rock.

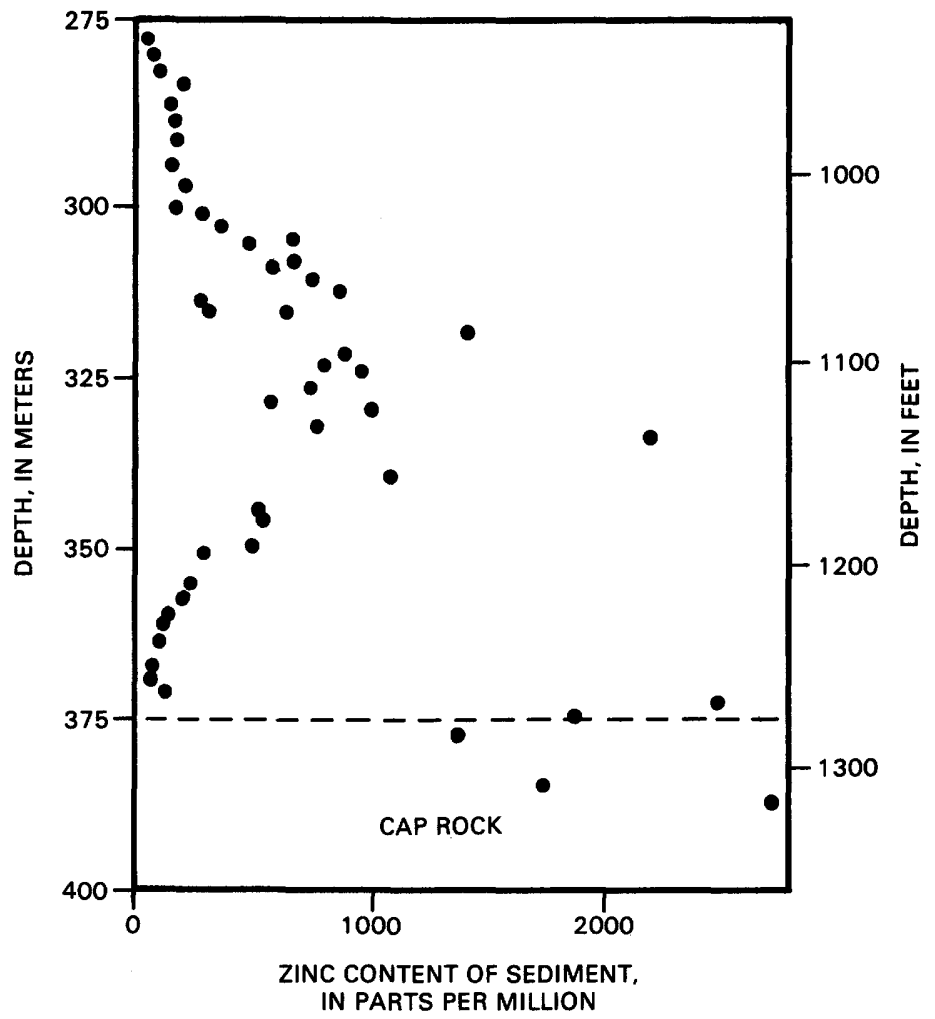

Figure 20. Total zinc (leached with hot nitric acid) of sediments from core 114 (see fig. 1) versus depth. Horizontal dashed line is contact between sediment and cap rock. 


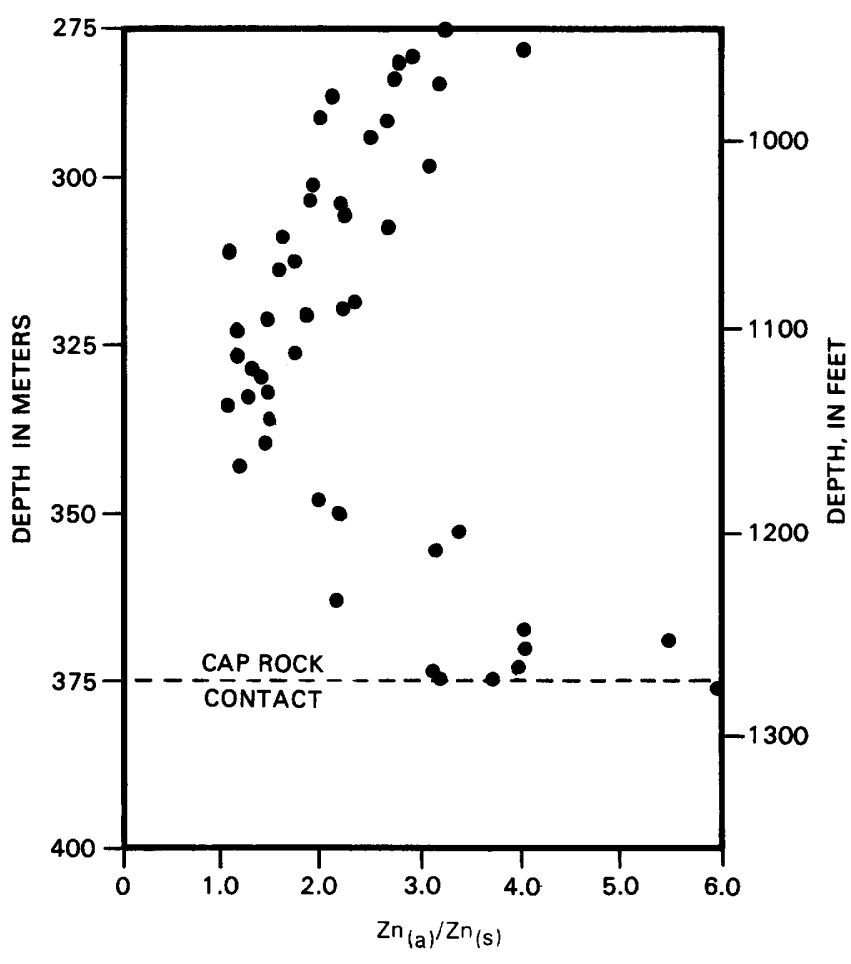

Figure 21. Ratio of "total" acid-leached zinc $(\mathrm{Zn})$ and "authigenic" zinc (leached with hydroxylamine-hydrochloride-acetic acid) $\left(Z n_{s}\right)$ of sediments from core 114 (see fig. 1) versus depth. Horizontal dashed line is contact between sediment and cap rock.

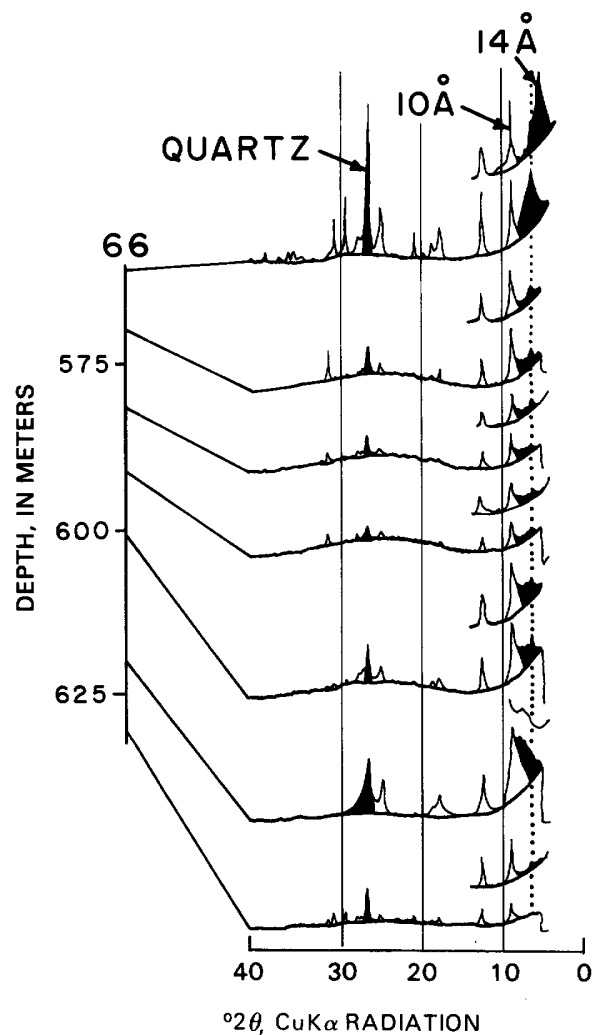

compounds and contributing sulfur for formation of the sulfides. In the sediments of the Gulf of Mexico slopecharacterized by a high rate of sedimentation, a high organic content, and a low oxygen supply-organic decomposition is slow, and does not go to completion. The extent of the degradation is not known, but the coexistence of sulfides and unoxidized organic material is evidence that all reactive oxygen has been consumed. The sulfide production resulting from the reduction of sulfate increases the concentration of sulfides of metals such as $\mathrm{Fe}, \mathrm{Zn}$, and Mo in the sediments. Local organic-rich zones, such as burrows, also concentrate metals and produce "hot spots" such as the arsenopyrite burrow-filling found

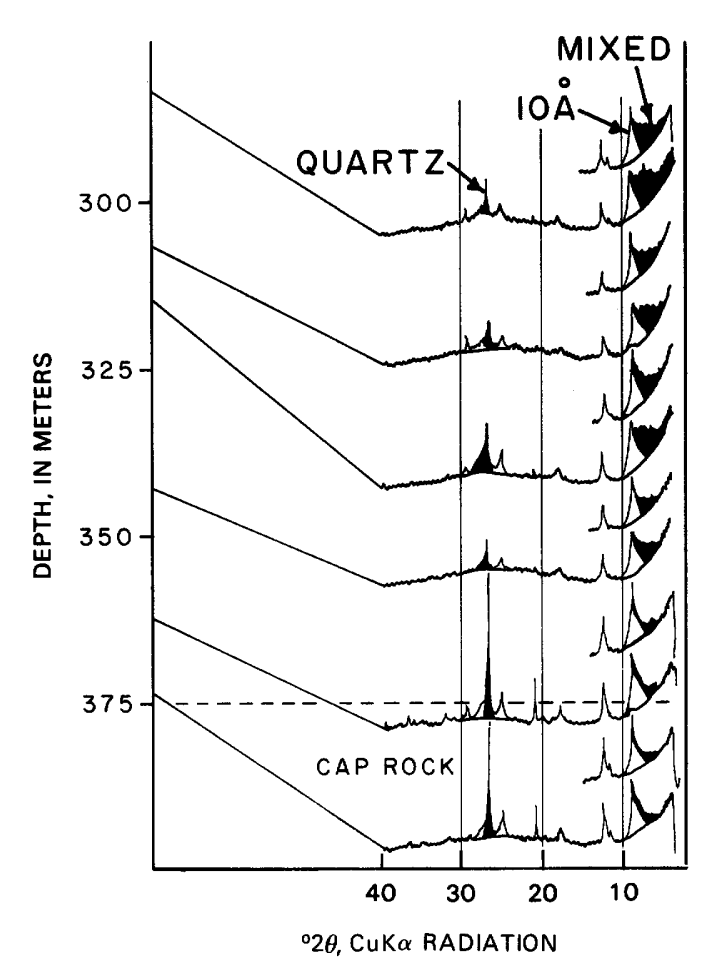

Figure 22. X-ray diffraction patterns of $<2-\mu \mathrm{m}$ size fractions of sediments from core 114 versus depth. MIXED represents clay minerals composed of random interstratification of smectite and illite. 10-Å peak probably represents illitic clay. Increase in intensity of quartz peak with depth is due to increase in crystallinity of quartz and increase of relative abundance of illite, which also has a strong diffraction peak in this region. Shorter pattern is paired with longer pattern below it and is of same sample that was glycolated to expand smectite to $17 \AA$.

Figure 23. $X$-ray diffraction patterns of $<2-\mu \mathrm{m}$ size fractions of sediments from core versus depth. Material is probably smectite as it expands to $17 \AA$ on glycolation. 10- $\AA$ material is probably illite. Quartz refers to $3.3-\AA$ peak, which is due to both quartz and illite in sample. Shorter patterns are glycolated versions of sample pattern following. 

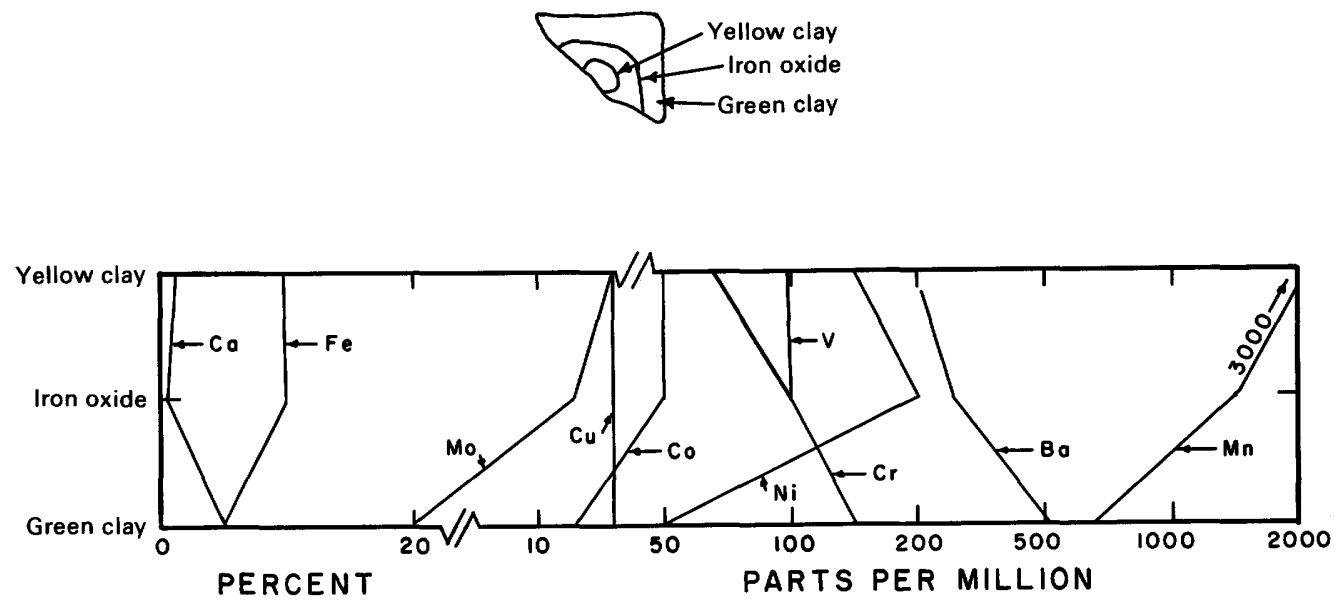

Figure 24. Diagram and metal distribution in "typical" nodule in cores immediately above salt cap rock. Calcium and iron are reported in percent; remaining elements are reported in parts per million. Data were produced by semiquantitative method of Grimes and Marranzino (1968).

in one of the cores examined in this study on the upper slope.

Whereas early diagenesis involves degradation of organic material, precipitation of cements, and formation of authigenic minerals, the major change in late-stage diagenesis is alteration of the original mineral constituents. In argillaceous sediments of the Gulf Coast, this change is chiefly the conversion of expandable clays minerals (smectite) to nonexpandable clay minerals (illite). This process has been discussed by many investigators and involves a stepwise conversion with the threshold of each step controlled predominantly by temperature; pore-water chemistry and pressure are secondary factors (Burst, 1969; Blattner, 1974).

Whether or not temperature was responsible for the emplacement of the salt domes in the area of the present study, as suggested by Gussow (1968), salt structures are known to be "hot" compared with the surrounding sediment. Oxygen isotope data of included water in such salt bodies confirm the fact that the salt was "hot" at some time during its history (Kreitler and Dutton, 1983). O'Brien and Lerche (1984) modeled the temperature distributions around salt structures and demonstrated that the hottest part of a salt structure is that part surrounding the leading edge. Thus, halokinesis in the Gulf Coast sediments may have produced a sufficient heat $\left(>150^{\circ} \mathrm{C}\right)$ to initiate clay-mineral transformations.

Burst (1969) and Perry and Hower (1972) demonstrated that expandable clay minerals are dewatered in three major stages: (1) the pore water of the sediments and interlayer water in excess of two water interlayers is removed by compaction; (2) the next to last interlayer of water is expelled, a process that requires heat $\left(80^{\circ}-\right.$ $100^{\circ} \mathrm{C}$ ); and (3) the remaining water is expelled and the layers realign, an extremely slow process in normal geologic setting that depends greatly on the thermal history of the area. The first step reduces the original interlayer water content by 50 percent, and the second step removes another 25 percent. Bruce (1983) calculated that these two processes yield about 200 liters of diagenetic water per cubic meter of sediment.

The effect of major pore-water cations on the dehydration and clay-mineral conversion was investigated by Blattner (1974), who demonstrated that at elevated temperatures these transformations are suppressed by the presence of calcium and magnesium but accelerated by the presence of potassium. A brine formed by the dissolution of salts rich in late-stage evaporities would therefore be enriched in potassium and associated brine elements, and, thus, would accelerate the clay-mineral transformation. Whereas heat is the dominant factor in the claymineral change, the composition of the pore water determines the rate of the transformation.

The diffusion of a brine created by the dewatering of clay minerals and the dissolution of salt toward the sediment-water interface would be influenced by the heat of the salt mass and aided by the fracturing caused by halokinesis. Lateral diffusion would be inhibited by the impervious nature of the sediments, which is not affected by the rising heat from the salt mass. Manheim and Bischoff (1969) suggested that this diffusion can be described by Fick's first law (steady-state diffusion), which predicts a concentration distribution linearly decreasing from the salt mass to the sediment-water interface. The chloride distributions measured in cores 114 and 66 were linear and coincided with the distribution predicted by the model. The $\mathrm{K} / \mathrm{Cl}$ and $\mathrm{Na} / \mathrm{Cl}$ ratios, however, did not. With respect to chloride, the relative level of sodium increased in the sediments below the $325-\mathrm{m}$ level in core 114 , whereas potassium increased with respect to chloride. These trends were apparently the result of the clay-mineral transformations, wherein 
potassium was fixed and sodium was expelled to form an illitic clay. This trend suggests that the transformation from stage two to three, as described by Burst (1969), occurred in the sediment near the $325-\mathrm{m}$ level.

The transformation of the clay minerals and subsequent brine formation also had a significant effect on the organic and inorganic species disseminated throughout the sediments. Organic material that had been adsorbed onto the clay minerals was expelled, and as the transformation proceeded, it was "flushed" toward the sedimentwater interface. The organic material that remained was oxidized with the sulfate in the ascending brine. Simplified, the reaction in the sediments was as follows:

$$
\mathrm{CH}_{4}+\mathrm{CaSO}_{4}+e \rightarrow \mathrm{CaCO}_{3}+\mathrm{H}_{2} \mathrm{~S}+\mathrm{H}_{2} \mathrm{O},
$$

where $e$ is the activation energy supplied to this system by sulfate-reducing bacteria that are common in these sediments and that apparently remain inactive for considerable lengths of time (Freely and Kulp, 1957). White and others (1963) suggested that most intraformational brines such as these are slightly acidic; therefore, as long as the organic material and (or) the sulfate in the pore water is dispersed, no carbonate should precipitate, and the carbonate in the sediment should be attacked. The chemical reaction, however, produced more water, thereby diluting the pore water and creating a steeper concentration gradient that accelerated the diffusion processes. As a result, more sulfate was introduced into the sediment, which led to further oxidation of any remaining organic material. Under these conditions, only the most stable organic and carbonate species remained-namely, plant material for the organic species and high-magnesium dolomite for the carbonates. The $\delta^{13} \mathrm{C}$ content of the organic material was highly negative, a common characteristic of plant material. The $\mathrm{Ca}$ and $\mathrm{Mg}$ analyses suggest that the carbonate material was high in Mg. Thus, the data suggest that the ascending fluids created an oxidizing environment above the salt structure. If, however, the organic material that was "flushed" during claymineral transformations and other organic material were concentrated due to their inability to migrate further with a decrease in the relative organic to sulfate concentration, sulfide should have been concentrated in the sediments.

Holmes (1977b) and Holmes and others (1974) demonstrated that metal sulfides in an oxidizing saline environment will dissolve, and metals such as zinc and lead will form stable chloride complexes. The presence of sulfate nodules immediately above the salt structures suggests that the ascending fluids were oxidizing. The form and trace-metal constituents of the nodules suggest that these originally were infauna burrows that were mineralized in a reducing environment caused by decaying organic material. Subsequently, the ascending sulfaterich brines oxidized many of the metal sulfides and formed the present mineral assemblage. As the metal-rich ascending brine entered the zone in which sulfide production was prevalent, the metals were again precipitated. This dissolution and precipitation formed an enriched zone in the sediments that marked the zone in which the most diagenetic activity caused by halokenesis occurred. At site 114 , the concentration of zinc and the "authigenic"/ "sulfide" ratio near the $325-\mathrm{m}$ level suggest that at this level such chemical processes were prevalent. The organic content, the carbonate content, and the cations in the pore water also changed at this level. All these changes suggest that the 325-m level was the diagenetic front at which the major chemical transformations took place.

\section{SUMMARY}

In the Gulf Coast geosyncline, the intrusion of salt into the argillaceous sediments had a significant effect on the diagenetic processes. The heat generated at the saltsediment interface dehydrated the clay minerals. The expressed water flushed dissolved organic materials toward the sediment-water interface and produced brine having an increased sulfate concentration by dissolving the salt and leaving an anhydrite residue; it also changed the clay mineralogy in the sediment column over the salt mass. The chemical reactions between the pore water and the sediments produced a diagenetic sulfide-rich front. Within this zone metals such as zinc and lead were concentrated; the metals were derived from the oxidized region below and transported into this sulfide zone as chloride complexes.

If the salt mass-with its anhydrite residue on the surface-had been intruded into a sedimentary unit rich in organic material, such as a hydrocarbon accumulation, common in the Tertiary of the Gulf of Mexico, the resulting chemical environment would have been such that limestone would have formed above the anhydrite of the salt mass. According to the chemical reaction presented herein, one product of the reaction, in addition to the formation of calcium carbonate, is water. One cubic meter of anhydrite can result in the production of 400 liters of water when reacting with organic material. This reaction was most likely at the carbonate-anhydrite interface and probably caused the hydration of anhydrite to gypsum. The result of such a process was a limestone-gypsum-anhydrite sequence-a sequence commonly referred to as cap rockfound on many salt domes throughout the Gulf Coast.

\section{REFERENCES CITED}

Berner, R. A., 1971, Principles of chemical sedimentology: New York, McGraw-Hill, 240 p.

Blattner, C. A., 1974, The interaction of clay minerals with distilled water and saline solutions at elevated temperatures: Binghamton, New York, State University of New York at Binghamton, Ph.D. dissertation, 264 p.

Salt-Induced Diagenesis of Argillaceous Sediments 
Bruce, C. H., 1983, Relation of illite/smectite diagenesis and development of structure in the northern Gulf of Mexico: American Association of Petroleum Geologists Bulletin, v. 67, p. 432.

Burst, J. F., 1969, Diagenesis of Gulf Coast clayey sediments and its possible relationship to petroleum migration: American Association of Petroleum Geologists Bulletin, v. 53, p. 73-93.

Carroll, D., 1970, Clay minerals-A guide to their X-ray identification: Geological Society of America Special Paper 126, $80 \mathrm{p}$.

Chester, R., and Hughes, M. J., 1967, A chemical technique for the separation of ferro-manganese minerals, carbonate minerals, and adsorbed trace elements from pelagic sediments: Chemical Geology, v. 2, p. 249-262.

Freely, H. W., and Kulp, J. L., 1957, Origin of the Gulf Coast salt dome sulfur deposits: American Association of Petroleum Geologists Bulletin, v. 41, p. 1802-1853.

Griffins, J. C., 1967, Scientific methods in the analyses of sediments: New York, McGraw-Hill, 508 p.

Grimes, D. L., and Marranzino, A. P., 1968, Direct-current arc and alternating current spark emission spectrographic field methods for semiquantitative analyses of geologic materials: U.S. Geological Survey Circular 591, 6 p.

Gussow, W. C., 1968, Salt diapirism; importance of temperature and energy source of emplacement, in Braunstein, J., and O'Brien, G. D., eds., Diapirism and diapirs: American Association Petroleum Geologists Memoir 8, p. 16-52.

Holmes, C. W., 1977a, Clay mineralogy, suspended and sea floor sediments, in Berryhill, H. L., Jr., and Trippet, A. R., eds., Environmental studies, south Texas outer continental shelf: Bureau of Land Management report, available from U.S. Department of Commerce National
Technical Information Service, Springfield, VA 22161, as Report PB289-144 AS.

1977b, Effects of dredge channels on trace-metal migration in an estuary: U.S. Geological Survey Journal of Research, v. 5, p. 243-251.

Holmes, C. W., and Booth, J. S., 1980, Impact of the Holocene transgression on depositional environments of the northern Gulf of Mexico continental margin: American Association of Petroleum Geologists Bulletin, v. 64, p. 724.

Holmes, C. W., Slade, E. A., and McLerran, C. J., 1974, Migration and redistribution of zinc and cadmium in marineestuarine system: Environmental Science and Technology, v. 8, p. 255-259.

Kreitler, C. W., and Dutton, S. P., 1983, Origin and diagenesis of caprock, Gyp Hill and Oakwood salt domes: Texas Bureau of Economic Geology Investigations Report 131, 58 p.

Lehner, P., 1969, Salt tectonics and Pleistocene stratigraphy on continental slope of northern Gulf of Mexico: American Association Petroleum Geologists Bulletin, v. 53, p. 24312479.

Manheim, F. T., and Bischoff, J. L., 1969, Geochemistry of pore waters from Shell Oil Company drill holes on the continental slope of the northern Gulf of Mexico: Chemical Geology, v. 4, p. 63-82.

O'Brien, J. J., and Lerche, I., 1984, The influence of salt domes on paleotemperature distributions: Geophysics, v. 49, p. 2032-2042.

Perry, E. A., and Hower, J., 1972, Late stage dehydration in deeply buried pelitic sediments: American Association of Petroleum Geologists Bulletin, v. 56, p. 2013-2021.

White, D. E., Hem, J. D., and Waring, G. A., 1963, Chemical composition of subsurface water: U.S. Geological Survey Professional Paper 440-F, 67 p. 


\title{
Sodium-Potassium lon Exchange During Smectite Diagenesis-A Theoretical Discussion
}

\author{
By DENNIS D. EBERL, U.S. Geological Survey, Box 25046, Denver Federal \\ Center, MS 404, Denver, Colorado 80225
}

\section{CONTENTS}

\author{
Abstract 364 \\ Introduction 364 \\ Preferential potassium selectivity by illite 364 \\ Effect of increasing temperature and pressure \\ Effect of increasing pore-water salinity 365 \\ Effect of increasing smectite layer charge 365 \\ Effect of decreasing interlayer water content 366 \\ Concentration of potassium in illite layers 366 \\ Conclusions 367 \\ References cited 368
}

FIGURES

1-4. Plots showing:

1. Effect of increasing temperature and pressure on exchange free energy for sodium-potassium exchange $\mathbf{3 6 5}$

2. Free energy of exchange as a function of pore-water molality $\mathbf{3 6 6}$

3. Free energy of exchange for sodium-potassium as a function of smectite-layer charge 366

4. Free energy of exchange for sodium-potassium exchange as a function of interlayer molality $\mathbf{3 6 7}$

5. Plot showing free energy of exchange for sodium-potassium exchange calculated from Coulomb's law $\mathbf{3 6 7}$ 


\begin{abstract}
When smectite reacts to form illite during burial diagenesis, the interlayer cation changes from dominantly sodium to almost entirely potassium. Approximate thermodynamic calculations based on a model that treats the smectite interlayer as a concentrated electrolyte solution suggest that this significant change in interlayer composition is related to a dehydration of potassium by interlayer electrical forces in response to an increase in smectite layer charge with burial depth. The smaller dehydrated potassium ion is strongly selected compared to the larger hydrated sodium ion in the clay interlayer because adsorption energy is inversely proportional to ionic radius, as shown by Coulomb's law.
\end{abstract}

\section{INTRODUCTION}

The work of Perry and Hower (1970) and Weaver and Beck (1971), among others, has firmly established that smectite reacts to form illite during burial diagenesis. Assuming a transformation mechanism, this reaction proceeds via the substitution of aluminum for silicon in the tetrahedral sheet of smectite, thereby generating a negative charge on the 2:1 layers that is balanced by an increase in interlayer cations (Hower and others, 1976). When the layer charge becomes sufficiently negative, smectite interlayers collapse around the interlayer cations and expel interlayer water, thereby becoming illite interlayers.

This reaction proceeds in a sodium-enriched pore water in which interlayer exchange sites of smectite are dominated by sodium. Yet, when smectite interlayers collapse to form illite, potassium is concentrated in the illite interlayers to the exclusion of sodium. Some simple calculations support this apparent anomaly. An exchange reaction betweem a sodium smectite $(\mathrm{NaX})$ and a potassium smectite $(\mathrm{K} X)$ is:

$$
\mathrm{Na} X+\mathrm{K}^{+} \leftrightarrows \mathrm{K} X+\mathrm{Na}^{+},
$$

where $\mathrm{Na}^{+}$and $\mathrm{K}^{+}$are each one equivalent of sodium and potassium ions in solution. The equilibrium constant $\left(K_{e x}\right)$ for this reaction is:

$$
K_{e x}=\frac{[\mathrm{K} X]\left[\mathrm{Na}^{+}\right]}{[\mathrm{Na} X]\left[\mathrm{K}^{+}\right]} .
$$

For the following approximate calculation, concentrations will be used to approximate activites. The standard free energy of exchange $\left(\Delta G_{e x}^{\circ}\right)$ can be calculated from

$$
\Delta G_{e x}^{\circ}=-R T \ln K_{e x}
$$

where $R$ is the gas constant and $T$ is absolute temperature. Assuming a $\frac{[\mathrm{KX}]}{[\mathrm{NaX}]}$ ratio for illite of 77 (Interlake, Montana illite, from Hower and Mowatt, 1966) and a pore water $\frac{\left[\mathrm{Na}^{+}\right]}{\left[\mathrm{K}^{+}\right]}$ratio of 250 (average value for Cretaceous oil field waters, from Collins, 1975), and neglecting the effects of ions other than $\mathrm{Na}^{+}$and $\mathrm{K}^{+}$on exchange constants, the free energy of exchange can be calculated from equations 2 and 3:

$$
\Delta G_{e x}^{\circ}=-24 \mathrm{~kJ} / \mathrm{eq} \text { (kilojoules per equivalent). }
$$

The average $\Delta G_{e x}^{\circ}$ measured at room temperature for data summarized in Eberl (1980) for sodium-potassium exchange on smectite is:

$$
\Delta G_{e x}^{\circ}=-1.7 \mathrm{~kJ} / \mathrm{eq},
$$

which is more than an order of magnitude too small to account for the interlayer chemistry of illite.

The present paper uses approximate thermochemical calculations, based on a model that treats the smectite interlayer as a concentrated electrolyte solution, to suggest a mechanism that leads to the concentration of potassium in illite.

\section{PREFERENTIAL POTASSIUM SELECTIVITY BY ILLITE}

Something happens during the formation of illite from smectite to increase the selectivity of the interlayer for potassium relative to sodium. Changes that occur during burial diagenesis that might affect sodiumpotassium selectivity with burial depth are: (1) increasing temperature and pressure; (2) increasing salinity of pore water; (3) increasing smectite layer charge; and (4) decreasing interlayer water content.

Approximate exchange free energies for equation 1 under these varying diagenetic conditions can be calculated from a modified version of the equation proposed by Cruickshank and Meares (1957) for ion-exchange resins, and later applied by Eisenman $(1961,1962)$ to glass electrodes and by Eberl (1980) to clay minerals. Assuming that interlayer water is at the same pressure as the pore water, the equation for exchange-free energy is:

$$
\begin{gathered}
\Delta G_{e x}^{\circ}=2 R T\left(\phi-\ln \gamma_{ \pm} \bar{m}_{ \pm}\right)_{\mathrm{NaX}}-2 R T\left(\phi-\ln \gamma_{ \pm} \bar{m}_{ \pm}\right)_{\mathrm{K} X} \\
-2 R T\left(\phi-\ln \gamma_{ \pm} m_{ \pm}\right)_{\mathrm{NaCl}}+2 R T\left(\phi-\ln \gamma_{ \pm} m_{ \pm}\right)_{\mathrm{KCl}},
\end{gathered}
$$

where $\phi$ is the practical osmotic coefficient, $\bar{m}_{ \pm}$is the mean ionic molality of the smectite interlayer water (assuming that the negative interlayer surfaces are the anion, the interlayer cation is the cation, and the interlayer water is the solvent), $m_{ \pm}$is the mean ionic molality of the pore water, and $\gamma_{ \pm}$is the mean ionic-activity coefficient for the subscripted species. The subscripted species $\mathrm{Na} X$ and $\mathrm{K} X$ are each one equivalent of sodium and 
potassium smectite, and $\mathrm{NaCl}$ and $\mathrm{KCl}$ refer to one equivalent of sodium and potassium chloride in the pore water.

The smectite interlayer can be modeled as a halide anion having an electric-field strength equivalent to that of the interlayer (Eberl, 1980). Hence, equation 4 can be solved for room-temperature conditions from the values of $\phi$ and $m_{ \pm}$that were presented as a function of molality and alkali halide chemistry by Robinson and Stokes (1959), and for diagenetic conditions from similar data presented by Helgeson and others (1981, figs. 152, 154 , and 157).

\section{Effect of increasing temperature and pressure}

The effect of increasing temperature and pressure on sodium-potassium selectivity is shown in figure 1 . Calculations for three interlayer molalities $(\bar{m})$ are plotted. Other diagenetic variables are constant: smectite layer charge is constant at the equivalent anionic radius

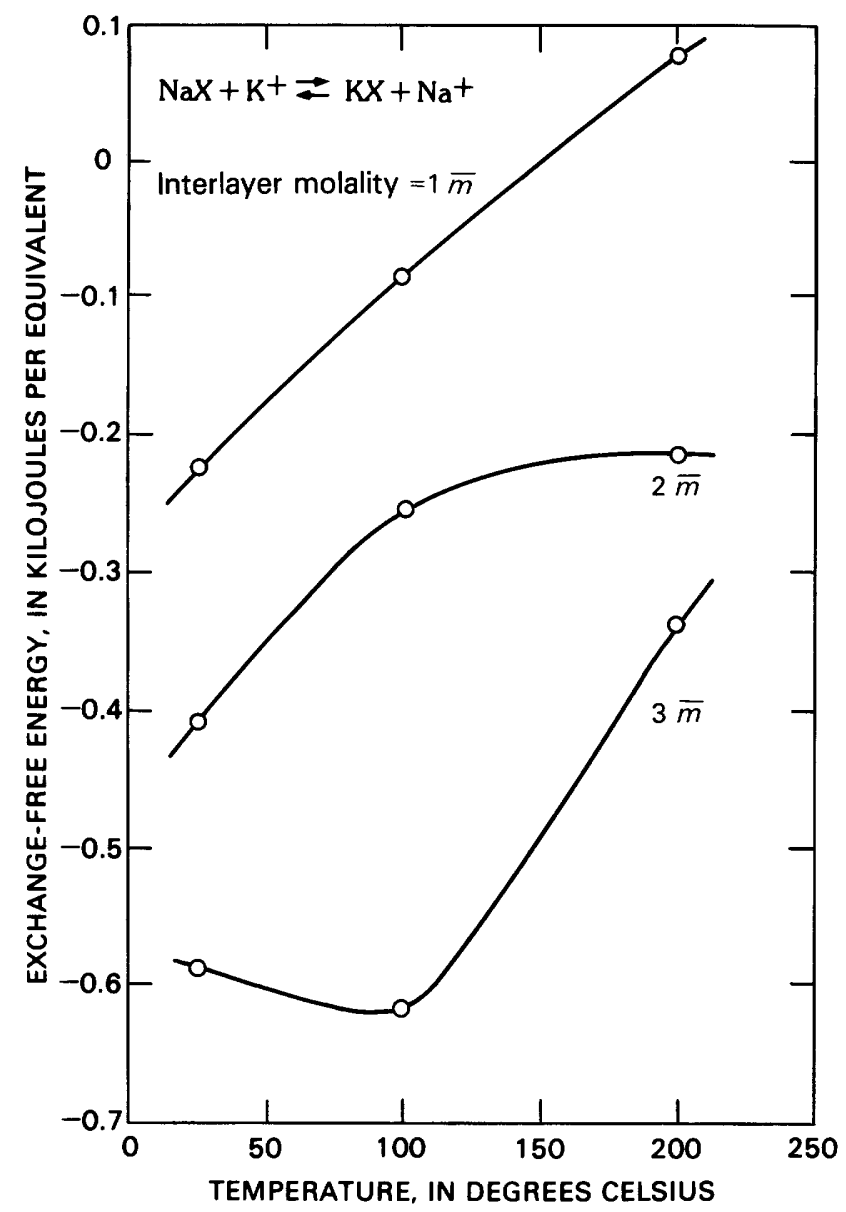

Figure 1. Effect of increasing temperature and pressure on free energy of exchange for sodium-potassium exchange at three interlayer water contents. Pressures correspond to liquid-vapor equilibrium for temperatures given. of the chloride ion, which corresponds to a layer charge of -0.57 equivalents per one-half unit cell, and the pore water is dilute. The curves were calculated from equation 4 using the osmotic and activity coefficients found in Helgeson and others (1981).

The curves show that the effect of increasing temperature and pressure on sodium-potassium selectivity will be small and will tend to increase interlayer preference for sodium rather than for potassium. In other words, the free energy change for equation 1 becomes more positive with increasing temperature and pressure. A minimal dependence on temperature $(T)$ and pressure $(P)$ also is predicted from the small enthalpy $\left(\Delta H^{\circ}\right)$ and volume $\left(\Delta V^{9}\right)$ change for the exchange reaction (as was discussed by Helfferich, 1962), according to Le Chatelier's principle, and to the following equations:

$$
\begin{aligned}
& \left(\frac{d \ln \mathrm{K}_{e x}}{\mathrm{dT}}\right)_{P}=\frac{\Delta H^{\circ}}{R T^{2}}, \text { and } \\
& \left(\frac{d \ln \mathrm{K}_{\mathrm{ex}}}{\mathrm{d} P}\right)_{T}=\frac{-\Delta H^{\circ}}{R T} .
\end{aligned}
$$

Thus, increasing temperature and pressure alone cannot be responsible for the remarkable increase in potassium selectivity by illite interlayers.

\section{Effect of increasing pore-water salinity}

Considering only sodium and potassium, increasing pore-water salinity also will tend to increase sodium selectivity (fig. 2). In this figure, temperature is $25^{\circ} \mathrm{C}$, pressure is atmospheric, and smectite layer charge is constant at the equivalent anionic radius of the chloride ion. Curves were calculated from equation 4 using the osmotic- and activity-coefficient data in Robinson and Stokes (1959). The trend of increasing free energy of exchange with increasing pore-water molality indicates that an increase in pore-water salinity with burial depth cannot be the answer.

\section{Effect of increasing smectite layer charge}

As was mentioned previously, layer charge increases during burial diagenesis by the substitution of aluminum for silicon in the tetrahedral sheet. The theoretical effect of increasing smectite layer charge is shown in figure 3. In this figure temperature is constant at $25^{\circ} \mathrm{C}$, and pressure is constant at 1 atmosphere; interlayer molality is $3.5 \bar{m}$, and the pore water is dilute. The curve was calculated from equation 4 using equivalent anionic radii for chloride, bromide, and iodide ions to represent various layer charges (see Eberl, 1980). Osmotic and 
activity coefficients used in this calculation are from Robinson and Stokes (1959). The curve indicates that increasing smectite layer charge tends to increase sodium adsorption, not potassium adsorption, for the range of layer charges shown.

\section{Effect of decreasing interlayer water content}

The effect of decreasing interlayer water content is shown in figure 4. This curve was calculated from equation 4 using the data in Robinson and Stokes (1959), assuming that the temperature is $25^{\circ} \mathrm{C}$, the pressure is atmospheric, the pore water is dilute, and the layer charge is constant at the equivalent anionic radius of the chloride ion. The data show that a decrease in the interlayer water content (that is, an increase in interlayer molality) tends to increase potassium adsorption. Here is a possible explanation for increased potassium selectivity during diagenesis. The effect for hydrated interlayers (fig. 4) is minor, but $\Delta G_{e x}^{\circ}$ does vary in the direction of increasing potassium selectivity. Furthermore, the effect can be large if interlayer potassium ions dehydrate completely.

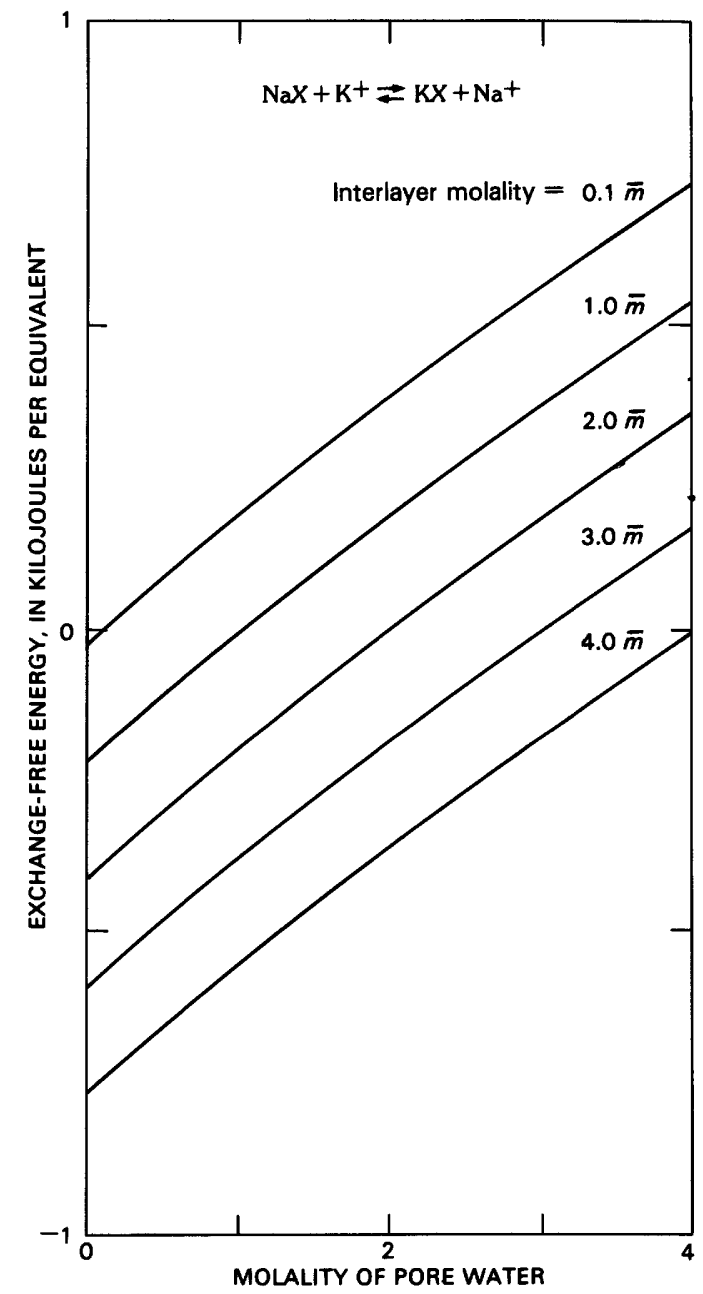

Figure 2. Free energy of exchange for sodiumpotassium exchange as function of pore-water molality for five interlayer water contents.

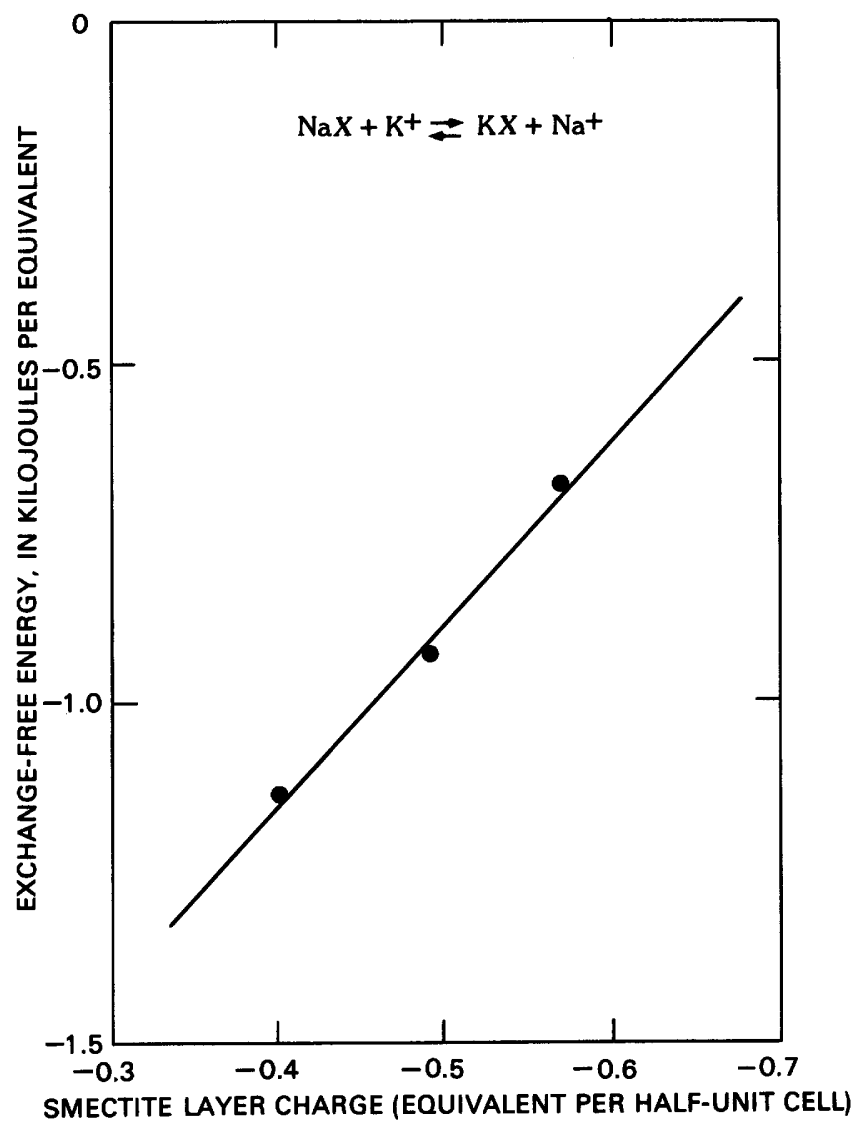

Figure 3. Free energy of exchange for sodium-potassium exchange as function of smectite layer charge.

\section{Concentration of potassium in illite interlayers}

A simple explanation for sodium-potassium selectivity is as follows. The ion preferred by the clay is the ion that is adsorbed with the greatest energy. Energy of adsorption $\left(E_{a d}\right)$ can be calculated approximately from the integrated form of Coulomb's law:

$$
E_{a d}=\frac{q_{c} q_{a} k}{r_{c}+r_{a}},
$$

where $q_{c}$ and $q_{a}$ are the charges on the cation (1+) and the anion (1-), $k$ is a constant $(1,389), r_{c}$ is the radius of the cation in Ångstrom units $(\AA)$, and $r_{a}$ is the radius of the anion in $\AA$.

Holding the radius of the anion (that is, the surfacecharge density of the clay interlayer) constant, equation 7 predicts that for univalent exchange, the cation with the smaller radius is preferred. Several different selectivities for sodium-potassium exchange are possible because these ions change radius as they change hydration state. Hence, a hydrated potassium ion is slightly preferred compared with a hydrated sodium ion because hydrated potassium has a slightly smaller radius. A hydrated potassium ion 
has a smaller hydrated radius than a hydrated sodium ion because the larger potassium ion has a smaller surfacecharge density, and, therefore, attracts fewer water molecules. If a potassium ion dehydrates and a sodium ion remains hydrated, the potassium ion is greatly preferred compared to sodium in the interlayer. If both dehydrate, sodium is preferred compared with potassium, a phenomenon that occurs in some aluminum-rich zeolites (Sherry, 1969).

Exchange energies for the above examples are depicted in figure 5. Radii used in equation 7 to calculate these data were taken from Nightengale (1959), Eisenman (1962), and Garrels and Tardy (1982). The hydrated radius of sodium is $3.58 \AA$, that of hydrated potassium is 3.31 $\AA$, that of dehydrated sodium is $0.98 \AA$, and that of dehydrated potassium is $1.33 \AA$. The equivalent radius of an aluminum-oxygen-silicon anionic interlayer site was calculated to be $2.1 \AA$ by Eisenman (1962). Exchange energies in figure 5 are not meant to be accurate because, for example, the "hydrated radius" is a function of how the radius is measured and may change between solution and interlayer. These values are presented, however, to

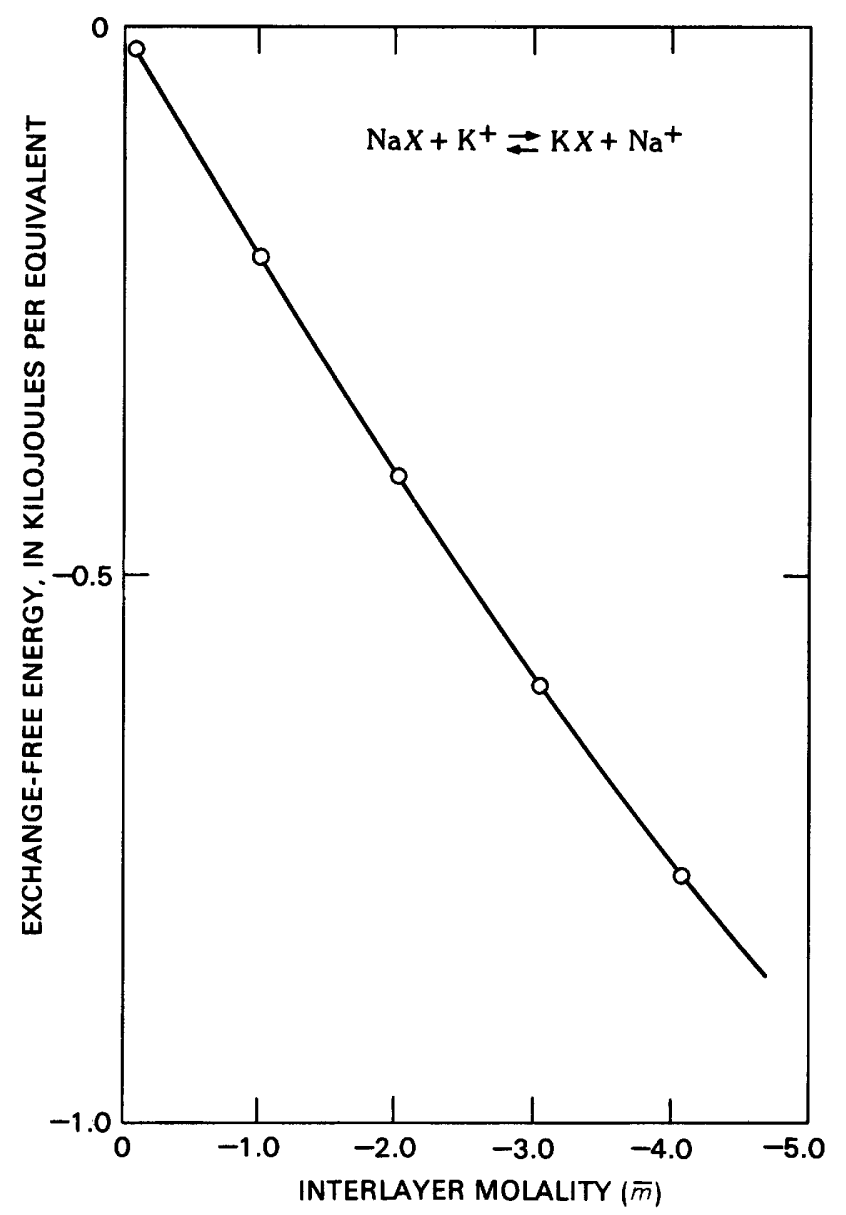

Figure 4. Free energy of exchange for sodium-potassium exchange as function of interlayer molality. show the possible magnitude of the effect of dehydration on exchange energies.

The layer charge at which ions dehydrate has been presented schematically as a break in slope in figure 5 . Interlayer cations dehydrate when a critical interlayer boundary potential has been exceeded due to an increase in smectite layer charge during diagenesis. This boundary potential is determined by the layer charge at which the energy of attraction of an interlayer cation for its hydration shell is exceeded by the energy of attraction of the cation for the smectite interlayer surfaces. The interlayer cation is thereby dehydrated by the surfaces; it then approaches the surfaces (crosses the "boundary") and is fixed, for example, to an aluminum-oxygen-silicon interlayer site by an energy determined by the site's electrostatic potential. This explanation assumes that (1) a hydrated interlayer cation "feels" the interlayer surfaces as planes of nearly uniform charge density, whereas a dehydrated cation "feels" a negative charge that is localized at a particular site in the 2:1 layer, and (2) smectite layers are converted into illite layers via a transformation-style reaction rather than via smectite dissolution and illite neoformation (see Eberl, 1984).

\section{CONCLUSIONS}

A cation in a smectite interlayer dehydrates in response to increasing layer charge when the energy of attraction between the cation and interlayer surfaces exceeds the energy of attraction between the cation and

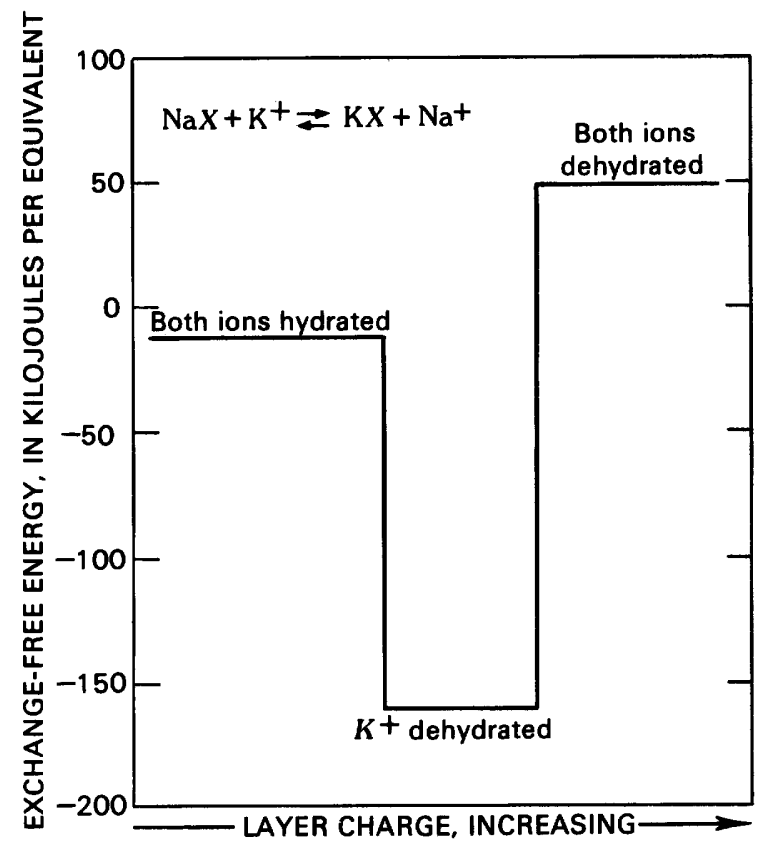

Figure 5. Free energy of exchange for sodiumpotassium exchange calculated from Coulomb's law. 
its hydration shell. As smectite layer charge increases during burial diagenesis, a potassium ion dehydrates before a sodium ion can dehydrate, because potassium has the smaller hydration energy. Hence, potassium is greatly preferred compared to sodium when the layer charge required for potassium dehydration has been exceeded. The dehydration of potassium by interlayer electrical forces leads simultaneously to increased selectivity for potassium, expulsion of interlayer water, and collapse of the smectite interlayer to form illite.

\section{REFERENCES CITED}

Collins, A. G., 1975, Geochemistrv of oilfield waters-Developments in petroleum science, v. 1: New York, Elsevier, 496 p.

Cruickshank, E. H., and Meares, P., 1957, The thermodynamics of cation exchange, Part 2-Comparison between resins and concentrated chloride solutions: Transactions of the Faraday Society, v. 53, p. 1299-1308.

Eberl, D. D., 1980, Alkali cation selectivity and fixation by clay minerals: Clays and Clay Minerals, v. 28, p. 161-172.

1984, Clay mineral formation and transformation in rocks and soils: Philosophical Transactions of the Royal Society of London A, v. 311, p. 241-257.

Eisenman, George, 1961, On the elementary origin of equilibrium ionic specificity, in Kleinzeller, A., and Kotyk, A., eds., Symposium on membrane transport and metabolism: New York, Academic Press, p. 163-179.

1962, Cation selective glass electrodes and their mode of operation: Biophysics Journal, v. 2, pt. 2 (supp.), p. 259-323.

Garrels, R. M., and Tardy, Yves, 1982, Born-Haber cycles for interlayer cations of mica, in van Olphen, H., and Veniale,
F., eds., Proceedings of the international clay conference, Bologna and Pavia, 1981: New York, Elsevier, p. 423-440.

Helfferich, Friedrich, 1962, Ion exchange: New York, McGrawHill, 624 p.

Helgeson, H. C., Kirkham, D. H., and Flowers, G. C., 1981, Theoretical prediction of the thermodynamic behavior of aqueous electrolytes at high pressures and temperatures. IV. Calculation of activity coefficients, osmotic coefficients, and apparent molal and standard and relative partial molal properties to $600^{\circ} \mathrm{C}$ and $5 \mathrm{~kb}$ : American Journal of Science, v. 281, no. 10, p. 1249-1516.

Hower, John, and Mowatt, T. C., 1966, Mineralogy of illites and mixed-layer illite/montmorillonites: American Mineralogist, v. 51, p. 825-854.

Hower, John, Eslinger, E. V., Hower, M. E., and Perry, E. A., 1976, Mechanism of burial metamorphism of argillaceous sediments-1. Mineralogical and chemical evidence: Geological Society of America Bulletin, v. 87, p. 725-737.

Nightengale, E. R., 1959, Phenomenological theory of ion solvation-Effective radii of hydrated ion: Journal of Physical Chemistry, v. 63, p. 1381-1387.

Perry, Edward, and Hower, John, 1970, Burial diagenesis in Gulf Coast pelitic sediments: Clays and Clay Minerals, v. 18 , p. 165-177.

Robinson, R. A., and Stokes, R. H., 1959, Electrolyte solutions (2d ed.): London, Butterworths Scientific Publications, $559 \mathrm{p}$.

Sherry, H. S., 1969, The ion-exchange properties of zeolites, in Marinsky, J. A., ed., Ion exchange, v. 2: New York, Marcel Dekker, p. 89-133.

Weaver, C. E., and Beck, K. C., 1971, Clay water diagenesis during burial-How mud becomes gneiss: Geological Society of American Special Paper 134, p. 1-78. 
................. 
-...- - - - 